\title{
Quality of
}

Surface Waters of the

\section{United States,}

\section{9}

Part 11. Pacific Slope Basins in California

GEOLOGICAL SURVEY WATER-SUPPLY PAPER 2149

Prepared in cooperation with the State of California and with other agencies

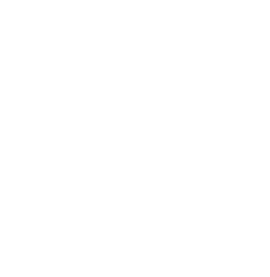


UNITED STATES DEPARTMENT OF THE INTERIOR

ROGERS C. B. MORTON, Secretary

\section{GEOLOGICAL SURVEY}

V. E. McKelvey, Director

Library of Congress catalog-card No. GS 43-68

For sale by the Superintendent of Documents, U.S. Government Printing Office Washington, D.C. 20402 - Price $\$ 2.70$ (paper cover)

Stock Number 2401-02517 


\section{.PREFACE}

This report was prepared by the U.S. Geological Survey in cooperation with the State of California, and with other agencies, by personnel of the Water Resources Division, E. L. Hendricks, chief hydrologist, G. W. Whetstone, assistant chief hydrologist for Scientific Publications and Data Management, under the general direction of G. A. Billingsley, chief, Reports Section, and B. A. Anderson, chief, Data Reports Unit.

The data were collected under the supervision of district chiefs of the Water Resources Division as follows:

R. S. Lord...................................................Menlo Park, Calif. S. F. Kapustka..............................................Portland, Oreg. 


\section{CONTENTS}

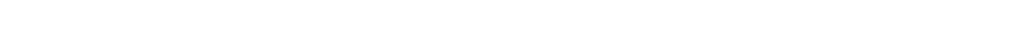

List of Water-Quality stations, in downstream order, for which

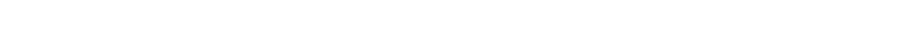

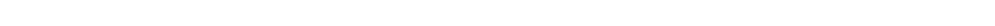

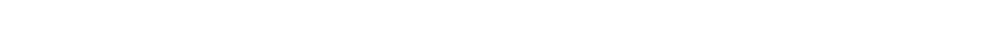

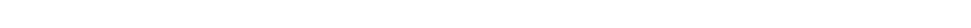

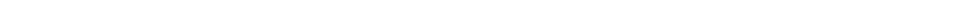

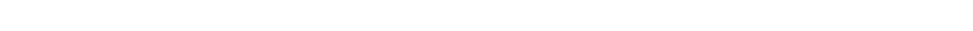

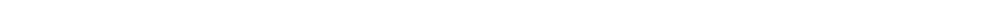

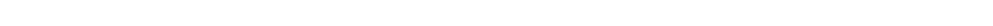

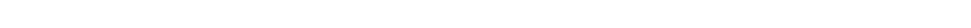

Silica.

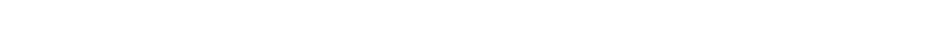

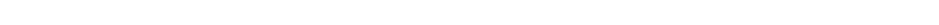

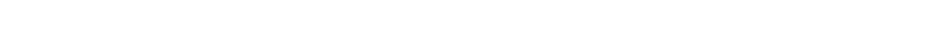

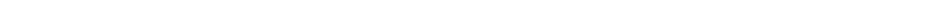

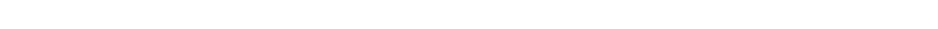

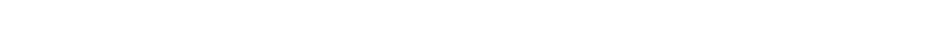

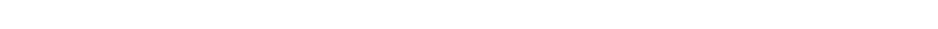

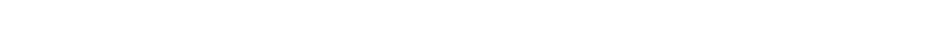

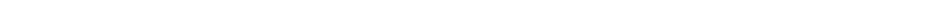

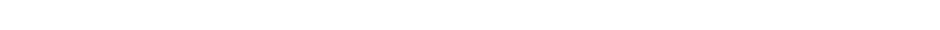

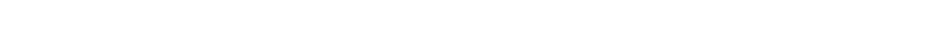

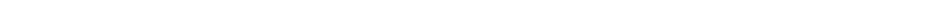

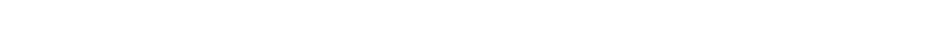

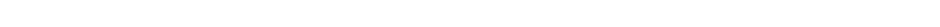

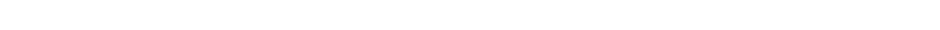

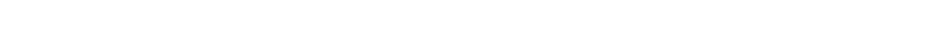

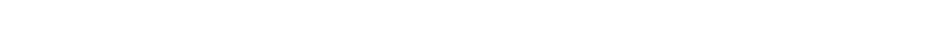

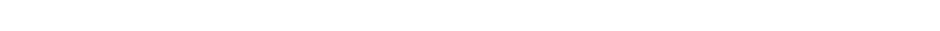

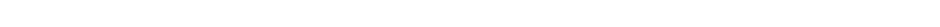

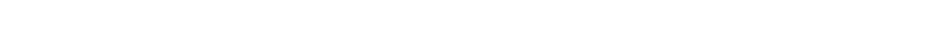

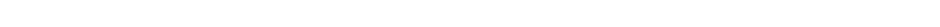

Cadmi um. . . . . . . . . . . . . . . . . . . . . . . . .

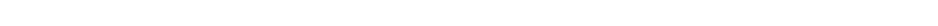

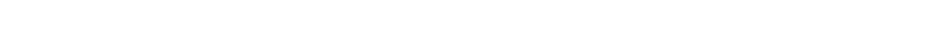

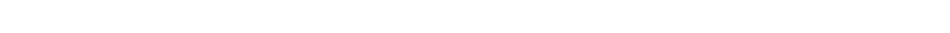

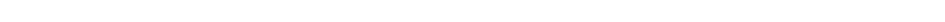

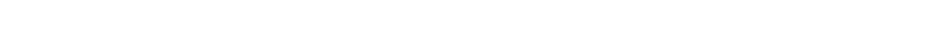

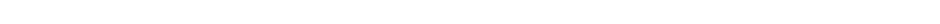

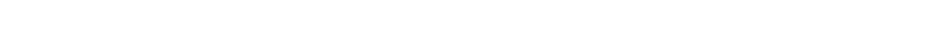

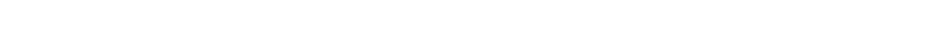

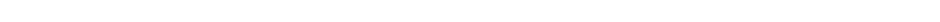

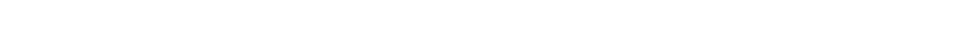

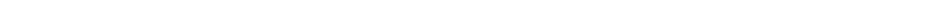

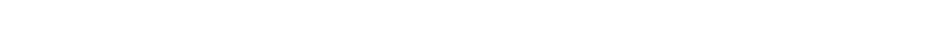

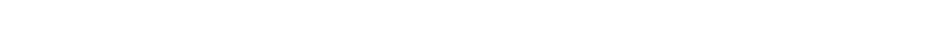

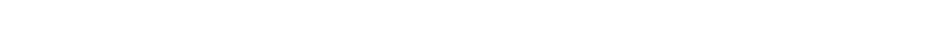

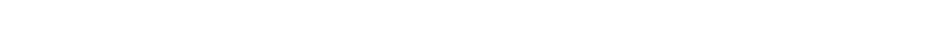

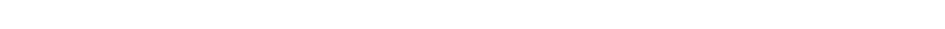

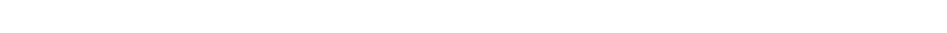

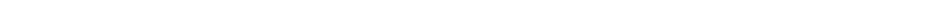

Turbidity. . . . . . . . . . . . . . . . . . . . . . . . .

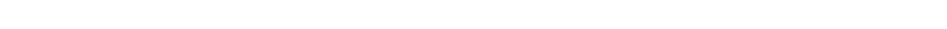

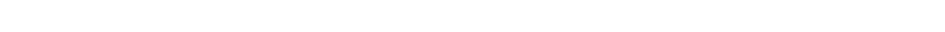

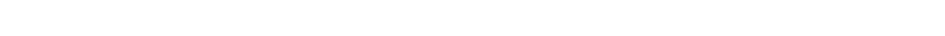

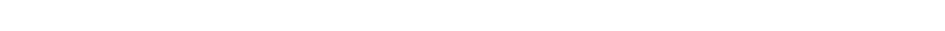

Biological and microbiological information............. 
Composition of surface waters--Continued

properties and characteristics of water--Continued

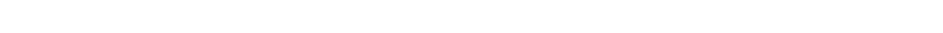

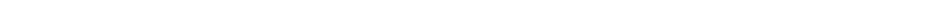

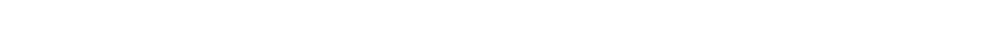

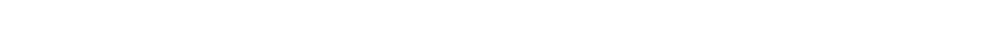

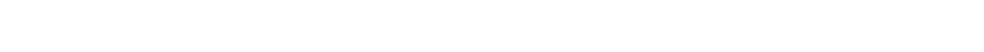

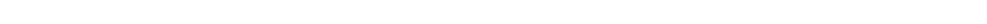

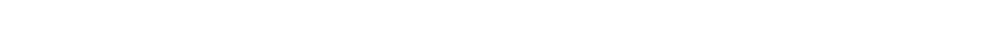

\section{$\overline{\text { ILLUSTRATION }}$}

Figure 1. Map of the United States showing basins covered by

the ten water-supply papers of quality of surface waters

in 1969. 


\title{
WATER-QUALITY STATIONS, IN DOWNSTREAM ORDER,
}

\section{FOR WHICH RECORDS ARE PUBLISHED}

\author{
[Letters after station nome designate type of data: (c) chemical,
}

(t) water temperature, (s) sediment]

PACIFIC SLOPE BASINS IN CALI FORNIA

SAN LUIS REY RIVER BASIN

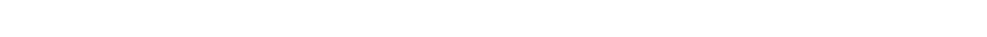

SANTA MARGARITA RIVER BASIN

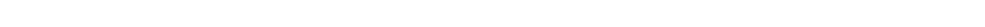

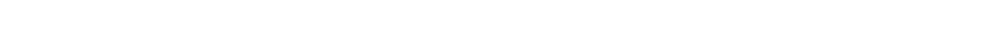

SANTA ANA RIVE R BASIN

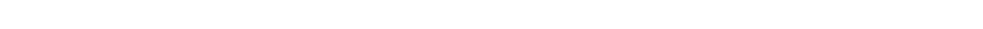

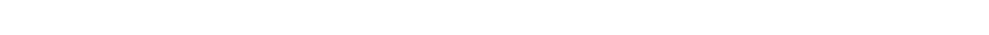

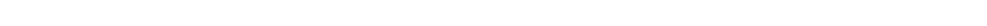

SAN GABRIEL RIVER BASIN

San Gabriel River at Azusa Powerhouse, at Azusa, Calif. (c)......

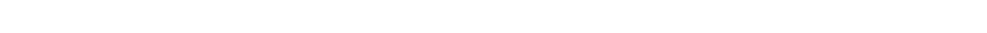

LOS ANGELES RIVER BASIN

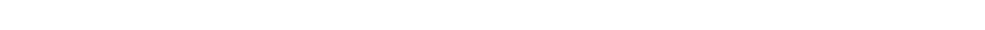
Hondo River:

Mission Creek near Montebel lo, Calif. (c)............... CALLEGUAS CREEK BAS IN

Call eguas Creek:

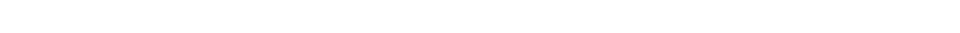

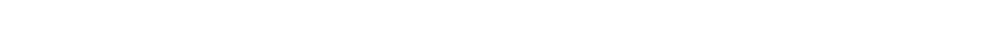
SANTA CLARA RIVER BASIN

Santa Clara River at Los Angeles-Ventura County

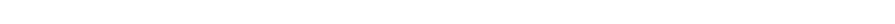

Se spe Creek near Wheeler Springs, Calif. $(t) \ldots \ldots \ldots \ldots \ldots \ldots \ldots$

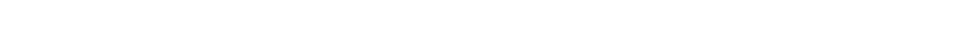

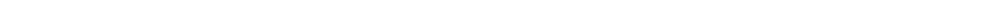

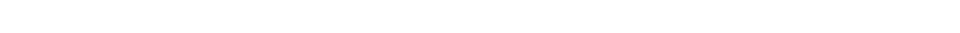

Saticoy diversion near Saticoy, Calif. $(t) \ldots \ldots \ldots \ldots \ldots \ldots \ldots$

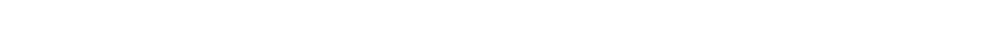
VENTURA RIVER BASIN

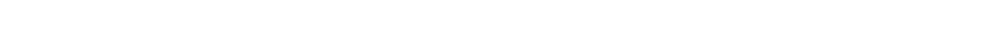
SANTA MARIA RI VER BASIN

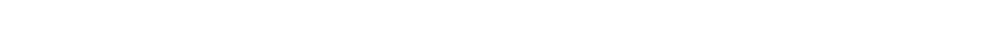
ARROYO GRANDE BASIN

Arroyo Grande above phoenix Creek, near Arroyo

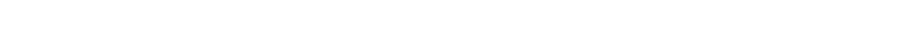

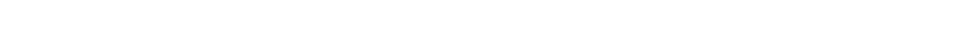

BIG SUR RIVER BASIN

Big Sur River near Big Sur, Calif. $(t) \ldots \ldots \ldots \ldots \ldots \ldots \ldots \ldots$

SALINAS RIVER BASIN

Salinas River:

Paso Robles Creek:

Santa Rita Creek:

Santa Rita Creek tributary near Templeton, Calif. (ts).....

Santa Rita Creek near Templeton, Calif. (ts)...............

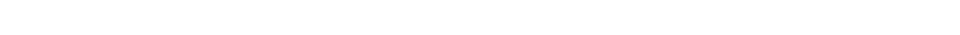

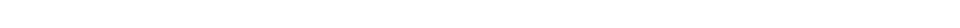

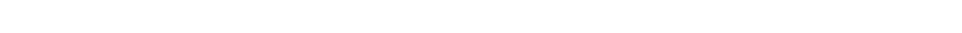

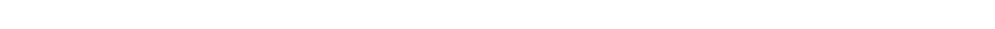

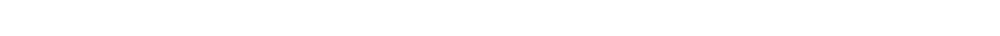
PA JARO RI VER BASIN

Pa jaro River:

Carnade ro Creek:

Uvas Creek above Uvas Reservoir, near Morgan

Hill, Calif. $(\mathrm{ts}) \ldots \ldots \ldots \ldots \ldots \ldots \ldots \ldots \ldots \ldots \ldots \ldots \ldots$ 
PACIFIC SLOPE BASINS IN CALIFORNIA--Continued

PAJARO RIVER BASIN--Continued

Pajaro River--Continued

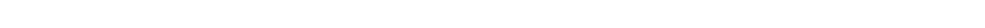

SOQUEL CREEK BASIN

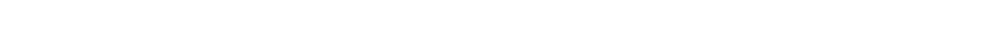

SAN LORENZO RIVER BASIN

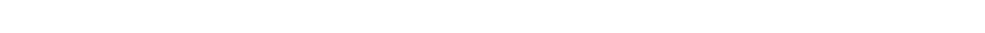
PESCADERO CREEK BASIN

Pescadero Creek near Pescadero, Calif. ( $t) \ldots \ldots \ldots \ldots \ldots \ldots \ldots \ldots$

COLMA CREEK BASIN

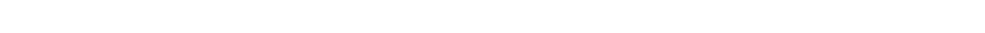

Spruce Branch at South San Francisco, Calif. (s).............. COYOTE CREEK BASIN

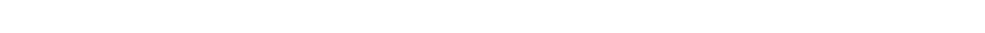

ALAMEDA CREEK BASIN

Alameda Creek:

Alamo Creek:

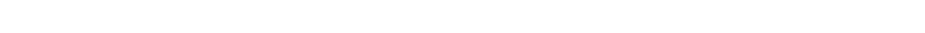

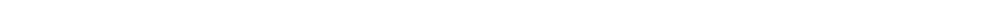
BUENA VISTA LAKE BASIN

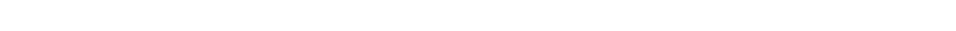
Kern River Canal No. 3 near Kernville, Calif. (t)...........

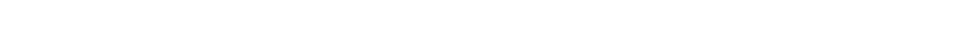
Borel Canal below Isabella Dam, Calif. $(t) \ldots \ldots \ldots \ldots \ldots \ldots$ TULARE LAKE BASIN

Tulare Lake:

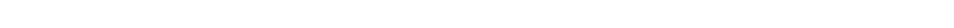

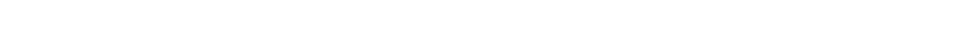
Middle Fork Kaweah River:

Marble Fork Kaweah River at Potwisha Camp, Calif. (t)....... East Fork Kaweah River below Eagle Creek, near Hammond,

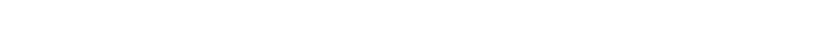

East Fork Kaweah River above Monarch Creek, near Hamnond,

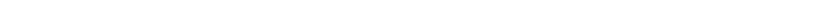

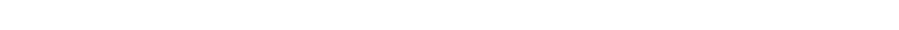

East Fork Kaweah River below Monarch Creek, near Hammond,

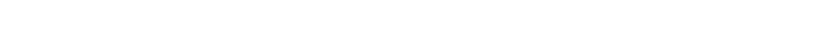

East Fork Kaweah River below Mosquito Creek, near Hammond,

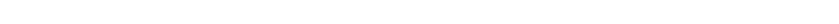

East Fork Kaweah River at Sequoia National Park boundary,

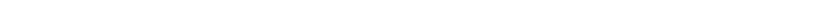

Atwell Creek above Mineral King Highway, near Hammond,

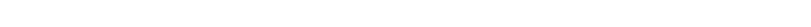

Redwood Creek above Mineral King Highway, near Hammond,

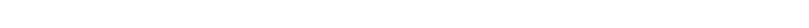

Squirrel Creek below Mineral King Highway, near Hanmond,

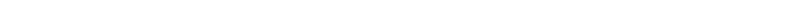

Crunigen Creek below Mineral King Highway, near Hammond,

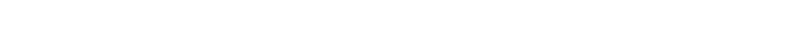

East Fork Kaweah River near Three Rivers, Calif. (cts).......

Kaweah River at Three Rivers, Calif. $(t) \ldots \ldots \ldots \ldots \ldots \ldots \ldots \ldots$

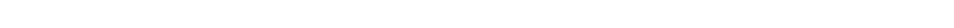

Kings River above North Fork, near Trimmer, Calif. ( $t) \ldots . . . \ldots$

North Fork Kings River above Dinkey Creek, at Balch Camp,

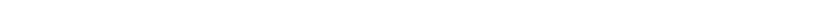

Kings River below North Fork, near Trimmer, Calif. (ct)........

Kings River at Peoples Weir, near Kingsburg, Calif. (c)....... SAN JOAQUIN RIVER BASIN

San Joaquin River:

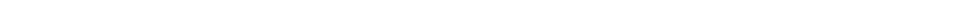

Willow Creek at mouth, near Auberry, Calif. $(t) \ldots \ldots \ldots \ldots \ldots \ldots$ Merced River at Happy Isles Bridge, near Yosemite, Calif. (ct).. Tuolumne River:

Clavey River:

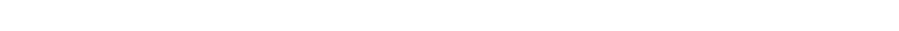

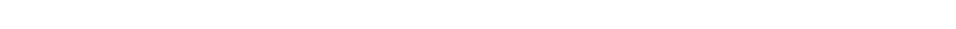

Middle Fork Stanislaus River at Hells Half Acre Bridge, near

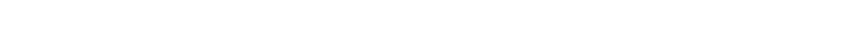

Stanislaus River below Goodwin Dam, nea Knights Ferry,

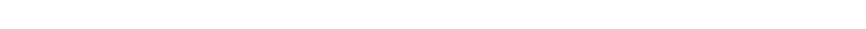


PACIFIC SLOPE BASINS IN CALIFORNIA--COnti nued SAN JOAQUIN RIVER BASIN--Conti nued

San Joaquin River--Continued

Stockt on Ship Canal at light 40, near Stockton, Calif. (c).....

Delta-Mendota Canal above Tracy pumping plant, near Tracy,

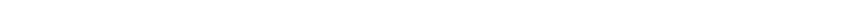

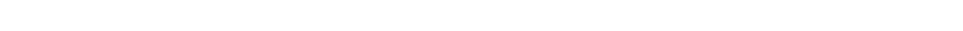

Mokelumne River near Mokelumne Hill, Calif. $(t) \ldots \ldots \ldots \ldots \ldots \ldots \ldots$

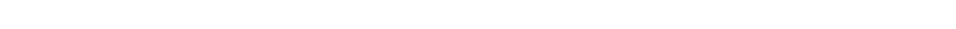

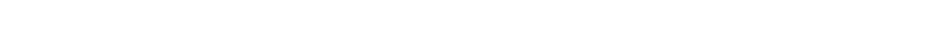

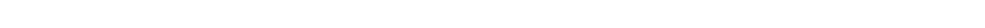
GOOSE LAKE BASIN

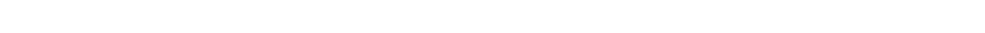

Goose Lake at Everly Ranch, near Willow Ranch, Calif. (c)........

Goose Lake at West Shore Log Landing, near Willow Ranch,

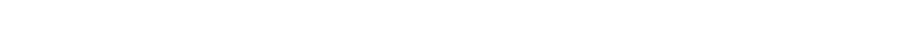

SACRAMENTO RIVER BASIN

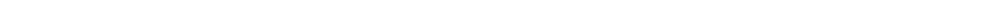

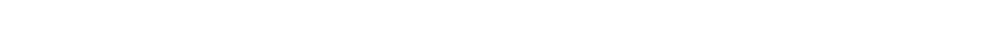
North Fork Pit River:

South Fork pit River near Likely, Calif. (c) .............

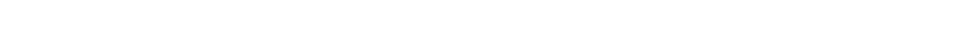

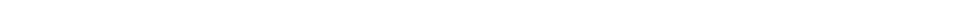

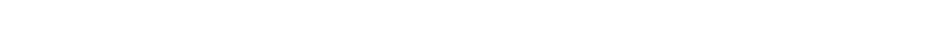

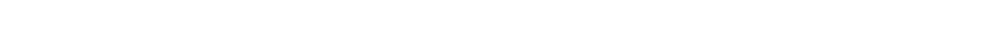

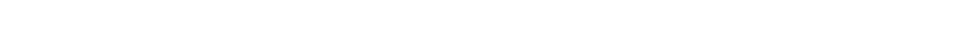
Cow Creek:

South Cow Creek near Millville, Calif. ( $t) \ldots \ldots \ldots \ldots \ldots \ldots \ldots$

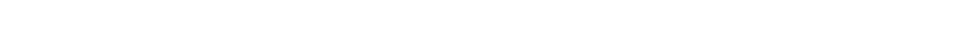
Middle Fork Cottonwood Creek near Ono, Cajif. $(t) \ldots \ldots \ldots \ldots \ldots$.

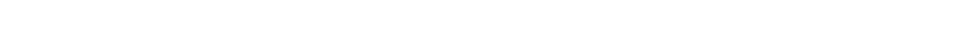
Battle Creek below Coleman Fish Hatchery, near Cottonwood,

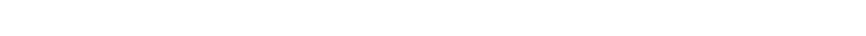

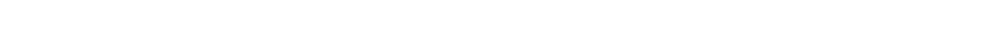

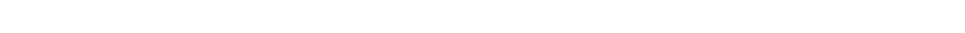

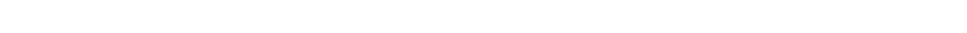

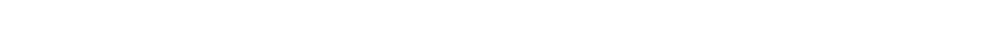

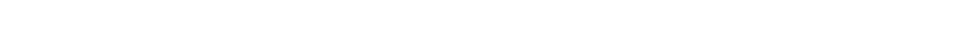
St ony Creek:

Little Stony Creek above East Park Reservoir, near Lodoga,

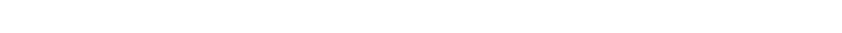

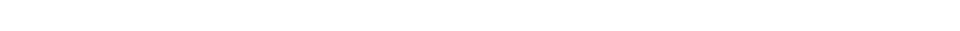

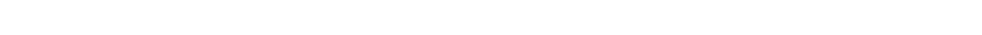

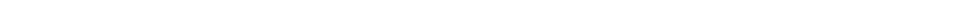

Sacramento Rive $r$ below Wilkins Slough, near Grimes, Calif. ( $t) . .$.

Sacramento Rive $r$ above Colusa Trough, at Knights Landing,

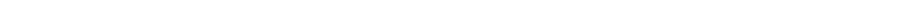

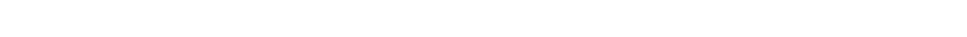

Middle Fork Feather River near Clio, Calif. $(t) \ldots \ldots \ldots \ldots \ldots \ldots \ldots$

Middle Fork Feather River near Merrimac, Calif. $(t) \ldots \ldots \ldots \ldots \ldots$

Feather River:

North Fork Feather River:

Indian Creek:

Little Grizzly Creek near Genesee, Calif. (t)..........

Indian Creek near Crescent Mills, Cálif. $(t) \ldots \ldots \ldots \ldots \ldots \ldots$

North Fork Feather River at Pulga, Calif. $(t) \ldots \ldots \ldots \ldots \ldots \ldots \ldots$

West Branch Feather River near Paradise, Calif. $(t) \ldots . . . .$. Lake Oroville:

Thermalito afterbay release to Feather River near Oroville,

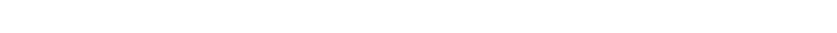

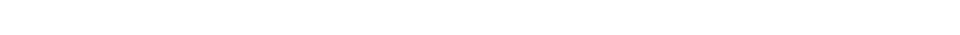

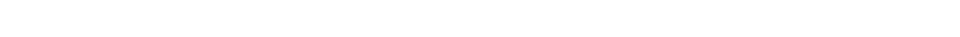

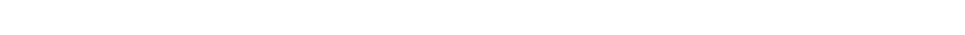

Middle Yuba River (head of Yuba River) above Oregon Creek,

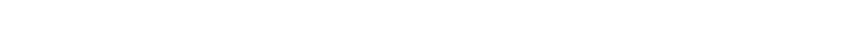

Oregon Creek near North San Juan, Calif. $(t) \ldots \ldots \ldots \ldots \ldots \ldots$

North Yuba River above Slate Creek, near Strawberry

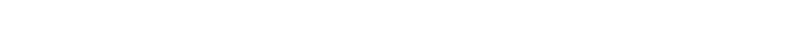

North Yuba River below New Builards Bar Dam, near North

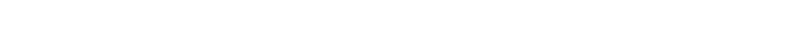

South Yuba River at Jones Bar, near Grass Vailey, 
PACIFIC SLOPE BASINS IN CALIFORNIA--COntinued

SACRAMENTO RIVER BASIN--Continued

Sacramen to River--Cont inued

Feather River--Continued

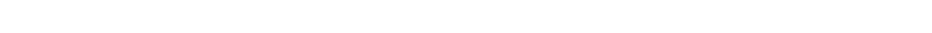

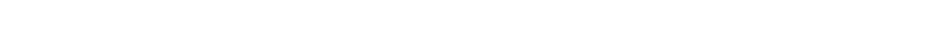

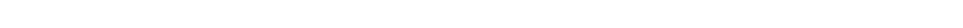

North Fork American River at North Fork Dam, Calif. (t)....... Middle Fork American River:

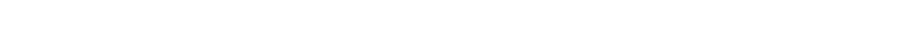

South Fork American River near Kyburz, Calif. (t).........

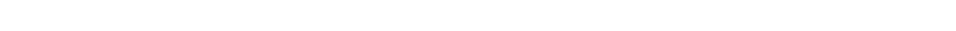

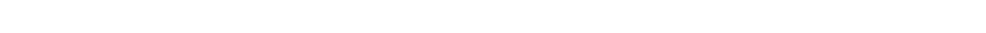

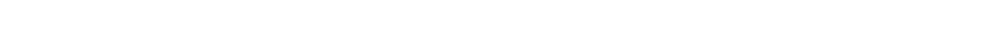
Yolo bypass:

Clear Lake (head of Cache Creek):

Adobe Creek:

Highland Creek below Highland Creek Dam, near

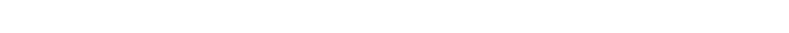

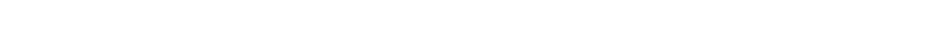

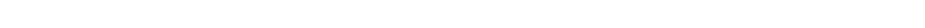

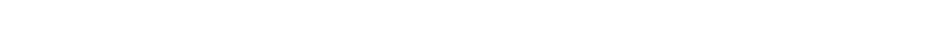

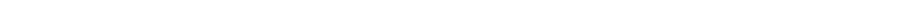

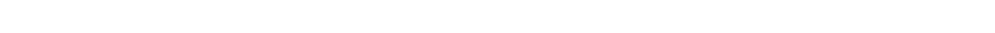
NAPA RIVER BASIN

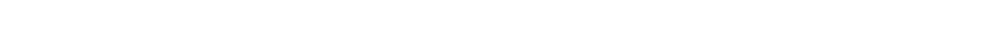

PINE CREEK BASIN

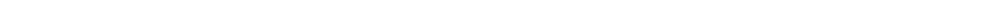

SALMON CREEK BASIN

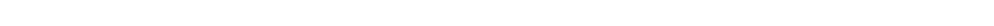

RUSSIAN RIVER BASIN

Russian River:

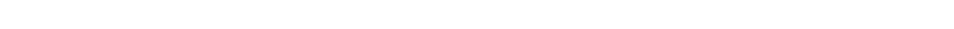

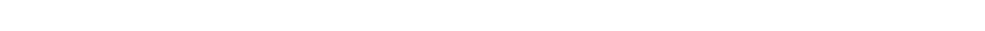

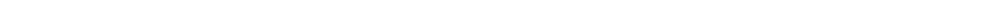

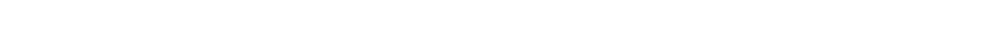

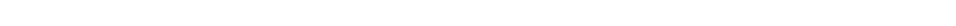

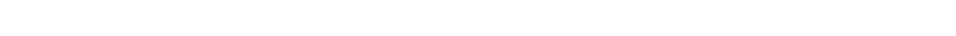

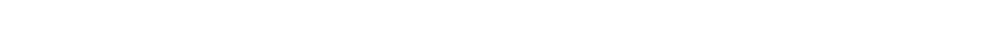
GARCIA RIVER BASIN

Garcia River near Point Arena, Calif. $(t) \ldots \ldots \ldots \ldots \ldots \ldots \ldots$

NAVAR RO RI VER BASIN

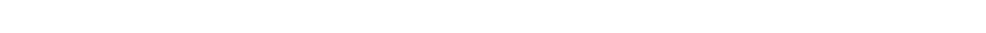

NOYA RIVER BASIN

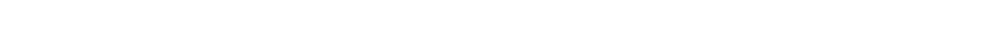

TE NMILE RIVER BASIN

Tenmile River:

Middle Fork Tenmile River near Fort Bragg, Calif. (t)........

MATTOLE RIVER BASIN

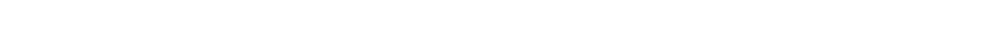

EEL RIVER BASIN

Eel River below Scott Dam, near Potter Valley, Calif. (ts)......

Potter Valley powerhouse tail race near Potter Valley,

Calif (ts) . . . . . .

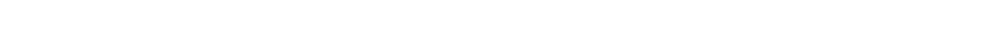

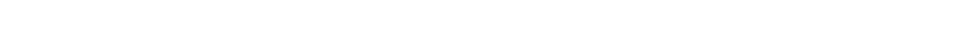

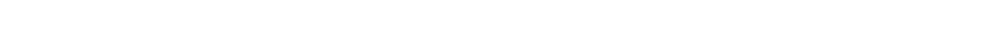

Middle Fork Eel River above Black Butte River, near Covelo,

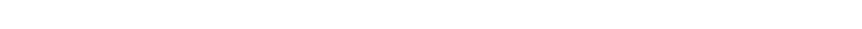

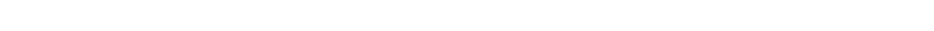

Middle Fork Eel River below Black Butte River, near Covelo,

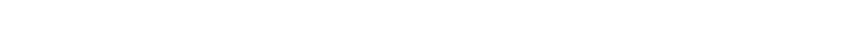

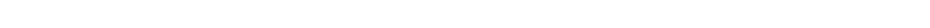

Middle Fork Eel River near Dos Rios, Calif. $(t s) \ldots \ldots \ldots \ldots \ldots \ldots$

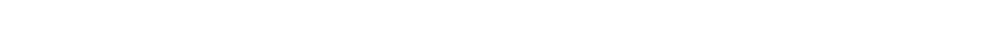

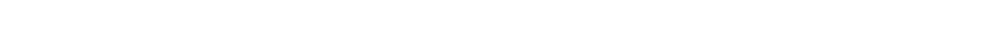

South Fork Eel River near Branscomb, Caiif. $(\mathrm{t}) \ldots \ldots \ldots \ldots \ldots \ldots \ldots$

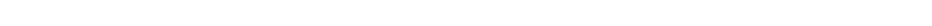

South Fork Eel River at Leggett, Calif. $(t) \ldots \ldots \ldots \ldots \ldots \ldots$

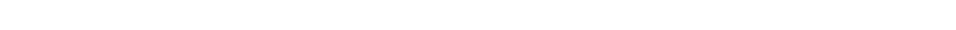

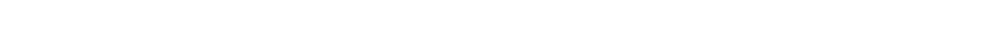

Van Duzen River near Dinsmores, Caijf. $(t) \ldots \ldots \ldots \ldots \ldots \ldots \ldots \ldots$ 
PACIFIC SLOPE BASINS IN CALIFORNIA--Conti nued

EEL RIVER BASIN--Continued

Ee1 River--Continued

Van Duzen River near Bridgeville, Calif. (ct) .................. Page

MAD RIVER BASIN

Mad River near Forest Glen, Calif. (ts) ................. 303

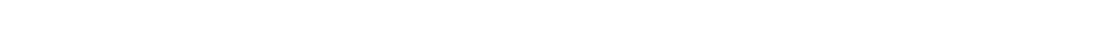

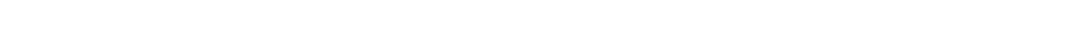

REDWOOD CREEK BASIN

Redwood Creek at Orick, Calif. (t).................... 309

KLAMATH RIVER BASIN
Crater Lake (closed basin) near Crater Lake, Oreg. (ct)......... 310

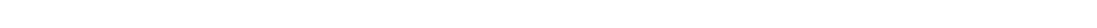

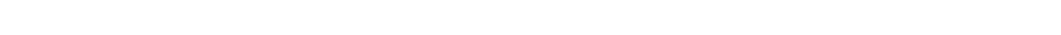

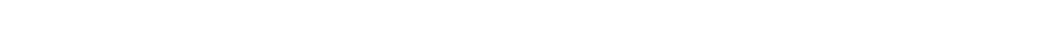

Scott River near Fort Jones, Calif. (c) ............... 317

Klamath River near Seiad Valley, Calif. $(t) \ldots \ldots \ldots \ldots \ldots \ldots \ldots \ldots \ldots \ldots . . \ldots \ldots$

Salmon River at Somes Bar, Calif. $(t) \ldots \ldots \ldots \ldots \ldots \ldots \ldots \ldots \ldots . \ldots \ldots$

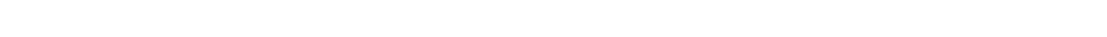

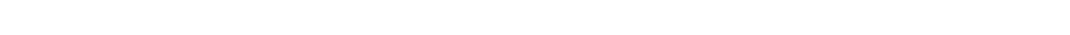

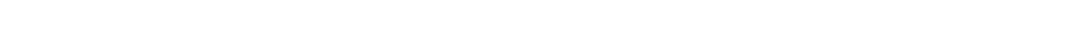
South Fork Trinity River:

Hayfork Creek near Hyampom, Calif. (t)............... 327

South Fork Trinity River below Hyampom, Calif. $(\mathrm{t}$ s $) \ldots \ldots \ldots \ldots . .328$

Trinity River at Hoopa, Calif. (cts)................. 331

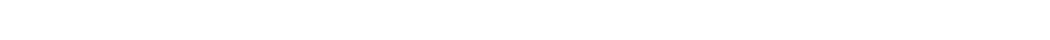

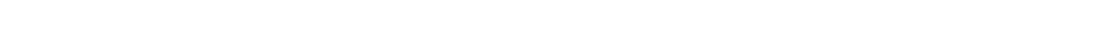

SMITH RIVER BASIN

Smith River near Crescent City, Calif. (ct)............... 338

Analyses of samples collected at miscellaneous sites in Pacific
slope basins in California $(\mathrm{cs}) \ldots \ldots \ldots \ldots \ldots \ldots \ldots \ldots \ldots \ldots$ 


\title{
QUALITY OF SURFACE WATERS OF THE
}

\section{UNITED STATES, 1969}

\author{
PART 11
}

\section{INTRODUCTION}

The water-quality investigations of the United States Geological Survey are concerned with chemical and physical characteristics of surface- and ground-water supplies of the Nation. The data herein deal with the amounts of matter in solution and in suspension in streams, and represent that portion of the National Water Data System collected by the U.S. Geological Survey in cooperation with State, municipal, and other Federal agencies.

The records of chemical analysis, water temperature, and suspended sediment of surface waters given in this volume serve as a basis for determining the suitability of waters for various uses. The flow and water quality of a stream are related to variations in rainfall and other forms of precipitation. In general, lower concentrations of dissolved solids may be expected during periods of high flow than during periods of low flow. Conversely, the suspended solids in some streams may change materially with relatively small variations in flow, whereas for other streams the quality of the water may remain relatively uniform throughout large ranges in discharge.

The Geological Survey has published annual records of chemical quality, water temperature, and suspended sediment since 1941. The records prior to 1948 were published each year in a single volume for the entire country, and in two volumes in 1948 and in 1949. From 1950 to 1958, the records were published in 4 volumes; from 1959 to 1963 in 5 volumes; from 1964 to 1967 in 6 volumes; and in 1968 in 10 volumes. The drainage basins covered by the 10 volumes are shown in Figure 1 . The shaded area in Figure 1 represents the section of the country covered in this volume for the water year 1969 (October 1, 1968 to September 30, 1969).

To meet interim requirements, water-quality records have been released by the Geological Survey in annual reports, beginning with the 1964 water year, by State. These reports are entitled, "Water Resources Data for (State), Part 2. Water Quality Records." Distribution of these reports is limited and primarily for local needs. Any revisions or corrections found necessary to the records published in these annual State reports have been made and published in this volume without reference.

The records herein are listed by drainage basins in a downstream direction along the main stream. All stations on a tributary entering above a mainstream station are listed before that station. A station on a tributary that enters between two mainstream stations is listed between them. A similar order is followed in listing stations on first rank, second rank, and other ranks of tributaries. In the list of water-quality stations in the front of this volume, the rank of the tributaries is indicated by an indention. Each indention represents one rank.

As an added means of identification, a station number has been assigned for each stream location where regular measurements of water quantity or quality have been made. The numbers have been assigned to conform with the standard downstream order of listing gaging stations. The numbering system consists of an 8-digit number, such as 11046500 . The first 2 digits, "l1" identifies the Part or hydrologic region used by the Geological Survey for reporting hydrologic data. The next 6 digits is the 
station number which represents the location of the station in the standard downstream order within each of the 16 parts (fig. 1). The complete number (11046500) appears just to the left of the station name. The assigned numbers are in numerical order but are not consecutive. Gaps are left in the numbers to allow for new stations that may be established.

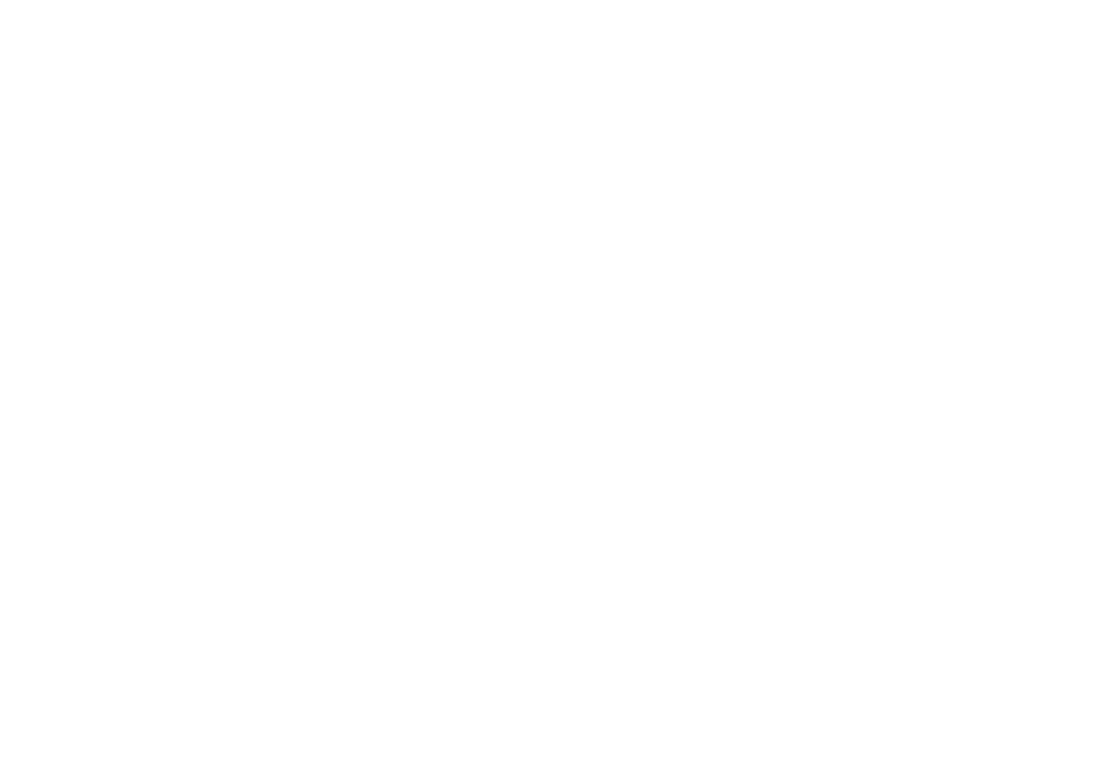

Figure 1.--Map of the United States showing basins covered by the 10 water-supply papers on quality of surface waters in 1969 . The shaded part represents the section of the country covered by this volume; the unshaded part represents the section of the country covered by other water-supply papers.

Descriptive statements are given for each sampling station where chemical analyses, temperature measurements, or sediment determinations have been made. These statements include location of the station, drainage area, periods of records available, extremes of dissolved solids, hardness, specific conductance, temperature, sediment loads, and other pertinent data. Records of discharge of the streams at or near the sampling station are included in most tables of analyses.

During the water year ending September 30, 1969, the Geological Survey maintained 188 stations on 129 streams for the study of chemical and physical characteristics of surface water. Samples were collected daily and monthly at 84 of these locations for chemical-quality studies. Samples also were collected less frequently at many other points. Water temperatures were measured continuously at 115 and daily at 28 stations. All surface water samples collected and analyzed during the year have not been included. Single analyses made of daily samples before compositing have not been reported. Specific conductance is determined and reported for almost all daily samples.

At chemical-quality stations where data are continuously recorded at the stream site (monitors), the records consist of daily maximum, minimum, and mean values for each constituent measured. More detailed records (hourly values) may be obtained by writing the district office listed under Division of Work on page 21 . 
Quantities of suspended sediment are reported for 67 stations during the year ending September 30, 1969. Sediment samples were collected one or more times daily at most stations, depending on the rate of flow and changes in stage of the stream. Particle-size distributions of sediments were determined at 48 stations.

Some of the stations for which data are published in this volume are included in special networks and programs. These stations are identified by their title, set in parentheses, under the station name.

Hydrologic bench-mark station is one that provides hydrologic data for a basin in which the hydrologic regimen will likely be governed solely by natural conditions. Data collected at a bench-mark station may be used to separate effects of natural from manmade changes in other basins which have been developed and in which the physiography, climate, and geology are similar to those in the undeveloped bench-mark basin.

International Hydrological Decade (IHD) River Stations provide a general index of runoff and materials in the water balance (discharge of water, and dissolved and transported solids) of the world. In the United States, IHD Stations provide indices of runoff and the general distribution of water in the principal river basins of the conterminous United States and Alaska.

Irrigation network stations are water-quality stations located at or near certain streamflow gaging stations west of the main stem of the Mississippi River. Data collected at these stations are used to evaluate the chemical quality of surface waters used for irrigation and the changes resulting from the drainage of irrigated lands. Prior to water year 1966, these data were published in the annual water-supply paper series, "Quality of Surface Waters for Irrigation, Western States."

Pesticide program is a network of regularly sampled water-quality stations where additional monthly samples are collected to determine the concentration and distribution of pesticides in streams whose waters are used for irrigation or in streams in areas where potential contamination could result from the application of the commonly used insecticides and herbicides.

Radiochemical program is a network of regularly sampled water-quality stations where additional samples are collected twice a year (at high and low flow) to be analyzed for radioisotopes. The streams that are sampled represent major drainage basins in the conterminous United States.

\section{COLLECTION AND EXAMINATION OF DATA}

Quality of water stations usually are located at or near points on streams where streamflow is measured by the U.S. Geological Survey. The concentration of solutes and sediments at different locations in the stream-cross section may vary widely with different rates of water discharge depending on the source of the material and the turbulence and mixing of the stream. In general, the distribution of sediment in a stream section is much more variable than the distribution of solutes. It is necessary to sample some streams at several verticals across the channel and especially for sediment, to uniformly traverse the depth of flow. These measurements require special sampling equipment to adequately integrate the vertical and lateral variability of the concentration in the section. These procedures yield a velocity-weighted mean concentration for the section.

The near uniformly dispersed ions of the solute load move with the velocity of the transporting water. Accordingly, the mean section concentration of solutes determined from samples is a precise measure of the total solute load. The mean section concentration obtained from suspended sediment samples is a less precise measure of the total sediment load, because the sediment samplers do not traverse the bottom 0.3 foot of the sampling vertical where the concentration of suspended sediment is greatest and because a significant part of the coarser particles in many streams move in essentially continuous contact with the bed and are not represented in the suspended sediment sample. Hence, the computed sediment loads presented 
in this report are usually less than the total sediment loads. For most streams the difference between the computed and total sediment loads will be small, in the order of a few percent.

\section{CHEMICAL QUALITY}

The methods of collecting and compositing water samples for chemical analysis are described by Brown, Skougstad, and Fishman (1970). No single method of compositing samples is applicable to all problems related to the study of water quality. Composites are made on the basis of dissolved-solids content as indicated by measurements of conductivity of daily samples, supplemented by other information such as chloride content, river stage, weather conditions and other background information of the stream.

\section{TEMPERATURE}

Daily water temperatures were measured at most of the stations at the time samples were collected for chemical quality or sediment content. So far as practicable, the water temperatures were taken at about the same time each day. Large streams have a small diurnal temperature change while small, shallow streams may have a daily range of several degrees and may follow closely the changes in air temperature. Some streams may be affected by waste-heat discharges.

At stations where continuously recording thermographs are present, the records consist of maximum and minimum temperatures for each day, and the monthly averages.

\section{SEDIMENT}

In general, suspended-sediment samples were collected daily with depth-integrating samplers (U.S. Inter-Agency, 1963). At some stations, samples were collected at a fixed sampling point at one vertical in the cross section. Depth-integrated samples were collected periodically at three or more verticals in the cross section to determine the cross-sectional distribution of the concentration of suspended sediment with respect to that at the daily sampling vertical. In streams where transverse distribution of sediment concentration ranged widely, samples were taken at two or more verticals to define more accurately the average concentration of the cross section. During periods of high or rapidly changing flow, samples generally were taken several times a day and, in some instances, hourly.

Sediment concentrations were determined by filtration-evaporation method. At many stations the daily mean concentration for some days was obtained by plotting the velocity-weighted instantaneous concentrations on the gage-height chart. The plotted concentrations, adjusted if necessary, for cross-sectional distribution were connected or averaged by continuous curves to obtain a concentration graph. This graph represented the estimated velocity-weighted concentration at any time, and for most periods daily mean concentrations were determined from the graph. The days were divided into shorter intervals when the concentration or water discharge were changing rapidly. During some periods of minor variation in concentration, the average concentration of the samples was used as the daily mean concentration. During extended periods of relatively uniform concentration and flow, samples for a number of days were composited to obtain average concentrations and average daily loads for each period. (See Expression of Results, p. 5.)

For periods when no samples were collected, daily loads of suspended sediment were estimated on the basis of water discharge, sediment concentrations observed immediately before and after the periods, and suspended-sediment loads for other periods of similar discharge. The estimates were further guided by precipitation records and sediment discharge at other stations in the same or adjacent basins. 
In many instances where there were no observations for several days, the suspendedsediment loads for individual days were not estimated, because numerous factors influencing the quantities of transported sediment made it very difficult to make accurate estimates for individual days. However, estimated loads of suspended sediment for missing days in an otherwise continuous period of sampling have been included in monthly and annual totals in order to provide a complete record. For some streams, samples were collected weekly, monthly, or less frequently, and only rates of sediment discharge at the time of sampling are shown.

In addition to the records of quantities of suspended sediment transported, records of particle sizes of sediment are included. The particle sizes of suspended sediment for many of the stations, and the particle sizes of the bed material for some of the stations were determined intermittently.

The size of particles carried in suspension by streams commonly ranges from colloids (finer than about 0.24 microns) to coarse sand $(2.0 \mathrm{~mm})$. The common methods of particle-size analysis cannot accommodate such a wide range. Hence, it was necessary to separate most samples into two parts, that part coarser than $0.062 \mathrm{~mm}$ and that part finer than $0.062 \mathrm{~mm}$. The separations were made by sieve or by fall velocity technique. The coarse fractions were classified by sieve separation or by visual-accumulation tube (U.S. Inter-Agency, 1957). The fine fractions were classified by the pipet method (Kilmer and Alexander, 1949) or the bottom withdrawal tube method (U.S. Inter-Agency, 1943).

\section{EXPRESSION OF RESULTS}

The quantities of solute concentrations analyzed in the laboratory are measured in either milligrams per liter or micrograms per liter. Milligrams per liter $(\mathrm{mg} / \mathrm{l}$, $\mathrm{MG} / \mathrm{L}$ ) is a unit which represents the weight of solute per unit volume of water. A microgram per liter (ug/l, UG/L) is one thousandth of a milligram per liter.

Milliequivalents per liter are not reported but they can be converted easily from milligrams per liter data. A milliequivalent per liter (me/l) is one thousandth of a gram equivalent weight of a constituent. Chemical equivalence in milliequivalents per liter can be obtained by (a) dividing the concentration in milligrams per liter by the combining weight of that ion, or (b) by multiplying the concentration (in $\mathrm{mg} / \mathrm{l}$ ) by the reciprocals of the combining weights. Table 1 on page 6 , lists the reciprocals of the combining atomic weights based on carbon-12 (International Union of Pure and Applied Chemistry, 1961).

The hardness of water is conventionally expressed in all water analyses in terms of an equivalent quantity of calcium carbonate. Such a procedure is required because hardness is caused by several different cations, present in variable proportions. It should be remembered that hardness is an expression in conventional terms of a property of water. The actual presence of calcium carbonate in the concentration given is not to be assumed. The hardness caused by calcium and magnesium (and other cations if significant) equivalent to the carbonate and bicarbonate is called carbonate hardness; the hardness in excess of this quantity is called noncarbonate hardness. Hardness or alkalinity values expressed in milligrams per liter as calcium carbonate may be converted to milliequivalents per liter by dividing by 50 .

The value usually reported as dissolved solids is the residue on evaporation after drying at $180^{\circ} \mathrm{C}$ for 1 hour. For some waters, particularly those containing moderately large quantities of soluble salts, the value reported is calculated from the quantities of the various determined constituents using the carbonate equivalent of the reported bicarbonate. The calculated sum of the constituents may be given instead of or in addition to the residue. In the analyses of most waters used for irrigation, the quantity of dissolved solids is given in tons per acre-foot as well as in milligrams per liter. 
Table 1.--Factors for conversion of chemical constituents in milligrams per liter to milliequivalents per liter

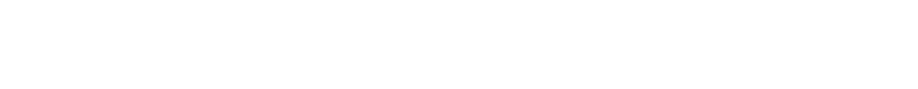

\begin{tabular}{|c|c|c|c|}
\hline Aluminum $\left(\Lambda J^{+3}\right)^{*} \ldots \ldots$ & 0.11119 & lodide $\left(I^{-1}\right)$. & \\
\hline nmmonia as NLi+1 & .05544 & $\operatorname{tron}(F+3)^{+3}$ & .053 \\
\hline Arsenic $(A s+2)^{*}$. & .04004 & $\operatorname{Lcad}(\mathrm{Pb}+2)^{*}$. & \\
\hline 32 riun $\left(\mathrm{Ba}^{+2}\right) \ldots$ & .01456 & ithinum $(L i+1)$. & \\
\hline 3 icarbonate $\left(\mathrm{HCO}_{3}{ }^{-1}\right)$. & .01639 & Vagnesium $(\mathrm{Mg}+2)$. & \\
\hline Bromicic $(13 \times-1) \ldots$ & .01251 & Mangancse $(M n+2)^{*}$. & \\
\hline Cadimiun $\left(\mathrm{CC}^{+2}\right)^{*}$ & .01779 & Mercury (ig +2$) * \ldots$ & \\
\hline Calcimm $\left(\mathrm{Ca}^{+2}\right)$. & .04990 & Nicled $(N i+2)^{*}$. & \\
\hline Catlonate $\left(\mathrm{CO}_{3}^{-2}\right)$ & .03333 & Nitrate $\left(\mathrm{NO}_{3}^{-1}\right)$ & \\
\hline Choricle $\left(\mathrm{Cl}^{-1}\right) \ldots$ & .02821 & Nitrite $\left(\mathrm{NO}_{0}^{-1}\right)$ & \\
\hline $\min (\mathrm{Cr}+6)^{*}$. & .11539 & 'leosphato $\left(\mathrm{PO}_{4}^{-3}\right)$. & \\
\hline$(\mathrm{CO}+3)^{*} \ldots$ & .0339 .1 & Zotassium $(K+1)$ & .023 \\
\hline Cupper $(\mathrm{Cu}+2)^{*}$ & & $(\mathrm{Na}+1)$. & \\
\hline ile $\left(\mathrm{CN}^{-1}\right)$ & .03814 & Stiontium $(\mathrm{Sr}+2)^{*}$ & \\
\hline & .05264 & Sulfate $\left(\mathrm{SO}_{4}^{-2}\right) \ldots$ & \\
\hline Hydrogen $\left(\mathrm{H}^{+1}\right)$. & .99209 & Sulfide $(S-2)$ & \\
\hline Hydroxide $\left(\mathrm{OH}^{-1}\right) \ldots$ & .05880 & $\operatorname{Zinc}(\mathrm{Zn}+2)^{*}$ & \\
\hline
\end{tabular}

* Constituent reported in micrograms per liter; multiply by factor and divide results by 1,000 .

Specific conductance is given for most analyses and was determined by means of a conductance bridge and using a standard potassium chloride solution as reference. Specific conductance values are expressed in micromhos per centimeter at $25^{\circ} \mathrm{C}$. Specific conductance in micromhos is 1 million times the reciprocal of specific resistance at $25^{\circ} \mathrm{C}$. Specific resistance is the resistance in ohms of a column of water 1 centimeter long and 1 square centimeter in cross section.

The discharge of the streams is reported in cubic feet per second (see Streamflow, p. 19) and the temperature in degrees Celsius ( $\left.{ }^{\circ} \mathrm{C}\right)$. Color is expressed in units of the platinum-cobalt scale proposed by Hazen (1892). A unit of color is produced by one milligram per liter of platinum in the form of the chloroplatinate ion. Hydrogenion concentration is expressed in terms of $\mathrm{pH}$ units. By definition the $\mathrm{pH}$ value of a solution is the negative logarithm of the concentration of gram ions of hydrogen.

An average of analyses for the water year is given for most daily sampling stations. Most of these averages are arithmetical, time-weighted, or discharge-weighted; when analyses during a year are all on 10-day composites of daily samples with no missing days, the arithmetical and time-weighted averages are equivalent. A time-weighted average represents the composition of water that would be contained in a vessel or reservoir that had received equal quantities of water from the river each day for the water year. A discharge-weighted average approximates the composition of water that would be found in a reservoir containing all of the water passing a given station during the year. A discharge-weighted average is computed by multiplying the discharge for the sampling period by the concentrations of individual constituents for the corresponding period and dividing the sum of the products by the sum of the discharges. For most streams, discharge-weighted averages are lower than arithmetical averages because at times of high discharge the rivers generally have low concentrations of dissolved solids.

A program for computing these averages by digital computer was instituted in the 1962 water year. This program extended computations to include averages for $\mathrm{pH}$ values expressed in terms of hydrogen ion and averages for the concentration of individual constituents expressed in tons per day. Concentrations in tons per day are computed the same as daily sediment loads.

The concentration of sediment in milligrams per liter is computed as $1,000,000$ times the ratio of the weight of sediment to the weight of water-sediment mixture. Daily 
sediment loads are expressed in tons per day and except for subdivided days, are usually obtained by multiplying daily mean sediment concentrations in $\mathrm{mg} / \mathrm{l}$ by the daily mean discharge in cubic feet per second, and the conversion factor, normally 0.0027 .

For those days when the published sediment discharge value differs from the value computed, the reader can assume that the sediment discharge for that day was computed by the subdivided-day method.

Particle-size analyses are expressed in percentages of material finer than classified sizes (in millimeters). The size classification used in this report agrees with recommendations made by the American Geophysical Union Subcommittee on Sediment Terminology. The classification is as follows:

\begin{tabular}{lcll} 
Classification & \multicolumn{2}{c}{ Size $(\mathrm{mm})$} & Method of analysis \\
Clay............ & 0.00024 & -0.004 & Sedimentation. \\
Silt .............. & .004 & -.062 & Sedimentation. \\
Sand............. & .062 & -2.0 & Sedimentation or sieve. \\
Gravel........ & 2.0 & -64.0 & Sieve.
\end{tabular}

The particle-size distributions given in this report are not necessarily representative of all the particle sizes of sediment intransport in the natural stream. Most of the organic matter is removed and the sample is subjected to mechanical and chemical dispersion before analysis in distilled water. Chemical dispersion is not used for native-water analysis (Guy 1969).

Prior to the 1968 water year, data for chemical constituents and concentrations of suspended sediment were reported in parts per million (ppm) and water temperatures were reported in degrees Fahrenheit $(\mathrm{F})$. In October 1967, the U.S. Geological Survey began reporting data for chemical constituents and concentrations of suspended sediment in milligrams per liter ( $\mathrm{mg} / \mathrm{l}$ ) and water temperatures are given in degrees Celsius (centigrade, ${ }^{\circ} \mathrm{C}$ ). In waters with a density of $1.000 \mathrm{~g} / \mathrm{ml}$ (grams per milliliter), parts per million and milligrams per liter can be considered equal. In waters with a density greater than $1.000 \mathrm{~g} / \mathrm{ml}$, values in parts per million should be multiplied by the density to convert to milligrams per liter. (See table 2 on page 8 .) Temperature, in degrees Celsius may be converted to degrees Fahrenheit by using the table on page 8 .

\section{COMPOSITION OF SURFACE WATERS}

All natural waters contain dissolved mineral matter. The quantity of dissolved mineral matter in a natural water depends primarily on the type of rocks or soils with which the water has been in contact and the length of time of contact. Ground water is generally more highly mineralized than surface runoff because it remains in contact with the rocks and soils for much longer periods. Some streams are fed by both surface runoff and ground water from springs or seeps. Such streams reflect the chemical character of their concentrated underground sources during dry periods and are more dilute during periods of heavy rainfall. The dissolved-solids content in a river is frequently increased by drainage from mines or oil fields, by the addition of industrial or municipal wastes, or--in irrigated regions--by drainage from irrigated lands.

The mineral constituents and physical properties of natural waters reported in the tables of analyses include those that have a practical bearing on water use. The results of analyses generally include silica, iron, calcium, magnesium, sodium, potassium (or sodium and potassium together calculated as sodium), carbonate, bicarbonate, sulfate, chloride, fluoride, nitrate, boron, $\mathrm{pH}$, dissolved solids, and specific conductance. Aluminum, manganese, color, acidity, dissolved oxygen, and other dissolved constituents and physical properties are reported for certain streams. Microbiologic (coliforms) and organic components (pesticides, total organic carbon) and minor elements (arsenic, cobalt, cadmium, copper, lead, mercury, nickel, strontium, zinc, etc.) are determined occasionally for some streams in connection with specific problems and the results are reported. The source and significance of the different constituents and properties of natural waters are discussed in the following paragraphs. The constituents are arranged in the order that they appear in the tables. 
Table 2.--Factors for conversion of sediment concentration in milligrams per liter to parts per million*

(All values calculated to three significant figures)

\begin{tabular}{|c|c|c|c|c|c|c|c|c|}
\hline \multicolumn{2}{|c|}{$\begin{array}{l}\text { Range of } \\
\text { concen- } \\
\text { tration } \\
\text { in } 1000 \\
\mathrm{mg} / 1\end{array}$} & $\begin{array}{l}\text { Di- } \\
\text { vide } \\
\text { by }\end{array}$ & $\begin{array}{l}\text { Range of } \\
\text { concen- } \\
\text { tration } \\
\text { in } 1000 \\
\mathrm{mg} / 1\end{array}$ & $\begin{array}{l}\text { Di- } \\
\text { vide } \\
\text { by }\end{array}$ & $\begin{array}{l}\text { Range of } \\
\text { concen- } \\
\text { tration } \\
\text { in } 1000 \\
\mathrm{mg} / 1\end{array}$ & $\begin{array}{l}\mathrm{Di}- \\
\text { vide } \\
\text { by }\end{array}$ & $\begin{array}{l}\text { Range of } \\
\text { concen- } \\
\text { tration } \\
\text { in } 1000 \\
\mathrm{mg} / 1\end{array}$ & $\begin{array}{l}\mathrm{Di}- \\
\text { vide } \\
\text { by }\end{array}$ \\
\hline 0 & -8 & 1.00 & $201-217$ & 1.13 & $411-424$ & 1.26 & $619-634$ & 1.39 \\
\hline 8.05 & $5-24$ & 1.01 & $218-232$ & 1.14 & $427-440$ & 1.27 & $636-650$ & 1.40 \\
\hline 24.2 & -40 & 1.02 & $234-248$ & 1.15 & $443-457$ & 1.28 & $652-666$ & 1.41 \\
\hline 40.5 & -56 & 1.03 & $250-264$ & 1.16 & $460-473$ & 1.29 & $668-682$ & 1.42 \\
\hline 56.5 & -72 & 1.04 & $266-280$ & 1.17 & $476-489$ & 1.30 & $684-698$ & 1.43 \\
\hline 72.5 & -88 & 1.05 & $282-297$ & 1.18 & $492-506$ & 1.31 & $700-715$ & 1.44 \\
\hline 88.5 & -104 & 1.06 & $299-313$ & 1.19 & $508-522$ & 1.32 & $717-730$ & 1.45 \\
\hline 105 & -120 & 1.07 & $315-329$ & 1.20 & $524-538$ & 1.33 & $732-747$ & 1.46 \\
\hline 121 & -136 & 1.08 & $331-345$ & 1.21 & $540-554$ & 1.34 & $749-762$ & 1.47 \\
\hline 137 & -152 & 1.09 & $347-361$ & 1.22 & $556-570$ & 1.35 & $765-780$ & 1.48 \\
\hline 153 & -169 & 1.10 & $363-378$ & 1.23 & $572-585$ & 1.36 & $782-796$ & 1.49 \\
\hline 170 & -185 & 1.11 & $380-393$ & 1.24 & $587-602$ & 1.37 & $798-810$ & 1.50 \\
\hline 186 & -200 & 1.12 & $395-409$ & 1.25 & $604-617$ & 1.38 & & \\
\hline
\end{tabular}

*Based on water density of $1.000 \mathrm{~g} / \mathrm{ml}$ and a specific gravity of sediment of $2.65 \mathrm{~g} / \mathrm{cc}$.

Table 3.--Degrees Celsius ( $C$ ) to degrees Fahrenheit $(F)^{*}$ (Temperature reported to nearest $0.5^{\circ} \mathrm{C}$ )

$\begin{array}{rrrrrrrrrr}{ }^{\circ} \mathrm{C} & { }^{\circ} \mathrm{F} & { }^{\circ} \mathrm{C} & { }^{\circ} \mathrm{F} & { }^{\circ} \mathrm{C} & { }^{\circ} \mathrm{F} & { }^{\circ} \mathrm{C} & { }^{\circ} \mathrm{F} & { }^{\circ} \mathrm{C} & { }^{\circ} \mathrm{F} \\ 0.0 & 32 & 10.0 & 50 & 20.0 & 68 & 30.0 & 86 & 40.0 & 104 \\ .5 & 33 & 10.5 & 51 & 20.5 & 69 & 30.5 & 87 & 40.5 & 105 \\ 1.0 & 34 & 11.0 & 52 & 21.0 & 70 & 31.0 & 88 & 41.0 & 106 \\ 1.5 & 35 & 11.5 & 53 & 21.5 & 71 & 31.5 & 89 & 41.5 & 107 \\ 2.0 & 36 & 12.0 & 54 & 22.0 & 72 & 32.0 & 90 & 42.0 & 108 \\ 2.5 & 36 & 12.5 & 54 & 22.5 & 72 & 32.5 & 90 & 42.5 & 108 \\ 3.0 & 37 & 13.0 & 55 & 23.0 & 73 & 33.0 & 91 & 43.0 & 109 \\ 3.5 & 38 & 13.5 & 56 & 23.5 & 74 & 33.5 & 92 & 43.5 & 110 \\ 4.0 & 39 & 14.0 & 57 & 24.0 & 75 & 34.0 & 93 & 44.0 & 111 \\ 4.5 & 40 & 14.5 & 58 & 24.5 & 76 & 34.5 & 94 & 44.5 & 112 \\ 5.0 & 41 & 15.0 & 59 & 25.0 & 77 & 35.0 & 95 & 45.0 & 113 \\ 5.5 & 42 & 15.5 & 60 & 25.5 & 78 & 35.5 & 96 & 45.5 & 114 \\ 6.0 & 43 & 16.0 & 61 & 26.0 & 79 & 36.0 & 97 & 46.0 & 115 \\ 6.5 & 44 & 16.5 & 62 & 26.5 & 80 & 36.5 & 98 & 46.5 & 116 \\ 7.0 & 45 & 17.0 & 63 & 27.0 & 81 & 37.0 & 99 & 47.0 & 117 \\ 7.5 & 45 & 17.5 & 63 & 27.5 & 81 & 37.5 & 99 & 47.5 & 117 \\ 8.0 & 46 & 18.0 & 64 & 28.0 & 82 & 38.0 & 100 & 48.0 & 118 \\ 8.5 & 47 & 18.5 & 65 & 28.5 & 83 & 38.5 & 101 & 48.5 & 119 \\ 9.0 & 48 & 19.0 & 66 & 29.0 & 84 & 39.0 & 102 & 49.0 & 120 \\ 9.5 & 49 & 19.5 & 67 & 29.5 & 85 & 39.5 & 103 & 49.5 & 121\end{array}$

$$
{ }^{*} \mathrm{C}=5 / 9(\mathrm{~F}-32) \text { or }{ }^{\circ} \mathrm{F}=9 / 5(\mathrm{C})+32 \text {. }
$$




\section{MINERAL CONSTITUENTS IN SOLUTION}

Silica $\left(\mathrm{SiO}_{2}\right)$

Silica is dissolved from practically all rocks. Some natural surface waters contain less than 5 milligrams per liter of silica and few contain more than $50 \mathrm{mg} / \mathrm{l}$, but the more common range is from 10 to $30 \mathrm{mg} / \mathrm{l}$. Silica affects the usefulness of a water because it contributes to the formation of boiler scale; it usually is removed from feed water for high-pressure boilers. Silica also forms troublesome deposits on the blades of steam turbines. However, it is not physiologically significant to humans, livestock, or fish, nor is it of importance in irrigation water.

Aluminum (Al)

Aluminum is usually present only in negligible quantities in natural waters except in areas where the waters have been in contact with the more soluble rocks of high aluminum content such as bauxite and certain shales. Acid waters often contain large amounts of aluminum. It may be troublesome in feed waters where it tends to be deposited as a scale on boiler tubes.

Iron $(\mathrm{Fe})$

Iron is dissolved from many rocks and soils. On exposure to air, normal basic waters that contain more than $1 \mathrm{mg} / 1$ of iron soon become turbid with the insoluble reddish ferric compounds produced by oxidation. Surface waters, therefore, seldom contain as much as $1 \mathrm{mg} / 1$ of dissolved iron, although some acid waters carry large quantities of iron in solution. Iron causes reddish-brown stains on porcelain or enameled ware and fixtures and on fabrics washed in the water. The highest desirable level of concentrations of iron in culinary and drinking water is $0.1 \mathrm{mg} / 1$ (100 ug/l) with a maximum permissible level of $1.0 \mathrm{mg} / 1(1000 \mathrm{ug} / 1)$. (International Standards for Drinking-Water (ISD-W), 1971).

Manganese (Mn)

Manganese is dissolved in appreciable quantities from rocks in some sections of the country. It resembles iron in its chemical behavior and in its occurrence in natural waters. However, manganese in rocks is less abundant than iron. As a result the concentration of manganese is much less than that of iron and is not regularly determined in many areas. It is especially objectionable in water used in laundry work and in textile processing. Concentrations as low as $0.2 \mathrm{mg} / 1(200 \mathrm{ug} / 1)$ may cause a dark-brown or black stain on fabrics and porcelain fixtures. Appreciable quantities of manganese are often found in waters containing objectionable quantities of iron.

\section{Calcium (Ca)}

Calcium is dissolved from almost all rocks and soils, but the highest concentrations are usually found in waters that have been in contact with limestone, dolomite, and gypsum. Calcium and magnesium make water hard and are largely responsible for the formation of boiler scale. Most waters associated with granite or silicious sands contain less than $10 \mathrm{mg} / \mathrm{l}$ of calcium; waters in areas where rocks are composed of dolomite and limestone contain from 30 to $100 \mathrm{mg} / \mathrm{l}$; and waters that have come in contact with deposits of gypsum may contain several hundred $\mathrm{mg} / \mathrm{l}$.

\section{Magnesium (Mg)}

Magnesium is dissolved from many rocks, particularly from dolomitic rocks. Its effect in water is similar to that of calcium. The magnesium in soft waters may amount to only 1 or $2 \mathrm{mg} / 1$, but water in areas that contain large quantities of dolomite or other magnesium-bearing rocks may contain from 20 to $100 \mathrm{mg} / 1$ or more of magnesium.

Sodium and potassium ( $\mathrm{Na}$ and $\mathrm{K}$ )

Sodium and potassium are dissolved from practically all rocks. Sodium is the predominant cation in some of the more highly mineralized waters found in the western United States. Natural waters that contain only 3 or $4 \mathrm{mg} / \mathrm{l}$ of the two together are likely to carry almost as much potassium as sodium. As the total quantity of these 
constituents increases, the proportion of sodium becomes much greater. Moderate quantities of sodium and potassium have little effect on the usefulness of the water for most purposes, but waters that carry more than 50 to $100 \mathrm{mg} / 1$ of the two may require careful operation of steam boilers to prevent foaming. More highly mineralized waters that contain a large proportion of sodium salts may be unsatisfactory for irrigation.

Bicarbonate, carbonate and hydroxide $\left(\mathrm{HCO}_{3}, \mathrm{CO}_{3}, \mathrm{OH}\right)$

Bicarbonate, carbonate, or hydroxide is sometimes reported as alkalinity. The alkalinity of a water is produced by anions or molecular species of weak acids which are not fully dissociated above a $\mathrm{pH}$ of 4.5. Since the major causes of alkalinity in most natural waters are carbonate and bicarbonate ions dissolved from carbonate rocks, the results are usually reported in terms of these constituents. Although alkalinity may suggest the presence of definite amounts of carbonate, bicarbonate or hydroxide, there are other ions that contribute to alkalinity such as silicates, phosphates, borates, possibly fluoride, and certain organic anions which may occur in colored waters. The significance of alkalinity to the domestic, agricultural, and industrial user is usually dependent upon the nature of the cations ( $\mathrm{Ca}, \mathrm{Mg}, \mathrm{Na}, \mathrm{K}$ ) associated with it. Alkalinity in moderate amounts does not adversely affect most users.

Hydroxide may occur in water that has been softened by the lime process. 1ts presence in streams usually can be taken as an indication of contamination and does not represent the natural chemical character of the water.

Sulfide (S)

Sulfide occurs in water as a result of bacterial and chemical processes. It usually is present as hydrogen sulfide. Variable amounts may be found in waters receiving sewage and (or) industrial wastes, such as from tanneries, papermills, chemical plants, and gas manufacturing work (California State Water Quality Control Board, 1963).

Waters containing sulfides, especially hydrogen sulfide, may be considered undesirable because of their odor. The toxicity to aquatic organisms differs significantly with the species and the nature of associated ions.

\section{Sulfate $\left(\mathrm{SO}_{4}\right)$}

Sulfate is dissolved from most sedimentary rocks. Large quantities may be derived from beds of gypsum, sodium sulfate deposits, and some types of shale. Organic material containing sulfur adds sulfate to the water as a phase of the sulfur cycle. In natural waters, concentrations range froma few $\mathrm{mg} / 1$ to several thousand $\mathrm{mg} / 1$.

ISD-W (1971) recommends $200 \mathrm{mg} / 1$ as the highest desirable level of sulfate concentration in drinking and culinary water.

Sulfates are less toxic to crops than chlorides.

Chloride (C1)

Chloride is dissolved from rock materials in all parts of the country. Surface waters in the humid regions are usually low in chloride, whereas streams in arid or semiarid regions may contain several hundred $\mathrm{mg} / \mathrm{l}$ of chloride leached from soils and rocks, especially where the streams receive return drainage from irrigated lands or are affected by ground-water-inflow carrying appreciable quantities of chloride. Large quantities of chloride in water that contains a high content of calcium and magnesium increases the water's corrosiveness. The presence of abnormal concentrations of chloride and nitrogenous material together in water supplies indicates possible pollution by human or animal wastes.

\section{Fluoride (F)}

Fluoride has been reported as being present in some rocks to about the same extent as chloride. However, the quantity of fluoride in natural surface waters is ordinarily very small compared to that of chloride. Investigations have proved that fluoride concentrations of about 0.6 to $1.7 \mathrm{mg} / 1$ reduced the incidence of dental caries and that concentrations greater than $1.7 \mathrm{mg} / \mathrm{l}$ also protect the teeth from cavities 
but cause an undesirable black stain (Durfor and Becker, 1964, p. 20). Public Health Service, 1962, states, "When fluoride is naturally present in drinking water, the concentration should not average more than the appropriate upper control limit $(0.6$ to $1.7 \mathrm{mg} / 1$ ). Presence of fluoride in average concentration greater than two times the optimum values shall constitute grounds for rejection of the supply." Concentration higher than the stated limits may cause mottled enamel in teeth, endemic cumulative fluorosis, and skeletal effects.

Bromide (Br)

Bromine is a very minor element in the earth's crust and is normally present in surface waters in only minute quantities. Measurable amounts may be found in some streams that receive industrial wastes, and some natural brines may contain rather high concentrations. It resembles chloride in that it tends to be concentrated in sea water.

Iodide (I)

lodide is considerably less abundant both in rocks and water than bromine. Measurable amounts may be found in some streams that receive industrial wastes, and some natural brines may contain rather high concentrations. It occurs in sea water to the extent of less than $1 \mathrm{mg} / \mathrm{l}$. Rankama and Sahama (1950) report iodide present in rainwater to the extent of 0.001 to $0.003 \mathrm{mg} / 1$ and in river water in about the same amount. Few waters will contain over $2.0 \mathrm{mg} / 1$.

Nitrogen, organic (N)

Organic nitrogen includes all nitrogenous organic compounds, such as amino acid, polypeptides, and proteins. It is present naturally in all surface waters as the result of inflow of nitrogenous products from the watershed and the normal biological life of the stream.

Organic nitrogen is not pathologically significant but is sometimes an indication of pollution.

Nitrogen, ammonia $\left(\mathrm{NH}_{4}\right.$, as $\left.\mathrm{N}\right)$

Ammonia nitrogen includes nitrogen in the forms of $\mathrm{NH}_{3}$ and $\mathrm{NH}_{4}^{+1}$. As a component of the nitrogen cycle, it is often present in water, but usually in only small amounts. More than $0.1 \mathrm{mg} / 1$ usually indicates organic pollution (Rudolph, 1931).

There is no evidence that ammonia nitrogen in water is physiologically significant to man or livestock. Fish, however, cannot tolerate large quantities.

Nitrite $\left(\mathrm{NO}_{2}\right)$

Nitrite is unstable in the presence of oxygen and is, therefore, absent or present in only minute quantities in most natural waters under aerobic condition. The presence of nitrite in water is sometimes an indication of organic pollution.

Recommended tolerances of nitrite in domestic water supplies differ widely. A generally accepted limit is $2 \mathrm{mg} / 1$, but as little as $0.1 \mathrm{mg} / 1$ has been proposed (California State Water Quality Control Board, 1963).

Nitrate $\left(\mathrm{NO}_{3}\right)$

Nitrate in water is considered a final oxidation product of nitrogenous material and may indicate contamination by sewage or other organic matter, such as agricultural runoff, or industrial waste. The quantities of nitrate present in surface waters are generally less than $5 \mathrm{mg} / 1$ (as $\mathrm{NO}_{3}$ ) and have no effect on the value of the water for ordinary uses.

It has been reported that as much as $2 \mathrm{mg} / 1$ of nitrate in boiler water tends to decrease intercrystalline cracking of boiler steel. Studies made by Faucett and Miller (1946), Waring (1949) and by the National Research Council (Maxcy, 1950) concluded that drinking water containing nitrates in excess of $44 \mathrm{mg} / \mathrm{l}$ (as $\mathrm{NO}_{3}$ ) should be regarded as unsafe for infant feeding. ISD-W (1971) sets $45 \mathrm{mg} / 1$ as the upper limit. 
Phosphorus (P)

Phosphorus is an essential element in the growth of plants and animals. It occurs in water as organically bound phosphorus or as phosphate $\left(\mathrm{PO}_{4}\right)$. Some sources that contribute nitrate, such as organic wastes are also important sources of phosphorus. The addition of phosphates in water treatment constitutes a possible source although the dosage is usually small. In some areas phosphate fertilizers may yield some phosphorus to water. Another important source is the use of phosphates in detergents. Domestic and industrial sewage effluents often contain considerable amounts of phosphorus. Concentrations of phosphorus found in water are not reported to be toxic to man, animal, or fish. However, the element can stimulate the growth of algae, which may cause taste and odor problems in public water treatment and esthetic problems in recreation areas.

Boron (B)

Boron in small quantities has been found essential for plant growth, but irrigation water containing more than $1 \mathrm{mg} / 1$ boron is detrimental to citrus and other boronsensitive crops. Boron is reported in Survey analyses of surface waters in arid and semiarid regions of the Southwest and West where irrigation is practiced or contemplated, but few of the surface waters analyzed have harmful concentrations of boron.

\section{Dissolved solids}

The reported quantity of dissolved solids--the residue on evaporation--consists mainly of the dissolved mineral constituents in the water. It may also contain some organic matter and water of crystallization. Waters with less than $500 \mathrm{mg} / \mathrm{l}$ of dissolved solids are usually satisfactory for domestic and some industrial uses. Water containing several thousand $\mathrm{mg} / \mathrm{l}$ of dissolved solids are sometimes successfully used for irrigation where practices permit the removal of soluble salts through the application of large volumes of water on well-drained lands, but generally water containing more than about $2,000 \mathrm{mg} / \mathrm{l}$ is considered to be unsuitable for long-term irrigation under average conditions.

\section{Arsenic (As)}

Arsenic compounds are present naturally in some waters, but the occurrence of quantities detrimental to health is rare. Weed killers, insecticides and many industrial effluents contain arsenic and are potential sources of water pollution. The upper limits of arsenic concentration in drinking water should not exceed $0.05 \mathrm{mg} / 1(50 \mathrm{ug} / 1)$ and it would seem wiser to keep the level as low as possible (ISD-W, 1971). Concentrations of 2-4 mg of arsenic per liter are reported not to interfere with the self-purification of streams (Rudolfs and others, 1944) but concentrations in excess of $15 \mathrm{mg} / 1 \mathrm{may}$ be harmful to some fish.

\section{Barium (Ba)}

Barium may replace potassium in some of the igneous rock minerals, especially feldspar, and barium sulfate (barite) is a common barium mineral of secondary origin. Only traces of barium are present in surface water and sea water. Because natural water contains sulfate, barium will dissolve only in trace amounts. Barium sometimes occurs in brines from oil-well wastes.

Bariut. concentrations in excess of $1.0 \mathrm{mg} / 1$ is not suitable for drinking and culinary use because of the serious toxic effects of barium on heart, blood vessels, and nerves.

Cadmium (Cd)

This element is found in nature largely in the form of the sulfide, and as an impurity in zinc-lead ores. The carbonate and hydroxide are not very soluble in water and will precipitate at high $\mathrm{pH}$ values; the chloride, nitrate, and sulfate are soluble and remain in solution under most $\mathrm{pH}$ conditions.

The extensive use of the element and its salts in metallurgy, electroplating, ceramics, and photography make it a frequent component of industrial wastes. 
The results of animal studies suggest that very small amounts of cadmium can produce nephrotoxic and cardiovascular effects. The reproductive organs of animals are specifically affected after parenteral administration of very small amounts of cadmium salts. The level of cadmium concentration proposed for water use is $0.01 \mathrm{mg} / 1$ (10 ug/1) or the lowest concentration that can be conveniently measured (1SD-W, 1971).

Chromium (Cr)

Few if any waters contain chromium from natural sources. Natural waters can probably contain only traces of chromium as a cation unless the $\mathrm{pH}$ is very low. When chromium is present in water, it is usually the result of pollution by industrial wastes. Concentrations of more than $0.05 \mathrm{mg} / 1$ of chromium in the hexavalent form constitute grounds for rejection of a water for domestic use on the basis of the standards of the U.S. Public Health Service (1962).

\section{Cobalt (Co)}

Cobalt occurs in nature in the minerals smaltite, (Co, Ni)As, and cobaltite, CoAsS. Alluvial deposits and soils derived from shales often contain cobalt in the form of phosphate or sulfate, but other soil types may be markedly deficient in cobalt in any form (Bear, 1955). Ruminant animals may be adversely affected by grazing on land deficient in cobalt.

For domestic water supplies, no maximum safe concentration has been established. Copper $(\mathrm{Cu})$

Copper is a fairly common trace constituent of natural water. Small amounts may be introduced into water by solution of copper and brass water pipes and other copperbearing equipment in contact with the water, or from copper salts added to control algae in open reservoirs. Copper salts such as the sulfate and chloride are highly soluble in waters with a low $\mathrm{pH}$ but in water of normal alkalinity the salts hydrolyze and the copper may be precipitated. In the normal $\mathrm{pH}$ range of natural water containing carbon dioxide, the copper might be precipitated as carbonate. The oxidized portions of sulfide-copper ore bodies contain other copper compounds. The presence of copper in mine water is common.

Copper imparts a disagreeable metallic taste to water. As little as $1.5 \mathrm{mg} / 1 \mathrm{can}$ usually be detected, and $5 \mathrm{mg} / 1$ can render the water unpalatable. Copper is not considered to be a cumulative systemic poison like lead and mercury; most copper ingested is excreted by the body and very little is retained. The pathological effects of copper are controversial, but it is generally believed very unlikely that humans could unknowingly ingest toxic quantities from palatable drinking water. The U.S. Public Health Service (1962) recommends that copper should not exceed $1.0 \mathrm{mg} / 1(10 \mathrm{ug} / 1)$ in drinking and culinary water. ISD- $W, 1971$ gives $0.05 \mathrm{mg} / 1(50 \mathrm{ug} / 1)$ as the highest desirable level.

Lead $(\mathrm{Pb})$

Lead seldom occurs in most natural waters, but industrial mine and smelter effluents may contain relatively large amounts of lead which contaminates the streams. Also, atmospheric contamination which is produced from several types of engine exhausts has considerably increased the availability of this element for solution in rainfall, resulting in contamination of lead in streams (Hem, 1970).

Lead in the form of sulfate is reported to be soluble in water to the extent of $31 \mathrm{mg} / 1$ (Seidell, 1940) at $25^{\circ} \mathrm{C}$. In natural water this concentration would not be approached, however, since a $\mathrm{pH}$ of less than 4.5 would probably be required to prevent formation of lead hydroxide and carbonate. It is reported (Pleissner, 1907) that at $18^{\circ} \mathrm{C}$ water free of carbon dioxide will dissolve the equivalent of $1.4 \mathrm{mg} / 1$ of lead and the solubility is increased nearly four fold by the presence of $2.8 \mathrm{mg} / 1$ of carbon dioxide in the solution. Presence of other ions may increase the solubility of lead. Reports on human tolerance of lead vary widely. U.S. Public Health Service (1962) states that lead shall not exceed $0.05 \mathrm{mg} / \mathrm{l}(50 \mathrm{ug} / \mathrm{l})$ in drinking and culinary water on carriers subject to Federal quarantine regulations. ISD-W, 1971 gives $0.10 \mathrm{mg} / 1(100 \mathrm{ug} / 1)$ as the upper limit. 


\section{Lithium (Li)}

Lithium is present in some minerals but is not abundant in nature. From available information, most fresh waters rarely contain lithium of concentrations exceeding $10 \mathrm{mg} / \mathrm{l}$, but larger quantities may be present in brines and thermal waters. Lithium is used in metallurgy, medicinal water, and some types of glass and storage batteries. Waste from such industries may contain lithium.

\section{Mercury (Hg)}

Mercury is the only common metal which is liquid at ordinary temperatures. It occurs free in nature but its chief source is cinnabar (HgS). Mercury compounds are virulent culminative poisons which are readily absorbed through the respiratory and gastrointestinal tracts or through unbroken skin (Weast and Selby, 1967).

The main source of high concentrations of dissolved mercury in water, in the form of highly toxic methyl mercury, $\mathrm{Hg}\left(\mathrm{CH}_{3}\right)_{2}$, comes from waste discharges from industrial users of mercury and from mercurial pesticides.

Fish from streams and lakes subject to mercury contamination have been found to contain amounts of mercury above the safe limits for food consumption. The U.S. Public Health Service has proposed that the upper limits of dissolved mercury in water for domestic use should not exceed 5 micrograms per liter $(0.005 \mathrm{mg} / 1)$. ISD-W, 1971 recommends $0.001 \mathrm{mg} / 1(1 \mathrm{ug} / \mathrm{l})$ as the upper limits of concentration.

Nickel ( $\mathrm{Ni})$

Elemental nickel seldom occurs in nature, but its compounds are found in many ores and minerals. Many nickel salts are quite soluble and may contribute to water pollution, especially when discharged from metal-plating industries.

No set limit of nickel concentration has been established for public water supply. Strontium (Sr)

Strontium is a typical alkaline-earth element and is similar chemically to calcium. Strontium may be present in natural water in amounts up to a few $\mathrm{mg} / \mathrm{l}$ much more frequently than the available data indicate. In most surface water the amount of strontium is small in proportion to calcium. However, in sea water the ratio of strontium to calcium is $1: 30$.

Zinc $(\mathrm{Zn})$

Zinc is abundant in rocks and ores but is only a minor constituent in natural water because the free metal and its oxides are only sparingly soluble. In most alkaline surface waters it is present only in trace quantities, but more may be present in acid water. Chlorides and sulfates of zinc are highly soluble. Zinc is used in many commercial products, and industrial wastes may contain large amounts.

Zinc in water does not cause serious effects on health, but produces undesirable esthetic effects. 1SD-W, 1971 gives $5 \mathrm{mg} / 1(5000 \mathrm{ug} / \mathrm{l})$ of zinc content as the highest desirable level for drinking water and $15 \mathrm{mg} / 1$ as the maximum permissible level.

\section{PROPERTIES AND CHARACTERISTICS OF WATER}

Dissolved solids

Theoretically, dissolved solids are anhydrous residues of the dissolved substances in water.

All solutes affect the chemical and physical properties of the water and result in an osmotic pressure. Water with several thousand $\mathrm{mg} / \mathrm{l}$ of dissolved solids is generally not palatable, although those accustomed to highly mineralized water may complain that less concentrated water tastes flat. The U.S. Public Health Service (1962) recommends that the maximum concentration of dissolved solids not exceed $500 \mathrm{mg} / 1$ in drinking and culinary water on carriers subject to Federal quarantine regulations, but permits 1,000 $\mathrm{mg} / 1$ if no better water is available. ISD-W (1971) recommends $500 \mathrm{mg} / 1$ as the highest desirable level and $1500 \mathrm{mg} / 1$ as the maximum permissible level. Reported livestock 
tolerances range from $3,000 \mathrm{mg} / 1$ (Colorado Agricultural Experiment Station, 1943) to $15,000 \mathrm{mg} / 1$ (Heller, 1933).

Industrial tolerances for dissolved solids differ widely, but few industrial processes will permit more than $1,000 \mathrm{mg} / 1$. The Geological Survey classifies the degree of salinity of these more mineralized bodies of water as follows (Swenson and Baldwin, 1965):

$\begin{array}{lll}\text { Dissolved solids (mg/1) } & \text { Degree of salinity } \\ \text { Less than } 1,000 \ldots \ldots \ldots & \ldots \ldots & \text { Nonsaline. } \\ 1,000 \text { to } 3,000 \ldots \ldots & \ldots \ldots & \text { Slightly saline. } \\ 3,000 \text { to } 10,000 \ldots \ldots & \ldots \ldots & \text { Moderately saline. } \\ 10,000 \text { to } 35,000 \ldots \ldots & \ldots & \text { Very saline. }\end{array}$

Hardness

Hardness is the characteristic of water that receives the most attention in industrial and domestic use. It is commonly recognized by the increased quantity of soap required to produce lather. The use of hard water is also objectionable because it contributes to the formation of scale in boilers, water heaters, radiators, and pipes, with the resultant decrease in rate of heat transfer, possibility of boiler failure, and loss of flow.

Hardness is caused almost entirely by compounds of calcium and magnesium. Other constituents--such as iron, manganese, aluminum, barium, strontium, and free acid--also cause hardness, although they usually are not present in quantities large enough to have any appreciable effect.

Generally, bicarbonate and carbonate determine the proportions of "carbonate" hardness of water. Carbonate hardness is the amount of hardness chemically equivalent to the amount of bicarbonate and carbonate in solution. Carbonate hardness is approximately equal to the amount of hardness that is removed from water by boiling.

Noncarbonate hardness is the difference between the hardness calculated from the total amount of calcium and magnesium in solution and the carbonate hardness. The scale formed at high temperatures by the evaporation of water containing noncarbonate hardness commonly is tough, heat resistant, and difficult to remove.

Although many people talk about soft water and hard water, there has been no firm line of demarcation. Water that seems hard to an easterner may seem soft to a westerner. In this report hardness of water is classified as follows:

\begin{tabular}{|c|c|}
\hline $\begin{array}{l}\text { Hardness range } \\
\text { (calcium carbonate in } \mathrm{mg} / \mathrm{l} \text { ) }\end{array}$ & Hardness description \\
\hline $\begin{array}{lllll}0-60 & \ldots & \ldots & \ldots & \ldots\end{array}$ & $\begin{array}{l}\text { Soft } \\
\text { Moderately hard } \\
\text { Hard } \\
\text { Very hard }\end{array}$ \\
\hline
\end{tabular}

Durfor and Becker, 1964, p. 23-27.

Acidity $\left(\mathrm{H}^{+1}\right)$

The use of the terms acidity and alkalinity is widespread in the literature of water analysis and is a cause of confusion to those who are more accustomed to seeing a $\mathrm{pH}$ of 7.0 used as a neutral point. Acidity of a natural water represents the content of free carbon dioxide and other uncombined gases, organic acids and salts of strong acids and weak bases that hydrolyze togive hydrogen ions. Sulfates of iron and aluminum in mine and industrial wastes are common sources of acidity.

Sodium adsorption ratio (SAR)

The term "sodium adsorption ratio (SAR)" was introduced by the U.S. Salinity Laboratory Staff (1954). It is a ratio expressing the relative activity of sodium ions 
in exchange reaction with soil and is an index of the sodium or alkali hazard to the soil. Sodium adsorption ratio is expressed by the equation:

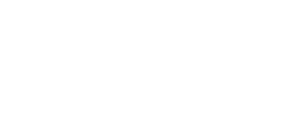

where the concentrations of the ions are expressed in milliequivalents per liter.

Waters are divided into four classes with respect to sodium or alkali hazard: low, medium, high, and very high, depending upon the SAR and the specific conductance. At a conductance of 100 micromhos per centimeter the dividing points are at SAR values of 10,18 , and 26 , but at 5,000 micromhos the corresponding dividing points are SAR values of approximately $2.5,6.5$, and 11 . Waters range in respect to sodium $\mathrm{h}$-zard from those which can be used for irrigation on almost all soils to those which are generally unsatisfactory for irrigation.

Specific conductance (micromhos per centimeter at $25^{\circ} \mathrm{C}$ )

Specific conductance is a convenient, rapid determination used to estimate the amount of dissolved solids in water. It is a measure of the ability of water to transmit a small electrical current (see p. 6). The more dissolved solids in water that can transmit electricity the greater the specific conductance of the water. Commonly, the amount of dissolved solids (in $\mathrm{mg} / \mathrm{l}$ ) is about 65 percent of the specific conductance (in micromhos). This relation is not constant from stream to stream or from well to well and it may even vary in the same source with changes in the composition of the water (Durfor and Becker, 1964 p. 27-29).

Specific conductance of most waters in the eastern United States is less than 1,000 micromhos, but in the arid western parts of the country, a specific conductance of more than 1,000 micromhos is common.

Hydrogen-ion concentration $(\mathrm{pH})$

Hydrogen-ion concentration is expressed in terms of $\mathrm{pH}$ units (see p. 6 ). The values of $\mathrm{pH}$ often are used as a measure of the solvent power of water or as an indicator of the chemical behavior certain solutions may have toward rock minerals.

The degree of acidity or alkalinity of water, as indicated by the hydrogen-ion concentration, expressed as $\mathrm{pH}$, is related to the corrosive properties of water and is useful in determining the proper treatment for coagulation that may be necessary at water-treatment plants. $\mathrm{A} \mathrm{pH}$ of 7.0 indicates that the water is neither acid nor alkaline. $\mathrm{pH}$ readings progressively lower than 7.0 denote increasing acidity and those progressively higher than 7.0 denote increasing alkalinity. The $\mathrm{pH}$ of most natural surface waters ranges between 6 and 8. Some alkaline surface waters have pH values greater than 8.0 and waters containing free mineral acid or organic matter usually have $\mathrm{pH}$ values less than 4.5 .

The investigator who utilizes $\mathrm{pH}$ data in his interpretations of water analyses should be careful to place $\mathrm{pH}$ values in their proper perspective.

\section{Temperature}

Temperature is an important factor in properly determining the quality of water. This is very evident for such a direct use as an industrial coolant. Temperature is also important, but perhaps not so evident, for its indirect influence upon aquatic biota, concentrations of dissolved gases, and distribution of chemical solutes in lakes and reservoirs as a consequence of thermal stratification and variation.

Surface water temperatures tend to change seasonally and daily with air temperatures, except for the outflow of large springs. Superimposed upon the annual temperature cycle is a daily fluctuation of temperature which is greater in warm seasons than in cold and greater in sunny periods than with a cloud cover. Natural warming is due mainly to absorption of a solar radiation by the water and secondarily to transfer of heat from the air. Condensation of water vapor at the water surface is reported to furnish measurable quantities of heat. Heat loss takes place largely through radiation, with further 
losses through evaporation and conduction to the air and to the streambed. Thus the temperature of a small stream generally reaches a maximum in mid- to late afternoon due to solar heating and reaches a minimum from early to mid-morning after nocturnal radiation.

Color

In water analysis the term "color" refers to the appearance of water that is free from suspended solids. Many turbid waters that appear yellow, red, or brown when viewed in the stream show very little color after the suspended matter has been removed. The yellow-to-brown color of some waters is usually caused by organic matter extracted from leaves, roots, and other organic substances in the ground. In some areas objectionable color in water results from industrial wastes and sewage. Clear deep water may appear blue as the result of a scattering of sunlight by the water molecules. Water for domestic use and some industrial uses should be free from any perceptible color. A color less than 15 units generally passes unnoticed (U.S. Public Health Service, 1962). Some swamp waters have natural color in excess of 300 units.

The extent to which a water is colored by material in solution is commonly reported as a part of a water analysis because a significant color in water may indicate the presence of organic material that may have some bearing on the dissolved solids content. Color in water is expressed in terms of units between 0 and 500 or more based on the above standard (see p. 6 ).

\section{Turbidity}

Turbidity is the optical property of a suspension with reference to the extent to which the penetration of light is inhibited by the presence of insoluble material. Turbidity is a function of both the concentration and particle size of the suspended material. It is reported in terms of $\mathrm{mg} / \mathrm{l}$ of silica or Jackson turbidity units (JTU).

Turbid water is abrasive in pipes, pumps, and turbine blades. Although turbidity does not directly measure the safety of drinking water, it is related to the consumer's acceptance of the water. The highest desirable level of turbidity for drinking water is 5 JTU with a maximum permissible level of 25 JTU (1SD-W, 1971).

Density at $20^{\circ} \mathrm{C}$

Density is the mass of any substance per unit volume at a designated standard temperature. Density should not be confused with specific gravity, which is a massto-mass relation.

The density value has some use in industries that utilize brines and whose basic unit of concentration of dissolved material is density. Density is used primarily by the chemist in the computation of milligrams per liter for highly mineralized waters.

\section{Dissolved oxygen (DO)}

Oxygen dissolved in water is derived from the air and from the oxygen given off in the process of photosynthesis by aquatic plants.

Dissolved oxygen in water has no adverse physiological effect and actually increases the palatability of the water. No minimum concentration of dissolved oxygen required to support fish life has been listed because the oxygen requirements of fish vary with the species and age, with temperature, and with concentration of other substances in the water.

Dissolved oxygen is responsible for many of the corrosion problems in industry. Chemical Oxygen demand (COD)

Chemical oxygen demand is a measure of the chemically oxidizable material in the water, and furnishes an approximation of the amount of organic and reducing material present. The determined value may correlate with natural-water color or with carbonaceous organic pollution from sewage or industrial wastes. 
Biochemical oxygen demand (BOD)

Biochemical oxygen demand is a measure of the oxygen required to oxidize the organic material usable as a source of food by aerobic organisms.

Biological and microbiological information

Biological and microbiological information is an important aspect in the evaluation of water quality. The kinds and amount of aquatic biota in a stream or lake can be useful "indicators" of environmental conditions and particularly of the degree of pollution of water with organic wastes (Doudoroff and Warren, 1957). Biological information includes qualitative and quantitative analyses of plankton, bottom organisms, and particulate inorganic and amorphous matter present. Microbiological information includes quantitative identification of certain bacteriological indicator organisms.

Chlorophyll (plant pigment).--The concentrations of photosynthetic pigments in natural waters vary with time and changing aquatic conditions. Concentrations of chlorophyll $\underline{\mathrm{a}}, \underline{\mathrm{b}}$, and $\underline{\mathrm{c}}$ (spectrophotometric determination) are used to estimate the biomass and photosynthetic capacity of phytoplankton (blue-green algae). Ratios between the different forms of chlorophyll are thought to indicate the taxonomic composition or the physiological state of the algae community (Slack, 1970).

Plankton.--Plankton is the floating (or weakly swimming) animal or plant life in a body of water consisting, chiefly of minute plants (as diatomes and blue-green algae) and of minute animals (as protozoan, entomostracans and various larvae). Algae are known to cause tastes and odor in water supply.

Plankton population in water is obtained by count level (the number of organisms per milliliter).

Coliform bacteria.--Coliform organisms have long been used as indicators of sewage pollution, although the group includes bacteria from diverse natural sources and habitats. For example, members of the coliform group are indigenous to soil and vegetation as well as feces. Standards for drinking-water quality provide definite minimums as to number of samples examined and the maximum number of coliform organisms allowable per 100 milliliters (ml) of finished water (Slack, 1970). The coliform population of water is determined either by the most probable number (MPN), or by the incubation membrane filter method, a direct count of coliform colonies per plate.

Fecal coliform bacteria.--Fecal coliform is that portion of the coliform group that is present in the intestinal tract of warm-blooded animals and is capable of producing gas from lactos in suitable culture medium at $44.5^{\circ} \mathrm{C}$. Organisms from other sources generally cannot produce gas in this manner. (American Public Health Assoc. and others, 1965). Thus, in general, the presence of fecal coliform organisms indicates recent pollution (Slack, 1970).

Organics

Phenols.-- Phenolic material in water resources is invariably the result of pollution. Phenols are widely used as disinfectants and in the synthesis of many organic compounds. Waste products from oil refineries, coke areas, and chemical plants may contain high concentrations. Fortunately, phenols decompose in the presence of oxygen and microorganisms, and their persistence downstream from point of entry is relatively short lived. The rate of decomposition is dependent on the environment.

Very low concentrations impart such a disagreeable taste to water that it is highly improbable that harmful amounts could be consumed unknowingly. Reported thresholds of detection of taste and odor range from 0.001 to $0.01 \mathrm{mg} / 1$.

Cyanide $(\mathrm{CN})$.--Cyanides are not found free in nature, but may become contaminants of water supplies by means of effluents from gasworks, coke ovens, steel mills, electroplating processes, and chemical industries. In natural streams and organic soils, simple cyanides are decomposed by bacterial action, whereas the metal-cyanide complexes are often quite stable and more resistant to degradation. The U.S. Public Health Service (1962) set a recommended limit of $0.01 \mathrm{mg}$ cyanide per liter and a 
mandatory limit of $0.2 \mathrm{mg} / 1$ for waters subject to interstate regulations. ISD-W (1971) sets the upper limit for drinking water as $0.05 \mathrm{mg} / \mathrm{l}$.

Detergents (methylene blue active substance, MBAS).-- Anionic surfactants in detergents resist chemical oxidation and biological breakdown. Soap is an example of this class and the synthetic members are sodium salts of organic sulfonates or sulfates (Rose, 1966). Their persistence in water over long periods of time contributes to pollution of both ground water and surface water. Some of the effects produced from detergent pollution are unpleasant taste, odor, and foaming (Wayman, and others, 1962). Although the physiological implications of MBAS to human beings is unknown, prolonged ingestion of this material by rats is believed to be nontoxic (Paynter, 1960). The U.S. Public Health Service (1962) recommends that MBAS should not exceed $0.5 \mathrm{mg} / 1$ in drinking and culinary waters. ISD-W (1971) sets $0.2 \mathrm{mg} / 1$ as the highest desirable level and $1.0 \mathrm{mg} / \mathrm{l}$ as the maximum permissible level.

Total Organic Carbon (TOC).-- Total organic carbon is a measure of the organically related carbonaceous content of water. It includes all natural and manmade organic compounds which are combustable at a temperature of $950^{\circ} \mathrm{C}$.

\section{Sediment}

Fluvial sediment generally is regarded as that material which is transported by, suspended in, or deposited by water. Suspended sediment is that part which remains in suspension in water owing to the upward components of turbulent currents or by colloidal suspension. Much fluvial sediment results from the natural process of erosion, which in turn is part of the geologic cycle of rock transformation. This natural process may be accelerated by agricultural practices. Sediment also is contributed by a number of industrial and construction activities. In certain sections, waste materials from mining, logging, oil-field, and other industrial operations introduce large quantities of suspended material.

The quantity of sediment, transported or available for transportation, is affected by climatic conditions, form or nature of precipitation, character of the solid mantle, plant cover, topography, and land use. The mode and rate of sediment erosion, transport, and deposition is determined largely by the size distribution of the particles or more precisely by the fall velocities of the particles in water. Sediment particles in the sand size range (larger than $0.062 \mathrm{~mm}$ ) do not appear to be affected by flocculation or dispersion resulting from the mineral constituents in solution. In contrast, the sedimentation diameter of clay and silt particles in suspension may vary considerably from point to point in a stream or reservoir, depending on the mineral matter in solution and in suspension and the degree of turbulence present. The size of sediment particles in transport at any point depends on the type of erodible and soluble material in the drainage area, the degree of flocculation present, time in transport, and characteristics of the transporting flow. The flow characteristics include velocity of water, turbulence, and the depth, width, and roughness of the channel. As a result of these variable characteristics, the size of particles transported, as well as the total sediment load, is in constant adjustment with the characteristics and physical features of the stream and drainage area.

\section{STREAMFLOW}

Most of the records of stream discharge, used in conjunction with the chemical analyses and in the computation of sediment loads in this volume, are published in the Geogogical Survey water-supply paper series, "Surface Water Supply of the United States, 1966-70." The discharge reported for a composite sample is usually the average of daily mean discharges for the composite period. The discharges reported in the tables of single analyses are either daily mean discharges or discharges obtained at the time samples were collected and computed from a stage-discharge relation or from a discharge measurement. 


\section{PUBLICATIONS}

Reports giving records of chemical quality and temperatures of surface waters and suspended-sediment loads of streams in the area covered by this volume for the water years 1941-69, are listed below:

Numbers of water-supply papers containing records for Part 11, 1941-69

$\begin{array}{rrrrrrrr}\text { Year } & \text { WSP } & \text { Year } & \text { WSP } & \text { Year } & \text { WSP } & \text { Year } & \text { WSP } \\ 1941 & 942 & 1949 & 1163 & 1957 & 1523 & 1965 & 1965 \\ 1942 & 950 & 1950 & 1189 & 1958 & 1574 & 1966 & 1995 \\ 1943 & 970 & 1951 & 1200 & 1959 & 1645 & 1967 & 2015 \\ 1944 & 1022 & 1952 & 1253 & 1960 & 1745 & 1968 & 2099 \\ 1945 & 1030 & 1953 & 1293 & 1961 & 1885 & 1969 & 2149 \\ 1946 & 1050 & 1954 & 1353 & 1962 & 1945 & & \\ 1947 & 1102 & 1955 & 1403 & 1963 & 1951 & & \\ 1948 & 1133 & 1956 & 1453 & 1964 & 1958 & & \end{array}$

Geological Survey reports containing chemical quality, temperature, and sediment data obtained before 1941 are listed below. Publications dealing largely with the quality of ground-water supplies and only incidentally covering the chemical composition of surface waters are not included. Publications that are out of print are preceded by an asterisk.

PROFESSIONAL PAPER

*135. Composition of river and lake waters of the United States, 1924.

BULLETINS

*479. The geochemical interpretation of water analyses, 1911.

770. The data of geochemistry, 1924.

\section{WATER-SUPPLY PAPERS}

*108. Quality of water in the Susquehanna River drainage basin, with an introductory chapter on physiographic features, 1904.

*161. Quality of water in the upper Ohio River basin and at Erie, Pa., 1906.

*193. The quality of surface waters in Minnesota, 1907.

*236. The quality of surface waters in the United States, Part 1, Analyses of waters east of the one hundredth meridian, 1909.

*237. The quality of the surface waters of California, 1910.

*239. The quality of surface waters of Illinois, 1910.

*273. Quality of the water supplies of Kansas, with a preliminary report on stream pollution by mine waters in southeastern Kansas, 1911.

*274. Some stream waters of the western United States, with chapters on sediment carried by the Rio Grande and the industrial application of water analyses, 1911.

*339. Quality of the surface waters of Washington, 1914.

*363. Quality of the surface waters of Oregon, 1914.

*418. Mineral springs of Alaska, with a chapter on the chemical character of some surface waters of Alaska, 1917.

*596-B. Quality of water of Colorado River in 1925-26, 1928.

*596-D. Quality of water of Pecos River in Texas, 1928.

*596-E. Quality of the surface waters of New Jersey, 1928.

*636-A. Quality of water of the Colorado River in 1926-28, 1930.

*636- B. Suspended matter in the Colorado River in 1925-28, 1930.

*638-D. Quality of water of the Colorado River in 1928-30, 1932.

*839. Quality of water of the Rio Grande basin above Fort Quitman, Tex., 1938. 
*889-E. Chemical charactex of surface water of Georgia, 1944.

*998. Suspended sediment in the Colorado River, 1925-41, 1947.

1048. Discharge and sediment loads in the Boise River drainage basin, Idaho, $1939-40,1948$.

1110-C. Quality of water of Conchas Reservoir, New Mexico, 1939-49, 1952.

Many of the reports listed are available for consultation in the larger public and institutional libraries. Copies of Geological Survey publications still in print may be purchased at a nominal cost from the Superintendent of Documents, Government Printing Office, Washington, D.C. 20402, who will, upon request, furnish lists giving prices.

\section{COOPERATION}

The records given in this report were obtained through the cooperation and support of the State of California, Iocal, and Federal agencies, and with funds appropriated directly to the U.S. Geological Survey. The State, local and Federal agencies that shared in the collection of these records are as follows:

California Department of Water Resources; California Regional Water Quality Control Board; Central Valley Region; California Department of Fish and Game; Imperial Irrigation District; Marin County; Monterey County Flood Control and Water Conservation District; Orange County Water District; San Diego County; San Bernardino Valley Municipal Water District; San Luis Obispo County Flood Control and Water Conservation District; San Mateo County; Santa Clara County Flood Control and Water District; United Water Conservation District; University of California; Ventura County Flood Control District; Bureau of Reclamation, U.S. Department of the Interior; Corps of Engineers, U.S. Army; Forest Service and Soil Conservation Service, U.S. Department of Agriculture. Agencies assisting in the collection of records: Alameda County Water District; Kings River Water Association; Metropolitan Water District of Southern California; Pacific Gas and Electric Company; Santa Cruz County Flood Control and Water Conservation District; Sierra Pacific Power Company; Southern California Edison Company; Yuba County Water Agency.

\section{DIVISION OF WORK}

The quality-of-water work was performed by the Water Resources Division of the Geological Survey, E. L. Hendricks, chief hydrologist, and under the direction of the district chiefs listed in the preface.

Correspondence regarding the records in this report or any additional information should be directed to the district chief of the appropriate Geological Survey-Water Resources Division district office as indicated below.

State

California

Oregon
District Office

Menlo Park 94025

Portland 97208
Address

855 Oak Grove Avenue

P. O. Box 3202

830 N.E. Holladay Street

\section{LITERATURE CITED}

Bartsch, A. F., 1948, Biological aspects of stream pollution: Sewage Works Jour., vol. 20, p. 292-302.

Bear, F. E., 1955, Chemistry of the soil: New York, Reinhold Co., 373 p.

Brown, Fugene, Skougstad, M. W., and Fishman, M. J., 1970, Methods for collection and analysis of water samples for dissolved minerals and gases: U.S. Geol. Survey Techniques of Water-Resources Inv., book 5, chap. Al, $160 \mathrm{p}$.

California State Water Quality Control Board, 1963, Water quality criteria: Pub. 3-A, p. 226.

Colorado Agriculture Experiment Station, 1943, Mineral tolerances in livestock drinking water: 56 th Ann. Rept. 
Doudoroff, Peter and Warren, C. E., 1957, Biological indices of water pollution with special reference to fish populations; Biological problems in water pollution: Cincinnati, U.S. Pub. Health Service, Robert A. Taft Sanitary Eng. Cent., p. 144-163.

Durfor, C. N. and Becker, E., 1964, Public water supplies of the 100 largest cities in the United States; 1962: U.S. Geol. Survey Water-Supply Paper 1812, p. 20.

Faucett, R. L. and Miller, H. C., 1946, Methemoglobinemia occuring in infants fed milk diluted with well waters of high nitrate content: Jour. Pediatrics, v. 29, p. 593.

Guy, H. P., 1969, Laboratory theory and methods for sediment analysis: U.S. Geol. Survey Techniques of Water-Resources Inv., book 5, chap. C1, 57 p.

Hazen, Allen, 1892, A new color standard for natural waters: Am. Chem. Jour. v. 12, p. $427-428$.

Heller, V. G., 1933, The effect of saline and alkaline waters on domestic animals: Oklahoma Agr. Mech. Coll. Expt. Sta. Bull. 217.

Hem, J. D., 1970, Study and interpretation of chemical characteristics of natural water, revised edition: U.S. Geol. Survey Water-Supply Paper 1473, 363 p.

International Union of Pure and Applied Chemistry, 1961, Table of Atomic weights based on carbon-12: Chem. and Eng. News, v. 39, no. 42, Nov, 20, 1961, p. 43.

Kilmer, V. J. and Alexander, L. T., 1949, Methods of making mechanical analyses of soils: Soil Sci., v. 68, p. 15-24.

Lane, E. W., and others, 1947, Report of the Subcommittee on sediment terminology: Am. Geophys. Union Trans., v. 28, no. 6, p. 936-938.

Magistad, O. C., and Christiansen, J. E., 1944, Saline Soils, their nature and management: U.S. Dept., Agriculture Circ. 707, p. 8-9.

Maxcy, K. F., 1950, Report on the relation of nitrate concentrations in well waters to the occurrence of methemoglobinemia: Natl. Research Council, Bull. Sanitary Eng. and Environment, App. D., p. 271.

Paynter, O. E., 1960, The chronic toxicity of dodecylbenzene sodium sulfonate: U.S. Public Health Conference on Physiological Aspects of Water Quality Proc., Washington, D.C., Sept. 8-9, 1960, p. 175-179.

Pleissner, M., 1907, Uber die Löslichkeit eimiger Bleiverbindungen in wasser: Arb. Kais. Gesundeitsamt. v. 26, p. 384-443.

Rankama, K., and Sahama, T. G., 1950, Geochemistry: Chicago Univ. Press, Chicago, I1l., p. 767.

Riffenburg, H. B., 1925, Chemical character of ground waters of the northern Great Plains: U.S. Geol. Survey Water-Supply Paper 560-B, p. 31-52.

Rose, Arthur and Elizabeth, 1966, The condensed chemical dictionary: Reinhold Pub. Corp., New York, 7th ed., p. 285.

Rudolfs, Willem, and others, 1944, Critical review of the literature of 1943: Sewage Works Jour., v. 16, p. 222.

Rudolph, Z, 1931, Principles of the determination of the physical and chemical standards of water for drinking, industrial, and domestic purposes: Water Pollution Abs. 4 (March).

Seidell, Atherton, 1940, Solubilities of inorganic and metal organic compounds, 3d ed., v. 1, D. van Nostrand, New York. p. 1409.

Slack, K. V., 1970, Selected interim procedures for biological and microbiological investigations: U.S. Geol. Survey, Water Resources Division, preliminary rept. by WRD Committee on Biology and Microbiology, 80 p. (open file).

Swenson, H. A. and Baldwin, H. L., 1965, A Primer on water quality: Washington, U.S. Govt. Printing Office, 27 p.

U.S. Inter-Agency Committee on Water Resources, Subcommittee on Sedimentation, A study of methods used in measurement and analysis of sediment loads in streams. Published by the St. Anthony Falls Hydraulic Laboratory, Minneapolis, Minn. 1943, A study of new methods of size analysis of suspended-sediment samplers, Rept. 7.

1957, The development and calibration of visual-accumulation tube: Rept 11. 1957, Some fundamentals of particle-size analysis: Rept. 12.

1959, Federal Inter-agency sedimentation instruments and reports: Rept. AA. 1963, Determinations of fluvial sediment discharge: Rept. 14.

U.S. Public Health Service, 1962, Drinking water standards: U.S. Dept. Health, Education, and Welfare, Public Health Service: Pub. no. 956. 
U.S. Salinity Laboratory Staff, 1954, Diagnosis and improvement of saline and alkali soils: U.S. Dept. Agriculture, Agriculture Handb. 60, p. 1-160.

Waring, F. H., 1949, Significance of nitrates in water supplies: Am. Water Works Assoc. Jour., v. 41 , no. 2 ,, p. $147-150$.

Wayman, C. H., 1962, Limitations of the methylene blue method for ABS determinations: U.S. Geol. Survey, Prof. Paper 450-B, art. 49, p. BI17-B120.

Wayman, C. H., Robertson, J. B., and Page, H. G., 1962, Foaming characteristics of synthetic-detergent solutions: U.S. Geol. Survey, Prof. Paper 450D, art. 178, p. D198.

Weast, R. C. and Selby, S. M., 1967, Handbook of chemistry and physics: Cleveland, The Chem. Rubber Co., 48th ed., p. B-120-121.

World Health Organization, 1971, International standards for drinking water, 3d ed: Geneva, Switzerland, World Health Organization, 70 p. 
LOCATION, --Lat $33^{\circ} 12^{\prime} 48^{\prime \prime}$, I Ing $117^{\circ} 22^{\prime} 33^{\prime \prime}$, In SW $3 \mathrm{SE}_{1} \mathrm{SW} \frac{1}{4}$ sec.14, T.11 S., R.5 W. , San Diego County, at gaglng station 0.7 mile upstream from bridge on'U, $\mathrm{S}$. Highway $101,1.1$ miles upstream from mouth, and 1.2 miles north of
Oceanside.

DRAINAGE AREA. $--557 \mathrm{sq} \mathrm{m} 1$.

PERIOD OF RECORD, --Sediment records: October 1968 to September 1969.

MONTHLY AND ANNUAL SUMMARY OF SUSPENDED-SEDIMENT DISCHARGE,

WATER YEAR OCTOBER 1968 TO SEPTEMBER 1969

\begin{tabular}{|c|c|c|}
\hline MONTH & $\begin{array}{l}\text { MEAN } \\
\text { DISCHA RGE } \\
\quad \text { (CFS) }\end{array}$ & $\begin{array}{l}\text { SUSPENDED-SEDIMENT } \\
\text { (TONS) }\end{array}$ \\
\hline $\begin{array}{l}\text { OCTOBER } 1968, \ldots \ldots \cdots \cdots \\
\text { NOVEMBER } \ldots \ldots \cdots \cdots \cdots \\
\text { DECEMBER } \ldots \ldots \ldots \ldots \ldots\end{array}$ & $\begin{array}{l}48.7 \\
54.0 \\
56.8\end{array}$ & $\begin{array}{l}3 \\
3 \\
3\end{array}$ \\
\hline 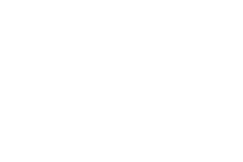 & $\begin{array}{l}1658.4 \\
8686 \\
1516 \\
389.9 \\
132.0 \\
86.3 \\
69.5 \\
46.7 \\
20.86\end{array}$ & $\begin{array}{r}13500 \\
427000 \\
5260 \\
82 \\
18 \\
8 \\
5 \\
3 \\
1\end{array}$ \\
\hline TOTIL FOR YEAR. . . . . & 12765,16 & 445886 \\
\hline
\end{tabular}

SUSPENDED-SEDIMENT DISCHARGE MEASUREMENTS AND PARTICLE-SIZE DISTRIBUTION, WATER YEAR OCTOBER 1968 TO SEPTEMBER 1969 (METHPIS IIF AWALYSIS: P, MOTTCM INITHURAWAL TUBE; C, CHEMICALLY OISPERSED; N, IN AATIVE WATER; P, PIPET; S, SIFVE; $\checkmark$, VISLAL ACCUMULATICA TLOE: W. IN OISTILLEC WATERI

$\checkmark$, VISLAL aCcumulation TLeE; W, IN OISTILLEC WATERI

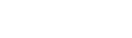

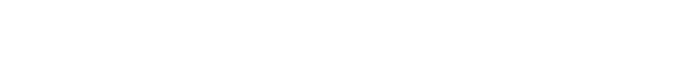

DATr ICFSI TRATILN DISCHARCE DINER THAN THE SIZE (IN MILLIMETERSI INDICATEO NETHOD ANALYJAP $26,13,15,5$ FFE $24 \ldots \ldots$ l1w FEH $24 \ldots \ldots$. 16UC 14 FEH $26 \ldots \ldots$ I 2 CUL 13

$\begin{array}{rrr}242 & 1880 & 1230 \\ 2600 & 5280 & 37100 \\ 2530 & 5760 & 39300 \\ 2000 & 21100 & 114000\end{array}$
$2530 \quad 5760 \quad 39300$ $\begin{array}{rrr}60 & 21100 & 114000\end{array}$ 
11044500 SANTA MARGARITA RIVER NEAR FALLBROOK, CALIF.

LOCATION. --Lat $33^{\circ} 23^{\prime} 54^{\prime \prime}$, Long $117^{\circ} 15^{\prime} 44^{\prime \prime}$, in NEłSE $\frac{1}{\text { NE }}+$ sec. 14, T.9 S., R.4 W., San Diego County, at gaging station $180 \mathrm{ft}$ upstream from De Luz Road, 1.3 miles northwest of Fallibrook, and 1.9 miles downtream from Sandia Canyon. DRAINAGE AREA. $-644 \mathrm{sq} \mathrm{mi}$.

PERIOD OF RECORD. --Chemtcal analyses: October 1966 to September 1969.

REMARKS. --Records furnished by California Department of Water Resources and reviewed by U.S. GeologicaI SUrvey. CHEMICAL ANALYSES, WATER YEAR OCTOBER 1968 TO SEPTEMBER 1969

\begin{tabular}{|c|c|c|c|c|c|c|c|c|c|c|c|c|}
\hline OATE & TIME & $\begin{array}{l}\text { MEAN } \\
\text { DIS- } \\
\text { CHARGE } \\
\text { (CFS) }\end{array}$ & $\begin{array}{l}\text { TEMPER- } \\
\text { ATURE } \\
\text { (OEG C) }\end{array}$ & $\begin{array}{l}\text { DIS- } \\
\text { SOLVED } \\
\text { OXYGEN } \\
\text { (MG/L) }\end{array}$ & $\begin{array}{l}\text { CAL- } \\
\text { CIUM } \\
\text { (CA) } \\
\text { (MG/L) }\end{array}$ & $\begin{array}{l}\text { MAG- } \\
\text { NE- } \\
\text { SIUM } \\
(M G) \\
(M G / L)\end{array}$ & $\begin{array}{l}\text { SODIUM } \\
\text { (NA) } \\
(M G / L)\end{array}$ & $\begin{array}{l}\text { PO- } \\
\text { TAS- } \\
\text { SIUM } \\
\text { (KI) } \\
\text { (MG/L) }\end{array}$ & $\begin{array}{l}\text { BICAR- } \\
\text { BONATE } \\
\text { IHCO3) } \\
\text { IMG/LI }\end{array}$ & $\begin{array}{l}\text { CAR- } \\
\text { RONATE } \\
\text { (CO3) } \\
\text { (MG/L) }\end{array}$ & $\begin{array}{l}\text { SULFATE } \\
\text { (SOLI) } \\
\text { (NG/L) }\end{array}$ & $\begin{array}{l}\text { CHLO- } \\
\text { RIOE } \\
\text { (CL) } \\
\text { (MG/L) }\end{array}$ \\
\hline $\begin{array}{l}\text { OEC. } \\
18 . . . \\
\text { MAR. }\end{array}$ & 1230 & 3.1 & 6 & I 1,2 & 90 & 31 & 113 & 3.0 & 290 & 0 & 139 & 149 \\
\hline JUNE & 1415 & 47 & 20 & 9.3 & 59 & 25 & 74 & 3.0 & 189 & 0 & 108 & 101 \\
\hline SEPT. & 1215 & 6.0 & 25 & 7.9 & 78 & 36 & 105 & 4.0 & 261 & 14 & 128 & 140 \\
\hline $26 \ldots$ & 1230 & 1.7 & 24 & 8.7 & 90 & 38 & 108 & 3.0 & 328 & 0 & 118 & 156 \\
\hline DATE & $\begin{array}{l}\text { FLUQ- } \\
\text { RIOE } \\
\text { (F) } \\
\text { IMG/L I }\end{array}$ & $\begin{array}{l}\text { NITRATE } \\
\text { (NOB) } \\
\text { (MG/L) }\end{array}$ & $\begin{array}{l}\text { BORON } \\
\text { (B) } \\
\text { (UG/LI) }\end{array}$ & $\begin{array}{l}\text { OIS- } \\
\text { SOLVEO } \\
\text { SOLIOS } \\
\text { IRESI- } \\
\text { OUE AT } \\
180 \text { CI } \\
\text { IMG/LI }\end{array}$ & $\begin{array}{l}\text { DIS- } \\
\text { SOLVEO } \\
\text { SOLIOS } \\
\text { ITONS } \\
\text { PER } \\
\text { AC-FTI }\end{array}$ & $\begin{array}{l}\text { HARO- } \\
\text { NESS } \\
\text { (CA,MG) } \\
\text { (MG/L) }\end{array}$ & $\begin{array}{l}\text { NON- } \\
\text { CAR- } \\
\text { BONATE } \\
\text { HARO- } \\
\text { NESS } \\
\text { (MG/L) }\end{array}$ & $\begin{array}{l}\text { PERCENT } \\
\text { SOOIUM }\end{array}$ & $\begin{array}{l}\text { SODIUM } \\
\text { AD- } \\
\text { SORP- } \\
\text { TION } \\
\text { RATIO }\end{array}$ & $\begin{array}{l}\text { ALKA- } \\
\text { LINITY } \\
\text { AS } \\
\text { CACO3 } \\
\text { (MGIL) }\end{array}$ & $\begin{array}{c}\text { PH } \\
\text { (UNITS) }\end{array}$ & $\begin{array}{l}\text { SPECI- } \\
\text { FIC } \\
\text { CONO- } \\
\text { UCTANCE } \\
\text { (MICROD- } \\
\text { MHOSI) }\end{array}$ \\
\hline $\begin{array}{l}\text { OEC. } \\
\text { I8... } \\
\text { MAR. }\end{array}$ & .5 & .8 & 130 & 718 & .98 & 352 & 114 & 41 & 2.6 & 238 & 8.0 & 1140 \\
\hline JUNE & .4 & 2.5 & 90 & 511 & .69 & 250 & 95 & 39 & 2.0 & 155 & 7.9 & 803 \\
\hline SEPT. & .5 & .5 & 180 & 657 & .84 & 343 & 106 & 40 & 2.5 & 237 & B. 4 & 1070 \\
\hline $26 \ldots$ & .6 & .2 & 160 & 671 & .91 & 381 & 112 & 38 & 2.4 & 269 & 8.0 & 1110 \\
\hline
\end{tabular}


11046000 SANTA MARGARITA RIVER AT YSIDORA, CALIF.

LOCATION. --Lat $33^{\circ} 14^{\prime} 38^{\prime \prime}$, long $117^{\circ} 22^{\prime} 56^{\prime \prime}$, in NEłSEłSEł sec.3, T.11 S., R.5 W., San Diego County, at gaging station on right bank, i mile downstream from Ysidora and about 2.5 miles upstream from mouth.

DRAINAGE AREA, --739 sq $\mathrm{m} 1$.

PERIOD OF RECORD. -- Water temperatures: October 1968 to September 1969.

Sedinent records: October 1967 to September 1969.

EXTREMES, --1968-69:

Sediment concentrations: Maximum dally, 13,000 $\mathrm{mg} / 2$ Feb. 24 ; minimum da12y, no flow for many days.

Sediment discharge: Maximum da11y, 534,000 tons Feb. 24 ; minimual datly, 0 ton on many days.

Period of record:

Sediment concentrations: Maximum da1ly, 13,000 mg/2 Feb. 24, 1969; minimum da1ly, no flow for many days, Sediment discharge: Yaximum da11y, 534,000 tons Feb. 24,1969 ; minimum daily, 0 ton on many days.

REMARKS, - No flow Oct. 1 to Jan, 24.

TEMPERATURE $\left(C^{\circ}\right)$ OF MATER, MATER YEAR OCTOBER 1968 TO SEPTEMBER 1969 (ONCE-DAILY MEASUREMENT)

$$
\text { oAr }
$$

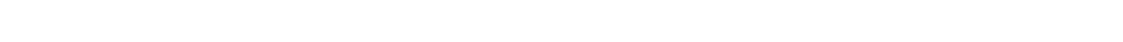

UСТORER.. -

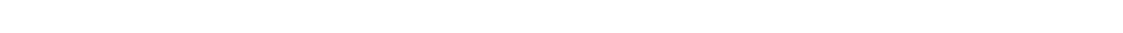

JAUUARY..

FAUUARY, MARCH.

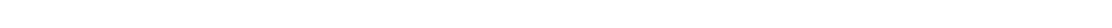

MAY.....
JUV....

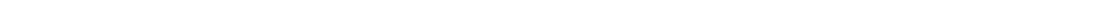

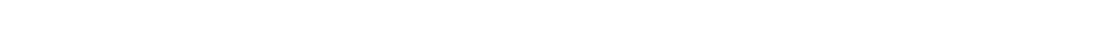


11046000 SANTA MARGARITA RIVER AT YSIDORA, CALIF.--ContInued

SUSPENDED-SEDIMENT DISCHARGE, WATER YEAR OCTOBER 1968 TO SEPTEMBER 1969

JANUARY

ME AN

CONCEN- SEDIMENT DISCHARGE (CFS) (MGIL) (TONS/DAY)

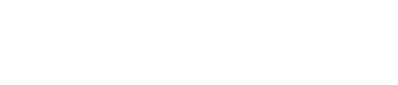

FEBRUARY

MARCH

1
2
3
4

$=$

$\begin{array}{ll}- & 0 \\ - & 0 \\ - & 0\end{array}$

$\begin{array}{ll}-- & 0 \\ =- & 0 \\ -- & 0 \\ -- & 0\end{array}$

16
17
18
19
20

20

21
22
23

23
24
25

$3850^{\circ}$
25

$\begin{array}{ll}26 & 4530 \\ 27 & 1480\end{array}$

4530
1480
509
282
159
118

31

TUTAL

10928

MEAN

CONCEN- SEDIMENT

SEDIMENT MEAN CONCEN-

88
72
66
45
39

110
105
100
95

$\begin{array}{cc}26 & 484 \\ 20 & 439 \\ 18 & 400 \\ 12 & 361 \\ 9.5 & 322 \\ 11300 & 290 \\ 3680 & 260 \\ 361 & 240 \\ 139 & 230 \\ 01 & 219\end{array}$

210

200

200
190
190

$\begin{array}{lll}61 & 200 & 180 \\ 36 & 185 & 170 \\ 24 & 170 & 160 \\ 64 & 178 & 160\end{array}$

$\begin{array}{lll}24 & 170 & 160 \\ 15 & 158 & 150\end{array}$

150
102
88
72

$\begin{array}{ll}z & 0 \\ z- & 0 \\ -- & 0 \\ -- & 0\end{array}$

117
111
111
300

111
300
447

283
427
521
14400
16400

16400

1030
514
500

514
500
--

42

203670

40284

150
130
100
75

50 8.6

140

131
115
144
144

45
31
47
112

148

215
309
529
13000

13000
8340

431

130
118
108
103

130
120
110

100
90

166
397
744

744
34000

386000

111

80
300
240
190

240
190
150

415
283
260
--
--
--

1450
392

350

--

84

120

120
100
90

90
85
80
75

$-$ $\begin{array}{lcccc}\text { IRATION } & \text { DISCHARGE } & \text { DISCHARGE } & \text { TRATION } & \text { DISCHARGE } \\ \text { (MG/L) } & \text { (TONS/DAY) } & \text { (CFS) } & \text { (MG/L) } & \text { (TONS/DAY) }\end{array}$

SEDIMENT

DISCHARGE

MEAN

CONCEN-
TRATION (MGIL)

$\begin{array}{ll}240 & 314 \\ 230 & 273\end{array}$

$220 \quad 238$

205
183

157

140

123

106

97

85
73
64
56

$$
56
$$

48

42
35
29
25

24

24
105

71
46
35

2810

MAY JUNE

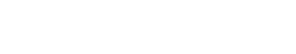

SEDIMENT MEAN

MEAN
CONCEN- SEDIMENT $\begin{array}{ccc}\text { DISCHARGE } & \text { DISCHARGE } & \text { TRATION } \\ \text { (TDNS/DAY) } & \text { (CFS) } & \text { DISCHARGE } \\ \text { (MG/L) } & \text { (TONS/DAY) }\end{array}$

2500030130

40
40
40
40 $\begin{array}{lll}3.7 & 3.0 & 40 \\ 3.6 & 2.8 & 40 \\ 3.4 & 2.5 & 40\end{array}$

.36
.33
.32
.30

15
15
15
13
13

24
23
22
21

60
60
60
60
60

20
18
17
16
14

60
55
55
55
55

3.2
2.7

2.5

$\begin{array}{ll}2.4 & 40 \\ 2.3 & 40\end{array}$

66
65
63

$11 \quad 60$

50

56
54

14
15

52

$\begin{array}{ll}11 & 14 \\ 10 & 13 \\ 9.8 & 12 \\ 9.5 & 11 \\ 9.1 & 10\end{array}$

$\begin{array}{ll}16 & 50 \\ 17 & 47 \\ 18 & 45 \\ 19 & 43\end{array}$

50
47
45
43
40

$\begin{array}{ll}11 & 14 \\ 10 & 13 \\ 9.8 & 12 \\ 9.5 & 11 \\ 9.1 & 10\end{array}$

55
55
55
55
55

2.1
1.9
1.8
1.6

$\begin{array}{ll}2.1 & 40 \\ 1.9 & 40\end{array}$

$\begin{array}{ll}8.8 & 9.6 \\ 8.2 & 9.0 \\ 7.9 & 8.0 \\ 7.5 & 7.5\end{array}$

1.5

$\begin{array}{ll}1.7 & 35 \\ 1.5 & 35 \\ 1.4 & 35 \\ 1.4 & 35 \\ 1.3 & 35\end{array}$

$\begin{array}{lll}1.3 & 1.2 & 35 \\ 1.2 & 1.1 & 35\end{array}$

$\begin{array}{ccc}1.2 & 1.2 & 35 \\ 1.1 & 1.0 & 35 \\ 1.0 & 1.0 & 35 \\ .93 & 1.0 & 35\end{array}$

1.0

35

$\begin{array}{ll}21 & 38 \\ 22 & 37 \\ 23 & 35 \\ 24 & 34\end{array}$

$\begin{array}{ll}6.7 & 6.7 \\ 6.5 & 6.1\end{array}$

6.1

6.7
6.1
5.4
5.3
5.0

50
50
50
50
50

.90
.82
.73
.72

.94
.90
.86
.89

.90
$: 86$
$: 89$

30
30
30
30
30

27

19
18
17
15

$\begin{array}{rrr}5.0 & 4.7 & 40 \\ 4.9 & 4.5 & 40 \\ 4.7 & 4.3 & 40 \\ 4.5 & 4.0 & 40 \\ 4.4 & 3.8 & 40 \\ -- & 3.5 & 40 \\ 273.9 & 354.3 & -\end{array}$

.51
.49
.46
.43
.41
.38

$.76 \quad 30$

$\begin{array}{ll}.73 & 30 \\ .71 & 30\end{array}$

.68

52.56

$\begin{array}{cc}-- & 30 \\ 45.67 & --\end{array}$ 
11046000 SANTA MARGARITA RIVER AT YSIDORA, CALIF.--COntInued

SUSPENDED-SEDIMENT DISCHARGE, WATER YEAR OCTOBER 1968 TO SEPTEMBER 1969 JULY AUGUST SEPTEMBER

\begin{tabular}{|c|c|c|c|c|c|c|c|c|c|}
\hline \multirow[b]{2}{*}{ UIAY } & \multicolumn{3}{|c|}{ Jut } & \multicolumn{3}{|c|}{ Augus? } & \multicolumn{3}{|c|}{ SEPIEMBEK } \\
\hline & $\begin{array}{l}\text { MEAN } \\
\text { DISCHARGE } \\
\text { (CFS) }\end{array}$ & $\begin{array}{l}\text { MEAN } \\
\text { CONCEN- } \\
\text { TRAILON } \\
\text { (MG/L) }\end{array}$ & $\begin{array}{l}\text { SEDIMENT } \\
\text { DISCHARGE } \\
\text { (TONS/DAY) }\end{array}$ & $\begin{array}{l}\text { MEAN } \\
\text { DISCHARGE } \\
\text { (CFS) }\end{array}$ & $\begin{array}{l}\text { MEAN } \\
\text { CONCEN- } \\
\text { IRAIION } \\
\text { (MG/L) }\end{array}$ & $\begin{array}{l}\text { SEDIMENT } \\
\text { DI SCHARGE } \\
\text { (TONS/DAY) }\end{array}$ & $\begin{array}{l}\text { MEAN } \\
\text { OISCHARGE } \\
\text { (CFS) }\end{array}$ & $\begin{array}{l}\text { MEAN } \\
\text { CONCFN- } \\
\text { IRAIICN } \\
\text { (MGILI }\end{array}$ & $\begin{array}{l}\text { SEDIMENT } \\
\text { DISCHARGE } \\
\text { (TONS/DAY) }\end{array}$ \\
\hline 1 & .65 & 20 & .04 & .38 & 10 & .01 & .35 & 10 & .01 \\
\hline 2 & .64 & 20 & .03 & .37 & 10 & .01 & .35 & 10 & .01 \\
\hline 3 & .62 & 20 & .03 & .37 & 10 & .01 & .35 & 10 & .01 \\
\hline 4 & .61 & 20 & .03 & .37 & 10 & .01 & .35 & 10 & .01 \\
\hline 5 &.$t 0$ & 20 & .03 & .37 & 10 & .01 & .35 & 10 & .01 \\
\hline 6 & .59 & 20 & .03 & .37 & 10 & .01 & .33 & 10 & .01 \\
\hline 7 & .58 & 20 & .03 & .37 & 10 & .01 & .33 & 10 & .01 \\
\hline 8 & .56 & 20 & .03 & .37 & 10 & .01 & .33 & 10 & .01 \\
\hline 7 & .55 & 20 & .03 & .37 & 10 & .01 & .33 & 10 & .01 \\
\hline 10 & .54 & 20 & .03 & .37 & 10 & $.0 \mathrm{I}$ & .33 & 10 & .01 \\
\hline 11 & .53 & 20 & .03 & .37 & 10 & .01 & .30 & 10 & .01 \\
\hline 12 & .52 & 20 & .03 & .37 & 10 & .01 & .30 & 10 & .61 \\
\hline 13 & .51 & 20 & .03 & .37 & 10 & .01 & .30 & 10 & .01 \\
\hline 14 & .50 & 20 & .03 & .37 & 10 & .01 & .30 & 10 & .01 \\
\hline 15 & .49 & 20 & .03 & .37 & 10 & .01 & .30 & 10 & . UI \\
\hline 16 & .47 & 20 & .03 & .36 & 10 & .01 & .28 & 10 & .01 \\
\hline 17 & .47 & 20 & .03 & .36 & 10 & .01 & .28 & 10 & .01 \\
\hline 18 & .47 & 20 & .03 & .36 & 10 & .01 & $.2 \mathrm{~B}$ & 10 & .01 \\
\hline 17 & .47 & 20 & .03 & .36 & 10 & .01 & .28 & 10 & .01 \\
\hline 20 & .47 & 20 & .03 & .36 & 10 & .01 & .28 & 10 & .01 \\
\hline 21 & .46 & 20 & .02 & .36 & 10 & .02 & .26 & 10 & .01 \\
\hline 22 & .46 & ח & .02 & .36 & 10 & .01 & .26 & 10 & .01 \\
\hline 23 & .45 & 20 & .02 & .36 & 10 & .01 & .26 & 10 & .01 \\
\hline 24 & .43 & 20 & .02 & .36 & 10 & .01 & .26 & 10 & .01 \\
\hline $2 b$ & .43 & 20 & .02 & .36 & 10 & .01 & .28 & 10 & .01 \\
\hline 26 & .43 & 20 & .02 & .36 & 10 & .01 & . 30 & 10 & .01 \\
\hline 37 & .42 & 20 & .02 & .36 & 10 & .01 & .33 & 10 & .01 \\
\hline 28 & .41 & 20 & .02 & .35 & 10 & .01 & .27 & 10 & .01 \\
\hline 23 & .40 & 20 & .02 & .35 & 10 & .01 & .24 & 10 & .01 \\
\hline 30 & .39 & 20 & .02 & .35 & 10 & .01 & .22 & 10 & .01 \\
\hline 31 & .39 & 20 & .02 & .35 & 10 & .01 & - & - & - \\
\hline TOTAL & 15.51 & -- & .83 & 11.28 & -- & .31 & $8.9 B$ & -- & .30 \\
\hline $\begin{array}{l}\text { TOTAL } \\
\text { TOTAL }\end{array}$ & $\begin{array}{l}\text { DISCHARSE F } \\
\text { SUSPENDED-S }\end{array}$ & $\begin{array}{l}\text { OR YEAR } \\
\text { EDIMENT }\end{array}$ & $\begin{array}{l}F S-D A Y S) \\
S C H A R G E \text { FOR }\end{array}$ & YEAR (TONS & & & & & $\begin{array}{r}58868.74 \\
1146768.50\end{array}$ \\
\hline
\end{tabular}

PARTICLE-SIZE DISTRIBUTION DF SUSPENDED SEDIMENT, WATER YEAR OCTOBER 1968 TO SEPTEMBER 1969 IMETHELS PA PARTICLE-SIZE DISTRIBUTION DF SUSPENDED SEDIMENT, WATER YEAR OCTOBER 1968 TO SEPTEMBER 1969, S, SIEVE:

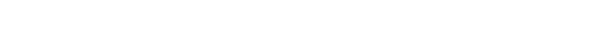

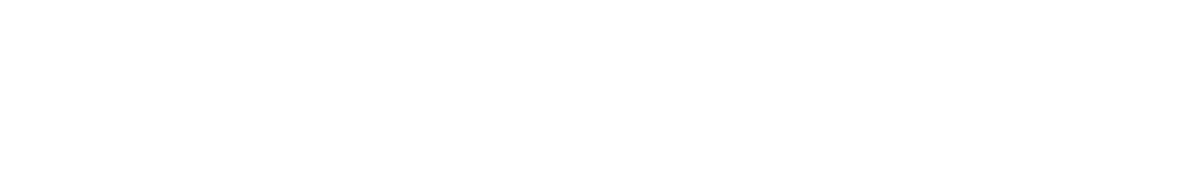

PARTICLE-S12E DISTRIBUTION OF SURFACE BED MATERIAL, WATER YEAR OCTOBER 1967 TO SEPTEMBER 1969 (METHOD OF ANALYSIS: H, HYDROMETER: O, OPTICAL AVALYZER: S, SIEVE: V, VISUAL ACCUMULATION TUBE)

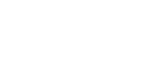
PARTICLE SILE

PERA- SAM- PERCENT FINER THAN THE SIZE IIN MILLIMETERSI INDICATEO METHOD

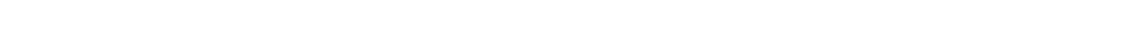

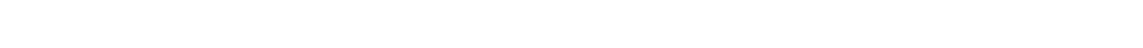


11066050 SANTA ANA RIVER AT COLTON, CALIF.

LOCATION, - Lat $34^{\circ} 03^{\prime} 4^{\prime \prime}$, long $117^{\circ} 18^{\prime} 30^{\prime \prime}$, T.1 S., R.4 W., San Bernardino County, 60 ft downstream from Southern Pacific Railroad bridge, $200 \mathrm{ft}$ downstream from Warm Ćreek, and 1 mile southeast of Colton.

PERIOD OF RECORD. --Chemical analyses: October 1966 to September 1969.

REMARKS. - Records furnished by California Department of Water Resources and reviewed by U.S. Geological Survey.

Wa ter discharge computed by combining the discharge of Santa Ana River at E Street, near San Bernardino (sta-

tioter discharge computed by combining the discharge of Santa Ana River at E Street, near San Bernardino

(station 11065000 ).

CHEMICAL ANALYSES, hATER YEAR OCTOBER 1968 TO SEPTEMBER 1969

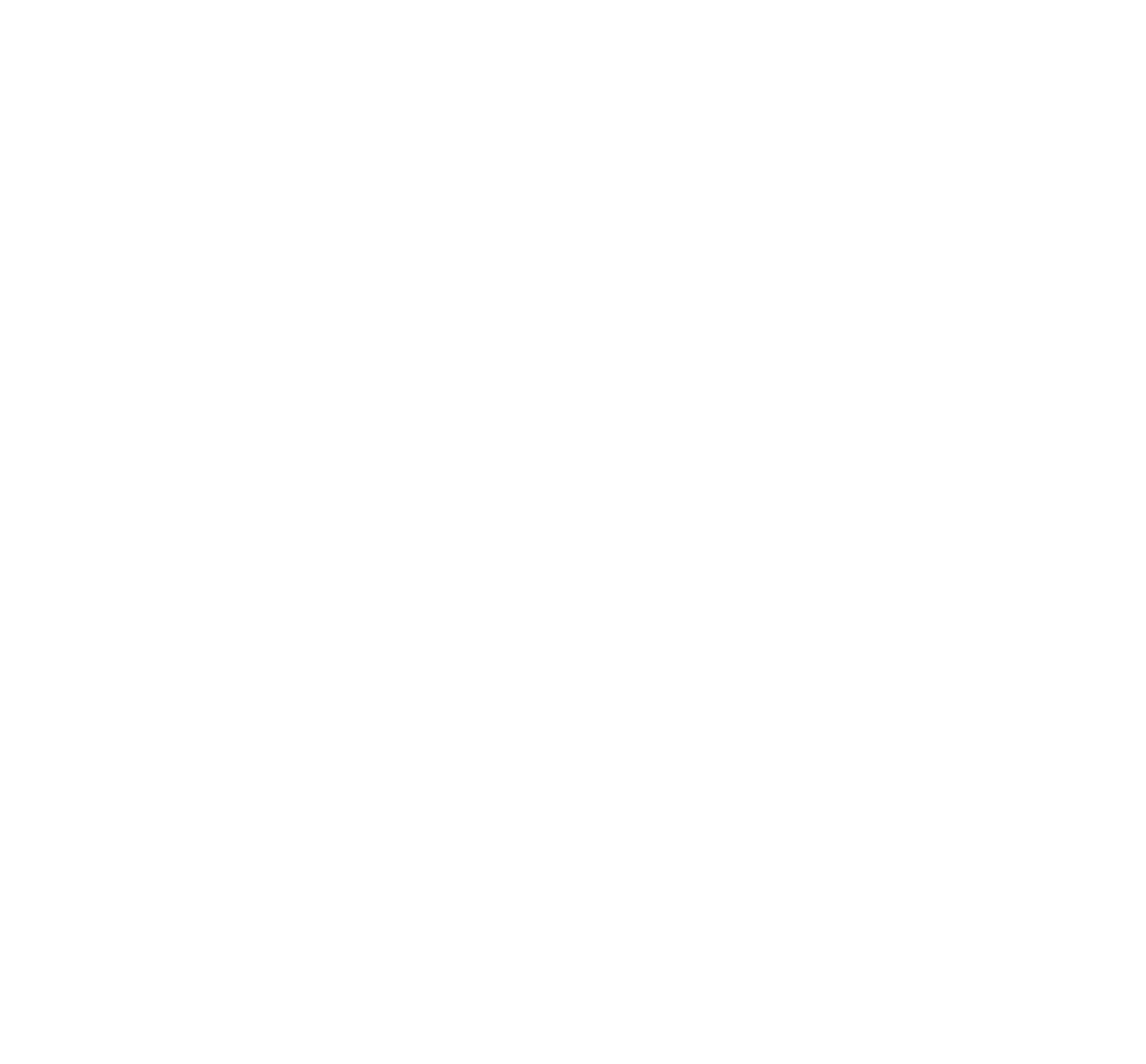


11074000 SANTA ANA RIVER BELOW PRADO DAM, CALIF.

LOCATION, --Lat $33^{\circ} 53^{\prime} 00^{\prime \prime}$, long $117^{\circ} 38^{\prime} 40^{\prime \prime}$, In La S1erra Grant, R1verside County, at gaging station at outlet channel, $2,500 \mathrm{ft}$ domstream from axis of Prado Dam and 4,5 miles west of Corona.

DRAINAGE AREA, --1,485 sq mi, not including 768 sq mi upstream fram Lake Elsinore.

PERIOD OF RECORD, --Chemical analyses: October 1966 to September 1969.

CHEMICAL ANALYSES, WATFR YEAR DCTOHER 2963 TO SEPTEMBER 1969

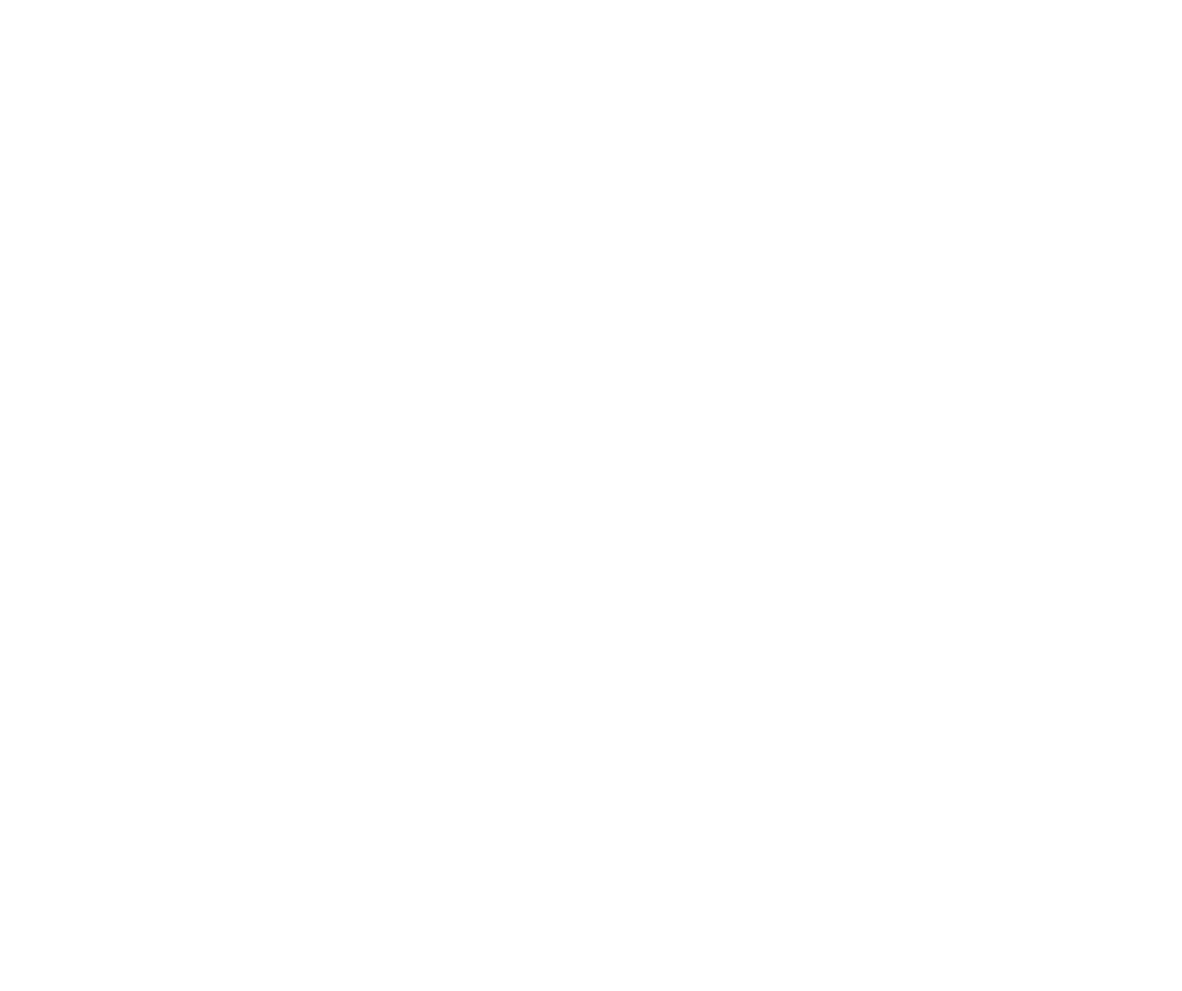


11074000 SANTA ANA RIVER BELOW PRADO DAM, CALIF,--COntInUEd

PERIOD OF RECORD. --Continued

Water temperatures: February to September 1968.
Sediment records: October 1966 to September 1967 (periodic).

REMARKS.-Chemical analyses for this station are performed by Callfornia Department of Water Resources and U.S, Geoi ogical Survey.

CHEMICAL ANALYSES, WATE2 YEAR JCTOBER 1963 TI SEPTEMBER 1969

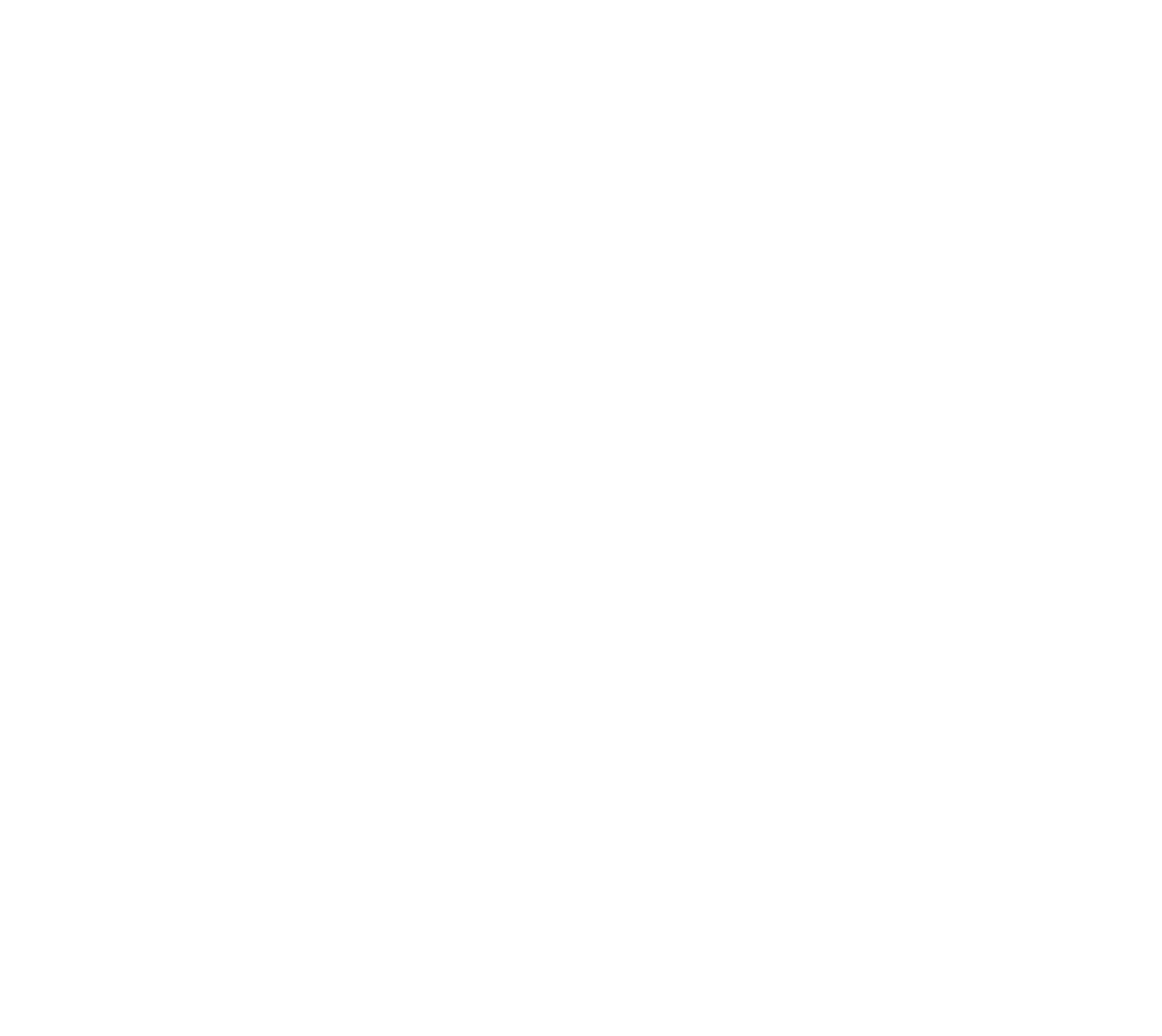


LOCATION. - Lat $33^{\circ} 44^{\circ} 56^{\prime \prime}$, Iong $117^{\circ} 54^{\prime} 30^{\prime \prime}$, in NW 1 SW on Fifth Street Bridge in Santa Ana, $1.8 \mathrm{miles}$ downst ream from Santiago Creek.

DRAINAGE AREA, --1,685 sq m1, not Including $768 \mathrm{sq}$ mi upstream from lake Elsinore.

PERIOD OF RECORD, -- Water temperatures: October 1967 to September 1969.

Sediment records: October 1967 to September 1969 .

EXTREMES . - $-1968-69$ :

Sediment concentrations: Maximum datly, 78,000 $\mathrm{mg} / \mathrm{I}$ Feb, 25; minimum daily, no flow for many days.

Sediment discharge: Maximum daily, 2,670,000 tons Feb. 25; minimum daily, 0 ton on many days.

Pertod of record:

Sediment concentrations: Maximum datly, 78,000 mg/l Feb. 25, 1969; mintmum dat1y, no flow for many days. Sediment discharge: Maximum datly, 2,670,000 tons Feb. 25, i969; minimum daily, 0 ton on many days. REMarks. - No flow Oct. 1-29, Oct. 31 to Nov. 14, Nov. 17 to Dec. 10, 12-15, 17-19, 21-24, Dec. 27 to Jan. 12,
15-17, June 1 to Sept. 30.

TEUPERATURE $\left({ }^{\circ} \mathrm{C}\right)$ OF WATER, WATER YEAR OCTOBER 1968 TO SEPTEMBER 1969 (ONCE-DAILY MEASUREMENT)

DAY

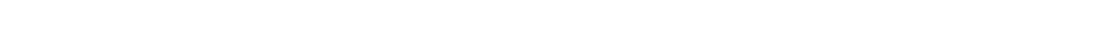

USTURER.. -- -- -- -- - - - - - - - - - - -

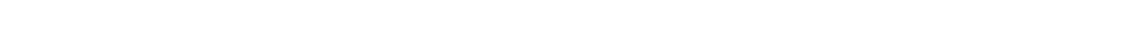

JANUARY.. -- - - - - - - - - - - -

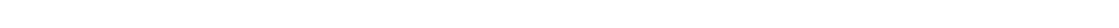

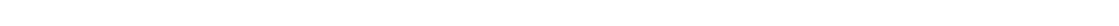
MYY.....

JULY.... SEPIEMRFR

PARTICLE-SIZE DISTRIBUTION OF SUSPENDED SEDIMENT, WATER YEAR OCTOBER 1968 TO SEPTEMBER 1969 (METHOUS OF aNALYSIS: B, BOTTOM WITHCRAWAL TUBE; C, CHEMICALLY OISPERSEO; N, IN NATIVE HATER; P, PIPET; S. SIEVE V. VISUAL ACCUMULATION TUBE; W. IN DISTILLED HATER)

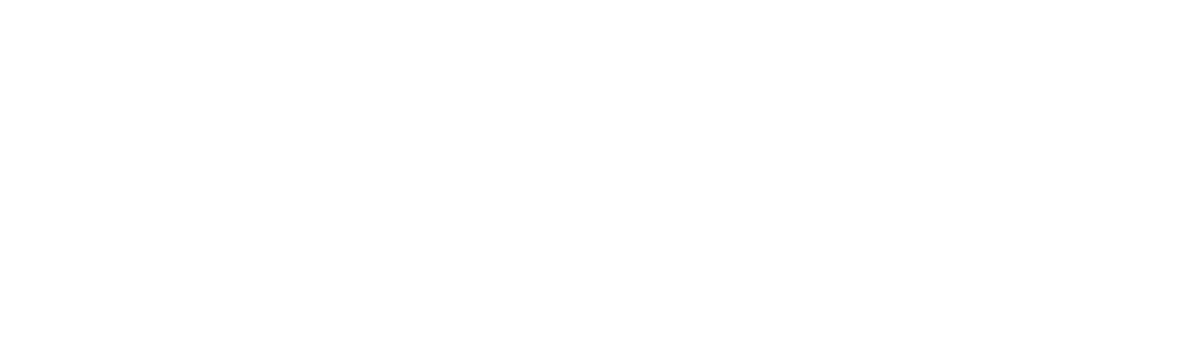

PARTICLE-SIZE DISTRIBUTION OF SURFACE BED MATERIAL, WATER YEAR OCTOBER 1968 TO SEPTEMBER 1969 (METHOD OF ANALYSIS: H, HYORDMETER; $O$, DPTICAL ANALYZER; S, SIEVE; $V$, VISUAL ACCUMULATION TUBE)

PARTICLE SIZE

WATER NUMBER

TEM- OF

THE SIZE (IN MILLIMETERS) INDICATEO

DATE TIME I T CI POINTS DISCHARGE

PERCENT FINER THAN IHE SIZE

ANALY -
SIS

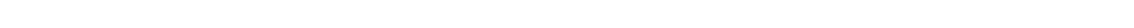

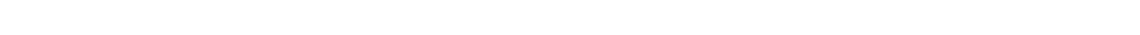


11078000 SANTA ANA RIVER AT SANTA ANA, CALIF,--Continued

SUSPENDED-SEDIMENT DISCHARGE, WATER YEAR OCTOBER 1968 TO SEPTEMBER 1969

OCTOBER

NOVEMBER

DECEMBER

MEAN COANCEN- SEDIMENT MEAN COENCENTRATION
(MGILI)

SEDIMENT

MEAN

TENCEN- SEDIMENT

SEDIMENT MEAN

MEAN

1
1
1
1
1
1
1
1
1
2

$\begin{array}{ll}=- & 0 \\ -- & 0 \\ -- & 0 \\ -- & 0\end{array}$

TRATION
IMGILI DISCHARGE DISCHARGE
(TONS/DAY)
(CFS)

SEDIMENT

TRATION DISCHARGE

0
0
0
0
0

$\begin{array}{ll}0 & = \\ 0 & = \\ 0 & = \\ 0 & = \\ 0 & = \\ 0 & = \\ 0 & =- \\ 0 & =- \\ 0 & =- \\ 0 & =- \\ 0 & =- \\ 0 & 1750 \\ 0.6 & \end{array}$

$\begin{array}{lll}6 & 0 \\ 8 & \\ 9 & 0\end{array}$

$.10 \quad 100$

$\begin{array}{ll}100 & 0.03 \\ = & 0 \\ \therefore- & 0 \\ -- & 0\end{array}$

0
0
0
0
0

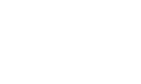

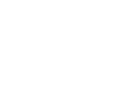

$\because$
$\because$
$\because$

$=$

21
27
23
24
25

$\begin{array}{lll}26 & 0 & = \\ 27 & 0 & = \\ 2 B & 0 & = \\ 29 & 0 & = \\ 30 & .40 & = \\ 31 & 0 & = \\ \text { THAL } & .40 & .-\end{array}$

$\begin{array}{lll}0 & \because & 0 \\ 0 & \because & 0 \\ 0 & \because & 0\end{array}$

$: \quad=\quad:$

$\because \quad 0$

$\begin{array}{ll}\because & 0 \\ \because & 0 \\ - & 0\end{array}$

$\begin{array}{ll}0 & = \\ 0 & = \\ 0 & = \\ 0 & = \\ 0.70 & \end{array}$

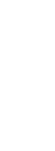

0
0
0
0
0
-0

54.03

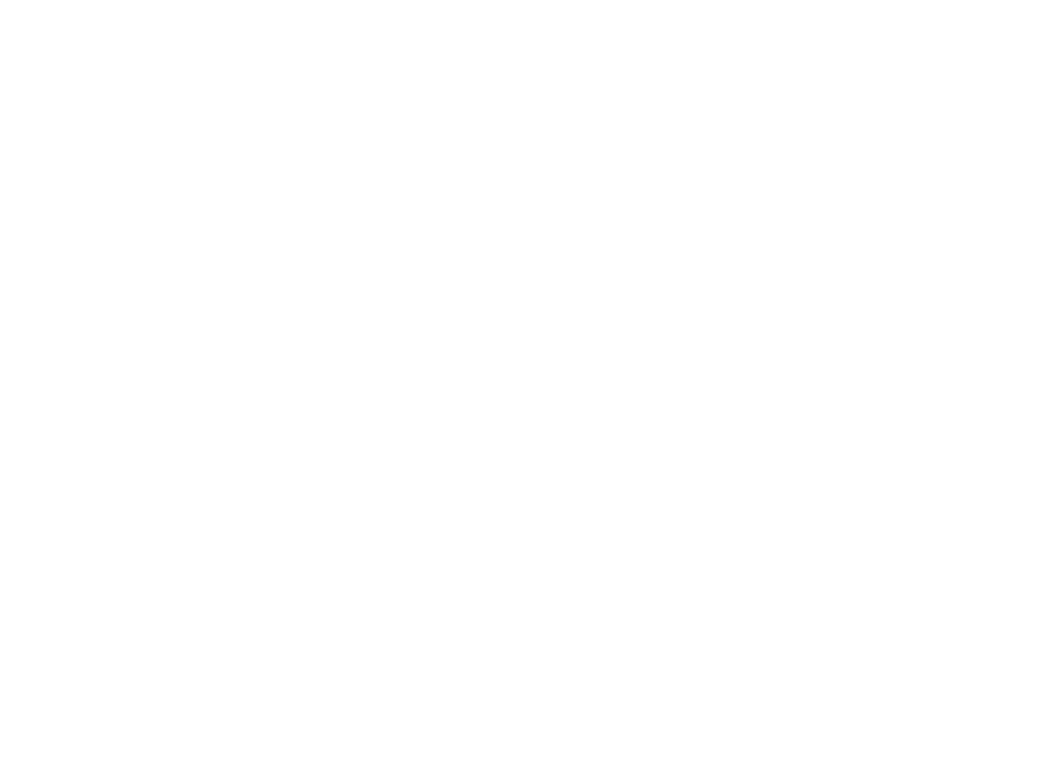


SANTA ANA RIVER BASIN

11078000 SANTA ANA RIVER AT SANTA ANA, CALIF.--Continued SUSPENDED-SEDIMENT DISCHARGE, WATER YEAR QCTOBER 1968 TQ SEPTEMBER 1969

\begin{tabular}{|c|c|c|c|c|c|c|c|c|c|}
\hline & \multicolumn{3}{|c|}{ APRIL } & \multicolumn{3}{|c|}{ MAY } & \multicolumn{3}{|c|}{ JUNE } \\
\hline DAY & $\begin{array}{l}\text { MEAN } \\
\text { DISCHAPGE } \\
\text { (CFS) }\end{array}$ & $\begin{array}{l}\text { MEAN } \\
\text { CONCEN- } \\
\text { TPAIIUN } \\
\text { (MG/L) }\end{array}$ & $\begin{array}{l}\text { SEDIMENT } \\
\text { DISCHARGE } \\
\text { (TQNS/DAY) }\end{array}$ & $\begin{array}{l}\text { MEAN } \\
\text { DISCHARGE } \\
\text { (CFS) }\end{array}$ & $\begin{array}{l}\text { MEAN } \\
\text { CONCEN- } \\
\text { IRATION } \\
\text { (MGIL) }\end{array}$ & $\begin{array}{l}\text { SEDIMENT } \\
\text { DISCHARGE } \\
\text { (TONS/DAY) }\end{array}$ & $\begin{array}{c}\text { MEAN } \\
\text { OISCHARGE } \\
\text { (CFS) }\end{array}$ & $\begin{array}{l}\text { MEAN } \\
\text { CONCEY- } \\
\text { IRATION } \\
\text { (MGIL) }\end{array}$ & $\begin{array}{l}\text { SEDIMENT } \\
\text { DISCHARGE } \\
\text { (TONS/DAY) }\end{array}$ \\
\hline l & 733 & 3000 & 5940 & 25 & 5400 & 365 & & & \\
\hline 2 & 706 & 2900 & 5530 & 25 & 4800 & 324 & & & \\
\hline 3 & 751 & 3200 & 6490 & 25 & 4400 & 297 & & & \\
\hline 4 & 796 & 3300 & 7090 & 35 & 4800 & 454 & & & \\
\hline 5 & 802 & 3400 & 7360 & 50 & 6100 & 824 & & & \\
\hline 0 & 795 & 3000 & 6440 & 160 & 24000 & 10400 & & & \\
\hline 7 & 751 & 2900 & 5880 & 210 & 30000 & 17000 & & & \\
\hline 8 & 733 & 2800 & 5540 & 210 & 18000 & 10200 & & & \\
\hline 9 & 687 & 2800 & 5190 & 220 & 16000 & 9500 & & & \\
\hline 10 & 642 & 2700 & 4680 & 180 & 15000 & 7290 & & & \\
\hline 11 & 596 & 2600 & 4180 & 145 & 15000 & 5870 & & & \\
\hline 12 & 551 & 2500 & 3720 & 125 & 14000 & 4730 & & & \\
\hline 13 & 527 & 2400 & 3410 & 125 & 14000 & 4730 & & & \\
\hline 14 & 471 & 2300 & 2920 & 155 & 20000 & 8370 & & & \\
\hline 15 & 420 & 2200 & 2490 & 135 & 19000 & 6930 & & & \\
\hline 16 & 366 & 2100 & 2080 & 135 & 18000 & 6560 & & & \\
\hline 17 & 248 & 2000 & 1340 & 145 & 20000 & 7830 & & & \\
\hline 18 & 185 & 1900 & 949 & 160 & 25000 & 10800 & & & \\
\hline 19 & 180 & 1800 & 875 & 185 & 30000 & 15000 & & & \\
\hline 20 & 175 & 1800 & 851 & 185 & 18000 & 8990 & & & \\
\hline 21 & 195 & 10000 & 5270 & 165 & 15000 & 6680 & & & \\
\hline 27 & 210 & 20000 & 11300 & 130 & 14000 & 4910 & & & \\
\hline 23 & 210 & 16000 & 9070 & 116 & 14000 & 4380 & & & \\
\hline 24 & 172 & 14000 & 6500 & 110 & 13000 & 3860 & & & \\
\hline 25 & 94 & 12000 & 3050 & 75 & 13000 & 2630 & & & \\
\hline 28 & 73 & 10000 & 1970 & 50 & 12000 & 1620 & & & \\
\hline 27 & 58 & 8600 & 1350 & 50 & 12000 & 1620 & & & \\
\hline $2 a$ & 43 & 7800 & 706 & 50 & 11000 & 1490 & & & \\
\hline 29 & 33 & 7000 & 624 & 36 & 10000 & 972 & & & \\
\hline 30 & 25 & 6200 & 419 & 1.0 & 600 & 1.6 & & & \\
\hline 31 & -- & - & -- & 1.0 & 500 & 1.4 & & & \\
\hline TOTAL & 12228 & - & 123414 & 3419.0 & -- & 164629.0 & 0 & -- & 0 \\
\hline $\begin{array}{l}\text { TOTAL } \\
\text { TOTAL }\end{array}$ & $\begin{array}{l}\text { DISCHARGE } \\
\text { SUSPENDED- }\end{array}$ & $\begin{array}{l}\text { FOR YEAR } \\
\text { SEDIMENT }\end{array}$ & $\begin{array}{l}\text { (CFS-DAYS) } \\
\text { DISCHARGE FOR }\end{array}$ & YEAR ITONS & & & & & $\begin{array}{r}196040.60 \\
11585094.57\end{array}$ \\
\hline
\end{tabular}


11082800 SAN GABRIEL RIVER AT AZUSA POTERHOUSE, AT AZUSA, CALIF,

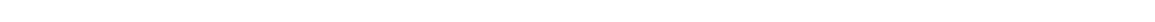
Azusa Powerhouse, 1 mile north of Azusa.

PERIOD OF RECORD. --Chemical analyses: October 1966 to September 1969.

REMRKS, --Records furnished by California Department of Water Resources and reviewed by U,S. Geological Survey.

CHEMICAL ANALYSES, WATER YEAR OCTOBER 1968 TO SEPTEMBER 1969

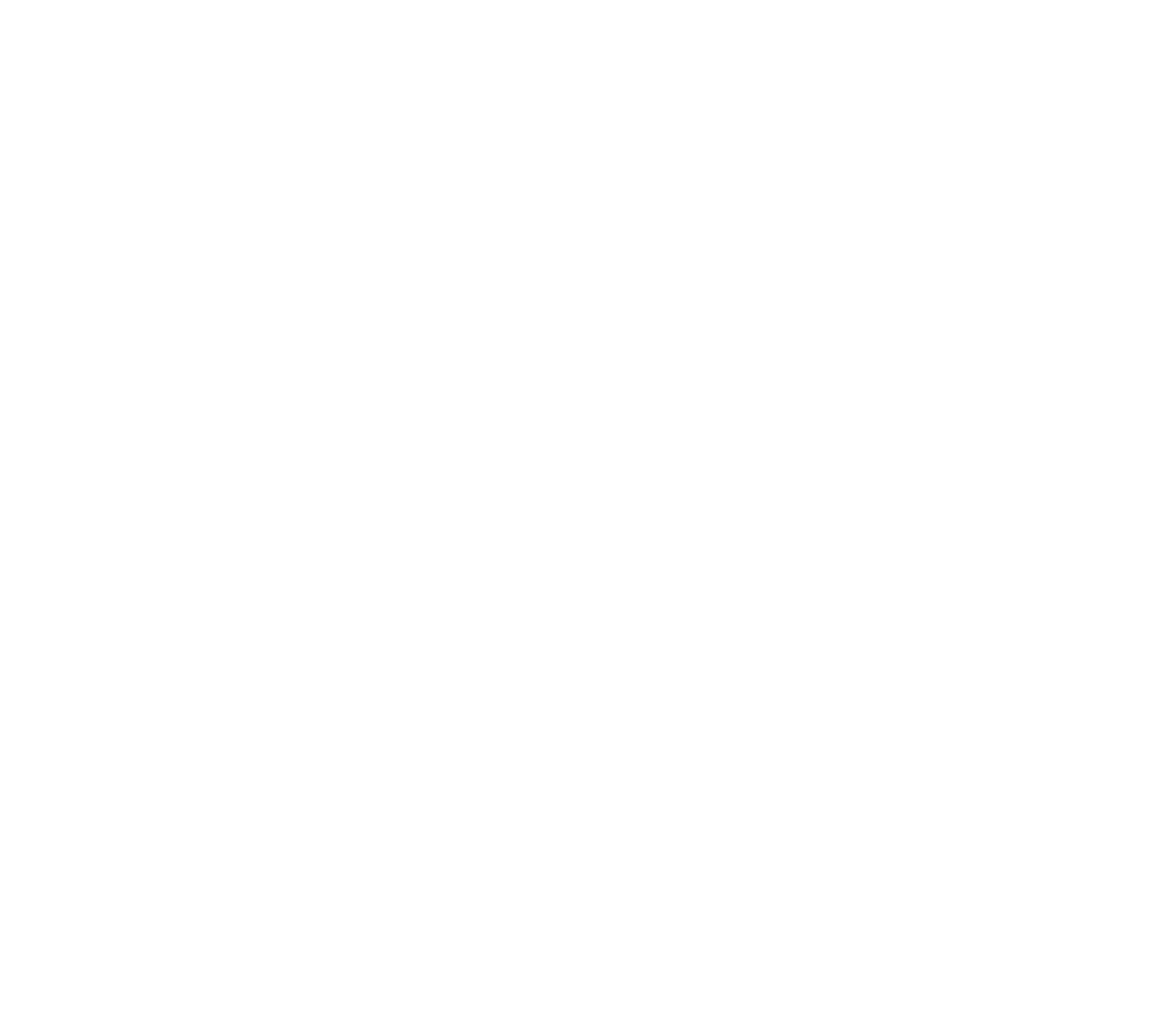


LOCATION, --LEt $34^{\circ} 01$ SAN GABRIBL RIVER RASIN Gabriel Boulevard ( 2 ' long $118^{\circ} 03^{\prime} 11 "$, In BeC.5, ROBd).

PERIOD OF RECORD, -CChemtCaI ane

REMARKs, - Recoxds furnien californta

CHEMICAL ANALYSES, WATER YEAR OCTOEER Regources and revieOed bY OOS.

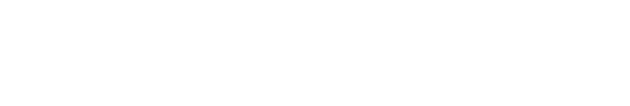

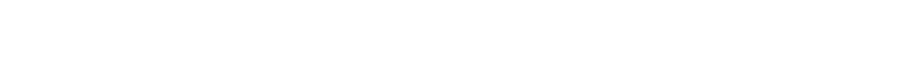

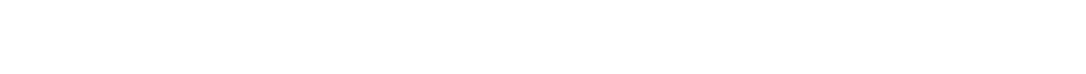

JAN... 1030

FEB... 1145

MAR... 1130

?P... 1130

$25 . \cdots \quad 1045$

MAY

JUNE. 1200

$20 .$.

Jut $\begin{array}{ll}20 . & 1300\end{array}$

$29 .$.

4U6." 0945

$20 .$.

1025

$19 . .$.

1115

$$
\begin{array}{cc}
15 & 17 \\
52 & 15 \\
34 & 14 \\
68 & 11 \\
228 & 16 \\
43 & 21 \\
129 & 20 \\
63 & 23 \\
55 & 24 \\
32 & 25 \\
11 & 20
\end{array}
$$

$10.5 \quad 80$

8.569

30

$30 \quad 102$

(MG/L) (CO3)

(CL)

$M G / L)$

$11.3 \quad 74$

a. 8

$11.4 \quad 42$

$10.2 \quad 56$

9.2102

9.960

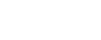

$=91$

-2
$--\quad 89$

29
28

28

$$
\text { (1) }
$$

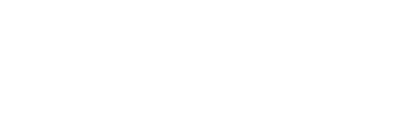

Nov...

190
450
530
560
$=-$
80
360
110
340
320
310
290

OEC.. 66 450

JAN... $51 \quad 530$

$17 . .$.

$F$ EB.

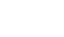

$4 P_{2}, \ldots \quad 18$

$25, \ldots$

गUNE

$20 .$,

Jili $20 .$.

RUG:

SEPT:

19...

16

695
637
669
661
230
301
698
111
634
639
610
538

9 
11097500 LOS ANGELES RIVER AT LOS ANGELES, CALIF.

LOCATION.--Lat $34^{\circ} 04^{\prime} 52^{\prime \prime}$, Iong $118^{\circ} 13^{\prime} 36^{\prime \prime}$, LOs Angeles County, at gaging station near Figueroa Street, Los Angeles, 800 ft upstream from Arroyo Seco.

DRAINAGE AREA. --514 sq $\mathrm{m} 1$.

PERIOD OF RECORD, --Chemlcal analyses: October 1966 to September 1969.

REMARKS. --Records furnished by California Department of Hater Resources and reviewed by U.s. Geological Survey. CHEMICAL ANALYSES, hater yeAR OCTOBER 1968 TO SEPTEMBER 1969

\begin{tabular}{|c|c|c|c|c|c|c|c|c|c|c|c|}
\hline DATE & $\begin{array}{l}\text { DIS- } \\
\text { CHARGE } \\
\text { (CFS) }\end{array}$ & $\begin{array}{l}\text { TEMPER- } \\
\text { ATURE } \\
\text { (DEG C) }\end{array}$ & $\begin{array}{l}\text { CAL- } \\
\text { CIUM } \\
\text { (CA) } \\
\{M G / L)\end{array}$ & $\begin{array}{c}\text { MAG- } \\
\text { NE- } \\
\text { SIUM } \\
\text { (MGI } \\
(M G / L)\end{array}$ & $\begin{array}{l}\text { SOO IUM } \\
\text { (NA) } \\
\text { (MG/L) }\end{array}$ & $\begin{array}{l}\text { PO- } \\
\text { TAS- } \\
\text { SIUM } \\
\text { (K) } \\
\text { (MG/L) }\end{array}$ & $\begin{array}{l}\text { BICAR- } \\
\text { BONATE } \\
\text { (HCOB) } \\
\text { (MGILI) }\end{array}$ & $\begin{array}{l}\text { CAR- } \\
\text { BONATE } \\
\text { (CQ3) } \\
\text { (MG/L) }\end{array}$ & $\begin{array}{l}\text { SULFATE } \\
\text { (SO4) } \\
\text { (MG/L) }\end{array}$ & $\begin{array}{l}\text { CHLO- } \\
\text { RIDE } \\
\text { (CL) } \\
(M G / L)\end{array}$ & $\begin{array}{l}\text { FLUO- } \\
\text { RIOE } \\
\text { IFI } \\
\text { IMG/LI }\end{array}$ \\
\hline $\begin{array}{l}\text { OCT. } \\
02 . . . \\
\text { NOV. }\end{array}$ & 11 & 16 & 82 & 32 & 166 & - & 196 & 0 & 303 & 135 & -- \\
\hline O6... & 7.4 & 14 & 80 & 28 & 166 & -- & 176 & 0 & 285 & 128 & -- \\
\hline $\begin{array}{l}04 \ldots \\
\text { JAN. }\end{array}$ & 7.8 & II & 76 & 35 & 214 & -- & 159 & 0 & 356 & 168 & -- \\
\hline$\underset{A P R}{02 \ldots}$ & 6.9 & 10 & 80 & 37 & 178 & -- & 179 & 0 & 317 & 133 & -- \\
\hline$\underset{\text { MAY }}{02} \cdot \cdots$ & 56 & 18 & 108 & 38 & 104 & -- & 140 & 48 & 320 & 86 & - \\
\hline $\begin{array}{l}07 \ldots . . \\
22 \ldots \\
\text { JUNE }\end{array}$ & $\begin{array}{l}27 \\
42\end{array}$ & $\begin{array}{l}20 \\
18\end{array}$ & $\begin{array}{l}64 \\
79\end{array}$ & $\begin{array}{l}28 \\
37\end{array}$ & $\begin{array}{l}111 \\
100\end{array}$ & $7 . \overline{0}$ & $\begin{array}{r}73 \\
219\end{array}$ & $\begin{array}{r}86 \\
0\end{array}$ & $\begin{array}{l}212 \\
241\end{array}$ & $\begin{array}{l}33 \\
87\end{array}$ & .7 \\
\hline $\begin{array}{l}04 \ldots . . \\
\text { JULY }\end{array}$ & 47 & 18 & 96 & 42 & 120 & -- & 185 & 0 & 298 & 104 & -- \\
\hline $\begin{array}{l}02 \ldots . . . \\
\text { SEPT. }\end{array}$ & 50 & 25 & 76 & 35 & 58 & -- & 145 & 28 & 195 & 76 & -- \\
\hline $\begin{array}{l}03 \ldots . . \\
19 . .\end{array}$ & $20^{--}$ & $\begin{array}{l}23 \\
19\end{array}$ & $\begin{array}{l}85 \\
82\end{array}$ & $\begin{array}{l}35 \\
27\end{array}$ & $\begin{array}{l}132 \\
120\end{array}$ & $9 . \overline{0}$ & $\begin{array}{l}173 \\
141\end{array}$ & a & $\begin{array}{l}288 \\
271\end{array}$ & $\begin{array}{l}116 \\
103\end{array}$ & $\overline{1 . \overline{2}}$ \\
\hline
\end{tabular}

\begin{tabular}{|c|c|c|c|c|c|c|c|c|c|c|}
\hline DATE & $\begin{array}{l}\text { NITRATE } \\
\text { (ND3) } \\
\text { (MG/L) }\end{array}$ & $\begin{array}{l}\text { DIS- } \\
\text { SOLVED } \\
\text { SOLIOS } \\
\text { (RESI- } \\
\text { DUE AT } \\
\text { IOO C) } \\
\text { (MG/L) }\end{array}$ & $\begin{array}{l}\text { DIS- } \\
\text { SOLVEO } \\
\text { SOLIOS } \\
\text { ITONS } \\
\text { PER } \\
\text { AC-FTI }\end{array}$ & $\begin{array}{l}\text { PERCENT } \\
\text { SODIUM }\end{array}$ & $\begin{array}{l}\text { HARD- } \\
\text { NESS } \\
\text { (CA,MG) } \\
\text { (MG/L) }\end{array}$ & $\begin{array}{l}\text { NON- } \\
\text { CAR- } \\
\text { BONATE } \\
\text { HARD- } \\
\text { NESS } \\
\text { (MG/L) }\end{array}$ & $\begin{array}{l}\text { SOOIUM } \\
\text { AO- } \\
\text { SORP- } \\
\text { YION } \\
\text { RATIO }\end{array}$ & $\begin{array}{l}\text { ALKA- } \\
\text { LINITY } \\
\text { AS } \\
\text { CACO3 } \\
\text { (MG/L) }\end{array}$ & $\begin{array}{c}P H \\
\text { (UNITS) }\end{array}$ & $\begin{array}{l}\text { SPECI- } \\
\text { FIC } \\
\text { COND- } \\
\text { UCTANCE } \\
\text { (MICRO- } \\
\text { MHOSI }\end{array}$ \\
\hline OCT. & 21 & 920 & 1.25 & 52 & 336 & 175 & 3.9 & 161 & 8.0 & - \\
\hline NOV. & 19 & 875 & 1.19 & 53 & 315 & 171 & 4.1 & 144 & 7.9 & -- \\
\hline $\begin{array}{l}04 . \cdots \\
\text { JAN." }\end{array}$ & 32 & 1040 & 1.41 & 58 & 334 & 204 & 5.1 & 130 & 7.8 & -- \\
\hline $\begin{array}{l}02 \ldots \\
A P R=\end{array}$ & 23 & 935 & 1.27 & 52 & 352 & 205 & 4.1 & 147 & 7.9 & - \\
\hline$\underset{M A Y}{02} \cdots$ & 24 & 805 & 1.09 & 35 & 426 & 231 & 2.2 & 194 & 9.2 & $m$ \\
\hline $\begin{array}{l}07 \ldots . . \\
22 \ldots \\
\text { JUNE }\end{array}$ & $\begin{array}{l}18 \\
18\end{array}$ & $\begin{array}{l}685 \\
701\end{array}$ & $\begin{array}{l}.93 \\
.95\end{array}$ & $\begin{array}{l}47 \\
38\end{array}$ & $\begin{array}{l}275 \\
349\end{array}$ & $\begin{array}{r}72 \\
169\end{array}$ & $\begin{array}{l}2.9 \\
2.3\end{array}$ & $\begin{array}{l}201 \\
180\end{array}$ & $\begin{array}{r}10.1 \\
7.5\end{array}$ & 1060 \\
\hline $\begin{array}{l}04 . \cdots \\
\text { JULY }\end{array}$ & 22 & 890 & 1.21 & 39 & 412 & 260 & 2.6 & 152 & 8.2 & - \\
\hline $\begin{array}{l}02 \ldots . . \\
\text { SEPT. }\end{array}$ & 15 & 610 & .83 & 27 & 334 & 168 & 1.4 & 165 & 9.0 & - \\
\hline $\begin{array}{l}03 \ldots . \\
19 . .\end{array}$ & $\begin{array}{l}11 \\
50\end{array}$ & $\begin{array}{l}915 \\
760\end{array}$ & $\begin{array}{l}1.24 \\
1.03\end{array}$ & $\begin{array}{l}45 \\
44\end{array}$ & $\begin{array}{l}356 \\
316\end{array}$ & $\begin{array}{l}207 \\
200\end{array}$ & $\begin{array}{l}3.0 \\
2.9\end{array}$ & $\begin{array}{l}148 \\
116\end{array}$ & $\begin{array}{l}8.6 \\
6.8\end{array}$ & 1150 \\
\hline
\end{tabular}


11102000 MISSION CREEK NEAR MONTEBELLO, CALIF.

LOCATION.--Lat $34^{\circ} 01^{\prime} 45^{\prime \prime}$, long $118^{\circ} 04^{\prime} 07^{\prime \prime}$, in La Merced Grant, Los Angeles County, at gaging station on San Gabriel Boulevard Bridge, 2 miles northeast of Montebello.

DRAINAGE AREA. $--4.16 \mathrm{sq} \mathrm{mi}$.

PERIOD ( F RECORD, --Chemical analyses: October 1968 to September 1969.

REMARKS, --Records furnished by California Department of Water Resources and reviewed by U.S. Geological Survey, Samples collected prior to 1969 water year at Mission Creek below whittier Narrows Dam (station 11102250). CHFMICAL ANALYSES, WATER YEAR OCTORER 1969 TO SEPTEMBER 1969

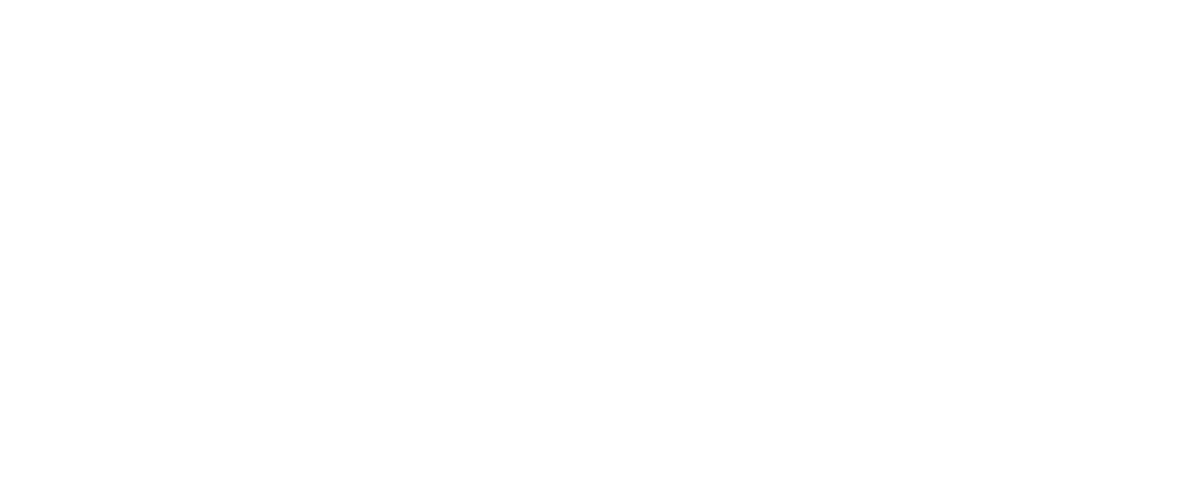

\begin{tabular}{|c|c|c|c|}
\hline & & & $\begin{array}{l}\text { SOLIOS } \\
\text { IRESI- }\end{array}$ \\
\hline & $\begin{array}{l}\text { NI TRATE } \\
\text { (NOA) }\end{array}$ & $\begin{array}{l}\text { BURON } \\
\text { (a) }\end{array}$ & $\begin{array}{l}\text { DUE A T } \\
180 \text { C }\end{array}$ \\
\hline DATE & {$[M G / L]$} & $(1 \mathrm{G} / \mathrm{L})$ & $(N G)$ \\
\hline r:ov. & 8. 2 & 40 & 529 \\
\hline DEC. & & & \\
\hline $20 \ldots$ & 8.7 & 90 & 540 \\
\hline $\begin{array}{c}17 \ldots \\
\text { FEH. }\end{array}$ & 10 & 130 & 493 \\
\hline $\begin{aligned} 21 \ldots \\
\text { NAR. }\end{aligned}$ & 14 & -- & 481 \\
\hline $24 \ldots$ & 13 & 100 & 505 \\
\hline $\begin{array}{r}25 \ldots \\
{ }_{n y}\end{array}$ & 12 & 90 & $5 ? 6$ \\
\hline$\underset{J U N F}{22} \ldots$ & 12 & 80 & 493 \\
\hline 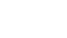 & 12 & 60 & 493 \\
\hline $\begin{array}{l}29 \ldots . . \\
\text { nug. }\end{array}$ & 9.5 & 90 & 487 \\
\hline $\begin{array}{c}20 \ldots . . \\
\text { SFPT. }\end{array}$ & 7.6 & 90 & 437 \\
\hline $19 \ldots$ & 8. 8 & 90 & 475 \\
\hline
\end{tabular}

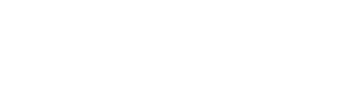

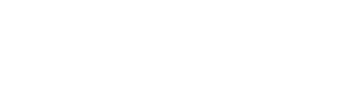
$\begin{array}{lll}A C-F T) & (C A, M G) & \text { NESS } \\ & \text { (MG/L) } & \text { (MG/L) }\end{array}$

$\begin{array}{ll}.72 & 376 \\ .73 & 341 \\ .67 & 374 \\ .65 & 354 \\ .69 & 377 \\ .72 & 398 \\ .67 & 374 \\ .66 & 375 \\ .66 & 362 \\ .59 & 351 \\ .65 & 375\end{array}$

$\begin{array}{ccc}103 & 11 & .5 \\ 162 & 11 & .5 \\ 168 & 9 & .4 \\ 165 & 11 & .5 \\ 167 & 11 & .5 \\ 183 & 11 & .5 \\ 180 & 12 & .5 \\ 174 & 12 & .9 \\ 168 & 12 & .5 \\ 154 & 13 & .6 \\ 176 & 12 & .5\end{array}$

$\begin{array}{lll}213 & 7.7 & 779 \\ 219 & 7.7 & 793 \\ 206 & 1.7 & 795 \\ 189 & 7.5 & 779 \\ 210 & 7.7 & 790 \\ 215 & 7.8 & 785 \\ 194 & 7.5 & 755 \\ 201 & 7.7 & 750 \\ 194 & 7.3 & 727 \\ 197 & 9.5 & 753 \\ 199 & 7.7 & 773\end{array}$


11105850 ARROYO SIMI NEAR SIMI, CALIF.

LOCATION, --Lat $34^{\circ} 16^{\prime} 41^{\prime \prime}$, Iong $118^{\circ} 47^{\prime} 43^{\prime \prime}$, on 1 ine between secs. 7 and $8, T .2$ N., R. 18 W., Ventura County, at gaging station on bridge on Kujask1 Road, 0.5 mile upst ream from Brea Canyon and 1.1 miles northwest of Simi.

DRAINAGE AREA, $--66.5 \mathrm{sq} \mathrm{m} 1$.

PERIOD OF RECORD. --Sediment records: October 1968 to September 1969.

EXTREMES.--1968-69:

Sediment concentrations: Maximum dafly, 25,100 mg/l Feb, 25; minimum dally, no flow for nany days.

Sediment discharge: Maximum da11y, 169,000 tons Feb. 25 ; minimum daily, 0 ton on many days.

REMARKS, -- No flow Oct, 1 to Nov, 14, Nov. 16 to Dec. 15, 17-24, Dec, 27 to Jan. 12, 15-17, Feb, 3, 4, 9-11, 13, $14,16-20$, Apr. 9 to Sept. 30. Sediment tables omitted for periods of no flow.

PARTICLE-SIZE DISTRIBUTION OF SUSPENDED SEDIMENT, WATER YEAR OCTOBER 1968 TO SEPTEMBER 1969
IMETHODS OF ANALYIS: B, BOTIOM WITHDRAWAL TUBE; C. CHEMICALLY OISPERSE; N, IN NATIVE WATER; P, PIPET; S, SIEVE; $V$, VISUAL ACCUMULATION TUBE; $W$. IN DISTILLED WATERI

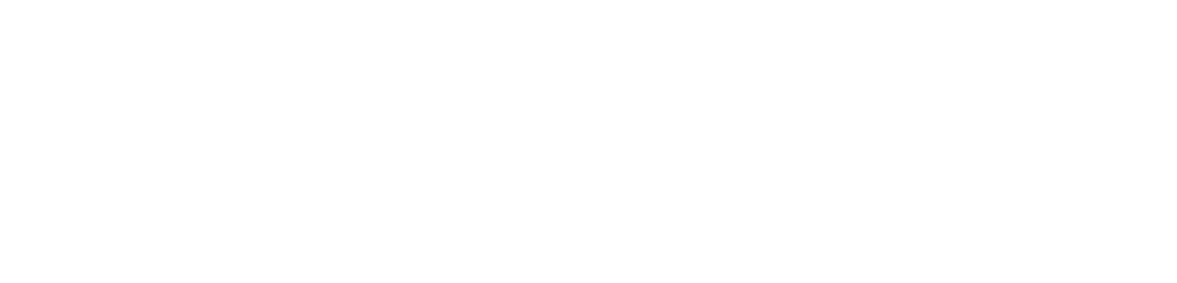

A SINGLE-STAGE SAMPLE.

PARTI LLE-SIZE DISTRIBUTION OF BED MATERIAL, WATER YEAR OCTOBER 1968 TO SEPTEMBER 1969
(METHOD OF ANALYSIS: H, HYDROMETER: U, OPTICAL ANALYZE: S, SIEVE; V, VISUAL ACCUMULAIION TUBE)

\begin{tabular}{|c|c|c|c|c|c|c|c|c|c|c|c|c|c|c|c|c|}
\hline \multirow[b]{2}{*}{ DATE } & \multirow[b]{2}{*}{ TIME } & \multirow{2}{*}{$\begin{array}{l}\text { WATER } \\
\text { TEM- } \\
\text { PERA- } \\
\text { TURE } \\
\left({ }^{\circ} \mathrm{C}\right)\end{array}$} & \multirow{2}{*}{$\begin{array}{l}\text { NUMBER } \\
\text { OF } \\
\text { SAM- } \\
\text { PLING } \\
\text { POINTS }\end{array}$} & \multirow{2}{*}{$\begin{array}{l}\text { DISCHARGE } \\
\text { (CFS) }\end{array}$} & \multicolumn{11}{|c|}{ PARTICLE SIZE } & \multirow[b]{2}{*}{$\begin{array}{c}\text { ME THOD } \\
\text { DF } \\
\text { ANALY } \\
\text { SIS }\end{array}$} \\
\hline & & & & & .062 & PERCENT & T FINER & THAN & THE $S$ & SIZE IIN & MIL & I ME IERS & S) INC & ICATED & 64.0 & \\
\hline $\begin{array}{ll}23, & 1968 \\
20, & 1969\end{array}$ & 1030 & & $\begin{array}{l}6 \\
1\end{array}$ & $\begin{array}{r}0 \\
96\end{array}$ & -2 & 4 & $\begin{array}{r}10 \\
3\end{array}$ & $\begin{array}{l}37 \\
34\end{array}$ & $\begin{array}{l}78 \\
85\end{array}$ & $\begin{array}{l}92 \\
97\end{array}$ & $\begin{array}{l}96 \\
99\end{array}$ & $\begin{array}{r}98 \\
100\end{array}$ & 99 & 100 & $=$ & $\begin{array}{l}S \\
S\end{array}$ \\
\hline
\end{tabular}

SUSPENDED-SEDIMENT DISCHARGE, WATER YEAR OCTOBER 1968 TD SEPTEMBER 1969 UCTOBER

NDVEMBER

OECEMBER

DAY MEAN
DI SCHARGE
ICFSI

MEAN
CONCEN- SEDIMENT $\begin{array}{llllll}\text { MEAN } & \text { SEDIMENT } & \text { MEAN } & \text { CDNCEN- } & \text { SEDIMENT } & \text { MEAN } \\ \text { ONCEN- } & \text { DEISCHARGE } & \text { DISCHARGE } & \text { TRAIION } & \text { DISCHARGE } & \text { DISCHARGE } \\ \text { RATIUN } & \text { DISCHS/DAY) } & \text { DICFS) }\end{array}$

MEAN
CONCEN-

MEAN (MG/L)

$$
\begin{array}{ccc}
\vdots \\
\vdots \\
\vdots \\
\vdots \\
\vdots \\
\vdots \\
\vdots \\
\vdots \\
\vdots \\
\vdots \\
\vdots
\end{array}
$$

\begin{tabular}{l}
0 \\
0 \\
0 \\
0 \\
0 \\
0 \\
0 \\
0 \\
0 \\
0 \\
0 \\
0 \\
0 \\
0 \\
6.0 \\
0 \\
0 \\
0 \\
0 \\
0 \\
0 \\
0 \\
0 \\
0 \\
0 \\
0 \\
0 \\
0 \\
0 \\
0 \\
0 \\
-0 \\
0.0 \\
\hline
\end{tabular}

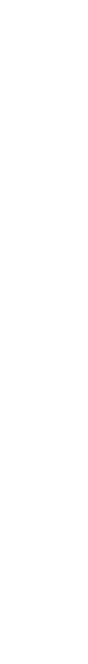

0
0
0
0
0
0
0
0
0
0
0
0
0
0
1.6
0
0
0
0
0
0
0
0
0
0
0
0
0
0
0
--
1.06

$\begin{array}{ll}0 & \\ 0 & \\ 0 & \\ 0 & \\ 0 & \\ 0 & \\ 0 & \\ 0 & \\ 0 & \\ 0 & \\ 0 & \\ 0 & \\ 0 & \\ 0 & \\ 0 & \\ .90 & \\ 0 & \\ 0 & \\ 0 & \\ 0 & \\ 0 & \\ 0 & \\ 0 & \\ 0 & \\ 6.4 & \\ 9.4 & \\ 0 & \\ 0 & \\ 0 & \\ 0 & \\ 0 & \\ 16.70 & \end{array}$

SEDI MENT DI SCHARGE (TONS/DAY)

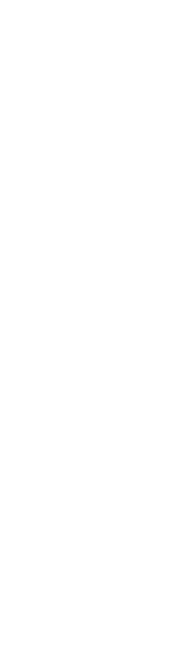


11105850 ARROYO SIMI NEAR SIMI, CALIF.--Continued

SUSPENDED-SEDIMENT DISCHARGE, WATER YEAR OCTOBER 1968 TO SEPTEMBER 1969

MARCH

\begin{tabular}{|c|c|c|c|c|c|c|c|c|c|}
\hline \multirow[b]{2}{*}{ DAY } & \multicolumn{3}{|c|}{ JANUARY } & \multicolumn{3}{|c|}{ FEBRUARY } & \multicolumn{3}{|c|}{ MARCH } \\
\hline & $\begin{array}{l}\text { MEAN } \\
\text { DISCHARGE } \\
\text { ICFSI }\end{array}$ & $\begin{array}{l}\text { MEAV } \\
\text { CNNCEY- } \\
\text { TRATIUN } \\
\text { (MG/L) }\end{array}$ & $\begin{array}{l}\text { SEDIMENT } \\
\text { DISCHARGE } \\
\text { (TONS/DAY) }\end{array}$ & $\begin{array}{l}\text { MEAN } \\
\text { DISCCHARGE } \\
\text { (CFS) }\end{array}$ & $\begin{array}{l}\text { MEAN } \\
\text { CONCEN- } \\
\text { TRATION } \\
\text { IMG/LI }\end{array}$ & $\begin{array}{l}\text { SEDIMENT } \\
\text { DISCHARGE } \\
\text { (TONS / DAY) }\end{array}$ & $\begin{array}{l}\text { MEAN } \\
\text { DISCHARGE } \\
\text { ICFSI }\end{array}$ & $\begin{array}{l}\text { MEAN } \\
\text { CONCEN- } \\
\text { IRATION } \\
\text { IMGILI }\end{array}$ & $\begin{array}{l}\text { SEDIMENT } \\
\text { DISCHARGE } \\
\text { (TONS / DAY) }\end{array}$ \\
\hline $\begin{array}{l}1 \\
2 \\
3 \\
4 \\
5\end{array}$ & $\begin{array}{l}0 \\
0 \\
0 \\
0 \\
0\end{array}$ & $\begin{array}{l}-- \\
= \\
-\end{array}$ & $\begin{array}{l}0 \\
0 \\
0 \\
0 \\
0\end{array}$ & $\begin{array}{l}.70 \\
0_{0}^{.40} \\
11\end{array}$ & $\begin{array}{r}40 \\
30 \\
=- \\
-=\end{array}$ & $\begin{array}{l}.08 \\
.03 \\
0 \\
33\end{array}$ & $\begin{array}{l}20 \\
15 \\
11 \\
8.0 \\
6.0\end{array}$ & $\begin{array}{l}400 \\
350 \\
300 \\
250 \\
200\end{array}$ & $\begin{array}{r}22 \\
14 \\
8.9 \\
5.4 \\
3.2\end{array}$ \\
\hline $\begin{array}{r}6 \\
7 \\
3 \\
9 \\
10\end{array}$ & $\begin{array}{l}0 \\
0 \\
0 \\
0 \\
0\end{array}$ & $\begin{array}{l}-- \\
-- \\
--\end{array}$ & $\begin{array}{l}0 \\
0 \\
0 \\
0 \\
0\end{array}$ & $\begin{array}{c}314 \\
2.6 \\
.40 \\
0 \\
0\end{array}$ & $\begin{array}{r}4830 \\
100 \\
50 \\
=- \\
=-\end{array}$ & $\begin{array}{c}7750 \\
.70 \\
.05 \\
0 \\
0\end{array}$ & $\begin{array}{l}4.0 \\
3.0 \\
2.0 \\
1.0 \\
8.0\end{array}$ & $\begin{array}{r}150 \\
100 \\
75 \\
50 \\
200\end{array}$ & $\begin{array}{l}1.6 \\
.81 \\
.41 \\
.14 \\
4.3\end{array}$ \\
\hline $\begin{array}{l}11 \\
12 \\
13 \\
14 \\
15\end{array}$ & $\begin{array}{r}0 \\
0 \\
10 \\
15 \\
0\end{array}$ & $\begin{array}{r}-- \\
300 \\
231 \\
--\end{array}$ & $\begin{array}{r}0 \\
0 \\
41 \\
29 \\
0\end{array}$ & $\begin{array}{l}0 \\
1.0 \\
0 \\
0 \\
1.0\end{array}$ & $\begin{array}{l}50 \\
\overline{50} \\
--\end{array}$ & $\begin{array}{l}0.14 \\
0_{0}^{0} \\
.14\end{array}$ & $\begin{array}{l}1.8 \\
1.5 \\
.90 \\
.60 \\
.50\end{array}$ & $\begin{array}{r}100 \\
50 \\
50 \\
50 \\
50\end{array}$ & $\begin{array}{l}.49 \\
.20 \\
.12 \\
.08 \\
.07\end{array}$ \\
\hline $\begin{array}{l}16 \\
17 \\
18 \\
11 \\
20\end{array}$ & $\begin{array}{r}0 \\
0 \\
63 \\
229 \\
149\end{array}$ & $\begin{array}{r}10 \\
908 \\
4500 \\
2950\end{array}$ & $\begin{array}{r}0 \\
0 \\
235 \\
7640 \\
3020\end{array}$ & $\begin{array}{l}0 \\
0 \\
0 \\
0 \\
0\end{array}$ & $\begin{array}{l}-- \\
-- \\
--\end{array}$ & $\begin{array}{l}0 \\
0 \\
0 \\
0 \\
0\end{array}$ & $\begin{array}{l}.40 \\
.30 \\
.20 \\
.10 \\
.10\end{array}$ & $\begin{array}{l}50 \\
50 \\
50 \\
50 \\
50\end{array}$ & $\begin{array}{l}.05 \\
.04 \\
.03 \\
.01 \\
.01\end{array}$ \\
\hline $\begin{array}{l}21 \\
22 \\
23 \\
24 \\
25\end{array}$ & $\begin{array}{c}498 \\
53 \\
5.0 \\
383 \\
1680\end{array}$ & $\begin{array}{r}5820 \\
500 \\
100 \\
6710 \\
20500\end{array}$ & $\begin{array}{c}12300 \\
72 \\
1.4 \\
9030 \\
152000\end{array}$ & $\begin{array}{r}15 \\
96 \\
1110 \\
640 \\
1290\end{array}$ & $\begin{array}{r}292 \\
3500 \\
20900 \\
7170 \\
25100\end{array}$ & $\begin{array}{r}113 \\
3250 \\
131000 \\
16000 \\
169000\end{array}$ & $\begin{array}{l}3.5 \\
.50 \\
.40 \\
.30 \\
.20\end{array}$ & $\begin{array}{r}200 \\
100 \\
50 \\
50 \\
50\end{array}$ & $\begin{array}{l}1.9 \\
.14 \\
.05 \\
.04 \\
.03\end{array}$ \\
\hline $\begin{array}{l}26 \\
27 \\
23 \\
29 \\
30 \\
31\end{array}$ & $\begin{array}{c}574 \\
98 \\
21 \\
1.8 \\
1.2 \\
.90\end{array}$ & $\begin{array}{r}10000 \\
1500 \\
400 \\
80 \\
60 \\
50\end{array}$ & $\begin{array}{r}25800 \\
397 \\
34 \\
.39 \\
.19 \\
.12\end{array}$ & $\begin{array}{l}76 \\
22 \\
35 \\
-- \\
-- \\
--\end{array}$ & $\begin{array}{r}1500 \\
450 \\
1110 \\
-- \\
--\end{array}$ & $\begin{array}{r}308 \\
27 \\
264 \\
\square \\
=\end{array}$ & $\begin{array}{l}.10 \\
.10 \\
.10 \\
.10 \\
.10 \\
.10\end{array}$ & $\begin{array}{l}50 \\
50 \\
50 \\
50 \\
50 \\
50\end{array}$ & $\begin{array}{l}.01 \\
.01 \\
.01 \\
.01 \\
.01 \\
.01\end{array}$ \\
\hline TUTAL & 3831.90 & - & 210800.10 & 3615.10 & - & 327746,14 & 89.90 & - & 64.08 \\
\hline & & APRIL & & & MAY & & & JUNE & \\
\hline DAY & $\begin{array}{l}\text { MEAN } \\
\text { DISCHARGE } \\
\text { (CFSI }\end{array}$ & $\begin{array}{l}\text { MEAN } \\
\text { CONCEN- } \\
\text { TRATION } \\
\text { (MGIL) }\end{array}$ & $\begin{array}{l}\text { SEDIMENT } \\
\text { DISCHARGE } \\
\text { (TONS/DAY) }\end{array}$ & $\begin{array}{l}\text { MEAN } \\
\text { DISCHARGE } \\
\text { (CFS) }\end{array}$ & $\begin{array}{l}\text { MEAN } \\
\text { CONCEN- } \\
\text { TRATION } \\
\text { IMGILI }\end{array}$ & $\begin{array}{l}\text { SEDIMENT } \\
\text { DISCHARGE } \\
\text { (TONS/DAY) }\end{array}$ & $\begin{array}{l}\text { MEAN } \\
\text { OISCHARGE } \\
\text { (CFS) }\end{array}$ & $\begin{array}{l}\text { MEAN } \\
\text { CONCEN- } \\
\text { TRATION } \\
\text { (MG/L) }\end{array}$ & $\begin{array}{l}\text { SEDIMENT } \\
\text { DISCHARGE } \\
\text { (TONS/DAY) }\end{array}$ \\
\hline
\end{tabular}$$
\begin{array}{crr}
.10 & 50 & .01 \\
4.7 & 300 & 3.8 \\
1.0 & 100 & .27 \\
13.30 & 50 & .04
\end{array}
$$$$
\begin{array}{llll}
6 & 1.0 & 300 & .81 \\
1 & .20 & 100 & .05 \\
9 & .10 & 50 & .01 \\
9 & 0 & -.01 & 0 .
\end{array}
$$

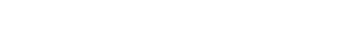$$
\begin{array}{llll}
11 & 0 & -- & 0 \\
12 & 0 & -- & 0
\end{array}
$$$$
\begin{array}{llll}
13 & 0 & -- & 0 \\
14 & 0 & -- & 0 \\
15 & 0 & -- & 0
\end{array}
$$$$
16 \quad 0000
$$$$
\begin{array}{llll}
17 & 0 & -- & 0 \\
18 & 0 & =- & 0 \\
19 & 0 & -- & 0 \\
20 & 0 & -
\end{array}
$$$$
21 \quad 0 \quad--\quad 00
$$$$
\begin{array}{llll}
21 & 0 & -- & 0 \\
22 & 0 & -- & 0 \\
23 & 0 & -- & 0 \\
24 & 0 & -- & 0 \\
25 & 0 &
\end{array}
$$$$
\begin{array}{llll}
26 & 0 & -- & 0 \\
27 & 0 & -- & 0
\end{array}
$$$$
\begin{array}{llll}
26 & 0 & -- & 0 \\
28 & 0 & -- & 0 \\
29 & 0 & -- & 0
\end{array}
$$$$
\begin{array}{llll}
30 & 0 & -- & 0 \\
31 & -- & -- & --
\end{array}
$$$$
\text { TOIAL } 20.40 \quad \ldots \quad 22.99
$$

TUTAL OISCHARTE FOR YEAR (CFS-DAYSI 
11106550 CALLEGUAS CREEK AT CAMARILLO STATB hOSPITAL, CALIF.

LOCATION, --Lat $34^{\circ} 10^{\prime} 46^{\prime \prime}$, long $119^{\circ} \mathrm{O} 2 \mathrm{2}^{\prime \prime}$, In Guadalasca Grant, Ventura County, at gaging station on county bridge, 1.0 mile northeast of Camarillo $\mathrm{state}$ Hospital and $1.4 \mathrm{miles}$ downstream from Conejo Creek.

DRAINAGE AREA. - -243 sq m1.

PERIOD OF RECORD.--Sediment records: October 1968 to September 1969.

EXTREMES, --1968-69:

Sediment concentrations: Maximum dally, 62,900 mg/1 Jan. 25 ; minimum datly, $40 \mathrm{mg} / 1$ on several days $1 \mathrm{n}$ January.

Sediment d1scharge: Maximum da11y, 1,700,000 tons Jan. 25; minimum dally, 0.05 ton Jan. 6.

PARTICLE-SIZE DISTRIBUTION OF SUSPENDED SEDIMENT, WATER YEAR OCTOBER 1968 TO SEPTEMBER 1969
(METHODS OF ANALYSIS: B, BOTTOM WITHURAWAL TUBE; C. CHEMICALLYY OISPERSEO; A, IN AATIVE WATER; P, PIPET; S, SIEVE $V$, VISUAL ACCUMULATION TUBE; $W$, IN DISTILLEO WATER)

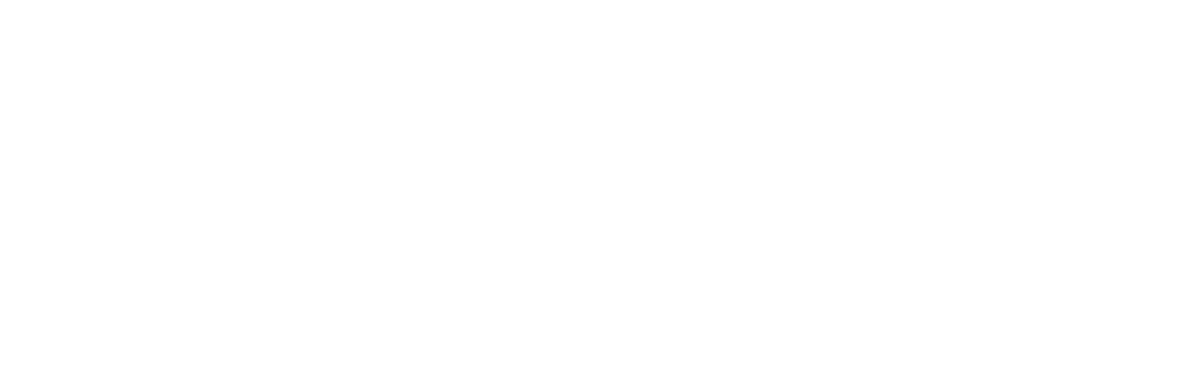

a Single-stage sample. 
11106550 CALLEGUaS CREEK aT CAMARILLO STATE hOSPITAL, CALIF.--Continued SUSPENDED-SEDIMENT DISCHARGE, WATER YEAR CCTOBER 1968 TO SEPTEMBER 1969

OCTOBER NOVEMBER DECEMBER

DAY

$\begin{array}{lll}\text { MEAN } & \text { MEDIMENT } \\ \text { CONCEN- } & \text { SEDIMENT }\end{array}$ (MG/L) (TONS/DAY)
MEAN MEAN CONCFN- SEDIMENT MEAN CONCEN- SEDIMENT IMATION DISCHARGE DISCHARGE TRATION DISCHARGE (TONS) (MGLL) (TONS/DAY)

1
1
1
1
14
15
16
17
19
20
21
22
23
25
26
27
28
39
31
10742

$\begin{array}{ll}1.7 & 50 \\ 1.7 & 50 \\ 1.7 & 50 \\ 1.7 & 50 \\ 1.7 & 50\end{array}$

.23
.23
.23
.23
.23

3.8
3.8
4.6
4.6
4.2

50
50
50
50
50

1.750

$\begin{array}{ll}1.7 & 50 \\ 1.7 & 50 \\ 1.7 & 50 \\ 1.7 & 50\end{array}$

.23

.23
.23
.23

3.4
2.9

2.9
2.1
2.1

$4.6 \quad 50$

$\begin{array}{ll}4.6 & 50 \\ 4.6 & 50 \\ 4.6 & 50\end{array}$

4.2

4.250

3.8
3.8
4.2

4.2
4.6

4.6
4.6

4.6
4.2
4.2

4.2

$3.8 \quad 50$

3.8
3.8
4.6
5.0

107.6

.62
.57
.62
.62
.57

.80
.90
1.7
1.7

.57
.57

.57
.51
.51
.57
.52

7.4
2.9
3.3
2.5
1.7 .62

1.7

.02

.62
.57
.57
.57

.80
.70
.70
-80
2.5

$.51 \quad 2.5$

2.5

2.9
2.5
2.5
2.5

.62
.68
.68

2.5

28.30

14.54
.51
.51
.62
.62

$\begin{array}{ll}2.5 & 50 \\ 2.1 & 50 \\ 1.7 & 50 \\ 2.5 & 50 \\ 2.1 & 50\end{array}$

$2.1 \quad 50$

$\begin{array}{lll}.46 & 2.9 & 50 \\ .39 & 3.4 & 50\end{array}$

.39
.28
$.2 \mathrm{~B}$

$\begin{array}{ll}3.4 & 50 \\ 2.5 & 50\end{array}$

.23

3.4

$\begin{array}{lll}.11 & 3.8 & 50 \\ .12 & 2.1 & 50\end{array}$

$\begin{array}{lll}.12 & 2.1 & 50 \\ .23 & 1.3 & 50 \\ .23 & 1.3 & 50\end{array}$

$\begin{array}{lll}.23 & 1.3 & 50 \\ .72 & .90 & 50\end{array}$

$\begin{array}{ll}2.5 & 50 \\ 2.5 & 50 \\ 1.7 & 50 \\ 2.5 & 50 \\ 2.9 & 50\end{array}$

.45
.34
.23

2.

3.4
2.5
1.5

$: .13$

.09
.09
.11
.34

2.5
2.5
1.7
2.1

.34
.39
.34

.34
.34
.34

7.4
3.
1.
2.

11.78

87.90

50
50
50
50
50
50
50
50
50
50
50
50
50
50
50
50
50
50
50
50
50
50
50
50
50
30
90
70
50
50
50

.34

$:_{.23}^{.23}$

.28

.39
.46

.46

. .34

.51

.28

.18

.34

.34
.32
.23

.34
.39

.46

.34

.23
.28

2.6

5.6

.72
.23
.23
.28

17.80

JANUARY

FEBRUARY

MEAN

CONCEN

$\begin{array}{cl}\text { MEAN } & \text { CONCEN- } \\ \text { DISCHARGE } & \text { TRATION } \\ \text { (CFS) } & \text { (MG/L) }\end{array}$

SEDIMENT MEAN
DISCHARGE

TRATION

$\begin{array}{cc}2.1 & 40 \\ 2.5 & 40 \\ .90 & 40 \\ .80 & 40\end{array}$ (TONS/DAY) (CFS)

500
450
400
350
1000

SEDIMENT

MARCH

MEAN CONCEN$\begin{array}{llll}\text { DISCHARGE } & \text { OISCHARGE } \\ \text { (TONS/DAY) } & \text { (CFS) } & \begin{array}{l}\text { TRATION } \\ \text { (MG/L) }\end{array} & \begin{array}{l}\text { DISCHARGE } \\ \text { (TONS/DAY) }\end{array}\end{array}$

$\begin{array}{cc}l & 2.1 \\ 2 & 2.5 \\ 3 & .90 \\ 4 & .80 \\ 5 & .60\end{array}$

.23
.27
.10
.09
.06

22
20
17
16
36

30
24
18
15
97

70

70
58
42
38
34
30
25
22
23

1400
1000
800

800
700

700
650

$12300 \quad 39400$

.05
.09
.14

695
23
13
12

500
450
450
400

31
16
15
17

600
500

500

450
500

$600-31$

$\begin{array}{rcr}11 & 1.3 & 40 \\ 12 & .70 & 40 \\ 13 & .80 & 40 \\ 14 & 56 & 3120\end{array}$

.14
.08
.09

11
11
10
10
10

350
300
250

10

10
8.9
6.8
6.8
6.2

16
16
17
17

300
295
290
285

13

$3.0 \quad 150$

$$
9.8
$$

9.0

200
230
300
350
400

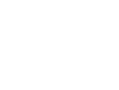

107000

9
10
14
16
17

4
11
15
18

14
14
13
13
12

280

$1150 \quad 13100$

158000

$\begin{array}{rr}1450 & 24200 \\ 85 & 3250 \\ 17 & 1100 \\ 879 & 12900\end{array}$

570
50
48700
1700000

26
81
2620
1230
6030

700
2650
29400
19000

$\begin{array}{rr}29400 & 457000 \\ 19000 & 816\end{array}$

$\begin{array}{r}81300 \\ \hline 9300 \quad 1340000\end{array}$

$1600 \quad 18600$

8850

8850
3000
3650

1740

17400
1620

$\begin{array}{cr}3650 & 4100 \\ -- & -- \\ -- & --\end{array}$

23

2700
1200
1000
700

700
600

TOTAL 14313.60

-. 2216063.3

$\Xi$

2018.0

-. 1942036.8

23.5

$\begin{array}{ll}280 & 11 \\ 275 & 10 \\ 270 & 9.5 \\ 270 & 9.5 \\ 265 & 8.6 \\ 265 & 8.6 \\ 260 & 7.7 \\ 260 & 7.7 \\ 255 & 6.9 \\ 250 & 6.8 \\ 245 & 6.3 \\ 240 & 5.8 \\ 235 & 5.4 \\ 230 & 5.0 \\ 225 & 4.6 \\ 220 & 4.2 \\ -0 & 1018.6\end{array}$


11106550 CALLEGUAS CREEK AT CAKRRILLO STATE hOSPITAL, CALIF.--Continued

SUSPENDED-SEDIMENT DISCHARGE, WATER YEAR OCTOBER 1968 TO SEPTEMBER 1969

\begin{tabular}{|c|c|c|c|c|c|c|c|c|c|}
\hline DAY & $\begin{array}{l}\text { MEAN } \\
\text { DISCHARGE } \\
\text { (CFS) }\end{array}$ & $\begin{array}{l}\text { APRIL } \\
\text { MEAN } \\
\text { CONCEN- } \\
\text { TRATION } \\
\text { (MGILI) }\end{array}$ & $\begin{array}{l}\text { SEDIMENT } \\
\text { DISCHARGE } \\
\text { (TDNS /DAY) }\end{array}$ & $\begin{array}{l}\text { MEAN } \\
\text { Ot SCHARGE } \\
\text { (CFS) }\end{array}$ & $\begin{array}{l}\text { MAY } \\
\text { MEAN } \\
\text { CONCEN- } \\
\text { TRATION } \\
\text { (MG/L) }\end{array}$ & $\begin{array}{l}\text { SEDIMENT } \\
\text { DISCHARGE } \\
\text { (TONS/DAY) }\end{array}$ & $\begin{array}{l}\text { MEAN } \\
\text { DISCHARGE } \\
\text { (CFS) }\end{array}$ & $\begin{array}{l}\text { JUNE } \\
\text { MEAN } \\
\text { CONCEN- } \\
\text { TRATION } \\
\text { (MGIL) }\end{array}$ & $\begin{array}{l}\text { SEDI MENT } \\
\text { DISCHARGE } \\
\text { (TONS /DAY) }\end{array}$ \\
\hline $\begin{array}{l}1 \\
2 \\
3 \\
4 \\
5\end{array}$ & $\begin{array}{l}6.5 \\
6.0 \\
5.5 \\
5.0 \\
13\end{array}$ & $\begin{array}{l}215 \\
210 \\
205 \\
200 \\
400\end{array}$ & $\begin{array}{l}3.8 \\
3.4 \\
3.0 \\
2.7 \\
14\end{array}$ & $\begin{array}{l}2.5 \\
2.5 \\
2.5 \\
2.5 \\
2.5\end{array}$ & $\begin{array}{l}100 \\
100 \\
100 \\
100 \\
100\end{array}$ & $\begin{array}{l}.68 \\
.68 \\
.68 \\
.68 \\
.68\end{array}$ & $\begin{array}{l}2.5 \\
2.5 \\
2.5 \\
2.5 \\
2.5\end{array}$ & $\begin{array}{l}90 \\
90 \\
90 \\
90 \\
90\end{array}$ & $\begin{array}{l}.61 \\
.61 \\
.61 \\
.61 \\
.61\end{array}$ \\
\hline $\begin{array}{r}6 \\
7 \\
8 \\
9 \\
10\end{array}$ & $\begin{array}{l}6.0 \\
4.5 \\
4.0 \\
3.5 \\
3.0\end{array}$ & $\begin{array}{l}250 \\
200 \\
180 \\
170 \\
160\end{array}$ & $\begin{array}{l}4.0 \\
2.4 \\
1.9 \\
1.6 \\
1.3\end{array}$ & $\begin{array}{l}2.5 \\
2.5 \\
2.5 \\
2.5 \\
2.5\end{array}$ & $\begin{array}{l}100 \\
100 \\
100 \\
100 \\
100\end{array}$ & $\begin{array}{l}.68 \\
.68 \\
.68 \\
.68 \\
.68\end{array}$ & $\begin{array}{l}2.5 \\
2.5 \\
2.5 \\
2.5 \\
2.5\end{array}$ & $\begin{array}{l}90 \\
90 \\
90 \\
90 \\
90\end{array}$ & $\begin{array}{l}.61 \\
.61 \\
.61 \\
.61 \\
.61\end{array}$ \\
\hline $\begin{array}{l}11 \\
12 \\
13 \\
14 \\
15\end{array}$ & $\begin{array}{l}2.5 \\
2.5 \\
2.5 \\
2.5 \\
2.5\end{array}$ & $\begin{array}{l}155 \\
150 \\
145 \\
140 \\
135\end{array}$ & $\begin{array}{l}1.0 \\
1.0 \\
.98 \\
.94 \\
.91\end{array}$ & $\begin{array}{l}2.5 \\
2.5 \\
2.5 \\
2.5 \\
2.5\end{array}$ & $\begin{array}{l}100 \\
100 \\
100 \\
100 \\
100\end{array}$ & $\begin{array}{l}.68 \\
.68 \\
.68 \\
.68 \\
.68\end{array}$ & $\begin{array}{l}2.5 \\
2.5 \\
2.5 \\
2.5 \\
2.5\end{array}$ & $\begin{array}{l}90 \\
90 \\
90 \\
90 \\
90\end{array}$ & $\begin{array}{l}.61 \\
.61 \\
.61 \\
.61 \\
.61\end{array}$ \\
\hline $\begin{array}{l}16 \\
17 \\
18 \\
19 \\
20\end{array}$ & $\begin{array}{l}2.5 \\
2.5 \\
2.5 \\
2.5 \\
2.5\end{array}$ & $\begin{array}{l}130 \\
125 \\
120 \\
120 \\
115\end{array}$ & $\begin{array}{l}.88 \\
.84 \\
.81 \\
.81 \\
.78\end{array}$ & $\begin{array}{l}2.5 \\
2.5 \\
2.5 \\
2.5 \\
2.5\end{array}$ & $\begin{array}{l}100 \\
100 \\
100 \\
100 \\
100\end{array}$ & $\begin{array}{l}.68 \\
.68 \\
.68 \\
.68 \\
.68\end{array}$ & $\begin{array}{l}2.5 \\
2.5 \\
2.5 \\
2.5 \\
2.5\end{array}$ & $\begin{array}{l}90 \\
90 \\
90 \\
90 \\
90\end{array}$ & $\begin{array}{l}.61 \\
.61 \\
.61 \\
.61 \\
.61\end{array}$ \\
\hline $\begin{array}{l}21 \\
22 \\
23 \\
24 \\
25\end{array}$ & $\begin{array}{l}2.5 \\
2.5 \\
2.5 \\
2.5 \\
2.5\end{array}$ & $\begin{array}{l}115 \\
110 \\
110 \\
105 \\
105\end{array}$ & $\begin{array}{l}.78 \\
.74 \\
.74 \\
.72 \\
.71\end{array}$ & $\begin{array}{l}2.5 \\
2.5 \\
2.5 \\
2.5 \\
2.5\end{array}$ & $\begin{array}{l}100 \\
100 \\
100 \\
100 \\
100\end{array}$ & $\begin{array}{l}.68 \\
.68 \\
.68 \\
.68 \\
.68\end{array}$ & $\begin{array}{l}2.5 \\
2.5 \\
2.5 \\
2.5 \\
2.5\end{array}$ & $\begin{array}{l}90 \\
90 \\
90 \\
90 \\
90\end{array}$ & $\begin{array}{l}.61 \\
.61 \\
.61 \\
.61 \\
.61\end{array}$ \\
\hline $\begin{array}{l}26 \\
27 \\
28 \\
29 \\
30 \\
31\end{array}$ & $\begin{array}{l}2.5 \\
2.5 \\
2.5 \\
2.5 \\
2.5 \\
-.-\end{array}$ & $\begin{array}{l}105 \\
105 \\
100 \\
100 \\
100 \\
--\end{array}$ & $\begin{array}{l}.71 \\
.71 \\
.68 \\
.68 \\
.68 \\
.-\end{array}$ & $\begin{array}{l}2.5 \\
2.5 \\
2.5 \\
2.5 \\
2.5 \\
2.5\end{array}$ & $\begin{array}{l}100 \\
100 \\
100 \\
100 \\
100 \\
100\end{array}$ & $\begin{array}{l}.68 \\
.68 \\
.68 \\
.68 \\
.68 \\
.68\end{array}$ & $\begin{array}{l}2.5 \\
2.5 \\
2.5 \\
2.5 \\
2.5 \\
--\end{array}$ & $\begin{array}{l}90 \\
90 \\
90 \\
90 \\
90 \\
--\end{array}$ & $\begin{array}{l}.61 \\
.61 \\
.61 \\
.61 \\
.61 \\
.-.\end{array}$ \\
\hline
\end{tabular}

TUTAL $\quad 107.0 \quad--$

54.19

21.08

18.30

\begin{tabular}{|c|c|c|c|c|c|c|c|c|c|}
\hline \multirow[b]{2}{*}{ DAY } & \multicolumn{3}{|c|}{ JULY } & \multicolumn{3}{|c|}{ AUGUST } & \multicolumn{3}{|c|}{ SEP TEMBER } \\
\hline & $\begin{array}{l}\text { MEAN } \\
\text { OISCHARGE } \\
\text { (CFS) }\end{array}$ & $\begin{array}{l}\text { MEAN } \\
\text { CONCEN- } \\
\text { TRATION } \\
\text { (MG/L) }\end{array}$ & $\begin{array}{l}\text { SEDIMENT } \\
\text { DISCHARGE } \\
\text { (TONS/DAY) }\end{array}$ & $\begin{array}{l}\text { MEAN } \\
\text { DI SCHARGE } \\
\text { (CFS) }\end{array}$ & $\begin{array}{l}\text { MEAN } \\
\text { CONCEN- } \\
\text { TRATION } \\
\text { (MGIL) }\end{array}$ & $\begin{array}{l}\text { SEDIMENT } \\
\text { DISCHARGE } \\
\text { (TONS /DAY) }\end{array}$ & $\begin{array}{l}\text { MEAN } \\
\text { OISCHARGE } \\
\text { (CFS) }\end{array}$ & $\begin{array}{l}\text { MEAN } \\
\text { CONCEN- } \\
\text { TRATION } \\
\text { (MGIL) }\end{array}$ & $\begin{array}{l}\text { SEDIMENT } \\
\text { DI SCHARGE } \\
\text { (TDNS/DAY) }\end{array}$ \\
\hline $\begin{array}{l}1 \\
2 \\
3 \\
4 \\
5\end{array}$ & $\begin{array}{l}2.5 \\
2.5 \\
2.5 \\
2.5 \\
2.5\end{array}$ & $\begin{array}{l}80 \\
80 \\
80 \\
80 \\
80\end{array}$ & $\begin{array}{l}.54 \\
.54 \\
.54 \\
.54 \\
.54\end{array}$ & $\begin{array}{l}2.5 \\
2.5 \\
2.5 \\
2.5 \\
2.5\end{array}$ & $\begin{array}{l}70 \\
70 \\
70 \\
70 \\
70\end{array}$ & $\begin{array}{l}.47 \\
.47 \\
.47 \\
.47 \\
.47\end{array}$ & $\begin{array}{l}2.5 \\
2.5 \\
2.5 \\
2.5 \\
2.5\end{array}$ & $\begin{array}{l}60 \\
60 \\
60 \\
60 \\
60\end{array}$ & $\begin{array}{l}.41 \\
.41 \\
.41 \\
.41 \\
.41\end{array}$ \\
\hline $\begin{array}{r}6 \\
7 \\
8 \\
9 \\
10\end{array}$ & $\begin{array}{l}2.5 \\
2.5 \\
2.5 \\
2.5 \\
2.5\end{array}$ & $\begin{array}{l}80 \\
80 \\
80 \\
80 \\
80\end{array}$ & $\begin{array}{l}.54 \\
.54 \\
.54 \\
.54 \\
.54\end{array}$ & $\begin{array}{l}2.5 \\
2.5 \\
2.5 \\
2.5 \\
2.5\end{array}$ & $\begin{array}{l}70 \\
70 \\
70 \\
70 \\
70\end{array}$ & $\begin{array}{l}.47 \\
.47 \\
.47 \\
.47 \\
.47\end{array}$ & $\begin{array}{l}2.5 \\
2.5 \\
2.5 \\
2.5 \\
2.5\end{array}$ & $\begin{array}{l}60 \\
60 \\
60 \\
60 \\
60\end{array}$ & $\begin{array}{l}.41 \\
.41 \\
.41 \\
.41 \\
.41\end{array}$ \\
\hline $\begin{array}{l}11 \\
12 \\
13 \\
14 \\
15\end{array}$ & $\begin{array}{l}2.5 \\
2.5 \\
2.5 \\
2.5 \\
2.5\end{array}$ & $\begin{array}{l}80 \\
80 \\
80 \\
80 \\
80\end{array}$ & $\begin{array}{l}.54 \\
.54 \\
.54 \\
.54 \\
.54\end{array}$ & $\begin{array}{l}2.5 \\
2.5 \\
2.5 \\
2.5 \\
2.5\end{array}$ & $\begin{array}{l}70 \\
70 \\
70 \\
70 \\
70\end{array}$ & $\begin{array}{l}.47 \\
.47 \\
.47 \\
.47 \\
.47\end{array}$ & $\begin{array}{l}2.5 \\
2.5 \\
2.5 \\
2.5 \\
2.5\end{array}$ & $\begin{array}{l}60 \\
60 \\
60 \\
60 \\
60\end{array}$ & $\begin{array}{l}.41 \\
.41 \\
.41 \\
.41 \\
.41\end{array}$ \\
\hline $\begin{array}{l}16 \\
17 \\
18 \\
19 \\
20\end{array}$ & $\begin{array}{l}2.5 \\
2.5 \\
2.5 \\
2.5 \\
2.5\end{array}$ & $\begin{array}{l}80 \\
80 \\
80 \\
80 \\
80\end{array}$ & $\begin{array}{l}.54 \\
.54 \\
.54 \\
.54 \\
.54\end{array}$ & $\begin{array}{l}2.5 \\
2.5 \\
2.5 \\
2.5 \\
2.5\end{array}$ & $\begin{array}{l}70 \\
70 \\
70 \\
70 \\
70\end{array}$ & $\begin{array}{l}.47 \\
.47 \\
.47 \\
.47 \\
.47\end{array}$ & $\begin{array}{l}2.5 \\
2.5 \\
2.5 \\
2.5 \\
2.5\end{array}$ & $\begin{array}{l}60 \\
60 \\
60 \\
60 \\
60\end{array}$ & $\begin{array}{l}.41 \\
.41 \\
.41 \\
.41 \\
.41\end{array}$ \\
\hline $\begin{array}{l}21 \\
22 \\
23 \\
24 \\
25\end{array}$ & $\begin{array}{l}2.5 \\
2.5 \\
2.5 \\
2.5 \\
2.5\end{array}$ & $\begin{array}{l}80 \\
80 \\
80 \\
80 \\
80\end{array}$ & $\begin{array}{l}.54 \\
.54 \\
.54 \\
.54 \\
.54\end{array}$ & $\begin{array}{l}2.5 \\
2.5 \\
2.5 \\
2.5 \\
2.5\end{array}$ & $\begin{array}{l}70 \\
70 \\
70 \\
70 \\
70\end{array}$ & $\begin{array}{l}.47 \\
.47 \\
.47 \\
.47 \\
.47\end{array}$ & $\begin{array}{l}2.5 \\
2.5 \\
2.5 \\
2.5 \\
2.5\end{array}$ & $\begin{array}{l}60 \\
60 \\
60 \\
60 \\
60\end{array}$ & $\begin{array}{l}.41 \\
.41 \\
.41 \\
.41 \\
.41\end{array}$ \\
\hline $\begin{array}{l}26 \\
27 \\
28 \\
29 \\
30 \\
31\end{array}$ & $\begin{array}{l}2.5 \\
2.5 \\
2.5 \\
2.5 \\
2.5 \\
2.5\end{array}$ & $\begin{array}{l}80 \\
80 \\
80 \\
80 \\
80 \\
80\end{array}$ & $\begin{array}{r}.54 \\
.54 \\
.54 \\
.54 \\
.54 \\
.54\end{array}$ & $\begin{array}{l}2.5 \\
2.5 \\
2.5 \\
2.5 \\
2.5 \\
2.5\end{array}$ & $\begin{array}{l}70 \\
70 \\
70 \\
70 \\
70 \\
70\end{array}$ & $\begin{array}{l}.47 \\
.47 \\
.47 \\
.47 \\
.47 \\
.47\end{array}$ & $\begin{array}{r}2.5 \\
2.5 \\
2.5 \\
2.5 \\
2.5 \\
-.-\end{array}$ & $\begin{array}{l}60 \\
60 \\
60 \\
60 \\
60 \\
--\end{array}$ & $\begin{array}{l}.41 \\
.41 \\
.41 \\
.41 \\
.41 \\
.-\end{array}$ \\
\hline IDTAL & 77.5 & -- & 16.74 & 77.5 & -- & 14.57 & 75.0 & - & 12.30 \\
\hline $\begin{array}{l}\text { TOTAL } \\
\text { TOTAL }\end{array}$ & $\begin{array}{l}\text { OI SCHARGE } \\
\text { SUSPENDED- }\end{array}$ & $\begin{array}{l}\text { OR YEAR } \\
\text { EDIMENT }\end{array}$ & $\begin{array}{l}\text { CFS-DAYS) } \\
\text { I SCHARGE FOR }\end{array}$ & YEAR ITONS & & & & & $\begin{array}{r}27718.40 \\
4159300.08\end{array}$ \\
\hline
\end{tabular}


LOCATION, --Lat $34^{\circ} 23^{\prime} 59^{\prime \prime}$, long $118^{\circ} 42^{\prime} 14^{\prime \prime}$, In San Francisco Grant, Ventura County, at gaglng stat1on on old diversion weir, $0.8 \mathrm{mile}$ west of Los Angeles-Ventura County Line.

DRAINAGE AREA, $--644 \mathrm{sq} \mathrm{ml}$.

PERIOD OF RECORD. --Chemical analy ses: January to September 1969.

Water temperatures: October 1968 to September 1969.

Sediment records: October 1968 to September 1969.

EXTR БM ВS. --1966-69:

Sediment concentrations: Maximum dally, not determined; minimum dally, 20 mg/l Jan, 6-12.
Sediment discharge: Maximum da1ly, 3,300,000 tons (estimated) Feb. 25; minlmum daily, 0.05 ton Jan. 7.

REMARKS, -- There no maximum or minimum is shown, temperature is once-daily reading.

CHEMICAL ANALYSES, JANUARY TO SEPTEMBER 1969

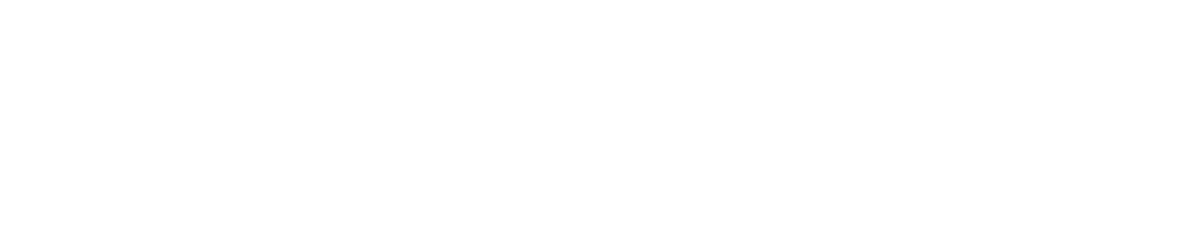

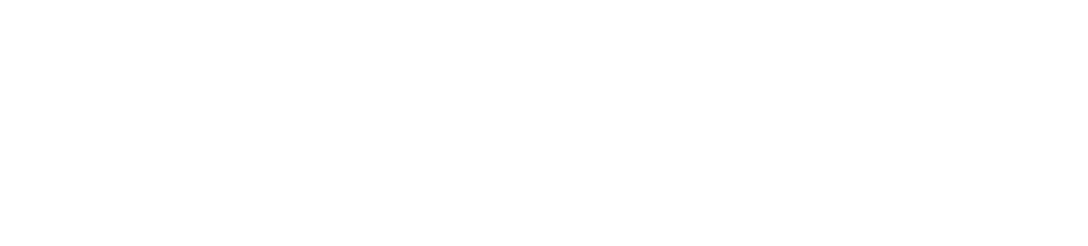

SPECIFIC CONDUCTANCE (UICROMHOS AT $25^{\circ} \mathrm{C}$ ), JUNE TO SEPTEMBER 1969

\begin{tabular}{|c|c|c|c|c|c|c|c|c|c|c|c|c|}
\hline & & JUN & & & JUL & & & AUG & & & SEP & \\
\hline $\begin{array}{c}\text { DAY } \\
1 \\
2 \\
5 \\
4 \\
5\end{array}$ & \begin{tabular}{l}
$\operatorname{MAX}$ \\
--- \\
\hdashline-- \\
\hdashline- \\
---
\end{tabular} & \begin{tabular}{c} 
MIN \\
--- \\
--- \\
\hdashline-- \\
$-\cdots$
\end{tabular} & $\begin{array}{c}\text { MEAN } \\
-\square \\
\square- \\
-\square \\
-\square\end{array}$ & $\begin{array}{r}\operatorname{MAX} \\
1950 \\
2050 \\
2040 \\
2090 \\
2130\end{array}$ & $\begin{array}{l}\text { MIN } \\
1900 \\
1940 \\
1960 \\
1990 \\
2060\end{array}$ & $\begin{array}{l}\text { MEAN } \\
1920 \\
1990 \\
2010 \\
2040 \\
2100\end{array}$ & $\begin{array}{r}\text { MAX } \\
2340 \\
2460 \\
2770 \\
2880 \\
2570\end{array}$ & $\begin{array}{r}M I N \\
2160 \\
2210 \\
2450 \\
2500 \\
2190\end{array}$ & $\begin{array}{l}\text { MEAN } \\
2240 \\
2290 \\
2590 \\
2670 \\
2400\end{array}$ & $\begin{array}{r}\text { MAX } \\
25600 \\
2430 \\
2450 \\
2410 \\
2460\end{array}$ & $\begin{array}{r}M 1 N \\
2390 \\
2260 \\
2290 \\
2190 \\
2150\end{array}$ & $\begin{array}{l}\text { MEAN } \\
2480 \\
2350 \\
2360 \\
2290 \\
2320\end{array}$ \\
\hline $\begin{array}{r}6 \\
7 \\
8 \\
9 \\
10\end{array}$ & $\begin{array}{l}--- \\
-- \\
--- \\
---\end{array}$ & $\begin{array}{l}--- \\
--- \\
--- \\
---\end{array}$ & $\begin{array}{l}--- \\
-\square \\
--- \\
--\end{array}$ & $\begin{array}{r}2220 \\
2320 \\
-\cdots \\
---\end{array}$ & $\begin{array}{r}2130 \\
2230 \\
--- \\
--- \\
---\end{array}$ & $\begin{array}{r}2160 \\
2270 \\
--0 \\
- \\
-\end{array}$ & $\begin{array}{l}2650 \\
2650 \\
2550 \\
2690 \\
2880\end{array}$ & $\begin{array}{l}2330 \\
2120 \\
2230 \\
2460 \\
2450\end{array}$ & $\begin{array}{l}2480 \\
2440 \\
2370 \\
2540 \\
2580\end{array}$ & $\begin{array}{l}2220 \\
2230 \\
2350 \\
2340 \\
2230\end{array}$ & $\begin{array}{l}2120 \\
2100 \\
2110 \\
2040 \\
1940\end{array}$ & $\begin{array}{l}2160 \\
2150 \\
2230 \\
2190 \\
2050\end{array}$ \\
\hline $\begin{array}{l}11 \\
12 \\
13 \\
14 \\
15\end{array}$ & $\begin{array}{l}-- \\
--- \\
--- \\
--\end{array}$ & $\begin{array}{l}--- \\
--- \\
-\cdots \\
---\end{array}$ & 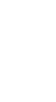 & 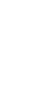 & 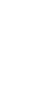 & 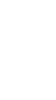 & $\begin{array}{l}2680 \\
2600 \\
2410 \\
2340 \\
2510\end{array}$ & $\begin{array}{l}2510 \\
2370 \\
2200 \\
2150 \\
2240\end{array}$ & $\begin{array}{l}2580 \\
2470 \\
2280 \\
2210 \\
2350\end{array}$ & $\begin{array}{l}2060 \\
2170 \\
2260 \\
2240 \\
2190\end{array}$ & $\begin{array}{l}1960 \\
1940 \\
1830 \\
1750 \\
1950\end{array}$ & $\begin{array}{l}2000 \\
2020 \\
2120 \\
2060 \\
2050\end{array}$ \\
\hline $\begin{array}{l}16 \\
17 \\
18 \\
19 \\
20\end{array}$ & $\frac{--}{--0}$ & $\begin{array}{l}--- \\
-20 \\
1910\end{array}$ & $\begin{array}{c}=- \\
\overline{-0} \\
\overline{-0}\end{array}$ & $\begin{array}{l}2250 \\
2270 \\
2300 \\
2350 \\
2420\end{array}$ & $\begin{array}{l}2060 \\
2100 \\
2150 \\
2200 \\
2220\end{array}$ & $\begin{array}{l}2100 \\
2150 \\
2190 \\
2250 \\
2320\end{array}$ & $\begin{array}{l}2650 \\
2610 \\
2300 \\
2280 \\
2260\end{array}$ & $\begin{array}{l}2450 \\
2280 \\
2210 \\
2130 \\
2090\end{array}$ & $\begin{array}{l}2550 \\
2430 \\
2250 \\
2220 \\
2190\end{array}$ & $\begin{array}{l}2000 \\
1980 \\
2030 \\
2020 \\
1950\end{array}$ & $\begin{array}{l}1890 \\
1880 \\
1870 \\
1910 \\
1890\end{array}$ & $\begin{array}{l}1940 \\
1930 \\
1950 \\
1960 \\
1910\end{array}$ \\
\hline $\begin{array}{l}21 \\
22 \\
23 \\
24 \\
25\end{array}$ & $\begin{array}{l}1960 \\
1920 \\
1900 \\
1880 \\
1850\end{array}$ & $\begin{array}{l}1850 \\
1840 \\
1830 \\
1820 \\
1770\end{array}$ & $\begin{array}{l}1920 \\
1900 \\
1880 \\
1850 \\
1810\end{array}$ & $\begin{array}{l}2360 \\
2490 \\
2540 \\
2550 \\
2570\end{array}$ & $\begin{array}{l}2180 \\
2340 \\
2340 \\
2430 \\
2240\end{array}$ & $\begin{array}{l}2270 \\
2420 \\
2450 \\
2500 \\
2410\end{array}$ & $\begin{array}{l}2300 \\
2170 \\
2220 \\
2170 \\
2150\end{array}$ & $\begin{array}{l}2040 \\
2040 \\
2050 \\
2050 \\
2070\end{array}$ & $\begin{array}{l}2190 \\
2110 \\
2130 \\
2110 \\
2110\end{array}$ & $\begin{array}{l}2070 \\
2070 \\
2070 \\
2110 \\
2280\end{array}$ & $\begin{array}{l}1940 \\
1890 \\
1930 \\
1980 \\
2060\end{array}$ & $\begin{array}{l}2010 \\
1980 \\
2000 \\
2030 \\
2160\end{array}$ \\
\hline $\begin{array}{l}26 \\
27 \\
78 \\
29 \\
30 \\
31\end{array}$ & $\begin{array}{l}1810 \\
1860 \\
1870 \\
1890 \\
1920 \\
-\end{array}$ & $\begin{array}{l}1720 \\
1720 \\
1740 \\
1780 \\
1840\end{array}$ & $\begin{array}{l}1800 \\
1800 \\
1790 \\
1840 \\
1870\end{array}$ & $\begin{array}{l}2560 \\
2610 \\
2580 \\
2560 \\
2590 \\
2620\end{array}$ & $\begin{array}{l}2320 \\
2460 \\
2280 \\
2220 \\
2420 \\
2300\end{array}$ & $\begin{array}{l}2420 \\
2530 \\
2390 \\
2350 \\
2520 \\
2480\end{array}$ & $\begin{array}{l}2650 \\
3200 \\
2800 \\
2520 \\
2360 \\
2510\end{array}$ & $\begin{array}{l}2150 \\
2450 \\
2370 \\
2230 \\
2200 \\
2210\end{array}$ & $\begin{array}{l}2300 \\
2700 \\
2580 \\
2360 \\
2260 \\
2280\end{array}$ & $\begin{array}{r}2140 \\
=- \\
=- \\
=-\end{array}$ & $\begin{array}{r}2060 \\
=- \\
=- \\
=-\end{array}$ & $\begin{array}{r}2090 \\
0- \\
\hdashline- \\
\hdashline\end{array}$ \\
\hline VTH & --- & $m$ & $=$ & $m$ & $\ldots$ & 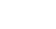 & 3200 & 2040 & 2363 & 2560 & 1750 & 2107 \\
\hline
\end{tabular}


SANTA CLARA RIVER BASIN

11108500 SANTA CLARA RIVER AT LOS ANGELES-VENTURA COUNTY LINE, CALIF.--Cont InUed PH (UNITS), JUNE TO SEPTEMBER 1969

\begin{tabular}{|c|c|c|c|c|c|c|c|c|}
\hline \multirow[b]{2}{*}{ DAY } & \multicolumn{2}{|c|}{ JUN } & \multicolumn{2}{|c|}{ JUL } & \multicolumn{2}{|c|}{ AUG } & \multicolumn{2}{|c|}{ SEP } \\
\hline & $\operatorname{MAX}$ & MIN & $\operatorname{MAX}$ & MIN & $\operatorname{MAX}$ & MIN & $\operatorname{MAX}$ & MIN \\
\hline $\begin{array}{l}1 \\
2 \\
3 \\
4 \\
5\end{array}$ & $\bar{m}$ & $\begin{array}{l}=- \\
=- \\
---\end{array}$ & $\begin{array}{l}7.9 \\
7.8 \\
7.8 \\
7.9 \\
7.9\end{array}$ & $\begin{array}{l}7.3 \\
7.3 \\
7.4 \\
7.5 \\
7.6\end{array}$ & $\begin{array}{l}7.6 \\
7.6 \\
7.5 \\
7.5 \\
7.6\end{array}$ & $\begin{array}{l}7.4 \\
7.4 \\
7.4 \\
7.4 \\
7.4\end{array}$ & $\begin{array}{l}7.5 \\
7.5 \\
7.5 \\
7.8 \\
7.9\end{array}$ & $\begin{array}{l}7.3 \\
7.3 \\
7.4 \\
7.4 \\
7.7\end{array}$ \\
\hline $\begin{array}{r}6 \\
8 \\
9 \\
10\end{array}$ & $\overline{-}$ & \begin{tabular}{l}
$\cdots$ \\
$\cdots$ \\
\hdashline-
\end{tabular} & \begin{tabular}{l}
7.8 \\
7.0 \\
\hdashline-0 \\
-0
\end{tabular} & \begin{tabular}{l}
7.7 \\
7.7 \\
\hdashline-
\end{tabular} & $\begin{array}{l}7.8 \\
7.8 \\
7.8 \\
7.7 \\
7.7\end{array}$ & $\begin{array}{l}7.5 \\
7.6 \\
7.6 \\
7.5 \\
7.5\end{array}$ & $\begin{array}{l}7.8 \\
7.8 \\
7.8 \\
7.7 \\
7.7\end{array}$ & $\begin{array}{l}7.7 \\
7.6 \\
7.6 \\
7.6 \\
7.5\end{array}$ \\
\hline $\begin{array}{l}11 \\
12 \\
13 \\
14 \\
15\end{array}$ & $\bar{m}$ & \begin{tabular}{l}
-- \\
\hdashline- \\
--
\end{tabular} & 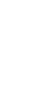 & $\overline{-}$ & $\begin{array}{l}7.7 \\
7.7 \\
7.8 \\
7.8 \\
7.8\end{array}$ & $\begin{array}{l}7.5 \\
7.6 \\
7.6 \\
7.7 \\
7.7\end{array}$ & $\begin{array}{l}7.0 \\
0.0 \\
7.8 \\
7.0 \\
7.8\end{array}$ & $\begin{array}{l}7.6 \\
7.7 \\
7.6 \\
7.7 \\
7.7\end{array}$ \\
\hline $\begin{array}{l}16 \\
17 \\
18 \\
19 \\
20\end{array}$ & $\overline{7.5}$ & $=$ & $\begin{array}{l}7.7 \\
7.8 \\
7.7 \\
7.8 \\
7.6\end{array}$ & $\begin{array}{l}7.5 \\
7.5 \\
7.5 \\
7.5 \\
7.4\end{array}$ & $\begin{array}{l}7.8 \\
7.8 \\
7.9 \\
7.9 \\
7.8\end{array}$ & $\begin{array}{l}7.7 \\
7.7 \\
7.7 \\
7.7 \\
7.5\end{array}$ & $\begin{array}{l}7.8 \\
7.7 \\
7.8 \\
7.8 \\
7.9\end{array}$ & $\begin{array}{l}7.7 \\
7.6 \\
7.7 \\
7.7 \\
7.8\end{array}$ \\
\hline $\begin{array}{l}21 \\
22 \\
23 \\
24 \\
25\end{array}$ & $\begin{array}{l}7.6 \\
7.6 \\
7.6 \\
7.8 \\
-2\end{array}$ & $\begin{array}{r}7.5 \\
7.5 \\
7.5 \\
7.5 \\
-.\end{array}$ & $\begin{array}{l}7.6 \\
7.5 \\
7.5 \\
7.6 \\
7.7\end{array}$ & $\begin{array}{l}7.3 \\
7.3 \\
7.3 \\
7.4 \\
7.5\end{array}$ & $\begin{array}{l}7.7 \\
7.8 \\
7.8 \\
7.7 \\
7.8\end{array}$ & $\begin{array}{l}7.6 \\
7.6 \\
7.6 \\
7.6 \\
7.6\end{array}$ & $\begin{array}{r}7.9 \\
7.9 \\
7.9 \\
7.9 \\
7.8\end{array}$ & $\begin{array}{l}7.7 \\
7.7 \\
7.7 \\
7.6 \\
7.6\end{array}$ \\
\hline $\begin{array}{l}26 \\
27 \\
28 \\
29 \\
30 \\
31\end{array}$ & $\begin{array}{l}0.0 \\
8.0 \\
8.0 \\
0.0 \\
0.0 \\
-\end{array}$ & $\begin{array}{l}7.5 \\
7.6 \\
7.6 \\
7.5 \\
7.5 \\
-.0\end{array}$ & $\begin{array}{l}7.7 \\
7.6 \\
7.6 \\
7.6 \\
7.5 \\
7.6\end{array}$ & $\begin{array}{l}7.5 \\
7.4 \\
7.4 \\
7.3 \\
7.3 \\
7.4\end{array}$ & $\begin{array}{l}7.7 \\
7.5 \\
7.5 \\
7.5 \\
7.5 \\
7.6\end{array}$ & $\begin{array}{l}7.5 \\
7.3 \\
7.3 \\
7.4 \\
7.4 \\
7.4\end{array}$ & \begin{tabular}{l}
7.0 \\
\hdashline-0 \\
\hdashline-0 \\
\hdashline-0
\end{tabular} & \begin{tabular}{l}
7.7 \\
\hdashline.- \\
\hdashline- \\
\hdashline- \\
--
\end{tabular} \\
\hline UNTH & $\cdots$ & - & $=-$ & $-\infty$ & 7.9 & 7.3 & 8.0 & 7.3 \\
\hline
\end{tabular}

CHLORIDE (CL), IN MILLIGRAYS PER LITER, JUNE TO SRPTBMBER $19 \theta 9$

\begin{tabular}{|c|c|c|c|c|}
\hline DAY & JUN & JUL & AUG & SEP \\
\hline $\begin{array}{l}1 \\
2 \\
3 \\
4 \\
5\end{array}$ & "- & $\begin{array}{l}{ }_{83}^{83} \\
77 \\
77 \\
79 \\
81\end{array}$ & $\begin{array}{l}899 \\
89 \\
75 \\
94 \\
92\end{array}$ & $\begin{array}{l}88 \\
82 \\
81 \\
85 \\
95 \\
90\end{array}$ \\
\hline $\begin{array}{r}6 \\
7 \\
8 \\
9 \\
10\end{array}$ & \begin{tabular}{l}
$\because$ \\
$\because \because$ \\
\hdashline
\end{tabular} & \begin{tabular}{c}
84 \\
89 \\
\hdashline$\because$ \\
\hdashline-
\end{tabular} & $\begin{array}{l}86 \\
877 \\
83 \\
86 \\
87\end{array}$ & $\begin{array}{l}86 \\
02 \\
82 \\
80 \\
80 \\
76\end{array}$ \\
\hline $\begin{array}{l}12 \\
12 \\
13 \\
13 \\
15 \\
15\end{array}$ & $\begin{array}{l}\because- \\
\because \because \\
\because \because\end{array}$ & $\begin{array}{l}\because- \\
\because \because \\
\because \because\end{array}$ & $\begin{array}{l}84 \\
78 \\
784 \\
73 \\
76\end{array}$ & $\begin{array}{l}76 \\
79 \\
79 \\
77 \\
76\end{array}$ \\
\hline $\begin{array}{l}16 \\
17 \\
18 \\
19 \\
20\end{array}$ & \begin{tabular}{l}
$\because \because$ \\
\hdashline$\because$ \\
\hdashline 9 \\
93
\end{tabular} & $\begin{array}{l}84 \\
90 \\
89 \\
87 \\
89\end{array}$ & $\begin{array}{l}81 \\
82 \\
83 \\
83 \\
86 \\
84\end{array}$ & $\begin{array}{l}71 \\
71 \\
74 \\
75 \\
79\end{array}$ \\
\hline $\begin{array}{l}21 \\
32 \\
73 \\
24 \\
24 \\
25\end{array}$ & $\begin{array}{l}95 \\
75 \\
80 \\
69 \\
62 \\
82\end{array}$ & $\begin{array}{l}84 \\
88 \\
900 \\
95 \\
95 \\
93\end{array}$ & $\begin{array}{l}95 \\
95 \\
91 \\
87 \\
86\end{array}$ & $\begin{array}{l}81 \\
80 \\
79 \\
80 \\
84\end{array}$ \\
\hline $\begin{array}{l}26 \\
27 \\
29 \\
29 \\
40 \\
31\end{array}$ & $\begin{array}{r}89 \\
95 \\
84 \\
79 \\
83 \\
-\end{array}$ & $\begin{array}{l}92 \\
93 \\
97 \\
93 \\
95 \\
97 \\
97\end{array}$ & $\begin{array}{r}89 \\
105 \\
96 \\
91 \\
88 \\
87\end{array}$ & \begin{tabular}{l}
05 \\
0 \\
\hdashline- \\
\hdashline- \\
\hdashline-
\end{tabular} \\
\hline VTH & --. & $\ldots$ & 87 & -. \\
\hline
\end{tabular}


PARTICLE-SIZE DETERMINATIONS OF SUSPENDED SEDIMENT, WATER YEAR OCTOBER 1968 TO SEPTEMBER 1969

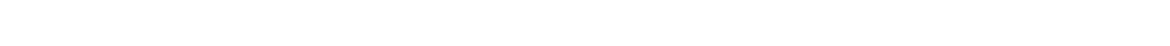

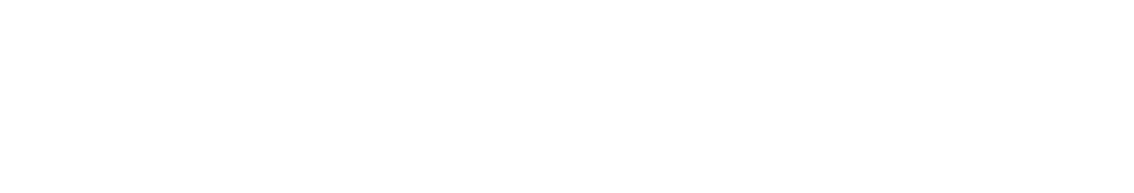

PARTICLE-5IZE DISTRIBUTION OF SURFACE BED MATERIAL, WATER YEAR OCTOBER 1968 TO SEPTEMBER 1969 (METHOD DF ANALYSIS: H, HYOROMETER; O, OPTICAL ANALYZER; S. SIEVE: V, VISUAL ACCUMULATION TUBE)

\begin{tabular}{|c|c|c|c|c|c|c|c|c|c|c|c|c|c|c|c|c|c|}
\hline \multirow[b]{3}{*}{ DATE } & \multirow[b]{3}{*}{ TIME } & \multirow{3}{*}{\multicolumn{2}{|c|}{$\begin{array}{l}\text { WATER NUMBER } \\
\text { IFM- OF } \\
\text { PERA- SAM- } \\
\text { TURE PLING } \\
\text { C CI POINTS }\end{array}$}} & \multirow{3}{*}{\multicolumn{2}{|c|}{$\begin{array}{l}\text { DISCHARGE } \\
\text { (CFS) }\end{array}$}} & \multicolumn{11}{|c|}{ PARTICLE SIZE } & \multirow{3}{*}{$\begin{array}{l}\text { METHOD } \\
\text { OF } \\
\text { ANALY- } \\
\text { SIS }\end{array}$} \\
\hline & & & & & & & PERCENT & FINER & THAN & & SIZE II & N MILL & I ME TEP & 5) IND & ICATED & & \\
\hline & & & & & & .062 & .125 & .250 & .500 & 1.00 & 2.00 & 4.00 & 8.00 & 16.0 & 32.0 & 64.0 & \\
\hline 21.1968 & -- & $\cdots$ & 9 & D & .80 & 5 & 8 & 24 & 55 & 75 & 85 & 89 & 91 & 94 & 98 & 100 & $s$ \\
\hline $5 \ldots \ldots$ & 1400 & 22 & 3 & & I. 9 & $=$ & - & 7 & $4 ?$ & 80 & 97 & 100 & $=$ & - & - & - & S \\
\hline 16.196$)$ & - & $\because$ & $?$ & D & 283 & 5 & 12 & 27 & 47 & 64 & 75 & 80 & 85 & 93 & 99 & 100 & s \\
\hline $27 \ldots \ldots$ & 0830 & $? 1$ & 3 & & 14 & I & 3 & 26 & 49 & 74 & 93 & 98 & 100 & -- & $-m$ & -- & 5 \\
\hline
\end{tabular}

D DAILY MEAN DISCHARGE. 
SANTA CLARA RIVER BASIN

11108500 SANTA CLARA RIVER AT LOS ANGELES-YENTURA COUNTY LINE, CALIF.--Continued

SUSPENDED-5EDIMENT DISCHARGE, WATER YEAR OCTOBER 1968 TO SEPTEMBER 1969

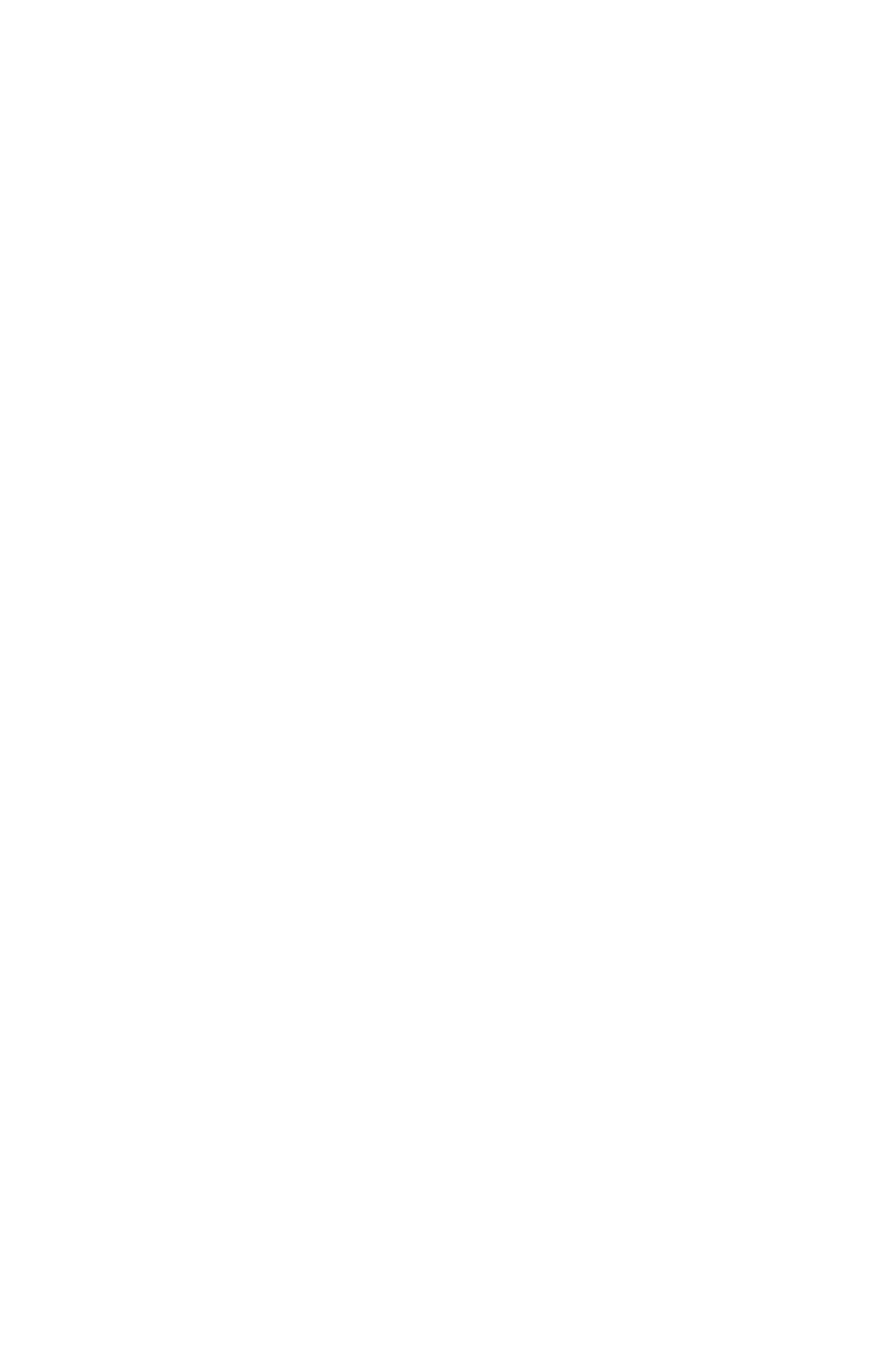


11108500 SANTA CLARA RIVER AT LOS ANGELES-VENTURA COUNTY LINE, CALIF.-COntInued

SUSPENDED-SEDIMENT DISCHARGE, WATER YEAR OCTOBER 1960 TO SEPTEMBER 1969

$$
\text { APRIL }
$$

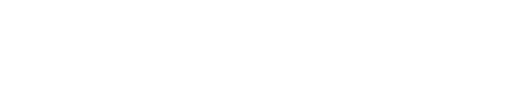

MAY

CONCEN-

TRATION (MG/L)

1750
1750
1750

$$
\begin{aligned}
& 165 \\
& 166 \\
& 168
\end{aligned}
$$$$
2450
$$$$
\begin{aligned}
& 2450 \\
& 2400 \\
& 2400
\end{aligned}
$$$$
\begin{aligned}
& 2400 \\
& 2370
\end{aligned}
$$$$
\begin{aligned}
& 1090 \\
& 1080 \\
& 1090 \\
& 1090
\end{aligned}
$$$$
165
$$

160
158

160
158
157
150

2300

2300
2200

2200
2200
2100

2200
2100

1352100

$\begin{array}{ll}127 & 2010 \\ 123 & 2000\end{array}$

$\begin{array}{ll}123 & 2000\end{array}$

$\begin{array}{ll}120 & 1900 \\ 118 & 1900\end{array}$

$115 \quad 1800$

$\begin{array}{ll}115 & 1800 \\ 114 & 1780 \\ 113 & 1750 \\ 112 & 1730 \\ 111 & 1710\end{array}$

$\begin{array}{ll}111 & 2000 \\ 109 & 2500\end{array}$

2500
2930
2800

$\begin{array}{ll}94 & 2600 \\ 91 & 2400 \\ 85 & 2300 \\ 86 & 2100\end{array}$

1020

994

939
933
851

765

689

664

616
605

605
595

539

548
534
523

523
512

509
589
702

807
741

660
590

528

488
436

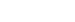

88
89
90
93
96

1750
1750
1800

1700
1600

1600
1600
1500
1400

1300

1300
1200
1150

1150
1140
1140

1140

1130
1130

1130
1130
1120
1120

1120

28200

1240
1230

1230
1230

1220
1220

1200

1600
1580 $\begin{array}{ll}111 & 1700 \\ 109 & 2000\end{array}$

$\begin{array}{ll}86 & 2100 \\ 85 & 1900\end{array}$

21747

1570

$-$

JULY

MEAN

CONCEN- SEDIMENT TRATIUN DISCHARE (MGLL) (TONS/DAY) DISCHARGE

MEAN

CONCEN- SEDIMENT MGTL

$\begin{array}{ll}22 & 1400 \\ 22 & 1400 \\ 22 & 1350 \\ 22 & 1300\end{array}$

TOTAL $617 \quad$-- 2594

1230
1220
1200
1200
1180
1160
1150
1130
1120
1100
1080
1060
1050
1040
1020
1010
1000
980
960
940
930
919
850
766
800
800

$=9$

TOTAL DISCHARGE FOR YEAR (CFS-DAYS)
TOTAL SUSPENDED-SEDIMENT DISCHARGE FOR YEAR (TONS)
1400
1350
1300
1250 (TONS/DAY)

83
83
80
77
74
70
69
68
65
64
63
59
58
54
53
52
49
48
48
44
44
43
40
39
38
35
35
32
29
30
30
1656
4

JUNE

CONCEN- SEDIMENT (ME/L) (TONS/DAY)

$\begin{array}{llll}416 & 51 & 1560 & 215 \\ 421 & 51 & 1530 & 213 \\ 425 & 52 & 1540 & 216 \\ 439 & 53 & 1530 & 219 \\ 467 & 55 & 1510 & 224 \\ 450 & 56 & 1500 & 227 \\ 423 & 57 & 1490 & 229 \\ 419 & 59 & 1480 & 236 \\ 389 & 60 & 1470 & 238 \\ 355 & 62 & 1450 & 243 \\ 326 & 63 & 1440 & 245 \\ 292 & 62 & 1430 & 239 \\ 261 & 60 & 1420 & 230 \\ 246 & 56 & 1410 & 213 \\ 234 & 52 & 1400 & 197\end{array}$

220
207

207
197
181
163

1390

$1390 \quad 180$

1370
1360

1360
1350

164
148
132

176
171
167
166

166
166

1340

1330
1330

1320
1310

1310
1300

112

100
95

162
161

156

213
216

1300
1300

1300
1300

1300
1350
1400

91

26
27
28
31
33
-

91
95
98

113

8491

1337

$-5156$

SEPTEMBER

MEAN

CONCEN- SEDIMENT SCHARGE TRATION DISCHARGS

(MG/L) TTONS/DAY

$\begin{array}{lll}14 & 900 & 34 \\ 14 & 1000 & 38 \\ 14 & 1100 & 42 \\ 14 & 1220 & 46 \\ 14 & 1200 & 45\end{array}$

$14 \quad 1200$

$\begin{array}{lll}14 & 1200 & 45 \\ 15 & 1050 & 45 \\ 15 & 900 & 43\end{array}$

$\begin{array}{lllll}1200 & 65 & 15 & 900 & 36 \\ 1280 & 64 & 15 & 750 & 30\end{array}$

$15 \quad 583$

$583 \quad 24$

$\begin{array}{lll}15 & 600 & 24 \\ 15 & 600 & 24 \\ 16 & 1000 & 43 \\ 16 & 1000 & 43\end{array}$

$\begin{array}{lll}16 & 1000 & 43 \\ 17 & 1100 & 50 \\ 17 & 1150 & 53 \\ 17 & 1000 & 46 \\ 18 & 1000 & 49\end{array}$

$\begin{array}{lll}18 & 1000 & 49 \\ 18 & 1000 & 49 \\ 19 & 1000 & 51 \\ 19 & 900 & 46 \\ 20 & 900 & 49\end{array}$

$\begin{array}{lrr}20 & 800 & 43 \\ 20 & 800 & 43 \\ 21 & 700 & 40 \\ 21 & 600 & 34 \\ 22 & 537 & 32 \\ -- & -- & - \\ 503 & -- & 1239\end{array}$

127677.95
9184350.10 
11111500 SESPE CREEK NEAR WHEELER SPRINGS, CALIF.

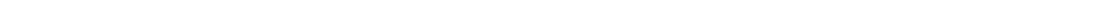

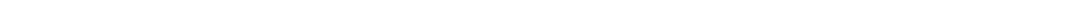
recorder at gaging station at Sespe Gorge, 1.6 miles upstream
Springs Dam ol te, and 5 m1les northeast of wheeler Springs.

DRAINAGE AREA. $-\mathbf{- 4 9 . 5}$ sq $\mathrm{m} 1$.

PERIOD OF RECORD. -- Wa ter temperatures: February 1962 to September 1969.

EXTREAES, --1968-69:

Wa ter temperatures: Maximum, $25.0^{\circ} \mathrm{C}$ sept. 2; min1mum, $3.0^{\circ} \mathrm{C}$ Dec. 21, 22.

Period of record:

Pa ter temperatures: Yaximum, 29. $0^{\circ} \mathrm{C}$ Aug. 11, 1964 ; mtntmum $(1962-64,1965-66,1967-69), 2.0^{\circ} \mathrm{C}$ Mar. 16,1963 , Jan. $7,13-15,1968$.

TEMPERATURE ( ${ }^{\circ} \mathrm{C}$ ) OF WATBR, WATER YEAR OCTOBER 1968 TO SBPTEMBER 1960

DAY

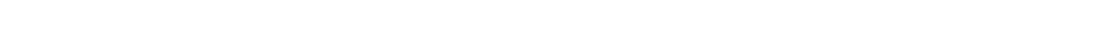

OCTOBER

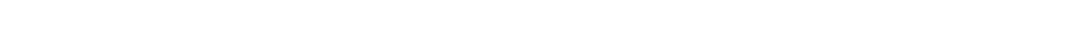

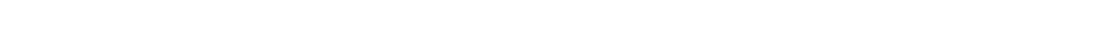

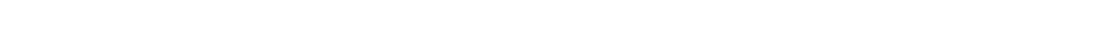

$\begin{array}{rllllllllllllllllllllllllllllllllll}\text { MAXIMUM } & 8 & 7 & 7 & 7 & 7 & 7 & 7 & 7 & 7 & 8 & 8 & 6 & 6 & 7 & 9 & 9 & 7 & 7 & 6 & 6 & 4 & 4 & 4 & 6 & 8 & 8 & 6 & 7 & 7 & 7 & 7 & 7\end{array}$

MINLMUM 7060

MAXIMUM

FEBRUARY

MAXIMUM

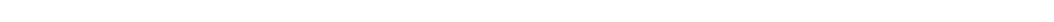

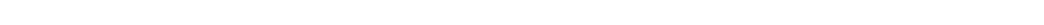

MAXIMUM

$\begin{array}{lllllllllllllllllllllllllllllllll}14 & 11 & 13 & 11 & 9 & 10 & 12 & 13 & 11 & 13 & 14 & 15 & 14 & 13 & 12 & 13 & 13 & 13 & 13 & 16 & 16 & 16 & 11 & 12 & 14 & 15 & 14 & 15 & 17 & 17 & -\end{array}$

MAXIMUM $151413111212131717191918181819192019212121212122 \quad 2221212122 \quad 2222$

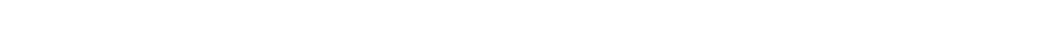
JUNE $\begin{array}{lllllllllllllllllllllllllllllllllll}\text { MAXIMUM } & 22 & 22 & 22 & 22 & 21 & 22 & 21 & 19 & 14 & 16 & 17 & 21 & 21 & 22 & 20 & 21 & 19 & 21 & 21 & 22 & 22 & 22 & 22 & 21 & 21 & 21 & 21 & 21 & 21 & 21 & \ldots \\ \text { MINIMUM } & 14 & 13 & 14 & 14 & 12 & 13 & 14 & 14 & 13 & 12 & 12 & 13 & 13 & 14 & 16 & 14 & 15 & 13 & 14 & 14 & 14 & 14 & 14 & 14 & 13 & 13 & 13 & 12 & 11 & 14 & -0\end{array}$ JUL MAX

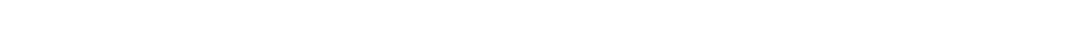
AUGUST

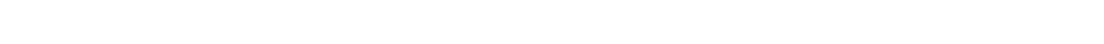

SEPTEMHER

$\begin{array}{llllllllllllllllllllllllllllllllllll}\text { MAXINUM } & 24 & 25 & 23 & 22 & 23 & 22 & 24 & 24 & 23 & 24 & 20 & 21 & 21 & 21 & 22 & 22 & 21 & 21 & 21 & 21 & 19 & 21 & 21 & 22 & 21 & 21 & 19 & 19 & 21 & 20 & -2 & 22 \\ \text { MINIMUM } & 13 & 14 & 14 & 12 & 13 & 14 & 15 & 14 & 13 & 13 & 9 & 9 & 8 & 11 & 12 & 13 & 12 & 13 & 13 & 12 & 11 & 11 & 11 & 13 & 11 & 11 & 9 & 9 & 9 & 9 & -2 & 12\end{array}$ 
11113000 SESPE CREEK NEAR FILLMORE, CALIF.

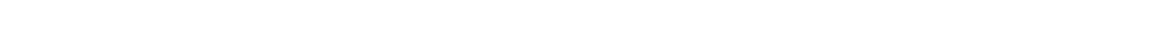
o. right bank, 0.1 mile downs tream from Little Sespe Creek and 3.5 miles north of Fillmore.

DRAINAGE AREA, --251 sq mi.

PERIOD OF RECORD. --Chemical analyses: October 1966 to September 1969.

Water temperatures: October 1966 to September 1969.

EXTREMES. - -1968-69:

Specific conduct ance: Maximum, 1,170 micromhos Sept. 22; minimum, 775 micromhos July 3.

Sediment concentrations: Maximum dajly, 31,800 mg/1 Jan, 25; mintmum daily, 1 mg/1 (estimated) on many days.

Sediment discharge: Maximum daily, 2,950,000 tons Jan. 25 ; minimun daily, 0 ton on many days.

Period of record:

Sediment concentrations: Maximum daily, 31,800 mg/1 Jan. 25, 1969; minimum daily, $0 \mathrm{mg} / 1$ on many days each

year.

Sediment discharge: Maximum daily, 2,950,000 tons Jan. 25, 1969; minimum daily, 0 ton on many days in 1968 and 1969 .

REMARKS. - Chemical-quality records partially furnished by California Department of Water Resources and reviewed by U.S. Geological Survey. Where no maximum or minimum is shown, temperature is once-daly reading.

CHEMICAL ANALYSES, WATER YEAR OCTOBER 1968 TO SEPTEMBER 1969

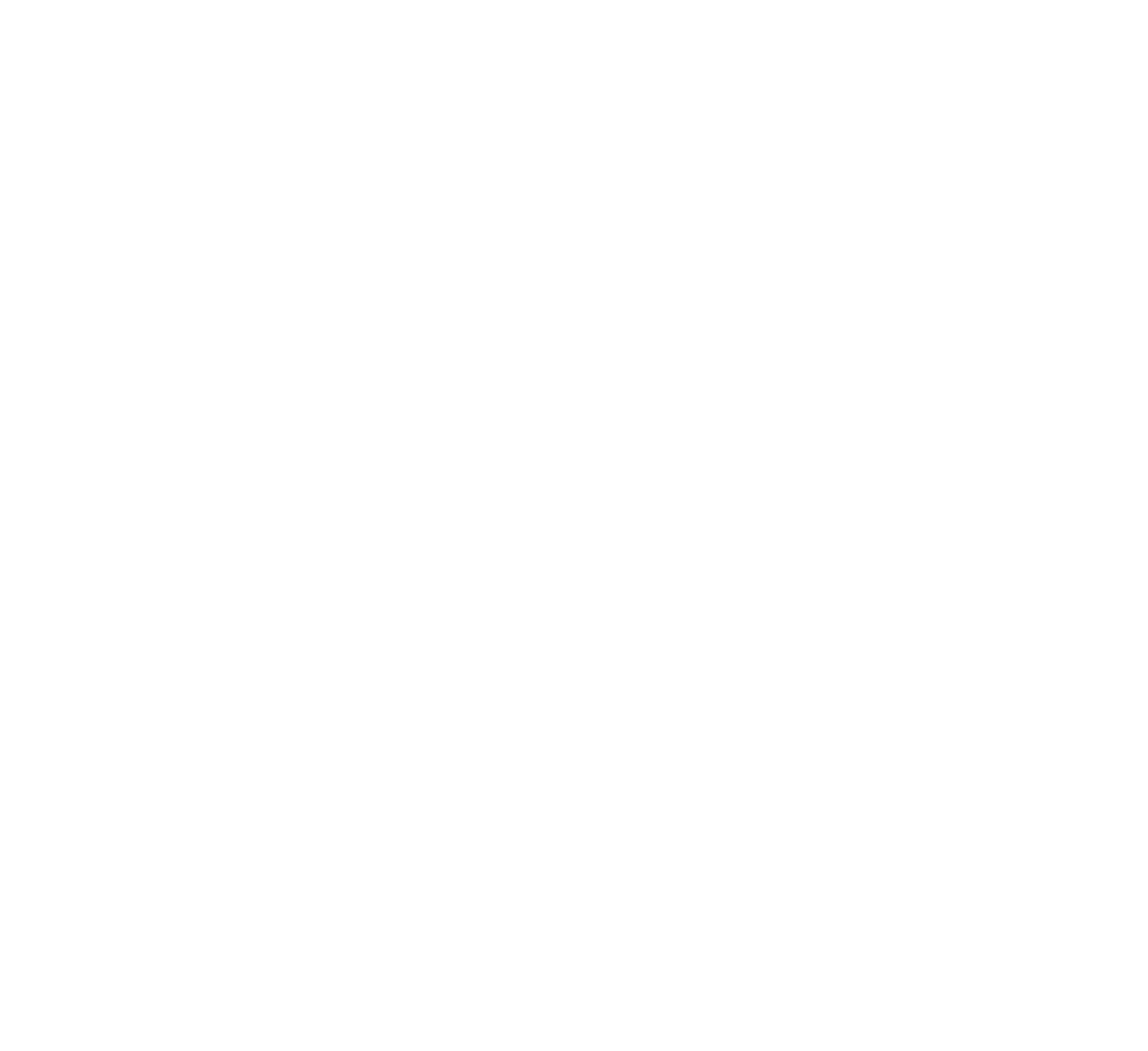


11113000 SESPE CREEK NEAR FILLMORE, CALIF.--Continued SPECIF IC CONDUCTANCE (MICROMHOS AT 25 ${ }^{\circ} \mathrm{C}$ ), JUNE TO SEPTEMBER 1969
(ONCE-DAILY MEASUREMENT)

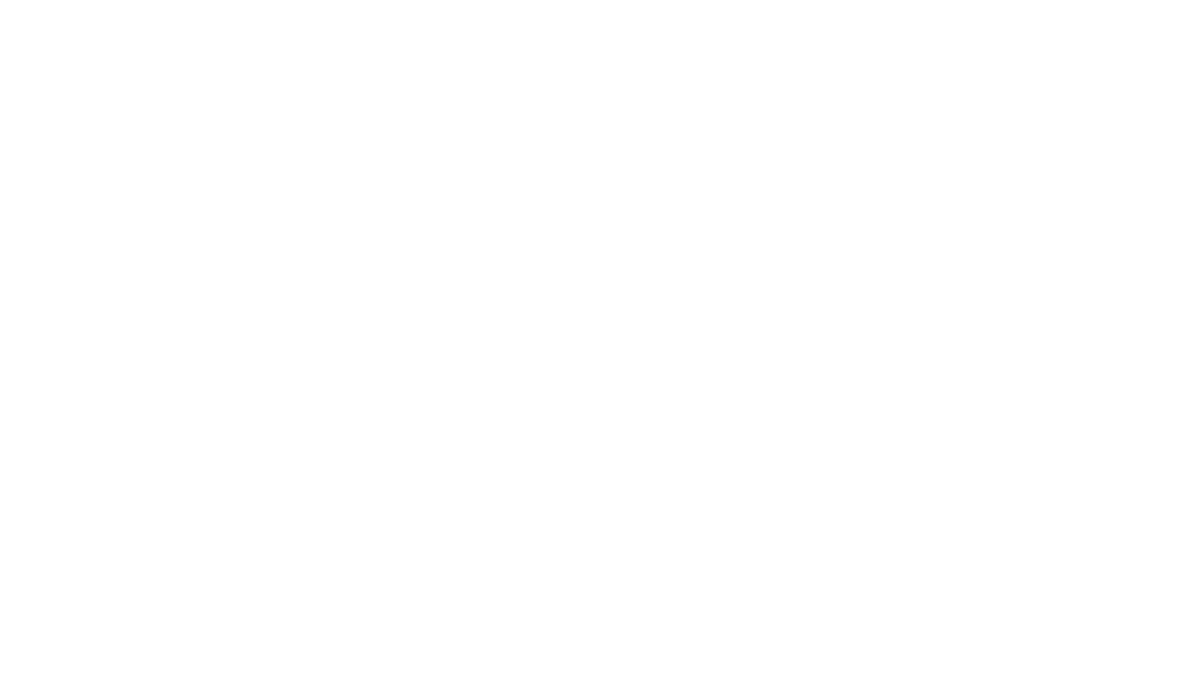

TELPERATURE ( ${ }^{\circ} \mathrm{C}$ ) OF WATER, WATER YEAR OCTOBER 1968 TO SEPTEMBER 1969

$$
\text { DAY }
$$

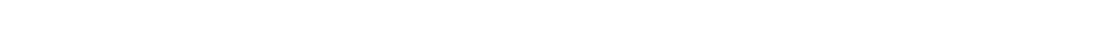

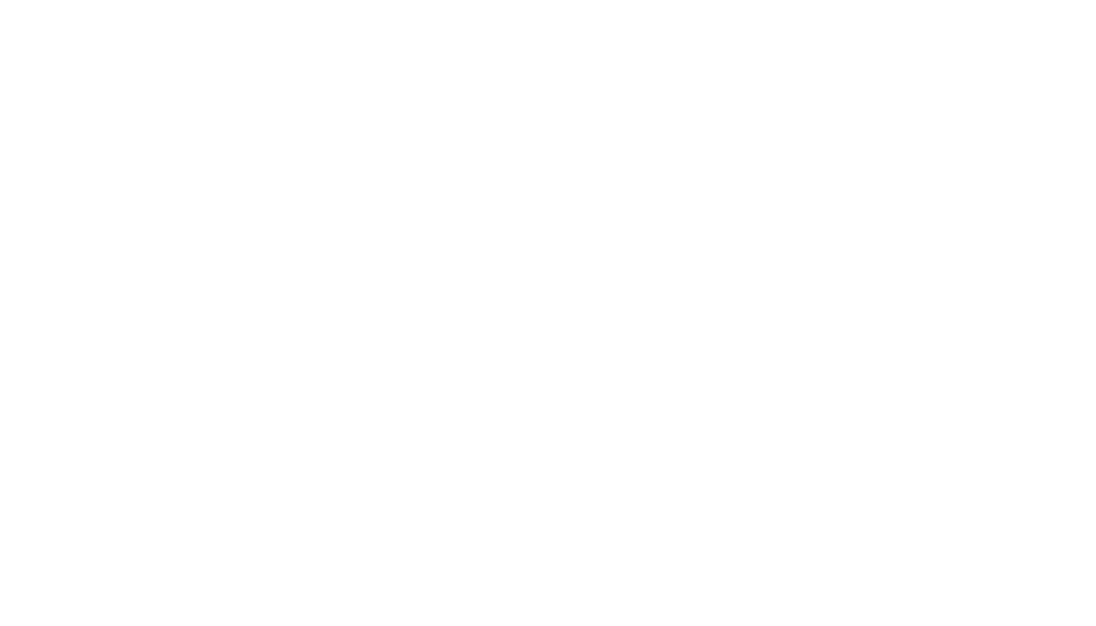


11113000 SESPE CREEK NEAR FILLMORE, CALIF.--COnt1nued

SUSPENDED-SEDIMENT DISCHARGE, WATER YEAR OCTOBER 1968 TO SEPTEMBER 1969

\begin{tabular}{|c|c|c|c|c|c|c|c|c|c|}
\hline \multirow[b]{2}{*}{ DAY } & \multirow{2}{*}{\multicolumn{2}{|c|}{$\begin{array}{l}\text { OCTOBER } \\
\text { MEAN } \\
\text { CONCEN- } \\
\text { TRAIION } \\
\text { (MGIL) }\end{array}$}} & \multirow[b]{2}{*}{$\begin{array}{l}\text { SED [MENT } \\
\text { DISCHARGE } \\
\text { (TONS/DAY) }\end{array}$} & \multirow{2}{*}{\multicolumn{2}{|c|}{$\begin{array}{cl} & \text { NOVEMBER } \\
\text { MEAN } & \text { MEAN } \\
\text { CONCEN- } \\
\text { OISCHARGE } & \text { TRAIION } \\
\text { (CFS) } & \text { (MG/L) }\end{array}$}} & \multirow[b]{2}{*}{$\begin{array}{l}\text { SEDIMENT } \\
\text { DISCHARGE } \\
\text { (TONS/DAY) }\end{array}$} & \multicolumn{3}{|c|}{ DECEMBER } \\
\hline & & & & & & & $\begin{array}{l}\text { MEAN } \\
\text { DISCHARGE } \\
\text { (CFS) }\end{array}$ & $\begin{array}{l}\text { MEAN } \\
\text { CONCEN- } \\
\text { PRAIION } \\
\text { (MG/L) }\end{array}$ & $\begin{array}{l}\text { SEDIMENT } \\
\text { DI SCHARGE } \\
\text { (TONS/DAY) }\end{array}$ \\
\hline $\begin{array}{l}1 \\
2 \\
3 \\
4 \\
5\end{array}$ & $\begin{array}{l}.10 \\
.10 \\
.10 \\
.10 \\
.10\end{array}$ & & & $\begin{array}{l}110 \\
110 \\
110 \\
110 \\
110\end{array}$ & & & $\begin{array}{l}.30 \\
.30 \\
.20 \\
.20 \\
.20\end{array}$ & $\begin{array}{l}=- \\
=- \\
=-\end{array}$ & $\begin{array}{l}0 \\
0 \\
0 \\
0 \\
0\end{array}$ \\
\hline $\begin{array}{r}6 \\
7 \\
8 \\
9 \\
10\end{array}$ & $\begin{array}{l}.10 \\
.10 \\
110 \\
.10 \\
.10\end{array}$ & & & $\begin{array}{l}.10 \\
.10 \\
.10 \\
.10 \\
.10\end{array}$ & & & $\begin{array}{l}.20 \\
.20 \\
.20 \\
.20 \\
.20\end{array}$ & $\begin{array}{l}= \\
= \\
=\end{array}$ & $\begin{array}{l}0 \\
0 \\
0 \\
D \\
0\end{array}$ \\
\hline $\begin{array}{l}11 \\
12 \\
13 \\
14 \\
15\end{array}$ & $\begin{array}{r}.10 \\
.10 \\
.10 \\
.80 \\
1.2\end{array}$ & & & $\begin{array}{l}.10 \\
.10 \\
.10 \\
.10 \\
.80\end{array}$ & & & $\begin{array}{l}.20 \\
.20 \\
.20 \\
.60 \\
9.2\end{array}$ & $\begin{array}{l}-- \\
\overline{11} \\
47\end{array}$ & $\begin{array}{l}0 \\
0 \\
0 \\
.02 \\
1.02\end{array}$ \\
\hline $\begin{array}{l}16 \\
17 \\
18 \\
19 \\
20\end{array}$ & $\begin{array}{l}.70 \\
.80 \\
.50 \\
.10 \\
.30\end{array}$ & & & $\begin{array}{l}1.0 \\
1.0 \\
1.0 \\
1.0 \\
1.0\end{array}$ & & & $\begin{array}{l}0.2 \\
6.1 \\
4.3 \\
2.7 \\
3.5\end{array}$ & $\begin{array}{r}30 \\
17 \\
10 \\
6 \\
4\end{array}$ & $\begin{array}{l}.66 \\
.28 \\
.12 \\
.04 \\
.04\end{array}$ \\
\hline $\begin{array}{l}21 \\
27 \\
23 \\
24 \\
25\end{array}$ & $\begin{array}{l}.70 \\
.40 \\
.10 \\
.10 \\
.10\end{array}$ & & & $\begin{array}{l}1.0 \\
1.0 \\
1.0 \\
.80 \\
.40\end{array}$ & & & $\begin{array}{l}4.2 \\
4.2 \\
4.8 \\
5.0 \\
28\end{array}$ & $\begin{array}{r}4 \\
4 \\
127\end{array}$ & $\begin{array}{r}.05 \\
.05 \\
.05 \\
.05\end{array}$ \\
\hline $\begin{array}{l}26 \\
27 \\
28 \\
29 \\
30 \\
31\end{array}$ & $\begin{array}{l}.10 \\
.10 \\
.10 \\
110 \\
.10 \\
110\end{array}$ & & & $\begin{array}{l}.40 \\
.30 \\
.30 \\
.30 \\
.30 \\
.+\end{array}$ & & & $\begin{array}{l}19 \\
12 \\
14 \\
12 \\
9.8 \\
9.6\end{array}$ & $\begin{array}{l}85 \\
55 \\
49 \\
20 \\
10 \\
5\end{array}$ & $\begin{array}{l}4.7 \\
1.8 \\
1.9 \\
.65 \\
.26 \\
.12\end{array}$ \\
\hline TDTAL & 7.70 & - & 0 & 13.00 & -- & 0 & 159.00 & $-\infty$ & 24.99 \\
\hline
\end{tabular}

\begin{tabular}{|c|c|c|c|c|c|c|c|c|c|}
\hline \multirow[b]{2}{*}{ DAY } & \multicolumn{3}{|c|}{ JANUARY } & \multicolumn{3}{|c|}{ FEBRUARY } & \multicolumn{3}{|c|}{ MARCH } \\
\hline & $\begin{array}{l}\text { MEAN } \\
\text { OI SCFARGE } \\
\text { ICFS I }\end{array}$ & 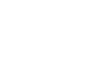 & $\begin{array}{l}\text { SEDIMENT } \\
\text { DISCARGE } \\
\text { (TONS/DAYY }\end{array}$ & $\begin{array}{l}\text { MEAN } \\
\text { OISCGARGE } \\
\text { (CFS) }\end{array}$ & 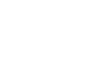 & $\begin{array}{l}\text { SEDIMENT } \\
\text { DDSCARGE } \\
\text { (TONS/DAYY }\end{array}$ & $\begin{array}{l}\text { MEAN } \\
\text { DISCHARGE } \\
\text { ICFSI }\end{array}$ & 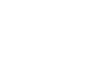 & $\begin{array}{l}\text { SEDIMENT } \\
\text { SISCHAGE } \\
\text { ITONS DAAYI }\end{array}$ \\
\hline $\begin{array}{l}1 \\
2 \\
3 \\
4 \\
5\end{array}$ & $\begin{array}{l}8 \\
7 \\
6 \\
6 \\
6\end{array}$ & 4 & $\begin{array}{l}.09 \\
.08 \\
.06 \\
.06\end{array}$ & $\begin{array}{r}2430 \\
1530 \\
948 \\
748 \\
873\end{array}$ & $\begin{array}{l}238 \\
185 \\
150 \\
110 \\
170\end{array}$ & $\begin{array}{r}1720 \\
778 \\
384 \\
222 \\
401\end{array}$ & $\begin{array}{l}2240 \\
1760 \\
1510 \\
1350 \\
1190\end{array}$ & $\begin{array}{l}817 \\
355 \\
403 \\
323 \\
260\end{array}$ & $\begin{array}{l}8940 \\
2640 \\
1640 \\
1190 \\
833\end{array}$ \\
\hline $\begin{array}{c}6 \\
7 \\
8 \\
9 \\
10\end{array}$ & $\begin{array}{l}5 \\
\vdots \\
6 \\
6 \\
6 \\
6\end{array}$ & $\begin{array}{l}4 \\
4 \\
4 \\
4\end{array}$ & $\begin{array}{l}.05 \\
.05 \\
.06 \\
.06\end{array}$ & $\begin{aligned} 6630 \\
1760 \\
1190 \\
998 \\
956\end{aligned}$ & $\begin{array}{r}12600 \\
3800 \\
1700 \\
300 \\
300\end{array}$ & $\begin{array}{r}296000 \\
18100 \\
5460 \\
4330 \\
730 \\
774\end{array}$ & $\begin{array}{l}140 \\
1030 \\
948 \\
884 \\
852 \\
852\end{array}$ & $\begin{array}{l}180 \\
180 \\
180 \\
200 \\
180\end{array}$ & $\begin{array}{l}539 \\
501 \\
461 \\
477 \\
414\end{array}$ \\
\hline $\begin{array}{l}11 \\
12 \\
13 \\
14 \\
15 \\
15\end{array}$ & $\begin{array}{r}6 \\
6 \\
12 \\
149 \\
22\end{array}$ & $\begin{array}{r}4 \\
52 \\
409 \\
48\end{array}$ & $\begin{array}{r}.06 \\
3.06 \\
239.6 \\
2.9\end{array}$ & $\begin{array}{l}980 \\
948 \\
716 \\
630 \\
630 \\
832\end{array}$ & $\begin{array}{r}190 \\
110 \\
80 \\
50 \\
1100\end{array}$ & $\begin{array}{r}503 \\
202 \\
155 \\
95 \\
3210\end{array}$ & $\begin{array}{l}780 \\
716 \\
665 \\
600 \\
558\end{array}$ & $\begin{array}{l}160 \\
140 \\
123 \\
110 \\
1100\end{array}$ & $\begin{array}{l}337 \\
271 \\
224 \\
178 \\
151\end{array}$ \\
\hline $\begin{array}{l}16 \\
17 \\
118 \\
19 \\
20\end{array}$ & $\begin{array}{r}17 \\
10 \\
14 \\
3890 \\
4080\end{array}$ & $\begin{array}{r}30 \\
29 \\
74 \\
0490 \\
7230\end{array}$ & $\begin{array}{r}1.4 \\
5.97 \\
144007 \\
113000\end{array}$ & $\begin{array}{l}996 \\
844 \\
836 \\
820 \\
812\end{array}$ & $\begin{array}{l}450 \\
190 \\
180 \\
150 \\
100\end{array}$ & $\begin{array}{r}1210 \\
433 \\
406 \\
332 \\
219\end{array}$ & $\begin{array}{l}528 \\
516 \\
522 \\
486 \\
468\end{array}$ & $\begin{array}{l}99 \\
99 \\
97 \\
96 \\
95\end{array}$ & $\begin{array}{l}141 \\
137 \\
137 \\
126 \\
120\end{array}$ \\
\hline $\begin{array}{l}21 \\
22 \\
23 \\
24 \\
25\end{array}$ & $\begin{array}{r}17200 \\
3010 \\
1390 \\
3410 \\
29100\end{array}$ & $\begin{array}{r}16200 \\
1970 \\
583 \\
2600 \\
31800\end{array}$ & $\begin{array}{r}971000 \\
18500 \\
2200 \\
32700 \\
2950000\end{array}$ & $\begin{array}{r}863 \\
1150 \\
5400 \\
19700 \\
22600\end{array}$ & $\begin{array}{r}130 \\
350 \\
160.00 \\
19800 \\
23800\end{array}$ & $\begin{array}{r}303 \\
1090 \\
209000 \\
1230000 \\
1970000\end{array}$ & $\begin{array}{l}528 \\
316 \\
486 \\
468 \\
434\end{array}$ & $\begin{array}{l}95 \\
90 \\
84 \\
78 \\
72\end{array}$ & $\begin{array}{r}135 \\
125 \\
110 \\
99 \\
84\end{array}$ \\
\hline $\begin{array}{l}26 \\
27 \\
28 \\
29 \\
30 \\
31\end{array}$ & $\begin{array}{r}20500 \\
5920 \\
5210 \\
4530 \\
3410 \\
2740\end{array}$ & $\begin{array}{r}19800 \\
5520 \\
2650 \\
1210 \\
729 \\
521\end{array}$ & $\begin{array}{r}1190000 \\
90700 \\
37300 \\
14700 \\
6970 \\
3930\end{array}$ & $\begin{array}{r}8460 \\
3110 \\
2720 \\
\because: \\
\because\end{array}$ & $\begin{array}{r}5430 \\
1980 \\
1480 \\
\because \\
\because \\
=\end{array}$ & $\begin{array}{r}141000 \\
16200 \\
11300 \\
= \\
=-\end{array}$ & $\begin{array}{l}406 \\
406 \\
406 \\
400 \\
400 \\
400\end{array}$ & $\begin{array}{l}86 \\
60 \\
34 \\
48 \\
42 \\
34\end{array}$ & $\begin{array}{l}72 \\
66 \\
39 \\
52 \\
43 \\
37\end{array}$ \\
\hline TOTAL & 10 & -- & 5575154.12 & 90470 & $\cdots$ & 10897 & 23563 & -- & L6333 \\
\hline
\end{tabular}


11113000 SESPE CREEK NEAR FILLMORE, CALIF.--Continued

SUSPENDED-SEDIMENT DISCHARGE, WATER YEAR OCTOBER 1968 TO SEPTEMBER 1969

\begin{tabular}{|c|c|c|c|c|c|c|c|c|c|}
\hline DAY & $\begin{array}{l}\text { MEAN } \\
\text { DISCHARGE } \\
\text { ICFSI }\end{array}$ & $\begin{array}{l}\text { APRIL } \\
\text { MEAN } \\
\text { CONCEN- } \\
\text { TRATION } \\
\text { (MG/L) }\end{array}$ & $\begin{array}{l}\text { SEDIMENT } \\
\text { DISCHARGE } \\
\text { (TONS/DAY) }\end{array}$ & $\begin{array}{l}\text { MEAN } \\
\text { DISCHARGE } \\
\text { (CFS) }\end{array}$ & $\begin{array}{l}\text { MAY } \\
\text { MEAN } \\
\text { CONCEN- } \\
\text { TRATION } \\
\text { (MG/L) }\end{array}$ & $\begin{array}{l}\text { SEDIMENT } \\
\text { DISCHARGE } \\
\text { (TONS/DAY) }\end{array}$ & $\begin{array}{l}\text { MEAN } \\
\text { OI SCHARGE } \\
\text { (CFS) }\end{array}$ & $\begin{array}{l}\text { JUNE } \\
\text { MEAN } \\
\text { CONCEN- } \\
\text { TRATION } \\
\text { (MG/L) }\end{array}$ & $\begin{array}{l}\text { SEDIMENT } \\
\text { DISCHARGE } \\
\text { (TONS/DAY) }\end{array}$ \\
\hline $\begin{array}{l}1 \\
2 \\
3 \\
4 \\
5\end{array}$ & $\begin{array}{l}365 \\
346 \\
390 \\
309 \\
364\end{array}$ & $\begin{array}{r}30 \\
500 \\
420 \\
130 \\
638\end{array}$ & $\begin{array}{r}30 \\
467 \\
442 \\
108 \\
627\end{array}$ & $\begin{array}{l}150 \\
148 \\
145 \\
158 \\
142\end{array}$ & $\begin{array}{l}13 \\
12 \\
12 \\
11 \\
11\end{array}$ & $\begin{array}{l}5.3 \\
4.8 \\
4.7 \\
4.7 \\
4.2\end{array}$ & $\begin{array}{l}69 \\
69 \\
68 \\
68 \\
68\end{array}$ & $\begin{array}{l}9 \\
9 \\
8 \\
8 \\
8\end{array}$ & $\begin{array}{l}1.7 \\
1.7 \\
1.5 \\
1.5 \\
1.5\end{array}$ \\
\hline $\begin{array}{r}6 \\
7 \\
9 \\
9 \\
10\end{array}$ & $\begin{array}{l}395 \\
318 \\
304 \\
304 \\
314\end{array}$ & $\begin{array}{r}800 \\
420 \\
230 \\
120 \\
60\end{array}$ & $\begin{array}{r}853 \\
361 \\
189 \\
98 \\
51\end{array}$ & $\begin{array}{l}136 \\
133 \\
129 \\
127 \\
125\end{array}$ & $\begin{array}{l}11 \\
10 \\
10 \\
10 \\
10\end{array}$ & $\begin{array}{l}4.0 \\
3.5 \\
3.5 \\
3.4 \\
3.4\end{array}$ & $\begin{array}{l}68 \\
69 \\
71 \\
73 \\
74\end{array}$ & $\begin{array}{l}7 \\
7 \\
7 \\
6 \\
6\end{array}$ & $\begin{array}{l}1.3 \\
1.3 \\
1.3 \\
1.2 \\
1.2\end{array}$ \\
\hline $\begin{array}{l}11 \\
12 \\
13 \\
14 \\
15\end{array}$ & $\begin{array}{l}318 \\
322 \\
296 \\
259 \\
216\end{array}$ & $\begin{array}{l}50 \\
40 \\
30 \\
28 \\
26\end{array}$ & $\begin{array}{l}43 \\
35 \\
24 \\
20 \\
15\end{array}$ & $\begin{array}{l}122 \\
120 \\
118 \\
116 \\
114\end{array}$ & $\begin{array}{l}10 \\
11 \\
11 \\
11 \\
12\end{array}$ & $\begin{array}{l}3.3 \\
3.5 \\
3.5 \\
3.4 \\
3.7\end{array}$ & $\begin{array}{l}74 \\
74 \\
73 \\
71 \\
68\end{array}$ & $\begin{array}{l}6 \\
5 \\
5 \\
5 \\
5\end{array}$ & $\begin{array}{l}1.2 \\
1.0 \\
.99 \\
.96 \\
.92\end{array}$ \\
\hline $\begin{array}{l}16 \\
17 \\
18 \\
19 \\
20\end{array}$ & $\begin{array}{l}210 \\
204 \\
204 \\
198 \\
195\end{array}$ & $\begin{array}{l}24 \\
22 \\
20 \\
20 \\
18\end{array}$ & $\begin{array}{l}14 \\
12 \\
12 \\
11 \\
9.5\end{array}$ & $\begin{array}{l}112 \\
108 \\
106 \\
104 \\
102\end{array}$ & $\begin{array}{l}12 \\
13 \\
13 \\
13 \\
13\end{array}$ & $\begin{array}{l}3.6 \\
3.8 \\
3.7 \\
3.7 \\
3.6\end{array}$ & $\begin{array}{l}66 \\
65 \\
63 \\
62 \\
59\end{array}$ & $\begin{array}{l}5 \\
5 \\
5 \\
5 \\
5\end{array}$ & $\begin{array}{l}.89 \\
.88 \\
.85 \\
.84 \\
.80\end{array}$ \\
\hline $\begin{array}{l}21 \\
22 \\
23 \\
24 \\
25\end{array}$ & $\begin{array}{l}192 \\
192 \\
189 \\
180 \\
174\end{array}$ & $\begin{array}{l}18 \\
17 \\
17 \\
16 \\
16\end{array}$ & $\begin{array}{l}9.3 \\
9.8 \\
8.7 \\
7.8 \\
7.5\end{array}$ & $\begin{array}{r}100 \\
98 \\
96 \\
92 \\
88\end{array}$ & $\begin{array}{l}13 \\
12 \\
12 \\
12 \\
11\end{array}$ & $\begin{array}{l}3.5 \\
3.2 \\
3.1 \\
3.0 \\
2.6\end{array}$ & $\begin{array}{l}59 \\
58 \\
56 \\
55 \\
54\end{array}$ & $\begin{array}{r}5 \\
5 \\
5 \\
5 \\
20\end{array}$ & $\begin{array}{r}.80 \\
.78 \\
.76 \\
.74 \\
2.9\end{array}$ \\
\hline $\begin{array}{l}26 \\
27 \\
28 \\
29 \\
30 \\
31\end{array}$ & $\begin{array}{l}171 \\
165 \\
160 \\
158 \\
152 \\
-2\end{array}$ & $\begin{array}{l}43 \\
15 \\
14 \\
14 \\
13 \\
-2\end{array}$ & $\begin{array}{l}20 \\
6.7 \\
6.0 \\
6.0 \\
5.3 \\
-.0\end{array}$ & $\begin{array}{l}85 \\
79 \\
77 \\
74 \\
73 \\
71\end{array}$ & $\begin{array}{r}11 \\
11 \\
10 \\
10 \\
10 \\
9\end{array}$ & $\begin{array}{l}2.5 \\
2.3 \\
2.1 \\
2.0 \\
2.0 \\
1.7\end{array}$ & $\begin{array}{l}53 \\
53 \\
51 \\
50 \\
48 \\
--\end{array}$ & $\begin{array}{l}20 \\
20 \\
20 \\
20 \\
20 \\
--\end{array}$ & $\begin{array}{l}2.9 \\
2.9 \\
2.8 \\
2.7 \\
2.6 \\
-. .\end{array}$ \\
\hline TOTAL & 7564 & -- & 3506.6 & 3448 & -- & 105.5 & 1909 & -- & 43.41 \\
\hline
\end{tabular}

\begin{tabular}{|c|c|c|c|c|c|c|c|c|c|}
\hline \multirow[b]{2}{*}{ oAr } & \multicolumn{3}{|c|}{ JULY } & \multicolumn{3}{|c|}{ AUGUST } & \multicolumn{3}{|c|}{ SEP TEMBER } \\
\hline & $\begin{array}{l}\text { MEAN } \\
\text { UISCAARGE } \\
\text { ICFSI }\end{array}$ & $\begin{array}{l}\text { MEAN } \\
\text { MONCFN- } \\
\text { TRATON } \\
\text { IMG/L) }\end{array}$ & $\begin{array}{l}\text { SEDIMENT } \\
\text { DISCHARGE } \\
\text { (TONS/DAY) }\end{array}$ & $\begin{array}{c}\text { MEN } \\
\text { OISCHARGE } \\
\text { (CFS) }\end{array}$ & $\begin{array}{l}\text { MEAN } \\
\text { CONCEN- } \\
\text { TRAIION } \\
\text { (MG/L) }\end{array}$ & $\begin{array}{l}\text { SEDIMENT } \\
\text { DISCHARGE } \\
\text { (TONS/DAY) }\end{array}$ & $\begin{array}{l}\text { MEAN } \\
\text { DISCAARGE } \\
\text { (CFS) }\end{array}$ & $\begin{array}{l}\text { MEAN } \\
\text { CONCEN- } \\
\text { TRAEION } \\
\text { (MG/L) }\end{array}$ & $\begin{array}{l}\text { SEDIMENT } \\
\text { DISCHARGE } \\
\text { (TONS/DAY) }\end{array}$ \\
\hline $\begin{array}{l}1 \\
2 \\
3 \\
4 \\
5\end{array}$ & $\begin{array}{l}46 \\
46 \\
43 \\
41 \\
41\end{array}$ & $\begin{array}{l}25 \\
25 \\
25 \\
25 \\
25\end{array}$ & $\begin{array}{l}3.1 \\
3.1 \\
2.9 \\
2.8 \\
2: 8\end{array}$ & $\begin{array}{l}25 \\
25 \\
24 \\
24 \\
21\end{array}$ & $\begin{array}{l}39 \\
39 \\
39 \\
39 \\
39\end{array}$ & $\begin{array}{l}2.6 \\
2.6 \\
2.5 \\
2.5 \\
2.2\end{array}$ & $\begin{array}{c}12 \\
11 \\
9.8 \\
9.8 \\
9.6\end{array}$ & $\begin{array}{l}30 \\
30 \\
30 \\
30 \\
30\end{array}$ & $\begin{array}{l}.97 \\
889 \\
879 \\
.79 \\
.78\end{array}$ \\
\hline $\begin{array}{r}6 \\
7 \\
8 \\
9 \\
10\end{array}$ & $\begin{array}{l}41 \\
41 \\
41 \\
40 \\
39\end{array}$ & $\begin{array}{l}30 \\
30 \\
30 \\
30 \\
30\end{array}$ & $\begin{array}{l}3.3 \\
3.3 \\
3.3 \\
3.2 \\
3.2\end{array}$ & $\begin{array}{l}20 \\
24 \\
24 \\
24 \\
25\end{array}$ & $\begin{array}{l}39 \\
38 \\
38 \\
38 \\
38\end{array}$ & $\begin{array}{l}2.1 \\
2.5 \\
2.5 \\
2.5 \\
2.6\end{array}$ & $\begin{array}{l}10 \\
10 \\
98.8 \\
8.6 \\
8.6\end{array}$ & $\begin{array}{l}28 \\
28 \\
28 \\
28 \\
28\end{array}$ & $\begin{array}{l}.76 \\
.76 \\
.74 \\
.65 \\
.65\end{array}$ \\
\hline $\begin{array}{l}\text { 位 } \\
12 \\
13 \\
14 \\
15\end{array}$ & $\begin{array}{l}38 \\
44 \\
44 \\
40 \\
37\end{array}$ & $\begin{array}{l}35 \\
35 \\
35 \\
35 \\
35\end{array}$ & $\begin{array}{l}3.6 \\
4.2 \\
4.2 \\
3.8 \\
3.5\end{array}$ & $\begin{array}{l}26 \\
27 \\
21 \\
16 \\
15\end{array}$ & $\begin{array}{l}38 \\
38 \\
38 \\
37 \\
37\end{array}$ & $\begin{array}{l}2.7 \\
2.8 \\
2.2 \\
1.6 \\
1.5\end{array}$ & $\begin{array}{l}8.6 \\
88.6 \\
88.6 \\
88.6 \\
8.6\end{array}$ & $\begin{array}{l}26 \\
26 \\
26 \\
26 \\
26\end{array}$ & $\begin{array}{l}.60 \\
.60 \\
600 \\
.60 \\
.60\end{array}$ \\
\hline $\begin{array}{l}16 \\
17 \\
18 \\
19 \\
20\end{array}$ & $\begin{array}{l}35 \\
34 \\
34 \\
31 \\
31\end{array}$ & $\begin{array}{l}40 \\
40 \\
40 \\
40 \\
40\end{array}$ & $\begin{array}{l}3.8 \\
3.7 \\
3.7 \\
3.3 \\
3.3\end{array}$ & $\begin{array}{l}16 \\
18 \\
21 \\
21 \\
21\end{array}$ & $\begin{array}{l}36 \\
36 \\
36 \\
36 \\
36\end{array}$ & $\begin{array}{l}1.6 \\
1: 7 \\
2: 0 \\
2: 0 \\
2: 0\end{array}$ & $\begin{array}{l}8.6 \\
99.4 \\
9.4 \\
9.4 \\
9.4\end{array}$ & $\begin{array}{l}24 \\
24 \\
24 \\
24 \\
24\end{array}$ & $\begin{array}{l}.56 \\
.61 \\
.61 \\
.61 \\
.61\end{array}$ \\
\hline $\begin{array}{l}21 \\
22 \\
23 \\
24 \\
25\end{array}$ & $\begin{array}{l}30 \\
28 \\
28 \\
28 \\
28\end{array}$ & $\begin{array}{l}40 \\
40 \\
41 \\
41 \\
41\end{array}$ & $\begin{array}{l}3.2 \\
3.0 \\
3.1 \\
3.1 \\
3.1\end{array}$ & $\begin{array}{l}21 \\
21 \\
21 \\
20 \\
19\end{array}$ & $\begin{array}{l}34 \\
34 \\
34 \\
34 \\
34\end{array}$ & $\begin{array}{l}1.9 \\
1: 9 \\
1: 9 \\
1: 8 \\
1: 8\end{array}$ & $\begin{array}{l}9.4 \\
9.4 \\
9.4 \\
9.4 \\
9.4\end{array}$ & $\begin{array}{l}22 \\
22 \\
22 \\
22 \\
22\end{array}$ & $\begin{array}{l}.56 \\
.56 \\
.56 \\
.56 \\
.56\end{array}$ \\
\hline $\begin{array}{l}26 \\
27 \\
28 \\
29 \\
30 \\
31\end{array}$ & $\begin{array}{l}27 \\
27 \\
27 \\
26 \\
26 \\
76\end{array}$ & $\begin{array}{l}41 \\
40 \\
40 \\
40 \\
40 \\
39\end{array}$ & $\begin{array}{l}3.0 \\
2.9 \\
2.9 \\
2.8 \\
2.8 \\
2.7\end{array}$ & $\begin{array}{l}19 \\
19 \\
19 \\
19 \\
19 \\
19\end{array}$ & $\begin{array}{l}32 \\
32 \\
32 \\
32 \\
32 \\
32\end{array}$ & $\begin{array}{l}1.6 \\
1.6 \\
1.6 \\
1.6 \\
1.6 \\
1.6\end{array}$ & $\begin{array}{l}9.4 \\
9.0 \\
9: 0 \\
8.6 \\
8.2\end{array}$ & $\begin{array}{l}20 \\
20 \\
31 \\
20 \\
20 \\
--\end{array}$ & $\begin{array}{r}.51 \\
.49 \\
.75 \\
.46 \\
.44 \\
-\end{array}$ \\
\hline TAL & 1088 & -- & 100.7 & 654 & -. & 63.5 & 279.6 & -- & 19.23 \\
\hline
\end{tabular}


11113000 SESPE CREEK NEAR FILLMORE, CALIF. - COnti nued

PARTICLE-SIZE DISTRIBUTION DF SUSPENDED SEDIMENT, WATER YEAR OCTOBER 1968 TO SEPTEMBER 1969 (METHODS OF ANALYSIS: B, BOTTOM HITHORAHAL TUBE: C, CHEMICALLY DISPERSED; N, IN NATIVE WATER; P, PIPET; S, SIEVE; $\checkmark$, VISUAL ACCUMULATION TUBE; W, IN DISTILLED WATER)

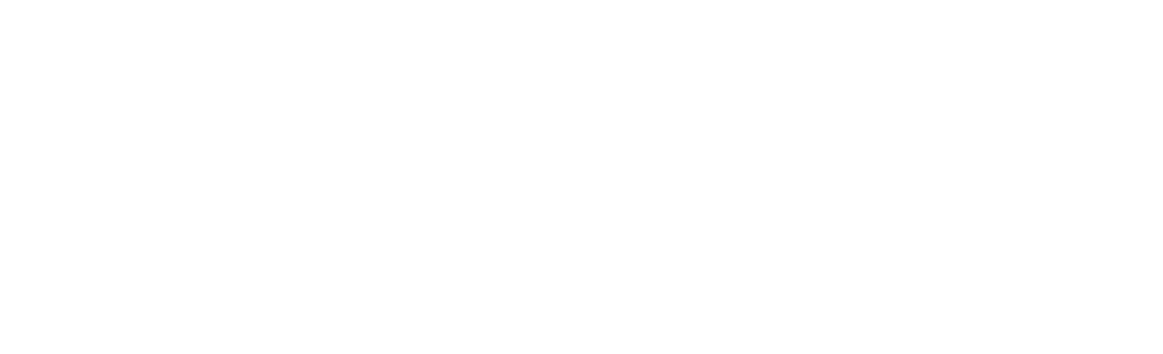

PARTICLE-SIZE DISTRIBUTION DF SURFACE BED MATERIAL, WATER YEAR OCTOBER 1968 TO SEPTEMBER 1969 (METHOD UF ANALYSIS: H, HYDROMETER; D. DPTICAL ANALYZER; S, SIEVE; $V$, VISUAL ACCUMULATION TUBE)

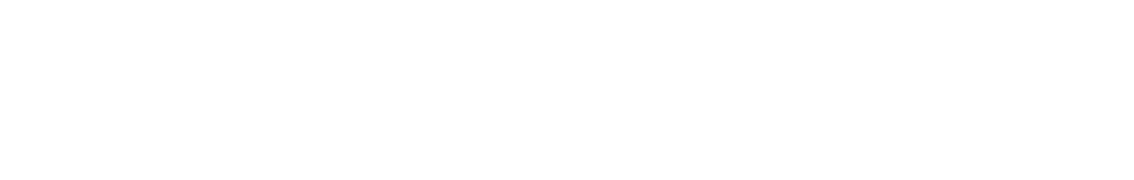

11113300 SANTA CLARA RIVER NEAR SANTA PAULA, CALIF.

LOCATI ON, - Lat $34^{\circ} 21^{\prime} 14^{\prime \prime}$, long $119^{\circ} \mathrm{O} 1^{\prime} 38^{\prime \prime}$, in sec.12, T. 3 N., R. 21 W., Vent ura County, 1.5 miles upstream from Santa Paula bridge and 1.8 miles east of Santa Pála.

PERIOD OF RECORD. --Chemical analyses: October 1966 to September 1969.

REMARKS.--Chemical analyses for this station are performed by California Department of Water Resources and U.S. Geological Survey. Water discharge given is difference between Santa Paula Creek near Santa Paula (station 11113500 ) and Saticoy Diversion near Saticoy (station 11113910) unpublished.

CHEMICAL ANALYSES, WATER YEAR UCTCBER 1909 TO SEPTEMBER 2969

\begin{tabular}{|c|c|c|c|c|c|c|c|c|c|c|c|c|}
\hline DATE & $\begin{array}{l}\text { OLS- } \\
\text { CHARGE } \\
\text { (CFS) }\end{array}$ & $\begin{array}{l}\text { TEMPER- } \\
\text { ATURE } \\
\text { (DEG C) }\end{array}$ & $\begin{array}{l}\text { DIS- } \\
\text { SOLVED } \\
\text { OXYGEN } \\
\text { (MG/L) }\end{array}$ & $\begin{array}{l}\text { CAL- } \\
\text { CIUM } \\
\text { (CA) } \\
(M G L L)\end{array}$ & $\begin{array}{l}\text { MAG- } \\
\text { NE- } \\
\text { SIUM } \\
(M G) \\
(M G U L)\end{array}$ & $\begin{array}{l}\text { SOOIUM } \\
\text { (NA) } \\
(M G / L)\end{array}$ & $\begin{array}{l}\text { PO- } \\
\text { TAS- } \\
\text { SIUM } \\
\text { (K) } \\
\text { (MG/L) }\end{array}$ & $\begin{array}{l}\text { BICAR- } \\
\text { BONATE } \\
\text { (HCE3) } \\
\text { (MGIL) }\end{array}$ & $\begin{array}{l}\text { CAR- } \\
\text { BONATE } \\
\text { (COB) } \\
\text { (MGIL) }\end{array}$ & $\begin{array}{l}\text { SULFATF } \\
\text { (SOA) } \\
\text { (YG/L) }\end{array}$ & $\begin{array}{l}\text { CHLO) } \\
\text { RIOF } \\
\text { (CL) } \\
\left.\text { ( }{ }^{\prime} \text { G } / L\right)\end{array}$ & $\begin{array}{l}\text { FLUN- } \\
\text { RIDE } \\
\text { IFI } \\
\text { IMG/L }\end{array}$ \\
\hline $\begin{array}{l}O C T . \\
15 . . \\
O E C .\end{array}$ & - & 21 & 9.6 & 190 & 72 & 151 & 6.0 & 206 & 0 & 712 & 65 & 1.3 \\
\hline J I7... & -- & -- & -- & 224 & 70 & 177 & -- & 325 & 0 & 804 & 73 & 1.0 \\
\hline $\begin{array}{l}14 \ldots \\
\text { FER. }\end{array}$ & -- & 16 & 7.6 & 96 & 32 & 12 & 4.0 & $1 \propto 0$ & 0 & 323 & 40 & 1.0 \\
\hline $\begin{array}{l}26 \ldots . . \\
\text { MAR. }\end{array}$ & 17400 & -- & -- & म9 & 23 & 37 & -- & 148 & 0 & 249 & 11 & .5 \\
\hline JUNE & 1450 & - & -- & 128 & 36 & 49 & -- & 223 & 0 & 334 & $1 B$ & .6 \\
\hline JULY & $\cdots$ & 26 & 7.6 & 150 & 46 & 92 & -- & 256 & 0 & 451 & 43 & .7 \\
\hline $25 \ldots$ & $\rightarrow$ & 26 & 7.6 & 141 & 49 & 72 & 4.0 & 220 & 0 & 458 & 29 & .9 \\
\hline
\end{tabular}

\begin{tabular}{|c|c|c|c|c|c|c|c|c|c|c|c|}
\hline DATE & $\begin{array}{l}\text { NITRATE } \\
\text { (NO3) } \\
\text { (MG/L) }\end{array}$ & $\begin{array}{l}\text { BORDN } \\
(B) \\
(13 G / L)\end{array}$ & $\begin{array}{l}\text { DIS- } \\
\text { SOLVED } \\
\text { SCLIDS } \\
\text { IRESI- } \\
\text { OUE AT } \\
\text { ISO C) } \\
\text { (MG LC) }\end{array}$ & $\begin{array}{l}\text { DIS- } \\
\text { SOLVED } \\
\text { SOLIDS } \\
\text { ITONS } \\
\text { PER } \\
\text { AC-FT\} }\end{array}$ & $\begin{array}{l}\text { HARD- } \\
\text { NFSS } \\
\text { (CA,MG) } \\
\text { (MGIL) }\end{array}$ & $\begin{array}{l}\text { NON- } \\
\text { CAR- } \\
\text { RONATE } \\
\text { HARD- } \\
\text { NFSS } \\
\text { IMGILI }\end{array}$ & $\begin{array}{l}\text { PERCEAT } \\
\text { SODIUM }\end{array}$ & $\begin{array}{l}\text { SODIUM } \\
\text { AD- } \\
\text { SORP- } \\
\text { TION } \\
\text { RATIU }\end{array}$ & $\begin{array}{l}\text { ALKA- } \\
\text { LINITY } \\
\text { AS } \\
\text { CACD3 } \\
\text { (MGSL) }\end{array}$ & $\begin{array}{c}\text { PH } \\
\text { (UNITS) }\end{array}$ & $\begin{array}{l}\text { SPECI- } \\
\text { FIC } \\
\text { COND- } \\
\text { UCTANCE } \\
\text { (MICRO- } \\
\text { MHOS) }\end{array}$ \\
\hline OCT. & & & & & & & & & & & \\
\hline DEC... & 12 & $B 70$ & 1510 & 2.05 & 771 & 520 & 30 & 2.4 & 251 & 8.0 & 1840 \\
\hline $\begin{array}{l}17 \ldots . . \\
\text { JAN. }\end{array}$ & 14 & 990 & 1680 & 2.28 & 847 & 580 & 31 & 2.6 & 267 & 7.8 & 2090 \\
\hline $14 \ldots$ & 5.8 & 770 & 725 & .99 & 371 & 240 & 29 & 1.6 & 131 & 7.6 & 988 \\
\hline $\begin{array}{l}26 . . . \\
\text { MAR. }\end{array}$ & -- & 100 & 557 & .76 & 317 & 196 & 20 & .9 & 121 & 7.9 & 751 \\
\hline IINE & B. 0 & 360 & 795 & 1.08 & 468 & 285 & 18 & 1.0 & 183 & 8. 0 & 1040 \\
\hline $\operatorname{JisL}_{\sin }^{05}$ & 14 & 560 & 1050 & 1.43 & 536 & 326 & 26 & 1.7 & 210 & 8.0 & 1390 \\
\hline $25 \ldots$ & 9.5 & 720 & 934 & 1.27 & 554 & 374 & 22 & 1.3 & 180 & Q. 2 & 2190 \\
\hline
\end{tabular}


11113500 SANTA PaUla CREEK NEAR SANTA PAUla, CALIF.

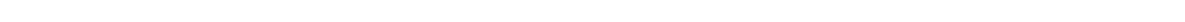
$15 \mathrm{ft}$ upstream from Santa Paula Water Works diversion dam, $200 \mathrm{ft}$ upstream from Hud Creek, and 3 miles north of Santa Paula.

DRAINAGE AREA. $-20,0 \mathrm{sq} \mathrm{mi}$.

PERIOD OF RECORD, --Chemical analyses: October 1966 to September 1969.

Water temperatures: April to September 1969.

EXTRENES.--April to September 1969

Specific conductance: Maximum daily, 893 micromhos Sept. 24 ; minimum daily, 654 micromhos Hay 2.

Water temperatures: Maximum, $30.0^{\circ} \mathrm{C}$ on severa 1 days in August; minimum, $12.0^{\circ} \mathrm{C}$ May $3-5$.

REMARKS. --Chemica 1-quality records furnished by California Department of Water Resources and reviewed by U, $S$.

Geoiogica1 Survey.

CHEMICAL ANALYSES, water YEAR OCTOBER 1968 TO SEPTEMBER 1969

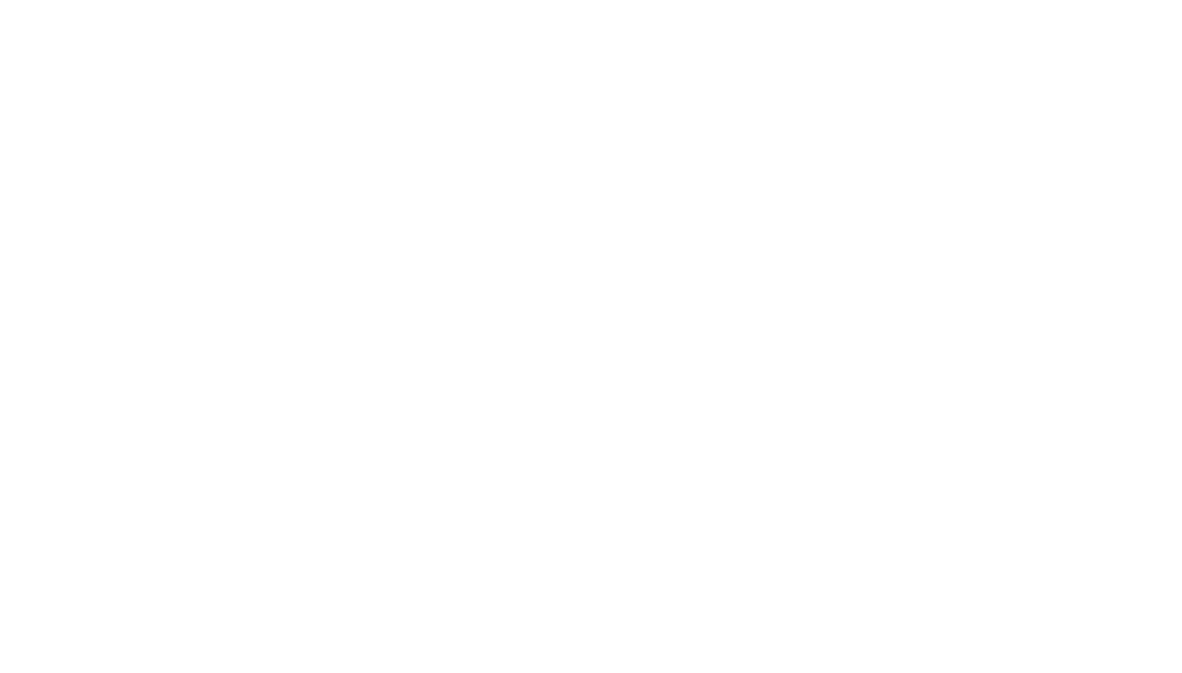

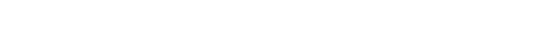

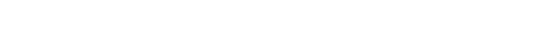

$\Delta N$.

$14 \ldots .200$

$20 \ldots$.

$20 \ldots$

$21 \ldots$

$21 \ldots$

$24 \ldots$

FEA.

$23 . . . \quad 136$

MAR. 200

APR.

$22 \ldots 172$

JUNE $05 . . .194$

JULY

-- 429

189

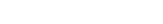

$\begin{array}{ll}2.3 & 400 \\ 1.9 & 400\end{array}$

871

--

$$
393
$$

168

239

$7.9 \quad 1230$

692
770

$11.0 \quad 150$

340

4.5

$110^{8.0}$

5.4
5.4

$\begin{array}{cr}601 & 308 \\ -- & 386 \\ -- & 186\end{array}$

$-\quad 186$

194

228
163
287
275

272

147
88
184

$9.0 \quad .4 \quad--90$

354

$-$

165

93
173

225

$7.9 \quad 1170$

$$
\text { -- } 130
$$

$\begin{array}{lllll}14 & .4 & 2.3 & 110 & 469\end{array}$

543

$-$

-. 306

-- $\quad 317$

$\begin{array}{rrr}210 & 7.3 & 1030 \\ 217 & 8.4 & 1060 \\ 84 & 7.7 & 515\end{array}$

$\begin{array}{ll}7.7 & 515 \\ 7.5 & 602\end{array}$

$6.7 \quad 400$

$\begin{array}{ll}7.3 & 251 \\ 6.4 & 433\end{array}$

-- 160

563

$-$

320 
11113500 SANTA PAULA CREEK NEAR SANTA PAULA, CALIF.--ContInued SPECIFIC CONDUCTANCE (MICROMHOS AT $25^{\circ} \mathrm{C}$ ), APRIL TO SEPTEMBER 1969

\begin{tabular}{|c|c|c|c|c|c|c|}
\hline DAY & $A P R$ & MAY & JUN & JUL & AUG & SEP \\
\hline 1 & $\cdots$ & 660 & 696 & 761 & 793 & 857 \\
\hline i & 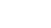 & 654 & $\begin{array}{l}707 \\
717\end{array}$ & $\begin{array}{l}757 \\
753\end{array}$ & 791 & $\begin{array}{r}850 \\
8447\end{array}$ \\
\hline & $\overline{-. .}$ & $\begin{array}{l}668 \\
676\end{array}$ & $\begin{array}{l}717 \\
731\end{array}$ & 753 & $\begin{array}{l}796 \\
800\end{array}$ & $\begin{array}{l}847 \\
886\end{array}$ \\
\hline 5 & $\ldots$ & 673 & 739 & 753 & 811 & $\begin{array}{l}830 \\
838\end{array}$ \\
\hline 6 & -.- & 658 & 751 & 771 & 813 & 841 \\
\hline 7 & $\cdots$ & 671 & 775 & 770 & 815 & 839 \\
\hline$\varepsilon$ & $=-$ & 683 & 775 & 764 & 815 & 842 \\
\hline 10 & $\overline{-}$ & $\begin{array}{l}703 \\
721\end{array}$ & $\begin{array}{l}791 \\
800\end{array}$ & $\begin{array}{l}767 \\
789\end{array}$ & $\begin{array}{l}817 \\
828\end{array}$ & $\begin{array}{l}849 \\
844\end{array}$ \\
\hline 11 & -.. & 723 & 810 & 799 & 829 & \\
\hline 12 & --- & 738 & 796 & 782 & 837 & $\begin{array}{l}400 \\
850\end{array}$ \\
\hline 13 & -- & 765 & 786 & 797 & 852 & 861 \\
\hline 14 & -- & 780 & 780 & 798 & 867 & 863 \\
\hline 15 & $\cdots$ & 804 & 778 & 802 & 365 & 870 \\
\hline 16 & - & 789 & 781 & 803 & 865 & 886 \\
\hline 17 & $\cdots$ & 795 & 774 & 803 & 867 & 880 \\
\hline 18 & $\cdots$ & 798 & 766 & 799 & 873 & 872 \\
\hline$\frac{19}{190}$ & $\cdots$ & $\begin{array}{l}794 \\
795\end{array}$ & $\begin{array}{l}762 \\
783\end{array}$ & 801 & 877 & 872 \\
\hline 21 & $\cdots$ & 784 & 782 & 813 & 878 & 884 \\
\hline 22 & $\cdots$ & 781 & 760 & 810 & 877 & \\
\hline 23 & -- & 767 & 775 & 808 & 871 & 892 \\
\hline $\begin{array}{l}74 \\
25\end{array}$ & $=$ & $\begin{array}{l}771 \\
777\end{array}$ & $\begin{array}{l}795 \\
792\end{array}$ & $\begin{array}{l}801 \\
796\end{array}$ & $\begin{array}{l}862 \\
855\end{array}$ & $\begin{array}{l}893 \\
885\end{array}$ \\
\hline 76 & & 771 & 785 & 791 & 852 & \\
\hline 27 & -.- & 772 & 778 & 787 & 851 & $\begin{array}{l}884 \\
891\end{array}$ \\
\hline 28 & $\ldots$ & 774 & 175 & 785 & 844 & 885 \\
\hline 29 & $\cdots$ & 760 & 765 & 780 & 854 & 880 \\
\hline 30 & 673 & 675 & 766 & 784 & $\begin{array}{l}858 \\
857\end{array}$ & 890 \\
\hline 31. & $\cdots$ & 676 & & & & \\
\hline VERAGE & -. & 737 & 769 & 785 & 843 & 867 \\
\hline
\end{tabular}

TEMPERATURE ( $\left.{ }^{\circ} \mathrm{C}\right)$ OF WATER, APRIL TO SEPTEMBER 1969 (ONCE-DAILY MEASUREMENT)

DAY

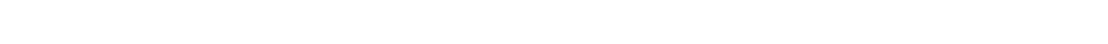
APR IL

MAXIMUM MAY

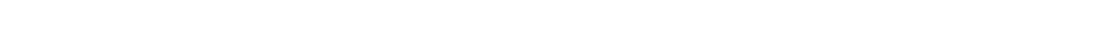
MINIMUM 14 14 12 12 12 -

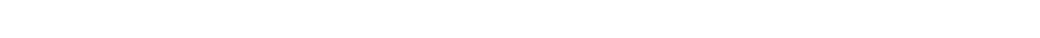

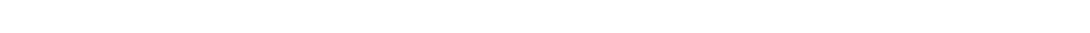
JuL $r$

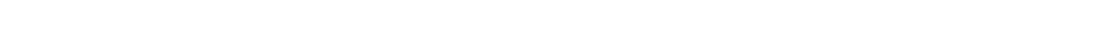

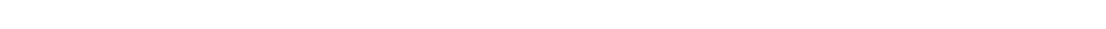
AUGUST

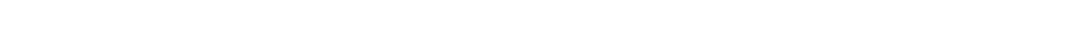

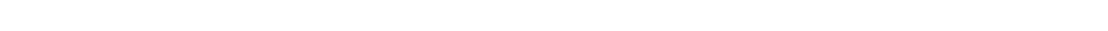

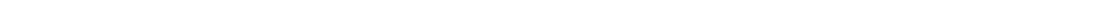

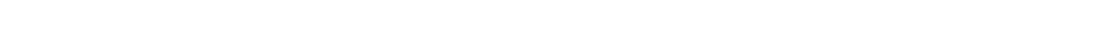


11113900 SATICOY DIVERSION NEAR SATICOY, CALIF.

LOCATION, --Lat $34^{\circ} 17^{\prime} 06^{\prime \prime}$, long $119^{\circ} 07^{\prime} 14^{\prime \prime}$, In Santa Paula y Sat1coy Grant, Ventura County, at gaging stat1on on diversion ditch, 0.7 mile downstream from Santa Clara River and 1.5 miles east of Saticoy,

PERIOD OF RECORD, --Specific conductance: April to September 1969 ,

Water temperatures: April to September 1969.

EXTREMES. --April to September 1969:

Specific conductance: Minimum, 1,120 micromhos Aug. 3.

Water temperatures: Maximum, $29.0^{\circ} \mathrm{C}$ Sept. 30.

SPECIFIC CONDUCTANCE (MICROMHOS AT $25^{\circ} \mathrm{C}$ ), APRIL TO SEPTEMBER 1969

\begin{tabular}{|c|c|c|c|c|c|c|c|c|c|c|c|c|}
\hline DAY & DCI & Nov & OEC & JAN & FEB & MAR & APR & MAY & JUN & JUL & AUG & SEF \\
\hline $\begin{array}{l}1 \\
2 \\
3 \\
4 \\
5\end{array}$ & $\begin{array}{l}--- \\
=- \\
=-\end{array}$ & $\begin{array}{l}--\overline{-} \\
\cdots- \\
\cdots-\end{array}$ & $\begin{array}{l}=- \\
=- \\
=- \\
--\end{array}$ & $\begin{array}{l}--- \\
--- \\
--- \\
--\end{array}$ & 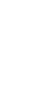 & 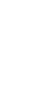 & $\bar{~}=$ & $\begin{array}{l}1260 \\
1280 \\
1310 \\
1320 \\
1300\end{array}$ & $\begin{array}{l}1400 \\
1410 \\
1370 \\
1350 \\
1350\end{array}$ & $\begin{array}{l}1320 \\
1340 \\
1340 \\
1340 \\
1340\end{array}$ & $\begin{array}{l}1260 \\
1140 \\
1120 \\
1160 \\
1190\end{array}$ & $\begin{array}{l}1190 \\
1190 \\
1190 \\
1190 \\
1200\end{array}$ \\
\hline $\begin{array}{r}6 \\
7 \\
8 \\
9 \\
10\end{array}$ & $\begin{array}{l}\overline{-} \\
\overline{-n} \\
\overline{-n}\end{array}$ & $\begin{array}{l}--- \\
--\overline{-} \\
\overline{--} \\
--\end{array}$ & $\begin{array}{l}=- \\
-- \\
-- \\
--\end{array}$ & $\begin{array}{l}-- \\
\cdots \\
\cdots\end{array}$ & 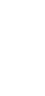 & $\begin{array}{l}-- \\
-- \\
-- \\
--\end{array}$ & $\begin{array}{l}\ddot{-} \\
\overline{-} \\
\overline{-}\end{array}$ & $\begin{array}{l}1300 \\
1320 \\
1320 \\
1330 \\
1340\end{array}$ & $\begin{array}{l}1360 \\
1360 \\
1350 \\
1350 \\
1370\end{array}$ & $\begin{array}{l}1330 \\
1330 \\
1340 \\
1370 \\
1410\end{array}$ & $\begin{array}{l}1200 \\
1200 \\
1190 \\
1180 \\
1180\end{array}$ & $\begin{array}{l}1190 \\
1180 \\
1180 \\
1210 \\
1260\end{array}$ \\
\hline $\begin{array}{l}11 \\
12 \\
15 \\
14 \\
15\end{array}$ & $\begin{array}{l}-- \\
\cdots \\
\cdots- \\
--\end{array}$ & $\begin{array}{l}-- \\
-- \\
--- \\
--\end{array}$ & $\begin{array}{l}--- \\
-- \\
-- \\
--\end{array}$ & $\begin{array}{l}--- \\
--- \\
---\end{array}$ & $\begin{array}{l}--- \\
\overline{--} \\
\overline{--}\end{array}$ & $\begin{array}{l}--- \\
-- \\
-- \\
--\end{array}$ & $\begin{array}{l}1130 \\
1160 \\
1170 \\
1180\end{array}$ & $\begin{array}{l}1400 \\
1400 \\
1400 \\
1400\end{array}$ & $\begin{array}{l}1370 \\
1360 \\
1350 \\
1350 \\
1350\end{array}$ & $\begin{array}{l}1350 \\
1280 \\
1280 \\
1400 \\
1350\end{array}$ & $\begin{array}{l}1180 \\
1180 \\
1190 \\
1190 \\
1200\end{array}$ & $\begin{array}{l}1230 \\
1200 \\
1190 \\
1180 \\
1180\end{array}$ \\
\hline $\begin{array}{l}16 \\
17 \\
18 \\
19 \\
20\end{array}$ & $\begin{array}{l}-\cdots \\
-\cdots \\
-\cdots \\
--- \\
-\end{array}$ & $\begin{array}{l}-- \\
-- \\
-- \\
--\end{array}$ & $\begin{array}{l}--- \\
-- \\
--- \\
---\end{array}$ & $\begin{array}{l}=- \\
=- \\
--\end{array}$ & $\begin{array}{l}=- \\
-\cdots \\
--\end{array}$ & $\begin{array}{l}--- \\
-- \\
--\end{array}$ & $\begin{array}{l}1190 \\
1200 \\
1200 \\
1210 \\
1220\end{array}$ & $\begin{array}{l}1400 \\
1400 \\
1400 \\
1410 \\
1410\end{array}$ & $\begin{array}{l}1350 \\
1360 \\
1370 \\
1390 \\
1390\end{array}$ & $\begin{array}{l}1400 \\
1350 \\
1360 \\
1300 \\
1230\end{array}$ & $\begin{array}{l}1190 \\
1180 \\
1170 \\
1180 \\
1190\end{array}$ & $\begin{array}{l}1170 \\
1180 \\
1180 \\
1190 \\
1200\end{array}$ \\
\hline $\begin{array}{l}26 \\
27 \\
28 \\
24 \\
30 \\
31\end{array}$ & $\begin{array}{l}--- \\
--- \\
--- \\
--- \\
---\end{array}$ & 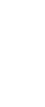 & \begin{tabular}{l}
-- \\
-- \\
\hdashline- \\
--- \\
--
\end{tabular} & 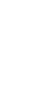 & $\begin{array}{l}-- \\
-- \\
-- \\
-- \\
--\end{array}$ & 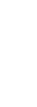 & $\begin{array}{l}1210 \\
1240 \\
1230 \\
1230 \\
1250 \\
-\end{array}$ & $\begin{array}{l}1410 \\
1410 \\
1420 \\
1430 \\
1410 \\
1410\end{array}$ & $\begin{array}{l}1370 \\
1370 \\
1350 \\
1340 \\
1320 \\
-\end{array}$ & $\begin{array}{l}1210 \\
1160 \\
1130 \\
1160 \\
1180 \\
1210\end{array}$ & $\begin{array}{l}1190 \\
1190 \\
1180 \\
1190 \\
1130 \\
1190\end{array}$ & $\begin{array}{r}1280 \\
1270 \\
1270 \\
1290 \\
-\cdots \\
---\end{array}$ \\
\hline VERAGE & $=$ & $\ldots$ & -.. & $\ldots$ & -- & -- & -- & 1373 & 1364 & 1293 & 1186 & 1210 \\
\hline
\end{tabular}

TEMPERA TURE $\left({ }^{\circ} \mathrm{C}\right)$ OF WATER, APRIL TO SEPTEMBER 1969

DAY

$\begin{array}{lllllllllllllllllllllllllllllllllllllllllllll}\text { MUNIH } & 1 & 2 & 3 & 4 & 5 & 6 & 7 & 8 & 9 & 10 & 11 & 12 & 13 & 14 & 15 & 16 & 17 & 18 & 19 & 20 & 21 & 22 & 23 & 24 & 25 & 26 & 27 & 28 & 29 & 30 & 31 & \text { AVER }\end{array}$

MAXIMUM --

MINIMUM -.

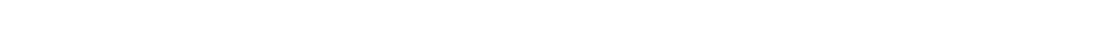

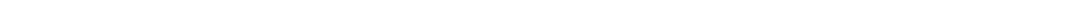

MAXIMUM $22 \begin{array}{lllllllllllllllllllllllllllllllll}21 & 22 & 21 & 21 & 22 & 20 & -- & 22 & 20 & 20 & 21 & 24 & 22 & 24 & 21 & 23 & 24 & 24 & 23 & 19 & 24 & 24 & 24 & 24 & 24 & 24 & 25 & 25 & 25 & -- & 23\end{array}$

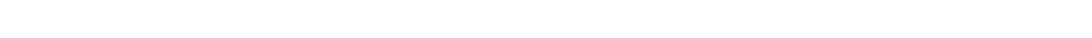

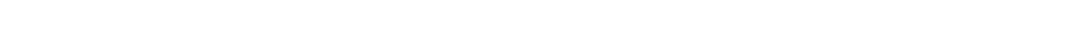

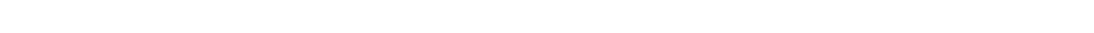
JGUST

MAXIMUM $26 \quad 26 \quad 25 \quad 26 \quad 26 \quad 25 \quad 26 \quad 26 \quad 26 \quad 25 \quad 25 \quad 26 \quad 26 \quad 25 \quad 24 \quad 24 \quad 25 \quad 24 \quad 24 \quad 24 \quad 25 \quad 24 \quad 24 \quad 24 \quad 24 \quad 24 \quad 24 \quad 24 \quad 23 \quad 24 \quad 24 \quad 25$

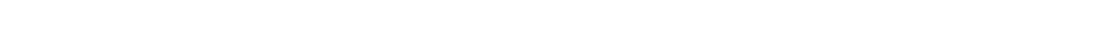
SEPTEMBER

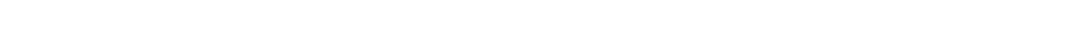


LOCATION.--Lat $34^{\circ} 16^{\circ} 29^{\prime \prime}$, 1ong $119^{\circ} 08^{\prime} 11^{\prime \prime}$, 1n Santa Clara Del Norte Grant, Ventura County, at gaglng stat1on on third pier from left levee of bridge on' State Highway 118,0.9 mile southeast of Saticoy.

DRAINAGE AREA. --1,595 sq mi.

PERIOD OF RECORD, --Chemical analyses: October 1968 to September 1969 (miscellaneous).

Water temperatures: October 1967 to September 1969.

Sediment records: October 1967 to September 1969.

EXTREMES. --1968 69:

Sediment concentrations: Waximum daily, 69,200 mg/l Feb. 25; minimum daily, no flow for many days.

Sediment discharge: Haximum da1ly, 20,400,000 tons Feb. 25; m1nimum da1ly, 0 ton on many days.

period of record:

Sediment concentrations: Haximum daily, 69,200 mg/1 Feb. 25, 1969; m1nimum daily, no flow for many days. Sediment discharge: Haximum daily, 20,400,000 tons Feb. 25, I969; minimum daliy, o ton on many days.

REMARKS. --No flow Oct. 1 to Jan. 18.

CHEMICAL ANALYSES, WATER YEAR OCTOBER 1968 TO SEPTEMBER 1959

\begin{tabular}{|c|c|c|c|c|c|c|c|c|c|c|c|c|}
\hline & $\begin{array}{l}\text { OIS- } \\
\text { CHAR UE }\end{array}$ & $\begin{array}{l}\text { TEMPER- } \\
\text { AIURE }\end{array}$ & $\begin{array}{l}\text { SILICA } \\
\text { (SII2) }\end{array}$ & $\begin{array}{l}\text { OIS- } \\
\text { SOLVFD } \\
\text { IRON } \\
\text { (FE) }\end{array}$ & $\begin{array}{l}\text { CAL- } \\
\text { CIUM } \\
\text { (CA) }\end{array}$ & $\begin{array}{l}\text { MAG- } \\
\text { NE- } \\
\text { SIUM } \\
\text { (MG) }\end{array}$ & $\begin{array}{l}\text { SOO IUM } \\
\text { (NA) }\end{array}$ & $\begin{array}{l}\text { PO- } \\
\text { TAS- } \\
\text { SIUM } \\
\text { (K) }\end{array}$ & $\begin{array}{l}\text { AICAR- } \\
\text { BONATE } \\
\text { (HCQ3) }\end{array}$ & $\begin{array}{l}\text { CAR- } \\
\text { BONATE } \\
\text { (COB) }\end{array}$ & $\begin{array}{l}\text { SULFATE } \\
\text { (SO4) }\end{array}$ & $\begin{array}{l}\text { CHLO- } \\
\text { RIOE } \\
\text { (CL) } \\
(\mathrm{MG} / \mathrm{L})\end{array}$ \\
\hline$A T E$ & (CFS) & IDFG CI & $(M G / L)$ & (UG/L) & $(M[\sigma / L)$ & $(4 \sigma / L)$ & IMG/L) & ( $4 G / L$ ) & $(M G / L)$ & IMG / I I & $(M G / L)$ & $(M G / L)$ \\
\hline
\end{tabular}

$\begin{array}{rrrr}\text { JAN. } & & & \\ 20 \ldots & 2800 & 12 & 6 \\ 21 \ldots & 65200 & 13 & 6 \\ 22 \ldots & 6700 & 13 & 6 \\ 25 \ldots & 154000 & -- & 6\end{array}$

$\begin{array}{ll}0.2 & \\ 0.2 & 10 \\ 6.4 & 10 \\ 5.5 & 10\end{array}$

$\begin{array}{rr}0 & 59 \\ 10 & 54 \\ 10 & 78 \\ 10 & 139\end{array}$

$\begin{array}{ll}16 & 35 \\ 11 & 13 \\ 14 & 23 \\ 23 & 38\end{array}$

$\begin{array}{rr}3.2 & 86 \\ 3.7 & 92 \\ 3.0 & 166 \\ 5.5 & 133\end{array}$

$\begin{array}{ll}0 & 183 \\ 0 & 129 \\ 0 & 143 \\ 0 & 379\end{array}$

13
3.5
7.0
16

TEMPERATURE $\left({ }^{\circ} \mathrm{C}\right)$ OF WATER, MATER YEAR OCTOBER 1968 TO SEPTEMBER 1969

$$
\text { (ONCE-DAILY MEASUREMENT) }
$$

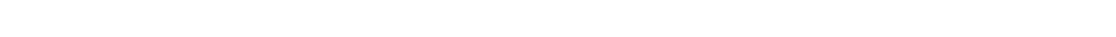
Остовср.. NIVEMHER. DHCEMЗFR. JAVUARY..

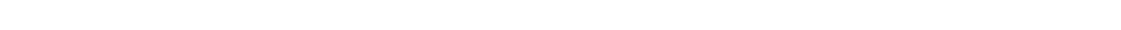
APRIL... MAY..... JULY..... AUGUST,.. SЕ АТЕMB̈R 
11113920 SANTA CLARA RIVER AT SATICOY, CALIF.--Continued SUSPENDED-SEDIMENT DISCHARGE, WATER YEAR OCTOBER 1968 TO SEPTEMBER 1969 JANUARY FEBRUARY MARCH MEAN
DISCHARGE
(CFS)

MEAN

DAY $\begin{array}{lll}\text { CDNCEN- } & \text { SEDIMENT } & \text { MEAN } \\ \text { TRATION } & \text { DISCHARGE } & \text { OISCHARGE }\end{array}$

MEAN CONCEN- SEDIMENT MEAN CONCENCONCEN- SEDIMENT (MG/L) (TONS/DAY) (CFSI TRATION DISCHARGE OISCHARGE TRATION DISCHARGE
TONS / DAY

770
740
710
704
698

1100 (CFS)

$5330 \quad 131000$

$\begin{array}{rrr}1100 & 2290 & 9080 \\ 690 & 1380 & 6380 \\ 430 & 824 & 4920 \\ 260 & 494 & 4000 \\ 160 & 302 & 3290\end{array}$

57100 $3800 \quad 33800$

$\begin{array}{lllll}6 & 0 & -- & 0 & 102 \\ 7 & 0 & - & 0\end{array}$

10200
2930
1800
1710

$\begin{array}{rr}41500 & 1340000 \\ 14900 & 126000\end{array}$

2800

2340

$\begin{array}{rrr}3300 & 16000 & 2170 \\ 2100 & 9700 & 1940\end{array}$

$2610 \quad 16500$

$217000 \quad 11700$

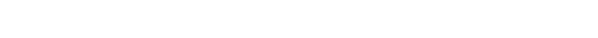

$\begin{array}{lll}0 & -\cdots\end{array}$

1550

2000

1440

1410
1160

$\begin{array}{ll}2100 & 8160 \\ 2160 & 8220\end{array}$

8370
8160
8220

1670

1800

1800
2160

3640

6580
14700

1440

2060

1800

1090

$\begin{array}{rr}0 & -- \\ 0 & =- \\ 0 & -- \\ 1700 & 4550\end{array}$

0
0
0
55200

946

5090

15500

1110

$\begin{array}{ll}3750 & 9580 \\ 3500 & 8940 \\ 3450 & 8810\end{array}$

1110

1220

3660

$\quad 4770$

$1800 \quad 5440$

32100

32100
5680

2480

\section{0}

243000

946
864

3450
3400

1120
1180

3900
11400

7930

5450

15500
5330 244000

5330
13900
6479000

853
1740
10400

10400
23500

53800
330000

$\begin{array}{lll}1180 & 1780 & 5670 \\ 1100 & 2100 & 6240 \\ 1010 & 2500 & 6820\end{array}$

$\begin{array}{rrr}1010 & 2500 & 6820 \\ 967 & 2620 & 6840\end{array}$

$\begin{array}{rrrrr}35800 & 2750000 & 967 & 2620 & 6840 \\ 69200 & 20400000 & 981 & 2100 & 5560\end{array}$

$25800-24500 \quad 1940000$

$24500 \quad 1940000$

$\begin{array}{rr}7200 & 151000 \\ 5450 & 56100 \\ 4350 & 30000 \\ 2690 & 12500\end{array}$

92300

$\begin{array}{rr}18300 & 1060000 \\ 9700 & 313000\end{array}$

19900
11800
10700

2100

5560

$9700 \quad 313000$

$953 \quad 1650$

932
1010 $\quad 1300 \quad 3250$

$\begin{array}{lll}810 & 1500 & 4090\end{array}$

$\begin{array}{lll}869 & 800 & 1880 \\ 848 & 600 & 1370\end{array}$

1710
1110

5260

204797

-- 27780930

62486

527020

\begin{tabular}{|c|c|c|c|c|c|c|c|c|c|}
\hline DAY & $\begin{array}{l}\text { MEAN } \\
\text { OISCHARGE } \\
\text { (CFS) }\end{array}$ & $\begin{array}{l}\text { APRIL } \\
\text { MEAN } \\
\text { CONCEN- } \\
\text { TRATION } \\
\text { (MG/L) }\end{array}$ & $\begin{array}{l}\text { SEDI MENT } \\
\text { DI SCHARGE } \\
\text { (TONS/DAY) }\end{array}$ & $\begin{array}{l}\text { MEAN } \\
\text { DISCHARGE } \\
\text { (CFS) }\end{array}$ & $\begin{array}{l}\text { MAY } \\
\text { MEAN } \\
\text { CONCEN- } \\
\text { TRATIION } \\
\text { (MG/L) }\end{array}$ & $\begin{array}{l}\text { SEDIMENT } \\
\text { DISCHARGE } \\
\text { (TONS /DAY) }\end{array}$ & $\begin{array}{l}\text { MEAN } \\
\text { DISCHARGE } \\
\text { (CFS) }\end{array}$ & $\begin{array}{l}\text { JUNE } \\
\text { MEAN } \\
\text { CONCEN- } \\
\text { TRATION } \\
\text { (MG IL) }\end{array}$ & $\begin{array}{l}\text { SEDIMENT } \\
\text { DISCHARGE } \\
\text { (TONS/DAY) }\end{array}$ \\
\hline $\begin{array}{l}1 \\
2 \\
3 \\
4 \\
5\end{array}$ & $\begin{array}{l}842 \\
842 \\
890 \\
844 \\
680\end{array}$ & $\begin{array}{l}500 \\
400 \\
372 \\
340 \\
330\end{array}$ & $\begin{array}{r}1140 \\
909 \\
894 \\
775 \\
608\end{array}$ & $\begin{array}{l}57 \\
55 \\
52 \\
50 \\
65\end{array}$ & $\begin{array}{l}260 \\
240 \\
240 \\
220 \\
220\end{array}$ & $\begin{array}{l}40 \\
36 \\
34 \\
30 \\
39\end{array}$ & $\begin{array}{l}15 \\
15 \\
13 \\
13 \\
13\end{array}$ & $\begin{array}{l}70 \\
70 \\
70 \\
70 \\
70\end{array}$ & $\begin{array}{l}2.8 \\
2.8 \\
2.5 \\
2.5 \\
2.5\end{array}$ \\
\hline $\begin{array}{r}6 \\
7 \\
8 \\
9 \\
10\end{array}$ & $\begin{array}{l}608 \\
528 \\
466 \\
406 \\
370\end{array}$ & $\begin{array}{l}330 \\
350 \\
390 \\
440 \\
470\end{array}$ & $\begin{array}{l}542 \\
499 \\
491 \\
482 \\
470\end{array}$ & $\begin{array}{l}35 \\
34 \\
34 \\
34 \\
33\end{array}$ & $\begin{array}{l}100 \\
100 \\
100 \\
100 \\
100\end{array}$ & $\begin{array}{l}9.5 \\
9.2 \\
9.2 \\
9.2 \\
8.9\end{array}$ & $\begin{array}{l}13 \\
12 \\
12 \\
11 \\
9.4\end{array}$ & $\begin{array}{l}65 \\
65 \\
65 \\
65 \\
65\end{array}$ & $\begin{array}{l}2.3 \\
2.1 \\
2.1 \\
1.9 \\
1.6\end{array}$ \\
\hline $\begin{array}{l}11 \\
12 \\
13 \\
14 \\
15\end{array}$ & $\begin{array}{l}345 \\
284 \\
252 \\
220 \\
200\end{array}$ & $\begin{array}{l}490 \\
500 \\
510 \\
510 \\
520\end{array}$ & $\begin{array}{l}456 \\
383 \\
347 \\
303 \\
281\end{array}$ & $\begin{array}{l}31 \\
29 \\
25 \\
24 \\
22\end{array}$ & $\begin{array}{r}100 \\
100 \\
100 \\
90 \\
90\end{array}$ & $\begin{array}{l}8.4 \\
7.8 \\
6.8 \\
5.8 \\
5.3\end{array}$ & $\begin{array}{r}8.9 \\
8.9 \\
8.5 \\
8.1 \\
11\end{array}$ & $\begin{array}{l}60 \\
60 \\
60 \\
60 \\
60\end{array}$ & $\begin{array}{l}1.4 \\
1.4 \\
1.4 \\
1.3 \\
1.8\end{array}$ \\
\hline $\begin{array}{l}16 \\
17 \\
18 \\
19 \\
20\end{array}$ & $\begin{array}{l}175 \\
160 \\
147 \\
135 \\
127\end{array}$ & $\begin{array}{l}520 \\
518 \\
510 \\
460 \\
400\end{array}$ & $\begin{array}{l}246 \\
224 \\
202 \\
168 \\
137\end{array}$ & $\begin{array}{l}21 \\
20 \\
20 \\
20 \\
19\end{array}$ & $\begin{array}{l}90 \\
90 \\
90 \\
90 \\
90\end{array}$ & $\begin{array}{l}5.1 \\
4.9 \\
4.9 \\
4.9 \\
4.6\end{array}$ & $\begin{array}{r}11 \\
9.8 \\
9.4 \\
8.9 \\
8.5\end{array}$ & $\begin{array}{l}52 \\
50 \\
50 \\
50 \\
50\end{array}$ & $\begin{array}{l}1.5 \\
1.3 \\
1.3 \\
1.2 \\
1.1\end{array}$ \\
\hline $\begin{array}{l}21 \\
22 \\
23 \\
24 \\
25\end{array}$ & $\begin{array}{r}111 \\
107 \\
96 \\
91 \\
85\end{array}$ & $\begin{array}{l}350 \\
317 \\
310 \\
310 \\
310\end{array}$ & $\begin{array}{r}105 \\
92 \\
80 \\
76 \\
71\end{array}$ & $\begin{array}{l}18 \\
17 \\
17 \\
17 \\
17\end{array}$ & $\begin{array}{l}85 \\
85 \\
83 \\
80 \\
80\end{array}$ & $\begin{array}{l}4.1 \\
3.9 \\
3.8 \\
3.7 \\
3.7\end{array}$ & $\begin{array}{l}8.1 \\
8.1 \\
7.2 \\
7.6 \\
7.6\end{array}$ & $\begin{array}{l}45 \\
45 \\
45 \\
45 \\
45\end{array}$ & $\begin{array}{r}.98 \\
.98 \\
.87 \\
.92 \\
.92\end{array}$ \\
\hline $\begin{array}{l}26 \\
27 \\
28 \\
29 \\
30 \\
31\end{array}$ & $\begin{array}{l}80 \\
77 \\
74 \\
72 \\
66 \\
--\end{array}$ & $\begin{array}{r}310 \\
300 \\
300 \\
280 \\
280 \\
--\end{array}$ & $\begin{array}{l}67 \\
62 \\
60 \\
54 \\
50 \\
--\end{array}$ & $\begin{array}{l}16 \\
16 \\
14 \\
14 \\
15 \\
15\end{array}$ & $\begin{array}{l}80 \\
80 \\
75 \\
75 \\
75 \\
75\end{array}$ & $\begin{array}{l}3.5 \\
3.5 \\
2.8 \\
2.8 \\
3.0 \\
3.0\end{array}$ & $\begin{array}{l}8.1 \\
8.1 \\
8.5 \\
8.9 \\
8.9 \\
--\end{array}$ & $\begin{array}{l}45 \\
45 \\
45 \\
45 \\
44 \\
--\end{array}$ & $\begin{array}{l}.98 \\
.98 \\
1.0 \\
1.1 \\
1.1 \\
-0\end{array}$ \\
\hline TOTAL & 9380 & - & 10272 & 856 & -- & 321.3 & 300.5 & -- & 46.63 \\
\hline
\end{tabular}


11113920 SANTA CLARA RIVER AT SATICOY, CALIF,---Cont1nued

SUSPENDED-SEDIMENT DISCHARGE, WATER YEAR OCTOBER 1968 TO SEPTEMBER 2969

\begin{tabular}{|c|c|c|c|c|c|c|c|c|c|}
\hline \multirow[b]{2}{*}{ DAY } & \multicolumn{3}{|c|}{ JULY } & \multicolumn{3}{|c|}{ AUGUST } & \multicolumn{3}{|c|}{ SEPTEMBER } \\
\hline & $\begin{array}{l}\text { MEAN } \\
\text { DISCHARGF } \\
\text { (CFS) }\end{array}$ & $\begin{array}{l}\text { MEAN } \\
\text { CONCEN- } \\
\text { TRATION } \\
\text { (MG/L) }\end{array}$ & $\begin{array}{l}\text { SEDIMENT } \\
\text { DI SCHARGE } \\
\text { (TONS/DAY) }\end{array}$ & $\begin{array}{l}\text { MEAN } \\
\text { OI SCHARGE } \\
\text { (CFS) }\end{array}$ & $\begin{array}{l}\text { MEAN } \\
\text { CONCEN- } \\
\text { TRATION } \\
\text { IMG/LI }\end{array}$ & $\begin{array}{l}\text { SEDIMENT } \\
\text { DISCHARGE } \\
\text { (TONS/DAY) }\end{array}$ & $\begin{array}{l}\text { MEAN } \\
\text { DISCHARGE } \\
\text { ICFSI }\end{array}$ & $\begin{array}{l}\text { MEAN } \\
\text { CONCEN- } \\
\text { TRATION } \\
\text { IMG/L) }\end{array}$ & $\begin{array}{l}\text { SEDIMENT } \\
\text { DISCHARGE } \\
\text { (TONS / DAY) }\end{array}$ \\
\hline $\begin{array}{l}1 \\
2 \\
3 \\
4 \\
5\end{array}$ & $\begin{array}{l}8.9 \\
8.9 \\
8.9 \\
8.9 \\
9.8\end{array}$ & $\begin{array}{l}45 \\
45 \\
45 \\
45 \\
45\end{array}$ & $\begin{array}{l}1.1 \\
1.1 \\
1.1 \\
1.1 \\
1.2\end{array}$ & $\begin{array}{l}6.6 \\
7.6 \\
8.5 \\
7.6 \\
8.1\end{array}$ & $\begin{array}{l}35 \\
35 \\
35 \\
35 \\
35\end{array}$ & $\begin{array}{l}.62 \\
.72 \\
.80 \\
.72 \\
.77\end{array}$ & $\begin{array}{l}8.5 \\
8.9 \\
9.4 \\
8.9 \\
9.4\end{array}$ & $\begin{array}{l}10 \\
10 \\
10 \\
10 \\
10\end{array}$ & $\begin{array}{l}.23 \\
.24 \\
.25 \\
.24 \\
.25\end{array}$ \\
\hline $\begin{array}{r}6 \\
7 \\
8 \\
9 \\
10\end{array}$ & $\begin{array}{l}9.8 \\
8.9 \\
8.9 \\
8.5 \\
7.2\end{array}$ & $\begin{array}{l}45 \\
45 \\
45 \\
45 \\
45\end{array}$ & $\begin{array}{l}1.2 \\
1.1 \\
1.1 \\
1.0 \\
.87\end{array}$ & $\begin{array}{l}8.5 \\
8.9 \\
9.4 \\
10 \\
11\end{array}$ & $\begin{array}{l}30 \\
30 \\
30 \\
30 \\
30\end{array}$ & $\begin{array}{l}.69 \\
.72 \\
.76 \\
.81 \\
.89\end{array}$ & $\begin{array}{l}9.4 \\
9.4 \\
9.4 \\
9.4 \\
9.4\end{array}$ & $\begin{array}{l}10 \\
10 \\
10 \\
10 \\
10\end{array}$ & $\begin{array}{l}.25 \\
.25 \\
.25 \\
.25 \\
.25\end{array}$ \\
\hline $\begin{array}{l}11 \\
12 \\
13 \\
14 \\
15\end{array}$ & $\begin{array}{l}7.6 \\
8.9 \\
8.9 \\
8.5 \\
8.1\end{array}$ & $\begin{array}{l}44 \\
40 \\
40 \\
40 \\
40\end{array}$ & $\begin{array}{l}.90 \\
.96 \\
.96 \\
.92 \\
.87\end{array}$ & $\begin{array}{l}11 \\
12 \\
11 \\
11 \\
10\end{array}$ & $\begin{array}{l}30 \\
30 \\
30 \\
30 \\
30\end{array}$ & $\begin{array}{l}.89 \\
.97 \\
.89 \\
.89 \\
.81\end{array}$ & $\begin{array}{l}9.4 \\
9.4 \\
9.4 \\
9.4 \\
9.4\end{array}$ & $\begin{array}{l}10 \\
10 \\
10 \\
10 \\
10\end{array}$ & $\begin{array}{l}.25 \\
.25 \\
.25 \\
.25 \\
.25\end{array}$ \\
\hline $\begin{array}{l}16 \\
17 \\
18 \\
19 \\
20\end{array}$ & $\begin{array}{l}7.6 \\
7.2 \\
7.2 \\
7.2 \\
7.6\end{array}$ & $\begin{array}{l}40 \\
40 \\
40 \\
40 \\
40\end{array}$ & $\begin{array}{l}.82 \\
.78 \\
.78 \\
.78 \\
.82\end{array}$ & $\begin{array}{l}8.1 \\
7.2 \\
7.2 \\
7.2 \\
7.6\end{array}$ & $\begin{array}{l}20 \\
20 \\
20 \\
20 \\
20\end{array}$ & $\begin{array}{l}.44 \\
.39 \\
.39 \\
.39 \\
.41\end{array}$ & $\begin{array}{l}9.8 \\
10 \\
12 \\
11 \\
10\end{array}$ & $\begin{array}{l}10 \\
10 \\
10 \\
10 \\
10\end{array}$ & $\begin{array}{l}.26 \\
.27 \\
.32 \\
.30 \\
.27\end{array}$ \\
\hline $\begin{array}{l}21 \\
22 \\
23 \\
24 \\
25\end{array}$ & $\begin{array}{l}7.2 \\
6.9 \\
7.2 \\
7.6 \\
7.6\end{array}$ & $\begin{array}{l}35 \\
35 \\
35 \\
35 \\
35\end{array}$ & $\begin{array}{l}.68 \\
.55 \\
.68 \\
.72 \\
.72\end{array}$ & $\begin{array}{l}8.1 \\
8.1 \\
8.1 \\
8.1 \\
8.5\end{array}$ & $\begin{array}{l}20 \\
20 \\
20 \\
20 \\
20\end{array}$ & $\begin{array}{l}.44 \\
.44 \\
.44 \\
.44 \\
.46\end{array}$ & $\begin{array}{l}10 \\
10 \\
10 \\
11 \\
12\end{array}$ & $\begin{array}{l}10 \\
10 \\
10 \\
10 \\
10\end{array}$ & $\begin{array}{l}.27 \\
.27 \\
.27 \\
.30 \\
.32\end{array}$ \\
\hline $\begin{array}{l}26 \\
27 \\
28 \\
29 \\
30 \\
31\end{array}$ & $\begin{array}{l}8.9 \\
9.4 \\
8.9 \\
9.4 \\
8.9 \\
7.6\end{array}$ & $\begin{array}{l}35 \\
35 \\
35 \\
35 \\
35 \\
35\end{array}$ & $\begin{array}{l}.84 \\
.89 \\
.84 \\
.89 \\
.84 \\
.72\end{array}$ & $\begin{array}{l}8.9 \\
9.4 \\
9.4 \\
9.4 \\
9.4 \\
8.5\end{array}$ & $\begin{array}{l}20 \\
20 \\
20 \\
10 \\
10 \\
10\end{array}$ & $\begin{array}{l}.48 \\
.51 \\
.51 \\
.25 \\
.25 \\
.23\end{array}$ & $\begin{array}{l}12 \\
12 \\
12 \\
13 \\
13 \\
--\end{array}$ & $\begin{array}{l}10 \\
10 \\
10 \\
10 \\
10 \\
--\end{array}$ & $\begin{array}{r}.32 \\
.32 \\
.32 \\
.35 \\
.35 \\
-.-\end{array}$ \\
\hline TOTAL & 257.1 & -- & 27.93 & 274.4 & -- & 18.42 & 306.9 & -- & 8.22 \\
\hline $\begin{array}{l}\text { TOTAL } \\
\text { TOTAL }\end{array}$ & $\begin{array}{l}\text { UISCHARGE F } \\
\text { SUSPENDED-S }\end{array}$ & $\begin{array}{l}\text { OR YEAR } \\
\text { EDIMENT }\end{array}$ & $\begin{array}{l}\text { CFS-OAYSI } \\
\text { ISCHARGE FOR }\end{array}$ & YEAR ITON & & & & & $\begin{array}{r}448447.90 \\
0490604.50\end{array}$ \\
\hline
\end{tabular}

PARTICLE-SIZE DISTRIBUTION OF SUSPENDED SEDIMENT, WATER YEAR OCTOBER 1968 TO SEPTEMBER 1969 IMFTHOOS OF ANALYSIS: B, BOTTOM WITHDRAWAL TUBE; C, CHEMICALLY TISPERSED: N, IN NATIVE WATER; P, PIPET; S, SIEVE;

\begin{tabular}{|c|c|c|c|c|c|c|c|c|c|c|c|c|c|c|c|c|c|c|c|c|}
\hline & DATE & TIME & $\begin{array}{l}\text { WATER } \\
\text { TFM- } \\
\text { PERA- } \\
\text { TURF } \\
\text { ICI }\end{array}$ & $\begin{array}{l}\text { OISCHARGE } \\
\text { (CFS) }\end{array}$ & $\begin{array}{l}\text { CDNCEN- } \\
\text { TRATION } \\
(M G / L)\end{array}$ & $\begin{array}{l}\text { SUSPENDED } \\
\text { SFDIMENT } \\
\text { OISCHARGE } \\
\text { (IONS/DAY) }\end{array}$ & $\begin{array}{l}\text { PERC } \\
.002\end{array}$ & .00 & & & $\begin{array}{l}\text { THAN } \\
.016\end{array}$ & $\begin{array}{l}\text { THE S } \\
6.031\end{array}$ & SIZE & $E \| \mathbb{N}$ & 125 & .250 & .500 & INOIC & $\begin{array}{l}\text { CATED } \\
2.00\end{array}$ & $\begin{array}{l}\text { ME THOD } \\
\text { DF } \\
\text { ANALY- } \\
\text { SIS }\end{array}$ \\
\hline $\begin{array}{l}\text { JAN } \\
\text { JAN } \\
\text { JAN } \\
\text { JAN } \\
\text { JAN }\end{array}$ & $\begin{array}{l}19,1967 \\
20 \ldots \ldots \ldots \\
25 \ldots \ldots \ldots \\
25 \ldots \ldots \ldots \\
26 \ldots \ldots\end{array}$ & $\begin{array}{l}1100 \\
0305 \\
1015 \\
1725 \\
1540\end{array}$ & $\begin{array}{l}11 \\
13 \\
14 \\
13 \\
13\end{array}$ & $\begin{array}{r}42 \\
14500 \\
163000 \\
56100 \\
28700\end{array}$ & $\begin{array}{r}2050 \\
13800 \\
91400 \\
71200 \\
21100\end{array}$ & $\begin{array}{r}232 \\
736000 \\
40200000 \\
10800000 \\
1640000\end{array}$ & $\begin{array}{l}67 \\
21 \\
26 \\
22 \\
17\end{array}$ & & $\begin{array}{l}34 \\
26 \\
19\end{array}$ & $\begin{array}{l}83 \\
31 \\
40 \\
32 \\
25\end{array}$ & $\begin{array}{l}93 \\
47 \\
60 \\
50 \\
34\end{array}$ & $\begin{array}{r}100 \\
60 \\
77 \\
66 \\
44\end{array}$ & & $\begin{array}{l}73 \\
73 \\
78 \\
54\end{array}$ & $\begin{array}{r}\overline{90} \\
100 \\
95 \\
71\end{array}$ & $\begin{array}{l}\overline{97} \\
\overline{99} \\
89\end{array}$ & $\begin{array}{r}100 \\
100 \\
97\end{array}$ & $\begin{array}{l}= \\
= \\
= \\
100\end{array}$ & $\begin{array}{l}= \\
= \\
=\end{array}$ & $\begin{array}{l}\text { SPWC } \\
\text { VPWC } \\
\text { SPHC } \\
\text { SPWC } \\
\text { VPWC }\end{array}$ \\
\hline $\begin{array}{l}\text { FEB } \\
\text { FES }\end{array}$ & $19 \ldots \ldots$ & $\begin{array}{l}0900 \\
1000\end{array}$ & $\begin{array}{l}10 \\
11\end{array}$ & $\begin{array}{r}16400 \\
970\end{array}$ & $\begin{array}{r}53400 \\
3420\end{array}$ & $\begin{array}{r}2360000 \\
8960\end{array}$ & $\begin{array}{l}22 \\
26\end{array}$ & & 23 & $\begin{array}{l}32 \\
53\end{array}$ & $\begin{array}{l}44 \\
71\end{array}$ & $\begin{array}{l}71 \\
82\end{array}$ & & $\begin{array}{l}73 \\
89\end{array}$ & $\begin{array}{l}94 \\
97\end{array}$ & $\begin{array}{r}99 \\
100\end{array}$ & 100 & $=$ & $=$ & $\begin{array}{l}\text { SPHC } \\
\text { VPWC }\end{array}$ \\
\hline
\end{tabular}


11118500 VEMTURA RIVER NEAR VENTURA, CALIF.

LOCATION (revised). --Lat $34^{\circ} 21^{\prime} 08^{\prime \prime}$, Iong $119^{\circ} 18^{\prime} 27^{\prime \prime}$, in southeast corner of Santa Ana Grant, Ventura County, at gaging station $50 \mathrm{ft}$ downs tream from county road bridge at Foster Memorial Park, 0.2 mile downstream from Coyote creek, and 5 dies north of Ventura.

DRAINAGE AREA, --188 sq $\mathrm{mt}$.

PERIOD OF RECORD. - Chemical analyses: October 1966 to September 1969.

Tater temperatures: October 1968 to September 1968

Sediment records: October 1968 to September 1969.

EXTREMES. $--1968-69$ :

Sediment concentrations: Maximum dajly, not determined; minimum daily, no flow for many days.
Sediment discharge: Haximum da11y, 2,220,000 tons (estimated) Jan. 25 ; minimum daily, 0 ton on many days.

REMARKS, --Prtor to June 1969, sampling site yas $450 \mathrm{ft}$ domstream. Sediment discharge estimated Jan. 21, 25, 26, Feb. 23-25. No flow Oct. 1 to Jan. 18. Chemical-quality records furnished by California Department of Water Resources and reviewed by U, S. Geological Survey. CHFMICAL ANALYSES, WATER YEAR OCTOBER 1969 TO SEPTEMBFK 1969

\begin{tabular}{|c|c|c|c|c|c|c|c|c|c|c|c|}
\hline DATE & $\begin{array}{l}\text { TEMPER- } \\
\text { ATURE } \\
\text { IDEG CI }\end{array}$ & $\begin{array}{l}\text { DIS- } \\
\text { SOLVED } \\
\text { OXYGEN } \\
\text { (MG/L) }\end{array}$ & $\begin{array}{l}\text { CAL- } \\
\text { CIUM } \\
\text { ICA) } \\
(M G / L)\end{array}$ & $\begin{array}{l}\text { MAG- } \\
\text { NE- } \\
\text { SIUN } \\
\text { [MG I } \\
\text { (MG/L) }\end{array}$ & $\begin{array}{l}\text { SODIUM } \\
\text { (NA) } \\
\text { (MG/L) }\end{array}$ & $\begin{array}{l}P O- \\
\text { TAS- } \\
\text { SIUM } \\
\text { IKI } \\
\text { (MGOL) }\end{array}$ & $\begin{array}{l}\text { BICAR- } \\
\text { AUNATE } \\
\text { (HCO3) } \\
\text { (MG/L) }\end{array}$ & $\begin{array}{l}\text { CAR- } \\
\text { BONATE } \\
\text { (CO3) } \\
\text { \{MG ILI I }\end{array}$ & $\begin{array}{l}\text { SULFATE } \\
\text { (SOA) } \\
\text { (MG/LI }\end{array}$ & $\begin{array}{l}\text { CHLCl- } \\
\text { O IOE } \\
\text { (CL) } \\
\text { (NGIL) }\end{array}$ & $\begin{array}{l}\text { FLUD- } \\
\text { RIDE } \\
\text { IF I } \\
\text { IMG /LI }\end{array}$ \\
\hline $\begin{array}{l}A P R . \\
21: \cdots \\
J U L Y\end{array}$ & 17 & 8.0 & 134 & 36 & 50 & 3.0 & 270 & 0 & 260 & 47 & .6 \\
\hline $25 \ldots$ & 26 & 16.0 & 68 & 34 & 54 & 2.0 & 95 & 0 & 256 & 50 & .5 \\
\hline OATE & $\begin{array}{l}\text { NITRATE } \\
\text { (NO3) } \\
\text { (NG/L) }\end{array}$ & $\begin{array}{l}\text { RORDN } \\
\text { (B) } \\
(U G / L)\end{array}$ & $\begin{array}{l}\text { DIS- } \\
\text { SOL VED } \\
\text { SOLIDS } \\
\text { IRESI - } \\
\text { OUE AT } \\
\text { IBO CI } \\
\text { IMG ILI }\end{array}$ & $\begin{array}{l}\text { OIS- } \\
\text { SOLVED } \\
\text { SOLIDS } \\
\text { TONS } \\
\text { PER } \\
A C-F T \text { I }\end{array}$ & $\begin{array}{l}\text { HARD- } \\
\text { NESS } \\
\text { (CA,MG) } \\
\text { (MG/L) }\end{array}$ & $\begin{array}{l}\text { NON- } \\
\text { CAR- } \\
\text { BONATE } \\
\text { HARD- } \\
\text { NESS } \\
\text { IMG/LI }\end{array}$ & $\begin{array}{l}\text { PERCENT } \\
\text { SODIUM }\end{array}$ & $\begin{array}{l}\text { SODIUM } \\
\text { AD- } \\
\text { SORP- } \\
\text { TION } \\
\text { RATIR }\end{array}$ & $\begin{array}{l}\text { ALKA- } \\
\text { LINITY } \\
A S \\
\text { CACO3 } \\
\text { (MG/LI }\end{array}$ & $\begin{array}{c}\text { PH } \\
\text { [UNITSI }\end{array}$ & $\begin{array}{l}\text { SPECI- } \\
\text { FIC } \\
\text { COND- } \\
\text { UCTANCE } \\
\text { IMICRI- } \\
\text { MHOSI }\end{array}$ \\
\hline $\begin{array}{l}\text { APR. } \\
211 . . . \\
\text { JULY }\end{array}$ & 39 & 720 & 715 & .97 & 483 & 262 & 18 & 1.0 & 221 & 7.9 & 1040 \\
\hline & 26 & 370 & 574 & .78 & 310 & 232 & 27 & 1.3 & 78 & 9.0 & 820 \\
\hline
\end{tabular}

TEYPERATURz ('C) OF WATER, WATER YEAR CTOBER 1968 TO SEPTEMBER 1968

(ONCE-DAILY MEAASURBKENT)

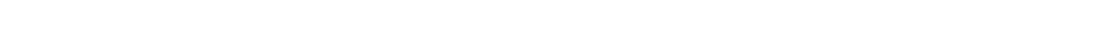
OCTURFR., -

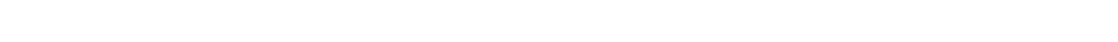

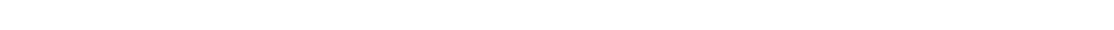

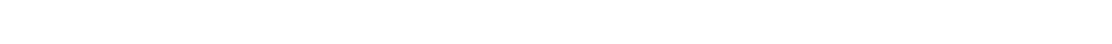
APRIL.... 16 대

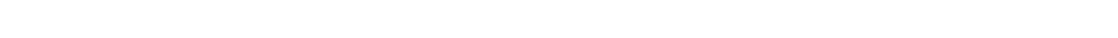
JULҮ.... - A.GUSTAZ̈ 
11118500 VENTURA RIVER NEAR VENTURA, CALIF.--Cont1nued

SUSPENDED-SEDIMENT DISCHARGE, WATER YEAR OCTOBER 1968 TO SEPTEMBER 1969

\begin{tabular}{|c|c|c|c|c|c|c|c|c|c|}
\hline \multirow[b]{2}{*}{ DAY } & \multicolumn{3}{|c|}{ JANUARY } & \multicolumn{3}{|c|}{ FEBRUARY } & \multicolumn{3}{|c|}{ MARCH } \\
\hline & $\begin{array}{l}\text { MEAN } \\
\text { DISCHARGE } \\
\text { ICFSI }\end{array}$ & $\begin{array}{l}\text { MEAN } \\
\text { CONCEN- } \\
\text { TRATION } \\
\text { (MG/L) }\end{array}$ & $\begin{array}{l}\text { SEDIMENT } \\
\text { DISCHARGE } \\
\text { (TONS/DAY) }\end{array}$ & $\begin{array}{l}\text { MEAN } \\
\text { OISCHARGE } \\
\text { (CFS) }\end{array}$ & $\begin{array}{l}\text { MEAN } \\
\text { CONCEN- } \\
\text { TRATION } \\
\text { (MG/L) }\end{array}$ & $\begin{array}{l}\text { SE DIMENT } \\
\text { DISCHARGE } \\
\text { (TONS / DAY) }\end{array}$ & $\begin{array}{l}\text { MEAN } \\
\text { DISCHARGE } \\
\text { (CFS) }\end{array}$ & $\begin{array}{l}\text { MEAN } \\
\text { CONCEN- } \\
\text { TRATIDN } \\
\text { (MG/L) }\end{array}$ & $\begin{array}{l}\text { SEDIMENT } \\
\text { DISCHARGE } \\
\text { (TONS/DAY) }\end{array}$ \\
\hline $\begin{array}{l}1 \\
2\end{array}$ & $\begin{array}{l}D \\
0\end{array}$ & $=$ & $\begin{array}{l}0 \\
0\end{array}$ & $\begin{array}{l}600 \\
500\end{array}$ & $\begin{array}{l}660 \\
500\end{array}$ & $\begin{array}{r}1070 \\
675\end{array}$ & $\begin{array}{l}1300 \\
1100\end{array}$ & $\begin{array}{l}960 \\
750\end{array}$ & $\begin{array}{l}3370 \\
2230\end{array}$ \\
\hline 3 & 0 & -- & 0 & 450 & 420 & 510 & 900 & 660 & 1600 \\
\hline 4 & 0 & -- & 0 & 400 & 440 & 475 & 650 & 824 & 1450 \\
\hline 5 & 0 & 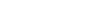 & 0 & 600 & 900 & 1460 & 530 & 940 & 1350 \\
\hline 6 & 0 & -- & 0 & 3500 & 6000 & 56700 & 440 & 1110 & 1320 \\
\hline 7 & 0 & -- & 0 & 1700 & 1500 & 6890 & 410 & 1820 & 2010 \\
\hline 8 & 0 & - & 0 & 1100 & 1300 & 3860 & 390 & 470 & 495 \\
\hline 9 & 0 & -- & 0 & 600 & 1300 & 2110 & 380 & 300 & 308 \\
\hline 10 & 0 & $=$ & 0 & 350 & 1300 & 1230 & 370 & 2050 & 2050 \\
\hline 11 & 0 & -- & 0 & 200 & 1300 & 702 & 360 & 2400 & 2330 \\
\hline 12 & 0 & -- & 0 & 150 & 1300 & 527 & 330 & 2510 & 2240 \\
\hline 13 & 0 & $\cdots$ & 0 & 130 & 1100 & 386 & 270 & 3360 & 2450 \\
\hline 14 & 0 & -- & 0 & 128 & 900 & 311 & 220 & 3800 & 2260 \\
\hline is & 0 & -- & 0 & 127 & 700 & 240 & 195 & 1200 & 632 \\
\hline 16 & 0 & -- & 0 & 126 & 600 & 204 & 170 & 1100 & 505 \\
\hline 17 & 0 & -- & 0 & 125 & 500 & 169 & 150 & 2970 & 1200 \\
\hline 18 & 0 & -- & 0 & 122 & 500 & 165 & 140 & 3200 & 1210 \\
\hline 19 & 1590 & 5070 & 65000 & 119 & 500 & 161 & 130 & 3100 & 1090 \\
\hline 20 & 893 & 2470 & 15600 & 117 & 400 & 126 & 120 & 2900 & 940 \\
\hline 21 & 6800 & -- & 460000 & 115 & 400 & 124 & 110 & 2970 & 882 \\
\hline 22 & 1500 & 3200 & 13000 & 113 & 640 & 195 & 105 & 800 & 227 \\
\hline 23 & 500 & 500 & 675 & 2000 & -. & 42000 & 100 & 700 & 189 \\
\hline 24 & 2000 & 5600 & 30200 & 14000 & -- & 1100000 & 98 & 2570 & 680 \\
\hline 25 & 20000 & - & 2220000 & 17000 & -- & 1600000 & 96 & 2700 & 700 \\
\hline 26 & 13000 & -- & 770000 & 5000 & 7600 & 103000 & 94 & 2820 & 716 \\
\hline 27 & 5000 & 3500 & 47300 & 2300 & 3000 & 18600 & 93 & 2600 & 653 \\
\hline 28 & 2800 & 2500 & 18900 & 1500 & 1600 & 6480 & 92 & 2390 & 594 \\
\hline 29 & 2000 & 1900 & 10300 & - & - & - & 95 & 800 & 205 \\
\hline 30 & 1300 & 1300 & 4560 & -- & -- & -- & 98 & 600 & 159 \\
\hline 31 & 900 & 900 & 2190 & -- & -- & -- & 100 & 1900 & 513 \\
\hline \multirow[t]{5}{*}{ TOTAL } & 58283 & -- & 3657725 & 53172 & -- & 2948370 & 9636 & -- & 36558 \\
\hline & & APRIL & & & MAY & & & JUNE & \\
\hline & & MEAN & & & MEAN & & & MEAN & \\
\hline & MEAN & CONCEN- & SEDIMENT & MEAN & CONCEN- & SEDIMENT & MEAN & CONCEN- & SEDIMENT \\
\hline & DISCHARGE & TRATIDN & DISCHARGE & DISCHARGE & TRATIDN & DISCHARGE & DISCHARGE & TRATION & DI SCHARGE \\
\hline & & & & & & & & & \\
\hline 1 & 105 & 1800 & 510 & 49 & 40 & 5.3 & 28 & 36 & 2.7 \\
\hline 2 & 105 & 1700 & 482 & 49 & 40 & 5.3 & 28 & 36 & 2.7 \\
\hline 3 & 102 & 1670 & 460 & 49 & 40 & 5.3 & 28 & 36 & 2.7 \\
\hline 4 & 100 & 1600 & 432 & 49 & 40 & 5.3 & 28 & 36 & 2.7 \\
\hline 5 & 98 & 600 & 159 & 48 & 35 & 4.5 & 27 & 36 & 2.0 \\
\hline 6 & 96 & 500 & 130 & 47 & 35 & 4.4 & 27 & 36 & 2.6 \\
\hline 7 & 94 & 600 & 152 & 46 & 35 & 4.3 & 27 & 36 & 2.6 \\
\hline ค & 91 & 800 & 197 & 44 & 30 & 3.6 & 27 & 36 & 2.6 \\
\hline 9 & 90 & 830 & 202 & 42 & 30 & 3.4 & 27 & 36 & 2.6 \\
\hline 10 & B8 & 800 & 190 & 41 & 30 & 3.3 & 27 & 36 & 2.6 \\
\hline 11 & 86 & 800 & 186 & 39 & 30 & 3.2 & 27 & 35 & 2.6 \\
\hline 1) & 85 & 800 & 184 & 38 & 30 & 3.1 & 27 & 35 & 2.6 \\
\hline 13 & 84 & 800 & 181 & 37 & 30 & 3.0 & 26 & 35 & 2.5 \\
\hline 14 & 82 & 800 & 177 & 36 & 30 & 2.9 & 26 & 35 & 2.5 \\
\hline 15 & 80 & 800 & 173 & 35 & 30 & 2.8 & 25 & 35 & 2.4 \\
\hline 16 & 77 & 750 & 156 & 35 & 30 & 2.8 & 25 & 35 & 2.4 \\
\hline 17 & 74 & 700 & 140 & 35 & 30 & 2.8 & 21 & 35 & 2.0 \\
\hline 18 & 72 & 700 & 136 & 34 & 30 & 2.8 & 21 & 35 & 2.0 \\
\hline 10 & 70 & 700 & 132 & 33 & 30 & 2.7 & 19 & 35 & 1.8 \\
\hline 20 & 68 & 600 & 110 & 33 & 30 & 2.7 & 17 & 35 & 1.6 \\
\hline 21 & 66 & 600 & 107 & 32 & 32 & 2.8 & 17 & 40 & 1.8 \\
\hline 22 & 65 & 2350 & 412 & 32 & 35 & 3.0 & 13 & 40 & 1.4 \\
\hline 23 & 63 & 600 & 102 & 31 & 35 & 2.9 & 15 & 40 & 1.6 \\
\hline 24 & 61 & 400 & 66 & 31 & 36 & 3.0 & 18 & 40 & 1.9 \\
\hline 25 & $\begin{array}{l}61 \\
58\end{array}$ & 200 & 31 & $\begin{array}{l}31 \\
30\end{array}$ & $\begin{array}{l}36 \\
36\end{array}$ & 2.9 & $\begin{array}{l}18 \\
18\end{array}$ & $\begin{array}{l}40 \\
40\end{array}$ & $\begin{array}{l}1.9 \\
1.9\end{array}$ \\
\hline 26 & 55 & 100 & 15 & 30 & 37 & 3.0 & 19 & 40 & 2.1 \\
\hline 27 & 53 & 80 & 11 & 29 & 37 & 2.9 & 17 & 40 & 1.8 \\
\hline 28 & 51 & 60 & 8.3 & 29 & 37 & 2.9 & is & 40 & 1.6 \\
\hline 27 & so & 40 & 5.4 & 29 & 37 & 2.9 & 13 & 40 & 1.4 \\
\hline $3 v$ & 50 & 40 & 5.4 & 29 & 37 & 2.9 & is & 43 & 1.3 \\
\hline $3 i$ & -- & -- & - & 29 & 37 & 2.9 & - & $\ldots$ & - \\
\hline TOTAL & 2319 & -- & 5252.1 & 1150 & -- & 105.6 & 664 & 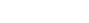 & 65.6 \\
\hline
\end{tabular}


11118500 VENTURA RIVER NEAR VENTURA, CALIF.--CONTInUEd

SUSPENDED-SEDIMENT DISCHARGF, WATER YEAR OCTOBER 1968 TO SEPTEMBER 1969

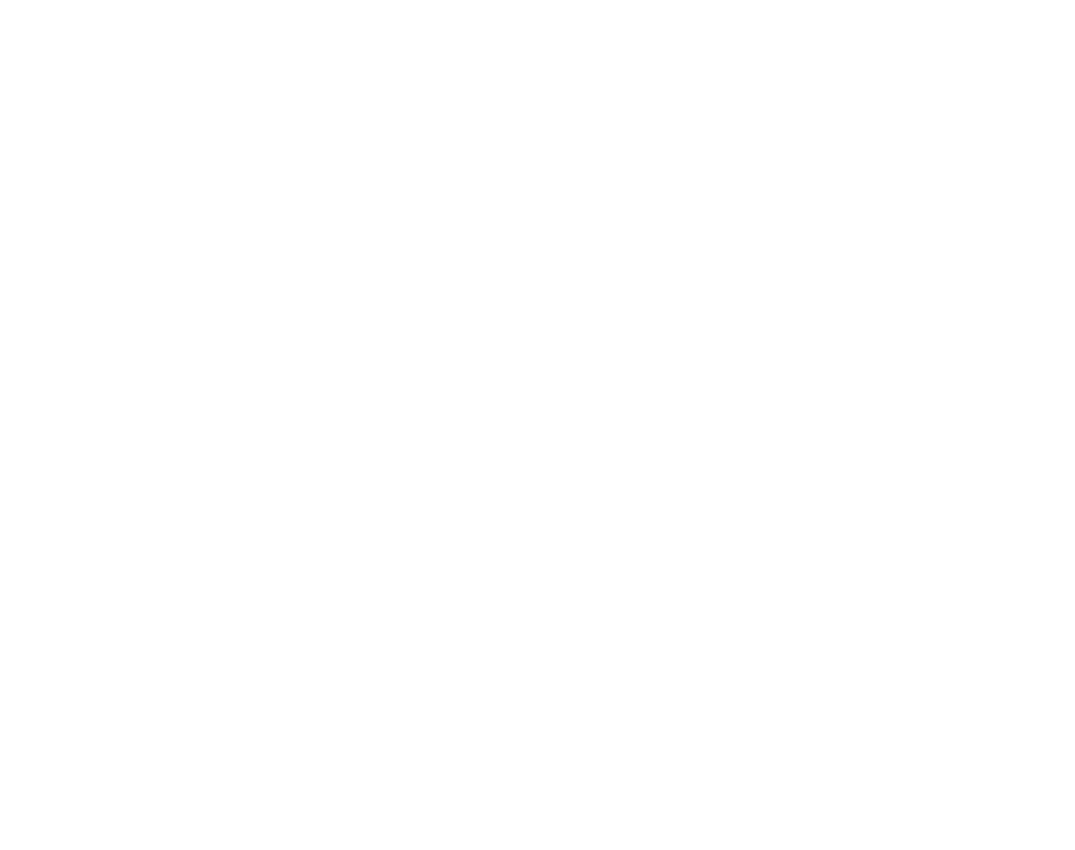

PARTICLE-DISTRIBUTION OF SUSPENDED SEDIMENT, WATER YEAR OCTOBER 1968 TO SEPTEMBER 1969
(METHODS OF ANALYSIS: 8, BDTTUM WITHDRAWAL TUBE; C, CHEMICALLY DISPERSED: N, IN NATIVE WATER: P. PIPET: S, SIEVE: (METHODS OF ANALYSIS: 8, BOTTUM WITHDRAWAL TUBE; C, CHEMICALLY OISPERSED: N, IN NATI
V. VISUAL ACCUMULATIDN TUBE; W, IN OISTILLED WATER)

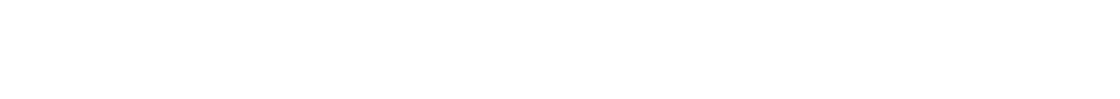

\begin{tabular}{|c|c|c|c|c|c|c|c|c|c|c|c|c|c|c|c|c|c|}
\hline $\begin{array}{l}\text { JAN } \\
\text { JAN } \\
\text { JAN } \\
\text { JAN } \\
\text { JAN }\end{array}$ & $\begin{array}{l}19,1969 \\
20 \ldots \ldots \ldots \\
20 \ldots \ldots \ldots \\
21 \ldots \ldots \ldots \\
24 \ldots \ldots\end{array}$ & 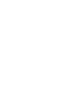 & $\begin{array}{r}152 \\
160 \\
3540 \\
12000 \\
2370\end{array}$ & $\begin{array}{r}197 \\
291 \\
13500 \\
20800 \\
2740\end{array}$ & $\begin{array}{r}81 \\
126 \\
129000 \\
674000 \\
17500\end{array}$ & $\begin{array}{l}62 \\
57 \\
22 \\
18 \\
15\end{array}$ & $\begin{array}{l}83 \\
76 \\
28 \\
22 \\
17\end{array}$ & $\begin{array}{l}92 \\
87 \\
36 \\
34 \\
26\end{array}$ & $\begin{array}{l}94 \\
93 \\
46 \\
45 \\
33\end{array}$ & $\begin{array}{l}95 \\
95 \\
59 \\
58 \\
41\end{array}$ & $\begin{array}{l}97 \\
98 \\
72 \\
71 \\
50\end{array}$ & $\begin{array}{r}98 \\
100 \\
86 \\
88 \\
66\end{array}$ & $\begin{array}{l}99 \\
9- \\
96 \\
97 \\
97\end{array}$ & $\begin{array}{r}100 \\
100 \\
100 \\
99\end{array}$ & $\begin{array}{c}-- \\
-- \\
100\end{array}$ & $\begin{array}{l}-- \\
-- \\
--\end{array}$ & $\begin{array}{l}\text { SBWC } \\
\text { SBWC } \\
\text { VPWC } \\
\text { VPWC } \\
\text { VPWC }\end{array}$ \\
\hline $\begin{array}{l}\text { JAN } \\
\text { JAN } \\
\text { FEB } \\
\text { FEB } \\
\text { FEB }\end{array}$ & $\begin{array}{r}24 \ldots \ldots \ldots \\
26 \ldots \ldots \ldots \\
4 \ldots \ldots \ldots \\
8 \ldots \ldots \ldots\end{array}$ & 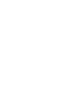 & $\begin{array}{r}4600 \\
14200 \\
404 \\
4160 \\
1070\end{array}$ & $\begin{array}{r}5300 \\
34400 \\
440 \\
7300 \\
1440\end{array}$ & $\begin{array}{r}65800 \\
1320000 \\
480 \\
82000 \\
4160\end{array}$ & $\begin{array}{l}16 \\
14 \\
18 \\
15 \\
30\end{array}$ & $\begin{array}{l}18 \\
18 \\
29 \\
16 \\
37\end{array}$ & $\begin{array}{l}27 \\
24 \\
39 \\
23 \\
52\end{array}$ & $\begin{array}{l}35 \\
31 \\
47 \\
26 \\
67\end{array}$ & $\begin{array}{l}45 \\
42 \\
51 \\
37 \\
83\end{array}$ & $\begin{array}{l}57 \\
52 \\
74 \\
46 \\
93\end{array}$ & $\begin{array}{l}72 \\
72 \\
88 \\
60 \\
98\end{array}$ & $\begin{array}{r}87 \\
89 \\
99 \\
84 \\
100\end{array}$ & $\begin{array}{r}97 \\
98 \\
100 \\
97 \\
--\end{array}$ & $\begin{array}{r}100 \\
100 \\
100 \\
--\end{array}$ & $\begin{array}{l}-- \\
-- \\
-- \\
--\end{array}$ & $\begin{array}{l}\text { VPWC } \\
\text { SPWC } \\
\text { VBWC } \\
\text { VPWC } \\
\text { VPWC }\end{array}$ \\
\hline $\begin{array}{l}F E B \\
F \in B \\
\text { MAR }\end{array}$ & $\begin{array}{l}11 \ldots \\
24 \ldots \\
12 \ldots\end{array}$ & 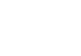 & $\begin{array}{r}184 \\
19600 \\
325\end{array}$ & $\begin{array}{r}1560 \\
29300 \\
4840\end{array}$ & $\begin{array}{r}775 \\
1550000 \\
4250\end{array}$ & $\begin{array}{l}28 \\
16 \\
25\end{array}$ & $\begin{array}{l}30 \\
16 \\
36\end{array}$ & $\begin{array}{l}40 \\
21 \\
57\end{array}$ & $\begin{array}{l}57 \\
32 \\
69\end{array}$ & $\begin{array}{l}68 \\
43 \\
85\end{array}$ & $\begin{array}{l}74 \\
54 \\
95\end{array}$ & $\begin{array}{r}60 \\
72 \\
100\end{array}$ & $\begin{array}{l}96 \\
92 \\
--\end{array}$ & $\begin{array}{l}99 \\
99 \\
-9\end{array}$ & $\begin{array}{r}100 \\
100 \\
--\end{array}$ & $\begin{array}{l}-- \\
-\end{array}$ & $\begin{array}{l}\text { VPWC } \\
\text { SPWE } \\
\text { VPWC }\end{array}$ \\
\hline
\end{tabular}


LOCATION.--Lat $34^{\circ} 38^{\circ} 33^{\prime \prime}$, long $120^{\circ} 34^{\prime} 13^{\prime \prime}$, In Guadalupe Grant, Santa Barbara County, at gaging etation on bridge on State H1 ghwey $1,0.3 \mathrm{mlle}$ north of Guada lupe and $4.3 \mathrm{miles}$ upstrean from mouth.

DRAINAGE AREA, $-1,741$ \$q $\mathrm{m}$.

PERIOD OF RECORD. -- Wa ter temperature s: October 1968 to September 1969

Sediment records: October 1968 to September 1969.

EXTREMES. $--1988-8 \theta$ :

Sediment concentrations: Xaximum da1ly, $59,200 \mathrm{mg} / 1$ Fob. 25; minimum da1ly, no flow for many daye.

Sediment discharge: Maximum da11y, 2,030,000 tons Feb, 23; minimum daily, o ton on many daye.

RMMARKs, -No flow Oct. 1 to Jan. 18, Mar. 23, 24, Mar. 27 to Apr. 1, Apr, 15 to Sept. 30. TEIAPBRATURE ( ${ }^{\circ} \mathrm{C}$ ) OF WATER, MATER YBAR OCTOBER 1868 TO SEPTBUBER 1968 (ONCE-DAILY GGASUREUERT)

MANTH $123445679910111213141516171819202122 \quad 2324 \quad 252627282930 \quad 31$ AGE OCTURER., NUVEMAER, DFCEMAFR, -.

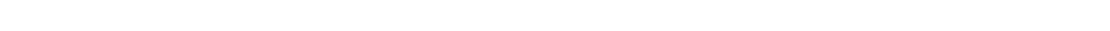

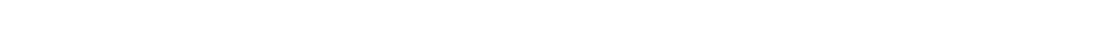
APRIL.... -. MAY..... JUNE.....

JULY..... - AUGUST:B:

SUSPENDED-SEDIMENT DISCHARGE, WATER YEAR OCTOBER 1968 TO SEPTEMBER 1969

\begin{tabular}{|c|c|c|c|c|c|c|c|c|c|}
\hline DAY & $\begin{array}{l}\text { MEAN } \\
\text { OI SCHARGE } \\
\text { (CFS) }\end{array}$ & $\begin{array}{l}\text { JANUARY } \\
\text { MEAN } \\
\text { CONCEN- } \\
\text { THATION } \\
\text { IMGILI }\end{array}$ & $\begin{array}{l}\text { SEDIMENT } \\
\text { DISCHARGE } \\
\text { (TONS/DAY) }\end{array}$ & $\begin{array}{l}\text { MEAN } \\
\text { DI SCHARGE } \\
\text { (CFS) }\end{array}$ & $\begin{array}{l}\text { FEARUAQY } \\
\text { MEAN } \\
\text { CONCEN- } \\
\text { TRATION } \\
\text { (YGIL) }\end{array}$ & $\begin{array}{l}\text { SEDIMENT } \\
\text { DISCHARGE } \\
\text { (TONS/DAY) }\end{array}$ & $\begin{array}{l}\text { MEAN } \\
\text { DISCHARGE } \\
\text { (CFS) }\end{array}$ & $\begin{array}{l}\text { MARCH } \\
\text { MEAN } \\
\text { CUNCEN- } \\
\text { TRATION } \\
\text { (MGIL) }\end{array}$ & $\begin{array}{l}\text { SEDIMENT } \\
\text { DISCHARGE } \\
\text { (TONS/DAY) }\end{array}$ \\
\hline $\begin{array}{l}1 \\
2 \\
3 \\
4 \\
5\end{array}$ & $\begin{array}{l}0 \\
0 \\
0 \\
0 \\
0\end{array}$ & $\begin{array}{l}= \\
=- \\
=-\end{array}$ & $\begin{array}{l}0 \\
0 \\
0 \\
0 \\
0\end{array}$ & $\begin{array}{l}60 \\
40 \\
20 \\
5.0 \\
0\end{array}$ & $\begin{array}{r}11000 \\
11000 \\
10000 \\
9500 \\
0\end{array}$ & $\begin{array}{r}1780 \\
1190 \\
540 \\
128 \\
0\end{array}$ & $\begin{array}{l}4920 \\
5280 \\
4140 \\
4260 \\
3750\end{array}$ & $\begin{array}{l}51500 \\
39500 \\
26400 \\
16000 \\
14800\end{array}$ & $\begin{array}{l}884000 \\
561000 \\
297000 \\
185000 \\
154000\end{array}$ \\
\hline $\begin{array}{r}6 \\
7 \\
9 \\
9 \\
10\end{array}$ & $\begin{array}{l}0 \\
0 \\
0 \\
0 \\
0\end{array}$ & $\begin{array}{l}= \\
= \\
= \\
=\end{array}$ & $\begin{array}{l}0 \\
0 \\
0 \\
0 \\
0\end{array}$ & $\begin{array}{r}432 \\
1730 \\
898 \\
300 \\
167\end{array}$ & $\begin{array}{l}23200 \\
27800 \\
16500 \\
12000 \\
12000\end{array}$ & $\begin{array}{r}44700 \\
131000 \\
44900 \\
9720 \\
5410\end{array}$ & $\begin{array}{l}2240 \\
1300 \\
1690 \\
1410 \\
1190\end{array}$ & $\begin{array}{r}18000 \\
13000 \\
20000 \\
9500 \\
13000\end{array}$ & $\begin{array}{r}109000 \\
45600 \\
91300 \\
36200 \\
41800\end{array}$ \\
\hline $\begin{array}{l}11 \\
22 \\
13 \\
14 \\
15\end{array}$ & $\begin{array}{l}0 \\
0 \\
0 \\
0 \\
0\end{array}$ & $\begin{array}{l}= \\
=- \\
= \\
=\end{array}$ & $\begin{array}{l}0 \\
0 \\
0 \\
0 \\
0\end{array}$ & $\begin{array}{l}114 \\
82 \\
27 \\
5.2 \\
3.0\end{array}$ & $\begin{array}{r}10000 \\
8600 \\
7300 \\
9700 \\
10000\end{array}$ & $\begin{array}{r}3080 \\
1900 \\
532 \\
136 \\
81\end{array}$ & $\begin{array}{r}1040 \\
548 \\
446 \\
614 \\
350\end{array}$ & $\begin{array}{l}9000 \\
7500 \\
4800 \\
5200 \\
7400\end{array}$ & $\begin{array}{l}25300 \\
11100 \\
5780 \\
8620 \\
6990\end{array}$ \\
\hline $\begin{array}{l}16 \\
17 \\
10 \\
19 \\
20\end{array}$ & $\begin{array}{r}0 \\
0 \\
0 \\
16 \\
389\end{array}$ & $\begin{array}{r}=- \\
1130 \\
16900\end{array}$ & $\begin{array}{r}0 \\
0 \\
0 \\
883 \\
\times 3400\end{array}$ & $\begin{array}{l}48 \\
.60 \\
1.9 \\
5.2 \\
24\end{array}$ & $\begin{array}{l}12000 \\
13000 \\
17000 \\
13000 \\
10300\end{array}$ & $\begin{array}{r}1560 \\
21 \\
87 \\
183 \\
664\end{array}$ & $\begin{array}{r}200 \\
120 \\
80 \\
30 \\
20\end{array}$ & $\begin{array}{l}9300 \\
7700 \\
6800 \\
5500 \\
3000\end{array}$ & $\begin{array}{l}5020 \\
2490 \\
1100 \\
446 \\
162\end{array}$ \\
\hline $\begin{array}{l}21 \\
22 \\
23 \\
24 \\
25\end{array}$ & $\begin{array}{r}2220 \\
125 \\
57 \\
25 \\
8540\end{array}$ & $\begin{array}{l}29400 \\
23100 \\
15400 \\
14000 \\
50200\end{array}$ & $\begin{array}{r}238000 \\
46800 \\
2490 \\
1020 \\
1520000\end{array}$ & $\begin{array}{r}34 \\
49 \\
165 \\
3670 \\
11700\end{array}$ & $\begin{array}{r}7400 \\
13600 \\
20300 \\
36200 \\
59200\end{array}$ & $\begin{array}{r}686 \\
1870 \\
12500 \\
510000 \\
2030000\end{array}$ & $\begin{array}{l}14 \\
1.8 \\
0 \\
0 \\
.30\end{array}$ & $\begin{array}{r}5000 \\
3100 \\
=- \\
4900\end{array}$ & $\begin{array}{c}189 \\
15 \\
0 \\
0 \\
4.0\end{array}$ \\
\hline $\begin{array}{l}26 \\
27 \\
28 \\
29 \\
30 \\
31\end{array}$ & $\begin{array}{r}7940 \\
2330 \\
674 \\
299 \\
179 \\
80\end{array}$ & $\begin{array}{l}49600 \\
35000 \\
20500 \\
14300 \\
12000 \\
11000\end{array}$ & $\begin{array}{r}1080000 \\
246000 \\
38700 \\
11600 \\
5850 \\
2380\end{array}$ & $\begin{array}{r}4600 \\
3490 \\
4230 \\
=- \\
=-\end{array}$ & $\begin{array}{r}28000 \\
25500 \\
52600 \\
=- \\
=-\end{array}$ & $\begin{array}{r}355000 \\
236000 \\
620000 \\
- \\
=\end{array}$ & $\begin{array}{l}0.40 \\
0 \\
0 \\
0 \\
0\end{array}$ & $\begin{array}{c}4600 \\
= \\
= \\
= \\
=\end{array}$ & $\begin{array}{l}5.0 \\
0 \\
0 \\
0 \\
0 \\
0\end{array}$ \\
\hline UTAL & 23474 & $-\infty$ & 3217123 & 31900.90 & -- & 4013668 & 33624.50 & $\cdots$ & 2272121.0 \\
\hline
\end{tabular}


11141000 SANTA Karia RIVER AT GUADALUPE, CALIF.--Cont1nued SUSPENDED-SEDIMENT DISCHARGE, WATER YEAR DCTOBER 1968 TD SEPTEMBER 1969

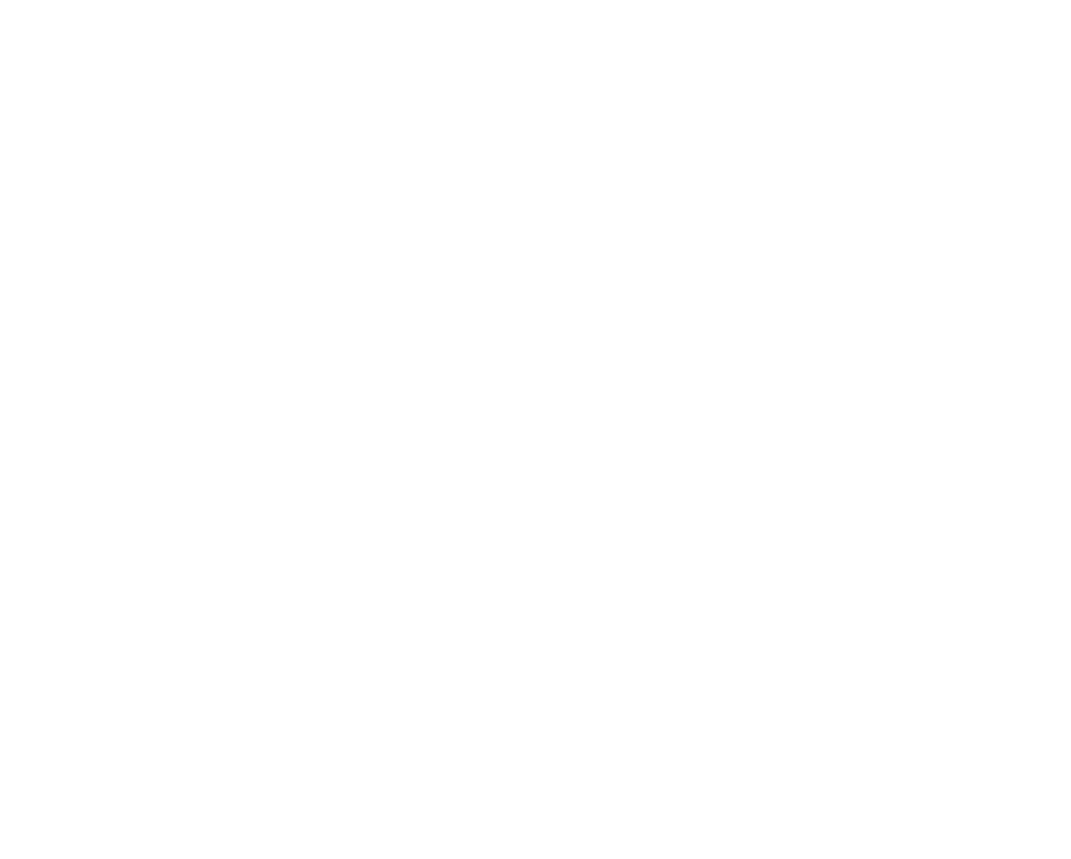

PARTICLE-SIZE DISTRIBUTION DF SUSPENDED SEDIMENT, WATER YEAR OCTOBER 1968 TO SEPTEMBER 1969
(METHDDS OF ANALYSIS: B, BOTTOM WITHDRAMAL TUBE: C, CHEYICALLY DISPERSED; N, IN NATIVE WATER: P. PIPET; S, SIEVE; V. VISUAL ACCUMULATION TUBE; W. IN DISTILLEO WATER ?

$$
\begin{aligned}
& \text { WATFR } \\
& \text { TEM- } \\
& \text { PERA- } \\
& \text { TURE }
\end{aligned}
$$

DATE IIME ( $C$ )

JAN 20, 1969091011

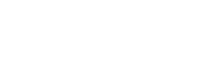
FEQ $7 \ldots \ldots 15001$

FEB $13 \ldots \ldots .0930$ FEB $25 \ldots \ldots 17151$ FEB $27 \ldots \ldots 174512$ MAK $4 \ldots \ldots$ C C $45=-$
parTICLE SIzE CONCEN-SEOIMENT PERCENT FINER THAN THE SIZE (IN MILLIMETERSI INCICATED DF

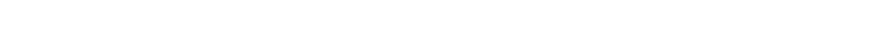

$\begin{array}{rrrrrrr}1750 & 24200 & 114000 & 38 & 44 & 55 & 71 \\ 4140 & 43900 & 491000 & 26 & 29 & 35 & 47 \\ 716 & 19100 & 36900 & 30 & 38 & 57 & 7 \\ 284 & 13900 & 10700 & 30 & 35 & 45 & 58 \\ 1270 & 19000 & 65200 & 21 & 26 & 32 & 44 \\ 30 & 7400 & 599 & 43 & 56 & 73 & 85 \\ 7920 & 63100 & 1350000 & 14 & 15 & 19 & 26 \\ 2400 & 29800 & 193000 & 17 & 21 & 27 & 37 \\ 4330 & 16700 & 195000 & 11 & 13 & 17 & 22\end{array}$

$$
\begin{array}{rrrrrrrrr}
71 & 78 & 82 & 90 & 98 & 100 & -- & -- & \text { VPWC } \\
47 & 57 & 64 & 75 & 91 & 97 & 100 & -- & \text { SPWC } \\
73 & 87 & 95 & 99 & 100 & -- & -- & -- & \text { VPWC } \\
58 & 70 & 82 & 95 & 99 & 100 & -- & -- & \text { VPWC } \\
44 & 59 & 75 & 91 & 98 & 100 & -- & -- & \text { VPWC } \\
85 & 90 & 96 & 100 & -- & -- & -- & -- & \text { VPWC }
\end{array}
$$

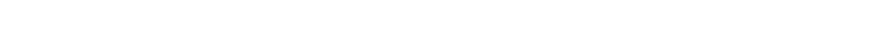


11141150 ARROYO GRANDE ABOVE PHOENIX CREEK, NEAR ARROYO GRANDE, CALIF.

LOCATION, --Lat $35^{\circ} 11^{\prime} 03^{\prime \prime}$, long $120^{\circ} 26^{\prime} 11^{\prime \prime}$, In Arroyo Grande Grant, San Luis Obispo County, at gaging station at county road bridge, $100 \mathrm{ft}$ upstream from Phoenix Creek and 8.8 miles northeast of Arroyo Grande.

DRAI NAGE AREA. $\rightarrow-13.4 \mathrm{sq} \mathrm{mi}$.

PERIOD OF RECORD, -- Water temperatures: October 1967 to September 1969.

Sediment records: October 1966 to September 1967 (periodic), October 1967 to September 1969.

EXTREMES. --1968-69:

Sediment concentrations: Maximum daily, 49,300 mg/1 Jan. 25; mintmum daily, $2 \mathrm{mg} / 1$ on several days during October and November.

Sediment discharge: Maximum daily, 69,700 tons Jan. 25; minimum daily, 0 ton on several days during October.

Period of record (1967-69):

Sediment concentrations: Maximum daily, 49,300 mg/l Jan, 25, 1969; minimum daily, $1 \mathrm{mg} / 1$ on several days in 1967 and 1968

Sediment discharge: Maximum dałly, 69,700 tons Jan. 25, 1969; minimum da1ly, 0 ton on many days in 1967 and 1968 .

REMARKS. - Total sediment load was sampled at control at gage Oct. 1 to Jan. 20 when control was damaged. Samples from Jan. 21 to Sept. 25 represent suspended sediment only. Total sediment discharge and concentration t1on, and suspended-sediment samples. Control was rebuilt and total-sediment discharge was sampled from Sept. 26 to end of water year.

TEMPERATURE $\left({ }^{\circ} \mathrm{C}\right)$ OF WATER, WATER YEAR OCTOBER 196B TO SEPTEMBER 1969 (ONCE-DAILY MEASUREMENT)

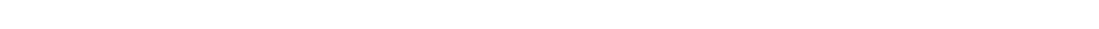

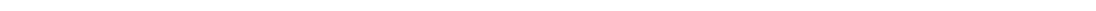

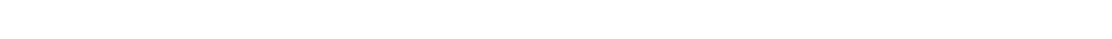

JAVUARY.. -- -- -- --

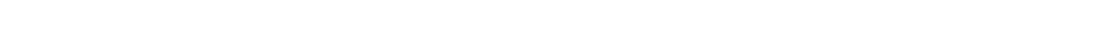

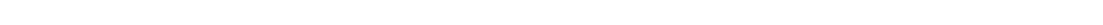

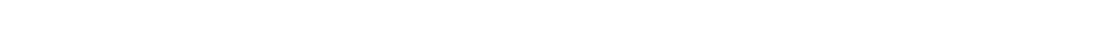

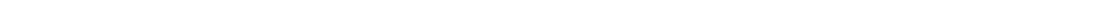
AUGUST...

TOTAL SEDIMENT DISCHARGE, WATER YEAR OCTOBER 1968 TO SEPTEMBER 1969

OC TOBER DISCHARGE
(CFS)

MEAN CONCEN- TOTAL, TRATION DISCHARGE (MGLL) (TONS LDAY)

\section{.82}

.89

.84

.82

11
16
11
6

3

$$
\begin{aligned}
& .02 \\
& .04 \\
& .02 \\
& .01 \\
& .01
\end{aligned}
$$

31.46

rOTAL
NOVEMBER

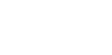

MEAN TOTAL
CONCEN- SEDIMEN TRATION DISCHARG
(MGIL) (TONS/DAY (MG/L)

1.0
1.0
1.6
1.1

2
2
24
5
5

.01
.01
.14
.01

1.0

1.0
1.0
1.0

1.0

1.0

1.1

1.1

1.3

1.9

1.5

1.1
1.1
1.1

1.0

1.0
1.1

1.1

1.1
1.1

.04

.02

.04
.02
.01

1.1
1.1
1.1

10
21
15
6
3
3
3
3
3
3
194
14
8
5
4
4
4
3
3
3
4
5
5
5
4
4
--

.03

.03
.06

.04
.02

.01

.01
.01
.01
.01

.01
1.2

.06

.02

.01
.01

.01

.01
.02
.01
.01

.01
.01

.01

.01

.01

.01
.01
.2

33.9

1.79

OECEMBER

MEAN CONCEN- TOTAL ISCHARGE TRATION SEDIMENT (CFS) (MGIL) (TONS/DAY)

$\begin{array}{lll}1.1 & 4 & .01 \\ 1.1 & 4 & .01 \\ 1.1 & 4 & .01 \\ 1.1 & 4 & .01 \\ 1.1 & 4 & .01\end{array}$

1.1

1.1

1.1
1.1
2.0

4
4
4
4

2.4

1.4

1.7

2. 0

1.8
1.5
1.4
1.4

1.4

1.4

1.4
1.4
1.5

1.8

2.3

1.5

1.8
1.7
1.7

1.7
1.7

150

27

45
25 
11141150 ARROYO GRANDE ABOVE PHOENIX CREEK, NEAR ARROYO GRANDE, CALIF.--CONTINUEd TOTAL SEDIMENT DISCHARGE, WATER YEAR OCTOBER 1968 TO SEPTEMBER 1969

\begin{tabular}{|c|c|c|c|c|c|c|c|c|c|}
\hline \multirow[b]{2}{*}{ DAY } & \multicolumn{3}{|c|}{ JANUARY } & \multicolumn{3}{|c|}{ FEBRUARY } & \multicolumn{3}{|c|}{ MARCH } \\
\hline & $\begin{array}{l}\text { MEAN } \\
\text { DISCHARGE } \\
\text { (CFS) }\end{array}$ & $\begin{array}{l}\text { MEAN } \\
\text { CONCEN- } \\
\text { TRATION } \\
\text { (MG/LI) }\end{array}$ & $\begin{array}{l}\text { TOTAL } \\
\text { SEDIMENT } \\
\text { DISCHARGE } \\
\text { (TONS/DAY) }\end{array}$ & $\begin{array}{l}\text { MEAN } \\
\text { DISCHARGE } \\
\text { (CFS) }\end{array}$ & $\begin{array}{l}\text { MEAN } \\
\text { CONCEN- } \\
\text { IRATION } \\
\text { (MG/LI) }\end{array}$ & $\begin{array}{l}\text { TOTAL } \\
\text { SEDIMENT } \\
\text { DISCHARGE } \\
\text { (TONS/DAY) }\end{array}$ & $\begin{array}{l}\text { MEAN } \\
\text { OISCHARGE } \\
\text { (CFS) }\end{array}$ & $\begin{array}{l}\text { MEAN } \\
\text { CONCEN- } \\
\text { TRATION } \\
\text { (MG/L) }\end{array}$ & $\begin{array}{l}\text { TOTAL } \\
\text { SEDIMENT } \\
\text { DISCHARGE } \\
\text { (TONS/DAY) }\end{array}$ \\
\hline $\begin{array}{l}1 \\
2 \\
3 \\
4 \\
5\end{array}$ & $\begin{array}{l}1.5 \\
1.5 \\
1.5 \\
1.5 \\
1.5\end{array}$ & $\begin{array}{l}70 \\
69 \\
65 \\
60 \\
51\end{array}$ & $\begin{array}{l}.28 \\
.28 \\
.26 \\
.24 \\
.21\end{array}$ & $\begin{array}{l}16 \\
13 \\
11 \\
14 \\
35\end{array}$ & $\begin{array}{l}2270 \\
1910 \\
1720 \\
1900 \\
9150\end{array}$ & $\begin{array}{r}98 \\
87 \\
51 \\
72 \\
865\end{array}$ & $\begin{array}{l}80 \\
60 \\
45 \\
35 \\
28\end{array}$ & $\begin{array}{r}23900 \\
16000 \\
11400 \\
8250 \\
7040\end{array}$ & $\begin{array}{r}5160 \\
2590 \\
1390 \\
780 \\
532\end{array}$ \\
\hline $\begin{array}{r}6 \\
7 \\
8 \\
9 \\
10\end{array}$ & $\begin{array}{l}1.5 \\
1.5 \\
1.5 \\
1.5 \\
1.5\end{array}$ & $\begin{array}{l}45 \\
44 \\
47 \\
53 \\
65\end{array}$ & $\begin{array}{l}.18 \\
.18 \\
.19 \\
.21 \\
.26\end{array}$ & $\begin{array}{l}70 \\
50 \\
35 \\
26 \\
23\end{array}$ & $\begin{array}{r}21300 \\
9780 \\
7560 \\
5210 \\
4320\end{array}$ & $\begin{array}{r}4030 \\
1320 \\
716 \\
366 \\
268\end{array}$ & $\begin{array}{l}23 \\
21 \\
19 \\
18 \\
23\end{array}$ & $\begin{array}{l}6010 \\
5310 \\
5500 \\
8020 \\
8520\end{array}$ & $\begin{array}{l}373 \\
301 \\
282 \\
390 \\
529\end{array}$ \\
\hline $\begin{array}{l}11 \\
12 \\
13 \\
14 \\
15\end{array}$ & $\begin{array}{l}1.6 \\
1.7 \\
2.7 \\
3.3 \\
1.9\end{array}$ & $\begin{array}{r}70 \\
70 \\
185 \\
251 \\
38\end{array}$ & $\begin{array}{l}.30 \\
.32 \\
2.0 \\
2.7 \\
.19\end{array}$ & $\begin{array}{l}19 \\
17 \\
14 \\
15 \\
20\end{array}$ & $\begin{array}{l}3700 \\
3640 \\
3390 \\
3580 \\
7070\end{array}$ & $\begin{array}{l}190 \\
167 \\
128 \\
145 \\
382\end{array}$ & $\begin{array}{l}21 \\
18 \\
20 \\
16 \\
14\end{array}$ & $\begin{array}{l}7460 \\
6130 \\
4780 \\
3590 \\
4050\end{array}$ & $\begin{array}{l}423 \\
298 \\
258 \\
155 \\
153\end{array}$ \\
\hline $\begin{array}{l}16 \\
17 \\
18 \\
19 \\
20\end{array}$ & $\begin{array}{r}1.8 \\
1.7 \\
7.3 \\
116 \\
45\end{array}$ & $\begin{array}{r}17 \\
9 \\
247 \\
10300 \\
4520\end{array}$ & $\begin{array}{l}.08 \\
.04 \\
8310^{.9} \\
1410\end{array}$ & $\begin{array}{l}16 \\
12 \\
13 \\
16 \\
15\end{array}$ & $\begin{array}{l}8450 \\
6700 \\
6410 \\
8870 \\
6400\end{array}$ & $\begin{array}{l}365 \\
217 \\
225 \\
383 \\
259\end{array}$ & $\begin{array}{l}14 \\
13 \\
13 \\
12 \\
12\end{array}$ & $\begin{array}{l}4600 \\
4760 \\
4640 \\
4480 \\
4510\end{array}$ & $\begin{array}{l}174 \\
167 \\
163 \\
145 \\
146\end{array}$ \\
\hline $\begin{array}{l}21 \\
22 \\
23 \\
24 \\
25\end{array}$ & $\begin{array}{r}139 \\
21 \\
14 \\
86 \\
391\end{array}$ & $\begin{array}{r}16400 \\
5330 \\
3490 \\
11100 \\
49300\end{array}$ & $\begin{array}{r}8150 \\
302 \\
132 \\
4340 \\
69700\end{array}$ & $\begin{array}{r}14 \\
20 \\
31 \\
165 \\
184\end{array}$ & $\begin{array}{r}4290 \\
3780 \\
21400 \\
40300 \\
33400\end{array}$ & $\begin{array}{r}162 \\
204 \\
2060 \\
24400 \\
16600\end{array}$ & $\begin{array}{l}16 \\
14 \\
12 \\
12 \\
12\end{array}$ & $\begin{array}{l}5760 \\
5790 \\
4100 \\
3020 \\
2720\end{array}$ & $\begin{array}{r}249 \\
219 \\
133 \\
98 \\
88\end{array}$ \\
\hline $\begin{array}{l}26 \\
27 \\
28 \\
29 \\
30 \\
31\end{array}$ & $\begin{array}{r}283 \\
150 \\
90 \\
60 \\
30 \\
20\end{array}$ & $\begin{array}{r}41000 \\
23700 \\
17900 \\
11200 \\
7670 \\
4570\end{array}$ & $\begin{array}{r}41800 \\
9600 \\
4350 \\
1810 \\
621 \\
247\end{array}$ & $\begin{array}{r}140 \\
80 \\
100 \\
-- \\
-- \\
--\end{array}$ & $\begin{array}{r}17800 \\
11400 \\
32100 \\
=- \\
--\end{array}$ & $\begin{array}{r}6730 \\
2460 \\
8670 \\
- \\
- \\
--\end{array}$ & $\begin{array}{l}11 \\
11 \\
11 \\
10 \\
10 \\
10\end{array}$ & $\begin{array}{l}3000 \\
3600 \\
3500 \\
2810 \\
2440 \\
2220\end{array}$ & $\begin{array}{r}89 \\
107 \\
104 \\
76 \\
66 \\
60\end{array}$ \\
\hline TOTAL & 1482.0 & -- & 148788.82 & 1184 & -- & 71598 & 634 & -- & 15698 \\
\hline & & APRIL & & & MAY & & & JUNE & \\
\hline DAY & $\begin{array}{l}\text { MEAN } \\
\text { DISCHARGE } \\
\text { (CFS) }\end{array}$ & $\begin{array}{l}\text { MEAN } \\
\text { CONCEN- } \\
\text { IRATION } \\
\text { (MG/L) }\end{array}$ & $\begin{array}{l}\text { TOTAL } \\
\text { SEDIMENT } \\
\text { DISCHARGE } \\
\text { (TONS/DAY) }\end{array}$ & $\begin{array}{l}\text { MEAN } \\
\text { DISCHARGE } \\
\text { (CFS) }\end{array}$ & $\begin{array}{l}\text { MEAN } \\
\text { CONCEN- } \\
\text { TRATION } \\
\text { IMG/L) }\end{array}$ & $\begin{array}{l}\text { TOTAL } \\
\text { SEDIMENT } \\
\text { DISCHARGE } \\
\text { (TONS/DAY) }\end{array}$ & $\begin{array}{l}\text { MEAN } \\
\text { DISCHARGE } \\
\text { (CFS) }\end{array}$ & $\begin{array}{l}\text { MEAN } \\
\text { CONCEN- } \\
\text { IRATION } \\
\text { (MG/L) }\end{array}$ & $\begin{array}{l}\text { TOTAL } \\
\text { SEDIMENT } \\
\text { DISCHARGE } \\
\text { (TONS/DAY) }\end{array}$ \\
\hline $\begin{array}{l}1 \\
2 \\
3 \\
4 \\
5\end{array}$ & $\begin{array}{l}11 \\
14 \\
19 \\
16 \\
22\end{array}$ & $\begin{array}{l}2320 \\
2880 \\
3800 \\
4170 \\
4950\end{array}$ & $\begin{array}{r}69 \\
109 \\
195 \\
180 \\
294\end{array}$ & $\begin{array}{l}2.4 \\
2.4 \\
2.3 \\
2.2 \\
2.2\end{array}$ & $\begin{array}{l}772 \\
772 \\
757 \\
741 \\
741\end{array}$ & $\begin{array}{l}5.0 \\
5.0 \\
4.7 \\
4.4 \\
4.4\end{array}$ & $\begin{array}{l}1.7 \\
1.7 \\
1.7 \\
1.7 \\
1.7\end{array}$ & $\begin{array}{l}436 \\
436 \\
479 \\
501 \\
545\end{array}$ & $\begin{array}{l}2.0 \\
2.0 \\
2.2 \\
2.3 \\
2.5\end{array}$ \\
\hline $\begin{array}{r}6 \\
7 \\
8 \\
9 \\
10\end{array}$ & $\begin{array}{l}14 \\
9.6 \\
8.2 \\
7.4 \\
6.8\end{array}$ & $\begin{array}{l}4710 \\
4280 \\
3660 \\
2800 \\
2120\end{array}$ & $\begin{array}{r}178 \\
111 \\
81 \\
56 \\
39\end{array}$ & $\begin{array}{l}2.1 \\
2.1 \\
2.0 \\
2.0 \\
1.9\end{array}$ & $\begin{array}{l}741 \\
741 \\
704 \\
648 \\
604\end{array}$ & $\begin{array}{l}4.2 \\
4.2 \\
3.8 \\
3.5 \\
3.1\end{array}$ & $\begin{array}{l}1.7 \\
1.8 \\
1.9 \\
2.0 \\
2.5\end{array}$ & $\begin{array}{l}566 \\
576 \\
604 \\
592 \\
622\end{array}$ & $\begin{array}{l}2.6 \\
2.8 \\
3.1 \\
3.2 \\
4.2\end{array}$ \\
\hline $\begin{array}{l}11 \\
12 \\
13 \\
14 \\
15\end{array}$ & $\begin{array}{l}6.0 \\
5.4 \\
4.8 \\
4.5 \\
4.2\end{array}$ & $\begin{array}{l}1730 \\
1510 \\
1310 \\
1320 \\
1320\end{array}$ & $\begin{array}{l}28 \\
22 \\
17 \\
16 \\
15\end{array}$ & $\begin{array}{l}1.9 \\
1.9 \\
1.8 \\
1.8 \\
1.8\end{array}$ & $\begin{array}{r}663 \\
760 \\
906 \\
1150 \\
1230\end{array}$ & $\begin{array}{l}3.4 \\
3.9 \\
4.4 \\
5.6 \\
6.0\end{array}$ & $\begin{array}{l}5.0 \\
4.8 \\
4.7 \\
4.8 \\
4.5\end{array}$ & $\begin{array}{l}889 \\
849 \\
788 \\
733 \\
675\end{array}$ & $\begin{array}{l}12 \\
11 \\
10 \\
9.1 \\
8.2\end{array}$ \\
\hline $\begin{array}{l}16 \\
17 \\
18 \\
19 \\
20\end{array}$ & $\begin{array}{l}4.2 \\
4.3 \\
4.2 \\
3.7 \\
3.3\end{array}$ & $\begin{array}{l}1320 \\
1550 \\
1760 \\
1700 \\
1680\end{array}$ & $\begin{array}{l}15 \\
18 \\
20 \\
17 \\
15\end{array}$ & $\begin{array}{l}1.8 \\
1.7 \\
1.7 \\
1.7 \\
1.7\end{array}$ & $\begin{array}{l}864 \\
523 \\
436 \\
370 \\
370\end{array}$ & $\begin{array}{l}4.2 \\
2.4 \\
2.0 \\
1.7 \\
1.7\end{array}$ & $\begin{array}{l}4.5 \\
4.4 \\
4.3 \\
4.2 \\
4.1\end{array}$ & $\begin{array}{l}642 \\
615 \\
603 \\
582 \\
569\end{array}$ & $\begin{array}{l}7.8 \\
7.3 \\
7.0 \\
6.6 \\
6.3\end{array}$ \\
\hline $\begin{array}{l}21 \\
22 \\
23 \\
24 \\
25\end{array}$ & $\begin{array}{l}3.1 \\
3.1 \\
3.4 \\
3.3 \\
3.2\end{array}$ & $\begin{array}{l}1790 \\
1670 \\
1630 \\
1460 \\
1390\end{array}$ & $\begin{array}{l}15 \\
14 \\
15 \\
13 \\
12\end{array}$ & $\begin{array}{l}1.7 \\
1.7 \\
1.7 \\
1.7 \\
1.7\end{array}$ & $\begin{array}{l}436 \\
436 \\
436 \\
458 \\
458\end{array}$ & $\begin{array}{l}2.0 \\
2.0 \\
2.0 \\
2.1 \\
2.1\end{array}$ & $\begin{array}{l}4.0 \\
4.0 \\
3.9 \\
3.8 \\
3.7\end{array}$ & $\begin{array}{l}574 \\
611 \\
655 \\
682 \\
641\end{array}$ & $\begin{array}{l}6.2 \\
6.6 \\
6.9 \\
7.0 \\
6.4\end{array}$ \\
\hline $\begin{array}{l}26 \\
27 \\
28 \\
29 \\
30 \\
31\end{array}$ & $\begin{array}{l}3.0 \\
2.9 \\
2.8 \\
2.6 \\
2.5 \\
-.\end{array}$ & $\begin{array}{r}1360 \\
1240 \\
1070 \\
912 \\
800 \\
-\sim\end{array}$ & $\begin{array}{c}11 \\
9.7 \\
8.1 \\
6.4 \\
5.4 \\
=-\end{array}$ & $\begin{array}{l}1.7 \\
1.7 \\
1.7 \\
1.7 \\
1.7 \\
1.7\end{array}$ & $\begin{array}{l}479 \\
501 \\
501 \\
501 \\
479 \\
436\end{array}$ & $\begin{array}{l}2.2 \\
2.3 \\
2.3 \\
2.3 \\
2.2 \\
2.0\end{array}$ & $\begin{array}{c}3.7 \\
3.6 \\
3.6 \\
3.5 \\
3.5 \\
-.\end{array}$ & $\begin{array}{l}581 \\
514 \\
484 \\
466 \\
476 \\
-\end{array}$ & $\begin{array}{l}5.8 \\
5.0 \\
4.7 \\
4.4 \\
4.5 \\
-.\end{array}$ \\
\hline TOTAL & 202.5 & -- & 1604.6 & 58.1 & - & 101.1 & 100.8 & - & 169.7 \\
\hline
\end{tabular}


11141150 ARROYO GRANDE ABOVE PHOENIX CREEK, NEAR ARROYO GRANDE, CALIF..--Cont InUed

TOTAL SEDIMENT DISCHARGE, WATER YEAR OCTOBER 1968 TO SEPTEMBER 1969

\begin{tabular}{|c|c|c|c|c|c|c|c|c|c|}
\hline \multirow[b]{2}{*}{ DAY } & \multicolumn{3}{|c|}{ JULY } & \multicolumn{3}{|c|}{ AUGUST } & \multicolumn{3}{|c|}{ SEPTEMBER } \\
\hline & $\begin{array}{l}\text { MEAN } \\
\text { DISCHARGE } \\
\text { (CFS) }\end{array}$ & $\begin{array}{l}\text { MEAN } \\
\text { CONCEN- } \\
\text { TRATI ON } \\
\text { (MG/L) }\end{array}$ & $\begin{array}{l}\text { TOTAL } \\
\text { SEDIMENT } \\
\text { DISCHARGE } \\
\text { (TONS/DAY) }\end{array}$ & $\begin{array}{l}\text { MEAN } \\
\text { OI SCHARGE } \\
\text { (CFS) }\end{array}$ & $\begin{array}{l}\text { MEAN } \\
\text { CONCEN- } \\
\text { TRATION } \\
\text { (MG/L) }\end{array}$ & $\begin{array}{l}\text { TOTAL } \\
\text { SEDIMENT } \\
\text { DISCHARGE } \\
\text { (TONS/DAY) }\end{array}$ & $\begin{array}{l}\text { MEAN } \\
\text { DISCHARGE } \\
\text { (CFS) }\end{array}$ & $\begin{array}{l}\text { MEAN } \\
\text { CONCEN- } \\
\text { TRAIIDN } \\
\text { (MG/L) }\end{array}$ & $\begin{array}{l}\text { TOTAL } \\
\text { SEDIMENT } \\
\text { DISCHARGE } \\
\text { (TONS/DAY) }\end{array}$ \\
\hline $\begin{array}{l}1 \\
2 \\
3 \\
4 \\
5\end{array}$ & $\begin{array}{l}3.4 \\
3.3 \\
3.2 \\
3.1 \\
3.1\end{array}$ & $\begin{array}{l}479 \\
505 \\
521 \\
526 \\
502\end{array}$ & $\begin{array}{l}4.4 \\
4.5 \\
4.5 \\
4.4 \\
4.2\end{array}$ & $\begin{array}{l}2.0 \\
2.0 \\
2.0 \\
2.0 \\
1.9\end{array}$ & $\begin{array}{l}592 \\
556 \\
518 \\
481 \\
468\end{array}$ & $\begin{array}{l}3.2 \\
3.0 \\
2.8 \\
2.6 \\
2.4\end{array}$ & $\begin{array}{l}.93 \\
.90 \\
.87 \\
.81 \\
.80\end{array}$ & $\begin{array}{l}199 \\
181 \\
192 \\
187 \\
176\end{array}$ & $\begin{array}{l}.50 \\
.44 \\
.45 \\
.41 \\
.38\end{array}$ \\
\hline $\begin{array}{r}6 \\
7 \\
8 \\
9 \\
10\end{array}$ & $\begin{array}{l}3.0 \\
3.0 \\
2.9 \\
2.9 \\
2.9\end{array}$ & $\begin{array}{l}481 \\
444 \\
421 \\
409 \\
421\end{array}$ & $\begin{array}{l}3.9 \\
3.6 \\
3.3 \\
3.2 \\
3.3\end{array}$ & $\begin{array}{l}1.9 \\
1.9 \\
2.4 \\
2.3 \\
2.1\end{array}$ & $\begin{array}{l}468 \\
682 \\
926 \\
934 \\
794\end{array}$ & $\begin{array}{l}2.4 \\
3.5 \\
6.0 \\
5.8 \\
4.5\end{array}$ & $\begin{array}{l}.86 \\
.92 \\
1.0 \\
1.1 \\
1.2\end{array}$ & $\begin{array}{l}172 \\
201 \\
193 \\
189 \\
213\end{array}$ & $\begin{array}{l}.40 \\
.50 \\
.52 \\
.56 \\
.69\end{array}$ \\
\hline $\begin{array}{l}11 \\
12 \\
13 \\
14 \\
15\end{array}$ & $\begin{array}{l}2.8 \\
2.8 \\
2.8 \\
3.5 \\
3.1\end{array}$ & $\begin{array}{l}463 \\
542 \\
556 \\
603 \\
526\end{array}$ & $\begin{array}{l}3.5 \\
4.1 \\
4.2 \\
5.7 \\
4.4\end{array}$ & $\begin{array}{l}2.1 \\
1.8 \\
1.9 \\
2.1 \\
2.1\end{array}$ & $\begin{array}{l}670 \\
556 \\
507 \\
476 \\
423\end{array}$ & $\begin{array}{l}3.8 \\
2.7 \\
2.6 \\
2.7 \\
2.4\end{array}$ & $\begin{array}{l}1.2 \\
1.3 \\
1.3 \\
1.3 \\
1.4\end{array}$ & $\begin{array}{l}204 \\
197 \\
185 \\
185 \\
206\end{array}$ & $\begin{array}{l}.66 \\
.69 \\
.65 \\
.65 \\
.78\end{array}$ \\
\hline $\begin{array}{l}16 \\
17 \\
18 \\
19 \\
20\end{array}$ & $\begin{array}{l}2.9 \\
2.7 \\
2.6 \\
2.5 \\
2.4\end{array}$ & $\begin{array}{l}498 \\
453 \\
442 \\
608 \\
679\end{array}$ & $\begin{array}{l}3.9 \\
3.3 \\
3.1 \\
4.1 \\
4.4\end{array}$ & $\begin{array}{l}1.8 \\
1.8 \\
1.7 \\
1.4 \\
1.4\end{array}$ & $\begin{array}{l}370 \\
350 \\
305 \\
265 \\
246\end{array}$ & $\begin{array}{l}1.8 \\
1.7 \\
1.4 \\
1.0 \\
.93\end{array}$ & $\begin{array}{l}1.4 \\
1.4 \\
1.4 \\
1.4 \\
1.4\end{array}$ & $\begin{array}{l}196 \\
190 \\
185 \\
185 \\
185\end{array}$ & $\begin{array}{l}.74 \\
.72 \\
.70 \\
.70 \\
.70\end{array}$ \\
\hline $\begin{array}{l}21 \\
22 \\
23 \\
24 \\
25\end{array}$ & $\begin{array}{l}2.3 \\
2.3 \\
2.2 \\
2.2 \\
2.2\end{array}$ & $\begin{array}{l}644 \\
596 \\
555 \\
505 \\
488\end{array}$ & $\begin{array}{l}4.0 \\
3.7 \\
3.3 \\
3.0 \\
2.9\end{array}$ & $\begin{array}{l}1.3 \\
1.3 \\
1.3 \\
1.2 \\
1.1\end{array}$ & $\begin{array}{l}217 \\
197 \\
185 \\
191 \\
178\end{array}$ & $\begin{array}{l}.76 \\
.69 \\
.65 \\
.62 \\
.53\end{array}$ & $\begin{array}{l}1.4 \\
1.5 \\
1.5 \\
1.5 \\
1.5\end{array}$ & $\begin{array}{l}185 \\
183 \\
188 \\
200 \\
220\end{array}$ & $\begin{array}{r}.70 \\
.74 \\
.76 \\
.81 \\
.89\end{array}$ \\
\hline $\begin{array}{l}26 \\
27 \\
28 \\
29 \\
30 \\
31\end{array}$ & $\begin{array}{l}2.1 \\
2.1 \\
2.1 \\
2.0 \\
2.0 \\
2.0\end{array}$ & $\begin{array}{l}459 \\
441 \\
459 \\
537 \\
666 \\
648\end{array}$ & $\begin{array}{l}2.6 \\
2.5 \\
2.6 \\
2.9 \\
3.6 \\
3.5\end{array}$ & $\begin{array}{l}1.1 \\
1.1 \\
1.1 \\
1.1 \\
1.1 \\
.99\end{array}$ & $\begin{array}{l}199 \\
199 \\
199 \\
199 \\
189 \\
195\end{array}$ & $\begin{array}{l}.59 \\
.59 \\
.59 \\
.59 \\
.56 \\
.52\end{array}$ & $\begin{array}{l}1.5 \\
1.5 \\
1.6 \\
1.6 \\
1.6 \\
--\end{array}$ & $\begin{array}{c}150 \\
180 \\
180 \\
180 \\
160 \\
--\end{array}$ & $\begin{array}{l}.61 \\
.73 \\
.78 \\
.78 \\
.69 \\
-.\end{array}$ \\
\hline TOTAL & 82.4 & -- & 114.6 & 51.29 & -- & 63.92 & 38.09 & - & 19.33 \\
\hline $\begin{array}{l}\text { TOTAL } \\
\text { TOTAL }\end{array}$ & $\begin{array}{l}\text { DISCHARGE } \\
\text { SUSPENDED }\end{array}$ & $\begin{array}{l}\text { FOR YEAR } \\
\text { SEDIMENT }\end{array}$ & $\begin{array}{l}\text { (CFS-OAYS) } \\
\text { DISCHARGE FOR }\end{array}$ & YEAR (TONS) & & & & & $\begin{array}{r}3944.94 \\
238170.53\end{array}$ \\
\hline
\end{tabular}
PARTICLE-SIZE DISTRIBUTION OF TOTAL SEDIMENT, WATER YEAR OCTOBER 1968 TO SEPTEMBER 1969
(METHODS OF ANALYSIS: B, BOTTOM WITHDRAWAL TUBE; C, CHEMICALLY DISPERSED; N, IN NATIVE WATER; P, PIPET; S, SIEVE
V, VISUAL ACCUMULATION TUBE; W, IN DISTILLED WATER)

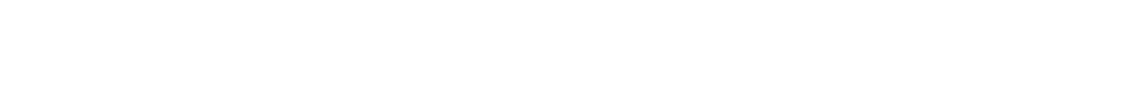

\begin{tabular}{|c|c|c|c|c|c|c|c|c|c|c|c|c|c|c|c|c|c|c|}
\hline $\begin{array}{l}\text { NOV } \\
\text { DEC } \\
\text { JAN } \\
\text { JAN }\end{array}$ & $\begin{array}{r}3,1968 \\
26, \ldots \ldots \\
14,1969 \\
20 . \ldots \ldots\end{array}$ & $\begin{array}{l}0735 \\
0930 \\
0715 \\
1540\end{array}$ & $\begin{array}{r}15 \\
9 \\
12 \\
14\end{array}$ & $\begin{array}{r}3.3 \\
3.6 \\
5.5 \\
11\end{array}$ & $\begin{array}{r}48 \\
210 \\
328 \\
1220\end{array}$ & $\begin{array}{l}.43 \\
2.0 \\
4.9 \\
36\end{array}$ & $\begin{array}{l}-- \\
-- \\
17\end{array}$ & $\begin{array}{l}=- \\
\overline{-} \\
19\end{array}$ & $\begin{array}{l}-- \\
-- \\
-- \\
24\end{array}$ & $\begin{array}{l}-- \\
-- \\
-- \\
27\end{array}$ & $\begin{array}{l}-- \\
-- \\
-- \\
33\end{array}$ & $\begin{array}{l}74 \\
63 \\
80 \\
42\end{array}$ & $\begin{array}{l}84 \\
65 \\
83 \\
77\end{array}$ & $\begin{array}{l}96 \\
84 \\
92 \\
98\end{array}$ & $\begin{array}{r}98 \\
98 \\
98 \\
100\end{array}$ & $\begin{array}{r}100 \\
100 \\
99 \\
--\end{array}$ & $\begin{array}{c}-- \\
100 \\
--\end{array}$ & $\begin{array}{l}S \\
S \\
S \\
\text { VPWC }\end{array}$ \\
\hline JAN & $26 \ldots \ldots$ & 0815 & 14 & 626 & 72700 & 123000 & 15 & 17 & 19 & 23 & 31 & 41 & 65 & 96 & 100 & - & -- & SPWC \\
\hline $\begin{array}{l}J A N \\
\text { JAN } \\
\text { FEB } \\
\text { FEB } \\
\text { FEB }\end{array}$ & $\begin{array}{r}26 \ldots \ldots \\
27 \ldots \ldots \ldots \\
5 \ldots \ldots \\
6 \ldots \ldots\end{array}$ & $\begin{array}{l}1250 \\
0845 \\
0910 \\
1305 \\
1240\end{array}$ & $\begin{array}{l}13 \\
11 \\
10 \\
12 \\
11\end{array}$ & $\begin{array}{r}342 \\
D 150 \\
36 \\
36 \\
070\end{array}$ & $\begin{array}{r}39100 \\
21700 \\
4160 \\
2800 \\
23300\end{array}$ & $\begin{array}{r}36100 \\
8790 \\
404 \\
272 \\
4400\end{array}$ & $\begin{array}{r}13 \\
8 \\
16 \\
13 \\
9\end{array}$ & $\begin{array}{r}15 \\
9 \\
17 \\
14 \\
9\end{array}$ & $\begin{array}{l}17 \\
10 \\
20 \\
16 \\
11\end{array}$ & $\begin{array}{l}21 \\
13 \\
24 \\
21 \\
13\end{array}$ & $\begin{array}{l}27 \\
17 \\
31 \\
28 \\
17\end{array}$ & $\begin{array}{l}35 \\
22 \\
43 \\
41 \\
26\end{array}$ & $\begin{array}{l}65 \\
36 \\
76 \\
76 \\
46\end{array}$ & $\begin{array}{l}91 \\
65 \\
98 \\
98 \\
80\end{array}$ & $\begin{array}{r}99 \\
80 \\
100 \\
100 \\
95\end{array}$ & $\begin{array}{r}100 \\
88 \\
-- \\
-- \\
98\end{array}$ & $\begin{array}{l}-2 \\
97 \\
-- \\
99\end{array}$ & $\begin{array}{l}\text { SPWC } \\
\text { SPWC } \\
\text { VPWC } \\
\text { VPWC } \\
\text { SPWC }\end{array}$ \\
\hline PR & & $\begin{array}{l}1055 \\
1515\end{array}$ & $\begin{array}{l}13 \\
22\end{array}$ & $\begin{array}{l}16 \\
4.8\end{array}$ & $\begin{array}{r}2050 \\
928\end{array}$ & $\begin{array}{l}89 \\
12\end{array}$ & $\begin{array}{l}19 \\
17\end{array}$ & $\begin{array}{l}20 \\
20\end{array}$ & $\begin{array}{l}26 \\
24\end{array}$ & $\begin{array}{l}32 \\
29\end{array}$ & $\begin{array}{l}40 \\
37\end{array}$ & $\begin{array}{l}46 \\
54\end{array}$ & $\begin{array}{l}62 \\
83\end{array}$ & $\begin{array}{l}91 \\
98\end{array}$ & $\begin{array}{r}98 \\
100\end{array}$ & 99 & 99 & $\begin{array}{l}\text { SPWC } \\
\text { VPWC }\end{array}$ \\
\hline
\end{tabular}

PARTICLE-SIZE DISTRIBUTION OF SURFACE BED MATERTAL, WATER YEAR OCTOBER 1968 TO SEPTEMBER 1969
TMETHUD OF ANALYSIS: H, HYOROMETER; O, OPTICAL ANALYZER; S, SIEVE: V, VISUAL ACCUMULAT TON TUBEI

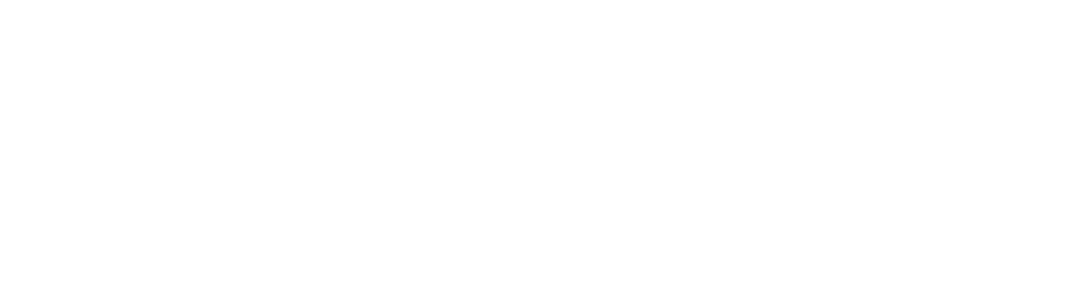

APR $\quad 7 \ldots \ldots . \quad 1000$

D DAILY MEAN DISCHARGE. 
11141280 LOPEZ CREEK NEAR ARROYO GRANDE, CALIF,

LOCATI ON, --Lat $35^{\circ} 13^{\prime} 48^{\prime \prime}$, long $120^{\circ} 28^{\prime} 22^{\prime \prime}$, In SE⿺𠃊丶万 station 0.7 mile upstream from unnamed tributary, 3.2 miles upstream from mouth, and $9.2 \mathrm{miles}$ northeast of
Arroyo Grande.

DRAINAGE AREA. --21.4 sq m1.

PERIOD OF RECORD.--Water temperatures: October 1967 to September 1969.

sediment records: Octaber 1967 to September 1969

EXTREMES. --1968-69:

Sediment concentrations: Maximum da $11 \mathrm{y}, 9,310 \mathrm{mg} / 1 \mathrm{Jan} .19 ; \mathrm{min} 1 \mathrm{mum}$ daily, $1 \mathrm{mg} / 1$ on many days during October to December. Sediment discharge: Maximum da1ly, 30,100 tons Jan. 25; minimum dally, 0 ton on several days during
October.

Period of record:

Sediment concentrations: Maximum daily, $9,310 \mathrm{mg} / 1 \mathrm{Jan} .19,1969 ; \mathrm{min} 1 \mathrm{mum}$ dally, $1 \mathrm{mg} / 1$ on many days in 1967

Sediment discharge: Maximum da11y, 30,100 tons Jan. 25, 1969; minimum da11y, 0 ton on several days in 1968. TEMPERATURE $\left({ }^{\circ} \mathrm{C}\right.$ ) OF WATER, WATER YEAR OCTOBER 1968 TO SEPTEMBER 1969 (ONCE-DAILY MEASUREMENT)

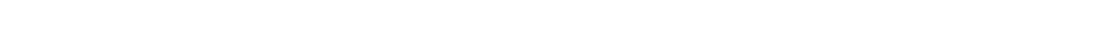

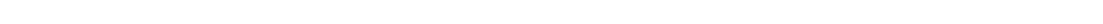

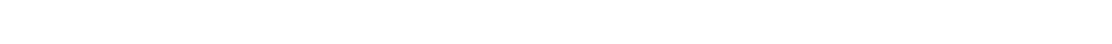

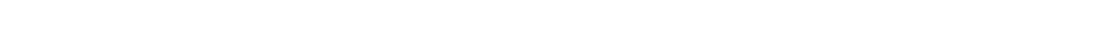

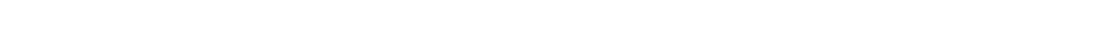

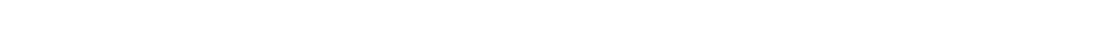

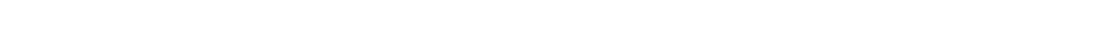

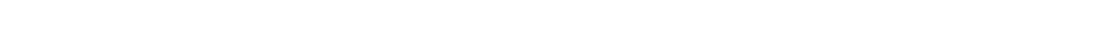

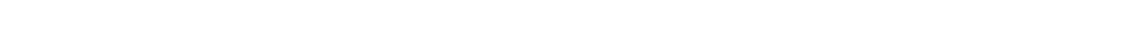

PARTICLE-SIZE DISTRIBUTION OF SUSPENDED SEDIMENT, WATER YEAR OCTOBER I958 TO SEPTEMBER 1969

IMETHOUS OF ANALYSIS: B, BOTTOM WI THDRAHAL TUBE; C, CHEMICALLY DISPERSEO: N, IN NATIVE WATER; P, PIPET: S, SIEVE; $V$, VISUAL ACCUMULATION TURE; W, IN OISTILLED WATER I

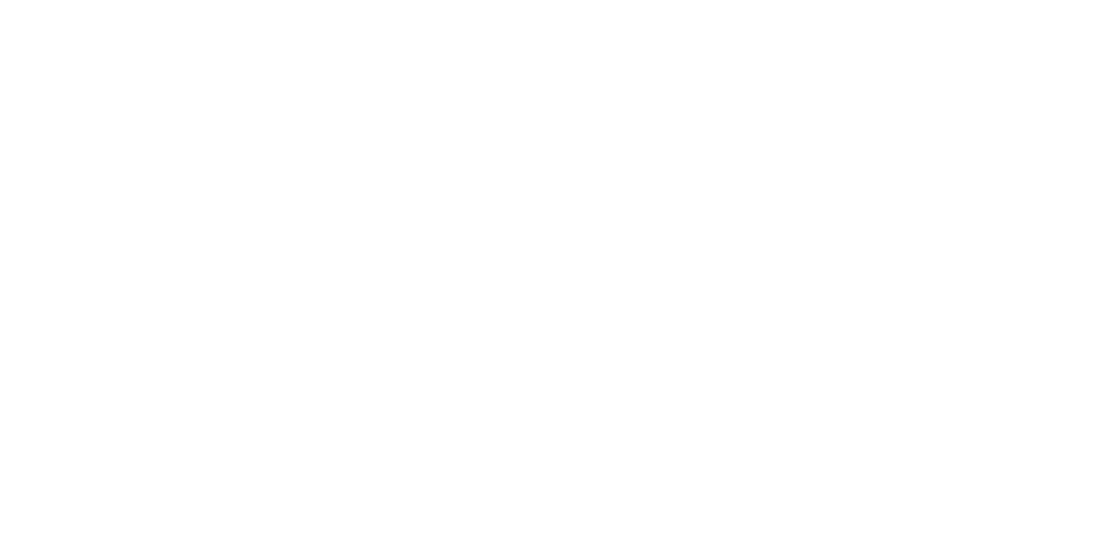

PARTICLE-SIZE DISTRIBUTION OF SURFACE BED MATERIAL, WAIER YEAR OCTOBER 1968 TO SEPTEMBER 1960 IMETHOO OF ANALYS IS: H, HYOROMETER; O, OPTICAL ANALYZER; S, SIEVE; V, VISUAL ACCUMULATION TUBEI

$$
\text { NUMBER PARTICLE SIZE }
$$

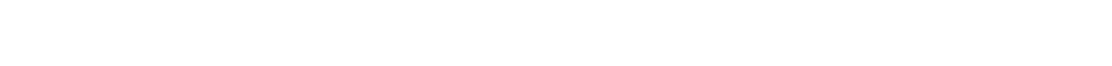

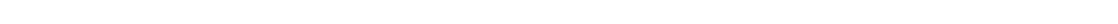


ARROYO GRANDE BASIN

11141280 LOPEZ CREEK NEAR ARROYO GRANDE, CALIF.--Continued

SUSPENDED-SEDIMENT DISCHARGE, WATER YEAR OCTOBER 1968 TO SEPTEMBER 1969

OCTIBER

NOVEMBER

DECEMBER

\begin{tabular}{|c|c|c|c|c|c|c|c|c|c|}
\hline & & MEAN & & & MEAN & & & MEAN & \\
\hline DAY & $\begin{array}{l}\text { MEAN } \\
\text { DISCHARGE } \\
\text { (CFS) }\end{array}$ & $\begin{array}{l}\text { CONCEN- } \\
\text { TRATION } \\
\text { (MG/L) }\end{array}$ & $\begin{array}{l}\text { SEDIMENT } \\
\text { DISCHARGE } \\
\text { (TDNS/DAY) }\end{array}$ & $\begin{array}{l}\text { MEAN } \\
\text { DISCHARGE } \\
\text { (CFS) }\end{array}$ & $\begin{array}{l}\text { CONCEN- } \\
\text { TRATION } \\
\text { (MG/L) }\end{array}$ & $\begin{array}{l}\text { SED IMENT } \\
\text { DISCHARGE } \\
\text { (TDNS/DAY) }\end{array}$ & $\begin{array}{l}\text { MEAN } \\
\text { DISCHARGE } \\
\text { (CFS) }\end{array}$ & $\begin{array}{l}\text { CDNCEN- } \\
\text { TRATION } \\
\text { (MG/L) }\end{array}$ & $\begin{array}{l}\text { SEDIMENT } \\
\text { DISCHARG } \\
\text { ITONS/DAY }\end{array}$ \\
\hline
\end{tabular}

$$
\begin{aligned}
& 1 \\
& 2 \\
& 3 \\
& 4 \\
& 5
\end{aligned}
$$$$
\begin{aligned}
& 1.6 \\
& 1.6 \\
& 1.6 \\
& 1.6 \\
& 1.6
\end{aligned}
$$

$$
\begin{aligned}
& 3 \\
& 1 \\
& 1 \\
& 1 \\
& 1
\end{aligned}
$$$$
\begin{aligned}
& 0_{0}^{.01} \\
& 0 \\
& 0
\end{aligned}
$$$$
\begin{aligned}
& 2.1 \\
& 2.1 \\
& 3.1 \\
& 2.9 \\
& 2.7
\end{aligned}
$$$$
\begin{aligned}
& 1.6 \\
& 1.5 \\
& 1.5 \\
& 1.5 \\
& 1.5
\end{aligned}
$$$$
\begin{aligned}
& 1 \\
& 1 \\
& 1 \\
& 1
\end{aligned}
$$$$
\begin{aligned}
& 0 \\
& 0 \\
& 0 \\
& 0 \\
& 0
\end{aligned}
$$$$
\begin{aligned}
& 2.5 \\
& 2.3 \\
& 2.3 \\
& 2.3 \\
& 2.3
\end{aligned}
$$$$
0
$$$$
\begin{array}{rr}
1.5 & 1 \\
1.6 & 1 \\
2.7 & 10 \\
3.4 & 3 \\
2.6 & 3
\end{array}
$$$$
\begin{aligned}
& 2.3 \\
& 2.3 \\
& 2.3 \\
& 2.5 \\
& 4.4
\end{aligned}
$$$$
\begin{array}{ll}
16 & 2.2 \\
17 & 2 . \\
18 & 2 . \\
19 & 2.0
\end{array}
$$$$
\begin{array}{ll}
2.2 & 4 \\
2.1 & 4 \\
2.1 & 4 \\
2.0 & 3 \\
2.0 & 3
\end{array}
$$$$
\begin{array}{ll}
21 & 22 \\
23 & 2.0 \\
24 & 1 . \\
25 & 1 .
\end{array}
$$$$
\begin{array}{ll}
.02 \\
0.2 \\
.02 \\
.02
\end{array}
$$$$
3.5
$$$$
\begin{aligned}
& 3.5 \\
& 3.1 \\
& 2.9 \\
& 2.8 \\
& 2.7
\end{aligned}
$$$$
\begin{aligned}
& .02 \\
& .03 \\
& .02 \\
& .01
\end{aligned}
$$$$
\begin{aligned}
& 2.7 \\
& 2.6 \\
& 2.5 \\
& 2.6 \\
& 2.5
\end{aligned}
$$$$
\begin{array}{ll}
0 & 2 . \\
0 & 2 . \\
.01 & 2.7 \\
.02 & 2.7 \\
.04 & 2.7
\end{array}
$$$$
.04
$$$$
\begin{aligned}
& .05 \\
& .05 \\
& .06 \\
& .05 \\
& .04
\end{aligned}
$$$$
\begin{aligned}
& 2.7 \\
& 2.7 \\
& 2.7 \\
& 2.7 \\
& 2.7
\end{aligned}
$$$$
\begin{aligned}
& 3 \\
& 3 \\
& 3 \\
& 3 \\
& 3 \\
& 3
\end{aligned}
$$$$
\text { (TONS/DAY) }
$$

$$
\begin{array}{ll}
1.8 & 1 \\
1.8 & 1 \\
2.0 & 1 \\
2.1 & 4 \\
2.3 & 6 \\
2.1 & 7
\end{array}
$$

TOTAL

59.4

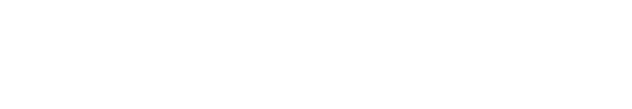

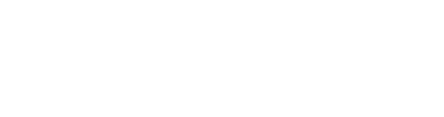

$$
4.7
$$<smiles>C1CCC(C2CCCCC2)CC1</smiles>
(CFS)

280
180
120
90
1340
3130
750
300
200
150
130
120
90
70
250

$$
\begin{array}{cr}
38 & 193 \\
19 & 145 \\
11 & 113 \\
7.5 & 89 \\
1560 & 75
\end{array}
$$

193
145
113
89
75

$\begin{array}{cc}485 & 253 \\ 320 & 125 \\ 240 & 73 \\ 210 & 50 \\ 190 & 38 \\ & \\ 180 & 34 \\ 175 & 34 \\ 200 & 35 \\ 140 & 19 \\ 100 & 14 \\ 75 & 11 \\ 44 & 5.9 \\ 23 & 3.0 \\ 20 & 2.3 \\ 22 & 2.7\end{array}$

16
17
18
19
20

$\begin{array}{rr}6.5 & 7 \\ 5.9 & 4 \\ 19 & 206 \\ 343 & 9310 \\ 218 & 2880\end{array}$

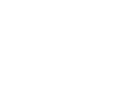

45
35
38
48

185
160
150
140

3780
336
89

336
89
42

70

70
71
64
50

2.7
2.7
2.7
2.7

2.7
3.1

3.5
3.2
3.1
3.6

3.6
4.6

5.3
4.5
4.1
3.9

3.9

3.7
3.8
3.8
3.9

3.9
4.4

6.7
6.0
5.5
5.5
5.2

5.2
5.0

.02
.02
.02
.02
.02

.02

.03
.03
.01

.01

.01

.04
.02
.04

.05

.04

.04

.04

.06

04
.03

.03

\section{3}

$21 \quad 404 \quad 1660$

16200
2190

42

100

$\begin{array}{ll}25 & 52 \\ 20 & 54 \\ 15 & 50 \\ 9.2 & 48 \\ 7.9 & 43\end{array}$

2290

547
208
809
30100

$\begin{array}{rr}41 & 120 \\ 62 & 210 \\ 164 & 1840 \\ 789 & 3570\end{array}$

3570
1500

$$
44
$$$$
\begin{aligned}
& 43 \\
& 45
\end{aligned}
$$

483

1500

8090

644
266

$\begin{array}{rr}266 & 233 \\ 122 & =- \\ 74 & =- \\ 57 & -\end{array}$

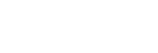

$\begin{array}{rr}730 & 310 \\ 1050 & 702\end{array}$

TOTAL 4493.9

$61631.59 \quad 3738$

2.9
3.8
4.0
4.4
4.2

7.4
7.8

7.8
5.4

5.8

5.0

4.9

4.5
4.4

$\begin{array}{lll}7- & 32 \\ -- & -- & 30 \\ -- & 29\end{array}$

$21313.6 \quad 1718$

777.4 
11141280 LOPEZ CREEK NEAR ARROYO GRANDE, CALIF.--Cont1nued

SUSPENDED-SEDIMENT DISCHARGE, WATER YEAR OCTOBER 1968 TO SEPTEMBER 1969

\begin{tabular}{|c|c|c|c|c|c|c|c|c|c|}
\hline \multirow[b]{2}{*}{ DAY } & \multicolumn{3}{|c|}{ APRIL } & \multicolumn{3}{|c|}{ MAY } & \multicolumn{3}{|c|}{ JUNE } \\
\hline & $\begin{array}{l}\text { MEAN } \\
\text { OISCHARGF } \\
\text { (CFS) }\end{array}$ & $\begin{array}{l}\text { MEAN } \\
\text { CONCEN- } \\
\text { TRATION } \\
\text { (MG/L) }\end{array}$ & $\begin{array}{l}\text { SEDIMENT } \\
\text { DISCHARGE } \\
\text { (TONS/DAY) }\end{array}$ & $\begin{array}{l}\text { MEAN } \\
\text { DISCHARGE } \\
\text { (CFS) }\end{array}$ & $\begin{array}{l}\text { MEAN } \\
\text { CONCEN- } \\
\text { TRATION } \\
\text { (MG/L) }\end{array}$ & $\begin{array}{l}\text { SEDIMENT } \\
\text { DISCHARGE } \\
\text { (TONS/DAY) }\end{array}$ & $\begin{array}{l}\text { MEAN } \\
\text { DISCHARGE } \\
\text { (CFS) }\end{array}$ & $\begin{array}{l}\text { MEAN } \\
\text { CONCEN- } \\
\text { TRATION } \\
\text { (MGIL) }\end{array}$ & $\begin{array}{l}\text { SEDIMENT } \\
\text { DISCHARGE } \\
\text { (TDNS/DAY) }\end{array}$ \\
\hline 1 & 27 & 35 & 2.6 & 16 & 20 & .86 & 14 & 14 & .53 \\
\hline 2 & 30 & 35 & 2.9 & 16 & 22 & .95 & 13 & 10 & .35 \\
\hline 3 & 32 & 41 & 3.5 & 16 & 17 & .73 & 13 & 8 & .28 \\
\hline 4 & 28 & 30 & 2.3 & 16 & 11 & .48 & 14 & 8 & .30 \\
\hline 5 & 58 & 726 & 154 & 16 & 9 & .39 & 15 & 8 & .32 \\
\hline 6 & 68 & 250 & 46 & 16 & 8 & .35 & 14 & 7 & .26 \\
\hline 7 & 45 & 100 & 12 & 16 & 9 & .39 & 14 & 7 & .26 \\
\hline 8 & 37 & 33 & 3.3 & 15 & 15 & .61 & 15 & 7 & .28 \\
\hline 9 & 34 & 28 & 2.6 & 16 & 21 & .91 & 15 & 8 & .32 \\
\hline 10 & 30 & 31 & 2.5 & 16 & 21 & .91 & 14 & $10^{\circ}$ & .38 \\
\hline 11 & 24 & 33 & 2.1 & 15 & 19 & .77 & 14 & 10 & .38 \\
\hline 12 & 24 & 32 & 2.1 & 16 & 16 & .69 & 13 & 9 & .32 \\
\hline 13 & 22 & 28 & 1.7 & 16 & 13 & .56 & 13 & 1 & .25 \\
\hline 14 & 21 & 22 & 1.2 & 16 & 11 & .48 & 13 & 7 & .25 \\
\hline 15 & 21 & 17 & .96 & 16 & 9 & .39 & 12 & 6 & .19 \\
\hline 16 & 23 & 16 & .99 & 15 & 8 & 32 & 12 & 6 & .19 \\
\hline 17 & 22 & 15 & .89 & 15 & 8 & .32 & 12 & 5 & .16 \\
\hline 18 & 21 & 15 & .85 & 15 & 8 & .32 & 12 & 5 & .16 \\
\hline 19 & 20 & 16 & .86 & 15 & 8 & .32 & 12 & 15 & .49 \\
\hline 20 & 20 & 18 & .97 & 15 & 8 & .32 & 13 & 53 & 1.9 \\
\hline 21 & 19 & 21 & 1.1 & 16 & 7 & .30 & 13 & 62 & 2.2 \\
\hline 22 & 19 & 22 & 1.1 & 15 & 5 & .20 & 12 & 62 & 2.0 \\
\hline 23 & 21 & 22 & 1.2 & 15 & 4 & .16 & 12 & 62 & 2.0 \\
\hline 24 & 19 & 20 & 1.0 & 16 & 4 & .17 & 12 & 62 & 2.0 \\
\hline 25 & 18 & 19 & .92 & 15 & 4 & .16 & 12 & 62 & 2.0 \\
\hline 26 & 17 & 16 & .73 & 15 & 4 & .16 & 12 & 64 & 2.1 \\
\hline 27 & 18 & 15 & .73 & 15 & 4 & .16 & 12 & 68 & 2.2 \\
\hline 28 & 18 & 14 & .68 & 14 & 4 & .15 & 12 & 70 & 2.3 \\
\hline 29 & 17 & 14 & .64 & 14 & 4 & .15 & 12 & 68 & 2.2 \\
\hline 30 & 16 & 16 & .69 & 13 & 6 & .21 & ii & 64 & 1.9 \\
\hline 31 & -- & -- & -- & 13 & 16 & .56 & $\cdots$ & $\rightarrow$ & - \\
\hline \multirow[t]{5}{*}{ TOTAL } & 789 & -- & 253.11 & 474 & - & 13.45 & 387 & - & 28.47 \\
\hline & \multicolumn{3}{|c|}{ JuLr } & \multicolumn{3}{|c|}{ AUGUST } & \multicolumn{3}{|c|}{ SEPTEM 8 ER } \\
\hline & & MEAN & & & MEAN & & & MEAN & \\
\hline & $\begin{array}{c}\text { MEAN } \\
\text { DI SCHARGE }\end{array}$ & $\begin{array}{l}\text { CONCEN- } \\
\text { TRATION }\end{array}$ & $\begin{array}{l}\text { SEDIMENT } \\
\text { DI SCHARGE }\end{array}$ & $\begin{array}{c}\text { MEAN } \\
\text { DISCHARGE }\end{array}$ & $\begin{array}{l}\text { CONCEN- } \\
\text { TRATION }\end{array}$ & $\begin{array}{l}\text { SED I MENT } \\
\text { DI SCHARGE }\end{array}$ & $\begin{array}{c}\text { MEAN } \\
\text { DISCHARGE }\end{array}$ & $\begin{array}{l}\text { CONCEN- } \\
\text { TRATIDN }\end{array}$ & $\begin{array}{l}\text { SE DI MENT } \\
\text { DI SCHARGE }\end{array}$ \\
\hline & (CFS) & $(M G / L)$ & (TONS/DAY) & (CFS) & $(M G / L)$ & (TONS/DAY) & (CFS) & $(M G / L)$ & (TONS/DAY) \\
\hline
\end{tabular}

\begin{tabular}{|c|c|c|}
\hline 1 & 11 & 58 \\
\hline 2 & 11 & 54 \\
\hline 3 & 11 & 51 \\
\hline 4 & 12 & 48 \\
\hline 5 & 12 & 46 \\
\hline 6 & 12 & 46 \\
\hline 7 & 12 & 45 \\
\hline 8 & 12 & 45 \\
\hline 9 & 12 & 38 \\
\hline 10 & 11 & 27 \\
\hline 11 & 11 & 22 \\
\hline 12 & 11 & 21 \\
\hline 13 & 11 & 22 \\
\hline 14 & 12 & 24 \\
\hline 15 & 11 & 26 \\
\hline 16 & 11 & 29 \\
\hline 17 & 10 & 34 \\
\hline 18 & 10 & 39 \\
\hline 19 & 9.4 & 37 \\
\hline 20 & 9.4 & 32 \\
\hline 21 & 9.4 & 28 \\
\hline 22 & 9.4 & 25 \\
\hline 23 & 9.4 & 22 \\
\hline 24 & 9.4 & 20 \\
\hline 25 & 9.4 & 18 \\
\hline 26 & 9.4 & 18 \\
\hline 27 & 9.4 & 17 \\
\hline 28 & 9.4 & 17 \\
\hline 29 & 8.7 & 16 \\
\hline 30 & 8.7 & 21 \\
\hline 31 & 8.0 & 36 \\
\hline & 322.4 & -- \\
\hline
\end{tabular}

$\begin{array}{ll}58 & 1.7 \\ 54 & 1.6 \\ 51 & 1.5 \\ 48 & 1.6 \\ 46 & 1.5 \\ 46 & 1.5 \\ 45 & 1.5 \\ 45 & 1.5 \\ 38 & 1.2 \\ 27 & .8 \\ 22 & .65 \\ 21 & .62 \\ 22 & .65 \\ 24 & .77 \\ 26 & .7\end{array}$

$\begin{array}{lll}1.7 & 8.0 & 53 \\ 1.6 & 8.0 & 52 \\ 1.5 & 8.0 & 46 \\ 1.6 & 6.5 & 38 \\ 1.5 & 6.5 & 35\end{array}$

53
52
44
38
35
35
44
52
30
18

1.1
1.1
.95
.67

8.0
8.0
6.9

$1.5 \quad 6.5$

6.5
6.5
6.8
6.5
5.8

.61
.77
.95

.77
.95
.53

6.9

$\begin{array}{ll}10 & .22 \\ 13 & .28 \\ 14 & .26 \\ 15 & .28\end{array}$

$\begin{array}{lll}6.5 & 30 \\ .80 & 5.8 & 18\end{array}$

.28

7.1

7.1
6.7
6.5

12

.28
.28
.26

$\begin{array}{lll}.65 & 8.0 & 14 \\ .62 & 8.0 & 13\end{array}$

$\begin{array}{lll}.65 & 7.2 & 12 \\ .78 & 7.2 & 12\end{array}$

.$: 30$

.28
.23
.23
.21

6.7

6.7
7.2
6.5

.

$\begin{array}{ll}.19 & 7.0 \\ .19 & 6.5 \\ .17 & 5.8 \\ .14 & 6.4 \\ .17 & 5.8\end{array}$

$\begin{array}{rr}.86 & 7.2 \\ .92 & 8.0 \\ 1.1 & 8.0 \\ .94 & 7.2 \\ .81 & 8.0\end{array}$

10
9
8
7

.16

$\begin{array}{ll}.19 & 6.5 \\ .26 & 6.5 \\ .25 & 5.7 \\ .25 & 5.5 \\ .25 & 5.5\end{array}$

6.516

$\begin{array}{lll}.71 & 7.2 & 10 \\ .63 & 8.0 & 12 \\ : 56 & 7.2 & 13 \\ .51 & 7.2 & 13 \\ .46 & 7.2 & 12 \\ .46 & 7.2 & \end{array}$

.23

5.5

$\begin{array}{ll}.19 & 5.6 \\ .15 & 5.7 \\ .12 & 5.6 \\ .11 & 5.5 \\ .10 & 5.5\end{array}$

$\begin{array}{rrr}.46 & 7.2 & 10 \\ .43 & 8.0 & 7 \\ .43 & 7.2 & 6 \\ .38 & 8.0 & 5 \\ .49 & 7.2 & 5 \\ .78 & 8.0 & 7\end{array}$

TOIAL DISCHARGE FOR YEAR (CFS-DAYS)
TOTAL SUSPENDED-SEDIMENT DISCHARGE FOR YEAR (TONS)

$28.34 \quad 227.5$

1.68

193.5 
11143000 BIG SUR RIVER NEAR BIG SUR, CALIF.

LOCATION, --Lat $36^{\circ} 14^{\prime} 45^{\prime \prime}$, long $121^{\circ} 46^{\prime} 20^{\prime \prime}$, in SWłSWł sec.29, T.19 S., R.2 E., Monterey County, tenperature recorder at gaging station on right bank at downstream side of bridge, 0.4 mile upstream from Post Creek and $2.6 \mathrm{miles}$ southeast of Big Sur.

DRAINAGE AREA. $--46.5 \mathrm{sq} \mathrm{mi}$.

PERIOD OF RECORD. - Fater temperatures: October 1965 to September 1969.

EXTREMES. --1968-69:

Water temperatures: Maximum, $19.0^{\circ} \mathrm{C}$ Aug. 9-12, $15 ; \mathrm{minimum}, 6.0^{\circ} \mathrm{C}$ Dec. $21,22$.

Period of record: Water temperatures: Maximum $(1965-67,1968-69), 20 .{ }^{\circ} \mathrm{C}$ Aug. $1,5,17,1966$; minimum $(1965-66,1967-69), 5.0^{\circ} \mathrm{C}$
Dec. 15,1967 .

REMARKS.--Recorder stopped Apr. 18 to May 8.

TEMPERATURE $\left({ }^{\circ} \mathrm{C}\right)$ OF WATER, WATER YEAR OCTOBER 1968 TO SEPTEMBER 1969

DAY

MUNTH

OCTOBER $\begin{array}{llllllllllllllllllllllllllllllllllllllll}\text { MAXIMUM } & 15 & 14 & 14 & 16 & 15 & 14 & 14 & 14 & 13 & 14 & 14 & 14 & 14 & 14 & 14 & 13 & 13 & 13 & 13 & 13 & 13 & 13 & 13 & 13 & 13 & 13 & 13 & 13 & 13 & 13 & 13 \\ \text { MINIMUM } & 14 & 14 & 14 & 14 & 14 & 14 & 14 & 13 & 13 & 13 & 13 & 14 & 14 & 14 & 13 & 13 & 13 & 13 & 13 & 13 & 13 & 13 & 13 & 13 & 13 & 13 & 13 & 13 & 13 & 12 & 12\end{array}$ NUVEMRER MAXIMUM $13 \begin{array}{llllllllllllllllllllllllllllllllllll}3 & 13 & 13 & 12 & 12 & 12 & 12 & 13 & 13 & 14 & 14 & 13 & 11 & 12 & 12 & 12 & 13 & 13 & 12 & 12 & 12 & 12 & 12 & 11 & 11 & 10 & 10 & 9 & 9 & -2\end{array}$

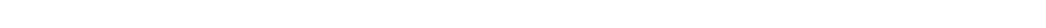
DECEMBER

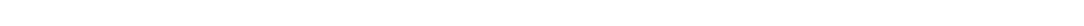
MINIMUM

JANUARY

$\begin{array}{llllllllllllllllllllllllllllllllllllll}\text { MAXIMUM } & 9 & 9 & 9 & 9 & 10 & 11 & 10 & 10 & 10 & 9 & 9 & 10 & 12 & 12 & 12 & 11 & 11 & 12 & 13 & 13 & 13 & 13 & 12 & 13 & 14 & 14 & 12 & 12 & 11 & 11 & 11 & 11 \\ \text { MINIMUM } & 8 & 8 & 8 & 9 & 9 & 10 & 9 & 9 & 9 & 8 & 8 & 9 & 10 & 12 & 9 & 10 & 9 & 10 & 12 & 13 & 13 & 12 & 11 & 12 & 13 & 12 & 12 & 11 & 10 & 10 & 9 & 10\end{array}$

FERRUAPY

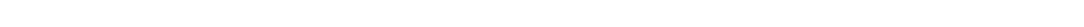

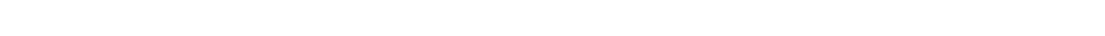

MARCH

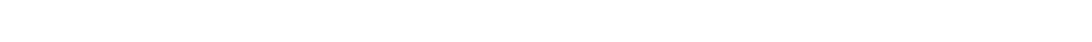

APRIL

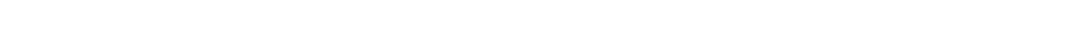

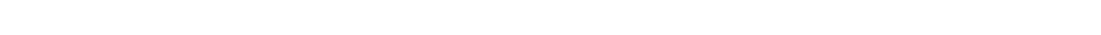

ar

MAXIMUM MINIMUM -

MAXIMUM $17 \begin{array}{lllllllllllllllllllllllllllllllllll}16 & 16 & 16 & 15 & 16 & 16 & 16 & 15 & 16 & 16 & 15 & 16 & 16 & 16 & 16 & 17 & 17 & 17 & 16 & 17 & 17 & 17 & 17 & 17 & 17 & 16 & 16 & 17 & 17 & - \\ \text { MINIMUM } & 16 & 15 & 14 & 14 & 14 & 14 & 14 & 14 & 14 & 14 & 14 & 14 & 14 & 15 & 14 & 15 & 15 & 15 & 15 & 15 & 16 & 14 & 16 & 16 & 16 & 16 & 14 & 14 & 14 & 14 & -2\end{array}$ $\begin{array}{rlllllllllllllllllllllllllllllll}\text { MINIMUM } & 16 & 15 & 14 & 14 & 14 & 14 & 14 & 14 & 14 & 14 & 14 & 14 & 14 & 15 & 14 & 15 & 15 & 15 & 15 & 15 & 16 & 14 & 16 & 16 & 16 & 16 & 14 & 14 & 14 & 14 & -\end{array}$

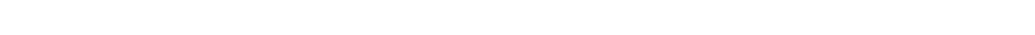

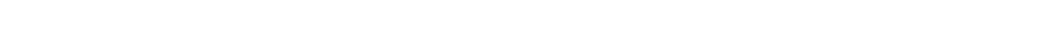

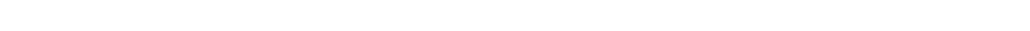

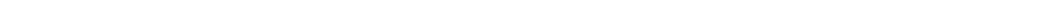

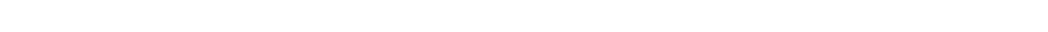
(1) 1

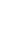


11147040 SANTA RITA CREEK TRIBUTARY NEAR TEMPLETON, CALIF.

LOCATION, --Lat $35^{\circ} 32^{\prime} 03^{\prime \prime}$, long $120^{\circ} 50^{\prime} 47^{\prime \prime}$, In Asuncion Grant, San Luis Obispo County, at gaging station on downstream pier of highway bridge, 0.2 mile downstream from unnamed tributary and 8,6 miles west of Templeton.

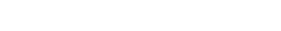

PERIOD OF RECORD.--Wa ter temperatures: October 1967 to September 1969.

Sediment records: October 1967 to September 1969.

EXTREMES. --1968-69:

Sediment concentrations: Maximum daily, 5,710 mg/1 Jan. 19; minimum daily, no flow for many days.

Sediment discharge: Maximum daily, 9,770 tons Jan. 19; minimum daily, 0 ton on many days.

Period of record:

Sediment concentrations: Maximum da1ly, 5,710 mg/2 Jan. 19, 1969; minimum da1ly, no flow for many days each Sediment discharge: Maximum dally, 9,770 tons Jan. 19, 1969; minimun dally, 0 ton on many days each year.

REMarks, - No flow Oct. 1 to Dec. 13, Dec. 23, June 24 to Sept. 30.

TEUPERATURE $\left({ }^{\circ} \mathrm{C}\right)$ OF WATER, WATER YEAR OCTOBER 1968 TO SEPTEMBER 1969 (ONCE-DA ILY MEASUREMENT)

DAY

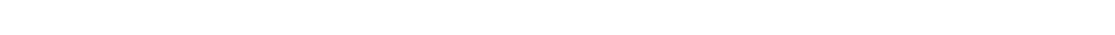

OC TOBER.. NOVEMAER,
DECEMBER,

JANUARY.. [-

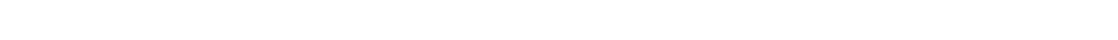

APRIL.... MAY,.... JULY..... AUGUST...

SUSPENDED-SEDIMENT DISCHARGE, WATER YEAR OCTOBER 1968 TO SEPTEMBER 1969
OC TOBER
NOVEMBER
DECEMBER

MEAN - SEDIMENT

CONCEN- SEDIMENT

DISCGARGE TONCEN- SEDIMENT MEATION

(MG/L)

(TONS/DAY)

MEAN
ISCWARGE (CFS)
MEAN

MONCEN- SEOIMENT TRATION DISCHARGE

$\begin{array}{lcl}0 & -- & 0 \\ 0 & -- & 0 \\ 0 & -- & 0 \\ 0 & -- & 0 \\ 0 & -- & 0 \\ 0 & -- & 0 \\ 0 & -- & 0 \\ 0 & -- & 0 \\ 0 & -- & 0 \\ 0 & -- & 0 \\ 0 & -- & 0 \\ 0 & -- & 0 \\ 0 & -- & 0 \\ 2.0 & 4 & .02 \\ 11 & 86 & 6.5 \\ 4.4 & 31 & .50 \\ .72 & 16 & .03 \\ .34 & 13 & .01 \\ .28 & 10 & .01 \\ .26 & 7 & 0 \\ .22 & 4 & 0 \\ .02 & 3 & 0 \\ 0 & -1 & 0 \\ 1.9 & 440 & 5.7 \\ 16 & 1070 & 68 \\ 9.1 & 155 & 5.4 \\ 2.2 & 15 & .09 \\ 5.0 & 84 & 2.1 \\ 3.2 & 19 & .16 \\ 1.4 & 9 & .03 \\ .82 & 3 & .01 \\ 580 & & 08.56\end{array}$

$58.86 \quad--\quad 88.56$ 
11147040 SANTA RITA CREEK TRIBUTARY NEAR TEMPLETON, CALIF...-Continued

SUSPENDED-SEDIMENT DISCHARGE, WATER YEAR OCTOBER 1968 TO SEPTEMBER 1969

\begin{tabular}{|c|c|c|c|c|c|c|c|c|c|}
\hline & \multicolumn{3}{|c|}{ JANUARY } & \multicolumn{3}{|c|}{ FEBRUARY } & \multicolumn{3}{|c|}{ MARCH } \\
\hline & & ME AN & & & MEAN & & & MEAN & \\
\hline & $\begin{array}{c}\text { MEAN } \\
\text { DISCHARGE }\end{array}$ & $\begin{array}{l}\text { CUNCEN- } \\
\text { TRATION }\end{array}$ & $\begin{array}{l}\text { SEDI MENT } \\
\text { DI SCHARGE }\end{array}$ & $\begin{array}{l}\text { MEAN } \\
\text { OISCHARGE }\end{array}$ & $\begin{array}{l}\text { CONCEN- } \\
\text { TRATION }\end{array}$ & $\begin{array}{l}\text { SED IMENT } \\
\text { DI SCHARGE }\end{array}$ & $\begin{array}{l}\text { MEAN } \\
\text { DISCHARGE }\end{array}$ & $\begin{array}{l}\text { CONCEN- } \\
\text { TRATION }\end{array}$ & $\begin{array}{l}\text { SEDIMENT } \\
\text { DISCHARGE }\end{array}$ \\
\hline DAY & (CFS) & $(M G / L)$ & (TONS/DAY) & (CFS) & $(M G / L)$ & (TONS / DAY) & (CFS) & $(M G / L)$ & (TONS/DAY) \\
\hline 1 & .56 & 3 & 0 & 15 & 20 & .81 & 43 & 50 & 5.8 \\
\hline 2 & .39 & 2 & 0 & 13 & 20 & .70 & 24 & 15 & .97 \\
\hline 3 & .28 & 2 & 0 & 10 & 20 & .54 & 16 & 9 & .39 \\
\hline 4 & .23 & 2 & 0 & 14 & 20 & .76 & 10 & 9 & .24 \\
\hline 5 & .20 & 2 & 0 & 25 & 70 & 4.7 & 7.2 & 7 & .14 \\
\hline 6 & .18 & 2 & 0 & 52 & 89 & 14 & 4.8 & 6 & .08 \\
\hline 1 & .17 & 2 & 0 & 27 & 25 & 1.8 & 3.5 & 5 & .05 \\
\hline 9 & .16 & 1 & 0 & 20 & 19 & 1.0 & 2.7 & 4 & .03 \\
\hline 9 & .18 & $\mathrm{t}$ & 0 & 18 & 17 & .83 & 2.1 & 3 & .02 \\
\hline 10 & .15 & 1 & 0 & 16 & 16 & .69 & 2.1 & 2 & .01 \\
\hline 11 & .15 & 1 & 0 & 14 & 15 & .57 & 1.4 & 2 & .01 \\
\hline $1 ?$ & .13 & $t$ & 0 & 22 & 154 & & 1.4 & 2 & .01 \\
\hline 13 & 30 & 384 & 67 & 14 & 50 & 1.9 & 1.4 & 2 & .01 \\
\hline 14 & 22 & 178 & 15 & 11 & 30 & .89 & 1.1 & 4 & .01 \\
\hline 15 & 3.9 & 14 & .15 & 93 & 154 & 48 & .90 & 7 & .02 \\
\hline 16 & 1.6 & 5 & .02 & 34 & 25 & 2.3 & .72 & 6 & .01 \\
\hline 17 & .84 & 2 & 0 & 22 & 11 & .65 & .72 & 6 & .01 \\
\hline 18 & 123 & 1570 & 1460 & 18 & 10 & .49 & .66 & 6 & .01 \\
\hline 19 & 496 & 5710 & 9770 & 17 & 10 & .46 & .66 & 6 & .01 \\
\hline 20 & 255 & 2280 & 2770 & 13 & 10 & .35 & .72 & 6 & .01 \\
\hline 21 & 127 & 1020 & 681 & 18 & 28 & 4.0 & .72 & 5 & .01 \\
\hline 2? & 38 & 45 & 4.6 & 25 & 18 & 1.2 & .55 & 5 & .01 \\
\hline 23 & 13 & 20 & .70 & 84 & 120 & 45 & .55 & 5 & .01 \\
\hline 24 & 159 & 1050 & 1200 & 405 & 2650 & 4410 & .45 & 5 & .01 \\
\hline 25 & 455 & 5000 & 9000 & 105 & 201 & 68 & .45 & 5 & .01 \\
\hline 26 & 133 & 748 & 401 & 49 & 40 & 5.3 & .45 & 4 & 0 \\
\hline 27 & 62 & 60 & 10 & 27 & 20 & 1.5 & .41 & 4 & 0 \\
\hline 28 & 51 & 130 & 18 & 75 & 187 & 47 & .41 & 4 & 0 \\
\hline 29 & 40 & 25 & 2.7 & -- & -- & -- & .37 & 4 & 0 \\
\hline 30) & 26 & 20 & 1.4 & -- & -- & -- & .37 & 4 & 0 \\
\hline 31 & 18 & 20 & .97 & -- & -- & $-\infty$ & .37 & 4 & 0 \\
\hline TUTAL & 2057.12 & - & 25402.54 & 1256 & -- & 4676.44 & 130.18 & -- & 7.89 \\
\hline
\end{tabular}

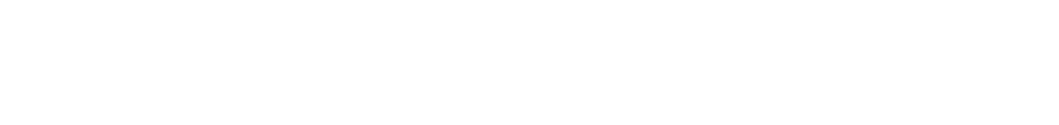

$\begin{array}{llllll}.72 & 5 & .01 & .13 & 2 & 0 \\ .60 & 5 & .01 & .13 & 2 & 0 \\ .60 & 5 & .01 & .13 & 2 & 0 \\ .60 & 5 & .01 & .13 & 2 & 0 \\ .60 & 5 & .01 & .12 & 2 & 0 \\ .67 & 4 & .01 & .12 & 2 & 0 \\ .70 & 4 & .01 & .12 & 2 & 0 \\ .67 & 4 & .01 & .12 & 2 & 0 \\ .65 & 4 & .01 & .13 & 2 & 0 \\ .62 & 4 & .01 & .13 & 2 & 0\end{array}$

$112.7 \quad 9$

$\begin{array}{ll}2.7 & 9 \\ 2.5 & 9 \\ 2.1 & 9 \\ 1.9 & 9 \\ 1.7 & 9\end{array}$

.07
.06
.05
.05

$$
.62
$$

.05

.55
.52
.52
.49
.50

.01
.01
.02
.02
.01

.12
.13
.12
.11
.10

.03

$\begin{array}{ll}1.6 & 8 \\ 1.4 & 8 \\ 1.3 & 8 \\ 1.2 & 8 \\ 1.1 & 8\end{array}$

.44
.38
.30
.29

$\begin{array}{ll}1.1 & 7 \\ 1.1 & 7 \\ 1.9 & 7 \\ 1.3 & 7 \\ 1.2 & 7\end{array}$

.03
.02

.29
.27

0
0
0
0
0

10

22

.02

.02
.04
.02
.02

.26
.25
.25
.25
.24

0
0
0
0
0

1.1
1.1
1.0
.90
.72
.72
--

.02
.02
.01
.01
.01

.22
.20
.17
.15
.13
.12

161.12

12.93

.09
.10
.09
.06

.06

$\begin{array}{lll}.04 & 1 & 0 \\ .01 & 1 & 0 \\ .01 & 1 & 0 \\ 0 & --- & 0 \\ 0 & -- & 0\end{array}$

TOTAL

126.94

YS)

TUTAL OISCHARGE FOR YEAR ICFS-DAYS)
TOTAL SUSPENDED-SEDIMENT DISCHARGE FOR YEAR (TONS)

$\begin{array}{llll}0 & 0 & -- & 0 \\ 0 & 0 & -- & 0 \\ 0 & 0 & -- & 0 \\ 0 & 0 & -- & 0 \\ 0 & 0 & -- & -- \\ 0 & -- & -- & 0\end{array}$

3644.33 30336.71 
11147040 SANTA RITA CREEK TRIBUTARY NEAR TEMPLETON, CALIF.--COntInued

PARTICLE-SIZE DISTRIBUTION OF SUSPENDED SEDIMENT, WATER YEAR OCTOBER 1968 TO SEPTEMBER 1969 IMETHODS OF ANALYSIS: B, BOTTOM HITHDRAWAL TUBE; C, CHEMICALLY DISPERSED: N, IN NATIVE HAIER: P, PIPET; S, SIEVE: V, VISUAL ACCUMULATION TUBE; $W$. IN OISTILLED HATER)

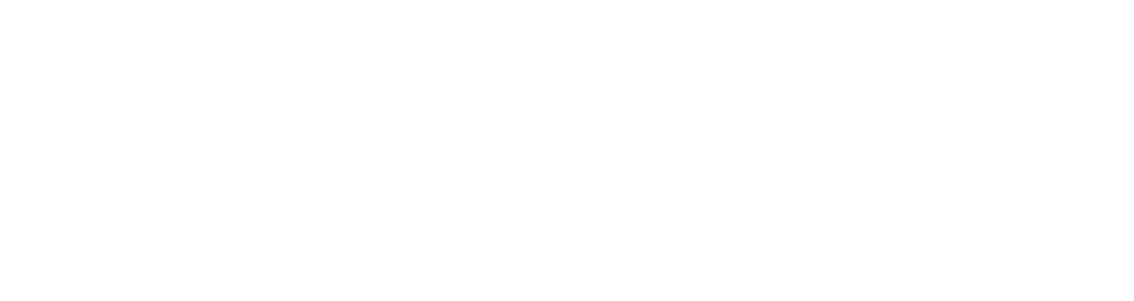

PARTICLE-SIZE DISTRIBUTION OF SURFACE BED MATERIAL, WATER YEAR OCTOBER 1968 TO SEPTEMBER 1969

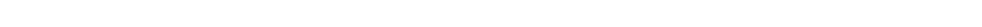

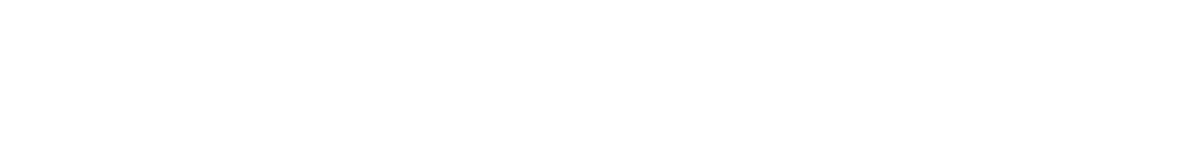

11147070 SANTA RITA CREEK NEAR TEMPLETON, CALIF.

LOCATION.--Lat $35^{\circ} 31^{\prime} 26^{\prime \prime}$, long $120^{\circ} 45^{\prime} 54^{\prime \prime}$, in Asuncion Grant, San Luis Obispo County, at gaging station 2.6 miles upstream from Paso Róbles Creek and 4 miles west of Tempieton.

DRAINAGE AREA. -- $18.2 \mathrm{sq} \mathrm{m} 1$.

PERIOD OF RECORD.--Wa ter temperatures: October 1967 to September 1969.

Sediment records: October 1967 to September 1969.

EXTREMES. --1968-69;

Sediment concentrations: Maximum da11y, 5,470 mg/1 Jan, 19; minimum da $11 \mathrm{y}$, no flow for many days.

Sediment discharge: Maximum daily, 30,500 tons Jan. 19; minimum da11y, $D$ ton on many days.

Pertod of record:

Sediment concentrations: Maximum dally, 5,470 mg/l Jan, 19, 1969; minimum daily, no flow for many days each Sediment discharge: Maximum da1ly, 30,500 tons Jan. 19, 1969; minimum da1ly, o ton on many days each year.

REMARKS. --No flow Oct. 1 to Dec. 14, July 25 to Sept. 30.

TEMPERATURE $\left({ }^{\circ} \mathrm{C}\right)$ OF WATER, WATER YEAR OCTOBER 1968 TO SEPTEMBER 1969 (ONCE-DAILY MEASUREMENT)

DAY

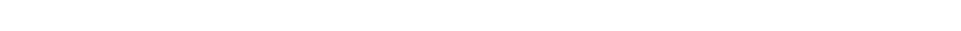

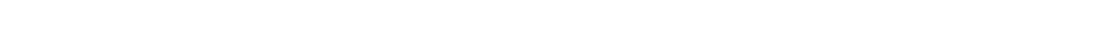

JANUARY.. =- 8 -

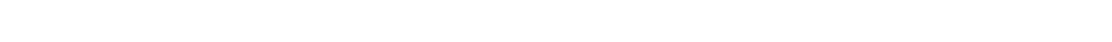

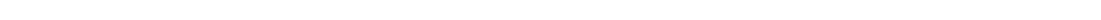

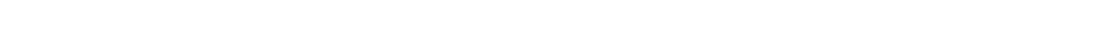

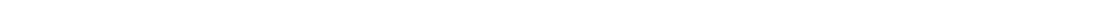

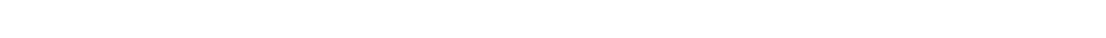


11147070 SANTA RITA CREEK NEAR TEMPLETON, CALIF.--Continued

SUSPENDED-SEDIMENT DISCHARGE, WATER YEAR OCTOBER 1968 TO SEPTEMBER 1969

\begin{tabular}{|c|c|c|c|c|c|c|c|c|c|}
\hline \multirow[b]{2}{*}{ OAY } & \multicolumn{3}{|c|}{ OCTOBER } & \multicolumn{3}{|c|}{ NOVEMBER } & \multicolumn{3}{|c|}{ DECEMBER } \\
\hline & $\begin{array}{l}\text { MEAN } \\
\text { CISCHARGE } \\
\text { (CFS) }\end{array}$ & $\begin{array}{l}\text { MEAN } \\
\text { CONCEN- } \\
\text { IRATION } \\
\text { (MG/L) }\end{array}$ & $\begin{array}{l}\text { SEDIMENT } \\
\text { DI SCHARGE } \\
\text { (TONS/DAY) }\end{array}$ & $\begin{array}{l}\text { MEAN } \\
\text { OISCHARGE } \\
\text { (CFS) }\end{array}$ & $\begin{array}{l}\text { MEAN } \\
\text { CONCEN- } \\
\text { TRATION } \\
\text { (MG } / L)\end{array}$ & $\begin{array}{l}\text { SEDIMENT } \\
\text { DI SCHARGE } \\
\text { (TONS/DAY) }\end{array}$ & $\begin{array}{l}\text { MEAN } \\
\text { OISCHARGE } \\
\text { (CFS) }\end{array}$ & $\begin{array}{l}\text { MEAN } \\
\text { CDNCEN- } \\
\text { TRATION } \\
\text { (MG/L) }\end{array}$ & $\begin{array}{l}\text { SEDIMENT } \\
\text { DISCHARGE } \\
\text { (TONS/DAY) }\end{array}$ \\
\hline l & & & & & & & 0 & - & 0 \\
\hline 2 & & & & & & & 0 & -- & 0 \\
\hline 3 & & & & & & & 0 & - & 0 \\
\hline 4 & & & & & & & 0 & 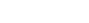 & 0 \\
\hline 5 & & & & & & & 0 & -- & 0 \\
\hline 6 & & & & & & & 0 & $\cdots$ & 0 \\
\hline 7 & & & & & & & 0 & - & 0 \\
\hline 8 & & & & & & & D & -- & 0 \\
\hline 9 & & & & & & & 0 & - & 0 \\
\hline 10 & & & & & & & 0 & - & 0 \\
\hline 11 & & & & & & & 0 & -- & 0 \\
\hline 12 & & & & & & & 0 & -- & 0 \\
\hline 13 & & & & & & & 0 & -- & 0 \\
\hline 14 & & & & & & & 0 & - & 0 \\
\hline 15 & & & & & & & 6.1 & 20 & .33 \\
\hline 16 & & & & & & & 13 & 170 & 9.0 \\
\hline 17 & & & & & & & 1.9 & 20 & .10 \\
\hline is & & & & & & & .90 & 15 & .04 \\
\hline 19 & & & & & & & .70 & 10 & .02 \\
\hline 20 & & & & & & & .60 & 5 & .01 \\
\hline 21 & & & & & & & .41 & 5 & .01 \\
\hline 22 & & & & & & & .35 & 4 & \\
\hline 23 & & & & & & & .35 & 3 & 0 \\
\hline 24 & & & & & & & .47 & 3 & 0 \\
\hline 25 & & & & & & & 20 & 190 & 21 \\
\hline 26 & & & & & & & 16 & 65 & 2.8 \\
\hline 27 & & & & & & & 4.7 & 17 & .22 \\
\hline 28 & & & & & & & 6.6 & 25 & .45 \\
\hline 29 & & & & & & & 9.8 & 25 & .66 \\
\hline 30 & & & & & & & 4.2 & 4 & .05 \\
\hline 31 & & & & & & & 2.9 & 5 & .04 \\
\hline \multirow[t]{5}{*}{ TOTAL } & 0 & - & 0 & 0 & -- & 0 & 68.98 & -- & 34.73 \\
\hline & & JANU ARY & & & FEBRUARY & & & MARCH & \\
\hline & & MEAN & & & MEAN & & & MEAN & \\
\hline & MEAN & CONCEN- & SEDIMENT & MEAN & CONCEN- & SEDIMENT & MEAN & CONCEN- & SEDIMENT \\
\hline & DISCHARGE & IRATION & DISCHARGE & DISCHARGE & TRATION & DI SCHARGE & DI SCHARGE & TRATION & DI SCHARGE \\
\hline DAY & (CFS) & $(M G / L)$ & (TONS/DAY) & (CFS) & $(M G / L)$ & (TONS/DAY & (CFS) & $(M G / L)$ & (TONS/DAY) \\
\hline 1 & 2.3 & 5 & .03 & 55 & 18 & 2.7 & 178 & 260 & 125 \\
\hline 2 & 1.9 & 4 & .02 & 44 & 16 & 1.9 & 122 & 102 & 34 \\
\hline 3 & 1.7 & 4 & .02 & 39 & 14 & 1.5 & 94 & 69 & 18 \\
\hline 4 & 1.5 & 4 & .02 & 34 & 12 & 1.1 & 75 & 64 & 13 \\
\hline 5 & 1.5 & 4 & .02 & 70 & 77 & 24 & 52 & 50 & 7.0 \\
\hline 6 & 1.3 & 4 & .01 & 200 & 275 & 150 & 51 & 64 & 8.8 \\
\hline 7 & 1.3 & 4 & .01 & 105 & 285 & 81 & 46 & 59 & 1.3 \\
\hline g & 1.3 & 4 & .01 & 74 & 150 & 30 & 41 & 48 & 5.3 \\
\hline 9 & 1.3 & 4 & .01 & 59 & 60 & 9.6 & 38 & 43 & 4.4 \\
\hline 10 & 1.2 & 4 & .01 & 50 & 30 & 4.1 & 37 & 142 & 14 \\
\hline 11 & 1.2 & 4 & .01 & 44 & 20 & 2.4 & 26 & 44 & 3.1 \\
\hline 12 & 1.3 & 4 & .01 & 54 & 40 & 5.8 & 19 & 127 & 6.5 \\
\hline 13 & 41 & 79 & 33 & 41 & 30 & 3.3 & 10 & 40 & 1.9 \\
\hline 14 & 64 & 105 & 18 & 29 & 23 & 1.8 & 19 & 753 & 44 \\
\hline 15 & 22 & 82 & 4.9 & 254 & 832 & 690 & 19 & 120 & 6.2 \\
\hline 16 & 11 & 38 & 1.1 & 137 & 73 & 27 & 18 & 18 & .87 \\
\hline 17 & & 20 & & 89 & 40 & 9.6 & 18 & 8 & .39 \\
\hline is & 185 & 763 & $1350^{\circ}$ & 77 & 50 & $10^{\circ}$ & 16 & 7 & .30 \\
\hline 19 & 1710 & 5470 & 30500 & 68 & 43 & 7.9 & 15 & 5 & .20 \\
\hline 20 & 742 & 2420 & 6060 & 55 & 18 & 2.7 & 15 & 367 & 19 \\
\hline 21 & $58 ?$ & 965 & 2460 & 63 & 253 & 78 & 16 & 300 & 13 \\
\hline 22 & 113 & 500 & 234 & 94 & 200 & 51 & 13 & 7 & \\
\hline 23 & 79 & 250 & 53 & 338 & 1230 & 1670 & 12 & 12 & .39 \\
\hline 24 & 366 & 1740 & 3290 & 1210 & 4170 & 17300 & 12 & 12 & .39 \\
\hline 25 & 1740 & 4280 & 27400 & 452 & 1300 & 1970 & 11 & 11 & .33 \\
\hline 26 & 602 & 1380 & 2600 & 206 & 210 & 117 & 9.4 & 7 & .18 \\
\hline 27 & 226 & 310 & 189 & 129 & 150 & 52 & 6.8 & 7 & .17 \\
\hline 28 & 184 & 228 & 117 & 238 & 984 & 749 & 7.7 & 9 & .19 \\
\hline 29 & 122 & 100 & 33 & - & - & - & 7.1 & 6 & .12 \\
\hline 30 & 97 & 25 & 6.5 & -- & -- & - & 6.5 & 6 & .11 \\
\hline 31 & 71 & 22 & 4.2 & - & - & - & 6.5 & 7 & .12 \\
\hline TOTAL & 7042.9 & - & 74414.32 & 4308 & - & 23053.4 & 1027.0 & -- & 334.51 \\
\hline
\end{tabular}


11147070 SANTA RITA CREEK NEAR TEXPLETON, CALIF.--COntinued

SUSPENDED-SEDIMENT DISCHARGE, WATER YEAR OCTOBER 1968 TO SEPTEMBER 1969

\begin{tabular}{|c|c|c|c|c|c|c|c|c|c|}
\hline DAY & $\begin{array}{l}\text { MEAN } \\
\text { DISCHARGE } \\
\text { (CFS) }\end{array}$ & $\begin{array}{l}\text { APRIL } \\
\text { MEAN } \\
\text { CONCEN- } \\
\text { TRATION } \\
\text { (MG/L) }\end{array}$ & $\begin{array}{l}\text { SEDIMENT } \\
\text { DISCHARGE } \\
\text { (TONS/DAY) }\end{array}$ & $\begin{array}{l}\text { MEAN } \\
\text { DISCHARGE } \\
\text { (CFS) }\end{array}$ & $\begin{array}{l}\text { MAY } \\
\text { MEAN } \\
\text { CONCEN- } \\
\text { TRATION } \\
\text { (MGLL) }\end{array}$ & $\begin{array}{l}\text { SEDIMENT } \\
\text { DI SCHARGE } \\
\text { (TONS/DAY) }\end{array}$ & $\begin{array}{l}\text { MEAN } \\
\text { DISCHARGE } \\
\text { (CFS) }\end{array}$ & $\begin{array}{l}\text { JUNE } \\
\text { MEAN } \\
\text { CONCEN- } \\
\text { TRAIION } \\
\text { (MGLL) }\end{array}$ & $\begin{array}{l}\text { SEDIMENT } \\
\text { DISCHARGE } \\
\text { (TONS/DAY) }\end{array}$ \\
\hline $\begin{array}{l}1 \\
2 \\
3 \\
4 \\
5\end{array}$ & $\begin{array}{r}6.5 \\
9.4 \\
14 \\
7.7 \\
121\end{array}$ & $\begin{array}{r}45 \\
156 \\
289 \\
16 \\
728\end{array}$ & $\begin{array}{l}10^{.07} \\
20^{.07} \\
415^{.33}\end{array}$ & $\begin{array}{l}7.1 \\
7.1 \\
7.1 \\
6.8 \\
6.2\end{array}$ & $\begin{array}{l}3 \\
3 \\
3 \\
3 \\
2\end{array}$ & $\begin{array}{l}.06 \\
.06 \\
.06 \\
.06 \\
.03\end{array}$ & $\begin{array}{l}2.4 \\
2.5 \\
2.3 \\
2.4 \\
2.4\end{array}$ & $\begin{array}{l}4 \\
5 \\
6 \\
4 \\
2\end{array}$ & $\begin{array}{l}.03 \\
.03 \\
.04 \\
.03 \\
.01\end{array}$ \\
\hline $\begin{array}{r}6 \\
7 \\
8 \\
9 \\
10\end{array}$ & $\begin{array}{l}89 \\
49 \\
38 \\
32 \\
28\end{array}$ & $\begin{array}{r}131 \\
32 \\
20 \\
16 \\
18\end{array}$ & $\begin{array}{l}37 \\
4.2 \\
2.1 \\
1.4 \\
1.4\end{array}$ & $\begin{array}{l}5.9 \\
6.0 \\
5.5 \\
5.1 \\
5.0\end{array}$ & $\begin{array}{r}4 \\
6 \\
8 \\
10 \\
7\end{array}$ & $\begin{array}{l}.06 \\
.10 \\
.12 \\
.14 \\
.09\end{array}$ & $\begin{array}{l}2.3 \\
2.2 \\
2.3 \\
2.4 \\
2.5\end{array}$ & $\begin{array}{l}4 \\
6 \\
6 \\
6 \\
6\end{array}$ & $\begin{array}{l}.02 \\
.04 \\
.04 \\
.04 \\
.04\end{array}$ \\
\hline $\begin{array}{l}11 \\
12 \\
13 \\
14 \\
15\end{array}$ & $\begin{array}{l}26 \\
24 \\
21 \\
19 \\
18\end{array}$ & $\begin{array}{l}17 \\
16 \\
12 \\
10 \\
11\end{array}$ & $\begin{array}{l}1.2 \\
1.0 \\
.68 \\
.51 \\
.53\end{array}$ & $\begin{array}{l}4.7 \\
4.3 \\
4.4 \\
4.2 \\
4.1\end{array}$ & $\begin{array}{l}5 \\
6 \\
8 \\
7 \\
6\end{array}$ & $\begin{array}{l}.06 \\
.07 \\
.10 \\
.08 \\
.07\end{array}$ & $\begin{array}{l}2.6 \\
2.5 \\
2.2 \\
2.1 \\
2.0\end{array}$ & $\begin{array}{r}7 \\
8 \\
8 \\
8 \\
10\end{array}$ & $\begin{array}{l}.05 \\
.05 \\
.05 \\
.05 \\
.05\end{array}$ \\
\hline $\begin{array}{l}16 \\
17 \\
18 \\
19 \\
20\end{array}$ & $\begin{array}{l}18 \\
17 \\
15 \\
14 \\
14\end{array}$ & $\begin{array}{r}12 \\
9 \\
6 \\
8 \\
9\end{array}$ & $\begin{array}{l}.58 \\
.41 \\
.24 \\
.30 \\
.34\end{array}$ & $\begin{array}{l}3.9 \\
3.3 \\
3.2 \\
3.0 \\
2.9\end{array}$ & $\begin{array}{l}4 \\
3 \\
4 \\
6 \\
4\end{array}$ & $\begin{array}{l}.04 \\
.03 \\
.03 \\
.05 \\
.03\end{array}$ & $\begin{array}{l}1.9 \\
1.8 \\
1.7 \\
1.5 \\
1.4\end{array}$ & $\begin{array}{l}12 \\
12 \\
12 \\
12 \\
12\end{array}$ & $\begin{array}{l}.06 \\
.06 \\
.06 \\
.05 \\
.05\end{array}$ \\
\hline $\begin{array}{l}21 \\
22 \\
23 \\
24 \\
25\end{array}$ & $\begin{array}{l}12 \\
12 \\
16 \\
14 \\
11\end{array}$ & $\begin{array}{l}4 \\
21 \\
10 \\
10 \\
10\end{array}$ & $\begin{array}{l}.13 \\
.68 \\
.43 \\
.38 \\
.30\end{array}$ & $\begin{array}{l}2.8 \\
2.7 \\
2.7 \\
2.7 \\
2.6\end{array}$ & $\begin{array}{l}3 \\
3 \\
4 \\
6 \\
8\end{array}$ & $\begin{array}{l}.02 \\
.02 \\
.03 \\
.04 \\
.06\end{array}$ & $\begin{array}{l}1.2 \\
1.0 \\
.89 \\
.74 \\
.62\end{array}$ & $\begin{array}{r}18 \\
24 \\
10 \\
6 \\
8\end{array}$ & $\begin{array}{l}.06 \\
.06 \\
.02 \\
.01 \\
.01\end{array}$ \\
\hline $\begin{array}{l}26 \\
27 \\
28 \\
29 \\
30 \\
31\end{array}$ & $\begin{array}{r}9.4 \\
9.8 \\
8.2 \\
7.7 \\
7.7 \\
-.-\end{array}$ & $\begin{array}{r}8 \\
6 \\
4 \\
3 \\
3 \\
-\end{array}$ & $\begin{array}{l}.20 \\
.14 \\
.09 \\
.06 \\
.06 \\
--\end{array}$ & $\begin{array}{l}2.5 \\
2.4 \\
2.3 \\
2.3 \\
2.1 \\
2.1\end{array}$ & $\begin{array}{l}6 \\
5 \\
6 \\
8 \\
6 \\
4\end{array}$ & $\begin{array}{l}.04 \\
.03 \\
.04 \\
.05 \\
.03 \\
.02\end{array}$ & $\begin{array}{l}.52 \\
.46 \\
.41 \\
.35 \\
.28 \\
.-\end{array}$ & $\begin{array}{l}10 \\
20 \\
31 \\
25 \\
22 \\
--\end{array}$ & $\begin{array}{l}.01 \\
.02 \\
.03 \\
.02 \\
.02 \\
.\end{array}$ \\
\hline TOTAL & 687.4 & - & 499.76 & 127.0 & -- & 1.72 & 49.87 & - & 1.11 \\
\hline
\end{tabular}

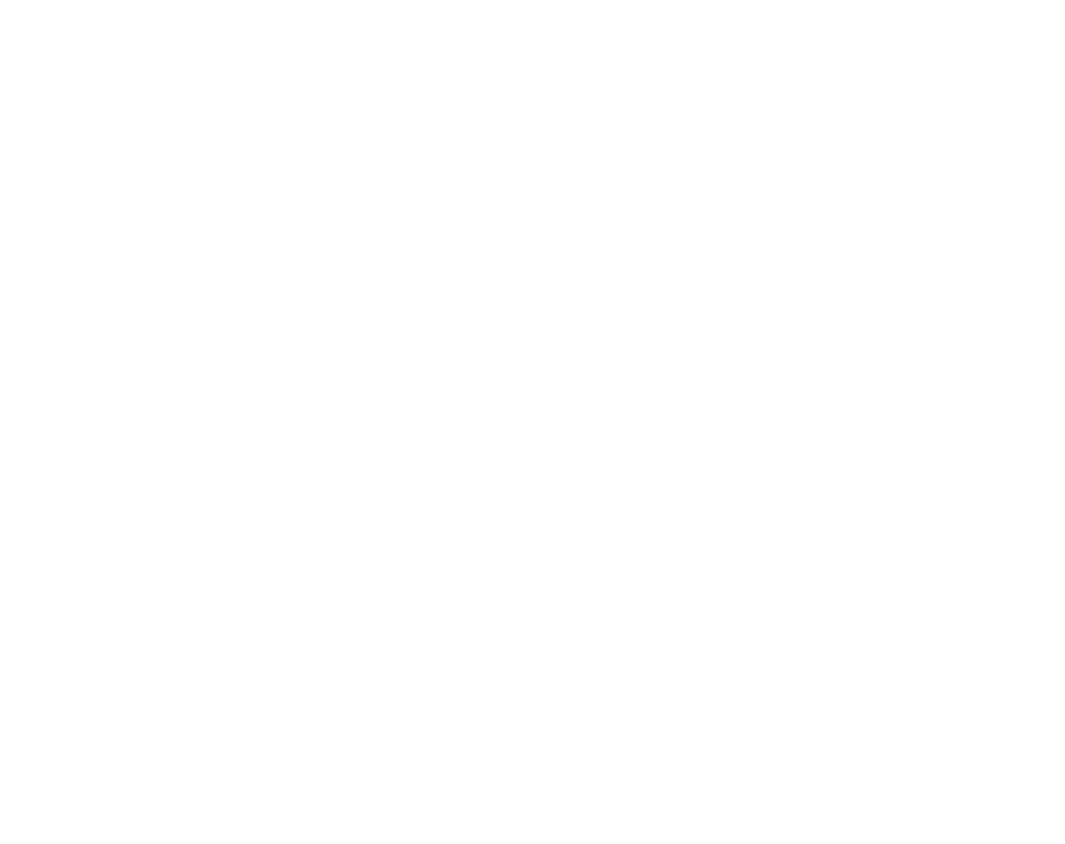


11147070 SANTA RITA CREEK NEAR TEMPLETON, CALIF.---Continued PARTICLE-SIZE DISTRIBUTION OF SUSPENDED SEDIMENT, WATER YEAR OCTOBER 1968 TO SEPTEMBER 1969
(METHODS OF ANALYSIS: B, BOTTOM WITHORAWAL TUBE; C, CHEMICALLY DISPERSED; N, IN NATIVE WATER; P, PIPET; S, SIEVE; V. VISUAL ACCUMULATION TUBE; W, IN DISTILLED WATER

\begin{tabular}{|c|c|c|c|c|c|c|c|c|c|c|c|c|c|c|c|c|c|c|c|}
\hline & DATE & TIME & $\begin{array}{l}\text { WATER } \\
\text { TEM- } \\
\text { PERA- } \\
\text { TURE } \\
(\text { C) }\end{array}$ & $\begin{array}{l}\text { OISCHARGE } \\
\text { (CFS) }\end{array}$ & $\begin{array}{l}\text { CONCEN- } \\
\text { TRATION } \\
\text { (MG/L) }\end{array}$ & $\begin{array}{l}\text { SUSPENDED } \\
\text { SEDIMENT } \\
\text { DISCHARGE } \\
\text { (TONSIDAY) }\end{array}$ & $\begin{array}{l}\text { PERCE } \\
.002\end{array}$ & ENT $F$ & FINE & & HAN T & THE $S$ & SIZE & IIN MI & AILLIME & JERSI & INDIC & CATEO & $\begin{array}{l}\text { METHOL } \\
\text { OF } \\
\text { ANALY } \\
\text { SIS }\end{array}$ \\
\hline $\begin{array}{l}F E B \\
F E B \\
\text { MAR }\end{array}$ & $\begin{array}{l}24 \ldots \ldots \\
24 \ldots \ldots \\
14 \ldots \ldots\end{array}$ & $\begin{array}{l}1400 \\
1600 \\
1730\end{array}$ & $\begin{array}{r}9 \\
10 \\
7\end{array}$ & $\begin{array}{r}530 \\
080 \\
22\end{array}$ & $\begin{array}{l}4700 \\
5900 \\
1560\end{array}$ & $\begin{array}{r}4800 \\
3100 \\
91\end{array}$ & $\begin{array}{l}22 \\
19 \\
47\end{array}$ & $\begin{array}{l}24 \\
24 \\
58\end{array}$ & $\begin{array}{l}4 \\
8\end{array}$ & $\begin{array}{l}34 \\
31 \\
74\end{array}$ & $\begin{array}{l}43 \\
39 \\
92\end{array}$ & $\begin{array}{l}52 \\
48 \\
99\end{array}$ & $\begin{array}{r}63 \\
57 \\
100\end{array}$ & $\begin{array}{l}79 \\
74 \\
-\end{array}$ & $\begin{array}{l}96 \\
96 \\
-\end{array}$ & $\begin{array}{l}100 \\
100 \\
-\end{array}$ & $=-$ & $=$ & $\begin{array}{l}\text { VPWC } \\
\text { VPWC } \\
\text { SPWC }\end{array}$ \\
\hline
\end{tabular}

11148800 NACIMIENTO RIVER NEAR BRYSON, CALIF.

LOCATION. --Lat $35^{\circ} 48^{\prime} 06^{\prime \prime}$, long $121^{\circ} 06^{\prime} 50^{\prime \prime}$, in NW $0.6 \mathrm{mile}$ upstream from Turtle Creek, $1.6 \mathrm{miles}$ west of Bryson, and $10 \mathrm{miles}$ southwest of Lockwood.

DRAINAGE AREA, $-140 \mathrm{sq} \mathrm{mi}$.

PERIOD OF RECORD. -- Wa ter temperatures: March 1958 to September 1959, October 1960 to September 1964 , March 1965 to September 1969

Sediment records: March 1958 to September 1959, October 1960 to September 1964, March 1965 to September 1969.

EXTREMES. --1968-69:

Sediment concentrations: Maximum daily, 4,360 mg/1 Jan. 25; minimum daily, no flow for many days.

Sediment discharge: Maximum daily, 242,000 tons Jan. 25; minimum daily, 0 ton on many days.

Period of record:

Sediment concentrations: Maximum daily, 6,860 mg/1 Nov. 13, 1960; minimum daily, no flow for many days each

Sediment discharge: Maximum daily, 242,000 tons Jan. 25, 1969; minimum daily, 0 ton on many days each year.

REMARKS.-No flow Oct. 1 to Dec. 10, Aug. 2 to Sept. 30.

REVISIONS. --Revised figures for mean discharge, sediment concentration, and sediment load for the water year 1967, superseding those previously published, are given herewith:

Dec. 6, 1966: Water discharge, 24,600 cfs; sediment concentration, $1,520 \mathrm{mg} / 1$; sediment discharge, 128,000 tons.

TEMPERATURE $\left({ }^{\circ} \mathrm{C}\right)$ OF WATER, WATER YEAR OCTOBER 1968 TO SEPTEMBER 1969 (ONCE-DAILY MEASUREMENT)

oAY

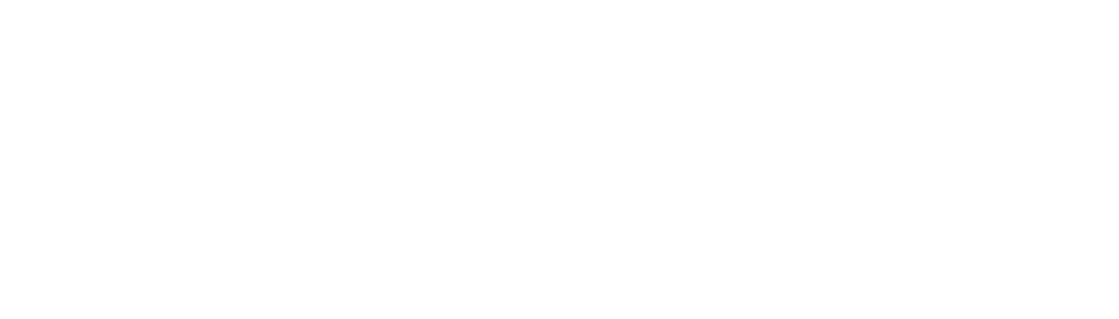

PARTICLE-SIZE DISTRIBUTION OF SUSPENDED SEDIMENT, WATER YEAR OCTOBER 1968 TO SEPTEMBER 1969 PARTICLE-SIZE DISTRIBUTION OF SUSPENDED SEDIMENT, WATER YEAR OCTOBER 1958 TO SEPTEMBER 1969
(METHODS OF ANALYSIS: B, BOTIOM WITHDRAWAL TUSE: C, CHEMICALLY DISPERSEO; N, IN NATIVE WATER: P. PIPET; S, SILVE:
V, VISUAL ACCUMULATION TUBE; W, IN DISTILLEO WATER)

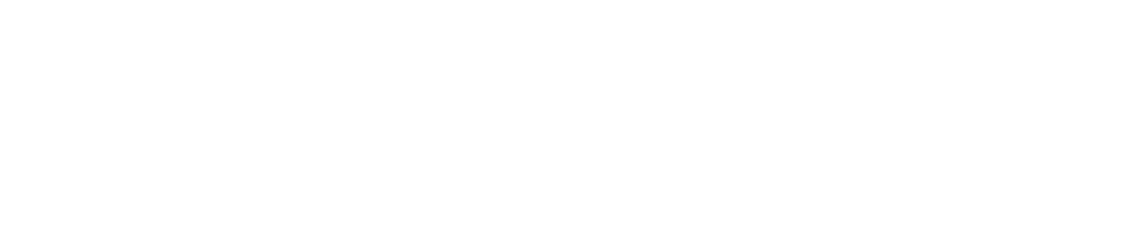


SALINAS RIVER BASIN

11148800 NACIMIENTO RIVER NEAR BRYSON, CALIF.--COntinued

SUSPENDED-SEDIMENT DISCHARGE, WATER YEAR DCTOBER 1968 TO SEPTEMBER 1969

OCTOBER

CONCEN- SEDIMENT TRATION DISCHARGE
(MG/L)

AY SCHARG
DI SCANARGE

NOVEMBER

DECEMBER

MEAN SEDIMENT MRATIDN DISCHARGE
MEAN ISCHARGE (CFS )

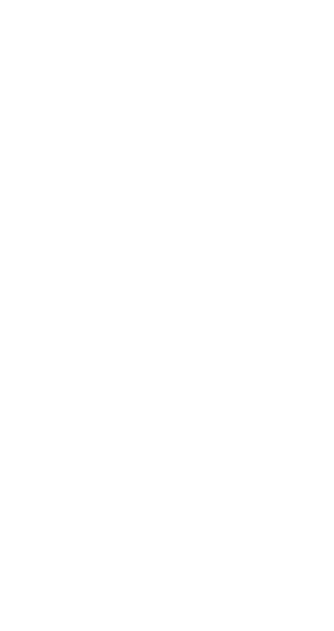

SEDIMENT (RATION DISCHARGE
(MG/L) (TONS/DAY)

$$
\begin{array}{r}
1 \\
2 \\
3 \\
4 \\
5 \\
6 \\
7 \\
8 \\
9 \\
10 \\
11 \\
12 \\
13 \\
14 \\
15 \\
16 \\
17 \\
18 \\
19 \\
20 \\
21 \\
22 \\
23 \\
24 \\
25 \\
26 \\
27 \\
28 \\
29 \\
30 \\
31 \\
191 \\
191 \\
\hline
\end{array}
$$

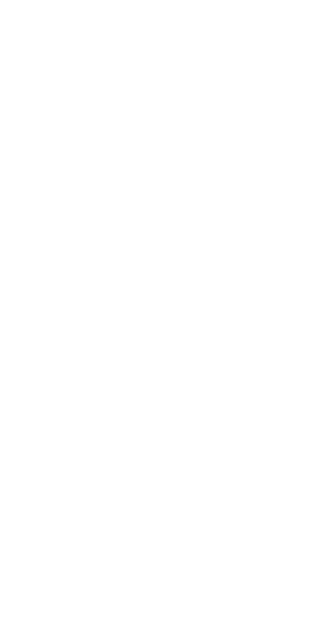$$
\begin{array}{ll}
=- & 0 \\
=- & 0 \\
=- & 0 \\
=- & 0 \\
=- & 0 \\
-- & 0
\end{array}
$$

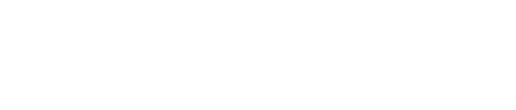

\section{FEBRUARY}

3211.2

CONCEN- SEDIMENT RATION DISCHARG

MARCH (CFS) IMGILI (TONSIDAY) D.

MEAN

MEAN
CONCEN- SEDIMENT $\begin{array}{ll}\text { CONCEN- } & \text { SEDIMENT } \\ \text { IRAIIDN } & \text { DISCHARGE }\end{array}$ DAY

89
73
66
56
52
46
42
38
35
33

4
3
3
3
3

$\begin{array}{ll}.96 & 984 \\ .59 & 850 \\ .53 & 742 \\ .45 & 665 \\ .42 & 1310\end{array}$

11
8
7
6

29
18
14
11
892

2320
1700
1340

1340
1050
812

628

1700
307

307
68

68
25
14

628
550

477
426

IMG/LI

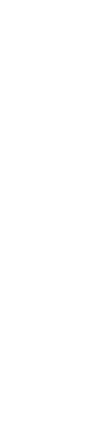

369.91

$\begin{array}{cc}90 & 564 \\ 25 & 115 \\ 13 & 47 \\ 12 & 34 \\ 11 & 24 \\ 6 & 10 \\ 5 & 7.4 \\ 4 & 5.2 \\ 4 & 4.6 \\ 3 & 3.2 \\ 2 & 1.9 \\ 2 & 1.7 \\ 2 & 1.6 \\ 2 & 1.5 \\ 2 & 1.3 \\ 3 & 1.8 \\ 3 & 1.7 \\ 2 & 1.0 \\ 1 & .49 \\ 1 & .47 \\ 2 & 1.0 \\ 2 & .87 \\ 6 & 2.4 \\ 11 & 4.1 \\ 8 & 2.7 \\ 5 & 1.6 \\ 4 & 1.2 \\ 4 & 1.1 \\ 3 & .76 \\ 3 & .70 \\ 3 & .67\end{array}$

\section{6}

81

346

346
320

301

243

225

207
193

183

175

188
161
149

149
137

125000

127

$\begin{array}{rr}155 & 1190 \\ 70 & 374 \\ 200 & 1510 \\ -- & -- \\ - & --\end{array}$

119
110

104
94

86
83

.76
.67

1170

88588

$546972.14 \quad 61160$

-- 160721

13517

844.96 
11148800 NACIXIENTO RIVER NEAR BRYSON, CALIF.--CONt1nued

SUSPENDED-SEDIMENT DISCHARGE, WATER YEAR OCTOBER 1968 TO SEPTEMBER 1969

\begin{tabular}{|c|c|c|c|c|c|c|c|c|c|}
\hline & & APR IL & & & MAY & & & JUNE & \\
\hline DAY & $\begin{array}{l}\text { MEAN } \\
\text { DISCHARGE } \\
\text { (CFS) }\end{array}$ & $\begin{array}{l}\text { MEAN } \\
\text { CONCEN- } \\
\text { TRATION } \\
\text { (MG/L) }\end{array}$ & $\begin{array}{l}\text { SEDIMENT } \\
\text { DI SCHARGE } \\
\text { (TONS/DAY) }\end{array}$ & $\begin{array}{l}\text { MEAN } \\
\text { DI SCHARGE } \\
\text { (CFS) }\end{array}$ & $\begin{array}{l}\text { MEAN } \\
\text { CONCEN- } \\
\text { IRATION } \\
\text { (MG/L) }\end{array}$ & $\begin{array}{l}\text { SEDIMENT } \\
\text { DI SCHARGE } \\
\text { (TONS/DAY) }\end{array}$ & $\begin{array}{l}\text { MEAN } \\
\text { DI SCHARGE } \\
\text { (CFS) }\end{array}$ & $\begin{array}{l}\text { MEAN } \\
\text { CONCEN- } \\
\text { TRATION } \\
\text { (MGIL) }\end{array}$ & $\begin{array}{l}\text { SEDIMENT } \\
\text { DI SCHARGE } \\
\text { (TONS/DAY) }\end{array}$ \\
\hline 1 & 77 & 3 & .62 & 76 & 2 & .41 & 18 & I & .05 \\
\hline$?$ & 43 & 4 & 1.0 & 73 & 1 & .20 & 18 & I & .05 \\
\hline 3 & 219 & 8 & 4.7 & 70 & 1 & .19 & 18 & 1 & .05 \\
\hline 4 & 130 & 2 & .70 & 70 & 1 & .19 & 20 & 1 & .05 \\
\hline 5 & 538 & 178 & 436 & 68 & l & .18 & 20 & 1 & .05 \\
\hline 6 & 850 & 160 & 367 & 60 & 2 & .32 & 22 & 1 & .06 \\
\hline 7 & 530 & 30 & 43 & 58 & 2 & .31 & 22 & 1 & .06 \\
\hline 9 & 389 & 6 & 6.3 & 58 & 3 & .47 & 21 & 1 & .06 \\
\hline 9 & 329 & 2 & 1.8 & 58 & 2 & .31 & 24 & 1 & .06 \\
\hline 10 & 291 & 1 & .79 & 56 & 2 & .30 & 27 & 1 & .07 \\
\hline 11 & 260 & 1 & .70 & 54 & 1 & .15 & 28 & 1 & .08 \\
\hline 12 & 225 & 1 & .61 & 48 & 1 & .13 & 30 & 1 & .08 \\
\hline 13 & 206 & i & .56 & 44 & 1 & .12 & 27 & 1 & .07 \\
\hline 14 & 191 & i & .52 & 44 & 1 & .12 & 24 & 1 & .06 \\
\hline 15 & 179 & 1 & .48 & 45 & 2 & .24 & 21 & 1 & .06 \\
\hline 16 & 155 & 2 & .84 & 43 & 2 & .23 & 19 & 1 & .05 \\
\hline 17 & 146 & 3 & 1.2 & 40 & 1 & .11 & 19 & 1 & .05 \\
\hline 18 & 137 & 6 & 2.2 & 36 & 1 & .10 & 18 & 1 & .05 \\
\hline 19 & 131 & 2 & .71 & 35 & 1 & .09 & 18 & 1 & .05 \\
\hline 20 & 128 & 1 & .35 & 33 & 1 & .09 & 16 & 1 & .04 \\
\hline 21 & 119 & 1 & .32 & 32 & 1 & .09 & 16 & 1 & .04 \\
\hline 22 & 113 & i & .31 & 30 & i & .00 & 16 & $i$ & .04 \\
\hline 23 & 134 & 2 & .72 & 28 & 1 & .08 & 15 & 1 & .04 \\
\hline 24 & 140 & 3 & 1.1 & 28 & 1 & .08 & 14 & 1 & .04 \\
\hline 25 & 113 & 2 & .61 & 27 & 1 & .07 & 12 & 4 & .13 \\
\hline 26 & 107 & 1 & .29 & 24 & 1 & .06 & 11 & 4 & .12 \\
\hline 27 & 95 & $i$ & .26 & 25 & i & .07 & il & 4 & .12 \\
\hline 29 & 86 & 2 & .46 & 24 & 1 & .06 & 9.8 & 4 & .11 \\
\hline 29 & 83 & 3 & .67 & 21 & 1 & .06 & 9.1 & 4 & .10 \\
\hline 30 & 83 & 2 & .45 & 20 & 1 & .05 & 8.4 & 4 & .09 \\
\hline 31 & -- & -- & -- & 18 & 1 & .05 & - & -- & -- \\
\hline \multirow[t]{4}{*}{ TOTAL } & 6277 & -- & 875.27 & 1346 & -- & 5.01 & 552.3 & -- & 1.98 \\
\hline & \multicolumn{3}{|c|}{ JULY } & \multicolumn{3}{|c|}{ AUGUST } & \multicolumn{3}{|c|}{ SEPTEMBER } \\
\hline & & $\begin{array}{l}\text { MEAN } \\
\text { CDNCEN- }\end{array}$ & SEDIMENT & & MEAN & SEDTMENT & & MEAN & \\
\hline & DISCHARGE & TRATION & DISCHARGE & DISCHARGE & TRATION & DISCHARGE & $\begin{array}{l}\text { MEAN } \\
\text { DISCHARGE }\end{array}$ & $\begin{array}{l}\text { CONCEN- } \\
\text { TRATION }\end{array}$ & DI SCHARGE \\
\hline DAY & (CFS) & $(M G / L)$ & (TCNS/DAY) & (CFS) & (MG/L) & (TONS / DAY) & (CFS) & $(M G / L)$ & (TONS/DAY) \\
\hline
\end{tabular}

$$
\begin{array}{llllll}
7.8 & 3 & .06 & .05 & 1 & 0 \\
7.1 & 3 & .06 & 0 & -- & 0 \\
6.5 & 3 & .05 & 0 & -- & 0 \\
5.4 & 3 & .04 & 0 & -- & 0 \\
4.9 & 3 & .04 & 0 & -- & 0
\end{array}
$$$$
\begin{array}{lllllll}
3 & 6.5 & 3 & .05 & 0 & -- & 0 \\
4 & 5.4 & 3 & .04 & 0 & -- & 0 \\
5 & 4.9 & 3 & .04 & 0 & -- & 0 \\
6 & 4.4 & 3 & .04 & 0 & -- & 0 \\
7 & 4.0 & 3 & .03 & 0 & -- & 0 \\
8 & 4.0 & 3 & .03 & 0 & -- & 0 \\
0 & 4.0 & 3 & .03 & 0 & -- & 0 \\
10 & 4.0 & 3 & .03 & 0 & -- & 0
\end{array}
$$$$
\begin{array}{lllllll}
11 & 3.6 & 5 & .05 & 0 & -- & 0 \\
12 & 3.2 & 8 & .07 & 0 & -- & 0 \\
13 & 2.8 & 4 & .03 & 0 & -- & 0 \\
14 & 2.5 & 3 & .02 & 0 & -- & 0 \\
15 & 2.5 & 2 & .01 & 0 & - & 0
\end{array}
$$$$
\begin{array}{lllllll}
16 & 2.3 & 2 & .01 & 0 & -- & 0 \\
17 & 2.3 & 2 & .01 & 0 & -- & 0 \\
18 & 2.0 & 2 & .01 & 0 & -- & 0 \\
19 & 2.0 & 2 & .01 & 0 & -- & 0 \\
70 & 2.0 & 2 & .01 & 0 & -- & 0
\end{array}
$$$$
\begin{array}{lllllll}
21 & 1.7 & 2 & .01 & 0 & -- & 0 \\
22 & 1.3 & 2 & .01 & 0 & -- & 0 \\
23 & .96 & 2 & .01 & 0 & -- & 0 \\
24 & .73 & 2 & 0 & 0 & -- & 0 \\
25 & .73 & 2 & 0 & 0 & -- & 0
\end{array}
$$$$
\begin{array}{lllllll}
26 & .62 & 1 & 0 & 0 & -- & 0 \\
27 & .62 & 1 & 0 & 0 & -- & 0 \\
28 & .54 & 1 & 0 & 0 & -- & 0
\end{array}
$$$$
\begin{array}{lllllll}
27 & .62 & 1 & 0 & 0 & - & 0 \\
28 & .54 & 1 & 0 & 0 & -- & 0 \\
29 & .46 & 1 & 0 & 0 & - & 0 \\
30 & .32 & 1 & 0 & 0 & - & 0 \\
31 & .20 & 1 & 0 & 0 & - & 0
\end{array}
$$

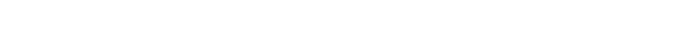

TOTAL DISCHARGE FOR YEAR ICFS-DAYSI 
11149900 SAN ANTONIO RIVER NEAR LOCKWOOD, CALIF.

LOCATION, --Lat $35^{\circ} 53^{\prime} 48^{\prime \prime}$, long $121^{\circ} 05^{\prime} 14^{\prime \prime}$, 1n Los Ojitos Grant, Monterey County, at gaging station at highway bridge, $0.4 \mathrm{~m} 1 \mathrm{e}$ upstream from Tule Canyon and $3.3 \mathrm{miles}$ south of Lockwood.

DRAINAGE AREA, --223 sq mi.

PERIOD OF RECORD. --Water temperatures: October 1965 to September 1969.

Sediment records: October 1965 to September 1969

EXTREMES . - - 1968-69

Sediment concentrat1ons: Max1mum da1ly, $6,880 \mathrm{mg} / 1 \mathrm{Jan}, 25$; min1mum daily, no flow for many days.

Sediment discharge: Maximum daily, 158,000 tons Jan. 25; minimum daily, 0 ton on many days.

Period of record:

Sediment concent rations: Maximum daily, 7,420 mg/1 Dec. 6,1966 ; minimum da1ly, no flow for many days each

Sed1ment discharge: Maximum daily, 161,000 tons Dec, 6, 1966; minimum daily, 0 ton on many days each year.

REMARKS. -- No flow Oct. 1 to Dec. 16, July 24 to Sept. 30.

TEMPERATURE $\left({ }^{\circ} \mathrm{C}\right)$ OF WATER, WATER YEAR OCTOBER 1968 TO SEPTEMBER 1969 (ONCE-DAILY MEASUREMENT)

oAY

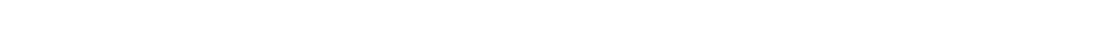

OCTOBER.. -- -- -- - - - - - - - - -

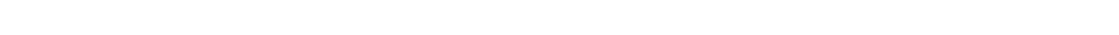

JANUARY.. -- -- 13 -- -- - - 12 FEBRUARY. 11 is 13 10 10 9

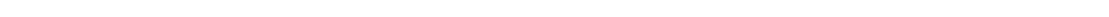
MAY.....

JULY....

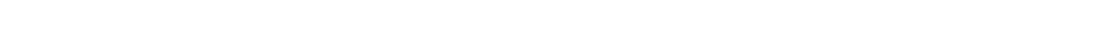

PARTICLE-SIZE DISTRIBUTION OF SUSPENDED SEDIMENT, WATER YEAR OCTOBER 1968 TO SEPTEMBER 1969

PARTICLE-SLZE DISTRIBUTION OF SUSPENDED SEDIMENT, WATER YEAR OCTOBER 1968 TO SEPTEMBER 1969
1METHOOS OF ANALYSIS: B, BOTTOM WITHDRAWAL IUBE: C, CHEMICALLY DISPERSED: N, IN NATIVE WATER; P, PLPET; S, SIEVE; $\checkmark$, VISUAL ACCUMULATION TURE; $W$, IN DISTILLED WAIERI

$$
\begin{aligned}
& V \text {. VISUAL aCCUMULATION TURE; W. IN DISTILLED WATER I } \\
& \text { PARTICLE SILE }
\end{aligned}
$$

TEM-

SUSPENDED

DATE TIME $I C$ C ISCHARGE TRATION DISCHARGE

PERCENT fINER thaN THE SILE (IN MLLLIMETERS) INDICATED METHO OF
ANALY JAN 14,1969083511 JAN $15 \ldots \ldots .0815$ JAN $19 \ldots \ldots .1720 \quad 12$ JAN $21 \ldots \ldots . \cdots, 0845 \quad 1505$

JAN $22 \ldots \ldots .0820 \quad 10$

JAN $22 \ldots \ldots . .1210 \quad 11$

JAN $25 \ldots \ldots .0900 \quad 12$

JAN $26 \ldots \ldots \ldots .1225 \quad 12$

JAN $27 \ldots \ldots . \quad 1115 \quad 10$ JAN $29 \ldots \ldots .11320 \quad 10$

$\begin{array}{rrr}1140 & 4240 & 13100 \\ 440 & 258 & 307 \\ 6340 & 3360 & 57500 \\ 2990 & 3630 & 29300 \\ 6190 & 4360 & 72900 \\ & & \\ 2730 & 4200 & 31000 \\ 2420 & 1820 & 11900 \\ 8220 & 10700 & 237000 \\ 8500 & 5620 & 129000 \\ 4880 & 4320 & 56900 \\ & & \\ 2480 & 1860 & 12500 \\ 1170 & 627 & 1980 \\ 964 & 554 & 1440\end{array}$

$\begin{array}{rrrrr}2 & 3 & 4 & 5 & 6 \\ -12 & 2 & 4 & 5 & 6 \\ 15 & 15 & 20 & 26 & 33 \\ 3 & 5 & 6 & 8 & 9 \\ 10 & 12 & 17 & 22 & 31 \\ 3 & 4 & 5 & 7 & 8 \\ 3 & 7 & 9 & 12 & 16 \\ 5 & 13 & 16 & 20 & 26 \\ 11 & 13 & 15 & 21 & 28 \\ 10 & 9 & 13 & 18 & 23 \\ 7 & 9 & & & \\ 5 & 7 & 8 & 11 & 15 \\ 2 & 3 & 6 & 8 & 9 \\ -- & - & 1 & 2 & 3\end{array}$

$\begin{array}{rrrrrr}8 & 12 & 35 & 87 & 97 & 100 \\ 2 & 20 & 35 & 69 & 96 & 100 \\ 1 & 59 & 74 & 85 & 99 & 100 \\ 6 & 41 & 74 & 92 & 98 & 100 \\ 2 & 67 & 84 & 95 & 100 & -- \\ 4 & 33 & 66 & 80 & 94 & 100 \\ 3 & 46 & 81 & 92 & 100 & -- \\ 5 & 55 & 80 & 95 & 99 & 100 \\ 8 & 71 & 89 & 94 & 99 & 100 \\ 3 & 67 & 91 & 96 & 99 & 100 \\ 9 & 39 & 83 & 98 & 100 & -- \\ 4 & 28 & 76 & 95 & 99 & 100 \\ 5 & 13 & 61 & 93 & 100 & -\end{array}$

PARTICLE-SIZE DISTRIBUTION OF SURFACE BED MATERIAL, WATER YEAR OCTOBER 1968 YO SEPTEMBER 1969

\begin{tabular}{|c|c|c|c|c|c|c|c|c|c|c|c|c|c|c|c|c|}
\hline \multirow{2}{*}{\multicolumn{2}{|c|}{ DATE }} & \multirow[b]{2}{*}{ TLME } & \multirow[t]{2}{*}{$\begin{array}{l}\text { WATER } \\
\text { I UM- } \\
\text { PERA- } \\
\text { TURE } \\
\text { I CI }\end{array}$} & $\begin{array}{l}\text { NUMBER } \\
\text { UF } \\
\text { SAM- } \\
\text { PLING }\end{array}$ & DISCHARGE & & \multicolumn{9}{|c|}{ PARTICLE SIZE } & \\
\hline & & & & POINTS & ICFSI & .062 & .125 & .250 & .500 & 1.00 & 2.00 & 4.00 & 8.00 & 16.0 & 32.0 & 64.0 \\
\hline DEC & 10,1968 & 1345 & & 5 & 0 & - & 1 & 6 & 29 & 50 & 65 & 73 & 80 & 87 & 100 & -- \\
\hline$O E C$ & $17 \ldots \ldots$ & 1515 & & 3 & 14 & - & -- & 2 & 25 & 63 & 89 & 97 & 98 & 100 & -- & -- \\
\hline JAN & 22,1969 & 1210 & & 5 & 2420 & -- & -- & 1 & 11 & 33 & 65 & 83 & 92 & 98 & 100 & -- \\
\hline JAN & $26 \ldots \ldots$ & 1225 & & 5 & 8500 & - & -- & $i$ & 5 & 30 & 60 & 79 & 90 & 100 & -- & - \\
\hline JAN & $26 \ldots \ldots$ & 1635 & & 5 & 4880 & -- & -- & -- & 3 & 24 & 55 & 74 & 85 & 100 & -- & -- \\
\hline JAN & $27 \ldots \ldots$ & 1115 & & 5 & 2480 & -- & -- & 1 & 5 & 29 & 65 & 85 & 93 & 100 & -- & -- \\
\hline JAN & $27 \ldots \ldots$ & 1320 & & 5 & 1170 & -- & 5 & 23 & 44 & 63 & 80 & 87 & 93 & 100 & -- & -- \\
\hline FEB & $11 \ldots \ldots$ & 1740 & & 5 & 592 & -- & - & 6 & 30 & 56 & 74 & 83 & 89 & 96 & 100 & - \\
\hline FEB & $25 \ldots \ldots$ & 1700 & & 5 & 2610 & -- & 3 & 17 & 35 & 52 & 70 & 80 & 87 & 94 & 100 & -- \\
\hline MAY & $16 \ldots \ldots$ & 1340 & & 3 & 70 & -- & - & 3 & 30 & 69 & 88 & 94 & 98 & 100 & -. & -- \\
\hline JUN & $26 \ldots \ldots$ & 1530 & & 3 & 16 & -- & -- & 4 & 34 & 72 & 90 & 96 & 99 & 100 & -- & -- \\
\hline
\end{tabular}

(METHOO OF AVALYSIS: H, HYDROMETER: 0, OPTICAL ANALYZER; S, SIEVE: Y, VISUAL ACCUMULATIDN TUBE

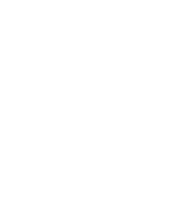


11149900 SAN ANTONIO RIVER NEAR LOCKWOOD, CALIF.--Continued

SUSPENDED-SEDIMENT DISCHARGE, WATER YEAR OCTOBER 1968 TO SEPTEMBER 1969

OCTOBER

NOVEMBER

CONCEN- SEDIMENT

TRATION DISCHARGE

MEAN
DISCHARGE
(CFS)

MEAN

CONCEN- SEDIMENT TRATION DISCHARGE

MEAN
DISCHARGE DISCHARGE

DECEMBER

DAY OISCHARGE (CFS)

DAY

0

MEAN

SEDIMENT
DISCHARGE
TRATIUN DISCHARGE
(MG/L) (TONS/DAY)

10
10
10
9

$\begin{array}{ll}1.7 & 666 \\ 1.5 & 526 \\ 1.4 & 400 \\ 1.1 & 336 \\ .91 & 397\end{array}$

MEAN MEAN (CFS) IRATION

$\begin{array}{ll}128 & 230 \\ 252 & 358 \\ 158 & 171 \\ 217 & 197 \\ 420 & 450\end{array}$

230
358
171
197
450

1590

6960
1180

1180
358

358
276

130
100

276
187

$\begin{array}{rr}200 & 341 \\ 316 & 1070 \\ 60 & 110 \\ 50 & 76\end{array}$

76
4240

819

494

$\begin{array}{rr}150 & 494 \\ 80 & 218 \\ 300 & 774 \\ 210 & 474\end{array}$

21
12
1320
43700
27200

1220

259
182
499
5500

30
25
191
2800
3050

43700
27200

956
836

\section{0}

2580
1360

4760

73600

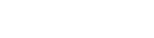

$\begin{array}{rr}370 & 1360 \\ 470 & 2220 \\ 6880 & 158000\end{array}$

158000
138000

16800
9570
2760
649

580
586
924
4330

25

25
20
279
2030

\section{.}

7830
2820
2110

1310
1010
836

1680

780

238
160

-.

513882.46

2240

1600
1930

2030
1360

39
32
840

840
29100

29100
11000

$\begin{array}{ll}280 & 1690 \\ 100 & 432 \\ 240 & 1250\end{array}$

240

1250

46978

$\because-$

$\overline{--}$

-- 62594

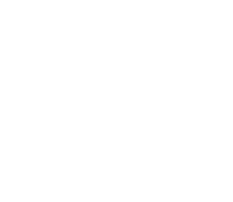

$\because \quad=-\quad 0$

$\begin{array}{lll}0 & -- & 0 \\ 0 & -- & 0\end{array}$

$\begin{array}{lll}0 & 34 & 0\end{array}$

14
12

13
12
12
14

12
120

236
132

132
97
97
80

$\begin{array}{ll}3 & 1.2 \\ 3 & .11 \\ 2 & .00\end{array}$

2
2
5
162

.07
.06
.06

$85^{.06}$

$346 \quad 225$

$\begin{array}{ll}97 & 35 \\ 39 & 10 \\ 78 & 20\end{array}$

35
10
20
8.2
2.9

937

387.96

MARCH

MEAN
CONCEN- SEDIMENT

TRATION DISCHARGE

(MG/L) (TONS/DAY)

$1680 \quad 200 \quad 907$

$1290 \quad 150 \quad 522$

$\begin{array}{lll}914 & 140 & 386\end{array}$

$722 \quad 190 \quad 370$

$\begin{array}{lll}722 & 190 & 370 \\ 610 & 250 & 412\end{array}$

562

508

465

152

100
150

231

430
420

400

376
350

222

$210-258$

$200 \quad 216$

$\begin{array}{ll}190 & 193 \\ 190 & 180\end{array}$

IUTAL $\quad 4697$

31767

328

$\begin{array}{lll}319 & 180 & 159\end{array}$

$\begin{array}{lll}302 & 180 & 147 \\ 278 & 190 & 143\end{array}$

$\begin{array}{lll}266 & 196 & 141 \\ 255 & 190 & 131 \\ 247 & 150 & 100 \\ 236 & 130 & 83\end{array}$

$\begin{array}{lll}236 & 130 & 83 \\ 225 & 120 & 73\end{array}$

$\begin{array}{lll}218 & 110 & 65 \\ 218 & 100 & 59\end{array}$

$218 \quad 90$

208

201
194

80
70
62

6639 
11149900 SAN ANTONIO RIVER NEAR LOCKWOOD, CALIF.--Conti nued

SUSPENDED-SEDIMENT DISCHARGE, WATER YEAR OCTOBER 1968 TO SEPTEMBER 1969

APRIL $\begin{array}{clc}\text { MEAN } & \text { MEAN } & \\ \text { CONCEN- } & \text { SEDIMENT } \\ \text { DISCHARGE } & \text { TRATION } & \text { DISCHARGE } \\ \text { (CFS) } & \text { (MG/L) } & \text { (TONS/DAY) }\end{array}$ $\begin{array}{clc}\text { MEAN } & \text { CONCEN- } & \text { SEDIMENT } \\ \text { DISCHARGE } & \text { TRATION } & \text { DISCHARGE } \\ \text { (CFS) } & \text { (MG/L) } & \text { (TONS/DAY) }\end{array}$ MEAN
DI SCHARGE
(CFS)

MAY

JUNE 183
176
179
153
$2 C 8$

72
78
120
100

36
37
58
41

58
41
101

298
251
240

240
200

152

100

100

125
68

68
65
56

100

95
90
90
86

38
32
29
27
24

70

20

20
16
15
12
12

81

MEAN CONCEN- SEDIMENT TRATION DISCHARGE
(MG/L) (TONS/DAY)

$\begin{array}{clc}\text { MEAN } & \text { MEAN } & \\ \text { CONCEN- } & \text { SEDIMENT } \\ \text { OISCHARGE } & \text { TRATION } & \text { DISCHARGE } \\ \text { (CFS) } & \text { (MG/L) } & \text { (TONS/DAY) }\end{array}$

3

30
30
30
30
30

$\begin{array}{ll}6.6 & 34 \\ 6.7 & 35 \\ 6.7 & 34 \\ 6.5 & 32 \\ 5.9 & 31\end{array}$

105

100
96

92
88

60
58
50
50

73

65
59
58
60

9
9
9

.83
.85
.83
.78

$\begin{array}{ll}5.3 & 30 \\ 4.8 & 31 \\ 4.7 & 28\end{array}$

$\begin{array}{ll}4.7 & 28 \\ 5.7 & 28 \\ 6.0 & 29\end{array}$

$\begin{array}{ll}6.0 & 27 \\ 7.1 & 27 \\ 8.1 & 29 \\ 8.4 & 26\end{array}$

8.1

$\begin{array}{ll}8.1 & 24 \\ 7.0 & 22 \\ 6.6 & 21\end{array}$

$\begin{array}{ll}5.7 & 22 \\ 4.6 & 20\end{array}$

$\begin{array}{ll}21 & 85 \\ 22 & 84\end{array}$

$\begin{array}{ll}22 & 84 \\ 23 & 90 \\ 24 & 95 \\ 25 & 92\end{array}$

$\begin{array}{rl}50 & 11 \\ 50 & 11 \\ 50 & 12 \\ 100 & 26\end{array}$

$31 \quad 49$

$\begin{array}{ll}26 & 85 \\ 27 & 80 \\ 28 & 76 \\ 29 & 76\end{array}$

$\begin{array}{ll}30 & 78 \\ 31 & --\end{array}$

TOTAL 4005

126

$\begin{array}{ll}23 & 45 \\ 15 & 44\end{array}$

10

8.2
6.5

$\begin{array}{ll}3.8 & 19 \\ 2.9 & 19\end{array}$

2.9

$\begin{array}{ll}1.6 & 17 \\ 1.3 & 15\end{array}$

$\begin{array}{ll}1.2 & 14 \\ 1.2 & 14 \\ 1.2 & 14 \\ 1.2 & 14 \\ 1.1 & 14 \\ 1.1 & -2\end{array}$

713

SEPTEMBER

JULY

1011.7

AUGUST

MEAN
CONCEN- SEDIMENT

MEAN CONCEN- SEDIMENT $\begin{array}{cl}\text { ISCHARGE } & \text { TRATIUN } \\ \text { (CFS) } & \text { (MG/L) }\end{array}$

MEAN DISCHARGE
(CFS) ISCHARGE
(CFS)

MEAN

CONCEN- SEDIMENT TRATION DISCHARGE

14
13
13
13
12

$\begin{array}{ll}7 & .26 \\ 7 & .25 \\ 6 & .21 \\ 6 & .21 \\ 6 & .19 \\ 5 & .15 \\ 5 & .16 \\ 5 & .16 \\ 5 & .15 \\ 5 & .15\end{array}$

$\begin{array}{lll}11 & -12 & .15 \\ 12 & 2 & -116\end{array}$

$\begin{array}{rl}6 & 11 \\ 7 & 12 \\ 9 & 12 \\ 9 & 11\end{array}$

10

11211

12
13
14
15

10

9.9

40.10

$\begin{array}{llll}16 & 8.2 & 3 & .07\end{array}$

$\begin{array}{llll}17 & 7.8 & 3 & .06 \\ 18 & 7.1 & 3 & .06 \\ 19 & 6.7 & 3 & .05 \\ 20 & 6.0 & 3 & .05\end{array}$

$\begin{array}{llll}21 & 5.2 & 3 & .04 \\ 22 & 3.5 & 3 & .03 \\ 23 & .57 & 3 & 0 \\ 24 & 0 & -- & 0 \\ 25 & 0 & -- & 0\end{array}$

26
27
28
29
30
31

TOTAL

216.27

--
$=-$
$=-$
$=-$
$=-$

0
0

$\begin{array}{lll}0 & -- & 0 \\ 0 & - & 0 \\ 0 & -- & 0 \\ 0 & -- & 0 \\ 0 & -- & 0 \\ 0 & & 0\end{array}$

TOTAL DISCHARGE FOR YEAR ICFS-DAYS

TOTAL SUSPENDED-SEDIMENT DISCHARGE FOR YEAR (IONS) 
11151870 ARROYO SECO NEAR GREENFIELD, CALIF.

LOCATION, --Lat $36^{\circ} 14^{\prime} 15^{\prime \prime}$, I Ing $121^{\circ} 28^{\prime} 50^{\prime \prime}$, in NEłSE sec.36, T.19 S., R.4 E., Monterey County, at gaglng station 0.6 mile downstrean from Rocky Creek and 14.5 miles southwest of Greenfield.

DRAINAGE AREA, - $-113 \mathrm{sq} \mathrm{mi}$.

PERIOD OF RECORD, - Water temperatures: October 1962 to September 1969.

Sediment records: October 1962 to September 1969

EXTR EM ES . --1968-69:

Sediment concentrations: Maximum daily, 1,340 ng $/ 1 \mathrm{Jan} .25$; minimum daily, $1 \mathrm{mg} / 1$ on many days.

Sediment concentrations: Maximum daily, 1,340 mg/1 Jan. 25 ; minimum daily, 1 mg/l on many days.
Sediment discharge: Maximum daily, 38,200 tons Jan. 25; minimum daily, 0 ton on several days during October.

Period of record:

Wa ter temperatures (1964-66): Minimum, 4.0 $0^{\circ} \mathrm{C}$ Dec, $18,20-24,1965$.

Sediment concentrations: Maximum daily, 3,040 mg/l Dec, 6, 1966; mintmum daily, no flow Aug. 25-27, 1966,

Aug. 17, 1968 .

Sediment discharge: Maximum daily, 84,800 tons Dec. 6, 1966; minimum daily, 0 ton on many days tn 1966 and 1968

TEMPERATURE $\left({ }^{\circ} \mathrm{C}\right)$ OF WATER, WATER YEAR OCTOBER 1968 TO SEPTEMBER 1969

(ONCE-DAILY MEASUREMENT)

$$
\text { DAY }
$$

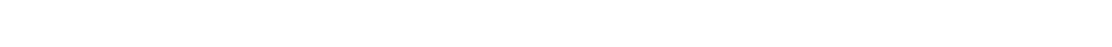

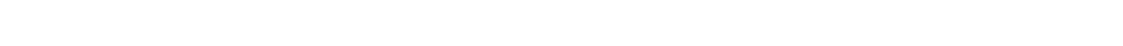
$\begin{array}{lrrrrrrrrrrrrrrrrrrrrrrrrrrrrrrrrrrrr}\text { NIVEMBER: } & 14 & 14 & 14 & 14 & 12 & 13 & 11 & 14 & 15 & 15 & 13 & 14 & 12 & 10 & 12 & 12 & 13 & 13 & 12 & 12 & -2 & 12 & 11 & -2 & 9 & 10 & 9 & 7 & 8 & 9 & -5 & 12 \\ \text { UECEMAFR. } & 8 & 7 & 7 & 7 & 7 & 6 & 8 & 9 & 7 & 9 & 9 & 7 & 8 & 9 & 9 & 8 & 7 & 6 & 6 & -2 & -- & 5 & -- & 6 & 8 & 8 & 6 & 8 & -- & -- & 6 & 7\end{array}$

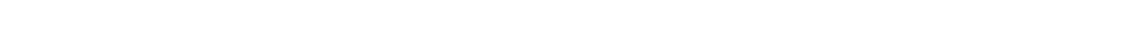

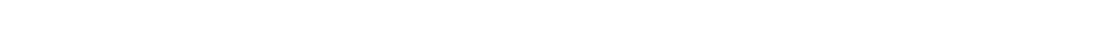

APRIL.... - -

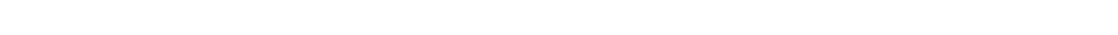

Juty.....

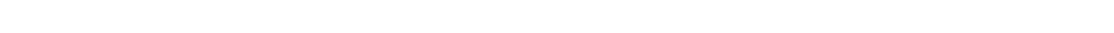

PARTICLE-SIZE DISTRIBUTION OF SUSPENDED SEDIMENT, WATER YEAR OCTOBER 1968 TO SEPTEMBER 1969 IMLTHDOS UF ANALYSIS: B, BOTTOM WITHORAWAL TUBE; C, CHEMICALLY DISPERSED; N. IN NATIVE WATER; P, PIPEI: S, SIEVE: $\checkmark$ VISUAL ACCUMULATION TUBE; W, IN DISTILLEO WATER

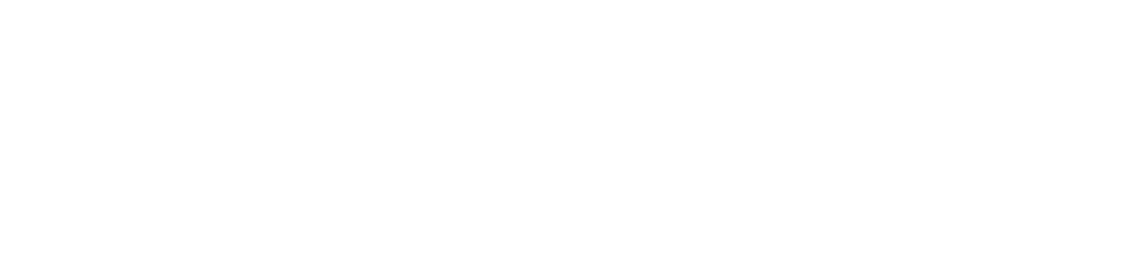


11151870 ARROYO SECO NEAR GREENFIELD, CALIF.--Continued

SUSPENDED-SEDIMENT DISCHARGE, WATER YEAR OCTOBER 1968 TO SEPTEMBER 1969

\begin{tabular}{|c|c|c|c|c|c|c|c|c|c|}
\hline & & OCTOBER & & & NOVEMBER & & & DECEMBER & \\
\hline DAY & $\begin{array}{l}\text { MEAN } \\
\text { DISCHARGE } \\
\text { (CFS) }\end{array}$ & $\begin{array}{l}\text { MEAN } \\
\text { CONCEN- } \\
\text { TRATION } \\
\text { (MG/L) }\end{array}$ & $\begin{array}{l}\text { SEDIMENT } \\
\text { DISCHARGE } \\
\text { (TONS/DAY) }\end{array}$ & $\begin{array}{l}\text { MEAN } \\
\text { DISCHARGE } \\
\text { (CFS) }\end{array}$ & $\begin{array}{l}\text { MEAN } \\
\text { CONCEN- } \\
\text { TRATION } \\
\text { (MG/L) }\end{array}$ & $\begin{array}{l}\text { SEDIMENT } \\
\text { DI SCHARGE } \\
\text { (TONS/DAY) }\end{array}$ & $\begin{array}{l}\text { MEAN } \\
\text { DISCHARGE } \\
\text { (CFS) }\end{array}$ & $\begin{array}{l}\text { MEAN } \\
\text { CONCEN- } \\
\text { TRATION } \\
\text { (MG /L) }\end{array}$ & $\begin{array}{l}\text { SEDIMENT } \\
\text { DISCHARGE } \\
\text { (TONS/DAY) }\end{array}$ \\
\hline $\begin{array}{l}1 \\
2 \\
3 \\
4 \\
5\end{array}$ & $\begin{array}{l}.60 \\
.75 \\
.90 \\
1.0 \\
.90\end{array}$ & $\begin{array}{r}3 \\
4 \\
10 \\
14 \\
5\end{array}$ & $\begin{array}{l}0 \\
.01 \\
.02 \\
.04 \\
.01\end{array}$ & $\begin{array}{l}4.2 \\
4.5 \\
14 \\
13 \\
7.5\end{array}$ & $\begin{array}{l}1 \\
1 \\
3 \\
4 \\
5\end{array}$ & $\begin{array}{l}.01 \\
.01 \\
.11 \\
.14 \\
.10\end{array}$ & $\begin{array}{l}8.4 \\
8.5 \\
8.0 \\
7.8 \\
7.7\end{array}$ & $\begin{array}{l}1 \\
2 \\
3 \\
1 \\
1\end{array}$ & $\begin{array}{l}.02 \\
.05 \\
.06 \\
.02 \\
.02\end{array}$ \\
\hline $\begin{array}{r}6 \\
7 \\
8 \\
9 \\
10\end{array}$ & $\begin{array}{l}.80 \\
1.2 \\
1.3 \\
1.5 \\
1.6\end{array}$ & $\begin{array}{l}3 \\
1 \\
1 \\
1 \\
1\end{array}$ & $\begin{array}{l}.01 \\
0 \\
0 \\
0 \\
0\end{array}$ & $\begin{array}{l}6.3 \\
5.9 \\
5.7 \\
5.6 \\
5.5\end{array}$ & $\begin{array}{l}1 \\
1 \\
1 \\
1 \\
2\end{array}$ & $\begin{array}{l}.02 \\
.02 \\
.02 \\
.02 \\
.03\end{array}$ & $\begin{array}{l}7.8 \\
8.0 \\
8.5 \\
8.2 \\
9.5\end{array}$ & $\begin{array}{r}1 \\
7 \\
1 \\
7 \\
10\end{array}$ & $\begin{array}{l}.02 \\
.15 \\
.02 \\
.15 \\
.26\end{array}$ \\
\hline $\begin{array}{l}11 \\
12 \\
13 \\
14 \\
15\end{array}$ & $\begin{array}{l}1.6 \\
1.9 \\
2.5 \\
3.6 \\
3.3\end{array}$ & $\begin{array}{l}1 \\
2 \\
4 \\
1 \\
2\end{array}$ & $\begin{array}{l}0 \\
.01 \\
.03 \\
.01 \\
.02\end{array}$ & $\begin{array}{l}5.6 \\
5.7 \\
5.7 \\
6.3 \\
20\end{array}$ & $\begin{array}{l}1 \\
1 \\
1 \\
1 \\
3\end{array}$ & $\begin{array}{l}.02 \\
.02 \\
.02 \\
.02 \\
.16\end{array}$ & $\begin{array}{r}28 \\
17 \\
13 \\
70 \\
142\end{array}$ & $\begin{array}{r}7 \\
1 \\
1 \\
20 \\
24\end{array}$ & $\begin{array}{r}.53 \\
.05 \\
.04 \\
5.5 \\
21\end{array}$ \\
\hline $\begin{array}{l}16 \\
17 \\
18 \\
19 \\
20\end{array}$ & $\begin{array}{l}3.0 \\
2.8 \\
2.7 \\
2.6 \\
2.5\end{array}$ & $\begin{array}{l}2 \\
1 \\
1 \\
1 \\
1\end{array}$ & $\begin{array}{l}.02 \\
.01 \\
.01 \\
.01 \\
.01\end{array}$ & $\begin{array}{l}16 \\
12 \\
10 \\
10 \\
9.6\end{array}$ & $\begin{array}{l}1 \\
1 \\
1 \\
2 \\
3\end{array}$ & $\begin{array}{l}.04 \\
.03 \\
.03 \\
.05 \\
.08\end{array}$ & $\begin{array}{r}114 \\
38 \\
26 \\
22 \\
20\end{array}$ & $\begin{array}{r}20 \\
2 \\
1 \\
2 \\
2\end{array}$ & $\begin{array}{r}7.9 \\
.21 \\
.07 \\
.12 \\
.11\end{array}$ \\
\hline $\begin{array}{l}21 \\
22 \\
23 \\
24 \\
25\end{array}$ & $\begin{array}{l}2.5 \\
2.5 \\
2.5 \\
2.5 \\
2.5\end{array}$ & $\begin{array}{l}1 \\
1 \\
1 \\
1 \\
1\end{array}$ & $\begin{array}{l}.01 \\
.01 \\
.01 \\
.01 \\
.01\end{array}$ & $\begin{array}{l}9.3 \\
9.2 \\
9.0 \\
8.8 \\
8.8\end{array}$ & $\begin{array}{l}2 \\
1 \\
2 \\
8 \\
1\end{array}$ & $\begin{array}{l}.05 \\
.02 \\
.05 \\
.19 \\
.02\end{array}$ & $\begin{array}{r}18 \\
16 \\
16 \\
25 \\
296\end{array}$ & $\begin{array}{r}2 \\
2 \\
1 \\
2 \\
44\end{array}$ & $\begin{array}{r}.10 \\
.09 \\
.04 \\
48^{.24}\end{array}$ \\
\hline $\begin{array}{l}26 \\
27 \\
28 \\
29 \\
30 \\
31\end{array}$ & $\begin{array}{l}2.4 \\
2.4 \\
2.5 \\
2.7 \\
3.3 \\
3.8\end{array}$ & $\begin{array}{l}1 \\
1 \\
1 \\
2 \\
2 \\
1\end{array}$ & $\begin{array}{l}.01 \\
.01 \\
.01 \\
.01 \\
.02 \\
.01\end{array}$ & $\begin{array}{l}8.9 \\
9.0 \\
8.6 \\
8.5 \\
8.4 \\
.-\end{array}$ & $\begin{array}{r}1 \\
1 \\
2 \\
1 \\
2 \\
-\end{array}$ & $\begin{array}{l}.02 \\
.02 \\
.05 \\
.02 \\
.05 \\
.-\end{array}$ & $\begin{array}{r}248 \\
101 \\
95 \\
88 \\
60 \\
48\end{array}$ & $\begin{array}{l}8 \\
2 \\
7 \\
7 \\
1 \\
1\end{array}$ & $\begin{array}{l}6.4 \\
.55 \\
2.5 \\
1.7 \\
.16 \\
.13\end{array}$ \\
\hline TOIAL & 66.65 & -- & .34 & 261.6 & - & 1.44 & 1583.4 & - & 96.21 \\
\hline DAY & $\begin{array}{l}\text { MEAN } \\
\text { DISCHARGE } \\
\text { (CFS) }\end{array}$ & $\begin{array}{l}\text { JANUARY } \\
\text { MEAN } \\
\text { COVCEN- } \\
\text { TRATION } \\
\text { (MG/LI) }\end{array}$ & $\begin{array}{l}\text { SEDIMENT } \\
\text { DI SCHARGE } \\
\text { (TONS/DAY) }\end{array}$ & $\begin{array}{c}\text { MEAN } \\
\text { DISCHARGE } \\
\text { (CFS) }\end{array}$ & $\begin{array}{l}\text { FEBRUARY } \\
\text { MEAN } \\
\text { CONCEN- } \\
\text { TRATION } \\
\text { (MG/L) }\end{array}$ & $\begin{array}{l}\text { SEDIMENT } \\
\text { DISCHARGE } \\
\text { (TONS/DAY) }\end{array}$ & $\begin{array}{l}\text { MEAN } \\
\text { OISCHARGE } \\
\text { (CFS) }\end{array}$ & $\begin{array}{l}\text { MARCH } \\
\text { MEAN } \\
\text { CONCEN- } \\
\text { TRATION } \\
\text { IMG/L) }\end{array}$ & $\begin{array}{l}\text { SEDIMENT } \\
\text { DISCHARGE } \\
\text { (TONS/DAY) }\end{array}$ \\
\hline $\begin{array}{l}1 \\
2 \\
3 \\
4 \\
5\end{array}$ & $\begin{array}{l}40 \\
35 \\
31 \\
28 \\
26\end{array}$ & $\begin{array}{l}1 \\
1 \\
2 \\
1 \\
1\end{array}$ & $\begin{array}{l}.11 \\
.09 \\
.08 \\
.08 \\
.07\end{array}$ & $\begin{array}{l}736 \\
663 \\
602 \\
621 \\
897\end{array}$ & $\begin{array}{r}7 \\
6 \\
4 \\
4 \\
22\end{array}$ & $\begin{array}{l}14 \\
11 \\
6.5 \\
6.7 \\
88\end{array}$ & $\begin{array}{l}2120 \\
1720 \\
1470 \\
1260 \\
1090\end{array}$ & $\begin{array}{l}33 \\
26 \\
26 \\
27 \\
15\end{array}$ & $\begin{array}{r}189 \\
121 \\
103 \\
92 \\
44\end{array}$ \\
\hline $\begin{array}{r}6 \\
7 \\
9 \\
10\end{array}$ & $\begin{array}{l}24 \\
22 \\
22 \\
20 \\
20\end{array}$ & $\begin{array}{l}1 \\
1 \\
1 \\
1 \\
1\end{array}$ & $\begin{array}{l}.06 \\
.06 \\
.06 \\
.05 \\
.05\end{array}$ & $\begin{array}{r}1580 \\
1180 \\
941 \\
811 \\
729\end{array}$ & $\begin{array}{r}44 \\
21 \\
12 \\
8 \\
6\end{array}$ & $\begin{array}{r}191 \\
67 \\
30 \\
18 \\
12\end{array}$ & $\begin{array}{l}967 \\
869 \\
785 \\
724 \\
681\end{array}$ & $\begin{array}{l}5 \\
3 \\
2 \\
2 \\
2\end{array}$ & $\begin{array}{l}13 \\
7.0 \\
4.2 \\
3.9 \\
3.7\end{array}$ \\
\hline $\begin{array}{l}11 \\
17 \\
17 \\
14 \\
15\end{array}$ & $\begin{array}{r}19 \\
19 \\
1560 \\
775 \\
304\end{array}$ & $\begin{array}{r}1 \\
1 \\
191 \\
28 \\
1\end{array}$ & $\begin{array}{c}.05 \\
1460^{.05} \\
59 \\
.82\end{array}$ & $\begin{array}{l}1100 \\
1490 \\
1070 \\
917 \\
2740\end{array}$ & $\begin{array}{r}21 \\
32 \\
12 \\
8 \\
101\end{array}$ & $\begin{array}{r}105 \\
129 \\
35 \\
20 \\
815\end{array}$ & $\begin{array}{l}613 \\
582 \\
537 \\
494 \\
459\end{array}$ & $\begin{array}{l}2 \\
2 \\
2 \\
1 \\
1\end{array}$ & $\begin{array}{l}3.3 \\
3.1 \\
2.9 \\
1.3 \\
1.2\end{array}$ \\
\hline $\begin{array}{l}16 \\
17 \\
18 \\
19 \\
20\end{array}$ & $\begin{array}{r}179 \\
128 \\
1620 \\
5890 \\
3290\end{array}$ & $\begin{array}{r}1 \\
1 \\
134 \\
682 \\
209\end{array}$ & $\begin{array}{r}. .48 \\
1750^{.35} \\
11900 \\
2570\end{array}$ & $\begin{array}{r}1680 \\
1340 \\
1220 \\
1140 \\
999\end{array}$ & $\begin{array}{r}21 \\
10 \\
6 \\
5 \\
5\end{array}$ & $\begin{array}{l}95 \\
36 \\
20 \\
15 \\
13\end{array}$ & $\begin{array}{l}430 \\
409 \\
395 \\
377 \\
375\end{array}$ & $\begin{array}{l}1 \\
1 \\
1 \\
2 \\
2\end{array}$ & $\begin{array}{l}1.2 \\
1.1 \\
1.1 \\
2.0 \\
2.0\end{array}$ \\
\hline $\begin{array}{l}21 \\
22 \\
23 \\
24 \\
25\end{array}$ & $\begin{array}{l}6170 \\
2700 \\
1370 \\
1920 \\
9520\end{array}$ & $\begin{array}{r}694 \\
140 \\
40 \\
106 \\
1340\end{array}$ & $\begin{array}{r}13800 \\
1020 \\
148 \\
1190 \\
38200\end{array}$ & $\begin{array}{r}904 \\
841 \\
1240 \\
6240 \\
3430\end{array}$ & $\begin{array}{r}5 \\
4 \\
40 \\
686 \\
115\end{array}$ & $\begin{array}{c}12 \\
9.1 \\
157 \\
13700 \\
1120\end{array}$ & $\begin{array}{l}370 \\
342 \\
323 \\
309 \\
295\end{array}$ & $\begin{array}{l}2 \\
2 \\
2 \\
2 \\
2\end{array}$ & $\begin{array}{l}2.0 \\
1.8 \\
1.7 \\
1.7 \\
1.6\end{array}$ \\
\hline $\begin{array}{l}26 \\
27 \\
29 \\
29 \\
30 \\
31\end{array}$ & $\begin{array}{r}8590 \\
2870 \\
1810 \\
1280 \\
1030 \\
846\end{array}$ & $\begin{array}{r}1310 \\
150 \\
40 \\
15 \\
10 \\
9\end{array}$ & $\begin{array}{r}37500 \\
1160 \\
195 \\
52 \\
28 \\
21\end{array}$ & $\begin{array}{r}2410 \\
1900 \\
2420 \\
=- \\
=- \\
--\end{array}$ & $\begin{array}{l}55 \\
29 \\
64 \\
=- \\
-\therefore\end{array}$ & $\begin{array}{r}358 \\
149 \\
429 \\
-- \\
--\end{array}$ & $\begin{array}{l}281 \\
270 \\
260 \\
251 \\
243 \\
236\end{array}$ & $\begin{array}{l}2 \\
2 \\
2 \\
2 \\
2 \\
2\end{array}$ & $\begin{array}{l}1.5 \\
1.5 \\
1.4 \\
1.4 \\
1.3 \\
1.3\end{array}$ \\
\hline TOTAL & 52158 & -- & 111055.46 & 41841 & -- & 17661.3 & 19537 & -- & 617.2 \\
\hline
\end{tabular}


11151870 ARROYO SECO NEAR GREENFIELD, CALIF, --Continued

SUSPENDED-SEDIMENT DISCHARGE, WATER YEAR OCTOBER 1968 TO SEPTEMBER 1969

\begin{tabular}{|c|c|c|c|c|c|c|c|c|c|}
\hline & & $\triangle P R I L$ & & & MAY & & & JUNE & \\
\hline DAY & $\begin{array}{l}\text { MEAN } \\
\text { DISCHARGE } \\
\text { (CFS) }\end{array}$ & $\begin{array}{l}\text { MEAN } \\
\text { CONCEN- } \\
\text { TRATION } \\
\text { (MG/L) }\end{array}$ & $\begin{array}{l}\text { SEDIMENT } \\
\text { DISCHARGE } \\
\text { (TONS/DAY) }\end{array}$ & $\begin{array}{l}\text { MEAN } \\
\text { DISCHARGE } \\
\text { (CFS) }\end{array}$ & $\begin{array}{l}\text { MEAN } \\
\text { CONCEN- } \\
\text { TRATION } \\
\text { (MG/L) }\end{array}$ & $\begin{array}{l}\text { SEDIMENT } \\
\text { DISCHARGE } \\
\text { (TONS/DAY) }\end{array}$ & $\begin{array}{l}\text { MEAN } \\
\text { DISCHARGE } \\
\text { (CFS) }\end{array}$ & $\begin{array}{l}\text { MEAN } \\
\text { CONCEN- } \\
\text { TRATION } \\
\text { (MGIL) }\end{array}$ & $\begin{array}{l}\text { SEDI MENT } \\
\text { DI SCHARG } \\
\text { ITONS/DAY }\end{array}$ \\
\hline
\end{tabular}

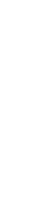

2
2
2
2
20

$\begin{array}{ll}1.2 & 127 \\ 1.3 & 126 \\ 1.5 & 124 \\ 1.2 & 124 \\ 31 & 119\end{array}$

127
126
124
124
119

2
2
2
2
2

.69
.68
.67
.67
.64

$\begin{array}{lll}63 & 5 & .85 \\ 64 & 5 & .86 \\ 63 & 5 & .85 \\ 62 & 5 & .84 \\ 63 & 5 & .85\end{array}$

$\begin{array}{ll}6 & 558 \\ 7 & 437 \\ 8 & 371\end{array}$

558
437
371
336

12

$\begin{array}{ll}12 & 116 \\ 3.5 & 114 \\ 2.0 & 112 \\ 1.8 & 111 \\ .80 & 108\end{array}$

271
253
236
225

225

$$
\begin{aligned}
& 8 \\
& 3 \\
& 2 \\
& 2 \\
& 1
\end{aligned}
$$

.31
.31
.30
.30

63
81
61
84

$\begin{array}{ll}.73 & 105 \\ .68 & 102\end{array}$

$\begin{array}{ll}.68 & 102 \\ .64 & 102\end{array}$

$\begin{array}{rr}.61 & 102 \\ .58 & 98\end{array}$

.28

.28
.28
.28
.28

66

66
65
60
56

.26

$\begin{array}{lll}16 & 201 & 1 \\ 17 & 190 & 1 \\ 18 & 183 & 1 \\ 19 & 176 & 1 \\ 20 & 169 & 1\end{array}$

$\begin{array}{ll}.54 & 96 \\ .51 & 92 \\ .49 & 90 \\ .48 & 89 \\ .46 & 85\end{array}$

169
162
159
184

96
92
90
89

$$
\begin{aligned}
& 21 \\
& 22 \\
& 23 \\
& 24 \\
& 25
\end{aligned}
$$$$
\begin{aligned}
& .44 \\
& .43 \\
& .50 \\
& .46 \\
& .42
\end{aligned}
$$

85
84

.50
.46
.42

82
80
78
76

.40
.38
1.1
1.4
1.1

26
27
28
29
30
31

148

148
142
137
134
130

1
1
3
4
3
--

75
76
73
69
67
64

68.652966

.26
.25
.24
.24
.23

50
49
52
54

.23

.44
.43
.21

51
49
46
43
42

.21
.20

TOTAL 7197

JULY

AUGUST

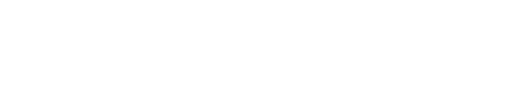

MEAN

$\begin{array}{ll}\text { CONCEN- } & \text { SEDIMENT } \\ \text { TRATION } & \text { DISCHARGE }\end{array}$

(MGIL) (TONS/DAY)
(TISATARE

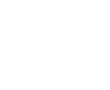

MEAN

CONCEN- SEDIMENT

TRATION DISCHARGE

35
33
32
31
30

$$
\begin{aligned}
& 5 \\
& 5 \\
& 5 \\
& 5 \\
& 5
\end{aligned}
$$

.47
.45
.43
.42
.41

13
13
12
10
9.8

.21
.18
.13
.11
.11

4.6
4.5
3.9
3.6
3.5

5
4
3
2
2

$$
\begin{aligned}
& .85 \\
& .82 \\
& .82 \\
& .86
\end{aligned}
$$

.89

$\begin{array}{rl}6 & 29 \\ 7 & 3 \\ 8 & 2 \\ 9 & 2 \\ 10 & 27\end{array}$

29
30
29
28
27

5
5
5
5
5

$\begin{array}{ll}.39 & 9.3 \\ .41 & 9.2 \\ .39 & 10 \\ .38 & 13\end{array}$

26

$\begin{array}{ll}11 & 26 \\ 12 & 25 \\ 13 & 25 \\ 14 & 24\end{array}$

5
5
5
5
5

.35
.34
.34
.32
.31

11

$.10 \quad 3$

.15
.22
.25
.18

3.8
5.5
0.7

5.5
6.7
5.6
4.8

.14
.14
.16
.16
.15

4.2
4.1

4.2
4.1
3.9
3.7

$\begin{array}{ll}3.7 & 4 \\ 3.9 & 5\end{array}$

.12
.12
.12
.12

4.1

4.7
5.0
5.4

.10
.09
.10
.10

5.9
6.2
5.8

5.8
5.5
5.1

.89
.88

.88
.81
.76

.76
.72

.68

.70
.73

.69

.66
.62
.58

. .98

.1

.53
.51

.51
.49
.-

$\begin{array}{ll}16 & 2 \\ 17 & 2 \\ 18 & 2 \\ 19 & 2 \\ 20 & 2\end{array}$

$\begin{array}{ll}21 & 19 \\ 22 & 18 \\ 23 & 17 \\ 24 & 17 \\ 25 & 17\end{array}$

6
6
6
12
16

.31
.29
.28
.55
.73

8.8
8.3
8.8
9.2
7.5

.73

7.5

$\begin{array}{ll}26 & 17 \\ 27 & 16 \\ 28 & 17 \\ 29 & 18 \\ 30 & 16 \\ 31 & 15\end{array}$

15
14
14
10
8

.69
.80
.84
.49
.35
.28

7.3
7.3
7.4
6.8

6.8
6.0
5.7

13.04

283.4

$\begin{array}{llrr}\text { TOTAL } & 720 & -- & 13.04\end{array}$

TOTAL OISCHARGE FOR YEAR (CFS-DAYS)
TOTAL SUSPENDED-SEDIMENT DISCHARGE FOR YEAR (TONS)

.06

4.9
4.9

5.2

4.8

3.89

144.4 
11152300 SALINAS RI VER NEAR ChUALAR, CALIF.

LOCATION.--Lat $36^{\circ} 33^{\prime} 14^{\prime \prime}$, Iong $121^{\circ} 32^{\prime} 50^{\prime \prime}$, In Guadalupe y Llanitos de Los Correos Grant, Monterey County, at county bridge on Chualar-River Road, 2 miles south west of Chualar and approximately $14 \mathrm{miles}$ upstream from gaging
station near Spreckels.

PERIOD OF RECORD.-- Water tenperatures: December 1966 to September 1969.

Sediment records: December 1966 to september 1969.

EXTREMES. --1968-69:

Sediment concentrations: Maximum daily, $18,900 \mathrm{mg} / 1$ Feb. 25 ; minimum daily, $6 \mathrm{mg} / 1$ Dec. 5 .

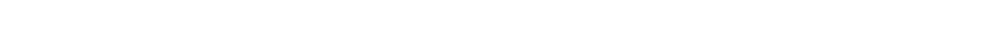

Pertod of record:

Sediment concentrations: Maximum daily, 18,900 mg/1 Feb. 25, 1969; minimum daily, no flow for several days in February and March 1968 .

Sediment discharge: Haximum da11y, 2,790,000 tons Feb. 26, 1969; minimum daily, 0 ton on severa 1 days in February and March 1968 .

REMARKS. - Chemical-quality data published for this station th the 1967 water year are now reported as Salinas River near Spreckels (station 11152500). Records of discharge are given for Salinas River near Spreckels (station 11152500 ). No apprectable inf low between sampling point and gaging station except during periods of heavy
local flow.

TEMPERATURE $\left({ }^{\circ} \mathrm{C}\right)$ OF WATER, WATER YEAR OCTOBER 1968 TO SEPTEMBER 1969 (ONCE-DAILY MEA SUREMENT)

DAY

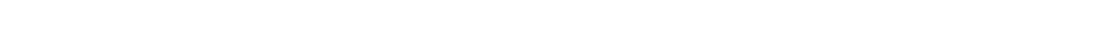

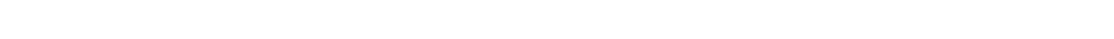

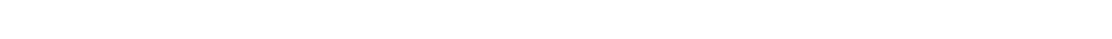

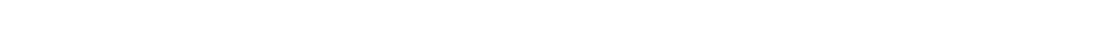

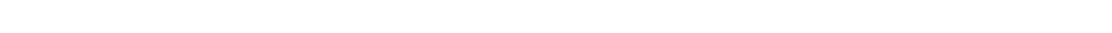

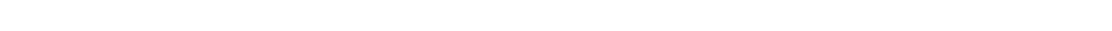

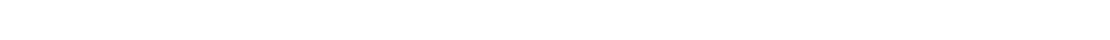

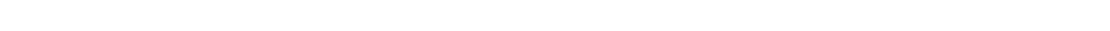

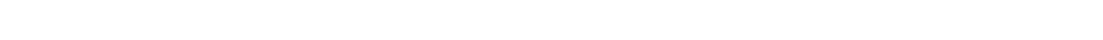

PARTICLE-SIZE DISTRIBUTION OF SUSPENDED SEDIHENT, WATER YEAR OCTOBER 1968 TO SEPTEMBER 1969 (METHODS OF ANALYSIS: B, BOTTOM WITHORAWAL TUBE; C. CHEMICALLY DISPERSED: N. IN NATIVE WATER: P, PIPET: S, SIEVE: V. VISUAL ACCUMULATION TUBE: W. IN DISTILLED WATER)

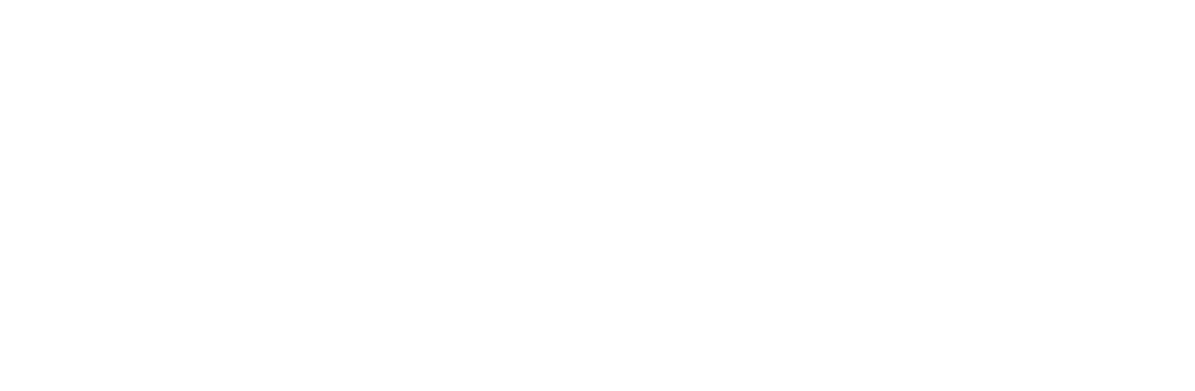


SALINAS RIVER BASIN

11152300 SALINAS RIVER NEAR CHUALAR, CALIF.--Continued

SUSPENDED-SEDIMENT DISCHARGE, WATER YEAR OCTOBER 1968 TO SEPTEMBER 1969

\begin{tabular}{|c|c|c|c|c|c|c|c|c|c|}
\hline \multirow[b]{2}{*}{ DAY } & \multicolumn{3}{|c|}{ DCTOBER } & \multicolumn{3}{|c|}{ NOVEMBER } & \multicolumn{3}{|c|}{ OECEMBER } \\
\hline & $\begin{array}{l}\text { MEAN } \\
\text { UISCHARGE } \\
\text { (CFS) }\end{array}$ & $\begin{array}{l}\text { MEAN } \\
\text { CONCEN- } \\
\text { TRATION } \\
\text { (MG/L) }\end{array}$ & $\begin{array}{l}\text { SEDIMENT } \\
\text { DISCHARGE } \\
\text { (TONS/DAY) }\end{array}$ & $\begin{array}{l}\text { MEAN } \\
\text { OISCHARGE } \\
\text { (CFS) }\end{array}$ & $\begin{array}{l}\text { MEAN } \\
\text { CONCEN- } \\
\text { TRATION } \\
\text { (MGIL) }\end{array}$ & $\begin{array}{l}\text { SEDIMENT } \\
\text { DISCHARGE } \\
\text { (TONS/DAY) }\end{array}$ & $\begin{array}{l}\text { MEAN } \\
\text { DI SCHARGE } \\
\text { (CFS) }\end{array}$ & $\begin{array}{l}\text { MEAN } \\
\text { CONCEN- } \\
\text { TRAT ION } \\
\text { IMG/LI }\end{array}$ & $\begin{array}{l}\text { SEDIMENT } \\
\text { DISCHARGE } \\
\text { (TONS /DAY) }\end{array}$ \\
\hline 1 & .94 & 71 & .18 & .95 & 28 & .07 & 5.0 & 36 & .49 \\
\hline 2 & 1.4 & 50 & .19 & 1.7 & 28 & .13 & 4.4 & 39 & .46 \\
\hline 3 & 2.5 & 40 & .27 & 1.7 & 28 & .13 & 4.3 & 20 & .23 \\
\hline 4 & 2.1 & 30 & .17 & .60 & 28 & .05 & 3.9 & 7 & .07 \\
\hline 5 & 2.0 & 25 & .14 & .72 & 28 & .05 & 4.3 & 6 & .07 \\
\hline 6 & 2.0 & 25 & .14 & 1.0 & 30 & .08 & 3.9 & 10 & .11 \\
\hline 7 & 2.0 & 25 & .14 & 1.4 & 26 & .10 & 3.3 & 10 & .09 \\
\hline 8 & 2.0 & 25 & .14 & 1.7 & 20 & .09 & 3.3 & 10 & .09 \\
\hline 9 & 2.0 & 25 & .14 & 2.2 & 20 & .12 & 2.8 & 10 &.$O B$ \\
\hline 10 & 2.0 & 25 & .14 & 3.2 & 19 & .16 & 3.6 & 10 & .10 \\
\hline 11 & 2.0 & 25 & .14 & 2.5 & 19 & .13 & 3.3 & 10 & .09 \\
\hline 12 & 2.0 & 25 & .14 & 3.4 & 19 & .17 & 3.0 & 10 & $.0 B$ \\
\hline 13 & 2.4 & 30 & .19 & 3.6 & 19 & .18 & 2.8 & 10 &.$O B$ \\
\hline 14 & 2.7 & 30 & .22 & 4.4 & 19 & .23 & 3.6 & 10 & .10 \\
\hline is & 2.9 & 30 & .23 & 6.3 & 19 & .32 & 3.6 & 10 & .10 \\
\hline 16 & 3.1 & 30 & .25 & 5.4 & 19 & .28 & 2.6 & 10 & .07 \\
\hline 17 & 5.7 & 30 & .46 & 7.2 & 15 & .29 & 2.4 & 16 & .10 \\
\hline is & 14 & 35 & 1.3 & 5.0 & 14 & .19 & 2.8 & 55 & .42 \\
\hline 19 & 14 & 35 & 1.3 & 4.3 & 14 & .16 & 2.6 & 112 & .79 \\
\hline 20 & 15 & 35 & 1.4 & 5.6 & 14 & .21 & 2.8 & 122 & .92 \\
\hline 21 & 15 & 35 & 1.4 & 5.9 & 13 & .21 & 2.6 & B5 & .60 \\
\hline 22 & 15 & 38 & 1.5 & 6.2 & 13 & .22 & 2.8 & 43 & .33 \\
\hline 23 & 16 & 30 & $i .3$ & 6.6 & 13 & .23 & 3.0 & 25 & .20 \\
\hline 24 & 16 & 20 & .86 & 6.2 & is & .25 & 2.8 & 29 & .22 \\
\hline 25 & 15 & 28 & 1.1 & 5.9 & 17 & .27 & 3.6 & 29 & .28 \\
\hline 26 & 9.3 & 25 & .63 & 6.2 & 19 & .32 & 4.3 & 20 & .23 \\
\hline 27 & 4.9 & 25 & .33 & 5.9 & 20 & .32 & 2.4 & 13 &.$O B$ \\
\hline 28 & 3.6 & 25 & .24 & 5.3 & 18 & .26 & 2.8 & 19 & .14 \\
\hline 29 & .94 & 25 & .06 & 5.3 & 16 & .23 & 2.2 & 30 & .18 \\
\hline 30 & .65 & 25 & .04 & 5.0 & 25 & .34 & 2.4 & 35 & .23 \\
\hline 31 & $.6 ?$ & 25 & .04 & - & - & - & 2.4 & 37 & .24 \\
\hline \multirow[t]{4}{*}{ TOTAL } & 179.75 & -- & 14.78 & 121.37 & -- & 5.79 & 99.6 & -- & 7.27 \\
\hline & & JANUARY & & & FEBRUARY & & & MARCH & \\
\hline & & MEAN & & & MEAN & & & MEAN & \\
\hline & MEAN & CONCEN- & SEDIMENT & MEAN & CONCEN- & SEDIMENT & MEAN & CONCEN- & SEDIMENT \\
\hline DAY & $\begin{array}{l}\text { OL SCHARGE } \\
\text { (CFS) }\end{array}$ & $\begin{array}{l}\text { TRATION } \\
\text { (MG/LI) }\end{array}$ & $\begin{array}{l}\text { DISCHARGE } \\
\text { (TONS/DAY) }\end{array}$ & $\begin{array}{l}\text { DISCHARGE } \\
\text { (CFS) }\end{array}$ & $\begin{array}{l}\text { TRATION } \\
\text { (MG/LI }\end{array}$ & $\begin{array}{l}\text { DISCHARGE } \\
\text { (TONS/DAY })\end{array}$ & $\begin{array}{l}\text { DISCHARGE } \\
\text { (CFSI }\end{array}$ & $\begin{array}{l}\text { TRATION } \\
\text { (MG/LI) }\end{array}$ & $\begin{array}{l}\text { DISCHARGE } \\
\text { (TONS / DAY) }\end{array}$ \\
\hline 1 & I & 37 & .10 & 7140 & 1200 & 23100 & 16600 & 8800 & 394000 \\
\hline 2 & $\mathrm{i}$ & 34 & .09 & 6090 & 1400 & 23000 & 15300 & 12000 & 496000 \\
\hline 3 & i & 30 & .08 & 5790 & 1590 & 24900 & 12000 & 8100 & 262000 \\
\hline 4 & i & 27 & .07 & 5200 & 1190 & 16700 & 10500 & 7200 & 204000 \\
\hline 5 & $i$ & 25 & .07 & 4800 & 730 & 9460 & 8950 & 7000 & 169000 \\
\hline 6 & $\mathbf{l}$ & 21 & .06 & 5200 & 2450 & 34400 & 8190 & 6500 & 144000 \\
\hline 7 & 2 & 19 & .10 & 6890 & 3290 & 64200 & 7420 & 6000 & 120000 \\
\hline 8 & 3 & 15 & .12 & 11500 & 4020 & 128000 & 7000 & 5500 & 104000 \\
\hline 9 & 3 & 13 & .11 & 6510 & 1840 & 32300 & 6500 & 5000 & 87800 \\
\hline 10 & 3 & 10 & .08 & 4850 & 1320 & 17300 & 6100 & 4500 & 74200 \\
\hline It & 2 & 10 & .05 & 4680 & 890 & 11200 & 5700 & 4000 & 61600 \\
\hline 12 & 3 & 802 & 11 & 4990 & 960 & 12900 & 5400 & 3000 & 43700 \\
\hline 13 & 4 & 1610 & 19 & 4340 & 1200 & 14100 & 5000 & 2000 & 27000 \\
\hline 14 & 3 & 450 & 3.6 & 3680 & 700 & 6960 & 4700 & 1650 & 20900 \\
\hline 15 & 234 & 2830 & $2560^{\circ}$ & 3620 & 1100 & 11600 & 4400 & 1290 & 15300 \\
\hline 16 & 108 & 3010 & 968 & 5000 & 2980 & 40700 & 4100 & 1050 & 11600 \\
\hline i7 & 26 & 1430 & 112 & 5540 & 2870 & 43400 & 3900 & 850 & 8950 \\
\hline IB & 8 & 260 & 5.6 & 4270 & 1320 & 15200 & 3720 & 750 & 7530 \\
\hline 19 & 39 & 410 & $136^{\circ}$ & 4380 & 1300 & 15400 & 3620 & 670 & 6550 \\
\hline 20 & 3370 & 6550 & 63300 & 4680 & 1400 & 17700 & 3520 & 750 & 7130 \\
\hline 21 & 4200 & 4740 & 54100 & 4230 & 1000 & 11400 & 3380 & 630 & 5750 \\
\hline & 11000 & 2020 & 57500 & 4110 & 920 & 10200 & 3300 & 760 & 6770 \\
\hline 73 & 16400 & 3110 & 138000 & 4660 & 1000 & 12600 & 3100 & 640 & 5360 \\
\hline 24 & 10500 & 1350 & 42100 & 8390 & 5410 & 158000 & 2900 & 550 & 4310 \\
\hline 25 & 4920 & 429 & 6080 & 36100 & 18900 & 2090000 & 2700 & $4 B O$ & 3500 \\
\hline $\begin{array}{l}26 \\
27\end{array}$ & $\begin{array}{l}18800 \\
53400\end{array}$ & $\begin{array}{l}12000 \\
15000\end{array}$ & $\begin{array}{r}895000 \\
2340000\end{array}$ & $\begin{array}{l}64800 \\
26400\end{array}$ & $\begin{array}{r}15100 \\
7750\end{array}$ & $\begin{array}{r}2790000 \\
562000\end{array}$ & $\begin{array}{l}2620 \\
2700\end{array}$ & $\begin{array}{l}500 \\
530\end{array}$ & $\begin{array}{l}3540 \\
3860\end{array}$ \\
\hline 28 & 26900 & 4870 & 374000 & $\begin{array}{l}20400 \\
18300\end{array}$ & 5700 & 282000 & 2580 & 500 & 3480 \\
\hline 29 & 14500 & 1900 & 74400 & - & - & 20 - & 2240 & 530 & 3210 \\
\hline 30 & $i 1400$ & 1400 & 43100 & -- & -- & - & 2100 & 500 & 2840 \\
\hline 31 & 8900 & 1200 & 28800 & -- & -- & - & 2140 & 360 & 2080 \\
\hline TOTAL & 184734 & -- & 4120196.13 & 276140 & $\cdots$ & 6478720 & 172380 & $=-$ & 2309860 \\
\hline
\end{tabular}


11152300 SALINAS RIVER NEAR CHUALAR, CALIF.--Continued

SUSPENDED-SEDIMENT DISCHARGE, WATER YEAR OCTOBER 1968 TO SEPTEMBER 1969

\begin{tabular}{|c|c|c|c|c|c|c|c|c|c|}
\hline \multirow[b]{2}{*}{ DAY } & \multicolumn{3}{|c|}{ APRIL } & \multicolumn{3}{|c|}{ MAY } & \multicolumn{3}{|c|}{ JUNE } \\
\hline & $\begin{array}{l}\text { MEAN } \\
\text { DISCHARGE } \\
\text { (CFS) }\end{array}$ & $\begin{array}{l}\text { MEAN } \\
\text { CONCEN- } \\
\text { TRATION } \\
\text { (MG /L) }\end{array}$ & $\begin{array}{l}\text { SEDIMENT } \\
\text { DISCHARGE } \\
\text { (TONS/DAY) }\end{array}$ & $\begin{array}{l}\text { MEAN } \\
\text { OISCHARGE } \\
\text { (CFS) }\end{array}$ & $\begin{array}{l}\text { MEAN } \\
\text { CDNCEN- } \\
\text { TRATION } \\
\text { (MG/L) }\end{array}$ & $\begin{array}{l}\text { SEDI MENT } \\
\text { DI SCHARGE } \\
\text { (TONS / DAY) }\end{array}$ & $\begin{array}{l}\text { MEAN } \\
\text { DISCHARGE } \\
\text { (CFS) }\end{array}$ & $\begin{array}{l}\text { MEAN } \\
\text { CDNCEN- } \\
\text { TRATION } \\
(M G / L)\end{array}$ & $\begin{array}{l}\text { SEDIMENT } \\
\text { DISCHARGE } \\
\text { (TONS/DAY) }\end{array}$ \\
\hline $\begin{array}{l}1 \\
2 \\
3 \\
4 \\
5\end{array}$ & $\begin{array}{l}2160 \\
2000 \\
2060 \\
2480 \\
2880\end{array}$ & $\begin{array}{r}400 \\
430 \\
670 \\
1570 \\
3300\end{array}$ & $\begin{array}{r}2330 \\
2320 \\
3730 \\
10800 \\
25700\end{array}$ & $\begin{array}{l}500 \\
470 \\
450 \\
440 \\
600\end{array}$ & $\begin{array}{l}91 \\
80 \\
72 \\
75 \\
76\end{array}$ & $\begin{array}{r}123 \\
102 \\
87 \\
89 \\
123\end{array}$ & $\begin{array}{l}440 \\
435 \\
430 \\
430 \\
430\end{array}$ & $\begin{array}{r}100 \\
104 \\
100 \\
96 \\
90\end{array}$ & $\begin{array}{l}119 \\
122 \\
116 \\
111 \\
104\end{array}$ \\
\hline $\begin{array}{r}6 \\
7 \\
8 \\
9 \\
10\end{array}$ & $\begin{array}{l}3340 \\
3260 \\
3000 \\
3160 \\
2800\end{array}$ & $\begin{array}{r}2960 \\
1200 \\
670 \\
630 \\
660\end{array}$ & $\begin{array}{r}26400 \\
10600 \\
5430 \\
5380 \\
4990\end{array}$ & $\begin{array}{l}730 \\
760 \\
760 \\
750 \\
730\end{array}$ & $\begin{array}{l}100 \\
152 \\
150 \\
156 \\
150\end{array}$ & $\begin{array}{l}197 \\
312 \\
308 \\
316 \\
296\end{array}$ & $\begin{array}{l}435 \\
440 \\
440 \\
430 \\
420\end{array}$ & $\begin{array}{l}80 \\
80 \\
81 \\
75 \\
70\end{array}$ & $\begin{array}{l}94 \\
95 \\
96 \\
87 \\
79\end{array}$ \\
\hline $\begin{array}{l}11 \\
12 \\
13 \\
14 \\
15\end{array}$ & $\begin{array}{l}2700 \\
3180 \\
2800 \\
2400 \\
2100\end{array}$ & $\begin{array}{l}480 \\
450 \\
440 \\
470 \\
450\end{array}$ & $\begin{array}{l}3500 \\
3860 \\
3330 \\
3050 \\
2550\end{array}$ & $\begin{array}{l}720 \\
690 \\
680 \\
660 \\
650\end{array}$ & $\begin{array}{r}152 \\
149 \\
98 \\
97 \\
96\end{array}$ & $\begin{array}{l}295 \\
278 \\
180 \\
173 \\
168\end{array}$ & $\begin{array}{l}415 \\
425 \\
435 \\
430 \\
425\end{array}$ & $\begin{array}{l}70 \\
85 \\
90 \\
90 \\
90\end{array}$ & $\begin{array}{r}78 \\
98 \\
108 \\
104 \\
103\end{array}$ \\
\hline $\begin{array}{l}16 \\
17 \\
18 \\
19 \\
20\end{array}$ & $\begin{array}{l}1900 \\
1700 \\
1500 \\
1350 \\
1250\end{array}$ & $\begin{array}{l}400 \\
350 \\
300 \\
300 \\
290\end{array}$ & $\begin{array}{r}2050 \\
1610 \\
1220 \\
1090 \\
979\end{array}$ & $\begin{array}{l}630 \\
620 \\
610 \\
500 \\
580\end{array}$ & $\begin{array}{r}100 \\
104 \\
100 \\
100 \\
90\end{array}$ & $\begin{array}{l}170 \\
174 \\
165 \\
162 \\
141\end{array}$ & $\begin{array}{l}420 \\
425 \\
425 \\
425 \\
420\end{array}$ & $\begin{array}{l}84 \\
100 \\
144 \\
150 \\
177\end{array}$ & $\begin{array}{r}95 \\
115 \\
165 \\
172 \\
201\end{array}$ \\
\hline $\begin{array}{l}21 \\
22 \\
23 \\
24 \\
25\end{array}$ & $\begin{array}{r}1100 \\
1000 \\
920 \\
840 \\
170\end{array}$ & $\begin{array}{l}280 \\
280 \\
180 \\
150 \\
150\end{array}$ & $\begin{array}{l}832 \\
756 \\
447 \\
340 \\
312\end{array}$ & $\begin{array}{l}570 \\
560 \\
540 \\
530 \\
520\end{array}$ & $\begin{array}{l}90 \\
80 \\
80 \\
80 \\
74\end{array}$ & $\begin{array}{l}139 \\
121 \\
117 \\
114 \\
104\end{array}$ & $\begin{array}{l}405 \\
405 \\
400 \\
400 \\
391\end{array}$ & $\begin{array}{r}100 \\
88 \\
80 \\
73 \\
90\end{array}$ & $\begin{array}{r}109 \\
96 \\
86 \\
79 \\
95\end{array}$ \\
\hline $\begin{array}{l}26 \\
27 \\
28 \\
27 \\
30 \\
31\end{array}$ & $\begin{array}{l}720 \\
670 \\
620 \\
580 \\
520 \\
--\end{array}$ & $\begin{array}{l}80 \\
80 \\
80 \\
70 \\
70 \\
--\end{array}$ & $\begin{array}{r}156 \\
145 \\
134 \\
110 \\
98 \\
--\end{array}$ & $\begin{array}{l}500 \\
490 \\
480 \\
470 \\
460 \\
450\end{array}$ & $\begin{array}{l}80 \\
88 \\
85 \\
86 \\
90 \\
98\end{array}$ & $\begin{array}{l}108 \\
116 \\
110 \\
109 \\
112 \\
118\end{array}$ & $\begin{array}{c}396 \\
405 \\
405 \\
400 \\
396 \\
--\end{array}$ & $\begin{array}{r}102 \\
80 \\
62 \\
64 \\
66 \\
--\end{array}$ & $\begin{array}{r}109 \\
87 \\
68 \\
69 \\
71 \\
-\end{array}$ \\
\hline TDTAL & 55740 & -- & 124249 & 18200 & -- & 5128 & 12578 & $-\infty$ & 3129 \\
\hline & & JULY & & & AUGUST & & & SEPTEMBER & \\
\hline DAY & $\begin{array}{l}\text { MEAN } \\
\text { DISCHARGE } \\
\text { (CFS) }\end{array}$ & $\begin{array}{l}\text { MEAN } \\
\text { CDNCEN- } \\
\text { TRATIDN } \\
\text { (MG/L) }\end{array}$ & $\begin{array}{l}\text { SEDIMENT } \\
\text { DI SCHARGE } \\
\text { (TONS/DAY) }\end{array}$ & $\begin{array}{l}\text { MEAN } \\
\text { DISCHARGE } \\
\text { (CFS) }\end{array}$ & $\begin{array}{l}\text { MEAN } \\
\text { CONCEN- } \\
\text { TRATION } \\
\text { (MG/L) }\end{array}$ & $\begin{array}{l}\text { SEDIMENT } \\
\text { DI SCHARGE } \\
\text { (TONS/DAY) }\end{array}$ & $\begin{array}{l}\text { MEAN } \\
\text { OISCHARGE } \\
\text { (CFS) }\end{array}$ & $\begin{array}{l}\text { MEAN } \\
\text { CONCEN- } \\
\text { TRATION } \\
\text { (MG/L) }\end{array}$ & $\begin{array}{l}\text { SEDIMENT } \\
\text { DISCHARGE } \\
\text { (TONS/DAY) }\end{array}$ \\
\hline
\end{tabular}

$\begin{array}{rlr}1 & 386 & 122 \\ 2 & 368 & 120 \\ 3 & 347 & 114 \\ 4 & 338 & \\ 5 & 334 & \\ & & \\ 6 & 330 & 75 \\ 7 & 326 & 72 \\ 8 & 338 & 80 \\ 9 & 338 & 82 \\ 10 & 321 & 90\end{array}$

$\begin{array}{rrr}122 & 127 & 199 \\ 120 & 119 & 196 \\ 114 & 107 & 190 \\ 90 & 82 & 186 \\ 76 & 69 & 186 \\ 75 & 67 & 183 \\ 72 & 63 & 183 \\ 80 & 73 & 180 \\ 82 & 75 & 180 \\ 90 & 78 & 180\end{array}$

$\begin{array}{rl}100 & 54 \\ 90 & 48 \\ 130 & 67 \\ 160 & 80 \\ 130 & 65 \\ 110 & 54 \\ 100 & 49 \\ 96 & 47 \\ 120 & 58 \\ 142 & 69\end{array}$

213
230
244
244
220
198
213
195
183
196

$\begin{array}{rr}52 & 30 \\ 110 & 68 \\ 182 & 120 \\ 100 & 66 \\ 62 & 37 \\ 60 & 32 \\ 60 & 35 \\ 60 & 32 \\ 57 & 28 \\ 60 & 32\end{array}$

$11 \quad 313 \quad 100$

$\begin{array}{lll}11 & 313 & \\ 12 & 305 & \\ 13 & 298 & 80 \\ 14 & 290 & 8 \\ 15 & 283 & 84\end{array}$

85

$\begin{array}{ll}85 & 180 \\ 74 & 180\end{array}$

$\begin{array}{ll}64 & 180 \\ 64 & 176 \\ 64 & 176\end{array}$

81
123
100
92

$\begin{array}{lll}16 & 272 & 90 \\ 17 & 264 & 92 \\ 18 & 261 & 80 \\ 19 & 261 & 74\end{array}$

$\begin{array}{lll}19 & 261 & 74 \\ 20 & 254 & 65\end{array}$

$66 \quad 180$

$\begin{array}{ll}66 & 183 \\ 56 & 183 \\ 52 & 180\end{array}$

92
92

95
95
94
110

180
183

130

$\begin{array}{ll}41 & 180 \\ 47 & 176\end{array}$

$\begin{array}{lll}21 & 250 & 60 \\ 22 & 247 & 70\end{array}$

$\begin{array}{rrr}22 & 247 & 70 \\ 23 & 240 & 84 \\ 24 & 230 & 100 \\ 25 & 220 & 112\end{array}$

54
62
67

180
176
176
176

140
157
150
148
100

39
60
49
44
44
46
47
46
53
64
68
75
71
70
49

209

230
247
294

$\begin{array}{rr}60 & 34 \\ 100 & 62 \\ 149 & 99 \\ 130 & 103 \\ 165 & 164\end{array}$

$\begin{array}{lll}26 & 216 & \\ 27 & 216 & \\ 28 & 216 & \\ 29 & 216 & 1 \\ 30 & 209 & 105 \\ 31 & 203 & \end{array}$

$\begin{array}{rl}90 & 52 \\ 82 & 48 \\ 90 & 5 \\ 105 & 6 \\ 105 & 59 \\ 103 & 56\end{array}$

TOTAL 8090

52
48
52
61
59
58

180

48
50
50
55
6
60

TOTAL DISCHARGE FDR YEAR ICFS-DAYS

TOTAL SUSPENDED-SEDIMENT DISCHARGE FOR YEAR (TONS)

$\begin{array}{rr}48 & 2 \\ 50 & 2 \\ 50 & 2 \\ 55 & 2 \\ 61 & 3 \\ 60 & 3 \\ \ldots & 157\end{array}$

391

$200 \quad 21$

$\begin{array}{lll}420 & 250 & 284 \\ 425 & 312 & 358\end{array}$

$\begin{array}{lll}425 & 312 & 358 \\ 435 & 280 & 329\end{array}$

$\begin{array}{lll}435 & 264 & 310\end{array}$

$\begin{array}{lll}440 & 240 & 285 \\ 450 & 180 & 266\end{array}$

$\begin{array}{lll}450 & 180 & 219 \\ 450 & 151 & 183\end{array}$

$\begin{array}{llll}23 & 456 & 140 & 17\end{array}$

$445 \quad 130 \quad 150$

$\begin{array}{ccc}456 & 122 & 150 \\ 461 & 120 & 149 \\ -- & - & \end{array}$

10082

4428

744575.72
3049408.97 
11152500 SALINAS RIVER NEAR SPRECKELS, CALIF.

LOCATION (revised). - Lat $36^{\circ} 37^{\prime} 52^{\prime \prime}$, long $121^{\circ} 40^{\prime} 17^{\prime \prime}$, in National Grant, Monterey County, at gaging station at

bridge on Sali nas-Monterey highway, $0.8 \mathrm{mile}$ upstream from El Toro'Creek, $1.6 \mathrm{miles}$ northwest of Spreckels, and

DRAINAGE AREA. - $-4,156 \mathrm{sq} \mathrm{mi}$ (revised).

PERIOD OF RECORD. --Chemical analyses: October 1958 to September 1969. REMARKS. --Chemical-quality records furnished by California Department of Water Resources and reviewed by Geologi-
cal Survey. CHEMICAL ANALYSES, WATER YEAR OCTOBER 1968 TO SEPTEMBER 1969

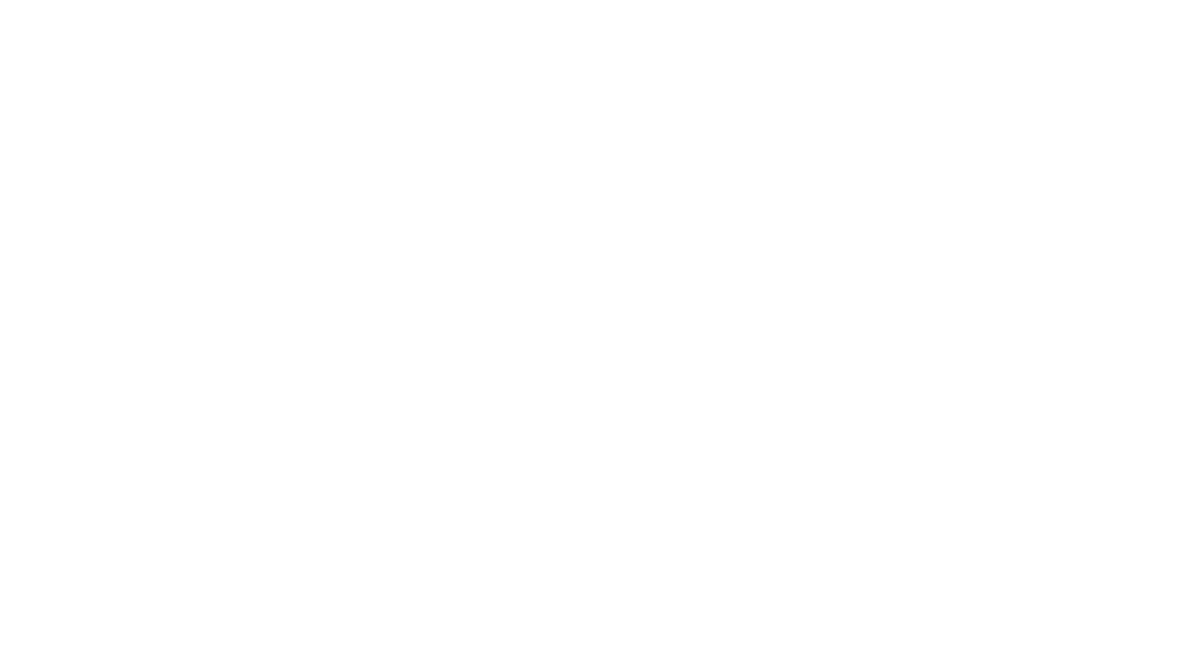


11153900 UVAS CREEK ABOVE UVAS RESERVOIR, NEAR MORGAN HILL, CALIF.

LOCATION. - Lat $37^{\circ} 05^{\prime} 34^{\prime \prime}$, long $121^{\circ} 43^{\circ} 02^{\prime \prime}$, in Las Uvas Grant, Santa Clara County, at gaging station 0.6 mile downstream from Little Uvas Creek, 0.9 mile upstream from Hay Canyon, and 4.4 miles southwest of Morgan Hill.

DRAINAGE AREA. --21,0 sq mi.

PERIOD OF RECORD.--Water temperatures: October 1965 to September 1969.

Sediment records: October 1965 to September 1969.

EXTREMES, --1968-69:

Sediment concentrations: Maximum da11y, $1,940 \mathrm{mg} / 1 \mathrm{Jan} .19$; minimum da1ly, $1 \mathrm{mg} / 1$ on many days.

Sediment discharge: Maximum daily, 9,980 tons Jan. 19; minimum daily, 0 ton on many days.

Period of record:

Sediment concentrations: Maximum da1ly, 2,400 mg/1 Jan, 21, 1967; minimum daily, $1 \mathrm{mg} / 1$ on many days each year.

Maximum daily, 22,200 tons Jan. 21, 1967; minimum daily, 0 ton on many days in 1965-68. TEIPERATURE $\left({ }^{\circ} \mathrm{C}\right)$ OF WATER, MATER YEAR $O$ CTOBER 1968 TO SEPTEUBER 1969 (ONCE-DAILY MEASUREMENT)

DAY

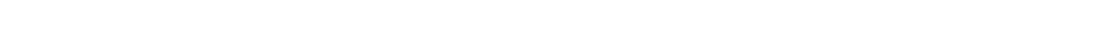

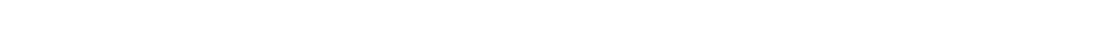
NUVEMBER,
DFCEMBER,

JANUARY.. - - - - - - - - - -

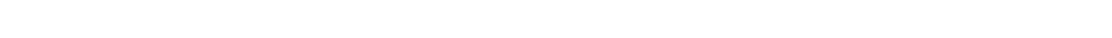

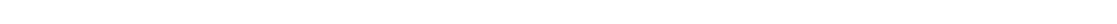
MAY......

JULY.... 21 -SEPTEMBER - - -

PARTICLE-SIZE DISTRIBUTION OF SUSPENDED SEDIMENT, WATER YEAR OCTDBER 196B TD SEPTEMBER 1969 (METHODS OF ANALYSIS: B, BOTTOM WITHDRAMAL TUBE; C, CHEMICALLY DISPERSED; N, IN iWATIVE WATER; P, PIPET; S, SIEVE;
V, VISUAL ACCUMULATION TUBE: W, IN DISTILLED WATER)

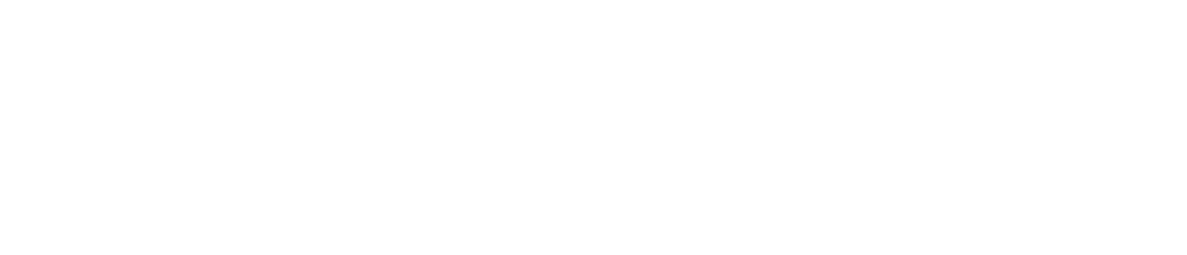

PARTICLE-SIZE DISTRIBUTION OF SURFACE BED MATERIAL, WATER YEAR OCTOBER 1967 TO SEPTEMBER 1968 (METHOD OF ANALYSIS: H. HYDROMETER; O, OPTICAL ANALYZER; S, SIEVE: V, VISUAL ACCUMULATION TUBE) NUMBER PARTICLE SILE

OF

THE SIZE (IN MILLIMETERS) INDICATED

$\begin{array}{lllllllllllllll}\text { DATE TIME PLING DISCHARGE } & \text { POINS (CFS) } & .062 & .125 & .250 & .500 & 1.00 & 2.00 & 4.00 & 8.00 & 16.0 & 32.0 & 64.0 & 128\end{array}$ 
11153900 UVAS CREEK ABOVE UVAS RESERVOIR, NEAR MORGAN HILL, CALIF.--CONTInUEd SUSPENDED-SEDIMENT DISCHARGE, WATER YEAR OCTOBER 1968 TO SEPTEMBER 1969 OCTOBER

NOVEMBER

OECEMBER

\begin{tabular}{|c|c|c|c|c|c|c|c|c|c|}
\hline DAY & $\begin{array}{c}\text { MEAN } \\
\text { DISHARGE } \\
\text { ICFS? }\end{array}$ & $\begin{array}{l}\text { MEAN } \\
\text { COANEN- } \\
\text { TRATIDN } \\
\text { IMG/L! }\end{array}$ & $\begin{array}{l}\text { SEDIMENT } \\
\text { DISCHARGE } \\
\text { (TONS/DAY) }\end{array}$ & $\begin{array}{c}\text { MEAN } \\
\text { OISCHARGE } \\
\text { (CFS) }\end{array}$ & $\begin{array}{l}\text { MEAN } \\
\text { CONAEN- } \\
\text { IRATION } \\
\text { MAG/L) }\end{array}$ & $\begin{array}{l}\text { SEDIMENT } \\
\text { DI SCHARGE } \\
\text { \{TONS/DAYY }\end{array}$ & $\begin{array}{c}\text { MEAN } \\
\text { OISCAARGE } \\
\text { ICFS) }\end{array}$ & $\begin{array}{l}\text { MEAN } \\
\text { CONCEN- } \\
\text { TRATINON } \\
\text { (MGSI) }\end{array}$ & $\begin{array}{l}\text { SEDIMENT } \\
\text { DI SCHARGE } \\
\text { (TONS/DAY) }\end{array}$ \\
\hline $\begin{array}{l}1 \\
2 \\
3 \\
4 \\
5\end{array}$ & $\begin{array}{l}.14 \\
.28 \\
.28 \\
.23 \\
.23\end{array}$ & $\begin{array}{l}8 \\
8 \\
8 \\
8 \\
8 \\
8\end{array}$ & $\begin{array}{l}0 \\
.01 \\
: 01 \\
0 \\
0\end{array}$ & $\begin{array}{l}1: 0 \\
1: 0 \\
4: 5 \\
2: 0 \\
1: 2\end{array}$ & $\begin{array}{c}5 \\
5 \\
10 \\
6 \\
2\end{array}$ & $\begin{array}{l}.01 \\
.01 \\
.12 \\
.03 \\
.01\end{array}$ & $\begin{array}{c}1.0 \\
1.2 \\
1.0 \\
: 92 \\
: 80\end{array}$ & $\begin{array}{l}1 \\
1 \\
1 \\
1 \\
1\end{array}$ & $\begin{array}{l}0 \\
0 \\
0 \\
0 \\
0\end{array}$ \\
\hline $\begin{array}{r}6 \\
7 \\
8 \\
9 \\
10\end{array}$ & $\begin{array}{r}.34 \\
.34 \\
.23 \\
.28 \\
.18\end{array}$ & $\begin{array}{l}8 \\
8 \\
8 \\
8 \\
8 \\
8\end{array}$ & $\begin{array}{l}.01 \\
0.01 \\
0.01 \\
0.01\end{array}$ & $\begin{array}{l}1: 0 \\
1: 5 \\
1: 2 \\
1: 0 \\
1: 0 \\
1: 0\end{array}$ & $\begin{array}{l}2 \\
2 \\
2 \\
2 \\
2\end{array}$ & $\begin{array}{l}.01 \\
0.01 \\
001 \\
0.01 \\
.01\end{array}$ & $\begin{array}{c}.92 \\
.92 \\
1.0 \\
13 \\
13\end{array}$ & $\begin{array}{r}1 \\
1 \\
1 \\
4 \\
18\end{array}$ & $\begin{array}{l}0 \\
0 \\
0 \\
: 01 \\
1: 1\end{array}$ \\
\hline $\begin{array}{l}11 \\
12 \\
13 \\
14 \\
15\end{array}$ & $\begin{array}{c}.18 \\
: 80 \\
2: 0 \\
1.2 \\
.92\end{array}$ & $\begin{array}{r}8 \\
8 \\
10 \\
8 \\
6\end{array}$ & $\begin{array}{l}0 \\
.02 \\
.05 \\
.03 \\
.01\end{array}$ & $\begin{array}{l}1: 0 \\
1: 0 \\
10.3 \\
1: 3 \\
5: 9\end{array}$ & $\begin{array}{r}2 \\
2 \\
2 \\
2 \\
30 \\
30\end{array}$ & $\begin{array}{l}: 01 \\
001 \\
001 \\
0.01 \\
: 01 \\
.48\end{array}$ & $\begin{array}{l}8.8 \\
3.2 \\
2.2 \\
2.2 \\
48.2\end{array}$ & $\begin{array}{r}21 \\
12 \\
5 \\
8 \\
219\end{array}$ & $\begin{array}{r}.54 \\
.54 \\
.03 \\
73^{-19}\end{array}$ \\
\hline $\begin{array}{l}16 \\
17 \\
18 \\
19 \\
20\end{array}$ & $\begin{array}{l}.80 \\
.68 \\
.68 \\
.80 \\
.80\end{array}$ & $\begin{array}{l}5 \\
5 \\
5 \\
5 \\
5\end{array}$ & $\begin{array}{l}.01 \\
001 \\
01 \\
01 \\
01 \\
001\end{array}$ & $\begin{array}{l}3.0 \\
2: 0 \\
1: 3 \\
1: 3 \\
1: 3\end{array}$ & $\begin{array}{r}10 \\
4 \\
2 \\
2 \\
1\end{array}$ & $\begin{array}{l}.08 \\
.02 \\
.01 \\
.01 \\
0.01\end{array}$ & $\begin{array}{r}17 \\
9.9 \\
609 \\
5.9 \\
5.1\end{array}$ & $\begin{array}{r}39 \\
3 \\
3 \\
2 \\
1\end{array}$ & $\begin{array}{c}2.8 \\
.08 \\
.06 \\
.03 \\
.01\end{array}$ \\
\hline $\begin{array}{l}21 \\
22 \\
23 \\
24 \\
25\end{array}$ & $\begin{array}{l}.40 \\
.58 \\
688 \\
.68 \\
.60\end{array}$ & $\begin{array}{l}5 \\
5 \\
5 \\
5 \\
5\end{array}$ & $\begin{array}{l}.01 \\
0.01 \\
0.01 \\
.01 \\
.01\end{array}$ & $\begin{array}{r}.92 \\
.48 \\
.48 \\
.80 \\
1.3\end{array}$ & $\begin{array}{l}1 \\
1 \\
1 \\
1 \\
1\end{array}$ & $\begin{array}{l}0 \\
0 \\
0 \\
0 \\
0\end{array}$ & $\begin{array}{r}4.5 \\
4.2 \\
4: 0 \\
5.0 \\
30.6\end{array}$ & $\begin{array}{r}1 \\
1 \\
1 \\
2 \\
29\end{array}$ & $\begin{array}{l}.01 \\
.01 \\
.01 \\
.03 \\
3.2\end{array}$ \\
\hline $\begin{array}{l}26 \\
27 \\
28 \\
29 \\
30 \\
31\end{array}$ & $\begin{array}{r}.58 \\
.58 \\
.48 \\
.68 \\
.80 \\
1.0\end{array}$ & $\begin{array}{l}5 \\
5 \\
5 \\
5 \\
5 \\
5\end{array}$ & $\begin{array}{l}01 \\
0.01 \\
0.01 \\
01 \\
01 \\
.01 \\
01\end{array}$ & \begin{tabular}{c}
1.3 \\
.80 \\
.80 \\
.80 \\
.92 \\
\hdashline-
\end{tabular} & $\begin{array}{l}1 \\
1 \\
1 \\
1 \\
1 \\
.1\end{array}$ & $\begin{array}{l}0 \\
0 \\
0 \\
0 \\
0 \\
--\end{array}$ & $\begin{array}{c}48 \\
14 \\
23 \\
16 \\
9.9 \\
8.8\end{array}$ & $\begin{array}{r}34 \\
7 \\
12 \\
5 \\
5 \\
4\end{array}$ & $\begin{array}{c}5.3 \\
.26 \\
.92 \\
.22 \\
.13 \\
.10\end{array}$ \\
\hline Total & 18.25 & -- & .32 & 44.00 & - & .87 & 306.26 & -- & 88.14 \\
\hline & & JANUARY & & & FEBRUARY & & & MARCH & \\
\hline DAY & $\begin{array}{l}\text { MEAN } \\
\text { DICHARG } \\
\text { ICFSI }\end{array}$ & $\begin{array}{l}\text { MEAN } \\
\text { MENCEN } \\
\text { TRATIIN } \\
\text { IMG ILI }\end{array}$ & $\begin{array}{l}\text { SEDIMENT } \\
\text { DISCHARGE } \\
\text { (TONS/DAY) }\end{array}$ & $\begin{array}{c}\text { MEAN } \\
\text { DISCHARGE } \\
\text { IEFS }\end{array}$ & $\begin{array}{l}\text { MEAN } \\
\text { COANEN- } \\
\text { TRATINON } \\
\text { IMG/LI }\end{array}$ & $\begin{array}{l}\text { SEDIAENT } \\
\text { DISCHARGE } \\
\text { (TONS/DAY) }\end{array}$ & $\begin{array}{l}\text { MEAN } \\
\text { OISGARGE } \\
\text { (CFS) }\end{array}$ & $\begin{array}{l}\text { MEAN } \\
\text { MEAEN- } \\
\text { TRAAENON } \\
\text { IMG ILI) }\end{array}$ & $\begin{array}{l}\text { SEDIMENT } \\
\text { DISCHARGE } \\
\text { (TONSDAYY) }\end{array}$ \\
\hline $\begin{array}{l}1 \\
2 \\
3 \\
4 \\
5\end{array}$ & $\begin{array}{l}7.3 \\
6.9 \\
6.3 \\
5.4 \\
4.8\end{array}$ & $\begin{array}{l}4 \\
4 \\
4 \\
4 \\
4\end{array}$ & $\begin{array}{l}.08 \\
.07 \\
.07 \\
.06 \\
.05\end{array}$ & $\begin{array}{r}121 \\
102 \\
89 \\
80 \\
165\end{array}$ & $\begin{array}{r}12 \\
10 \\
8 \\
4 \\
62\end{array}$ & $\begin{array}{c}3.9 \\
2.8 \\
119 \\
57\end{array}$ & $\begin{array}{l}362 \\
255 \\
197 \\
160 \\
134\end{array}$ & $\begin{array}{l}34 \\
20 \\
13 \\
10 \\
6\end{array}$ & $\begin{array}{c}36 \\
14 \\
6.9 \\
4.3 \\
2.2\end{array}$ \\
\hline $\begin{array}{r}6 \\
7 \\
8 \\
9 \\
10\end{array}$ & $\begin{array}{l}4.3 \\
3.8 \\
3.8 \\
3.6 \\
3.4\end{array}$ & $\begin{array}{l}3 \\
3 \\
3 \\
3 \\
3\end{array}$ & $\begin{array}{l}.03 \\
.03 \\
.03 \\
.03 \\
.03\end{array}$ & $\begin{array}{l}378 \\
193 \\
153 \\
134 \\
116\end{array}$ & $\begin{array}{r}125 \\
22 \\
18 \\
17 \\
15\end{array}$ & $\begin{array}{c}145 \\
12 \\
7.4 \\
6.2 \\
4.7\end{array}$ & $\begin{array}{r}115 \\
100 \\
88 \\
79 \\
71\end{array}$ & $\begin{array}{l}5 \\
4 \\
4 \\
5 \\
5\end{array}$ & $\begin{array}{l}1.6 \\
1.1 \\
1.95 \\
1.96\end{array}$ \\
\hline $\begin{array}{l}11 \\
12 \\
13 \\
14 \\
15\end{array}$ & $\begin{array}{c}3.6 \\
33.3 \\
357 \\
93 \\
27\end{array}$ & $\begin{array}{r}4 \\
3 \\
550 \\
223 \\
27\end{array}$ & $\begin{array}{c}.04 \\
790.03 \\
60 \\
2.0\end{array}$ & $\begin{array}{l}370 \\
278 \\
180 \\
158 \\
898\end{array}$ & $\begin{array}{r}243 \\
152 \\
18 \\
24 \\
440\end{array}$ & $\begin{array}{c}126 \\
129 \\
8.7 \\
10 \\
1330\end{array}$ & $\begin{array}{l}64 \\
61 \\
56 \\
51 \\
46\end{array}$ & $\begin{array}{l}4 \\
3 \\
2 \\
2 \\
2\end{array}$ & $\begin{array}{l}.69 \\
.49 \\
.30 \\
.28 \\
.25\end{array}$ \\
\hline $\begin{array}{l}16 \\
17 \\
18 \\
19 \\
20\end{array}$ & $\begin{array}{r}18 \\
14 \\
515 \\
1700 \\
877\end{array}$ & $\begin{array}{r}4 \\
3 \\
979 \\
1940 \\
386\end{array}$ & $\begin{array}{l}\quad 19 \\
3840 \\
911 \\
9980 \\
974\end{array}$ & $\begin{array}{l}305 \\
217 \\
183 \\
158 \\
132\end{array}$ & $\begin{array}{r}50 \\
21 \\
12 \\
9 \\
7\end{array}$ & $\begin{array}{c}41 \\
12 \\
5.9 \\
3.8 \\
2.5\end{array}$ & $\begin{array}{l}42 \\
39 \\
36 \\
33 \\
36\end{array}$ & $\begin{array}{l}1 \\
1 \\
4 \\
B \\
5\end{array}$ & $\begin{array}{r}.11 \\
.11 \\
.39 \\
: 71 \\
.49\end{array}$ \\
\hline $\begin{array}{l}21 \\
22 \\
223 \\
24 \\
25\end{array}$ & $\begin{array}{r}701 \\
293 \\
185 \\
304 \\
1060\end{array}$ & $\begin{array}{r}297 \\
97 \\
32 \\
139 \\
562\end{array}$ & $\begin{array}{r}607 \\
80 \\
16 \\
342 \\
1830\end{array}$ & $\begin{array}{l}117 \\
117 \\
273 \\
689 \\
411\end{array}$ & $\begin{array}{r}7 \\
6 \\
97 \\
376 \\
75\end{array}$ & $\begin{array}{r}2.2 \\
1.9 \\
93 \\
1010 \\
83\end{array}$ & $\begin{array}{l}37 \\
37 \\
34 \\
31 \\
30\end{array}$ & $\begin{array}{l}2 \\
2 \\
2 \\
2 \\
2\end{array}$ & $\begin{array}{l}.20 \\
-20 \\
-18 \\
-117 \\
.16\end{array}$ \\
\hline $\begin{array}{l}26 \\
27 \\
28 \\
29 \\
30 \\
31\end{array}$ & $\begin{array}{l}916 \\
299 \\
238 \\
177 \\
201 \\
145\end{array}$ & $\begin{array}{r}354 \\
77 \\
28 \\
17 \\
28 \\
15\end{array}$ & $\begin{array}{c}1190 \\
67 \\
18 \\
8.1 \\
16 \\
5.9 \\
5.9\end{array}$ & $\begin{array}{r}253 \\
222 \\
584 \\
-= \\
=-\end{array}$ & $\begin{array}{r}31 \\
20 \\
241 \\
-= \\
=-\end{array}$ & $\begin{array}{r}21 \\
12 \\
405 \\
-- \\
--\end{array}$ & $\begin{array}{l}28 \\
27 \\
26 \\
25 \\
23 \\
22\end{array}$ & $\begin{array}{l}3 \\
3 \\
2 \\
2 \\
3 \\
3\end{array}$ & $\begin{array}{r}.23 \\
.22 \\
.14 \\
.14 \\
.19 \\
.18\end{array}$ \\
\hline OTAL & 8166.5 & -- & 19826.85 & 2076 & -- & 3838.76 & 2345 & -- & 74.94 \\
\hline
\end{tabular}


11153900 UVAS CREEK ABOVE UVAS RESERVOIR, NEAR MORGAN HILL, CALIF.-_CONTinued

SUSPENDED-SEDIMENT DISCHARGE, WATER YEAR OCTOBER 1968 TO SEPTEMBER 1969

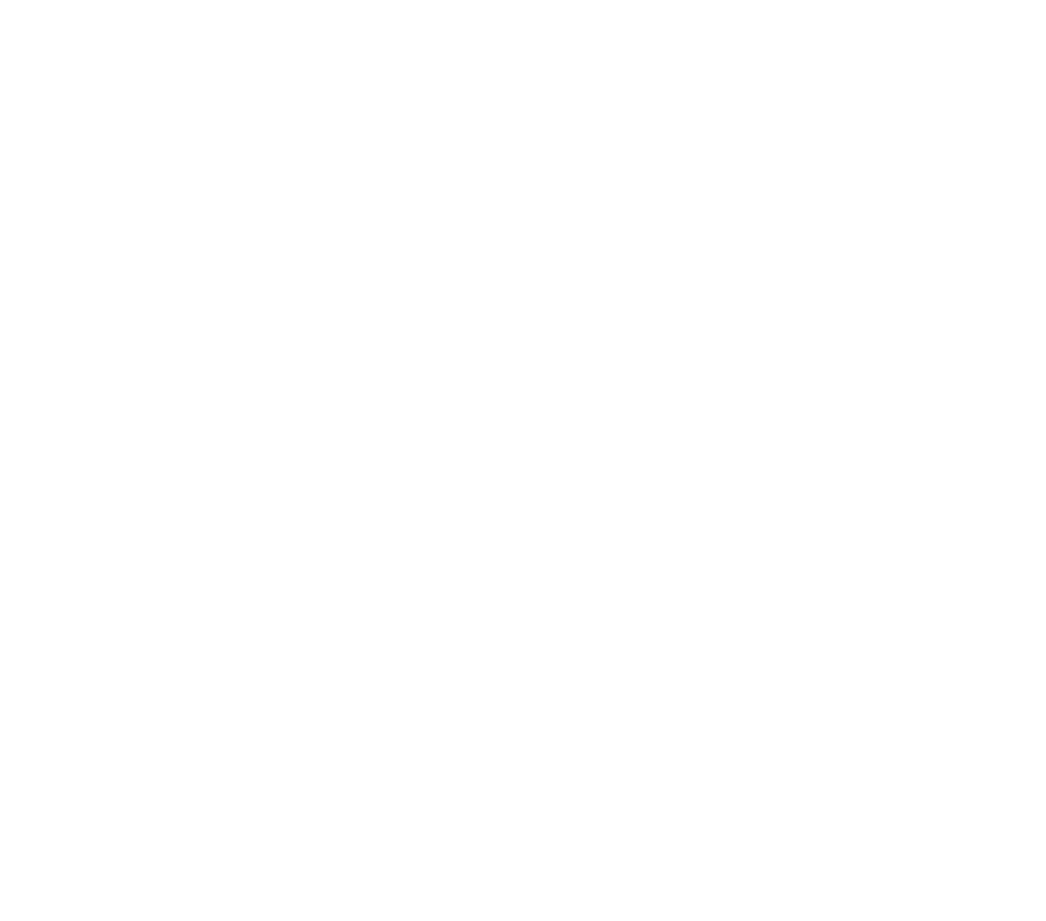

$\begin{array}{ll}2.7 & 1 \\ 2.7 & 1 \\ 2.1 & 2 \\ 2.2 & 2\end{array}$
(TONS/DAY) (CFS)

1.2
1.1
1.1
.98
.71

13
14
14
14

.04
.04
.04
.04
.03

.17
.35
.43
.37

13
13
13
13

13
13
13

.01
.01
.02
.01
.01

$\begin{array}{llll}2.3 & 3 & .02 & .52 \\ 2.1 & 4 & .02 & .80 \\ 2.1 & 4 & .02 & .91 \\ 1.8 & 5 & .02 & .84\end{array}$

$\begin{array}{ll}14 & .02 \\ 14 & .03\end{array}$

14

14
14

.03
.03

.41

13
13
13
13

.01

.03
.03

.52
.25

13

.02
.02
.01

$\begin{array}{llll}1.8 & 6 & .03 & .29 \\ 1.4 & 6 & .02 & .68 \\ 1.9 & 7 & .04 & .36 \\ 1.2 & 7 & .02 & .59 \\ .66 & 8 & .01 & .65\end{array}$

14
14

$\begin{array}{ll}11 & 1.8 \\ 12 & 1.4 \\ 13 & 1.9 \\ 14 & 1.2 \\ 15 & .66\end{array}$

.01

.03
.02
.02

.36

13
13
13
13

13
13
13
13
13

$\begin{array}{cc}.92 & 8 \\ .77 & 8 \\ .99 & 8 \\ 1.5 & 9 \\ 1.4 & 9\end{array}$

.02
.02
.02
.04

.73
.70
.45
.95
.98

.03
.03
.02
.04

.04
.04

13
13
13
12

.02
.02
.01
.02
.03

.70
.83
.47
.65
.44

.03
.03
.02
.02

.02
.02
.02

.27
.49
.31
.38
.24

12
12
11
11

$\begin{array}{lll}.02 & .33 & 11 \\ .02 & .34 & 10 \\ .02 & .30 & 10\end{array}$

.02
.04
.03

.03
.04
.05

.54
.48
.54
.61
.54
.46

13
13
13
13
13
13

TOTAL

.73

21.55

--

IOIAL DISCHARGE FOR YEAR ICFS-DAYS)

0.81

.01

.01

.01

.02

.01

.01

.01

.01

.01

.01

.02

.36 
11159000 PAJARO RIVER AT CHITTENDEN, CALIF.

LOCATION.--lat $36^{\circ} 54^{\circ} 01^{\prime \prime}$, long $121^{\circ} 35^{\prime} 48^{\prime \prime}$, in Salsipuedes Grant, Santa Cruz County, at gaging station on State highway bridge, 0.6 mile downstream from Pescadero Creek, 0.6 mile southeast of Chittenden, and $2.3 \mathrm{miles}$ downstream from San Benito River.

DRAINAGE AREA, $--1,186 \mathrm{sq} \mathrm{m} 1$.

PERIOD OF RECORD. --Chemical analyses: October 1953 to September 1969.

REMARKS.--Records furnished by California Department of Water Resources and reviewed by U.S. Geological Survey. CHEMICAL aNalYSES, hater year OCTOBER 1968 TO SEPTEMBER 1969

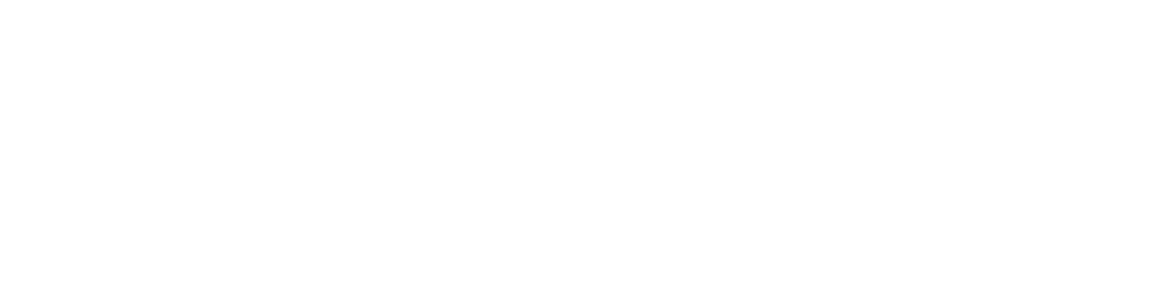

\begin{tabular}{|c|c|c|c|c|c|c|c|c|c|c|c|}
\hline DATE & $\begin{array}{l}\text { NITRATE } \\
\text { (NOA) } \\
\text { (MG/L) }\end{array}$ & $\begin{array}{l}\text { BORON } \\
\text { (BI } \\
\text { IUG/L) }\end{array}$ & $\begin{array}{l}\text { DIS- } \\
\text { SOLVED } \\
\text { SOLIDS } \\
\text { IRESI- } \\
\text { DUE AT } \\
\text { ISO CI } \\
\text { (NGILI) }\end{array}$ & $\begin{array}{l}\text { DIS- } \\
\text { SOLVEO } \\
\text { SOLIOS } \\
\text { ITONS } \\
\text { PER } \\
\text { AC-FTI }\end{array}$ & $\begin{array}{l}\text { HARD- } \\
\text { NESS } \\
\text { (CA, MG) } \\
\text { (MG/L) }\end{array}$ & $\begin{array}{l}\text { NON- } \\
\text { CAR- } \\
\text { 8ONATE } \\
\text { HARD- } \\
\text { NESS } \\
\text { (MGIL) }\end{array}$ & $\begin{array}{l}\text { PERCENT } \\
\text { SOOIUR }\end{array}$ & $\begin{array}{l}\text { SOOIUM } \\
\text { AD- } \\
\text { SORP- } \\
\text { TION } \\
\text { RATIO }\end{array}$ & $\begin{array}{l}\text { ALKA- } \\
\text { LINIIY } \\
\text { AS } \\
\text { CACDB } \\
\text { (MG/L) }\end{array}$ & $\begin{array}{c}\text { PH } \\
\text { (UNITS) }\end{array}$ & $\begin{array}{l}\text { SPECI- } \\
\text { FIC } \\
\text { CDND- } \\
\text { UCTANCE } \\
\text { (AICRO- } \\
\text { MHOS) }\end{array}$ \\
\hline $\begin{array}{l}\text { NOV. } \\
15 . . . \\
\text { JAN. }\end{array}$ & + & 1000 & - & -- & 669 & 251 & 48 & 4.8 & 417 & 8.6 & 2310 \\
\hline $\begin{array}{l}15 \ldots . . \\
\text { MAR. }\end{array}$ & -- & 590 & - & - & 405 & 169 & 41 & 2.7 & 235 & 8.5 & 1240 \\
\hline$\underset{\text { MAY }}{05 . \cdots}$ & -- & 220 & -- & .25 & 183 & 36 & 26 & 2.9 & 147 & 8.2 & 474 \\
\hline $\begin{array}{l}14 \ldots \\
\text { JULY }\end{array}$ & 27 & 380 & 723 & .98 & 451 & 131 & 28 & 1.6 & 320 & 8.2 & 1030 \\
\hline $03 \ldots$ & $\cdots$ & 760 & $\cdots$ & - & 493 & 87 & 35 & 2.4 & 406 & 8.3 & 1370 \\
\hline
\end{tabular}


LOCATION.--Lat $36^{\circ} 59^{\prime} 29^{\prime \prime}$, long $121^{\circ} 57^{\prime} 17^{\prime \prime}$, in NE sec. 10 , T.11 S., R.1 W., Santa Cruz County, temperature recorder at gaging station on left bank, 0.2 mile upstream from high way bridge in town of Soquel and 0.4 mile downstream from Bates Creek.

DRAINAGE AREA, $--40.2 \mathrm{sq} \mathrm{m} 1$.

PERIOD OF RECORD.--Chemical analyses: October 1953 to September 1966.

Water temperatures: Jamuary 1966 to September 1969.

EXTREMES, --1968-69:

Water temperatures: Haximum, 24.0 $0^{\circ} \mathrm{C}$ July 23-25, Aug. 4; mini mum, 4.0 ${ }^{\circ} \mathrm{C} \mathrm{DeC}, 20-22$.

Period of record.--1967-69.

Water temperatures: laximum, $30.5^{\circ} \mathrm{C}$ Aug. 29,1968 ; minimum (1968-69), 4.0 $0^{\circ} \mathrm{C}$ Dec. 20-22, 1968 .

TEMPERATURE ( ${ }^{\circ} \mathrm{C}$ ) OF TATER, WATER YEAR OCTOBER 1968 TO SEPTEMBER 1969

DAY

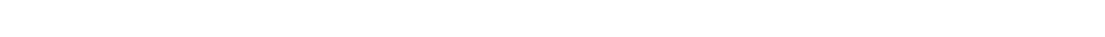

OC TURER

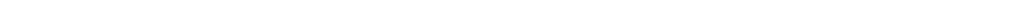

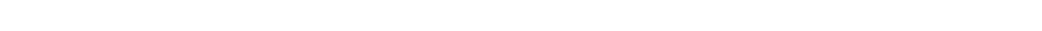

MAXIMUM $14 \quad 14 \quad 15 \quad 1516 \quad 15 \quad 16 \quad 16 \quad 18 \quad 1816 \quad 16 \quad 14 \quad 10 \quad 12 \quad 16 \quad 15 \quad 15 \quad 16 \quad 16 \quad 16 \quad 15 \quad 15 \quad 14 \quad 13 \quad 13 \quad 12 \quad 12 \quad 12 \quad 12 \quad=$

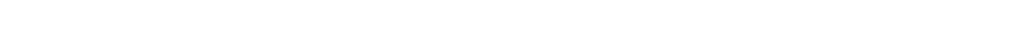

DECEMBFQ

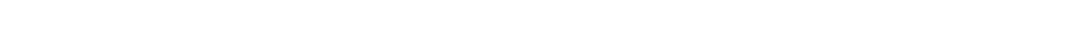

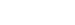

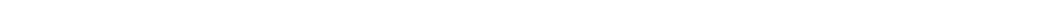

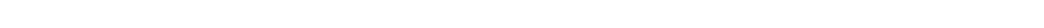

FEBRUARY

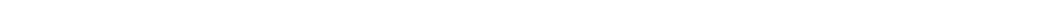

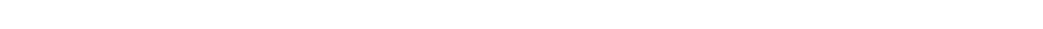

MARCH

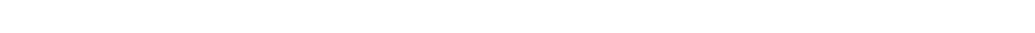

MINIMUM APRIL

MAXIMUM $14 \quad 12 \quad 14 \begin{array}{llllllllllllllllllllllllllllll}2 & 12 & 12 & 13 & 14 & 14 & 16 & 16 & 14 & 14 & 13 & 15 & 16 & 16 & 17 & 16 & 17 & 18 & 14 & 16 & 16 & 16 & 17 & 18 & 18 & 18 & 18 & -\end{array}$ MAY MINIMUM $10 \begin{array}{llllllllllllllllllllllllllllll}11 & 11 & 10 & 18 & 15 & 15 & 13 & 13 & 14 & 14 & 14 & 14 & 12 & 12 & 14 & 14 & 15 & 16 & 16 & 15 & 15 & 15 & 14 & 16 & 16 & 15 & 14 & 15 & 16 & 16\end{array}$ JUN

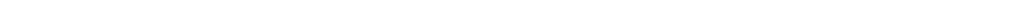
JULIY

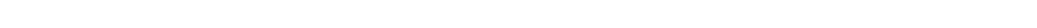

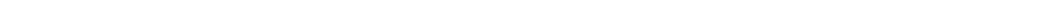
AUGUSI $\begin{array}{llllllllllllllllllllllllllllllll}\text { MAXIMUM } & 22 & 23 & 23 & 24 & 23 & 19 & 23 & 23 & 22 & 23 & 23 & 23 & 22 & 22 & 22 & 22 & 18 & 21 & 22 & 22 & 22 & 22 & 22 & 23 & 23 & 22 & 22 & 22 & 22 & 21 & 21 \\ \text { MINIMUM } & 16 & 17 & 16 & 16 & 16 & 16 & 16 & 18 & 16 & 16 & 16 & 15 & 16 & 16 & 16 & 16 & 16 & 16 & 16 & 16 & 16 & 16 & 16 & 16 & 16 & 16 & 15 & 15 & 15 & 15 & 15\end{array}$ SEPTEMRER

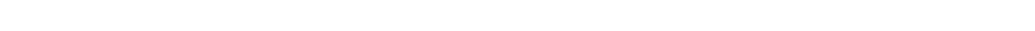

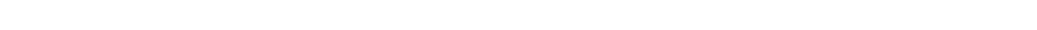


LOCATION.--Lat $37^{\circ} 01^{\prime} 49^{\prime \prime}$, long $122^{\circ} 03^{\prime} 24^{\prime \prime}$, In Canada del Rincon Grant, Santa Cruz County, temperature recorder at gaging station on right bank, 0.5 mile south of Big Trees station on Southern Paciftc Ratlroad, 1.6 miles
downstream from Zayante Creek, and 4 miles north of Santa Cruz.

DRAINAGE AREA, -- 111 sq $\mathrm{mi}$.

OERIOD OF RECORD.--Chemical analyses: October 1953 to September 1966, January to September 1969.

Water temperatures: May 1966 to September 1969

EXTREMES. - -1968-69:

Water temperatures: Maximum, $22.0^{\circ} \mathrm{C}$ on seversl days during July and August; minimum, $5.0^{\circ} \mathrm{C}$ Dec. $21,22$.

Period of record: Water temperatures: Maximum $(1966-67,1968-69), 22.0^{\circ} \mathrm{C}$ on several days during July and August in $1969 ; \mathrm{mini}-$
mum, 2,0

REMARKS.-Chemical-quality records furnished by California Department of Water Resources and reviewed by U.S.

Geological Survey. Temperature recorder stopped Oct.1-6, Oct. 10 to Dec. 4, Feb. 3-20, Mar. 4-11, Apr. 28 to May 1, June 29 to July 2 ; bulb out of water Sept. 7-11.

$$
\text { CHEMICAL ANALYSES, JANUARY TO SEPTEMBER } 1969
$$

\begin{tabular}{|c|c|c|c|c|c|c|c|c|c|c|c|c|}
\hline DATE & TI ME & $\begin{array}{l}\text { DIS- } \\
\text { CHARGE } \\
\text { (CFS) }\end{array}$ & $\begin{array}{l}\text { TEMPER- } \\
\text { ATURE } \\
\text { IOEG CI }\end{array}$ & $\begin{array}{l}\text { DIS- } \\
\text { SOLVED } \\
\text { OXYGEN } \\
\text { (MG/L) }\end{array}$ & $\begin{array}{l}\text { CAL- } \\
\text { CIUM } \\
(C A \mid \\
(M G / L)\end{array}$ & $\begin{array}{l}\text { MAG- } \\
\text { NE- } \\
\text { SIUM } \\
\text { (MG) } \\
(M G / L)\end{array}$ & $\begin{array}{l}\text { SOOIUM } \\
(N A) \\
(M G / L)\end{array}$ & $\begin{array}{l}\text { PO- } \\
\text { TAS- } \\
\text { SIUM } \\
\text { (K) } \\
\text { (MG/L) }\end{array}$ & $\begin{array}{l}\text { B ICAR- } \\
\text { BONATE } \\
\text { (HCO3) } \\
\text { (MG/L) }\end{array}$ & $\begin{array}{l}\text { CAR- } \\
\text { BONATE } \\
\text { (CO3) } \\
\text { (MGIL) }\end{array}$ & $\begin{array}{l}\text { SULFATE } \\
\text { (SO4) } \\
\text { (MG/L) }\end{array}$ & $\begin{array}{l}\text { CHLO- } \\
\text { RIDE } \\
I C L I \\
\text { IMG/L }\end{array}$ \\
\hline $\begin{array}{l}\text { JAN. } \\
\text { OB... } \\
\text { MAR. }\end{array}$ & 0830 & 58 & 7 & 12.5 & 40 & $-\infty$ & 22 & -- & 126 & 0 & -- & 22 \\
\hline $\begin{array}{l}\text { MAR. } \\
12 \ldots \\
\text { MAY }\end{array}$ & 0700 & 432 & 8 & 11.9 & 30 & - & 11 & -- & 90 & 0 & $\rightarrow$ & 11 \\
\hline JuLY... & 0630 & 121 & 10 & 11.0 & 38 & 8.0 & 17 & 1.4 & 116 & 0 & 46 & 14 \\
\hline $\begin{array}{l}\text { O2... } \\
\text { SEPT. }\end{array}$ & 1500 & 44 & 23 & 8.6 & 38 & -- & 19 & -- & 129 & 0 & -- & 18 \\
\hline $26 \ldots$ & 1300 & 23 & 17 & 9.4 & 38 & $\cdots$ & 21 & -- & 130 & 0 & -- & 22 \\
\hline DAT & $\begin{array}{l}\text { NITRATE } \\
\text { (NO3) } \\
\text { (MG/L) }\end{array}$ & $\begin{array}{l}\text { BORON } \\
(8) \\
(U G / L)\end{array}$ & $\begin{array}{l}\text { DIS- } \\
\text { SOLVEC } \\
\text { SOLIDS } \\
\text { IRESI- } \\
\text { OUE AT } \\
\text { IBO CI } \\
\text { IMGIL) }\end{array}$ & $\begin{array}{l}\text { OIS- } \\
\text { SOLVEO } \\
\text { SOLIDS } \\
\text { ITONS } \\
\text { PER } \\
\text { AC-FTI }\end{array}$ & $\begin{array}{l}\text { HARO- } \\
\text { NESS } \\
\text { ICA, MG } \\
\text { (MG/L) }\end{array}$ & $\begin{array}{l}\text { NON- } \\
\text { CAR- } \\
\text { BONATE } \\
\text { HARD- } \\
\text { NESS } \\
\text { (MG/L) }\end{array}$ & $\begin{array}{l}\text { PERCENT } \\
\text { SOOIUM }\end{array}$ & $\begin{array}{l}\text { SODIUM } \\
\text { AD- } \\
\text { SORP- } \\
\text { TION } \\
\text { RATIO }\end{array}$ & $\begin{array}{l}\text { ALKA- } \\
\text { LINITY } \\
\text { AS } \\
\text { CACO3 } \\
\text { (MGILI) }\end{array}$ & $\begin{array}{c}\text { PH } \\
\text { IUNITS }\end{array}$ & $\begin{array}{l}\text { SPECI- } \\
\text { FIC } \\
\text { COND- } \\
\text { UCTANCE } \\
\text { IMICRO- } \\
\text { MHOS I }\end{array}$ & \\
\hline
\end{tabular}

JAN.
OB...
MAR.
$12 \ldots .$.
MAY
O1...
JUIY
O2...
SEPT.
$26 \ldots$.

$\begin{array}{cccc}70 & -- & -- & 137 \\ 30 & -- & -- & 111 \\ -- & 206 & .28 & 128 \\ -- & -- & -- & 130 \\ -- & -- & -- & 129\end{array}$

$\begin{array}{rrrrrr}34 & 32 & 1.0 & 103 & 7.8 & 387 \\ 37 & 24 & .6 & 74 & 7.9 & 267 \\ 33 & 22 & .7 & 95 & 8.3 & 325 \\ 24 & 30 & .8 & 106 & 8.3 & 332 \\ 22 & 33 & .9 & 107 & 8.0 & 342\end{array}$

TEMPERATURE $\left({ }^{\circ} \mathrm{C}\right)$ OF WATER, WATER YEAR OCTOBER 1968 TO SEPTEMBER 1969

$\begin{array}{llllllllllllllllllllllllllllllllllllllllllllllll}\text { MUNTH } & 1 & 2 & 3 & 4 & 5 & 6 & 7 & 8 & 9 & 10 & 11 & 12 & 13 & 14 & 15 & 16 & 17 & 18 & 19 & 20 & 21 & 22 & 23 & 24 & 25 & 26 & 27 & 28 & 29 & 30 & 31 & \text { AGER }\end{array}$

OCTOB

MAXIMUM --

MINIMUM -

JVEMEER

MAXIMUM

DECEMHER

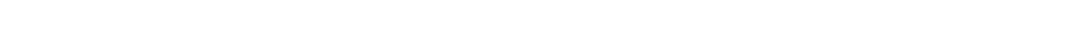

$\begin{array}{lllllllllllllllllllllllllllll}8 & 8 & 9 & 12 & 12 & 10 & 8 & 8 & 10 & 11 & 9 & 8 & 7 & 8 & 6 & 5 & 5 & 7 & 9 & 9 & 9 & 8 & 9 & 10 & 9 & 8\end{array}$

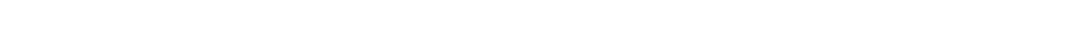

MINIMUM

EBP.UARY

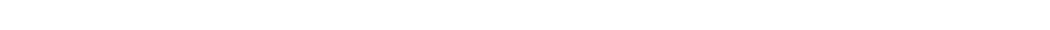

MINIM

$\begin{array}{llllllllllllllllllllllll}10 & 10 & 10 & 11 & 10 & 11 & 12 & 12 & 10 & 12 & 13 & 13 & 13 & 13 & 13 & 14 & 14 & 14 & 14 & 14\end{array}$

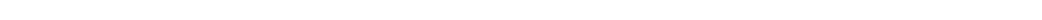

APRIL

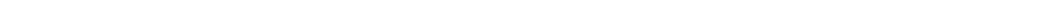

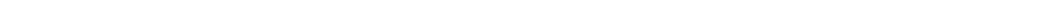
$\operatorname{Mar}$

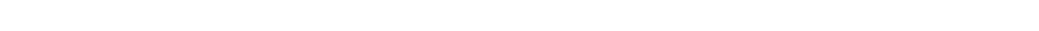
MINIMUM -- $1010 \quad 9 \quad 10 \quad 12 \quad 13 \quad 12 \quad 12 \quad 13 \quad 13 \quad 14 \quad 13 \quad 11 \quad 12 \quad 12 \quad 13 \quad 14 \quad 13 \quad 14 \quad 14 \quad 14 \quad 14 \quad 14 \quad 15 \quad 14 \quad 14 \quad 13 \quad 14 \quad 15 \quad 15$

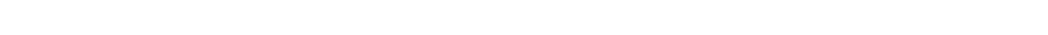

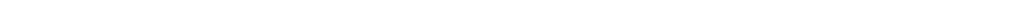
MINIMUM -- -- $14 \quad 16 \quad 15 \quad 15 \quad 15 \quad 15 \quad 15 \quad 15 \quad 15 \quad 15 \quad 15 \quad 15 \quad 15 \quad 14 \quad 15 \quad 15 \quad 16 \quad 16 \quad 16 \quad 16 \quad 16 \quad 17 \quad 17 \quad 16 \quad 16 \quad 16 \quad 1615 \quad 15$ QUGUST

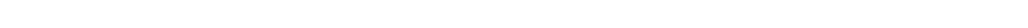

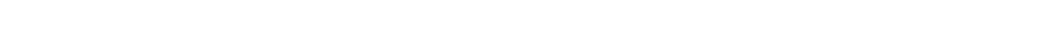
SEPTEMBER

$\begin{array}{llllllllllllllllllllllllllllllll}\text { MAXIMUM } & 20 & 20 & 20 & 20 & 20 & 21 & \ldots & -- & -- & -- & -- & 19 & 18 & 18 & 17 & 18 & 18 & 19 & 18 & 18 & 18 & 18 & 18 & 18 & 18 & 18 & 17 & 18 & 18 & 18 & \ldots \\ \text { MINIMUM } & 14 & 15 & 15 & 14 & 15 & 15 & \ldots & \ldots & -\ldots & -- & -- & 16 & 15 & 14 & 14 & 14 & 13 & 15 & 15 & 14 & 14 & 13 & 14 & 14 & 14 & 15 & 15 & 14 & 15 & 14 & \ldots-\end{array}$ 
11162500 PESCADERO CREEK NEAR PESCADERO, CALIF.

LOCATION.--Lat $37^{\circ} 15^{\prime} 39^{\prime \prime}$, IOng $122^{\circ} 19^{\prime} 40^{\prime \prime}$, in SW sec.5, T. 8 S., R.4 W., San Mateo County, temperature recorder at gaging station on left bank at downstream side of highway bridge, 3.0 miles east of Péscadero and $5.3 \mathrm{mil} \theta$ upstream from mouth.

DRAINAGE AREA. - -45.9 sq m1.

PERIOD OF RECORD, -W Water temperatures: Apr11 1965 to September 1969.

EXTREMES. - -1968-69:

Water temperatures: $H a x i m u m, 20.0^{\circ} \mathrm{C}$ July 20-26; minimum, 4.0 $0^{\circ} \mathrm{C}$ Dec, $20-22$.

Period of record:

Water temperatures: Maximum, $22.0^{\circ} \mathrm{C}$ on several days in 1965-68; m1 nimum $(1965-66,1967-69), 2.0^{\circ} \mathrm{C} \mathrm{Dec} .19$, 1965 .
t

REMARKS. --Recorder malfunction Aug. 8 to Sept. 9, no temperature range available.

TEMPERATURE ( ${ }^{\circ} \mathrm{C}$ ) OF MATER, MATER YEAR OCTOBER 1968 TO SEPTEMBER 1969 DAY

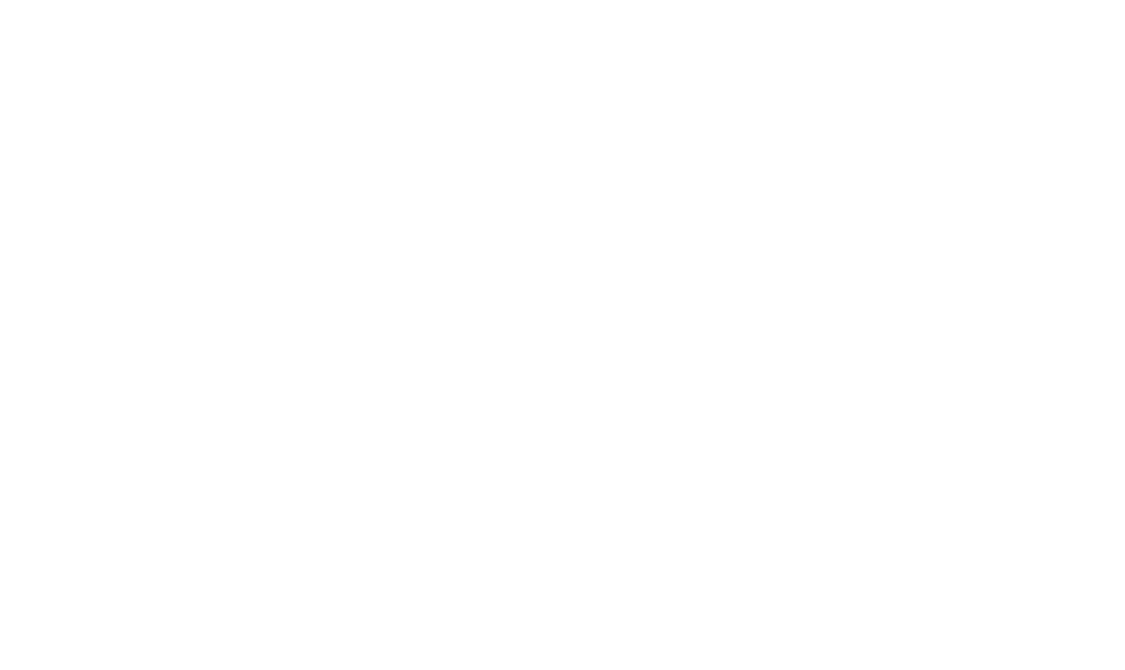


11162720 COLMA CREEK AT SOUTH SAN FRANCISCO, CALIF.

LOCATION,-Lat $37^{\circ} 39^{\prime} 14^{\prime \prime}$, long $122^{\circ} 25^{\prime} 31^{\prime \prime}$, in Buri Buri Grant, San Mateo County, at gaging station in Orange Memortal Park, 10 mile southwest of South San Franctsco Post Off 1 ce.

DRAINAGE AREA. $--10.9 \mathrm{sq} \mathrm{m} 1$.

PERIOD OF RECORD, --Sediment records: October 1965 to September 1969.

EXTREMES, $--1968-69$ :

Sediment concentrations: Maximum dally, $6,370 \mathrm{mg} / 1 \mathrm{Jan} .20 ; \mathrm{mintmum}$ daily, $2 \mathrm{mg} / 1 \mathrm{Dec} .3$.

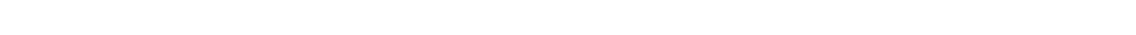
1968

Sediment discharge: Maximum da1ly, 26,900 tons Jan, 21, 1967; minimum dally, 0 ton Nov. 11-13, 1967, May 29 , June 2,1969 .

SUSPENDED-SEDIMENT DISCHARGE, WATER YEAR OCTOBER 1968 TO SEPTEMBER 1969 OC TOBER

NOVEMBER

OECEMBER

$D A$
1
1
11
13
15
16
11
1
20
21
22
2
24
26
27
29
30
31

MEAN

CONCEN- SEDIMENT MEAN CONCEN-

SEDIMENT

$\begin{array}{ccc}\text { DISCHARGE } & \text { OISCHARGE } \\ \text { (TONS/DAY) } & \text { TRFS) } & \text { TRAIION } \\ \text { (MGIL) } & \text { DISCHARGE } \\ \text { (TONS/DAY) }\end{array}$

MEAAN
OISCHARGE
(CFS)

ME AN

DISCHARGE

(MGJL)

1.2

.80

40
40

1.6

.09
.13
.17
.17
.17

21

20.80

60
941
918
60
40

$2.1 \quad 40$

2.1

.23

.23
.23
.28

4.0
1.2

1.2
.60

.60

2.140

2.1

14

$47^{.23}$

$47^{.23}$
175
9.4

11.7

4.4

9.4

$44^{.60}$

3.7
.60
$4^{6}$

$\begin{array}{ll}41 & 163 \\ 18 & 165\end{array}$

$163^{-19}$
$165^{-13}$
.13

8.3
1.6
1.2
2.1

SEDIMENT

TRATION DISCHARGE

$.6 \quad 80$

1.6

2.1

.30

.30
.34
.28

.28
.28
.23

3.8
1.6
7.4
1.2

7.4
1.2
1.2

97

40

40

2.7
.13

.13
.06
.06

1.2

440
15
2
20

(TONS/DAY)

$2.1 \quad 50$

$\begin{array}{ll}21 & 2.6 \\ 22 & 3.2 \\ 23 & 2.6 \\ 24 & 1.6 \\ 25 & 1.6\end{array}$

1.

1. 2

.28
.35
.28

.28
.17
.17

1.2
3.3
1.9

513
362
40
2200

86

86
9.5
.06

764
153

$\begin{array}{rr}1.2 & 10 \\ 3.6 & 74 \\ 8.9 & 232 \\ 29 & 1160 \\ 69 & 3090\end{array}$

35

.06

.11

2.03
7.9
234

234
1490

3.8
1.6
35
12
75

40
40
1410
364
2200

${ }_{663}^{.017}$

22
1540

1.0
.26

12.16

2.1

100
60

100
60
230
50

50

.13

5.1
1.6
1.2

60
458
130
40

.57

.13
.13

.13
2.10
2.13

1.2
2.1
1.2
21

40

40
30

.23

2.1
2.1

2.1
2.1
1.6
7.7

3.3

$12^{.17}$

12.0

1.2

1.6

16
4.1

21

60
40
648
3580

.56
.13

.13
.34

98

.13
.10
$282^{.09}$
3.6

29
5.9
30
2.1
1.6
1.6

2310

2440

333

307

.45
.22

250.57

174.60

1646.48

456.4

7225.74 
11162720 COLMA CREEK AT SOUTH SAN FRANCISCO, CALIF.---Cont1nued

SUSPENDED-SEDIMENT DISCHARGE, WATER YEAR OCTOBER 1968 TO SEPTEMBER 1969

\begin{tabular}{|c|c|c|c|c|c|c|c|c|c|}
\hline \multirow[b]{2}{*}{ DAY } & \multirow{2}{*}{\multicolumn{2}{|c|}{$\begin{array}{l}\text { JANUARY } \\
\text { MEAN } \\
\text { CONCEN- } \\
\text { TRATION } \\
\text { (MG/L) }\end{array}$}} & \multirow[b]{2}{*}{$\begin{array}{l}\text { SEDIMENT } \\
\text { DISCHARGE } \\
\text { (TONS / DAY) }\end{array}$} & \multirow{2}{*}{$\begin{array}{l}\text { MEAN } \\
\text { DI SCHARGE } \\
\text { (CFS) }\end{array}$} & \multirow{2}{*}{$\begin{array}{l}\text { FEBRUARY } \\
\text { MEAN } \\
\text { CONCEN- } \\
\text { TRATION } \\
\text { (MG/LI) }\end{array}$} & \multirow[b]{2}{*}{$\begin{array}{l}\text { SEDIMENT } \\
\text { DISCHARGE } \\
\text { (TONS/DAY) }\end{array}$} & \multirow[b]{2}{*}{$\begin{array}{l}\text { MEAN } \\
\text { DISCHARGE } \\
\text { (CFS) }\end{array}$} & \multirow{2}{*}{$\begin{array}{l}\text { MARCH } \\
\text { MEAN } \\
\text { CONCEN- } \\
\text { JRATION } \\
\text { (MG/L) }\end{array}$} & \multirow[b]{2}{*}{$\begin{array}{l}\text { SEDIMENT } \\
\text { DISCHARGE } \\
\text { (TONS/DAY) }\end{array}$} \\
\hline & & & & & & & & & \\
\hline $\begin{array}{l}1 \\
2 \\
3 \\
4 \\
5\end{array}$ & $\begin{array}{l}1.6 \\
1.2 \\
1.2 \\
1.2 \\
1.2\end{array}$ & $\begin{array}{l}40 \\
40 \\
39 \\
38 \\
37\end{array}$ & $\begin{array}{l}.17 \\
.11 \\
.13 \\
.12 \\
.12\end{array}$ & $\begin{array}{c}19 \\
5.9 \\
3.8 \\
4.4 \\
138\end{array}$ & $\begin{array}{r}1050 \\
100 \\
20 \\
70 \\
5090\end{array}$ & $\begin{array}{r}110 \\
1.6 \\
.82 \\
3570^{.83}\end{array}$ & $\begin{array}{l}19 \\
29 \\
8.2 \\
6.6 \\
5.2\end{array}$ & $\begin{array}{r}250 \\
1220 \\
150 \\
80 \\
50\end{array}$ & $\begin{array}{c}13 \\
258 \\
3.3 \\
1.4 \\
.70\end{array}$ \\
\hline $\begin{array}{r}6 \\
7 \\
8 \\
9 \\
10\end{array}$ & $\begin{array}{l}1.2 \\
1.6 \\
1.6 \\
1.6 \\
2.1\end{array}$ & $\begin{array}{l}36 \\
36 \\
36 \\
35 \\
50\end{array}$ & $\begin{array}{l}.12 \\
.16 \\
.16 \\
.15 \\
.28\end{array}$ & $\begin{array}{l}83 \\
12 \\
7.4 \\
6.6 \\
5.2\end{array}$ & $\begin{array}{r}3340 \\
400 \\
200 \\
100 \\
60\end{array}$ & $\begin{array}{c}1790 \\
13 \\
4.0 \\
1.8 \\
.84\end{array}$ & $\begin{array}{l}4.4 \\
4.4 \\
3.8 \\
3.2 \\
2.1\end{array}$ & $\begin{array}{l}31 \\
31 \\
30 \\
30 \\
30\end{array}$ & $\begin{array}{l}.37 \\
.37 \\
.31 \\
.26 \\
.17\end{array}$ \\
\hline $\begin{array}{l}11 \\
12 \\
13 \\
14 \\
15\end{array}$ & $\begin{array}{r}14 \\
37 \\
127 \\
5.2 \\
2.6\end{array}$ & $\begin{array}{r}437 \\
1780 \\
5330 \\
500 \\
400\end{array}$ & $\begin{array}{r}31 \\
611 \\
3000 \\
7.0 \\
2.8\end{array}$ & $\begin{array}{c}136 \\
13 \\
8.2 \\
96 \\
82\end{array}$ & $\begin{array}{r}6250 \\
200 \\
100 \\
3280 \\
3820\end{array}$ & $\begin{array}{c}3570 \\
7.0 \\
2.2 \\
2240 \\
1730\end{array}$ & $\begin{array}{l}1.2 \\
36 \\
2.6 \\
2.1 \\
2.1\end{array}$ & $\begin{array}{r}30 \\
1620 \\
80 \\
50 \\
30\end{array}$ & $\begin{array}{r}478.10 \\
.56 \\
.28 \\
.17\end{array}$ \\
\hline $\begin{array}{l}16 \\
17 \\
18 \\
19 \\
20\end{array}$ & $\begin{array}{l}2.1 \\
1.6 \\
123 \\
162 \\
143\end{array}$ & $\begin{array}{r}350 \\
333 \\
4210 \\
5490 \\
6370\end{array}$ & $\begin{array}{l}2.0 \\
1.4 \\
3590 \\
4170 \\
3400\end{array}$ & $\begin{array}{l}17 \\
29 \\
15 \\
5.9 \\
5.2\end{array}$ & $\begin{array}{r}300 \\
1450 \\
440 \\
100 \\
60\end{array}$ & $\begin{array}{r}14 \\
311 \\
25 \\
1.6 \\
.84\end{array}$ & $\begin{array}{l}5.4 \\
11 \\
2.6 \\
2.1 \\
20\end{array}$ & $\begin{array}{r}209 \\
906 \\
80 \\
30 \\
966\end{array}$ & $\begin{array}{l}20 \\
54 \\
150^{\circ .17}\end{array}$ \\
\hline $\begin{array}{l}21 \\
22 \\
23 \\
24 \\
25\end{array}$ & $\begin{array}{r}98 \\
18 \\
22 \\
68 \\
109\end{array}$ & $\begin{array}{r}4050 \\
354 \\
743 \\
2370 \\
3190\end{array}$ & $\begin{array}{r}1720 \\
18 \\
141 \\
1020 \\
2410\end{array}$ & $\begin{array}{r}34 \\
27 \\
112 \\
131 \\
57\end{array}$ & $\begin{array}{r}1220 \\
750 \\
4790 \\
5470 \\
2600\end{array}$ & $\begin{array}{r}290 \\
389 \\
4290 \\
3630 \\
636\end{array}$ & $\begin{array}{l}2.1 \\
1.6 \\
1.6 \\
2.1 \\
2.1\end{array}$ & $\begin{array}{l}80 \\
60 \\
40 \\
40 \\
40\end{array}$ & $\begin{array}{l}.45 \\
.26 \\
.17 \\
.23 \\
.23\end{array}$ \\
\hline $\begin{array}{l}26 \\
27 \\
28 \\
29 \\
30 \\
31\end{array}$ & $\begin{array}{c}105 \\
44 \\
35 \\
43 \\
46 \\
8.2\end{array}$ & $\begin{array}{r}3300 \\
1470 \\
1500 \\
1170 \\
2870 \\
400\end{array}$ & $\begin{array}{r}3550 \\
475 \\
220 \\
1180 \\
981 \\
8.9\end{array}$ & $\begin{array}{l}25 \\
36 \\
94 \\
-\therefore \\
=-\end{array}$ & $\begin{array}{r}1220 \\
1410 \\
4220 \\
=- \\
=- \\
=-\end{array}$ & $\begin{array}{r}128 \\
305 \\
1680 \\
=- \\
=- \\
--\end{array}$ & $\begin{array}{l}2.6 \\
2.1 \\
1.6 \\
2.1 \\
2.1 \\
2.1\end{array}$ & $\begin{array}{l}35 \\
35 \\
35 \\
30 \\
30 \\
30\end{array}$ & $\begin{array}{l}.25 \\
.20 \\
.15 \\
.17 \\
.17 \\
.17\end{array}$ \\
\hline TOTAL & 1228.2 & -- & 26620.64 & 1208.6 & -- & 24742.53 & 193.1 & -- & 984.17 \\
\hline DAY & $\begin{array}{l}\text { MEAN } \\
\text { DISCHARGE } \\
\text { (CFS) }\end{array}$ & $\begin{array}{l}\text { APRIL } \\
\text { MEAN } \\
\text { CONCEN- } \\
\text { TRAIION } \\
\text { (MG/L) }\end{array}$ & $\begin{array}{l}\text { SEDIMENT } \\
\text { DISCHARGE } \\
\text { (TONS/DAY) }\end{array}$ & $\begin{array}{l}\text { MEAN } \\
\text { OI SCHARGE } \\
\text { (CFS) }\end{array}$ & $\begin{array}{l}\text { MAY } \\
\text { MEAN } \\
\text { CONCEN- } \\
\text { TRAIION } \\
\text { (MG/L) }\end{array}$ & $\begin{array}{l}\text { SEDIMENT } \\
\text { DISCHARGE } \\
\text { (TONS/DAY) }\end{array}$ & $\begin{array}{l}\text { MEAN } \\
\text { OISCHARGE } \\
\text { (CFS) }\end{array}$ & $\begin{array}{l}\text { JUNE } \\
\text { MEAN } \\
\text { CONCEN- } \\
\text { TRATION } \\
\text { IMG/LI }\end{array}$ & $\begin{array}{l}\text { SEDIMENT } \\
\text { DISCHARGE } \\
\text { (TONS/DAY) }\end{array}$ \\
\hline $\begin{array}{l}1 \\
2 \\
3 \\
4 \\
5\end{array}$ & $\begin{array}{l}2.1 \\
31 \\
1.6 \\
5.4 \\
100\end{array}$ & $\begin{array}{r}30 \\
1670 \\
78 \\
251 \\
5000\end{array}$ & $2247^{.34}$ & $\begin{array}{l}2.1 \\
1.2 \\
1.2 \\
.80 \\
1.2\end{array}$ & $\begin{array}{l}29 \\
29 \\
29 \\
29 \\
29\end{array}$ & $\begin{array}{l}.16 \\
.09 \\
.09 \\
.06 \\
.09\end{array}$ & $\begin{array}{l}.80 \\
.21 \\
.60 \\
.80 \\
1.6\end{array}$ & $\begin{array}{r}6 \\
6 \\
6 \\
6 \\
15\end{array}$ & $\begin{array}{l}.01 \\
.01 \\
.01 \\
.06\end{array}$ \\
\hline $\begin{array}{r}6 \\
7 \\
8 \\
9 \\
10\end{array}$ & $\begin{array}{l}26 \\
3.2 \\
2.6 \\
19 \\
2.6\end{array}$ & $\begin{array}{r}1610 \\
111 \\
80 \\
953 \\
120\end{array}$ & $\begin{array}{r}441 \\
.96 \\
127^{.56} \\
.84\end{array}$ & $\begin{array}{l}1.2 \\
1.2 \\
1.2 \\
1.2 \\
1.6\end{array}$ & $\begin{array}{l}29 \\
29 \\
29 \\
29 \\
29\end{array}$ & $\begin{array}{l}.09 \\
.09 \\
.09 \\
.09 \\
.13\end{array}$ & $\begin{array}{l}2.6 \\
2.1 \\
2.6 \\
2.6 \\
2.1\end{array}$ & $\begin{array}{l}20 \\
20 \\
20 \\
20 \\
20\end{array}$ & $\begin{array}{l}.14 \\
.11 \\
.14 \\
.14 \\
.11\end{array}$ \\
\hline $\begin{array}{l}11 \\
12 \\
13 \\
14 \\
15\end{array}$ & $\begin{array}{l}2.6 \\
2.1 \\
1.6 \\
1.6 \\
2.6\end{array}$ & $\begin{array}{r}100 \\
70 \\
60 \\
40 \\
40\end{array}$ & $\begin{array}{l}.70 \\
.40 \\
.26 \\
.17 \\
.28\end{array}$ & $\begin{array}{l}1.6 \\
1.6 \\
1.6 \\
1.2 \\
.31\end{array}$ & $\begin{array}{r}29 \\
29 \\
29 \\
29 \\
6\end{array}$ & $\begin{array}{l}.13 \\
.13 \\
.13 \\
.09 \\
.01\end{array}$ & $\begin{array}{l}1.6 \\
1.6 \\
1.2 \\
1.2 \\
1.2\end{array}$ & $\begin{array}{l}20 \\
20 \\
20 \\
20 \\
20\end{array}$ & $\begin{array}{l}.09 \\
.09 \\
.06 \\
.06 \\
.08\end{array}$ \\
\hline $\begin{array}{l}16 \\
17 \\
18 \\
19 \\
20\end{array}$ & $\begin{array}{l}2.6 \\
3.2 \\
2.6 \\
3.2 \\
3.8\end{array}$ & $\begin{array}{l}40 \\
35 \\
35 \\
30 \\
30\end{array}$ & $\begin{array}{l}.28 \\
.30 \\
.25 \\
.26 \\
.31\end{array}$ & $\begin{array}{l}.31 \\
.31 \\
.31 \\
.31 \\
.31\end{array}$ & $\begin{array}{l}6 \\
6 \\
6 \\
6 \\
6\end{array}$ & $\begin{array}{l}.01 \\
.01 \\
.01 \\
.01 \\
.01\end{array}$ & $\begin{array}{l}1.2 \\
1.2 \\
1.6 \\
1.6 \\
2.6\end{array}$ & $\begin{array}{l}20 \\
20 \\
20 \\
20 \\
20\end{array}$ & $\begin{array}{l}.06 \\
.06 \\
.09 \\
.09 \\
.14\end{array}$ \\
\hline $\begin{array}{l}21 \\
22 \\
23 \\
24 \\
25\end{array}$ & $\begin{array}{r}3.2 \\
3.8 \\
15 \\
3.8 \\
2.1\end{array}$ & $\begin{array}{r}30 \\
40 \\
1160 \\
80 \\
70\end{array}$ & 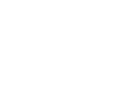 & $\begin{array}{l}.43 \\
.80 \\
1.2 \\
1.6 \\
1.6\end{array}$ & $\begin{array}{l}6 \\
6 \\
6 \\
6 \\
6\end{array}$ & $\begin{array}{l}.01 \\
.01 \\
.02 \\
.03 \\
.03\end{array}$ & $\begin{array}{l}2.1 \\
2.1 \\
1.6 \\
2.1 \\
2.1\end{array}$ & $\begin{array}{l}21 \\
21 \\
21 \\
21 \\
22\end{array}$ & $\begin{array}{l}.12 \\
.12 \\
.09 \\
.12 \\
.12\end{array}$ \\
\hline $\begin{array}{l}26 \\
27 \\
28 \\
29 \\
30 \\
31\end{array}$ & $\begin{array}{l}2.6 \\
3.2 \\
2.6 \\
2.6 \\
2.6 \\
-.\end{array}$ & $\begin{array}{l}60 \\
50 \\
40 \\
35 \\
30 \\
--\end{array}$ & $\begin{array}{l}.42 \\
.43 \\
.28 \\
.25 \\
.21 \\
. .\end{array}$ & $\begin{array}{l}1.2 \\
.80 \\
.31 \\
.21 \\
.31 \\
.60\end{array}$ & $\begin{array}{l}6 \\
6 \\
6 \\
6 \\
6 \\
6\end{array}$ & $\begin{array}{r}.02 \\
.01 \\
.01 \\
0.01 \\
.01 \\
.01\end{array}$ & $\begin{array}{l}2.1 \\
1.6 \\
1.6 \\
1.6 \\
1.2 \\
-.-\end{array}$ & $\begin{array}{l}22 \\
22 \\
22 \\
23 \\
23 \\
--\end{array}$ & $\begin{array}{l}.12 \\
.10 \\
.10 \\
.10 \\
.07 \\
.-\end{array}$ \\
\hline TOTAL & 260.9 & $\cdots$ & 3629.56 & 29.82 & -- & 1.68 & 49.11 & -- & 2.59 \\
\hline
\end{tabular}


11162720 COLMa CREEK aT SOUTh SAN FRANCISCO, CALIF.--Continued

SUSPENDED-SEDIMENT DISCHARGE, WATER YEAR OCTOBER 1968 TO SEPTEMBER 1969

\begin{tabular}{|c|c|c|c|c|c|c|c|c|c|}
\hline \multirow[b]{2}{*}{ DAY } & \multicolumn{3}{|c|}{ JULY } & \multicolumn{3}{|c|}{ AUGUST } & \multicolumn{3}{|c|}{ SEP TEMBER } \\
\hline & $\begin{array}{l}\text { MEAN } \\
\text { OISCHARGE } \\
\text { (CFS) }\end{array}$ & $\begin{array}{l}\text { MEAN } \\
\text { CONCEN- } \\
\text { TRATION } \\
\text { (MG/L) }\end{array}$ & $\begin{array}{l}\text { SEDIMENT } \\
\text { DISCHARGE } \\
\text { (TONS/DAY) }\end{array}$ & $\begin{array}{l}\text { MEAN } \\
\text { DISCHARGE } \\
\text { (CFS) }\end{array}$ & $\begin{array}{l}\text { MEAN } \\
\text { CONCEN- } \\
\text { TRATION } \\
\text { (MG/L) }\end{array}$ & $\begin{array}{l}\text { SEDIMENT } \\
\text { DISCHARGE } \\
\text { (TONS/DAY) }\end{array}$ & $\begin{array}{l}\text { MEAN } \\
\text { DISCHARGE } \\
\text { (CFS) }\end{array}$ & $\begin{array}{l}\text { MEAN } \\
\text { CONCEN- } \\
\text { TRATION } \\
\text { IMGILI }\end{array}$ & $\begin{array}{l}\text { SEDIMENT } \\
\text { DISCHARGE } \\
\text { (TONS / DAY) }\end{array}$ \\
\hline $\begin{array}{l}1 \\
2 \\
3 \\
4 \\
5\end{array}$ & $\begin{array}{l}1.6 \\
1.6 \\
1.2 \\
1.2 \\
1.2\end{array}$ & $\begin{array}{l}23 \\
23 \\
23 \\
23 \\
23\end{array}$ & $\begin{array}{l}.10 \\
.10 \\
.07 \\
.07 \\
.07\end{array}$ & $\begin{array}{l}3.8 \\
3.8 \\
3.2 \\
3.2 \\
2.6\end{array}$ & $\begin{array}{l}23 \\
23 \\
23 \\
23 \\
23\end{array}$ & $\begin{array}{l}.24 \\
.24 \\
.20 \\
.20 \\
.16\end{array}$ & $\begin{array}{l}2.0 \\
1.8 \\
2.2 \\
2.1 \\
1.2\end{array}$ & $\begin{array}{l}23 \\
23 \\
23 \\
23 \\
23\end{array}$ & $\begin{array}{l}.12 \\
.11 \\
.14 \\
.13 \\
.07\end{array}$ \\
\hline $\begin{array}{r}6 \\
7 \\
8 \\
9 \\
10\end{array}$ & $\begin{array}{l}1.2 \\
.43 \\
1.2 \\
2.1 \\
2.1\end{array}$ & $\begin{array}{l}23 \\
23 \\
23 \\
23 \\
23\end{array}$ & $\begin{array}{l}.07 \\
.03 \\
.07 \\
.13 \\
.13\end{array}$ & $\begin{array}{l}2.1 \\
2.1 \\
2.1 \\
2.6 \\
2.6\end{array}$ & $\begin{array}{l}23 \\
40 \\
30 \\
23 \\
23\end{array}$ & $\begin{array}{l}.13 \\
.23 \\
.17 \\
.16 \\
.16\end{array}$ & $\begin{array}{l}1.6 \\
1.2 \\
1.2 \\
.80 \\
1.2\end{array}$ & $\begin{array}{l}23 \\
23 \\
23 \\
23 \\
23\end{array}$ & $\begin{array}{l}.10 \\
.07 \\
.07 \\
.05 \\
.07\end{array}$ \\
\hline $\begin{array}{l}11 \\
12 \\
13 \\
14 \\
15\end{array}$ & $\begin{array}{l}1.6 \\
2.1 \\
2.6 \\
1.2 \\
3.2\end{array}$ & $\begin{array}{l}23 \\
23 \\
23 \\
23 \\
23\end{array}$ & $\begin{array}{l}.10 \\
.13 \\
.16 \\
.07 \\
.20\end{array}$ & $\begin{array}{l}2.1 \\
3.2 \\
2.1 \\
2.1 \\
3.2\end{array}$ & $\begin{array}{l}23 \\
23 \\
23 \\
23 \\
23\end{array}$ & $\begin{array}{l}.13 \\
.20 \\
.13 \\
.13 \\
.20\end{array}$ & $\begin{array}{l}.80 \\
.80 \\
1.2 \\
1.2 \\
.80\end{array}$ & $\begin{array}{l}23 \\
23 \\
23 \\
23 \\
23\end{array}$ & $\begin{array}{l}.05 \\
.05 \\
.07 \\
.07 \\
.05\end{array}$ \\
\hline $\begin{array}{l}16 \\
17 \\
18 \\
19 \\
20\end{array}$ & $\begin{array}{l}2.6 \\
2.6 \\
3.8 \\
3.8 \\
3.8\end{array}$ & $\begin{array}{l}23 \\
23 \\
23 \\
23 \\
23\end{array}$ & $\begin{array}{l}.16 \\
.16 \\
.24 \\
.24 \\
.24\end{array}$ & $\begin{array}{l}3.8 \\
2.6 \\
3.2 \\
2.1 \\
2.0\end{array}$ & $\begin{array}{l}23 \\
23 \\
23 \\
23 \\
23\end{array}$ & $\begin{array}{l}.24 \\
.16 \\
.20 \\
.13 \\
.12\end{array}$ & $\begin{array}{l}.80 \\
1.6 \\
2.1 \\
1.6 \\
1.5\end{array}$ & $\begin{array}{l}23 \\
23 \\
23 \\
23 \\
23\end{array}$ & $\begin{array}{l}.05 \\
.10 \\
.13 \\
.10 \\
.09\end{array}$ \\
\hline $\begin{array}{l}21 \\
22 \\
23 \\
24 \\
25\end{array}$ & $\begin{array}{l}2.6 \\
2.6 \\
3.8 \\
2.6 \\
3.8\end{array}$ & $\begin{array}{l}23 \\
23 \\
23 \\
23 \\
23\end{array}$ & $\begin{array}{l}.16 \\
.16 \\
.24 \\
.16 \\
.24\end{array}$ & $\begin{array}{l}1.9 \\
1.8 \\
1.6 \\
1.4 \\
1.8\end{array}$ & $\begin{array}{l}23 \\
23 \\
23 \\
23 \\
23\end{array}$ & $\begin{array}{l}.12 \\
.11 \\
.10 \\
.09 \\
.11\end{array}$ & $\begin{array}{l}1.4 \\
1.5 \\
1.9 \\
2.1 \\
2.1\end{array}$ & $\begin{array}{l}23 \\
23 \\
23 \\
23 \\
23\end{array}$ & $\begin{array}{l}.09 \\
.09 \\
.12 \\
.13 \\
.13\end{array}$ \\
\hline $\begin{array}{l}26 \\
27 \\
28 \\
29 \\
30 \\
31\end{array}$ & $\begin{array}{l}2.6 \\
2.6 \\
3.8 \\
2.6 \\
3.8 \\
3.8\end{array}$ & $\begin{array}{l}23 \\
23 \\
23 \\
23 \\
23 \\
23\end{array}$ & $\begin{array}{l}.16 \\
.16 \\
.24 \\
.16 \\
.24 \\
.24\end{array}$ & $\begin{array}{l}1.6 \\
1.6 \\
1.6 \\
2.2 \\
2.0 \\
1.8\end{array}$ & $\begin{array}{l}23 \\
23 \\
23 \\
23 \\
23 \\
23\end{array}$ & $\begin{array}{l}.10 \\
.10 \\
.10 \\
.14 \\
.12 \\
.11\end{array}$ & $\begin{array}{l}2.1 \\
2.1 \\
1.6 \\
1.6 \\
2.1 \\
=.1\end{array}$ & $\begin{array}{l}23 \\
23 \\
23 \\
23 \\
23 \\
--\end{array}$ & $\begin{array}{r}.13 \\
.13 \\
.10 \\
.10 \\
.13 \\
--\end{array}$ \\
\hline TOTAL & 75.73 & - & 4.70 & 73.8 & $\cdots$ & 4.73 & 46.20 & - & 2.84 \\
\hline $\begin{array}{l}\text { TOTAL } \\
\text { TOTAL }\end{array}$ & $\begin{array}{l}\text { DISCHARGE } \\
\text { SUSPENDED- }\end{array}$ & $\begin{array}{l}\text { OR YEAR } \\
\text { EDIMENT }\end{array}$ & $\begin{array}{l}\text { FS-DAYSI } \\
\text { SCHARGE FD }\end{array}$ & & & & & & $\begin{array}{r}3889.36 \\
65116.23\end{array}$ \\
\hline
\end{tabular}

PARTICLE-SIZE DISTRIBUTION OF SUSPENDED SEDIMENT, WATER YEAR OCTOBER 1968 TO SEPTEMBER 1969
IMETHODS OF ANALYSIS: B, BDTTOM WITHDRAWAL TUBE C. CHEMICALLY DISPERSED N, IN NATIVE WATER; P, PIPET, S, SIEVE V, VISUAL ACCUMULATION TUBE, W. IN DISTILLED WATERI

PARTICLE SIZE

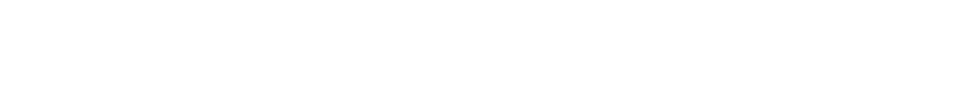

DATE TIME IUE DISCHARGE TRATION DISCHARGE
(CFS) (MG/L) ITONS/DAY)

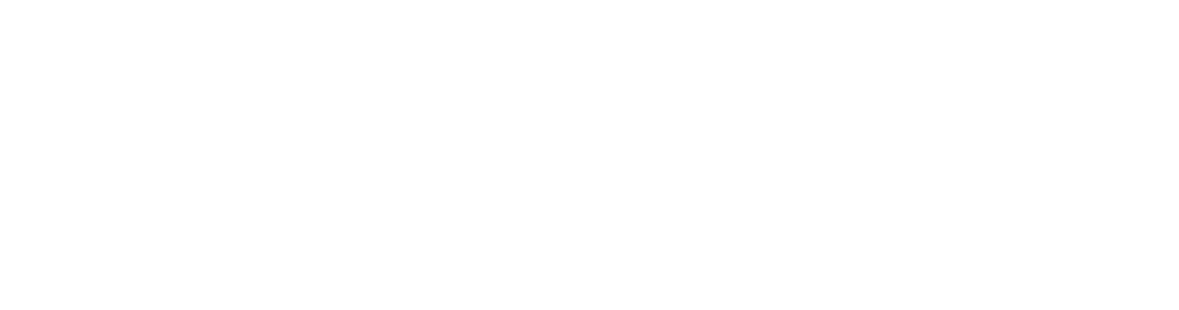


11162722 SPRUCE BRANCH AT SOUTH SAN FRANCISCO, CALIF.

LOCATION, --Lat $37^{\circ} 38^{\prime} 46^{\prime \prime}$, long $122^{\circ} 25^{\prime} 15^{\prime \prime}$, in Buri Buri Grant, San Mateo County, at gaging station 0.5 mile upstream from mouth and 1.0 mile southwest of South San Francisco Post Office.

DRAINAGE AREA. - $-0.70 \mathrm{sq} \mathrm{mi}$ (revised).

PERIOD OF RECORD.--Sediment records: October 1965 to September 1969 (discontinued).

EXTREMES. -- Period of record (1965-67):

Sediment concentrations: Maximum daily, 6,350 mg/l Jan, 21, 1967; minimum daily, no flow for many days in 65-67.

MONTHLY AND ANNUAL SUMMARY OF SU SPENDED-SEDIMENT DISCHARGE,

\begin{tabular}{|c|c|c|}
\hline MONTH & $\begin{array}{l}\text { DISCHA RGE } \\
\text { (CFS) }\end{array}$ & $\begin{array}{l}\text { SED IMENT } \\
\text { DISCHARGE } \\
\text { (TONS) }\end{array}$ \\
\hline $\begin{array}{l}\text { OCTOBER } 1968, \ldots \ldots \ldots \ldots \\
\text { NOVEMBER } \ldots \ldots \ldots \ldots \ldots \ldots \\
\text { DECEEMBER. } \ldots \ldots \ldots \ldots \ldots \ldots\end{array}$ & $\begin{array}{r}5.80 \\
15.57 \\
33.50\end{array}$ & $\begin{array}{r}29 \\
305 \\
1,260\end{array}$ \\
\hline 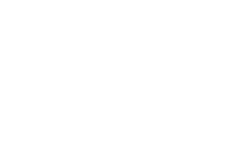 & $\begin{array}{r}109.62 \\
105.80 \\
13.50 \\
15.42 \\
.47 \\
.53 \\
1.09 \\
1.44 \\
1.48\end{array}$ & $\begin{array}{r}14,490 \\
9,910 \\
199 \\
807 \\
0 \\
.03 \\
.42 \\
0.51\end{array}$ \\
\hline TOTAL FOR YEAR, & 304,22 & $27,000,96$ \\
\hline
\end{tabular}

PARTICLE-SIZE DISTRIBUTION OF SUSPENDED SEDIMENT, WATER YEAR OCTOBER 196B TO SEPTEMBER 1969
IMETHOUS OF ANALYSIS: B, BOT TOM WITHDRAWAL TUBE; C, CHEMICALLY DISPERSED; N, IN NATIVE WATER; P. PIPET; S, SIEVE; $\checkmark$. VISUAL ACCUMULATIUN TUBE; W, IN DISTILLED WATER,

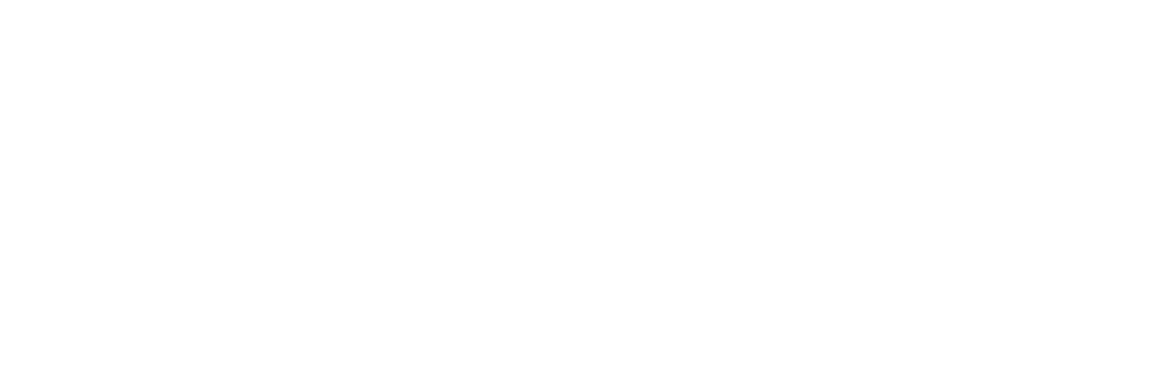


11169800 COYOTE CREEK NEAR GILROY, CALIF.

LOCATION, -- Lat $37^{\circ} 04^{\prime} 40^{\prime \prime}$, long $121^{\circ} 29^{\prime} 36^{\prime \prime}$, in NEł̧SEł sec.11, T. 10 S, , R. 4 E., Santa Clara County, at gaging station 0.7 mile downstream from Bear Creek, 5.0 miles upstream from Coyote Creek Dam, and 6.4 miles northeast of Gilroy.

DRAI NAGE AREA.--109 sq $\mathrm{mi}$.

PERIOD OF RECORD, - Water temperatures: December 1964 to September 1969.

Sediment records: December 1964 to September 1969.

EXTREMES. --1968-69:

Sediment concentrations: Maximum daily, 3,220 mg/1 Jan, 19; minimum daily, no flow for many days.

Sediment discharge: Maximum daily, 41,600 tons Jan. 19; minimum daily, 0 ton on many days.

Period of record (1965-69):

Sediment concentrations: Maximum da1ly, 3,220 mg/1 Jan. 19, 1969; minimum daily, no flow for many days each

sediment discharge: Maximum dally, 41,600 tons Jan. 19, 1969 ; minimum daily, 0 ton on many days each year. REMARKS. --No flow Oct, 1 to Dec, 15, Sept, 26-30.

TEMPERATURE ( ${ }^{\circ} \mathrm{C}$ ) OF WATER, WATER YEAR OCTOBER 1968 TO SEPTEMBER 1969 (ONCE-DAILY MEASUREMENT)

$$
\text { DAY }
$$

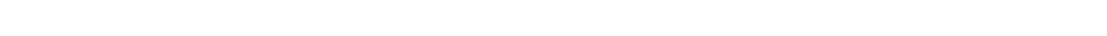
OCTOBER., NUVEMEER,
DECEMBER,

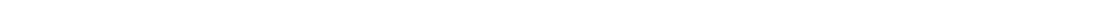

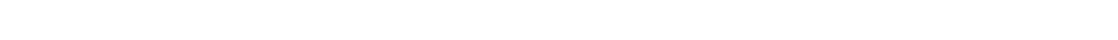
APRIL.... - - - 8 - 8 -

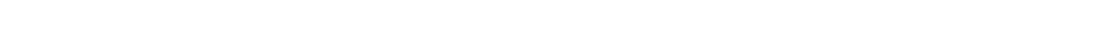

JULY....

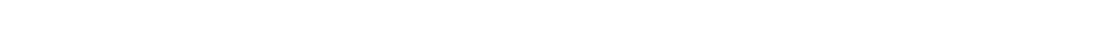

SUSPENDED-SEDIMENT DISCHARGE, WATER YEAR DCTOBER 1968 TO SEPTEMBER 1969 UCTOBER NOVEMBER

DECEMBER

\begin{tabular}{|c|c|c|c|c|c|c|c|c|c|}
\hline UAY & $\begin{array}{l}\text { MEAN } \\
\text { DISCHARGE } \\
\text { (CFS) }\end{array}$ & $\begin{array}{l}\text { MEAN } \\
\text { CONCEN- } \\
\text { TRATION } \\
\text { (MGIL) }\end{array}$ & $\begin{array}{l}\text { SEDIMENT } \\
\text { DISCHARGE } \\
\text { (TONS/DAY) }\end{array}$ & $\begin{array}{c}\text { MEAN } \\
\text { DISCHARGE } \\
\text { (CFS ) }\end{array}$ & $\begin{array}{l}\text { MEAN } \\
\text { CDNCEN- } \\
\text { TRATION } \\
\text { (MG/L) }\end{array}$ & $\begin{array}{l}\text { SEDIMENT } \\
\text { DISCHARGE } \\
\text { (TONS/DAY) }\end{array}$ & $\begin{array}{l}\text { MEAN } \\
\text { DISCHARGE } \\
\text { (CFS) }\end{array}$ & $\begin{array}{l}\text { MEAN } \\
\text { CONCEN-- } \\
\text { TRAIION } \\
\text { (MG/L) }\end{array}$ & $\begin{array}{l}\text { SEDIMENT } \\
\text { DISCHARGE } \\
\text { (TONS/DAY) }\end{array}$ \\
\hline 1 & & & & & & & 0 & -- & 0 \\
\hline 2 & & & & & & & 0 & -- & 0 \\
\hline 3 & & & & & & & 0 & -- & 0 \\
\hline 4 & & & & & & & 0 & -- & 0 \\
\hline 5 & & & & & & & 0 & $=-$ & 0 \\
\hline 6 & & & & & & & 0 & $\rightarrow$ & 0 \\
\hline 7 & & & & & & & 0 & -- & 0 \\
\hline B & & & & & & & 0 & - & 0 \\
\hline 9 & & & & & & & 0 & -- & 0 \\
\hline 10 & & & & & & & 0 & - & 0 \\
\hline 11 & & & & & & & 0 & $=$ & 0 \\
\hline 12 & & & & & & & 0 & -- & 0 \\
\hline 13 & & & & & & & 0 & -- & 0 \\
\hline 14 & & & & & & & 0 & -- & 0 \\
\hline 15 & & & & & & & 0 & $\cdots$ & 0 \\
\hline 16 & & & & & & & 6.1 & 3 & .09 \\
\hline 17 & & & & & & & 2.2 & 3 & .02 \\
\hline 18 & & & & & & & .74 & 3 & .01 \\
\hline 19 & & & & & & & .61 & 3 & 0 \\
\hline 20 & & & & & & & .51 & 3 & 0 \\
\hline 21 & & & & & & & .38 & 5 & .01 \\
\hline 22 & & & & & & & .31 & 4 & \\
\hline 23 & & & & & & & .28 & 3 & 0 \\
\hline 24 & & & & & & & .51 & 5 & $.0 \mathrm{I}$ \\
\hline 25 & & & & & & & 60 & 20 & 7.7 \\
\hline 26 & & & & & & & 167 & 37 & 18 \\
\hline 27 & & & & & & & 54 & 8 & 1.2 \\
\hline 29 & & & & & & & 37 & 5 & .50 \\
\hline 27 & & & & & & & 42 & 4 & .45 \\
\hline 30 & & & & & & & 24 & 3 & .19 \\
\hline 31 & & & & & & & 15 & 3 & .12 \\
\hline TUTAL & 0 & - & 0 & 0 & -- & 0 & 410.64 & -- & 28.30 \\
\hline
\end{tabular}


11169800 COYOTE CREEK NEAR GILROY, CALIF.--Continued

SUSPENDED-SEDIMENT DISCHARGE, WATER YEAR OCTOBER 1968 TO SEPTEMBER 1969

JANUARY

FEBRUARY

MARCH

\begin{tabular}{|c|c|c|c|c|c|c|c|c|c|}
\hline \multirow[b]{2}{*}{ DAY } & \multicolumn{3}{|c|}{ JANUARY } & \multicolumn{3}{|c|}{ FEBRUARY } & \multicolumn{3}{|c|}{ MARCH } \\
\hline & $\begin{array}{l}\text { MEAN } \\
\text { OISCHARGE } \\
\text { (CFS) }\end{array}$ & $\begin{array}{l}\text { MEAN } \\
\text { CONCEN- } \\
\text { TRATION } \\
\text { (MG/L) }\end{array}$ & $\begin{array}{l}\text { SEDIMENT } \\
\text { DISCHARGE } \\
\text { (TONS/DAY) }\end{array}$ & $\begin{array}{l}\text { MEAN } \\
\text { DISCHARGE } \\
\text { (CFS) }\end{array}$ & $\begin{array}{l}\text { MEAN } \\
\text { CONCEN- } \\
\text { TRATION } \\
\text { (MG/LI) }\end{array}$ & $\begin{array}{l}\text { SED IMENT } \\
\text { DISCHARGE } \\
\text { (TONS /DAY) }\end{array}$ & $\begin{array}{l}\text { MEAN } \\
\text { DISCHARGE } \\
\text { (CFS) }\end{array}$ & $\begin{array}{l}\text { MEAN } \\
\text { CONCEN- } \\
\text { TRATI IN } \\
\text { (MG/L) }\end{array}$ & $\begin{array}{l}\text { SEDIMENT } \\
\text { DISCHARGE } \\
\text { (TONS/DAY) }\end{array}$ \\
\hline $\begin{array}{l}1 \\
2 \\
3 \\
4 \\
5\end{array}$ & $\begin{array}{r}11 \\
8.0 \\
6.2 \\
4.9 \\
4.0\end{array}$ & $\begin{array}{l}2 \\
1 \\
4 \\
8 \\
9\end{array}$ & $\begin{array}{l}.06 \\
.02 \\
.07 \\
.11 \\
.10\end{array}$ & $\begin{array}{l}239 \\
230 \\
176 \\
139 \\
162\end{array}$ & $\begin{array}{r}5 \\
5 \\
5 \\
5 \\
32\end{array}$ & $\begin{array}{l}3.2 \\
3.1 \\
2.4 \\
1.9 \\
26\end{array}$ & $\begin{array}{r}1520 \\
809 \\
543 \\
396 \\
298\end{array}$ & $\begin{array}{r}312 \\
86 \\
29 \\
14 \\
11\end{array}$ & $\begin{array}{c}1390 \\
197 \\
43 \\
15 \\
8.9\end{array}$ \\
\hline $\begin{array}{r}6 \\
7 \\
3 \\
9 \\
10\end{array}$ & $\begin{array}{l}3.3 \\
2.8 \\
2.4 \\
2.1 \\
1.8\end{array}$ & $\begin{array}{l}15 \\
25 \\
15 \\
11 \\
10\end{array}$ & $\begin{array}{l}.13 \\
.19 \\
.10 \\
.06 \\
.05\end{array}$ & $\begin{array}{r}1250 \\
707 \\
391 \\
266 \\
199\end{array}$ & $\begin{array}{r}599 \\
123 \\
21 \\
10 \\
6\end{array}$ & $\begin{array}{r}2170 \\
267 \\
22 \\
7.2 \\
3.2\end{array}$ & $\begin{array}{l}237 \\
197 \\
165 \\
146 \\
128\end{array}$ & $\begin{array}{l}99 \\
13 \\
14 \\
15 \\
17\end{array}$ & $\begin{array}{l}5.8 \\
6.9 \\
6.2 \\
5.9 \\
5.9\end{array}$ \\
\hline $\begin{array}{l}11 \\
12 \\
13 \\
14 \\
15\end{array}$ & $\begin{array}{r}1.7 \\
2.1 \\
61 \\
170 \\
50\end{array}$ & $\begin{array}{r}10 \\
10 \\
30 \\
40 \\
5\end{array}$ & $\begin{array}{r}.05 \\
.06 \\
8.9 \\
23 \\
.68\end{array}$ & $\begin{array}{r}365 \\
701 \\
368 \\
273 \\
1400\end{array}$ & $\begin{array}{r}134 \\
167 \\
35 \\
8 \\
1130\end{array}$ & $\begin{array}{c}303 \\
359 \\
37 \\
5.9 \\
5710\end{array}$ & $\begin{array}{r}108 \\
110 \\
99 \\
84 \\
77\end{array}$ & $\begin{array}{l}19 \\
26 \\
20 \\
20 \\
19\end{array}$ & $\begin{array}{l}5.5 \\
7.7 \\
5.3 \\
4.5 \\
4.0\end{array}$ \\
\hline $\begin{array}{l}16 \\
17 \\
18 \\
19 \\
20\end{array}$ & $\begin{array}{r}27 \\
18 \\
442 \\
4340 \\
2020\end{array}$ & $\begin{array}{r}2 \\
2 \\
482 \\
3220 \\
1340\end{array}$ & $\begin{array}{r}.15 \\
2370^{.10} \\
41600 \\
8110\end{array}$ & $\begin{array}{l}890 \\
509 \\
392 \\
375 \\
313\end{array}$ & $\begin{array}{r}232 \\
42 \\
22 \\
20 \\
18\end{array}$ & $\begin{array}{r}653 \\
58 \\
23 \\
20 \\
15\end{array}$ & $\begin{array}{l}71 \\
67 \\
63 \\
58 \\
62\end{array}$ & $\begin{array}{l}20 \\
20 \\
21 \\
22 \\
24\end{array}$ & $\begin{array}{l}3.8 \\
3.6 \\
3.6 \\
3.4 \\
4.0\end{array}$ \\
\hline $\begin{array}{l}21 \\
22 \\
23 \\
24 \\
25\end{array}$ & $\begin{array}{r}2590 \\
1540 \\
437 \\
469 \\
3890\end{array}$ & $\begin{array}{r}1790 \\
753 \\
48 \\
110 \\
2910\end{array}$ & $\begin{array}{r}13500 \\
4620 \\
64 \\
558 \\
39700\end{array}$ & $\begin{array}{r}262 \\
308 \\
723 \\
2580 \\
1820\end{array}$ & $\begin{array}{r}15 \\
16 \\
129 \\
1830 \\
1380\end{array}$ & $\begin{array}{r}11 \\
13 \\
275 \\
16000 \\
7080\end{array}$ & $\begin{array}{l}73 \\
59 \\
52 \\
48 \\
45\end{array}$ & $\begin{array}{l}24 \\
23 \\
23 \\
22 \\
22\end{array}$ & $\begin{array}{l}4.7 \\
3.7 \\
3.2 \\
2.9 \\
2.7\end{array}$ \\
\hline $\begin{array}{l}26 \\
27 \\
28 \\
29 \\
30 \\
31\end{array}$ & $\begin{array}{r}2610 \\
800 \\
650 \\
425 \\
343 \\
274\end{array}$ & $\begin{array}{r}1730 \\
151 \\
129 \\
35 \\
26 \\
10\end{array}$ & $\begin{array}{c}16500 \\
366 \\
229 \\
40 \\
24 \\
7.4\end{array}$ & $\begin{array}{r}1490 \\
831 \\
1330 \\
-- \\
--\end{array}$ & $\begin{array}{r}618 \\
110 \\
539 \\
-- \\
--\end{array}$ & $\begin{array}{r}2910 \\
247 \\
2500 \\
=- \\
=-\end{array}$ & $\begin{array}{l}44 \\
41 \\
39 \\
37 \\
36 \\
35\end{array}$ & $\begin{array}{l}22 \\
22 \\
22 \\
22 \\
22 \\
22\end{array}$ & $\begin{array}{l}2.6 \\
2.4 \\
2.3 \\
2.2 \\
2.1 \\
2.1\end{array}$ \\
\hline TOTAL & 21206.3 & -- & 127722.23 & 18689 & -- & 38725.9 & 5747 & -- & 1760.9 \\
\hline & & APRIL & & & MAY & & & JUNE & \\
\hline DAY & $\begin{array}{c}\text { MEAN } \\
\text { OISCHARGE } \\
\text { (CFS) }\end{array}$ & $\begin{array}{l}\text { MEAN } \\
\text { CONCEN- } \\
\text { TRATIDN } \\
\text { (MG/L) }\end{array}$ & $\begin{array}{l}\text { SEDIMENT } \\
\text { DISCHARGE } \\
\text { (TONS/DAY) }\end{array}$ & $\begin{array}{l}\text { MEAN } \\
\text { DISCHARGE } \\
\text { (CFS) }\end{array}$ & $\begin{array}{l}\text { MEAN } \\
\text { CONCEN- } \\
\text { TRATION } \\
\text { (MG/L) }\end{array}$ & $\begin{array}{l}\text { SEDIMENT } \\
\text { DISCHARGE } \\
\text { (TONS/DAY) }\end{array}$ & $\begin{array}{l}\text { MEAN } \\
\text { DISCHARGE } \\
\text { (CFS) }\end{array}$ & $\begin{array}{l}\text { MEAN } \\
\text { CONCEN- } \\
\text { TRATIION } \\
\text { (MGLI) }\end{array}$ & $\begin{array}{l}\text { SEDIMENT } \\
\text { DISCHARGE } \\
\text { (TONS/DAY) }\end{array}$ \\
\hline
\end{tabular}

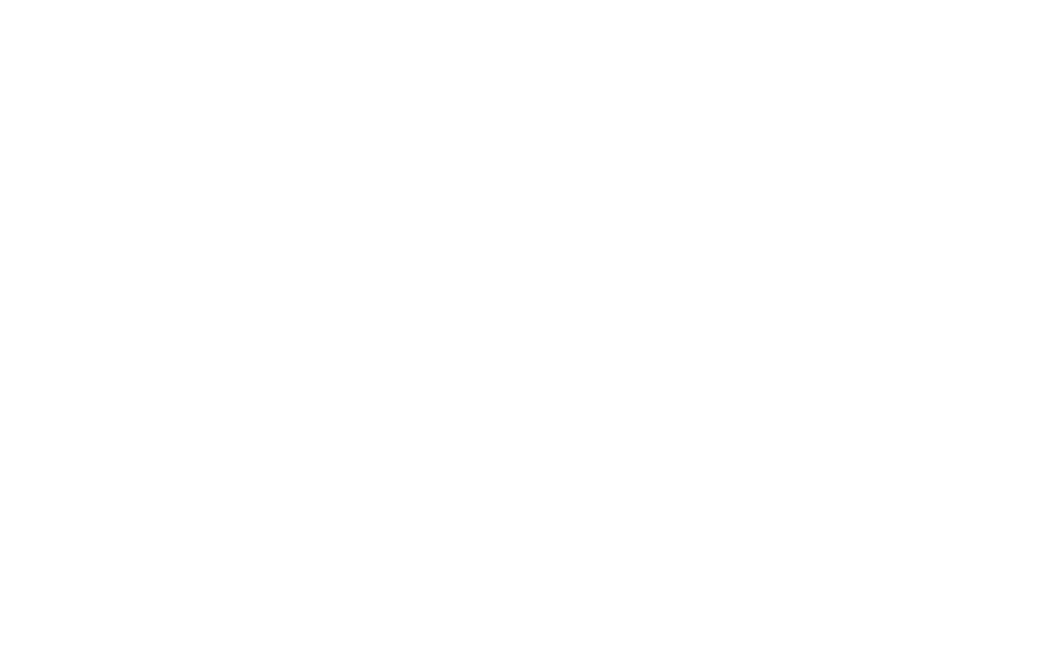


11169800 COYOTE CREEK NEAR GILROY, CALIF.-- COntinued

SUSPENDED-SEDIMENT DISCHARGE, WATER YEAR OCTOBER 1960 TO SEPTEMBER 1969

\begin{tabular}{|c|c|c|c|c|c|c|c|c|c|}
\hline DAY & $\begin{array}{l}\text { MEAN } \\
\text { DISCHARGE } \\
\text { (CFS) }\end{array}$ & $\begin{array}{l}\text { JULY } \\
\text { MEAN } \\
\text { CONCEN- } \\
\text { TRATION } \\
\text { IMG/L) }\end{array}$ & $\begin{array}{l}\text { SEDIMENT } \\
\text { DISCHARGE } \\
\text { (TONS/DAY) }\end{array}$ & $\begin{array}{l}\text { MEAN } \\
\text { DISCHARGE } \\
\text { (CFS) }\end{array}$ & $\begin{array}{l}\text { AUGUST } \\
\text { MEAN } \\
\text { CONCEN- } \\
\text { TRATION } \\
\text { (MGILI }\end{array}$ & $\begin{array}{l}\text { SEDIMENT } \\
\text { DISCHARGE } \\
\text { (TONS/DAY) }\end{array}$ & $\begin{array}{l}\text { MEAN } \\
\text { DISCHARGE } \\
\text { (CFS) }\end{array}$ & $\begin{array}{l}\text { SEPTEMBER } \\
\text { MEAN } \\
\text { CONCEN- } \\
\text { TRATION } \\
\text { (MG/l }\end{array}$ & $\begin{array}{l}\text { SEDIMENT } \\
\text { DISCHARGE } \\
\text { (TONS/DAY) }\end{array}$ \\
\hline $\begin{array}{l}1 \\
2 \\
3 \\
4 \\
5\end{array}$ & $\begin{array}{l}1.7 \\
1.5 \\
1.4 \\
1.3 \\
1.3\end{array}$ & $\begin{array}{l}5 \\
5 \\
5 \\
5 \\
5\end{array}$ & $\begin{array}{r}.02 \\
.02 \\
.02 \\
.02 \\
.02\end{array}$ & $\begin{array}{l}.36 \\
.34 \\
.33 \\
.35 \\
.39\end{array}$ & $\begin{array}{l}5 \\
5 \\
5 \\
5 \\
5\end{array}$ & $\begin{array}{l}0 \\
0 \\
0 \\
0 \\
.01\end{array}$ & $\begin{array}{l}.13 \\
.15 \\
.05 \\
.03 \\
.03\end{array}$ & $\begin{array}{l}7 \\
7 \\
7 \\
7 \\
7\end{array}$ & $\begin{array}{l}0 \\
0 \\
0 \\
0 \\
0\end{array}$ \\
\hline $\begin{array}{r}6 \\
7 \\
8 \\
9 \\
10\end{array}$ & $\begin{array}{l}1.4 \\
1.3 \\
1.2 \\
1.2 \\
1.2\end{array}$ & $\begin{array}{l}5 \\
5 \\
5 \\
5 \\
5\end{array}$ & $\begin{array}{l}.02 \\
.02 \\
.02 \\
.02 \\
.02\end{array}$ & $\begin{array}{l}.36 \\
.34 \\
.27 \\
.27 \\
.26\end{array}$ & $\begin{array}{l}5 \\
5 \\
5 \\
5 \\
5\end{array}$ & $\begin{array}{l}0 \\
0 \\
0 \\
0 \\
0\end{array}$ & $\begin{array}{l}.03 \\
.06 \\
.07 \\
.05 \\
.05\end{array}$ & $\begin{array}{l}7 \\
7 \\
7 \\
7 \\
7\end{array}$ & $\begin{array}{l}0 \\
0 \\
0 \\
0 \\
0\end{array}$ \\
\hline $\begin{array}{l}11 \\
12 \\
13 \\
14 \\
15\end{array}$ & $\begin{array}{l}1.1 \\
1.1 \\
1.0 \\
.98 \\
.86\end{array}$ & $\begin{array}{l}5 \\
5 \\
5 \\
5 \\
5\end{array}$ & $\begin{array}{l}.01 \\
.01 \\
.01 \\
.01 \\
.01\end{array}$ & $\begin{array}{l}.21 \\
.19 \\
.18 \\
.18 \\
.18\end{array}$ & $\begin{array}{l}6 \\
6 \\
6 \\
6 \\
6\end{array}$ & $\begin{array}{l}0 \\
0 \\
0 \\
0 \\
0\end{array}$ & $\begin{array}{l}.03 \\
.03 \\
.03 \\
.03 \\
.03\end{array}$ & $\begin{array}{l}7 \\
7 \\
7 \\
7 \\
7\end{array}$ & $\begin{array}{l}0 \\
0 \\
0 \\
0 \\
0\end{array}$ \\
\hline $\begin{array}{l}16 \\
17 \\
18 \\
19 \\
20\end{array}$ & $\begin{array}{l}.84 \\
.77 \\
.70 \\
.60 \\
.58\end{array}$ & $\begin{array}{l}5 \\
5 \\
5 \\
5 \\
5\end{array}$ & $\begin{array}{l}.01 \\
.01 \\
.01 \\
.01 \\
.01\end{array}$ & $\begin{array}{l}.18 \\
.15 \\
.27 \\
.12 \\
.11\end{array}$ & $\begin{array}{l}6 \\
6 \\
6 \\
6 \\
6\end{array}$ & $\begin{array}{l}0 \\
0 \\
0 \\
0 \\
0\end{array}$ & $\begin{array}{l}.03 \\
.03 \\
.03 \\
.03 \\
.03\end{array}$ & $\begin{array}{l}7 \\
7 \\
7 \\
7 \\
7\end{array}$ & $\begin{array}{l}0 \\
0 \\
0 \\
0 \\
0\end{array}$ \\
\hline $\begin{array}{l}21 \\
22 \\
23 \\
24 \\
25\end{array}$ & $\begin{array}{l}.67 \\
.59 \\
.59 \\
.57 \\
.51\end{array}$ & $\begin{array}{l}5 \\
5 \\
5 \\
5 \\
5\end{array}$ & $\begin{array}{l}.01 \\
.01 \\
.01 \\
.01 \\
.01\end{array}$ & $\begin{array}{l}.11 \\
.09 \\
.08 \\
.09 \\
.13\end{array}$ & $\begin{array}{l}6 \\
6 \\
6 \\
6 \\
6\end{array}$ & $\begin{array}{l}0 \\
0 \\
0 \\
0 \\
0\end{array}$ & $\begin{array}{l}.03 \\
.02 \\
.02 \\
.01 \\
.01\end{array}$ & $\begin{array}{l}7 \\
7 \\
7 \\
7 \\
7\end{array}$ & $\begin{array}{l}0 \\
0 \\
0 \\
0 \\
0\end{array}$ \\
\hline $\begin{array}{l}26 \\
27 \\
28 \\
29 \\
30 \\
31\end{array}$ & $\begin{array}{l}.50 \\
.49 \\
.47 \\
.45 \\
.39 \\
.37\end{array}$ & $\begin{array}{l}5 \\
5 \\
5 \\
5 \\
5 \\
5\end{array}$ & $\begin{array}{l}.02 \\
.02 \\
.01 \\
.01 \\
.01 \\
0.01\end{array}$ & $\begin{array}{l}.18 \\
.19 \\
.20 \\
.36 \\
.32 \\
.18\end{array}$ & $\begin{array}{l}6 \\
6 \\
6 \\
6 \\
6 \\
6\end{array}$ & $\begin{array}{l}0 \\
0 \\
0 \\
.01 \\
.01\end{array}$ & $\begin{array}{r}0 \\
0 \\
0 \\
0 \\
0 \\
--\end{array}$ & $\begin{array}{l}= \\
=- \\
=- \\
=-\end{array}$ & $\begin{array}{l}0 \\
0 \\
0 \\
0 \\
0 \\
--\end{array}$ \\
\hline TOTAL & 27.58 & -- & .40 & 6.87 & -- & .03 & 1.04 & $\cdots$ & 0 \\
\hline $\begin{array}{l}\text { TOTAL } \\
\text { TOTAL }\end{array}$ & $\begin{array}{l}\text { D2SCHARGE } \\
\text { SUSPENDED- }\end{array}$ & $\begin{array}{l}\text { YEAR } \\
\text { DIMENT }\end{array}$ & $\begin{array}{l}\text { S-DAYSI } \\
\text { SCHARGE FOR }\end{array}$ & YEAR & & & & & $\begin{array}{r}47702.73 \\
.68280 .05\end{array}$ \\
\hline
\end{tabular}

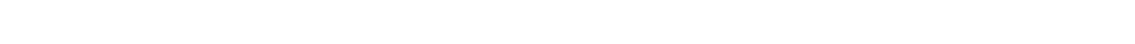
$\checkmark$, VISUAL ACCUMULATION TUBE; W, IN OISTILLEO WATERI

WATER

TEM-

SUSPENDED

PARTICLE SILE

CONCEN- SEOIMENT PERCENT FINER THAN THE SIZE IIN MILLIMETERSI INOICATEO

DATE ISCHARGE TRATION DISCHARGE

TIME T

JAN 19, 1969090011

$\begin{array}{llr}7650 & 5270 & 207000 \\ 2880 & 2470 & 19200\end{array}$

$.002 .004 .008 .016 .031 .062 \quad .125 .250 .5001 .00 \quad 2.00$

JAN 19

170012

107000
19200

JAN $20 \ldots \ldots 133012$

JAN $25 . . . .1130$ 10

414

414
5740

$\begin{array}{rr}606 & 2420 \\ 42 & 47\end{array}$

47
63100

$\begin{array}{lll}216 & 20 & 30 \\ 22 & 31 & 44\end{array}$

FEB $15 \ldots \ldots .140010$

2310
2880

$\begin{array}{lr}1570 & 9790 \\ 1770 & 13800\end{array}$

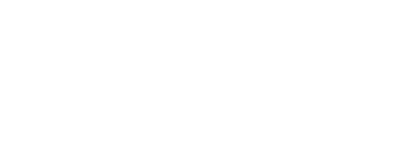


11176500 ARROYO VALLE NEAR LIVERMORE, CALIF.

LOCATION. --Lat $37^{\circ} 37^{\prime} 24^{\prime \prime}$, long $121^{\circ} 45^{\prime} 28^{\prime \prime}$, in $\mathrm{V}_{\mathrm{a}} 1 \mathrm{le}$ de San Jose Grant, Alameda County, temperature recorder at

gaging station on $r$ ght bank, $900 \mathrm{ft}$ downstream from highway bridge, $1.1 \mathrm{~m} 1 \mathrm{les}$ upstream $\mathrm{from}$ Dry Creek,
1.3 miles downstream from De 1 Valle Dam, 4.1 miles south of Livermore, and 6.9 miles southeast of Pleasanton. DRAINAGE AREA, $-147 \mathrm{sq} \mathrm{m} 1$.

PERIOD OF RECORD. --Chemical analyses: December 1958 to July 1966

Water temperatures: October 1959 to September 1961, October 1962 to September 1969.

Sediment records: October 1962 to September 1967.

EXTREMES . - -1968-69:

Hater temperatures: Maximum, $23.0^{\circ} \mathrm{C}$ Sept. $10 ; \mathrm{m} 1$ nimum, $7.0^{\circ} \mathrm{C}$ on severa 1 days during December to February.

Period of record (1963-69):

Water temperatures: Maximum, $30.5^{\circ} \mathrm{C}$ June 14,1966 ; minimum, 4.0 ${ }^{\circ} \mathrm{C}$ Jan. 2, Dec. 28, 1966, Dec. $13-15,1967$. REMARKS. --No flow Oct. 1 to Dec, 24, Jan. 1-17. No record Feb. 14, 15.

TEMPERATURE $\left({ }^{\circ} \mathrm{C}\right)$ OF WATER, WATER YEAR OCTOBER 1968 TO SEPTEMBER 1969

DAY

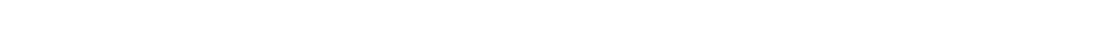

QECEMBER

MAXIMUM --

MAXIMUA -

MINIMUM
FEREARY

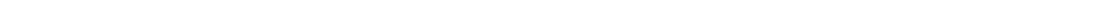

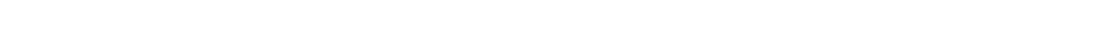

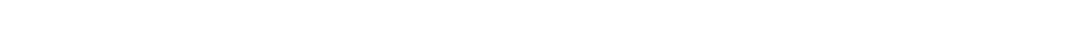

MININ

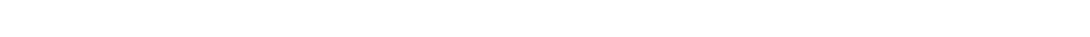

MAY MAX

MAXIMUM $15 \quad 16 \quad 13 \quad 15 \quad 16 \quad 16 \quad 13 \quad 13 \quad 13 \quad 13 \quad 12 \quad 13 \quad 10$

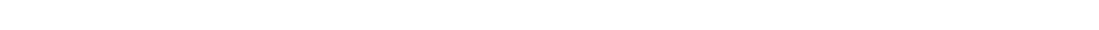

JUNE

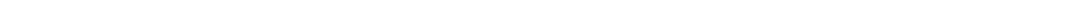

MAXIMUM $212020212020202021 \quad 2020201918192020212020202020 \quad 2020 \quad 202020 \quad 2020 \quad 20 \quad 20$

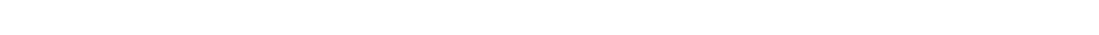
AUGUST

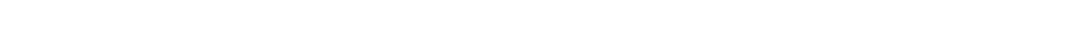

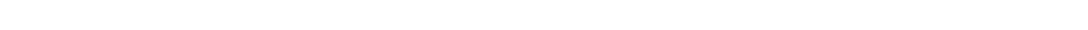

SEPTEMBER

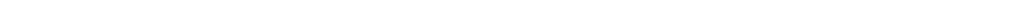

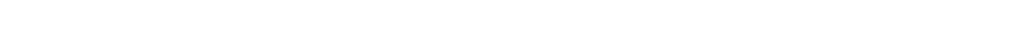


11179000 ALAMEDA CREEK NEAR NILES, CALIF.

LOCATION. --Lat $37^{\circ} 35^{\prime} 14^{\prime \prime}$, long $121^{\circ} 57^{\prime} 35^{\prime \prime}$, in NW $\frac{1}{4}$ sec.15, T. 4 S., R. 1 W., Alameda County, at gaging station 0.3 mile downstream from rail road bridge and 1.2 miles northeast of Niles.

DRAI NAGE AREA, $--633 \mathrm{sq} \mathrm{mi}$.

PERIOD OF RECORD. --Chemical analyses: February 1952 to September 1967, October 1968 to September 1969 Water temperatures: July 1956 to Septerber 1969.

EXTREMES. --1968-69:

Water temperatures: Maximum, $25.0^{\circ} \mathrm{C}$ on severa 1 days during May, July to September; mini rum, $6.0^{\circ} \mathrm{C} \mathrm{Dec} .22$.

Sediment concentrations: Maximu daily, 4, $280 \mathrm{mg} / 1$ Jan. 26 ; mint mum daily, $5 \mathrm{mg} / 1 \mathrm{Oct}$. 13, Nov. 12, $13,29$.

Sediment concentrations: Maximu daily, $4,280 \mathrm{mg} / \mathrm{Jan}$; 26 ; minimum dally, $5 \mathrm{mg} / 1$ Oct.
Sediment

Period of record:

Water temperatures: Maximum $(1956-62,1964-69), 31.0^{\circ} \mathrm{C}$ June 1, 1960; minimum, 3. $0^{\circ} \mathrm{C}$ Jan. 5, 1961, Jan. 14, 1963.

Sediment concentrations: Maximum daily, 5,340 mg/1 Apr. 3, 1958; minimum daily, no flow for many days in

$1957,1959-61$.

Sediment discharge: Maximum daily, 285,000 tons Apr. 3, 1958; minimum daily, 0 ton on many days in 1957, 1959-61.

REMARKS. --Chemical-quality records furnished by California Department of Water Resources and reviewed by U.S. Geo-

logical Survey.

CHEMICAL ANALYSES, WAIER YEAR OCTOBER 1968 TO SEPTEMBER 1969

\begin{tabular}{|c|c|c|c|c|c|c|c|c|c|c|c|c|}
\hline & TIME & $\begin{array}{l}\text { OIS- } \\
\text { CHARGF }\end{array}$ & $\begin{array}{l}\text { TEMPER - } \\
\text { ATURE }\end{array}$ & $\begin{array}{l}\text { DIF } \\
\text { SOLVED } \\
\text { OXYGEN }\end{array}$ & $\begin{array}{l}\text { CAL- } \\
\text { CIUM } \\
\text { (CA) }\end{array}$ & $\begin{array}{c}\text { MAG- } \\
\text { NE- } \\
\text { SIUM } \\
\text { (MG) }\end{array}$ & $\begin{array}{l}\text { SOOIUM } \\
\text { (NA) }\end{array}$ & $\begin{array}{l}\text { PO- } \\
\text { TAS- } \\
\text { SIUM } \\
\text { (K) }\end{array}$ & $\begin{array}{l}\text { BICAR- } \\
\text { BONATE } \\
\text { IHCO3) }\end{array}$ & $\begin{array}{l}\text { CAR- } \\
\text { BONATE } \\
\text { (CO3) }\end{array}$ & $\begin{array}{l}\text { SULFATE } \\
\text { ISO4) }\end{array}$ & $\begin{array}{l}\text { CHLO- } \\
\text { RIOE } \\
\text { (CL) } \\
\text { (MGIL }\end{array}$ \\
\hline OATE & & (CFS) & (DEG C) & (NG/L) & $(M G / L)$ & $(M G / L)$ & $(M G / L)$ & $(M G / L)$ & (MG/L) & (MG $/ L)$ & $(M G / L)$ & IMG $/ L$ \\
\hline
\end{tabular}

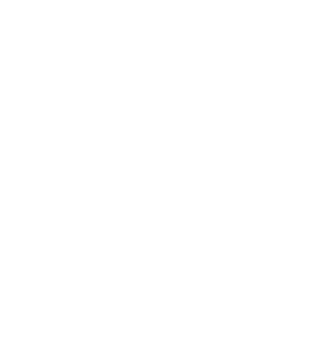

$\begin{array}{rrrrr}14 & 10.4 & - & -- & 50 \\ 13 & 10.1 & -- & -- & 5 \\ 12 & 12.2 & 36 & -- & 68 \\ 7 & 11.4 & 32 & -- & 5 \\ 8 & 11.1 & 27 & -- & 27 \\ 10 & 11.6 & 40 & -- & 29 \\ 15 & 12.2 & 34 & 21 & 37 \\ 16 & 11.4 & 66 & 31 & 6 \\ 18 & 8.1 & 54 & -- & 6 \\ 18 & 8.0 & 48 & -- & 5\end{array}$

50
54
68
59
27
29
37
69
60
53
PERCENT
SOOIUM

$\begin{array}{ccccc}-- & 129 & 0 & -- & 68 \\ -- & 126 & 0 & -- & 71 \\ -- & 152 & 0 & -- & 88 \\ -- & 127 & 0 & - & 72 \\ -- & 130 & 0 & -- & 23 \\ -- & 162 & 0 & -- & 31 \\ 1.7 & 178 & 0 & 52 & 38 \\ 3.1 & 273 & 0 & 105 & 74 \\ -- & 235 & 0 & -- & 65 \\ -- & 221 & 8 & -- & 52\end{array}$

\begin{tabular}{|c|c|c|c|c|c|c|c|c|c|c|c|}
\hline DATE & $\begin{array}{l}\text { NITRAIE } \\
\text { (NO3) } \\
\text { (MG/L) }\end{array}$ & $\begin{array}{l}\text { BORON } \\
\text { (B) } \\
(U G / L)\end{array}$ & $\begin{array}{l}\text { DIS- } \\
\text { SCLVED } \\
\text { SOL IDS } \\
\text { IRESI- } \\
\text { OUE AI } \\
\text { I8O CI } \\
\text { IMG LL) }\end{array}$ & $\begin{array}{l}\text { OIS- } \\
\text { SOLVED } \\
\text { SOLIDS } \\
\text { ITONS } \\
\text { PER } \\
\text { AC-FTI }\end{array}$ & $\begin{array}{l}\text { HARD- } \\
\text { NESS } \\
\text { (CA,MG) } \\
\text { (MG/L) }\end{array}$ & $\begin{array}{l}\text { NON- } \\
\text { CAR- } \\
\text { BONATE } \\
\text { HARO- } \\
\text { NESS } \\
\text { IMGIL) }\end{array}$ & $\begin{array}{l}\text { PERCENT } \\
\text { SOOIUM }\end{array}$ & $\begin{array}{l}\text { SOOIUM } \\
\text { AD- } \\
\text { SORP- } \\
\text { TION } \\
\text { RATIO }\end{array}$ & $\begin{array}{l}\text { ALKA- } \\
\text { LINITY } \\
\text { AS } \\
\text { CACO } 3 \\
\text { (MG/L) }\end{array}$ & $\begin{array}{c}\text { PH } \\
\text { (UNITS) }\end{array}$ & $\begin{array}{l}\text { SPECI } \\
\text { FIC } \\
\text { COND- } \\
\text { UCTANC } \\
\text { (4ICRO- } \\
\text { MHOS) }\end{array}$ \\
\hline $\begin{array}{l}\text { OCT. } \\
16 . . .\end{array}$ & -- & 230 & -- & - & 131 & 25 & 45 & 1.9 & 106 & B. 0 & 509 \\
\hline $\begin{array}{l}07 . . \\
\text { DEC. }\end{array}$ & -- & 320 & -- & -- & 132 & 29 & 47 & 2.0 & 103 & 8.0 & 529 \\
\hline$\underset{\text { JAN. }}{10}$ & 14 & 420 & $\cdots$ & -- & 172 & 47 & 62 & 3.1 & 125 & 8.3 & 686 \\
\hline $\begin{array}{l}08 . . . \\
F E B .\end{array}$ & $\cdots$ & 470 & -- & -- & 168 & 64 & 62 & 2.9 & 104 & 7.7 & 619 \\
\hline OB... & 5.1 & 330 & -- & - & 111 & 4 & 47 & 1.4 & 107 & 8.1 & 344 \\
\hline $\begin{array}{l}12 \ldots \\
\triangle P R\end{array}$ & -- & 310 & -- & $\rightarrow$ & 183 & 50 & 39 & 1.3 & 133 & 8.3 & 492 \\
\hline MAY & 3.7 & 310 & 290 & .39 & 171 & 25 & 32 & 1.2 & 146 & 8.2 & 517 \\
\hline $\begin{array}{l}\text { O1.... } \\
\text { JUNE }\end{array}$ & 9.6 & - & 510 & .69 & 293 & 69 & 34 & 1.8 & 224 & 8.3 & 861 \\
\hline Qú... & 6.8 & 540 & + & - & 258 & 65 & 49 & 2.2 & 193 & 8.3 & 120 \\
\hline $13 \ldots$ & 7.7 & 490 & -- & -- & 236 & 41 & 49 & 2.1 & 194 & 8.4 & 667 \\
\hline
\end{tabular}

TEMPERATURE $\left({ }^{\circ} \mathrm{C}\right)$ OF WATER, WATER YEAR OCTOBER 1968 TO SEPTEMBER 1969 (ONCE-DAILY MEASUREMENT)

DAY

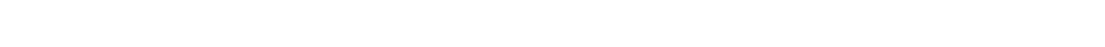

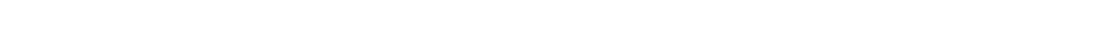

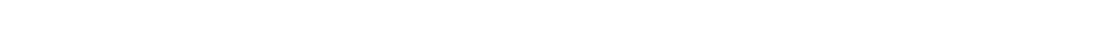

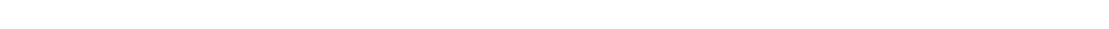

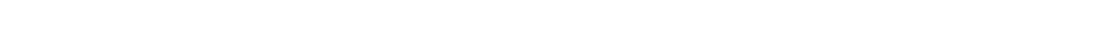

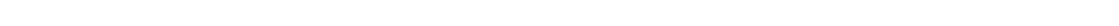
APRIL.... $17 \begin{array}{lllllllllllllllllllllllllllllllllll}13 & 15 & 15 & 13 & 13 & 15 & 17 & 15 & 17 & 18 & 16 & 15 & 16 & 17 & 18 & 16 & 18 & 18 & 19 & 20 & 18 & 16 & 17 & 17 & 19 & 19 & 20 & 20 & 16 & -2 & 17\end{array}$ $\begin{array}{llllllllllllllllllllllllllllllllll}\text { MAY....... } & 16 & 19 & 18 & 19 & 21 & 21 & 21 & 20 & 22 & 22 & 20 & 20 & 20 & 20 & 21 & 21 & 23 & 21 & 22 & 22 & 22 & 22 & 21 & 21 & 20 & 22 & 22 & 23 & 22 & 24 & 25 & 21 \\ \text { JUNE..... } & 23 & 23 & 23 & 21 & 19 & 22 & 18 & 17 & 17 & 20 & 18 & 18 & 20 & 18 & 20 & 23 & 22 & 24 & 24 & 22 & 21 & 22 & 23 & 23 & 22 & 22 & 22 & 19 & 21 & 24 & - & \end{array}$ $\begin{array}{llllllllllllllllllllllllllllllllllllllllll}\text { JULY..... } & 23 & 21 & 24 & 21 & 23 & 22 & 23 & 23 & 24 & 24 & 24 & 25 & 25 & 24 & 24 & 25 & 25 & 25 & 25 & 25 & 25 & 25 & 25 & 24 & 24 & 25 & 24 & 24 & 24 & 23 & 24 & 24\end{array}$

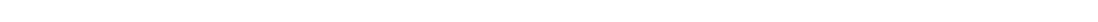


ALAMEDA CREEK BASIN

11179000 ALAMEDA CREEK NEAR NILES, CALI F.--Cont inued

SUSPENDED-SEDIMENT DISCHARGE, WATER YEAR OCTOBER 1968 TO SEPTEMBER 1969

$$
\text { OCTOBER }
$$

NOVEABER

DECEABER

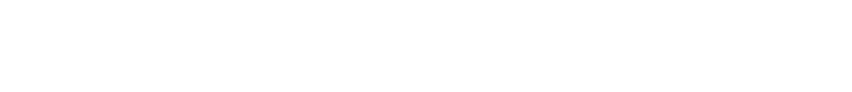

MONCEN- SEDIMENT

IRATION DISCHARGE

$\begin{array}{llll}17 & 5 & .23 & 47 \\ 17 & 9 & .41 & 49 \\ 25 & 5 & .34 & 50 \\ 24 & 7 & .45 & 45 \\ 26 & 9 & .63 & 14\end{array}$

$\begin{array}{rrrr}47 & 13 & 1.6 & 47 \\ 49 & 25 & 3.4 & 42 \\ 50 & 21 & 3.0 & 31 \\ 45 & 67 & 6.9 & 30 \\ 14 & 148 & 5.6 & 30\end{array}$

(MG/L) (TONS/DAY)

6

$.54 \quad 20$

25
27
63
58
50

8
19
19
11

$\begin{array}{ll}.54 & 20 \\ 1.5 & 40 \\ 3.7 & 38 \\ 3.0 & 35 \\ 1.5 & 33\end{array}$

75

3.6

$\begin{array}{ll}12 & 1.5 \\ 14 & 1.6 \\ 13 & 1.1 \\ 11 & .89 \\ 11 & .89\end{array}$

$\begin{array}{ll}11 & 56 \\ 12 & 54 \\ 13 & 54 \\ 14 & 56 \\ 15 & 56\end{array}$

$\begin{array}{ll}2.6 & 25 \\ 1.9 & 24 \\ 2.0 & 26 \\ 2.3 & 24 \\ 1.8 & 22\end{array}$

$\begin{array}{ll}16 & 47 \\ 17 & 46 \\ 18 & 43 \\ 19 & 42\end{array}$

20

$\begin{array}{ll}1.0 & 24 \\ 1.2 & 13 \\ 1.3 & 11 \\ .79 & 11 \\ .91 & 7.6\end{array}$

7.6

$\begin{array}{ll}1.1 & 9.1 \\ 1.2 & 7.3 \\ 1.2 & 35 \\ 1.84 & 48 \\ 1.1 & 47\end{array}$

$\begin{array}{ll}.65 & 45 \\ 1.0 & 42 \\ 1.3 & 47 \\ 1.4 & 45 \\ 1.3 & 47 \\ .95 & -0\end{array}$

45
42
47
45
47
-

40.14

931.0

$\begin{array}{ll}3.6 & 30 \\ 3.1 & 31 \\ 1.6 & 31 \\ .95 & 31 \\ 1.3 & 12\end{array}$

12
17
12
18

.97

1.4
1.0
1.5

$\begin{array}{ll}.81 & 31 \\ .32 & 22 \\ .35 & 12 \\ 1.7 & 13 \\ . .3 & 41\end{array}$

$\begin{array}{rl}33 & 3.2 \\ 87 & 5.2 \\ 59 & 1.9 \\ 297 & 11 \\ 385 & 43\end{array}$

24

2.3

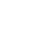

.53
.36
.21

101

$\begin{array}{rrr}.36 & 36 & 130\end{array}$

$\begin{array}{rr}.25 & 74 \\ .20 & 48 \\ 2.5 & 48 \\ 4.4 & 38 \\ 2.3 & 53\end{array}$

1.6
2.0
2.4
.61

2.4
.61
.89

176
48
27
27
56
54

60.58

1335

20

4.9
4.8
9.8

1.8
2.3

2.3

361
50

14.4

6.4
6.4
5.5

708.67

\begin{tabular}{|c|c|c|c|c|c|c|c|c|}
\hline \multicolumn{3}{|c|}{ JANUARY } & \multicolumn{3}{|c|}{ FEBRUARY } & \multicolumn{3}{|c|}{ MARCH } \\
\hline $\begin{array}{l}\text { MEAN } \\
\text { OISCARGE } \\
\text { (CFS) }\end{array}$ & 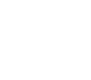 & $\begin{array}{l}\text { SEDIMENT } \\
\text { DISCARRGE } \\
\text { (TONS/DAYY }\end{array}$ & $\begin{array}{l}\text { MEAN } \\
\text { O1SGARGE } \\
\text { ICFSI }\end{array}$ & $\begin{array}{l}\text { MEAN } \\
\text { MENEN- } \\
\text { TRATION } \\
\text { THG/L) }\end{array}$ & $\begin{array}{l}\text { SEDIMENT } \\
\text { DISCHARGE } \\
\text { (TONS/DAY) }\end{array}$ & $\begin{array}{c}\text { MEAN } \\
\text { DISCAAGEE } \\
\text { (CFS) }\end{array}$ & 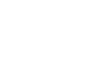 & $\begin{array}{l}\text { SEDIAENT } \\
\text { DISCARARE } \\
\text { (TONS DAAY) }\end{array}$ \\
\hline $\begin{array}{l}52 \\
45 \\
35 \\
41 \\
41\end{array}$ & $\begin{array}{l}32 \\
26 \\
19 \\
15 \\
15\end{array}$ & $\begin{array}{l}4.5 \\
3.2 \\
1.8 \\
1.8 \\
1.7 \\
1.7\end{array}$ & $\begin{array}{r}132 \\
103 \\
83 \\
67 \\
106\end{array}$ & $\begin{array}{c}110 \\
80 \\
48 \\
27 \\
67\end{array}$ & $\begin{array}{l}39 \\
22 \\
11 \\
4.9 \\
21\end{array}$ & $\begin{array}{l}3670 \\
2420 \\
2050 \\
1800 \\
1530\end{array}$ & $\begin{array}{r}2110 \\
780 \\
620 \\
490 \\
460\end{array}$ & $\begin{array}{r}22000 \\
5100 \\
3430 \\
2380 \\
1900\end{array}$ \\
\hline $\begin{array}{l}40 \\
41 \\
39 \\
39 \\
38\end{array}$ & $\begin{array}{l}18 \\
24 \\
19 \\
14 \\
12\end{array}$ & $\begin{array}{l}1.9 \\
2.7 \\
2.0 \\
1.5 \\
1.2\end{array}$ & $\begin{array}{r}1270 \\
430 \\
195 \\
133 \\
97\end{array}$ & $\begin{array}{r}2430 \\
972 \\
175 \\
110 \\
70\end{array}$ & $\begin{array}{r}9370 \\
1370 \\
92 \\
40 \\
48\end{array}$ & $\begin{array}{l}794 \\
615 \\
445 \\
340 \\
332\end{array}$ & $\begin{array}{r}351 \\
220 \\
165 \\
114 \\
98\end{array}$ & $\begin{array}{l}787 \\
365 \\
198 \\
114 \\
88\end{array}$ \\
\hline $\begin{array}{l}37 \\
12 \\
16 \\
44 \\
19\end{array}$ & $\begin{array}{l}19 \\
37 \\
48 \\
84 \\
72\end{array}$ & $\begin{array}{r}1.9 \\
1.2 \\
2.6 \\
10.6 \\
3.7\end{array}$ & $\begin{array}{l}299 \\
783 \\
227 \\
161 \\
514\end{array}$ & $\begin{array}{r}343 \\
1300 \\
330 \\
160 \\
622\end{array}$ & $\begin{array}{r}636 \\
3160 \\
217 \\
70 \\
1180\end{array}$ & $\begin{array}{l}299 \\
326 \\
369 \\
304 \\
271\end{array}$ & $\begin{array}{l}85 \\
114 \\
225 \\
162 \\
192\end{array}$ & $\begin{array}{l}69 \\
100 \\
224 \\
133 \\
140\end{array}$ \\
\hline $\begin{array}{r}42 \\
41 \\
43 \\
696 \\
568\end{array}$ & $\begin{array}{r}65 \\
34 \\
132 \\
1030 \\
1020\end{array}$ & $\begin{array}{l}7.4 \\
3.8 \\
17 \\
3080 \\
1610\end{array}$ & $\begin{array}{l}455 \\
238 \\
472 \\
321 \\
194\end{array}$ & $\begin{array}{l}655 \\
240 \\
485 \\
367 \\
220\end{array}$ & $\begin{array}{l}917 \\
158 \\
658 \\
332 \\
115\end{array}$ & $\begin{array}{l}248 \\
240 \\
178 \\
164 \\
166\end{array}$ & $\begin{array}{l}174 \\
210 \\
114 \\
91 \\
332\end{array}$ & $\begin{array}{r}117 \\
136 \\
55 \\
40 \\
164\end{array}$ \\
\hline $\begin{array}{r}655 \\
400 \\
148 \\
107 \\
2010\end{array}$ & $\begin{array}{r}786 \\
180 \\
105 \\
65 \\
2900\end{array}$ & $\begin{array}{r}1430 \\
212 \\
42 \\
19 \\
20200\end{array}$ & $\begin{array}{r}155 \\
259 \\
590 \\
878 \\
1720\end{array}$ & $\begin{array}{r}120 \\
457 \\
1610 \\
1840 \\
1630\end{array}$ & $\begin{array}{r}50 \\
336 \\
3040 \\
4530 \\
7750\end{array}$ & $\begin{array}{l}193 \\
139 \\
121 \\
107 \\
104\end{array}$ & $\begin{aligned} 338 \\
116 \\
95 \\
95 \\
95\end{aligned}$ & $\begin{array}{r}185 \\
44 \\
31 \\
27 \\
27\end{array}$ \\
\hline $\begin{array}{r}2220 \\
608 \\
684 \\
378 \\
419 \\
268\end{array}$ & $\begin{array}{r}4280 \\
1080 \\
693 \\
352 \\
734 \\
276\end{array}$ & $\begin{array}{r}32900 \\
1910 \\
1600 \\
414 \\
917 \\
211\end{array}$ & $\begin{array}{r}2130 \\
1770 \\
2440 \\
=- \\
=-\end{array}$ & $\begin{array}{r}1440 \\
780 \\
1320 \\
-- \\
--\end{array}$ & $\begin{array}{r}8280 \\
3730 \\
11400 \\
- \\
--\end{array}$ & $\begin{array}{r}102 \\
99 \\
96 \\
111 \\
111 \\
91\end{array}$ & $\begin{array}{r}95 \\
95 \\
95 \\
95 \\
288 \\
280 \\
180\end{array}$ & $\begin{array}{l}26 \\
25 \\
25 \\
28 \\
87 \\
44\end{array}$ \\
\hline 9826 & -- & 64614.8 & 16222 & -- & 57546.9 & 17865 & -- & 38089 \\
\hline
\end{tabular}


11179000 ALAMEDA CREEK NEAR NILES, CALIF,--Continued

SUSPENDED-SEDIMENT DISCHARGE, WATER YEAR OCTOBER 1968 TD SEPTEMBER 1969

\begin{tabular}{|c|c|c|c|c|c|c|c|c|c|}
\hline DAY & $\begin{array}{l}\text { MEAN } \\
\text { DISCHARGE } \\
\text { (CFS) }\end{array}$ & $\begin{array}{l}\text { APRIL } \\
\text { MEAN } \\
\text { CDNCEN- } \\
\text { TRAIION } \\
\text { (MG LL) }\end{array}$ & $\begin{array}{l}\text { SEDIMENT } \\
\text { DISCHARGE } \\
\text { (TONS/DAY) }\end{array}$ & $\begin{array}{l}\text { MEAN } \\
\text { DI SCHARGE } \\
\text { (CFS) }\end{array}$ & $\begin{array}{l}\text { MAY } \\
\text { MEAN } \\
\text { CONCEN- } \\
\text { TRATION } \\
\text { IMG/LI) }\end{array}$ & $\begin{array}{l}\text { SEDIMENT } \\
\text { DISCHARGE } \\
\text { (TDNS / DAY) }\end{array}$ & $\begin{array}{l}\text { MEAN } \\
\text { DISCHARGE } \\
\text { ICFS I }\end{array}$ & $\begin{array}{l}\text { JUNE } \\
\text { MEAN } \\
\text { CONCEN- } \\
\text { TRATION } \\
\text { IMG/LI }\end{array}$ & $\begin{array}{l}\text { SEDIMENT } \\
\text { DISCHARGE } \\
\text { (TONS/DAY) }\end{array}$ \\
\hline $\begin{array}{l}1 \\
2 \\
3 \\
4 \\
5\end{array}$ & $\begin{array}{r}90 \\
96 \\
121 \\
93 \\
131\end{array}$ & $\begin{array}{r}115 \\
75 \\
66 \\
39 \\
53\end{array}$ & $\begin{array}{l}28 \\
19 \\
22 \\
9.8 \\
20\end{array}$ & $\begin{array}{l}29 \\
27 \\
23 \\
27 \\
28\end{array}$ & $\begin{array}{l}12 \\
20 \\
20 \\
21 \\
14\end{array}$ & $\begin{array}{l}. .94 \\
1.5 \\
1.2 \\
1.5 \\
1.1\end{array}$ & $\begin{array}{l}39 \\
31 \\
29 \\
31 \\
30\end{array}$ & $\begin{array}{l}26 \\
17 \\
10 \\
10 \\
10\end{array}$ & $\begin{array}{l}2.7 \\
1.4 \\
.78 \\
.84 \\
.81\end{array}$ \\
\hline $\begin{array}{r}6 \\
7 \\
8 \\
9 \\
10\end{array}$ & $\begin{array}{l}229 \\
195 \\
172 \\
154 \\
146\end{array}$ & $\begin{array}{r}119 \\
79 \\
49 \\
31 \\
26\end{array}$ & $\begin{array}{l}74 \\
42 \\
23 \\
13 \\
10\end{array}$ & $\begin{array}{l}28 \\
47 \\
67 \\
78 \\
79\end{array}$ & $\begin{array}{l}17 \\
22 \\
28 \\
38 \\
68\end{array}$ & $\begin{array}{l}1.3 \\
2.8 \\
5.1 \\
8.0 \\
15\end{array}$ & $\begin{array}{l}30 \\
31 \\
31 \\
28 \\
19\end{array}$ & $\begin{array}{r}15 \\
12 \\
12 \\
9 \\
7\end{array}$ & $\begin{array}{l}1.2 \\
1.0 \\
1.0 \\
.68 \\
.36\end{array}$ \\
\hline $\begin{array}{l}11 \\
12 \\
13 \\
14 \\
15\end{array}$ & $\begin{array}{l}158 \\
142 \\
129 \\
119 \\
111\end{array}$ & $\begin{array}{l}40 \\
36 \\
40 \\
30 \\
35\end{array}$ & $\begin{array}{l}17 \\
14 \\
14 \\
9.6 \\
10\end{array}$ & $\begin{array}{l}79 \\
79 \\
64 \\
43 \\
24\end{array}$ & $\begin{array}{l}56 \\
43 \\
38 \\
37 \\
32\end{array}$ & $\begin{array}{l}12 \\
9.2 \\
6.6 \\
4.3 \\
2.1\end{array}$ & $\begin{array}{l}16 \\
16 \\
17 \\
17 \\
18\end{array}$ & $\begin{array}{r}8 \\
7 \\
9 \\
9 \\
17\end{array}$ & $\begin{array}{l}.35 \\
.30 \\
.41 \\
.41 \\
.83\end{array}$ \\
\hline $\begin{array}{l}16 \\
17 \\
18 \\
19 \\
20\end{array}$ & $\begin{array}{r}100 \\
94 \\
88 \\
84 \\
79\end{array}$ & $\begin{array}{l}30 \\
34 \\
27 \\
28 \\
34\end{array}$ & $\begin{array}{l}8.1 \\
8.2 \\
6.4 \\
6.4 \\
7.3\end{array}$ & $\begin{array}{l}18 \\
42 \\
48 \\
46 \\
46\end{array}$ & $\begin{array}{l}25 \\
39 \\
37 \\
28 \\
24\end{array}$ & $\begin{array}{l}1.2 \\
4.4 \\
4.8 \\
3.5 \\
3.0\end{array}$ & $\begin{array}{l}14 \\
11 \\
8.6 \\
8.6 \\
7.9\end{array}$ & $\begin{array}{l}29 \\
28 \\
20 \\
13 \\
15\end{array}$ & $\begin{array}{l}1.1 \\
.83 \\
.46 \\
.30 \\
.32\end{array}$ \\
\hline $\begin{array}{l}21 \\
22 \\
23 \\
24 \\
25\end{array}$ & $\begin{array}{l}74 \\
71 \\
65 \\
65 \\
54\end{array}$ & $\begin{array}{l}19 \\
14 \\
16 \\
22 \\
22\end{array}$ & $\begin{array}{l}3.8 \\
2.7 \\
2.8 \\
3.9 \\
3.2\end{array}$ & $\begin{array}{l}45 \\
.4 \\
43 \\
45 \\
50\end{array}$ & $\begin{array}{l}21 \\
17 \\
23 \\
27 \\
28\end{array}$ & $\begin{array}{l}2.6 \\
2.0 \\
2.7 \\
3.3 \\
3.8\end{array}$ & $\begin{array}{l}21 \\
25 \\
27 \\
27 \\
24\end{array}$ & $\begin{array}{l}24 \\
13 \\
14 \\
11 \\
13\end{array}$ & $\begin{array}{l}1.5 \\
.88 \\
1.0 \\
.80 \\
.84\end{array}$ \\
\hline $\begin{array}{l}26 \\
27 \\
28 \\
29 \\
30 \\
31\end{array}$ & $\begin{array}{l}51 \\
45 \\
41 \\
40 \\
36 \\
--\end{array}$ & $\begin{array}{l}15 \\
18 \\
19 \\
22 \\
14 \\
-\end{array}$ & $\begin{array}{l}2.1 \\
2.2 \\
2.1 \\
2.4 \\
1.4 \\
-\end{array}$ & $\begin{array}{l}49 \\
40 \\
39 \\
36 \\
32 \\
39\end{array}$ & $\begin{array}{l}22 \\
13 \\
16 \\
19 \\
18 \\
35\end{array}$ & $\begin{array}{l}2.9 \\
1.4 \\
1.7 \\
1.8 \\
1.6 \\
3.7\end{array}$ & $\begin{array}{l}23 \\
18 \\
16 \\
28 \\
29 \\
--\end{array}$ & $\begin{array}{r}9 \\
9 \\
12 \\
15 \\
31 \\
--\end{array}$ & $\begin{array}{r}.56 \\
.44 \\
.52 \\
1.1 \\
2.4 \\
.-\end{array}$ \\
\hline TOTAL & 3073 & $\cdots$ & 388.8 & 1384 & -- & 117.04 & 671.1 & $\rightarrow$ & 26.12 \\
\hline
\end{tabular}

\begin{tabular}{|c|c|c|c|c|c|c|c|c|c|}
\hline \multirow[b]{2}{*}{ DAY } & \multicolumn{3}{|c|}{ JuLr } & \multicolumn{3}{|c|}{ AUGUST } & \multicolumn{3}{|c|}{ SEPTEMGER } \\
\hline & $\begin{array}{l}\text { MEAN } \\
\text { DISCHARGE } \\
\text { (CFS) }\end{array}$ & $\begin{array}{l}\text { MEAN } \\
\text { COANEN- } \\
\text { TRATIDN } \\
\text { IAG LILI }\end{array}$ & $\begin{array}{l}\text { SEDIMENT } \\
\text { DISCHARGE } \\
\text { (TONS/DAY) }\end{array}$ & $\begin{array}{c}\text { MEAN } \\
\text { DISCHARE } \\
\text { ICFSI }\end{array}$ & $\begin{array}{l}\text { MEAN } \\
\text { CONCEN- } \\
\text { TRATION } \\
\text { IMG/LI }\end{array}$ & $\begin{array}{l}\text { SEDIMENT } \\
\text { DISCHARGE } \\
\text { (TONS DAYY) }\end{array}$ & $\begin{array}{c}\text { MEAN } \\
\text { OISCHARGE } \\
\text { ICFSI }\end{array}$ & $\begin{array}{l}\text { MEAN } \\
\text { CONEN- } \\
\text { TRATION } \\
\text { IMG/LI }\end{array}$ & $\begin{array}{l}\text { SEDIMENT } \\
\text { DISCHAREE } \\
\text { (TONS / DAY) }\end{array}$ \\
\hline $\begin{array}{l}1 \\
2 \\
3 \\
4 \\
5\end{array}$ & $\begin{array}{l}23 \\
19 \\
12 \\
11 \\
18\end{array}$ & $\begin{array}{l}25 \\
20 \\
23 \\
23 \\
13 \\
9\end{array}$ & $\begin{array}{l}1.6 \\
1: 0 \\
: 75 \\
: 39 \\
.44\end{array}$ & $\begin{array}{l}27 \\
26 \\
25 \\
25 \\
26\end{array}$ & $\begin{array}{l}20 \\
28 \\
25 \\
29 \\
27\end{array}$ & $\begin{array}{l}1.5 \\
2.0 \\
1.7 \\
2.0 \\
1.9\end{array}$ & $\begin{array}{l}50 \\
56 \\
51 \\
53 \\
49\end{array}$ & $\begin{array}{l}23 \\
24 \\
20 \\
18 \\
18\end{array}$ & $\begin{array}{l}3.1 \\
3.6 \\
2.8 \\
2.6 \\
2.4\end{array}$ \\
\hline $\begin{array}{r}8 \\
7 \\
8 \\
9 \\
10\end{array}$ & $\begin{array}{l}18 \\
14 \\
14 \\
15 \\
15\end{array}$ & $\begin{array}{l}12 \\
22 \\
14 \\
11 \\
10\end{array}$ & $\begin{array}{l}.58 \\
.83 \\
.53 \\
.45 \\
.41\end{array}$ & $\begin{array}{l}25 \\
26 \\
27 \\
27 \\
26\end{array}$ & $\begin{array}{l}23 \\
28 \\
30 \\
30 \\
25\end{array}$ & $\begin{array}{l}1.6 \\
2.0 \\
2.2 \\
2.2 \\
2.8\end{array}$ & $\begin{array}{l}42 \\
42 \\
45 \\
39 \\
43\end{array}$ & $\begin{array}{l}23 \\
24 \\
17 \\
16 \\
31\end{array}$ & $\begin{array}{l}2.6 \\
2.7 \\
2.1 \\
1.7 \\
3.6\end{array}$ \\
\hline $\begin{array}{l}11 \\
12 \\
13 \\
14 \\
15\end{array}$ & $\begin{array}{l}20 \\
26 \\
27 \\
30 \\
23\end{array}$ & $\begin{array}{l}15 \\
15 \\
17 \\
19 \\
22\end{array}$ & $\begin{array}{l}: 81 \\
1: 1 \\
1: 2 \\
1: 5 \\
1.4\end{array}$ & $\begin{array}{l}25 \\
25 \\
25 \\
25 \\
26\end{array}$ & $\begin{array}{l}23 \\
36 \\
26 \\
30 \\
35\end{array}$ & $\begin{array}{l}1.6 \\
2.4 \\
1.8 \\
2.0 \\
2.5\end{array}$ & $\begin{array}{l}37 \\
36 \\
36 \\
38 \\
36\end{array}$ & $\begin{array}{l}29 \\
18 \\
29 \\
19 \\
12\end{array}$ & $\begin{array}{l}2.9 \\
1: 7 \\
208 \\
1: 9 \\
1 . .2\end{array}$ \\
\hline $\begin{array}{l}16 \\
17 \\
18 \\
19 \\
20\end{array}$ & $\begin{array}{l}21 \\
21 \\
21 \\
22 \\
23\end{array}$ & $\begin{array}{l}23 \\
31 \\
25 \\
18 \\
26\end{array}$ & $\begin{array}{l}1: 3 \\
1: 8 \\
1: 4 \\
1: 1 \\
1: 6\end{array}$ & $\begin{array}{l}32 \\
35 \\
34 \\
34 \\
33\end{array}$ & $\begin{array}{l}37 \\
35 \\
28 \\
30 \\
28\end{array}$ & $\begin{array}{l}3.2 \\
3.3 \\
2.0 \\
2.8 \\
2.5\end{array}$ & $\begin{array}{l}38 \\
38 \\
37 \\
37 \\
41\end{array}$ & $\begin{array}{l}10 \\
11 \\
21 \\
16 \\
8\end{array}$ & $\begin{array}{ll}1: 0 \\
1: 1 \\
2: 1 \\
1: 6 \\
: 89\end{array}$ \\
\hline $\begin{array}{l}21 \\
22 \\
23 \\
24 \\
25\end{array}$ & $\begin{array}{l}22 \\
23 \\
21 \\
23 \\
27\end{array}$ & $\begin{array}{l}27 \\
24 \\
28 \\
24 \\
38\end{array}$ & $\begin{array}{l}1.6 \\
1.5 \\
1.6 \\
1.5 \\
2.8\end{array}$ & $\begin{array}{l}37 \\
48 \\
45 \\
37 \\
39\end{array}$ & $\begin{array}{l}29 \\
32 \\
25 \\
27 \\
26\end{array}$ & $\begin{array}{l}2.9 \\
4.1 \\
3.0 \\
2.7 \\
2.7\end{array}$ & $\begin{array}{l}48 \\
46 \\
38 \\
37 \\
38\end{array}$ & $\begin{array}{l}29 \\
22 \\
19 \\
19 \\
18\end{array}$ & $\begin{array}{l}1.2 \\
2: 7 \\
1: 9 \\
1: 9 \\
1: 8\end{array}$ \\
\hline $\begin{array}{l}26 \\
27 \\
28 \\
29 \\
30 \\
31\end{array}$ & $\begin{array}{l}27 \\
28 \\
25 \\
27 \\
26 \\
27\end{array}$ & $\begin{array}{l}29 \\
29 \\
24 \\
29 \\
25 \\
26\end{array}$ & $\begin{array}{l}2.1 \\
2.2 \\
1.6 \\
2.1 \\
1.8 \\
1.9\end{array}$ & $\begin{array}{l}39 \\
38 \\
39 \\
40 \\
46 \\
49\end{array}$ & $\begin{array}{l}18 \\
19 \\
17 \\
17 \\
24 \\
25\end{array}$ & $\begin{array}{l}1.9 \\
1.9 \\
1.8 \\
1.8 \\
3.0 \\
3.3\end{array}$ & $\begin{array}{l}41 \\
38 \\
39 \\
44 \\
38 \\
--\end{array}$ & $\begin{array}{l}19 \\
17 \\
11 \\
20 \\
19 \\
--\end{array}$ & $\begin{array}{l}2.1 \\
1: 7 \\
1.2 \\
2.2 \\
1.9 \\
-.\end{array}$ \\
\hline TOTAL & 869 & -- & 40.89 & 1011 & - & 72.7 & 1251 & -- & 63.19 \\
\hline
\end{tabular}


11179000 ALAMEDA CREEK NEAR NILES, CALIF.--Conti nued

PARTICLE-SIZE DISTRIBUTION OF SUSPENDED SEDIMENT, WATER YEAR OCTOBER 1968 TO SEPTEMBER 1969 (METHODS DF ANALYSIS: B, BOTTOM WI THORAWAL TUBE; C, CHEMICALLY DISPERSED; N, IN NATIVE WATER; P, PIPET; S, SIEVE;
V, VISUAL ACCUMULATION TUBE: W, IN DISTILLEO WATER)

\begin{tabular}{|c|c|c|c|c|c|c|c|c|c|c|c|c|c|c|c|c|c|c|c|}
\hline & OATE & TIME & $\begin{array}{l}\text { WATER } \\
\text { TEM- } \\
\text { PERA- } \\
\text { TURE } \\
\text { I C I }\end{array}$ & $\begin{array}{l}\text { OISCHARGE } \\
\text { (CFS) }\end{array}$ & $\begin{array}{l}\text { CONCEN- } \\
\text { TRATION } \\
\text { (MG/L) }\end{array}$ & $\begin{array}{l}\text { SUSPENOEO } \\
\text { SEDIMENT } \\
\text { DISCHARGE } \\
\text { (TONS/OAY) }\end{array}$ & $\begin{array}{l}\text { PERCE } \\
.002\end{array}$ & .004 & $\begin{array}{l}\text { FINER } \\
4.00\end{array}$ & & $\begin{array}{l}\text { HAN T } \\
.016\end{array}$ & $\begin{array}{l}\text { THE SI } \\
.031\end{array}$ & $\begin{array}{r}.212 \quad 1 \\
.062\end{array}$ & $\begin{array}{l}\text { I IN MIL } \\
2.125\end{array}$ & .250 & .500 & 1.00 & $\begin{array}{l}\text { CATEO } \\
2.00\end{array}$ & $\begin{array}{l}\text { METHOD } \\
\text { OF } \\
\text { ANALY- } \\
\text { SIS }\end{array}$ \\
\hline & $4 \ldots \ldots$ & 1610 & 10 & 1780 & 403 & 1940 & 45 & 56 & 6 & 5 & 72 & 76 & 88 & 95 & 100 & -- & -- & - & VBWC \\
\hline
\end{tabular}

PARTICLE-SIZE DISTRIBUTION OF SURFACE BED MATERIAL, WATER YEAR OCTOBER 1967 TO SEPTEMBER 1968

(METHOO OF ANALYSIS: H, HYDROMETER; O, OPIICAL ANALYZER; S, SIEVE; $V$, VISUAL ACCUMULATION TUBE)

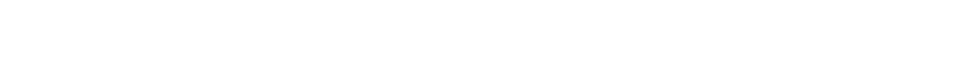

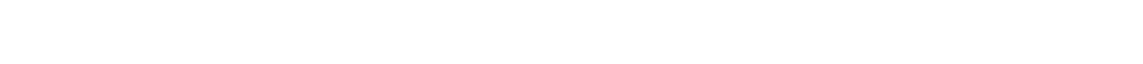
SEP $9.1968 \quad 1130$

$\begin{array}{lllllllllllll}68 & 7 & 16 & 32 & 47 & 61 & 77 & 88 & 94 & 100 & \ldots & -\end{array}$

BUENA VISTA LAKE BASIN

11185350 KERN RIVER NEAR QUAKING ASPEN CAMP, CALIF.

LOCATION,--Lat $36^{\circ} 08^{\prime} 04^{\prime \prime}$, long $118^{\circ} 25^{\prime} 49^{\prime \prime}$, in SW $\frac{1}{4} \mathrm{SW} \frac{1}{4}$ sec. 32 , T. 20 S., R. 33 E., Tulare County, temperature recorder at gaging station on right bank, 0.4 mile upst ream from Little Kern River and 6.8 miles east of Quaking Aspen DRAINAGE AREA. -530 sq $\mathrm{mi}$.

PERIOD OF RECORD, --Water temperatures: October 1965 to September 1969.

EXTREMES. - $-1968-69$ :

Water temperatures: Maximum, $17.0^{\circ} \mathrm{C}$ on several days during July and August; minimum, freezing point on several days during February and March.

Period of record:

Water temperatures: Maximum, $21.0^{\circ} \mathrm{C}$ July 26, 28, 1966, July 21, 1968; minimum, freezing point on several days during January and February 1966, and February and March 1969 .

REMARKS, - No record for period Jan. 16 to Feb. 10.

TEMPERATURE $\left({ }^{\circ} \mathrm{C}\right)$ OF WATER, WATER YEAR OCTOBER 1968 TO SEPTEMBER 1969

DAY

MUNTH $\quad 1 \quad 2 \quad 3 \quad 4 \quad 5 \quad 6 \quad 7 \quad 8 \quad 9$\begin{tabular}{lllllllllllllllllllllllll}
\hline & 11 & 12 & 13 & 14 & 15 & 16 & 17 & 18 & 19 & 20 & 21 & 22 & 23 & 24 & 25 & 26 & 27 & 28 & 29 & 30 & 31 & AVER
\end{tabular}

DCTUBFP

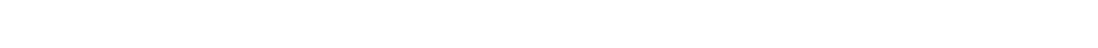

VIIVI MUSF

$\begin{array}{llllllllllllllllllllllllllllllllllll}M A X I M I M M & 8 & 9 & 8 & 8 & 7 & 7 & 8 & 7 & 8 & 8 & 8 & 8 & 8 & 7 & 6 & 6 & 6 & 6 & 6 & 6 & 6 & 6 & 6 & 6 & 5 & 4 & 3 & 3 & 3 & 3 & -- & 6 & 6 \\ M \text { MVIMUN } & 7 & 7 & 7 & 6 & 4 & 4 & 6 & 6 & 6 & 6 & 7 & 7 & 7 & 4 & 2 & 4 & 4 & 4 & 4 & 4 & 4 & 4 & 4 & 4 & 3 & 2 & 7 & 2 & 2 & 3 & -- & 5 & 5\end{array}$

DECEMSE

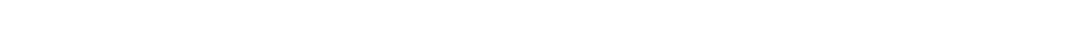

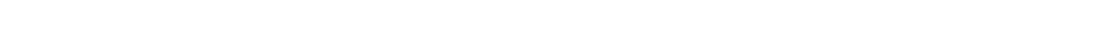

JANUA?Y

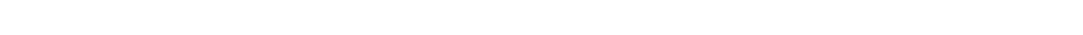

MAXIMUM -

MaXimim

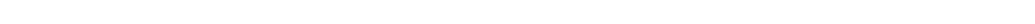

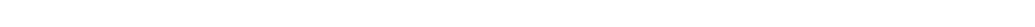

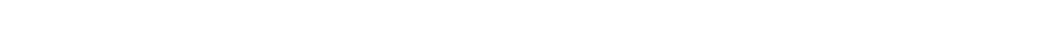

MAY

$\begin{array}{lllllllllllllllllllllllllllllllll}M & (M I J M & 8 & 8 & 8 & 7 & 7 & 8 & 8 & 8 & 8 & 8 & 8 & 8 & 8 & 7 & 7 & 8 & 8 & 8 & 8 & 8 & 8 & 8 & 8 & 8 & 8 & 8 & 8 & 8 & 8 & 8 & 8\end{array}$

$\begin{array}{llllllllllllllllllllllllllllllllllll} & 1\end{array}$

MAXIMUM

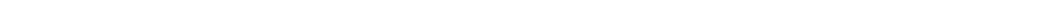

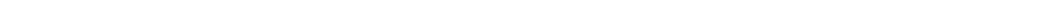

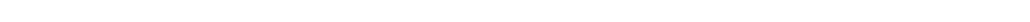

AUSUSi

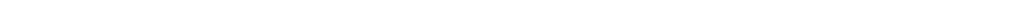

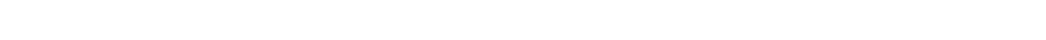

MAKIMUM $14 \begin{array}{llllllllllllllllllllllllllllllllllllllll} & 14 & 14 & 14 & 13 & 14 & 15 & 14 & 14 & 13 & 13 & 12 & 13 & 14 & 14 & 14 & 13 & 13 & 13 & 13 & 13 & 13 & 13 & 13 & 13 & 13 & 13 & 13 & 13 & -1\end{array}$

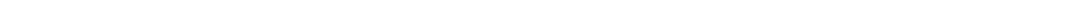


11185500 KERN RIVER CANAL NO. 3 NEAR KERNVILLE, CALIF,

LOCATION. --Lat $35^{\circ} 54^{\prime} 20^{\prime \prime}$, Iong $118^{\circ} 28^{\prime} 00^{\prime \prime}$, in NE $\frac{1}{4}$ sec.25, T. 23 S., R. 32 E., Kern County, temperature recorder at gaging station on left bank, 4 miles downstream from intake and 12 miles north of Kernvilie.

PERIOD OF RECORD. -- Fater temperatures: October 1962 to September 1969 (discontinued).

EXTREMES, $-1968-69$ :

Water temperatures: Uaximum, $21.0^{\circ} \mathrm{C}$ Aug. $4,5,22 ; \mathrm{minimum}, 1.0^{\circ} \mathrm{C}$ on many days during December to March.

Period of record:

Water temperatures: Maximum, 22. $0^{\circ} \mathrm{C}$ July 22-25, 1968; minimum (1962-66, 1967-69), f reezing point on several days during December and January of most years.

REMARKS, --No flow Oct, 1-18, Jan, 26 .

TEUPERATURE $\left({ }^{\circ} \mathrm{C}\right)$ OF WATER, WATER YEAR OCTOBER 1968 TO SEPTEMBER 1969

DAY

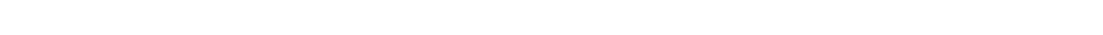

OCIOBER

MAXIMUM MOVE MAER

MINIMUM

MAXIMUM

MINITLM

JANUARY

MAXIMUM

MINIMUM

FERRUAPY

MAXIMUM

MINIMUM

MARCH

MAXIMUM

MIN

$\begin{array}{rrrrrrrrrrrrrrrrrrrrrrrrrrrrrrrrrrr}\text { MAXIMUM } & 7 & 7 & 7 & 7 & 7 & 7 & 7 & 7 & 7 & 8 & 8 & 9 & 8 & 8 & 8 & 8 & 9 & 9 & 9 & 9 & 10 & 11 & 9 & 10 & 9 & 10 & 10 & 11 & 14 & 10 & -- & 9 & 9 & 9 \\ \text { MINIMUM } & 5 & 4 & 4 & 5 & 6 & 5 & 4 & 4 & 5 & 6 & 6 & 6 & 6 & 6 & 5 & 6 & 7 & 7 & 7 & 7 & 8 & 8 & 8 & 7 & 7 & 7 & 8 & 8 & 8 & 9 & -2 & 6 & 6\end{array}$

MAY

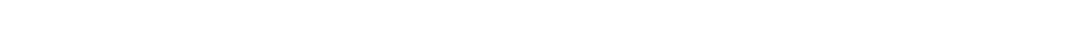

JUNE

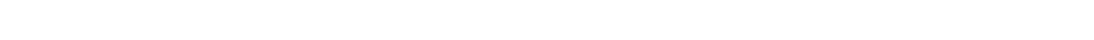

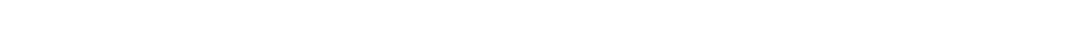

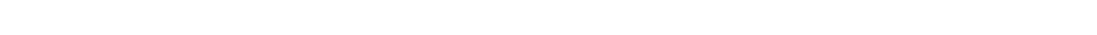

AUGUST

MAXIMUM $19192021 \quad 21 \quad 191918 \quad 1919191919192019191818 \quad 1818 \quad 21 \quad 1818 \quad 181817 \quad 17 \quad 17 \quad 17 \quad 17 \quad 19$

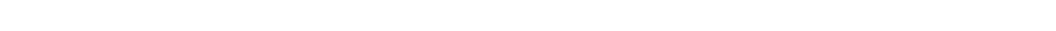

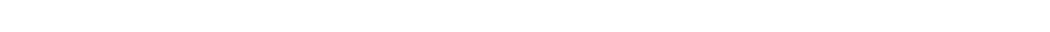

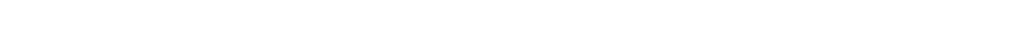


LOCATION, --Lat $35^{\circ} 45^{\prime} 34^{\prime \prime}$, long $118^{\circ} 25^{\prime} 12^{\prime \prime}$, in NE $\frac{1}{4}$ NW at gaging station on left bank, 0.5 mile upstream from highway bridge at Kernville, 1,7 miles upstream from Caldwell Creek, 9.5 miles upstream from Isabella Dam, and 42 miles northeast of Bakersfield,

DRAINAGE AREA. --1,009 sq mi.

PERIOD OF RECORD, --Water temperatures: June 1962 to September 1969.

Sediment records: October 1966 to September 1969 (partia1 records).

EXTRE UIES. - -1968-69:

Water temperatures: Maximum, $20.0^{\circ} \mathrm{C}$ Aug. 10; minimum, 2. $0^{\circ} \mathrm{C}$ Dec. 20-23, 27, 28.

Perlod of record:

Water temperatures: Maximum $(1962-63,1964-69), 26.5^{\circ} \mathrm{C}$ Aug. $5,6,8,1966$; min $1 m u m, 1.0^{\circ} \mathrm{C} J a n .13,14,1963$, Jan. 1, 1965, and on several days during January 1966.

REMARKS, --Clock stopped June 11-24; range in temperature, $12.0^{\circ} \mathrm{C}$ to $13.0^{\circ} \mathrm{C}$

TEXPERATURE $\left({ }^{\circ} \mathrm{C}\right)$ OF WATER, WATER YEAR OCTOBER 1968 TO SEPTEMBER 1969

DAY

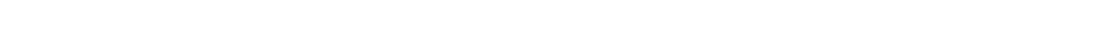

OCTOBER

$\begin{array}{llllllllllllllllllllllllllllllllll}\text { MAXIMUM } & 18 & 18 & 16 & 18 & 18 & 18 & 18 & 18 & 16 & 18 & 18 & 18 & 16 & 18 & 16 & 18 & 16 & 16 & 14 & 14 & 14 & 11 & 11 & 10 & 11 & 11 & 11 & 11 & 11 & 11 & 10 & 15 \\ \text { MINIMUM } & 15 & 15 & 15 & 14 & 15 & 16 & 16 & 15 & 15 & 15 & 15 & 14 & 16 & 16 & 14 & 16 & 13 & 14 & 13 & 14 & 11 & 10 & 10 & 10 & 10 & 10 & 10 & 10 & 10 & 10 & 9 & 13\end{array}$

NOVEMBER

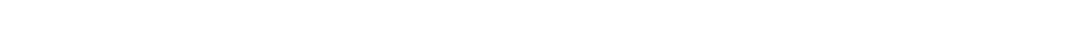

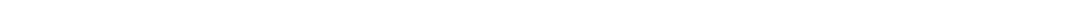

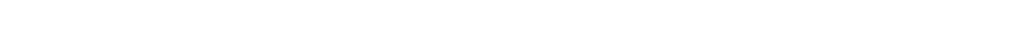

JANUARY

$\begin{array}{llllllllllllllllllllllllllllllll}\text { MAXIMUM } & 4 & 4 & 5 & 5 & 6 & 6 & 6 & 6 & 5 & 5 & 4 & 5 & 6 & 6 & 6 & 5 & 5 & 4 & 5 & 5 & 6 & 6 & 5 & 5 & 6 & 6 & 6 & 6 & 4 & 4 & 4 \\ \text { MINIMUM } & 3 & 3 & 4 & 4 & 4 & 4 & 4 & 4 & 4 & 4 & 4 & 4 & 5 & 5 & 5 & 4 & 4 & 4 & 4 & 5 & 5 & 4 & 4 & 4 & 4 & 6 & 6 & 4 & 3 & 3 & 3\end{array}$

MINIMUM

$\begin{array}{llllllllllllllllllllllllllllllll}\text { MAXIMUM } & 5 & 5 & 5 & 5 & 6 & 5 & 6 & 6 & 6 & 7 & 6 & 8 & 8 & 8 & 8 & 7 & 7 & 7 & 7 & 8 & 8 & 8 & 8 & 5 & 6 & 8 & 8 & 6 & \ldots & \ldots-\end{array}$

MINIMUM

$\begin{array}{llllllllllllllllllllllllllllllll}\text { MAXIMUM } & 7 & 7 & 7 & 7 & 7 & 8 & 8 & 7 & 7 & 6 & 7 & 6 & 6 & 7 & 8 & 8 & 8 & 8 & 8 & 8 & 8 & 8 & 8 & 8 & 8 & 8 & 8 & 9 & 9 & 9 & 9 \\ \text { MINIMUM } & 6 & 6 & 6 & 6 & 6 & 6 & 6 & 6 & 6 & 6 & 5 & 6 & 4 & 5 & 6 & 6 & 6 & 6 & 6 & 6 & 6 & 6 & 6 & 6 & 7 & 7 & 7 & 7 & 7 & 7 & 7\end{array}$

$\begin{array}{lllllllllllllllllllllllllllllllllllllllll}3 & 4 & 4 & 4 & 5 & 3 & 3 & 5 & 5 & 6 & 6 & 6 & 6 & 6 & 7 & 6 & 6 & 6 & 6 & 7 & 8 & 8 & 5 & 4 & 4 & 4 & 6 & 6 & - & -7 & -\end{array}$

APRIL

$\begin{array}{lllllllllllllllllllllllllllllllllll}\text { MAXIMUM } & 9 & 9 & 8 & 9 & 9 & 8 & 8 & 9 & 9 & 10 & 10 & 11 & 11 & 10 & 10 & 10 & 10 & 10 & 11 & 11 & 11 & 11 & 11 & 10 & 10 & 10 & 10 & 10 & 11 & 11 & --\end{array}$ MINIMUIH

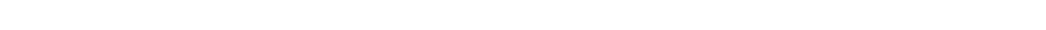
UM $1091099910101010 \quad 101010 \quad 101010 \quad 101010 \quad 11 \quad 11 \quad 11 \quad 11 \quad 11 \quad 12 \quad 12 \quad 12 \quad 12 \quad 12 \quad 12 \quad 12 \quad 12$

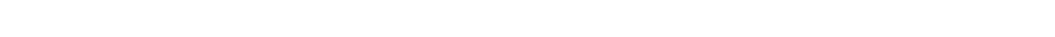

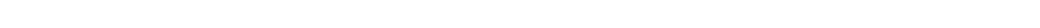

JULY MINIAUM $14 \quad 14 \quad 14 \quad 14 \quad 14 \quad 14 \quad 15 \quad 16 \quad 16 \quad 16 \quad 16 \quad 16 \quad 17 \quad 16 \quad 16 \quad 18 \quad 17 \quad 18 \quad 1818 \quad 17 \quad 16 \quad 17 \quad 17 \quad 17 \quad 17 \quad 1817 \quad 18 \quad 1818$ AUGUST

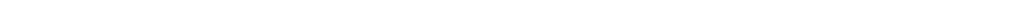

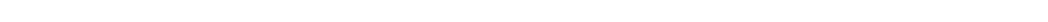
SEPIEMBER

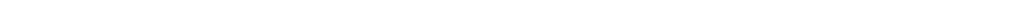

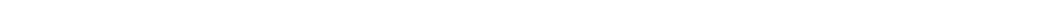
4 4 7 8 10 11 $--$ 17
16 18 17 17
16

SÜSPENDED-SEDIMENT DISCHARGE MEASUREMENTS AND PARTICLE-SIZE DISTRIBUTION, HATER YEAR OCTDBER 1968 TO SEPTEMBER 1969 (METHODS OF ANALYSIS: B, BOTIOM WITHDRAWAL TURE; C, CHEMICALLY DISPERSED; N, IN NATIVE HATER; P, PIPET; S, SIEVE;

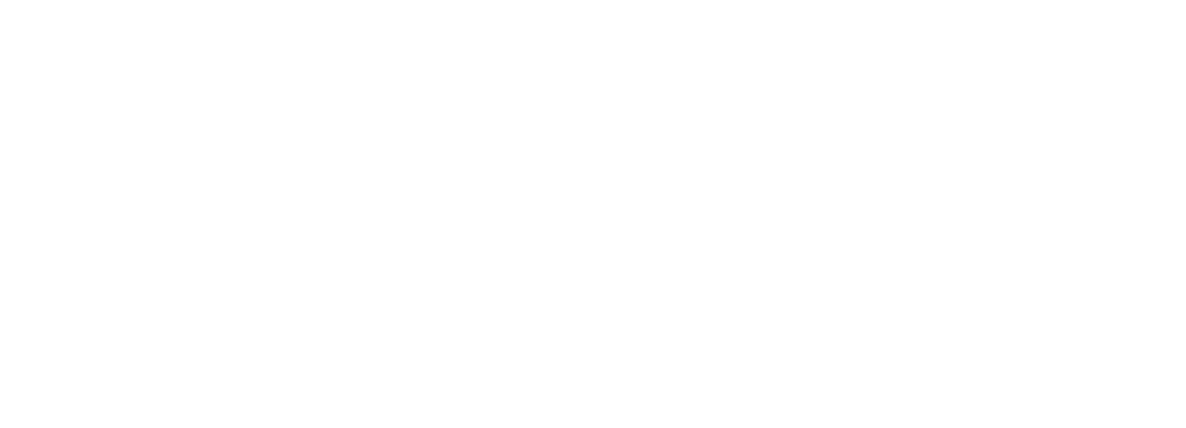


11187300 BOREL CANAL BELOW ISABELla DAK, CALIF.

LOCATION,--Lat $35^{\circ} 38^{\prime} 32^{\prime \prime}$, Iong $118^{\circ} 28^{\prime} 09^{\prime \prime}$, In NEł sec, 30, T. 28 S., R. 33 E., Kern County, temperature recorder at gaging stat ion on right bank, $500 \mathrm{ft}$ downstream from Isabelia Dam and 3 miles upstream from point where canal

PERIOD OF RECORD.--Water temperatures: October 1958 to September 1969.

EXTREMES. - -1968-69:

Water temperatures: Max 1 mum, $23.0^{\circ} \mathrm{C}$ Sept. 2-14; mintmum, $4.0^{\circ} \mathrm{C}$ on several days during February and March.

pertod of record:

Water temperatures: Maximum, $26.5^{\circ} \mathrm{C}$ July 31 to Aug. 1,1959 ; min1mum, $0.5^{\circ} \mathrm{C}$ Jan. $17,18,1960$.

REMARKS. --No flow Oct. 22 to Nov, 13.

TEMPERATURE $\left({ }^{\circ} \mathrm{C}\right)$ OF WATER, WATER YEAR OCTOBER 1968 TO SEPTEMBER 1969

OAY

MUNTH 234567891011

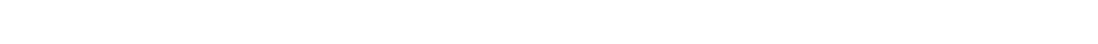

TTOBER NUVEMBER

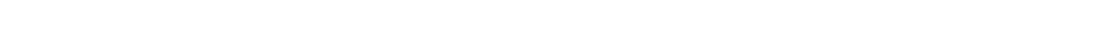

DECFMER

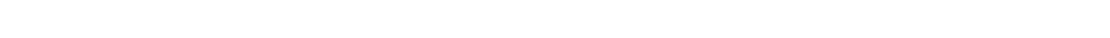

MINIMUM

MAXIMUM

MAX IMUM

FLBRUARY

MAXIMUM

MINIMUM

MAXIMU

MINIMUM

APRIL

$\begin{array}{llllllllllllllllllllllllllllllllllllllll}\text { MAXIMUM } & 10 & 11 & 11 & 13 & 12 & 12 & 13 & 13 & 11 & 11 & 13 & 12 & 12 & 12 & 12 & 12 & 13 & 12 & 13 & 13 & 14 & 13 & 12 & 12 & 12 & 13 & 14 & 14 & 13 & 12 & -- & 12 \\ \text { IINIMUM } & 10 & 10 & 11 & 11 & 12 & 11 & 11 & 11 & 11 & 11 & 11 & 11 & 11 & 12 & 12 & 11 & 11 & 11 & 11 & 12 & 12 & 12 & 12 & 12 & 12 & 11 & 12 & 13 & 12 & 12 & -- & 11\end{array}$ MINIMUH MAY

MAXIMUM MINIMUA JUNE

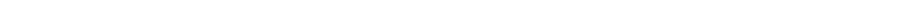

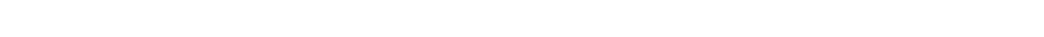

JULY

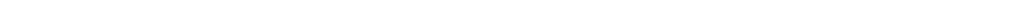
MINIMUM $17 \begin{array}{lllllllllllllllllllllllllllllll}16 & 16 & 16 & 17 & 17 & 17 & 17 & 17 & 17 & 17 & 17 & 17 & 17 & 17 & 17 & 17 & 17 & 17 & 17 & 17 & 17 & 17 & 17 & 17 & 17 & 17 & 18 & 18 & 18 & 18\end{array}$ AUGUST

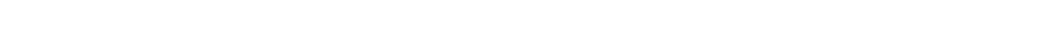
MINIMUM

SEPTEMBER

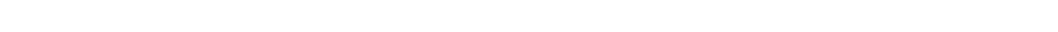

$\begin{array}{lllllllllllllllllllllllllllllllll}7 & 7 & 7 & 7 & 7 & 8 & 8 & 7 & 7 & 7 & 7 & 7 & 7 & 7 & 7 & 7 & 7 & 7 & 7 & 7 & 7 & 7 & 7 & 7 & 7 & 7 & 7 & 7 & 7 & 7 & 7 & 7\end{array}$

$\begin{array}{lllllllllllllllllllllllllllllllll}6 & 6 & 6 & 6 & 6 & 6 & 6 & 6 & 7 & 6 & 6 & 6 & 6 & 6 & 6 & 6 & 6 & 6 & 6 & 6 & 6 & 6 & 5 & 5 & 4 & 4 & 4 & 4 & -- & -- & -- & 6 & 6\end{array}$

$\begin{array}{ccccccccccccccccccccccccccccccccc}4 & 4 & 4 & 5 & 6 & 5 & 5 & 6 & 6 & 6 & 6 & 7 & 7 & 7 & 8 & 7 & 7 & 7 & 9 & 10 & 9 & 9 & 10 & 11 & 13 & 14 & 15 & 14 & 14 & 14 & 11 & B \\ 4 & 4 & 4 & 4 & 5 & 5 & 5 & 5 & 6 & 6 & 6 & 6 & 7 & 7 & 7 & 7 & 7 & 7 & 7 & 8 & 9 & 9 & 9 & 9 & 11 & 12 & 12 & 12 & 11 & 11 & 10 & 7\end{array}$

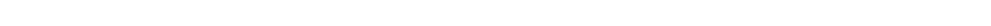


11203200 TULE RIVER NEAR SPRINGVILLE, CALIF.

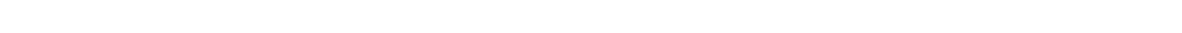
recorder at gaging station to ft downstream from highway bridge, 3.5 miles southwest of Springvilie, and

DRAINAGE AREA, $-247 \mathrm{sq}$ m1 (revised),

PERIOD OF RECORD. - Chemical analyses: November 1963 to July 1966.

Water temperatures: October 1965 to September 1967, October 1968 to September 1969.

EXTREMES. - Period of record $(1965-57)$ :

Water temperatures: Maximum, 30.0 ${ }^{\circ} \mathrm{C}$ Aug. 19, 20, 1967; minimum (1966-67), 3. $5^{\circ} \mathrm{C} \mathrm{Dec.} 28,1966$.

REMARKS, - No thermograph record Jan. 20 to Sept. 1 . Where no maximum or minimum is shown, once-datly temperatures are reported. prior to Mar. 20, 1968, gage was located 1.9 miles upstream.

TEMPERATURE ( ${ }^{\circ} \mathrm{C}$ ) OF WATER, WATER YEAR OCTOBER 1968 TO SEPTEMBER 1969

DAY

MONTH MAXIMUM

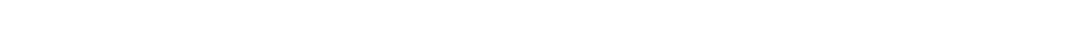

NOVEMBER, - - - - - - - -

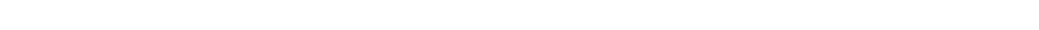

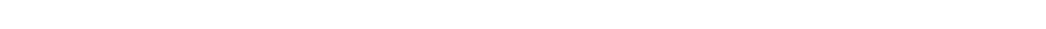

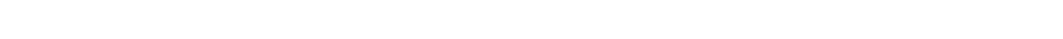

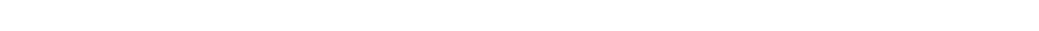

JANUARY.. -

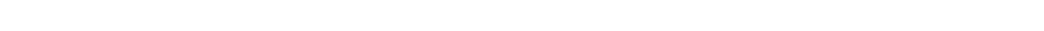

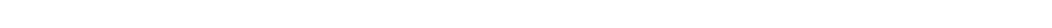

FERRUARY,

MAXIMIJM MINIMUM

MARCH.....

MAXIMUM

MINIMUM

MAXIMUM MAXIMUM MINIMUM

MAXIMÜM MINIMUM

MINIMUM
JUNE......

MAXIMUM

MAXINIMUM
MIY.....

MAXIMUM

MINIMUM

AUGUST...

MAXIMUM

MINIMUM

MAXIMUM

MINIMUM

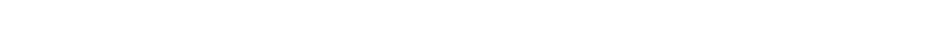
[-

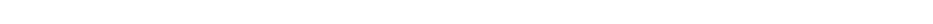
-

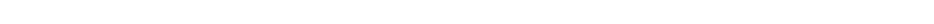
-

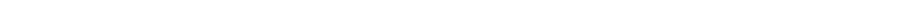

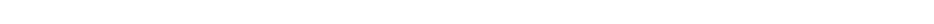
"- - -

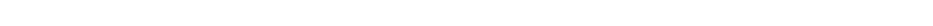
[-

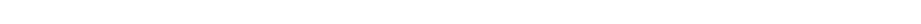

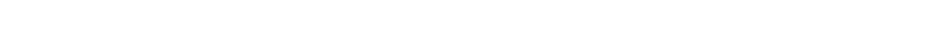


11204900 TULE RIVER BELOW SUCCESS DAM, CALIF.

LOCATION, --Lat $36^{\circ} 03^{\prime} 23^{\prime \prime}$, long $118^{\circ} 55^{\prime} 22^{\prime \prime}$, in SW sec.35, T, 21 S, , R, 26 E., Tulare County, at gaging station

$1,000 \mathrm{ft}$ downstream from Success Dam and $5 \mathrm{miles}$ east of Porterville.

DRAINAGE AREA. --393 sq $\mathrm{m} 1$.

PERIOD OF RECORD. --Chemical analyses: December 1961 to September 1969.

REMARKS.--Records furnished by California Department of Water Resources and reviewed by U,S. Geological Survey. CHEMICAL ANALYSES, WATER YEAR OCTOBER 1968 TO SEPTEMBER 1969

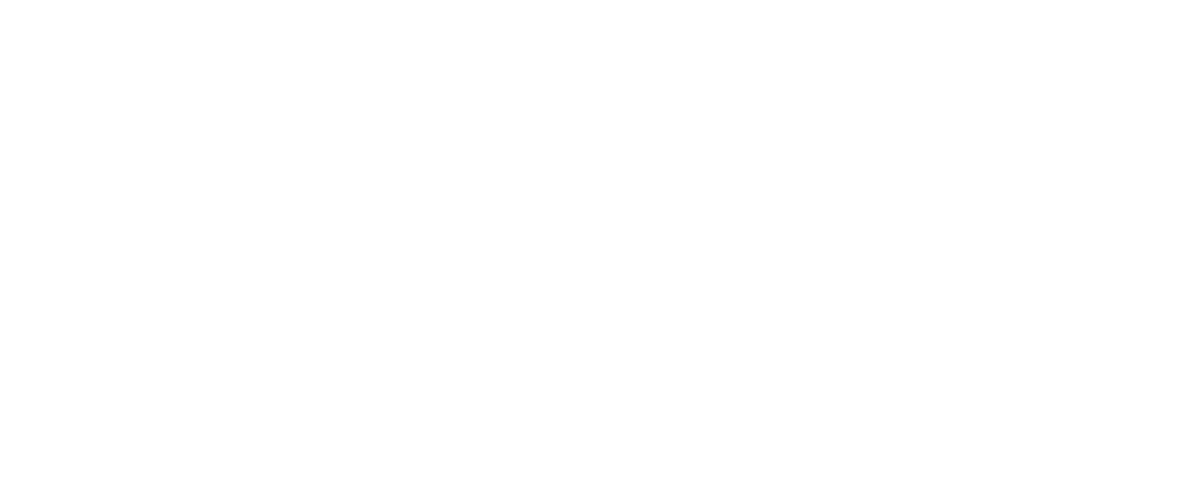

\begin{tabular}{|c|c|c|c|c|c|c|c|c|c|c|c|}
\hline DATE & $\begin{array}{l}\text { NITRATE } \\
\text { (NO3) } \\
\text { (MG/L) }\end{array}$ & $\begin{array}{l}\text { BORON } \\
\text { (B) } \\
(U G / L)\end{array}$ & $\begin{array}{l}\text { CIS- } \\
\text { SOLVED } \\
\text { SOL IOS } \\
\text { IRESI- } \\
\text { OUE AT } \\
180 \text { CI } \\
\text { IMG ILI }\end{array}$ & $\begin{array}{l}\text { DIS- } \\
\text { SOLVED } \\
\text { SOLIOS } \\
\text { (TONS } \\
\text { PER } \\
\text { AC-FT) }\end{array}$ & $\begin{array}{l}\text { HARD- } \\
\text { NESSS } \\
(C A, M G) \\
(M G G / L)\end{array}$ & $\begin{array}{l}\text { NON- } \\
\text { CAR- } \\
\text { BONATE } \\
\text { HARD- } \\
\text { NESS } \\
\text { (MG/L) }\end{array}$ & $\begin{array}{l}\text { PERCENT } \\
\text { SOOIUM }\end{array}$ & $\begin{array}{l}\text { SOOIUM } \\
\text { AD- } \\
\text { SORP- } \\
\text { TION } \\
\text { RATIO }\end{array}$ & $\begin{array}{l}\text { ALKA- } \\
\text { LINIIY } \\
\text { AS } \\
\text { CACO3 } \\
\text { IMG/L) }\end{array}$ & $\begin{array}{c}\text { PH } \\
\text { (UNITS) }\end{array}$ & $\begin{array}{l}\text { SPECI- } \\
\text { FIC } \\
\text { CONO- } \\
\text { UCTANCE } \\
\text { (MICRO- } \\
\text { MHOS }\end{array}$ \\
\hline $\begin{array}{l}\text { oct. } \\
\text { os... } \\
\text { Nov. }\end{array}$ & $\cdots$ & 0 & - & -- & 137 & 0 & 21 & .6 & 151 & 8.1 & 310 \\
\hline $04 \ldots$ & - & 170 & -- & $\cdots$ & 142 & 0 & 22 & .7 & 162 & 8.4 & 352 \\
\hline $17 .$. & - & 70 & -- & - & 141 & 0 & 23 & .7 & 163 & B. 3 & 364 \\
\hline $\begin{array}{l}\text { JAN. } \\
\text { Ob.... }\end{array}$ & -- & 30 & -- & -- & 137 & 0 & 22 & .7 & 152 & 8.3 & 325 \\
\hline $10 .$. & - & 20 & - & -- & 52 & 0 & 23 & .4 & 54 & 7.6 & 131 \\
\hline $\begin{array}{l}\text { MAR. } \\
04 . .\end{array}$ & -- & 20 & -- & - & 63 & 6 & 20 & .4 & 57 & 8. 1 & 139 \\
\hline $\begin{array}{l}\text { APR. } \\
07 . . .\end{array}$ & -. & 20 & -- & -- & 55 & 0 & 20 & .4 & 55 & 7.8 & 137 \\
\hline $\begin{array}{l}\operatorname{MAr} \\
05 \ldots . . .\end{array}$ & .3 & -- & 93 & .13 & 44 & 0 & 24 & .4 & 48 & 8.0 & 115 \\
\hline $03 \ldots$ & -- & 10 & -- & -- & 38 & 0 & 23 & .4 & 43 & 7.4 & 100 \\
\hline $\begin{array}{l}\text { JuLr } \\
07 . . .\end{array}$ & -- & 0 & -- & -- & 40 & D & 22 & .4 & 45 & 7.5 & 102 \\
\hline $\begin{array}{l}\text { AUG. } \\
\text { 04... }\end{array}$ & -- & 0 & -- & -- & 44 & 0 & 20 & .3 & 47 & 7.5 & 107 \\
\hline
\end{tabular}


11208000 MARBLE FORK KAWEAH RIVER AT POTHISHA CAMP, CALIF.

LOCATION.- Lat $36^{\circ} 31^{\prime} 08^{\prime \prime}$, long $118^{\circ} 48^{\prime} 03^{\prime \prime}$, in SE sec. 23, T. 16 S, R. 29 E. , Tulare County, temperature recorder at gaging station on' left bank, 0.1 mile north of Potwlsha Camp and 0.3 mile upstream from confluence with Middle Fork Kaweah River.

DRAINAGE AREA, --51.4 sq m1.

PERIOD OF RECORD. --Water temperatures: January 1962 to September 1969.

EXTRENES. - 1968-69:

Water temperatures: Maximum, $20.0^{\circ} \mathrm{C}$ Sept. 8, 10; minimum, 2.0 $0^{\circ} \mathrm{C} \mathrm{Dec.} \mathrm{22,} \mathrm{Jan,} \mathrm{29,} \mathrm{31,} \mathrm{Feb.} 7$.

Period of record:

Water temperatures: Maximum, $23.5^{\circ} \mathrm{C}$ on several days during 1964,1966 , and 1968 ; min1mum (1963-69), $1.0^{\circ} \mathrm{C}$ on several days during 1965 and 1967 .

TEMPERATURE $\left({ }^{\circ} \mathrm{C}\right)$ OF WATER, WATER YEAR OCTOBER 1968 TO SEPTEMBER 1969

DAY

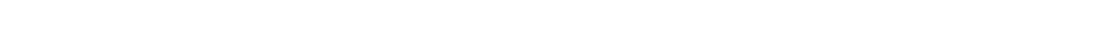

OCTOBER $\begin{array}{llllllllllllllllllllllllllllllllllll}\text { MAXIMUM } & 16 & 16 & 16 & 15 & 15 & 15 & 15 & 15 & 15 & 14 & 14 & 14 & 14 & 14 & 12 & 12 & 12 & 12 & 12 & 13 & 13 & 12 & 13 & 13 & 13 & 13 & 13 & 13 & 13 & 13 & 12 & 14 \\ \text { MINIMUM } & 15 & 14 & 14 & 14 & 14 & 14 & 14 & 14 & 14 & 13 & 13 & 13 & 14 & 12 & 10 & 10 & 10 & 11 & 11 & 11 & 11 & 11 & 11 & 11 & 12 & 12 & 12 & 13 & 13 & 12 & 11 & 12\end{array}$ NOVEMRER

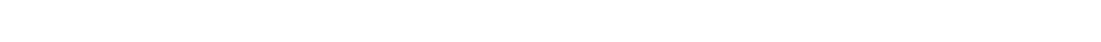

MINIMUM
DECEMBER
MAXIMUM

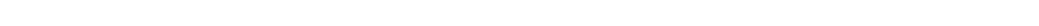

$\begin{array}{llllllllllllllllllllllllllllllllll}M I N I M U M & 5 & 4 & 4 & 5 & 5 & 5 & 6 & 6 & 6 & 6 & 7 & 5 & 5 & 6 & 6 & 7 & 6 & 5 & 4 & 3 & 3 & 2 & 4 & 6 & 6 & 4 & 4 & 4 & 5 & 6 & 6 & 5\end{array}$

$\begin{array}{llllllllllllllllllllllllllllllllllll}\text { MAXIMUM } & 7 & 7 & 7 & B & 8 & 9 & 8 & 8 & 6 & 6 & 6 & 7 & 7 & 7 & 7 & 6 & 6 & 6 & 6 & 7 & 7 & 5 & 5 & 6 & 6 & 6 & 5 & 4 & 3 & 4 & 3 & 6 \\ \text { MINIMUN } & 6 & 7 & 7 & 7 & 8 & 7 & 7 & 6 & 6 & 6 & 5 & 6 & 7 & 7 & 6 & 5 & 5 & 5 & 6 & 6 & 3 & 4 & 4 & 5 & 6 & 5 & 4 & 3 & 2 & 3 & 2 & 5\end{array}$

MINIMUN

FEBRUARY

MAXIMUM $4 \begin{array}{llllllllllllllllllllllllllllllll} & 5 & 6 & 5 & 4 & 4 & 4 & 4 & 5 & 6 & 6 & 6 & 6 & 6 & 6 & 6 & 6 & 6 & 4 & 5 & 5 & 4 & 4 & 6 & 6 & 6 & 6 & 6 & \ldots & \ldots & \ldots\end{array}$

MINIMUM

AARCH

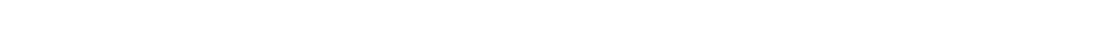

MAXIMUM

MAY MINUM

MAXIMUM MINIMUM

JUNE

MAXIMUM

$\begin{array}{lllllllllllllllllllllllllllllll}4 & 4 & 4 & 4 & 4 & 4 & 4 & 3 & 4 & 4 & 4 & 4 & 4 & 3 & 4 & 5 & 6 & 6 & 5 & 5 & 6 & 5 & 6 & 6 & 5 & 6 & 6 & 6 & 6 & 6\end{array}$

$\begin{array}{llllllllllllllllllllllllllllllll}7 & 6 & 6 & 8 & 7 & 4 & 7 & 8 & 7 & 7 & 9 & 9 & 7 & 7 & 7 & 8 & 9 & 7 & 9 & 9 & 9 & 9 & 7 & 7 & 7 & 8 & 9 & 10 & 10 & 9 & \cdots\end{array}$

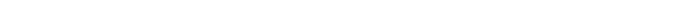

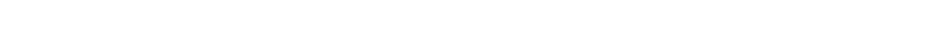
MINI MUM

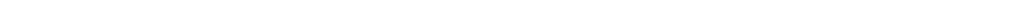
MIVIMUM

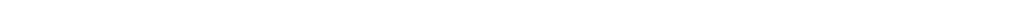

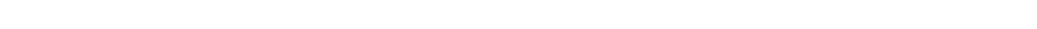
SEPTEYBEO

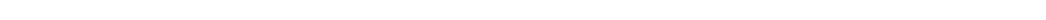

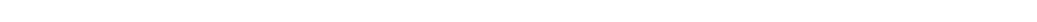


11208605 EAST FORK KAWEAF RIVER BELOW EAGLE CREEK, NEAR HAMMOND, CALIF.

LOCATION.--Lat $36^{\circ} 26^{\prime} 44^{\prime \prime}$, long $118^{\circ} 35^{\prime} 38^{\prime \prime}$, in NW 1 SW 1 sec.15, T.17 S., R. 31 E., Tulare County, on r1ght bank 0.5 mile downstream from Eagle Creek and $15.5 \mathrm{miles}$ east of Hammond.

DRAINAGE AREA. $--9.92 \mathrm{sq} \mathrm{mi}$

PERIOD OF RECORD.--Chemical analyses: August 1968 to September 1969.

Sediment records: October 1968 to September 1969 (partial records)

CHEMICAL ANALYSES, IN MILLIGRAMS PER LITER, AUGUST AND SEPTEMBER 1968

\begin{tabular}{|c|c|c|c|c|c|c|c|c|c|c|c|}
\hline DATE & TIME & $\begin{array}{l}\text { DTS- } \\
\text { CHARGF } \\
\text { (CFS) }\end{array}$ & $\begin{array}{l}\text { TEMPER- } \\
\text { ATURE } \\
\text { (DEG C) }\end{array}$ & $\begin{array}{l}\text { SILICA } \\
\text { (SID2) }\end{array}$ & $\begin{array}{l}\text { DIS- } \\
\text { SOLVED } \\
\text { [RON } \\
\text { (FE) }\end{array}$ & $\begin{array}{l}\text { CAL- } \\
\text { CIUM } \\
\text { (CA) }\end{array}$ & $\begin{array}{l}\text { MAG- } \\
\text { NE- } \\
\text { SIUM } \\
(M G)\end{array}$ & $\begin{array}{l}\text { SODIUM } \\
\text { (NA) }\end{array}$ & $\begin{array}{l}\text { PO- } \\
\text { TAS- } \\
\text { SIUM } \\
\text { (K) }\end{array}$ & $\begin{array}{l}\text { BICAR- } \\
\text { BONATE } \\
\text { (HCO3) }\end{array}$ & $\begin{array}{l}\text { CAR- } \\
\text { ECAATE } \\
\text { (CC } 3)^{-}\end{array}$ \\
\hline $\begin{array}{l}\text { AUG. } \\
27 \ldots \\
27 \ldots\end{array}$ & $\begin{array}{l}15: 5 \\
083 n\end{array}$ & 8.5 & $\begin{array}{r}13 \\
7\end{array}$ & $7: 2$ & $\begin{array}{l}.02 \\
.08\end{array}$ & $\begin{array}{l}26 \\
27\end{array}$ & $\begin{array}{l}1.2 \\
1.2\end{array}$ & $\begin{array}{l}1.3 \\
1.6\end{array}$ & .5 & $\begin{array}{l}8 \mathrm{C} \\
7 \mathrm{E}\end{array}$ & $\begin{array}{l}c \\
c\end{array}$ \\
\hline DATE & $\begin{array}{l}\text { SULFATE } \\
\text { (SD 4) }\end{array}$ & $\begin{array}{l}\text { CHLCD- } \\
\text { RIDE } \\
\text { (CL) }\end{array}$ & $\begin{array}{l}\text { FLUN- } \\
\text { PINE } \\
\text { (F) }\end{array}$ & $\begin{array}{l}\text { NITRATE } \\
\text { (NO3) }\end{array}$ & $\begin{array}{c}\text { BORON } \\
(B)\end{array}$ & $\begin{array}{l}\text { OIS- } \\
\text { SOLVED } \\
\text { SOLIDS } \\
\text { (SUM OF } \\
\text { CONSTI- } \\
\text { TUENTS) }\end{array}$ & $\begin{array}{l}\text { HARD- } \\
\text { NESS } \\
(C A, M G)\end{array}$ & $\begin{array}{l}\text { NON- } \\
\text { CAR- } \\
\text { BONATE } \\
\text { HARD- } \\
\text { NESS }\end{array}$ & $\begin{array}{l}\text { SPECI- } \\
\text { FIC } \\
\text { CONO- } \\
\text { UCTANCE } \\
\text { (MICRO- } \\
\text { MHDS) }\end{array}$ & PH & $\begin{array}{l}\text { CIS- } \\
\text { SOLVED } \\
\text { SOLIDS } \\
\text { IYCNS } \\
\text { PER } \\
\text { AC-FII }\end{array}$ \\
\hline $\begin{array}{l}\text { AUG. } \\
27 \ldots . \\
27 \ldots\end{array}$ & $\begin{array}{l}7.0 \\
8.0\end{array}$ & $\begin{array}{l}\text { PEPCENT } \\
\text { SOOIUM }\end{array}$ & $\begin{array}{l}\text { SCOIUM } \\
\text { AL- } \\
\text { SORP- } \\
\text { TION } \\
\text { RATIO }\end{array}$ & $\begin{array}{l}\text { ALKA- } \\
\text { LINTTY } \\
\text { AS } \\
\text { CACES }\end{array}$ & $\begin{array}{l}\text { DISS- } \\
\text { PLVED } \\
\text { OXYGEN }\end{array}$ & $\begin{array}{l}\text { AMMONI A } \\
\text { (NH4) }\end{array}$ & $\begin{array}{l}\text { ORGANIC } \\
\text { NITRO- } \\
\text { GEN } \\
\text { (N) }\end{array}$ & $\begin{array}{l}\text { OR THO } \\
\text { PHOS- } \\
\text { PHATE } \\
\text { (PO4) }\end{array}$ & $\begin{array}{l}\text { PHOS- } \\
\text { PHATE } \\
\text { (PO4) }\end{array}$ & $\begin{array}{l}7.6 \\
7.8 \\
\text { COLI- } \\
\text { FORM } \\
\text { (CCL- } \\
\text { ONIES } \\
\text { PER } \\
100 \mathrm{ML}\end{array}$ & .11 \\
\hline
\end{tabular}

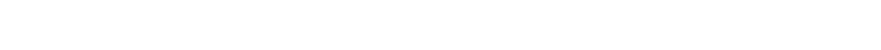

CHEMICAL ANALYSES, HATER YEAR OCTOBER 1968 TO SEPTEMBER 1969

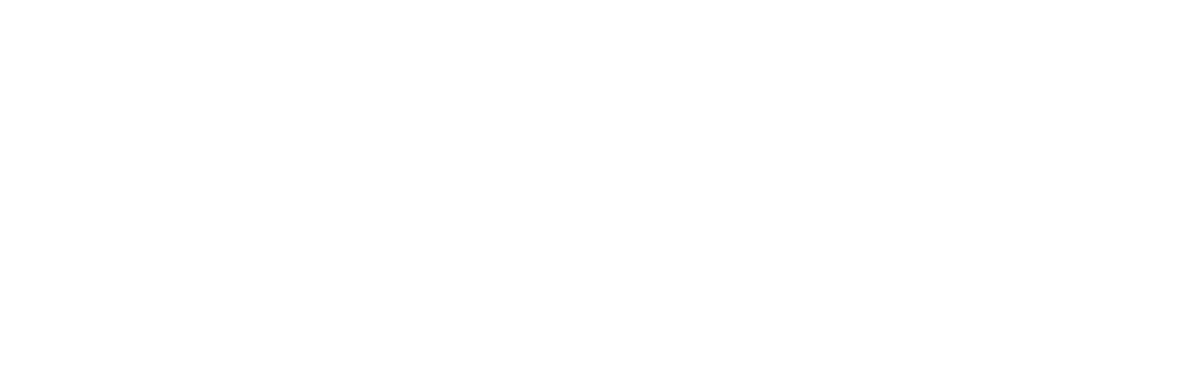

\begin{tabular}{|c|c|c|c|}
\hline $\begin{array}{l}\mathrm{CC} T . \\
01 . .\end{array}$ & 9.0 & .5 & .1 \\
\hline JUNE & & & \\
\hline $18 \ldots$ & 6.0 & .3 & .1 \\
\hline $29 \ldots$ & 3.0 & .2 & .1 \\
\hline AUG. & & & \\
\hline $25 \ldots$ & 6.0 & .2 & $\cdot 1$ \\
\hline & $\begin{array}{l}\text { SCD IUM } \\
\text { AD- }\end{array}$ & ALKA- & \\
\hline & SORP- & LINIIY & DIS- \\
\hline PERCENT & TION & $A S$ & SOLVED \\
\hline SonIUM & RATIOO & $\mathrm{CACOB}$ & OXYGEN \\
\hline
\end{tabular}

$\begin{array}{rrrr}1.0 & 0 & 102 & 84 \\ .6 & 30 & 46 & 35 \\ .2 & 0 & 37 & 32 \\ .1 & 0 & 49 & 40\end{array}$

\begin{tabular}{|c|c|c|c|}
\hline 5 & 172 & 7.5 & .14 \\
\hline 5 & 78 & 7.1 & .06 \\
\hline 6 & 68 & 6.5 & .05 \\
\hline 6 & 87 & 7.2 &.$C 7$ \\
\hline $\begin{array}{l}\text { URTHO } \\
\text { PHOS- } \\
\text { PHATE } \\
\text { (PO4) } \\
\text { (MG/L) }\end{array}$ & $\begin{array}{l}\text { PHCS- } \\
\text { PHATE } \\
\text { (PC4) } \\
\text { (MG/L) }\end{array}$ & $\begin{array}{c}\text { COLI- } \\
\text { FORM } \\
\text { (CCL- } \\
\text { ONIES } \\
\text { PER } \\
100 \mathrm{NL})\end{array}$ & $\begin{array}{l}\text { TOTAL } \\
\text { ORGANIC } \\
\text { CARBON } \\
\text { (C) } \\
\text { (MG/L) }\end{array}$ \\
\hline
\end{tabular}

CHEM-

$\begin{array}{llll}\text { ORGANIC } & \text { TOTAL } \\ \text { ICAL } & \text { NITRO- NITRO- PHOS }\end{array}$

OXYGEN AMMONIA GEN GEN PHATE

OEMAND (NH4)
$(M G / L)$

$(M G / L) \quad(M G / L) \quad(M G / L)$

$(M G / L) \quad 100 \mathrm{NL}$

$\begin{array}{cccc}\text { กC. T. } & & \\ \text { DI... } & 5 & .1 & 79\end{array}$

$\begin{array}{llll}\text { JUNE } & 5 & .1 & 79 \\ 18 \ldots . . . & 4 & .1 & 30\end{array}$

$9.9 \quad 1.2$

.02

$10.7 \quad 1.2$

.00

.23

$\begin{array}{ll}0 . & .01 \\ .08 & .02\end{array}$

JULY $29 . .2 \quad 2 \quad .0 \quad 26$

$10.0 \quad 1.7$

.04

-. .03

.00

AUG.

$9.8 \quad 1.4$

.13

-- .09

.04

$\begin{array}{rrr}.04 & 35 & -- \\ .06 & 3 & -- \\ .01 & 7 & - \\ .04 & 19 & .0\end{array}$


11208605 EAST FORK KAWEAH RIVER BELOW EAGLE CREEK, NEAR HAMMOND, CALIF.--CONTI nUEd SUSPENDED-SEDIMENT DISCHARGE MEASUREMENTS, WATER YEAR OCTOBER 1968 TO SEPTEMBER 1969

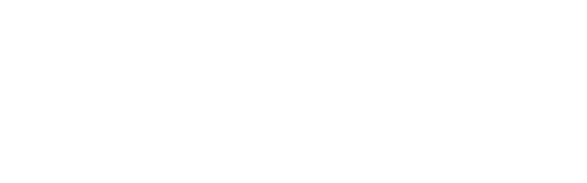

11208607 EAST FORK KAHEAH RIVER ABOVE MONARCH CREEK, NEAR HAMMOND, CALIF.

LOCATION, --Lat $36^{\circ} 27^{\prime} 01^{\prime \prime}$, long $118^{\circ} 35^{\prime} 40^{\prime \prime}$, in SE łNW' sec. 15, T.17 S, , R. 31 E., Tulare County, at bridge at Mineral King, $1,000 \mathrm{ft}$ upstréam from Monarch Creek and 14.9 mil lés east of Hammond.

PERIOD OF RECORD.--Chemical analyses: July 1968 to September 1969.

Sediment records: August 1967 to September 1969 (partial records)

CHEMICAL ANALYSES, IN MILLIGRAMS PER LITER, JULY TD SEPTEMBER 1968

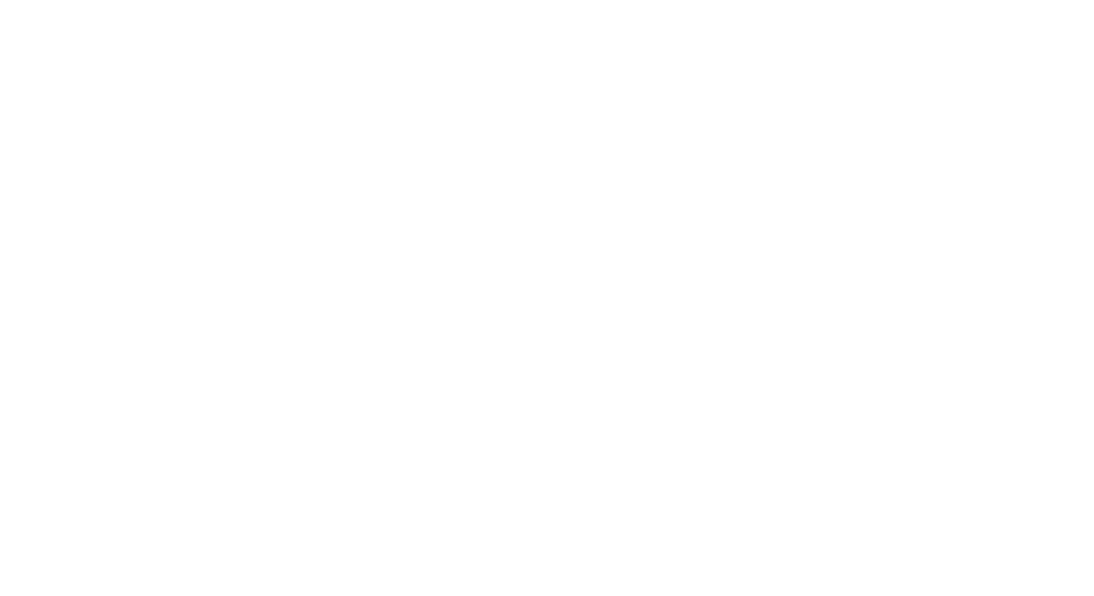

CHEMICAL ANALYSES, WATER YEAR UTCTOBER 1968 TO SEPTEMBER 1969

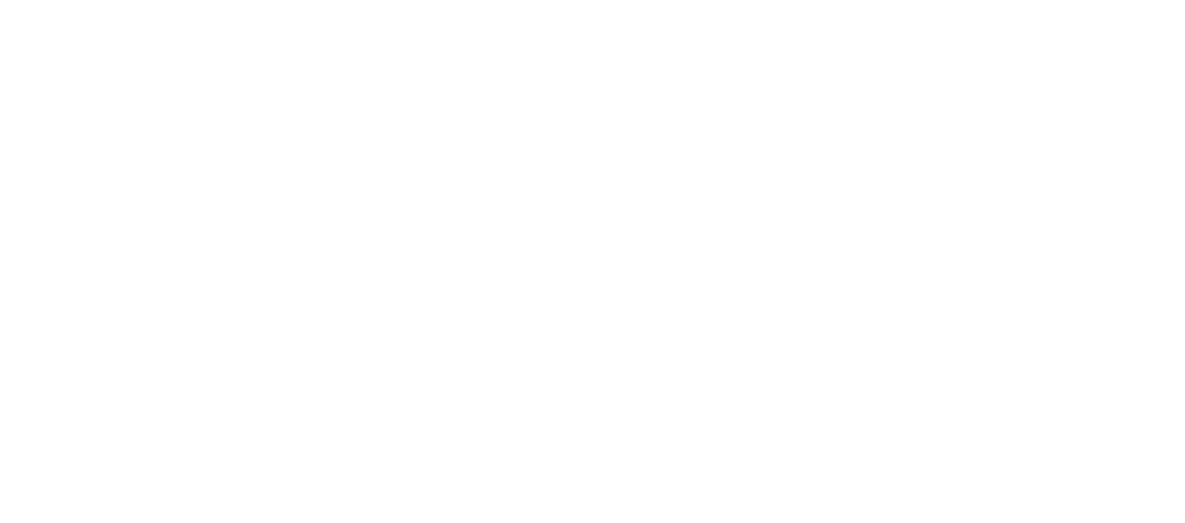


11208607 EAST FORK KAWEAH RIVER ABOVE MONARCH CREEK, NEAR HAMMOND, CALIF,

SUSPENDED-SEDIMENT DISCHARGE MEASUREMENTS, AUGUST 1968 TंO SEPTEMBER 1969

\begin{tabular}{|c|c|c|c|c|c|c|}
\hline & DATR & IIME & $\begin{array}{l}\text { WATER } \\
\text { TEM- } \\
\text { PERA- } \\
\text { TUQF } \\
\text { I C.I }\end{array}$ & $\begin{array}{l}\text { DISCHARGE } \\
\text { (CFS) }\end{array}$ & $\begin{array}{l}\text { CONCEN- } \\
\text { TRATION } \\
\text { (MG/L) }\end{array}$ & $\begin{array}{l}\text { SUSPENDED } \\
\text { SEDIMENT } \\
\text { DISCHARGE } \\
\text { (IONS/DAY) }\end{array}$ \\
\hline $\begin{array}{l}\triangle \cup G \\
A \cup G\end{array}$ & $\begin{array}{r}1.1968 \\
27 \ldots \ldots\end{array}$ & 0730 & 7 & $\begin{array}{l}8.0 \\
7.1\end{array}$ & $\begin{array}{l}1 \\
5\end{array}$ & $\begin{array}{l}.02 \\
.10\end{array}$ \\
\hline JUL & 29,1969 & 1130 & 9 & 85 & 7 & 1.6 \\
\hline
\end{tabular}

\section{MONA RCH CREEK NEAR HAMMOND, CALIF .}

LOCATION.--Lat $36^{\circ} 27^{\circ} 09^{\prime \prime}$, long $118^{\circ} 35^{\prime} 37^{\prime \prime}$, in SEłNW' sec.15, T.17 S, R. 31 E. Tulare County, at gaging station on right bank, $0.2 \mathrm{mil}$ le upstream from mouth, $0.3 \mathrm{mile}$ northeast of Minerai King, and 14.9 miles east of Hammonds

DRAINAGE AREA. $-\sim 1,89 \mathrm{sq} \mathrm{ml}$.

PERIOD OF RECORD. --Chemical analyses: July 1968 to September 1969

Water temperatures: October 1968 to September 1969.

Sediment records: October 1967 to Sept ember 1969 (partial records)

EXTREMES. - -1968-69:

Water temperatures: Maxımum, $13.0^{\circ} \mathrm{C}$ on several days in August.

REMARKS.--Clock stopped Nov, 2-30; range in temperature, $2.0^{\circ} \mathrm{C}$ to $6.0^{\circ} \mathrm{C}$. No record for period Dec. 1 to May 20 , June 17,18

CHEMICAL ANALYSES, IN MILLIGRAMS PER LITER, JULY TO SEPTEMBER 1968

\begin{tabular}{|c|c|c|c|c|c|c|c|c|c|c|c|}
\hline LATE & TIME & $\begin{array}{l}\text { UIS- } \\
\text { CHARGE } \\
\text { (CFS) }\end{array}$ & $\begin{array}{l}\text { TEMPER- } \\
\text { ATURE } \\
\text { (WEG C) }\end{array}$ & $\begin{array}{l}\text { SILICA } \\
\text { (S102) }\end{array}$ & $\begin{array}{l}\text { UIS- } \\
\text { SOLVEO } \\
\text { IRON } \\
\text { (FE) }\end{array}$ & $\begin{array}{l}\text { CAL- } \\
\text { CIUM } \\
\text { (CA) }\end{array}$ & $\begin{array}{l}\text { MAG- } \\
\text { NE- } \\
\text { SIUM } \\
(M G)\end{array}$ & $\begin{array}{l}\text { SODIUM } \\
\text { (NA) }\end{array}$ & $\begin{array}{l}\text { PO- } \\
\text { IAS- } \\
\text { SIUM } \\
\text { (K) }\end{array}$ & $\begin{array}{l}\text { BIC, AR- } \\
\text { BONAIE } \\
\text { (HCOZ) }\end{array}$ & $\begin{array}{l}\text { CAR- } \\
\text { BONATE } \\
\text { (COB) }\end{array}$ \\
\hline $\begin{array}{l}\text { JULY } \\
26 . . .\end{array}$ & 0740 & 2.7 & 9 & 7.1 & .00 & 11 & .3 & 1.0 & .2 & 33 & 0 \\
\hline $\begin{array}{l}\text { AUG. } \\
27 \ldots . .\end{array}$ & 0900 & 1.8 & $B$ & 7.8 & .15 & 13 & .6 & 1.5 & .3 & 38 & 0 \\
\hline
\end{tabular}

\begin{tabular}{|c|c|c|c|c|c|c|c|c|c|c|}
\hline DATE & $\begin{array}{l}\text { SULFATE } \\
\text { (SO4) }\end{array}$ & $\begin{array}{l}\text { CHL J- } \\
\text { RIUt } \\
\text { (CL) }\end{array}$ & $\begin{array}{l}\text { FLUD- } \\
\text { RIDE } \\
(+1)\end{array}$ & $\begin{array}{l}\text { NIFRATE } \\
\text { (NOB) }\end{array}$ & $\begin{array}{l}\text { Borav } \\
\text { (B) }\end{array}$ & $\begin{array}{l}\text { OIS- } \\
\text { SOLVED } \\
\text { SOLIDS } \\
\text { ISUM UF } \\
\text { CONSII- } \\
\text { TUENISI }\end{array}$ & $\begin{array}{l}\text { HARD- } \\
\text { NESS } \\
\text { (CA,MG) }\end{array}$ & $\begin{array}{l}\text { NGN- } \\
\text { CAR- } \\
\text { BONATE } \\
\text { HARD- } \\
\text { NESS }\end{array}$ & $\begin{array}{l}\text { SPEC I- } \\
\text { FIC } \\
\text { COND- } \\
\text { UCT ANCE } \\
\text { (MICRO- } \\
\text { MHOS) }\end{array}$ & $\mathrm{PH}$ \\
\hline \multirow{7}{*}{$\begin{array}{l}\text { JULY } \\
26 \ldots \\
\text { AUU. } \\
27 \ldots\end{array}$} & & $B$ & 2 & $B$ & P & 40 & 28 & 1 & 65 & 7.1 \\
\hline & & & & & & & & 1 & & .1 \\
\hline & 5.0 & .4 & -1 & .1 & .03 & 48 & 35 & 4 & 76 & 7.3 \\
\hline & & PERCENT & $\begin{array}{c}\text { SCOIUM } \\
\text { AD- } \\
\text { SCRP- } \\
\text { TIUN }\end{array}$ & $\begin{array}{l}\text { ALKA- } \\
\text { LINITY } \\
\text { AS }\end{array}$ & $\begin{array}{l}\text { DIS- } \\
\text { SOLVED }\end{array}$ & $\triangle M M C N I A$ & $\begin{array}{l}\text { URGANIC } \\
\text { NI TRO- } \\
\text { GEN }\end{array}$ & $\begin{array}{l}\text { ORTHO } \\
\text { PHIS- } \\
\text { PHATE }\end{array}$ & $\begin{array}{l}\text { PHOS- } \\
\text { PHATE }\end{array}$ & $\begin{array}{l}\text { COLI- } \\
\text { FORM } \\
\text { ICIL- } \\
\text { ONIES } \\
\text { PER }\end{array}$ \\
\hline & Dait & SOJIUM & KAIIO & $\mathrm{CACO} 3$ & OXYGEN & $\left(\mathrm{NH}_{4}\right)$ & $(N)$ & $(P 04)$ & $(P 04)$ & $100 \mathrm{ML})$ \\
\hline & $\begin{array}{l}\text { JULY } \\
26 \ldots\end{array}$ & 6 & .1 & 27 & 8.6 & .18 & .00 & .00 & .02 & 17 \\
\hline & $\begin{array}{l}A U 15 . \\
27 \ldots\end{array}$ & $\rightarrow$ & .1 & 31 & 9.7 & .00 & .93 & .03 & .02 & 74 \\
\hline
\end{tabular}




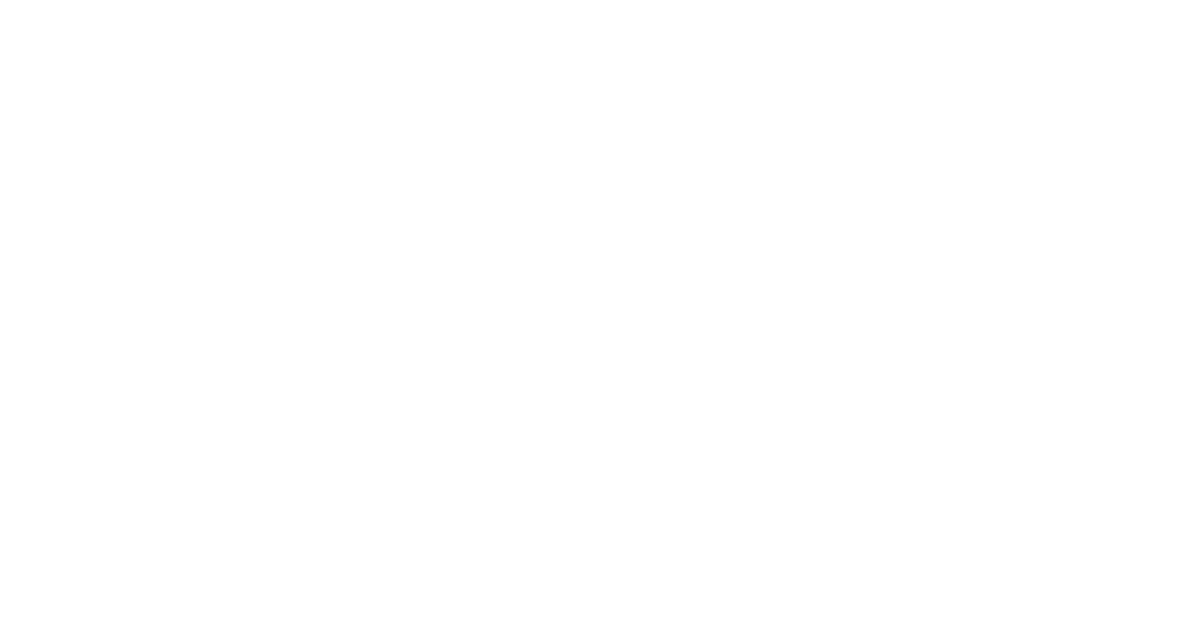
OCT.

\begin{tabular}{|c|c|c|c|c|c|c|c|c|c|c|c|}
\hline $01 \ldots$ & 6.0 & $\therefore 0$ & $=1$ & .8 & 20 & 60 & 42 & 3 & 96 & 7.5 & .08 \\
\hline $\begin{array}{l}29 \ldots \\
\text { DEC.. }\end{array}$ & 6.0 & 2.7 & .1 & .3 & 0 & $5 s$ & 43 & 4 & 92 & 7.5 & .08 \\
\hline $\begin{array}{l}07 . . \\
\text { JAN. }\end{array}$ & 4.0 & I. 0 & .2 & .6 & 0 & 42 & 29 & 3 & 69 & 6.8 & .06 \\
\hline FEB... & 5.0 & .7 & .3 & .5 & 0 & 50 & 36 & 1 & 81 & 7.7 & .07 \\
\hline MAR... & 5.0 & .4 & .0 & $\cdot 1$ & 0 & 44 & 32 & 2 & 72 & 7.1 & .06 \\
\hline $\begin{array}{l}25 \ldots . . \\
A 9 R .\end{array}$ & 5.0 & .4 & .1 & 1.2 & 10 & 72 & 58 & 4 & 119 & 7.4 & .10 \\
\hline$\underset{\operatorname{maY}}{22} \ldots$ & 3.0 & .4 & .1 & .4 & 0 & $4 t$ & 37 & 4 & 79 & 7.1 & .06 \\
\hline JUNE & 3.0 & .3 & .0 & .6 & 40 & 31 & 22 & 2 & 51 & 6.8 & .04 \\
\hline JULY $_{Y}{ }^{\prime}$ & 3.0 & .4 & .1 & .4 & 30 & 28 & 18 & 2 & 44 & 7.1 & .04 \\
\hline $\begin{array}{l}29 . . . \\
\text { AUG. }\end{array}$ & 2.0 & .4 & .1 & .2 & 0 & 19 & 13 & 2 & 32 & 6.3 & .03 \\
\hline 25. & 3.0 & .2 & .1 & .2 & 20 & 29 & 20 & I & 47 & 7.2 & .04 \\
\hline
\end{tabular}

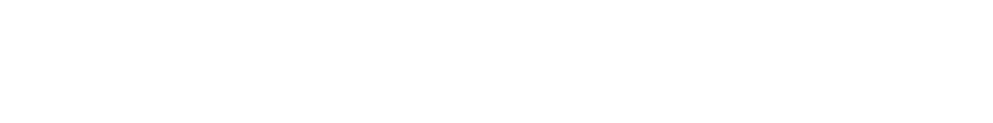

\begin{tabular}{|c|c|c|c|c|c|c|c|c|c|c|}
\hline $01 \ldots$ & 1 & 39 & 10.1 & -- & & & ? & & & \\
\hline $29 . \ldots$ & 1 & 39 & 10.3 & 1.0 & .00 & .32 & . & .04 & .04 & 53 \\
\hline DEC. & & & & & & & & & & 00 \\
\hline $07 \ldots$ & .1 & 26 & 11.5 & .6 & .05 & .04 & .11 & .03 & .04 & 10 \\
\hline $\begin{array}{r}18, \ldots . \\
18 .\end{array}$ & .1 & 35 & 11.7 & .7 & .08 & .48 & .54 & .02 & .11 & 1 \\
\hline $\begin{array}{l}F \in B . \\
08 . . .\end{array}$ & 1 & 30 & 116 & - & $-\pi$ & 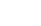 & - & 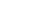 & - & \\
\hline MAR. & & & 1200 & & & & & & & \\
\hline $25 \ldots$ & . 1 & 54 & 12.2 & .6 & -- & -- & -- & -- & -- & - \\
\hline $\begin{array}{l}\triangle P R_{0} \\
22 \ldots\end{array}$ & 1 & 33 & 112 & 29 & & & & & & \\
\hline MAY & $\cdot 1$ & 35 & 120 & 2.4 & .00 & .00 & 0.14 & .02 & - & 1 \\
\hline IUNE & - 1 & 20 & 11.5 & 3.1 & .06 & .12 & .17 & .00 & .04 & 1 \\
\hline $18 \ldots$ & .1 & 16 & 12.0 & 2.4 & .10 & .03 & .11 & .02 & .04 & 1 \\
\hline $29 \ldots$ & .0 & 11 & 9.5 & 2.8 & .08 & .00 & 06 & 04 & 04 & 1 \\
\hline AUG. & & & & & & & & & 80 & \\
\hline $25 \ldots$ & .1 & 19 & 8.4 & 3.3 & .10 & .36 & .44 & .09 & .09 & 6 \\
\hline
\end{tabular}


11208610 MONARCH CREEK NEAR HAMMOND, CALIF.--Cont1 1nued

TEMPERATURE $\left({ }^{\circ} \mathrm{C}\right)$ OF WATER, WATER YEAR OCTOBER 1968 TO SEPTEMBER 1969

DAY

$\begin{array}{llllllllllllllllllllllllllllllllllllll}\text { MONTH } & 1 & 2 & 3 & 4 & 5 & 6 & 7 & 8 & 9 & 10 & 11 & 12 & 13 & 14 & 15 & 16 & 17 & 18 & 19 & 20 & 21 & 22 & 23 & 24 & 25 & 26 & 27 & 28 & 29 & 30 & 31 & \text { AGER- }\end{array}$

OC TOBER

$\begin{array}{llllllllllllllllllllllllllllllllll}\text { MAXIMUM } & 3 & 3 & 2 & 3 & 3 & 3 & 3 & 3 & 3 & 3 & 3 & 3 & 3 & 3 & 4 & 3 & 3 & 3 & 3 & 3 & 3 & 3 & 3 & 3 & 3 & 3 & 3 & 3 & 4 & 4 & 4 & 3 \\ \text { INIMUM } & 1 & 1 & 2 & 1 & 1 & 1 & 1 & 2 & 2 & 2 & 2 & 2 & 3 & 2 & 2 & 2 & 2 & 2 & 2 & 2 & 1 & 1 & 2 & 2 & 2 & 2 & 2 & 2 & 3 & 4 & 4 & 2\end{array}$

NOVEMBE

МАХТМUM 4 - - - -

MINIMUM 3 I

DECFMHFR

МАХІМИМ --

MINIMUM -- -- -- -- --

JANUARY

MАХIMUM -- --

YINIMUM

FBRUARY

MAXIMUM -- -- --

MINIMUM

MARCH

MAXIMUM --

APRIL

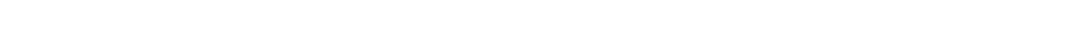

MAY MAXI

MAXIMUM

JUNF

$\begin{array}{llllllllllllllllllllllllllllllllllllll}\text { MAXIMUM } & 5 & 5 & 5 & 5 & 6 & 6 & 6 & 6 & 6 & 6 & 6 & 6 & 6 & 6 & 7 & 7 & - & -- & 7 & 7 & 7 & 8 & 8 & 8 & 8 & 7 & 7 & 7 & 8 & 8 & -- & 7 \\ \text { MININUM } & 3 & 3 & 3 & 3 & 4 & 4 & 4 & 5 & 6 & 6 & 5 & 5 & 4 & 4 & 6 & 6 & - & -- & 6 & 6 & 6 & 6 & 6 & 6 & 6 & 6 & 6 & 6 & 6 & 6 & -- & 5\end{array}$ JULY

MAXIMUM MINIMUM
MUGST

MAXIMUM MINIMUM

SEPIEMBER

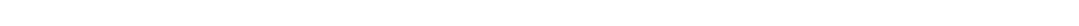

$\begin{array}{lrlllllllllllrrrrrrrrrrrrrrrrrrrrrrr}\text { MAXIMUM } & 12 & 12 & 12 & 11 & 11 & 11 & 11 & 11 & 11 & 11 & 10 & 9 & 9 & 10 & 9 & 9 & 9 & 8 & 8 & 8 & 8 & 8 & 7 & 7 & 7 & 7 & 7 & 7 & 6 & 6 & -2 & 9 \\ \text { MINIMUM } & 11 & 11 & 11 & 10 & 10 & 10 & 10 & 10 & 10 & 9 & 8 & 8 & 8 & 8 & 8 & 8 & 7 & 7 & 7 & 7 & 7 & 7 & 6 & 6 & 6 & 6 & 6 & 6 & 5 & 5 & -- & 8 & 8\end{array}$

SUSPENDED-SEDIMENT DISCHARGE MEASUREMENTS, WATER YEARS OCTOBER 1967 TO SEPTEMBER 1969

\begin{tabular}{|c|c|c|c|c|c|c|}
\hline & DUTE & TIME & $\begin{array}{l}\text { WATER } \\
\text { TEM- } \\
\text { PERA- } \\
\text { TURE } \\
(C)\end{array}$ & $\begin{array}{l}\text { DI SCHARGE } \\
\text { (CFS) }\end{array}$ & $\begin{array}{l}\text { CONCEN- } \\
\text { TRATION } \\
\text { (MGIL) }\end{array}$ & $\begin{array}{l}\text { SUSPENDED } \\
\text { SEOIMENT } \\
\text { DISCHARGE } \\
\text { ITONS/OAY) }\end{array}$ \\
\hline $\begin{array}{l}A \cup G \\
A \cup G\end{array}$ & $\begin{array}{r}2.1968 \\
27 . \ldots \ldots\end{array}$ & $\begin{array}{l}1800 \\
0945\end{array}$ & $\begin{array}{r}14 \\
8\end{array}$ & $\begin{array}{l}2.4 \\
1.8\end{array}$ & $\frac{1}{1}$ & $0^{.01}$ \\
\hline $\begin{array}{l}\text { OLT } \\
\text { OCT } \\
\text { OEC } \\
\text { JAN } \\
\text { FES }\end{array}$ & $\begin{array}{r}1,1969 \\
29 \ldots \ldots \\
7 \ldots \ldots \ldots \\
18,1969 \\
8 \ldots \ldots\end{array}$ & $\begin{array}{l}0900 \\
0930 \\
1100 \\
0930 \\
1620\end{array}$ & $\begin{array}{l}4 \\
4 \\
1 \\
2 \\
0\end{array}$ & $\begin{array}{l}1.0 \\
1.98 \\
2.5 \\
2.0\end{array}$ & $\begin{array}{l}1 \\
1 \\
1 \\
1\end{array}$ & $\begin{array}{l}0 \\
0 \\
0 \\
.01 \\
.01\end{array}$ \\
\hline $\begin{array}{l}\text { MAR } \\
A P R \\
\text { MAY } \\
\text { JUV } \\
\text { JUL }\end{array}$ & $\begin{array}{l}25 \ldots \ldots \ldots \\
22 \ldots \ldots \ldots \\
21 \ldots \ldots \ldots \\
17 \ldots \ldots \ldots \\
29 \ldots \ldots\end{array}$ & $\begin{array}{l}1100 \\
0900 \\
0900 \\
1300 \\
1330\end{array}$ & $\begin{array}{r}4 \\
3 \\
4 \\
6 \\
10\end{array}$ & $\begin{array}{l}2.4 \\
16 \\
52 \\
29 \\
25\end{array}$ & $\begin{array}{l}2 \\
6 \\
3 \\
1 \\
1\end{array}$ & $\begin{array}{l}.01 \\
.26 \\
.42 \\
.08 \\
.07\end{array}$ \\
\hline AUG & $25 \ldots \ldots$ & 1440 & 12 & 6.0 & 2 & .03 \\
\hline
\end{tabular}


11208615 BAST FORK KAWEAH RIVER BELOW MONARCH CREEK, NEAR HAMMOND, CALIF.

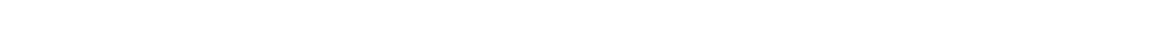
downstream from Monarch Creek and 14.6 miles east of Hamnond.

DRAINAGE AREA, - - $12.1 \mathrm{sq} \mathrm{m} 1$.

PERIOD OF RECORD. --Chemical analy ses: July 1968 to September 1969 Sediment records: October 1967 to September 1969 (partial records).

CHEMICAL ANALYSES, IN MILLIGRAMS PER LITER, JULY TO SEPTEMBER 1968

\begin{tabular}{|c|c|c|c|c|c|c|c|c|c|c|c|}
\hline DATE & TIME & $\begin{array}{l}\text { DIS- } \\
\text { CHARGE } \\
\text { ICFSI }\end{array}$ & $\begin{array}{l}\text { TEMPER- } \\
\text { ATURE } \\
\text { IDEG CI }\end{array}$ & $\begin{array}{l}\text { SILICA } \\
\text { (SIO2) }\end{array}$ & $\begin{array}{l}\text { OIS- } \\
\text { SOL VEN } \\
\text { IRON } \\
\text { (FE) }\end{array}$ & $\begin{array}{l}\text { CAL- } \\
\text { CIUM } \\
\text { (CA) }\end{array}$ & $\begin{array}{l}\text { MAG- } \\
\text { NE- } \\
\text { SIUM } \\
\text { (MG) }\end{array}$ & $\begin{array}{l}\text { SODIUM } \\
\text { (NA) }\end{array}$ & $\begin{array}{l}\text { PO- } \\
\text { TAS- } \\
\text { SIIJM } \\
(K)\end{array}$ & $\begin{array}{l}\text { BICAR- } \\
\text { BONATE } \\
\text { (HCO3) }\end{array}$ & $\begin{array}{l}\text { CAR- } \\
\text { BONATE } \\
\text { (COB) }\end{array}$ \\
\hline $\begin{array}{l}\text { JULY } \\
25 \ldots . . \\
\text { SEPT. }\end{array}$ & -- & 11 & 15 & 7.3 & .01 & 24 & $\mathrm{I} .0$ & 1.3 & .5 & 72 & 0 \\
\hline $30 \ldots$ & 1630 & 3.9 & 10 & 32 & .01 & 31 & 1.5 & 2.5 & .9 & 101 & 0 \\
\hline DATE & $\begin{array}{l}\text { SULFATE } \\
\text { (SO4) }\end{array}$ & $\begin{array}{l}\text { CHLO- } \\
\text { RIDE } \\
\text { (CL) }\end{array}$ & $\begin{array}{l}\text { FLUO- } \\
\text { RIDE } \\
\text { |F| }\end{array}$ & $\begin{array}{l}\text { NITRATE } \\
\text { (N03) }\end{array}$ & $\begin{array}{c}\text { BORON } \\
(B)\end{array}$ & $\begin{array}{l}\text { DIS- } \\
\text { SOLVED } \\
\text { SULIDS } \\
\text { (SUM OF } \\
\text { CONSTI- } \\
\text { TUENTS) }\end{array}$ & $\begin{array}{l}\text { HARD- } \\
\text { NESS } \\
\text { (CA,MG) }\end{array}$ & $\begin{array}{l}\text { NON- } \\
\text { CAR- } \\
\text { BONATE } \\
\text { HARD- } \\
\text { NESS }\end{array}$ & $\begin{array}{l}\text { SPEC I- } \\
\text { FIC } \\
\text { COND- } \\
\text { UCTANCE } \\
\text { IMICRO- } \\
\text { MHOSI }\end{array}$ & $\mathrm{PH}$ & $\begin{array}{l}\text { OIS- } \\
\text { SOLVED } \\
\text { SOLIOS } \\
\text { ITONS } \\
\text { PER } \\
\text { AC-FTI }\end{array}$ \\
\hline $\begin{array}{l}\text { JULY } \\
25 . . . \\
\text { SEPT. }\end{array}$ & 7.0 & .4 & .1 & $\cdot B$ & .00 & 77 & 64 & 5 & 130 & 7.6 & .10 \\
\hline $30 \ldots$ & DAIE & $\begin{array}{l}\text { PERCENT } \\
\text { SOUIUM }\end{array}$ & $\begin{array}{c}\text { SOOIUM } \\
\text { AD- } \\
\text { SORP- } \\
\text { TIION } \\
\text { RATIU }\end{array}$ & $\begin{array}{l}\text { ALKA- } \\
\text { LINITY } \\
\text { AS } \\
\text { CACD3 }\end{array}$ & $\begin{array}{l}\text { DISS- } \\
\text { OLVED } \\
\text { OXYGEN }\end{array}$ & $\begin{array}{l}\text { AMMONIA } \\
\text { (NH4) }\end{array}$ & $\begin{array}{c}\text { ORC,ANIC } \\
\text { NI IRO- } \\
\text { GEN } \\
\text { (N) }\end{array}$ & $\begin{array}{l}\text { ORTHO } \\
\text { PHOS- } \\
\text { PHATE } \\
\text { (PO4) }\end{array}$ & $\begin{array}{l}\text { PHOS- } \\
\text { PHATE } \\
\text { (PO4) }\end{array}$ & $\begin{array}{l}7.6 \\
\text { COLI- } \\
\text { FORM } \\
\text { ICOL- } \\
\text { ONIES } \\
\text { PER } \\
100 \mathrm{MLI} \text { ) }\end{array}$ & .17 \\
\hline & $\begin{array}{l}\text { JULY } \\
25 \ldots . . \\
\text { SEPT. }\end{array}$ & 4 & .1 & 59 & 6.8 & .18 & .00 & .03 & .03 & $=-$ & \\
\hline & $30 \ldots$ & 6 & .1 & 83 & ล. 8 & 2.6 & .41 & .13 & .20 & 48 & \\
\hline
\end{tabular}

CHEMICAL ANALYSES, WATER YEAR OCTOBER 1968 TO SEPTEMBER 1969

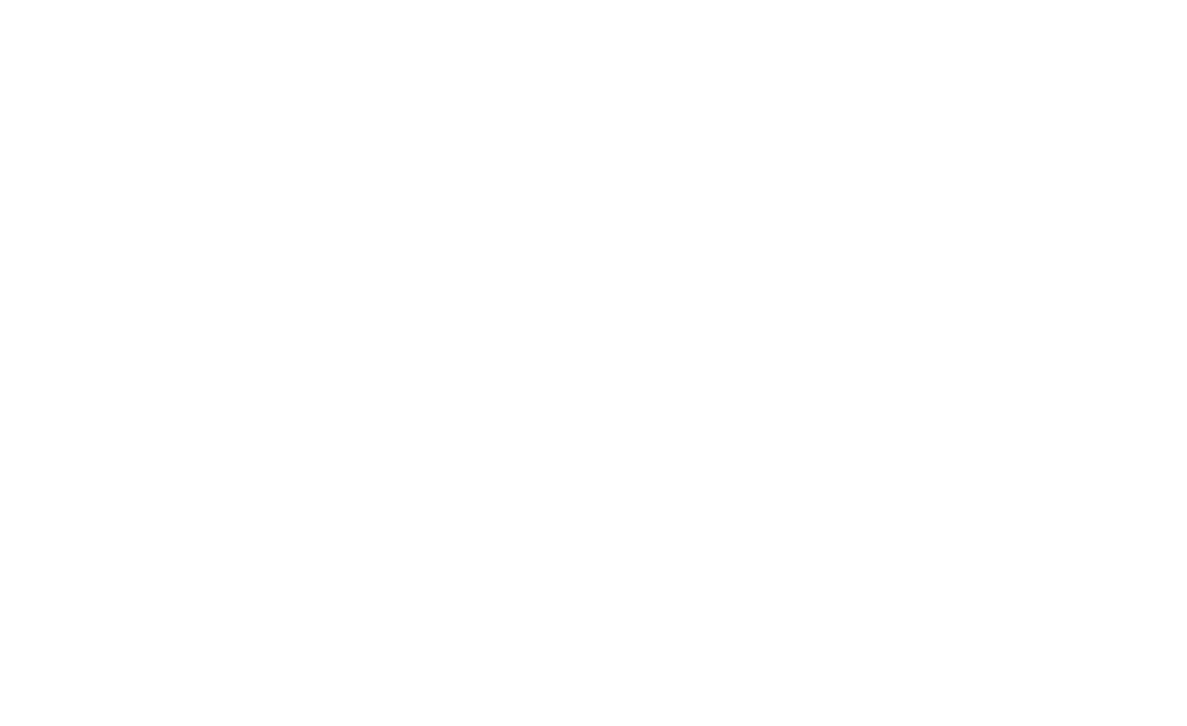


11208515 EAST FORK KAWEAH RIVER BELOM MONARCH CREEK, NEAR HAMMOND, CALIF,_-COntInued SUSPENDED-SEDIMENT DISCHARGE MEASUREMENTS, WATER YEARS OCTOBER 1967 TO SEPTEMBER 1969

\begin{tabular}{|c|c|c|c|c|c|c|}
\hline & DATE & TIME & $\begin{array}{l}\text { WAIER } \\
\text { TEM- } \\
\text { PERA- } \\
\text { TURE } \\
\text { I CI }\end{array}$ & $\begin{array}{l}\text { DI SCHARGE } \\
\text { (CFS) }\end{array}$ & $\begin{array}{l}\text { CONCEN- } \\
\text { TRATION } \\
\text { (MG/L) }\end{array}$ & $\begin{array}{l}\text { SUSPENDEO } \\
\text { SEDIMENT } \\
\text { DI SCHARGE } \\
\text { (TONSIOAY) }\end{array}$ \\
\hline $\begin{array}{l}\text { AUG } \\
\text { AUG } \\
\text { SEP }\end{array}$ & $\begin{array}{r}2.1968 \\
27 \ldots \ldots \ldots \\
30 \ldots \ldots\end{array}$ & $\begin{array}{l}0745 \\
1230 \\
1630\end{array}$ & $\begin{array}{r}8 \\
13 \\
10\end{array}$ & $\begin{array}{l}10 \\
9.0 \\
3.9\end{array}$ & $\begin{array}{r}1 \\
29 \\
1\end{array}$ & $\begin{array}{l}.03 \\
.70 \\
.01\end{array}$ \\
\hline $\begin{array}{l}\text { OC : } \\
\text { JUN } \\
\text { JULL } \\
\text { AUG }\end{array}$ & $\begin{array}{l}15,1968 \\
17,1963 \\
29, \ldots \ldots \\
25, \ldots .\end{array}$ & $\begin{array}{l}1550 \\
1615 \\
1450 \\
1545\end{array}$ & $\begin{array}{r}8 \\
5 \\
11 \\
12\end{array}$ & $\begin{array}{r}10 \\
168 \\
110 \\
33\end{array}$ & $\begin{array}{l}2 \\
4 \\
2 \\
2\end{array}$ & $\begin{array}{l}.05 \\
1.8 \\
.59 \\
.18\end{array}$ \\
\hline
\end{tabular}

11208620 EAST FORK KAWEAH RIVER BELOW MOSQUITO CREEK, NEAR HAMMOND, CALIF.

LOCATION. --Lat $36^{\circ} 27^{\prime} 05^{\prime \prime}$, long $118^{\circ} 37^{\prime} 04^{\prime \prime}$, in SW $\frac{1}{4} \mathrm{NW}_{1}$ sec.16, T.17 S., R. $13 \mathrm{E}$., Tulare County, Sequola National Forest, at gaging station on right bank, $300 \mathrm{ft}$ downstream from losquito Creek and 13.2 miles east of Hammond, DRAINAGE AREa. --16.0 sq mi.

PERIOD OF RECORD. --Chemical analyses: July 1968 to September 1969.

Water temperatures: August 1968 to September 1969.

Sediment records: August 1967 to September 1969 (partial records).

EXTREMES. --1968-69:

Water temperatures: Maximum, $16.0^{\circ} \mathrm{C}$ Aug. 22-24; minimum, freezing point on many days during December and January.

Period of record:

Mater temperatures: Maximum, $16.0^{\circ} \mathrm{C}$ Aug. 22-24, 1969; minimum, freezing point on many days during December 1968 and January 1969 .

CHEMICAL ANALYSES, IN MILLIGRAMS PER LITER, JULY TO SEPTEMBER 1968

\begin{tabular}{|c|c|c|c|c|c|c|c|c|c|c|c|}
\hline DATE & TIME & $\begin{array}{l}\text { OIS- } \\
\text { CHARGE } \\
\text { (CFSI }\end{array}$ & $\begin{array}{l}\text { TEMPER- } \\
\text { ATURE } \\
\text { (DEG C) }\end{array}$ & $\begin{array}{l}\text { SILICA } \\
\text { (SI02) }\end{array}$ & $\begin{array}{l}\text { OIS- } \\
\text { SULVEO } \\
\text { IRON } \\
\text { (FE) }\end{array}$ & $\begin{array}{l}\text { CAL- } \\
\text { CIUM } \\
\text { (CA) }\end{array}$ & $\begin{array}{l}\text { MAG- } \\
\text { NE- } \\
\text { SIUM } \\
\text { (MG) }\end{array}$ & $\begin{array}{l}\text { SODIUAM } \\
\text { (NA) }\end{array}$ & $\begin{array}{l}\text { PO- } \\
\text { TAS- } \\
\text { SIJM } \\
(K)\end{array}$ & $\begin{array}{l}\text { B ICAR- } \\
\text { BONATE } \\
\text { (HCD3) }\end{array}$ & $\begin{array}{l}\text { CAR- } \\
\text { RONA,E } \\
\text { ICOBI }\end{array}$ \\
\hline $\begin{array}{l}\text { JULY } \\
26 \ldots \\
\text { AUG... } \\
27 \ldots\end{array}$ & 1345 & 19 & 12 & 8.3 & $\begin{array}{l}.00 \\
.01\end{array}$ & 27 & 1.3 & 2.1 & .1 & 80 & $a$ \\
\hline DATE & $\begin{array}{l}\text { SULFATE } \\
\text { (SUA) }\end{array}$ & $\begin{array}{l}\text { CHLO- } \\
\text { RIJE } \\
(\mathrm{CL})\end{array}$ & $\begin{array}{l}\text { FLUQD- } \\
\text { RIOE } \\
\text { (F) }\end{array}$ & $\begin{array}{l}\text { MITRATE } \\
\text { (NO3) }\end{array}$ & $\begin{array}{l}\text { BORON } \\
(B)\end{array}$ & $\begin{array}{l}\text { OIS- } \\
\text { SOLVED } \\
\text { SOLIOS } \\
\text { (SUM UF } \\
\text { CONSTI- } \\
\text { TUENTS) }\end{array}$ & $\begin{array}{l}\text { HARD- } \\
\text { NESS } \\
(C A, M G)\end{array}$ & $\begin{array}{l}\text { NON- } \\
\text { CAP- } \\
\text { RONATE } \\
\text { HARO- } \\
\text { NESS }\end{array}$ & $\begin{array}{l}\text { SPECI- } \\
\text { FIC } \\
\text { COND- } \\
\text { UCTANCE } \\
\text { (MICRO- } \\
\text { MHOS) }\end{array}$ & $\mathrm{PH}$ & $\begin{array}{l}\text { DIS- } \\
\text { SULVED } \\
\text { SOLIOS } \\
\text { ITONS } \\
\text { PER } \\
\text { AC-FTI }\end{array}$ \\
\hline $\begin{array}{l}\text { JULY } \\
26 \ldots \\
\text { AUG. } \\
27 . .\end{array}$ & $\begin{array}{l}7.0 \\
21\end{array}$ & $\begin{array}{c}.0 \\
.8\end{array}$ & $\begin{array}{l}.1 \\
.1\end{array}$ & $\begin{array}{r}1.0 \\
.1\end{array}$ & $\begin{array}{l}.00 \\
.04\end{array}$ & $\begin{array}{l}79 \\
90\end{array}$ & $\begin{array}{l}64 \\
73\end{array}$ & $\begin{array}{l}3 \\
7\end{array}$ & 135 & $\begin{array}{l}7.5 \\
7.7\end{array}$ & $\begin{array}{r}.11 \\
.12\end{array}$ \\
\hline & DATE & $\begin{array}{l}\text { PERCENT } \\
\text { SUDIUIH }\end{array}$ & $\begin{array}{l}\text { SUDIUM } \\
\text { AO- } \\
\text { SURP- } \\
\text { TION } \\
\text { RATIO }\end{array}$ & $\begin{array}{l}\text { ALKA- } \\
\text { I INITY } \\
\text { AS } \\
\text { CACO3 }\end{array}$ & $\begin{array}{l}\text { DISS- } \\
\text { TLVED } \\
\text { OXYGEN }\end{array}$ & $\begin{array}{l}\text { AMMUNIA } \\
\text { (NH4) }\end{array}$ & $\begin{array}{l}\text { ORGANIC } \\
\text { NI TRO- } \\
\text { GEN } \\
\text { (N) }\end{array}$ & $\begin{array}{l}\text { ORTHO } \\
\text { PHOS- } \\
\text { PHATE } \\
\text { IPD4) }\end{array}$ & $\begin{array}{l}\text { PHUS- } \\
\text { PHATE } \\
\text { (PO4) }\end{array}$ & $\begin{array}{l}\text { COL I- } \\
\text { FORM } \\
\text { ICOL- } \\
\text { ONIES } \\
\text { PER } \\
100 \mathrm{ML} \text { ) }\end{array}$ & \\
\hline
\end{tabular}

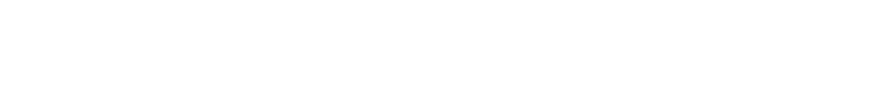


11208620 EAST FORK KATEAH RIVER BELOW YOSQUITO CREEK, NEAR HAMMOND, CALIF.--COnt Inued CHEMICAL ANALYSES, MATER YEAR OCTOBER 1968 TO SEPTEMBER 1969

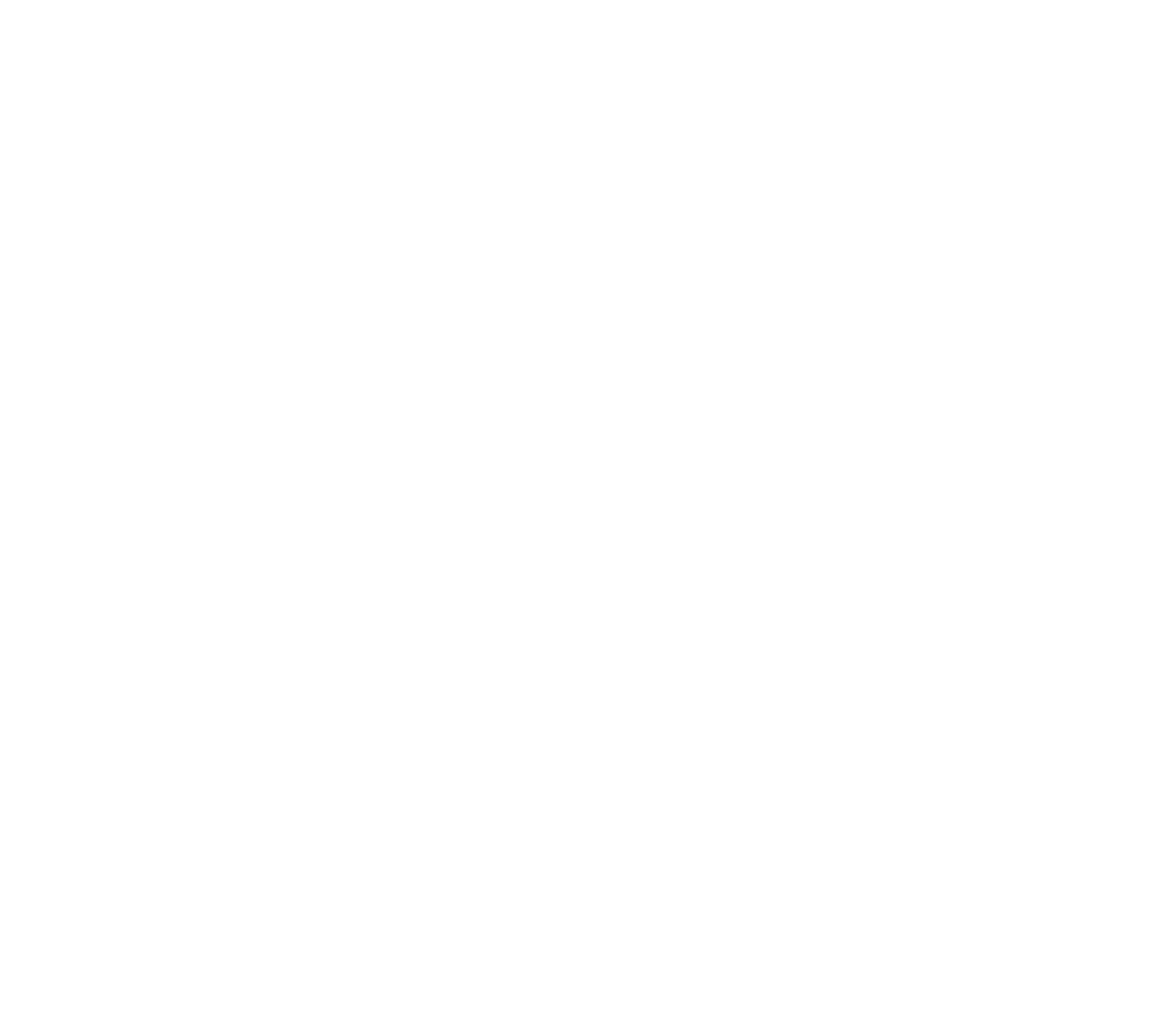

\begin{tabular}{|c|c|c|c|}
\hline $\begin{array}{l}\text { OCT, } \\
02 \ldots \\
\angle 9, \ldots\end{array}$ & $\begin{array}{l}7 \\
6\end{array}$ & .1 & $\begin{array}{l}85 \\
94\end{array}$ \\
\hline UEC. & & & \\
\hline JAN... & 6 & .1 & 81 \\
\hline${ }_{\text {MAK. }}^{18 . .}$ & 6 & .1 & 78 \\
\hline $\begin{array}{l}\angle 5 \ldots . \\
\triangle P{ }_{A}\end{array}$ & 6 & .1 & 67 \\
\hline $\operatorname{MAY}_{\operatorname{MA}}^{22}$ & 5 & .1 & 47 \\
\hline JUNE & 7 & .1 & 28 \\
\hline $\begin{array}{l}18 . . \\
\text { JuLE }\end{array}$ & 6 & .1 & 28 \\
\hline $\begin{array}{c}29 . . . \\
\text { AUG. }\end{array}$ & 3 & .0 & 25 \\
\hline $25 \ldots$ & 5 & .1 & 42 \\
\hline
\end{tabular}

$\begin{array}{rrrrrr}9.8 & .0 & - & -- & - & - \\ 10.2 & .7 & - & -- & - & - \\ 11.4 & .8 & .04 & .00 & .04 & .00 \\ 11.8 & 1.1 & .04 & .16 & .29 & .00 \\ 10.9 & .0 & .12 & .61 & .80 & .00 \\ 11.3 & 3.1 & .22 & .19 & .46 & .05 \\ 13.4 & 2.7 & .05 & .20 & .44 & .02 \\ 11.4 & 3.2 & .30 & .29 & .22 & .18 \\ 9.8 & 1.5 & .01 & .00 & .03 & .01 \\ 7.6 & 1.5 & .06 & .18 & .23 & .18\end{array}$

.-
-04
.04
.04
.08
-18
.14
.26
.03
.27

-- 
11208620 EAST FORK KAWEAH RIVER BELOW MOSQUITO CREEK, NEAR HAMMOND, CALIF.--CONTInUed

TEMPERATURE ( $\left.{ }^{\circ} \mathrm{C}\right)$ OF WATER, AUGUST TO SEPTEMBER 1968

DAY

$\begin{array}{llllllllllllllllllllllllllllllllllllllllllll}\text { MUNTH } & 1 & 2 & 3 & 4 & 5 & 6 & 7 & 8 & 9 & 10 & 11 & 12 & 13 & 14 & 15 & 16 & 17 & 18 & 19 & 20 & 21 & 22 & 23 & 24 & 25 & 26 & 27 & 28 & 29 & 30 & 31 & \text { AGE }\end{array}$

AUGUST

MAXIMUM - - - -

SEPTEMBER

MAXIMUM $14 \begin{array}{lllllllllllllllllllllllllllllllllllll}14 & 14 & 14 & 14 & 14 & 14 & 14 & 14 & 13 & 13 & 13 & 13 & 12 & 12 & 13 & 12 & 12 & 12 & 11 & 10 & 9 & 10 & 11 & 11 & 11 & 11 & 11 & 9 & 9 & -- & 12\end{array}$

TEMPERATURE ( ${ }^{\circ} \mathrm{C}$ ) OF WATER, WATER YEAR OCTOBER 1968 TO SEPTEMBER 1969

DAY

MONTH $1233456 \quad 7 \quad 8 \quad 91011 \quad 1213141516171819202122 \quad 232425 \quad 262728293031$ AGE

OCTOSER

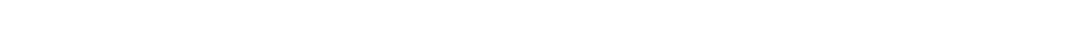

MOVEMBER

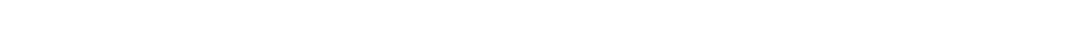

$\begin{array}{lllllllllllllllllllllllllllllllll}41 N \text { IMUM } & 5 & 5 & 5 & 4 & 4 & 4 & 5 & 5 & 5 & 6 & 6 & 4 & 4 & 2 & 2 & 2 & 3 & 4 & 4 & 4 & 4 & 3 & 3 & 2 & 2 & 1 & 2 & 1 & 1 & 2 & -2 & -1\end{array}$

DECEMBER

$\begin{array}{llllllllllllllllllllllllllllllllllllll}\text { MAXIMUM } & 2 & 1 & 2 & 2 & 2 & 3 & 2 & 2 & 3 & 2 & 1 & 1 & 2 & 1 & 2 & 2 & 0 & 1 & 1 & 0 & 0 & 1 & 2 & 2 & 1 & 0 & 0 & 0 & 0 & 0 & 1 & 1 \\ \text { MINIMUUM } & 1 & 0 & 1 & 1 & 1 & 2 & 2 & 2 & 2 & 1 & 0 & 0 & 0 & 0 & 0 & 0 & 0 & 0 & 0 & 0 & 0 & 0 & 1 & 1 & 0 & 0 & 0 & 0 & 0 & 0 & 0 & 0 & 0\end{array}$

MINIMUM

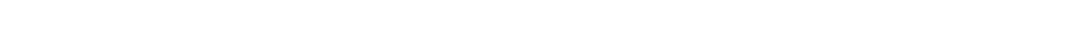

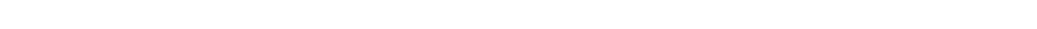

FEBRUARY

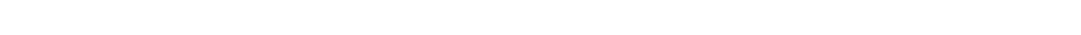

MAXIMUM 1

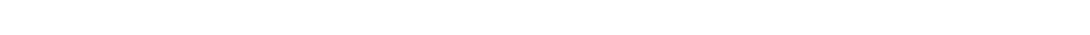

APRIL

MINIMUM -

MAXIMUM $4 \begin{array}{lllllllllllllllllllllllllllllllllll} & 4 & 4 & 4 & 5 & 5 & 5 & 6 & 5 & 5 & 5 & 6 & 5 & 5 & 5 & 5 & 5 & 5 & 5 & 5 & 5 & 5 & 5 & 5 & 5 & 4 & 4 & 4 & 4 & 4 & 5\end{array}$

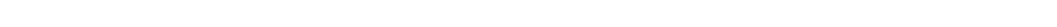

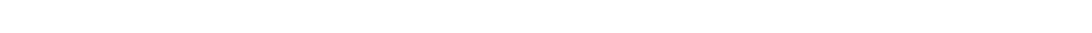

MAXIMUM AUGUST

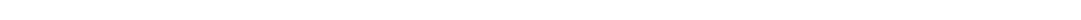

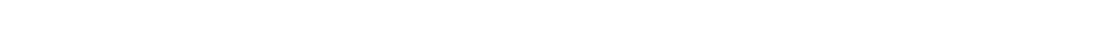
SEPTEMAER

$\begin{array}{lllllllllllllllllllllllllllllllllllllll}\text { MAXIMUM } & 15 & 15 & 14 & 14 & 14 & 13 & 13 & 14 & 14 & 14 & 13 & 13 & 13 & 13 & 13 & 13 & 13 & 13 & 13 & 12 & 11 & 12 & 12 & 12 & 12 & 12 & 12 & 11 & 11 & 11 & \ldots- & 13 \\ \text { MINIIMUM } & 12 & 12 & 12 & 11 & 11 & 12 & 12 & 12 & 12 & 11 & 11 & 11 & 10 & 11 & 11 & 11 & 11 & 10 & 10 & 11 & 9 & 10 & 10 & 9 & 10 & 10 & 9 & 9 & 10 & 10 & -2 & 11\end{array}$

SUSPENDED-SEDIMENT DISCHARGE MEASUREMENTS, AUGUST 1968 TO SEPTEMBER 1969

\begin{tabular}{|c|c|c|c|c|c|c|}
\hline & OATE & TIME & $\begin{array}{l}\text { WATER } \\
\text { TEM- } \\
\text { PERA- } \\
\text { TURE } \\
\text { I CI }\end{array}$ & $\begin{array}{l}\text { DISCHARGE } \\
\text { (CFS) }\end{array}$ & $\begin{array}{l}\text { CONCEN- } \\
\text { TRATION } \\
\text { (MGIL) }\end{array}$ & $\begin{array}{l}\text { SUSPENDED } \\
\text { SEDIMENT } \\
\text { OISCHARGE } \\
\text { (TONS/OAY) }\end{array}$ \\
\hline $\begin{array}{l}\text { AUG } \\
\text { AUG }\end{array}$ & $\begin{array}{r}2,1968 \\
27 \ldots \ldots\end{array}$ & $\begin{array}{l}0905 \\
1345\end{array}$ & $\begin{array}{l}10 \\
12\end{array}$ & $\begin{array}{l}10 \\
9.6\end{array}$ & $\begin{array}{r}1 \\
10\end{array}$ & $\begin{array}{r}.03 \\
.26\end{array}$ \\
\hline $\begin{array}{l}\text { OCT } \\
\text { OCT } \\
\text { OCT } \\
\text { OEC } \\
\text { JAN }\end{array}$ & $\begin{array}{r}1,1968 \\
15 \ldots \ldots \ldots \\
29 \ldots \ldots \ldots \\
7 \ldots \ldots \\
18,1969\end{array}$ & $\begin{array}{l}1100 \\
1500 \\
1100 \\
1330 \\
1115\end{array}$ & $\begin{array}{l}7 \\
8 \\
6 \\
2 \\
2\end{array}$ & $\begin{array}{l}4.4 \\
8.0 \\
5.4 \\
7.4 \\
10\end{array}$ & $\begin{array}{l}6 \\
1 \\
1 \\
2 \\
1\end{array}$ & $\begin{array}{l}.07 \\
.02 \\
.01 \\
.04 \\
.03\end{array}$ \\
\hline $\begin{array}{l}\text { MAR } \\
\text { APR } \\
\text { MAY } \\
\text { JUN } \\
\text { JUL }\end{array}$ & $\begin{array}{l}25 \ldots \ldots \ldots \\
22 \ldots \ldots \ldots \\
21 \ldots \ldots \ldots \\
18 \ldots \ldots \ldots \\
29 \ldots \ldots\end{array}$ & $\begin{array}{l}1400 \\
1200 \\
1330 \\
1450 \\
1600\end{array}$ & $\begin{array}{r}4 \\
4 \\
5 \\
7 \\
10\end{array}$ & $\begin{array}{r}17 \\
96 \\
280 \\
205 \\
116\end{array}$ & $\begin{array}{r}11 \\
24 \\
32 \\
9 \\
3\end{array}$ & $\begin{array}{c}.50 \\
6.2 \\
5.0 \\
.94\end{array}$ \\
\hline$A \cup G$ & $25 \ldots \ldots$ & 1700 & 15 & 41 & 2 & .22 \\
\hline
\end{tabular}


11208625 EAST FORK KAWEAH RIVER AT SEQUOIA NATIONAL PARK BOUNDARY, NEAR HAMMOND, CALIF.

LOCATION, - Lat $36^{\circ} 27^{\prime} 30^{\prime \prime}$, long $118^{\circ} 39^{\prime} 11^{\prime \prime}$, In SW $\frac{1}{4}$ SW $\frac{1}{4}$ sec.7, T.17 s., R.31 E., Tulare County, Sequo1a Nat1ona1 Park, at gaging station on right bank, 0.6 mile southwest of Silver C1ty and 11.4 miles east of hammond.

DRAINAGE AREA. --23.7 sq mi.

PERIOD OF RECORD. --Chemical analyse s: July 1968 to September 1969.

Water temperatures: August 1968 to September 1969 .
Sediment records: August 1967 to September 1969 (partial records),

EXTREMES, -- August to September 1968:

Water temperatures: Maximum, $17.0^{\circ} \mathrm{C}$ Aug. 3.

EXTREMES, $-1968-69$ :

Vater temperatures: Maximum, $14.0^{\circ} \mathrm{C}$ July 31 , Aug. $3,4,10$; minimum, freezing point on many days during winter months.

Pertod of record:

Water temperatures: Maximum, $17.0^{\circ} \mathrm{C}$ Aug. 3,1968 ; minimum, freezing point on many days during winter months.

REMARKS.--CIock stopped Nov. 27 to Dec. 6, Feb. 9 to Mar. 25, June 19 to July 29, Aug. 25 to Sept. 30 ; range in temperature, $2.0^{\circ} \mathrm{C}$ to $3.0^{\circ} \mathrm{C}, 0.0^{\circ} \mathrm{C}$ to $2.0^{\circ} \mathrm{C}, 5.0^{\circ} \mathrm{C}$ to $10^{\circ} 0^{\circ} \mathrm{C}$, and $5.0^{\circ} \mathrm{C}$ to $13.0^{\circ} \mathrm{C}$, respectively. No record Dec. $7-10$.

CHEMICAL ANALYSES, IN MILLIGRAMS PER LITER, JULY TO SEPTEMBER 1968

\begin{tabular}{|c|c|c|c|c|c|c|c|c|c|c|c|}
\hline DATE & TIME & $\begin{array}{l}\text { DIS- } \\
\text { CHARGE } \\
\text { (CFS) }\end{array}$ & $\begin{array}{l}\text { TEMPER- } \\
\text { ATURE } \\
\text { (OEG C) }\end{array}$ & $\begin{array}{l}\text { SILICA } \\
\text { (SIO2) }\end{array}$ & $\begin{array}{l}\text { DIS- } \\
\text { SOLVED } \\
\text { IRDN } \\
\text { (FE) }\end{array}$ & $\begin{array}{l}\text { CAL- } \\
\text { CIUM } \\
\text { (CA) }\end{array}$ & $\begin{array}{l}\text { MAG- } \\
\text { NE- } \\
\text { SIUM } \\
\text { (MG) }\end{array}$ & $\begin{array}{l}\text { SOO IUM } \\
\text { (NA) }\end{array}$ & $\begin{array}{l}\text { PO- } \\
\text { TAS- } \\
\text { SIUM } \\
\text { IKI }\end{array}$ & $\begin{array}{l}\text { BIC AR- } \\
\text { BONATE } \\
\text { (HCD3) }\end{array}$ & $\begin{array}{l}\text { CAR- } \\
\text { BONATE } \\
\text { (CO3) }\end{array}$ \\
\hline $\begin{array}{l}\text { JULY } \\
25 . . . \\
\text { AUG. }\end{array}$ & 1445 & 12 & 16 & 8.7 & .00 & 22 & 1.0 & 1.8 & .7 & 69 & 0 \\
\hline $27 \ldots$ & 1615 & 6.9 & 15 & 9.5 & .01 & 24 & 1.2 & 2.4 & .7 & 74 & 0 \\
\hline DATE & $\begin{array}{l}\text { SULFATE } \\
\text { (SO4) }\end{array}$ & $\begin{array}{l}\text { CHLO- } \\
\text { RIUE } \\
(\mathrm{CL})\end{array}$ & $\begin{array}{l}\text { FLUO- } \\
\text { RIDE } \\
\text { If I }\end{array}$ & $\begin{array}{l}\text { NI TRATE } \\
\text { (NO3) }\end{array}$ & $\begin{array}{c}\text { BORON } \\
(B)\end{array}$ & $\begin{array}{l}\text { DIS- } \\
\text { SULVED } \\
\text { SOLIDS } \\
\text { ISUM OF } \\
\text { CUNSTI- } \\
\text { TUENTSI }\end{array}$ & $\begin{array}{l}\text { HARD- } \\
\text { NESS } \\
\text { ICA,MG I }\end{array}$ & $\begin{array}{l}\text { NON- } \\
\text { CAR- } \\
\text { BDNATE } \\
\text { HARO- } \\
\text { NESS }\end{array}$ & $\begin{array}{l}\text { SPECI- } \\
\text { FIC } \\
\text { COND- } \\
\text { UCTANCE } \\
\text { (MICRO- } \\
\text { MHOS) }\end{array}$ & $P_{H}$ & $\begin{array}{l}\text { DIS- } \\
\text { SOLVED } \\
\text { SOLIOS } \\
\text { ITONS } \\
\text { PER } \\
\text { AC }-F T \text { FT }\end{array}$ \\
\hline $\begin{array}{l}\text { JULY } \\
25 \ldots . . \\
\text { AUG. } \\
27 . .\end{array}$ & 7.0 & .6 & .2 & .8 & .00 & 77 & 59 & 2 & 126 & 7.6 & .10 \\
\hline
\end{tabular}

\begin{tabular}{|c|c|c|c|c|c|c|c|c|c|}
\hline DATE & $\begin{array}{l}\text { PERCENT } \\
\text { SOUIUM }\end{array}$ & $\begin{array}{l}\text { SODIUM } \\
\text { AO- } \\
\text { SORP- } \\
\text { TION } \\
\text { RATIO }\end{array}$ & $\begin{array}{l}\text { ALKA- } \\
\text { LINITY } \\
\text { AS } \\
\text { CACD3 }\end{array}$ & $\begin{array}{l}\text { DISS- } \\
\text { OLVED } \\
\text { OXYGEN }\end{array}$ & $\begin{array}{l}\text { AMMON I A } \\
(\text { NH4 })\end{array}$ & $\begin{array}{l}\text { ORG ANIC } \\
\text { NITRO- } \\
\text { GEN } \\
\text { (N) }\end{array}$ & $\begin{array}{l}\text { ORTHO } \\
\text { PHOS- } \\
\text { PHATE } \\
\text { (PO4) }\end{array}$ & $\begin{array}{l}\text { PHOS- } \\
\text { PHATE } \\
\text { (PO4) }\end{array}$ & $\begin{array}{c}\text { COLI- } \\
\text { FORM } \\
\text { ICOL- } \\
\text { ONIES } \\
\text { PER } \\
100 \mathrm{ML}\end{array}$ \\
\hline $\begin{array}{l}\text { JULY } \\
25 \ldots . . \\
\text { AUG... } \\
27 \ldots\end{array}$ & 6 & $\begin{array}{l}.1 \\
.1\end{array}$ & 57 & A. 0 & $\begin{array}{l}.04 \\
.00\end{array}$ & $\begin{array}{l}.00 \\
.51\end{array}$ & $\begin{array}{l}.04 \\
.00\end{array}$ & $\begin{array}{l}.08 \\
.03\end{array}$ & -- \\
\hline
\end{tabular}




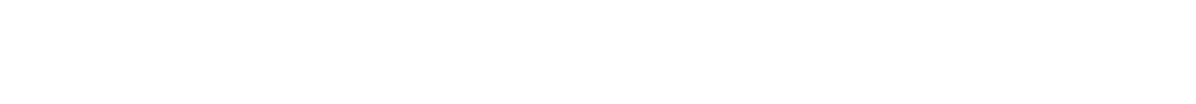

\begin{tabular}{|c|c|c|}
\hline $\begin{array}{r}\text { OCT. } \\
01 . . . \\
29 . .\end{array}$ & $\begin{array}{l}1400 \\
1330\end{array}$ & $\begin{array}{l}5.4 \\
6.4\end{array}$ \\
\hline $\begin{array}{l}\text { OEC. } \\
07 . . .\end{array}$ & 1550 & 9.4 \\
\hline $\begin{array}{l}\text { FEB. } \\
08 . . .\end{array}$ & 1130 & \\
\hline $\begin{array}{l}\text { MAR. } \\
26 . . . \\
\text { APR. }\end{array}$ & 1000 & 30 \\
\hline $22 \cdots$ & 1600 & 169 \\
\hline JUNE & 1615 & 528 \\
\hline JuLY." & 0400 & 282 \\
\hline $\begin{array}{l}30 \ldots \\
\text { AUG, }\end{array}$ & 0900 & 155 \\
\hline $25 \ldots$ & 1200 & 39 \\
\hline
\end{tabular}

8
6
1
0
2
4
9
3
10
13

10
2
5
9
6
23
9
16
22

$\begin{array}{ccc}11 & 0 & 26 \\ 11 & 0 & 30 \\ 11 & 10 & 26 \\ 11 & 0 & 17 \\ 11 & 10 & 15 \\ 8.1 & 20 & 12 \\ 3.4 & 10 & 8.2 \\ 8.2 & 20 & 8.5 \\ 5.4 & 20 & 9.1 \\ 7.2 & 0 & 14\end{array}$

$\begin{array}{lllll}1.6 & 3.3 & 1.0 & 90 & 0 \\ 1.6 & 3.3 & .8 & 98 & 0 \\ 1.5 & 2.7 & .8 & 85 & 0 \\ 1.1 & 2.1 & .7 & 54 & 0 \\ 1.0 & 2.1 & .7 & 52 & 0 \\ .7 & 1.3 & .7 & 39 & 0 \\ .4 & .9 & .5 & 23 & 0 \\ .5 & .9 & .3 & 26 & 0 \\ .5 & .5 & .4 & 28 & 0 \\ .8 & 1.3 & .5 & 44 & 0\end{array}$

\begin{tabular}{|c|c|c|c|c|c|c|c|c|c|c|c|c|}
\hline & & CHLO- & FLUO- & & & $\begin{array}{c}\text { OAS- } \\
\text { SULVED } \\
\text { SUL lOS } \\
\text { I SUM OF }\end{array}$ & HARO- & $\begin{array}{l}\text { NON- } \\
\text { CAR- } \\
\text { BDNATE }\end{array}$ & $\begin{array}{l}\text { SPECI- } \\
\text { FIC } \\
\text { COND- }\end{array}$ & & $\begin{array}{l}\text { DLS- } \\
\text { SOLVED } \\
\text { SOLIOS }\end{array}$ & \\
\hline ATE & $\begin{array}{l}\text { SULFATE } \\
\text { (SO4) } \\
\text { (MG/L) }\end{array}$ & $\begin{array}{l}\text { KIOE } \\
(C L \mid \\
(M G / L)\end{array}$ & $\begin{array}{l}\text { RIOE } \\
(\mathrm{F}\rangle \\
(M G / L)\end{array}$ & $\begin{array}{l}\text { NITRATE } \\
\text { (NO3) } \\
(M L / L)\end{array}$ & $\begin{array}{l}\text { BORON } \\
(B) \\
(U G / L)\end{array}$ & $\begin{array}{l}\text { CONST L } \\
\text { TUENTS) } \\
\text { (MG/L) }\end{array}$ & $\begin{array}{l}\text { NESS } \\
(C A, M G) \\
(M G / L)\end{array}$ & $\begin{array}{l}\text { HARQ- } \\
\text { NESS } \\
\text { (MG/L) }\end{array}$ & $\begin{array}{l}\text { UCTANCE } \\
\text { (MICRO- } \\
\text { MHOS) }\end{array}$ & $\begin{array}{c}\text { PH } \\
\text { (UNITS) }\end{array}$ & $\begin{array}{c}\text { (TONS } \\
\text { PER } \\
\text { AC-FT) }\end{array}$ & $\begin{array}{l}\text { PERCENT } \\
\text { SODIUM }\end{array}$ \\
\hline
\end{tabular}

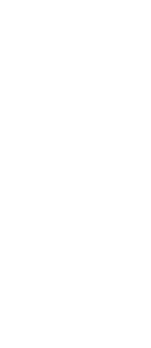
$\begin{array}{lllll}.0 & .3 & .1 & .2 & 20 \\ .0 & .3 & .1 & .0 & 0 \\ .0 & 1.0 & .3 & .2 & 0 \\ .0 & .4 & .0 & .6 & 40 \\ 4.0 & .2 & .2 & .4 & 30 \\ .0 & .4 & .1 & .2 & 0 \\ .0 & .3 & .0 & .4 & 10 \\ .0 & .2 & .1 & .3 & 0 \\ .0 & .2 & .1 & .1 & 0 \\ .0 & .2 & .0 & .1 & 0\end{array}$

20
0
0
40
30
0
10
0
0
0

$\begin{array}{rr}96 & 72 \\ 101 & 82 \\ 93 & 72 \\ 64 & 47 \\ 01 & 4 \\ 47 & 33 \\ 30 & 22 \\ 35 & 23 \\ 33 & 24 \\ 50 & 39\end{array}$

72
82
71
47
42
33
22
23
24
38

$\begin{array}{rrrrr}0 & 162 & 7.7 & .13 & 9 \\ 2 & 169 & 7.9 & .14 & 8 \\ 1 & 154 & 7.5 & .13 & 8 \\ 3 & 102 & 7.5 & .09 & 9 \\ 0 & 97 & 7.5 & .08 & 10 \\ 1 & 78 & 6.8 & .06 & 8 \\ 3 & 49 & 6.8 & .04 & 8 \\ 2 & 55 & 7.1 & .05 & 8 \\ 1 & 56 & 6.5 & .04 & 4 \\ 2 & 85 & 7.5 & .07 & 7\end{array}$

DATE

$\begin{array}{cl}\text { SODIUM } & \\ \text { AD- } & \text { ALKA- } \\ \text { SORP- } & \text { LINITY } \\ \text { TION } & \text { AS } \\ \text { RATIO } & \text { CACOS } \\ \text { I MGILI }\end{array}$

DIS-
SOLVED
OXYGEN
(MG/L)

BIO-
CHEH-
ICAL
OXYGEN AMHONIA
DEMAND (NHA)
IMG/L) (MG/L)

$\begin{array}{ll}\text { ORGANIC } & \text { TOTAL } \\ \text { NITRO- } & \text { NITRO- } \\ \text { GEN } & \text { GEN } \\ \text { (N) } & \text { (N) } \\ \text { (MG/LI } & \text { (MG/L) }\end{array}$

ORTHO
PHOS-
PHATE
(PO4)
(MG/L)

$\begin{array}{lcc} & \text { COLI- } & \\ \text { PORM } & \text { TOTAL } \\ \text { PHOS- } & \text { ICOL- } & \text { URGANIC } \\ \text { PHATE } & \text { ONIES } & \text { CARBDN } \\ \text { (POA) } & \text { PER } & \text { IC) } \\ \text { (MG/L) } & 100 \mathrm{ML}) & \text { (MG/L) }\end{array}$

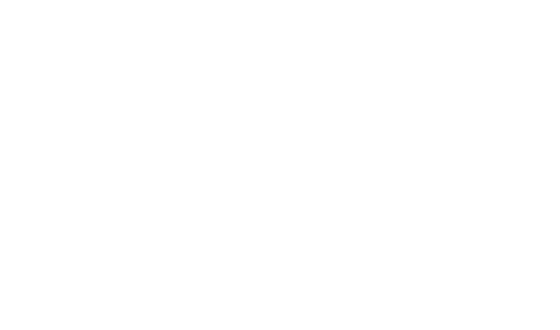

$\begin{array}{cc}.51 & .51 \\ .78 & .80 \\ 1.7 & 2.4 \\ .13 & .85 \\ 1.1 & 1.6 \\ .63 & .70 \\ .12 & .26 \\ .08 & .19 \\ .03 & .06 \\ .17 & .20\end{array}$

$\begin{array}{llll}.05 & .02 & 44 & -- \\ .08 & .07 & 27 & - \\ .00 & .12 & -- & - \\ .03 & .06 & -- & - \\ .02 & .09 & -- & - \\ .02 & - & 9 & - \\ .03 & .26 & 1 & - \\ .02 & .07 & 1 & - \\ .00 & .04 & 7 & 1.0 \\ .04 & .04 & 26 & .0\end{array}$


11208625 EAST FORK KATEAH RI VER AT SEQUOI A NATIONAL PARK BOUNDARY, NEAR hamMond, CALIF, --Cont InUed TEMPERATURE ( ${ }^{\circ} \mathrm{C}$ ) OF WATER, AUGUST TO SEPTEMBER 1968

DAY

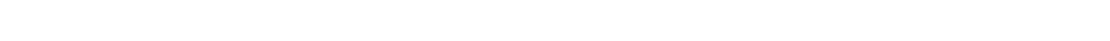

AUGUST

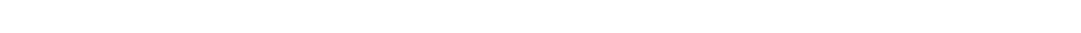
SEPTEMBER

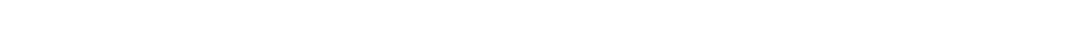

TELPERATURE $\left({ }^{\circ} \mathrm{C}\right)$ OF TATER, WATER YEAR OCTOBER 1968 TO SEPTEMBER 1969

DAY

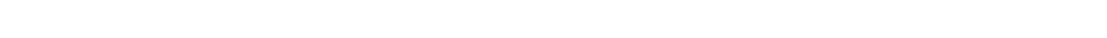

OCTOB

$\begin{array}{llllllllllllllllllllllllllllllllll}\text { MAXIMUM } & 9 & 9 & 9 & 9 & 9 & 9 & 9 & 8 & 8 & 8 & 8 & 8 & 8 & 9 & 8 & 7 & 8 & 8 & 7 & 7 & 7 & 7 & 7 & 7 & 7 & 7 & 7 & 7 & 7 & 6 & 6 & 8 \\ \text { MINIMUM } & 8 & 7 & 7 & 7 & 8 & 7 & 7 & 6 & 7 & 7 & 7 & 6 & 7 & 8 & 6 & 6 & 6 & 6 & 6 & 7 & 6 & 6 & 6 & 6 & 6 & 6 & 6 & 6 & 6 & 6 & 5 & 6\end{array}$

NOVEMGER

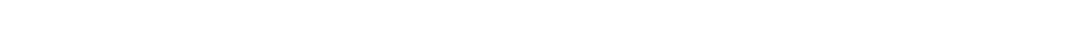

OECEMBE

MAXIMUM - - - - - - - - - - - - - -

MANUARY

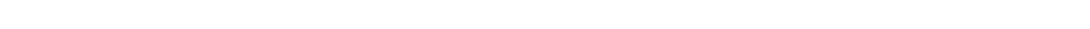

MINIMUM

FBRUARY

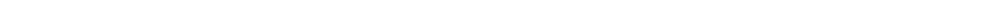

MINIMUM

MAXIMUM

MINIMUM

APRIL

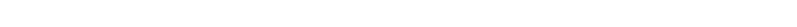

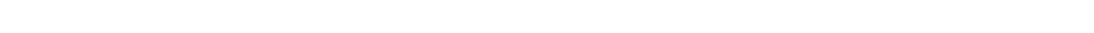

MAY

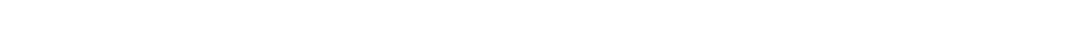

JUNE

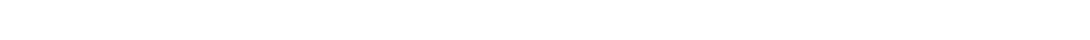

MAXIMUM

MINIMUM

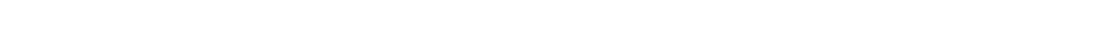
SEPTEMBER

MAXIMUM

SUSPENDED-SEDIMENT DISCHARge MEASUREMENTS, AUGUST 1968 IO SEPTEMBER 1969

\begin{tabular}{|c|c|c|c|c|c|c|}
\hline & DATE & IIME & $\begin{array}{l}\text { WATER } \\
\text { TEM- } \\
\text { PERA- } \\
\text { TURE } \\
\text { I CI }\end{array}$ & $\begin{array}{l}\text { DISCHARGE } \\
\text { (CFS) }\end{array}$ & $\begin{array}{l}\text { CONCEN- } \\
\text { YRATIION } \\
\text { (MG/L) }\end{array}$ & $\begin{array}{l}\text { SUSPENDED } \\
\text { SEOIMENT } \\
\text { DISCHARGE } \\
\text { (IONS/OAY) }\end{array}$ \\
\hline $\begin{array}{l}\text { AUG } \\
\text { AUG }\end{array}$ & $\begin{array}{r}2.1968 \\
27 . \ldots \ldots\end{array}$ & $\begin{array}{l}1050 \\
1615\end{array}$ & $\begin{array}{l}14 \\
15\end{array}$ & 10 & i & $\begin{array}{l}.03 \\
.02\end{array}$ \\
\hline $\begin{array}{l}O C T \\
O C T \\
F E B \\
M A R \\
\text { APR }\end{array}$ & $\begin{array}{r}1,1968 \\
29 . \ldots \ldots 9 \\
8,1969 \\
26 \ldots \ldots \ldots \\
22 \ldots \ldots \ldots\end{array}$ & $\begin{array}{l}1400 \\
1230 \\
1130 \\
1030 \\
1600\end{array}$ & $\begin{array}{l}8 \\
6 \\
0 \\
2 \\
4\end{array}$ & $\begin{array}{l}5.4 \\
6.5 \\
23 \\
30 \\
169\end{array}$ & $\begin{array}{r}2 \\
1 \\
7 \\
14 \\
18\end{array}$ & $\begin{array}{l}.03 \\
.02 \\
.43 \\
1.1 \\
8.2\end{array}$ \\
\hline $\begin{array}{l}\text { MAY } \\
\text { JUN } \\
\text { JUL } \\
\text { AUG }\end{array}$ & $\begin{array}{l}29 \ldots \ldots \ldots \\
18 \ldots \ldots \ldots \\
30 \ldots \ldots \ldots \\
25 \ldots \ldots\end{array}$ & $\begin{array}{l}1615 \\
0900 \\
0900 \\
1045\end{array}$ & $\begin{array}{r}9 \\
5 \\
10 \\
13\end{array}$ & $\begin{array}{r}528 \\
282 \\
155 \\
39\end{array}$ & $\begin{array}{r}88 \\
8 \\
4 \\
4\end{array}$ & $\begin{array}{c}125 \\
6.1 \\
1.7 \\
.42\end{array}$ \\
\hline
\end{tabular}


11208630 ATWELL CREEK ABOVE MINERAL KING HIGHWAY, NEAR HAMUOND, CALIF,

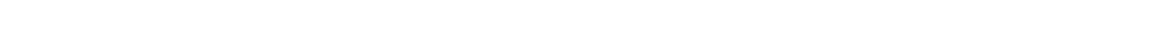
west of Atwe 11 M111s Ranger Station and $10.4 \mathrm{miles}$ east of Hamnond.

DRAI NAGE AREA, $-0.66 \mathrm{sq} \mathrm{m} 1$.

PERIOD OF RECORD.--Chemical analyses: July 1968 to September 1969.

Sediment records: August 1967 to September 1969 (part1al records).

CHEMICAL ANALYSES, IN MILLIGRAMS PER LITER, JULY TO SEPTEMBER 1968

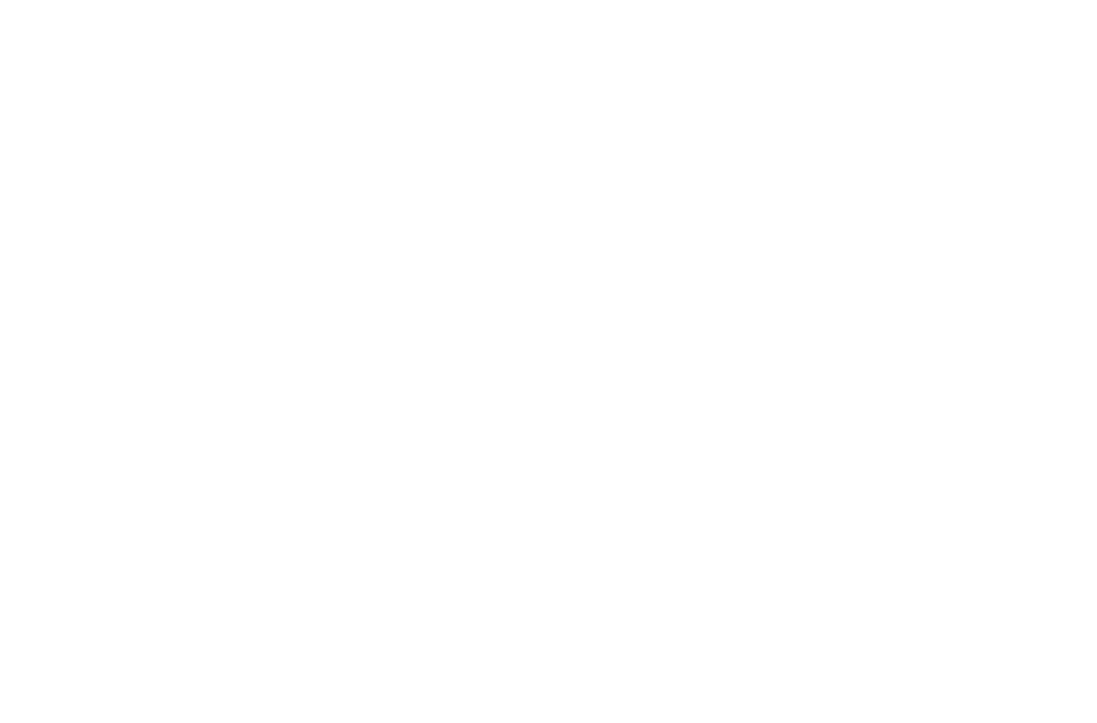


11208630 ATWELL CREEK ABOVE MINERAL KING HIGHWAY, NEAR HAMMOND, CALIF.--Conti nued CHEMICAL ANALYSES, WATER YEAR OCTOBER 1968 TO SEPTEMBER 1969

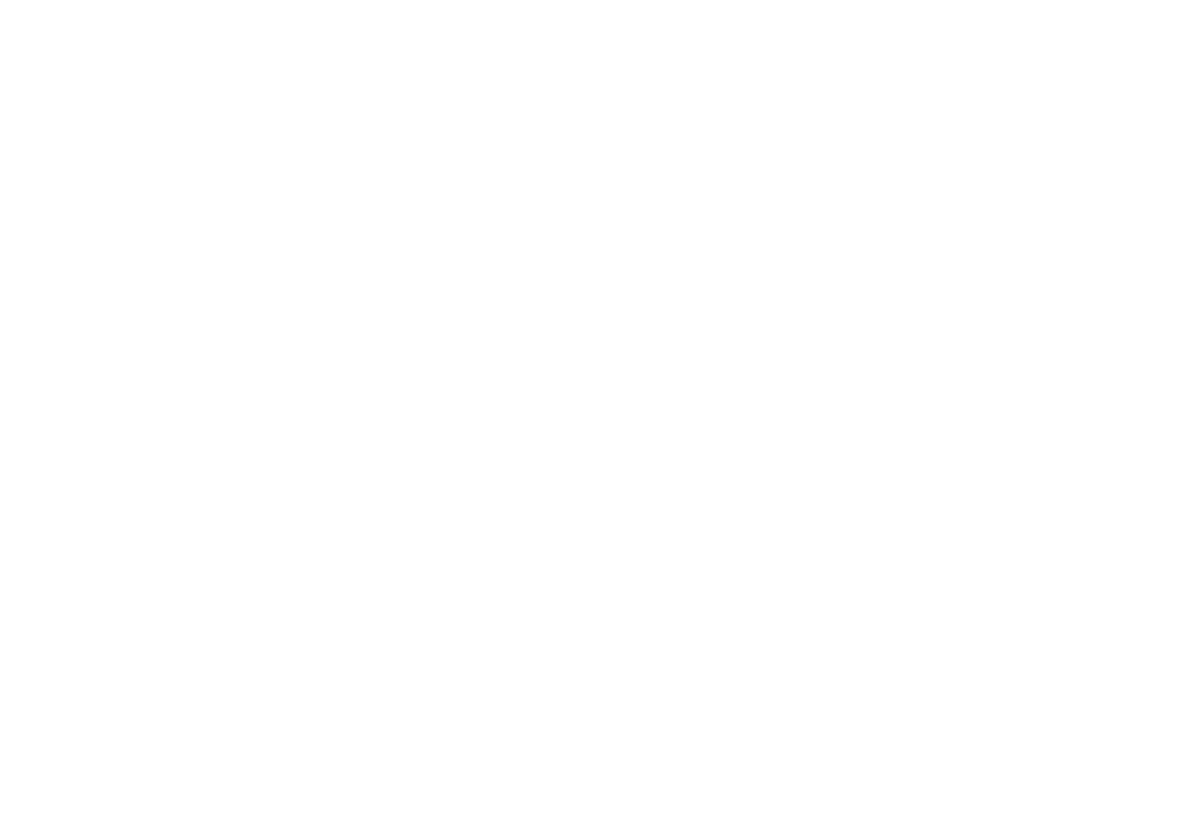

SUSPENDED-SEDIMENT DISCHARGE MEASUREMENTS, AUGUST 1968 TO SEPTEMBER 1969

\begin{tabular}{|c|c|c|c|c|c|c|}
\hline & DUTE & IIME & $\begin{array}{l}\text { WATER } \\
\text { TEM- } \\
\text { PERA- } \\
\text { TURE } \\
\text { I CI }\end{array}$ & $\begin{array}{l}\text { DISCMARGE } \\
\text { (CFS) }\end{array}$ & $\begin{array}{l}\text { CONCEN- } \\
\text { TRAIION } \\
\text { (MG/L) }\end{array}$ & $\begin{array}{l}\text { SUSPENDED } \\
\text { SEOIMENT } \\
\text { DISCHARGE } \\
\text { I TDNS/DAY) }\end{array}$ \\
\hline $\begin{array}{l}\text { AUG } \\
\text { AUG } \\
\text { SEP }\end{array}$ & $\begin{array}{r}2,1968 \\
28 . \ldots \ldots \\
30 \ldots \ldots\end{array}$ & $\begin{array}{l}1140 \\
0800 \\
1500\end{array}$ & $\begin{array}{r}11 \\
9 \\
9\end{array}$ & $\begin{array}{l}.10 \\
.08 \\
.04\end{array}$ & $\begin{array}{l}1 \\
1 \\
1\end{array}$ & $\begin{array}{l}0 \\
0 \\
0\end{array}$ \\
\hline $\begin{array}{l}\text { MAY } \\
\text { JUN } \\
\text { JUL } \\
\text { AUG }\end{array}$ & $\begin{array}{l}5.1969 \\
19 \ldots \ldots \\
29 \ldots \ldots \\
26 \ldots \ldots\end{array}$ & $\begin{array}{l}1045 \\
1000 \\
1740 \\
0750\end{array}$ & $\begin{array}{r}4 \\
12 \\
11\end{array}$ & $\begin{array}{l}3.4 \\
5.6 \\
1.4 \\
.67\end{array}$ & $\begin{array}{l}3 \\
6 \\
1 \\
2\end{array}$ & $\begin{array}{l}.03 \\
.09 \\
0\end{array}$ \\
\hline
\end{tabular}


11208650 REDWOOD CREEK ABOVE MINERAL KING HIGHWAY, NEAR HAMMOND, CALIF.

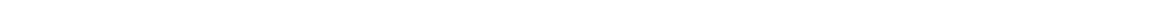
upstream from Mineral King Road and 8.9 miles east of Hammond.

DRAI NAGE AREA. $-1.38 \mathrm{sq} \mathrm{m} 1$.

PERIOD OF RECORD.--Chemical analyses: July 1968 to September 1969.

Sediment records: August 1967 to September 1969 (partial records).

CHEMICAL ANALYSES, IN MILLIGRAMS PER LITER, JULY TO SEPTEMBER 1968

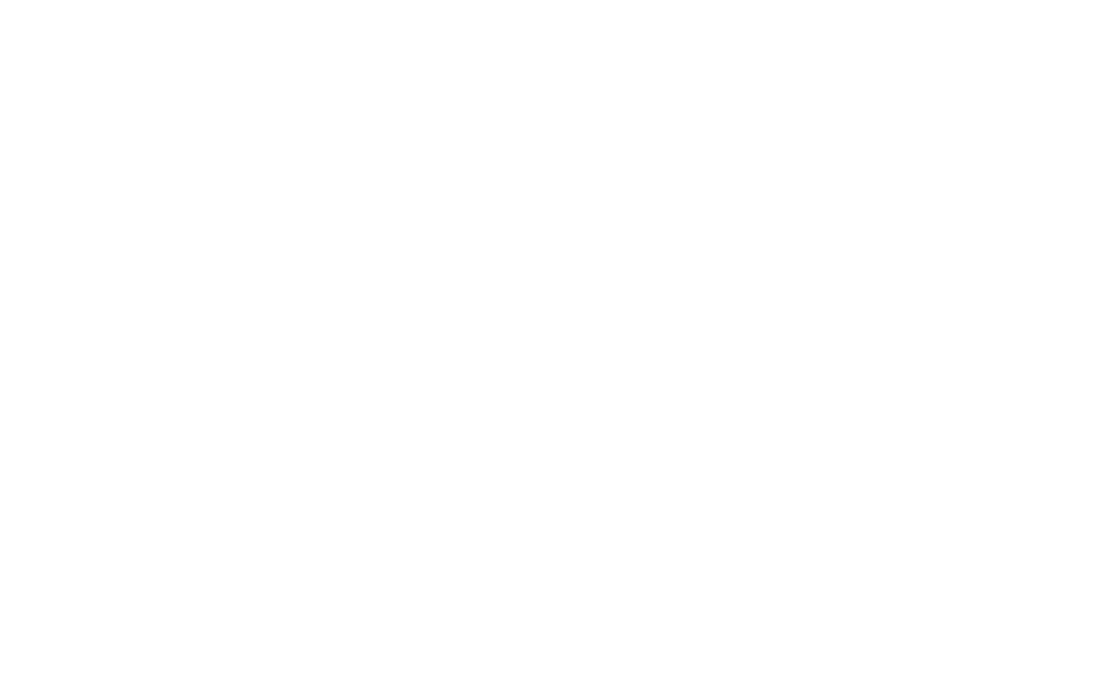


11208650 REDWOOD CREEK ABOVE MINERAL KING HIGHWAY, NEAR HAMOND, CALIF.--Continued CHEMICAL ANALYSES, WATER YEAR OCTOBER 1968 TO SEPTEMBER 1969

\begin{tabular}{|c|c|c|c|c|c|c|c|c|c|c|c|c|}
\hline DAIE & TIME & $\begin{array}{l}\text { DIS- } \\
\text { CHARGE } \\
\text { I CFSI }\end{array}$ & $\begin{array}{l}\text { TEMPER- } \\
\text { ATURE } \\
\text { (DEG C) }\end{array}$ & $\begin{array}{c}\text { AIR } \\
\text { TEMPER- } \\
\text { ATURE } \\
\text { (OEG C) }\end{array}$ & $\begin{array}{l}\text { SILICA } \\
\text { (SIOZ) } \\
\text { (HGIL) }\end{array}$ & $\begin{array}{l}\text { OIS- } \\
\text { SOLVEO } \\
\text { IRON } \\
\text { (FE) } \\
\text { (UG/L) }\end{array}$ & $\begin{array}{l}\text { CAL- } \\
\text { CIUM } \\
\text { ICAI } \\
\text { (MG/L) }\end{array}$ & $\begin{array}{c}\text { MAG- } \\
\text { NE- } \\
\text { SIUM } \\
\text { (MG) } \\
(M G / L)\end{array}$ & $\begin{array}{l}\text { SODIUM } \\
\text { (NA) } \\
\text { (HGAL) }\end{array}$ & $\begin{array}{l}\text { PO- } \\
\text { TAS- } \\
\text { SIUH } \\
\text { (K) } \\
\text { (MG/L) }\end{array}$ & $\begin{array}{l}\text { B ICAR- } \\
\text { BONATE } \\
\text { (KCOZ) } \\
\text { (MG/L) }\end{array}$ & $\begin{array}{l}\text { CAR- } \\
\text { BONAT } \\
\text { (CO3) } \\
\text { (MG/L }\end{array}$ \\
\hline \multicolumn{13}{|l|}{ maY } \\
\hline JUNE & 1220 & 10 & 6 & B & 13 & 20 & 2.7 & .4 & 2.4 & .8 & 14 & 0 \\
\hline $\begin{array}{l}19 . . \\
\text { JULY }\end{array}$ & 1100 & 6.0 & 10 & 16 & 17 & 30 & 3.1 & .5 & 2.6 & .7 & 18 & 0 \\
\hline $\begin{array}{l}\text { 30... } \\
\text { AUG. }\end{array}$ & 1100 & 1.5 & 15 & 19 & 20 & 30 & 4.3 & .7 & 3.0 & 1.1 & 24 & 0 \\
\hline $26 \ldots$ & 0845 & .91 & 11 & 19 & 22 & 10 & 5.2 & .8 & 3.6 & 1.0 & 27 & 0 \\
\hline
\end{tabular}

\begin{tabular}{|c|c|c|c|c|c|c|c|c|c|c|c|}
\hline DATE & $\begin{array}{l}\text { SULFATE } \\
\text { (SOG) } \\
\text { (MG/L) }\end{array}$ & $\begin{array}{l}\text { CHLO- } \\
\text { RIDE } \\
\text { (CL) } \\
\text { (MG/L) }\end{array}$ & $\begin{array}{l}\text { FLUO- } \\
\text { RIDE } \\
\text { (F) } \\
\text { (MG/L) }\end{array}$ & $\begin{array}{l}\text { Ni YRATE } \\
\text { (NO3) } \\
\text { (MG/L) }\end{array}$ & $\begin{array}{l}\text { BORDN } \\
\text { (B) } \\
\text { (UG/L) }\end{array}$ & $\begin{array}{l}\text { DIS- } \\
\text { SOLVED } \\
\text { SOLIDS } \\
\text { ISUM OF } \\
\text { CONSTI- } \\
\text { TUENTS' } \\
\text { (MG/L) }\end{array}$ & $\begin{array}{l}\text { HARD- } \\
\text { NESS } \\
\text { (CA, MG) } \\
\text { (MG/L) }\end{array}$ & $\begin{array}{l}\text { NON- } \\
\text { CAR- } \\
\text { BONAIE } \\
\text { HARD- } \\
\text { NESS } \\
\text { (MG/L) }\end{array}$ & $\begin{array}{c}\text { PH } \\
\text { (UNIIS) }\end{array}$ & $\begin{array}{l}\text { DIS- } \\
\text { SOLVEO } \\
\text { SOLIDS } \\
\text { ITQNS } \\
\text { PER } \\
\text { AC-FTI }\end{array}$ & $\begin{array}{l}\text { PERCEN T } \\
\text { SODIUM }\end{array}$ \\
\hline \multirow{5}{*}{$\begin{array}{l}\text { MAY } \\
\text { O5... } \\
\text { JUNE } \\
29 . . . \\
\text { JULY } \\
30 . . . \\
\text { AUG.. } \\
26 . . .\end{array}$} & & & & & & & & & & & \\
\hline & 1.0 & .4 & .1 & .0 & 10 & 28 & 8 & 0 & 6.8 & .04 & 36 \\
\hline & 1.0 & .4 & .1 & .0 & 0 & 34 & 10 & 0 & 6.8 & .05 & 35 \\
\hline & .0 & .4 & .1 & .0 & 0 & 42 & 14 & 0 & 7.0 & .06 & 30 \\
\hline & 1.0 & .2 & .0 & .0 & 0 & 47 & 16 & 0 & 7.3 & .06 & 31 \\
\hline DATE & $\begin{array}{c}\text { SODIUA } \\
\text { AD- } \\
\text { SORP- } \\
\text { IION } \\
\text { RATIO }\end{array}$ & $\begin{array}{l}\text { ALKA- } \\
\text { LINITY } \\
\text { AS } \\
\text { CACD3 } \\
\text { (MG/L) }\end{array}$ & $\begin{array}{l}\text { DIS- } \\
\text { SOLVED } \\
\text { OXYGEN } \\
\text { IMG/LI }\end{array}$ & $\begin{array}{l}\text { OIO- } \\
\text { CHEM- } \\
\text { ICAL } \\
\text { OXYGEN } \\
\text { DEMAND } \\
\text { ING/L) }\end{array}$ & $\begin{array}{l}\text { AMMDNIA } \\
\text { (NHA) } \\
\text { (MG/L) }\end{array}$ & $\begin{array}{c}\text { ORGANIC } \\
\text { NIIRO- } \\
\text { GEN } \\
\text { (N) } \\
\text { (MG/L) }\end{array}$ & $\begin{array}{l}\text { TOTAL } \\
\text { NITRD- } \\
\text { GEN } \\
\text { IN) } \\
\text { (MG/L) }\end{array}$ & $\begin{array}{l}\text { ORTHO } \\
\text { PHOS- } \\
\text { PHATE } \\
\text { (PO4) } \\
\text { (MG/L) }\end{array}$ & $\begin{array}{l}\text { PHOS- } \\
\text { PHATE } \\
\text { (PO4) } \\
\text { (MG/L) }\end{array}$ & $\begin{array}{l}\text { COLI- } \\
\text { FORM } \\
\text { ICOL- } \\
\text { ONIES } \\
\text { PER } \\
100 \mathrm{ML}\end{array}$ & $\begin{array}{l}\text { TOYAL } \\
\text { ORGANIC } \\
\text { CARBON } \\
\text { (C) } \\
\text { (MG/L) }\end{array}$ \\
\hline $\begin{array}{l}\operatorname{mar} \\
05 . . .\end{array}$ & .4 & 11 & 11.2 & .0 & .09 & .38 & .45 & .02 & -- & 1 & -- \\
\hline $\begin{array}{l}\text { JUNE } \\
19 . . \\
\text { JULY }\end{array}$ & .4 & 15 & 11.3 & 2.3 & .05 & .16 & .20 & .03 & $.0 \mathrm{~B}$ & 69 & - \\
\hline $30 .$. & .4 & 20 & 9.2 & .9 & .04 & .00 & .03 & .00 & .07 & 104 & -- \\
\hline AUG... & .4 & 22 & 8.5 & 1.7 & .17 & .28 & .41 & .03 & .03 & 83 & 1.0 \\
\hline
\end{tabular}

SUSPENDED-SEDIMENT DISCHARGE MEASUREMENTS, AUGUST 1968 TO SEPTEMBER 1969

\begin{tabular}{|c|c|c|c|c|c|c|}
\hline & DAIE & TIME & $\begin{array}{l}\text { WATER } \\
\text { TEM- } \\
\text { PERA- } \\
\text { TURE } \\
\text { (C) }\end{array}$ & $\begin{array}{l}\text { DISCHARGE } \\
\text { (CFS) }\end{array}$ & $\begin{array}{l}\text { CONCEN- } \\
\text { TRAT (ON } \\
\text { (HG/L) }\end{array}$ & $\begin{array}{l}\text { SUSPENDED } \\
\text { SED (MENT } \\
\text { DISCHARGE } \\
\text { ITDNS/OAY) }\end{array}$ \\
\hline $\begin{array}{l}\text { AUG } \\
\text { AUG } \\
\text { SEP }\end{array}$ & $\begin{array}{r}2,1968 \\
28 \ldots \ldots \\
30 \ldots \ldots\end{array}$ & $\begin{array}{l}1215 \\
1300 \\
1400\end{array}$ & $\begin{array}{r}15 \\
9 \\
11\end{array}$ & $\begin{array}{l}.30 \\
.12 \\
.09\end{array}$ & $\begin{array}{l}2 \\
1 \\
1\end{array}$ & $\begin{array}{l}0 \\
0 \\
0\end{array}$ \\
\hline $\begin{array}{l}\text { MAY } \\
\text { JUN } \\
\text { JUL } \\
\text { AUG }\end{array}$ & $\begin{array}{r}5,1969 \\
19 \ldots \ldots \\
30 \ldots \ldots \\
26 \ldots \ldots\end{array}$ & $\begin{array}{l}1220 \\
1100 \\
1100 \\
0845\end{array}$ & $\begin{array}{r}10 \\
15 \\
11\end{array}$ & $\begin{array}{c}10 \\
6.0 \\
1.5 \\
.91\end{array}$ & $\begin{array}{l}5 \\
3 \\
2 \\
3\end{array}$ & $\begin{array}{l}.14 \\
.05 \\
.01 \\
.01\end{array}$ \\
\hline
\end{tabular}


11208680 SQUIRREL CREEK BELOW MINERAL KING HIGHWAY, NEAR HAMMOND, CALIF.

LOCATION, - Lat $36^{\circ} 26^{\prime} 38^{\prime \prime}$, long $118^{\circ} 46^{\prime} 00^{\prime \prime}$, in SEłSE sec. 13 , T. 17 S., R. 29 E., Tulare County, on right bank 300 ft upstream from old Mineral King Road, at Sequola National Park boundary, and 5.4 miles east of Hamond.

DRAINAGE AREA. $--5.80 \mathrm{sq} \mathrm{mt}$.

PERIOD OF RECORD. - Chemical analyses: July 1968 to September 1969.

Sediment records: August 1967 to September 1969 (partia1 records).

CHEMical analyses, IN Milligrams Per Liter, JULy to SEPtember 1968

\begin{tabular}{|c|c|c|c|c|c|c|c|c|c|c|c|}
\hline UATE & TINE & $\begin{array}{l}\text { OIS- } \\
\text { CHARGE } \\
\text { (CFS) }\end{array}$ & $\begin{array}{l}\text { TEMPER- } \\
\text { ATURE } \\
\text { (DEG [) }\end{array}$ & $\begin{array}{l}\text { SILICA } \\
\text { (SIOZ) }\end{array}$ & $\begin{array}{l}\text { DIS- } \\
\text { SOLVEO } \\
\text { IRUN } \\
\text { (FE) }\end{array}$ & $\begin{array}{l}\text { CAL- } \\
\text { CIUM } \\
\text { (CA) }\end{array}$ & $\begin{array}{l}\text { MAG- } \\
\text { NE- } \\
\text { SIUM } \\
\text { (MG) }\end{array}$ & $\begin{array}{l}\text { SOOIUM } \\
\text { (NA) }\end{array}$ & $\begin{array}{l}\text { PO- } \\
\text { TAS- } \\
\text { SIUM } \\
(\mathrm{K})\end{array}$ & $\begin{array}{l}8 \text { ICAR- } \\
\text { BONAIE } \\
\text { (HCD3) }\end{array}$ & $\begin{array}{l}\text { CAR- } \\
\text { BONAIF } \\
\text { (CO3) }\end{array}$ \\
\hline $\begin{array}{l}\text { JULY } \\
25 \ldots .\end{array}$ & -- & .12 & 19 & 31 & .08 & 8.5 & 1.7 & B. 7 & 2.0 & 52 & 0 \\
\hline $\begin{array}{l}\text { AUG. } \\
28 \ldots \\
\text { SEPT... }\end{array}$ & 1420 & .14 & 20 & 29 & .09 & 7.7 & 1.5 & 8.4 & 1.9 & 46 & 0 \\
\hline $30 .$. & 1205 & .07 & 14 & 13 & .06 & 9.2 & 1.9 & 10 & 2.1 & 62 & 0 \\
\hline DATE & $\begin{array}{l}\text { SULFATE } \\
\left(50_{4}\right)\end{array}$ & $\begin{array}{l}\text { CHL D- } \\
\text { RIDE } \\
(C L)\end{array}$ & $\begin{array}{l}\text { FLUO- } \\
\text { RIOE } \\
\text { (F) }\end{array}$ & $\begin{array}{l}\text { NITRATE } \\
\text { (NO3) }\end{array}$ & $\begin{array}{c}\text { BORON } \\
(B)\end{array}$ & $\begin{array}{l}\text { DIS- } \\
\text { SOL VEO } \\
\text { SOLIDS } \\
\text { (SUM DF } \\
\text { CONSTI- } \\
\text { TUENTS' }\end{array}$ & $\begin{array}{l}\text { HARO- } \\
\text { NESS } \\
\text { (CA,MG) }\end{array}$ & $\begin{array}{l}\text { NON- } \\
\text { CAR- } \\
\text { BONATE } \\
\text { HARD- } \\
\text { NESS }\end{array}$ & $\begin{array}{l}\text { SPEC I- } \\
\text { FIC } \\
\text { COND- } \\
\text { UCTANCE } \\
\text { (MICRO- } \\
\text { MHOS ) }\end{array}$ & PH & $\begin{array}{l}\text { DIS- } \\
\text { SHLVED } \\
\text { SDLIDS } \\
\text { ITUNS } \\
\text { PER } \\
\text { AC-FTI }\end{array}$ \\
\hline \multirow{8}{*}{$\begin{array}{l}\text { JULY } \\
25 \ldots . . \\
\text { AUG. } \\
28 \ldots \\
\text { SEPT. } \\
30 \ldots\end{array}$} & & & & & & & & & & & \\
\hline & 1.0 & 1.4 & .2 & 2.3 & .00 & 83 & 28 & 0 & 92 & 7.5 & .11 \\
\hline & 2.0 & 1.2 & .1 & 1.6 & .02 & 77 & 25 & 0 & $B 7$ & 7.3 & .10 \\
\hline & 1.0 & 1.8 & .2 & .8 & .00 & 71 & 31 & 0 & 105 & 7.4 & .10 \\
\hline & RATE & $\begin{array}{l}\text { PERCENT } \\
\text { SODIUM }\end{array}$ & $\begin{array}{l}\text { SODIUM } \\
\text { AD- } \\
\text { SORP- } \\
\text { TION } \\
\text { RATIO }\end{array}$ & $\begin{array}{l}\text { ALKA- } \\
\text { LINITY } \\
\text { AS } \\
C A C O 3\end{array}$ & $\begin{array}{l}\text { DIS- } \\
\text { SOLVED } \\
\text { OXYGEN }\end{array}$ & $\begin{array}{c}\text { AMMON LA } \\
\text { (NH4) }\end{array}$ & $\begin{array}{l}\text { ORGANIC } \\
\text { NITRO- } \\
\text { GEN } \\
\text { (N) }\end{array}$ & $\begin{array}{l}\text { ORTHO } \\
\text { PHOS- } \\
\text { PHATE } \\
\text { (PO4) }\end{array}$ & $\begin{array}{l}\text { PHOS- } \\
\text { PHATE } \\
\text { (P04) }\end{array}$ & $\begin{array}{l}\text { COLI- } \\
\text { FORM } \\
\text { (COL- } \\
\text { ONIES } \\
\text { PER } \\
100 \text { ML) }\end{array}$ & \\
\hline & $\begin{array}{l}\text { JULY } \\
25 . . . \\
\text { AUG. }\end{array}$ & 38 & .7 & 43 & 8.0 & .10 & .05 & .05 & .16 & - & \\
\hline & $\begin{array}{l}28, \ldots \\
\text { SEPT. }\end{array}$ & 40 & .7 & 38 & B. 4 & .00 & 2.4 & .11 & .13 & -. & \\
\hline & $30 \ldots$ & 40 & .8 & 51 & 9.3 & .19 & $.5 B$ & .14 & .15 & 3200 & \\
\hline
\end{tabular}


11208680 SQUIRREL CREEK BELOW MINERAL KING HIGHWAY, NEAR HAMMOND, CALIF. - - ContI nued CHEMICAL ANALYSES, WATER YEAR OCTOBER 1968 TO SEPTEMBER 1969

\begin{tabular}{|c|c|c|c|c|c|c|c|c|c|c|c|c|}
\hline DATE & VIME & $\begin{array}{l}\text { DIS- } \\
\text { CHARGE } \\
\text { (CFS) }\end{array}$ & $\begin{array}{l}\text { TEMPER- } \\
\text { ATURE } \\
\text { IDEG C) }\end{array}$ & $\begin{array}{c}\text { AIR } \\
\text { TEMPER- } \\
\text { ATURE } \\
\text { (DEG C) }\end{array}$ & $\begin{array}{l}\text { SILICA } \\
\text { (SIOZI) } \\
\text { (MGIL) }\end{array}$ & $\begin{array}{l}\text { DIS- } \\
\text { SOLVEO } \\
\text { IRUN } \\
\text { IFE I } \\
\text { (UG/L) }\end{array}$ & $\begin{array}{l}\text { CAL- } \\
\text { CIUM } \\
\text { (CA) } \\
(M G / L)\end{array}$ & $\begin{array}{l}M A G- \\
N E- \\
S I U M \\
(M G) \\
(M G / L)\end{array}$ & $\begin{array}{l}\text { SODIUM } \\
\text { (NA) } \\
\text { (MG/L) }\end{array}$ & $\begin{array}{l}\text { PO- } \\
\text { TAS- } \\
\text { SIUM } \\
\text { (KI) } \\
\text { (MG/L) }\end{array}$ & $\begin{array}{l}\text { BICAR- } \\
\text { BONATE } \\
\text { (HCO3) } \\
\text { (MG/L) }\end{array}$ & $\begin{array}{l}\text { CAR- } \\
\text { BUNATE } \\
\text { (CO3) } \\
\text { (MG/L) }\end{array}$ \\
\hline \\
\hline JUNE & 1330 & 17 & $1 \mathrm{i}$ & 10 & 20 & 20 & 4.2 & * & 3.4 & 1.3 & 24 & 0 \\
\hline JuLY. & 1230 & 13 & 16 & 28 & 24 & 40 & 4.7 & .9 & 4.1 & 1.3 & 30 & 0 \\
\hline $\begin{array}{l}30 . . . \\
\text { QuG. }\end{array}$ & $1<40$ & 3.6 & 20 & 29 & 27 & 100 & 5.7 & 1.2 & 5.0 & 1.9 & 34 & 0 \\
\hline $26 \ldots$ & 0950 & 1.4 & 15 & 19 & 28 & 60 & 6.0 & 1.2 & 5.5 & 1.7 & 37 & 0 \\
\hline & & $\mathrm{CHLU}-$ & FLUO- & & & $\begin{array}{l}\text { DIS- } \\
\text { SULVED } \\
\text { SOLIDS } \\
\text { ISUM OF }\end{array}$ & HARD- & $\begin{array}{l}\text { NON- } \\
\text { CAR- } \\
\text { BONAIE }\end{array}$ & $\begin{array}{l}\text { SPECI- } \\
\text { FIC } \\
\text { COND- }\end{array}$ & & $\begin{array}{l}\text { OIS- } \\
\text { SOLVEO } \\
\text { SOLIDS }\end{array}$ & \\
\hline DATE & $\begin{array}{l}\text { SULFATE } \\
\text { (SOG) } \\
\text { (MG/L) }\end{array}$ & $\begin{array}{l}\text { RIOE } \\
\text { ICLI } \\
\text { (AG/L) }\end{array}$ & $\begin{array}{l}\text { RIDE } \\
\text { (F) } \\
\text { (MG/L) }\end{array}$ & $\begin{array}{c}\text { NITRATE } \\
\text { (NO3) } \\
(M G / L)\end{array}$ & $\begin{array}{l}\text { BURON } \\
\text { (B) } \\
\text { (UG/L) }\end{array}$ & $\begin{array}{l}\text { CONSTI- } \\
\text { TUENTS) } \\
\text { (MGIL) }\end{array}$ & $\begin{array}{c}\text { NESS } \\
(C A, M G) \\
(M G / L)\end{array}$ & $\begin{array}{l}\text { HARO- } \\
\text { NESS } \\
\text { (MG/L) }\end{array}$ & $\begin{array}{l}\text { UCIANCE } \\
\text { IMICRO- } \\
\text { MHOSI }\end{array}$ & $\begin{array}{c}\text { PH } \\
\text { (UNITS) }\end{array}$ & $\begin{array}{l}\text { TIONS } \\
\text { PER } \\
A C-F T \text { T }\end{array}$ & $\begin{array}{l}\text { PERCENI } \\
\text { SOUIUM }\end{array}$ \\
\hline \multicolumn{13}{|l|}{ MAY } \\
\hline JUNE & I . D & 1.0 & .0 & .1 & 30 & 44 & 14 & 0 & 48 & 6.8 & .06 & 35 \\
\hline JULY & 1.0 & .8 & .2 & .0 & 100 & 52 & 15 & 0 & 52 & 6.8 & .07 & 34 \\
\hline \multirow{8}{*}{$\begin{array}{l}30 . . . \\
\text { AUG. } \\
26 \ldots . .\end{array}$} & 1.0 & 1.2 & .0 & .0 & 0 & 60 & 19 & 0 & 65 & 6.5 & .08 & 34 \\
\hline & .0 & .8 & .1 & .1 & 20 & 61 & 20 & 0 & 68 & 7.3 & .08 & 35 \\
\hline & DATE & $\begin{array}{l}\text { SODI UM } \\
\text { AD- } \\
\text { SORP- } \\
\text { TION } \\
\text { RATIO }\end{array}$ & $\begin{array}{l}\text { ALKA- } \\
\text { LINITY } \\
\text { AS } \\
\text { CACO3 } \\
\text { (MG/L) }\end{array}$ & $\begin{array}{l}\text { DIS- } \\
\text { SOLVED } \\
\text { OXYGEN } \\
\text { (MGIL) }\end{array}$ & $\begin{array}{l}\text { BIO- } \\
\text { CHEM- } \\
\text { ICAL } \\
\text { OXYGEN } \\
\text { DEMAND } \\
\text { IMG/L) }\end{array}$ & $\begin{array}{l}\text { AMMON IA } \\
\text { (NH4) } \\
\text { (MG/L) }\end{array}$ & $\begin{array}{c}\text { ORGANIC } \\
\text { NIT RO- } \\
\text { GEN } \\
\text { (N) } \\
\text { (MG/C) }\end{array}$ & $\begin{array}{l}\text { IOTAL } \\
\text { NITRO- } \\
\text { GFN } \\
\text { INI } \\
\text { (MG/L) }\end{array}$ & $\begin{array}{l}\text { ORTHO } \\
\text { PHOS= } \\
\text { PHATE } \\
\text { IPO4I } \\
\text { (MG/L) }\end{array}$ & $\begin{array}{l}\text { PHOS- } \\
\text { PHATE } \\
\text { (PO4) } \\
\text { (MGIL) }\end{array}$ & $\begin{array}{c}\text { COLI- } \\
\text { FORN } \\
\text { ICOL- } \\
\text { ONIES } \\
\text { PER } \\
100 \mathrm{ML} \text { I }\end{array}$ & \\
\hline & MAY & & & & & & & & & & & \\
\hline & JUNE & .5 & 20 & 11.1 & 2.6 & .09 & .54 & .63 & .08 & - & 1 & \\
\hline & $\operatorname{JuL}_{\text {Jur }}^{19}$ & .5 & 25 & 10.1 & 1.9 & .13 & .17 & .27 & .07 & .12 & 26 & \\
\hline & $\begin{array}{l}30 . . . \\
\text { AUG. }\end{array}$ & .5 & 28 & 8.7 & 1.8 & .04 & .00 & .03 & .07 & .08 & $\cdots$ & \\
\hline & $26 \ldots$ & .5 & 30 & 8.7 & 1.7 & .03 & .27 & .31 & .06 & .10 & 75 & \\
\hline
\end{tabular}

SUSPENDED-SEDIMENT DISCHARGE MEASUREMENTS, AUGUST 1968 TO SEPTEMBER 1969

\begin{tabular}{|c|c|c|c|c|c|c|}
\hline & DATE & TIME & $\begin{array}{l}\text { WATER } \\
\text { TEM- } \\
\text { PERA- } \\
\text { TURE } \\
\text { I CI }\end{array}$ & $\begin{array}{l}\text { DI SCHARGE } \\
\text { (CFS) }\end{array}$ & $\begin{array}{l}\text { CONCEN- } \\
\text { TRATION } \\
\text { (MG/L) }\end{array}$ & $\begin{array}{l}\text { SUSPENOEO } \\
\text { SEDI MENT } \\
\text { OISCHARGE } \\
\text { (TONS/OAY) }\end{array}$ \\
\hline $\begin{array}{l}\text { AUG } \\
\text { AUG } \\
\text { SEP }\end{array}$ & $\begin{array}{r}2,1968 \\
28 . \ldots \ldots \\
30 \ldots \ldots\end{array}$ & $\begin{array}{l}1255 \\
1400 \\
1200\end{array}$ & $\begin{array}{l}23 \\
20 \\
14\end{array}$ & $\begin{array}{l}.10 \\
.14 \\
.07\end{array}$ & $\begin{array}{l}3 \\
8 \\
1\end{array}$ & $\begin{array}{l}0 \\
0 \\
0\end{array}$ \\
\hline $\begin{array}{l}\text { DEC } \\
\text { MAY } \\
\text { JUN } \\
\text { JUL } \\
\text { AUG }\end{array}$ & $\begin{array}{r}11,1968 \\
5,1969 \\
19 \ldots \ldots \ldots \\
30 \ldots \ldots \ldots \\
26, \ldots \ldots\end{array}$ & $\begin{array}{l}1220 \\
1330 \\
1230 \\
1240 \\
0950\end{array}$ & $\begin{array}{l}4 \\
11 \\
16 \\
20 \\
15\end{array}$ & $\begin{array}{l}1.4 \\
19 \\
13 \\
3.6 \\
1.4\end{array}$ & $\begin{array}{r}20 \\
16 \\
13 \\
4 \\
2\end{array}$ & $\begin{array}{l}.08 \\
.82 \\
.46 \\
.04 \\
.01\end{array}$ \\
\hline
\end{tabular}


11208715 CRUNIGEN CREEK BELOW MINERAL KING HIGHWAY, NEAR HAMONOND, CALIF.

LOCATION.--Lat $36^{\circ} 26^{\prime} 55^{\prime \prime}$, Iong $118^{\circ} 16^{\prime} 18^{\prime \prime}$, In SW upstream from old Minera1 K1ng Road and 5.0 m1les east of Hammond.

DRAI NAGE AREA. $--1.58 \mathrm{sq}$ m1.

PERIOD OF RECORD.--Chem1cal analyses: October 1968 to September 1969.

Sediment records: October 1968 to September 1969 (partial records):

CHEMICAL ANALYSES, WATER YEAR OCTOBER 1968 TO SEPIEMBER 1969

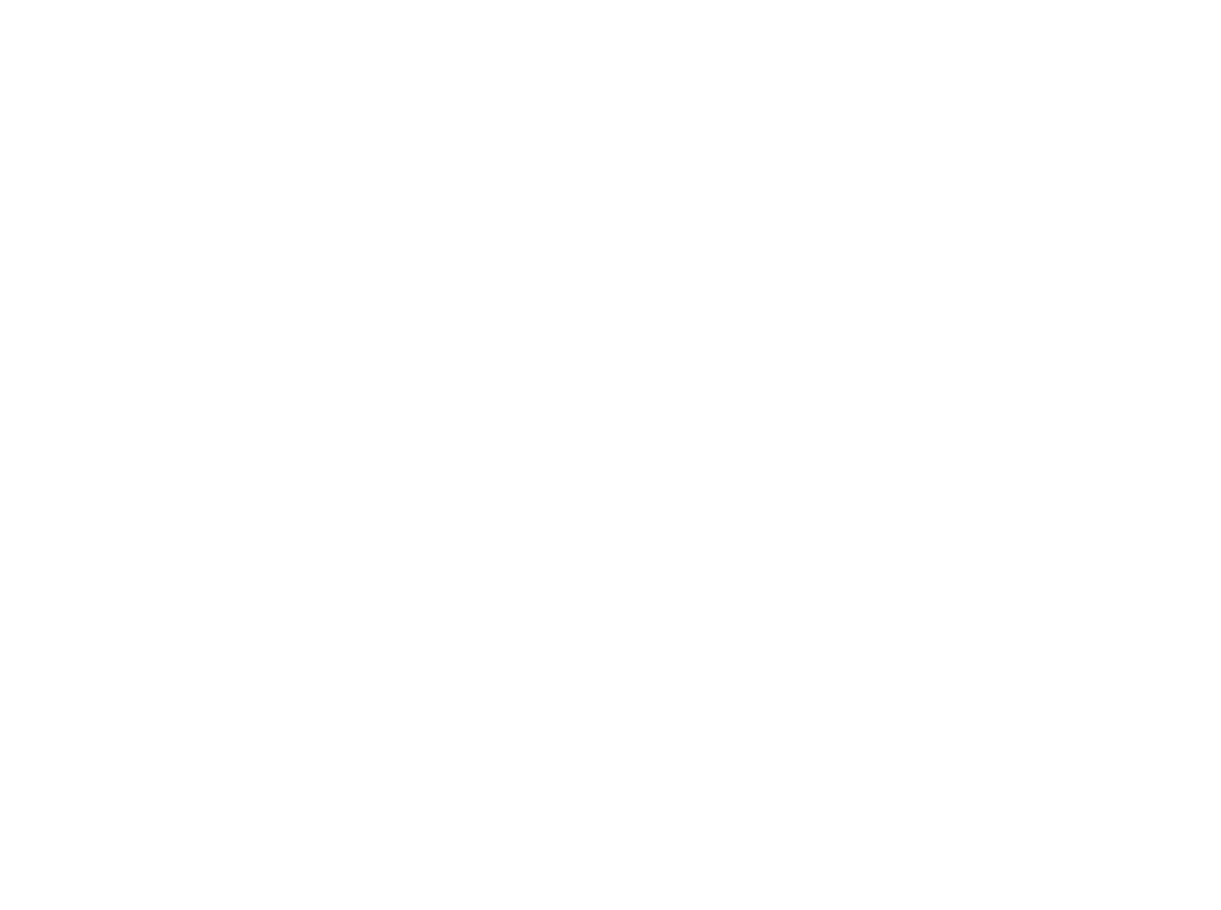

SUSPENDED-SEDIMENT DI SCHARGE MEASUREMENTS, WATER YEAR OCTOBER 1968 TO SEPTEMBER 1969

\begin{tabular}{|c|c|c|c|c|c|c|}
\hline & DATE & TIME & $\begin{array}{l}\text { WATER } \\
\text { TEM- } \\
\text { PERA- } \\
\text { TURE } \\
\text { ( C) }\end{array}$ & $\begin{array}{l}\text { DISCHARGE } \\
\text { (CFS) }\end{array}$ & $\begin{array}{l}\text { CONCEN- } \\
\text { IRAIION } \\
\text { (MG/L) }\end{array}$ & $\begin{array}{l}\text { SUSPENDED } \\
\text { SEDI MENT } \\
\text { DISCHARGE } \\
\text { (TONS/DAY) }\end{array}$ \\
\hline $\begin{array}{l}\text { DEC } \\
\text { MAY }\end{array}$ & $\begin{aligned} 11, & 1968 \\
5, & 1969\end{aligned}$ & $\begin{array}{l}1305 \\
1445\end{array}$ & $\begin{array}{r}8 \\
13\end{array}$ & 1.20 & $\begin{array}{r}26 \\
5\end{array}$ & $\begin{array}{l}.01 \\
.02\end{array}$ \\
\hline MAY & $23 \ldots \ldots$ & 1200 & 17 & .83 & 5 & .01 \\
\hline JUN & $19 \ldots \ldots$ & 1330 & 18 & .95 & 28 & .07 \\
\hline JUL & $30 \ldots \ldots$ & 1330 & 21 & .16 & 2 & 0 \\
\hline AUG & $26 \ldots \ldots$ & 1245 & 19 & .23 & 4 & 0 \\
\hline
\end{tabular}


11208730 EAST FORK KAWEAH RIVER NEAR THREE RIVERS, CALIF.

LOCATION.--Lat $36^{\circ} 27^{\prime} 05^{\prime \prime}$, long $118^{\circ} 47^{\prime} 15^{\prime \prime}$, in NW $\frac{1}{4}$ sec.14, T.17 S., R. 29 E., Tulare County, at gaging station on left bank just downstream from diversion dam, 6.6 miles east of Three Rivers.

DRAINAGE AREA. $--85.8 \mathrm{sq} \mathrm{m} 1$.

PERIOD OF RECORD. - Chemical analy ses: July 1968 to September 1969.

Water temperatures: June 1968 to September 1969.

Sediment records: August 1968 to September 1969 (partial records).

EXTREMES,-- June to September 1968:

Water temperatures: Maxinum, 22. $0^{\circ} \mathrm{C}$ Aug. 3, 4.

EXTREXES, --1968-69:

Water temperatures: Maximum, $18.0^{\circ} \mathrm{C}$ on several days during July and August; minimum, $1.0^{\circ} \mathrm{C}$ on several days during December and January.

Period of record:

Nater temperatures: Maximum, $22.0^{\circ} \mathrm{C}$ Aug. $3,4,1968$; minimum, $1.0^{\circ} \mathrm{C}$ on several days during December 1968 and January 1969.

REMARKS. --Records of water temperatures furnished by Southern California Edison Company. The reported discharge is the combined $f$ low of East Fork Kaweah River and East Fork Kaweah River No. 1 conduit near Three Rivers, Calif. CHEMiCAL ANALYSES, IN MILLIGRAMS PER LiteR, JULY TO SEPTEMBER 1968

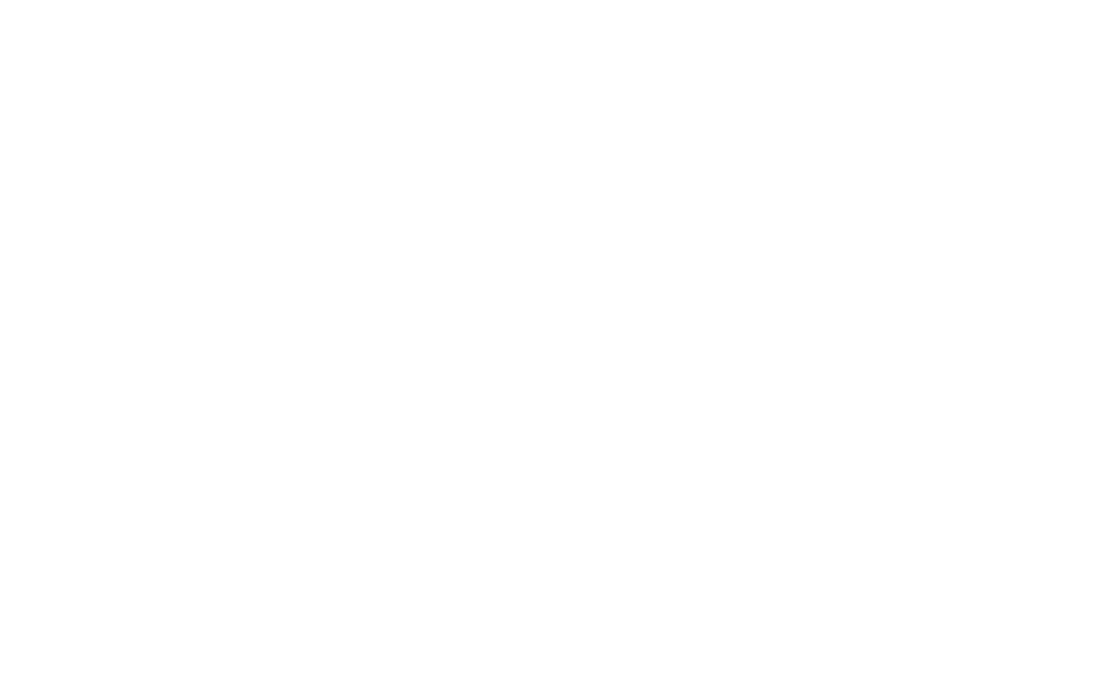




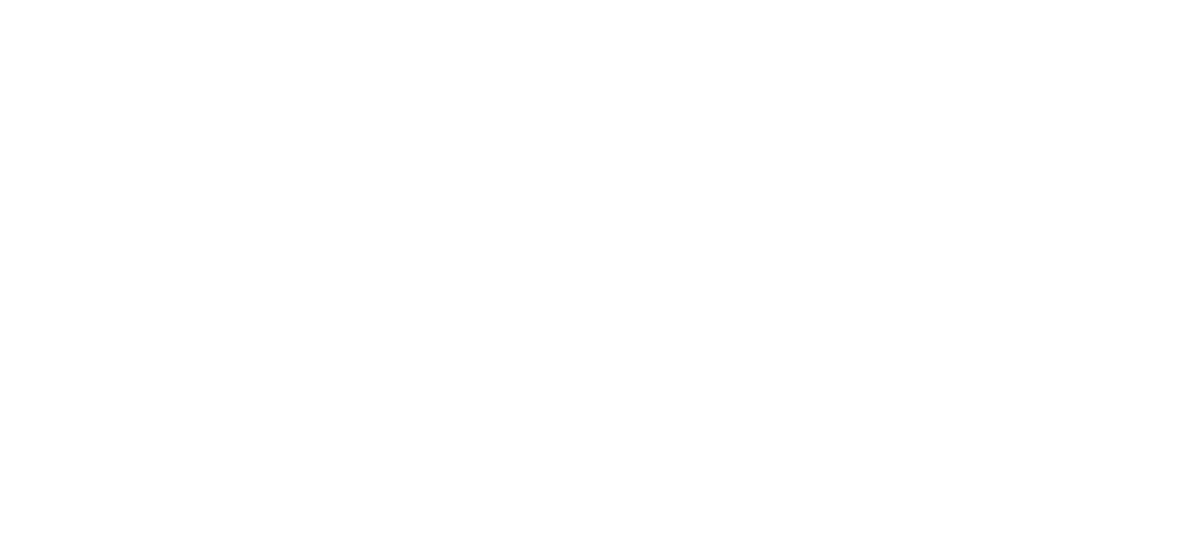

\begin{tabular}{|c|c|c|c|}
\hline OCT. & 3.0 & 1.5 & .1 \\
\hline $\begin{array}{l}\text { OEC. } \\
\text { IL... } \\
\text { JAN. }\end{array}$ & 3.0 & 1.2 & .3 \\
\hline $\begin{array}{l}14 \ldots . . \\
\text { MAK. }\end{array}$ & 3.0 & .6 & .2 \\
\hline MAY $20 .$. & 1.0 & .6 & .2 \\
\hline $\begin{array}{c}05 . . . \\
24 \ldots \\
\text { JUNE }\end{array}$ & $\begin{array}{l}3.0 \\
2.0\end{array}$ & $\begin{array}{r}.4 \\
.3\end{array}$ & $\begin{array}{l}.0 \\
.0\end{array}$ \\
\hline${ }_{\text {JULY }}^{19 . . .}$ & 2.0 & .5 & .1 \\
\hline $\begin{array}{l}30 . . . \\
\text { AUG. }\end{array}$ & 1.0 & .4 & .0 \\
\hline $26 \ldots$ & 3.0 & .4 & .0 \\
\hline
\end{tabular}

$\begin{array}{lrll}.3 & 0 & 69 & 40 \\ .6 & 0 & 58 & 32 \\ .7 & 30 & 46 & 20 \\ .3 & 30 & 56 & 20 \\ .0 & 20 & 41 & 20 \\ .2 & 40 & 25 & 13 \\ .1 & 20 & 27 & 12 \\ .0 & 0 & 31 & 18 \\ .1 & 0 & 49 & 28\end{array}$

\begin{tabular}{|c|c|c|c|c|}
\hline 0 & & 102 & 7.7 & .09 \\
\hline 0 & & 87 & 6.9 & .08 \\
\hline 0 & & 58 & 7.3 & .06 \\
\hline 0 & & 64 & 7.3 & .08 \\
\hline $\begin{array}{l}0 \\
0\end{array}$ & & $\begin{array}{l}53 \\
33\end{array}$ & $\begin{array}{l}6.8 \\
6.6\end{array}$ & $\begin{array}{l}.06 \\
.03\end{array}$ \\
\hline 0 & & 35 & 6.8 & .04 \\
\hline 0 & & 46 & 6.5 & .04 \\
\hline 0 & & 13 & 7.4 & .07 \\
\hline & $\begin{array}{l}\text { OR THO } \\
\text { PHOS- } \\
\text { PHATE } \\
\text { (PO4) } \\
\text { (MG/L) }\end{array}$ & $\begin{array}{l}\text { PHCS - } \\
\text { PHATE } \\
\text { PPC4I } \\
\text { IMCILI }\end{array}$ & $\begin{array}{c}\text { COLI- } \\
\text { FCAN } \\
\text { ICCL- } \\
\text { CAIES } \\
\text { PER } \\
\text { ICO MLI }\end{array}$ & $\begin{array}{l}\text { ICTAL } \\
\text { ORGANIC } \\
\text { CARBCN } \\
\text { (C) } \\
\text { (MG/L) }\end{array}$ \\
\hline
\end{tabular}

oc $T$.

\begin{tabular}{|c|c|c|}
\hline $31 . .$. & 20 & .3 \\
\hline $\begin{array}{c}\text { CEC. } \\
11 \ldots\end{array}$ & 22 & .3 \\
\hline $\begin{array}{l}\text { JAN. } \\
14 \ldots . . \\
\text { MAR. }\end{array}$ & 26 & .3 \\
\hline $2 C \ldots$ & 32 & .5 \\
\hline $\begin{array}{l}\text { MAY } \\
05 . . . \\
29 . .\end{array}$ & $\begin{array}{l}21 \\
17\end{array}$ & .3 \\
\hline $\begin{array}{l}\text { JUAE } \\
19 . . .\end{array}$ & 18 & .2 \\
\hline JULY & & \\
\hline $\begin{array}{l}30 . . . \\
\text { AUG. }\end{array}$ & 12 & .1 \\
\hline $26 \ldots$ & 16 & .2 \\
\hline
\end{tabular}

9.0
12.6
12.2
13.1
11.7
12.3
--
10.2
8.9

$\begin{array}{ll}-- & - \\ .05 & .1 \\ .01 & .30 \\ .32 & - \\ .23 & .3 \\ .00 & .24 \\ .03 & .11 \\ .04 & .0 \\ .04 & .1\end{array}$

$\begin{array}{rr}-- & . \\ .26 & .02 \\ .47 & .07 \\ -- & .1 \\ .56 & .01 \\ .29 & .03 \\ .15 & .04 \\ .03 & .00 \\ .20 & .03\end{array}$

$\begin{array}{ccc}-- & 268 & -- \\ .09 & -- & - \\ .19 & 14 & -- \\ .21 & -- & -- \\ .- & 1 & -- \\ .07 & 14 & -- \\ .03 & 20 & -- \\ .04 & 18 & .0\end{array}$


11208730 EAST FORK KAWEAH RIVER NEAR THREE RIVERS, CALIF.--Cont inued

TEMPERATURE $\left({ }^{\circ} \mathrm{C}\right)$ OF MATER, JUNE TO SEPTEMBER 1968

DAY

MONTH $\quad 1 \quad 2 \quad 3 \quad 4 \quad 5 \quad 6 \quad 7 \quad 8 \quad 9 \quad 1011 \quad 12 \quad 1314 \quad 15 \quad 16 \quad 17 \quad 18 \quad 1920 \quad 21 \quad 22 \quad 23 \quad 24 \quad 25 \quad 26 \quad 27 \quad 28 \quad 2930 \quad 31 \quad$ AGE

JUNE

MAXIMUM -JULY

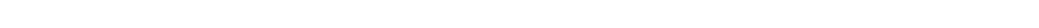

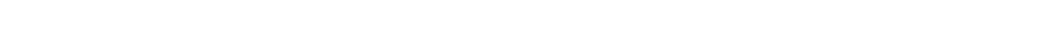
AUGUST

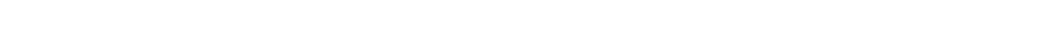
MINIMUM

$\begin{array}{llllllllllllllllllllllllllllllllll}\text { MAXIMUM } & 21 & 21 & 21 & 20 & 20 & 20 & 20 & 20 & 20 & 19 & 19 & 19 & 19 & 18 & 18 & 18 & 18 & 18 & 18 & 17 & 17 & 15 & 14 & 14 & 14 & 15 & 16 & 16 & 16 & 16 & -- \\ \text { MINIMUM } & 20 & 20 & 19 & 19 & 19 & 19 & 19 & 19 & 19 & 19 & 19 & 18 & 18 & 18 & 18 & 18 & 18 & 17 & 17 & 17 & 15 & 14 & 13 & 13 & 14 & 14 & 15 & 16 & 16 & 15 & --\end{array}$

TEMPERATURE ( $\left.{ }^{\circ} \mathrm{C}\right)$ OF WATER, WATER YEAR OCTOBER 1968 TO SEPTEMBER 1969

OAY

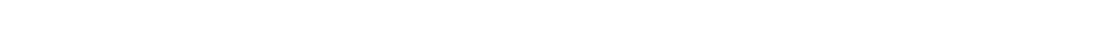

OCTORER

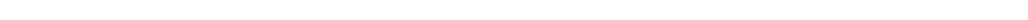

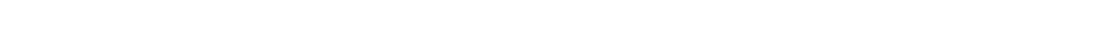

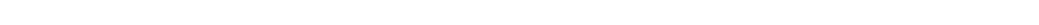

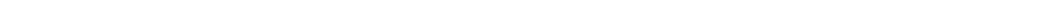
DECEMBER

$\begin{array}{llllllllllllllllllllllllllllllllll}\text { MAXIMUM } & 3 & 3 & 3 & 3 & 3 & 3 & 4 & 4 & 4 & 4 & 6 & 5 & 4 & 4 & 5 & 5 & 5 & 3 & 2 & 2 & 2 & 1 & 2 & 3 & 3 & 3 & 2 & 2 & 2 & 2 & 2 \\ \text { MINIMUM } & 3 & 3 & 2 & 2 & 3 & 3 & 3 & 4 & 4 & 4 & 4 & 4 & 3 & 2 & 4 & 5 & 3 & 2 & 2 & 2 & 1 & 1 & 1 & 2 & 3 & 2 & 1 & 1 & 2 & 2 & 2\end{array}$

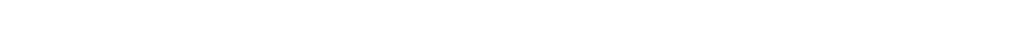

MINIMUM

FERTARY

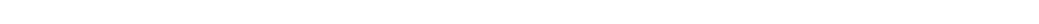

M.IVIMUM

ARCH $\begin{array}{llllllllllllllllllllllllllllllll}6 & 6 & 6 & 4 & 5 & 5 & 4 & 4 & 4 & 4 & 4 & 4 & 4 & 5 & 6 & 7 & 8 & 8 & 7 & 7 & 7 & 8 & 8 & 8 & 8 & 8 & 8 & 9 & 9 & 9 & 8 \\ 4 & 4 & 3 & 3 & 3 & 4 & 3 & 3 & 3 & 3 & 3 & 3 & 3 & 3 & 3 & 4 & 5 & 5 & 5 & 4 & 6 & 5 & 5 & 5 & 5 & 5 & 6 & 6 & 6 & 6 & 7\end{array}$

MINIMUN

RIL

YAXIMUM
MINIMUM MAY

MAXIMUM MINIMUSM

MAXIMUM MINIMUM JuLy

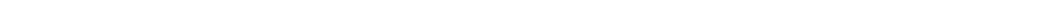

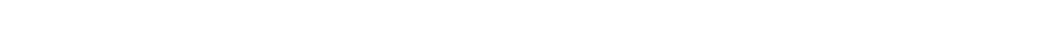

MAXIMUM $18 \quad 17 \quad 17 \quad 18 \quad 18 \quad 16 \quad 16 \quad 16 \quad 16 \quad 17 \quad 17 \quad 17 \quad 17 \quad 17 \quad 18 \quad 18 \quad 17 \quad 17 \quad 16 \quad 17 \quad 17 \quad 16 \quad 17 \quad 17 \quad 17 \quad 16 \quad 16 \quad 16 \quad 15 \quad 15 \quad 16$ MINIMUM $13 \quad 14 \quad 14 \quad 15 \quad 14 \quad 13 \quad 13 \quad 14 \quad 14 \quad 16 \quad 15 \quad 15 \quad 15$ 15 $16 \quad 16 \quad 16 \quad 14 \quad 14 \quad 14 \quad 14 \quad 14 \quad 14 \quad 15 \quad 14 \quad 14 \quad 14 \quad 13 \quad 13 \quad 13 \quad 13$

$\begin{array}{llllllllllllllllllllllllllllllllllll}\text { MAXIMUM } 17 & 17 & 17 & 17 & 16 & 16 & 17 & 17 & 17 & 17 & 17 & 16 & 16 & 15 & 15 & 14 & 14 & 14 & 14 & 14 & 13 & 13 & 14 & 14 & 14 & 14 & 14 & 14 & 15 & 15 & =\end{array}$

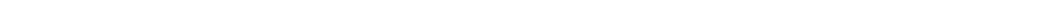
7 3 $\begin{array}{rlllllllllllllllllllllllllllllll}8 & 7 & 7 & 8 & 8 & 6 & 7 & 8 & 7 & 8 & 10 & 10 & 9 & 8 & 7 & 9 & 9 & 9 & 9 & 10 & 10 & 9 & 7 & 7 & 7 & 9 & 9 & 9 & 10 & 9 & \cdots \\ 6 & 6 & 4 & 5 & 5 & 4 & 3 & 4 & 6 & 6 & 6 & 7 & 7 & 6 & 4 & 5 & 6 & 7 & 6 & 7 & 7 & 7 & 6 & 6 & 4 & 5 & 6 & 6 & 6 & 6 & --\end{array}$

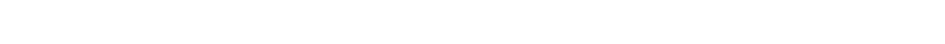
$\begin{array}{lllllllllllllllllllllllllllllll}12 & 12 & 12 & 12 & 12 & 11 & 9 & 8 & 8 & 9 & 10 & 13 & 13 & 11 & 11 & 11 & 12 & 13 & 13 & 12 & 13 & 13 & 12 & 12 & 12 & 12 & 12 & 12 & 13 & --\end{array}$ 


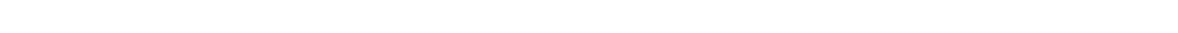
at gaging station on'right bank opposite schoolhouse in Three Rivers, 0.25 mile downstream from North Fork
Kaweah River.

DRAI NAGE AREA, -418 sq $\mathrm{m} 1$.

PERIOD OF RECORD.--Chemical analyses: November 1963 to July 1966.

Wa ter temperatures: October 1965 to December 1966, January 1968 to September 1969.

EXXTEMES. --1968-69:

Water temperatures: Maximum, $26.0^{\circ} \mathrm{C}$ Sept. 3,8 ; minimum, 3.0 $0^{\circ} \mathrm{C}$ Dec. 22.

Pertod of record:

Water temperatures: Maximum, $28.5^{\circ} \mathrm{C}$ Aug. 18,1966 ; minimum, $3.0^{\circ} \mathrm{C}$ Dec. $22,1968$.

REMARKS. --Recorder malfunctioned Oct. 1 to Nov, 6, Mar. 10-14, 20-28, Apr. 19 to June 1, July 4-31, Sept. 9-15;

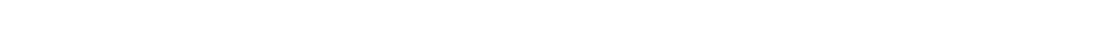

TEMPERATURE $\left({ }^{\circ} \mathrm{C}\right)$ OF WATER, WATER YEAR OCTOBER 1968 TO SEPTEMBER 1969

DAY

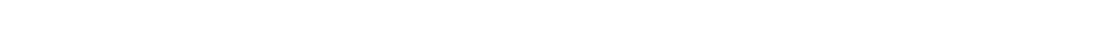

OC TURER

MAXIMUM -

MINIMUM

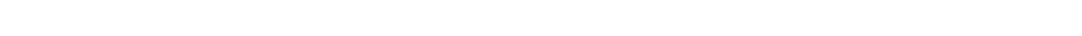

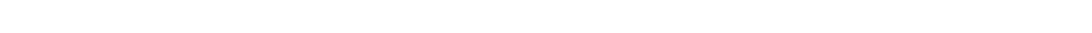

OECEMBER

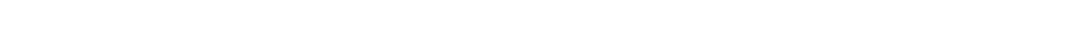

JANUARY

MAXIMUM

MAXIMUM

MINIMUM

MAXIMUM

MAXIMUM

MINIMU

MAXIMUM
MINIMUM

APQIL

MAXIMUM

MINIMUM MAY

MAXIMUM

MIN IMUM JUV

MAXI IMUM MIN

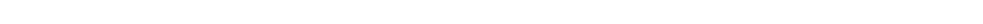

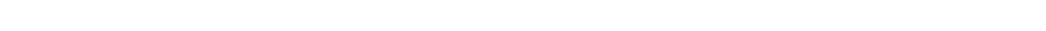
MINIMUM 18 18 19 18 18 18 18 20 8 
11210950 KANEAH RIVER BELOW TERMINUS DAM, CALIF.

LOCATION.-Lat $36^{\circ} 24^{\prime} 51^{\prime \prime}$, long $119^{\circ} 00^{\circ} 42^{\prime \prime}$, in SEł⿱SSE 0.6 mile downstream from Terminus Dam and 2.2 miles northeast of Lemoncove.

DRAINAGE AREA, -561 sq $\mathrm{m} 1$.

PERIOD OF RECORD.--Chemical analyses: December 1961 to September 1969.

REMARXS. -Records furnished by California Department of Water Resources and reviewed by U.S. Geological Survey, CHEMICAL ANAL,YSES, WATER YEAR BCTOBER 1,968 TO SEPTEMEER 1969

\begin{tabular}{|c|c|c|c|c|c|c|c|c|c|c|c|c|}
\hline DATE & TIME & $\begin{array}{l}\text { DIS- } \\
\text { CHARGE } \\
\text { (CFS) }\end{array}$ & $\begin{array}{l}\text { TEMPER- } \\
\text { ATURE } \\
\text { (DEG C) }\end{array}$ & $\begin{array}{l}\text { DIS- } \\
\text { SOLVED } \\
\text { OXYGEN } \\
\text { (MG/L) }\end{array}$ & $\begin{array}{l}\text { CAL- } \\
\text { CIUM } \\
\text { (CA) } \\
\text { (MG/L) }\end{array}$ & $\begin{array}{l}\text { MAG- } \\
\text { NE- } \\
\text { SIUM } \\
\text { (MG) } \\
\text { (MGLL) }\end{array}$ & $\begin{array}{l}\text { SOOIUM } \\
\text { (NA) } \\
\text { (MGIL) }\end{array}$ & $\begin{array}{l}\text { PO- } \\
\text { TAS- } \\
\text { SIUM } \\
\text { (K) } \\
\text { (MG/L) }\end{array}$ & $\begin{array}{l}\text { BICAR- } \\
\text { BONATE } \\
\text { (HCO3) } \\
\text { (MGIL) }\end{array}$ & $\begin{array}{l}\text { CAR- } \\
\text { BONATE } \\
\text { (CD3) } \\
\text { (MG/L) }\end{array}$ & $\begin{array}{l}\text { SULFATE } \\
\text { (SOA) } \\
\text { (MGRL) }\end{array}$ & $\begin{array}{l}\text { CHLO- } \\
\text { RIDE } \\
\text { (CLL) } \\
\text { (NG/L }\end{array}$ \\
\hline DEC... & 0840 & 48 & 16 & 8.6 & - & -- & 6.3 & -- & 68 & 0 & - & 5.0 \\
\hline MAR... & 1320 & 2110 & 7 & 11.7 & -- & - & 3.3 & -- & 35 & 0 & -- & 2.0 \\
\hline $\begin{array}{l}05 \ldots \\
\text { APR. }\end{array}$ & $0 B 10$ & 1780 & 7 & 11.2 & $\cdots$ & - & 4.2 & -- & 49 & 0 & - & 2.2 \\
\hline$\underset{M A Y}{D 7 . .}$ & 0925 & 1830 & 10 & 9.3 & - & -- & 4.4 & -- & 43 & 0 & -- & 1.8 \\
\hline $\begin{array}{l}\text { O5... } \\
\text { JUNE }\end{array}$ & 1025 & 2980 & 12 & 11.2 & 8.1 & 1.9 & 3.4 & 1.2 & 33 & 0 & 2.1 & 1.3 \\
\hline
\end{tabular}

\begin{tabular}{|c|c|c|c|c|c|c|c|c|c|c|c|}
\hline DATE & $\begin{array}{l}\text { NITRATE } \\
\text { (NOB) } \\
\text { (MG/L) }\end{array}$ & $\begin{array}{l}\text { BORON } \\
(B) \\
(U G / L)\end{array}$ & $\begin{array}{l}\text { DIS- } \\
\text { SOLVED } \\
\text { SOLIOS } \\
\text { (RESI- } \\
\text { OUE AI } \\
1 B O C \text { C) } \\
\text { (HELIL) }\end{array}$ & $\begin{array}{l}\text { DIS- } \\
\text { SDLVED } \\
\text { SOLIDS } \\
\text { (TONS } \\
\text { PER } \\
\text { AC-FT) }\end{array}$ & $\begin{array}{l}\text { HARO- } \\
\text { NESS } \\
\text { (CA,MG) } \\
\text { (NG/L) }\end{array}$ & $\begin{array}{l}\text { NON- } \\
\text { CAR- } \\
\text { BONATE } \\
\text { HARD- } \\
\text { NESS } \\
\text { (MG/L) }\end{array}$ & $\begin{array}{l}\text { PERCENT } \\
\text { SODIUM }\end{array}$ & $\begin{array}{l}\text { SODIUM } \\
\text { AD- } \\
\text { SORP- } \\
\text { TION } \\
\text { RATIO }\end{array}$ & $\begin{array}{l}\text { ALKA- } \\
\text { LINITY } \\
\text { AS } \\
\text { CACO3 } \\
\text { (MGIL) }\end{array}$ & $\begin{array}{c}P H \\
\text { (UNITS) }\end{array}$ & $\begin{array}{l}\text { SPECI } \\
\text { FIC } \\
\text { CONO- } \\
\text { UCTANC } \\
\text { IMICRO } \\
\text { MHOS }\end{array}$ \\
\hline $\begin{array}{l}\text { DCT. } \\
\text { OT... } \\
\text { NOV. }\end{array}$ & $\cdots$ & 0 & -- & $m$ & 50 & 0 & 20 & .4 & 52 & 7.5 & 125 \\
\hline OEC... & - & 90 & -- & - & 59 & 3 & 19 & .4 & 58 & 7.4 & 168 \\
\hline JAN... & -- & 0 & -- & - & 56 & 6 & 19 & .3 & 50 & 7.7 & 129 \\
\hline FEB... & - & 0 & -- & - & 52 & 6 & 19 & .3 & 46 & T.T & 118 \\
\hline O6... & -- & 0 & -- & $\cdots$ & 31 & 2 & 19 & .3 & 29 & 7.4 & 74 \\
\hline $\begin{array}{l}05 \ldots . . \\
\text { APR. }\end{array}$ & -- & 10 & -- & -- & 38 & 0. & 19 & .3 & 40 & 7.8 & 99 \\
\hline$\underset{\text { MAY }}{07 . .}$ & -- & 0 & -- & - & 31 & 0 & 24 & .3 & 35 & 7.8 & 69 \\
\hline OS... & .5 & -- & 66 & .09 & 28 & 1 & 20 & $\cdot 3$ & 27 & 7.8 & 66 \\
\hline JULY... & -- & 0 & -- & -- & 12 & o & 20 & .2 & 13 & 6.8 & 33 \\
\hline AUG... & $\sim$ & 0 & -- & -- & 14 & 0 & 23 & .2 & 15 & 7.1 & 36 \\
\hline $04 \ldots$ & - & 0 & -- & -- & 13 & 0 & 19 & .2 & 13 & 7.4 & 34 \\
\hline
\end{tabular}


11213500 KINGS RI VER ABOVE NORTH FORK, NEAR TRIMOER, CALIF.

LOCATION, --Lat $36^{\circ} 51^{\prime} 48^{\prime \prime}$, long $119^{\circ} 07^{\prime} 24^{\prime \prime}$, in NE 1 sec.27, T.12 s., R, 26 E., Fresno County, temperature recorder at gaging station on right bank at Rogers Crossing, 0.9 mile upstream from North Fork, 2.9 miles south of Balch Camp, and 9.6 miles southeast of Trimmer.

DRAINAGE AREA, - -952 sq $m i$.

PERIOD OF RECORD. --Chemical analyses: October 1953 to September 1955.

Water temperatures: December 1965 to September 1969.

EXTREMES, -1968-69:

Water temperatures: Maximum, $20.0^{\circ} \mathrm{C}$ Sept. $2,3,8-10 ;$ minimum, $2.0^{\circ} \mathrm{C}$ Dec. 21,22, Jan. $29,30$.

Period of record (1966-69):

Water temperatures: Maximum (1967-69), $23.0^{\circ} \mathrm{C}$ on several days during July and August 1968; mintmum, freezing potnt Dec. 14, 15, 1967.

REMARKS.--Clock stopped Oct, 1-7, no temperature range avałlable; Oct. 25 to Nov. 26 , range in temperature, 8. $0^{\circ} \mathrm{C}$ to $15.0^{\circ} \mathrm{C}$.

TEMPERATURE $\left({ }^{\circ} \mathrm{C}\right)$ OF WATER, WATER YEAR OCTOBER 1968 TO SEPTEMBER 1969

DAY

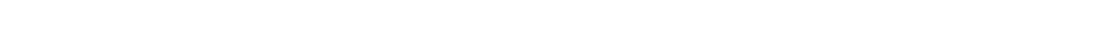

OCTOBER

MAXIMUM --

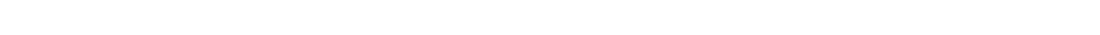

MAXIMUM

DECEMBER

MAXIMUM $89 \begin{array}{llllllllllllllllllllllllllllllllllll} & 7 & 6 & 6 & 6 & 6 & 7 & 7 & 7 & 8 & 8 & 7 & 6 & 8 & 8 & 8 & 8 & 6 & 6 & 5 & 4 & 4 & 6 & 7 & 8 & 7 & 5 & 6 & 6 & 6 & 6 & 7\end{array}$

MINIMUM

JAVUARY

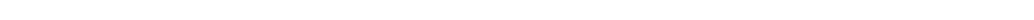

MAXIMUM

FEORUARY

MAXIMUM

MINIMUM

MARCH

APQIL

MAXIMUM

MINIMUM MINIMUM JUNE

MAXIMUM $12 \quad 12 \quad 12 \quad 12 \quad 12 \quad 13 \quad 12 \quad 12 \quad 11 \quad 11 \quad 11 \quad 12 \quad 13 \quad 13 \quad 13 \quad 12 \quad 11 \quad 13 \quad 13 \quad 13 \quad 14 \begin{array}{lllllllllllll}14 & 14 & 13 & 13 & 12 & 12 & 12 & 13 & 14 & --\end{array}$ JULY

MAXIMUM $14: 1614$ MINIMUM $10 \begin{array}{llllllllllllllllllllllllllllll}10 & 10 & 10 & 10 & 14 & 14 & 14 & 14 & 14 & 14 & 15 & 15 & 15 & 15 & 16 & 16 & 16 & 16 & 16 & 16 & 16 & 16 & 16 & 16 & 16 & 16 & 17 & 17 & 17 & 17 \\ 12 & 12 & 12 & 12 & 12 & 13 & 12 & 13 & 13 & 13 & 14 & 14 & 14 & 14 & 14 & 14 & 15 & 14 & 15 & 15 & 15 & 16\end{array}$ AUGUST

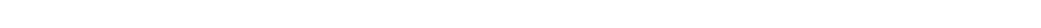

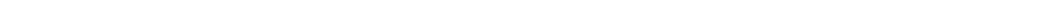
SEPTEMAE?

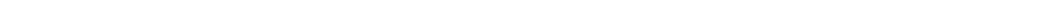
MINIMUM $16 \quad 17 \quad 17 \quad 16 \quad 16 \quad 16 \quad 16 \quad 17 \quad 1717 \quad 17 \quad 16 \quad 16 \quad 16 \quad 16 \quad 16 \quad 16 \quad 16 \quad 16 \quad 16 \quad 14 \quad 15 \quad 15 \quad 16 \quad 16 \quad 16 \quad 16 \quad 16 \quad 17 \quad 16 \quad-$ 
11216500 NORTH FOFK KINGS RIVER ABOVE DINKEY CREEK, AT BALCH CAMP, CALIF.

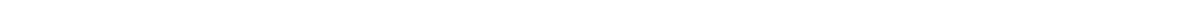
temperature recorder'at gaging station on left bank, $100 \mathrm{ft}$ downstream from bridge at Balch Camp, $200 \mathrm{ft}$ upstream from Dinkey Creek, and $9.3 \mathrm{miles}$ east of Trimmer.

DRAI NAGE AREA. $--250 \mathrm{sq} \mathrm{mi}$,

PERIOD OF RECORD. - Water temperatures: September 1967 to September 1969.

EXTREMES, -1968-69;

Water temperatures: Maximum, $21.0^{\circ} \mathrm{C}$ July $29-31$; minimum, 2. $0^{\circ} \mathrm{C}$ sometime during period Dec. 3-23.

Pertod of record:

Water temperatures: Maximum, 26, $0^{\circ} \mathrm{C}$ June $22,23,25-27,1968$; mintmum, freezing point Dec. 14-16, $21,1967$.

REMARKS. - Recorder stopped Oct. 3 to Nov. 21, Dec. 3-23, Jan. 4-20, Feb. 11-25, Mar. 9 to Apr. 24, Apr. 30 to June 2 , June $8-24$; ranges in temperature, $5.0^{\circ} \mathrm{C}$ to $16.0^{\circ} \mathrm{C}, 2.0^{\circ} \mathrm{C}$ to $10.0^{\circ} \mathrm{C}, 5.0^{\circ} \mathrm{C}$ to $9.0^{\circ} \mathrm{C}, 6.0^{\circ} \mathrm{C}$ to $10.0^{\circ} \mathrm{C}$, $5.0^{\circ} \mathrm{C}$ to $18.0^{\circ} \mathrm{C}, 4.0^{\circ} \mathrm{C}$ to $10.0^{\circ} \mathrm{C}$, and $8.0^{\circ} \mathrm{C}$ to $14.0^{\circ} \mathrm{C}$, respectively.

TEMPERATURE $\left({ }^{\circ} \mathrm{C}\right)$ OF WATER, WATER YEAR OCTOBER 1968 TO SEPTEMBER 1969

DAY

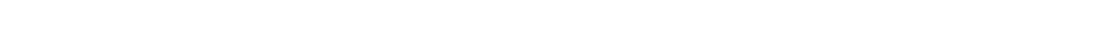

OCTOBFR

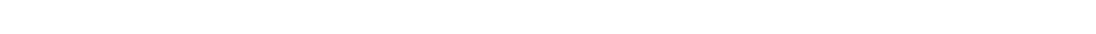

NUVEMBFR

MAXIMUM -

MINIMUM

DECEMAE

MAXIMUM

MINIMUM

JANLARY

MAX LMUM

MINIMUY

MAXIMUM
MINIMUM

MARCH

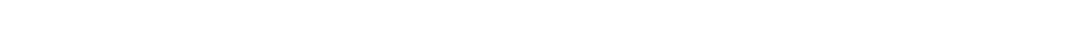

MENIMUN
APRIL
MAXIMUR

HAXIMUM -

MINIMUM -

MAXIMUM --

MINIMUM -
JUNE

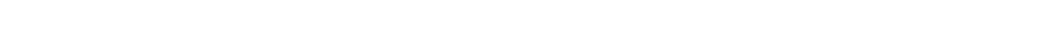

JuLY

MAXIMUM $12 \quad 12 \quad 1212 \quad 1212 \quad 12 \quad 1213 \quad 1313 \quad 13 \quad 13 \quad 13 \quad 1414 \quad 15 \quad 15 \quad 14 \quad 14 \quad 18 \quad 16 \quad 14 \quad 15 \quad 15 \quad 15 \quad 13 \quad 1921 \quad 21 \quad 21$ MINIMUM $10 \begin{array}{llllllllllllllllllllllllllllll}11 & 11 & 11 & 11 & 11 & 11 & 12 & 12 & 12 & 12 & 13 & 12 & 13 & 12 & 13 & 12 & 12 & 13 & 13 & 12 & 12 & 12 & 11 & 11 & 11 & 11 & 15 & 15 & 15\end{array}$ AUGUST

MAXIMUM $20 \quad 18202020201919191820202020202020191919191919191919191918 \quad 1819$

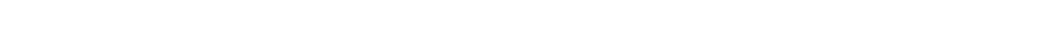

$\begin{array}{lllllllllllllllllllllllllllllllllll}\text { MAXIMUM } & 19 & 20 & 19 & 19 & 19 & 18 & 19 & 20 & 19 & 19 & 18 & 18 & 18 & 18 & 18 & 17 & 18 & 18 & 17 & 16 & 17 & 17 & 18 & 18 & 18 & 17 & 18 & 17 & 18 & 18 & \cdots\end{array}$

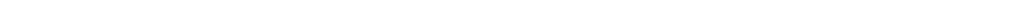


11218500 KINGS RIVER BELOW NORTH FORK, NEAR TRIUMER, CALIF.

LOCATION. - Lat $36^{\circ} 53^{\prime} 04^{\prime \prime}$, long $119^{\circ} 09^{\circ} 07^{\prime \prime}$, In Not sec.16, T.12 S, R. 26 E., Fresno County, on right bank 1 mile downstream from gaging station, 1.8 miles downstream from North Fork, 2.2 miles southwest of Balch Camp, and $7,7 \mathrm{miles}$ southeast of Trimmer.

DRAINAGE AREA. $--1,342 \mathrm{sq}$ mi (at gaging station).

PERIOD OF RECORD. --Chemical analyses: October 1955 to July 1963, October 1967 to September 1969.

Water temperatures: Oc tober 1966 to September 1969.

EXTREMES. --1968-69:

Water temperatures: Maximum, $21.0^{\circ} \mathrm{C}$ Sept. 7,$8 ;$ minimum, 2.0 $0^{\circ} \mathrm{C} \mathrm{Jan} .28-30$.

pertod of record:

Water temperatures: Maximu, $21.0^{\circ} \mathrm{C}$ Sept. $7,8,1969$; minimum, freezing point on several days in December 1966 and January 1967.

REMARKS. --Chemical-quality records furntshed by California Department of Water Resources and reviewed by U.S.

Geological Survey. Temperature subject to fluctuation because of powerplant operation upstream. Clock

stopped Oct. $18-25$, May $22-25$; range in temperature, $11.0^{\circ} \mathrm{C}$ to $14.0^{\circ} \mathrm{C}$, and $8.0^{\circ} \mathrm{C}$ to $10.0^{\circ} \mathrm{C}$, respect 1 ve $1 \mathrm{y}$.

Thermograph malfunction May 26 to June 18, Aug. 10-25; no recorded temperature range. CHEMiCAL ANALYSES, hater yeAR oCtOBER 1968 TO SEPTEMBER 1969

\begin{tabular}{|c|c|c|c|c|c|c|c|c|c|c|c|c|}
\hline DATE & TIME & $\begin{array}{l}\text { OIS- } \\
\text { CHARGE } \\
\text { (CFS) }\end{array}$ & $\begin{array}{l}\text { TEMPER- } \\
\text { ATURE } \\
\text { (DEG C) }\end{array}$ & $\begin{array}{l}\text { DIS- } \\
\text { SOLVED } \\
\text { OXYGEN } \\
\text { (MG/L) }\end{array}$ & $\begin{array}{l}\text { CAL- } \\
\text { CIUM } \\
\text { (CA) } \\
(M G / L)\end{array}$ & $\begin{array}{l}\text { MAG- } \\
\text { NE- } \\
\text { SIUM } \\
\text { (MG) } \\
\text { (MG/L) }\end{array}$ & $\begin{array}{l}\text { SODIUM } \\
\text { (NA) } \\
(M \div / L)\end{array}$ & $\begin{array}{l}\text { PO- } \\
\text { TAS- } \\
\text { SIUM } \\
\text { (K) } \\
\text { (MG/L) }\end{array}$ & $\begin{array}{l}\text { BICAR- } \\
\text { BONATE } \\
\text { (HCD3I } \\
\text { (MGLL) }\end{array}$ & $\begin{array}{l}\text { CAR- } \\
\text { BONATE } \\
\text { (CO3) } \\
\text { (MG/L) }\end{array}$ & $\begin{array}{l}\text { SULFATE } \\
(\mathrm{SOA}) \\
(\mathrm{MG} / \mathrm{L})\end{array}$ & $\begin{array}{l}\text { CHLO- } \\
\text { RIDE } \\
\text { (CL) } \\
\text { (MG/L) }\end{array}$ \\
\hline OCT. & 1145 & 540 & 15 & 10.1 & - & -- & 4.0 & -- & 27 & 0 & -- & 2.1 \\
\hline $12 \ldots$ & 1120 & 381 & 12 & 11.5 & - & -- & 3.1 & -- & 20 & 0 & -- & 1.8 \\
\hline OQ... & -- & 244 & -- & $\cdots$ & -- & -- & 3.4 & $\cdots$ & 23 & 0 & -- & 2.0 \\
\hline $\begin{array}{l}13 . . \\
13 . \\
\text { FEB. }\end{array}$ & 1100 & 500 & 7 & 12.0 & -- & -- & 3.0 & -- & 21 & 0 & -- & 1.8 \\
\hline $10 \ldots$ & 1130 & 1150 & 6 & 12.0 & -- & -- & 3.5 & -- & 31 & 0 & -- & 1.4 \\
\hline $\begin{array}{l}\text { MAR. } \\
10 . . \\
\text { APR. }\end{array}$ & 1200 & 1430 & 6 & 11.8 & -- & -- & 3.9 & -- & 38 & 0 & -- & 1.4 \\
\hline $14 \ldots$ & 1145 & $450 n$ & 8 & 12.0 & -- & - & 2.7 & $\cdots$ & 21 & 0 & -- & .8 \\
\hline $12 \ldots$ & 1210 & 13600 & 10 & 11.0 & 2.7 & .4 & 1.3 & .6 & 12 & 0 & .8 & .6 \\
\hline $\begin{array}{l}10 . . . \\
\text { JULY }\end{array}$ & 1100 & 12000 & 7 & 12.0 & -- & -- & 1.0 & -- & 9 & 0 & -- & 1.2 \\
\hline $\begin{array}{l}14 \ldots . \\
\text { AUG. }\end{array}$ & 1110 & 10600 & 13 & 10.2 & -- & -- & .8 & -- & 8 & 0 & -- & .5 \\
\hline 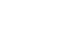 & $\cdots$ & 4460 & $\cdots$ & $\cdots$ & -- & - & .8 & - & 9 & 0 & - & .5 \\
\hline $08 .$. & 1350 & 1030 & 12 & 12.0 & $\ldots$ & -- & 1.7 & -- & 16 & 0 & -- & .8 \\
\hline
\end{tabular}

\begin{tabular}{|c|c|c|c|c|c|c|c|c|c|c|c|}
\hline DATE & $\begin{array}{l}\text { NITRATE } \\
\text { (NOB) } \\
\text { (MG/L) }\end{array}$ & $\begin{array}{l}\text { BORON } \\
(B) \\
(U G / L)\end{array}$ & $\begin{array}{l}\text { OIS- } \\
\text { SOUVD } \\
\text { SOLIDS } \\
\text { IRESI- } \\
\text { OUE AT } \\
180 \text { CI } \\
\text { IMG/L) }\end{array}$ & $\begin{array}{l}\text { DIS- } \\
\text { SOLVED } \\
\text { SOLIDS } \\
\text { (TONS } \\
\text { PER } \\
\text { AC-FT) }\end{array}$ & $\begin{array}{l}\text { HARD- } \\
\text { NESS } \\
\text { (CA,MG) } \\
\text { (MG/L) }\end{array}$ & $\begin{array}{l}\text { NON- } \\
\text { CAR- } \\
\text { BONATE } \\
\text { HARO- } \\
\text { NESS } \\
\text { IMG/LI }\end{array}$ & $\begin{array}{l}\text { PERCENT } \\
\text { SODIUM }\end{array}$ & $\begin{array}{l}\text { SODIUM } \\
\text { AD- } \\
\text { SORP- } \\
\text { IION } \\
\text { RATIO }\end{array}$ & $\begin{array}{l}\text { ALKA- } \\
\text { LINITY } \\
\text { AS } \\
\text { CACO3 } \\
\text { (MG/L) }\end{array}$ & $\begin{array}{c}\mathrm{PH} \\
\text { (UNITS) }\end{array}$ & $\begin{array}{l}\text { SPECI- }- \\
\text { FIC } \\
\text { COND- } \\
\text { UCTANCE } \\
\text { (MICRO- } \\
\text { MHOSI }\end{array}$ \\
\hline $\begin{array}{l}\text { OCT. } \\
14 \ldots . . .\end{array}$ & -- & 20 & -- & -- & 22 & 0 & 28 & .4 & 22 & 7.3 & 62 \\
\hline $12 \ldots$ & - & 10 & -- & - & 15 & 0 & 31 & .3 & 16 & 7.3 & 47 \\
\hline JAN... & -- & 0 & - & -- & 19 & 0 & 28 & .3 & 19 & 7.5 & 52 \\
\hline $\begin{array}{l}13 \ldots \\
F \in B .\end{array}$ & - & 0 & -- & -- & 19 & 2 & 26 & .3 & 17 & 7.5 & 43 \\
\hline $\begin{array}{l}10 . . \\
\text { MAR.. }\end{array}$ & -- & 0 & -- & - & 27 & 2 & 22 & .3 & 25 & 7.2 & 67 \\
\hline${ }_{A P R}^{10 \ldots .}$ & - & 0 & -- & - & 30 & 0 & 22 & $\cdot 3$ & 31 & 7.7 & 78 \\
\hline $\operatorname{maY}_{\operatorname{maY}}$ & - & - & - & - & 16 & o & 27 & .3 & 17 & 7.0 & 44 \\
\hline JUNE & .4 & -- & 31 & .04 & 8 & 0 & 24 & .2 & 10 & 7.3 & 25 \\
\hline JULY... & -- & 0 & $-\cdots$ & -- & o & 0 & 27 & .2 & 7 & 6.9 & 19 \\
\hline $\begin{array}{l}14 \ldots . \\
\text { AUG. }\end{array}$ & -- & 0 & -- & -- & 7 & 0 & 20 & .1 & 7 & 6.8 & 15 \\
\hline $\begin{array}{l}04 . . . \\
\text { SEPT. }\end{array}$ & - & 0 & -- & - & 6 & o & 22 & .1 & 7 & 7.6 & 18 \\
\hline $08 \ldots$ & -- & 0 & -- & - & 12 & 0 & 24 & .2 & 13 & 7.2 & 33 \\
\hline
\end{tabular}


11218500 KINGS RIVER BELOW NORTH FORK, NEAR TRIMMER, CALIF.--Continued

TEMPERATURE ( ${ }^{\circ} \mathrm{C}$ ) OF WATER, WATER YEAR OCTOBER 1968 TO SEPTEMBER 1969 OAY

MONIH

OC IOBFR

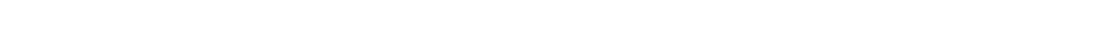

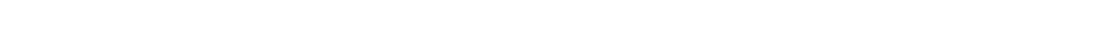

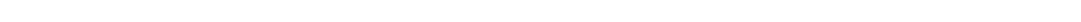

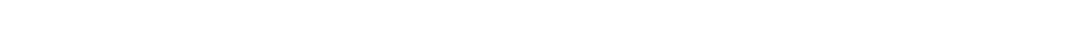

JANUARY

MAXIMUM

MINIMUM

$\begin{array}{lllllllllllllllllllllllllllllllllllllll}\text { MAXIMUM } & 6 & 6 & 7 & 7 & 6 & 6 & 6 & 6 & 7 & 8 & 6 & 6 & 7 & 7 & 6 & 7 & 6 & 6 & 6 & 8 & 8 & 8 & 8 & 8 & 9 & 9 & 8 & 8 & -- & -- & --\end{array}$

MINIMUM

$\begin{array}{llllllllllllllllllllllllllllllllll}\text { MAXIMUM } & 8 & 8 & 8 & 8 & 8 & 8 & 8 & 8 & 8 & 8 & 8 & 7 & 6 & 7 & 8 & 8 & 8 & 8 & 8 & 8 & 8 & 8 & 8 & 8 & 8 & 8 & 7 & 7 & 7 & 7 & 7\end{array}$

MINIMUA

MAXIMUM

MINIMUM

$\begin{array}{llllllllllllllllllllllllllllllll}7 & 8 & 7 & 6 & 7 & 8 & 7 & 7 & 7 & 8 & 7 & 6 & 6 & 5 & 6 & 5 & 7 & 6 & 6 & 6 & 6 & 6 & 6 & 6 & 6 & 6 & 5 & 5 & 5 & 5 & 6\end{array}$

\begin{tabular}{lllllllllllllllllllllllllllllllll} 
& 5 & 5 & 4 & 6 & 5 & 4 & 4 & 6 & 5 & 7 & 8 & 7 & 7 & 4 & 5 & 6 & 7 & 6 & 7 & 7 & 6 & 5 & 6 & 5 & 7 & 7 & 8 & 8 & 8 & 8 & -- \\
\hline IMUM & 4 & 4 & 3 & 3 & 3 & 2 & 2 & 3 & 4 & 4 & 6 & 6 & 4 & 2 & 3 & 4 & 5 & 4 & 4 & 5 & 4 & 4 & 4 & 4 & 5 & 4 & 5 & 5 & 5 & 7 & --
\end{tabular}

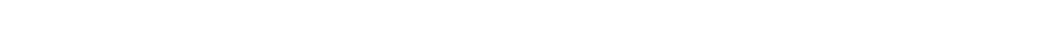

JUNE

MAXIMUM -- -- - - - - - - - - - - - - -

MAXIMUM $13 \quad 13 \quad 14 \quad 14 \quad 13 \quad 14 \quad 14 \quad 16 \quad 14 \quad 14 \quad 15 \quad 15 \quad 15 \quad 15 \quad 15 \quad 15 \quad 15 \quad 15 \quad 16 \quad 16 \quad 16 \quad 16 \quad 16 \quad 17 \quad 17 \quad 17 \quad 17 \quad 18 \quad 18 \quad 18 \quad 18$

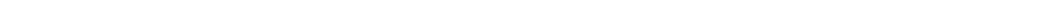
AUGUSI

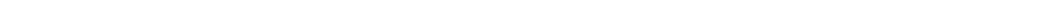

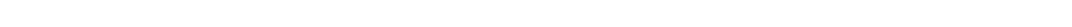
SEPTEMBER

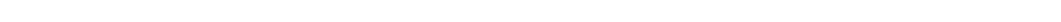

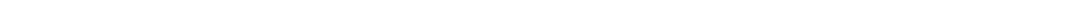

11222700 KINGS RIVER AT PEOPLES WEIR, NEAR KINGSBURG, CALIF.

LOCATION, --Lat $36^{\circ} 29^{\prime} 06^{\prime \prime}$, I ong $119^{\circ} 32^{\prime} 22^{\prime \prime}$, in NW sec.1, T.17 S., R. 22 E., Fresno County, approximately 0.2 mi le downstream from gaging station

PERIOD OF RECORD.--Chemical analyses: October 1953 to September 1969.

REMARKS, --Records furnished by California Department of Water Resources and reviewed by U.S. Geological Survey. CHEMICAL anALYSES, WATER YeAR oCtOBER 1968 to SEPTEMBER 1969

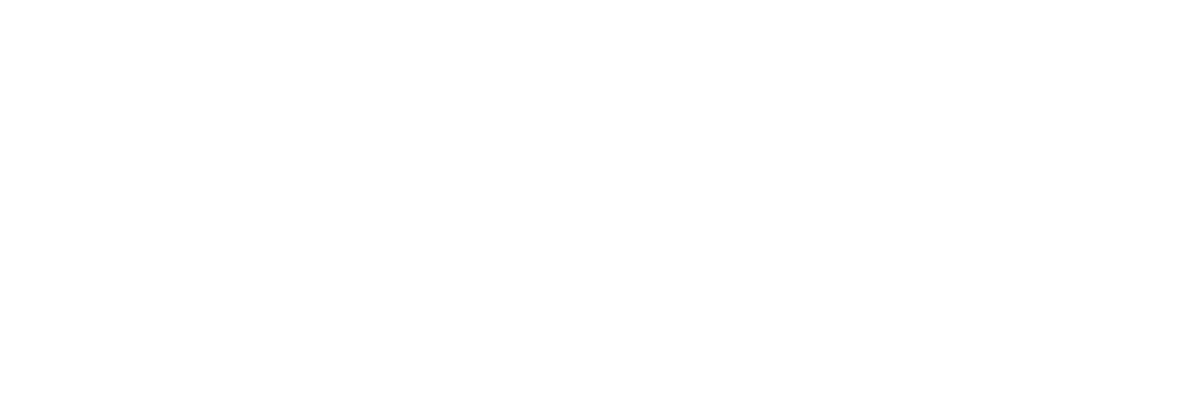

$\begin{array}{cccc}-- & -- & 41 & 0 \\ 55 & .07 & 20 & 0 \\ -- & -- & 12 & 1 \\ -- & -- & 17 & 0\end{array}$

$\begin{array}{lllll}26 & .5 & 44 & 7.8 & 114 \\ 22 & .3 & 20 & 8.1 & 51 \\ 19 & .2 & 11 & 7.0 & 28 \\ 24 & .3 & 19 & 7.4 & 47\end{array}$


11237000 BIG CREEK BELOW HUNTINGTON LAKE, CALIF.

LOCATION, --Lat $37^{\circ} 13^{\prime} 19^{\prime \prime}$, long $119^{\circ} 12^{\prime} 43^{\prime \prime}$, In SW $\frac{1}{4}$ NW est, temperature recorder at gaging station on right bank, $1,200 \mathrm{ft}$ upstream from Grouse Creek and 1 'mile est, temperature recorder at gag
downstream from Huntington Lake.

DRAI NAGE AREA. $-81.1 \mathrm{sq} \mathrm{mi}$.

PERIOD OF RECORD, --Water temperatures: July 1961 to September 1969.

EXTREMES, $--1968-69$ :

Water temperatures: Maximum $18.0^{\circ} \mathrm{C}$ Aug. $5-9,11-14$; minimum, freezing point on many days during December to March.

Period of record:

Water temperatures: Maximum, $18.0^{\circ} \mathrm{C}$ Aug. $5-9,11-14,1969 ;$ minimum $(1961-63,1965-69)$, freezing point on several days durtng winter periods.

TEMPERATURE $\left({ }^{\circ} \mathrm{C}\right)$ OF WATER, WATER YEAR OCTOBER 1968 TO SEPTEMBER 1969

OAY

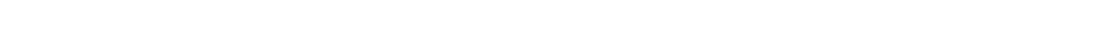

OCTOBER

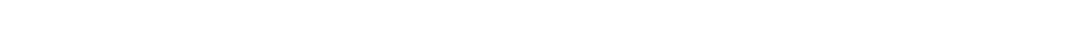

NOVEMAER

$\begin{array}{lllllllllllllllllllllllllllllllllll}\text { MAXIMUM } & 9 & 9 & 9 & 8 & B & 8 & 8 & 8 & B & 8 & 8 & 8 & 7 & 7 & 6 & 6 & 7 & 7 & 6 & 6 & 6 & 6 & 6 & 6 & 4 & 5 & 5 & 4 & 5 & 5 & -- & 7 \\ \text { MINIMUM } & 8 & 8 & 7 & 7 & 7 & 7 & 7 & 7 & 7 & 7 & 7 & 6 & 6 & 5 & 4 & 6 & 6 & 6 & 6 & 6 & 5 & 6 & 5 & 4 & 4 & 4 & 4 & 4 & 4 & 4 & -- & & 6\end{array}$

MINIMUM

MAXIMUM

MINIMUM
JANUARY

MAXIMUM

MINIMUM

MAXIMUM

MINIMUM

MAPCH MIN

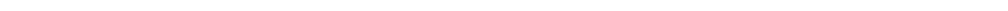

MINIMUM

APRIL MIN

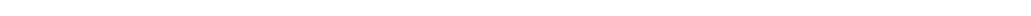

MAXIMUM $4 \begin{array}{lllllllllllllllllllllllllllllllllll} & 4 & 3 & 4 & 5 & 5 & 5 & 5 & 5 & 5 & 5 & 5 & 5 & 5 & 6 & 6 & 6 & 6 & 6 & 6 & 6 & 6 & 7 & 7 & 7 & 7 & 7 & 8 & 8 & 8 & 9 & 6\end{array}$

JUNE

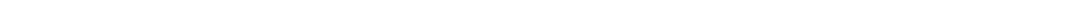

JULY $\begin{array}{llllllllllllllllllllllllllllllll}M A X 1 M U M & 12 & 12 & 12 & 12 & 12 & 12 & 12 & 13 & 12 & 12 & 12 & 12 & 12 & 12 & 13 & 13 & 13 & 13 & 13 & 13 & 13 & 13 & 13 & 13 & 13 & 13 & 11 & 13 & 12 & 13 & 12\end{array}$

MGUST

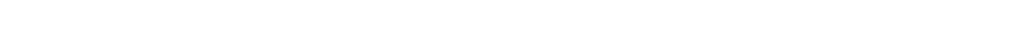

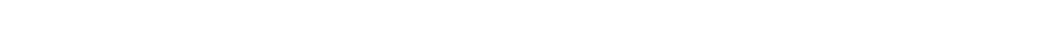
SEPTEMHER

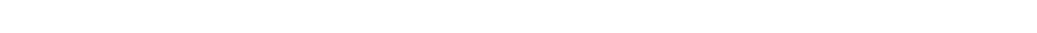

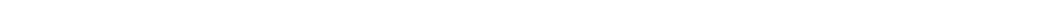


11246500 WILLOW CREEK AT MOUTH, NEAR AUBERRY, CALIF.

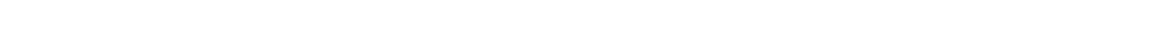
est, temperature recorder at gaglng station on left bank, $40 \mathrm{ft}$ upstream from bridge, $0.4 \mathrm{~m} 11 \mathrm{e}$ upstream $\mathrm{from}$ mouth, 1.3 miles downstream from whiskey Creek, and 4.3 miles northeast of Auberry.

DRAINAGE AREA. - $-130 \mathrm{sq} \mathrm{mi}$.

PERIOD OF RECORD. --Water temperatures: October 1960 to September 1969.

EXTREHES, - - 1968-69:

Water temperatures: Maximum recorded, $27.0^{\circ} \mathrm{C}$ Aug. 14 ; minimum $3.0^{\circ} \mathrm{C} \mathrm{Dec.} 21,22$.

Period of record:

Water temperatures: Maximum $(1960-63,1964-69), 33.0^{\circ} \mathrm{C}$ Aug. 5,$1966 ;$ minimum, $2.0^{\circ} \mathrm{C}$ on several days in 1961 , $1965-68$.

REMARKS.--No flow Oct. 1-6. Recorder malfunction Jan, 27 to Feb. 3; probe inoperative June 3 to July 3 , and Aug. 15 to Sept. 4 .

TEMPERATURE $\left({ }^{\circ} \mathrm{C}\right)$ OF WATER, WATER YEAR OCTOBER 1968 TO SEPTEMBER 1969

$$
\text { CAY }
$$

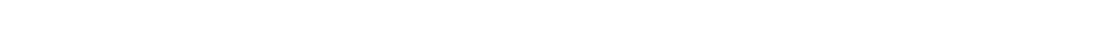

OCTOBER

MAXINUM -

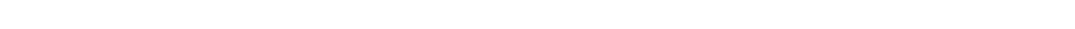
NOVEMHER

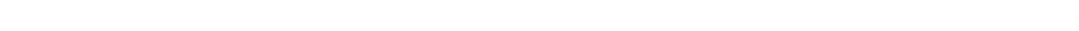
$\begin{array}{cllllllllllllllllllllllllllllllllll}M I N I M U M & 13 & 13 & 12 & 12 & 12 & 11 & 12 & 11 & 11 & 11 & 12 & 12 & 11 & 9 & 9 & 9 & 10 & 11 & 10 & 9 & 9 & 10 & 11 & 10 & 8 & 8 & 7 & 7 & 6 & 8 & -7\end{array}$ DECEMBER $\begin{array}{llllllllllllllllllllllllllllllllllll}\text { MAXIMUM } & 8 & 8 & 7 & 7 & 7 & 7 & 7 & 8 & 8 & 8 & 9 & 7 & 7 & 8 & 8 & 8 & 7 & 6 & 6 & 4 & 4 & 4 & 6 & 6 & 7 & 7 & 5 & 6 & 6 & 6 & 7 & 7 \\ \text { MININUM } & 8 & 7 & 6 & 6 & 6 & 6 & 7 & 7 & 7 & 7 & 7 & 5 & 5 & 7 & 8 & 7 & 5 & 4 & 4 & 4 & 3 & 3 & 4 & 6 & 6 & 5 & 4 & 4 & 5 & 6 & 6 & 5 & 5\end{array}$ JANUARY

$\begin{array}{llllllllllllllllllllllllllllllllll}M \triangle X \text { MUM } & 7 & 7 & 7 & 7 & 7 & 8 & 8 & 8 & 7 & 7 & 6 & 7 & 8 & 8 & 8 & 8 & 8 & 9 & 9 & 8 & 8 & 7 & 6 & 8 & 8 & 8 & \ldots & \ldots & - & \ldots & --\end{array}$ MAXIMUM --

MAXIMUM

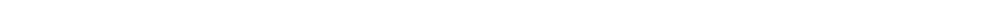

MINIMUM

APQIL

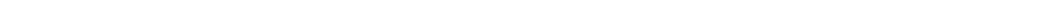

MINIMUM MAY

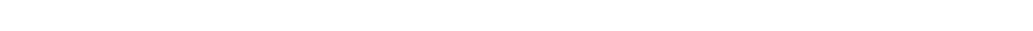

MAKIMUA 17 17 -MINIMUM 17 17 17 JULY

MAXIMUM -AUGUSI

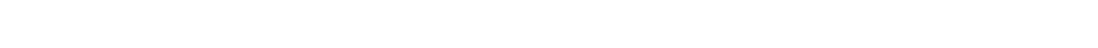
SEP IEMBE

$\begin{array}{llllllllllllllllllllllllllllllll}\text { MAXIMUM } & -- & -- & -2 & 24 & 23 & 23 & 24 & 24 & 24 & 23 & 23 & 22 & 22 & 21 & 21 & 21 & 21 & 20 & 20 & 19 & 20 & 20 & 20 & 20 & 20 & 20 & 20 & 21 & 20 & -2 & 21 \\ \text { MIN!MUM } & -- & -- & -- & 19 & 19 & 20 & 21 & 20 & 19 & 19 & 19 & 18 & 18 & 18 & 17 & 17 & 17 & 18 & 18 & 16 & 16 & 16 & 17 & 17 & 17 & 17 & 17 & 18 & 17 & -- & 18\end{array}$ 
11264500 MERCED RIVER AT HAPPY ISLES BRIDGE, NEAR YOSEMITE, CALIF.

LOCATION.--Lat $37^{\circ} 43^{\prime} 54^{\prime \prime}$, long $119^{\circ} 33^{\prime} 28^{\prime \prime}$, Mariposa County, Yosemite National Park, at gaging station on right bank, $10 \mathrm{ft}$ downst rean from footbridge at Happy isles, $0.4 \mathrm{mile}$ downstream from Ilislouette Creek, and $2.0 \mathrm{miles}$ southeast of Yosemite National Park headquarters.

DRAINAGE AREA. --181 sq $\mathrm{m} 1$.

PERIOD OF RECORD. --Chemical analyses: March 1968 to September 1969.

Water temperatures: Oc tober 1965 to September 1969.

EXTREMES, --1968-69:

Water temperatures: Maximum, $17.0^{\circ} \mathrm{C}$ on several days during Ju1y and August; minimum, freezing point on many days during December to February.

Period of record:

Water temperatures: Maximum $(1966-69), 17.0^{\circ} \mathrm{C}$ on many days during June to August of most years; minimum, freezing point on many days during winter periods.

REMARKS. --Chemical-quality records furnished by California Department of Water Resources and reviewed by U.S, Geological Survey. Thermograph malfunction Feb. 20 to Mar. 24, May 12-15, 18, 28-30, June 2-4, June 22 to
July 3, July 30 to Aug. 1, Aug. 8-11, 24, Aug. 30 to Sept. 1, 8-10, 24, 29, 30; no temperature ranges available.

CHEMICAL ANAL YSES, watek YEAR UCTOBER I9SP TO SEPTEMBER 1969

\begin{tabular}{|c|c|c|c|c|c|c|c|c|c|c|c|c|}
\hline "A It & II पE & $\begin{array}{c}\text { ISS- } \\
2+A H G t \\
(C+5)\end{array}$ & $\begin{array}{l}\text { TEMPER- } \\
\text { ATURE } \\
\text { (2EG C) }\end{array}$ & $\begin{array}{l}\text { AIR } \\
\text { TEMPER- } \\
\text { ATURE } \\
\text { (JE: } C \text { ) }\end{array}$ & $\begin{array}{l}\text { DIS- } \\
\text { SOLVED } \\
\text { UXYGEN } \\
(4 C / L)\end{array}$ & $\begin{array}{l}\text { SILICA } \\
|S I O Z| \\
\left.\mid{ }^{\prime} G / L\right)\end{array}$ & $\begin{array}{l}\text { DIS- } \\
\text { SULVED } \\
\text { IROV } \\
\text { (FE) } \\
\text { (UG/L) }\end{array}$ & $\begin{array}{c}\text { CAL- } \\
\text { CIUY } \\
\text { (CA) } \\
(M G / L)\end{array}$ & $\begin{array}{c}\text { MAG- } \\
N E- \\
S I U M \\
(Y G) \\
(M G / L)\end{array}$ & $\begin{array}{l}\text { SODIUM } \\
\text { INAI } \\
\text { (MG/L) }\end{array}$ & $\begin{array}{l}P I- \\
\text { TAS- } \\
\text { SIUM } \\
(K) \\
(M G / L)\end{array}$ & $\begin{array}{l}\text { BICAR- } \\
\text { BUNATE } \\
\text { (HCO3) } \\
\text { IMG/L) }\end{array}$ \\
\hline $1+\ldots$ & 1030 & 137 & 4 & 1 & 12.0 & 4.8 & -- & 1.2 & .3 & 1.5 & .3 & 7 \\
\hline 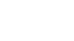 & 1030 & 78 & - & -- & -- & 0.5 & - & 2.5 & .1 & 2.4 & .5 & 7 \\
\hline $\begin{array}{c}23 \ldots \\
A P K\end{array}$ & 1145 & 177 & 1 & 2 & 11.0 & H. L & -- & 2.1 & $\cdot 3$ & 2.0 & .4 & 8 \\
\hline juit. & 1400 & 1230 & 3 & 23 & 12.0 & 5.9 & 20 & 1.0 & $\cdot 2$ & 1.0 & .3 & 9 \\
\hline JULY & 1243 & $13 \geq 0$ & 7 & 15 & 11.0 & 4.5 & 30 & .3 & .1 & .7 & .2 & 4 \\
\hline sopr. & isou & $0<s$ & is & 14 & 11.0 & 2.8 & 10 & .6 & $\cdot 1$ & .4 & .1 & 2 \\
\hline
\end{tabular}

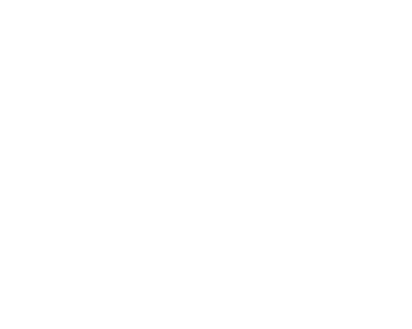

$\begin{array}{ccccc}.02 & 5 & 0 & 6.9 & 28 \\ .02 & 4 & 0 & 6.7 & 21 \\ .03 & 6 & 0 & 6.5 & 31 \\ .07 & 7 & 0 & 6.1 & 28 \\ .03 & 6 & 0 & 6.9 & 24 \\ .02 & 4 & 0 & 6.3 & 14 \\ .01 & 2 & 0 & 6.3 & 10 \\ .01 & 2 & 0 & 6.2 & 9 \\ .02 & 0 & 0 & 6.2 & 24\end{array}$


11264500 MERCED RIVER AT HAPPY ISLES BRIDGE, NEAR YOSEMITE, CALIF. --Cont inued CHEMICAL ANALYSES, HATER YEAR OCTIBBER 1968 IO SEPTEMBER 1969

\begin{tabular}{|c|c|c|c|c|c|c|c|c|c|}
\hline DAIE & $\begin{array}{l}\text { PERCENT } \\
\text { SODIUM }\end{array}$ & $\begin{array}{l}\text { SODIUM } \\
\text { AD- } \\
\text { SORP- } \\
\text { TION } \\
\text { RATIO }\end{array}$ & $\begin{array}{l}\text { ALKA- } \\
\text { LINITY } \\
\text { AS } \\
\text { CACD } \\
\text { IMG/LI) }\end{array}$ & $\begin{array}{l}\text { PHOS- } \\
\text { PHATE } \\
\text { (PD4) } \\
\text { (MG/L) }\end{array}$ & $\begin{array}{l}\text { ORTHO } \\
\text { PHOS- } \\
\text { PHATE } \\
\text { (PO4) } \\
\text { (MG /L) }\end{array}$ & $\begin{array}{l}\text { ORGANIC } \\
\text { NITRO- } \\
\text { GEN } \\
\text { (N) } \\
\text { IMG/LI }\end{array}$ & $\begin{array}{l}\text { AMYONIA } \\
(\text { NHA) } \\
\text { (MG/L) }\end{array}$ & $\begin{array}{l}\text { COLI- } \\
\text { FORM } \\
\text { ICOL- } \\
\text { ONIES } \\
\text { PER } \\
\text { IOO ML) }\end{array}$ & $\begin{array}{l}\text { BIO- } \\
\text { CHEM- } \\
\text { ICAL } \\
\text { OXYGEN } \\
\text { JEMAND } \\
\text { IMG/LI }\end{array}$ \\
\hline OCT. & 39 & .4 & 6 & .09 & .17 & .46 & .03 & 10 & 1.2 \\
\hline $\begin{array}{l}\text { NOV. } \\
19 . . . \\
\text { DEC. }\end{array}$ & 44 & .4 & 6 & .09 & .03 & .00 & .08 & 13 & .7 \\
\hline $\begin{array}{l}18 \ldots \\
F E B .\end{array}$ & 42 & .4 & 6 & .02 & .00 & .06 & .08 & -- & -- \\
\hline MAR... & 40 & .4 & 7 & .13 & .05 & .79 & .15 & 6 & 2.1 \\
\hline $\begin{array}{l}25 . . . \\
A P R .\end{array}$ & 41 & $\cdot 3$ & 7 & .06 & .02 & .84 & .13 & 1 & .0 \\
\hline $\begin{array}{l}29 . . . \\
\text { JUNE }\end{array}$ & 33 & .2 & 7 & -- & -- & -- & -- & 1 & .7 \\
\hline JuLy & 33 & .2 & 3 & .05 & .00 & .09 & .01 & 2 & .0 \\
\hline $\begin{array}{l}30 . . . \\
\text { SEPT. }\end{array}$ & 33 & .1 & 2 & .10 & .07 & .08 & .04 & 0 & 1.4 \\
\hline $26 \ldots$ & 37 & .3 & 6 & .02 & .02 &.$O B$ & .08 & 21 & .7 \\
\hline
\end{tabular}

TEMPERATURE $\left({ }^{\circ} \mathrm{C}\right)$ OF WATER, WATER YEAR OCTOBER 1968 TO SEPTEMBER 1969

DAY

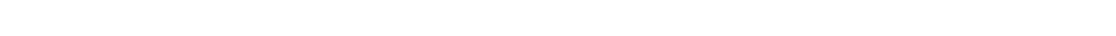
$\begin{array}{rrrrrrrrrrrrrrrrrrrrrrrrrrrrrrrrrrrr}\text { MAXIMUM } & 12 & 13 & 12 & 13 & 13 & 12 & 12 & 13 & 13 & 12 & 11 & 11 & 10 & 9 & 8 & 8 & 8 & 8 & 8 & 8 & 8 & 8 & 8 & 8 & 9 & 9 & 9 & 9 & 8 & 8 & 7 & 10 \\ \text { MINIMUM } & 9 & 9 & 9 & 9 & 9 & 9 & 9 & 8 & 8 & 8 & 8 & 9 & 10 & 8 & 7 & 7 & 7 & 8 & 8 & 8 & 8 & 7 & 7 & 8 & 8 & 8 & 8 & 8 & 8 & 7 & 6 & 8\end{array}$ NOVEMBER

$\begin{array}{lllllllllllllllllllllllllllllllllllll}\text { MARIMUM } & 6 & 8 & 8 & 6 & 7 & 6 & 7 & 7 & 8 & 8 & 8 & 7 & 3 & 3 & 3 & 4 & 6 & 6 & 5 & 5 & 5 & 6 & 6 & 5 & 2 & 2 & 2 & 2 & 2 & 2 & \cdots & 5 \\ \text { MINIMUM } & 6 & 6 & 5 & 4 & 5 & 4 & 5 & 5 & 6 & 6 & 6 & 3 & 2 & 2 & 2 & 3 & 4 & 4 & 4 & 4 & 4 & 4 & 4 & 2 & 2 & 2 & 2 & 1 & 1 & 2 & \cdots & 4\end{array}$

DECEMBER

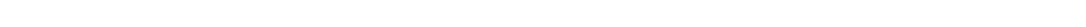

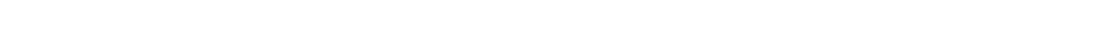

JANUARY

$\begin{array}{lllllllllllllllllllllllllllllllllll}\text { MAXIMUM } & 2 & 2 & 3 & 3 & 3 & 3 & 3 & 3 & 2 & 1 & 2 & 4 & 3 & 3 & 1 & 2 & 1 & 3 & 3 & 4 & 3 & 3 & 2 & 3 & 4 & 3 & 1 & 1 & 0 & 0 & 0 & 2\end{array}$

$\begin{array}{llllllllllllllllllllllllllllllllllll}\text { MINIMUM } & 1 & 1 & 2 & 2 & 3 & 2 & 2 & 1 & 1 & 1 & 1 & 2 & 2 & 1 & 1 & 1 & 1 & 1 & 2 & 3 & 2 & 1 & 1 & 2 & 3 & 1 & 1 & 0 & 0 & 0 & 0 & 1\end{array}$

FERUARY

MAXIMUMM

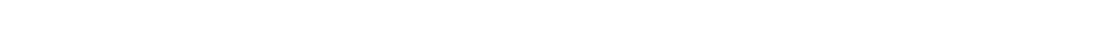
MAXIMUM MINIPUA - - - - - - $\begin{array}{lllllllllllllllllllllllllllllllllll}\text { MAXIMUM } & 5 & 4 & 4 & 6 & 4 & 3 & 4 & 5 & 5 & 7 & 7 & 6 & 5 & 3 & 5 & 6 & 6 & 5 & 7 & 7 & 6 & 6 & 4 & 4 & 6 & 6 & 7 & 7 & 6 & 6 & -- & 5 \\ \text { MINIMUM } & 2 & 2 & 1 & 2 & 1 & 1 & 0 & 2 & 2 & 3 & 3 & 3 & 2 & 1 & 1 & 2 & 2 & 3 & 2 & 3 & 3 & 3 & 2 & 2 & 1 & 2 & 2 & 3 & 2 & 2 & -- & 2\end{array}$

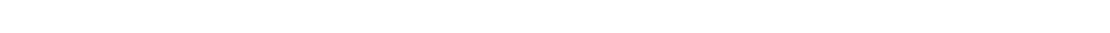
$\begin{array}{lllllllllllllllllllllllllllllllll}\text { MAXIMUM } & 6 & 5 & 5 & 5 & 7 & 7 & 8 & 8 & 7 & 7 & 7 & -- & -- & -- & -- & 8 & 7 & -- & 7 & 8 & 8 & 8 & 8 & 8 & 8 & 9 & 9 & -- & -- & -- & 9 & -- \\ \text { MINIMUM } & 2 & 3 & 3 & 3 & 4 & 4 & 4 & 4 & 4 & 4 & 4 & -- & -- & -- & -- & 4 & 4 & -- & 3 & 4 & 5 & 5 & 5 & 5 & 5 & 5 & 5 & -- & -- & -- & 6 & --\end{array}$ JUNE MAXIMUM

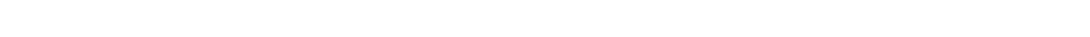
MAXIMUM -MIMIMUM AUGUST

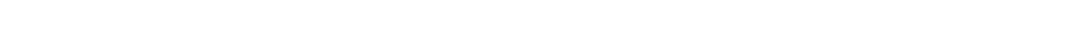

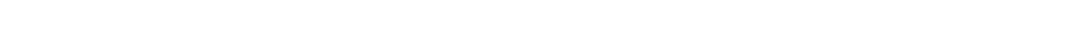




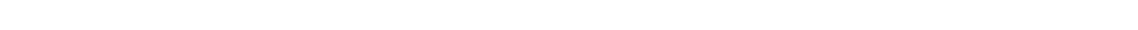
station on left bank, 1,500 ft downstream from Mud Lake and 5.7 miles southeast of Pinecrest.

DRAINAGE AREA. --11.9 sq $\mathrm{mi}$.

PERIOD OF RECORD. - Water temperatures: October 1964 to September 1969.

EXTREMES, --1968-69:

Wate $r$ temperatures: Maximum, $19.0^{\circ} \mathrm{C}$ on many days during July to September; minimum, freezing point on many days during winter periods.

periad of record:

Water temperatures: Maximum, $25.0^{\circ} \mathrm{C}$ Aug. 17, 1966; minimum, freezing point on many days during winter periods. REMARKS. --Stream frozen during most of winter.

TEMPERATURE $\left({ }^{\circ} \mathrm{C}\right)$ OF WATER, WATER YEAR OCTOBER 1968 TO SEPTEMBER 1969

OAY

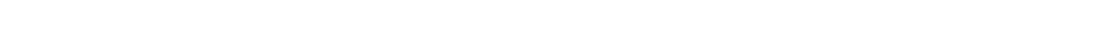

OC TUBER

$\begin{array}{lrlllllllllllllllllllllllllllllllllll}\text { MAXINUM } & 16 & 16 & 15 & 16 & 15 & 13 & 13 & 12 & 11 & 11 & 11 & 10 & 10 & 8 & 7 & 9 & 10 & 10 & 9 & 9 & 9 & 9 & 9 & 9 & 9 & 9 & 9 & 9 & 9 & 8 & 6 & 11 \\ \text { MINIMUM } & 13 & 13 & 13 & 13 & 12 & 11 & 10 & 10 & 10 & 10 & 10 & 10 & 8 & 7 & 6 & 7 & 8 & 9 & 8 & 8 & 8 & 8 & 8 & 8 & 8 & 8 & 8 & 8 & 8 & 6 & 6 & 9\end{array}$

MAXINIMUM
VUVEMSE?

MAXIMUM
MIVIMUM

MINIMUM
CCEMBER

MAXIMUM

MINIMUM

MAXIMUM

MAXIMU

FERRUARY

MAXIMUM

MINIMUM

MRCH
MAXIMUMM

MITSIMUa

APRIL

MAXIMUM

MINIMUM

MAXIMUM

MININUM

JUNE

MAXIMUM

MINIMUM

MULY

MINIMUM

UGUST

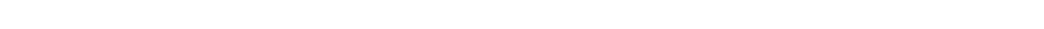

STPIEMBER

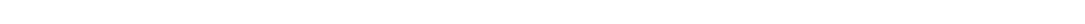

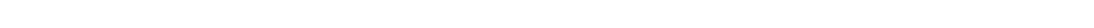


11290000 TUOLUMNE RIVER AT MODESTO, CALIF.

LOCATION. --Lat $37^{\circ} 37^{\prime} 38^{\prime \prime}$, long $120^{\circ} 59^{\prime} 11^{\prime \prime}$, in SEłSW sec.33, T. 3 S., R.9 E., Stanislaus County, temperature recorder at gaging station on left bank at bridge on Ninth Street in Nodesto, 0.2 mile downstream from Dry creek.

DRAINAGE AREA. $--1,884 \mathrm{sq} \mathrm{mi}$.

PERIOD OF RECORD. --Water temperatures: July 1965 to September 1969.

EXTREMES, --1968-69:

Water temperatures: Maximum, $29.0^{\circ} \mathrm{C}$ Aug. 17,21 ; minimum, $8.0^{\circ} \mathrm{C}$ on many days during December to February.

Period of record:

Water temperatures: Maximum $(1965-67,1968-69), 29.0^{\circ} \mathrm{C}$ on several days in 1966,1967, and $1969 ; \mathrm{minimum}$ $8.0^{\circ} \mathrm{C}$ on many days during winter periods most years.

REMARKS. --Recorder inoperative Oct. 1-21. Clock stopped Feb. 6 to Mar. 5; range in temperature, 8. $0^{\circ} \mathrm{C}$ to $9.0^{\circ} \mathrm{C}$. TEMPERATURE $\left({ }^{\circ} \mathrm{C}\right.$ ) OF WATER, WATER YEAR OCTOBER 1968 TO SEPTEMBER 1969 DAY

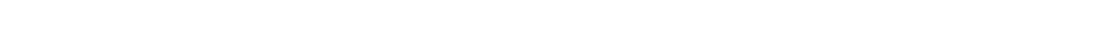

OC TOBER

MAXIMUM MINIMUM - -

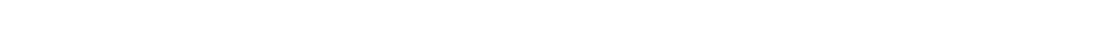

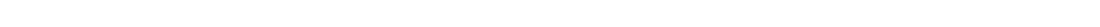

DLCEMBER

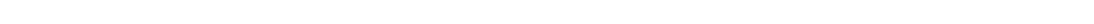

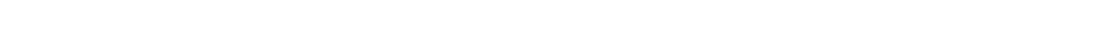

JANUARY

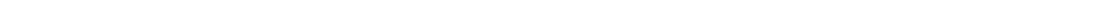

FEBRUARY

MAXIMUM

MINIMUM

MAXIMUM

MINIMUM

RIL

MAXIMUM

MINIMUM

MAXIMUM

MINIMUM

MAXIMUM

MANIMU
JULY
MAXIMU

$\begin{array}{llllllllllllllllllllllllllllllll}8 & 8 & 8 & 8 & 9 & 9 & 8 & 8 & 9 & 8 & 8 & 9 & 9 & 9 & 9 & 8 & 8 & 8 & 8 & 9 & 9 & 10 & 10 & 10 & 10 & 10 & 9 & 9 & 8 & 9 & 8 & 9\end{array}$

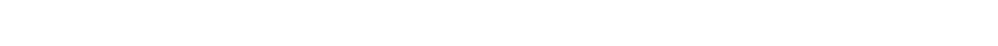

-- --

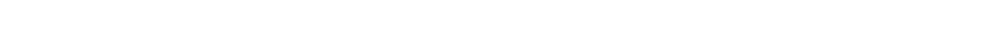

MAXI MUM

MINIMUM

MAST

MAXIMUM

SEPTEMBER

MAXIMUM

MINIMUM

$18 \begin{array}{llllllllllllllllllllllllllllllllll}10 & 10 & 11 & 11 & 10 & 11 & 11 & 11 & 12 & 12 & 12 & 12 & 12 & 12 & 12 & 13 & 13 & 13 & 13 & 13 & 14 & 13 & 13 & 13 & 13 & 13 & 13 & 13 & 13 & -2 & 12 \\ 11 & 11 & 11 & 11 & 12 & 12 & 12 & 12 & 17 & 13 & 13 & 12 & 12 & 12 & 12 & 12 & 12 & 12 & -2 & 11\end{array}$

$\begin{array}{lllllllllllllllllllllllllllllllll}13 & 13 & 14 & 14 & 14 & 16 & 16 & 15 & 15 & 15 & 16 & 16 & 15 & 15 & 15 & 15 & 14 & 14 & 16 & 15 & 15 & 15 & 16 & 16 & 16 & 16 & 16 & 15 & 15 & 15 & 15 & 15\end{array}$

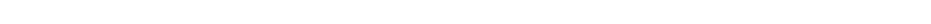

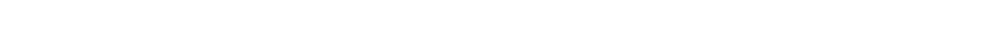

$\begin{array}{llllllllllllllllllllllllllllllll}21 & 22 & 23 & 24 & 24 & 24 & 23 & 23 & 23 & 23 & 20 & 21 & 21 & 21 & 22 & 21 & 20 & 21 & 23 & 24 & 23 & 23 & 24 & 25 & 25 & 25 & 25 & 25 & 25 & 26 & 27\end{array}$

$\begin{array}{llllllllllllllllllllllllllllllllllllllllll}28 & 28 & 28 & 28 & 28 & 28 & 28 & 28 & 28 & 28 & 28 & 28 & 28 & 28 & 28 & 29 & 28 & 28 & 28 & 29 & 28 & 28 & 27 & 27 & 27 & 27 & 27 & 26 & 27 & 26 & 28\end{array}$ $\begin{array}{lllllllllllllllllllllllllllllllllllll}26 & 26 & 26 & 26 & 26 & 25 & 25 & 26 & 26 & 27 & 26 & 26 & 26 & 25 & 24 & 23 & 23 & 24 & 24 & 24 & 23 & 24 & 23 & 24 & 24 & 24 & 24 & 22 & 21 & 21 & -5 & 24 \\ 23 & 24 & 24 & 24 & 24 & 23 & 24 & 23 & 23 & 23 & 24 & 23 & 23 & 22 & 22 & 21 & 21 & 21 & 22 & 22 & 21 & 22 & 22 & 22 & 22 & 22 & 22 & 20 & 20 & 20 & - & 2\end{array}$ 
11292700 MIDDLE FORK STANISLAUS RIVER AT HELLS HALF ACRE BRIDGE, NEAR PINECREST, CALIF.

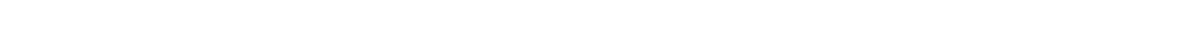
at gaging station on left bank, $200 \mathrm{ft}$ upstream from Donneli powerhouse, $800 \mathrm{ft}$ downstream from Helis Half Acre
Bridge, 1.1 miles upstream from Cow Creek, and 4.7 miles northwest of Pinecrest.

DRAINAGE AREA. - -287 sq ms.

PERIOD OF RECORD. --Water temperatures: October 1965 to September 1969.

EXTREMES, - -1968-69: Water temperatures: Maximum, $21.0^{\circ} \mathrm{C} J u l y ~ 29,30 ;$ minimum, freezing point on several days during December,
February, and March.

Period of record:

Water temperatures. Maximum (1966-69), 22.0 ${ }^{\circ} \mathrm{C}$ sometime during period June 7-26, and on June 27,1968 ; minimum, on several days during winter perzods.

REMARKS. --Clock stopped Apr. 23, 24, Aug. 26 to Sept. 30 ; ranges in temperature, $3.0^{\circ} \mathrm{C}$ to $8.0^{\circ} \mathrm{C}$, and $12.0^{\circ} \mathrm{C}$ to $18.0^{\circ} \mathrm{C}$, respectively.

TEMPERATURE $\left({ }^{\circ} \mathrm{C}\right)$ OF WATER, HATER YEAR OCTOBER 1968 TO SEPTEMBER 1969

$$
\text { DAY }
$$

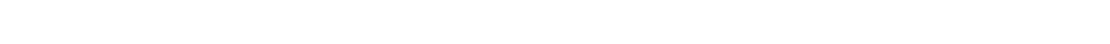

OC TOAEO

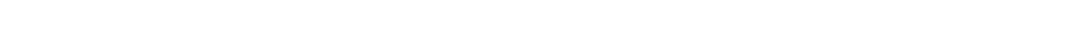

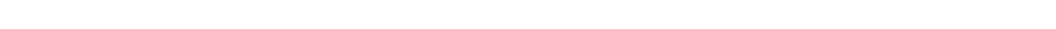

TOVEMBED

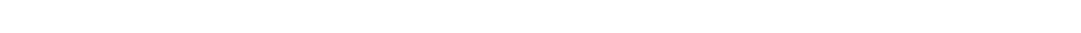

MAXINUM

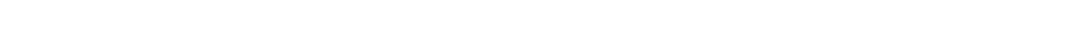

ANIIARY

MAXIMUM

MINIMUM

MAXIMUM

MARCH

MAXIMUM

MANIMUM

APRIL

MAXIRUM

MAY

MAXIMUM

NAXINUM

JULY

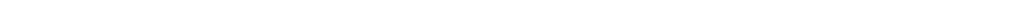

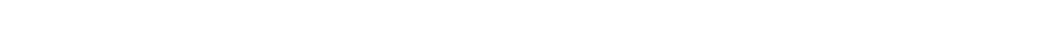
AUGUST

MAXIMUM $191920191919191818181919191919191919181819191918 \quad 18 \ldots \ldots$

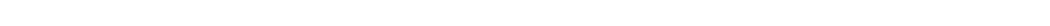

SEPTIMMBER

MAXIMIIM 
11302000 STANISLAUS RIVER BELOW GOODWIN DAM, NEAR KNIGHTS FERRY, CALIF.

LOCATION (revised).--Lat $37^{\circ} 51^{\prime} 06^{\prime \prime}$, I Ong $120^{\circ} 38^{\prime} 13^{\prime \prime}$, in Rancheria Del Rio Estanislao Grant, Calaveras County, temperature recorder at gaging station on right bank, $250 \mathrm{ft}$ upstream from Owl Creek, 0.9 mile downstream from
Goodwin Dam, and 2.9 miles northeast of Knights Ferry.

DRAINAGE AREA. $--986 \mathrm{sq} \mathrm{mi}$.

PERIOD OF RECORD, --Water temperatures: February 1966 to September 1969.

EXTRENES, - 1968-69:

Water texperatures: Maximum, $24.0^{\circ} \mathrm{C}$ on several days in September.

Period of record:

Water temperatures: Maximum, $27.0^{\circ} \mathrm{C}$ June 25,1968 ; minimum $(1966-68), 6.0^{\circ} \mathrm{C}$ sometime during period Jan, $13-31$, 1968.

REMARKS, - Clock stopped Oct. 11 to Nov. 1, Nov. 12 to Dec. 3, May 27 to June 2 , June 3 to July 1 , Ju1y 2 to Aug. 14; ranges in temperature, $17.0^{\circ} \mathrm{C}$ to $19.0^{\circ} \mathrm{C}, 12.0^{\circ} \mathrm{C}$ to $17.0^{\circ} \mathrm{C}, 12.0^{\circ} \mathrm{C}$ to $13.0^{\circ} \mathrm{C}, 12.0^{\circ} \mathrm{C}$ to $16.0^{\circ} \mathrm{C}$, and $16.0^{\circ} \mathrm{C}$ to $23.0^{\circ} \mathrm{C}$, respectively. Recorder malfunctioned Jan. 9-21, Jan, 24 to Feb. 4, Feb. 6 to Mar. 4 , Mar. 9 to Apr. 2.

TEUPERATURE $\left({ }^{\circ} \mathrm{C}\right)$ OF TATER, WATER YEAR OCTOBER 1968 TO SEPTEMBER 1969

DAY

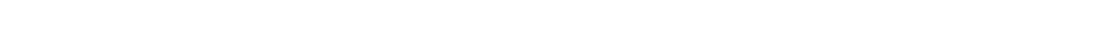

OCTCBER

MAXIMUM --

NOVEMBER

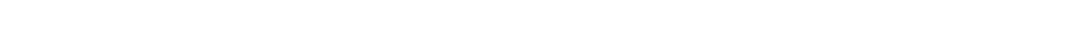

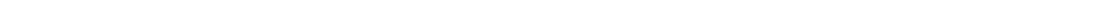

$\begin{array}{rlllllllllllllllllllllllllllllllll}\text { MAXIMUM } & -- & -- & - & 13 & 13 & 12 & 12 & 13 & 13 & 13 & 13 & 13 & 12 & 12 & 12 & 12 & 12 & 12 & 12 & 11 & 11 & 10 & 10 & 10 & 10 & 10 & 10 & 9 & 9 & 9 & 9 & 11 \\ M I N I M U M & -- & -- & 12 & 12 & 12 & 12 & 12 & 12 & 13 & 12 & 11 & 11 & 11 & 11 & 11 & 11 & 11 & 11 & 11 & 10 & 10 & 10 & 10 & 10 & 10 & 9 & 9 & 9 & 9 & 9 & 11\end{array}$

JANUAD.Y

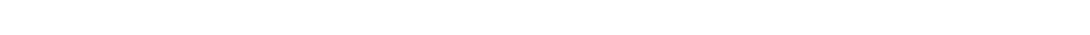

FEBRUARY

MAXIMUM --

MARCH

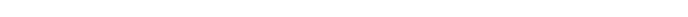

MINIMUR -

APRIL

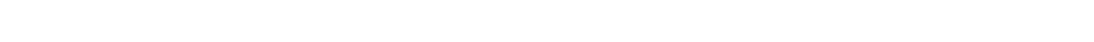

MAY MINI

MAXIMUM $10 \begin{array}{lllllllllllllllllllllllllllllllllllll}10 & 11 & 11 & 11 & 11 & 11 & 11 & 11 & 12 & 13 & 13 & 13 & 13 & 12 & 12 & 12 & 12 & 12 & 12 & 12 & 12 & 12 & 12 & 12 & 12 & \ldots & \ldots & \ldots & \ldots & \ldots & 12\end{array}$

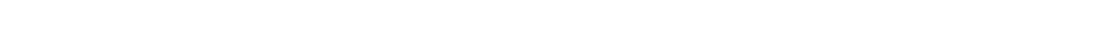

JUNE

MAXIMUM

JULY

MAXIMUM

MAXIMUM -

AUGUST

MAXIMUM --

SEPTEMBE

MAXIMUM $23 \begin{array}{llllllllllllllllllllllllllllllllll}23 & 23 & 23 & 23 & 23 & 23 & 24 & 24 & 24 & 24 & 24 & 24 & 24 & 23 & 24 & 23 & 23 & 23 & 24 & 24 & 24 & 23 & 21 & 20 & 20 & 20 & 20 & 20 & 20 & -1\end{array}$

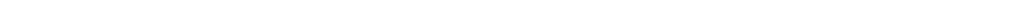


LOCATION.--Lat $37^{\circ} 40^{\circ} 34^{\prime \prime}$, long $121^{\circ} 15^{\prime} 55^{\prime \prime}$, In El Pescadero Grant, San Joaquin County, at gaging station on left bank, $12 \mathrm{ft}$ downst ream from Durham Ferry h1ghway brıdge, 2.6 miles downstream from Stan1slaus Rtver, and 3.2 miles nor theast of Vernalis.

DRAI NAGE AREA, - $-13,540 \mathrm{sq} \mathrm{mi}$.

PERIOD OF RECORD.--Chemical analyses: March 1951 to September 1969.

Water temperatures: March 1951 to September 1969.

EXTREMES, - -1968-69:

Water temperatures: Maxtmum, $25.0^{\circ} \mathrm{C}$ Aug. $20 ; \mathrm{minimum}, 6.0^{\circ} \mathrm{C} \mathrm{Jan} .10$

ntrations: Max1mum dafly, $365 \mathrm{mg} / 1$ Jan. 27 ; mintmum daily, $34 \mathrm{mg} / 1 \mathrm{Dec} .4,5$

Sediment dtscharge: Maxtmum daily, 41,100 tons Jan. 27; minimum datly, 136 tons Nov. 14.

Per1od of record:

Pater temperatures: Maximum, $29.5^{\circ} \mathrm{C}$ June 14 , Aug. 9, Sept. 2, 1966; min1mum, 3. $0^{\circ} \mathrm{C}$ Jan. $24,1962$.

Sediment concent rations: Maximum da1ly, 1,590 mg/1 Dec. 25,$1964 ; \mathrm{m} 1 \mathrm{n} 1 \mathrm{mum}$ da $11 \mathrm{y}, 9 \mathrm{mg} / 1 \mathrm{Jan} .4,1960$

REMARKS, --Chem1cal-quality samples collected by Callfornia Department of Water Resources.

CHEMICAL ANALYSES, WATER YEAR JCTOBER 1968 TO SEPTEMBER 1969

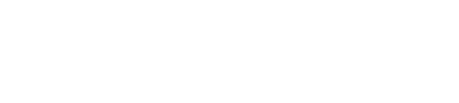

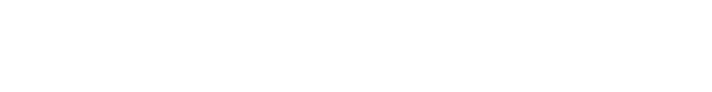

OCT. $\quad 1130 \quad 16 \quad 8.1 \quad 26$

$\begin{array}{llll}\text { NOV. } & 1130 & 16 & 8.1 \\ 08 . . & 2020 & 14 & 7.9\end{array}$

$\begin{array}{lllll}\text { OS... } & 2020 & 14 & 7.9 & 13 \\ \text { OEC. } & 2080 & 11 & 9.6 & -\end{array}$

$\begin{array}{lllll}11 \ldots & 2080 & 11 & 9.6 & - \\ \text { JAN. } & 7560 & & -- & 12\end{array}$

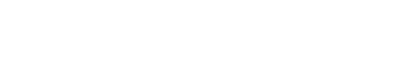

$19 \ldots 25700 \quad 12 \quad$-. $\quad 14$

$\begin{array}{lllll}\text { APR. } & & & & \\ \text { O2... } & 25300 & -- & 7.4 & 11\end{array}$

$16700 \quad-10.7$

$04 \ldots$

AUG.

$07 . .$.

$16700 \quad-7 \quad 8.7 \quad 14$

B.6 11

$7.9 \quad 12$

$5.8 \quad 17$

$0 \quad 46$

$\begin{array}{lllll}17 \ldots & 3090 & 22 & 8.2 & 18\end{array}$

40

10

28

$23 \quad 115$

$5.0 \quad 13$

460

190

$--$

23

$14 \quad 67$

$4.4 \quad 1$

320

133

$$
2.3
$$

10

20

18$$
6.1 \quad 24
$$

160

35

16

2.8

2.5

2.0

1.8

1.5

1.3

.9

1.7

3.6

57

$$
2 \text {. }
$$
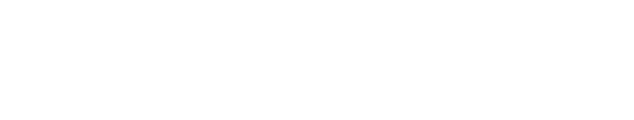

OE..

JAN.

17.
JAN.
FEB.

FEB...

MAR.

19.
$\triangle P R$.

D2...

MAY

JUNE

JUNE

JULY

Aug..

AUG...

SEPT.

$\begin{array}{ccc}79 & 150 & . \\ 53 & 84 & . \\ 65 & 94 & . \\ 20 & 22 & . \\ 28 & 25 & . \\ 38 & 31 & . \\ 39 & 27 & . \\ 13 & 17 & . \\ 8.0 & 8.6 & . \\ 23 & 34 & . \\ 48 & 93 & . \\ 45 & 71 & .\end{array}$

.2
.1
.3
.2
.1
.2
.2
.1
.0
.3
.2
.1

$\begin{array}{ll}8.6 & -- \\ 3.9 & -. \\ .6 & .05 \\ 3.4 & .78 \\ 2.3 & .35 \\ 2.1 & .33 \\ 1.6 & -. \\ 1.9 & .35 \\ .1 & .19 \\ 3.1 & .48 \\ 2.5 & 1.1 \\ 4.8 & .82\end{array}$

300
180
290
110
90
210
220
10
$12 Q$
50
200
150

$\begin{array}{rrr}214 & 58 & 549 \\ 128 & 119 & 334 \\ 115 & 44 & -2 \\ 54 & 6 & 129 \\ 64 & 13 & 148 \\ 78 & 19 & 180 \\ 71 & 19 & 165 \\ 44 & 5 & 100 \\ 26 & 5 & 58 \\ 70 & 19 & 153 \\ 154 & 39 & 363 \\ 128 & 29 & 302\end{array}$

$7.8 \quad 946$

$7.4 \quad 574$

8.7 590

6.9218

$7.4 \quad 248$

7.5307

$7.3 \quad 290$

7.1163

$6.9 \quad 92$

$7.7 \quad 255$

$7.4 \quad 673$

$7.6 \quad 544$ 
11303500 SAN JOAQUIN RIVER NEAR VERNALIS, CALIF.--CONTInUed

CHEMICAL ANALYSES. WATER YEAR OCTOBER 1968 TO SEPTEMBER 1969

\begin{tabular}{|c|c|c|c|c|c|}
\hline OATE & $\begin{array}{l}\text { DIS- } \\
\text { SOLVEO } \\
\text { SOLIOS } \\
\text { ITONS } \\
\text { PER } \\
\text { AC-FTI }\end{array}$ & $\begin{array}{l}\text { PERCENT } \\
\text { SODIUM }\end{array}$ & $\begin{array}{c}\text { SOOIUM } \\
\text { AO- } \\
\text { SORP- } \\
\text { TION } \\
\text { RATIO }\end{array}$ & $\begin{array}{l}\text { ALKA- } \\
\text { LINITY } \\
\text { AS } \\
\text { CACOB } \\
\text { (MGIL) }\end{array}$ & $\begin{array}{l}\text { IUR- } \\
810- \\
118 \\
146 / 1\end{array}$ \\
\hline $\begin{array}{l}\text { OCT. } \\
\text { O9.... } \\
\text { NOV. }\end{array}$ & .75 & 53 & 3.4 & 156 & - \\
\hline OE... & .45 & 52 & 2.6 & 109 & 35 \\
\hline & .43 & 57 & 3.0 & 71 & 25 \\
\hline FEB. & .18 & 46 & 1.3 & 48 & 30 \\
\hline $\begin{array}{c}13 \ldots . . \\
\text { MAR... } \\
19 . .\end{array}$ & .21 & 44 & 1.3 & 51 & 91 \\
\hline $\begin{array}{c}A P R \\
02 \ldots\end{array}$ & .24 & $4 b$ & 1.6 & 59 & 10 \\
\hline MAY & .22 & 46 & 1.5 & 52 & 49 \\
\hline JUNE & .14 & 40 & .9 & 39 & 30 \\
\hline JuLY & .08 & 38 & .6 & 21 & 45 \\
\hline $\begin{array}{l}09 . . . \\
\text { AUG. }\end{array}$ & .21 & 42 & 1.2 & 51 & 40 \\
\hline SEPI: & .49 & 50 & 2.6 & 115 & \\
\hline $11 \ldots$ & .41 & 48 & 2.2 & 99 & 32 \\
\hline
\end{tabular}

TEMPERATURE $\left({ }^{\circ} \mathrm{C}\right)$ OF WATER, WATER YEAR OCTOBER 1968 TO SEPTEMBER 1969

DAY

MONTH

$\begin{array}{llllllllllllllllll}15 & 16 & 17 & 18 & 19 & 20 & 21 & 22 & 23 & 24 & 25 & 26 & 27 & 28 & 29 & 30 & 31 & \text { AVER }\end{array}$

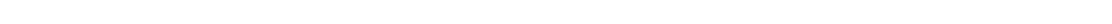

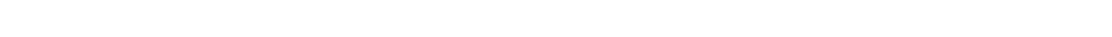

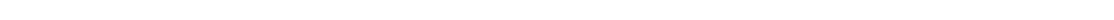

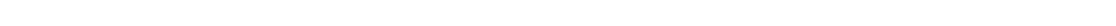

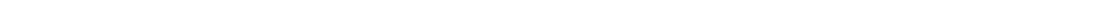
$\begin{array}{lllllllllllllllllllllllllllllllll}\text { APRIL.... } & 14 & 14 & 15 & 14 & 14 & 15 & 13 & 14 & 14 & 14 & 14 & 15 & 14 & 15 & 14 & 15 & 15 & 16 & 16 & 16 & 16 & 18 & 16 & 16 & 14 & 14 & 14 & 14 & 15 & 16 & -- & 15\end{array}$

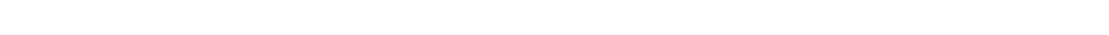

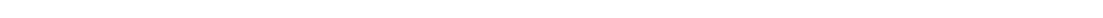

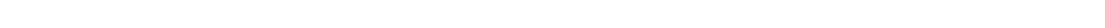

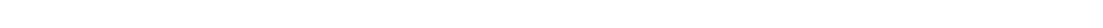

PARTICLE-SIZE DISTRIBUTIDN OF SUSPENDED SEDIMENT DISCHARGE, WATER YEAR 1968 TO SEPTEMBER 1969 IMETHODS OF AINALYSIS: B, BOTTOM WITHORAWAL TUBE; C, CHEMICALLY DISPERSED; N, IN NATIVE WATER; P, PIPET: S, SIEVE:

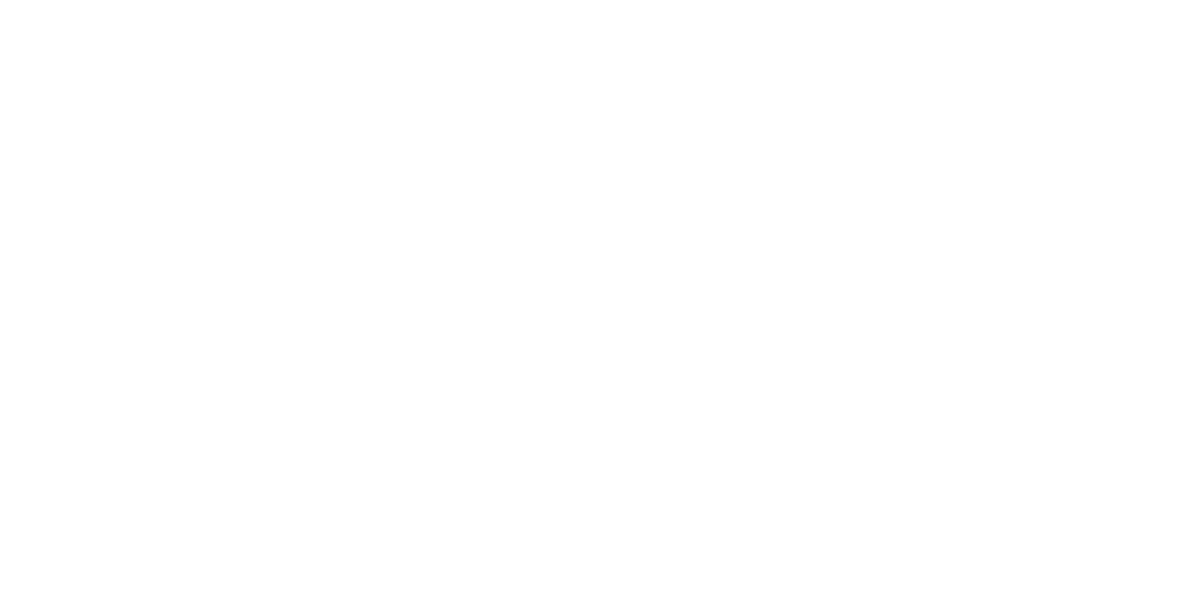


11303500 SAN JOAQUIN RIVER NEAR VERNALIS, CALIF.--Continued

SUSPENDED-SEDIMENT DISCHARGE, WATER YEAR OCTOBER 1968 TD SEPTEMBER 1969

OC TOBER

MEAN CONCEN-

DAY ISCHARGE
(CFSI
(MG/LI)

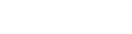

$103 \quad 289$

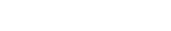

1840

1040
1010

1060

1110

1260

1240

1190
1130

1120

1120

1040

1270
1630
1970

2000
1820

1820

1630

1330

1180

1120

1150

1210
1290

1560

1660
1720

1720
1770

1810

TOTAL 42910 $\begin{array}{lll}94 & 282 & 2100 \\ 99 & 315 & 2100\end{array}$

$\begin{array}{lll}81 & 247 & 1870 \\ 72 & 218 & 1830\end{array}$

$\begin{array}{lll}68 & 206 & 1780 \\ 66 & 185 & 1620\end{array}$

$\begin{array}{rrr}67 & 185 & 1620 \\ 87 & 298 & 1390 \\ 118 & 519 & 1330\end{array}$

$\begin{array}{lll}101 & 537 & 1410\end{array}$

$\begin{array}{lll}94 & 508 & 1440 \\ 89 & 437 & 1500\end{array}$

$\begin{array}{lll}89 & 437 & 1500 \\ 95 & 418 & 1500\end{array}$

$\begin{array}{lll}98 & 394 & 1470 \\ 93 & 334 & 1440\end{array}$

$86 \quad 274 \quad 1400$

$\begin{array}{lll}86 & 274 & 1400 \\ 83 & 251 & 1380\end{array}$

$\begin{array}{lll}82 & 255 & 1350 \\ 83 & 271 & 1310 \\ 84 & 293 & 1280\end{array}$

$92 \quad 388 \quad 1290$

$\begin{array}{lll}80 & 359 & 1290 \\ 74 & 344 & 1290\end{array}$

$\begin{array}{lll}74 & 344 & 1290 \\ 77 & 368 & 1410\end{array}$

10094

1650

48130
$97 \quad 330 \quad 2020$

365
623
$96 \quad 275 \quad 2020$

$\begin{array}{lll}84 & 281 & 2020 \\ 82 & 263 & 1980 \\ 81 & 247 & 1940\end{array}$

NOVEMBER

DECEMBER

MEAN
OISCHARGE
(CFS)

CONCEN- SEDIMENT $\begin{array}{lcccc}\text { IRATION } & \text { DISCHARGE } & \text { OISCHARGE } & \text { TRATION } & \text { DISCHARGE } \\ \text { (MG/L) } & \text { (TONS/DAY) } & \text { (CFS) } & \text { (MG/L) } & \text { (TONS/DAY) }\end{array}$

46

$\begin{array}{ll}60 & 2 \\ 66 & 3 \\ 86 & 4 \\ 86 & 4 \\ 79 & 4 \\ 76 & 4 \\ 77 & 4 \\ 72 & 3 \\ 60 & 3 \\ 55 & \end{array}$

298
339 $\quad 1700$

$\begin{array}{ll}339 & 1690 \\ 469 & 1700\end{array}$

$\begin{array}{ll}488 & 1740 \\ 448 & 1750\end{array}$

$54 \quad 248$

$\begin{array}{ll}415 & 1800 \\ 412 & 2070\end{array}$

$\begin{array}{ll}412 & 2070 \\ 377 & 2240\end{array}$

$303 \quad 2290$

$\begin{array}{lll}52 & 250 & 2080 \\ 52 & 227 & 2080\end{array}$

$\begin{array}{ll}165 & 2040 \\ 136 & 2140\end{array}$

$194 \quad 2320$

$191 \quad 2120$

$\begin{array}{ll}215 & 2070 \\ 227 & 2420\end{array}$

$\begin{array}{ll}227 & 2420 \\ 222 & 2610\end{array}$

204

$\begin{array}{ll}204 & 2590 \\ 194 & 2730\end{array}$

$193 \quad 2740$

$\begin{array}{ll}180 & 2750 \\ 169 & 2840\end{array}$

$160 \quad 2760$

$\begin{array}{ll}160 & 2760 \\ 160 & 3060 \\ 167 & 4180\end{array}$

$206 \quad 4460$

$\begin{array}{ll}276 & 4490 \\ -- & 4440\end{array}$

7763

78520

$\begin{array}{ll}41 & 187 \\ 34 & 156\end{array}$

$34 \quad 160$

$41 \quad 199$

$66 \quad 369$

$\begin{array}{ll}74 & 448 \\ 69 & 408 \\ 61 & 352\end{array}$

$\begin{array}{ll}59 & 331 \\ 58 & 326\end{array}$

$\begin{array}{ll}56 & 308 \\ 55 & 318\end{array}$

$70 \quad 401$

$\begin{array}{ll}62 & 347 \\ 76 & 497\end{array}$

$\begin{array}{ll}74 & 521 \\ 61 & 425\end{array}$

$74 \quad 517$

74
70

$\begin{array}{ll}74 & 520 \\ 66 & 506\end{array}$

$80 \quad 596$

9117
$136 \quad 1530$

$142 \quad 1710$

$\begin{array}{ll}143 & 1730 \\ 129 & 1550\end{array}$

-- 17303

\begin{tabular}{|c|c|c|c|c|c|c|c|c|c|}
\hline \multirow[b]{2}{*}{ DAY } & \multicolumn{3}{|c|}{ JANUARY } & \multicolumn{3}{|c|}{ FEBRUARY } & \multicolumn{3}{|c|}{ MARCH } \\
\hline & $\begin{array}{l}\text { MEAN } \\
\text { OI SCHARGE } \\
\text { (CFS) }\end{array}$ & $\begin{array}{l}\text { MEAN } \\
\text { CONCEN- } \\
\text { TRATION } \\
\text { (MGIL) }\end{array}$ & $\begin{array}{l}\text { SED I MENT } \\
\text { DI S CHARGE } \\
\text { (TONS/DAY) }\end{array}$ & $\begin{array}{l}\text { MEAN } \\
\text { DISCHARGE } \\
\text { ICFSI }\end{array}$ & $\begin{array}{l}\text { MEAN } \\
\text { CONCEN- } \\
\text { TRATION } \\
\text { (MG/L) }\end{array}$ & $\begin{array}{l}\text { SEDIMENT } \\
\text { DISCHARGE } \\
\text { (TONS/DAY) }\end{array}$ & $\begin{array}{l}\text { MEAN } \\
\text { DISCMARGE } \\
\text { (CFS) }\end{array}$ & $\begin{array}{l}\text { MEAN } \\
\text { CONCEN- } \\
\text { TRATION } \\
\text { IMG/LI }\end{array}$ & $\begin{array}{l}\text { SEDIMENT } \\
\text { DISCHARGE } \\
\text { (TONS/DAY) }\end{array}$ \\
\hline 1 & 4320 & 112 & 1310 & 31000 & 161 & 13500 & 47600 & 122 & 15700 \\
\hline 2 & 4200 & 116 & 1320 & 29900 & 149 & 12000 & 46200 & 121 & 15100 \\
\hline 3 & 4160 & 137 & 1540 & 28700 & 138 & 10700 & 44200 & 116 & 13800 \\
\hline 4 & 3690 & 93 & 927 & 27000 & 114 & 8310 & 41800 & 125 & 14100 \\
\hline 5 & 3230 & 82 & 715 & 26900 & 97 & 7050 & 39300 & 121 & 12800 \\
\hline 6 & 2880 & 69 & 537 & 26900 & 135 & 9810 & 36400 & 120 & 11800 \\
\hline 7 & 2780 & 59 & 443 & 27000 & 132 & 9620 & 34000 & 110 & 10100 \\
\hline 8 & 2990 & 68 & 549 & 27300 & 160 & 11800 & 32200 & 100 & 8690 \\
\hline i & 2950 & 77 & 613 & 28100 & 160 & 12100 & 31000 & 107 & 8960 \\
\hline 10 & 3000 & 77 & 624 & 30000 & 141 & 11400 & 30400 & 94 & 7720 \\
\hline 11 & 3200 & 58 & 501 & 31500 & 141 & 12000 & 30000 & 86 & 6970 \\
\hline 12 & 3320 & 69 & 619 & 31900 & 120 & 10300 & 29900 & 77 & 6220 \\
\hline 13 & 3340 & 88 & 794 & 32400 & 113 & 9890 & 29800 & 75 & 6030 \\
\hline 14 & 3580 & 91 & 880 & 32900 & 106 & 9420 & 29200 & 85 & 6700 \\
\hline 15 & 6180 & 94 & 1570 & 32800 & 105 & 9300 & 28400 & 84 & 6440 \\
\hline 16 & 7700 & 130 & 2700 & 32800 & 106 & 9390 & 28100 & 74 & 5610 \\
\hline 17 & 7580 & 165 & 3370 & 32900 & 108 & 9590 & 27900 & 75 & 5650 \\
\hline 18 & 7650 & 150 & 3100 & 32900 & 103 & 9150 & 27300 & 75 & 5530 \\
\hline 19 & 7770 & 132 & 2770 & 32900 & 101 & 8970 & 26700 & 73 & 5260 \\
\hline 20 & 9350 & 140 & 3530 & 34200 & 96 & 8860 & 26300 & 70 & 4970 \\
\hline 21 & 14000 & 238 & 9000 & 35200 & 100 & 9500 & 26000 & 66 & 4630 \\
\hline 22 & 23100 & 355 & 22100 & 35300 & 105 & 10000 & 26000 & 70 & 4910 \\
\hline 23 & 29600 & 161 & 12900 & 34200 & 101 & 9330 & 26400 & 77 & 5490 \\
\hline 24 & 27200 & 123 & 9030 & 33600 & 106 & 9620 & 26800 & 78 & 5640 \\
\hline 23 & 26300 & 135 & 9590 & 34800 & 135 & 12700 & 27100 & 81 & 5930 \\
\hline 26 & 29100 & 233 & 18300 & 38800 & 136 & 14200 & 27200 & 12 & 5290 \\
\hline 27 & 41700 & 365 & 41100 & 44000 & $\begin{array}{l}130 \\
108\end{array}$ & 12800 & 27100 & 63 & 4610 \\
\hline 28 & 39000 & 202 & 21300 & 45600 & 121 & 14900 & 26500 & 54 & 3860 \\
\hline 29 & 36800 & 224 & 22300 & - & -2 & -- & 26000 & 57 & 4000 \\
\hline 30 & 35000 & 200 & 18900 & -- & -- & -- & 25800 & 69 & 4810 \\
\hline 31 & 32600 & 174 & 15300 & -- & -- & -- & 25500 & 63 & 4340 \\
\hline TOTAL & 428250 & -- & 228232 & 911500 & -- & 296210 & 957100 & -- & 231660 \\
\hline
\end{tabular}


11303500 SAN JOAQUI N RIVER NEAR VERNALIS, CALIF.--Cont1nued

SUSPENDED-SEDIMENT DISCHARGE, WATER YEAR OCTOBER 1968 TO SEPTEMBER 1969

\begin{tabular}{|c|c|c|c|c|c|c|c|c|c|}
\hline & & APRIL & & & Mar & & & JUNE & \\
\hline DAY & $\begin{array}{l}\text { MEAN } \\
\text { OI SCHARGE } \\
\text { (CFS) }\end{array}$ & $\begin{array}{l}\text { MEAN } \\
\text { CONCEN- } \\
\text { IRATION } \\
\text { IMG/L) }\end{array}$ & $\begin{array}{l}\text { SEDIMENT } \\
\text { DISCHARGE } \\
\text { (TONS / DAY) }\end{array}$ & $\begin{array}{l}\text { MEAN } \\
\text { DISCHARGE } \\
\text { (CFS I }\end{array}$ & $\begin{array}{l}\text { MEAN } \\
\text { CONCEN- } \\
\text { IRATION } \\
\text { (MGILI) }\end{array}$ & $\begin{array}{l}\text { SEDIMENT } \\
\text { DISCHARGE } \\
\text { (TONS/DAY) }\end{array}$ & $\begin{array}{l}\text { MEAN } \\
\text { OI SCHARGE } \\
\text { (CFS) }\end{array}$ & $\begin{array}{l}\text { MEAN } \\
\text { CONCEN- } \\
\text { TRATION } \\
\text { (MGIL) }\end{array}$ & $\begin{array}{l}\text { SEDIMENT } \\
\text { DISCHARGE } \\
\text { (TONS / DAY) }\end{array}$ \\
\hline $\begin{array}{l}1 \\
2 \\
3 \\
4 \\
5\end{array}$ & $\begin{array}{l}25500 \\
25300 \\
24700 \\
24100 \\
23400\end{array}$ & $\begin{array}{l}68 \\
84 \\
87 \\
84 \\
99\end{array}$ & $\begin{array}{l}4680 \\
5740 \\
5800 \\
5470 \\
6250\end{array}$ & $\begin{array}{l}16900 \\
16900 \\
16800 \\
16100 \\
15900\end{array}$ & $\begin{array}{l}104 \\
103 \\
109 \\
113 \\
115\end{array}$ & $\begin{array}{l}4750 \\
4700 \\
4940 \\
4910 \\
4940\end{array}$ & $\begin{array}{l}33500 \\
33500 \\
33600 \\
33600 \\
33600\end{array}$ & $\begin{array}{l}77 \\
81 \\
80 \\
88 \\
92\end{array}$ & $\begin{array}{l}6960 \\
7330 \\
7260 \\
7980 \\
8350\end{array}$ \\
\hline $\begin{array}{r}6 \\
7 \\
8 \\
9 \\
10\end{array}$ & $\begin{array}{l}23200 \\
24300 \\
25400 \\
26600 \\
27400\end{array}$ & $\begin{array}{r}96 \\
97 \\
98 \\
103 \\
124\end{array}$ & $\begin{array}{l}6010 \\
6360 \\
6720 \\
7400 \\
9170\end{array}$ & $\begin{array}{l}16400 \\
16700 \\
16900 \\
17200 \\
17400\end{array}$ & $\begin{array}{l}113 \\
103 \\
102 \\
108 \\
101\end{array}$ & $\begin{array}{l}5000 \\
4640 \\
4650 \\
5020 \\
4740\end{array}$ & $\begin{array}{l}33600 \\
33600 \\
33800 \\
34100 \\
34500\end{array}$ & $\begin{array}{l}88 \\
86 \\
84 \\
89 \\
92\end{array}$ & $\begin{array}{l}7980 \\
7800 \\
7670 \\
8190 \\
8570\end{array}$ \\
\hline $\begin{array}{l}11 \\
12 \\
13 \\
14 \\
15\end{array}$ & $\begin{array}{l}27000 \\
26000 \\
25100 \\
24400 \\
23700\end{array}$ & $\begin{array}{l}74 \\
67 \\
76 \\
73 \\
77\end{array}$ & $\begin{array}{l}5390 \\
4700 \\
5150 \\
4810 \\
4930\end{array}$ & $\begin{array}{l}17200 \\
17800 \\
19600 \\
21300 \\
23000\end{array}$ & $\begin{array}{l}112 \\
123 \\
127 \\
112 \\
108\end{array}$ & $\begin{array}{l}5200 \\
5910 \\
6720 \\
6440 \\
6710\end{array}$ & $\begin{array}{l}35000 \\
34900 \\
34000 \\
32600 \\
31200\end{array}$ & $\begin{array}{r}94 \\
99 \\
100 \\
102 \\
105\end{array}$ & $\begin{array}{l}8880 \\
9330 \\
9180 \\
8980 \\
8850\end{array}$ \\
\hline $\begin{array}{l}16 \\
17 \\
18 \\
19 \\
20\end{array}$ & $\begin{array}{l}22600 \\
21500 \\
20600 \\
20200 \\
19900\end{array}$ & $\begin{array}{r}80 \\
87 \\
88 \\
101 \\
92\end{array}$ & $\begin{array}{l}4880 \\
5050 \\
4890 \\
5510 \\
4940\end{array}$ & $\begin{array}{l}25100 \\
27200 \\
29000 \\
30300 \\
30900\end{array}$ & $\begin{array}{l}95 \\
90 \\
89 \\
92 \\
80\end{array}$ & $\begin{array}{l}6440 \\
6610 \\
6970 \\
7530 \\
6670\end{array}$ & $\begin{array}{l}29700 \\
27300 \\
2620.0 \\
26200 \\
25600\end{array}$ & $\begin{array}{l}109 \\
119 \\
121 \\
110 \\
107\end{array}$ & $\begin{array}{l}8740 \\
8770 \\
8560 \\
7780 \\
7400\end{array}$ \\
\hline $\begin{array}{l}21 \\
22 \\
23 \\
24 \\
25\end{array}$ & $\begin{array}{l}19900 \\
19700 \\
19100 \\
18400 \\
17900\end{array}$ & $\begin{array}{r}90 \\
89 \\
102 \\
108 \\
109\end{array}$ & $\begin{array}{l}4840 \\
4730 \\
5260 \\
5370 \\
5270\end{array}$ & $\begin{array}{l}31200 \\
31300 \\
31500 \\
31900 \\
32200\end{array}$ & $\begin{array}{l}90 \\
94 \\
86 \\
88 \\
97\end{array}$ & $\begin{array}{l}7580 \\
7940 \\
7310 \\
7580 \\
8430\end{array}$ & $\begin{array}{l}24100 \\
22900 \\
21700 \\
20800 \\
20500\end{array}$ & $\begin{array}{l}114 \\
116 \\
114 \\
120 \\
119\end{array}$ & $\begin{array}{l}7420 \\
7170 \\
6680 \\
6740 \\
6590\end{array}$ \\
\hline $\begin{array}{l}26 \\
27 \\
28 \\
29 \\
30 \\
31\end{array}$ & $\begin{array}{r}17700 \\
17700 \\
17700 \\
17400 \\
17100\end{array}$ & $\begin{array}{r}106 \\
98 \\
89 \\
96 \\
106 \\
--\end{array}$ & $\begin{array}{r}5070 \\
4680 \\
4250 \\
4510 \\
4890 \\
--\end{array}$ & $\begin{array}{l}32400 \\
32400 \\
32500 \\
32700 \\
33000 \\
33300\end{array}$ & $\begin{array}{r}88 \\
101 \\
90 \\
90 \\
84 \\
89\end{array}$ & $\begin{array}{l}7700 \\
8840 \\
7900 \\
7950 \\
7480 \\
8000\end{array}$ & $\begin{array}{r}20600 \\
20000 \\
17900 \\
15200 \\
12800 \\
--\end{array}$ & $\begin{array}{r}119 \\
115 \\
129 \\
167 \\
189 \\
-\end{array}$ & $\begin{array}{c}6620 \\
6210 \\
6230 \\
6850 \\
6530 \\
-\ldots\end{array}$ \\
\hline TOTAL & 663500 & -- & 162720 & 763000 & -- & 200200 & 836600 & - & 231600 \\
\hline & & JuLY & & & AUGUST & & & SEPTEMBER & \\
\hline OAY & $\begin{array}{c}\text { MEAN } \\
\text { OI SCHARGE } \\
\text { (CFS) }\end{array}$ & $\begin{array}{l}\text { MEAN } \\
\text { CONCEN- } \\
\text { TRATIDN } \\
\text { (MG/L) }\end{array}$ & $\begin{array}{l}\text { SEDIMENT } \\
\text { DISCHARGE } \\
\text { (TONS/DAY) }\end{array}$ & $\begin{array}{l}\text { MEAN } \\
\text { OISCHARGE } \\
\text { (CFS) }\end{array}$ & $\begin{array}{l}\text { MEAN } \\
\text { CONCEN- } \\
\text { TRATION } \\
\text { (MG/L) }\end{array}$ & $\begin{array}{l}\text { SEDIMENT } \\
\text { DI SCHARGE } \\
\text { (TONS/DAY) }\end{array}$ & $\begin{array}{l}\text { MEAN } \\
\text { OI SCHARGE } \\
\text { (CFS) }\end{array}$ & $\begin{array}{l}\text { MEAN } \\
\text { CONCEN- } \\
\text { TRATION } \\
\text { (MGIL) }\end{array}$ & $\begin{array}{l}\text { SEDIMENT } \\
\text { DISCHARGE } \\
\text { (TONS / DAY) }\end{array}$ \\
\hline $\begin{array}{l}1 \\
2 \\
3 \\
4 \\
5\end{array}$ & $\begin{array}{r}11200 \\
10100 \\
9450 \\
8500 \\
8260\end{array}$ & $\begin{array}{l}200 \\
192 \\
178 \\
176 \\
181\end{array}$ & $\begin{array}{l}6050 \\
5240 \\
4540 \\
4040 \\
4040\end{array}$ & $\begin{array}{l}2370 \\
2410 \\
2460 \\
2450 \\
2340\end{array}$ & $\begin{array}{l}84 \\
72 \\
63 \\
66 \\
77\end{array}$ & $\begin{array}{l}538 \\
469 \\
418 \\
437 \\
486\end{array}$ & $\begin{array}{l}2700 \\
2700 \\
2680 \\
2710 \\
2790\end{array}$ & $\begin{array}{r}92 \\
108 \\
106 \\
102 \\
95\end{array}$ & $\begin{array}{l}671 \\
787 \\
767 \\
746 \\
716\end{array}$ \\
\hline $\begin{array}{r}6 \\
7 \\
8 \\
9 \\
10\end{array}$ & $\begin{array}{l}8660 \\
8540 \\
8110 \\
7650 \\
6860\end{array}$ & $\begin{array}{l}167 \\
152 \\
147 \\
141 \\
139\end{array}$ & $\begin{array}{l}3900 \\
3500 \\
3220 \\
2910 \\
2570\end{array}$ & $\begin{array}{l}2250 \\
2220 \\
2210 \\
2210 \\
2230\end{array}$ & $\begin{array}{l}73 \\
85 \\
91 \\
88 \\
89\end{array}$ & $\begin{array}{l}443 \\
509 \\
543 \\
525 \\
536\end{array}$ & $\begin{array}{l}2880 \\
2980 \\
3250 \\
3300 \\
3260\end{array}$ & $\begin{array}{l}92 \\
92 \\
84 \\
80 \\
95\end{array}$ & $\begin{array}{l}715 \\
740 \\
737 \\
713 \\
836\end{array}$ \\
\hline $\begin{array}{l}11 \\
12 \\
13 \\
14 \\
15\end{array}$ & $\begin{array}{l}6910 \\
6930 \\
6430 \\
6080 \\
5620\end{array}$ & $\begin{array}{l}138 \\
127 \\
119 \\
115 \\
114\end{array}$ & $\begin{array}{l}2570 \\
2380 \\
2070 \\
1890 \\
1730\end{array}$ & $\begin{array}{l}2280 \\
2170 \\
2140 \\
2090 \\
2040\end{array}$ & $\begin{array}{r}90 \\
88 \\
109 \\
101 \\
97\end{array}$ & $\begin{array}{l}554 \\
516 \\
630 \\
570 \\
534\end{array}$ & $\begin{array}{l}3250 \\
3210 \\
3120 \\
3150 \\
3160\end{array}$ & $\begin{array}{r}98 \\
94 \\
100 \\
98 \\
93\end{array}$ & $\begin{array}{l}860 \\
815 \\
842 \\
833 \\
793\end{array}$ \\
\hline $\begin{array}{l}16 \\
17 \\
18 \\
19 \\
20\end{array}$ & $\begin{array}{l}5700 \\
6640 \\
5910 \\
4350 \\
3750\end{array}$ & $\begin{array}{r}111 \\
101 \\
91 \\
109 \\
112\end{array}$ & $\begin{array}{l}1710 \\
1810 \\
1450 \\
1280 \\
1130\end{array}$ & $\begin{array}{l}1990 \\
2110 \\
2280 \\
2320 \\
2320\end{array}$ & $\begin{array}{r}92 \\
82 \\
87 \\
103 \\
94\end{array}$ & $\begin{array}{l}494 \\
467 \\
536 \\
645 \\
589\end{array}$ & $\begin{array}{l}3070 \\
3090 \\
3090 \\
3000 \\
3200\end{array}$ & $\begin{array}{l}90 \\
83 \\
78 \\
78 \\
84\end{array}$ & $\begin{array}{l}746 \\
692 \\
651 \\
632 \\
726\end{array}$ \\
\hline $\begin{array}{l}21 \\
22 \\
23 \\
24 \\
25\end{array}$ & $\begin{array}{l}3790 \\
3830 \\
3630 \\
3140 \\
2940\end{array}$ & $\begin{array}{r}112 \\
110 \\
108 \\
104 \\
93\end{array}$ & $\begin{array}{r}1150 \\
1140 \\
1060 \\
882 \\
738\end{array}$ & $\begin{array}{l}2320 \\
2330 \\
2320 \\
2420 \\
2580\end{array}$ & $\begin{array}{r}101 \\
103 \\
98 \\
104 \\
100\end{array}$ & $\begin{array}{l}633 \\
648 \\
614 \\
680 \\
697\end{array}$ & $\begin{array}{l}3260 \\
3300 \\
3270 \\
3200 \\
3240\end{array}$ & $\begin{array}{l}83 \\
73 \\
78 \\
76 \\
81\end{array}$ & $\begin{array}{l}731 \\
650 \\
689 \\
657 \\
709\end{array}$ \\
\hline $\begin{array}{l}26 \\
27 \\
28 \\
29 \\
30 \\
31\end{array}$ & $\begin{array}{l}2820 \\
2950 \\
3020 \\
2930 \\
2670 \\
2520\end{array}$ & $\begin{array}{r}100 \\
100 \\
97 \\
93 \\
90 \\
75\end{array}$ & $\begin{array}{l}761 \\
797 \\
791 \\
736 \\
649 \\
510\end{array}$ & $\begin{array}{l}2500 \\
2440 \\
2470 \\
2500 \\
2620 \\
2670\end{array}$ & $\begin{array}{r}93 \\
99 \\
101 \\
99 \\
101 \\
95\end{array}$ & $\begin{array}{l}628 \\
652 \\
674 \\
668 \\
714 \\
685\end{array}$ & $\begin{array}{r}3480 \\
3590 \\
4190 \\
4680 \\
4850 \\
--\end{array}$ & $\begin{array}{r}81 \\
89 \\
103 \\
89 \\
106 \\
--\end{array}$ & $\begin{array}{r}761 \\
863 \\
1170 \\
1120 \\
1390 \\
--\end{array}$ \\
\hline TOTAL & 179890 & 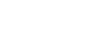 & 67244 & 72060 & -- & 17732 & 97650 & -- & 23758 \\
\hline $\begin{array}{l}\text { TOTAL } \\
\text { TOTAL }\end{array}$ & $\begin{array}{l}\text { OISCHARGE F } \\
\text { SUSPENDED-S }\end{array}$ & $\begin{array}{l}\text { :DR YEAR } \\
\text { SEDIMENT }\end{array}$ & $\begin{array}{l}\text { CFS-OAYSI } \\
\text { ISCHARGE FOR }\end{array}$ & YEAR (TONS) & & & & & $\begin{array}{l}5079110 \\
1494516\end{array}$ \\
\hline
\end{tabular}


11311150 STOCKTON SHIP CANAL AT LIGHT 40, NEAR STOCKTON, CALIF.

LOCATION, --Lat $37^{\circ} 58^{\prime} 40^{\prime \prime}$, long $121^{\circ} 23^{\prime} 00^{\prime \prime}$, T.2 N., R.5 E., San Joaquin County, on left bank at L1ght 40 , approximately 7 miles northwest of stockton.

PERIOD OF RECORD.--Chem1cal analyses: February 1968 to September 1969.

REMARKS, --Records furnished by U.S. Bureau of Reclamation and reviewed by U.S. Geological Survey. CHEMICAL ANALYSES, WATER YEAR OCTOBER 1968 TO SEPTEMBER 1969

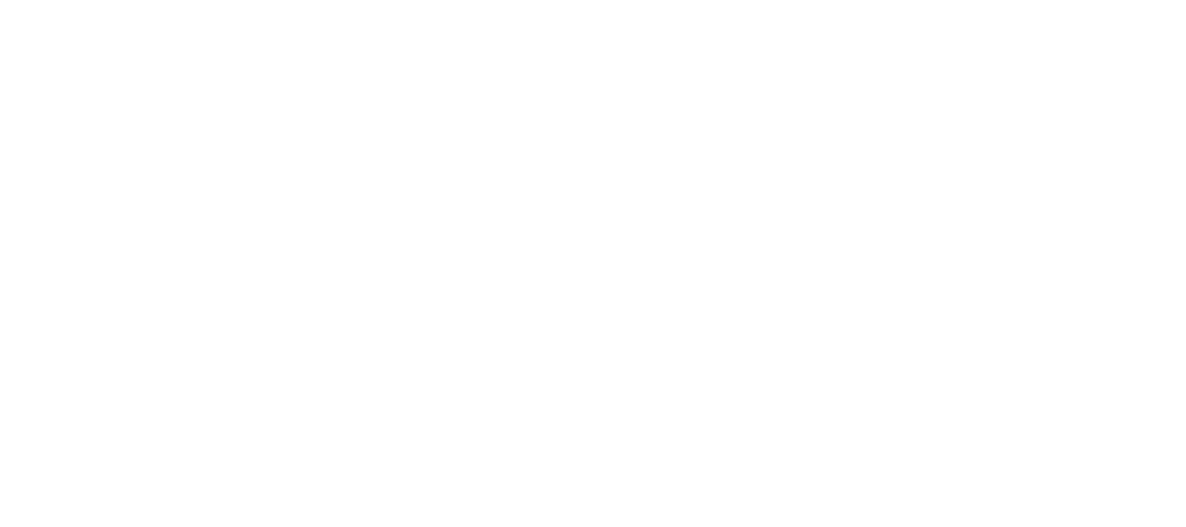

11312990 DELTA-MENDOTA CANAL ABOVE TRACY PUMPI NG PLANT, NEAR TRACY, CALIF. LOCATION,--Lat $37^{\circ} 48^{\prime} 45^{\prime \prime}$, long $121^{\circ} 34^{\prime} 40^{\prime \prime}$, In sec. 30, T.1 S., R.4 E., Contra Costa County, at Byron Road bridge,
1.1 miles upstream from Tracy Pumping Plant and 9.2 miles northwest of Tracy.

PERIOD OF RECORD. --Chemical analyses: October 1953 to September 1969.

REMARKS. --Chemical-quality records furnished by Californ1a Department of Water Resources and reviewed by U.S. Geological Survey. Records of discharge are given for Delta-Mendota Canal at Tracy Pumping Plant, near Tracy CHEMICAL ANALYSES, hater year octOBER 1968 to SePtember 1969

\begin{tabular}{|c|c|c|c|c|c|c|c|c|c|c|c|}
\hline DATE & $\begin{array}{l}\text { MEAN } \\
\text { OIS- } \\
\text { CHARGE } \\
\text { (CFS) }\end{array}$ & $\begin{array}{l}\text { TEMPER- } \\
\text { A TURE } \\
\text { (DEG C) }\end{array}$ & $\begin{array}{l}\text { DIS- } \\
\text { SOLVED } \\
\text { DXYGEN } \\
\text { (MG/L) }\end{array}$ & $\begin{array}{l}\text { CAL } \\
\text { CIUN } \\
\text { (CA) } \\
\text { (MG/L) }\end{array}$ & $\begin{array}{c}\text { MAG- } \\
\text { NE- } \\
\text { SIUM } \\
\text { (MG) } \\
\text { (MG/L) }\end{array}$ & $\begin{array}{l}\text { SOOI UM } \\
\text { (NA) } \\
\text { (MG/L) }\end{array}$ & $\begin{array}{l}\text { PO- } \\
\text { IAS- } \\
\text { SIUM } \\
\text { (K) } \\
\text { (MG/L) }\end{array}$ & $\begin{array}{l}\text { BICAR- } \\
\text { BONATE } \\
\text { (HCD3) } \\
\text { (MG/L) }\end{array}$ & $\begin{array}{l}\text { CAR- } \\
\text { BONATE } \\
\text { (CD3) } \\
\text { (MG/L) }\end{array}$ & $\begin{array}{l}\text { SULFATE } \\
\text { (SO4) } \\
(M G / L)\end{array}$ & $\begin{array}{l}\text { CHLO- } \\
\text { RIDE } \\
(C L) \\
(M G / L)\end{array}$ \\
\hline OCT. & 4410 & 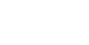 & -- & 17 & 12 & 32 & 2.2 & 105 & 0 & 23 & 37 \\
\hline $\begin{array}{l}\text { NOV. } \\
\text { O6... } \\
\text { DEC. }\end{array}$ & 3130 & - & - & 19 & 13 & 42 & 2.9 & 100 & 0 & 27 & 57 \\
\hline $\operatorname{lig}_{\text {FEB. }}^{11 \ldots}$ & 180 & -- & -- & 41 & 23 & 114 & 5.1 & 153 & 0 & 102 & 150 \\
\hline $\begin{array}{l}05 . . . \\
\text { MAR. }\end{array}$ & 2870 & - & -- & 8.5 & 11 & 25 & 2.6 & 61 & 0 & 26 & 28 \\
\hline $\begin{array}{l}05 \ldots . . \\
\text { APR. }\end{array}$ & 2900 & - & -- & 17 & 8.4 & 27 & 2.1 & 71 & 0 & 33 & 30 \\
\hline $\begin{array}{l}09 . . . \\
\text { SEPT. }\end{array}$ & 1690 & - & - & 16 & 5.8 & 25 & 1.6 & 58 & 0 & 27 & 31 \\
\hline $17 \ldots$ & 1950 & 22 & 8.2 & - & -- & 48 & -- & 112 & 0 & $\cdots$ & 58 \\
\hline DAIE & $\begin{array}{l}\text { NITRATE } \\
\text { (ND3) } \\
\text { (MG/L) }\end{array}$ & $\begin{array}{l}\text { BORON } \\
\text { (B) } \\
\text { (UG/L) }\end{array}$ & $\begin{array}{l}\text { OIS- } \\
\text { SOLVEO } \\
\text { SOLIOS } \\
\text { IRESI- } \\
\text { OUE AT } \\
\text { IBO C) } \\
\text { (MGIL) }\end{array}$ & $\begin{array}{l}\text { OIS- } \\
\text { SOLVEO } \\
\text { SOLIOS } \\
\text { ITONS } \\
\text { PER } \\
\text { AC-FT) }\end{array}$ & $\begin{array}{l}\text { HARD- } \\
\text { NESS } \\
(C A, M G) \\
(M G / L)\end{array}$ & $\begin{array}{l}\text { NON- } \\
\text { CAR- } \\
\text { BDNATE } \\
\text { HARD- } \\
\text { NESS } \\
\text { (MG/L) }\end{array}$ & $\begin{array}{l}\text { PERCENT } \\
\text { SODIUM }\end{array}$ & $\begin{array}{c}\text { SODIUM } \\
\text { AD- } \\
\text { SORP- } \\
\text { TION } \\
\text { RATIO }\end{array}$ & $\begin{array}{l}\text { ALKA- } \\
\text { LINITY } \\
\text { AS } \\
\text { CACD3 } \\
\text { (MG/L) }\end{array}$ & $\begin{array}{c}\text { PH } \\
\text { (UNITS) }\end{array}$ & $\begin{array}{l}\text { SPECI- } \\
\text { FIC } \\
\text { COND- } \\
\text { UCTANCE } \\
\text { (MICRO- } \\
\text { MHOSI }\end{array}$ \\
\hline $\begin{array}{l}\text { Oct. } \\
\text { O9... } \\
\text { Nov. }\end{array}$ & 2.8 & 140 & 198 & .27 & 92 & 6 & 42 & 1.5 & B6 & 8.1 & 361 \\
\hline OG... & 6.1 & 220 & 226 & .31 & 100 & 18 & 47 & 1.8 & 82 & 7.8 & 458 \\
\hline FEB... & 9.0 & 560 & 530 & .72 & 196 & 10 & 55 & 3.5 & 125 & B. 1 & 952 \\
\hline $\begin{array}{l}\text { O5.... } \\
\text { MAR. }\end{array}$ & 3.2 & 210 & 161 & .22 & 66 & 16 & 44 & 1.3 & 50 & 7.5 & 254 \\
\hline $\begin{array}{l}\text { 05... } \\
\text { APR. }\end{array}$ & 5.3 & 190 & 184 & .25 & 17 & 19 & 42 & 1.3 & 58 & 7.7 & 295 \\
\hline $\begin{array}{l}09 . . . \\
\text { SEPI. }\end{array}$ & 2.6 & 170 & 172 & .23 & 64 & 16 & 45 & 1.4 & 48 & 7.9 & 266 \\
\hline $17 \ldots$ & - & 110 & - & $\cdots$ & 108 & 16 & 49 & 2.0 & 92 & 7.6 & 448 \\
\hline
\end{tabular}


11313050 DELTA-MENDOTA CANAL NEAR MENDOTA, CALIF.

LOCATION. --Lat $36^{\circ} 47^{\prime} 11^{\prime \prime}$, long $120^{\circ} 23^{\prime} 04^{\prime \prime}$, In sec.19, T.13 S., R.15 E. , Fresno County, approximately 1 mile upstream from control gates into Mendota pool and 2 miles north of Mendota.

PERIOD OF RECORD.--Chemical analyses: October 1953 to September 1969.

REMARKS. - Chemica1-quality records furnished by California Department of Water Resources and reviewed by U.S. Geological Survey.

CHEMICAL ANALYSES, WATER YEAR OCTOBER 1968 TO SEPTEMBER 1969

\begin{tabular}{|c|c|}
\hline DATE & $\begin{array}{l}\text { MEAN } \\
\text { DIS- } \\
\text { CHARGE } \\
\text { (CFS) }\end{array}$ \\
\hline $\begin{array}{r}\text { OCT. } \\
09 . .\end{array}$ & 1560 \\
\hline $\begin{array}{l}\text { NOV. } \\
\text { O6... } \\
\text { OEC.. }\end{array}$ & 389 \\
\hline FEB. & .01 \\
\hline MAR.. & .01 \\
\hline $\begin{array}{l}05 \ldots \\
A P R\end{array}$ & .01 \\
\hline $\begin{array}{r}09 . . \\
\text { SEPT. } \\
08 . .\end{array}$ & 1730 \\
\hline
\end{tabular}

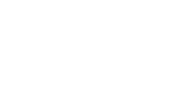

PO-

TAS- BICAR-

SIUM BONATE

(K) (HCO3)

$\begin{array}{ll}\text { CAR- } & \text { CHLQ- } \\ \text { BONATE SULFATE RIDE NITRATE }\end{array}$ (C03) (SO4) (CL) (NO3)

$(M G / L)$ (MG/L) (MG/L) (MG/L) IMG/L)

$\begin{array}{ccc}18 & 12 & 35 \\ 21 & 14 & 49 \\ 40 & 24 & 114 \\ 41 & 23 & 99 \\ 54 & 31 & 144 \\ 8.3 & 3.0 & 7.2 \\ -- & -- & 54\end{array}$

$$
\begin{aligned}
& 2.3 \\
& 2.9 \\
& 5.3 \\
& 4.9 \\
& 4.2 \\
& 1.5
\end{aligned}
$$

106

(MG/L) (MG/L)

$2.9 \quad 106$

$5.3 \quad 152$

$4.9 \quad 148$

4.2

142

\begin{tabular}{|c|c|c|c|c|c|c|c|c|c|c|}
\hline DATE & $\begin{array}{c}\text { BORON } \\
(B) \\
(U G / L)\end{array}$ & $\begin{array}{l}\text { OIS- } \\
\text { SOLVED } \\
\text { SOLIOS } \\
\text { IRESI- } \\
\text { DUE AT } \\
\text { IBO CI } \\
\text { (MG LI) }\end{array}$ & $\begin{array}{l}\text { DIS- } \\
\text { SOLVEO } \\
\text { SOLIOS } \\
\text { (TONS } \\
\text { PER } \\
\text { AC-FII }\end{array}$ & $\begin{array}{l}\text { HARD- } \\
\text { NESS } \\
\text { (CA, MG) } \\
\text { (AG } / L \text { ) }\end{array}$ & $\begin{array}{l}\text { NON- } \\
\text { CAR- } \\
\text { BONATE } \\
\text { MARD- } \\
\text { NESS } \\
\text { (MG/LI I }\end{array}$ & $\begin{array}{l}\text { PERCENT } \\
\text { SODIUM }\end{array}$ & $\begin{array}{l}\text { SOOIUM } \\
\text { AD- } \\
\text { SORP- } \\
\text { IION } \\
\text { RAYIO }\end{array}$ & $\begin{array}{l}\text { ALKA- } \\
\text { LINITY } \\
\text { AS } \\
\text { CACOB } \\
\text { (MG/LI) }\end{array}$ & $\begin{array}{c}\text { PH } \\
\text { (UNITSI }\end{array}$ & $\begin{array}{l}\text { SPECI- } \\
\text { FIC } \\
\text { COND- } \\
\text { UCTANCE } \\
\text { (MICRO- } \\
\text { MHOSI }\end{array}$ \\
\hline $\begin{array}{l}\text { OCT. } \\
09 . . .\end{array}$ & 130 & 218 & .30 & 95 & 8 & 44 & 1.6 & 87 & 8.2 & 384 \\
\hline $\begin{array}{l}\text { NOV. } \\
\text { O6... } \\
\text { DEC. }\end{array}$ & 250 & 279 & .38 & 110 & 23 & 48 & 2.0 & 87 & 7. $a$ & 493 \\
\hline FEB. & 630 & 524 & .71 & 199 & 74 & 55 & 3.5 & 125 & 8.2 & 925 \\
\hline MAR... & 560 & 513 & .70 & 195 & 74 & 51 & 3.1 & 121 & 8.1 & 895 \\
\hline $\begin{array}{l}05 . . . \\
\text { APR. }\end{array}$ & 1000 & 762 & 1.04 & 262 & 146 & 54 & 3.9 & 116 & 8.2 & 1200 \\
\hline $\begin{array}{l}09 . . . \\
\text { SEPT. }\end{array}$ & 0 & 88 & .12 & 33 & 0 & 31 & .5 & 38 & 7.6 & 101 \\
\hline $08 \ldots$ & 200 & - & -- & 128 & 35 & 48 & 2.1 & 93 & 7.5 & 540 \\
\hline
\end{tabular}

$\begin{array}{rcr}27 & 42 & 2.5 \\ 50 & 58 & 7.0 \\ 121 & 133 & 8.4 \\ 120 & 124 & 6.8 \\ 260 & 140 & 6.1 \\ 7.6 & 2.6 & .9 \\ -- & 71 & --\end{array}$


LOCATION, --Lat $38^{\circ} 18^{\prime} 46^{\prime \prime}$, I ong $120^{\circ} 43^{\prime} 09^{\prime \prime}$, In SW $\frac{1}{4} S W$ sec. 1, T. 5 N., R.11 E., Calaveras County, temperature recorder at gaging station on downstream stde of bridge, i.2 miles northwest of Mokelumne Hill and $8 \mathrm{miles}$
downstream from confluence of North and South Forks.

DRAINAGE AREA. --544 sq $\mathrm{mi}$.

PERIOD OF RECORD. - Water temperatures: February 1961 to September 1969.

EXTREMES. $-1968-69$ :

Water temperatures: Maximum, $19.0^{\circ} \mathrm{C}$ July $25 ; \mathrm{m} 1 \mathrm{nimum}, 4.0^{\circ} \mathrm{C}$ on several days during January to March.

Period of record:

Water temperatures: Maxtmum, $24.5^{\circ} \mathrm{C}$ Aug. 5, 1967; minimum (1961-65, 1966-69), 1.0 $0^{\circ} \mathrm{C} \mathrm{Jan}, 31$, Feb. 1,1968 , TEMPERATURE $\left({ }^{\circ} \mathrm{C}\right)$ OF WATER, WATER YEAR OCTOBER 1968 TO SEPTEMBER 1969

DAY

$\begin{array}{lllllllllllllllllllllllllllllllllll}\text { MONTH } & 1 & 2 & 3 & 4 & 5 & 6 & 7 & 8 & 9 & 10 & 11 & 12 & 13 & 14 & 15 & 16 & 17 & 18 & 19 & 20 & 21 & 22 & 23 & 24 & 25 & 26 & 27 & 28 & 29 & 30 & 31 & \text { AGE }\end{array}$

OC TUBFR

$\begin{array}{lllllllllllllllllllllllllllllllllllllllll}\text { MAXIMUM } & 15 & 15 & 15 & 15 & 16 & 17 & 15 & 14 & 14 & 14 & 14 & 14 & 14 & 14 & 13 & 13 & 13 & 14 & 14 & 13 & 14 & 14 & 14 & 14 & 15 & 14 & 14 & 14 & 14 & 14 & 13 & 14 \\ \text { MINIMUM } & 13 & 13 & 14 & 14 & 14 & 13 & 13 & 13 & 13 & 13 & 13 & 14 & 13 & 13 & 12 & 12 & 12 & 12 & 12 & 13 & 13 & 12 & 12 & 12 & 13 & 13 & 13 & 13 & 13 & 13 & 13 & 13\end{array}$

NOVEMRER

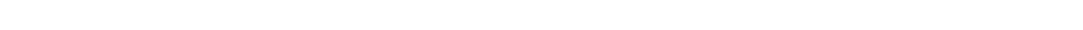

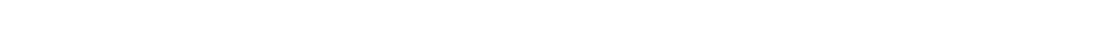

OECEMBER

MAXIMUM $9090 \begin{array}{lllllllllllllllllllllllllllllll} & 9 & 8 & 8 & 8 & 8 & 9 & 9 & 9 & 9 & 8 & 7 & 7 & 9 & 8 & 7 & 7 & 7 & 6 & 6 & 6 & 6 & 6 & 7 & 6 & 5 & 6 & 6 & 6 & 6 & 7\end{array}$

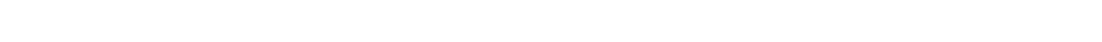

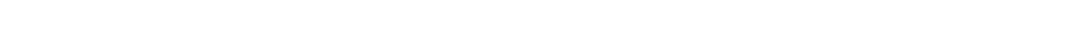

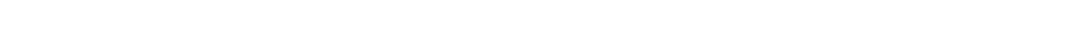

EBRUARY

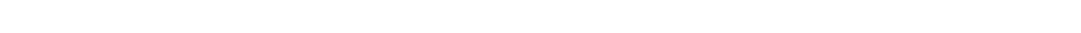

MARCH

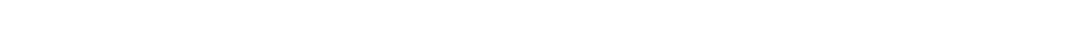

MPINIMUM

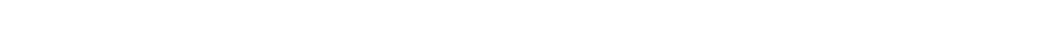

MAXIMUM 11,111010111212121212121212111112121212121213131313121212131314 $\begin{array}{lllllllllllllllllllllllllllllllll}\text { MAXIMUM } & 11 & 11 & 10 & 10 & 11 & 12 & 12 & 12 & 12 & 12 & 12 & 12 & 12 & 11 & 11 & 12 & 12 & 12 & 12 & 12 & 12 & 13 & 13 & 13 & 13 & 12 & 12 & 12 & 13 & 13 & 14 \\ \text { MINIMUM } & 10 & 10 & 10 & 9 & 10 & 11 & 12 & 12 & 12 & 12 & 12 & 12 & 11 & 11 & 10 & 11 & 11 & 11 & 10 & 10 & 11 & 11 & 11 & 11 & 10 & 10 & 10 & 10 & 11 & 11 & 12\end{array}$

JUNE $\begin{array}{lllllllllllllllllllllllllllllllllllll}\text { MAXIMUM } & 14 & 14 & 14 & 14 & 14 & 14 & 14 & 14 & 13 & 12 & 12 & 13 & 14 & 14 & 15 & 14 & 14 & 14 & 14 & 14 & 14 & 14 & 14 & 15 & 14 & 14 & 14 & 14 & 14 & 15 & \ldots \\ \text { MINIMUM } & 12 & 12 & 12 & 12 & 12 & 12 & 12 & 12 & 12 & 12 & 12 & 11 & 12 & 12 & 13 & 14 & 13 & 13 & 13 & 13 & 13 & 13 & 14 & 13 & 13 & 13 & 13 & 13 & 12 & 13 & -\end{array}$ JULY

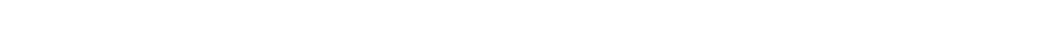
MINIMUM $13 \quad 14 \begin{array}{lllllllllllllllllllllllllllll}4 & 14 & 14 & 14 & 15 & 15 & 15 & 15 & 14 & 15 & 15 & 15 & 15 & 15 & 15 & 15 & 14 & 14 & 14 & 14 & 14 & 14 & 14 & 14 & 14 & 14 & 14 & 14 & 14\end{array}$ AUTUST

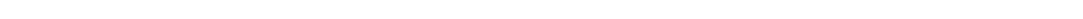

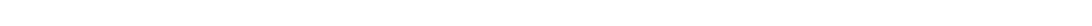
SEPTEMBEK

MAXIMUM $14 \begin{array}{lllllllllllllllllllllllllllllllll} & 14 & 14 & 15 & 15 & 14 & 14 & 14 & 15 & 15 & 15 & 15 & 15 & 15 & 14 & 14 & 14 & 15 & 14 & 15 & 15 & 14 & 16 & 15 & 15 & 15 & 15 & 18 & 16 & 16 & \cdots & 15\end{array}$

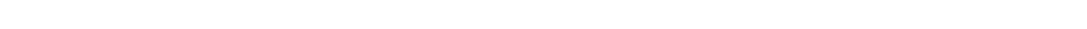


11325500 MOKELUUNE RIVER AT WOODBRIDGE, CALIF.

LOCATION. --Lat $38^{\circ} 09^{\prime} 31^{\prime \prime}$, long $121^{\circ} 18^{\prime} 09^{\prime \prime}$, in NW tion on right bank at Woodbridge, 0.3 mile downstream from county highway bridge and 0.4 mile downstream from

DRAINAGE AREA. --661 sq $\mathrm{mi}$

PERIOD OF RECORD.--Chemical analyses: March 1951 to September 1963, April 1968 to September 1959

Water temperatures: March 1951 to September 1958, November 1960 to September 1969.

EXTREMES.--1968-69:

Water temperatures: Maximum, 21. $0^{\circ} \mathrm{C}$ Aug. 14-19; minimum, 6. $0^{\circ} \mathrm{C}$ Dec, 21-24.

Period of record:

Mater temperatures: Maximum $(1951-54,1956-58,1960-69), 28.5^{\circ} \mathrm{C}$ July 9, 1951; minimum (1951-55, 1956-58,
$1961-69), 1.5^{\circ} \mathrm{C}$ Jan. $29,30,1954$.

REMARKS. - Chemical-quality records furnished by California Department of Water Resources and reviewed by U.S. Geological Survey.

CHEMICAL ANALYSES, WATER YEAR OCTOBER 1968 TO SEPTEMBER 1969

\begin{tabular}{|c|c|c|c|c|c|c|c|c|}
\hline DATE & TIME & $\begin{array}{l}\text { DIS- } \\
\text { CHARGE } \\
\text { (CFS) }\end{array}$ & $\begin{array}{l}\text { TEMPER- } \\
\text { ATURE } \\
\text { (OEG C) }\end{array}$ & $\begin{array}{l}\text { DIS- } \\
\text { SOLVED } \\
\text { OXYGEN } \\
\text { (MG/L) }\end{array}$ & $\begin{array}{l}\text { CAL- } \\
\text { CIUM } \\
\text { (CA) } \\
\text { (MG/L) }\end{array}$ & $\begin{array}{l}\text { SOOIUM } \\
\text { (NA) } \\
\text { (MG/L) }\end{array}$ & $\begin{array}{l}\text { BICAR- } \\
\text { BONATE } \\
\text { (HCO3) } \\
\text { (MGIL) }\end{array}$ & $\begin{array}{l}\text { CAR- } \\
\text { BONATE } \\
\text { (CO3) } \\
\text { (MG/L) }\end{array}$ \\
\hline $\begin{array}{l}\text { OCT. } \\
10 . . . \\
\text { MAR. }\end{array}$ & 0800 & 38 & 15 & 9.5 & 6.0 & 2.5 & 25 & 0 \\
\hline $03 . .$. & 1225 & 2360 & 9 & 12.6 & 4.3 & 2.1 & 20 & 0 \\
\hline DATE & $\begin{array}{l}\text { CHLO- } \\
\text { RIDE } \\
\text { (CL) } \\
\text { (MG/L) }\end{array}$ & $\begin{array}{l}\text { HARO- } \\
\text { NESS } \\
(C A, M G) \\
(M G / L)\end{array}$ & $\begin{array}{l}\text { NON- } \\
\text { CAR- } \\
\text { BONATE } \\
\text { HARD- } \\
\text { NESS } \\
\text { (MG }\end{array}$ & $\begin{array}{l}\text { PERCENT } \\
\text { SODIUM }\end{array}$ & $\begin{array}{l}\text { SODIUM } \\
\text { AD- } \\
\text { SORP- } \\
\text { TION } \\
\text { RATIO }\end{array}$ & $\begin{array}{c}\text { ALKA- } \\
\text { LINITY } \\
\text { AS } \\
\text { CACD3 } \\
\text { (MG/L) }\end{array}$ & $\begin{array}{c}P H \\
\text { (UNITS) }\end{array}$ & $\begin{array}{l}\text { SPECI- } \\
\text { FIC } \\
\text { CONO- } \\
\text { UCTANCE } \\
\text { (MICRO- } \\
\text { MHOSI) }\end{array}$ \\
\hline
\end{tabular}

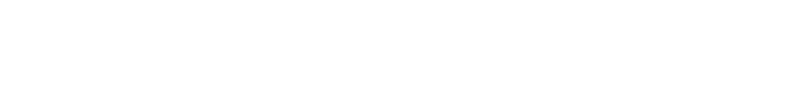

TEMPERATURE ( ${ }^{\circ} \mathrm{C}$ ) OF FATER, TATER YEAR OCTOBER 1968 TO SEPTEMBER 1969

$$
\text { OAY }
$$

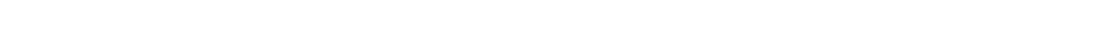

OC TOBER

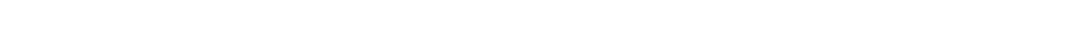

$\begin{array}{lllllllllllllllllllllllllllllllll}\text { MANIMUM } & 17 & 17 & 17 & 17 & 17 & 17 & 17 & 17 & 17 & 16 & 16 & 16 & 16 & 16 & 15 & 14 & 14 & 14 & 14 & 14 & 15 & 15 & 15 & 15 & 15 & 15 & 15 & 16 & 15 & 14 & 16\end{array}$

MAXIMR

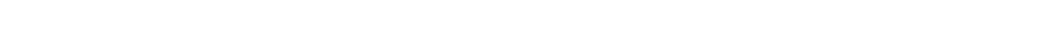

MINIMUM $14 \begin{array}{lllllllllllllllllllllllllllllllll}14 & 14 & 13 & 13 & 14 & 13 & 13 & 13 & 14 & 14 & 14 & 12 & 11 & 11 & 11 & 11 & 11 & 12 & 13 & 13 & 13 & 13 & 12 & 12 & 11 & 11 & 10 & 10 & 10 & -2\end{array}$

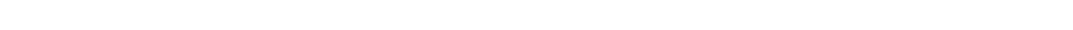

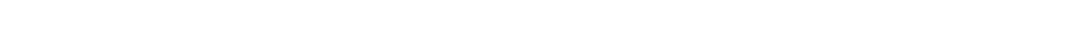

ANUARY

MAXIMUM

FEBRAQY

MAXIMUM

MINIMUM

MARCH

MINIMUM

APR IL

MAXIMUM

AAY

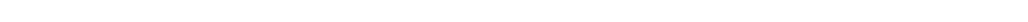

UNE

MAXIMUM $13 \quad 13 \quad 14 \quad 14 \quad 14 \quad 14 \quad 14 \quad 14 \quad 14 \quad 14 \quad 14 \quad 14 \quad 14 \quad 14 \quad 14 \quad 14 \quad 14 \quad 14 \quad 14 \quad 14 \quad 14 \quad 14 \quad 15 \quad 16 \quad 16 \quad 16 \quad 16 \quad 16 \quad 17 \quad 17 \quad-$

MINIMUM

ULY Y

MAXIMUM $17 \quad 17 \quad 17 \quad 1717 \quad 17 \quad 17 \quad 17 \quad 17 \quad 17 \quad 18 \quad 18 \quad 18 \quad 1819191919 \quad 191919192020 \quad 201919191919 \quad 20$

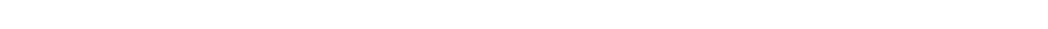

AUGUST

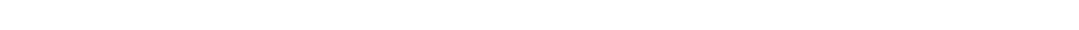
MINIMUM $20202019191919191919192020202121 \quad 212120202020202019191919191919 \quad 20$

SEPTEMBER

$\begin{array}{lllllllllllllllllllllllllllllllllllll}\text { MAXIMMUM } & 19 & 19 & 19 & 19 & 19 & 18 & 18 & 18 & 18 & 18 & 18 & 18 & 18 & 18 & 18 & 18 & 18 & 18 & 17 & 17 & 17 & 17 & 17 & 17 & 17 & 17 & 17 & 17 & 17 & 17 & -- & 18 \\ \text { MINIMMUM } & 19 & 19 & 19 & 19 & 18 & 18 & 18 & 18 & 18 & 18 & 18 & 18 & 18 & 18 & 18 & 18 & 18 & 17 & 17 & 17 & 17 & 17 & 17 & 17 & 17 & 17 & 17 & 17 & 17 & 17 & -- & 18\end{array}$ 


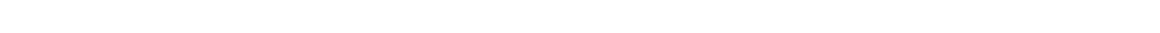

on downstream side of midstream pier of highway bridge at Michigan Bar, 5.5 miles southwest of Latrobe and DRAINAGE AREA. $-\mathbf{5 3 6}$ sq $\mathrm{m} 1$.

PERIOD OF RECORD. --Chemical analyses: October 1953 to September 1963, January 1968 to September 1969. Water temperatures: October 1962 to September 1969

EXTREMES, - 1968-69:

Water temperatures: Maximum, $27.0^{\circ} \mathrm{C}$ on several days during July to September; minimum, 3.0 $0^{\circ} \mathrm{C}$ Dec. 21,22 Sediment concentrations: Maximum daily, 1,220 mg/1 Jan. 21; minimum dally, $1 \mathrm{mg} / 1$ on many days.

作

period of record:

Fater temperatures: Maximum (1965-69), 30.0 ${ }^{\circ} \mathrm{C}$ Aug. 26, 27, 1967; minimum (1963-69), 2.0 $0^{\circ} \mathrm{C}$ on several days during December in 1965. and 1967, and January 1968. Sediment concentrations: Maximum daily, $3,070 \mathrm{mg} / 1$ Feb. 1,1963 ; minimum, $1 \mathrm{mg} / 1$ on many days during $1962-69$.
Sediment discharge: Maximum da11y, 245,00 tons Feb. 1,1963 ; minimum daily, 0.01 ton on several days during 1962-67.

REMARKS, --Chemical-quality data furnished by California Department of Water Resources and reviewed by U.S. Geological Survey. Where no maximum or minimum is shown, temperature is once-daily reading.

CHEMICAL ANALYSES, WATER YEAR OCTOBER 1968 TO SEPTEMBER 1969

\begin{tabular}{|c|c|c|c|c|c|c|c|c|}
\hline DATE & TIME & $\begin{array}{l}\text { DIS- } \\
\text { CHARGE } \\
\text { (CFS) }\end{array}$ & $\begin{array}{l}\text { TEMPER- } \\
\text { ATURE } \\
\text { (DEG C) }\end{array}$ & $\begin{array}{l}\text { DIS- } \\
\text { SOLVED } \\
\text { OXYGEN } \\
\text { (MG/L I }\end{array}$ & $\begin{array}{l}\text { CAL- } \\
\text { CIUM } \\
(C A) \\
(M G / L)\end{array}$ & $\begin{array}{l}\text { SODIUM } \\
\text { (NA) } \\
\text { (MG/L) }\end{array}$ & $\begin{array}{l}\text { BICAR- } \\
\text { BONATE } \\
\text { IHCOBI } \\
\text { (MG/L) }\end{array}$ & $\begin{array}{l}\text { CAR- } \\
\text { BONATE } \\
\text { (CO3) } \\
\text { (MG/L) }\end{array}$ \\
\hline $\begin{array}{l}\text { MAR. } \\
04 \ldots . .\end{array}$ & 1510 & 1770 & 9 & 12.9 & B.6 & 3.4 & 50 & 0 \\
\hline DATE & $\begin{array}{l}\text { CHLO- } \\
\text { RIDE } \\
\text { (CL I } \\
\text { (MG/L) }\end{array}$ & $\begin{array}{l}\text { HARD- } \\
\text { NESS } \\
(C A, M G) \\
(M G / L)\end{array}$ & $\begin{array}{l}\text { NON- } \\
\text { CAR- } \\
\text { BONATE } \\
\text { HARD- } \\
\text { NESS } \\
\text { (MG/L) }\end{array}$ & $\begin{array}{l}\text { PERCENT } \\
\text { SODIUM }\end{array}$ & $\begin{array}{l}\text { SODIUM } \\
\text { AD- } \\
\text { SORP- } \\
\text { TIDN } \\
\text { RATIO }\end{array}$ & $\begin{array}{l}\text { ALKA- } \\
\text { LINITY } \\
\text { AS } \\
\text { CACO3 } \\
\text { (MG/L) }\end{array}$ & $\begin{array}{c}\text { PH } \\
\text { (UNITSI }\end{array}$ & $\begin{array}{l}\text { SPECI- } \\
\text { FIC } \\
\text { CONO- } \\
\text { UCTANCE } \\
\text { (MICRO- } \\
\text { MHOS) }\end{array}$ \\
\hline $\begin{array}{l}\text { MAR. } \\
04 \ldots . . .\end{array}$ & 2.0 & 45 & 4 & 26 & .3 & 41 & 7.6 & 99 \\
\hline
\end{tabular}

TEMPERATURE $\left({ }^{\circ} \mathrm{C}\right)$ OF WATER, WATER YEAR OCTOBER 1968 TO SEPTEMBER 1969

CAY

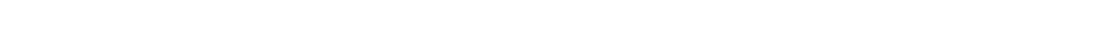

OCTOHER.. -- -- -- - - - - - - - - - - -

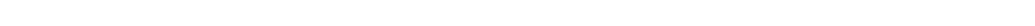

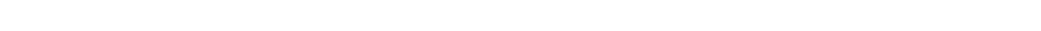

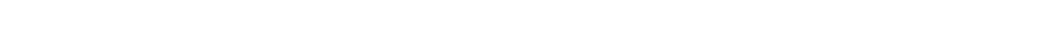

$\begin{array}{lllllllllllllllllllllllllllllllllllll}\text { MAXIMINM } & 16 & 16 & 16 & 15 & 15 & 14 & 15 & 14 & 14 & 15 & 16 & 16 & 14 & 12 & 12 & 12 & 13 & 13 & 13 & 13 & 13 & 13 & 13 & 13 & 12 & 11 & 10 & 8 & 8 & 8 & -= \\ \text { MINIMUM } & 14 & 15 & 15 & 14 & 14 & 14 & 14 & 14 & 13 & 13 & 14 & 14 & 12 & 11 & 11 & 11 & 12 & 13 & 12 & 12 & 12 & 12 & 12 & 12 & 11 & 9 & 8 & 8 & 7 & 8 & -=\end{array}$

DECEMBFR. - -

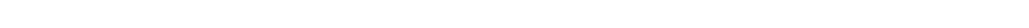

JANUARY.. - - - - - - - - - - - -

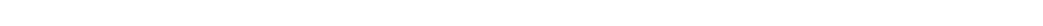

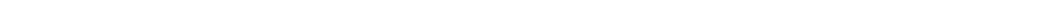

FEBRUAPY.

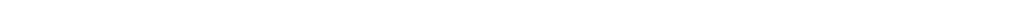

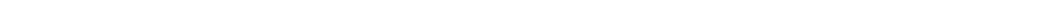

MAXIMUM --

MINIMUM --

APRIL.Z.̈ $\begin{array}{llllllllllllllllllllllllllllllllllllll}\text { MAXIMUM } & 11 & 11 & 11 & 12 & 12 & 11 & 11 & 12 & 12 & 12 & 13 & 13 & 13 & 12 & 12 & 12 & 13 & 13 & 13 & 13 & 14 & 14 & 13 & 12 & 12 & 12 & 13 & 14 & 14 & 14 & =- \\ \text { MINIMUM } & 10 & 10 & 11 & 10 & 11 & 10 & 10 & 10 & 11 & 11 & 12 & 13 & 11 & 11 & 10 & 11 & 12 & 12 & 11 & 12 & 12 & 13 & 12 & 10 & 10 & 11 & 12 & 12 & 13 & 12 & --\end{array}$

$\begin{array}{rlllllllllllllllllllllllllllllll}\text { MAXiMuM } & 13 & 13 & 13 & 13 & 14 & 15 & 15 & 14 & 15 & 15 & 15 & 15 & 15 & 14 & 14 & 15 & 16 & 16 & 16 & 16 & 16 & 17 & 17 & 17 & 17 & 17 & 17 & 17 & 17 & 18 & 19\end{array}$

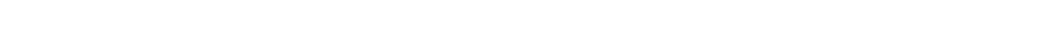

JUNE....

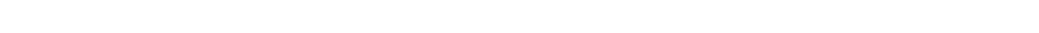
$\begin{array}{llllllllllllllllllllllllllllllllllll}\text { MAXIMUM } & 23 & 23 & 23 & 23 & 23 & 23 & 24 & 24 & 24 & 24 & 24 & 25 & 25 & 25 & 25 & 25 & 25 & 26 & 26 & 26 & 27 & 27 & 27 & 26 & 26 & 26 & 26 & 26 & 26 & 26 & 25\end{array}$

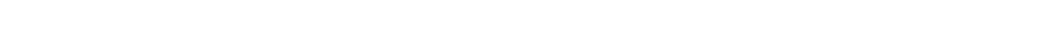

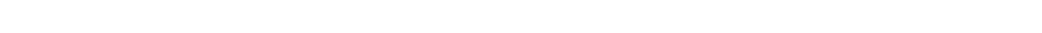

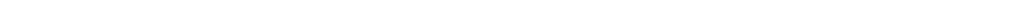

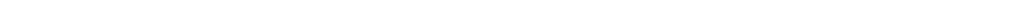

SEPTEMBER - - - -

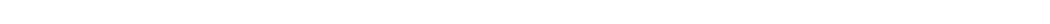


SAN JOAQUIN RIVER BASIN

11335000 COSUMNES RIVER AT MICHIGAN BAR, CALIF,--Continued

SUSPENDED-SEDIMENT DISCHARGE, WATER YEAR OCTOBER 1968 TO SEPTEMBER 1969

OCTOBER

MEAN MEAN
DISCHARGE
(CFS) TRATION DISCHARGE DISCANARGE

NOVEMBER

MEAN CONCEN- SEDIMENT MEAN

DECE'MBER

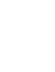

7.6
8.2
8.2
7.9
7.9

8.5

8.8

9.1

10
11
12
16
26

36
26
22
19
18

$\begin{array}{ll}21 & 17 \\ 22 & 16 \\ 23 & 16 \\ 24 & 16\end{array}$

7
16
16
16

$\begin{array}{ll}26 & 15 \\ 27 & 14 \\ 28 & 14 \\ 29 & 1 \\ 30 & 1 \\ 31 & 19\end{array}$

TOTAL

$$
\begin{array}{r}
2 \\
2 \\
12 \\
52 \\
18
\end{array}
$$

.17
$17^{-17}$
73
8.0

68
86
90
71

2.0
1.1
.68

.68
.53

.35

.45
.14

.14
1.0
.55

1.1
.73
.44
1.1
.55

.23
.20

.20
.18
.18

.18
.18
.20

.24

.20

.18

.33
.33
.-

112.33 $\begin{array}{ll}.04 & 31 \\ .02 & 31 \\ .02 & 183 \\ .02 & 456 \\ .02 & 164\end{array}$

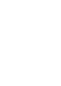

$\begin{array}{ll}.02 & 93 \\ .02 & 66 \\ .02 & 50 \\ .02 & 49\end{array}$

.02
.03

.03

.03
.04
.07

.10
.07
.06
.05
.05

.09
.04
.04
.04

.04
.04
.04

$.04 \quad 73$

$\begin{array}{ll}.04 & 88 \\ .04 & 75\end{array}$

.04
.04
.04
.09

1.36
FEBRUARY

CONCEN- SEDIMENT

$\begin{array}{lll}\text { MEAN } & \text { CDNCEN- } & \text { SEDIMENT } \\ \text { DISCHARGE } & \text { MRATION } & \text { DISCHARGE DISCHARGE }\end{array}$ (CFS) (MG/L) (TONS/DAY) DISCHARE

2
2
2
2
2

$$
\begin{array}{ll}
1.2 & 1990 \\
1.1 & 1800 \\
.99 & 1560 \\
.94 & 1420 \\
.92 & 2040
\end{array}
$$

177
177

177

222
326
3280
4430

4430
1590

1120
754
873
7070
13200

18800

18800
10200

10200
4420
3660

3660
7540

11700

5890

4500

3400
2730

2730
2180

TOTAL 109700

$$
\begin{aligned}
& 2 \\
& 3 \\
& 1 \\
& 2 \\
& 3
\end{aligned}
$$

$$
.92
$$

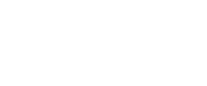

$\begin{array}{rrr}2 & 1.2 & 1620 \\ 2 & 1.8 & 3160 \\ 277 & 3840 & 2090 \\ 170 & 2450 & 1930\end{array}$

$\begin{array}{rrr}20 & 2450 & 1930 \\ & 86 & 3160\end{array}$

$\begin{array}{rr}10 & 30 \\ 5 & 10 \\ 14 & 48 \\ 514 & 11800\end{array}$

514
780

11800
27800

3220
2320

2320
2460
2410

$1220 \quad 62800$

$663 \quad 19500$

100

2600
988
11600

988
11600

35500
3980

3980
1220

716
339
241

241 -.

$185561.31 \quad 63510$

1880

1590

2350

\begin{tabular}{|c|c|c|c|c|}
\hline $\begin{array}{l}30 \\
18 \\
12 \\
20 \\
25\end{array}$ & $\begin{array}{r}161 \\
87 \\
51 \\
77 \\
146\end{array}$ & $\begin{array}{l}3640 \\
2440 \\
2280 \\
1830 \\
1560\end{array}$ & $\begin{array}{r}87 \\
25 \\
17 \\
10 \\
8\end{array}$ & $\begin{array}{r}855 \\
165 \\
105 \\
49 \\
34\end{array}$ \\
\hline $\begin{array}{r}170 \\
50 \\
17 \\
18 \\
10\end{array}$ & $\begin{array}{r}1800 \\
329 \\
81 \\
74 \\
37\end{array}$ & $\begin{array}{l}1420 \\
1300 \\
1180 \\
1200 \\
1290\end{array}$ & $\begin{array}{l}7 \\
7 \\
8 \\
6 \\
7\end{array}$ & $\begin{array}{l}27 \\
25 \\
25 \\
19 \\
24\end{array}$ \\
\hline $\begin{array}{r}33 \\
85 \\
30 \\
20 \\
100\end{array}$ & $\begin{array}{l}184 \\
725 \\
169 \\
104 \\
853\end{array}$ & $\begin{array}{r}1080 \\
1020 \\
1070 \\
941 \\
878\end{array}$ & $\begin{array}{r}4 \\
10 \\
6 \\
5\end{array}$ & $\begin{array}{l}12 \\
11 \\
29 \\
15 \\
12\end{array}$ \\
\hline $\begin{array}{l}85 \\
30 \\
23 \\
20 \\
20\end{array}$ & $\begin{array}{l}739 \\
188 \\
153 \\
130 \\
118\end{array}$ & $\begin{array}{l}860 \\
878 \\
896 \\
923 \\
970\end{array}$ & $\begin{array}{l}3 \\
4 \\
4 \\
5 \\
4\end{array}$ & $\begin{array}{r}7.0 \\
9.5 \\
9.7 \\
12 \\
10\end{array}$ \\
\hline $\begin{array}{l}15 \\
15 \\
81 \\
86 \\
60\end{array}$ & $\begin{array}{r}76 \\
64 \\
567 \\
791 \\
492\end{array}$ & $\begin{array}{l}1480 \\
1150 \\
1190 \\
1100 \\
1130\end{array}$ & $\begin{array}{r}21 \\
8 \\
5 \\
5 \\
4\end{array}$ & $\begin{array}{l}84 \\
25 \\
15 \\
15 \\
12\end{array}$ \\
\hline $\begin{array}{l}37 \\
38 \\
35 \\
-\because \\
--\end{array}$ & $\begin{array}{r}298 \\
228 \\
226 \\
=- \\
=-\end{array}$ & $\begin{array}{l}1180 \\
1240 \\
1400 \\
1560 \\
1800 \\
2090\end{array}$ & $\begin{array}{r}4 \\
6 \\
8 \\
14 \\
22 \\
26\end{array}$ & $\begin{array}{r}13 \\
20 \\
30 \\
59 \\
107 \\
147\end{array}$ \\
\hline- & 8948 & 42876 & -- & 1982.2 \\
\hline
\end{tabular}

2960

2980

220

$\begin{array}{rrr}1010 & 35500 & 2980 \\ 250 & 3980 & 2220 \\ 100 & 1220 & 2390 \\ 78 & 716 & -- \\ 46 & 339 & -- \\ 41 & 241 & -- \\ -- & 185561.31 & 63510\end{array}$

MEAN
CONCEN- SEDIMENT TRATION DISCHARG (TONS/DAY)

MEAN
CONCEN- SEDIMENT

\section{:}

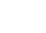
18 
11335000 COSUMNES RIVER AT MICHIGAN BAR, CALIF.--Continued

SUSPENDED-SEDIMENT DISCHARGE, WATER YEAR OCTOBER 1968 TO SEPTEMBER 1969

\begin{tabular}{|c|c|c|c|c|c|c|c|c|c|}
\hline \multirow[b]{2}{*}{ DAY } & \multicolumn{3}{|c|}{ APRIL } & \multicolumn{3}{|c|}{ MAY } & \multicolumn{3}{|c|}{ JUNE } \\
\hline & $\begin{array}{l}\text { MEAN } \\
\text { DI SCHARGE } \\
\text { (CFS) }\end{array}$ & $\begin{array}{l}\text { MEAN } \\
\text { CONCEN- } \\
\text { TRATION } \\
\text { (MG/L) }\end{array}$ & $\begin{array}{l}\text { SEDIMENT } \\
\text { DISCHARGE } \\
\text { (TONS /DAY) }\end{array}$ & $\begin{array}{l}\text { MEAN } \\
\text { OISCHARGE } \\
\text { (CFS) }\end{array}$ & $\begin{array}{l}\text { MEAN } \\
\text { CONCEN- } \\
\text { TRATI ON } \\
\text { (MG/L) }\end{array}$ & $\begin{array}{l}\text { SEDIMENT } \\
\text { DI SCHARGE } \\
\text { (TONS/DAY) }\end{array}$ & $\begin{array}{l}\text { MEAN } \\
\text { OISCHARGE } \\
\text { (CFS) }\end{array}$ & $\begin{array}{l}\text { MEAN } \\
\text { CONCEN- } \\
\text { TRATION } \\
\text { (MG/L) }\end{array}$ & $\begin{array}{l}\text { SEDIMENT } \\
\text { DISCHARGE } \\
\text { (TONS/DAY) }\end{array}$ \\
\hline 1 & 2150 & 28 & 163 & 1630 & 11 & 48 & 746 & 6 & 12 \\
\hline 2 & 2140 & 26 & 150 & 1600 & 8 & 35 & 730 & 6 & 12 \\
\hline 3 & 2120 & 26 & 149 & 1510 & 8 & 33 & 698 & 5 & 9.4 \\
\hline 4 & 1800 & 17 & 83 & 1420 & 7 & 27 & 669 & 5 & 9.0 \\
\hline 5 & 3600 & 257 & 2830 & 1350 & 7 & 26 & 627 & 5 & 8.5 \\
\hline 6 & 3470 & 13 & 122 & 1410 & 8 & 30 & 585 & 5 & 1.9 \\
\hline 7 & 2570 & 36 & 250 & 1510 & 11 & 45 & 544 & 5 & 7.3 \\
\hline 8 & 2140 & 18 & 104 & 1630 & 13 & 57 & 490 & 3 & 4.0 \\
\hline 9 & 1900 & 17 & 87 & 1770 & 14 & 67 & 448 & 3 & 3.6 \\
\hline 10 & 1740 & 14 & 66 & 1820 & 13 & 64 & 425 & 3 & 3.4 \\
\hline 11 & 1730 & 14 & 65 & 1800 & 11 & 53 & 390 & 3 & 3.2 \\
\hline 12 & 1830 & 15 & 74 & 1740 & 14 & 66 & 400 & 4 & 4.3 \\
\hline 13 & 1940 & 18 & 94 & 1650 & 11 & 49 & 370 & 5 & 5.0 \\
\hline 14 & 1910 & 12 & 62 & 1580 & 10 & 43 & 345 & 5 & 4.7 \\
\hline 15 & 1790 & 9 & 43 & 1440 & 12 & 47 & 335 & 4 & 3.6 \\
\hline 16 & 1650 & 13 & 58 & 1330 & 10 & 36 & 370 & 4 & 4.0 \\
\hline is & 1590 & 11 & 47 & 1290 & 10 & 35 & 390 & 3 & 3.2 \\
\hline 18 & 1670 & 8 & 36 & 1300 & 10 & 35 & 345 & 4 & 3.7 \\
\hline 19 & 1720 & 9 & 42 & 1270 & 9 & 31 & 330 & 5 & 4.5 \\
\hline 20 & 1730 & 9 & 42 & 1160 & B & 25 & 310 & 5 & 4.2 \\
\hline 21 & 1820 & 12 & 59 & 1070 & 8 & 23 & 298 & 5 & 4.0 \\
\hline 22 & 2020 & 18 & 98 & 1030 & 9 & 25 & 278 & 5 & 3.8 \\
\hline 23 & 2280 & 32 & 197 & 1030 & 7 & 19 & 258 & 4 & 2.8 \\
\hline 24 & 2220 & 23 & 138 & 1020 & 8 & 22 & 246 & 3 & 2.0 \\
\hline 25 & 1800 & 13 & 63 & 980 & 7 & 19 & 216 & 3 & 1.7 \\
\hline 26 & 1600 & 8 & 35 & 923 & 6 & 15 & 215 & 3 & 1.7 \\
\hline 27 & 1480 & $B$ & 32 & $B 87$ & 6 & 14 & 204 & 3 & 1.7 \\
\hline 28 & 1450 & 8 & 31 & 851 & 7 & 16 & 194 & 3 & 1.6 \\
\hline 29 & 1530 & 12 & 50 & 797 & 5 & 11 & 180 & 3 & 1.5 \\
\hline 30 & 1590 & 11 & 47 & 779 & 6 & 13 & 171 & 3 & 1.4 \\
\hline 31 & -- & -- & -- & 754 & 6 & 12 & -- & - & - \\
\hline \multirow[t]{3}{*}{ TOTAL } & 58980 & -- & 5317 & 40331 & -- & 1041 & 11807 & -- & 139.7 \\
\hline & & JULY & & & AUGUST & & & SEPTEMBER & \\
\hline & $\begin{array}{l}\text { MEAN } \\
\text { DISCHARGE } \\
\text { (CFS) }\end{array}$ & $\begin{array}{l}\text { MEAN } \\
\text { CONCEN- } \\
\text { TRAIION } \\
\text { (MG/L) }\end{array}$ & $\begin{array}{l}\text { SEDIMENT } \\
\text { DISCHARGE } \\
\text { (TONS/DAY) }\end{array}$ & $\begin{array}{l}\text { MEAN } \\
\text { OI SCHARGE } \\
\text { (CFS) }\end{array}$ & $\begin{array}{l}\text { MEAN } \\
\text { CONCEN- } \\
\text { IRATION } \\
\text { (MG/L) }\end{array}$ & $\begin{array}{l}\text { SEDIMENT } \\
\text { DISCHARGE } \\
\text { (TONS/DAY) }\end{array}$ & $\begin{array}{l}\text { MEAN } \\
\text { DISCHARGE } \\
\text { (CFS) }\end{array}$ & $\begin{array}{l}\text { MEAN } \\
\text { CONCEN- } \\
\text { TRATIDN } \\
\text { (MG/L) }\end{array}$ & $\begin{array}{l}\text { SEDIMENT } \\
\text { DISCHARGE } \\
\text { (TONS/DAY) }\end{array}$ \\
\hline
\end{tabular}

4

$\begin{array}{lllll}1 & 164 & 2 & .89 & 49 \\ 2 & 164 & 2 & .89 & 46 \\ 3 & 155 & 2 & .84 & 44 \\ 4 & 152 & 1 & .41 & 43 \\ 5 & 141 & 1 & .38 & 42\end{array}$

.75

$\begin{array}{rrrrr}6 & 139 & 2 & .75 & 41 \\ 7 & 136 & 2 & .73 & 40 \\ 8 & 128 & 2 & .69 & 39 \\ 9 & 126 & 2 & .68 & 39 \\ 10 & 118 & 2 & .64 & 38\end{array}$

$\begin{array}{rr}11 & 115 \\ 12 & 107 \\ 13 & 102 \\ 14 & 97\end{array}$

.68

41
40
39
39
38

$\begin{array}{ll}2 & .62 \\ 2 & .58 \\ 2 & .55 \\ 2 & .52 \\ 2 & .50\end{array}$

38
36
36
34
32

1
1
4
6
3

.13
.12
.48
.70
.34

27
27
26
25
27

(MG/L)

.

.15

.14

1693

$\begin{array}{ll}17 & 86 \\ 18 & 82 \\ 19 & 73 \\ 20 & 70\end{array}$

.75
.70
.44
.59

31

3
3
2
3
3

.59
.57

31
31
31

2
2
2
4
3

.22
.22
.21
.42

29
29

29
29
30
33

.16

$21 \quad 68$

$\begin{array}{ll}22 & 64 \\ 23 & 62 \\ 24 & 64 \\ 25 & 62\end{array}$

$\begin{array}{ll}.55 & 30 \\ .52 & 30 \\ .50 & 30 \\ .52 & 30 \\ .50 & 30\end{array}$

$26 \quad 57$

$\begin{array}{ll}27 & 56 \\ 28 & 57 \\ 29 & 54\end{array}$

$\begin{array}{ll}30 & 51 \\ 31 & 50\end{array}$

TOTAL 2986

3
3
3
3
3
3
3
2
3
4
3
-

.50

.46
.45

.45
.31
.44

.44
.55
.41

17.93

.31

38

. .32

.09

TOTAL OISCHARGE FOR YEAR (CFS-DAYS)

TOTAL SUSPENDED-SEDIMENT DISCHARGE FOR YEAR (TONS)

$\begin{array}{llll}.31 & 32 & 4 & .35 \\ .29 & 30 & 3 & : 24 \\ : 49 & 29 & 4 & : 31 \\ : 55 & 28 & 2 & : 15 \\ .17 & 26 & 1 & .07\end{array}$

$\begin{array}{llll}.25 & 26 & 1 & .07 \\ .49 & 26 & 2 & .14 \\ .50 & 26 & 4 & .28 \\ .50 & 25 & 5 & .34 \\ .50 & 26 & 6 & .42\end{array}$

$\begin{array}{ll}-49 & 26 \\ -49 & 26 \\ -49 & 26\end{array}$

$\begin{array}{ll}.41 & 26 \\ .24 & 24\end{array}$

$\begin{array}{rr}-16 & 23 \\ .23 & 23\end{array}$

$\begin{array}{ll}.23 & 23 \\ .26 & 23 \\ .24 & 23\end{array}$

.24
.30
.15

22

10.66

807

.35
.24
.31

.15

.42
.42
.49

.49
.56
.52

$$
.3
$$

.43
.43

.43
.25
.12

.12
.12
-

8.07 
11335000 COSUnNES RIVER AT MICHIGAN BAR, CALIF.--Cont1 nued

PARTICLE-SIZE DISTRIBUTION DF SUSPENDED-SEDIMENT DISCHARGE, WATER YEAR OCTOBER 1968 TO SEPTEMBER 1969 IME THODS OF ANALYSIS: 8, BOITOM WITHDRAHAL TUBE; C. CHEMICALLY OISPERSED; N, IN NATIVE WATER; P, PIPET; S. SIEVE; $\checkmark$, VISUAL ACCUMULATION TUBE: W. IN DISTILLED WATERI

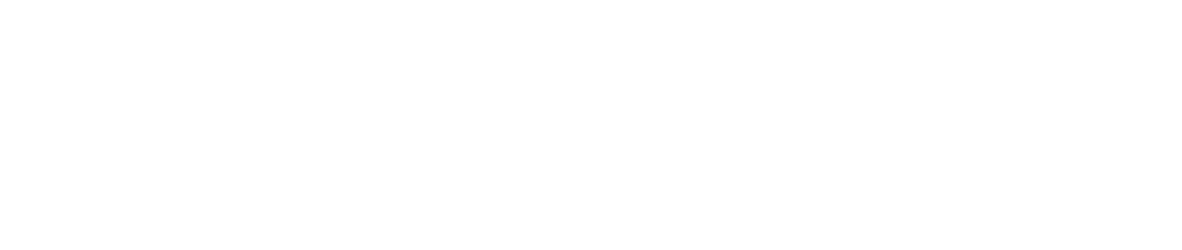

11337200 SAN JOAQUIN RIVER AT ANTIOCH, CALIF.

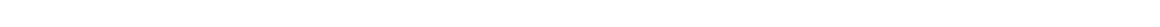
station at Antioch, 4.5 miles from mouth.

PERIOD OF RECORD.--Chemical analyses: October 1962 to September 1969.

REMARKs. --No discharge records available. Chemical-quallty records furnished by California Department of Water Resources and reviewed by U.S. Geological Survey.

CHENICAL ANALYSES, WATER YEAR OCTOBER 1968 ID SEPIEMBER 1969

\begin{tabular}{|c|c|c|c|c|c|c|c|c|c|c|c|}
\hline DATE & I IME & $\begin{array}{l}\text { TEMPER- } \\
\text { ATURE } \\
\text { (DEG C) }\end{array}$ & $\begin{array}{l}\text { DIS- } \\
\text { SOLVED } \\
\text { OXYGEN } \\
\text { (MGIL ) }\end{array}$ & $\begin{array}{l}\text { CAL- } \\
\text { CIUM } \\
\text { (CA) } \\
\text { (MG/L) }\end{array}$ & $\begin{array}{l}\text { MAG- } \\
\text { NE- } \\
\text { SIUM } \\
\text { (MG) } \\
\text { (MG IL) }\end{array}$ & $\begin{array}{c}\text { SODIUM } \\
\text { (NA) } \\
\text { (MG/L) }\end{array}$ & $\begin{array}{l}\text { PO- } \\
\text { TAS- } \\
\text { SIUM } \\
\text { (K) } \\
\text { (MG/L) }\end{array}$ & $\begin{array}{l}\text { 8ICAR- } \\
\text { BDNAIE } \\
\text { (HCOZ) } \\
\text { (MG/L) }\end{array}$ & $\begin{array}{l}\text { CAR- } \\
\text { BONAIE } \\
\text { (COB) } \\
\text { (AG/L) }\end{array}$ & $\begin{array}{l}\text { SULFATE } \\
\text { (SO4) } \\
\text { (MG/L) }\end{array}$ & $\begin{array}{l}\text { CHLO- } \\
\text { RIDE } \\
\text { ICLI) } \\
\text { (MG/L }\end{array}$ \\
\hline $\begin{array}{l}\text { ocr. } \\
\text { ol... } \\
\text { nov. }\end{array}$ & 0800 & 19 & 8.1 & 32 & -- & 210 & $\cdots$ & 105 & 0 & - & 371 \\
\hline $\begin{array}{l}14 \ldots . . \\
\text { DEC. }\end{array}$ & 1020 & 14 & 8.6 & 20 & 43 & 191 & 10 & 80 & 0 & 52 & 342 \\
\hline $\begin{array}{r}09 . . . \\
\text { FEB. }\end{array}$ & 1350 & 11 & 8.7 & 20 & 32 & 165 & 11 & 71 & 0 & 48 & 286 \\
\hline $\begin{array}{l}05 . . \\
\text { APR. }\end{array}$ & 1345 & 8 & 9.9 & 12 & 7.8 & 16 & 2.5 & 52 & 0 & 22 & 20 \\
\hline JUNE... & 1425 & 17 & 9.5 & 13 & 7.4 & 25 & 1.4 & 60 & 0 & 28 & 31 \\
\hline $03 \ldots$ & 1230 & 19 & 9.3 & B. B & 3.9 & 12 & 1.2 & 35 & 0 & 10 & 15 \\
\hline
\end{tabular}

\begin{tabular}{|c|c|c|c|c|c|c|c|c|c|c|c|}
\hline DATE & $\begin{array}{l}\text { NI IRATE } \\
\text { (NO3) } \\
\text { (MG/L) }\end{array}$ & $\begin{array}{c}\text { 80RON } \\
(8) \\
(U G / L)\end{array}$ & $\begin{array}{l}\text { DIS- } \\
\text { SOLVED } \\
\text { SDLIOS } \\
\text { (RESI- } \\
\text { DUE AI } \\
\text { IBO C) } \\
\text { (MGIL) }\end{array}$ & $\begin{array}{l}\text { OIS- } \\
\text { SOLVED } \\
\text { SOLIIDS } \\
\text { ITONS } \\
\text { PER } \\
\text { AC-FII }\end{array}$ & $\begin{array}{l}\text { HARD- } \\
\text { NESS } \\
\text { (CA,MG) } \\
\text { (MG } / L)\end{array}$ & $\begin{array}{l}\text { NON- } \\
\text { CAR- } \\
\text { BDNATE } \\
\text { HARD- } \\
\text { NESS } \\
\text { (MG/L) }\end{array}$ & $\begin{array}{l}\text { PERCENT } \\
\text { SODIUM }\end{array}$ & $\begin{array}{l}\text { SODIUM } \\
\text { AD- } \\
\text { SORP- } \\
\text { IION } \\
\text { RATIO }\end{array}$ & $\begin{array}{l}\text { ALKA- } \\
\text { LINIIY } \\
\text { AS } \\
\text { CACO3 } \\
\text { (MGIL) }\end{array}$ & $\begin{array}{c}\text { PH } \\
\text { (UNITS) }\end{array}$ & $\begin{array}{l}\text { SPECI- } \\
\text { FIC } \\
\text { COND- } \\
\text { UCTANCE } \\
\text { (MICRO- } \\
\text { MHOS) }\end{array}$ \\
\hline OCT. & - & - & - & - & 214 & 128 & 85 & 10 & 86 & 8.2 & 1410 \\
\hline $\begin{array}{l}\text { NOV. } \\
14 . . . \\
\text { OEC. }\end{array}$ & 2.7 & 80 & 713 & .97 & 183 & 117 & 63 & 5.5 & 66 & 8.1 & 1310 \\
\hline $\begin{array}{l}\text { DEC. } \\
\text { O9... } \\
\text { FEB. }\end{array}$ & 2.4 & 120 & 625 & .85 & 149 & 91 & 65 & 5.3 & 58 & 7.9 & 1120 \\
\hline $\begin{array}{l}\text { 05.... } \\
\text { APR. }\end{array}$ & 4.1 & 110 & 107 & .15 & 62 & 19 & 35 & .9 & 43 & 7.6 & 208 \\
\hline JUNE & 1.5 & 70 & 172 & .23 & 63 & 14 & 46 & 1.4 & 49 & 7.8 & 262 \\
\hline $03 . .$. & .8 & 0 & 90 & .12 & 38 & 9 & 40 & 18 & 29 & 1.8 & 136 \\
\hline
\end{tabular}


11337705 GOOSE LAKE AT WILLON RANCH, CALIF.

LOCATION. --Lat $41^{\circ} 54^{\prime} 14^{\prime \prime}$, long $120^{\circ} 21^{\prime} 55^{\prime \prime}$, in NW Goose Lake, 0.5 mile northwest of Wiliow Ranch.

PERIOD OF RECORD, -Chemical analyses: May to September 1969.

REMARKS. --Sampled b1-annually during high and low stage condttions,

CHEMICAL ANALYSES, MAY TO SEPTEMBER 1969

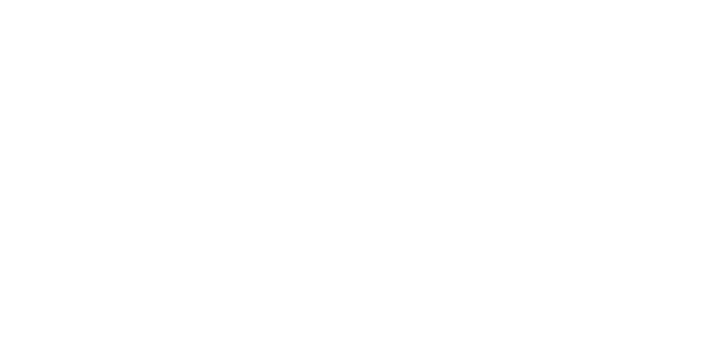

11337713 GOOSE LAKE AT EVERLY RANCH, NEAR WILLOW RANCH, CALIF.

LOCATION.--Lat $41^{\circ} 32^{\prime} 17^{\prime \prime}$, long $120^{\circ} 29^{\prime} 49^{\prime \prime}$, In NW łSEł sec.32, T.47 N., R.19 E., Hodoc County, at went edge of

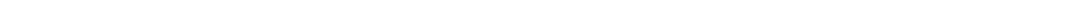
Goose Lake, 0.8 m1le so

PERIOD OF RECORD, -Chemical analyen: Hay to September 1969.

REMARKS, --Sampl ed b1-annually during h1gh and low wtage condttion.

CHEMICAL ANALYSES, MAY TO SEPTEMBER 1969

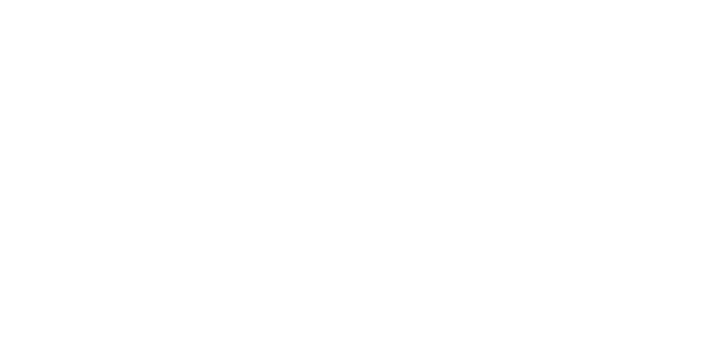

11337720 GOOSE LAKE AT WEST SHORE LOG LANDING, NEAR WILLOW RANCH, CALIF,

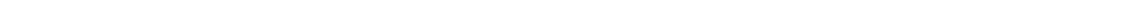
Lake at Log Landing near California-Oregon State 11 ne, 8.3 miles northwest of pillow Ranch, and $10,3 \mathrm{~m} 110 \mathrm{~s}$ we st of town of New Pine Creek.

PERIOD OF RECORD. - Chemical enalyses: May to September 1969.

REMARKS.--Sampled bi-annually during high and low wage condt tions.

CHEMICAL ANALYSES, MAY TO SEPTEMBER 1969

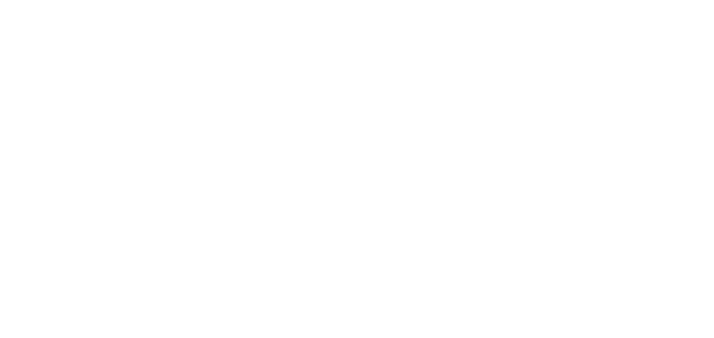


11341400 SACRAMENTO RIVER NEAR MOUNT SHASTA, CALIF.

LOCATION, --Lat $41^{\circ} 15^{\prime} 56^{\prime \prime}$, long $122^{\circ} 18^{\prime} 32^{\prime \prime}$, In SEł⿱㇒日勺: 1 sec.33, T.40 N., R.4 W., Siskiyou County, temperature recorde at gaging station on' left bank, 200 ft upstream from Stínk Creek, 0.3 mile upstream from Southern Pac1fic Railroad bridge, and $3.3 \mathrm{~m} 1 \mathrm{les}$ south of Mount Shasta.

DRAI NAGE AREA, --134 sq $\mathrm{ml}$.

PERJOD OF RECORD.--Water temperatures: October 1965 to September 1969.

EXTREMES. - -1968-69: Water temperatures: Maximum, $17.0^{\circ} \mathrm{C}$ Sept. 16,17 ; minimum, $2.0^{\circ} \mathrm{C}$ somet1me during period Dec. 14 to Feb. 7 ,
Mar. 6,7 .

Period of record:

Water temperatures: Maximum (1966-69), $17.0^{\circ} \mathrm{C}$ on many days during July and August 1968, Sept. 16, 17, 1969; m1n1mum (1965-66, 1967-69), $2.0^{\circ} \mathrm{C}$ on several days dur1ng January 1968, somet1me dur1ng per1od Dec. 14, 1968, to Feb. 7, 1969, and $\mathrm{Mar} .6,7,1969$.

REMARKS.--Clock stopped Nov, 21 to Dec. 6, Dec. 14 to Feb. 7, Feb. 11 to Mar. 5, Mar. 8 to Apr. 8; ranges in temperature, $5.0^{\circ} \mathrm{C}$ to $7.0^{\circ} \mathrm{C}, 2.0^{\circ} \mathrm{C}$ to $5.0^{\circ} \mathrm{C}, 3.0^{\circ} \mathrm{C}$ to $4.0^{\circ} \mathrm{C}$, and $3.0^{\circ} \mathrm{C}$ to $5.0^{\circ} \mathrm{C}$, respectively.

TEMPERATURE $\left({ }^{\circ} \mathrm{C}\right)$ OF WATER, WATER YEAR OCTOBER 1968 TO SEPTEKBER 1969

DAY

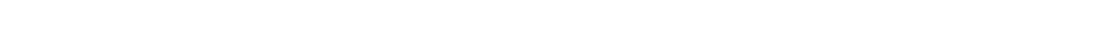

OC TOBER

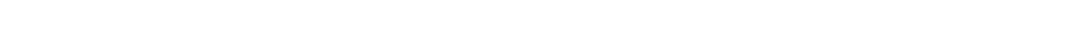

NOVENBED

MAXIMUM 9

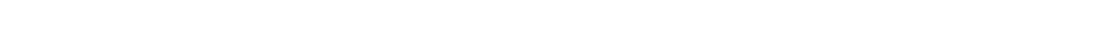

DECEMBER

MAXIMUM -

MININUM

JANUARY

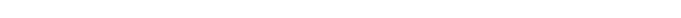

MINIMUM -2

FERRUARY

MAXIMUM -

MINIMUM

$M A C H$

MXIMUM --

PRIL

MAXINUM -

MAY

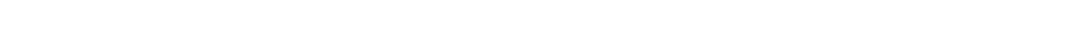

JUNE

MAXIMUN MINIMUM

ULY

$\begin{array}{llllllllllllllllllllllllllllllll} & 8 & 7 & 7 & 8 & 8 & 8 & 9 & 9 & 9 & 9 & 9 & 9 & 9 & 9 & 9 & 9 & 9 & 9 & 9 & 9 & 9 & 9 & 9 & 9 & 9 & 9 & 9 & -2\end{array}$

Maximum

$\begin{array}{llllllllllllllllllllllllllllllllll}\text { MINIMUM } & 10 & 10 & 10 & 10 & 10 & 10 & 10 & 10 & 11 & 11 & 11 & 11 & 11 & 11 & 11 & 11 & 11 & 11 & 11 & 11 & 11 & 12 & 13 & 12 & 12 & 12 & 12 & 12 & 12 & 12 & 12 \\ \text { AUGUST } & & & & & & & & \end{array}$

$\begin{array}{lllllllllllllllllllllllllllllllllll}14 & 14 & 14 & 14 & 15 & 15 & 15 & 15 & 15 & 15 & 16 & 15 & 15 & 15 & 15 & 15 & 15 & 15 & 15 & 15 & 15 & 15 & 15 & 15 & 15 & 15 & 15 & 15 & 15 & 15 & 15\end{array}$

SEPTEMEER

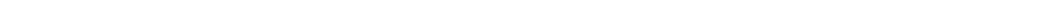
ER-

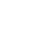
. $:$

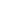


11342000 SACRAMENTO RIVER AT DELTA, CALIF.

LOCATION. --Lat $40^{\circ} 56^{\prime} 23^{\prime \prime}$, long $122^{\circ} 24^{\prime} 58^{\prime \prime}$, in NW sec.35, T. 36 N., R. 5 W. , Shasta County, on Bureau of Reclamation property at gaging station on left bank, 0.2 mile downstream from Dog Creek, 0.6 mile southeast of Delta, and 2.8 miles south of Lamolne.

DRAINAGE AREA. $--425 \mathrm{sq} \mathrm{mi}$.

PERIOD OF RECORD.--Chemical analy ses: December 1953 to September 1969.

Water temperatures: June to September 1951, October 1953 to September 1957, October 1962 to September 1969.

EXTREMES.--1968-69:

Water temperatures: Maximum, $25.0^{\circ} \mathrm{C}$ July 20-22; minimum, freezing point Dec. 22-25.

Period of record:

Water temperatures: Maximum (1951, 1953-57, 1963-69), 28.0 ${ }^{\circ} \mathrm{C}$ July 6, 1968; minimum, freezing point on several days in $1964,1967-68$.
days

REMARKS.--Chemical-quality records furnished by California Department of Water Resources and reviewed by U.S. Geological Survey.

CHEMICAL ANALYSES, WATER YEAR OCTOBER 1968 TO SEPTEMBER 1969

\begin{tabular}{|c|c|c|c|c|c|c|c|c|c|c|c|c|}
\hline DATE & TIME & $\begin{array}{l}\text { OIS- } \\
\text { CHARGE } \\
\text { (CFS) }\end{array}$ & $\begin{array}{l}\text { TEMPER- } \\
\text { ATURE } \\
\text { (DEG C) }\end{array}$ & $\begin{array}{l}\text { DIS- } \\
\text { SOLVED } \\
\text { OXYGEN } \\
\text { (MG/L) }\end{array}$ & $\begin{array}{l}\text { TUR- } \\
\text { OID- } \\
\text { ITY } \\
\text { INGR) }\end{array}$ & $\begin{array}{l}\text { CAL- } \\
\text { CIUM } \\
\text { (CA) } \\
\text { (MGIL) }\end{array}$ & $\begin{array}{c}\text { MAG- } \\
\text { NE- } \\
\text { SIUM } \\
\text { (MG) } \\
\text { (MGIL) }\end{array}$ & $\begin{array}{l}\text { SODIUM } \\
\text { (NA) } \\
\text { (MGNL) }\end{array}$ & $\begin{array}{l}\text { PO- } \\
\text { TAS- } \\
\text { S1UM } \\
\text { (KI } \\
\text { (MG L) }\end{array}$ & $\begin{array}{l}\text { BICAR- } \\
\text { BDNATE } \\
\text { (HCOZ) } \\
\text { (MG/L) }\end{array}$ & $\begin{array}{l}\text { CAR- } \\
\text { BONATE } \\
\text { (CO3) } \\
\text { (AG/L) }\end{array}$ & $\begin{array}{l}\text { SULFAT } \\
\text { (SDA) } \\
\text { (MG) }\end{array}$ \\
\hline $\begin{array}{l}\text { DCT. } \\
09 . . . \\
\text { NoV. }\end{array}$ & 1300 & 190 & 11 & 11.8 & 1.0 & -. & - & 12 & - & 81 & 0 & - \\
\hline $\begin{array}{l}13 \ldots . . \\
\text { OEC. }\end{array}$ & 1005 & 396 & 7 & 12.6 & 40 & -- & -- & 7.7 & - & 70 & 0 & - \\
\hline JAN.". & 0920 & 5860 & 7 & 11.4 & 250 & - & -- & 3.2 & - & 34 & 0 & $\sim$ \\
\hline $\begin{array}{l}20 . . \\
\text { FEB. }\end{array}$ & 1040 & 5090 & 6 & 12.2 & 35 & $=$ & -- & 2.7 & $\rightarrow$ & 38 & 0 & $\sim$ \\
\hline $\begin{array}{l}17 . . \\
\text { MAR." }\end{array}$ & 0900 & 2840 & 0 & 12.4 & 5.0 & 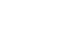 & - & 2.6 & +- & 42 & 0 & - \\
\hline $\begin{array}{l}10 . . . \\
\text { APR. }\end{array}$ & 0855 & 1230 & 4 & 13.3 & 2.0 & - & -- & 3.4 & - & 50 & 0 & -- \\
\hline MAY & 1000 & 3440 & 8 & 13.9 & 4.0 & -- & -- & 2.0 & - & 43 & 0 & -- \\
\hline JUNE & 1000 & 3950 & 12 & 12.1 & 10 & 2.3 & 6.0 & 1.4 & .0 & 37 & 0 & .0 \\
\hline JULY.. & 1145 & 1120 & 11 & 11.5 & 4.0 & -- & -- & 2.6 & - & 45 & 0 & - \\
\hline $\begin{array}{l}07 . . . \\
\text { AUG. }\end{array}$ & 0955 & 444 & 16 & 10.3 & 4.0 & -- & -- & 5.5 & - & 58 & 0 & $=$ \\
\hline SEPT. & 1030 & 236 & 19 & 10.1 & 2.0 & - & -- & 8.8 & -- & 71 & 0 & -- \\
\hline $15 \ldots$ & 1030 & 242 & 15 & 11.0 & -. & 7.6 & 7.5 & 11 & .5 & 70 & 0 & .0 \\
\hline
\end{tabular}

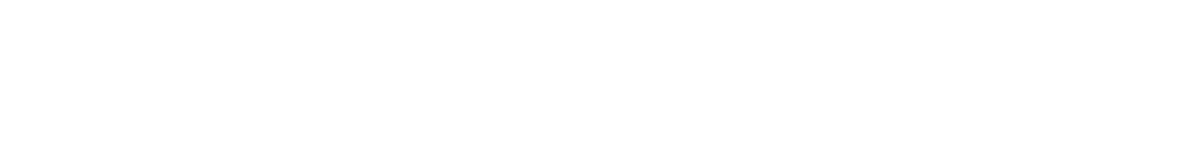

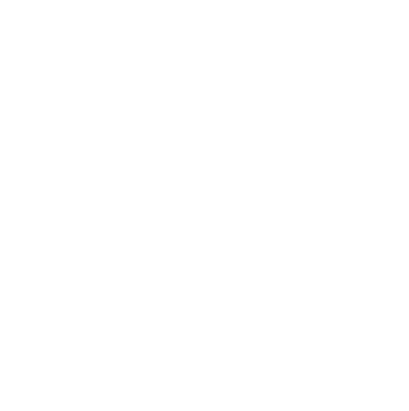

$\begin{array}{ccccc}-- & - & 57 & 0 & 31 \\ - & -- & 63 & 6 & 21 \\ - & -- & 30 & 2 & 19 \\ -- & -- & 30 & 0 & 16 \\ -- & -- & 38 & 4 & 13 \\ -- & -- & 43 & 43 & 15 \\ 43 & -- & 35 & 0 & 11 \\ -- & .06 & 30 & 0 & 9 \\ -- & -- & 36 & 0 & 14 \\ - & -- & 48 & 0 & 20 \\ 97 & -- & 53 & 0 & 27\end{array}$

$\begin{array}{rrrr}.7 & 66 & 8.0 & 159 \\ .4 & 57 & 8.1 & 136 \\ .3 & 28 & 7.0 & 71 \\ .2 & 31 & 7.6 & 72 \\ .2 & 34 & 7.6 & 79 \\ .2 & 0 & 7.5 & 94 \\ .1 & 35 & 7.6 & 77 \\ .1 & 30 & 7.6 & 64 \\ .2 & 37 & 7.5 & 79 \\ .3 & 48 & 8.2 & 108 \\ .5 & 58 & 8.1 & 134 \\ .7 & 57 & 7.8 & 139\end{array}$


11342000 SACRAMENTO RIVER AT DELTA, CALIF.--Continued

TEIPERATURE ( ${ }^{\circ} \mathrm{C}$ ) OF WATER, WATER YEAR OCTOBER 1968 TO SEPTEMBER 1969

DAY

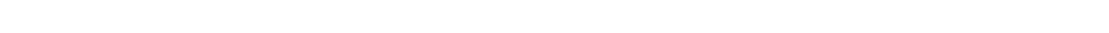

OC TOBER

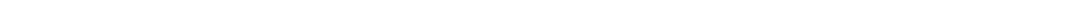

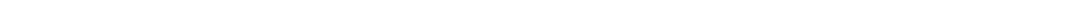
NOVEMBER

MAXIMUM $10=9 \begin{array}{lllllllllllllllllllllllllllllllll} & 11 & 11 & 12 & 9 & 12 & 12 & 15 & 14 & 12 & 11 & 9 & 6 & 5 & 6 & 8 & 10 & 11 & 11 & 10 & 10 & 10 & 9 & 9 & 7 & 8 & 8 & 6 & 6 & -- & 10\end{array}$

DECENBER

MAXIMUM $6 \begin{array}{llllllllllllllllllllllllllllllll}6 & 5 & 6 & 6 & 8 & 7 & 6 & 6 & 7 & 8 & 7 & 5 & 5 & 3 & 6 & 6 & 5 & 5 & 5 & 3 & 2 & 2 & 0 & 0 & 3 & 5 & 5 & 3 & 5 & 4 & 4\end{array}$

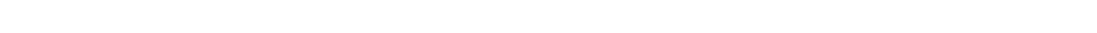

JANUARY

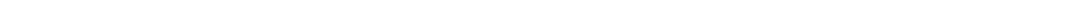

BERARY

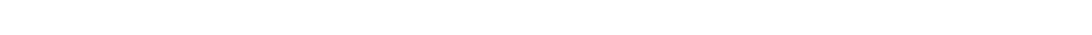

MARCH

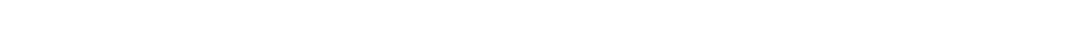

$\begin{array}{llllllllllllllllllllllllllllllllll}\text { MININUM } & 4 & 5 & 4 & 5 & 6 & 6 & 5 & 5 & 7 & 5 & 5 & 6 & 5 & 5 & 5 & 6 & 7 & 6 & 5 & 6 & 6 & 6 & 6 & 6 & 5 & 6 & 6 & 6 & 6 & 7 & 7 & 6\end{array}$

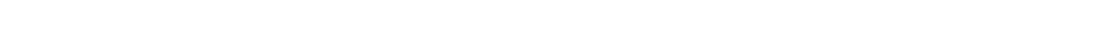
MAY

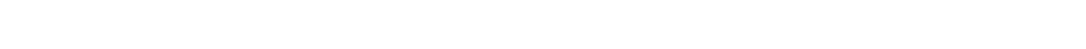
JUNE

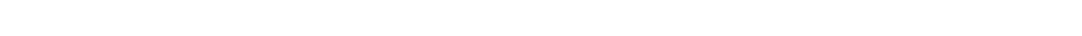

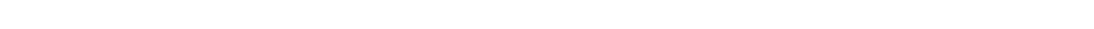

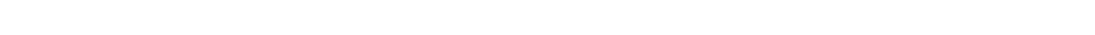
AUGUST

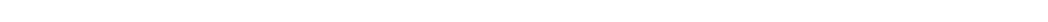

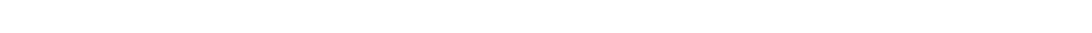
SEPTEMBER

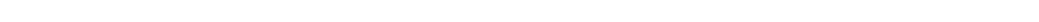

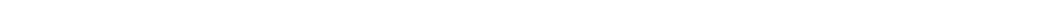

11345500 SOUTH FORK PIT RIVER NEAR LIKELY, CALIF,

LOCATION,--Lat $41^{\circ} 13^{\prime} 51^{\prime \prime}$, long $120^{\circ} 26^{\prime} 10^{\prime \prime}$, In NE fSE sec.11, T. 39 N., R.13 E., Modoc County, at gaging station $400 \mathrm{ft}$ downstream from high way bridge; 1,4 miles downstream from 'Nest Vailey Creek, and 3.5 miles east of Likely.

DRAINAGE AREA, $-\mathbf{- 2 4 7}$ sq mi.

PERIOD OF RECORD, --Chemical analyses: October 1958 to September 1969.

REMARKS,--Records furnished by California Department of Water Resources and reviewed by U.S. Geological Survey. CHEMICAL ANALYSES, WATER YEARI OCTOBER 1968 TO SEPIEMBER 1969

\begin{tabular}{|c|c|c|c|c|c|c|c|c|c|c|c|}
\hline OATE & $\begin{array}{ll}\text { OIS- } & \text { TE } \\
\text { CHARGE } & A \\
\text { ICFSI } & \text { IO }\end{array}$ & $\begin{array}{l}\text { TEMPER- } \\
\text { ATURE } \\
\text { IOEG CI }\end{array}$ & $\begin{array}{l}\text { DIS- } \\
\text { SOLVED } \\
\text { OXYGEN } \\
\text { IMG/LI }\end{array}$ & $\begin{array}{l}\text { TUR- } \\
8 \text { ID- } \\
\text { ITY } \\
\text { IMG/LI }\end{array}$ & $\begin{array}{l}\text { CAL- } \\
\text { CIUM } \\
\text { (CA) } \\
\text { (MG/L) }\end{array}$ & $\begin{array}{l}\text { MAG- } \\
\text { NE- } \\
\text { SIUM } \\
\text { I MGI } \\
\text { (MGILI }\end{array}$ & $\begin{array}{l}\text { SO0IUM } \\
\text { (NA) } \\
\text { IMGILI) }\end{array}$ & $\begin{array}{l}\text { PQ- } \\
\text { TAS- } \\
\text { SIUM } \\
\text { IKI } \\
\text { IMGILI }\end{array}$ & $\begin{array}{l}\text { BICAR- } \\
\text { OONATE } \\
\text { IHCOZ) } \\
\text { (MG/LI) }\end{array}$ & $\begin{array}{l}\text { CAR- } \\
\text { 8ONATE } \\
\text { (COB) } \\
\text { ( MG/L) }\end{array}$ & $\begin{array}{l}\text { SULFATE } \\
\text { (SO4) } \\
\text { (MG/L) }\end{array}$ \\
\hline $\begin{array}{l}\text { OCT. } \\
\text { OB... } \\
\text { NOV. }\end{array}$ & 67 & 12 & 10.6 & 20 & $\cdots$ & - & 11 & $\cdots$ & 91 & 0 & -- \\
\hline JAN:" & 13 & 2 & 12.5 & 4.0 & $\cdots$ & -- & 6.1 & - & 64 & 0 & -- \\
\hline MAY & 161 & 1 & 12.1 & 75 & -- & -- & 4.2 & - & 42 & 0 & -- \\
\hline SEPT. & 684 & 16 & 8.9 & 25 & 7.7 & 3.2 & 4.2 & 1.8 & 43 & 0 & 2.6 \\
\hline $16 \ldots$ & 87 & 17 & 8.3 & 19 & 12 & 4.9 & 8.6 & 3.2 & 77 & 0 & .0 \\
\hline DATE & $\begin{array}{l}\text { NITRATE } \\
\text { (NO3) } \\
\text { (MG/LI }\end{array}$ & $\begin{array}{l}\text { 8ORON } \\
\text { (8I } \\
\text { IUG/LI I }\end{array}$ & $\begin{array}{l}\text { DIS- } \\
\text { SOLVEO } \\
\text { SOLIOS } \\
\text { IRESI- } \\
\text { DUE AT } \\
\text { I8D C) } \\
\text { (HG/L) }\end{array}$ & $\begin{array}{l}\text { DIS- } \\
\text { SOLVED } \\
\text { SOLIDS } \\
\text { (TONS } \\
\text { PER } \\
\text { AC-FT) }\end{array}$ & $\begin{array}{l}\text { HARD- } \\
\text { NESS } \\
\text { (CA, MG) } \\
\text { (MG/L) }\end{array}$ & $\begin{array}{l}\text { NON- } \\
\text { CAR- } \\
\text { BONATE } \\
\text { HARO- } \\
\text { NESS } \\
\text { IMG/LI }\end{array}$ & $\begin{array}{l}\text { PERCENT } \\
\text { SOOIUM }\end{array}$ & $\begin{array}{l}\text { SOOIUM } \\
\text { AD- } \\
\text { SORP- } \\
\text { TION } \\
\text { RATIO }\end{array}$ & $\begin{array}{l}\text { ALKA- } \\
\text { LINITY } \\
\text { AS } \\
\text { CACO3 } \\
\text { IMGILI }\end{array}$ & $\begin{array}{c}P H \\
\text { IUNITSI }\end{array}$ & $\begin{array}{l}\text { SPECI- } \\
\text { FIC } \\
\text { COND- } \\
\text { UCTANCE } \\
\text { (MICRO- } \\
\text { MHOS I }\end{array}$ \\
\hline $\begin{array}{l}\text { OCT. } \\
\text { OO... } \\
\text { Nov. }\end{array}$ & - & 0 & $\cdots$ & - & 59 & 0 & 29 & .6 & 75 & 8.1 & 164 \\
\hline JAN. & -- & 0 & $\cdots$ & - & 45 & 0 & 23 & .4 & 52 & 8.0 & 108 \\
\hline $\operatorname{MAY}^{21} \ldots$ & $=$ & 0 & $\cdots$ & - & 32 & 0 & 22 & $\cdot 3$ & 34 & 7.5 & 80 \\
\hline SEPT. & 1.7 & 90 & 66 & .09 & 32 & 0 & 21 & .3 & 35 & 7.2 & 82 \\
\hline $16 .$. & .2 & 10 & 109 & .15 & 50 & 0 & 26 & .3 & 63 & 8.3 & 138 \\
\hline
\end{tabular}


11348500 PIT RIVER NEAR CANBY, CALIF.

LOCATION. --Lat $41^{\circ} 24^{\prime} 22^{\prime \prime}$, long $120^{\circ} 55^{\prime} 36^{\prime \prime}$, in NW on right bank at lower end of Warm Spring Valley, 4 miles southwest of Canby.

DRAINAGE AREA, - - 1,431 sq mi, excluding Goose Lake basin.

PERIOD OF RECORD, -Chemical analyses: October 1958 to September 1969.

Water temperatures: March 1965 to September 1969.

Sediment records: Detober 1966 to September 1969 (partial records).

EXTREMES. --1968-69:

Water temperatures: Maximum, $28.0^{\circ} \mathrm{C}$ July 20 ; minimun, freezing point on many days during November to February.

Period of record:

Water temperatures: Maximum, $28.0^{\circ} \mathrm{C}$ on several days during June and July in 1968 and $1969 ; \mathrm{minimum}$ (1965-66, 1967-69), freezing point on many days during November to February of most years.

REMARKS. --Chemical-quality records furnished by California Department of Water Resources and reviewed by U.S.

Geological Survey. Récorder malfunctioned Dct. 23, 24, and Feb. 3-10.

CHEMICAL ANALYSES, WATER YEAR OCTOBER 1968 TO SEPTEMBER 1969

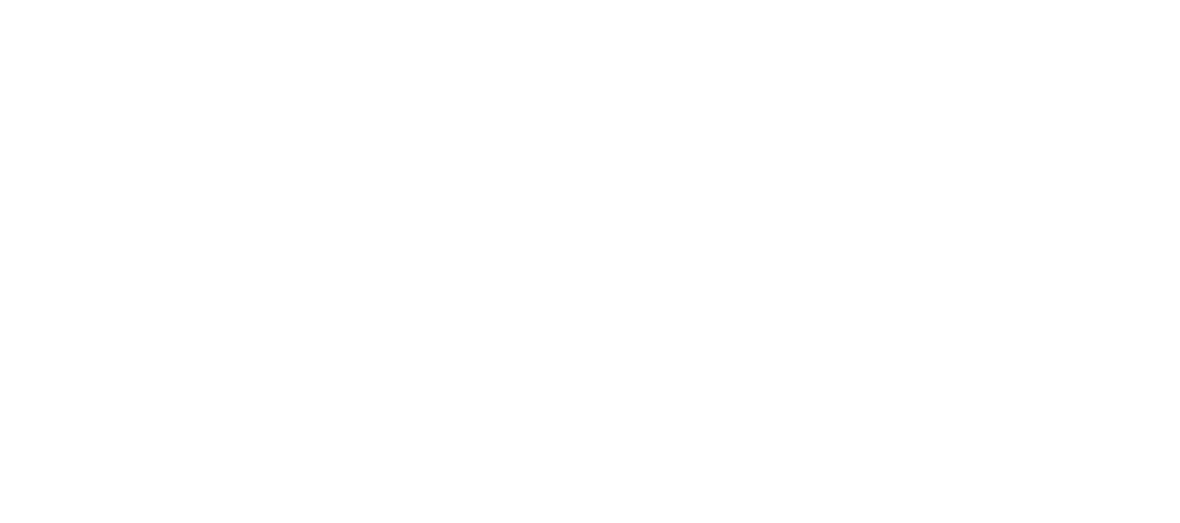

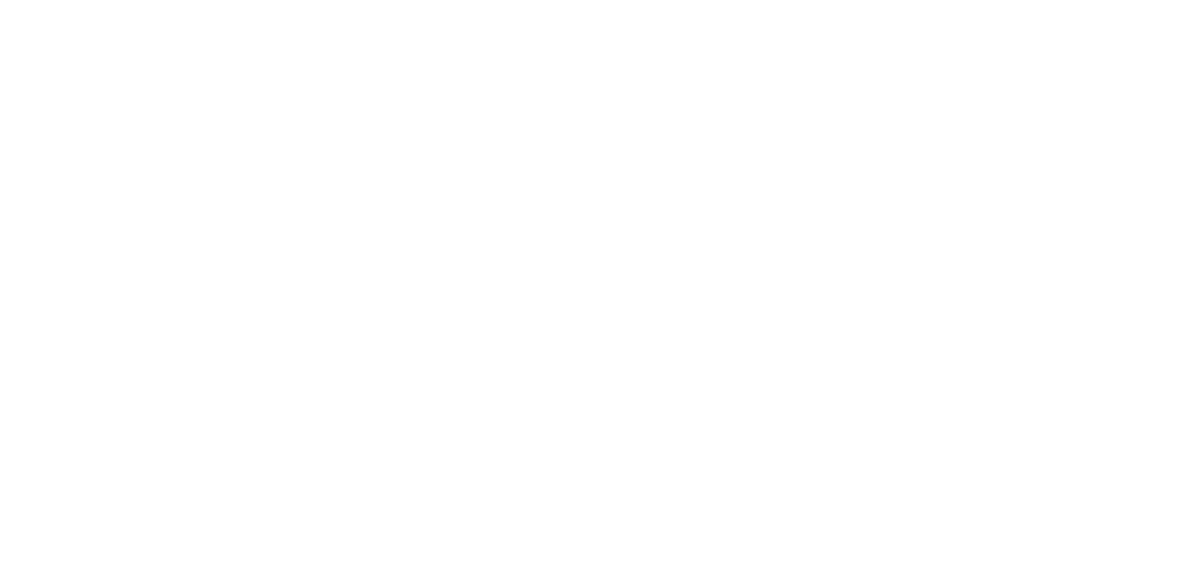


11348500 PIT RIVER REAR CANBY, CALIF.--CONTInued

TEMPERATURE $\left({ }^{\circ} \mathrm{C}\right.$ ) OF WATER, WATER YEAR OCTOBER 1968 TO SEPTEMBER 1969

DAY

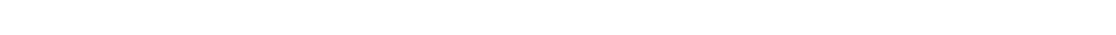

OCTOBEA

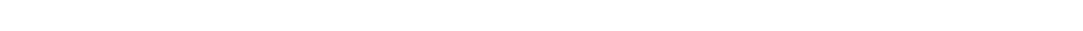

MINIMUM 11 12 12 14 14 -

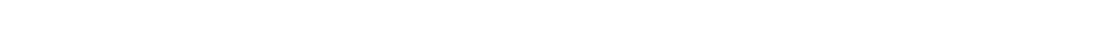

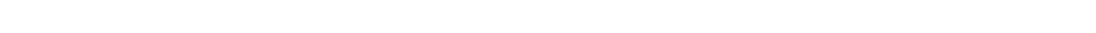

JANUARY

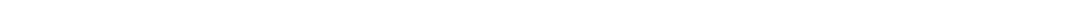
$\begin{array}{rllllllllllllllllllllllllllllllll}\text { MINIMUM } & 0 & 0 & 0 & 0 & 0 & 0 & 0 & 0 & 0 & 0 & 0 & 0 & 0 & 0 & 0 & 0 & 0 & 0 & 0 & 1 & 1 & 0 & 0 & 0 & 0 & 0 & 0 & 0 & 0 & 0 & 0 & 0\end{array}$

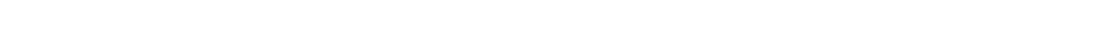
MARCH

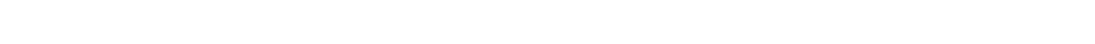
APQIL

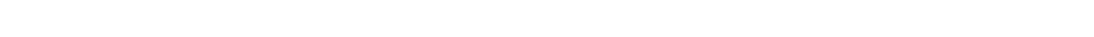
MAY

MAXIMUM $13131311141718191919191818171719201918192022 \quad 22 \quad 212018181921 \quad 2424$

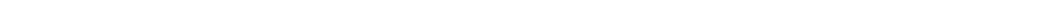
UNE

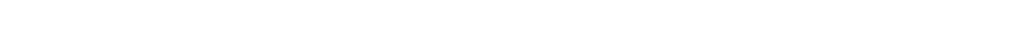

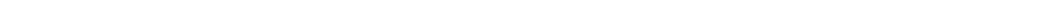

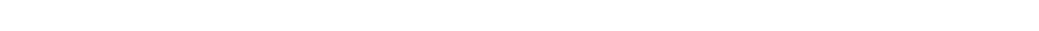

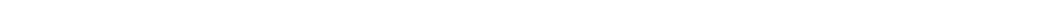

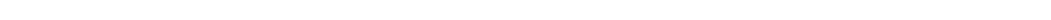

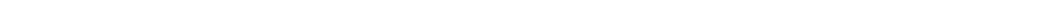
SEPTEMBER

MAXIMUM $23 \begin{array}{lllllllllllllllllllllllllllllllllllllll} & 22 & 22 & 21 & 20 & 22 & 22 & 23 & 24 & 23 & 22 & 22 & 21 & 20 & 18 & 17 & 18 & 18 & 17 & 16 & 17 & 17 & 16 & 18 & 18 & 19 & 19 & 18 & 17 & 17 & =\end{array}$

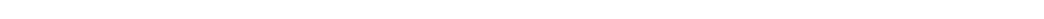

18
15
22
15
25
19
23
18
20
16

SUSPENDED-SEDIMENT DISCHARGE MEASUREMENTS AND PARTICLE-SIZE DISTRIBUTION, WATER YEAR OCTOBER 1968 TO SEPTEMBER 1969 IMETHODS OF ANALYSIS: B, BOTTON WITHDRAWAL TUBE: C, CHEMICALLY DISPERSED: N, IN NATIVE WATER: P, PIPET: S, SIEVE: $V$, VISUAL ACCUMULATION TUBE: W. IN DISTILLED WATER

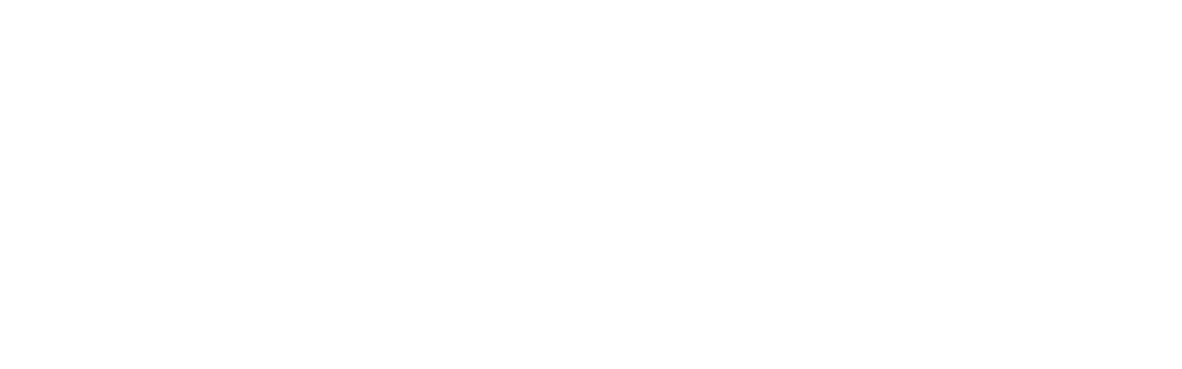


11365000 PIT RIVER NEAR MONTGOMERY CREEK, CALIF.

LOCATION. --Lat $40^{\circ} 50^{\prime} 36^{\prime \prime}$, long $122^{\circ} 00^{\prime} 58^{\prime \prime}$, in SE sec.31, T.35 N., R.1 W., Shasta County, at gaging station on right bank, 0.5 mile upstream from potem Creek, 1.9 miles downstream from Pit No. 7 dam and powerhouse, and 5.0 miles west of town of Montgomery Creek.

DRAINAGE AREA. --4,951 sq mi, excluding Goose Lake basin.

PERIOD OF RECORD. --Chemical analy ses: October 1958 to September 1969.

Nater temperatures: June to September 1951, October 1953 to September 1957, October 1958 to August 1959.

REMARKS. --Records furnished by Californta Department of Water Resources and reviewed by U.S. Geological Survey. CHEMICAL ANALYSES, WATER YEAR OCTOBER 1968 TO SEPTEMBER 1969

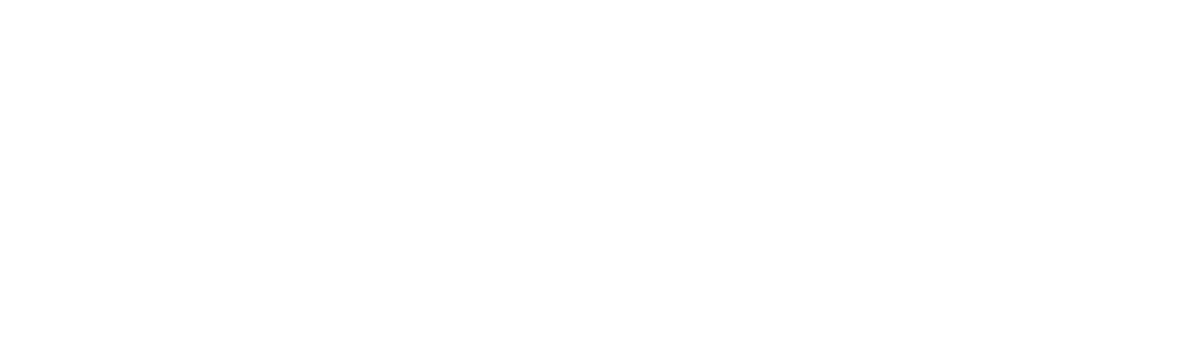

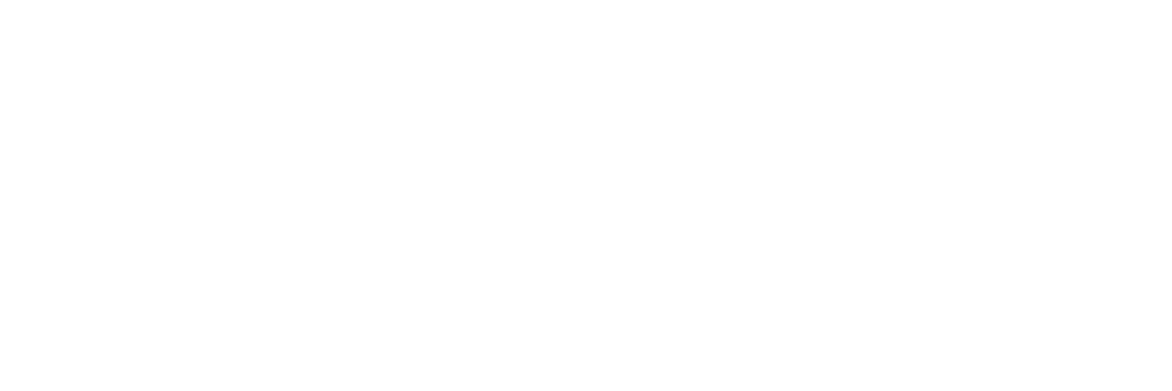


11368000 McCLOUd RIVER ABOVE SHASTA LAKE, CALIF,

LOCATION. -Lat $40^{\circ} 57^{\prime} 30^{\prime \prime}$, long $122^{\circ} 13^{\prime} 07^{\prime \prime}$, in NW , upstream from Shasta Lake, 0.2 mile downstream from Big Bollibokka Crék and 11.3 miles east of Lamoine.

DRAINAGE AREA, - 604 sq mi.

PERIOD OF RECORD, --Chemical analyses: October 1958 to September 1969.

Water temperatures: June to September 1951, October 1953 to September 1959.

REMARKS. --Records furnished by California Department of Vater Resources and revtewed by U.S. Geological Survey. CHEMtCal analyses, hater year OCTOBER 1968 to SEPTEMBER 1969

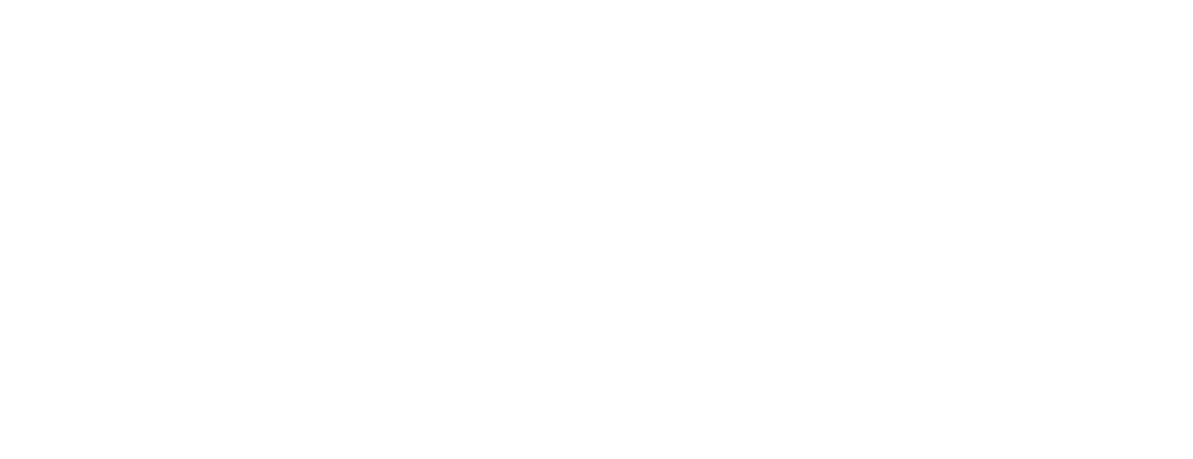

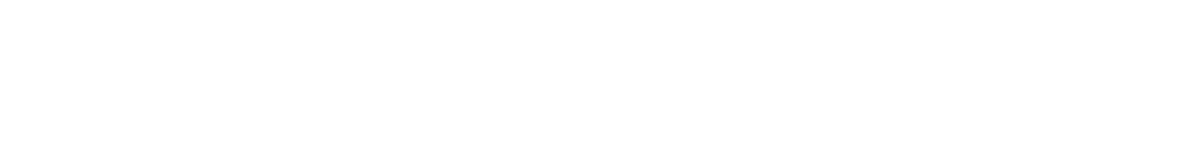

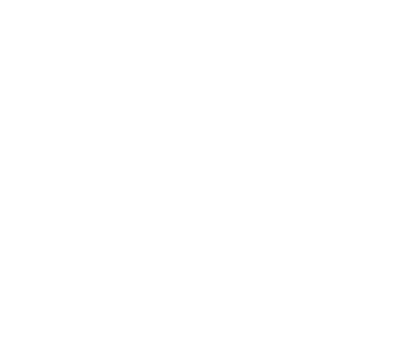

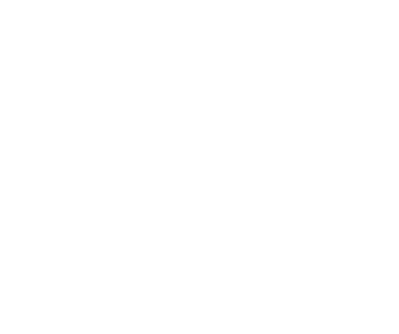

$\begin{array}{llll}-- & - & 42 & 0 \\ -- & -- & 50 & 0 \\ -- & -- & 41 & 0 \\ -- & -- & 30 & 3 \\ -- & -- & 38 & 0 \\ 53 & -07 & 33 & 0 \\ -- & -- & 45 & 0 \\ -- & -- & 48 & 0 \\ -- & -- & 47 & 0 \\ 83 & .11 & 44 & 0\end{array}$

$\begin{array}{rrrrr}22 & .4 & 49 & 7.8 & 105 \\ 18 & .3 & 51 & 8.1 & 113 \\ 19 & .3 & 42 & 7.6 & 99 \\ 13 & .2 & 27 & 6.8 & 62 \\ 12 & .2 & 39 & 7.6 & 86 \\ 16 & .2 & 36 & 7.3 & 79 \\ 13 & .2 & 48 & 7.7 & 102 \\ 16 & .3 & 49 & 8.4 & 110 \\ 18 & .3 & 52 & 8.4 & 131 \\ 22 & .4 & 50 & 7.7 & 107\end{array}$


11370500 SACRAMENTO RIVER AT KESWICK, CALIF.
(Formerly published as Sacramento River at Keswick Dam, near Kegwick, Calif.)

LOCATION (revised). --Lat $40^{\circ} 36^{\prime} 04^{\prime \prime}$, long $122^{\circ} 26^{\prime} 36^{\prime \prime}$, in SW $\frac{1}{\text { NW }} \frac{1}{4}$ sec. 28, T. 32 N., R. 5 W., Shasta County, at gaging station 0.4 mile upstream from Middle Creek, 0.8 mile downtream from Keswick Dam, 1.6 miles downstream from Keswick, and $10 \mathrm{miles}$ downstream from Shasta Dam.

DRAINAGE AREA. $--6,468$ sq $\mathrm{m} 1$, excluding Goose Lake basin.

PERIOD OF RECORD. --Chem1cal analyses: October 1951 to September 1953 (partial records). December 1953 to September 1969 (monthly).

REMARKS.--October 1967 to September 1968; samples collected $0.8 \mathrm{mile}$ upstream from gaging station. Records furnished by California Department of Water Resources and reviewed by U.S. Geological Survey. CHEMICAL ANALYSES, WATER YEAR OCTOBER 1968 TO SEPTEMBER 1969

\begin{tabular}{|c|c|c|c|c|c|c|c|c|c|c|c|c|}
\hline DATE & $\begin{array}{l}\text { MEAN } \\
\text { DIS- } \\
\text { CHARGE } \\
\text { (CFS) }\end{array}$ & $\begin{array}{l}\text { TEMPER- } \\
\text { ATURE } \\
(O E G C)\end{array}$ & $\begin{array}{l}\text { DIS- } \\
\text { SOLVED } \\
\text { OXYGEN } \\
\text { IMG/L) }\end{array}$ & $\begin{array}{l}\text { TUR- } \\
\text { BID- } \\
\text { ITY } \\
\text { IMG/L) }\end{array}$ & $\begin{array}{l}\text { CAL- } \\
\text { CIUM } \\
\text { (CA) } \\
\text { (MG/L) }\end{array}$ & $\begin{array}{l}\text { MAG- } \\
\text { NE- } \\
\text { SIUM } \\
\text { (MG) } \\
(M G / L)\end{array}$ & $\begin{array}{l}\text { SOOIUM } \\
\text { (NA) } \\
(M G / L)\end{array}$ & $\begin{array}{l}\text { PO- } \\
\text { TAS- } \\
\text { SIUM } \\
(K) \\
(M G / L)\end{array}$ & $\begin{array}{l}\text { B [CAR- } \\
\text { BDNATE } \\
\text { (HCO3) } \\
\text { (MG/L) }\end{array}$ & $\begin{array}{l}\text { CAR- } \\
\text { BONATE } \\
\text { (CD3) } \\
\text { (MG/L) }\end{array}$ & $\begin{array}{l}\text { SULFATE } \\
(S D 4) \\
\text { (MG/L) }\end{array}$ & $\begin{array}{l}\text { CHLO- } \\
\text { RIOE } \\
\text { ICLI } \\
\text { I MG } / L\end{array}$ \\
\hline $\begin{array}{l}\text { OCT. } \\
\text { 07... }\end{array}$ & 7190 & 13 & 9.5 & 2.0 & - & -- & 6.5 & - & 63 & 0 & 2.8 & 2.0 \\
\hline $\begin{array}{l}\text { NOV. } \\
\text { O6... } \\
\text { DEC. }\end{array}$ & 6940 & 13 & 9.3 & 4.0 & -- & -- & 6.4 & - & 61 & 0 & 6.4 & 2. \\
\hline $\begin{array}{l}05 . . . \\
\text { JAN. }\end{array}$ & 6640 & 12 & 10.2 & 4.0 & 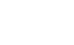 & -- & 7.6 & -- & $6 \mathrm{~B}$ & 0 & 2.6 & 2.8 \\
\hline $\begin{array}{c}06 . . . \\
F \in B .\end{array}$ & 3100 & 8 & 11.6 & 20 & - & - & 6.3 & - & 61 & 0 & 6.1 & \\
\hline $\begin{array}{l}03 . . . \\
M A R .\end{array}$ & 13000 & 7 & 13.4 & $7 \mathrm{C}$ & $=$ & -- & 5.7 & $-\infty$ & 57 & 0 & 6.2 & \\
\hline 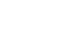 & 12000 & 6 & 12.1 & $=$ & $\cdots$ & -- & 5.0 & - & 52 & 0 & 4.4 & \\
\hline MAY & 6030 & 7 & 13.1 & 15 & - & -- & 5.4 & - & 54 & 0 & 6.1 & \\
\hline $\begin{array}{l}\text { O2.... } \\
\text { JUNE }\end{array}$ & 11900 & 8 & 12.6 & 11 & 9.9 & 4.0 & 5.7 & 1.0 & 56 & 0 & 4.4 & \\
\hline JuLY & 14500 & 9 & 11.5 & 10 & - & - & 4.6 & $=$ & 50 & 0 & 5.4 & \\
\hline $\begin{array}{l}\text { O2... } \\
\text { AUG. }\end{array}$ & 12400 & 9 & 11.7 & 9.0 & -- & -- & 4.6 & - & 53 & 0 & 2.3 & \\
\hline SEPT. & 12600 & 10 & 9.9 & 10 & - & -- & 5.0 & $\cdots$ & 57 & 0 & 2.8 & \\
\hline $02 \ldots$ & 12000 & 10 & 9.3 & 10 & 9.3 & 5.6 & 4.1 & .4 & 55 & 0 & 2.5 & 1. \\
\hline
\end{tabular}

\begin{tabular}{|c|c|c|c|c|c|c|c|c|c|c|c|}
\hline OATE & $\begin{array}{c}\text { NitRATE } \\
\text { (NOO) } \\
\text { (MG/L) }\end{array}$ & $\begin{array}{l}\text { BORON } \\
181 \\
16 G / L 1\end{array}$ & $\begin{array}{l}\text { DIS- } \\
\text { SOLVED } \\
\text { SOLIDS } \\
\text { IRESI- } \\
\text { OUE AT } \\
\text { I80 CI } \\
\text { IMGLL) }\end{array}$ & $\begin{array}{l}\text { DIS- } \\
\text { SOLVEO } \\
\text { SOLIDS } \\
\text { ITONS } \\
\text { PER } \\
\text { AC-FTI }\end{array}$ & $\begin{array}{l}\text { HARD- } \\
\text { NESS } \\
\text { (CA,MG) } \\
\text { (MG/L) }\end{array}$ & $\begin{array}{l}\text { NON- } \\
\text { CAR- } \\
\text { BONATE } \\
\text { HARD- } \\
\text { NESS } \\
\text { (MG/L) }\end{array}$ & $\begin{array}{l}\text { PERCENT } \\
\text { SOO IUM }\end{array}$ & $\begin{array}{l}\text { SOOIUM } \\
\text { AD- } \\
\text { SORP- } \\
\text { TION } \\
\text { RATIO }\end{array}$ & $\begin{array}{l}\text { ALKA- } \\
\text { LINITY } \\
\text { AS } \\
\text { CACO3 } \\
\text { (MG/L) }\end{array}$ & $\begin{array}{c}\text { PH } \\
\text { (UNITS) }\end{array}$ & $\begin{array}{l}\text { SPECI } \\
\text { FIC } \\
\text { COND- } \\
\text { UCTANCE } \\
\text { (MICRO- } \\
\text { MHOS }\end{array}$ \\
\hline OCT. & $\cdots$ & 0 & -- & - & 46 & 0 & 24 & .4 & 52 & 7.8 & 114 \\
\hline $\begin{array}{l}06 . . \\
\text { DEC. }\end{array}$ & - & 10 & -- & - & 61 & 11 & 70 & 1.1 & 50 & 8.1 & 122 \\
\hline $\begin{array}{l}\text { O5... } \\
\text { JAN, }\end{array}$ & -- & 0 & -- & -- & 50 & 0 & 25 & .5 & 56 & 7,9 & 126 \\
\hline $\begin{array}{r}06 \ldots \\
F E B .\end{array}$ & $\cdots$ & 0 & -- & - & 48 & 0 & 22 & .4 & 50 & 7.8 & 125 \\
\hline $03, .$. & $\cdots$ & 10 & -- & - & 43 & 0 & 22 & .4 & 47 & 7.2 & 118 \\
\hline $\begin{array}{l}04 \ldots \\
\triangle P P R\end{array}$ & -- & 0 & -- & - & 44 & 1 & 20 & .3 & 43 & 7.5 & 109 \\
\hline MAY & -- & 0 & -- & - & 40 & 0 & 23 & .4 & 44 & 7.5 & 107 \\
\hline OZZ... & .5 & 50 & 63 & .09 & 41 & 0 & 23 & .4 & 46 & 7.6 & 107 \\
\hline JuL... & $\cdots$ & 40 & -- & -- & 39 & 0 & 20 & .3 & 41 & 7.5 & 100 \\
\hline $\begin{array}{l}02 . . \\
\text { AUG. }\end{array}$ & - & 0 & -- & -- & 42 & 0 & - & -- & 43 & B. 0 & 101 \\
\hline SEPT. & $\cdots$ & 30 & $\cdots$ & - & 42 & 0 & 21 & .3 & 47 & 7.8 & 104 \\
\hline $02 \ldots$ & .2 & 40 & 72 & .10 & 46 & 1 & 16 & .3 & 45 & 7.5 & 116 \\
\hline
\end{tabular}


LOCATION, --Lat $40^{\circ} 30^{\prime} 48^{\prime \prime}$, 1 ong $122^{\circ} 31^{\prime} 23^{\prime \prime}$ (unsurveyed), Shasta County, temperature recorder at gag 1 ng 5 tat1on on left bank at highway hridge on Redding-Igo road, 1,0 mile northeast of Igo, 8.3 miles southwest of Redding, and 10.4 miles upstream from mouth.

DRAINAGE AREA. -228 sq $m 1$.

PERIOD OF RECORD.--Chemical analyses: October 1958 to September 1966.

Water temperatures: March 1965 to September 1969.

EXTREMES, --1968-69:

Water temperatures: Maximum, $19.0^{\circ} \mathrm{C}$ on several days during June; minimum recorded, $3.0^{\circ} \mathrm{C} \mathrm{Jan.} 29,30$.

Period of record:

Water temperatures: Maximum, $21.0^{\circ} \mathrm{C}$ July 1, 1967; minimum, 2.0 ${ }^{\circ} \mathrm{C}$ sometime during period Jan. 3 to Feb. 1 , 1968 .

REMARKS. --Recorder malfunctioned Oct. 14 to Nov. 5 , Feb, 18 to Mar, 3 ; ranges 1 n temperature, $10.0^{\circ} \mathrm{C}$ to $12.0^{\circ} \mathrm{C}$ and $3.0^{\circ} \mathrm{C}$ to $8.0^{\circ} \mathrm{C}$, respectively.

TEMPERATURE ("C) OF WATER, WATER YEAR OCTOBER 1968 TO SEPTEMBER 1969

OAY

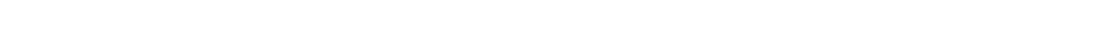

OCTOBER

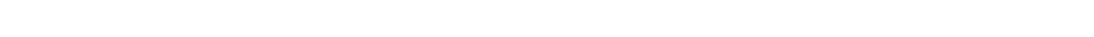

NOVEMBER

MAXIMUM -

DECFMBFR

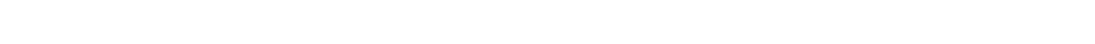

JANUARY

MAXIMUM $7 \begin{array}{llllllllllllllllllllllllllllllllll}7 & 7 & 8 & 7 & 7 & 7 & 7 & 6 & 6 & 6 & 7 & 8 & 8 & 7 & 7 & 6 & 6 & 7 & 9 & 9 & 8 & 7 & 7 & 8 & 8 & 6 & 6 & 4 & 5 & 6 & 7 & 7\end{array}$

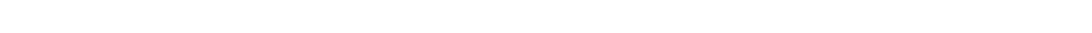

MINIMUM

MAXIML

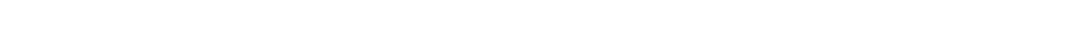

APRIL

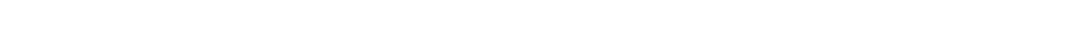

MaY MINI

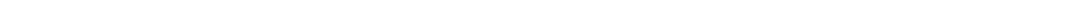

JUNE

$\begin{array}{lllllllllllllllllllllllllllllll} & 9 & 9 & 9 & 0 & 11 & 11 & 12 & 12 & 13 & 13 & 13 & 13 & 12 & 11 & 12 & 13 & 14 & 12 & 12 & 13 & 13 & 14 & 15 & 14 & 13 & 12 & 13 & 14 & 14 & 14\end{array}$

$\begin{array}{lllllllllllllllllllllllllllllllllll}\text { MAXIMUM } & 17 & 18 & 19 & 19 & 19 & 18 & 18 & 18 & 15 & 15 & 16 & 19 & 19 & 19 & 19 & 19 & 19 & 19 & 19 & 18 & 19 & 19 & 19 & 18 & 18 & 17 & 17 & 17 & 17 & 18 & -2\end{array}$

JULY

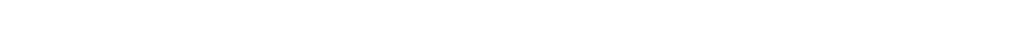

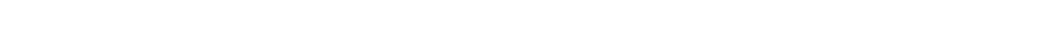
AUGUST

MAXIMUM $17 \begin{array}{lllllllllllllllllllllllllllllllllll}18 & 18 & 18 & 17 & 17 & 17 & 17 & 17 & 17 & 17 & 17 & 17 & 17 & 17 & 17 & 17 & 17 & 17 & 17 & 17 & 17 & 17 & 17 & 16 & 16 & 16 & 16 & 16 & 16 & 16\end{array}$ MINIMUM 15 16 16 15 15 15 15 I5 15 15 15 15 15 15 15 15 15 15 15 15 15 15 15 15 15 14 14 14 15 14 14 SEPTEMBER

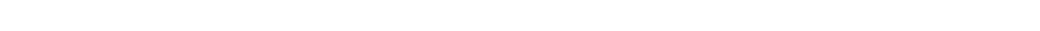
$\begin{array}{llllllllllllllllllllllllllllllll}\text { MAXINIMUM } & 16 & 16 & 16 & 16 & 16 & 16 & 16 & 16 & 16 & 16 & 16 & 16 & 16 & 16 & 15 & 15 & 15 & 15 & 15 & 15 & 16 & 16 & 15 & 15 & 15 & 15 & 15 & 15 & 14 & 14 & 2 \\ \text { MINIMUM } & 14 & 14 & 13 & 13 & 13 & 13 & 13 & 14 & 14 & 14 & 13 & 14 & 14 & 14 & 13 & 13 & 12 & 13 & 13 & 13 & 12 & 13 & 13 & 13 & 13 & 13 & 13 & 13 & 13 & 12 & -\end{array}$ 
LOCATION.--Lat $40^{\circ} 32^{\prime} 56^{\prime \prime}$, long $122^{\circ} 05^{\prime} 29^{\prime \prime}$, In NW 1 NE at gaging station on' left bank, 2.5 miles upstream from old Cow Creek and $4.4 \mathrm{miles}$ east of Millville.

DRAYNAGE AREA. --77.3 sq mi.

PERIOD OF RECORD, - Water temperatures: December 1965 to September 1969.

EXTREMES. --1968-69:

Water temperatures: Maximum, $30.0^{\circ} \mathrm{C}$ sometime during period July 20 to Aug. 11 ; minimum, freezing point sometime during period Dec, 6 to Jan. 14 .

Period of record:

Water temperatures: Maximum, $31.0^{\circ} \mathrm{C}$ Aug. 6, 7, 1966; minimum, freezing point sometime during period Dec. 6 , 1968 , to Jan. $14,1969$.

REMARKS. -- Recorder stopped Nov, 21 to Jan. 14, Jan. 23 to Mar. 7 May 9-14 May 22 to June 5 Ju1y 20 to Aug. 11 ; ranges in temperature, $0.0^{\circ} \mathrm{C}$ to $11.0^{\circ} \mathrm{C}, 2.0^{\circ} \mathrm{C}$ to $9.0^{\circ} \mathrm{C}, 11.0^{\circ} \mathrm{C}$ to
$30.0^{\circ} \mathrm{C}$, respectively. No record Oct. 1-4 and June 22 to July 10

TEIPERATURE $\left({ }^{\circ} \mathrm{C}\right)$ OF WATER, WATER YEAR OTTOBER 1968 TO SEPTEKBER 1969

DAY

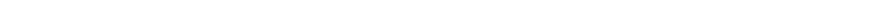

DCTDBER

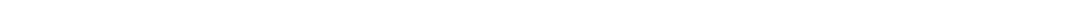

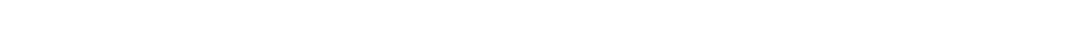

MDVEMBER

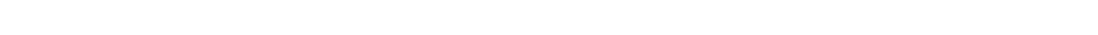

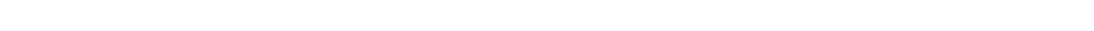

MAXIMUM -.

Minikum -

JANUARY

MAXIMUM -

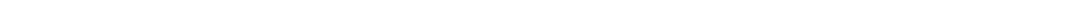

MAXIMUK -. -. -

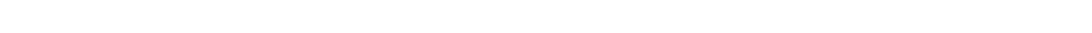

MARCH

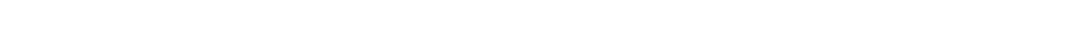

APRIL

$\begin{array}{lllllllllllllllllllllllllllllllllllllll}\text { MAXIMUM } & 10 & 9 & 8 & 10 & 10 & 9 & 10 & 11 & 11 & 11 & 12 & 12 & 9 & 10 & 11 & 11 & 11 & 11 & 11 & 12 & 13 & 13 & 12 & 10 & 11 & 12 & 12 & 13 & 13 & 12 & \cdots & 11\end{array}$

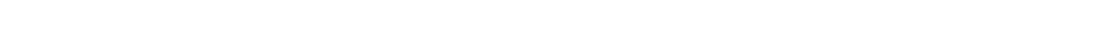

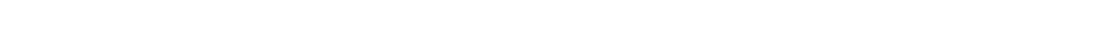

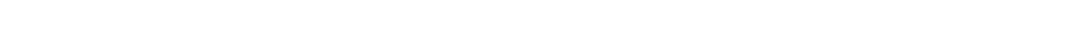

UNE

MAXIMUM -

MINIMUM -. - - - -

MAXIMUM -.

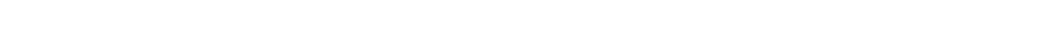

AUGUST

MAXIMUM -

MINTMUM

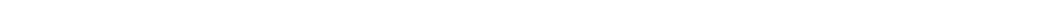

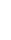
2 $-$ $-$ $-$ $-$ $-$ 
11374000 COM CREEK NEAR MILLVILLE, CALIF.

LOCATION. --Lat $40^{\circ} 30^{\prime} 19^{\prime \prime}$, Iong $122^{\circ} 13^{\prime} 56^{\prime \prime}$, in NE $\frac{1}{1}$ NW $\frac{1}{4}$ sec.32, T.31 N., R, 3 W. , Shasta County, temperature recorder at gaging station on $r$ ght bank, 2.9 miles upstream from mouth, 4.2 miles southwest of uillville, and 4.3 miles downstream from Little Cow Creek.

DRAINAGE AREA. $-\mathbf{- 4 2 5}$ sq $\mathrm{m} 1$.

PERIOD OF RECORD. --Chemical analy ses: October 1958 to September 1966.

Water temperatures: October 1965 to September 1969.

EXTREMES, --1968-69:

Water temperatures: Maxtmum, $30.0^{\circ} \mathrm{C}$ on several days during July and August; mintmum, 1. $0^{\circ} \mathrm{C}$ Dec, $24,25$.

Period of record:

Water temperatures: Maximum $(1966-67,1968-69), 32.0^{\circ} \mathrm{C}$ Aug. 3, 4, 7, 1966; minimum, f reezing point Dec, 14, 15, 1967, Jan. 10, 11, 1968.

REMARKS, -Clock stopped Dec, 4-6, Jan. 29 to Feb. 6, Mar. 8, 9, Sept, 15-24; ranges in temperature, $3.0^{\circ} \mathrm{C}$ to $5.0^{\circ} \mathrm{C}$, $2.0^{\circ} \mathrm{C}$ to $6.0^{\circ} \mathrm{C}, 6.0^{\circ} \mathrm{C}$ to $9.0^{8} \mathrm{C}$, and $21.0^{\circ} \mathrm{C}$ to $25.0^{\circ} \mathrm{C}$, respectively. Temperature probe burled Dec. 30 to Jan. 9, Sept. 29,30

TEIPERATURE $\left({ }^{\circ} \mathrm{C}\right)$ OF WATER, WATER YEAR OCTOBER 1968 TO SEPTEMBER 1969

DAY

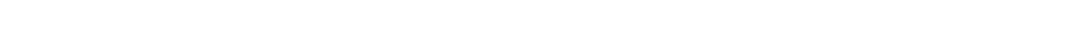

OCTOBE

MAXIMUM --

MINI MUM NOVEMBER

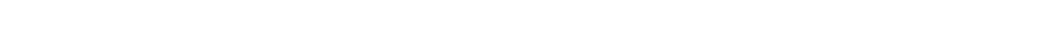

DECEMBER

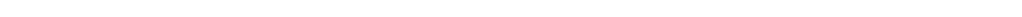

MINIMUM $6 \begin{array}{llllllllllllllllllllllllllllll} & 5 & 4 & \ldots & - & 5 & 6 & 7 & 8 & 7 & 5 & 6 & 6 & 6 & 5 & 5 & 5 & 5 & 5 & 5 & 4 & 3 & 1 & 1 & 5 & 5 & 4 & 6 & \ldots & \ldots\end{array}$

JANUARY

MAXIMUM -.

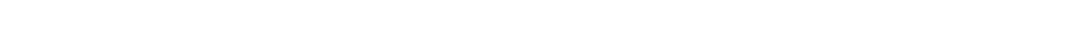

FEBRUARY

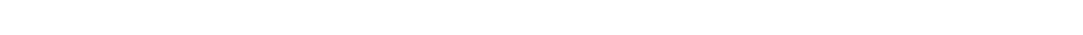

MINCH

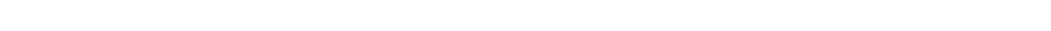

MINIMUM $6 \begin{array}{llllllllllllllllllllllllllllllll} & 6 & 6 & 5 & 5 & 6 & 5 & 5 & -1 & - & 6 & 6 & 7 & 6 & 6 & 7 & 8 & 8 & 7 & 7 & 9 & 9 & 8 & 9 & 8 & 8 & 9 & 9 & 10 & 11 & 11 & 12\end{array}$

APRIL

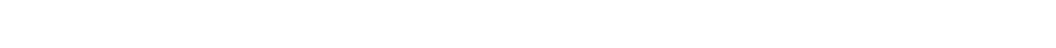
MAY

MAY MAXIMUM

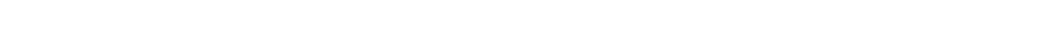
UNE

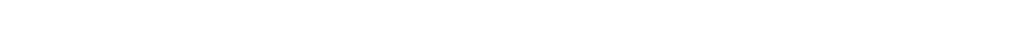

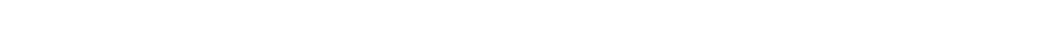
ULY

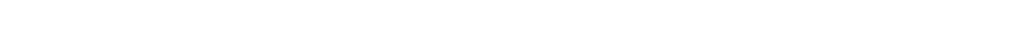

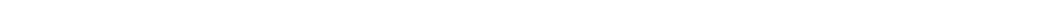

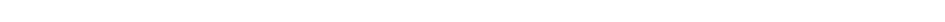

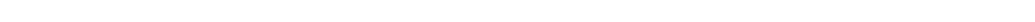
MINTAUM

MAXIMUA

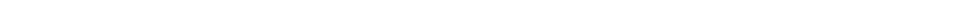


11374400 MIDDLE FOFK COTTONWOOD CREEK NEAR ONO, CALIF.

LOCATION, --Lat $40^{\circ} 23^{\prime 25} "$, long $122^{\circ} 31^{\prime} 15^{\prime \prime}$, In SE⿺𠃊tse sec, 3, T.29 N, , R. 6 w., Shasta County, temperature recorder at gaging station on' left bank, 0.4 mile upstream from Xorth Fork and $7.8 \mathrm{~m} 110 \mathrm{~s}$ southeast of Ono.

DRAI NAGE AREA. $--249 \mathrm{sq} \mathrm{mi}$.

PERIOD OF RECORD, --Fater temperatures: October 1963 to September 1965, Ju1y 1968 to September 1969.

Sediment records: October 1963 to September 1969 (partial records).

EXTREMS, --1968-69:

Water temperatures: Meximum, 31. $0^{\circ} \mathrm{C}$ July 20-22; minimum, freezing point Dec. 25, 26, Fel. 6.

EXTREXIS. -- July 1966 to September 1969:

Water temperatures: Maximum, 31.0 ${ }^{\circ} \mathrm{C}$ July 27, Aug. 1, 2, 1968, July 20-22, 1969; minimum, freezing point

REMARKs. --Clock stopped Sept. 21-26; range $1 \mathrm{n}$ temperature, $20.0^{\circ} \mathrm{C}$ to $25.0^{\circ} \mathrm{C}$.

TELPERATURE $\left({ }^{\circ} \mathrm{C}\right)$ OF WATER, WATER YEAR OCTOBER 1968 TO SEPTEMBER 1969

DAY

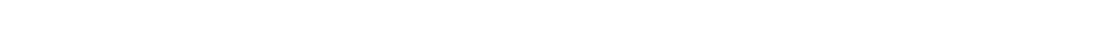

OCTOBER

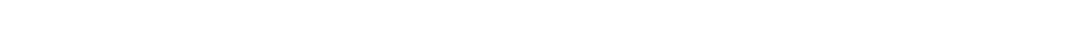

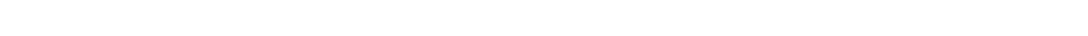

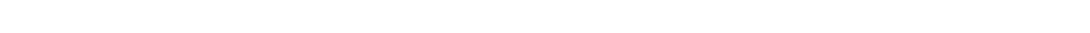

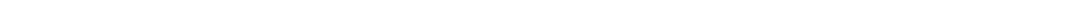

$\begin{array}{llllllllllllllllllllllllllllllllllll}\text { MAXIMUM } & 8 & 8 & 6 & 6 & 8 & 8 & 8 & 8 & 9 & 11 & 10 & 8 & 6 & 6 & 8 & 7 & 7 & 7 & 7 & 5 & 3 & 2 & 1 & 1 & 1 & 1 & 3 & 4 & 4 & 4 & 5 & 6 \\ \text { MINIMUM } & 6 & 5 & 4 & 3 & 6 & 6 & 7 & 8 & 8 & 9 & 7 & 5 & 5 & 5 & 6 & 5 & 5 & 5 & 4 & 2 & 1 & 1 & 1 & 1 & 0 & 0 & 2 & 2 & 2 & 2 & 3 & 4\end{array}$

JANUARY

MAXIMUM $60 \begin{array}{llllllllllllllllllllllllllllllllllllll} & 6 & 6 & 7 & 7 & 7 & 7 & 8 & 7 & 7 & 8 & 6 & 7 & 6 & 7 & 8 & 8 & 5 & 5 & 5 & 5 & 6 & 7 & 7 & 8 & 7 & 7 & 7 & 6 & 5 & 5 & 7\end{array}$

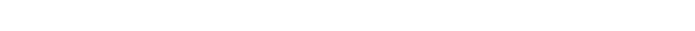

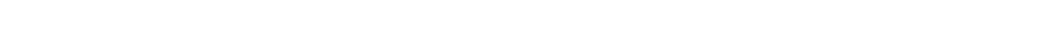

MARCH

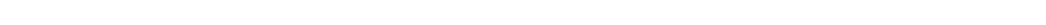

MINIMUM

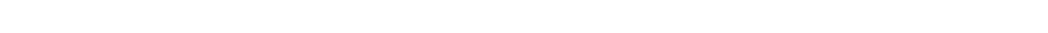

MaY

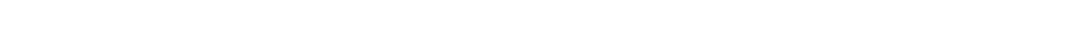

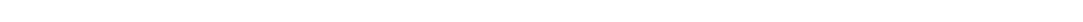

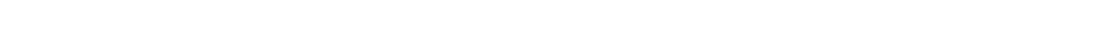

$\begin{array}{lllllllllllllllllllllllllllllllll}\text { MAXIMUM } & 27 & 27 & 26 & 27 & 27 & 27 & 28 & 28 & 29 & 29 & 28 & 27 & 28 & 28 & 28 & 28 & 29 & 29 & 30 & 31 & 31 & 31 & 30 & 30 & 30 & 30 & 29 & 30 & 30 & 30 & 30 & 29 \\ \text { MINIMUM } & 20 & 21 & 20 & 20 & 20 & 21 & 21 & 21 & 22 & 22 & 22 & 22 & 21 & 22 & 22 & 22 & 21 & 23 & 23 & 25 & 25 & 25 & 26 & 25 & 24 & 24 & 25 & 24 & 24 & 24 & 24 & 23\end{array}$

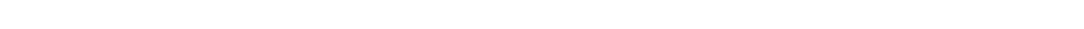

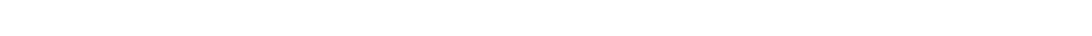

SEPTEMBER

$\begin{array}{lllllllllllllllllllllllllllllllllll}\text { MAXIMUM } & 28 & 28 & 28 & 27 & 27 & 28 & 27 & 28 & 28 & 28 & 28 & 28 & 27 & 26 & 26 & 25 & 25 & 24 & 24 & 24 & - & - & -- & -- & - & -- & 24 & 24 & 23 & 24 & - & 26 \\ \text { MINIMUM } & 22 & 22 & 22 & 22 & 22 & 21 & 23 & 22 & 23 & 23 & 23 & 23 & 22 & 22 & 21 & 21 & 20 & 22 & 21 & 21 & - & - & - & -- & - & - & 20 & 20 & 21 & 19 & - & 22\end{array}$

SUSPENDED-SEDIMENT DISCHARGE MEASUREMENTS AND PARTICLE-SIZE DISTRIBUTION, HATER YEAR OCTOGER 1968 TO SEPTEMBER 1969 MF ANALYSIS: B, BOTIOM WITHDRAWAL TUBE; C, CHEMICALLY DISPERSEDI N, IN NATIVE WATER: P, PIPET: S. SIEVE:

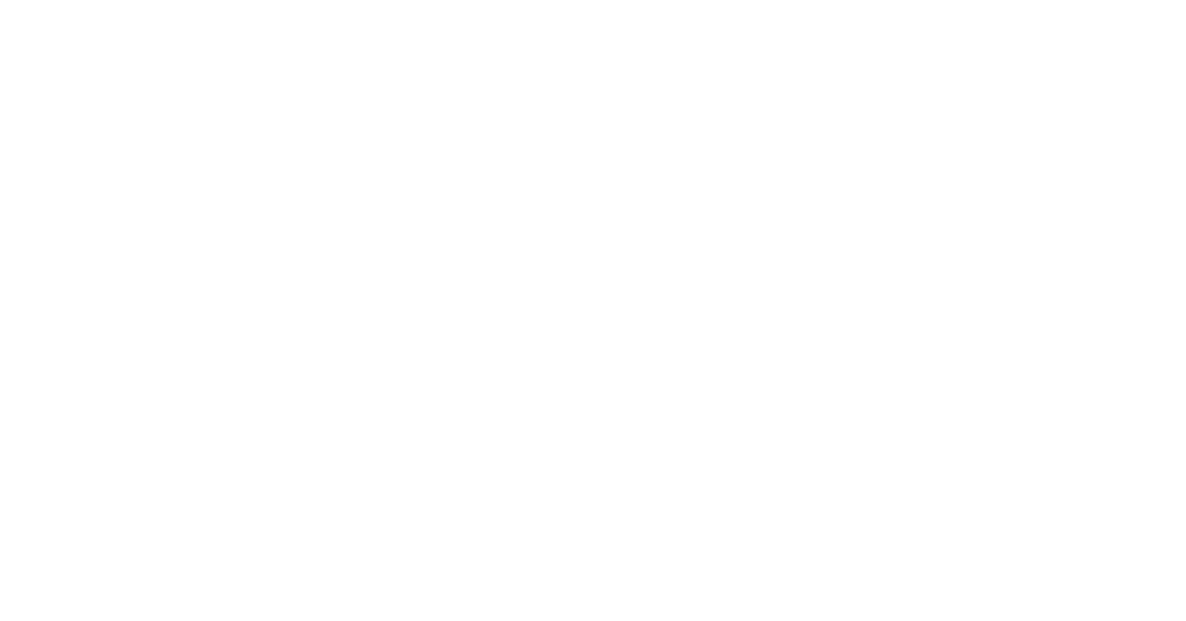


11376000 COTTONWOOD CREEK NEAR COTTONWOOD, CALIF.

LOCATION, -- Lat $40^{\circ} 23^{\prime} 10^{\prime \prime}$, long $122^{\circ} 14^{\prime} 12^{\prime \prime}$, in NE⿺ sec. 7, T. 29 N., R. 3 W., Tehama County, at gaging station 2 miles east of Cottonwood and 2.4 miles upstream from mouth.

DRAINAGE AREA, --922 sq mi.

PERIOD OF RECORD. --Chemical analyses: October 1953 to September 1969.

Water temperatures: October 1982 to September 1967.

Sediment records: October 1962 to September 1967.

REMARKS, --Records furnished by California Department of Water Regources and reviewed by U,S. Geological Survey, CHEMICAL ANALYSES, WATER YEAR OCTOBER 196 B TO SEPTEMBER 1969

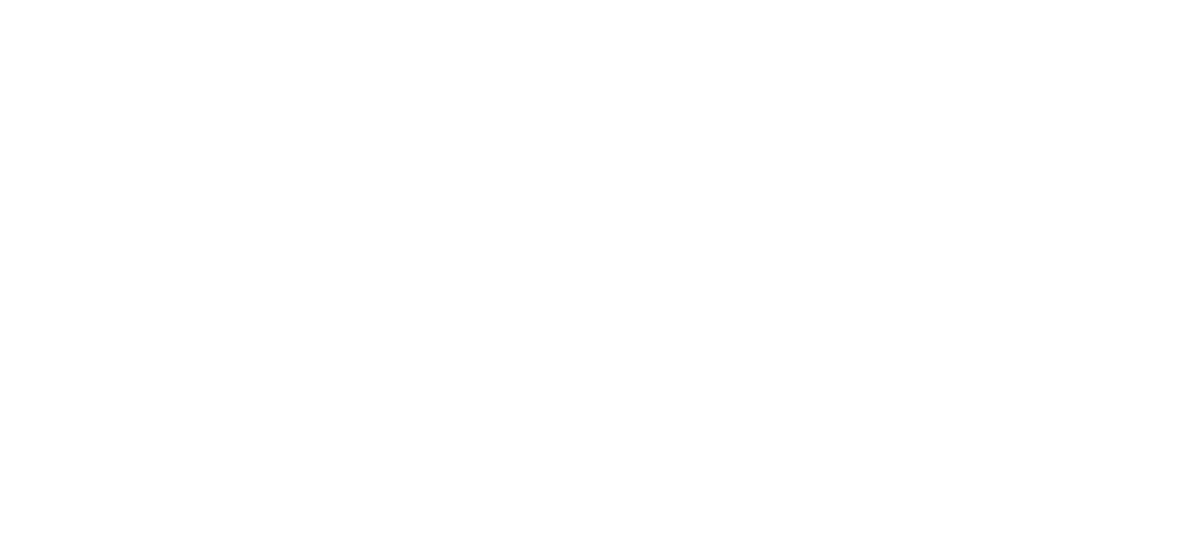

\begin{tabular}{|c|c|c|c|c|c|c|c|c|c|c|c|}
\hline DATE & $\begin{array}{l}\text { NITRATE } \\
\text { (NO3) } \\
\text { (MG/L) }\end{array}$ & $\begin{array}{l}\text { BURON } \\
(B) \\
(U G / L)\end{array}$ & $\begin{array}{l}\text { OIS- } \\
\text { SOLVEO } \\
\text { SOLIOS } \\
\text { (RESI- } \\
\text { OUE AT } \\
\text { IBO C) } \\
\text { (MGIL) }\end{array}$ & $\begin{array}{l}\text { OLS- } \\
\text { SOLVEO } \\
\text { SOLIOS } \\
\text { ITONS } \\
\text { PER } \\
\text { AC-FTI }\end{array}$ & $\begin{array}{l}\text { HARO- } \\
\text { NESS } \\
\text { (CA,MG) } \\
\text { (MG/L) }\end{array}$ & $\begin{array}{l}\text { NON- } \\
\text { CAR- } \\
\text { BONATE } \\
\text { HARD- } \\
\text { NESS } \\
\text { (MGIL) }\end{array}$ & $\begin{array}{l}\text { PERCENT } \\
\text { SODIUM }\end{array}$ & $\begin{array}{l}\text { SODIUM } \\
\text { AD- } \\
\text { SORP- } \\
\text { TION } \\
\text { AATIO }\end{array}$ & $\begin{array}{l}\text { ALKA- } \\
\text { LINITY } \\
\text { AS } \\
\text { CACO3 } \\
\text { (MG/L) }\end{array}$ & $\begin{array}{c}\text { PH } \\
\text { (UNITS) }\end{array}$ & $\begin{array}{l}\text { SPECI- } \\
\text { FIC } \\
\text { CONO- } \\
\text { UCTANCE } \\
\text { (MICRO- } \\
\text { MHOS I }\end{array}$ \\
\hline $\begin{array}{l}\text { OCT. } \\
\text { OP.... } \\
\text { NOV. }\end{array}$ & - & 0 & -- & -- & 68 & 0 & 20 & .4 & 75 & 8.0 & 162 \\
\hline OEC... & - & 0 & - & - & 131 & 25 & 17 & .5 & 106 & B. 4 & 294 \\
\hline $\begin{array}{l}\text { OS... } \\
\text { JAN. }\end{array}$ & -- & 0 & - & - & 136 & 22 & 18 & .5 & 114 & 8.3 & 337 \\
\hline $\begin{array}{l}06 \ldots . . \\
\text { FEB. }\end{array}$ & -- & 20 & $=$ & -- & 104 & 20 & 15 & .3 & 84 & 8.2 & 216 \\
\hline $\begin{array}{l}\text { O3... } \\
\text { MAR. }\end{array}$ & -- & 0 & -- & -- & 123 & 16 & 13 & .3 & 107 & B. 3 & 263 \\
\hline $\begin{array}{l}04 . . \\
\text { APR. }\end{array}$ & -- & 0 & -- & -- & 125 & 20 & 13 & .3 & 105 & 8.3 & 267 \\
\hline MAY & -- & 0 & $=$ & -- & 80 & 5 & 11 & .2 & 75 & 7.8 & 273 \\
\hline$\underset{\text { JUNE }}{01 \ldots . .}$ & .0 & 10 & 92 & .13 & 80 & 3 & 11 & .2 & 75 & 7.9 & 174 \\
\hline $\begin{array}{l}02 \ldots . . \\
\text { JULY }\end{array}$ & -- & 30 & -- & -- & 17 & 2 & 13 & .3 & 75 & 7.7 & 172 \\
\hline $\begin{array}{l}02 \ldots \\
\text { AUG. }\end{array}$ & -- & 0 & - & - & 111 & 4 & 13 & .3 & 107 & 8.3 & 235 \\
\hline SEPT. & - & 20 & -- & -- & 98 & 1 & 15 & .3 & 97 & B. 0 & 216 \\
\hline $03 \ldots$ & .2 & 20 & 96 & .13 & B7 & 0 & 15 & .3 & 89 & 8.0 & 193 \\
\hline
\end{tabular}


11376550 BATTLE CREEK BELOW COLEMAN FISH HATCHERY, NEAR COTTONWOOD, CALIF,

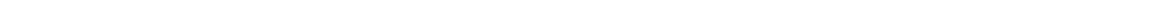
at Coleman F1sh Hatchery, $300 \mathrm{ft}$ upstream from saging station, 3.7 miles downstream from Spring Branch,
5.7 miles upstream from mouth, and 7.0 miles east of Cottonwood.

DRAINAGE AREA. $--358 \mathrm{sq} \mathrm{mi}$.

PERIOD OF RECORD. --Chem1cal analyses: October 1961 to September 1966.

Water temperatures: December 1965 to September 1969.

Sediment records: October 1965 to September 1969 (partial records).

EXTREMES. - 1968-69:

Water temperatures: Maximum, $22.0^{\circ} \mathrm{C}$ July 21 ; minimum, $2.0^{\circ} \mathrm{C} \mathrm{DeC}, 23,24$.

Period of record:

Water temperatures: Maximum, $22.0^{\circ} \mathrm{C}$ July 21,$1969 ;$ minimum, $2.0^{\circ} \mathrm{C} \mathrm{Dec} .23,24,1968$.

REMARKS. -- Clock stopped June 9-16; range in temperature, $12.0^{\circ} \mathrm{C}$ to $17.0^{\circ} \mathrm{C}$.

TEMPERATURE $\left({ }^{\circ} \mathrm{C}\right)$ OF TATER, MATER YEAR OCTOBER 1968 TO SEPTEMBER 1969

DAY

MUNTH

OCTUHER

MAXIMUM $14 \begin{array}{llllllllllllllllllllllllllllllllllllllll}4 & 15 & 14 & 14 & 14 & 12 & 12 & 12 & 12 & 12 & 13 & 13 & 11 & 12 & 12 & 13 & 13 & 13 & 13 & 12 & 12 & 13 & 13 & 13 & 13 & 13 & 13 & 13 & 11 & 11 & 13\end{array}$

MINIMUM

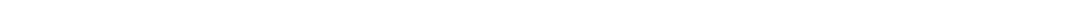

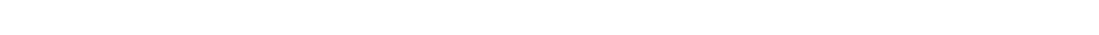

DECEMAER

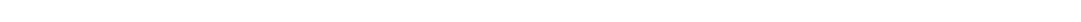

MINIMUM

JANUARY

MAXIMUA

MARCH

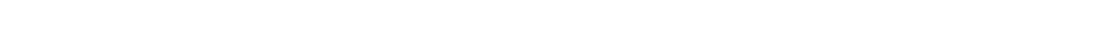

APR IL

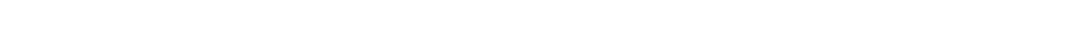

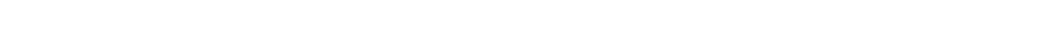

MAXIMUM $13 \quad 13 \quad 12 \quad 12 \quad 14 \quad 15 \quad 14 \quad 14 \quad 14 \quad 14 \quad 14 \quad 14 \quad 14 \quad 13 \quad 13 \quad 14 \quad 15 \quad 14 \quad 13 \quad 14 \quad 15 \quad 16 \quad 16 \quad 15 \quad 15 \quad 14 \quad 14 \quad 1517 \quad 17 \quad 17$

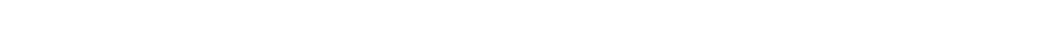
MNE

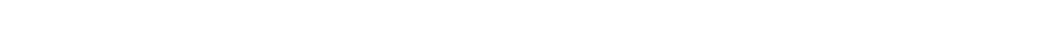

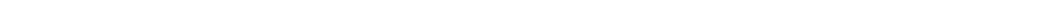
UEY

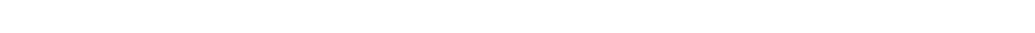
MINIMUM $15 \quad 16 \quad 15 \quad 15 \quad 1616 \quad 16 \quad 16 \quad 17 \quad 17 \quad 17 \quad 16 \quad 16 \quad 17 \quad 17 \quad 16 \quad 16 \quad 17 \quad 17 \quad 17 \quad 1817 \quad 17 \quad 17 \quad 17 \quad 17 \quad 17 \quad 16 \quad 16 \quad 16 \quad 16$ AUGUST

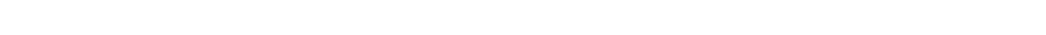
$\begin{array}{llllllllllllllllllllllllllllllllll}M & 16\end{array}$

$\begin{array}{llllllllllllllllllllllllllllllllllllllllll}\text { MAXIMUM } & 17 & 17 & 17 & 17 & 17 & 17 & 17 & 16 & 17 & 17 & 17 & 17 & 17 & 16 & 16 & 14 & 14 & 15 & 15 & 15 & 14 & 14 & 14 & 15 & 16 & 15 & 16 & 15 & 14 & 14 & \ldots & 16 \\ \text { MINIMUM } & 14 & 14 & 15 & 14 & 14 & 14 & 14 & 14 & 15 & 15 & 15 & 15 & 14 & 14 & 13 & 13 & 13 & 13 & 14 & 13 & 12 & 13 & 13 & 13 & 13 & 14 & 14 & 13 & 13 & 13 & - & 14\end{array}$

SUSPENDED-SEDIMENT DISCHARGE MEASUREMENTS AND PARTICLE-SIZE BISTRIBUT ION, WATER YEAR OCTOBER 1968 TO SEPTEMBER 1969
(METHOOS OF ANALYSIS: B, BOTTM WITHORAWAL TUBE; C, CHEMICALLY DISPERSED: N, IN NATIVE WATER; P, PIPET: S. SIEVE;

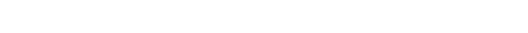

\begin{tabular}{|c|c|c|c|c|c|c|c|c|c|c|c|c|c|c|c|c|c|c|c|}
\hline & DATE & TIME & $\begin{array}{l}\text { WATER } \\
\text { TEM- } \\
\text { PERA- } \\
\text { TURE } \\
\text { I C) }\end{array}$ & $\begin{array}{l}\text { DI SCHARGE } \\
\text { [CFS) }\end{array}$ & $\begin{array}{l}\text { CONCEN- } \\
\text { TRATION } \\
\text { (MG/L) }\end{array}$ & $\begin{array}{l}\text { SUSPENDEO } \\
\text { SEDIMENT } \\
\text { OISCHARGE } \\
\text { (TDNS/OAY) }\end{array}$ & $\begin{array}{l}\text { PERCE } \\
.002\end{array}$ & ENT $F$ & $\begin{array}{l}\text { FI NE } \\
14.0\end{array}$ & & $\begin{array}{l}\text { THAN } \\
.016\end{array}$ & THE SI & IZE I & $\begin{array}{l}11 N M I \\
2.125\end{array}$ & .5 .250 & .500 & 1.00 & $\begin{array}{l}\text { CATED } \\
2.00\end{array}$ & $\begin{array}{l}\text { METHDO } \\
\text { OF } \\
\text { ANALY- } \\
\text { SIS }\end{array}$ \\
\hline $\begin{array}{l}\text { AUE } \\
\text { SEP }\end{array}$ & $11 \ldots \ldots$ & $\begin{array}{l}1040 \\
1425\end{array}$ & $\begin{array}{l}17 \\
15\end{array}$ & $\begin{array}{l}324 \\
297\end{array}$ & $\begin{array}{l}10 \\
12\end{array}$ & $\begin{array}{l}8.7 \\
9.6\end{array}$ & $=$ & $=$ & - & $m$ & $\because$ & $=$ & $=$ & $=$ & $=-$ & $\because$ & $\because$ & $=$ & \\
\hline
\end{tabular}


11377200 SACRAMENTO RIVER AT BEND, CALIF.

LOCATION (revised), - Lat $40^{\circ} 15^{\prime} 51^{\prime \prime}$, long $122^{\circ} 13^{\prime} 19^{\prime \prime}$, in NW $\frac{1}{4} \mathrm{SE} \frac{1}{4}$ sec. 20 , T. 28 N., R. 3 w., Tehama County, at highway bridge at Bend, $0.1 \mathrm{mile}$ upstream from Spring Creek, 2.7 miles downstream from gaging station, and approximately 6 miles north of Red Bluff.

DRAINAGE AREA.--8,904 sq $\mathrm{m} 1$ (revised), excluding Goose Lake basin (at gaging station).

PERIOD OF RECORD. --Chemtcal analy ses: May 1955 to September 1969.

Water temperatures: May 1955 to September 1969.
Sediment records: October 1957 to September 1969.

EXTREMES, $-1968-69$ :

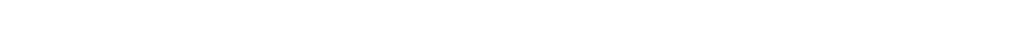

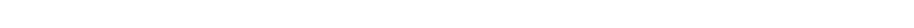

Period of record:

Water temperatures: Maximum (1955-66), $19.0^{\circ} \mathrm{C}$ June 1,2960 ; minimum, $3.5^{\circ} \mathrm{C}$ Jan. 22,1962, DeC, 24,1968, Sediment concentrations: Maximum da11y, 2,920 mg/1 Dec. 24, 1964; minimum daily, 1 mg/1 on many days in 1964 , Ju1y $12,1967$.

Sediment discharge: Maximum da11y, 876,000 tons Dec, 22, 1964; mintmum dai1y, 12 tons Dec. 8-10, 15, 1964.

REMARKS. - Records of dally discharge data given for Sacramento River above Bend Bridge, near Red Bluff (station 11377100 ). No appreciable inflow between sampling point and gaging station.

CHEMICAL ANALYSES, WATER YEAR OCTOBER 1968 TO SEPTEMBER 1969

\begin{tabular}{|c|c|c|c|c|c|c|c|c|c|c|c|c|}
\hline OAIE & $\begin{array}{l}\text { DIS- } \\
\text { CHARGE } \\
\text { (CFS) }\end{array}$ & $\begin{array}{l}\text { TEMPER- } \\
\text { ATURE } \\
\text { (DEG C) }\end{array}$ & $\begin{array}{l}\text { DIS- } \\
\text { SOLVED } \\
\text { DXYGEN } \\
\text { (MG/LL) }\end{array}$ & $\begin{array}{l}\text { CAL- } \\
\text { CIUM } \\
\text { (CA) } \\
\text { (MG/L) }\end{array}$ & $\begin{array}{l}\text { MAG- } \\
\text { NE- } \\
\text { SIUM } \\
\text { (MG) } \\
\text { (MG/L) }\end{array}$ & $\begin{array}{l}\text { SODIUM } \\
\text { (NA) } \\
\text { (MG/L) }\end{array}$ & $\begin{array}{l}\text { PO- } \\
\text { IAS- } \\
\text { SIUM } \\
\text { (K) } \\
\text { (MG/L) }\end{array}$ & $\begin{array}{l}\text { BICAR- } \\
\text { BONATE } \\
\text { (HCOB) } \\
\text { (MG/L) }\end{array}$ & $\begin{array}{l}\text { CAR- } \\
\text { BONATE } \\
\text { (CO3) } \\
\text { (MG/LI }\end{array}$ & $\begin{array}{l}\text { SULFATE } \\
\text { (SO4) } \\
\text { (MG/L) }\end{array}$ & $\begin{array}{l}\text { CHLO- } \\
\text { RIDE } \\
\text { ICLI) } \\
\text { (MGILI }\end{array}$ & $\begin{array}{l}\text { NITRAT } \\
\text { (NO3) } \\
\text { (MGIL }\end{array}$ \\
\hline OC1. & 7000 & 13 & 10.8 & -- & - & 7.0 & 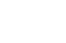 & 66 & 0 & -- & 2.2 & .0 \\
\hline $\begin{array}{l}\text { Nav. } \\
\text { OB... } \\
\text { JAN, }\end{array}$ & 7450 & 12 & 11.0 & - & - & 7.7 & $\rightarrow$ & 70 & 0 & -- & 3.5 & .7 \\
\hline $\begin{array}{l}03 \ldots \\
\text { MAR... }\end{array}$ & 9700 & 7 & 11.5 & -- & - & 7.7 & - & 65 & 0 & -- & 4.6 & 2.7 \\
\hline MAY 03 & 26200 & 6 & $11 . B$ & -- & -- & 5.0 & -- & 60 & 0 & -- & $2 \cdot 2$ & .8 \\
\hline $\begin{array}{l}01 . . . \\
\text { Juery }\end{array}$ & 14500 & 10 & 12.3 & 11 & 4.5 & 5.3 & .8 & 53 & 0 & 8.7 & 2.9 & .5 \\
\hline $\begin{array}{l}\text { OZ... } \\
\text { SEPT. }\end{array}$ & 13500 & 11 & 10.4 & - & - & 5.4 & -- & 58 & 0 & -- & 2.2 & .2 \\
\hline $03 \ldots$ & 11900 & 12 & 10.6 & 8.9 & 5.4 & 4.4 & .7 & 57 & 0 & 1.8 & 2.0 & .2 \\
\hline
\end{tabular}

\begin{tabular}{|c|c|c|c|c|c|c|c|c|c|c|c|}
\hline DATE & $\begin{array}{l}\text { PHOS- } \\
\text { PHATE } \\
\text { (PQ4) } \\
\text { (MG/L) }\end{array}$ & $\begin{array}{l}\text { BORON } \\
\text { (B) } \\
(\cup G / L)\end{array}$ & $\begin{array}{l}\text { OIS- } \\
\text { SOLVED } \\
\text { SOLIOS } \\
\text { (RESI- } \\
\text { DUE AI } \\
\text { 18O C) } \\
\text { (MG IL) }\end{array}$ & $\begin{array}{l}\text { OIS- } \\
\text { SOLVED } \\
\text { SOLIOS } \\
\text { (TONS } \\
\text { PER } \\
\text { AC-FI) }\end{array}$ & $\begin{array}{l}\text { HARD- } \\
\text { NESS } \\
(C A, M G) \\
(M G / L)\end{array}$ & $\begin{array}{l}\text { NON- } \\
\text { CAR- } \\
\text { BONATE } \\
\text { HARD- } \\
\text { NESS } \\
\text { (MG/L) }\end{array}$ & $\begin{array}{l}\text { PERCENT } \\
\text { SODIUM }\end{array}$ & $\begin{array}{l}\text { SODIUM } \\
\text { AD- } \\
\text { SORP- } \\
\text { TION } \\
\text { RATIO }\end{array}$ & $\begin{array}{l}\text { ALKA- } \\
\text { LINITY } \\
\text { AS } \\
\text { CACOB } \\
\text { (MG/L) }\end{array}$ & $\begin{array}{c}P H \\
\text { IUNITS }\end{array}$ & $\begin{array}{l}\text { SPEC1- } \\
\text { FIC } \\
\text { COND- } \\
\text { UCTANCE } \\
\text { (MICRO- } \\
\text { MHOSI }\end{array}$ \\
\hline $\begin{array}{c}\text { oct. } \\
07 \ldots . . .\end{array}$ & .07 & 0 & - & -- & 49 & 0 & 24 & .4 & 54 & 7.6 & 120 \\
\hline $\begin{array}{l}\text { NOV. } \\
\text { DG... } \\
\text { JAN. }\end{array}$ & .02 & 10 & -- & - & 56 & 0 & 23 & .4 & 57 & B. 2 & 130 \\
\hline $\begin{array}{l}\text { D3... } \\
\text { MAR. }\end{array}$ & .26 & 50 & - & - & 59 & 6 & 22 & .4 & 53 & 7.8 & 147 \\
\hline MAY 03 & .06 & 0 & -- & - & 50 & 1 & 18 & -3 & 49 & 7.6 & 119 \\
\hline $\begin{array}{l}\text { ol... } \\
\text { JuLY }\end{array}$ & .11 & 30 & 87 & .12 & 46 & 3 & 20 & .3 & 43 & 7.6 & 119 \\
\hline $\begin{array}{l}02 . . . \\
\text { SEPT. }\end{array}$ & - & 0 & - & -- & 46 & 0 & 20 & .3 & 48 & 8.3 & 108 \\
\hline $03 \ldots$ & -- & 10 & 71 & .10 & 44 & 0 & 17 & .3 & 47 & 7.5 & 105 \\
\hline
\end{tabular}

TEMPERATURE $\left({ }^{\circ} \mathrm{C}\right)$ OF WATER, WATER YEAR OCTOBER 1968 TO SEPTEMBER 1969 (ONCE-DAILY MEASUREMENT)

DAY

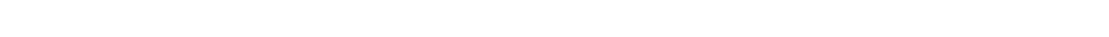

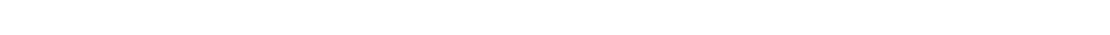

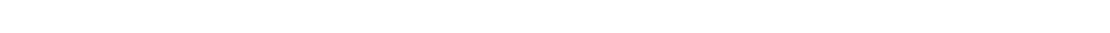
$\begin{array}{lllllllllllllllllllllllllllllllllllllllllllll}\text { JANUARY.. } & 6 & 7 & 7 & 7 & 6 & 7 & - & \ldots & \cdots & 7 & 6 & 6 & 7 & 7 & 7 & 6 & 6 & 6 & 8 & B & 7 & 6 & 7 & 7 & 7 & 7 & 6 & 7 & 6 & 7 & 7\end{array}$ $\begin{array}{llllllllllllllllllllllllllllllllllll}\text { FEBRUARY: } & 7 & 7 & 7 & 6 & 6 & 6 & 6 & 6 & 7 & 7 & -7 & 7 & 7 & 7 & 7 & 7 & - & 7 & 7 & -- & 7 & 6 & -5 & 6 & 6 & 6 & 7 & 7 & -7 & -- & -7 & 7\end{array}$

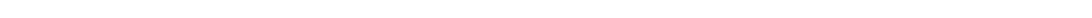

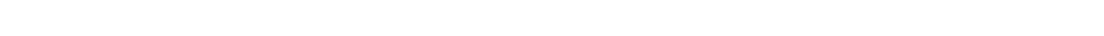

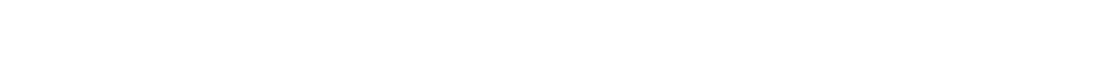

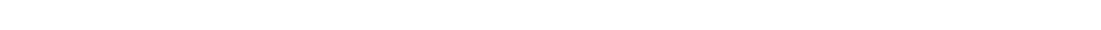


11377200 SACRAMENTO RIVER AT BEND, CALIF.--CONTI nuEd

SUSPENDED-SEDIMENT DISCHARGE, WATER YEAR OCTOBER 1968 TO SEPTEMBER 1969

\begin{tabular}{|c|c|c|c|c|c|c|c|c|c|}
\hline & & OCTOBER & & & NOVEMBER & & & DECEMBER & \\
\hline DAY & $\begin{array}{l}\text { MEAN } \\
\text { DISCHARGE } \\
\text { (CFS) }\end{array}$ & $\begin{array}{l}\text { MEAN } \\
\text { CONCEN- } \\
\text { TRATION } \\
\text { (MG/L) }\end{array}$ & $\begin{array}{l}\text { SEDIMENT } \\
\text { DISCHARGE } \\
\text { (TONS/DAY }\end{array}$ & $\begin{array}{l}\text { MEAN } \\
\text { OI SCHARGE } \\
\text { (CFS) }\end{array}$ & $\begin{array}{l}\text { MEAN } \\
\text { CONCEN- } \\
\text { IRAIION } \\
\text { (MGIL) }\end{array}$ & $\begin{array}{l}\text { SEDIMENT } \\
\text { DISCHARGE } \\
\text { ITONS/DAYI }\end{array}$ & $\begin{array}{c}\text { MEAN } \\
\text { OISCHARGE } \\
\text { (CFS) }\end{array}$ & $\begin{array}{l}\text { MEAN } \\
\text { CONCEN- } \\
\text { TRAIION } \\
\text { IMGIL) }\end{array}$ & $\begin{array}{l}\text { SEDIMENT } \\
\text { DISCHARGE } \\
\text { (TONS/DAY) }\end{array}$ \\
\hline 1 & 9320 & 2 & 50 & 7670 & 5 & 104 & 7730 & 3 & 63 \\
\hline 2 & 8410 & 2 & 45 & 7710 & 5 & 104 & 7820 & 4 & 84 \\
\hline 3 & 8100 & 2 & 44 & 8290 & 9 & 201 & 7620 & 3 & 62 \\
\hline 4 & 7710 & 3 & 62 & 8090 & 5 & 109 & 7560 & 4 & 82 \\
\hline 5 & 7420 & 3 & 60 & 7820 & 7 & 148 & 7550 & 4 & 82 \\
\hline 6 & 7440 & 4 & 80 & 1710 & 6 & 125 & 7510 & 3 & 61 \\
\hline 7 & 7400 & 4 & BO & 7740 & 4 & 84 & 7490 & 4 & 81 \\
\hline 8 & 7350 & 5 & 99 & 7690 & 5 & 104 & 7650 & 4 & 83 \\
\hline 9 & 7350 & 5 & 99 & 7730 & 5 & 104 & 7830 & 30 & 634 \\
\hline 10 & 7350 & 5 & 99 & 7760 & 4 & 84 & 20100 & 229 & 15900 \\
\hline 11 & 7530 & 4 & 81 & 7780 & 4 & 84 & 16300 & 178 & 8790 \\
\hline 12 & 8050 & 6 & 130 & 8410 & 5 & 114 & 9740 & 35 & 920 \\
\hline 13 & 8350 & 11 & 248 & 8250 & 4 & 89 & 8540 & 25 & 576 \\
\hline 14 & 8420 & 13 & 296 & 8160 & 4 & 88 & 19300 & 144 & 7890 \\
\hline 15 & 8180 & 10 & 221 & 8160 & 6 & 132 & 19000 & 140 & B340 \\
\hline 16 & 8010 & 5 & 108 & 8290 & 8 & 179 & 14700 & 119 & 5530 \\
\hline 17 & 8000 & 5 & 108 & 7980 & 6 & 129 & 9780 & 24 & 634 \\
\hline 18 & 7960 & 4 & 86 & 8240 & 5 & 111 & 8410 & 21 & 477 \\
\hline 19 & 7980 & 4 & 86 & 8480 & 5 & 114 & 7730 & 12 & 250 \\
\hline 20 & 7980 & 4 & 86 & 8010 & 6 & 130 & 7420 & 8 & 160 \\
\hline 21 & 7940 & 5 & 107 & 7820 & 4 & 84 & 7190 & 6 & 116 \\
\hline 22 & 7920 & 4 & 86 & 7840 & 4 & 83 & 7110 & 6 & 115 \\
\hline 23 & 7830 & 4 & 85 & 7640 & 3 & 62 & 7280 & 6 & 118 \\
\hline 24 & 7820 & 5 & 106 & 7650 & 3 & 62 & 23400 & 185 & 11700 \\
\hline 25 & 7800 & 6 & 126 & 7830 & 5 & 106 & 34600 & 210 & 19600 \\
\hline 26 & 7800 & 6 & 126 & 7710 & 4 & 8 3 & 19800 & 100 & 5350 \\
\hline 27 & 7800 & 7 & 147 & 7620 & 3 & 62 & 12800 & 60 & 2070 \\
\hline 28 & 7820 & 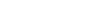 & 127 & 7550 & 4 & 82 & 25500 & 332 & 24000 \\
\hline 29 & 8160 & $B$ & 176 & 7550 & 5 & 102 & 17400 & 102 & 5460 \\
\hline 30 & 8560 & 9 & 208 & 7650 & 2 & 41 & 11600 & 26 & 814 \\
\hline 31 & 8200 & 5 & 111 & $\cdots$ & -- & -- & 9740 & 20 & 526 \\
\hline TOTAL & 245960 & -- & 3573 & 236630 & -- & 3104 & 386200 & -- & 120568 \\
\hline & & JANUARY & & & FEBRUARY & & & MARCH & \\
\hline & & MEAN & & & MEAN & & & MEAN & \\
\hline & MEAN & CONCEN- & SEDIMENT & MEAN & CONCEN- & SEDIMENT & MEAN & CONCEN- & SEDIMENT \\
\hline OAY & $\begin{array}{l}\text { DISCHARGE } \\
\text { (CFS) }\end{array}$ & $\begin{array}{l}\text { TRATIUN } \\
\text { IMG/LI) }\end{array}$ & $\begin{array}{l}\text { DISCHARGE } \\
\text { (rONS/DAY) }\end{array}$ & $\begin{array}{l}\text { D1 SCHARGE } \\
\text { (CFS) }\end{array}$ & $\begin{array}{l}\text { TRATIDN } \\
\text { (MG/L) }\end{array}$ & $\begin{array}{l}\text { DISCHARGE } \\
\text { (TONS/DAY) }\end{array}$ & $\begin{array}{l}\text { OISCHARGE } \\
\text { (CFS) }\end{array}$ & $\begin{array}{l}\text { RRATION } \\
\text { (MG/L) }\end{array}$ & $\begin{array}{l}\text { DISCHARGE } \\
\text { (TONS/DAY) }\end{array}$ \\
\hline 1 & 8620 & 20 & 465 & 29100 & 59 & 4640 & 41400 & 221 & 27000 \\
\hline 2 & 8670 & 40 & 936 & 24700 & 100 & 6670 & 26900 & 90 & 6540 \\
\hline 3 & 9170 & 110 & 2720 & 20700 & $5 i$ & 2850 & 26100 & 85 & 5990 \\
\hline 4 & 9510 & 185 & 4750 & 19800 & 31 & 1660 & 21300 & 40 & 2300 \\
\hline 5 & 9320 & 178 & 4480 & 26100 & 290 & 20400 & 19600 & 40 & 2120 \\
\hline 6 & 8580 & 93 & 2150 & 36100 & 465 & 45300 & 17100 & 40 & 1850 \\
\hline 7 & 8000 & 71 & 1530 & 25200 & 90 & 6120 & 15400 & 39 & 1620 \\
\hline 8 & 7350 & 57 & 1130 & 22200 & 45 & 2700 & 14300 & 38 & 1470 \\
\hline 9 & 6750 & 44 & 802 & 37900 & $5 i$ & 5220 & 13900 & 38 & 1430 \\
\hline 10 & 6380 & 29 & 500 & 33800 & 90 & 8210 & 13600 & 37 & 1360 \\
\hline 11 & 13000 & 302 & 18500 & 44800 & 143 & 21700 & 12500 & 36 & 1220 \\
\hline 12 & 59800 & 770 & 124000 & 71600 & 240 & 46400 & 11800 & 36 & 1150 \\
\hline 13 & 80000 & 810 & 175000 & 55000 & 105 & 15600 & 11200 & 36 & 1090 \\
\hline 14 & 32400 & 441 & 42100 & 55800 & 300 & 45200 & 10900 & 34 & 1000 \\
\hline 15 & 18300 & 170 & 8400 & 73500 & 350 & 69500 & 10400 & 32 & 899 \\
\hline 16 & 14300 & 89 & 3440 & 59800 & 90 & 14500 & 10100 & 30 & 818 \\
\hline 17 & 11800 & 58 & 1850 & 53300 & 70 & 10100 & 9810 & 75 & 1990 \\
\hline ia & 11400 & 44 & 1350 & 52600 & 57 & 8100 & 10900 & 47 & 1380 \\
\hline 19 & 27300 & 202 & 16700 & 51000 & 01 & 8400 & 10700 & 40 & 1160 \\
\hline 20 & 48900 & 570 & 75300 & 49800 & 80 & 10800 & 10600 & 40 & 1140 \\
\hline & 58900 & 740 & 118000 & 41000 & 98 & 10800 & 11200 & 39 & 1180 \\
\hline 22 & 81100 & 530 & 116000 & 30200 & 42 & 3420 & 10900 & 35 & 1030 \\
\hline 23 & 66900 & 220 & 39700 & 31000 & 94 & 7870 & 10800 & 27 & 787 \\
\hline 24 & 62800 & 98 & 16600 & 38800 & 88 & 10100 & 10800 & $2 B$ & $B 16$ \\
\hline 25 & 63900 & 70 & 12100 & 35200 & 100 & 9500 & 10800 & 28 & 816 \\
\hline 26 & 71500 & 160 & 30900 & 27800 & 56 & 4200 & 10800 & 27 & 787 \\
\hline 27 & 66000 & 68 & 12100 & 24900 & 45 & 3030 & 11000 & 41 & 1220 \\
\hline 28 & 62800 & 70 & 11900 & 42900 & 255 & 30600 & 11500 & 82 & 2550 \\
\hline 29 & 49700 & 50 & 6710 & - & - & - & 11900 & 70 & 2250 \\
\hline 30 & 16000 & 49 & 4840 & -- & -- & -- & 12200 & 102 & 3360 \\
\hline 31 & 35200 & 47 & 4470 & -- & -- & - & 12400 & 100 & 3350 \\
\hline TOTAL & 1054950 & -- & 859423 & 1119600 & - & 433590 & 442810 & -- & 81673 \\
\hline
\end{tabular}


11377200 SACRAMENTO RIVER AT BEND, CALIF.--Continued

SUSPENDED-SEDIMENT DISCHARGE, WATER YEAR OCTOBER 1968 TO SEPTEMBER 1969

$\begin{array}{cc} & \\ & \\ & \text { MEAN } \\ \text { DISCHARGE } \\ \text { ICFSI }\end{array}$

APRIL

MEAN

CONCEV- SEDIMENT MEAN

JUNE

DISCHARGE DISCHARGE
MGILI)

MEAN
CONCEN- SEDIMENT MEAN

CONCEN-
TRATION DISCHARGE DISCHARGE
(MG/L)

MEAN

SEDIMENT

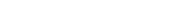

14200
14100

$\begin{array}{lll}39 & 1190 & 14000 \\ 36 & 1020 & 13800 \\ 34 & 1190 & 13700\end{array}$

MG/L.)

(CFS)

DISCHARGE

20
18
18

$\begin{array}{ll}767 & 15700 \\ 685 & 15700 \\ 680 & 15600 \\ 633 & 15500\end{array}$

NS/DAY

1660

13700
14100

$\begin{array}{ll}776 & 14300\end{array}$

$\begin{array}{ll}575 & 14500 \\ 589 & 14700\end{array}$

14700

$\begin{array}{ll}554 & 14800 \\ 683 & 14900\end{array}$

$779 \quad 15800$

$\begin{array}{ll}612 & 16600 \\ 515 & 14300\end{array}$

$\begin{array}{ll}451 & 17900 \\ 464 & 18900\end{array}$

$\begin{array}{ll}464 & 18900 \\ 787 & 18700 \\ 572 & 18700\end{array}$

$\begin{array}{ll}572 & 18700 \\ 539 & 18400\end{array}$

$\begin{array}{rr}567 & 18300 \\ 877 & 18100 \\ 1670 & 17300\end{array}$

$\begin{array}{ll}1670 & 17300 \\ 1660 & 17300\end{array}$

$\begin{array}{rr}1660 & 17300 \\ 920 & 17200\end{array}$

$784 \quad 17200$

$\begin{array}{ll}724 & 17100 \\ 646 & 16900\end{array}$

746
724

$945 \quad 16700$

15700

$30663 \quad 498700$

$\begin{array}{ll}633 & 15500 \\ 592 & 15400\end{array}$

$\begin{array}{ll}11 & 466 \\ 12 & 509 \\ 10 & 471 \\ 10 & 419 \\ 10 & 419\end{array}$

$\begin{array}{lll}16 & 592 & 15400\end{array}$

$\begin{array}{lll}16 & 592 & 15400 \\ 18 & 685 & 15300 \\ 22 & 849 & 15300\end{array}$

$\begin{array}{lrr}25 & 979 & 15400 \\ 28 & 1110 & 15500\end{array}$

15500

$\begin{array}{lll}27 & 1080 & 15500 \\ 29 & 1170 & 15400\end{array}$

$27 \quad 1150 \quad 15300$

$\begin{array}{rrr}27 & 1210 & 15200 \\ 24 & 927 & 15100\end{array}$

$33 \quad 1590 \quad 15000$

$\begin{array}{lll}32 & 1630 & 14900 \\ 27 & 1360 & 14900\end{array}$

$24 \quad 1210 \quad 15000$

$20 \quad 988 \quad 14900$

$\begin{array}{lll}17 & 831 & 14800 \\ 16 & 747 & 14800\end{array}$

$15 \quad 701 \quad 14700$

$14 \quad 650 \quad 14700$

$\begin{array}{lll}14 & 650 & 14700 \\ 13 & 600 & 14700\end{array}$

$\begin{array}{lll}12 & 548 & 14600 \\ 14 & 635 & 14600\end{array}$

$14 \quad 631 \quad 14500$

27429

453100

416
413

413
499
460

377

374
330

328

367

405

402
322

324
324

362

360
440
437

437
318

18

318

315
315
352

1520

\begin{tabular}{|c|c|c|c|c|c|c|c|c|}
\hline & & JULY & & & AUGUST & & & SEPTEMB \\
\hline DAY & $\begin{array}{l}\text { MEAN } \\
\text { OISCHARGE } \\
\text { (CFS) }\end{array}$ & $\begin{array}{l}\text { MEAN } \\
\text { CONCEN- } \\
\text { IRATION } \\
\text { (MG/L) }\end{array}$ & $\begin{array}{l}\text { SEDIMENT } \\
\text { DISCHARGE } \\
\text { (TONS/DAY) }\end{array}$ & $\begin{array}{l}\text { MEAN } \\
\text { OI SCHARGE } \\
\text { (CFS) }\end{array}$ & $\begin{array}{l}\text { MEAN } \\
\text { CONCEN- } \\
\text { TRATION } \\
\text { (MG/L) }\end{array}$ & $\begin{array}{l}\text { SEDIMENT } \\
\text { DISCHARGE } \\
\text { (TONS/DAY) }\end{array}$ & $\begin{array}{l}\text { MEAN } \\
\text { DISCHARGE } \\
\text { (CFS) }\end{array}$ & $\begin{array}{l}\text { MEAN } \\
\text { CONCEN } \\
\text { TRATIO } \\
\text { (MG/L) }\end{array}$ \\
\hline 1 & 14200 & 8 & 307 & 12100 & 5 & 163 & 12000 & \\
\hline 2 & 13300 & 8 & 287 & 12100 & 5 & 163 & 12000 & \\
\hline 3 & 12700 & 8 & 274 & 12100 & 5 & 163 & 11700 & \\
\hline 4 & 12700 & 5 & 171 & 12100 & 4 & 131 & 10900 & \\
\hline 5 & 12700 & 5 & 171 & 12000 & 4 & 130 & 10000 & \\
\hline 6 & 12700 & 5 & 171 & 12100 & 5 & 163 & 9430 & \\
\hline 7 & 12600 & 6 & 204 & 12000 & 5 & 162 & 9430 & \\
\hline 8 & 12600 & 6 & 204 & 12100 & 5 & 163 & 9430 & \\
\hline 9 & 12600 & 7 & 238 & 12100 & 5 & 163 & 9430 & \\
\hline 10 & 12500 & 1 & 236 & 12100 & 5 & 163 & 9390 & \\
\hline 11 & 12500 & 5 & 169 & 12100 & 5 & 163 & 9380 & \\
\hline 12 & 12500 & 5 & 169 & 12100 & 4 & 131 & 9380 & \\
\hline 13 & 12500 & 5 & 169 & 12100 & 4 & 131 & 9390 & \\
\hline 14 & 12500 & 6 & 203 & 12100 & 4 & 131 & 9390 & \\
\hline 15 & 12500 & 5 & 169 & 12000 & 4 & 130 & $\$ 190$ & \\
\hline 16 & 12400 & 4 & 134 & 12100 & 5 & 163 & 9390 & \\
\hline 17 & 12300 & 4 & 133 & 12100 & 5 & 163 & 9390 & \\
\hline IA & 12300 & 6 & 199 & 12000 & 5 & 162 & 9450 & \\
\hline 19 & 12300 & 7 & 232 & 12000 & 5 & 162 & 9480 & \\
\hline 20 & 12300 & 7 & 232 & 12100 & 5 & 163 & 9470 & \\
\hline 21 & 12300 & 6 & 199 & 12000 & 5 & 162 & 9480 & \\
\hline 22 & 12300 & 5 & 166 & 12000 & 6 & 194 & 9470 & \\
\hline 23 & 12400 & 6 & 201 & 12000 & 6 & 194 & 9410 & \\
\hline 24 & 12300 & 5 & 166 & 12000 & 6 & 194 & 9410 & \\
\hline 25 & 12300 & 3 & 100 & 12000 & 5 & 162 & 9410 & \\
\hline 26 & 12300 & 3 & 100 & 12000 & 4 & 130 & 9390 & \\
\hline 27 & 12300 & 4 & 133 & 12000 & 4 & 130 & 9410 & \\
\hline 28 & 12200 & 4 & 132 & 12000 & 4 & 130 & 9430 & \\
\hline 29 & 12200 & 4 & 132 & 12000 & 4 & 130 & 9450 & \\
\hline 30 & 12200 & 4 & 132 & 12000 & 4 & 130 & 7430 & \\
\hline 31 & 12200 & 5 & 165 & 12000 & 4 & 130 & - & \\
\hline TOTAL & 387700 & - & 5698 & 373500 & - & 4749 & 297110 & \\
\hline
\end{tabular}

SPTEMBER

SEDIMENT

DISCHARGE

130

130

126
118
108

127

153

153

101

127
127

101
101

101

101

102
102

102

102

128
127
227
102

127
127
127
179
204

3714

TOTAL SUSPENDED-SEDIMENT DISCHARGE FOR YEAR (TONS) 
PARTICLE-SIZE DISTRIBUTION OF SUSPENDED SEDIMENT, WATER YEAR OCTOBER 1968 TO SEPTEMBER 1969
IMETHOUS OF ANALYSIS: B, BOTTOM WITHDRAWAL TUBE; C. CHEMICALLY OISPERSED; N, IN NATIVE WATER: P, PIPET: S, SIEVE; V. VISUAL ACCUMULATION TUBE: W, IN DISTILLED WATERI

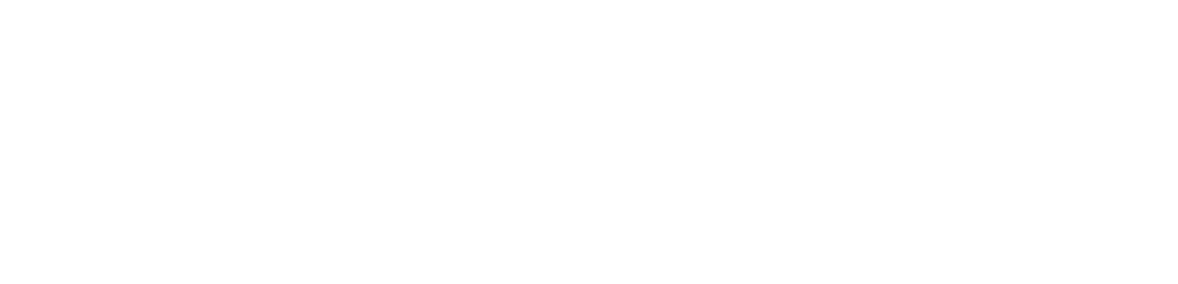

11381620 MILL CREEK AT MOUTH, NEAR LOS MOLINOS, CALIF.

LOCATION. --Lat $40^{\circ} 02^{\prime} 34^{\prime \prime}$, long $122^{\circ} 05^{\prime} 57^{\prime \prime}$, T.25 N, , R.2 W., in Rio de Los Molinos land grant, Tehama County,

at bridge on U.S. Highway $99,0.8$ mile upstream from confluence with Sacramento River and 4.7 miles downstrean from gaging station near Los Molinos.

DRAINAGE AREA,--131 sq mi (upsis-uäï from gaging station).

PERIOD OF RECORD, --Chemical analyses: October 1953 to September 1969

REMARKS.--Chemical-quality records furnished by California Department of Water Resources and revlewed by U.S. Geological Survey. No discharge records available.

CHEMICAL ANALYSES, WATER YEAR OCTOBER 1968 TO SEPTEMBER 1969

\begin{tabular}{|c|c|c|c|c|c|c|c|c|c|c|c|}
\hline DATE & $\begin{array}{l}\text { TEMPER- } \\
\text { A TURE } \\
\text { (OEG C) }\end{array}$ & $\begin{array}{l}\text { DIS- } \\
\text { SOLVED } \\
\text { OXYGEN } \\
\text { (MGSL) }\end{array}$ & $\begin{array}{l}\text { TUR- } \\
\text { BID- } \\
\text { ITY } \\
\text { (MGIL) }\end{array}$ & $\begin{array}{l}\text { CAL- } \\
\text { CIUM } \\
(C A) \\
(M G / L)\end{array}$ & $\begin{array}{c}\text { MAG- } \\
\text { NE- } \\
\text { SIUM } \\
\text { (MG) } \\
\text { (MG/L) }\end{array}$ & $\begin{array}{l}\text { SOOIUM } \\
\text { (NA) } \\
\text { (MG/L) }\end{array}$ & $\begin{array}{l}\text { PO- } \\
\text { TAS- } \\
\text { SIUM } \\
\text { (K) } \\
\text { (MG/LI }\end{array}$ & $\begin{array}{l}\text { BICAR- } \\
\text { BONATE } \\
(H C Q 3) \\
(M G / L)\end{array}$ & $\begin{array}{l}\text { CAR- } \\
\text { BONATE } \\
\text { (CO3) } \\
\text { (MG/LI }\end{array}$ & $\begin{array}{l}\text { SULFATE } \\
(\text { SO4) } \\
(M G / L)\end{array}$ & $\begin{array}{l}\text { CHLOE } \\
\text { RIDE } \\
\text { (CLI) } \\
(M G / L)\end{array}$ \\
\hline $\begin{array}{c}\text { DCT. } \\
07 . . .\end{array}$ & 15 & 11.2 & 1.0 & - & -- & 18 & -- & 92 & 0 & -- & 21 \\
\hline NOV. & 11 & 11.8 & 20 & - & -- & 14 & -- & 51 & 0 & -- & - \\
\hline MAR... & 7 & 12.7 & 4.0 & - & - & 13 & -- & 55 & 0 & -- & 13 \\
\hline $\begin{array}{l}03 . . \\
\text { APR. }\end{array}$ & 6 & 13.1 & 4.0 & - & -- & 6.1 & - & 52 & 0 & -- & 5.2 \\
\hline & I I & I I. 8 & 9.0 & 6.7 & 2.8 & 6.3 & 1.1 & 30 & 0 & 13 & 6.3 \\
\hline $\begin{array}{l}\text { O3... } \\
\text { SEPT. }\end{array}$ & 18 & 10.7 & 12 & - & -- & 8.6 & -- & 35 & 0 & -- & 7.4 \\
\hline $04 \ldots$ & 22 & 10.3 & {$[.0$} & I 2 & 6.6 & 14 & 2.0 & 61 & 0 & 12 & 15 \\
\hline & & & $\begin{array}{l}\text { CIS- } \\
\text { SOLVEA } \\
\text { SCLIOS } \\
\text { IRESI- }\end{array}$ & $\begin{array}{l}\text { DIS- } \\
\text { SOLVED } \\
\text { SOLIDS }\end{array}$ & HARD- & $\begin{array}{l}\text { NON- } \\
\text { CAR- } \\
\text { BDNATE }\end{array}$ & & $\begin{array}{c}\text { SODLUM } \\
\text { AO- } \\
\text { SORP- }\end{array}$ & $\begin{array}{l}\text { ALKA- } \\
\text { LINITY }\end{array}$ & & $\begin{array}{l}\text { SPFCI- } \\
\text { FIC } \\
\text { COND- }\end{array}$ \\
\hline DATE & $\begin{array}{l}\text { N1 TRATE } \\
\text { (NO3) } \\
\text { (MG/L) }\end{array}$ & $\begin{array}{l}\text { BORON } \\
(8) \\
\text { (UG/L) }\end{array}$ & $\begin{array}{l}\text { DUE AT } \\
\text { I } 80 \mathrm{Cl} \\
(\mathrm{MG} / \mathrm{L})\end{array}$ & $\begin{array}{l}\text { (TDNS } \\
\text { PER } \\
A C-F T)\end{array}$ & $\begin{array}{l}\text { NESS } \\
(C A, M G) \\
(M G / L)\end{array}$ & $\begin{array}{l}\text { HARD- } \\
\text { NESS } \\
(M G / L)\end{array}$ & $\begin{array}{l}\text { PERCENT } \\
\text { SODIUM }\end{array}$ & $\begin{array}{r}\text { TION } \\
\text { RATIO }\end{array}$ & $\begin{array}{l}\text { AS } \\
\text { CACD3 } \\
\text { (MG/L) }\end{array}$ & $\begin{array}{c}P H \\
\text { (UNITS) }\end{array}$ & $\begin{array}{l}\text { UCTANCE } \\
\text { (MICRO- } \\
\text { MHOS) }\end{array}$ \\
\hline
\end{tabular}

nCT

\begin{tabular}{|c|c|c|c|c|c|c|}
\hline $07 . .$. & - & 570 & -- & -- & 83 & 8 \\
\hline $04 \ldots$ & - & 530 & - & - & 57 & 15 \\
\hline JAN. & & & & & & \\
\hline $\begin{array}{l}03 . . . \\
\text { MAR, }\end{array}$ & -- & 370 & - & $\cdots$ & 57 & 12 \\
\hline $\begin{array}{l}\text { MAR. } \\
\text { 03.... }\end{array}$ & & & & & & \\
\hline $\begin{array}{l}03 . \cdots \\
A P R \text {. }\end{array}$ & - & 100 & $\cdots$ & - & 40 & 0 \\
\hline JULY & $-I$ & 170 & 42 & .08 & 28 & 3 \\
\hline $03 \ldots$ & $\cdots$ & 210 & -- & - & 43 & 14 \\
\hline SEPT. & & & & & & \\
\hline $04 \ldots$ & .0 & 350 & 122 & .17 & 57 & 7 \\
\hline
\end{tabular}

$\begin{array}{rrrrr}32 & .9 & 75 & 8.1 & 252 \\ 35 & .8 & 42 & 8.0 & 181 \\ 33 & .7 & 45 & 7.9 & 162 \\ 25 & .4 & 43 & 7.6 & 112 \\ 32 & .5 & 25 & 7.3 & 88 \\ 30 & .6 & 29 & 8.0 & 120 \\ 34 & .8 & 50 & 8.2 & 178\end{array}$


11382000 THONES CREEK AT PASKENTA, CALIF.

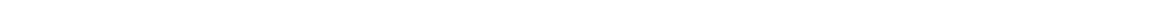
left bank, 0.2 mile upstream from Digger Creek and 0.3 mile upstream from highway bridge at Paskenta.

DRAINAGE AREA, - -194 sq mi.

PERIOD OF RECORD.--Chemical analyses: October 1958 to September 1969.

Water temperatures: Dctober 1961 to September 1969

Sedinent records: October 1962 to September 1969.

EXTREUES.--1968-69:

Water temperatures: Haximum, $34.0^{\circ} \mathrm{C}$ Aug. 2 ; minimum, freezing point on several days during December and

January.
Sediment concentrations: Waximum da $11 \mathrm{y}, 8,080 \mathrm{mg} / 1$ Jan. $20 ;$ minimum daily, $1 \mathrm{mg} / 1$ on many days.

Sediment discharge: Maximum daily, 162,000 tons Jan. 20; minimum daily, 0.01 ton Oct. 4, 9-11.

Period of record:

Water temperatures: Maximum, $34.5^{\circ} \mathrm{C}$ Aug. $18,23,1967$; minimum, freezing point on several days during December and January of most years.

Sediment concentrations: Maximum da1ly, 60,200 mg/1 Dec, 22, 1964; minimum da1ly, no flow Oct. $4,1964$.

Sediment discharge: Maximum dally, 5,070,000 tons Dec. 22, 1964; minimum daily, 0 ton Oct. 4, 1964 .

REMARKS.--Chemical-quality records furnished by California Department of Water Resources and revlewed by U.S. Geological Survey. No temperature record $\mathrm{Nay}_{2} 27-29$; range in temperature, $9.0^{\circ} \mathrm{C}$ to $14.0^{\circ} \mathrm{C}$.

CHEMICAL ANALYSES, hater YeAR OCTOBER 1968 TO SEPIEMBER 1969

\begin{tabular}{|c|c|c|c|c|c|c|c|c|c|c|c|}
\hline DATE & $\begin{array}{l}\text { MEAN } \\
\text { OIS- } \\
\text { CHARGE } \\
\text { (CFS) }\end{array}$ & $\begin{array}{l}\text { TEMPER- } \\
\text { ATURE } \\
\text { IDEG CI }\end{array}$ & $\begin{array}{l}\text { DIS- } \\
\text { SOLVED } \\
\text { OXYGEN } \\
\text { (MG/L) }\end{array}$ & $\begin{array}{l}\text { CAL- } \\
\text { CIUM } \\
\text { (CA) } \\
(M G / L)\end{array}$ & $\begin{array}{l}\text { MAG- } \\
\text { NE- } \\
\text { SIUH } \\
\text { (MG) } \\
\text { (MG /L) }\end{array}$ & $\begin{array}{l}\text { SOOIUM } \\
\text { (NA) } \\
\text { (NG/L) }\end{array}$ & $\begin{array}{l}\text { PO- } \\
\text { TAS- } \\
\text { SIUH } \\
\text { (K) } \\
\text { (MG/L) }\end{array}$ & $\begin{array}{l}\text { B ICAR- } \\
\text { BDNATE } \\
\text { (HCOZ) } \\
\text { (HG/L) }\end{array}$ & $\begin{array}{l}\text { CAR- } \\
\text { BONATE } \\
\text { (CD3) } \\
\text { (HG/L) }\end{array}$ & $\begin{array}{c}\text { SULFATE } \\
\text { (SO4) } \\
\text { (MG/L) }\end{array}$ & $\begin{array}{l}\text { CHLO- } \\
\text { RIOE } \\
\text { (CL) } \\
\text { (MG/L) }\end{array}$ \\
\hline ост. & & & & & & & & & & & \\
\hline $\begin{array}{l}\text { 07... } \\
\text { Nov. }\end{array}$ & 4.0 & 17 & 11.6 & -- & -- & 15 & - & 133 & 0 & -- & 25 \\
\hline $\begin{array}{l}04 \ldots \\
\text { OEC.. }\end{array}$ & 57 & 13 & 10.9 & -- & - & 12 & -- & 117 & 0 & $-\infty$ & 13 \\
\hline $\begin{array}{l}05 . . . \\
\text { JAN. }\end{array}$ & 47 & 7 & 12.5 & $=$ & -- & 8.9 & -- & 112 & 2 & -- & 8.2 \\
\hline $\begin{array}{l}03 \ldots . . \\
\text { FEB. }\end{array}$ & 192 & 7 & 12.6 & -- & -- & 7.1 & -- & 131 & 0 & -- & 4.3 \\
\hline $\begin{array}{l}03 . . . \\
\text { MAR." }\end{array}$ & 519 & 5 & 13.3 & - & $=$ & 4.2 & - & 102 & 0 & -- & 1.9 \\
\hline $\begin{array}{l}03 . . . \\
A P R .\end{array}$ & 434 & 7 & 12.4 & -- & -- & 5.0 & - & 157 & 0 & $\cdots$ & 2.4 \\
\hline $\begin{array}{l}01 \ldots . . \\
\text { 30... } \\
\text { JUNE }\end{array}$ & $\begin{array}{l}2070 \\
2370\end{array}$ & $\begin{array}{r}6 \\
12\end{array}$ & $\begin{array}{l}12.8 \\
12.0\end{array}$ & $\overline{15}$ & 3.0 & $\begin{array}{l}3.0 \\
2.2\end{array}$ & $\overline{8}$ & $\begin{array}{l}65 \\
55\end{array}$ & $\begin{array}{l}0 \\
0\end{array}$ & $\overline{10}$ & $\begin{array}{r}.7 \\
1.5\end{array}$ \\
\hline $\begin{array}{l}03 . . \\
\text { Jutr }\end{array}$ & 428 & 18 & 9.8 & -- & -- & 2.0 & - & 55 & 0 & -- & 7.2 \\
\hline $\begin{array}{l}\text { 03... } \\
\text { AUG. }\end{array}$ & 71 & 21 & 9.5 & -- & $-\rightarrow$ & 5.4 & -- & 111 & 0 & -- & 3.8 \\
\hline SEPT: & 13 & 28 & 8.3 & - & -- & 9.2 & -- & 130 & 0 & -- & 12 \\
\hline $04 \ldots$ & 8.3 & 23 & 8.7 & 38 & 12 & 11 & 1.3 & 114 & 0 & 51 & 17 \\
\hline
\end{tabular}

\begin{tabular}{|c|c|c|c|c|c|c|c|c|c|c|}
\hline DATE & $\begin{array}{l}\text { NITRATE } \\
\text { (NOB) } \\
\text { (AG/L) }\end{array}$ & $\begin{array}{l}\text { PHOS- } \\
\text { PHAIE } \\
\text { (PO\&) } \\
\text { (MG/L) }\end{array}$ & $\begin{array}{l}\text { BORON } \\
\{B\} \\
\{U G / L)\end{array}$ & $\begin{array}{l}\text { HARO- } \\
\text { NESS } \\
(C A, H G) \\
(M G / L)\end{array}$ & $\begin{array}{l}\text { NON- } \\
\text { CAR- } \\
\text { BONATE } \\
\text { HARO- } \\
\text { NESS } \\
\text { (MG/L) }\end{array}$ & $\begin{array}{l}\text { PERCENT } \\
\text { SODIUM }\end{array}$ & $\begin{array}{l}\text { SOD TuM } \\
\text { AD- } \\
\text { SORP- } \\
\text { TION } \\
\text { RATIO }\end{array}$ & $\begin{array}{l}\text { ALKA- } \\
\text { LINITY } \\
\text { AS } \\
\text { CACO3 } \\
\text { (MG/L) }\end{array}$ & $\begin{array}{c}P_{H} \\
\text { (UNITS) }\end{array}$ & $\begin{array}{l}\text { SPEC1- } \\
\text { FIC } \\
\text { CONO- } \\
\text { UCIANCE } \\
\text { (MICRO- } \\
\text { MHOS I }\end{array}$ \\
\hline $\begin{array}{l}\text { oct. } \\
\text { or... }\end{array}$ & .0 & .01 & 0 & 182 & 73 & 15 & .5 & 109 & 8.1 & 451 \\
\hline $04 \ldots$ & 1.5 & .08 & 110 & 151 & 55 & 15 & .4 & 96 & 8.3 & 343 \\
\hline $05 . .$. & .1 & .06 & 80 & 130 & 35 & 13 & .3 & 95 & 8.4 & 281 \\
\hline $\begin{array}{l}03 . . \\
F E B .\end{array}$ & 1.2 & .46 & BO & 132 & 25 & 10 & .3 & 107 & 8.3 & 277 \\
\hline MAR,... & .1 & .00 & 0 & 112 & 28 & $B$ & .2 & 84 & 8.2 & 207 \\
\hline APR, & .1 & .09 & 10 & 150 & 21 & 7 & .2 & 129 & 8.1 & 290 \\
\hline $\begin{array}{c}\text { APR, } \\
\text { O1.... } \\
30 . . \\
\text { JUNEE }\end{array}$ & $: ?$ & $\begin{array}{l}3.5 \\
.72\end{array}$ & $\begin{array}{l}30 \\
10\end{array}$ & $\begin{array}{l}59 \\
50\end{array}$ & $\begin{array}{l}6 \\
5\end{array}$ & 10 & $: 2$ & $\begin{array}{l}53 \\
45\end{array}$ & 7.9 & $\begin{array}{l}128 \\
109\end{array}$ \\
\hline $\begin{array}{l}03 \ldots \\
\text { JuLY }\end{array}$ & .1 & .07 & 10 & 50 & 5 & 8 & .1 & 45 & 7.9 & 110 \\
\hline $03 . .$. & .1 & - & 0 & 113 & 22 & 9 & .2 & 91 & 8.2 & 232 \\
\hline $11 \ldots$ & 1.3 & -- & 40 & 150 & 43 & 12 & .3 & 107 & 8.2 & 322 \\
\hline $04 \ldots$. & .0 & - & 60 & 144 & 50 & 14 & .4 & 94 & 8.1 & 334 \\
\hline
\end{tabular}


11382000 THOMES CREEK AT PASKENTA, CALIF.--Continued

TEMPERATURE $\left({ }^{\circ} \mathrm{C}\right)$ OF NATER, WATER YEAR OCTOBER 1968 TO SEPTEMBER 1969

DAY

DCTUBFP

MAXIMUM $24 \begin{array}{llllllllllllllllllllllllllllllll}24 & 23 & 22 & 22 & 22 & 17 & 19 & 19 & 19 & 19 & 17 & 18 & 16 & 19 & 21 & 21 & 19 & 19 & 20 & 19 & 19 & 20 & 21 & 21 & 20 & 20 & 18 & 17 & 17 & 18\end{array}$

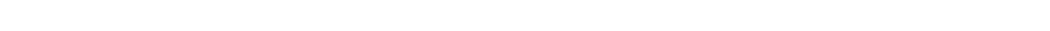
NOVEMPER

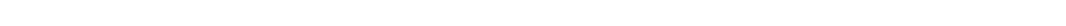

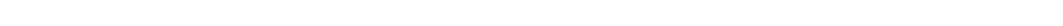

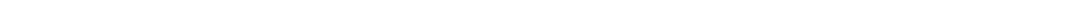

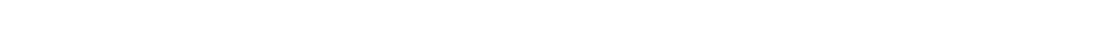
JAYUAPY

MAXIMUM $60 \begin{array}{lllllllllllllllllllllllllllllllll} & 8 & 8 & 6 & 7 & 6 & 4 & 6 & 4 & 4 & 3 & 4 & 6 & 6 & 6 & 6 & 6 & 4 & 6 & 7 & 8 & 7 & 4 & 6 & 7 & 7 & 6 & 5 & 2 & 3 & 5 & 6\end{array}$ MINIHUM

$\begin{array}{lllllllllllllllllllllllllllllllll}\text { MAXIMUM } & 7 & 7 & 9 & 5 & 5 & 7 & 7 & 6 & 7 & 7 & 8 & 8 & 7 & 4 & 7 & 7 & 7 & 7 & 7 & 8 & 5 & 6 & 7 & 8 & 8 & 7 & 5 & 5 & \ldots-2 & \ldots-\end{array}$ MINIMUM

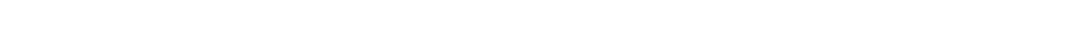

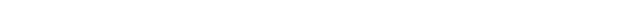

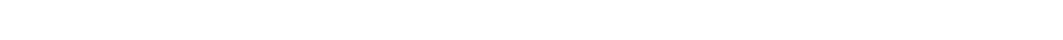

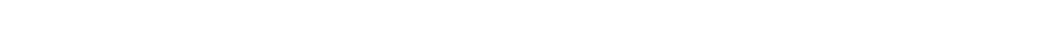

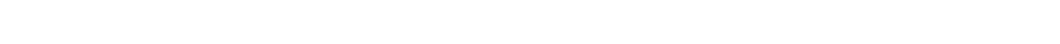

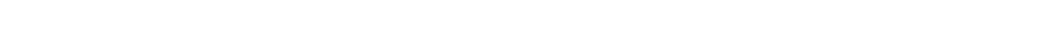

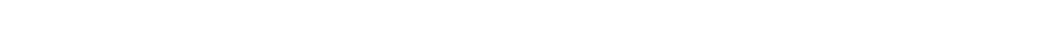
AUGUST

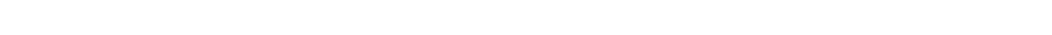
$\begin{array}{lllllllllllllllllllllllllllllllll}\text { MINIMUN } & 23 & 25 & 24 & 22 & 22 & 22 & 23 & 24 & 24 & 26 & 24 & 23 & 22 & 24 & 24 & 24 & 22 & 23 & 23 & 24 & 24 & 24 & 24 & 23 & 22 & 22 & 22 & 22 & 22 & 21 & 22\end{array}$

$\begin{array}{llllllllllllllllllllllllllllllllll}\text { MAXIMUM } 29 & 29 & 28 & 28 & 28 & 28 & 27 & 30 & 29 & 29 & 28 & 30 & - & -- & -- & 24 & 26 & 26 & 23 & 23 & 23 & 23 & 23 & -- & 25 & 26 & 25 & 25 & 25 & 26 & --\end{array}$

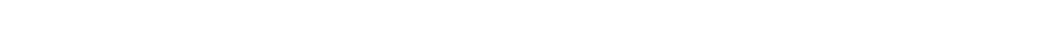

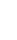
? 10 3 11 16 22 31 21 31 23 26

SUSPENDED-SEDIMENT DISCHARGE, WATER YEAR OCTOBER 1968 TO SEPTEMBER 1969

NOVEMBER

DECEMBER

\begin{tabular}{|c|c|c|c|c|c|c|c|c|c|}
\hline \multirow[b]{2}{*}{ DAY } & \multicolumn{3}{|c|}{ OC TOBER } & \multicolumn{3}{|c|}{ NOVEMBER } & \multicolumn{3}{|c|}{ DECEMBER } \\
\hline & $\begin{array}{l}\text { MEAN } \\
\text { O1SCAARGE } \\
\text { (CF S S) }\end{array}$ & $\begin{array}{l}\text { MEAN } \\
\text { MONCEN- } \\
\text { TRATON } \\
\text { IMGLLI }\end{array}$ & $\begin{array}{l}\text { SEDIMENT } \\
\text { DISCHARGE } \\
\text { (TONS/DAY) }\end{array}$ & $\begin{array}{l}\text { MEAN } \\
\text { OISCAARGE } \\
\text { |CFSIS| }\end{array}$ & $\begin{array}{l}\text { MEAN } \\
\text { COACEN- } \\
\text { TRAIDN } \\
\text { (MGLL) }\end{array}$ & $\begin{array}{l}\text { SEDIMENT } \\
\text { DISCHARGE } \\
\text { ITONS/DAYI) }\end{array}$ & $\begin{array}{c}\text { MEAN } \\
\text { OISCAARGE } \\
\text { ICFSI }\end{array}$ & $\begin{array}{l}\text { MEAN } \\
\text { CONACN- } \\
\text { TRATON } \\
\text { IMG LIS }\end{array}$ & $\begin{array}{l}\text { SEDIMENT } \\
\text { DISCHARGE } \\
\text { (TONS DAAY) }\end{array}$ \\
\hline $\begin{array}{l}1 \\
2 \\
3 \\
4 \\
5\end{array}$ & $\begin{array}{l}3.8 \\
3: 8 \\
4: 0 \\
3: 8 \\
4.0\end{array}$ & $\begin{array}{l}7 \\
2 \\
2 \\
1 \\
2\end{array}$ & $\begin{array}{l}.07 \\
.02 \\
02 \\
.01 \\
.02\end{array}$ & $\begin{array}{l}16 \\
68 \\
90 \\
57 \\
50\end{array}$ & $\begin{array}{r}3 \\
28 \\
39 \\
6 \\
4\end{array}$ & $\begin{array}{l}8.13 \\
8.1 \\
9.5 \\
.92 \\
.54\end{array}$ & $\begin{array}{l}60 \\
52 \\
48 \\
47 \\
47\end{array}$ & $\begin{array}{l}2 \\
1 \\
1 \\
1 \\
1\end{array}$ & $\begin{array}{l}.32 \\
: 14 \\
: 13 \\
: 13 \\
.13\end{array}$ \\
\hline $\begin{array}{r}6 \\
7 \\
8 \\
9 \\
10\end{array}$ & $\begin{array}{l}4.0 \\
4: 0 \\
4: 6 \\
3: 8 \\
4.0\end{array}$ & $\begin{array}{l}2 \\
2 \\
2 \\
1 \\
1\end{array}$ & $\begin{array}{l}.02 \\
02 \\
02 \\
02 \\
.01 \\
01\end{array}$ & $\begin{array}{l}48 \\
45 \\
43 \\
42 \\
45\end{array}$ & $\begin{array}{l}8 \\
3 \\
1 \\
1 \\
1\end{array}$ & $\begin{array}{l}1.0 \\
.36 \\
.12 \\
.11 \\
.12\end{array}$ & $\begin{array}{r}51 \\
51 \\
85 \\
94 \\
1530\end{array}$ & $\begin{array}{r}1 \\
1 \\
40 \\
30 \\
4070\end{array}$ & $\begin{array}{r}: 14 \\
: 14 \\
9.2 \\
7 \% 6 \\
27400\end{array}$ \\
\hline $\begin{array}{l}11 \\
12 \\
13 \\
14 \\
15\end{array}$ & $\begin{array}{l}4.6 \\
6.5 \\
21.5 \\
24 \\
19\end{array}$ & $\begin{array}{l}1 \\
2 \\
7 \\
5 \\
4\end{array}$ & $\begin{array}{l}.01 \\
.04 \\
.40 \\
.32 \\
.21\end{array}$ & $\begin{array}{l}44 \\
66 \\
59 \\
55 \\
62\end{array}$ & $\begin{array}{r}1 \\
28 \\
18 \\
1 \\
1 \\
2\end{array}$ & $\begin{array}{c}.12 \\
9: 3 \\
2: 0 \\
: 15 \\
: 33\end{array}$ & $\begin{array}{l}548 \\
214 \\
2167 \\
205 \\
653\end{array}$ & $\begin{array}{r}1200 \\
180 \\
90 \\
90 \\
1050\end{array}$ & $\begin{array}{r}1780 \\
104 \\
41 \\
50 \\
2890\end{array}$ \\
\hline $\begin{array}{l}16 \\
17 \\
18 \\
19 \\
20\end{array}$ & $\begin{array}{l}16 \\
14 \\
13 \\
11 \\
10\end{array}$ & $\begin{array}{l}4 \\
5 \\
4 \\
4 \\
5\end{array}$ & $\begin{aligned}: 11 \\
: 19 \\
: 19 \\
: 12\end{aligned}$ & $\begin{array}{r}58 \\
60 \\
222 \\
205 \\
205 \\
134\end{array}$ & $\begin{array}{r}13 \\
15 \\
357 \\
40 \\
15\end{array}$ & $\begin{array}{c}2.47 \\
28.4 \\
28 \\
22 \\
5.4\end{array}$ & $\begin{array}{l}275 \\
180 \\
145 \\
145 \\
137\end{array}$ & $\begin{array}{r}200 \\
75 \\
56 \\
50 \\
43\end{array}$ & $\begin{array}{r}149 \\
36 \\
22 \\
20 \\
16\end{array}$ \\
\hline $\begin{array}{l}21 \\
22 \\
23 \\
24 \\
25\end{array}$ & $\begin{array}{l}9.6 \\
9.0 \\
8: 3 \\
7: 1 \\
7.1\end{array}$ & $\begin{array}{l}2 \\
6 \\
7 \\
5 \\
5\end{array}$ & $\begin{array}{l}: 05 \\
: 15 \\
: 16 \\
: 10 \\
: 10\end{array}$ & $\begin{array}{l}92 \\
74 \\
64 \\
56 \\
60\end{array}$ & $\begin{array}{l}4 \\
1 \\
1 \\
1\end{array}$ & $\begin{array}{r}.99 \\
.20 \\
117 \\
: 15 \\
.16\end{array}$ & $\begin{array}{l}127 \\
127 \\
130 \\
500 \\
513\end{array}$ & $\begin{array}{r}20 \\
19 \\
140 \\
700 \\
652\end{array}$ & $\begin{array}{r}6.99 \\
6.5 \\
490 \\
990 \\
979\end{array}$ \\
\hline $\begin{array}{l}26 \\
27 \\
28 \\
29 \\
30 \\
31\end{array}$ & $\begin{array}{l}6.5 \\
6.5 \\
5.9 \\
711 \\
11 \\
20\end{array}$ & $\begin{array}{l}8 \\
8 \\
5 \\
2 \\
1 \\
2\end{array}$ & $\begin{array}{l}.14 \\
0.14 \\
0.08 \\
0.09 \\
0.11 \\
.11\end{array}$ & $\begin{array}{l}57 \\
52 \\
50 \\
49 \\
58 \\
-0\end{array}$ & $\begin{aligned} 1 \\
1 \\
1 \\
1 \\
2 \\
-2\end{aligned}$ & $\begin{array}{l}.15 \\
: 14 \\
: 14 \\
: 13 \\
.31 \\
--.\end{array}$ & $\begin{array}{l}394 \\
255 \\
458 \\
275 \\
2198 \\
148\end{array}$ & $\begin{array}{r}210 \\
125 \\
190 \\
90 \\
90 \\
60\end{array}$ & $\begin{array}{r}223 \\
86 \\
235 \\
67 \\
46 \\
24\end{array}$ \\
\hline TOTAL & 277.0 & $-\cdot$ & 3.06 & $20 B \mathrm{~L}$ & -- & 349.51 & 7755 & -- & 35138.33 \\
\hline
\end{tabular}


SACRAMENTO RIVER BASIN

11382000 THOMES CREEK AT PASKENTA, CALIF. --Cont1nued

SUSPENDED-SEDIMENT DISCHARGE, WATER YEAR OCTOBER 1968 TO SEPTEMBER 1969

\begin{tabular}{|c|c|c|c|c|c|c|c|c|c|}
\hline \multirow[b]{2}{*}{ DAY } & \multicolumn{3}{|c|}{ JANUARY } & \multicolumn{3}{|c|}{ FEBRUARY } & \multicolumn{3}{|c|}{ MARCH } \\
\hline & $\begin{array}{l}\text { MEAN } \\
\text { DISCHARGE } \\
\text { (CFS) }\end{array}$ & $\begin{array}{l}\text { MEAN } \\
\text { CONCEV- } \\
\text { TRATION } \\
\text { (MGIL) }\end{array}$ & $\begin{array}{l}\text { SEDIMENT } \\
\text { DISCHARGE } \\
\text { (TONS/DAY) }\end{array}$ & $\begin{array}{l}\text { MEAN } \\
\text { OISCHARGE } \\
\text { (CFS) }\end{array}$ & $\begin{array}{l}\text { MEAN } \\
\text { CONCEN- } \\
\text { TRATION } \\
\text { (MG/L) }\end{array}$ & $\begin{array}{l}\text { SEDIMENT } \\
\text { DI SCHARGE } \\
\text { (TONS/DAY) }\end{array}$ & $\begin{array}{l}\text { MEAN } \\
\text { OISCHARGE } \\
\text { (CFS) }\end{array}$ & $\begin{array}{l}\text { MEAN } \\
\text { CONCEN- } \\
\text { TRATION } \\
\text { (MGIL) }\end{array}$ & $\begin{array}{l}\text { SEDIMENT } \\
\text { DISCHARGE } \\
\text { (TONS/DAY) }\end{array}$ \\
\hline $\begin{array}{l}1 \\
2 \\
3 \\
4 \\
5\end{array}$ & $\begin{array}{l}130 \\
134 \\
192 \\
498 \\
690\end{array}$ & $\begin{array}{r}41 \\
50 \\
90 \\
321 \\
340\end{array}$ & $\begin{array}{r}14 \\
18 \\
47 \\
432 \\
633\end{array}$ & $\begin{array}{l}690 \\
630 \\
519 \\
477 \\
630\end{array}$ & $\begin{array}{l}262 \\
213 \\
216 \\
266 \\
305\end{array}$ & $\begin{array}{l}488 \\
362 \\
303 \\
343 \\
519\end{array}$ & $\begin{array}{l}540 \\
512 \\
434 \\
404 \\
416\end{array}$ & $\begin{array}{r}160 \\
190 \\
130 \\
125 \\
80\end{array}$ & $\begin{array}{r}233 \\
263 \\
152 \\
136 \\
90\end{array}$ \\
\hline $\begin{array}{r}6 \\
7 \\
8 \\
9 \\
10\end{array}$ & $\begin{array}{l}760 \\
730 \\
670 \\
533 \\
452\end{array}$ & $\begin{array}{l}381 \\
440 \\
260 \\
320 \\
100\end{array}$ & $\begin{array}{l}782 \\
867 \\
470 \\
461 \\
122\end{array}$ & $\begin{array}{l}750 \\
596 \\
491 \\
980 \\
940\end{array}$ & $\begin{array}{l}315 \\
220 \\
180 \\
700 \\
525\end{array}$ & $\begin{array}{r}638 \\
354 \\
239 \\
1850 \\
1330\end{array}$ & $\begin{array}{l}440 \\
410 \\
404 \\
404 \\
366\end{array}$ & $\begin{array}{l}75 \\
59 \\
79 \\
61 \\
60\end{array}$ & $\begin{array}{l}89 \\
65 \\
86 \\
67 \\
59\end{array}$ \\
\hline $\begin{array}{l}11 \\
12 \\
13 \\
14 \\
15\end{array}$ & $\begin{array}{r}732 \\
3260 \\
4130 \\
1900 \\
1170\end{array}$ & $\begin{array}{r}182 \\
5120 \\
5040 \\
1820 \\
800\end{array}$ & $\begin{array}{r}536 \\
45100 \\
57000 \\
10200 \\
2530\end{array}$ & $\begin{array}{l}1690 \\
1320 \\
1000 \\
1060 \\
1170\end{array}$ & $\begin{array}{r}2040 \\
1100 \\
1050 \\
625 \\
540\end{array}$ & $\begin{array}{l}9570 \\
3920 \\
2840 \\
1790 \\
1710\end{array}$ & $\begin{array}{l}350 \\
345 \\
325 \\
325 \\
360\end{array}$ & $\begin{array}{l}53 \\
60 \\
53 \\
45 \\
66\end{array}$ & $\begin{array}{l}50 \\
56 \\
47 \\
39 \\
64\end{array}$ \\
\hline $\begin{array}{l}16 \\
17 \\
18 \\
19 \\
20\end{array}$ & $\begin{array}{r}990 \\
960 \\
1110 \\
3180 \\
7320\end{array}$ & $\begin{array}{r}480 \\
340 \\
450 \\
3070 \\
8080\end{array}$ & $\begin{array}{r}1280 \\
881 \\
1350 \\
36300 \\
162000\end{array}$ & $\begin{array}{r}1030 \\
940 \\
900 \\
780 \\
690\end{array}$ & $\begin{array}{l}390 \\
325 \\
350 \\
260 \\
225\end{array}$ & $\begin{array}{r}1080 \\
825 \\
851 \\
548 \\
419\end{array}$ & $\begin{array}{l}477 \\
760 \\
910 \\
810 \\
930\end{array}$ & $\begin{array}{l}137 \\
725 \\
550 \\
300 \\
500\end{array}$ & $\begin{array}{r}176 \\
1490 \\
1350 \\
656 \\
1260\end{array}$ \\
\hline $\begin{array}{l}21 \\
22 \\
23 \\
24 \\
25\end{array}$ & $\begin{array}{l}6160 \\
2900 \\
1740 \\
1460 \\
1820\end{array}$ & $\begin{array}{r}5780 \\
3060 \\
1610 \\
900 \\
1800\end{array}$ & $\begin{array}{r}99800 \\
24600 \\
7560 \\
3550 \\
8850\end{array}$ & $\begin{array}{l}564 \\
519 \\
540 \\
931 \\
556\end{array}$ & $\begin{array}{l}200 \\
190 \\
150 \\
580 \\
180\end{array}$ & $\begin{array}{r}305 \\
266 \\
219 \\
1930 \\
270\end{array}$ & $\begin{array}{l}1160 \\
1050 \\
1420 \\
1550 \\
1670\end{array}$ & $\begin{array}{l}551 \\
300 \\
4125 \\
400 \\
600\end{array}$ & $\begin{array}{r}1730 \\
851 \\
1630 \\
1670 \\
2710\end{array}$ \\
\hline $\begin{array}{l}26 \\
27 \\
28 \\
29 \\
30 \\
31\end{array}$ & $\begin{array}{r}3050 \\
1470 \\
1110 \\
950 \\
950 \\
780\end{array}$ & $\begin{array}{r}3330 \\
1200 \\
950 \\
720 \\
450 \\
290\end{array}$ & $\begin{array}{r}28500 \\
4760 \\
2850 \\
1850 \\
1150 \\
611\end{array}$ & $\begin{array}{r}477 \\
580 \\
780 \\
-- \\
-- \\
--\end{array}$ & $\begin{array}{r}145 \\
170 \\
380 \\
-\square \\
=-\end{array}$ & $\begin{array}{l}187 \\
266 \\
800 \\
\square- \\
-\therefore\end{array}$ & $\begin{array}{l}2000 \\
2540 \\
3060 \\
3140 \\
2900 \\
2680\end{array}$ & $\begin{array}{l}595 \\
1050 \\
1450 \\
1800 \\
1800 \\
1550\end{array}$ & $\begin{array}{r}3210 \\
7200 \\
12000 \\
15300 \\
14100 \\
11200\end{array}$ \\
\hline TOTAL & 51931 & -- & 505104 & 22230 & - & 34222 & 33092 & -- & 78029 \\
\hline DAY & $\begin{array}{l}\text { MEAN } \\
\text { DI SCHARGE } \\
\text { (CFS) }\end{array}$ & $\begin{array}{l}\text { APRIL } \\
\text { MEAN } \\
\text { CONCEN- } \\
\text { TRATION } \\
\text { (MGLL) }\end{array}$ & $\begin{array}{l}\text { SEDIMENT } \\
\text { DISCHARGE } \\
\text { (TONS/DAY) }\end{array}$ & $\begin{array}{c}\text { MEAN } \\
\text { OISCHARGE } \\
\text { (CFS) }\end{array}$ & $\begin{array}{l}\text { MAY } \\
\text { MEAN } \\
\text { CONCEN- } \\
\text { TRATION } \\
\text { (MG/L) }\end{array}$ & $\begin{array}{l}\text { SEDIMENT } \\
\text { DISCHARGE } \\
\text { (TONS/DAY) }\end{array}$ & $\begin{array}{l}\text { MEAN } \\
\text { OISCHARGE } \\
\text { (CFS) }\end{array}$ & $\begin{array}{l}\text { JUNE } \\
\text { MEAN } \\
\text { CONCEN- } \\
\text { TRATIIQN } \\
\text { (MG/L) }\end{array}$ & $\begin{array}{l}\text { SEDIMENT } \\
\text { DISCHARGE } \\
\text { (TONS / DAY) }\end{array}$ \\
\hline $\begin{array}{l}1 \\
2 \\
3 \\
4 \\
5\end{array}$ & $\begin{array}{l}2070 \\
1820 \\
1360 \\
1180 \\
1420\end{array}$ & $\begin{array}{r}1320 \\
1000 \\
800 \\
650 \\
600\end{array}$ & $\begin{array}{l}7380 \\
4910 \\
2940 \\
2070 \\
2300\end{array}$ & $\begin{array}{r}1880 \\
1160 \\
930 \\
620 \\
640\end{array}$ & $\begin{array}{l}400 \\
320 \\
560 \\
260 \\
200\end{array}$ & $\begin{array}{r}2030 \\
1000 \\
1410 \\
435 \\
346\end{array}$ & $\begin{array}{l}484 \\
458 \\
428 \\
410 \\
399\end{array}$ & $\begin{array}{l}30 \\
25 \\
36 \\
30 \\
37\end{array}$ & $\begin{array}{l}39 \\
31 \\
42 \\
33 \\
40\end{array}$ \\
\hline $\begin{array}{r}6 \\
7 \\
8 \\
9 \\
10\end{array}$ & $\begin{array}{r}1060 \\
760 \\
750 \\
830 \\
840\end{array}$ & $\begin{array}{l}375 \\
340 \\
325 \\
298 \\
325\end{array}$ & $\begin{array}{r}1070 \\
698 \\
638 \\
668 \\
737\end{array}$ & $\begin{array}{l}1090 \\
2150 \\
2370 \\
2840 \\
3100\end{array}$ & $\begin{array}{r}240 \\
280 \\
770 \\
800 \\
1100\end{array}$ & $\begin{array}{r}706 \\
1630 \\
4930 \\
6130 \\
9210\end{array}$ & $\begin{array}{l}372 \\
335 \\
290 \\
260 \\
246\end{array}$ & $\begin{array}{r}27 \\
23 \\
25 \\
20 \\
9\end{array}$ & $\begin{array}{l}27 \\
21 \\
20 \\
14 \\
6.0\end{array}$ \\
\hline $\begin{array}{l}11 \\
12 \\
13 \\
14 \\
15\end{array}$ & $\begin{array}{l}1640 \\
2440 \\
1910 \\
1320 \\
1040\end{array}$ & $\begin{array}{l}420 \\
680 \\
420 \\
340 \\
340\end{array}$ & $\begin{array}{r}1860 \\
4480 \\
2170 \\
1210 \\
955\end{array}$ & $\begin{array}{l}2280 \\
2470 \\
1670 \\
1300 \\
1030\end{array}$ & $\begin{array}{l}720 \\
600 \\
430 \\
460 \\
130\end{array}$ & $\begin{array}{r}4430 \\
4000 \\
1940 \\
1610 \\
362\end{array}$ & $\begin{array}{l}232 \\
232 \\
229 \\
220 \\
208\end{array}$ & $\begin{array}{r}10 \\
11 \\
8 \\
9 \\
9\end{array}$ & $\begin{array}{l}6.3 \\
6.9 \\
4.9 \\
5.3 \\
5.1\end{array}$ \\
\hline $\begin{array}{l}16 \\
17 \\
18 \\
19 \\
20\end{array}$ & $\begin{array}{l}1180 \\
2090 \\
2520 \\
2420 \\
2700\end{array}$ & $\begin{array}{l}270 \\
330 \\
445 \\
410 \\
523\end{array}$ & $\begin{array}{r}860 \\
1860 \\
3030 \\
2680 \\
3830\end{array}$ & $\begin{array}{r}1000 \\
1080 \\
1050 \\
870 \\
740\end{array}$ & $\begin{array}{r}280 \\
220 \\
270 \\
160 \\
90\end{array}$ & $\begin{array}{l}756 \\
642 \\
765 \\
376 \\
180\end{array}$ & $\begin{array}{l}220 \\
208 \\
205 \\
235 \\
217\end{array}$ & $\begin{array}{l}19 \\
21 \\
11 \\
13 \\
15\end{array}$ & $\begin{array}{c}11 \\
12 \\
6.1 \\
8.2 \\
8.8\end{array}$ \\
\hline $\begin{array}{l}21 \\
22 \\
23 \\
24 \\
25\end{array}$ & $\begin{array}{l}3340 \\
3840 \\
3640 \\
2590 \\
1700\end{array}$ & $\begin{array}{l}800 \\
900 \\
800 \\
360 \\
260\end{array}$ & $\begin{array}{l}7210 \\
8330 \\
7860 \\
2520 \\
1190\end{array}$ & $\begin{array}{l}730 \\
760 \\
790 \\
760 \\
650\end{array}$ & $\begin{array}{r}100 \\
97 \\
110 \\
93 \\
127\end{array}$ & $\begin{array}{l}197 \\
199 \\
235 \\
191 \\
223\end{array}$ & $\begin{array}{l}180 \\
157 \\
145 \\
132 \\
112\end{array}$ & $\begin{array}{l}15 \\
10 \\
10 \\
10 \\
4\end{array}$ & $\begin{array}{l}7.3 \\
4.2 \\
3.9 \\
3.6 \\
1.2\end{array}$ \\
\hline $\begin{array}{l}26 \\
27 \\
28 \\
29 \\
30 \\
31\end{array}$ & $\begin{array}{r}1300 \\
1410 \\
2140 \\
2680 \\
2370 \\
0\end{array}$ & $\begin{array}{r}220 \\
275 \\
360 \\
800 \\
380 \\
--\end{array}$ & $\begin{array}{r}172 \\
1050 \\
2080 \\
5790 \\
2430 \\
=-\end{array}$ & $\begin{array}{l}580 \\
540 \\
491 \\
491 \\
540 \\
512\end{array}$ & $\begin{array}{r}108 \\
69 \\
50 \\
80 \\
128 \\
65\end{array}$ & $\begin{array}{r}169 \\
101 \\
66 \\
106 \\
187 \\
90\end{array}$ & $\begin{array}{r}111 \\
104 \\
96 \\
91 \\
85 \\
-9\end{array}$ & $\begin{array}{r}5 \\
3 \\
3 \\
2 \\
1 \\
--\end{array}$ & $\begin{array}{r}1.5 \\
.84 \\
.78 \\
.49 \\
.23 \\
.-\end{array}$ \\
\hline TOTAL & 56360 & -- & 86598 & 37114 & -- & 44652 & 7101 & -- & 371.64 \\
\hline
\end{tabular}


11382000 THOMES CREEK AT PASKENTA, CALIF.--COnti nued

SUSPENDED-SEDIMENT DISCHARGE, WATER YEAR OCTOBER 1968 TO SEPTEMBER 1969

SEP TEMBER

AY

MEAN
CONCEN-

SEDIMENT $\begin{array}{lll}\text { SEDIMENT } & \text { MEAN } & \text { MEAN } \\ \text { DISCHARGE } & \text { DISCHARGE } & \text { TRATION }\end{array}$

SEDIMENT (MGIL) TONS/DAY) (CFS) (MGIL)
(CF) (TONS/DAY)

MEAN
DISCHARGE

MEAN
CONCEN- SEDIMENT $\begin{array}{ll}80 & 2 \\ 78 & 2 \\ 71 & 2 \\ 69 & 1\end{array}$

2
2
2
1
1
1
1
1
1
1

$\begin{array}{lll}.43 & 21 & 1 \\ .42 & 20 & 1 \\ .38 & 19 & 2 \\ .19 & 18 & 2 \\ .18 & 16 & 2 \\ .17 & 16 & 2 \\ .17 & 15 & 2 \\ .16 & 15 & 2 \\ .15 & 14 & 3 \\ .14 & 14 & 4\end{array}$

.06
.05
.10
.10
.09
.09
.08
.08
.11
.15 (CFS) IMATION DISCHARGE TTONSTDAYI

11
12 13

$14 \quad 44$

$\begin{array}{ll}16 & 42 \\ 17 & 40\end{array}$

$\begin{array}{ll}17 & 40 \\ 18 & 38 \\ 19 & 36 \\ 20 & 35\end{array}$

.1

14

.13
.12
.11
.24

13
13
13
13
13

.2

13

.34
.22
.10
.19

13
13
13
13
13

9.6
9.6
9.0
8.3

2
2
2
2

8.

8.3
8.3
8.3
8.3
8.3

.18
.28
.21

7.7
7.7
7.7
7.7

. 28

7.7

.18
.18
.18
.18
.04

7.1
7.1
7.7
7.7

7.7
8.3

8.3

.10
.10

.27
.25
. .06

12

$\begin{array}{ll}21 & 33 \\ 22 & 31 \\ 23 & 30 \\ 24 & 28\end{array}$

3
3
2
1
1

.16
.08
.08

11

.14
.14
.19

.19
.19
.12

11

$\begin{array}{ll}26 & 26 \\ 27 & 26 \\ 28 & 24\end{array}$

$\begin{array}{ll}28 & 24 \\ 29 & 24 \\ 30 & 23 \\ 31 & 22\end{array}$

2
2
3
3
2
2

TOTAL 1362

--

6.09

TOTAL DISCHARGE FOR YEAR (CFS-DAYS)
TOTAL SUSPENDED-SEDIMENT DISCHARGE FOR YEAR (TONS)

PARTICLE-SIZE DISTRIBUTION OF SUSPENDED SEDIMENT, WATER YEAR OCTOBER 1968 TO SEPTEMBER 1969,
(METHOOS OF ANALYSIS: B, BOTTOM WITHORAWAL TUBE; CC CHEMICALLY DISPERSED; N, IN NATIVE WATER; P, PIPET; S, SIEVE; $\checkmark$, VISUAL ACCUMULATION TUBE: W, IN DISTILLED WATER'

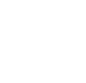

DATE

DEC 10.19680710

DEC $10 \ldots \ldots+1025$

JAN $14,1969 \quad 1445$

JAN $19 \ldots \ldots . . .1110$

JAN $20 \ldots \ldots . .1120$

FEB 5 MAR $30 . \ldots . .1300$
SUSPENOED

PARTICLE SIZE

SUSPENDED
CONCEN-SEDIMENT PERCENT FINER THAN THE SIZE IIN MILLIMETERS) INOICATED OF

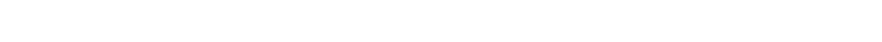
$\begin{array}{rrr}274 & 600 & 444 \\ 2190 & 9190 & 54300 \\ 4800 & 8650 & 112000 \\ 920 & 1630 & 4050\end{array}$ $\begin{array}{rrr}920 & 1630 & 4050 \\ 2280 & 1810 \quad 11200\end{array}$

$\begin{array}{lll}26 & 34 & 4 \\ 16 & 18 & 25 \\ 16 & 20 & 26 \\ 12 & 22 & 3 \\ 10 & 14 & 20 \\ 15 & 18 & 23 \\ 16 & 21 & 27 \\ 19 & 17 & 24 \\ 14 & 18 & 28\end{array}$

2710
6180 $3180 \quad 23300$ $6180 \quad 6660 \quad 111000$ $\begin{array}{rrr}535 & 263 & 380 \\ 3320 & 2340 & 21000\end{array}$

$\begin{array}{rrrrrrrrrr}41 & 49 & 53 & 65 & 73 & 83 & 95 & 100 & - & \text { V8WC } \\ 25 & 39 & 50 & 63 & 78 & 91 & 98 & 100 & - & \text { VBWC } \\ 26 & 46 & 51 & 61 & 74 & 85 & 91 & 98 & 100 & \text { VPWC } \\ 30 & 41 & 50 & 58 & 68 & 81 & 94 & 99 & 100 & \text { VPWC } \\ 20 & 31 & 42 & 54 & 68 & 86 & 97 & 100 & -- & \text { VPWC } \\ & & & & & & & & & \\ 23 & 34 & 46 & 58 & 73 & 89 & 97 & 100 & - & \text { VPWC } \\ 27 & 39 & 51 & 61 & 74 & 85 & 93 & 97 & 100 & \text { SPWC } \\ 24 & 33 & 39 & 40 & 43 & 50 & 74 & 96 & 100 & \text { SBWC } \\ 28 & 37 & 48 & 58 & 70 & 82 & 92 & 97 & 100 & \text { SPWC }\end{array}$


11383800 SACRAMEKTO RIVER NEAR HAMILTON CITY, CALIF.

LOCATION.-Lat $39^{\circ} 45^{\prime} 06^{\prime \prime}$, long $121^{\circ} 59^{\prime} 40^{\prime \prime}$, in NEłNEł sec.20, R.1 W., T.22 N., But te County, at state-operated gaging station on State Highway 32 bridge, 1.3 miles northeast of Hamiltón City and $2.4 \mathrm{miles}$ upstream from

PERIOD OF RECORD. --Chemical analyses: October 1953 to September 1969.

REMARKS. --Records furnished by California Department of Water Resources and reviewed by v.S. Geological Survey. CHEMICAL ANALYSES, WATER YEAR OCTOBER 1968 TO SEPTEMBER 1969

\begin{tabular}{|c|c|c|c|c|c|c|c|c|c|c|c|c|}
\hline DATE & $\begin{array}{l}\text { MEAN } \\
\text { DIS- } \\
\text { CHARGE } \\
\text { (CFS) }\end{array}$ & $\begin{array}{l}\text { TEMPER- } \\
\text { ATURE } \\
\text { IDEG C) }\end{array}$ & $\begin{array}{l}\text { DIS- } \\
\text { SOLVED } \\
\text { OXYGEN } \\
\text { IMG/LI }\end{array}$ & $\begin{array}{l}\text { TUR- } \\
\text { BID- } \\
\text { ITY } \\
\text { (MG/L) }\end{array}$ & $\begin{array}{l}\text { CAL- } \\
\text { CIUMA } \\
(C A) \\
(M G / L)\end{array}$ & $\begin{array}{c}M A G- \\
N E- \\
S I U M \\
(M G) \\
(M G / L)\end{array}$ & $\begin{array}{l}\text { SODIUM } \\
\text { (NA) } \\
\text { (MG/L) }\end{array}$ & $\begin{array}{l}\text { PO- } \\
\text { YAS- } \\
\text { SIUM } \\
\text { (KI) } \\
\text { (MG/L) }\end{array}$ & $\begin{array}{l}\text { BICAR- } \\
\text { BONATE } \\
\text { (HCO3) } \\
\text { (HG/L) }\end{array}$ & $\begin{array}{l}\text { CAR- } \\
\text { BONATE } \\
\text { (CO3) } \\
\text { (MGIL) }\end{array}$ & $\begin{array}{l}\text { SULFATE } \\
\text { (SO4) } \\
\text { (MG/L) }\end{array}$ & $\begin{array}{l}\text { CHLO- } \\
\text { RIDE } \\
\text { (CL) } \\
\text { (MG/L) }\end{array}$ \\
\hline $\begin{array}{c}\text { OCT. } \\
\text { 03... } \\
\text { Nov. }\end{array}$ & 7670 & 15 & 9.9 & 3.0 & -- & - & 7.2 & $\rightarrow$ & 68 & D & - & 2.7 \\
\hline $\begin{array}{l}\text { Or... } \\
\text { JAN. }\end{array}$ & 7900 & 13 & 10.1 & 5.0 & -- & -- & 8.2 & -- & 72 & 0 & + & 4.2 \\
\hline & 8310 & 6 & 16.8 & 35 & -- & -- & 8.0 & -- & 79 & 0 & $\cdots$ & 5.0 \\
\hline$\underset{\text { MAY }}{07 \ldots}$ & 20000 & 8 & 11.3 & 45 & - & - & 6.3 & -- & 71 & 0 & - & 3.0 \\
\hline o8... & 16400 & 13 & 11.1 & 35 & 10 & 4.9 & 5.3 & 1.0 & 55 & 0 & 6.1 & 3.6 \\
\hline SEDT.. & 11100 & 15 & 11.4 & 12 & - & -- & 5.4 & -- & 57 & 0 & $\cdots$ & 2.2 \\
\hline $03 \ldots$ & 10700 & 16 & 11.1 & 7.0 & 9.8 & 4.5 & 4.9 & 1.2 & 56 & 0 & 4.1 & 2.0 \\
\hline
\end{tabular}

\begin{tabular}{|c|c|c|c|c|c|c|c|c|c|c|c|}
\hline DATE & $\begin{array}{l}\text { NITRATE } \\
\text { (ND3) } \\
\text { (MG/C) }\end{array}$ & $\begin{array}{l}\text { BORON } \\
\text { (B) } \\
(U G / C)\end{array}$ & $\begin{array}{l}\text { DIS- } \\
\text { SOLVED } \\
\text { SOLIOS } \\
\text { IRESI- } \\
\text { DUE AT } \\
180 \text { CI } \\
\text { (MGILI }\end{array}$ & $\begin{array}{l}\text { DIS- } \\
\text { SOLVED } \\
\text { SOL IDS } \\
\text { ITONS } \\
\text { PER } \\
\text { AC-FII }\end{array}$ & $\begin{array}{l}\text { HARD- } \\
\text { NESS } \\
\text { (CA, MG) } \\
(M G / L)\end{array}$ & $\begin{array}{l}\text { NON- } \\
\text { CAR- } \\
\text { BONATE } \\
\text { HARD- } \\
\text { NESS } \\
\text { (MG/L) }\end{array}$ & $\begin{array}{l}\text { PERCENT } \\
\text { SODIUM }\end{array}$ & $\begin{array}{l}\text { SODIUM } \\
\text { AD- } \\
\text { SORP- } \\
\text { TION } \\
\text { RATID }\end{array}$ & $\begin{array}{l}\text { ALKA- } \\
\text { LINITY } \\
\text { AS } \\
\text { CACO3 } \\
\text { (MG/L) }\end{array}$ & $\begin{array}{c}\text { PH } \\
\text { IUNITSI }\end{array}$ & $\begin{array}{l}\text { SPECI } \\
\text { FIC } \\
\text { CONO- } \\
\text { UCTANC } \\
\text { IMICRO } \\
\text { MHOSI }\end{array}$ \\
\hline $\begin{array}{l}\text { OCT. } \\
\text { O3.... } \\
\text { Nov. }\end{array}$ & - & 140 & -- & - & 50 & 0 & 24 & .4 & 56 & 7.8 & 124 \\
\hline $\begin{array}{l}\text { OT... } \\
\text { JAN. }\end{array}$ & - & 70 & - & - & 51 & 0 & 26 & .5 & 59 & 7.8 & 137 \\
\hline O9... & - & 20 & -- & -- & 77 & 12 & 18 & .4 & 65 & 8.1 & 171 \\
\hline MAY 07. & $\sim$ & 0 & -- & - & 75 & 12 & 15 & .3 & 63 & 8.3 & 162 \\
\hline Jut & .5 & 90 & 70 & .10 & 45 & 0 & 20 & .3 & 45 & 7.6 & 113 \\
\hline $\begin{array}{l}\text { O8.... } \\
\text { SEPT. }\end{array}$ & $m$ & 0 & $\cdots$ & + & 46 & 0 & 20 & .3 & 47 & 7.5 & 114 \\
\hline $03 \ldots$ & .0 & 40 & 65 & .09 & 43 & 0 & 19 & .3 & 46 & 7.7 & 110 \\
\hline
\end{tabular}


LOCATION. - Lat $39^{\circ} 46^{\prime} 35^{\prime \prime}$, long $121^{\circ} 45^{\prime} 10^{\prime \prime}$ (unsurveyed), Butte County, at gaging stat1on 1.8 m 1 les upstream from golf clubhouse in Bidwell Park, 2.6 miles upstream from Lindo Channel, and 7 miles northeast of Chtco. DRAINAGE AREA. --72.2 sq mi.

PERIOD OF RECORD. --Chemicrl snalyses: October 1953 to September 1969.

REMARKS. --Records furntshed by California Department of Water Resources and reviewed by U.s. Geological Survey. CHEMICAL ANALYSES, hater YEAR OCTOBER 2968 TO SEPTEMBER 1969

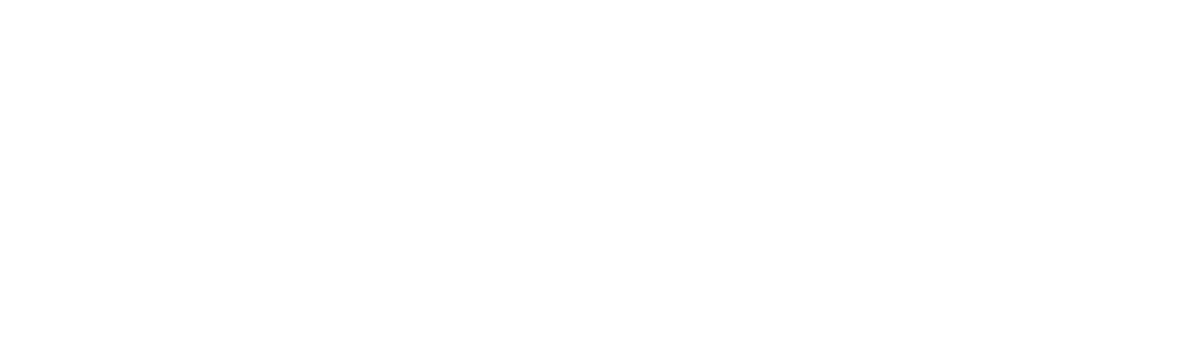

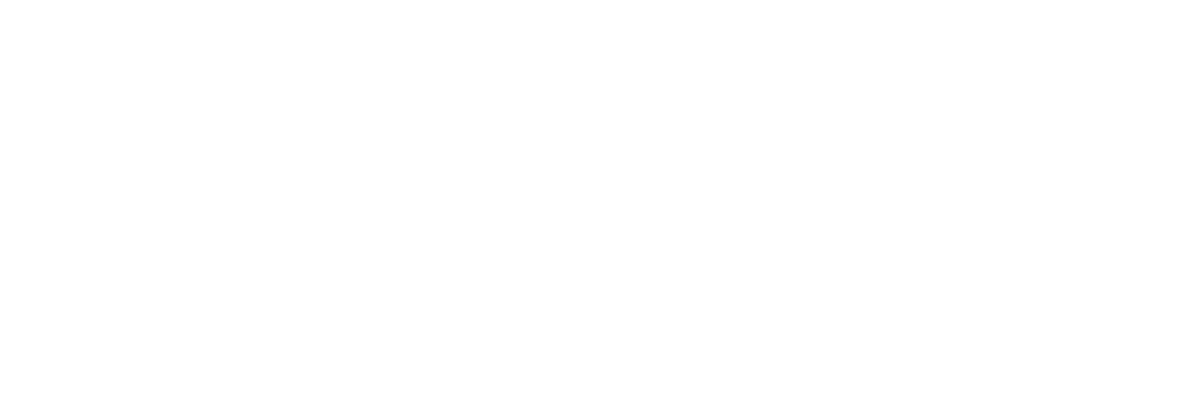


11384600 LITTLE STONY CREEK ABOVE EAST PARK RESERVOIR, NEAR LODOGA, CALIF,

LOCATION, --Lat $39^{\circ} 17^{\prime} 48^{\prime \prime}$, long $122^{\circ} 32^{\prime} 22^{\prime \prime}$, in SE 1 NW sec. 28, T.17 N., R.6 W., Colusa County, temperature recorder at gaging station on left bank, $1.1 \mathrm{miles}$ upstream from county bridge on Lodoga-Stonyford road, $1.4 \mathrm{~m} 1 \mathrm{les}$
downstream from Frenzel Creek, and $2.8 \mathrm{mlles}$ southwest of Lodoga.

DRAINAGE AREA, $-25.6 \mathrm{sq} \mathrm{m} 1$.

PERIOD OF RECORD.--Wiater temperatures: May 1967 to September 1969.

EXTREMES. $-1988-69$ :

Water temperatures: Maximum, $30.0^{\circ} \mathrm{C}$ July 20-24; min1mum, freezing point Dec, 21-23.

Period of record:

Water temperatures: Maximum, $30.0^{\circ} \mathrm{C}$ July 20-24, 1969; minimum, freezing point Dec, 21-23, 1968.

REMARKS. -CClock stopped OCt. 1,2 Nov, 3-12, June 4 to July 2 ; ranges in temperature, $16.0^{\circ} \mathrm{C}$ to $21.0^{\circ} \mathrm{C}, 9.0^{\circ} \mathrm{C}$ to $13.0^{\circ} \mathrm{C}$, and $21.0^{\circ} \mathrm{C}$ to $28.0^{\circ} \mathrm{C}$, respectively. Probe out of water Sept. 4-30.

\section{TELPERATURE (' $\mathrm{C}$ ) OF WATER, WATER YEAR OCTOBER I868 TO SEPTEKBER 1989}

DAY

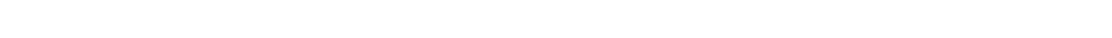

OCTUBER

$\begin{array}{llllllllllllllllllllllllllllllllllll}\text { MAXIMUM -- - } & 20 & 20 & 19 & 19 & 17 & 16 & 16 & 17 & 16 & 16 & 16 & 14 & 14 & 15 & 15 & 15 & 14 & 15 & 14 & 15 & 16 & 16 & 16 & 16 & 15 & 14 & 14 & 12 & 12 & 16 \\ \text { MINIMLM -- - } & 16 & 16 & 16 & 15 & 13 & 12 & 12 & 14 & 14 & 14 & 13 & 11 & 10 & 11 & 11 & 11 & 10 & 11 & 11 & 11 & 11 & 12 & 12 & 12 & 11 & 11 & 12 & 10 & 9 & 12\end{array}$

NOV=MHER

AXIMil 11 11

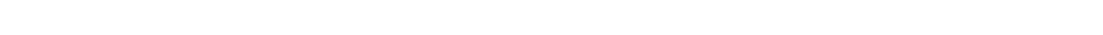

DEC CIMTIRK

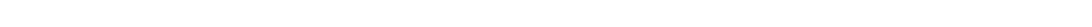

MINIMUM

JANUARY

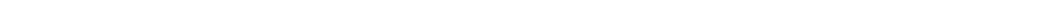

MINI MUM

FERKUARY

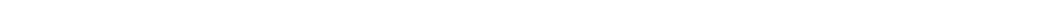

MINIMUM

MAQCH

$M A I M U M$

MINIMUM

APRIL

$\begin{array}{llllllllllllllllllllllllllllllll} & 5 & 5 & 5 & 5 & 5 & 5 & 5 & 5 & 5 & 5 & 5 & 4 & 4 & 5 & 6 & 7 & 6 & 6 & 7 & 6 & 6 & 7 & 7 & 6 & 6 & 7 & 7 & 8 & 8 & 8\end{array}$ MaY MAXI

MAXIMUM MINIMUM

JUNF

$\begin{array}{llllllllllllllllllllllllllllllll}11 & 10 & 10 & 11 & 12 & 13 & 13 & 15 & 15 & 15 & 15 & 15 & 13 & 13 & 14 & 16 & 15 & 14 & 14 & 15 & 16 & 18 & 18 & 17 & 17 & 16 & 16 & 18 & 19 & 19\end{array}$

Jut

Maximim $\begin{array}{lllllllllllllllllllllllllllllll}\text { MAXIMIMM } & -- & -2 & 26 & 2 b & 66 & 27 & 27 & 27 & 28 & 28 & 28 & 28 & 28 & 28 & 2 B & 29 & 29 & 29 & 30 & 30 & 30 & 30 & 30 & 29 & 29 & 29 & 29 & 29 & 29 & 29 \\ \text { MINIMUM } & -- & 19 & 19 & 70 & 20 & 20 & 20 & 20 & 20 & 21 & 21 & 22 & 21 & 21 & 21 & 21 & 21 & 22 & 22 & 27 & 23 & 23 & 23 & 22 & 22 & 22 & 22 & 20 & 19 & 18\end{array}$ AUGUST

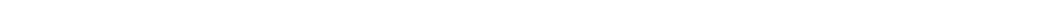

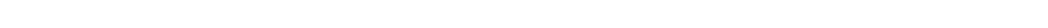

STPTEMER

MAXIMUS

MINIMIJM

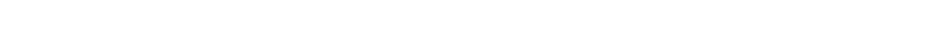


11388000 STONY CREEK BELON BLACK BUTTE DAM, NEAR ORLAND, CALIF.

LOCATION (revised).--Lat $39^{\circ} 49^{\prime}$ O $7^{\prime \prime}$, long $122^{\circ} 19^{\prime} 26^{\prime \prime}$, In SW $\$$ sec. $28^{\circ}$, T. 23 N, , R.4 W. , Tehama County, at gaging station on left bank, $200 \mathrm{ft}$ downstream from road bridge, $0.6 \mathrm{mi}$ le downstream from Black Butte Dam, and

DRAINAGE AREA. --741 sq mi.

PERIOD OF RECORD, --Chemical analyses: October 1957 to September 1969.

Nater temperatures: June to September 1969.

EXTRE MES. - June to September 1969:

Nater temperatures: Maximum, $27.0^{\circ} \mathrm{C}$ on several days in August.

REMARKS. --Chemical-quality records furnished by Caltfornia Department of Water Resources and reviewed by U.S.

Geological Survey. Recorder clock stopped Sept. 6-30; range in temperature, $24.0^{\circ} \mathrm{C}$ to $25.0^{\circ} \mathrm{C}$.

CHEMICAL ANALYSES, WATER YEAR OCTOBER 1968 TO SEPTEMBER 1969

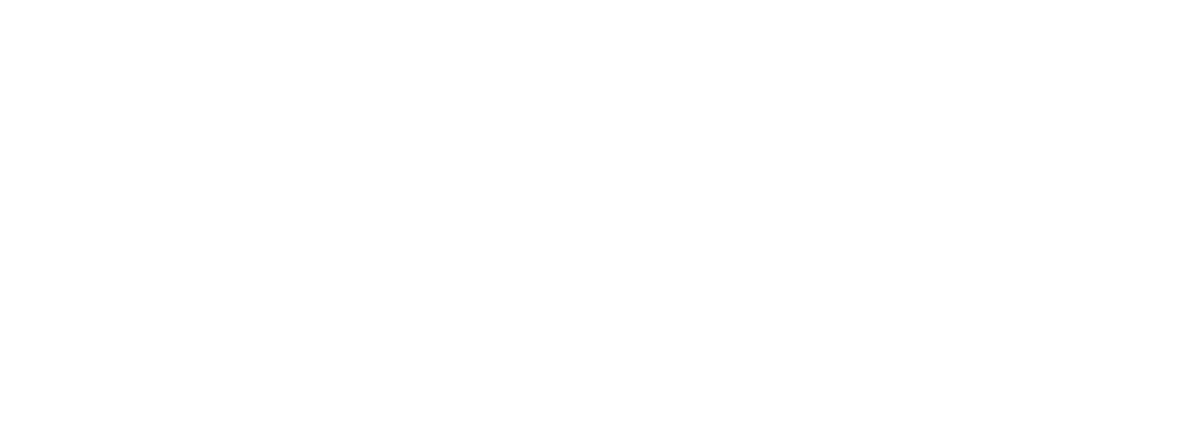

\begin{tabular}{|c|c|c|c|c|c|c|c|c|c|c|c|}
\hline DATE & $\begin{array}{l}\text { PHOS- } \\
\text { PHATE } \\
\text { (PO4) } \\
\text { (MG/L) }\end{array}$ & $\begin{array}{l}\text { BQRON } \\
\text { (B) } \\
\text { (UG/L) }\end{array}$ & $\begin{array}{l}\text { DIS- } \\
\text { SOLVEO } \\
\text { SOLIDS } \\
\text { (RESI- } \\
\text { DUE AI } \\
\text { IBO C) } \\
\text { (MGIL) }\end{array}$ & $\begin{array}{l}\text { DIS- } \\
\text { SOLVED } \\
\text { SOL IOS } \\
\text { ITONS } \\
\text { PER } \\
\text { AC-FTI }\end{array}$ & $\begin{array}{l}\text { HARD- } \\
\text { NESS } \\
(C A, M G) \\
(M G / L)\end{array}$ & $\begin{array}{l}\text { NON- } \\
\text { CAR- } \\
\text { BONATE } \\
\text { HARO- } \\
\text { NESS } \\
\text { (MG/L) }\end{array}$ & $\begin{array}{l}\text { PERCENT } \\
\text { SODIUM }\end{array}$ & $\begin{array}{l}\text { SODIUM } \\
\text { AO- } \\
\text { SORP- } \\
\text { TION } \\
\text { RATIO }\end{array}$ & $\begin{array}{l}\text { ALKA- } \\
\text { LINITY } \\
\text { AS } \\
\text { CACO3 } \\
\text { (MGIL) }\end{array}$ & $\begin{array}{c}\text { PH } \\
\text { (UNITS) }\end{array}$ & $\begin{array}{l}\text { SPECI- } \\
\text { FIC } \\
\text { CONO- } \\
\text { UCTANCE } \\
\text { (MICRD- } \\
\text { MHOS) }\end{array}$ \\
\hline $\begin{array}{l}\text { OCT. } \\
\text { O3... } \\
\text { NOV. }\end{array}$ & .50 & 310 & -- & - & 169 & 6 & 18 & .6 & 163 & 8.0 & 383 \\
\hline JAN.. & .11 & 250 & -- & -- & 182 & 2 & 17 & .5 & 180 & 8.3 & 416 \\
\hline $\begin{array}{l}09, . . \\
\text { FEB. }\end{array}$ & .26 & 90 & -- & -- & 165 & 30 & 18 & .6 & 135 & 8.3 & 394 \\
\hline MAR... & .11 & 20 & -- & -- & 107 & 15 & 16 & .4 & 92 & 7.7 & 237 \\
\hline OP... & .01 & 60 & -- & - & 135 & 16 & 15 & .4 & 119 & 8.3 & 309 \\
\hline MAY & .13 & 0 & - & - & 125 & 15 & 17 & .5 & 110 & 7.9 & 287 \\
\hline juLY... & .11 & 50 & 128 & .17 & 111 & 6 & 16 & .4 & 105 & 7.9 & 266 \\
\hline $\begin{array}{l}\text { OB.... } \\
\text { SEPT. }\end{array}$ & -- & 30 & $\cdots$ & -- & 123 & 13 & 16 & .4 & 110 & 8.2 & 272 \\
\hline $03 \ldots$ & $m$ & -- & 164 & .22 & 152 & 0 & 16 & .5 & 158 & -- & - \\
\hline
\end{tabular}

TEUPERATURE ( $\left.{ }^{\circ} \mathrm{C}\right)$ OF MATER, JUNE TO SEPTEYBER 1969 (ONCE-DAILY MEASUREMENT)

DAY

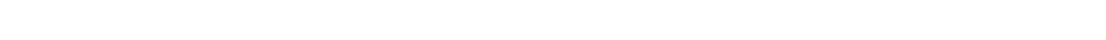
JUNE

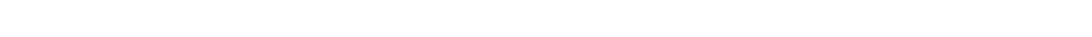

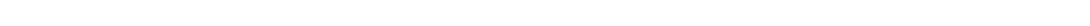
$\begin{array}{lllllllllllllllllllllllllllllllllllll}\text { MAXIMUM } & 23 & 23 & 23 & 23 & 23 & 23 & 23 & 23 & 23 & 24 & 24 & 23 & 24 & 24 & 24 & 24 & 24 & 24 & 24 & 24 & 24 & 24 & 24 & 24 & 24 & 24 & 24 & 25 & 24 & 25 & 25 & 24\end{array}$

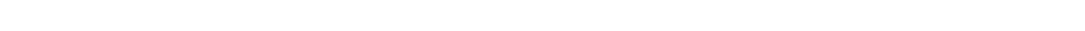
AUGUST $\begin{array}{lllllllllllllllllllllllllllllllll}\text { MAXIMUM } & 25 & 26 & 26 & 26 & 26 & 26 & 26 & 26 & 27 & 27 & 25 & 27 & 27 & 27 & 27 & 27 & 27 & 26 & 27 & 27 & 27 & 26 & 26 & 26 & 26 & 26 & 26 & 26 & 26 & 26 & 26 & 26 \\ \text { MINIMUM } & 24 & 24 & 24 & 24 & 25 & 25 & 25 & 25 & 25 & 25 & 25 & 25 & 26 & 26 & 26 & 25 & 25 & 25 & 25 & 25 & 25 & 25 & 25 & 25 & 25 & 25 & 25 & 25 & 25 & 25 & 25 & 25\end{array}$ SEPTEMBER

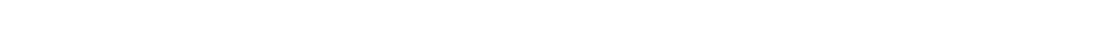


11389000 SACRAMENTO RIVER AT BUTTE CITY, CALIF,

LOCATION, --Lat $39^{\circ} 27^{\prime} 28^{\prime \prime}$, 1 long $121^{\circ} 59^{\prime} 35^{\prime \prime}$, In SE at gaging station on left bank, $100 \mathrm{ft}$ upstream $\mathrm{from}$ highwy bridge, 0.5 mile south of Butte City, and at mile 115.8 upstream from Sacramento.

DRAINAGE AREA. $-12,096 \mathrm{sq} \mathrm{mi}$.

PERIOD OF RECORD. --Chemical analyses: May 1955 to September 1966.

Water temperatures: Way 1955 to September 1958, October 1959 to September 1967 , July to September 1969.

EXTREMES. - Period of record (1955-58, 1959-67):

Water temperatures: Waximum, 24, $0^{\circ} \mathrm{C}$ June 2, 3, 5, 7, 1960; minimum (1955-57, 1959-62, 1963-67), freez1ng TEMPERATURE ( ${ }^{\circ} \mathrm{C}$ ) OF WATER, JULY TO SEPTEMBER 1969

CAY

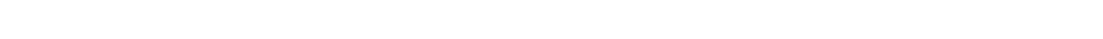
JULY

MAXIMUM - -

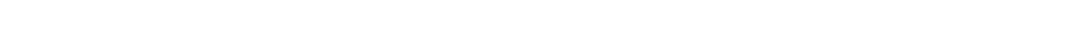
AUGUST

MAXIMUM $18191919191919181919191919191919191919191919191918181817 \quad 17 \quad 17 \quad 17 \quad 19$

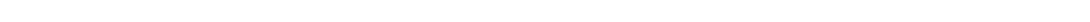
SEPTEMBER

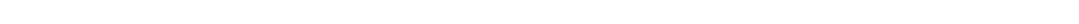

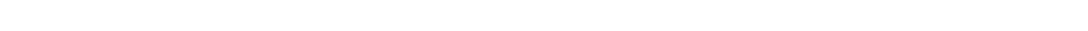

11390000 BUTTE CREEK NEAR CHICO, CALIF.

LOCATION. --Lat $39^{\circ} 43^{\prime} 34^{\prime \prime}$, long $121^{\circ} 42^{\prime} 28^{\prime \prime}$, In NW 1 NWt sec.36, T.22 N., R.2 E., Butte County, at gaging station 0.7 mile downstream from Little Butte Creek and 7.5 miles east of Chico.

DRAINAGE AREA, - $-147 \mathrm{sq} \mathrm{mi}$.

PERIOD OF RECORD. --Chemical analy ses: October 1953 to September 1969

Vater temperatures: November 1961 to September 1969.

EXTREHES, - $1968-69$ :

Water temperatures: Maxisum, $23.0^{\circ} \mathrm{C}$ Ju1y 22-25; minimum, 3. $0^{\circ} \mathrm{C}$ Dec. 21,22

Period of record:

Water temperatures: Maximum (1961-64, 1965-69), 26. $0^{\circ} \mathrm{C}$ July 21, 22, 1966; minimum, 1.0 ${ }^{\circ} \mathrm{C}$ Dec. $14,15,1967$.

REMARKS. --Chemical-quality records furnished by California Department of Water Resources and reviewed by U.S. Geological Survey. Recorder clock stopped Apr. $16-30$, Way 14 to June 10 , June 17 to July 1 ; ranges in tempera-
ture, $8.0^{\circ} \mathrm{C}$ to $10.0^{\circ} \mathrm{C}, 9.0^{\circ} \mathrm{C}$ to $15.0^{\circ} \mathrm{C}$, and $14.0^{\circ} \mathrm{C}$ to $16.0^{\circ} \mathrm{C}$, respectively. No record Nov. 27,28, Sept. $1-3$, 29,30 .

CHEMICAL ANALYSES, WATER YeAR OCTOBER 1968 TO SEPTEMBER 1969

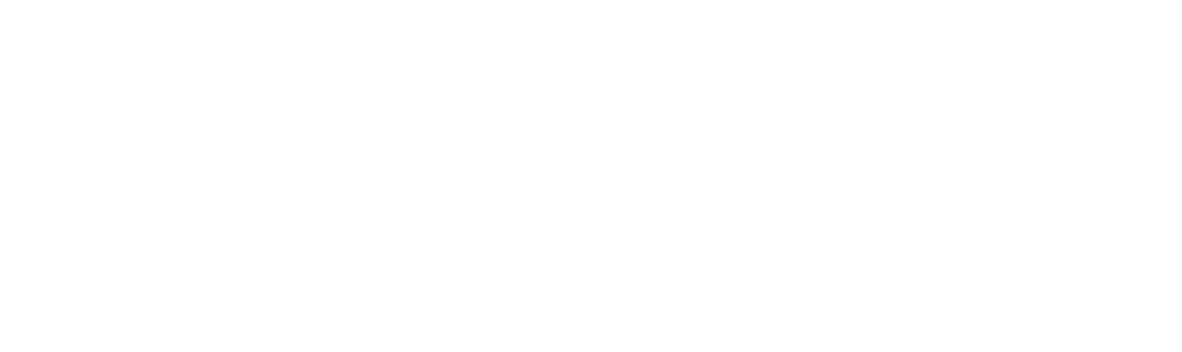

\begin{tabular}{|c|c|c|c|c|c|c|c|c|c|c|c|}
\hline DATE & $\begin{array}{l}\text { NI TRATE } \\
\text { (NO3) } \\
\text { (NG/L) }\end{array}$ & $\begin{array}{l}\text { BORON } \\
\text { (B) } \\
\text { (UG/L) }\end{array}$ & $\begin{array}{l}\text { DIS- } \\
\text { SOLVEO } \\
\text { SOLIOS } \\
\text { (RESI- } \\
\text { DUE AI } \\
\text { I8O C) } \\
\text { (MG IL) }\end{array}$ & $\begin{array}{l}\text { OIS- } \\
\text { SDLVED } \\
\text { SDLIOS } \\
\text { ITONS } \\
\text { PER } \\
\text { AC-FTI }\end{array}$ & $\begin{array}{l}\text { HARD- } \\
\text { NESS } \\
(C A, M G) \\
(M G / L)\end{array}$ & $\begin{array}{l}\text { NON- } \\
\text { CAR- } \\
\text { gONATE } \\
\text { HARD- } \\
\text { NESS } \\
\text { I MG/LI }\end{array}$ & $\begin{array}{l}\text { PERCENT } \\
\text { SODIUN }\end{array}$ & $\begin{array}{l}\text { SODIUM } \\
\text { AD- } \\
\text { SORP- } \\
\text { TION } \\
\text { RATIO }\end{array}$ & $\begin{array}{l}\text { ALKA- } \\
\text { LINI IY } \\
\text { AS } \\
\text { CACD3 } \\
\text { ( MG/LI) }\end{array}$ & $\begin{array}{c}\text { PH } \\
\text { (UNITS) }\end{array}$ & $\begin{array}{l}\text { SPECI- } \\
\text { FIC } \\
\text { COND- } \\
\text { UCTANCE } \\
\text { (MICRD- } \\
\text { MHOSI }\end{array}$ \\
\hline $\begin{array}{l}\text { OCT. } \\
\text { O3... } \\
\text { NOV. }\end{array}$ & $-\infty$ & 0 & -- & - & 46 & 0 & 15 & .2 & 51 & 7.9 & 124 \\
\hline $\begin{array}{l}\text { O7... } \\
\text { JAN. }\end{array}$ & -- & 40 & -- & -- & 49 & 0 & 14 & .2 & 53 & 8.1 & 108 \\
\hline $\begin{array}{l}09 . . \\
\text { MAR. }\end{array}$ & -- & 0 & - & -- & 44 & 0 & 12 & .2 & 45 & 8.0 & 92 \\
\hline$\underset{\text { MAY }}{07 . . .}$ & -- & 0 & -- & - & 38 & 2 & 11 & .1 & 36 & 7.3 & 77 \\
\hline JULY... & .0 & 80 & 35 & .05 & 22 & 0 & 13 & -1 & 23 & 7.3 & 49 \\
\hline SEP... & -- & 0 & -- & -- & 39 & 0 & 14 & .2 & 42 & 7.9 & 88 \\
\hline $03 \ldots$ & .0 & 60 & 95 & .13 & 45 & 0 & 13 & .2 & 48 & 7.5 & 103 \\
\hline
\end{tabular}


11390000 BUTTE CREEK NEAR CHICO, CALIF.--CONtinued

TEMPERATURE ( ${ }^{\circ} \mathrm{C}$ ) OF WATER, WATER YEAR OCTOBER 1968 TO SEPTEMBER 1969

DAY

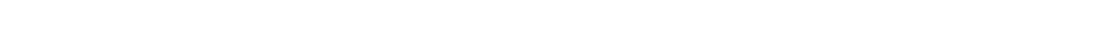

OCTOBEP

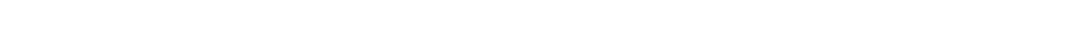

NDVEMBER

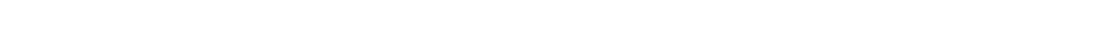

DECEMAER

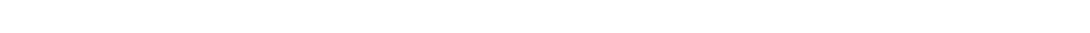

MINIMUM

MAXIMUM

MERTINIJM

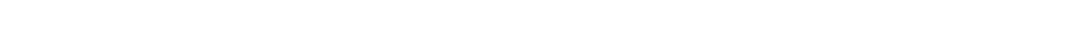

Minimo

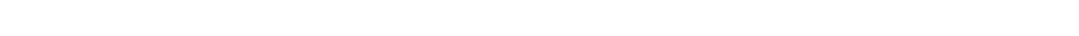

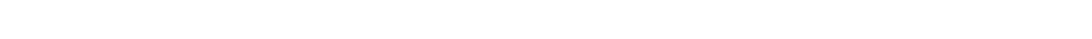

MINIMUM -

ULY

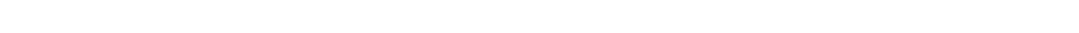
MINIMUM - $1717 \quad 17171818 \quad 1819191919191919191919192020 \quad 2021 \quad 2120 \quad 202019191918 \quad 19$ UGUST

MAXIMUM $21 \quad 2121 \quad 21 \quad 202020192020 \quad 212019201919191919191919191918181818181818 \quad 19$

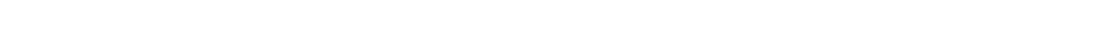

MAXIMUM --

MINIMUM - - 
11390500 SACRAMENTO RIVER BELOW WILKINS SLOUGH, NEAR GRIMES, CALIF.

LOCATION. - Lat $39^{\circ} 00^{\prime} 36^{\prime \prime}$, long $121^{\circ} 49^{\prime} 25^{\prime \prime}$, in NW 1 NE 1 sec. 2, T. 13 N., R. 1 E., Colusa County, temperature recorder at gaging station on right bank, 1,200 ft downstream from $11 \mathrm{kins}$ Slough, $5.8 \mathrm{~m} 1 \mathrm{les}$ southeast of Grimes, and at mile 62.9 upstream from Sacramento.

DRAINAGE AREA. $-12,940 \mathrm{sq} \mathrm{m} 1$.

PERIOD OF RECORD, - Water temperatures: October 1966 to September 1969.

EXTREMES, --1968-69:

Water temperatures: Maximum, $20.0^{\circ} \mathrm{C}$ July 23 ; minimum, $4.0^{\circ} \mathrm{C}$ Dec, 26.

Period of record:

Water temperatures: Maximum, $21.0^{\circ} \mathrm{C}$ on several days in June 1968 ; mintmum, 4. $0^{\circ} \mathrm{C} \mathrm{Dec} .26,1968$.

TEMPERATURE $\left({ }^{\circ} \mathrm{C}\right.$ ) OF WATER, WATER YEAR OCTOBER 1968 TO SEPTEMBER 1969

OAY

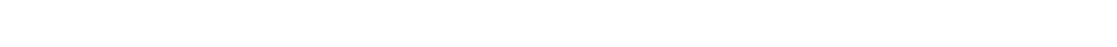

DCTOBER

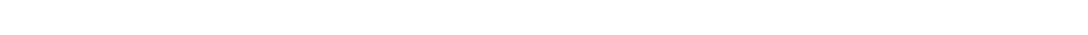

MINIMUM 17
NOVEMHFR

$\begin{array}{llllllllllllllllllllllllllllllllllll}M A X I M U M & 14 & 14 & 13 & 13 & 13 & 14 & 14 & 13 & 13 & 14 & 14 & 14 & 14 & 13 & 11 & 11 & 11 & 12 & 12 & 13 & 13 & 13 & 13 & 13 & 12 & 12 & 12 & 11 & 11 & 11 & -- & 13 \\ M I N I M U M & 14 & 13 & 13 & 13 & 13 & 13 & 13 & 13 & 13 & 13 & 14 & 14 & 13 & 11 & 11 & 11 & 11 & 11 & 12 & 12 & 13 & 13 & 13 & 12 & 12 & 12 & 11 & 11 & 11 & 11 & -- & 12\end{array}$

DECEMGF:

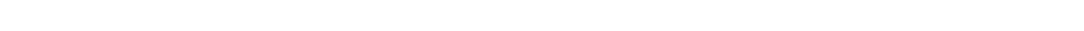

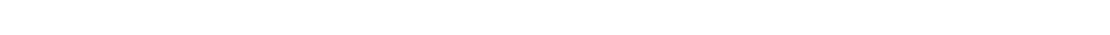

$\begin{array}{llllllllllllllllllllllllllllllllllllll}\text { MAXIMLIM } & 6 & 7 & 8 & 8 & 8 & 8 & 8 & 8 & 8 & 7 & 7 & 7 & 6 & 6 & 6 & 6 & 6 & 6 & 6 & 6 & 8 & 8 & 8 & 7 & 7 & 7 & 7 & 7 & 6 & 7 & 7 & 7\end{array}$

$\begin{array}{lllllllllllllllllllllllllllllllll}\text { MIVIPUM } & 6 & 6 & 7 & 7 & 8 & 8 & 8 & 8 & 7 & 7 & 6 & 6 & 5 & 5 & 6 & 6 & 6 & 6 & 6 & 6 & 6 & 8 & 7 & 7 & 7 & 7 & 7 & 6 & 6 & 6 & 6\end{array}$

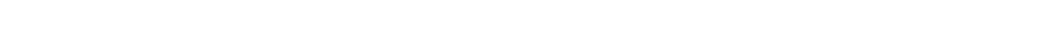

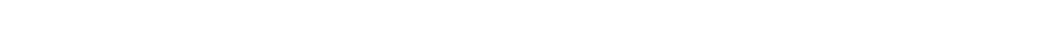

MAXIPUM $99 \begin{array}{lllllllllllllllllllllllllllllll} & 9 & 10 & 11 & 11 & 11 & 12 & 12 & 11 & 11 & 11 & 12 & 12 & 12 & 12 & 12 & 12 & 13 & 13 & 13 & 13 & 13 & 14 & 14 & 14 & 15 & 15 & 15 & 15 & 15\end{array}$

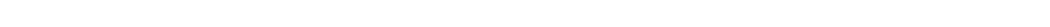
APRII

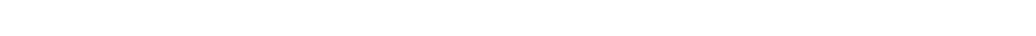

MAXIMUM

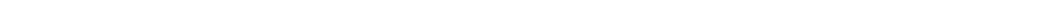

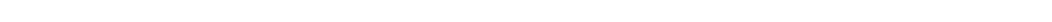
JUVE

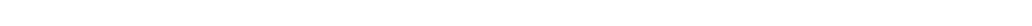

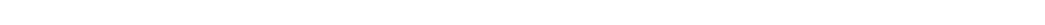
JULY

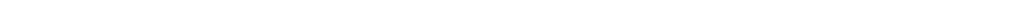
MINIMUM $1617171717181818 \quad 181818181818$ 18 $181818 \quad 18181919191919191919181818$ AUGUST

MAXIMUM $19191919191919191919191818 \quad 18181818 \quad 1818181819191918181818181717$ MINIMUM

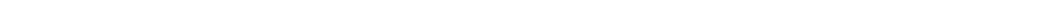

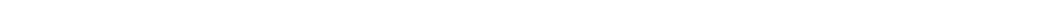


11390650 SACRAKENTO RI VER ABOVE COLUSA TROUGH, AT KNIGHTS LANDING, CALIF.

LOCATION, --Lat $38^{\circ} 48^{\prime} 18^{\prime \prime}$, long $121^{\circ} 43^{\prime} 22^{\prime \prime}$, in NW sec.14, T.11 N., R. 2 E., Yolo County, approximately 200 yards upstream from State Highway 24 bridge at Knights Landing, and approximately $0.3 \mathrm{mile}$ upstream from gaging sta-
tion.

PERIOD OF RECORD, --Chemical analy ses: July 1960 to September 1969.

REMARKS. --Records furnished by California Department of Water Resources and reviewed by U.S. Geological Survey. CHEMICAL ANALYSES, WATER YEAR OCTOBER 1968 TO SEPTEMBER 1969

\begin{tabular}{|c|c|c|c|c|c|c|c|c|c|c|c|}
\hline OATE & $\begin{array}{l}\text { MEAN } \\
\text { DIS- } \\
\text { CHARGE } \\
\text { (CFS) }\end{array}$ & $\begin{array}{l}\text { IEMPER- } \\
\text { ATURE } \\
\text { (OEG C) }\end{array}$ & $\begin{array}{l}\text { DIS- } \\
\text { SOLVED } \\
\text { OXYGEN } \\
\text { IMG/LI }\end{array}$ & $\begin{array}{l}\text { CAL- } \\
\text { CIUM } \\
\text { (CA) } \\
\text { (MGIL) }\end{array}$ & $\begin{array}{l}\text { MAG- } \\
\text { NE- } \\
\text { SIUM } \\
\text { (MG) } \\
\text { (MG } / L \text { ) }\end{array}$ & $\begin{array}{l}\text { SOOIUA } \\
\text { (NA) } \\
\text { (MG/L) }\end{array}$ & $\begin{array}{l}\text { PO- } \\
\text { TAS- } \\
\text { SIUM } \\
\text { (K) } \\
\text { (MG/L) }\end{array}$ & $\begin{array}{l}\text { BICAR- } \\
\text { BONATE } \\
\text { (HCO3) } \\
\text { (MG/L) }\end{array}$ & $\begin{array}{l}\text { CAR- } \\
\text { BONATE } \\
\text { (CO3) } \\
\text { (\$G/L) }\end{array}$ & $\begin{array}{l}\text { SULFATE } \\
\text { (SOA) } \\
\text { (MG/L) }\end{array}$ & $\begin{array}{l}\text { CHLO- } \\
\text { RIDE } \\
\text { ICLI } \\
\text { IMG/L }\end{array}$ \\
\hline $\begin{array}{l}\text { OCT. } \\
\text { O4.... } \\
\text { NOV. }\end{array}$ & 9280 & 17 & 9.7 & -- & -- & 7.2 & $\cdots$ & 70 & 0 & -- & 2.6 \\
\hline $\begin{array}{l}\text { OB.... } \\
\text { DEC. }\end{array}$ & 9380 & 13 & 10.0 & -- & - & 9.2 & $-\infty$ & 77 & 0 & - & 5.4 \\
\hline $\begin{array}{l}\text { O6... } \\
\text { JAN. }\end{array}$ & 9020 & 8 & 11.4 & - & - & 9.4 & - & 78 & 0 & -- & 5.2 \\
\hline $\begin{array}{c}10 \ldots . . \\
\text { FEB. } \\
07 . . .\end{array}$ & 11800 & 6 & 11.7 & $=$ & -- & 9.2 & -- & 87 & 0 & -- & 6.0 \\
\hline $\begin{array}{l}\text { MAR. } \\
\text { O6.... } \\
\text { APR. }\end{array}$ & 25700 & 9 & 11.3 & $\cdots$ & -- & 7.9 & - & 87 & 0 & -- & 4.5 \\
\hline$\underset{\text { MAY }}{09 .}$ & 17500 & 11 & 10.6 & -- & -- & 7.1 & -- & 67 & 0 & - & 4.6 \\
\hline IUNE & 12600 & 15 & 10.1 & 12 & 5.8 & 6.6 & 1.1 & 66 & 0 & 6.6 & 3.8 \\
\hline SULY... & 14100 & 16 & 10.0 & -- & -- & 7.2 & $\cdots$ & 63 & 0 & -- & 5.1 \\
\hline $\begin{array}{l}\text { O7... } \\
\text { AUG. }\end{array}$ & 10100 & 21 & 9.7 & -- & -- & 7.0 & -- & 66 & 0 & - & 3.3 \\
\hline $\begin{array}{l}04 \ldots . \\
\text { SEPT. }\end{array}$ & 8940 & 21 & 9.1 & -- & - & 7.0 & - & 63 & 0 & -- & 3.4 \\
\hline $02 \ldots$ & 11700 & 18 & 10.3 & 9.8 & 6.7 & 7.8 & .5 & 67 & 0 & 5.1 & 3.5 \\
\hline
\end{tabular}

\begin{tabular}{|c|c|c|c|c|c|c|c|c|c|c|c|}
\hline DATE & $\begin{array}{l}\text { NITRATE } \\
\text { (NO3) } \\
\text { (MG/L) }\end{array}$ & $\begin{array}{l}\text { BORAN } \\
\text { (B) } \\
\text { (UG/L) }\end{array}$ & $\begin{array}{l}\text { CIS- } \\
\text { SCLVEO } \\
\text { SOLIDS } \\
\text { (RESI- } \\
\text { DUE AT } \\
\text { IBO C) } \\
\text { (MG/L) }\end{array}$ & $\begin{array}{l}\text { DIS- } \\
\text { SOLVED } \\
\text { SOLIDS } \\
\text { (IONS } \\
\text { PER } \\
\text { AC-FT) }\end{array}$ & $\begin{array}{l}\text { HARD- } \\
\text { NESS } \\
\text { (CA,MG) } \\
\text { (MG/L) }\end{array}$ & $\begin{array}{l}\text { NON- } \\
\text { CAR- } \\
\text { BONATE } \\
\text { HARO- } \\
\text { NESS } \\
\text { IMG/L, }\end{array}$ & $\begin{array}{l}\text { PERCENT } \\
\text { SODIUM }\end{array}$ & $\begin{array}{l}\text { SODIUM } \\
\text { AO- } \\
\text { SORP- } \\
\text { TIOM } \\
\text { RATCO }\end{array}$ & $\begin{array}{l}\text { ALKA- } \\
\text { LINITY } \\
\text { AS } \\
\text { CACO3 } \\
\text { (MG/L) }\end{array}$ & $\begin{array}{c}\text { PH } \\
\text { (UNITS) }\end{array}$ & $\begin{array}{l}\text { SPECI- } \\
\text { FIC } \\
\text { COND- } \\
\text { UCTANCE } \\
\text { (MICRO- } \\
\text { MHOSI }\end{array}$ \\
\hline $\begin{array}{l}\text { DCT. } \\
\text { O4... } \\
\text { NOV. }\end{array}$ & -- & 30 & - & -- & 52 & 0 & 23 & .4 & 57 & 7.1 & 130 \\
\hline DEC... & - & 30 & $-\sim$ & -- & 57 & 0 & 26 & .5 & 63 & 7.8 & 150 \\
\hline JAN... & $=$ & 80 & $\cdots$ & -- & 64 & 0 & 24 & .5 & 64 & 8.0 & 157 \\
\hline $\begin{array}{l}10 \ldots . . \\
\text { FEB. }\end{array}$ & -- & 10 & -- & $\cdots$ & 82 & 11 & 20 & .4 & 71 & 8.0 & 183 \\
\hline $\begin{array}{c}07 . . \\
M A R\end{array}$ & -- & 0 & - & - & 54 & 0 & 21 & .4 & 54 & 7.3 & 135 \\
\hline $\begin{array}{l}06 \ldots . . \\
\text { APR. }\end{array}$ & -- & 0 & - & - & 73 & 2 & 19 & .4 & 71 & 7.5 & 175 \\
\hline$\underset{\text { MAY }}{09 . . .}$ & -- & 0 & $\cdots$ & - & 55 & 0 & 22 & .4 & 55 & 7.6 & 143 \\
\hline $\begin{array}{l}\text { O7... } \\
\text { JUNE }\end{array}$ & .6 & 0 & 94 & .13 & 54 & 0 & 21 & .4 & 54 & 7.6 & 137 \\
\hline JuL... & -- & 40 & - & -- & 50 & 0 & 24 & .4 & 52 & 7.4 & 131 \\
\hline $\begin{array}{l}07 . . . \\
\text { AUG. }\end{array}$ & -- & 0 & -- & -- & 59 & 5 & 21 & .4 & 54 & 8.2 & 133 \\
\hline SEPT. & -- & 0 & + & -- & 58 & 6 & 21 & .4 & 52 & 7.9 & 129 \\
\hline $02 \ldots$ & .2 & 70 & 100 & .14 & 52 & 0 & 24 & .5 & 55 & 7.7 & 138 \\
\hline
\end{tabular}


11390700 COLUSA TROUGH NEAR COLUSA, CALIF.

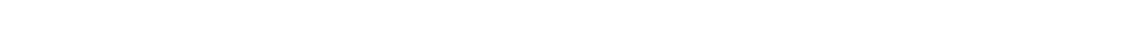
gaging station 3 miles west of Colusa on State Highway 20 and 6 miles northeast of wilitams.

PERIOD OF RECORD.---Chemical analyses: October 1953 to September 1969.

REMARKS, --Records furnished by Californ1B Department of WBter Resources and reviewed by U.S. Geological Survey. CHEMical anALYSES, WATER YeAR OCTOBER 1968 to SEPTEMBER 1969

\begin{tabular}{|c|c|c|c|c|c|c|c|c|c|c|c|c|}
\hline OATE & TIME & $\begin{array}{l}\text { DIS- } \\
\text { CHARGE } \\
\text { (CFS) }\end{array}$ & $\begin{array}{l}\text { TEMPER - } \\
\text { ATURE } \\
\text { (DEG CI }\end{array}$ & $\begin{array}{l}\text { DIS- } \\
\text { SOLVED } \\
\text { OXYGEN } \\
\text { (MG/L) }\end{array}$ & $\begin{array}{c}\text { CAL- } \\
\text { CIUM } \\
\text { (CA) } \\
(\mathrm{MG} / \mathrm{L})\end{array}$ & $\begin{array}{l}\text { MAG- } \\
\text { NE- } \\
\text { SIUM } \\
\text { (MG) } \\
\text { (MGIL) }\end{array}$ & $\begin{array}{l}\text { SODIUM } \\
\text { (NA) } \\
\text { (MG/L) }\end{array}$ & $\begin{array}{l}\text { PO- } \\
\text { TAS- } \\
\text { SIUM } \\
\text { (K) } \\
\text { (MG/L) }\end{array}$ & $\begin{array}{l}\text { BICAR- } \\
\text { BONATE } \\
\text { (HCO3) } \\
\text { (MGIL) }\end{array}$ & $\begin{array}{l}\text { CAR- } \\
\text { BONATE } \\
\text { (CO3) } \\
\text { (MG/L) }\end{array}$ & $\begin{array}{l}\text { SULFATE } \\
\text { (SOA) } \\
\text { (MG/L) }\end{array}$ & $\begin{array}{l}\text { CHLO- } \\
\text { RIOE } \\
\text { (CL) } \\
\text { (MG/L }\end{array}$ \\
\hline $\begin{array}{l}\text { OCT. } \\
\text { O4... } \\
\text { NOV:. }\end{array}$ & 0830 & 217 & 18 & 8.4 & 34 & 29 & 59 & 1.6 & 213 & 0 & 76 & 35 \\
\hline $\begin{array}{l}\text { O8... } \\
\text { OEC. }\end{array}$ & 0915 & 671 & 13 & 8.8 & 22 & 22 & 45 & 3.6 & 163 & 0 & 53 & 22 \\
\hline $\begin{array}{l}\text { O6... } \\
\text { JAN. }\end{array}$ & 0915 & 143 & 7 & 11.2 & 51 & 62 & 146 & 2.6 & 316 & 7 & 221 & 95 \\
\hline $\begin{array}{l}10 \ldots . . \\
\text { FEB }\end{array}$ & 0950 & 306 & 5 & 11.9 & 44 & 45 & 146 & 3.1 & 320 & 0 & 228 & 90 \\
\hline MAR... & 0840 & 2570 & 7 & 10.2 & 19 & 11 & 38 & 3.0 & 113 & 0 & 47 & 21 \\
\hline $\begin{array}{l}\text { O6.... } \\
\text { APR.: }\end{array}$ & 1035 & 2520 & 10 & 9.8 & 34 & 24 & $\begin{array}{l}59 \\
89\end{array}$ & 2.7 & 216 & 0 & 82 & 31 \\
\hline $\begin{array}{c}\text { MAY } \\
07 \ldots\end{array}$ & 1005 & 479 & 20 & 8.0 & 26 & 20 & 54 & 2.3 & 160 & 0 & 92 & 28 \\
\hline $\begin{array}{l}\text { JUNE } \\
\text { O9... } \\
\text { JULY }\end{array}$ & 0920 & 648 & 20 & 8.1 & 27 & 21 & 56 & 1.1 & 198 & 0 & 79 & 28 \\
\hline $\begin{array}{l}07 . . . \\
\text { AUG. }\end{array}$ & 0920 & 422 & 24 & 7.4 & 32 & 23 & 60 & .8 & 230 & 0 & 73 & 26 \\
\hline $\begin{array}{l}\text { 05... } \\
\text { SEPT. }\end{array}$ & 0925 & 822 & 23 & 7.7 & 30 & 22 & 50 & 1.3 & 219 & 5 & 50 & 20 \\
\hline $02 \ldots$ & 1510 & 1120 & 23 & 8.4 & 30 & 20 & 48 & 1.4 & 229 & 0 & 42 & 20 \\
\hline
\end{tabular}

\begin{tabular}{|c|c|c|c|c|c|c|c|c|c|c|c|}
\hline DATE & $\begin{array}{l}\text { NITRATE } \\
\text { (ND3) } \\
\text { (MG/L) }\end{array}$ & $\begin{array}{l}\text { BORON } \\
\text { (B) } \\
(U G / L)\end{array}$ & $\begin{array}{l}\text { OIS- } \\
\text { SOLVEO } \\
\text { SOLIDS } \\
\text { IRESI- } \\
\text { OUE AT } \\
\text { I8O C) } \\
\text { IMGILI }\end{array}$ & $\begin{array}{l}\text { DIS- } \\
\text { SOLVED } \\
\text { SOLIOS } \\
\text { (TONS } \\
\text { PER } \\
\text { AC-FT) }\end{array}$ & $\begin{array}{l}\text { HARD- } \\
\text { NESS } \\
\text { (CA,MG) } \\
\text { (MG/L) }\end{array}$ & $\begin{array}{l}\text { NON- } \\
\text { CAR- } \\
\text { BONATE } \\
\text { HARD- } \\
\text { NESS } \\
\text { (MG/L) }\end{array}$ & $\begin{array}{l}\text { PERCENT } \\
\text { SOOIUM }\end{array}$ & $\begin{array}{l}\text { SOOIUM } \\
\text { AD- } \\
\text { SORP- } \\
\text { TION } \\
\text { RATIO }\end{array}$ & $\begin{array}{l}\text { ALKA- } \\
\text { LINITY } \\
\text { AS } \\
\text { CACO3 } \\
\text { (MG/L) }\end{array}$ & $\begin{array}{c}\text { PH } \\
\text { (UNITS) }\end{array}$ & $\begin{array}{l}\text { SPECI- } \\
\text { FIC } \\
\text { COND- } \\
\text { UCTANCE } \\
\text { (MICRO- } \\
\text { MHOSI }\end{array}$ \\
\hline $\begin{array}{l}\text { OCT. } \\
\text { O4... } \\
\text { NOV. }\end{array}$ & 1.5 & 130 & 322 & .44 & 174 & 0 & 38 & 1.8 & 175 & 8,1 & 595 \\
\hline $\begin{array}{l}08 . . . \\
\text { OEC. }\end{array}$ & 2.6 & 160 & 269 & .37 & 124 & 0 & 39 & 1.6 & 134 & 8.2 & 453 \\
\hline $\begin{array}{l}\text { O6.... } \\
\text { JAN. }\end{array}$ & 1.7 & 360 & 764 & 1.04 & 319 & 48 & 45 & 3.2 & 271 & 8.5 & 1220 \\
\hline $\begin{array}{l}10 . . \\
\text { FEg. }\end{array}$ & 2.7 & 400 & 746 & 1.01 & 297 & 34 & 52 & 3.7 & 262 & 8.3 & 1210 \\
\hline MAR... & 6.7 & 160 & 228 & $\cdot 31$ & 93 & 0 & 46 & 1.7 & 93 & 7.8 & 369 \\
\hline $\begin{array}{l}\text { 06... } \\
\text { APR. }\end{array}$ & 10 & 190 & 357 & .49 & 182 & 5 & 41 & 1.9 & 177 & 7.9 & 613 \\
\hline MAY & 2.6 & 140 & 462 & .63 & 205 & 11 & 48 & 2.7 & 194 & 7.9 & 791 \\
\hline OT... & 3.5 & 260 & 299 & .41 & 146 & 15 & 44 & 1.9 & 131 & 7.6 & 527 \\
\hline JuLY... & 1.5 & 280 & 352 & .48 & 155 & 0 & 44 & 2.0 & 162 & 8.0 & 536 \\
\hline $\begin{array}{l}\text { O7.... } \\
\text { AUG. }\end{array}$ & 1.6 & 230 & 342 & .47 & 176 & 0 & 43 & 2.0 & 289 & 8.2 & 568 \\
\hline SEPT: & 1.2 & 190 & 286 & .39 & 164 & 0 & 39 & 1.7 & 188 & 8.4 & 489 \\
\hline $02 \ldots$ & .8 & 230 & 298 & .41 & 159 & 0 & 40 & 1.7 & 188 & 8.2 & 485 \\
\hline
\end{tabular}


LOCATION, --Lat $39^{\circ} 45^{\prime} 14^{\prime \prime}$, Iong $120^{\circ} 35^{\prime} 42^{\prime \prime}$, in SE⿺⿻一𠃋十 gaging station 0.6 mile upstream from Frazier Creek, 1.0 mile northwest of Clio, and 2.2 miles southeast of Blalrsden.

DRAT NAGE AREA, --686 sq $\mathrm{mi}$.

PERIOD OF RECORD. --Water temperatures: October 1963 to September 1969.

EXTREMES, --1968-69:

Water temperatures: Maximum, $24.0^{\circ} \mathrm{C}$ July 22-26; minimum, freezing point on many days during January to March.

Period of record:

Water temperatures: Maximum, 26. $0^{\circ} \mathrm{C}$ Aug. 3, 1966; minimum (1963-66, 1968-69), freezing point on many days in December 1963, and January to March 1969 .

TELPERATURE $\left({ }^{\circ} \mathrm{C}\right)$ OF WATER, WATER YEAR OCTOBER 1968 TO SEPTEMBER 1969

OAY

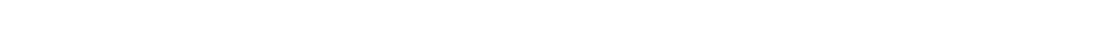

OCTORFR

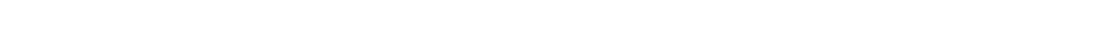

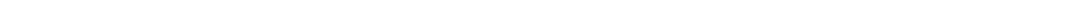

$\begin{array}{rllllllllllllllllllllllllllllllllllllllllll}\text { MAXIMUM } & 7 & 7 & 7 & 8 & 8 & 7 & 7 & 7 & 8 & 8 & 7 & 7 & 7 & 5 & 5 & 6 & 5 & 7 & 7 & 6 & 7 & 7 & 7 & 6 & 5 & 4 & 4 & 3 & 3 & 3 & -- & 6\end{array}$

MECFIME

$\begin{array}{rlllllllllllllllllllllllllllllllll}\text { MAXIMUM } & 3 & 3 & 2 & 2 & 2 & 2 & 2 & 3 & 3 & 2 & 2 & 2 & 1 & 2 & 1 & 1 & 1 & 1 & 1 & 1 & 1 & 1 & 1 & 1 & 1 & 1 & 1 & 1 & 1 & 1 & 1 & 1\end{array}$

JANUARY

MAXIMUM 1

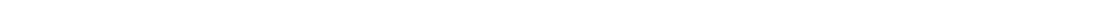

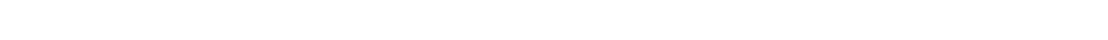

MINIMIJM

$\begin{array}{llllllllllllllllllllllllllllllllll}\text { MAXIMUM } & 0 & 0 & 0 & 0 & 0 & 1 & 1 & 1 & 1 & 1 & 1 & 1 & 1 & 1 & 1 & 1 & 1 & 1 & 1 & 1 & 1 & 1 & 1 & 1 & 2 & 1 & 1 & 2 & 3 & 4 & 6 & 1 \\ \text { MINIMUM } & 0 & 0 & 0 & 0 & 0 & 0 & 1 & 1 & 1 & 1 & 1 & 1 & 1 & 1 & 1 & 1 & 1 & 1 & 1 & 1 & 1 & 1 & 1 & 1 & 1 & 1 & 1 & 1 & 2 & 2 & 3 & 1\end{array}$

$\operatorname{Min}$

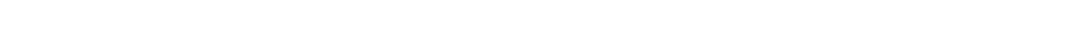

$\begin{array}{llllllllllllllllllllllllllllllllllllll}\text { MAXIMUM } & 11 & 11 & 11 & 11 & 9 & 10 & 11 & 11 & 11 & 12 & 13 & 14 & 14 & 14 & 13 & 13 & 14 & 13 & 13 & 13 & 12 & 13 & 13 & 13 & 13 & 13 & 13 & 13 & 14 & 16 & 17 & 13 \\ \text { MINIMUM } & 11 & 11 & 11 & 9 & 9 & 9 & 10 & 11 & 11 & 11 & 12 & 13 & 13 & 13 & 12 & 13 & 13 & 13 & 13 & 12 & 12 & 12 & 13 & 13 & 13 & 13 & 13 & 13 & 13 & 14 & 16 & 12\end{array}$

JUNE

$\begin{array}{lllllllllllllllllllllllllllllllll}\text { MAXIMUM } & 18 & 18 & 17 & 18 & 18 & 18 & 18 & 18 & 16 & 16 & 14 & 14 & 16 & 16 & 16 & 18 & 18 & 18 & 18 & 18 & 18 & 19 & 19 & 19 & 19 & 18 & 18 & 18 & 18 & 19 & -- & 17 \\ \text { MINIMUM } & 16 & 16 & 16 & 17 & 16 & 15 & 15 & 16 & 14 & 14 & 13 & 13 & 13 & 16 & 16 & 16 & 17 & 17 & 17 & 17 & 17 & 18 & 18 & 17 & 17 & 16 & 16 & 15 & 16 & 17 & -7 & 16\end{array}$

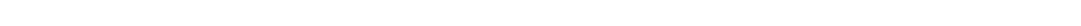

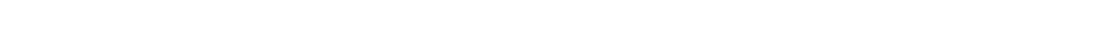

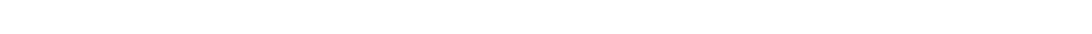
MINIMUM $17 \quad 18 \quad 18 \quad 18 \quad 1716 \quad 16 \quad 16 \quad 16 \quad 17 \quad 17 \quad 16 \quad 17 \quad 17 \quad 16 \quad 16 \quad 16 \quad 1616 \quad 16 \quad 16 \quad 16 \quad 17 \quad 17 \quad 16 \quad 16 \quad 14 \quad 14 \quad 14 \quad 14 \quad 15$ SETEMTS

$\begin{array}{lllllllllllllllllllllllllllllllllll}M A X I M U M & 16 & 16 & 16 & 16 & 14 & 14 & 15 & 15 & 15 & 14 & 14 & 14 & 14 & 13 & 12 & 12 & 12 & 12 & 12 & 12 & 12 & 12 & 12 & 12 & 12 & 12 & 12 & 12 & 12 & 12 & \cdots & 13\end{array}$ 
11394500 MIDDLE FORK FEATHER RIVER NEAR MERRIMAC, CALIF.

LOCATION, --Lat $39^{\circ} 42^{\prime} 30^{\prime \prime}$, long $121^{\circ} 16^{\prime} 10^{\prime \prime}$, 1n NW 1 NE $\frac{1}{4}$ sec.2, T.21 N., R.6 E., Butte County, temperature recorder at gaging station $400 \mathrm{ft}$ downstream from bridge on Milsap Bar Road, 500 ft downstream from Litt le North Fork, gaging station $400 \mathrm{ft}$ downstream from bridge on Milsap Bar Road, 500
4.5 miles southeast of Merrimac, and 20 miles northeast of Orovilie.

DRAINAGE AREA, - 1, $062 \mathrm{sq} \mathrm{m} 1$.

PERIOD OF RECORD. --Chemical analyses: July 1963 to June 1966.

Water temperatures: October 1962 to September 1969.

EX TREMES, - -1968-69:

Water temperatures: Maximum, $21.0^{\circ} \mathrm{C}$ July 23-26; minimum, 2.0 ${ }^{\circ} \mathrm{C}$ Dec. 21, 22, Jan. $29-31$.

Period of record:

Water temperatures: Maximum (1964-69), $24.0^{\circ} \mathrm{C}$ Aug. 3,$1966 ;$ min1mum $(1962-64,1965-69), 0.5^{\circ} \mathrm{C}$ Jan. 26,27, 1966 , and on several days during December 1967 to February 1968.

REMARKS. $-\rightarrow$ No record Feb. 22 to Mar. 5.

TEMPERATURE ( ${ }^{\circ} \mathrm{C}$ ) OF WATER, MATER YEAR OCTOBER 1968 TO SEPTEMBER 1969

DAY

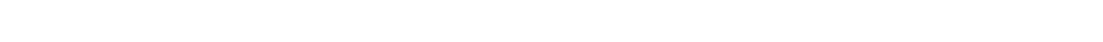

OCTORER

MAXIMUM $16 \quad 16 \quad 16 \quad 16 \quad 16 \quad 16 \quad 15 \quad 14 \quad 14 \quad 14 \quad 13 \quad 13 \quad 13 \quad 13 \quad 13 \quad 12 \quad 12 \quad 13 \quad 13 \quad 13 \quad 13 \quad 13 \quad 13 \quad 13 \quad 13 \quad 13 \quad 13 \quad 13 \quad 13 \quad 13 \quad 13 \quad 14$

MINIMUM $14 \quad 15 \quad 14 \quad 15$

$\begin{array}{rrrrrrrrrrrrrrrrrrrrrrrrrrrrrrrrrrrrrrrrrrrrr}\text { MAXIMUM } & 12 & 10 & 10 & 10 & 10 & 10 & 10 & 10 & 11 & 11 & 11 & 11 & 10 & 8 & 7 & 8 & 9 & 9 & 10 & 10 & 9 & 9 & 9 & 9 & 8 & 7 & 7 & 6 & 5 & 5 & -- & 9 \\ \text { MINIMUM } & 10 & 10 & 10 & 10 & 10 & 10 & 10 & 10 & 10 & 11 & 10 & 10 & 8 & 7 & 6 & 7 & 7 & 9 & 9 & 9 & 9 & 9 & 9 & 8 & 7 & 6 & 6 & 6 & 5 & 5 & -- & 8\end{array}$

DECEMREP

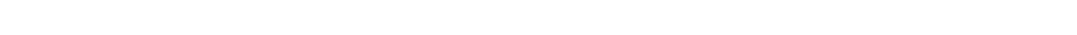

MiNIMUM

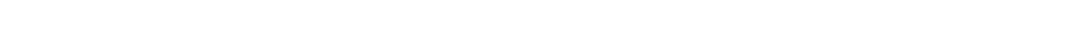

FERRUARY

MAXIMUM

MINIMUM

MANTMU

MAXIMUM

APRIL

MAXIMUN

MAY

MAXIMUM

MINIMUM JUNE

$\begin{array}{lllllllllllllllllllllllllllllllll}\text { MAXIMUM } & 12 & 12 & 13 & 13 & 13 & 13 & 13 & 13 & 12 & 12 & 12 & 13 & 15 & 15 & 14 & 14 & 14 & 14 & 15 & 15 & 15 & 16 & 16 & 16 & 16 & 15 & 14 & 14 & 15 & 15 & -- \\ \text { MINIMUM } & 11 & 11 & 12 & 13 & 12 & 13 & 13 & 12 & 12 & 12 & 12 & 12 & 13 & 14 & 14 & 14 & 14 & 14 & 14 & 15 & 15 & 15 & 16 & 15 & 15 & 14 & 13 & 13 & 13 & 14 & --\end{array}$ JULY

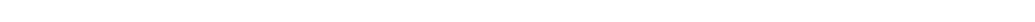

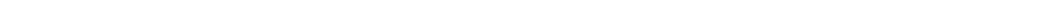
AUGUST

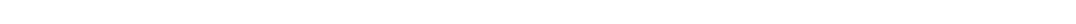

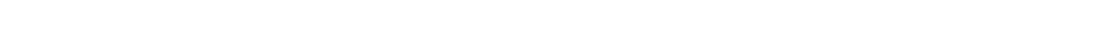

SEPTFMRFR

$\begin{array}{llllllllllllllllllllllllllllllllll}\text { MAXIMUM } & 18 & 18 & 18 & 18 & 18 & 18 & 18 & 18 & 18 & 18 & 18 & 18 & 18 & 18 & 16 & 16 & 16 & 16 & 16 & 16 & 16 & 15 & 15 & 15 & 16 & 16 & 16 & 16 & 16 & 16 & -- & 17 \\ \text { MININUM } & 16 & 17 & 17 & 16 & 17 & 16 & 17 & 17 & 17 & 17 & 17 & 17 & 17 & 16 & 16 & 15 & 15 & 15 & 15 & 15 & 14 & 14 & 14 & 14 & 14 & 14 & 15 & 15 & 15 & 15 & -- & 16\end{array}$ 
LOCATION. - Lat $40^{\circ} 00^{\prime} 50^{\prime \prime}$, long $120^{\circ} 45^{\prime} 11^{\prime \prime}$, in NE est, temperature recorder at gaging station on right bank, 2 miles south of Genesee and $2.5 \mathrm{miles}$ upstream from Indian Creek.

DRAI NAGE AREA, $--29.6 \mathrm{sq} \mathrm{mi}$.

PERIOD OF RECORD. --Water temperatures: August 1964 to September 1969.

EXTREMES, $-1968-69$ :

Water temperatures: Maximum, $17.0^{\circ} \mathrm{C}$ sometime during period June 28 to July 24 ; minimum, freezing point on several days during November and December.

Perlod of record:

Water temperatures: Maximum, $19.5^{\circ} \mathrm{C}$ Aug. $2,3,1966$; mininum, freezing point on many days during winter periods.

REMARKS,-Clock stopped Feb, 14 to May 14 , June 28 to July 24 ; ranges in temperature, $2.0^{\circ} \mathrm{C}$ to $8.0^{\circ} \mathrm{C}$, and $8.0^{\circ} \mathrm{C}$ to $17.0^{\circ} \mathrm{C}$, respectively.

TEMPERATURE ( $\left.{ }^{\circ} \mathrm{C}\right)$ OF WATER, WATER YEAR OCTOBER 1968 TO SEPTEUBER 1969

DAY

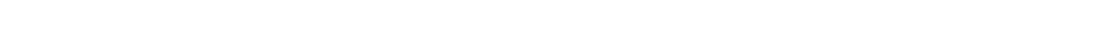

OCTOBER

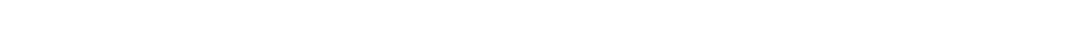

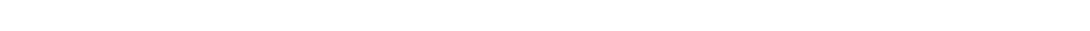

MINIMUM 45050

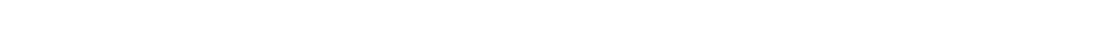

JANUARY

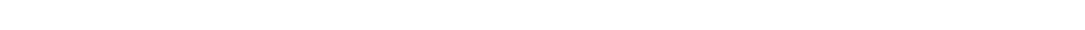

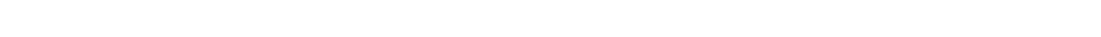

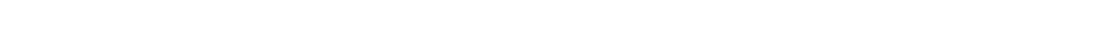

MARCH

MAXIMUM APRIL

MAXIMUM MAY

MAXIMUA

MINIMUM

UNE

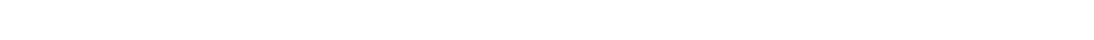

JULY

MAXIMUM

AUGUST

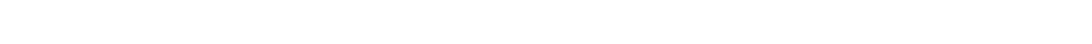

MINIMUM

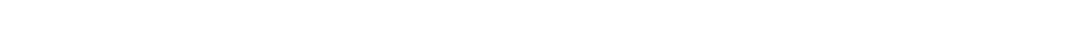

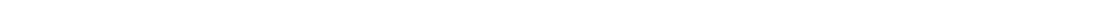


11401500 INDIAN CREEK NEAR CRESCENT MILLS, CALIF.

LOCATION. - Lat $40^{\circ} 04^{\prime} 42^{\prime \prime}$ (revised), long $120^{\circ} 55^{\prime} 36^{\prime \prime}$, in SW $f$ Sw $\frac{1}{4}$ sec.25, T. $26 \mathrm{~N}$, , R.9 E., Plumas County, temperature recorder at gaging station on left bank, $0.8 \mathrm{mlle}$ upstream from Dixie Creek and 1.5 miles south of Crescent M111s.

DRAINAGE AREA. - $739 \mathrm{sq} m 1$.

PERIOD OF RECORD. --Chemical analyses: October 1958 to September 1963.

Water temperatures: October 1962 to September 1969.

EXTREMES. $-1968-69$ :

Water temperatures: Maximum, $23.0^{\circ} \mathrm{C}$ July 21, 22, 24; minimum, freezing point on many days during December to February.

Period of record.--(1962-65, 1966-69): Water temperatures: Maximum, 28.0 $\mathrm{C}$ July 28-28, 1963; minimum (1962-64, 1966-69), freezing point on many
days during witer periods. REMARKs, - Clock stopped Feb. $3-11$, Apr. 24 to May 12, Aug. 9 to Sept, 10 ; ranges in temperature, $0.0^{\circ} \mathrm{C}$ to $4.0^{\circ} \mathrm{C}$,
$8.0^{\circ} \mathrm{C}$ to $15.0^{\circ} \mathrm{C}$, and $14.0^{\circ} \mathrm{C}$ to $20.0^{\circ} \mathrm{C}$, respectively.

TEMPERATURE ( ${ }^{\circ} \mathrm{C}$ ) OF WATER, WATER YEAR OCTOBER 1968 TO SEPTEMBER 1969

DAY

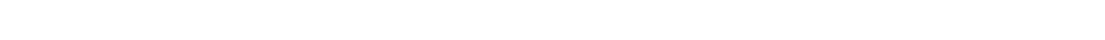

OCTOBF

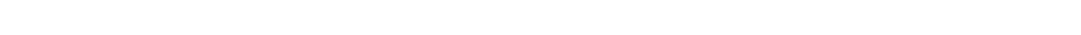

NOVEMBER

$\begin{array}{rrrrrrrrrrrrrrrrrrrrrrrrrrrrrrrrr}\text { MAXIMUM } & 9 & 10 & 9 & 10 & 11 & 9 & 10 & 10 & 13 & 11 & 10 & 9 & 7 & 6 & 7 & 8 & 9 & 9 & 10 & 9 & 9 & 9 & 9 & 9 & 8 & 7 & 7 & 7 & 7 & 6 & -2 & 9 \\ \text { MINIMUM } & 6 & 8 & 8 & 8 & 8 & 7 & 7 & 7 & 9 & 8 & 8 & 7 & 5 & 6 & 6 & 7 & 8 & 8 & 8 & 8 & 9 & 9 & 9 & 8 & 7 & 6 & 6 & 6 & 6 & 6 & -2 & 7\end{array}$

DECEMBER

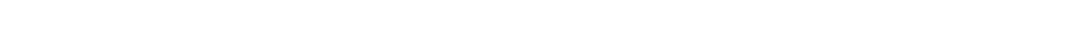

MAXIMUM

MAXIMUM

FERUARY

MAXIMUM

MINIMUM

MARCH MAXIMUM

MAXIMUM

APRIL

MAXIMUM

MINIMUM

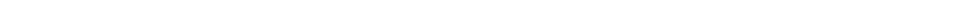

$\begin{array}{llllllllllllllllllllllllllllllllll}3 & 3 & 3 & 5 & 5 & 4 & 4 & 3 & 2 & 1 & 1 & 2 & 1 & 3 & 3 & 3 & 2 & 1 & 2 & 3 & 2 & 2 & 1 & 1 & 2 & 2 & 1 & 0 & 0 & 2 & 1 & 2 \\ 1 & 3 & 1 & 1 & 1 & 0 & 0 & 0 & 0 & 0 & 1 & 1 & 1 & 0 & 0 & 1 & 2 & 1 & 1 & 0 & 0 & 1 & 0 & 0 & 0 & 0 & 0 & 0 & & 1\end{array}$

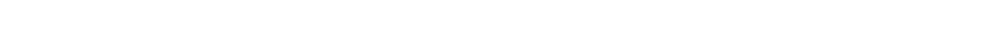

$\begin{array}{llllllllllllllllllllllllllllllllll}6 & 4 & 4 & 6 & 6 & 4 & 6 & 6 & 5 & 6 & 7 & 6 & 7 & 7 & 7 & 7 & 7 & 7 & 7 & 5 & 7 & 8 & 9 & 9 & 9 & 9 & 9 & 8 & 8 & 8 & 7 & 7 \\ 2 & 3 & 2 & 2 & 2 & 3 & 2 & 3 & 3 & 2 & 4 & 4 & 3 & 3 & 3 & 4 & 5 & 4 & 3 & 3 & 4 & 4 & 5 & 5 & 4 & 5 & 5 & 5 & 4 & 4 & 5 & 4\end{array}$

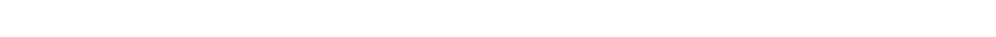

MINIMUM -

$\begin{array}{llllllllllllllllllllllllllllllllll}\text { MAXIMUM } & 16 & 17 & 17 & 17 & 17 & 17 & 17 & 17 & 15 & 16 & 17 & 18 & 18 & 18 & 18 & 18 & 18 & 18 & 19 & 19 & 19 & 20 & 19 & 20 & 19 & 19 & 18 & 19 & 20 & 20 & \ldots- & 18 \\ \text { MINIMUM } & 14 & 14 & 15 & 16 & 15 & 15 & 15 & 14 & 13 & 15 & 16 & 16 & 17 & 17 & 16 & 17 & 16 & 17 & 17 & 17 & 17 & 18 & 18 & 17 & 16 & 16 & 15 & 15 & 15 & 16 & - & 16\end{array}$

$\begin{array}{lllllllllllllllllllllllllllllllll}\text { MAXIMUM } & 20 & 20 & 20 & 20 & 21 & 21 & 21 & 21 & 21 & 21 & 20 & 20 & 21 & 20 & 20 & 21 & 22 & 22 & 22 & 22 & 23 & 23 & 22 & 23 & 22 & 22 & 20 & 21 & 20 & 20 & 20 & 21 \\ \text { MINIMUM } & 16 & 16 & 16 & 17 & 17 & 17 & 18 & 18 & 18 & 19 & 19 & 18 & 18 & 19 & 18 & 19 & 18 & 19 & 19 & 18 & 19 & 19 & 19 & 19 & 19 & 18 & 18 & 17 & 18 & 17 & 16 & 18\end{array}$ AUGUST

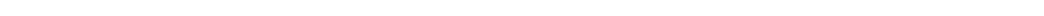

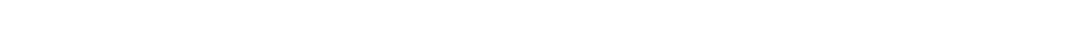

SEPTEMBEP

MAXIMUM --

MINIMUM - 
LOCATION, -Lat 39 47'39", long $121^{\circ} 27^{\prime} 03^{\prime \prime}$, in NE sec.6, T. 22 N., R.5 E., Butte County, Plumas National Forest, temperature recorder at gaging station on left bank between railroad and highway bridges, $0.5 \mathrm{mile}$ downstream $f$ rom Flea Valley Creek and Pulga and 1.5 miles downstream from Poe Dam.

DRAINAGE AREA. $--1,953$ sq $\mathrm{mit}$.

PERIOD OF RECORD.--Chemical analyses: July 1963 to June 1966.

Water temperatures: October 1962 to September 1969.

EXTREMES. - 1968-69:

Water temperatures: Maximum, $24.0^{\circ} \mathrm{C}$ July 20-24; mintmum, 3. $0^{\circ} \mathrm{C} \mathrm{Jan.} 29,30$.

Period of record: Water temperatures: Maxtmum (1963-64, 1965-66, 1967-69), 24.0 $0^{\circ} \mathrm{C}$ on several days $1 \mathrm{n} 1968$ and $1969 ; \mathrm{min} 1 \mathrm{mum}$
(1963-65, 1966-69), $1.0^{\circ} \mathrm{C}$ Jan. 12, 13, 1963.

REMARKS.- Recorder stopped Dec, 16 to Jan. 2; range in temperature, $3.0^{\circ} \mathrm{C}$ to $7.0^{\circ} \mathrm{C}$; bulb out of water Feb. $3-8$, 24,27 , Mar. 3-18, 25-27, June 5 to July 8 .

TEMPERATURE $\left({ }^{\circ} \mathrm{C}\right)$ OF WATER, WATER YEAR OCTOBER, 1968 TO SEPTEMBER 1969

DAY

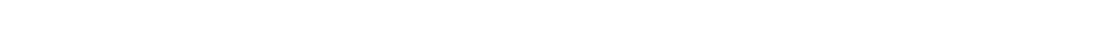

OC TOBER

MAXIMUM $17 \quad 17 \quad 18 \quad 18 \quad 18 \quad 17 \quad 16 \quad 15 \quad 15 \quad 15 \quad 15 \quad 14 \quad 14 \quad 13 \quad 13 \quad 13 \quad 14 \quad 14 \quad 14 \quad 14 \quad 14 \quad 13 \quad 13 \quad 14 \quad 14 \quad 13 \quad 14 \quad 13 \quad 13 \quad 12 \quad 12$

$\begin{array}{lllllllllllllllllllllllllllllllll}\text { MAXIMUM } & 17 & 17 & 18 & 18 & 18 & 17 & 16 & 15 & 15 & 15 & 15 & 14 & 14 & 13 & 13 & 13 & 14 & 14 & 14 & 14 & 14 & 13 & 13 & 14 & 14 & 13 & 14 & 13 & 13 & 12 & 12 \\ \text { MINIMUM } & 14 & 15 & 15 & 16 & 16 & 16 & 14 & 13 & 13 & 13 & 14 & 13 & 13 & 12 & 11 & 12 & 12 & 12 & 12 & 12 & 11 & 12 & 11 & 11 & 12 & 12 & 12 & 12 & 12 & 11 & 11\end{array}$

NOVEMBER

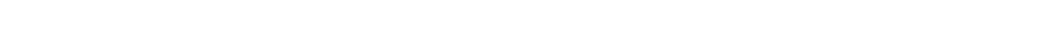

MINIMUM

MAXI MUM

MINIMUH

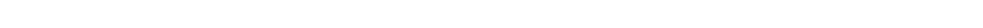

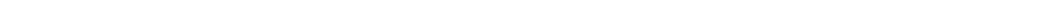

MINIMUM

MAXIMUM

MAIIMUM

MARCH

MAXIMUM

MINIMUM

MPRIL
MAXI MUM

MINIMUM

MAY

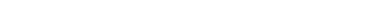

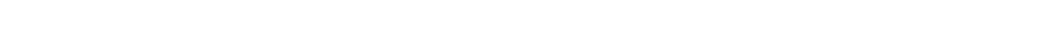
JUN

MAXIMUM 14 15 15 15 19 -

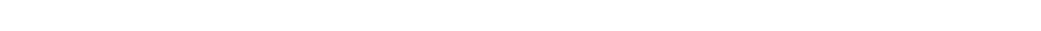<smiles>[AlH2]</smiles>

MAXIMUM -MINIMUA -- - - - - - - - - 1919191919191919191920202020212120202019191919 AUGUST

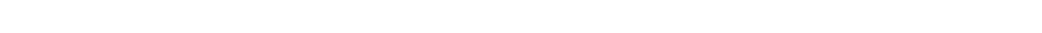

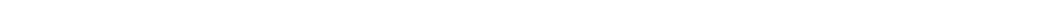
STPYEMBER

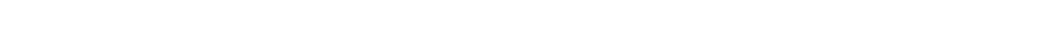

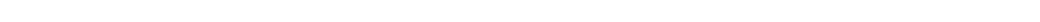


LOCATION, - Lat $39^{\circ} 47^{\prime} 12^{\prime \prime}$, long $121^{\circ} 33^{\prime} 42^{\prime \prime}$, 1n SEłSEł sec.6, T.22 N., R.4 B., Butte County, temperature recorder at gaging station on right bank (revised), 0.6 mile upstream from Griffin Gulch and 4.0 miles northeast of Paradise.

DRAINAGE AREA, - 110 sq $m 1$.

PERIOD OF RECORD.--Water temperatures: October 1962 to September 1969.

EXTREMES. $--1968-69$ :

Water temperatures: Maximum, $28.0^{\circ} \mathrm{C}$ Aug. 3 ; m1nimum, 2. $0^{\circ} \mathrm{C}$ Dec. 20-24,

Period of record:

Water temperatures: Maximum $(1962-63,1964-69), 30.5^{\circ} \mathrm{C}$ Aug. 18,1967 ; m1n1mum, $1.5^{\circ} \mathrm{C} \mathrm{Jan.} 12-14,1963$.

REMARKS, --No record July 5-30.

TEMPERATURE $\left({ }^{\circ} \mathrm{C}\right)$ OF WATER, WATER YEAR OCTOBER 1968 TO SEPTEMBER 1969

DAY

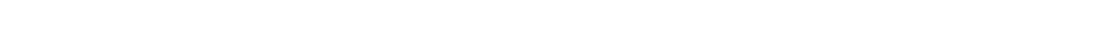

OC TOBER

MAXIMUM $19 \begin{array}{llllllllllllllllllllllllllllllllllllll} & 19 & 19 & 18 & 18 & 18 & 17 & 16 & 15 & 16 & 16 & 14 & 12 & 11 & 11 & 10 & 11 & 12 & 13 & 13 & 13 & 13 & 12 & 12 & 12 & 13 & 13 & 13 & 13 & 12 & 11 & 14\end{array}$

$\begin{array}{llllllllllllllll}10 & 11 & 11 & 12 & 11 & 12 & 11 & 12 & 12 & 12 & 12 & 12 & 12 & 11 & 10 & 13\end{array}$

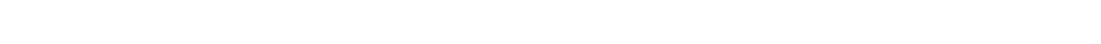

MINIMUM

MAXIMUM $6 \begin{array}{lllllllllllllllllllllllllllllllllll}6 & 6 & 4 & 4 & 4 & 4 & 5 & 6 & 7 & 7 & 6 & 5 & 4 & 4 & 6 & 6 & 5 & 4 & 4 & 4 & 2 & 2 & 2 & 4 & 5 & 5 & 5 & 5 & 4 & 4 & 4\end{array}$

$\begin{array}{lllllllllllllllllllllllllllllllll}\text { MAXIMUM } & 6 & 6 & 4 & 4 & 4 & 4 & 5 & 6 & 7 & 7 & 6 & 5 & 4 & 4 & 6 & 6 & 5 & 4 & 4 & 4 & 2 & 2 & 2 & 4 & 5 & 5 & 5 & 5 & 4 & 4 & 4 \\ \text { MINIMUM } & 6 & 4 & 4 & 4 & 4 & 4 & 4 & 5 & 6 & 6 & 5 & 4 & 4 & 4 & 4 & 5 & 4 & 4 & 4 & 2 & 2 & 2 & 2 & 2 & 4 & 5 & 5 & 4 & 4 & 4 & 4\end{array}$

JANUARY

$\begin{array}{lllllllllllllllllllllllllllllllll}\text { MAXIMIMN } & 5 & 6 & 6 & 6 & 6 & 5 & 5 & 5 & 4 & 4 & 4 & 6 & 6 & 6 & 6 & 6 & 6 & 5 & 6 & 6 & 6 & 6 & 4 & 5 & 6 & 6 & 6 & 6 & 4 & 4 & 4 \\ \text { MIVIMUM } & 4 & 5 & 6 & 6 & 5 & 5 & 5 & 4 & 4 & 3 & 3 & 4 & 6 & 6 & 6 & 6 & 5 & 5 & 5 & 5 & 5 & 4 & 4 & 4 & 5 & 5 & 5 & 4 & 4 & 4 & 3\end{array}$

MIVIMUM
FERRUARY
MAXIMUM

MAXIMUM

MAXIMUM

MINIMU

MAXIMUMM

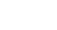

$\begin{array}{lllllllllllllllllllllllllllllllll}\text { MAXIMUM } & 8 & 7 & 7 & 8 & 8 & 7 & 7 & 8 & 8 & 8 & 9 & 9 & 8 & 8 & 8 & 8 & 9 & 9 & 8 & 9 & 9 & 9 & 8 & 6 & 7 & 8 & 9 & 9 & 9 & 9 & =-\end{array}$

MAY

MAXIMUM $9 \begin{array}{llllllllllllllllllllllllllllllllllll}9 & 9 & 9 & 9 & 9 & 9 & 10 & 10 & 10 & 10 & 9 & 9 & 9 & 9 & 10 & 10 & 10 & 10 & 9 & 10 & 10 & 11 & 11 & 11 & 11 & 11 & 10 & 11 & 12 & 12 & 12\end{array}$ UNE $\begin{array}{lllllllllllllllllllllllllllllllllllll}\text { MAXIMUM } & 12 & 13 & 13 & 13 & 13 & 13 & 13 & 12 & 11 & 11 & 11 & 12 & 13 & 14 & 14 & 14 & 14 & 15 & 14 & 15 & 15 & 16 & 17 & 16 & 15 & 15 & 15 & 16 & 16 & 17 & \cdots \\ \text { MINIMUM } & 10 & 10 & 11 & 11 & 12 & 12 & 12 & 11 & 11 & 11 & 11 & 11 & 12 & 13 & 14 & 13 & 14 & 14 & 13 & 14 & 14 & 14 & 15 & 14 & 13 & 13 & 13 & 13 & 13 & 14 & --\end{array}$ JULY

MAXIMUM 18 1818 18 18 MINIMUM 15 is is 16 AUSUST

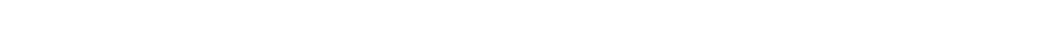
MINIMUM

$\begin{array}{llllllllllllllllllllllllllllllllllllllll}\text { MAXIMUM } & 26 & 26 & 25 & 25 & 24 & 26 & 24 & 26 & 26 & 25 & 24 & 24 & 24 & 23 & 22 & 21 & 21 & 20 & 21 & 21 & 21 & 21 & 20 & 21 & 21 & 21 & 21 & 21 & 21 & 22 & -.\end{array}$

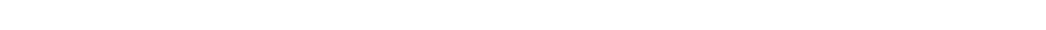


11406920 THERMALITO AFTERBAY RELEASE TO FEATHER RIVER NEAR OROVILLE, CALIF.

LOCATION. - Lat $39^{\circ} 27^{\prime} 23^{\prime \prime}$, long $121^{\circ} 38^{\prime} 10^{\prime \prime}$, in NW $\frac{1}{3 S E} \frac{1}{4}$ sec. 33 , T. 19 N., R. 3 E., But te County, temperature recorder at gaging station on left bank of outlet channel, $955 \mathrm{ft}$ downstream from centerline of Thermalito Afterbay
Dam and 5.7 miles southeast of Oroville.

PERIOD OF RECORD.--Water temperatures: May 1968 to September 1969.

EXTREMES. - $1968-69$ :

Water temperatures: Maximum, $25.0^{\circ} \mathrm{C}$ June $23 ;$ minimum, $6.0^{\circ} \mathrm{C}$ Dec. 22-25, Jan. $10-12$.

REMARKS. - Temperature is 11 sted only when water is released from Thermalito Afterbay. Due to the complete regula $t$ ion of the Feather River below Oroville Dam, the temperature of the water released from Thermalito Afterbay affects the temperature of the Feather River below the Oroville project.

TEMPERATURE ( $\left.{ }^{\circ} \mathrm{C}\right)$ OF WATER, WATER YEAR OCTOBER 1968 TO SEPTEMBER 1969

DAY

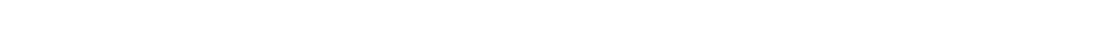

MINIMUM

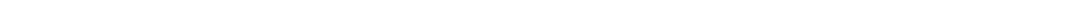
$\begin{array}{llllllllllllllllllllllllllllllll}\text { ANNINUM } & 15 & 14 & 14 & 14 & 14 & 14 & 14 & 14 & 14 & 14 & 14 & 14 & 12 & 11 & 11 & 11 & 11 & 11 & 12 & 12 & 12 & 12 & 12 & 12 & 11 & 11 & 11 & 10 & 10 & 10 & 0-\end{array}$

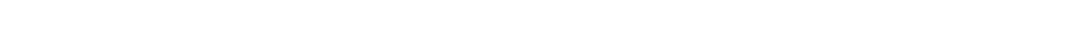

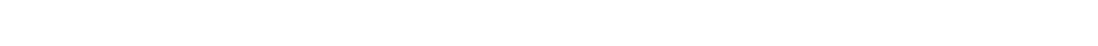

MAXIMUM $7 \begin{array}{llllllllllllllllllllllllllllllll} & 7 & 7 & 7 & 7 & 7 & 7 & 7 & 7 & 7 & 6 & 7 & 8 & 8 & 8 & 8 & 8 & 8 & 9 & 10 & 11 & 10 & 9 & 9 & 9 & 9 & 8 & 8 & 8 & 8 & 8 & 8\end{array}$

$\begin{array}{llllllllllllllllllllllllllllllllll}\text { MINIMUM } & 7 & 7 & 7 & 7 & 7 & 7 & 7 & 7 & 7 & 6 & 6 & 6 & 7 & 8 & 8 & 8 & 8 & 8 & 8 & 9 & 10 & 9 & 8 & 8 & 9 & 8 & B & 8 & 7 & 8 & 8 & 8\end{array}$

MAXIMUM

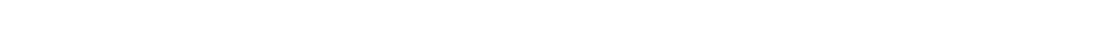

MARCH

MAXIMUM $8 \begin{array}{llllllllllllllllllllllllllllllllllllll} & 8 & 8 & 8 & 9 & 9 & 8 & 9 & 8 & 9 & 9 & 8 & 9 & 9 & 10 & 10 & 9 & 11 & 10 & 9 & 9 & 9 & 10 & 11 & 11 & 11 & 11 & 12 & 12 & 13 & 13\end{array}$

MINIMUM

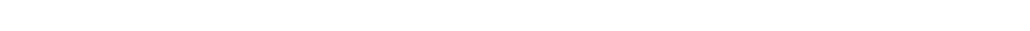

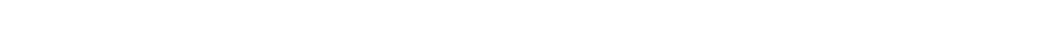
MAY

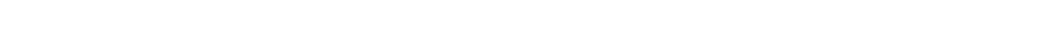

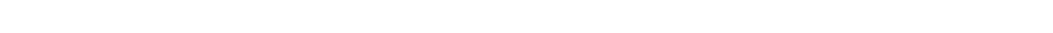
$\begin{array}{lllllllllllllllllllllllllllllllll}\text { MAXK1MUM } & 18 & 18 & 18 & 18 & 18 & 18 & 18 & 18 & 19 & 19 & 19 & 19 & 19 & 20 & 23 & 24 & 23 & 23 & 23 & 22 & 21 & 22 & 25 & 24 & 23 & 23 & 23 & 23 & 22 & 22 & -\end{array}$

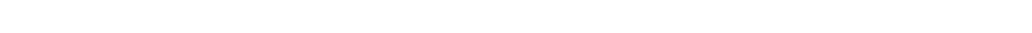

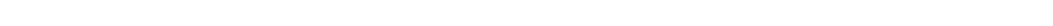

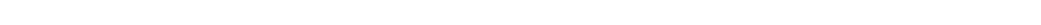
AUGUST

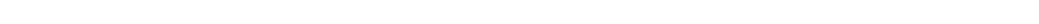

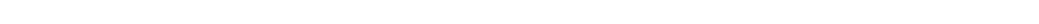
SEPTEMBER

MAXIMUM

$\begin{array}{lllllllllllllllllllllllllllllllllll}19 & 18 & 16 & 16 & 16 & 16 & 17 & 16 & 17 & 17 & 17 & 16 & 16 & 17 & 17 & 16 & 16 & 15 & 16 & 16 & 17 & 17 & 17 & 17 & 16 & 16 & 16 & 16 & 17 & 17 & \cdots\end{array}$

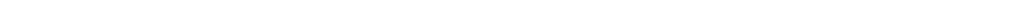


11407000 FEATHER RIVER AT OROVILLE, CALIF.

LOCATION (revised).--Lat $39^{\circ} 31^{\prime} 13^{\prime \prime}$, long $121^{\circ} 32^{\prime} 48^{\prime \prime}$, in Fernandez Land Grant, Butte County, near gaging station 300 ft upstream from fish barrier dam on Feather River and 0.6 mile northeast of Orovilie.

DRAI NAGE AREA, $--3,624$ sq mi.

PERIOD OF RECORD, --Chemical analyses: October 1953 to September 1969.

Water temperatures: October 1953 to September 1954, November 1956 to September 1969.

Sediment records: November 1956 to September 1969.

EXTREMES. - -1968-69:

Water temperatures: Maximum, $17.0^{\circ} \mathrm{C}$ on many days during July and August.

Sediment concentrations: Haximum dally, $44 \mathrm{mg} / 1 \mathrm{Jan} .21$; minimum dally, $1 \mathrm{mg} / 1$ on several days during October, November, and September.

Sediment discharge: Maximum dally, 3,750 tons Jan. 22; minimum da1ly, 1.1 tons on several days during October, November and September.

Period of record:

Water temperatures: Maximum $(1956-67,1968-69), 27.0^{\circ} \mathrm{C}$ Sept. $10,12,1959$; mintmum $(1956-67), 1.5^{\circ} \mathrm{C}$ Dec. 27, 1959, Jan. 23-25, 1962 .

Sediment concentrations: Maximum da11y, 4,100 mg/1 Feb. 1,$1963 ;$ ninimum da1ly, $1 \mathrm{mg} / 1$ on many days $1 \mathrm{n}$
1961-62, 1964, 1968-69.

Sediment discharge: Haximum da11y, 1,500,000 tons Feb. 1, 1963; minimum da11y, 1.0 ton June 9, $10,1968$.

REMARKS. - Chemical and sediment sampling point varies from 0.2 to 1.5 miles downstream from gaging station. Thermograph recorder is at fish hatchery near gaging station, and represents the water temperatures at Therma11 to diversion dam 0.5 mile upst ream from the gaging station.

CHEMICAL ANALYSES, hater YeAR OCTOBER 1968 TO SEPTEMBER 1969

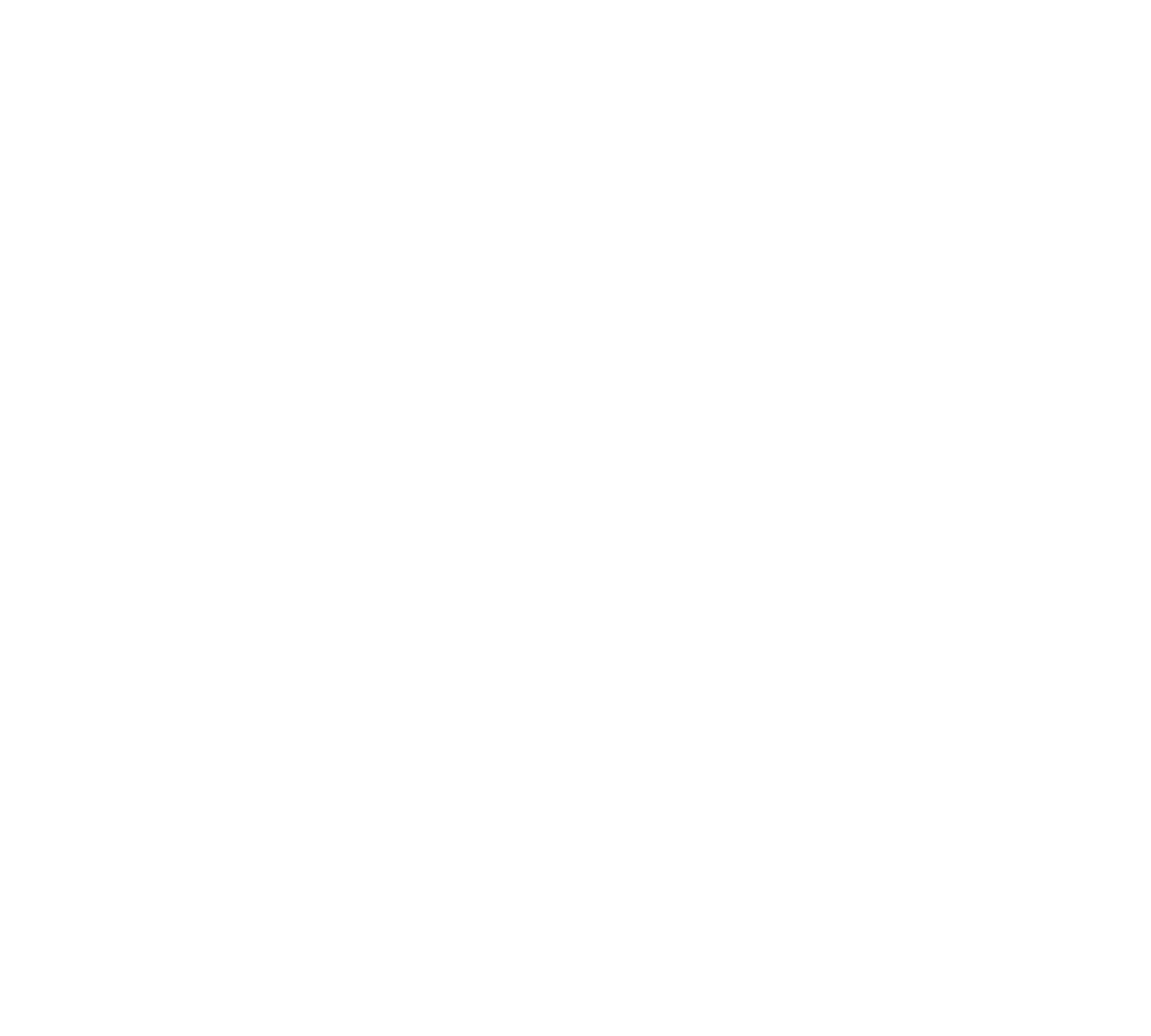


11407000 FEATHER RIVER AT OROVILLE, CALIF.--Continued CHEMICAL ANALYSES, WATER YEAR OCTOBER 1968 TO SEPTEMBER 1969

\begin{tabular}{|c|c|c|c|c|c|c|}
\hline DATE & $\begin{array}{l}\text { HARD- } \\
\text { NESS } \\
(\mathrm{CA}, M G) \\
(\mathrm{MG} / \mathrm{L})\end{array}$ & $\begin{array}{l}\text { NON- } \\
\text { CAR- } \\
\text { BDNATE } \\
\text { HAKD- } \\
\text { NESS } \\
\text { (MG/L) }\end{array}$ & $\begin{array}{l}\text { PHOS - } \\
\text { PHAIE } \\
\text { (PO4) } \\
\text { (AG/L) }\end{array}$ & $\begin{array}{l}\text { URTHO } \\
\text { PHOS- } \\
\text { PHATE } \\
\text { (POAI } \\
\text { (MG/L) }\end{array}$ & $\begin{array}{c}\text { ORGANIC } \\
\text { NIIRU- } \\
\text { GEN } \\
\text { (N) } \\
\text { (MG/L) }\end{array}$ & $\begin{array}{l}\text { AMMUN I A } \\
\text { (NH4) } \\
\text { (MG/L) }\end{array}$ \\
\hline $\begin{array}{l}\mathrm{OCT} . \\
03 \ldots .\end{array}$ & 34 & 0 & .01 & .01 & 1.9 & .00 \\
\hline Nov. & & & & & & \\
\hline $\begin{array}{c}01 \ldots \\
D E C .\end{array}$ & 37 & 0 & .03 & .08 & 2.1 & .01 \\
\hline $\begin{array}{l}03 \ldots \\
\text { JAN. }\end{array}$ & 38 & 0 & .08 & .03 & .13 & .06 \\
\hline $\begin{array}{l}\text { O3.... } \\
\text { FEe. }\end{array}$ & 36 & 0 & .04 & .03 & .10 & .06 \\
\hline $\begin{array}{l}04 \ldots . \\
\text { MAK. }\end{array}$ & 37 & 0 & .20 & .10 & .16 & .15 \\
\hline $\begin{array}{l}04 \ldots \\
29 \ldots\end{array}$ & $\begin{array}{l}31 \\
32\end{array}$ & $\begin{array}{l}0 \\
0\end{array}$ & 16 & .10 & .31 & .09 \\
\hline MAY & & & & & & \\
\hline JUNE & 32 & 0 & $\cdots$ & .06 & .46 & .12 \\
\hline $\begin{array}{l}05 \ldots . . \\
\text { JuL }\end{array}$ & 27 & 0 & .00 & .00 & .00 & .08 \\
\hline $02 \ldots$ & 26 & 0 & -- & -- & -- & -- \\
\hline SEPT. & 30 & 0 & .09 & .05 & .26 & .00 \\
\hline $\begin{array}{l}04 \ldots \\
30 \ldots\end{array}$ & $\begin{array}{l}30 \\
30\end{array}$ & $\begin{array}{l}0 \\
0\end{array}$ & $\begin{array}{l}.04 \\
.00\end{array}$ & $\begin{array}{l}.00 \\
.03\end{array}$ & $\begin{array}{l}.05 \\
.06\end{array}$ & $\begin{array}{l}.09 \\
.08\end{array}$ \\
\hline
\end{tabular}

TEMPERATURE $\left({ }^{\circ} \mathrm{C}\right)$ OF WATER, MATER YEAR OCTOBER 1968 TO SEPTEMBER 1969

DAY

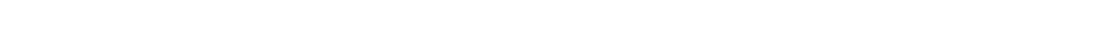

OC TOBER

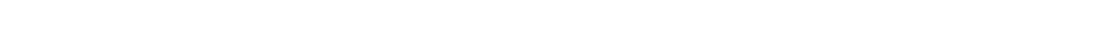
NOVEMBER

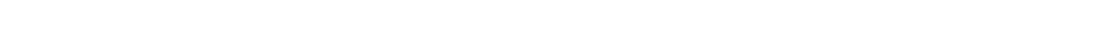

DECEMBFR

$\begin{array}{lllllllllllllllllllllllllllllllllll}\text { MAXIMUM } & 9 & 9 & 9 & 9 & 9 & 9 & 9 & 9 & 9 & 9 & 9 & 9 & 9 & 9 & 8 & 8 & 8 & 9 & 8 & 7 & 8 & 7 & 7 & 7 & 7 & 7 & 6 & 6 & 6 & 7 & 6 & 8 \\ \text { MINIMUM } & 9 & 8 & 8 & 7 & 8 & 7 & 7 & 8 & 8 & 8 & 8 & 8 & 7 & 8 & 7 & 6 & 6 & 7 & 6 & 4 & 4 & 6 & 6 & 6 & 6 & 5 & 6 & 6 & 5 & 4 & 4 & 6\end{array}$

MINIMUM

MAXIMUM --

MINIMUM

RRUARY

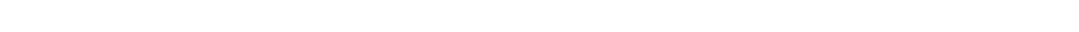

MARCH

MAXIMUM

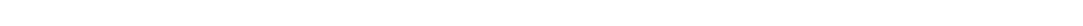

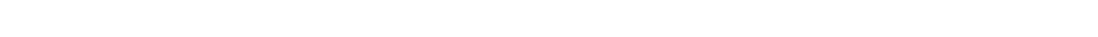

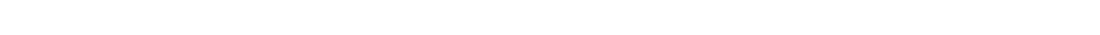

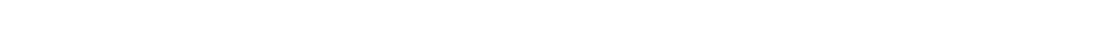

JUNE

$\begin{array}{lllllllllllllllllllllllllllllllllllll}\text { MAXIMUM } & 13 & 13 & 13 & 13 & 13 & 13 & 13 & 13 & 13 & 13 & 13 & 13 & 13 & 13 & 14 & 14 & 14 & 14 & 15 & 15 & 15 & 15 & 16 & 16 & 16 & 16 & 16 & 16 & 15 & 15 & -- & 14 \\ \text { MINIMUM } & 12 & 12 & 12 & 12 & 13 & 13 & 13 & 13 & 13 & 13 & 13 & 13 & 13 & 13 & 13 & 13 & 13 & 13 & 13 & 14 & 14 & 14 & 14 & 14 & 15 & 15 & 14 & 14 & 14 & 14 & -- & 13\end{array}$

JULY

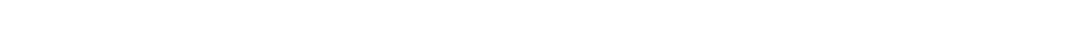

$\begin{array}{llllllllllllllllllllllll}16 & 16 & 16 & 16 & 16 & 16 & 16 & 16 & 15 & 16 & 16 & 16 & 15 & 16 & 15 & 14 & 14 & 15 & 14 & 14 & 14 & 15 & 16 & 15\end{array}$

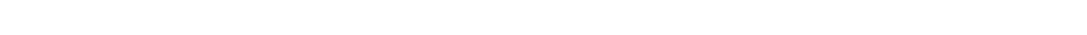

SEPTEMBER

$\begin{array}{lllllllllllllllllllllllllllllllllllllll}\text { MAXIMUM } & 12 & 13 & 12 & 12 & 12 & 12 & 12 & 13 & 13 & 13 & 13 & 13 & 12 & 13 & 13 & 13 & 13 & 13 & 13 & 13 & 12 & 12 & 12 & 12 & 12 & 13 & 13 & 13 & 13 & 12 & \ldots- & 13 \\ \text { MINIMUM } & 12 & 12 & 12 & 12 & 12 & 12 & 12 & 12 & 12 & 13 & 13 & 12 & 12 & 12 & 12 & 12 & 12 & 13 & 13 & 12 & 12 & 11 & 11 & 12 & 12 & 12 & 12 & 13 & 12 & 11 & \ldots & 12\end{array}$

PARTICLE-SIZE DISTRIBUTION OF SUSPENDED SEDIMENT, WATER YEAR OCTOBER 1968 TO SEPTEMBER 1969
(METHODS OF ANALYSIS: B. BOTTOM WITHORAWAL TUBE: C. CHEMICALLY DISPERSED; N, IN NATIVE WATER; P, PIPET; S, SIEVE: V, VISUAL ACCUMULATION TUBE: W, IN DISTILLED WATER)
, WITH

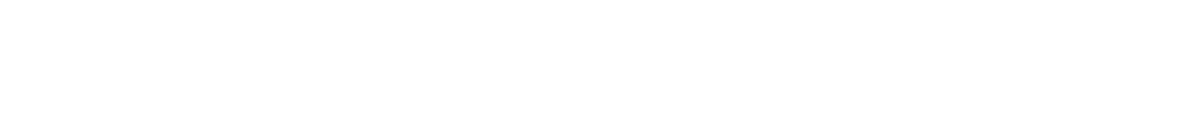


11407000 FEATHER RIVER AT OROVILLE, CALIF,_- Continued

SUSPENDED-SEDIMENT DISCHARGE, WATER YEAR OCTOBER 1968 TO SEPTEMBER 1969

\begin{tabular}{|c|c|c|c|c|c|c|c|c|c|}
\hline & & OCTUBER & & & NOVEMBER & & & DECEMBER & \\
\hline DAY & $\begin{array}{l}\text { MEAN } \\
\text { OISCHARGE } \\
\text { (CFS) }\end{array}$ & $\begin{array}{l}\text { MEAN } \\
\text { CUNCEN- } \\
\text { TRAIION } \\
\text { (MGIL) }\end{array}$ & $\begin{array}{l}\text { SEDI MENT } \\
\text { DISCHARGE } \\
\text { (TONS/DAY) }\end{array}$ & $\begin{array}{l}\text { MEAN } \\
\text { OISCHARGE } \\
\text { (CFS) }\end{array}$ & $\begin{array}{l}\text { MEAN } \\
\text { CONCEN- } \\
\text { TRATIION } \\
\text { (MG/L) }\end{array}$ & $\begin{array}{l}\text { SEDI MENT } \\
\text { DI SCHARGE } \\
\text { (TONS/DAY) }\end{array}$ & $\begin{array}{l}\text { MEAN } \\
\text { OISCHAKGE } \\
\text { (CFS) }\end{array}$ & $\begin{array}{l}\text { MEAN } \\
\text { CONCEN- } \\
\text { IRATION } \\
\text { (MG/L) }\end{array}$ & $\begin{array}{l}\text { SEDIMENT } \\
\text { DI SCHARGE } \\
\text { (TONS/DAY) }\end{array}$ \\
\hline $\begin{array}{l}1 \\
2 \\
3 \\
4 \\
5\end{array}$ & $\begin{array}{l}402 \\
402 \\
393 \\
402 \\
412\end{array}$ & $\begin{array}{l}2 \\
2 \\
2 \\
2 \\
2\end{array}$ & $\begin{array}{l}2.2 \\
2.2 \\
2.1 \\
2.2 \\
2.2\end{array}$ & $\begin{array}{l}393 \\
412 \\
412 \\
422 \\
402\end{array}$ & $\begin{array}{l}1 \\
4 \\
3 \\
3 \\
3\end{array}$ & $\begin{array}{l}1.1 \\
4.4 \\
3.3 \\
3.4 \\
1.3\end{array}$ & $\begin{array}{l}402 \\
402 \\
402 \\
402 \\
412\end{array}$ & $\begin{array}{l}4 \\
6 \\
3 \\
5 \\
9\end{array}$ & $\begin{array}{c}4.3 \\
6.5 \\
3.3 \\
5.4 \\
10\end{array}$ \\
\hline $\begin{array}{r}6 \\
7 \\
8 \\
9 \\
10\end{array}$ & $\begin{array}{l}402 \\
402 \\
393 \\
393 \\
393\end{array}$ & $\begin{array}{l}2 \\
2 \\
1 \\
1 \\
1\end{array}$ & $\begin{array}{l}2.2 \\
2.2 \\
1.1 \\
1.1 \\
1.1\end{array}$ & $\begin{array}{l}402 \\
412 \\
422 \\
422 \\
422\end{array}$ & $\begin{array}{l}4 \\
3 \\
2 \\
2 \\
2\end{array}$ & $\begin{array}{l}4.3 \\
3.3 \\
2.3 \\
2.3 \\
2.3\end{array}$ & $\begin{array}{l}402 \\
384 \\
402 \\
402 \\
402\end{array}$ & $\begin{array}{l}3 \\
5 \\
6 \\
6 \\
7\end{array}$ & $\begin{array}{l}3.3 \\
5.2 \\
6.5 \\
6.5 \\
7.6\end{array}$ \\
\hline $\begin{array}{l}11 \\
12 \\
13 \\
14 \\
15\end{array}$ & $\begin{array}{l}402 \\
412 \\
412 \\
412 \\
412\end{array}$ & $\begin{array}{l}2 \\
2 \\
3 \\
3 \\
3\end{array}$ & $\begin{array}{l}2.2 \\
2.2 \\
3.3 \\
3.3 \\
3.3\end{array}$ & $\begin{array}{l}412 \\
402 \\
402 \\
412 \\
412\end{array}$ & $\begin{array}{l}3 \\
4 \\
3 \\
3 \\
4\end{array}$ & $\begin{array}{l}3.3 \\
4.3 \\
3.3 \\
3.3 \\
4.4\end{array}$ & $\begin{array}{l}393 \\
399 \\
411 \\
411 \\
392\end{array}$ & $\begin{array}{r}6 \\
6 \\
4 \\
10 \\
11\end{array}$ & $\begin{array}{l}6.4 \\
6.5 \\
4.4 \\
11 \\
12\end{array}$ \\
\hline $\begin{array}{l}16 \\
17 \\
18 \\
19 \\
20\end{array}$ & $\begin{array}{l}412 \\
412 \\
412 \\
412 \\
402\end{array}$ & $\begin{array}{l}3 \\
4 \\
4 \\
4 \\
4\end{array}$ & $\begin{array}{l}3.3 \\
4.4 \\
4.4 \\
4.4 \\
4.3\end{array}$ & $\begin{array}{l}412 \\
422 \\
422 \\
422 \\
422\end{array}$ & $\begin{array}{l}5 \\
4 \\
3 \\
3 \\
3\end{array}$ & $\begin{array}{l}5.6 \\
4.6 \\
3.4 \\
3.4 \\
3.4\end{array}$ & $\begin{array}{l}411 \\
402 \\
392 \\
382 \\
402\end{array}$ & $\begin{array}{r}11 \\
8 \\
9 \\
7 \\
5\end{array}$ & $\begin{array}{l}12 \\
8.7 \\
9.5 \\
7.2 \\
5.4\end{array}$ \\
\hline $\begin{array}{ll}21 & 1 \\
2 & 2 \\
2 & 3 \\
2 & 4 \\
2 & 5\end{array}$ & $\begin{array}{l}393 \\
384 \\
374 \\
374 \\
384\end{array}$ & $\begin{array}{l}4 \\
4 \\
4 \\
4 \\
4\end{array}$ & $\begin{array}{l}4.2 \\
4.1 \\
4.0 \\
4.0 \\
4.1\end{array}$ & $\begin{array}{l}412 \\
412 \\
402 \\
412 \\
412\end{array}$ & $\begin{array}{l}3 \\
3 \\
3 \\
3 \\
2\end{array}$ & $\begin{array}{l}3.3 \\
3.3 \\
3.3 \\
3.3 \\
2.2\end{array}$ & $\begin{array}{l}402 \\
411 \\
420 \\
420 \\
420\end{array}$ & $\begin{array}{l}4 \\
4 \\
4 \\
4 \\
4\end{array}$ & $\begin{array}{l}4.3 \\
4.4 \\
4.5 \\
4.5 \\
4.5\end{array}$ \\
\hline $\begin{array}{l}26 \\
27 \\
28 \\
29 \\
30 \\
31\end{array}$ & $\begin{array}{l}393 \\
393 \\
393 \\
393 \\
393 \\
393\end{array}$ & $\begin{array}{l}4 \\
4 \\
4 \\
6 \\
4 \\
3\end{array}$ & $\begin{array}{l}4.2 \\
4.2 \\
4.2 \\
0.4 \\
4.2 \\
3.2\end{array}$ & $\begin{array}{l}422 \\
412 \\
422 \\
422 \\
402 \\
-+\end{array}$ & $\begin{array}{r}2 \\
3 \\
5 \\
5 \\
5 \\
-\end{array}$ & $\begin{array}{l}2.3 \\
3.3 \\
5.7 \\
5.7 \\
5.4 \\
.-\end{array}$ & $\begin{array}{l}411 \\
411 \\
420 \\
411 \\
411 \\
411\end{array}$ & $\begin{array}{l}3 \\
3 \\
3 \\
3 \\
4 \\
4\end{array}$ & $\begin{array}{l}3.3 \\
3.3 \\
3.4 \\
3.3 \\
4.4 \\
4.4\end{array}$ \\
\hline IOIAL & 12361 & - & 100.5 & 12391 & - & 106.8 & 12555 & -- & 186.0 \\
\hline OAY & $\begin{array}{l}\text { MEAN } \\
\text { OISCHARGE } \\
\text { (CF S) }\end{array}$ & $\begin{array}{l}\text { JANUARY } \\
\text { MEAN } \\
\text { CUNCEN- } \\
\text { IRAT ION } \\
\text { (MG/L) }\end{array}$ & $\begin{array}{c}\text { SED IMENT } \\
\text { DI SCHARGE } \\
\text { (TONS/DAY) }\end{array}$ & $\begin{array}{l}\text { MEAN } \\
\text { OISCHARGE } \\
\text { (CFS) }\end{array}$ & $\begin{array}{l}\text { FEBRUARY } \\
\text { MEAN } \\
\text { CONCEN- } \\
\text { IRATION } \\
\text { (MG/L) }\end{array}$ & $\begin{array}{l}\text { SEDIMENT } \\
\text { DISCHARGE } \\
\text { (TONS / DAY) }\end{array}$ & $\begin{array}{l}\text { MEAN } \\
\text { OISCHARGE } \\
\text { (CFS) }\end{array}$ & $\begin{array}{l}\text { MARCH } \\
\text { MEAN } \\
\text { CONCEN- } \\
\text { TRATION } \\
(M G / L)\end{array}$ & $\begin{array}{l}\text { SEDIMENT } \\
\text { DISCHARGE } \\
\text { (TONS/DAY) }\end{array}$ \\
\hline $\begin{array}{l}1 \\
5 \\
3 \\
4 \\
5\end{array}$ & $\begin{array}{l}411 \\
411 \\
420 \\
411 \\
411\end{array}$ & $\begin{array}{l}3 \\
3 \\
4 \\
2 \\
2\end{array}$ & $\begin{array}{l}3.3 \\
3.3 \\
4.3 \\
2.2 \\
2.2\end{array}$ & $\begin{array}{r}2030 \\
411 \\
392 \\
402 \\
402\end{array}$ & $\begin{array}{l}13 \\
14 \\
13 \\
15 \\
14\end{array}$ & $\begin{array}{l}72 \\
16 \\
14 \\
16 \\
15\end{array}$ & $\begin{array}{l}2920 \\
2880 \\
2920 \\
1750 \\
1020\end{array}$ & $\begin{array}{l}11 \\
12 \\
21 \\
12 \\
13\end{array}$ & $\begin{array}{r}87 \\
93 \\
166 \\
57 \\
36\end{array}$ \\
\hline $\begin{array}{r}6 \\
7 \\
8 \\
9 \\
10\end{array}$ & $\begin{array}{l}402 \\
402 \\
392 \\
392 \\
392\end{array}$ & $\begin{array}{l}2 \\
2 \\
2 \\
2 \\
2\end{array}$ & $\begin{array}{l}2.2 \\
2.2 \\
2.1 \\
2.1 \\
2.1\end{array}$ & $\begin{array}{r}411 \\
402 \\
402 \\
411 \\
1820\end{array}$ & $\begin{array}{r}13 \\
10 \\
8 \\
8 \\
10\end{array}$ & $\begin{array}{c}14 \\
11 \\
8.7 \\
8.9 \\
49\end{array}$ & $\begin{array}{l}997 \\
616 \\
382 \\
402 \\
411\end{array}$ & $\begin{array}{r}9 \\
8 \\
11 \\
12 \\
13\end{array}$ & $\begin{array}{l}24 \\
13 \\
11 \\
13 \\
14\end{array}$ \\
\hline $\begin{array}{l}11 \\
12 \\
13 \\
14 \\
15\end{array}$ & $\begin{array}{l}402 \\
430 \\
472 \\
402 \\
392\end{array}$ & $\begin{array}{l}9 \\
10 \\
11 \\
10 \\
9\end{array}$ & $\begin{array}{l}9.8 \\
12 \\
14 \\
11 \\
9.5\end{array}$ & $\begin{array}{r}5650 \\
8570 \\
6270 \\
534 \\
805\end{array}$ & $\begin{array}{r}32 \\
15 \\
7 \\
9 \\
11\end{array}$ & $\begin{array}{r}488 \\
347 \\
119 \\
13 \\
24\end{array}$ & $\begin{array}{l}420 \\
411 \\
392 \\
382 \\
392\end{array}$ & $\begin{array}{l}17 \\
14 \\
12 \\
11 \\
10\end{array}$ & $\begin{array}{l}19 \\
16 \\
13 \\
11 \\
11\end{array}$ \\
\hline $\begin{array}{l}16 \\
17 \\
18 \\
19 \\
20\end{array}$ & $\begin{array}{l}392 \\
382 \\
402 \\
420 \\
411\end{array}$ & $\begin{array}{l}21 \\
21 \\
15 \\
14 \\
15\end{array}$ & $\begin{array}{l}22 \\
22 \\
16 \\
16 \\
17\end{array}$ & $\begin{array}{l}1840 \\
2480 \\
9680 \\
8920 \\
6140\end{array}$ & $\begin{array}{r}13 \\
7 \\
7 \\
8 \\
8\end{array}$ & $\begin{array}{r}65 \\
47 \\
183 \\
193 \\
133\end{array}$ & $\begin{array}{l}411 \\
430 \\
430 \\
392 \\
382\end{array}$ & $\begin{array}{l}9 \\
8 \\
8 \\
7 \\
7\end{array}$ & $\begin{array}{l}10 \\
9.3 \\
9.3 \\
7.4 \\
7.2\end{array}$ \\
\hline $\begin{array}{l}21 \\
22 \\
23 \\
24 \\
25\end{array}$ & $\begin{array}{r}13000 \\
37400 \\
24800 \\
18200 \\
5020\end{array}$ & $\begin{array}{r}44 \\
33 \\
10 \\
8 \\
6\end{array}$ & $\begin{array}{r}3230 \\
3750 \\
670 \\
393 \\
81\end{array}$ & $\begin{array}{r}3310 \\
808 \\
844 \\
2510 \\
4100\end{array}$ & $\begin{array}{r}7 \\
9 \\
14 \\
14 \\
15\end{array}$ & $\begin{array}{r}63 \\
20 \\
32 \\
95 \\
166\end{array}$ & $\begin{array}{l}402 \\
440 \\
430 \\
420 \\
382\end{array}$ & $\begin{array}{l}7 \\
7 \\
7 \\
6 \\
6\end{array}$ & $\begin{array}{l}7.6 \\
8.3 \\
8.1 \\
6.8 \\
6.2\end{array}$ \\
\hline $\begin{array}{l}26 \\
27 \\
28 \\
29 \\
30 \\
31\end{array}$ & $\begin{array}{l}17200 \\
22400 \\
24800 \\
24400 \\
24000 \\
16200\end{array}$ & $\begin{array}{l}11 \\
22 \\
19 \\
16 \\
16 \\
12\end{array}$ & $\begin{array}{r}511 \\
1330 \\
1270 \\
1050 \\
1040 \\
525\end{array}$ & $\begin{array}{r}4430 \\
5830 \\
4620 \\
=- \\
=-\end{array}$ & $\begin{array}{l}14 \\
13 \\
11 \\
=- \\
=\end{array}$ & $\begin{array}{l}107 \\
205 \\
137 \\
=- \\
--\end{array}$ & $\begin{array}{l}392 \\
392 \\
402 \\
420 \\
411 \\
420\end{array}$ & $\begin{array}{l}6 \\
6 \\
6 \\
5 \\
5 \\
5\end{array}$ & $\begin{array}{l}0.4 \\
6.4 \\
6.5 \\
5.7 \\
5.5 \\
5.7\end{array}$ \\
\hline TOIAL. & 235569 & -- & 14025.5 & 84424 & -- & 2720.6 & 22851 & - & 700.4 \\
\hline
\end{tabular}


11407000 FEATHER RIVER AT OROVILLE, CALIF.--Continued

SUSPENDED-SEDIMENT DISCHARGE, WATER YEAR OCTOBER 1968 TO SEPTEMBER 1969

\begin{tabular}{|c|c|c|c|c|c|c|c|c|c|}
\hline DAY & $\begin{array}{l}\text { MEAN } \\
\text { OISCHARGE } \\
\text { (CFS) }\end{array}$ & $\begin{array}{l}\text { APRIL } \\
\text { MEAN } \\
\text { CUNCEN- } \\
\text { TRATION } \\
\text { (MG/L) }\end{array}$ & $\begin{array}{l}\text { SEDIMENT } \\
\text { DISCHARGE } \\
\text { (TONS/DAY) }\end{array}$ & $\begin{array}{l}\text { MEAN } \\
\text { DISCHARGE } \\
\text { ICFSI }\end{array}$ & $\begin{array}{l}\text { MAY } \\
\text { MEAN } \\
\text { CONCEN- } \\
\text { TRAT ION } \\
\text { (MG/L) }\end{array}$ & $\begin{array}{l}\text { SEDIMENT } \\
\text { DI SCHARGE } \\
\text { (TONS/DAY) }\end{array}$ & $\begin{array}{l}\text { MEAN } \\
\text { O(SCHARGE } \\
\text { (CFS) }\end{array}$ & $\begin{array}{l}\text { JUNE } \\
\text { MEAN } \\
\text { CONCEN- } \\
\text { TRATION } \\
\text { (MG/L) }\end{array}$ & $\begin{array}{l}\text { SEDIMENT } \\
\text { DISCHARGE } \\
\text { (TONS/DAY) }\end{array}$ \\
\hline $\begin{array}{l}1 \\
2 \\
3 \\
4 \\
5\end{array}$ & $\begin{array}{r}430 \\
440 \\
430 \\
2490 \\
2390\end{array}$ & $\begin{array}{l}7 \\
6 \\
7 \\
9 \\
9\end{array}$ & $\begin{array}{l}8.1 \\
7.1 \\
8.1 \\
61 \\
58\end{array}$ & $\begin{array}{l}440 \\
420 \\
440 \\
364 \\
373\end{array}$ & $\begin{array}{l}6 \\
4 \\
3 \\
3 \\
3\end{array}$ & $\begin{array}{l}7.1 \\
4.5 \\
3.6 \\
2.9 \\
3.0\end{array}$ & $\begin{array}{l}400 \\
410 \\
400 \\
391 \\
391\end{array}$ & $\begin{array}{l}4 \\
4 \\
3 \\
3 \\
4\end{array}$ & $\begin{array}{l}4.3 \\
4.4 \\
3.2 \\
3.2 \\
4.2\end{array}$ \\
\hline $\begin{array}{r}6 \\
7 \\
8 \\
9 \\
10\end{array}$ & $\begin{array}{l}2390 \\
2300 \\
2390 \\
2340 \\
2300\end{array}$ & $\begin{array}{l}9 \\
7 \\
7 \\
5 \\
4\end{array}$ & $\begin{array}{l}58 \\
43 \\
45 \\
32 \\
25\end{array}$ & $\begin{array}{l}402 \\
411 \\
420 \\
411 \\
373\end{array}$ & $\begin{array}{l}7 \\
5 \\
4 \\
6 \\
5\end{array}$ & $\begin{array}{l}7.6 \\
5.5 \\
4.5 \\
6.7 \\
5.0\end{array}$ & $\begin{array}{l}400 \\
400 \\
400 \\
400 \\
410\end{array}$ & $\begin{array}{l}7 \\
6 \\
5 \\
4 \\
4\end{array}$ & $\begin{array}{l}7.6 \\
6.5 \\
5.4 \\
4.3 \\
4.4\end{array}$ \\
\hline $\begin{array}{l}11 \\
12 \\
13 \\
14 \\
15\end{array}$ & $\begin{array}{l}2340 \\
2390 \\
2430 \\
2340 \\
2430\end{array}$ & $\begin{array}{l}5 \\
7 \\
6 \\
8 \\
9\end{array}$ & $\begin{array}{l}32 \\
45 \\
39 \\
52 \\
59\end{array}$ & $\begin{array}{l}373 \\
382 \\
392 \\
402 \\
382\end{array}$ & $\begin{array}{r}6 \\
4 \\
12 \\
7 \\
9\end{array}$ & $\begin{array}{c}6.0 \\
4.1 \\
13 \\
7.6 \\
9.3\end{array}$ & $\begin{array}{l}431 \\
431 \\
410 \\
391 \\
391\end{array}$ & $\begin{array}{l}3 \\
3 \\
2 \\
2 \\
3\end{array}$ & $\begin{array}{l}3.5 \\
3.5 \\
2.2 \\
2.1 \\
3.2\end{array}$ \\
\hline $\begin{array}{l}16 \\
17 \\
18 \\
19 \\
20\end{array}$ & $\begin{array}{l}2390 \\
2410 \\
1490 \\
1510 \\
1430\end{array}$ & $\begin{array}{r}10 \\
7 \\
8 \\
7 \\
7\end{array}$ & $\begin{array}{l}65 \\
46 \\
32 \\
29 \\
27\end{array}$ & $\begin{array}{l}382 \\
373 \\
373 \\
373 \\
364\end{array}$ & $\begin{array}{l}8 \\
8 \\
5 \\
5 \\
2\end{array}$ & $\begin{array}{l}8.3 \\
8.1 \\
5.0 \\
5.0 \\
2.0\end{array}$ & $\begin{array}{l}391 \\
410 \\
410 \\
400 \\
410\end{array}$ & $\begin{array}{l}3 \\
4 \\
4 \\
3 \\
3\end{array}$ & $\begin{array}{l}3.2 \\
4.4 \\
4.4 \\
3.2 \\
3.3\end{array}$ \\
\hline $\begin{array}{l}21 \\
22 \\
23 \\
24 \\
25\end{array}$ & $\begin{array}{r}1150 \\
420 \\
430 \\
420 \\
420\end{array}$ & $\begin{array}{l}6 \\
4 \\
6 \\
8 \\
7\end{array}$ & $\begin{array}{r}19 \\
4.5 \\
7.0 \\
9.1 \\
7.9\end{array}$ & $\begin{array}{l}364 \\
364 \\
369 \\
391 \\
382\end{array}$ & $\begin{array}{l}7 \\
3 \\
3 \\
5 \\
5\end{array}$ & $\begin{array}{l}6.9 \\
2.9 \\
3.0 \\
5.3 \\
5.2\end{array}$ & $\begin{array}{l}420 \\
410 \\
410 \\
410 \\
420\end{array}$ & $\begin{array}{l}2 \\
3 \\
4 \\
6 \\
4\end{array}$ & $\begin{array}{l}2.3 \\
3.3 \\
4.4 \\
6.6 \\
4.5\end{array}$ \\
\hline $\begin{array}{l}26 \\
27 \\
28 \\
29 \\
30 \\
31\end{array}$ & $\begin{array}{l}420 \\
402 \\
420 \\
420 \\
430 \\
--\end{array}$ & $\begin{array}{r}6 \\
9 \\
10 \\
8 \\
7 \\
--\end{array}$ & $\begin{array}{r}6.8 \\
9.8 \\
11 \\
9.1 \\
8.1 \\
-1\end{array}$ & $\begin{array}{l}382 \\
362 \\
353 \\
391 \\
400 \\
400\end{array}$ & $\begin{array}{l}6 \\
4 \\
4 \\
4 \\
6 \\
4\end{array}$ & $\begin{array}{l}6.2 \\
3.9 \\
3.8 \\
4.2 \\
6.5 \\
4.3\end{array}$ & $\begin{array}{l}420 \\
420 \\
420 \\
410 \\
420 \\
--\end{array}$ & $\begin{array}{r}3 \\
3 \\
3 \\
3 \\
2 \\
--\end{array}$ & $\begin{array}{l}3.4 \\
3.4 \\
3.4 \\
3.3 \\
2.3 \\
--\end{array}$ \\
\hline TOT AL & 43992 & -- & 862.6 & 12008 & -- & 171.0 & 12237 & - & 117.4 \\
\hline
\end{tabular}
$\begin{array}{clcc}\text { MEAN } & \text { MEAN } & & \\ \text { CONCEN- } & \text { SEDIMENT } & \text { MEAN } \\ \text { DISCHARGE } & \text { TRATION } & \text { DISCHARGE } & \text { OISCHARGE } \\ \text { ICFSI } & \text { IMG/L) } & \text { (TONS/DAY) } & \text { (CFS) }\end{array}$

AUGUST

MEAN

SEDIMENT MEAN CONCEN- SEDIMENT ICFSI
IMG/L) (TONS/DAY)

$\begin{array}{rl}1 & 420 \\ 2 & 420 \\ 3 & 431 \\ 4 & 431 \\ 5 & 431 \\ 6 & 431 \\ 7 & 431 \\ 8 & 420 \\ 9 & 431 \\ 10 & 431\end{array}$

2
3
4
3
3
3
2
2
2
2
2
2
2
3
3

$\begin{array}{ll}2.3 & 400 \\ 3.4 & 400 \\ 4.7 & 410 \\ 3.5 & 410 \\ 3.5 & 391 \\ 3.5 & 382 \\ 2.3 & 410 \\ 2.3 & 410 \\ 2.3 & 400 \\ 2.3 & 400\end{array}$

400
400
410
410
391
382
410
410
400
400

2

$\begin{array}{r}2 \\ 3 \\ 4 \\ 4 \\ 3 \\ 5 \\ 4 \\ 4 \\ 4 \\ 3 \\ 3 \\ 3 \\ 3 \\ 3 \\ 4 \\ 3 \\ 4 \\ 4 \\ 4 \\ 4 \\ 5 \\ 10 \\ 8 \\ 7 \\ 6 \\ 4 \\ 2 \\ 2 \\ 2 \\ 2 \\ 4 \\ \hline\end{array}$

$\begin{array}{ll}2.2 & 392 \\ 3.2 & 392 \\ 4.4 & 392 \\ 4.4 & 382 \\ 3.2 & 392 \\ 5.2 & 392 \\ 4.4 & 392 \\ 4.4 & 392 \\ 4.3 & 392 \\ 3.2 & 392\end{array}$

$\begin{array}{ll}8 & 8.5 \\ 4 & 4.2 \\ 3 & 3.2 \\ 2 & 2.1 \\ 2 & 2.1 \\ 2 & 2.1 \\ 2 & 2.1 \\ 1 & 1.1 \\ 1 & 1.1 \\ 3 & 3.2\end{array}$

$\begin{array}{ll}2.3 & 410 \\ 2.3 & 410 \\ 2.3 & 400 \\ 3.6 & 400\end{array}$

$\begin{array}{ll}3.3 & 392 \\ 3.3 & 392 \\ 3.2 & 392 \\ 3.2 & 382\end{array}$

2
2
2
3

$\begin{array}{ll}3.2 & 411 \\ 4.3 & 411 \\ 4.4 & 411 \\ 4.4 & 402\end{array}$

3.3400

$\begin{array}{ll}3.1 & 400 \\ 2.2 & 410 \\ 5.4 & 410 \\ 2.2 & 400\end{array}$

400

$\begin{array}{ll}5.4 & 400 \\ 4.3 & 400 \\ 3.2 & 400 \\ 2.2 & 400\end{array}$

400
400

400
410

395

$\begin{array}{ll}26 & 400 \\ 27 & 400 \\ 28 & 410 \\ 29 & 400 \\ 30 & 410 \\ 31 & 410\end{array}$

$\begin{array}{ll}2.2 & 382 \\ 2.2 & 382 \\ 2.2 & 382 \\ 2.2 & 382 \\ 3.3 & 382 \\ 2.2 & 392\end{array}$

IOTAL 12877

91.9

12350

TOTAL UISCHARGE FOR YEAR (CFS-DAYS)

TOTAL SUSPENDED-SEDIMENT DISCHARGE FOR YEAR (TONS) 
11407150 FEATHER RIVER NEAR GRIDLEY, CALIF.

LOCATION, --Lat $39^{\circ} 22^{\prime} 00^{\prime \prime}$, long $121^{\circ} 38^{\prime} 46^{\prime \prime}$, in SW sec.33, T.18 N., R. 3 E., Butte County, at gaging station on right bank, $300 \mathrm{ft}$ upstream from highway bridge and 2.7 miles east of Gridley.

DRAINAGE AREA, $-3,676 \mathrm{sq} \mathrm{mi}$.

PERI OD OF RECORD. - Water temperatures: October 1964 to September 1969.

Sediment records: October 1964 to September 1969

EXTREMES. $-1968-69$ :

Water temperatures: Minimum, $6.0^{\circ} \mathrm{C}$ Dec. 22.

Sediment concentrations: Maximum da11y, $310 \mathrm{mg} / 1 \mathrm{Jan} .22$; minimum da1ly, $1 \mathrm{mg} / 1 \mathrm{Dec}, 12$

Sediment discharge: Maximum daily, 42,100 tons Jan. 22; minimum daily, 2.4 tons Dec. 12

Period of record:

Water temperatures: Minimum, $4.0^{\circ} \mathrm{C}$ on several days during December and January of most years.

Sediment concentrations: Maximum dally, 1,340 mg/1 Dec. 23, 1964; minimum daily, $1 \mathrm{mg} / 1 \mathrm{Dec} .12,1968$. Sediment discharge: Maximum da11y, 527,000 tons Dec. 23, 1964; minimum da11y, 1.4 tons Oct. $27,1966$.

TEMPERATURE ( ${ }^{\circ} \mathrm{C}$ ) OF WATER, TATER YEAR OCTOBER 1968 TO SEPTEMBER 1969 (ONCE-DAILY MEASUREMENT)

DAY

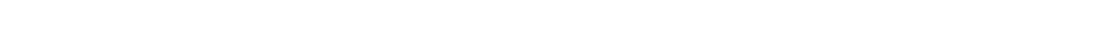

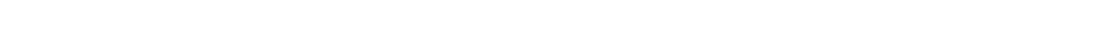

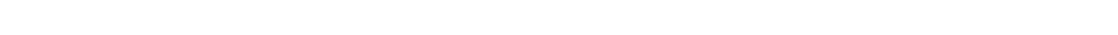

$\begin{array}{llllllllllllllllllllllllllllllllllllllllllll}\text { JANUARY.. } & 8 & 7 & 7 & 7 & 7 & 7 & 7 & 7 & 7 & 7 & - & 8 & 8 & 9 & 9 & 8 & 8 & 8 & 9 & 10 & 9 & 9 & 7 & 8 & 9 & 7 & 7 & 7 & 7 & 7 & 1 & 8\end{array}$

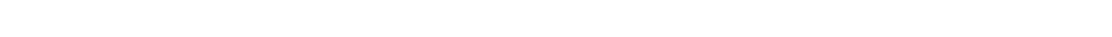

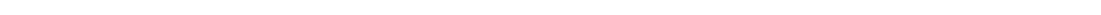

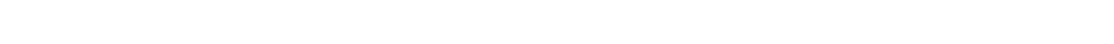

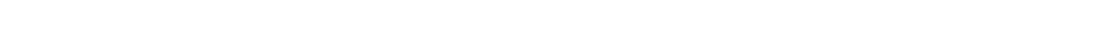

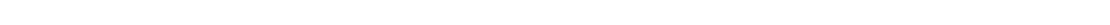

PARTICLE-SIZE DISTRIBUTION OF SUSPENDED SEDIMENT, HATER YEAR OCTOBER 1968 TO SEPTEMBER 1969

IMETHOES UF ANALYSIS: B, BOTIOM HITHDRAWAL TUBE; C, CHEMICALLY DISPERSED: N, IN NATIVE WATER; P, PIPET: S, SIEVE:

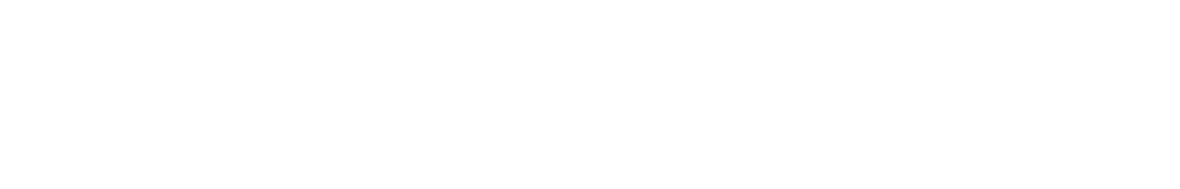


11407150 FEATHER RIVER NEAR GRIDLEY, CALIF,--Continued

SUSPENDED-SEDIMENT DISCHARGE, WATER YEAR OCTOBER 1968 TO SEPTEMBER 1969

$$
\text { OCTOBER }
$$

MEAN DISCHARGF

MEAN
CONCFN-

SEDIMENT MEAN

DAY (CFS)

4

$\begin{array}{ll}9.6 & 1100 \\ 9.5 & 1130 \\ 9.7 & 1160 \\ 12 & 1140 \\ 12 & 1140\end{array}$

$\begin{array}{ll}17 & 1110 \\ 9.8 & 1080\end{array}$

$9.7 \quad 1090$

$9.8 \quad 1100$

$7.7 \quad 1110$

$\begin{array}{ll}11.7 & 1110 \\ 16 & 1120 \\ 14 & 1080 \\ 15 & 1100\end{array}$

$15 \quad 1100$

$\begin{array}{ll}16 & 946 \\ 19 & 920 \\ 18 & 934\end{array}$

1160

1140

1130

1120

1130

$$
\begin{aligned}
& 1100 \\
& 1090
\end{aligned}
$$

1100
1100

1100

1140
1130

1130
1100

TOTAL 31978
NOVEMBFR

\begin{tabular}{|c|c|c|c|c|c|c|c|c|c|}
\hline \multirow[b]{2}{*}{ DAY } & \multicolumn{3}{|c|}{ JANUARY } & \multicolumn{3}{|c|}{ FEBRUARY } & \multicolumn{3}{|c|}{ MARCH } \\
\hline & $\begin{array}{l}\text { MEAN } \\
\text { DI SCHARGE } \\
\text { (CFS) }\end{array}$ & $\begin{array}{l}\text { MEAN } \\
\text { CUNCEN- } \\
\text { TRATION } \\
\text { IMG/LI }\end{array}$ & $\begin{array}{l}\text { SEDIMENT } \\
\text { DISCHARGE } \\
\text { (TONS/DAY) }\end{array}$ & $\begin{array}{l}\text { MEAN } \\
\text { DISCHARGE } \\
\text { (CFS) }\end{array}$ & $\begin{array}{l}\text { MEAN } \\
\text { CONCEN- } \\
\text { TRATION } \\
\text { (MG/L) }\end{array}$ & $\begin{array}{l}\text { SED IMENT } \\
\text { DI SCHARGE } \\
\text { (TONS/DAY) }\end{array}$ & $\begin{array}{l}\text { MEAN } \\
\text { DISCHARGE } \\
\text { (CFS) }\end{array}$ & $\begin{array}{l}\text { MEAN } \\
\text { CONCEN- } \\
\text { TRATION } \\
\text { (MG/L) }\end{array}$ & $\begin{array}{l}\text { SEDIMENT } \\
\text { DI SCHARGE } \\
\text { (TONS/DAY) }\end{array}$ \\
\hline 1 & 877 & 5 & 12 & 17600 & 55 & 2610 & 12400 & 16 & 536 \\
\hline 2 & 877 & 5 & 12 & 12000 & 43 & 1390 & 12400 & 17 & 569 \\
\hline 3 & 877 & 5 & 12 & 10600 & 43 & 1230 & 12300 & 16 & 531 \\
\hline 4 & 877 & 6 & 14 & 9950 & 37 & 994 & 12000 & 22 & 713 \\
\hline 5 & 864 & 4 & 9.3 & 9780 & 38 & 1000 & 10900 & 13 & 383 \\
\hline 6 & 856 & 4 & 9.2 & 10400 & 31 & 870 & 10100 & 16 & 436 \\
\hline 7 & 856 & 4 & 9.2 & 10900 & 32 & 942 & 9800 & 14 & 370 \\
\hline 8 & 836 & 5 & 11 & 10300 & 33 & 918 & 8570 & 15 & 347 \\
\hline 9 & 845 & 3 & 6.8 & 11000 & 34 & 1010 & 7690 & 17 & 353 \\
\hline 10 & 841 & 4 & 9.1 & 13300 & 36 & 1290 & 7030 & 13 & 247 \\
\hline 11 & 893 & 5 & 12 & 17600 & 27 & 1280 & 5490 & 14 & 208 \\
\hline 12 & 994 & 93 & 250 & 21800 & 33 & 1940 & 4620 & 15 & 187 \\
\hline 13 & 4210 & 85 & 966 & 20500 & 26 & 1440 & 4490 & 13 & 158 \\
\hline 14 & 3190 & 23 & 198 & 14300 & 20 & 772 & 4110 & 14 & 155 \\
\hline 15 & 1200 & 13 & 42 & 14100 & 26 & 990 & 4120 & 13 & 145 \\
\hline 16 & 1070 & 9 & 26 & 14900 & 27 & 1090 & 4370 & 15 & 177 \\
\hline 17 & 989 & 10 & 27 & 15500 & 15 & 628 & 5180 & 13 & 182 \\
\hline 18 & 948 & 10 & 26 & 15400 & 18 & 748 & 5280 & 24 & 342 \\
\hline 19 & 1070 & 16 & 46 & 14200 & 14 & 537 & 6220 & 21 & 353 \\
\hline 20 & 1650 & 24 & 107 & 12300 & 17 & 565 & 7790 & 20 & 421 \\
\hline 21 & 13000 & 149 & 8230 & 11700 & 17 & 537 & 9230 & 25 & 623 \\
\hline 22 & 50300 & 310 & 42100 & 12000 & 14 & 454 & 10800 & 28 & 816 \\
\hline 23 & 39200 & 80 & 8470 & 12400 & 22 & 737 & 10600 & 16 & 458 \\
\hline 24 & 37300 & 60 & 6040 & 12300 & 23 & 764 & 8730 & 7 & 265 \\
\hline 25 & 21000 & 38 & 2150 & 13500 & 20 & 729 & 5880 & 12 & 191 \\
\hline 26 & 29300 & 62 & 4900 & 12100 & 20 & 853 & 5730 & 17 & 263 \\
\hline 27 & 35700 & 40 & 3860 & 12100 & 20 & 653 & 5600 & 9 & 136 \\
\hline 28 & 38500 & 40 & 4160 & 12000 & 15 & 486 & 5450 & 12 & 177 \\
\hline 29 & 38500 & 32 & 3330 & - & - & -- & 5440 & 13 & 191 \\
\hline 30 & 38000 & 33 & 3390 & -- & -- & - & 5440 & 11 & 162 \\
\hline 31 & 34100 & 28 & 2580 & - & -- & -- & 5440 & 10 & 147 \\
\hline TOT AL & 399720 & $\cdots$ & 91014.6 & 374530 & -- & 27257 & 233200 & -- & 10142 \\
\hline
\end{tabular}

DECEMBER 
11407150 FEATHER RIVER NEAR GRIDLEY, CALIF,--Continued

SUSPENDED-SEDIMENT DISCHARGE, WATER YEAR OCTOBER 1968 TO SEPTEMBER 1969

\begin{tabular}{|c|c|c|c|c|c|c|c|c|c|}
\hline & & APRIL & & & MAY & & & JUNE & \\
\hline DAY & $\begin{array}{l}\text { MEAN } \\
\text { DISCHARGE } \\
\text { (CFS) }\end{array}$ & $\begin{array}{l}\text { MEAN } \\
\text { CONCEN- } \\
\text { IRATION } \\
\text { (MG/L) }\end{array}$ & $\begin{array}{l}\text { SEDIMENT } \\
\text { DI SCHARGE } \\
\text { (IONS/DAY) }\end{array}$ & $\begin{array}{l}\text { MEAN } \\
\text { DISCHARGE } \\
\text { (CFS) }\end{array}$ & $\begin{array}{l}\text { MEAN } \\
\text { CONCEN- } \\
\text { TRATION } \\
\text { (MG/L) }\end{array}$ & $\begin{array}{l}\text { SEDIMENT } \\
\text { DISCHARGE } \\
\text { (TONS/DAY) }\end{array}$ & $\begin{array}{l}\text { MEAN } \\
\text { DISCHARGE } \\
\text { (CFS) }\end{array}$ & $\begin{array}{l}\text { MEAN } \\
\text { CONCEN- } \\
\text { TRATION } \\
\text { (MG/L) }\end{array}$ & $\begin{array}{l}\text { SEDIMENT } \\
\text { DISCHARGE } \\
\text { (IONS/DAY) }\end{array}$ \\
\hline I & $544 \mathrm{D}$ & 26 & 382 & 10400 & 13 & 365 & 6250 & 25 & 422 \\
\hline 2 & 5790 & 37 & 578 & 10200 & 13 & 358 & 5480 & 15 & 222 \\
\hline 3 & 10500 & 28 & 794 & 8390 & 18 & 408 & 4340 & 7 & 82 \\
\hline 4 & 14700 & 26 & 1030 & 8160 & il & 242 & 4330 & 7 & $B 2$ \\
\hline 5 & 15700 & ID & 424 & 8200 & 8 & 177 & 3450 & 9 & 84 \\
\hline 6 & 15800 & 30 & 1280 & B180 & 7 & 155 & 3360 & 9 & 82 \\
\hline 7 & 16100 & 35 & 1520 & 3190 & 9 & 199 & 2400 & 8 & 52 \\
\hline 8 & 16100 & 5 & 217 & 8120 & 10 & 219 & 1430 & 8 & 31 \\
\hline 9 & 16100 & 12 & 522 & 8090 & 7 & 153 & 1210 & 8 & 26 \\
\hline 10 & 15900 & 22 & 944 & 8060 & 7 & 152 & 1210 & 5 & 20 \\
\hline 11 & 15400 & 10 & 416 & 6160 & 9 & 198 & 1200 & 4 & 13 \\
\hline 12 & 15500 & 29 & 1210 & 8130 & 7 & 154 & 1180 & 4 & 13 \\
\hline 13 & 15400 & 22 & 915 & B 130 & 7 & 154 & 1170 & 4 & 13 \\
\hline 14 & 15400 & 14 & 582 & 9710 & 7 & 184 & 1140 & 3 & 9.2 \\
\hline is & 15500 & 16 & 670 & 10700 & 30 & 867 & 1130 & 3 & 9.2 \\
\hline 16 & 15600 & 16 & 674 & 10800 & 29 & 846 & 1130 & 3 & 9.2 \\
\hline 17 & 15800 & 17 & 725 & 10700 & 11 & 318 & 1130 & 3 & 9.2 \\
\hline 18 & 14900 & 16 & 644 & 10600 & ii & 315 & 1140 & 5 & 15 \\
\hline 19 & 15200 & 18 & 739 & 10600 & is & 429 & 1140 & 5 & 15 \\
\hline 20 & 14600 & 21 & 828 & 10600 & 16 & 458 & 1310 & 5 & 13 \\
\hline 21 & 14600 & IB & 710 & 10600 & 17 & 487 & 1560 & 4 & 17 \\
\hline 22 & 14000 & I5 & 567 & 10000 & 7 & 189 & 1550 & 4 & 17 \\
\hline 23 & 14300 & 20 & 772 & 8910 & 7 & 168 & 1550 & 4 & 17 \\
\hline 24 & 14100 & 18 & 685 & 8010 & 7 & 151 & 1530 & 4 & 17 \\
\hline 25 & 14200 & 13 & 498 & 8000 & 25 & 540 & 1530 & 4 & 17 \\
\hline $2 B$ & 14100 & 14 & 533 & 7220 & 10 & 195 & 1160 & 4 & 13 \\
\hline 27 & 14100 & 12 & 457 & 6120 & 12 & 198 & 1130 & 4 & 12 \\
\hline $20^{\circ}$ & 14100 & 17 & 647 & 6080 & in & 164 & 1130 & $i$ & 9.2 \\
\hline 29 & 12600 & 13 & 442 & 6100 & 11 & 181 & 1130 & 3 & 9.2 \\
\hline 30 & 11900 & 13 & 418 & 6180 & 13 & 217 & I1 20 & 3 & 9.1 \\
\hline 31 & - & - & -- & 6240 & 20 & 337 & - & -- & - \\
\hline TOTAL & 423430 & -- & 20823 & 267580 & -- & 9178 & 58520 & -- & 1364.3 \\
\hline & & JULY & & & AUIGUST & & & SFPTEMEEP & \\
\hline & & "CAN & & & MEAN & & & MEAN & \\
\hline & M[A. & CONCFN- & SEDIMENT & MEAN & CONCEN- & SEDIMENT & $M L A N$ & CUINCE :- & SEDIMENT \\
\hline & DISCLAATLE & T2ATIUN & DI SCHARGE & UISCHARGE & FRATIDN & DI SCHARGE & OISCHARGE & TRATITIN & DISCHARGE \\
\hline DAY & (CFS) & $(N G / L)$ & (TONS/DAY) & (CFS) & (MG/L) & (TONS/DAY) & (CFS) & $(" \mathrm{G} / \mathrm{L})$ & (TONS/DAY) \\
\hline $\mathrm{t}$ & 1130 & 1 & 9.7 & 4280 & 9 & 104 & 6700 & 4 & 72 \\
\hline ; & 1137 & 4 & 12 & 4260 & a & $n$ & 5780 & 5 & 32 \\
\hline 3 & 1110 & 4 & 12 & 4220 & q & 91 & $683 \mathrm{C}$ & 6 & 111 \\
\hline$\div$ & liio & 4 & 12 & 4640 & 8 & 100 & 6830 & 5 & 92 \\
\hline 5 & 1700 & 4 & 13 & 5330 & b & 96 & 6817 & 4 & 74 \\
\hline$t$ & $18 / 4 \pi$ & 4 & 21 & 0200 & 5 & 84 & 6790 & 4 & 73 \\
\hline 7 & 2050 & 6 & 33 & $x+70$ & 5 & 86 & 6750 & 5 & 91 \\
\hline ; & 2060 & ? & 39 & 6960 & 4 & 75 & 6760 & 4 & 73 \\
\hline c) & 2270 & 8 & 47 & 6,200 & 4 & 71 & $6>600$ & 4 & 73 \\
\hline 1 i. & $2 \times 10$ & a & 56 & 5790 & 4 & 62 & 6760 & 4 & 73 \\
\hline 11 & 7510 & 6 & 42 & $64: 0$ & 5 & 87 & 6750 & 4 & 73 \\
\hline 1) &, $5+0$ & 6 & 42 & 6950 & 5 & 94 & 6740 & 5 & 91 \\
\hline 13 & 2540 & 6 & 42 & $(450)$ & 5 & 94 & 6740 & 5 & 91 \\
\hline 14 & 2620 & 5 & 35 & 6910 & 5 & 33 & 6710 & 4 & 72 \\
\hline is & $20>n$ & 's & 35 & 6900 & 5 & 93 & 6710 & 3 & 54 \\
\hline 15 & 2600 & b & 35 & $\in B<0$ & ; & $9 ?$ & 6740 & 3 & 55 \\
\hline 17 & $255 n$ & 6 & 41 & 6810 & 6 & Ili1 & 6750 & 3 & $5 b$ \\
\hline$i^{2}$ & $25+3$ & 6 & 41 & 6890 & s & 112 & 6790 & 4 & 73 \\
\hline 1 , & .540 & s & 34 & 6890 & 4 & 74 & 6750 & 4 & 73 \\
\hline 2.3 & 2540 & 5 & 34 & 4,480 & 5 & 43 & 6700 & 4 & 72 \\
\hline 21 & 25,40 & b & 34 & $68+0$ & 4 & 74 & 5600 & 4 & 72 \\
\hline 21 & $<5,50$ & 5 & 34 & 6840 & 4 & 74 & 6710 & 4 & 72 \\
\hline 23 & 3350 & 6 & 54 & 6810 & 4 & 74 & 6720 & 4 & 73 \\
\hline 24 & +030 & 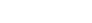 & 65 & 6760 & 7 & 128 & 5700 & 3 & 54 \\
\hline 25 & 4310 & 7 & 81 & 6020 & $h$ & $11^{n}$ & $t 700$ & 3 & 54 \\
\hline 25 & $4 \times 30$ & $t$ & $8 \mathrm{~L}$ & $68>0$ & 4 & 74 & 6700 & 5 & 30 \\
\hline 27 & +230 & ? & 93 & 6820 & 4 & 74 & 0320 & 7 & 119 \\
\hline 23 & 4300 & 5 & 93 & $6 R 30$ & 4 & 74 & 5330 & 6 & 86 \\
\hline 27 & 4370 & 7 & 82 & $68>0$ & 4 & 74 & 4340 & 6 & 70 \\
\hline 30 & $43 \geq 3$ & $B$ & 93 & 0700 & 4 & 75 & 3316 & 3 & 54 \\
\hline 3 & 4300 & 7 & 104 & .0740 & 4 & $7 x$ & -. & -- & - \\
\hline TUTAL & $4424 \pi$ & -- & 1451.2 & 133620 & -- & 2705 & 174630 & $\ldots$ & 2277 \\
\hline $\begin{array}{l}\text { TUTIL } \\
\text { TOTAL }\end{array}$ & $\begin{array}{l}\text { U13CHARLF } \\
\text { SUSPENDED }\end{array}$ & $\begin{array}{l}\text { FIP YEAR } \\
\text { SEDIMENT }\end{array}$ & $\begin{array}{l}\text { CFS-1)AYSI } \\
\text { ISCHARGE FOR }\end{array}$ & YEAR ITONS & & & & & $\begin{array}{l}2325344 \\
167399.2\end{array}$ \\
\hline
\end{tabular}


LOCAT ION. --Lat $39^{\circ} 08^{\prime} 20^{\prime \prime}$, Iong $121^{\circ} 36^{\prime} 17^{\prime \prime}$, in NEł sec. 23 , T.15 N., R. 3 E. , Yuba County, at gaging station on 1eft bank at 5 th Street rail road bridge in'Yuba City, $0.7 \mathrm{mile}$ upstream from confluence with Yuba $R 1$ ver and at mile 28.0 upstream from mouth.

DRAINAGE AREA, $-3,974 \mathrm{sq} \mathrm{mi}$.

PERIOD OF RECORD. - Water temperatures: July 1964 to September 1969.

Sediment records: October 1964 to September 1969.

EXTREMES, - - 1968-69:

Sediment concentrations: Maximum daily, $420 \mathrm{mg} / \mathrm{I} \mathrm{Jan,} \mathrm{22;} \mathrm{min1mum} \mathrm{daily,} 6 \mathrm{mg} / 1 \mathrm{Jan}, 9,10$

Sediment discharge: Maximum daily, 46,900 tons Jan. 22; minimum daily, is tons Jan. 9 , 10 .

Period of record:

Water temperatures (1964-67); Maximum, $31.5^{\circ} \mathrm{C}$ July 29,1964 ; minimum $(1964-65), 3.5^{\circ} \mathrm{C}$ on several days in January 1965.

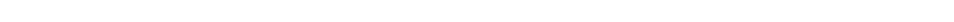
Sediment discharge: Maximum daily, 334,000 tons Dec. 24, 1964; minimum daily, 12 tons Oct. $27,1966$.

TEMPERATURE $\left({ }^{\circ} \mathrm{C}\right)$ OF WATER, WATER YEAR OCTOBER 1968 TO SEPTEMBER 1969 (ONCE-DAILY MEASUREMENT)

DAY

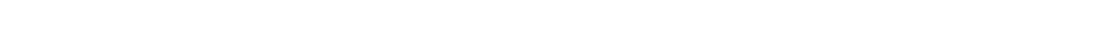

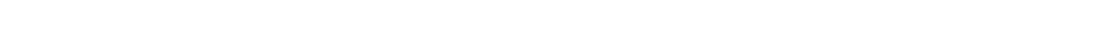

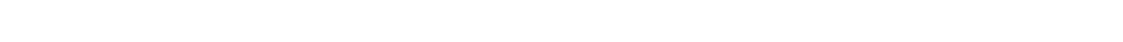

$\begin{array}{llllllllllllllllllllllllllllllllllllll}\text { JANUAKY.. } & - & 8 & 8 & 9 & - & 7 & 7 & 7 & 7 & 7 & 7 & - & 9 & 9 & 7 & 7 & 7 & 7 & - & 12 & 12 & 9 & 7 & 7 & 8 & - & 7 & 7 & 6 & 4 & 6 & 8\end{array}$

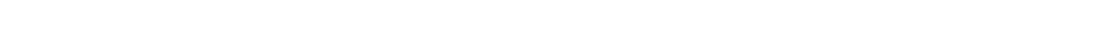

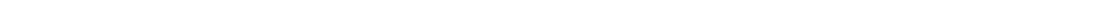
MAY.....

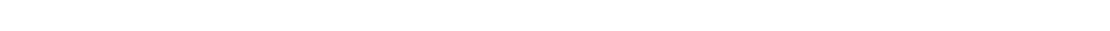

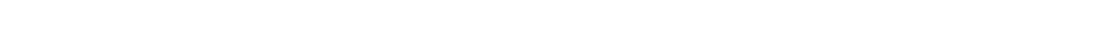

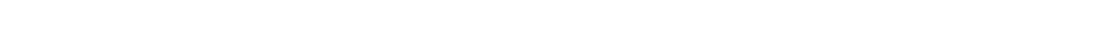

PARTICLE-SIZE DISTRIBUTION OF SUSPENDED SEDIMENT, WATER YEAR DCTOBER 1968 TO SEPTEMBER 1969 (MLTHIOOS DF ANALYSIS: P. BOFTOM WITHDRARAL TUHE; C, CHFMICALLY DISPFRSER; N, IN NATIVE WATER; P. PIPET; S, SIEVE;

WIFER

TrC.

PE\&A-

nat: IIME 1 CI

JAN 13, 136) 0755 , D 8900

Jait $14 \ldots \ldots .0745 \quad 8 \quad$ D 16000

JAN $21 \ldots \ldots .075012 \quad$ D 9900

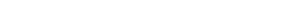

JAN $2 ? . . .2$. 120010 D $144 C 0$

D DAILY MEAN DI SCHARGE. SUSPENDED
CONCEN- SEDIMENT

PAPTICLE SIZE

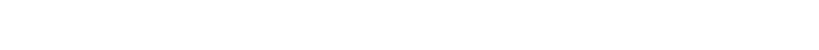

$\begin{array}{rr}34 & 2020 \\ 322 & 13700 \\ 68 & 1800 \\ 391 & 43700 \\ 553 & 61800\end{array}$

$\begin{array}{rrr}-- & -- & -- \\ -1 & - & -- \\ 8 & 9 & 30 \\ 16 & 11 & 21 \\ 17 & 29\end{array}$

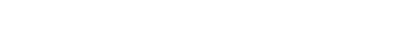
SIS SRWC $\operatorname{sinc}$ 
11407700 FEATHER RIVER AT YUBA CITY, CALIF.--Continued

SUSPENDED-SEDIMENT DISCHARGE, WATER YEAR OCTOBER 1968 TO SEPTEMBER 1969

\begin{tabular}{|c|c|c|c|c|c|c|c|c|c|}
\hline \multirow[b]{2}{*}{ DAY } & \multicolumn{3}{|c|}{ OC TOBER } & \multicolumn{3}{|c|}{ NUVEMBER } & \multicolumn{3}{|c|}{ DECEMBER } \\
\hline & $\begin{array}{l}\text { MEAN } \\
\text { OISCHARGE } \\
\text { (CFS) }\end{array}$ & $\begin{array}{l}\text { MEAN } \\
\text { CONCEN- } \\
\text { TRATIUN } \\
\text { (MG/L) }\end{array}$ & $\begin{array}{l}\text { SEDIMENT } \\
\text { DI SCHARGF } \\
\text { (TONS/DAY) }\end{array}$ & $\begin{array}{l}\text { MEAN } \\
\text { DISCHARGE } \\
\text { (CFS) }\end{array}$ & $\begin{array}{l}\text { MEAN } \\
\text { CONCSN- } \\
\text { TRAT ION } \\
\text { (MGIL) }\end{array}$ & $\begin{array}{l}\text { SEDIMENT } \\
\text { DI SCHARGE } \\
\text { (TONS/DAY) }\end{array}$ & $\begin{array}{l}\text { MEAN } \\
\text { OISCHARGE } \\
\text { (CFS) }\end{array}$ & $\begin{array}{l}\text { MEAN } \\
\text { CONCEN- } \\
\text { TRATION } \\
\text { (MG/L) }\end{array}$ & $\begin{array}{l}\text { SEDIMENT } \\
\text { DI SCHARGE } \\
\text { (TONS/DAY) }\end{array}$ \\
\hline 1 & 1090 & 13 & 38 & 1290 & 16 & 56 & 1190 & 13 & 42 \\
\hline 2 & 1050 & 15 & 43 & 1320 & 15 & 53 & II BO & 13 & 41 \\
\hline 3 & 1050 & 14 & 40 & 1500 & 18 & 73 & I 170 & 10 & 32 \\
\hline 4 & 1060 & 13 & 37 & 1510 & ia & 78 & 1150 & 7 & 22 \\
\hline 5 & 1070 & 14 & 40 & 1470 & 19 & 75 & 1150 & 7 & 22 \\
\hline 6 & $105 n$ & 14 & 40 & 1430 & 21 & BI & 1150 & 9 & 28 \\
\hline 7 & 1020 & 14 & 39 & 1380 & 22 & 82 & 1140 & 11 & 34 \\
\hline g & 1030 & 13 & 36 & 1340 & 21 & $7 t$ & I 140 & i1 & 34 \\
\hline 9 & 1030 & 11 & 31 & I 330 & 20 & 77 & 1150 & 12 & 37 \\
\hline 10 & 1030 & 10 & 28 & 1340 & 20 & 72 & 1230 & 14 & 46 \\
\hline 11 & $10 \times 0$ & 11 & 31 & 1330 & 20 & 72 & 1460 & 24 & 95 \\
\hline 17 & 1140 & 12 & 37 & 1380 & 15 & 56 & 1390 & 18 & B8 \\
\hline 13 & 1200 & 13 & 42 & 1350 & is & 58 & 1320 & 14 & 68 \\
\hline 14 & 1200 & 14 & 45 & 1350 & 14 & 51 & 1690 & 45 & 205 \\
\hline 15 & 1200 & 14 & 45 & 1450 & 12 & 47 & 2130 & 90 & 518 \\
\hline 16 & 1390 & 13 & 49 & 1440 & 14 & 54 & 2330 & 137 & 880 \\
\hline 17 & 1410 & 14 & 53 & 1790 & 15 & 52 & 1760 & 55 & 261 \\
\hline iy & 1340 & 15 & 56 & 1290 & 16 & 56 & 1640 & 21 & 93 \\
\hline 19 & 1370 & 15 & 55 & 1360 & 19 & 79 & 1860 & 17 & 85 \\
\hline 20 & 1360 & I 3 & 48 & 1330 & $i^{8}$ & 65 & 1640 & 14 & 62 \\
\hline 21 & 1350 & 12 & 44 & 1780 & 17 & 51 & 1430 & 10 & 31 \\
\hline 22 & 1340 & 13 & 47 & 1220 & 16 & 53 & 1440 & 10 & 39 \\
\hline 23 & 1340 & 15 & 54 & 1200 & is & 5? & 1460 & 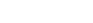 & 35 \\
\hline 24 & 1340 & 16 & 58 & $11+0$ & 16 & 51 & 1720 & 11 & 51 \\
\hline 25 & 1320 & 16 & 57 & 1170 & 17 & 54 & 2480 & 64 & 429 \\
\hline 26 & 1270 & 15 & 5? & 1150 & 15 & 47 & 24917 & 64 & 430 \\
\hline 27 & 1300 & 13 & 46 & 1150 & 1) & 37 & 1920 & 34 & 176 \\
\hline 20 & 1290 & 13 & 45 & 1150 & 11 & 34 & 1580 & 25 & 107 \\
\hline 29 & 1340 & 14 & 51 & 1150 & II & 34 & 1700 & 25 & 115 \\
\hline 30 & 1430 & 17 & 66 & 1190 & 12 & 34 & 1590 & 17 & 73 \\
\hline 31 & 1340 & 16 & 58 & - & -- & -- & 1420 & 10 & 38 \\
\hline \multirow[t]{4}{*}{ TOTAL } & 37880 & -- & 1411 & 37350 & -- & 1754 & 48150 & - & 4205 \\
\hline & & JANUARY & & & FEPRUARY & & & MARCH & \\
\hline & MEAN & $\begin{array}{l}\text { NEAV } \\
\text { CONCEN- }\end{array}$ & SEDIMENT & & $\begin{array}{l}\text { MEAV } \\
\text { CONCFN- }\end{array}$ & & MEAN & $\begin{array}{l}\text { MEAN } \\
\text { CUVCEIS- }\end{array}$ & \\
\hline & DISCHAQGE & TRATIUN & DI SCHARGE & $\begin{array}{l}\text { MEAN } \\
\text { DISCHARGE }\end{array}$ & TRATION & DI SCHARGE & DISCHARGE & TRATION & $\begin{array}{l}\text { SEDIMENT } \\
\text { DI SCHARGE }\end{array}$ \\
\hline DAY & (CFS) & $(N G / L)$ & (TONS/DAY) & (CFS) & $(M G / L)$ & (TONS/DAY) & (CFS) & $(M G / L)$ & (TONS/DAY) \\
\hline 1 & 1310 & 8 & 28 & 26700 & 241 & 17400 & 14360 & 136 & 5250 \\
\hline 2 & 1240 & b & 27 & 14500 & 259 & iston & 15200 & 120 & 4920 \\
\hline 3 & 1180 & 11 & 35 & 11000 & 208 & 6180 & 14100 & 115 & 4380 \\
\hline 4 & 1210 & 12 & 39 & 9900 & 153 & 4090 & 13300 & 196 & $704 \mathrm{U}$ \\
\hline 5 & 1120 & 11 & 35 & 10800 & 130 & 3790 & 12000 & 170 & 5170 \\
\hline 6 & 1150 & 11 & 34 & 11900 & 130 & 4185 & 10900 & 131 & 4090 \\
\hline ? & 1140 & 11 & 34 & $1291 / 0$ & 150 & 5220 & 10500 & 148 & 4200 \\
\hline 3 & 1120 & 12 & 36 & 11700 & 125 & 3053 & 7382 & 128 & 3240 \\
\hline 9 & 1140 & 6 & 18 & liv700 & 135 & 3900 & $\$ 400$ & 128 & 2900 \\
\hline 10 & 1120 & 6 & is & 13400 & $13 n$ & 5870 & 8010 & 115 & 2490 \\
\hline 11 & 1200 & 30 & 97 & 15500 & 280 & $1>5,00$ & 6370 & 107 & 1840 \\
\hline 1? & .760 & 164 & 1220 & 22200 & $\$ 00$ & IBGO? & 5430 & 32 & 1200 \\
\hline 13 & 2900 & 400 & 9610 & $\angle 5200$ & 220 & 15600 & 5030 & 89 & 1220 \\
\hline 14 & 16000 & 380 & 16400 & 17800 & 140 & 748.3 & 4820 & 71 & 924 \\
\hline 15 & 5000 & 160 & 2160 & 15300 & 110 & $454 i$ & 4620 & 68 & 848 \\
\hline 15 & 3020 & 70 & 571 & 21100 & 90 & 3130 & 4600 & 81 & 1010 \\
\hline 17 & 2350 & 40 & 254 & 19600 & 160 & 8470 & 5020 & 102 & 1380 \\
\hline is & 2110 & 30 & 171 & 18600 & 150 & 7290 & 5300 & 38 & 1260 \\
\hline 19 & 1680 & 100 & 994 & 15800 & 148 & 6710 & 5460 & 89 & 1310 \\
\hline 20 & 58170 & 150 & 2350 & 14300 & 119 & 4590 & 6910 & 147 & 2740 \\
\hline 21 & 3800 & $10 c$ & 2650 & 12300 & 123 & 4080 & 7950 & 170 & 3650 \\
\hline 22 & 41400 & 420 & 46900 & 12300 & 136 & 4520 & 10300 & 262 & 7290 \\
\hline 23 & 48100 & 260 & 33800 & 12000 & 123 & 3990 & 10600 & 245 & 7013 \\
\hline 24 & 41600 & 255 & $\angle 8600$ & 12500 & 144 & 4860 & 10000 & 223 & 6020 \\
\hline 25 & 31300 & 157 & 13300 & 13 яกо & 156 & 5810 & 8450 & 136 & 2370 \\
\hline 26 & 21800 & 83 & 4890 & 14200 & 147 & 5710 & 5770 & 94 & $15 ? 0$ \\
\hline 27 & 40700 & 73 & 2020 & 13460 & 119 & 4310 & 5760 & 87 & 1350 \\
\hline 29 & 41300 & 84 & 9370 & 12500 & 111 & 3750 & 5450 & 68 & 1000 \\
\hline 29 & 40200 & 136 & 14800 & - & $\ldots$ & - & 5240 & 80 & 1130 \\
\hline 30 & 39800 & 162 & 17000 & -- & - & -- & 5410 & 76 & 1110 \\
\hline 31 & 37500 & 171 & 17300 & -- & -- & -- & 5290 & 63 & 700 \\
\hline TIAL & 455120 & -- & 230761 & 476300 & -- & 133020 & 248130 & - & 91362 \\
\hline
\end{tabular}


11407700 FEATHER RIVER AT YUBA CITY, CALIF...-Continued

SUSPENDED-SEDIMENT DISCHARGE, WATER YEAR OCTOBER 1968 TD SEPTEMBER 1969

\begin{tabular}{|c|c|c|c|c|c|c|c|c|c|}
\hline \multirow[b]{2}{*}{ UAY } & \multicolumn{3}{|c|}{$\triangle P R I L$} & \multicolumn{3}{|c|}{ MaY } & \multicolumn{3}{|c|}{ JUNE } \\
\hline & 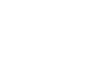 & $\begin{array}{l}\text { MEAN } \\
\text { CONCEN- } \\
\text { THATLI)N } \\
\text { (MG/L) }\end{array}$ & $\begin{array}{l}\text { SEDIMENT } \\
\text { DISCHARGE } \\
\text { (TONS/DAY) }\end{array}$ & $\begin{array}{l}\text { MFAN } \\
\text { UISCHADEE } \\
(C,+S)\end{array}$ & $\begin{array}{l}\text { MFAN } \\
\text { CONCEN- } \\
\text { TPATION } \\
\text { (MG/L) }\end{array}$ & $\begin{array}{l}\text { SEDIMENT } \\
\text { DISCHARGE } \\
\text { (TONS/DAY) }\end{array}$ & $\begin{array}{l}\text { MEAN } \\
\text { DISCHARGE } \\
\text { (CFS) }\end{array}$ & $\begin{array}{l}\text { MEAN } \\
\text { CONCEN- } \\
\text { IPATI IN } \\
\text { (MG/L) }\end{array}$ & $\begin{array}{l}\text { SEDIMENT } \\
\text { DISCHARGE } \\
\text { (TDNS/DAY) }\end{array}$ \\
\hline 1 & 4740 & 58 & 742 & 105000 & $6 n$ & 1700 & 6190 & 50 & 836 \\
\hline 2 & 5Оमㄱ & 58 & 795 & 10100 & 57 & 1550 & 5980 & 52 & 840 \\
\hline 3 & $75>0$ & 160 & 3293 & 13970 & 107 & $244 n$ & 4400 & 50 & 594 \\
\hline it & 11600 & 26,4 & 8279 & $80>0$ & 88 & 1920 & 4240 & 46 & 527 \\
\hline$b$ & 13417 & 200 & 7450 & 8050 & 88 & 1910 & 3960 & 40 & 428 \\
\hline 0 & $144,1] 0$ & 158 & 6140 & 8040 & $P Q$ & 1910 & 3430 & 34 & 315 \\
\hline 7 & 14900 & 158 & 6760 & 8040 & 88 & 1910 & 2830 & 27 & 206 \\
\hline 3 & $143 \cup n$ & 147 & 5080 & 1990 & 70 & 1510 & 2020 & 20 & 109 \\
\hline$\Rightarrow$ & 145.111 & 140 & 5480 & $78 \geqslant 0$ & 63 & 1340 & 1560 & 15 & 63 \\
\hline 10 & $13110 n$ & $16 d$ & 6,850 & 7320 & 70 & 1500 & 1480 & 14 & 56 \\
\hline I 1 & $23,3,0$ & 192 & 7520 & 3060 & 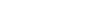 & 1440 & 1490 & 20 & 80 \\
\hline 12 & is 2,10 & $17^{\circ}$ & $71 R 0$ & 8150 & 62 & 1360 & 1490 & 26 & 105 \\
\hline I3 & $13 ? 00$ & 173 & 7310 & 8100 & 54 & 1180 & 1470 & 26 & 103 \\
\hline 14 & 15,200 & 193 & 7510 & 5030 & 56 & 1370 & 1460 & 23 & 91 \\
\hline 15 & 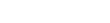 & 266 & 0620 & 10500 & 43 & 1220 & 1440 & 21 & 82 \\
\hline 16 & I toun & $1 P 7$ & 0160 & 11000 & 54 & $I \in 00$ & 1390 & 16 & 60 \\
\hline 17 & 101130 & 228 & $3+10$ & 10300 & 47 & 1380 & 1400 & 15 & 57 \\
\hline$i a$ & 15000 & 231 & $9.32 n$ & 10700 & 42 & 1240 & 1380 & 16 & 60 \\
\hline 17 & 15,710 & 214 & 7070 & 10700 & 37 & 1090 & 1370 & 16 & 59 \\
\hline 20 & 15811 & $? 14$ & 기 & 10360 & 42 & 1240 & 1370 & 16 & 59 \\
\hline 21 & 150,20 & 214 & 9070 & 10000 & 51 & 1490 & 1520 & 20 & 82 \\
\hline ? & $147 \mathrm{nn}$ & 217 & 8017 & 10500 & $4 ?$ & 1190 & 1620 & 24 & 105 \\
\hline 23 & 14632 & $|R|$ & 7450 & $\$ 450$ & $3 ?$ & 816 & 1700 & 25 & 115 \\
\hline 24 & 14800 & $13 t$ & 7430 & EL30 & 69 & 1490 & 1650 & 25 & 111 \\
\hline 25 & 13909 & 200 & 751 & 7390 & 34 & $203 n$ & 1600 & 23 & 99 \\
\hline 26. & 198,00 & 10,5 & 3910 & 7900 & 59 & 1220 & 1500 & 21 & 85 \\
\hline 27 & $14(4) 0$ & 91 & 3440 & 6360 & 29 & 498 & 1400 & 20 & 76 \\
\hline$?$ & 14300 & 84 & 3400 & 6200 & 35 & 586 & 1250 & 21 & 71 \\
\hline$\because 9$ & isiun & 78 & 2760 & \&150 & 41 & 691 & 1300 & 21 & 74 \\
\hline 3) & $122(11)$ & 74 & 2570 & $B<10$ & 44 & 733 & 1250 & 22 & 74 \\
\hline 31 & -. & -- & -- & 6240 & 47 & 792 & -- & -- & -- \\
\hline \multirow[t]{5}{*}{ TOIAL } & 411840 & - & $1+1535$ & $\angle 63810$ & -- & 42341 & 65140 & $-\infty$ & 5622 \\
\hline & & JULY & & & AUGIUST & & & SEPTENBER & \\
\hline & & MEAN & & & MEAN & & & MFAN & \\
\hline & MEA & CONCEN- & SEDIMENT & UFA.V & CONCEN- & SEDIMENT & MEAN & CONCEV- & SED IMENT \\
\hline & $\begin{array}{l}J 1, C+A^{2}, F \\
\left(C T^{-5}\right)\end{array}$ & $\begin{array}{l}\text { I'AIIUV } \\
\text { (M;/L) }\end{array}$ & $\begin{array}{l}\text { DISCHARGE } \\
\text { (TDNS/DAY) }\end{array}$ & $\begin{array}{l}\text { DISCHALGF } \\
\text { (CFS) }\end{array}$ & TRATION & $\begin{array}{l}\text { DISCHARGE } \\
\text { (TONS (DAY) }\end{array}$ & $\begin{array}{l}\text { DISCHAKGF } \\
\text { (CFS) }\end{array}$ & $\begin{array}{l}\text { TRATION } \\
\text { MGGLI }\end{array}$ & $\begin{array}{l}\text { DISCHARGE } \\
\text { (TONS/DAY) }\end{array}$ \\
\hline & & & & & & & & & \\
\hline 1 & $1>40$ & $?$ & 74 & 4.730 & 73 & 794 & 6890 & 86 & 1490 \\
\hline$?$ & 1240 & $>1$ & 70 & $3+10$ & RO & 862 & $690 \mathrm{C}$ & 90 & 1680 \\
\hline 3 & $i>20$ & 20 & So & 3390 & 8) & 983 & 7020 & 88 & 1670 \\
\hline 4 & 1200 & is & 5 & 4010 & 77 & 834 & 6980 & 76 & 1430 \\
\hline 5 & 1170 & 17 & 54 & 2280 & 83 & 1180 & 7020 & 73 & 1380 \\
\hline 6 & $14+n$ & 21 & 84 & $5+10$ & 74 & 1500 & 7000 & 83 & 1570 \\
\hline 7 & 1005 & 35 & $18 n$ & 5910 & 94 & 15,00 & 7030 & $8>$ & 1610 \\
\hline 3 & $1 \varepsilon 70$ & 15 & 177 & 5420 & 106 & 1950 & 7020 & 88 & 1670 \\
\hline ; & 19377 & $3 b$ & 177 & 6470 & 124 & 2170 & 7030 & 75 & 1420 \\
\hline 11) & 370 & 38 & 235 & 5740 & 117 & 1812 & 7000 & 80 & 1510 \\
\hline 11 & $i 3: 0$ & 45 & 283 & 5,400 & Ro & 1370 & 6780 & 82 & 1550 \\
\hline 17 & .220 & 48 & 295 & 6440 & 88 & 1540 & 6980 & 77 & 1450 \\
\hline 13 & $? 23 n$ & 48 & 237 & 6520 & 133 & 2340 & 6970 & $6 \rightarrow$ & 1300 \\
\hline 14 & 33 & $4 \rightarrow$ & 107 & 6520 & 159 & 2800 & 6950 & 66 & 1240 \\
\hline 15 & $22+10$ & 50 & 101 & DSOD & 141 & 2470 & 6750 & 65 & 1220 \\
\hline 16 & 2230 & $5 ?$ & 320 & 6470 & 111 & 1940 & 6370 & 66 & 1240 \\
\hline 17 & .270 & 48 & $\angle 88$ & 6500 & 105 & 1940 & 6950 & 70 & 1310 \\
\hline$i^{p}$ & $2(2,4)$ & 38 & 214 & 6540 & 104 & 1940 & 7000 & 73 & 1380 \\
\hline 13 & 2000 & 31 & 172 & 6570 & $\rightarrow 3$ & 1650 & 6780 & 71 & 1340 \\
\hline 26 & 102 & 31 & 176 & $D 620$ & 76 & 1360 & 6940 & $7 !$ & 1330 \\
\hline 21 & 2120 & 34 & 195 & 6600 & 76 & 1350 & 6890 & 73 & 1360 \\
\hline $2 ?$ & 3030 & 37 & $20+$ & SosuO & 73 & 1416 & 6870 & 80 & 1480 \\
\hline 23 & $\therefore 3: 11$ & 1,4 & 249 & $B C, 80$ & 78 & 1410 & 6900 & 82 & 1530 \\
\hline 24 & $(3+31)$ & 6,7 & 631 & 6650 & 77 & 1380 & 6860 & 77 & 1430 \\
\hline 24 & 4050 & 87 & 497 & 6050 & 77 & 1380 & 6860 & 74 & 1370 \\
\hline 26 & $4 \cot 00$ & ค 2 & 496 & 6770 & 77 & 1410 & $687 \mathrm{C}$ & 73 & 1350 \\
\hline 27 & 410317 & ys & 937 & 6700 & 77 & 1410 & 6780 & 71 & 1300 \\
\hline 24 & $4(151)$ & 20 & 987 & 6820 & 77 & 1420 & 5780 & 62 & 1000 \\
\hline 21 & 4650 & 33 & $10 / 0$ & 4870 & 76 & 1410 & 5040 & 51 & 694 \\
\hline 21 & $40>0$ & BD & +32 & 6870 & 63 & 1280 & 4050 & 39 & 426 \\
\hline 31 & 4000 & $7 \varepsilon$ & 784 & 6990 & 71 & $13>0$ & -0 & -- & -2 \\
\hline TuIN & $76,4 \cdot 0$ & -- & 11634 & 190810 & -- & 47713 & 202660 & -- & 40730 \\
\hline $\begin{array}{l}\text { TUIAL } \\
\text { TDTAL }\end{array}$ & $\begin{array}{l}\text { I.ISCHAD it } \\
\text { SUSPENDED- }\end{array}$ & $\begin{array}{l}\text { WF VEAR } \\
\text { EDIMENT ID }\end{array}$ & $\begin{array}{l}\text { FS-FAYS } \\
\text { SCHARGE FOR }\end{array}$ & YEAR ITONS & & & & & $\begin{array}{r}2471410 \\
862096\end{array}$ \\
\hline
\end{tabular}


11409000 MIDDLE YUBA RIVER ABOVE OREGON CREEK, NEAR NORTH SAN JUAN, CALIF.

LOCATION. --Lat $39^{\circ} 23^{\prime} 36^{\prime \prime}$, I long $121^{\circ} 04^{\prime} 50^{\prime \prime}$, In SE 1 sec. 28 , T.18 N, , R.8 E., Nevada County, temperature recorder at gaging station on'left bank, 1,000' ft upstream from Oregon'Creek and 2 miles northeast of North San Juan. DRAINAGE AREA. $--162 \mathrm{sq} \mathrm{mi}$.

PERIOD OF RECORD. - Water temperatures: February 1965 to September 1969 (discontinued).

Sediment records: October 1966 to September 1969 (partial records).

EXTREKES. --1968-69:

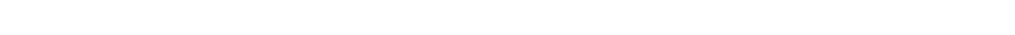

period of record:

Water temperatures: Maximum, $27.0^{\circ} \mathrm{C}$ on several days during June to August 1968; minimum, freezing point on several days during December to February of most years.

REMARKS,--Clock stopped Dec. $19-25$, July 28 to Sept, 30 ; ranges in temperature, $3.0^{\circ} \mathrm{C}$ to $7.0^{\circ} \mathrm{C}$, and $19.0^{\circ} \mathrm{C}$ to $25.0^{\circ} \mathrm{C}$, respectively.

TEMPERATURE $\left({ }^{\circ} \mathrm{C}\right)$ OF WATER, WATER YEAR OCTOBER 1968 TO SEPTEMBER 1969

DAY

MONTH

OCTOBER

$\begin{array}{lllllllllllllllllllllllllllllllllllllll}\text { MAXIMUM } & 17 & 18 & 18 & 18 & 17 & 17 & 16 & 15 & 14 & 14 & 15 & 15 & 14 & 13 & 12 & 13 & 13 & 13 & 13 & 13 & 13 & 13 & 13 & 13 & 13 & 13 & 12 & 13 & 12 & 12 & 11 & 14 \\ \text { MINIMUM } & 15 & 16 & 16 & 16 & 16 & 16 & 14 & 13 & 13 & 13 & 13 & 14 & 13 & 12 & 11 & 11 & 11 & 11 & 11 & 11 & 11 & 11 & 11 & 11 & 11 & 11 & 11 & 11 & 11 & 10 & 9 & 12\end{array}$

NOVEMBER

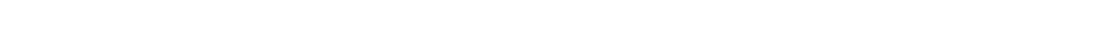

DECEMBFR

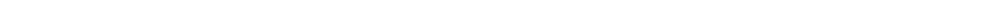

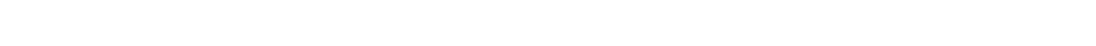

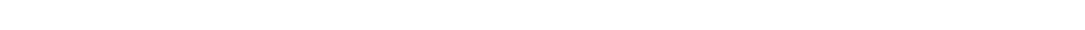

$\begin{array}{llllllllllllllllllllllllllllllllll}\text { MINIMUM } & 5 & 5 & 5 & 6 & 6 & 6 & 5 & 6 & 5 & 4 & 4 & 4 & 5 & 6 & 6 & 6 & 5 & 5 & 5 & 6 & 7 & 7 & 8 & 9 & 7 & 5 & 5 & 7 & 6 & 6 & 6 & 6\end{array}$

FERRUARY

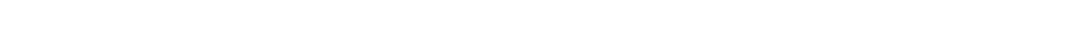

MINIMUM

MARCH

MAXIMUUM

MINIMUM

APRIL

MAXIMUM
MINIMUM

MAY

MAXIMUM

MINIMUM

$\begin{array}{lllllllllllllllllllllllllllllllllllll}5 & 5 & 5 & 5 & 5 & 5 & 5 & 5 & 5 & 5 & 6 & 6 & 5 & 6 & 5 & 5 & 5 & 6 & 6 & 6 & 5 & 5 & 5 & 5 & 4 & 4 & 4 & 4 & \ldots & \ldots & \ldots\end{array}$

$\begin{array}{lllllllllllllllllllllllllllllllll}5 & 5 & 5 & 6 & 6 & 6 & 6 & 6 & 6 & 6 & 6 & 6 & 6 & 6 & 6 & 6 & 6 & 7 & 7 & 6 & 7 & 7 & 7 & 7 & 7 & 7 & 8 & 8 & 8 & 8 & 8 \\ 4 & 5 & 5 & 5 & 5 & 6 & 5 & 6 & 6 & 5 & 6 & 6 & 5 & 5 & 5 & 5 & 6 & 6 & 6 & 6 & 6 & 6 & 6 & 6 & 6 & 6 & 6 & 6 & 6 & 6 & 6\end{array}$

$\begin{array}{llllllllllllllllllllllllllllllllllll}7 & 7 & 6 & 7 & 7 & 6 & 7 & 8 & 8 & 9 & 9 & 9 & 8 & 7 & 7 & 8 & 9 & 9 & 9 & 9 & 10 & 10 & 8 & 6 & 7 & 8 & 9 & 9 & 10 & 9 & -1\end{array}$

$\begin{array}{lllllllllllllllllllllllllllllllll}6 & 6 & 5 & 5 & 5 & 4 & 5 & 6 & 7 & 6 & 7 & 7 & 6 & 6 & 5 & 6 & 7 & 8 & 6 & 7 & 7 & 7 & 5 & 5 & 5 & 6 & 6 & 8 & 8 & 7 & -7\end{array}$

$\begin{array}{rrrrrrrrrrrrrrrrrrrrrrrrrrrrrrrr}9 & 9 & 8 & 9 & 10 & 11 & 11 & 11 & 11 & 10 & 10 & 10 & 9 & 9 & 9 & 10 & 11 & 11 & 10 & 10 & 11 & 11 & 12 & 12 & 11 & 11 & 11 & 11 & 17 & 13 & 17 \\ 7 & 7 & 6 & 5 & 7 & 9 & 8 & 8 & 8 & 7 & 7 & 7 & 7 & 7 & 7 & 8 & 8 & 8 & 8 & 8 & 9 & 9 & 9 & 9 & 8 & 9 & 9 & 9 & 10 & 11 & 13\end{array}$

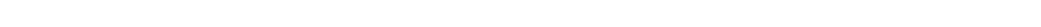
$\begin{array}{lllllllllllllllllllllllllllllllll}\text { MAXIMUM } & 17 & 18 & 19 & 18 & 19 & 19 & 18 & 18 & 16 & 15 & 15 & 15 & 16 & 19 & 19 & 19 & 19 & 18 & 19 & 20 & 19 & 20 & 20 & 20 & 19 & 19 & 19 & 19 & 19 & 20 & \ldots & 18 \\ \text { MINIMUM } & 14 & 14 & 15 & 16 & 15 & 15 & 15 & 15 & 14 & 13 & 14 & 13 & 14 & 15 & 16 & 16 & 16 & 16 & 16 & 16 & 16 & 16 & 17 & 17 & 16 & 16 & 15 & 15 & 15 & 16 & -- & 15\end{array}$ JULY

MAXIMUM $20 \begin{array}{lllllllllllllllllllllllllllllllllll}21 & 21 & 21 & 21 & 22 & 22 & 22 & 23 & 23 & 23 & 23 & 23 & 23 & 23 & 24 & 24 & 24 & 25 & 25 & 25 & 26 & 26 & 26 & 26 & 75 & 25 & -- & -- & -- & -- & 23\end{array}$ AUGUST

MAXIMUM

MINIMUM

SEPIEMBER

MAXIMUM

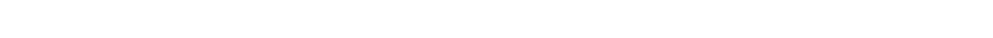

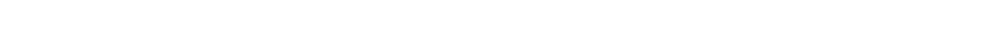

SUSPENDED-SEDIMENT DISCHARGE MEASUREMENTS, WATER YEAR OCTOBER 1968 TO SEPTEMBER 1969

\begin{tabular}{|c|c|c|c|c|c|c|}
\hline & DATE & TIME & $\begin{array}{l}\text { WATER } \\
\text { TEM- } \\
\text { PERA- } \\
\text { TURE } \\
\text { I CI }\end{array}$ & $\begin{array}{l}\text { DISCHARGE } \\
\text { (CFS) }\end{array}$ & $\begin{array}{l}\text { CONCEN- } \\
\text { TRATION } \\
\text { (MG/L) }\end{array}$ & $\begin{array}{l}\text { SUSPENDEO } \\
\text { SEOIMEVT } \\
\text { DI SCHARGE } \\
\text { (TONS/DAY) }\end{array}$ \\
\hline $0<\mathrm{r}$ & 30,1960 & 1545 & 11 & 51 & 1 & .13 \\
\hline NOV & $26 \ldots \ldots$ & 1200 & 6 & 66 & i & .18 \\
\hline$J \triangle N$ & 3,1969 & 1500 & 6 & 169 & I & .46 \\
\hline$F E B$ & $5 \ldots \ldots$ & 1630 & 5 & 640 & 10 & 17 \\
\hline MAR & $4 \ldots \ldots$ & 1330 & 5 & 430 & 7 & 8.1 \\
\hline$A P R$ & $28 \ldots \ldots$ & 1645 & 8 & 750 & 4 & 8.1 \\
\hline MAY & $15 \ldots \ldots$ & 1425 & 7 & 1690 & 14 & 64 \\
\hline JUL & $28 \ldots \ldots$ & 1345 & 23 & 35 & 1 & .09 \\
\hline SEP & $3 \ldots \ldots$ & 0745 & 22 & 56 & 2 & .30 \\
\hline SEP & $30 \ldots$. & 1230 & 16 & 56 & 4 & .60 \\
\hline
\end{tabular}




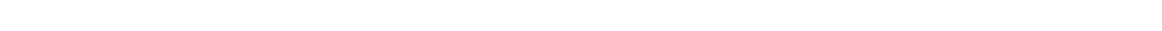
temperature recorder at gaging station on right bank, $0.7 \mathrm{mile}$ upstream from mouth and $2.7 \mathrm{miles}$ northeast of

DRAINAGE AREA. - - 34.4 sq $\mathrm{mi}$.

PERIOD OF RECORD. --Water temperatures: February 1965 to September 1969 (discontinued).

EXTREMES, --1968-69:

Water temperatures: Maximum, $26.0^{\circ} \mathrm{C}$ July $22 ; \mathrm{m} 2 n 1 m u m, 2.0^{\circ} \mathrm{C}$ Dec. 20-22.

Period of record:

Water temperatures: Maximum, $26.5^{\circ} \mathrm{C}$ Aug. 17, 18, 1966; minimu, freezing point Jan. $30,31,1968$. TEMPERATURE $\left({ }^{\circ} \mathrm{C}\right)$ OF WATER, WATER YEAR OCTOBER 1968 TO SEPTEMBER 1969

OAY

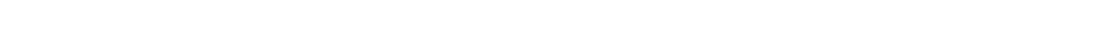

OCTOBER

$\begin{array}{lllllllllllllllllllllllllllllllllll}\text { MAXIMUM } & 17 & 17 & 18 & 18 & 17 & 17 & 16 & 14 & 14 & 15 & 15 & 14 & 14 & 13 & 13 & 14 & 14 & 14 & 14 & 14 & 14 & 14 & 14 & 14 & 14 & 14 & 14 & 14 & 14 & 12 & 12 & 15 \\ \text { MINIMUM } & 13 & 14 & 14 & 14 & 14 & 14 & 13 & 11 & 11 & 12 & 13 & 13 & 13 & 12 & 11 & 11 & 11 & 14 & 11 & 11 & 11 & 11 & 12 & 12 & 12 & 12 & 12 & 11 & 12 & 11 & 9 & 12\end{array}$

MINIMUM

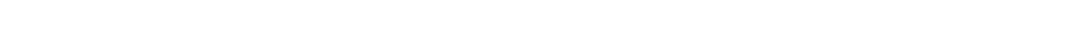

$\begin{array}{llllllllllllllllllllllllllllllllllll}\text { MINIMUM } & 9 & 10 & 1.1 & 10 & 10 & 9 & 9 & 9 & 10 & 10 & 10 & 9 & 7 & 6 & 6 & 7 & 8 & 9 & 9 & 8 & 7 & 9 & 7 & 9 & 7 & 6 & 5 & 5 & 5 & 5 & -- & 8 & 8 & \end{array}$

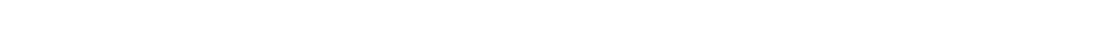

MINIMUM $6 \begin{array}{llllllllllllllllllllllllllllllllll}6 & 5 & 4 & 4 & 5 & 5 & 5 & 7 & 7 & 9 & 7 & 5 & 5 & 7 & 7 & 6 & 5 & 5 & 4 & 2 & 2 & 2 & 3 & 4 & 5 & 5 & 5 & 5 & 5 & 4 & 6 & 5\end{array}$

JANUARY

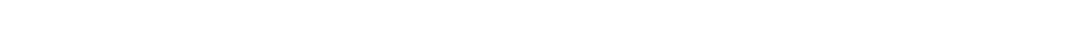

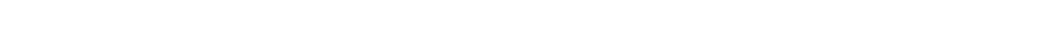

ERHUARY

$\begin{array}{llllllllllllllllllllllllllllllll}\text { MAXIMUM } & 5 & 6 & 6 & 6 & 6 & 6 & 7 & 7 & 7 & 8 & 8 & 7 & 6 & 6 & 6 & 7 & 7 & 7 & 7 & 6 & 5 & 5 & 5 & 4 & 4 & 5 & 6 & 6 & -2 & -- & -- \\ \text { MINIMUM } & 4 & 5 & 5 & 5 & 4 & 5 & 6 & 6 & 7 & 7 & 7 & 6 & 5 & 5 & 5 & 5 & 5 & 6 & 6 & 4 & 3 & 4 & 3 & 3 & 3 & 4 & 4 & 4 & -- & --\end{array}$

MINIMUM

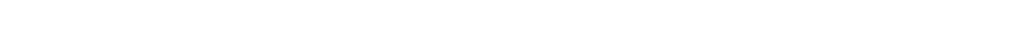

MINIMUM

POIL $\begin{array}{lllllllllllllllllllllllllllllllllll}\text { MAXIMUM } & 9 & 7 & 7 & 9 & 8 & 8 & 9 & 10 & 9 & 11 & 11 & 10 & 9 & 8 & 9 & 10 & 10 & 10 & 11 & 11 & 12 & 12 & 10 & 9 & 10 & 11 & 11 & 12 & 12 & 11 & --\end{array}$ MAY MINIMUM

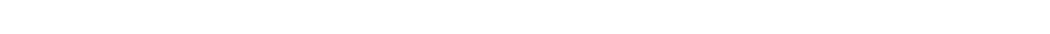
JUNE

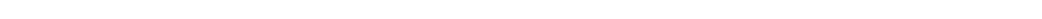

$\begin{array}{llllllllllllllllllllllllllllllll}\text { MAXIMUM } & 19 & 20 & 21 & 20 & 20 & 20 & 20 & 16 & 18 & 17 & 16 & 16 & 18 & 21 & 21 & 21 & 20 & 20 & 21 & 21 & 21 & 22 & 22 & 22 & 20 & 20 & 20 & 21 & 21 & 22 & -- \\ \text { MINIMUM } & 14 & 14 & 15 & 15 & 15 & 15 & 15 & 15 & 14 & 13 & 14 & 13 & 14 & 15 & 15 & 15 & 15 & 16 & 15 & 15 & 16 & 16 & 17 & 16 & 15 & 15 & 14 & 14 & 14 & 15 & -1\end{array}$ JULYY

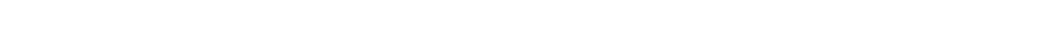
MINIMUM

AUGUSI

$\begin{array}{lllllllllllllllllllllllllllllllll} & & \end{array}$ MINIMUM

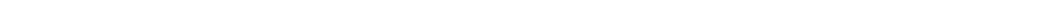

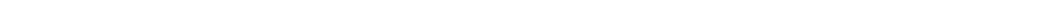


11413100 NORTH YUBA RIVER ABOVE SLATE CREEK, NEAR STRAWBERRY VALLEY, CALIF,

LOCATION.--Lat $39^{\circ} 31^{\prime} 29^{\prime \prime}$, long $121^{\circ} 05^{\prime} 26^{\prime \prime}$, in NE $\frac{1}{4} W_{4} \frac{1}{4}$ sec.9, T. 19 N., R.8 E., Yuba County, Tahoe National Forest, temperature recorder at gaging station on left bank, 500 ft upstream from Slate Creek and 2.8 miles southeast temperature recorder
of St rawberry valley.

DRAI NAGE AREA. --351 sq mi.

PERIOD OF RECORD. -- Hater temperatures: September 1968 to July 1969 (disconti nued).

EXTREMES. -- September 1968 to July 1969:

Water temperatures: Maximum, $22.0^{\circ} \mathrm{C}$ July $22,24,25,28,1969$; minimum, 2.0 ${ }^{\circ} \mathrm{C}$ Jan. 31, Feb. 4, 5, 1969.

TEMPERATURE $\left({ }^{\circ} \mathrm{C}\right.$ ) OF WATER, SEPTEMBER 1968

DAY

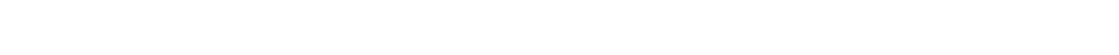

SEPTEMRER

MAXIMUM

TEIPERATURE ( $\left.{ }^{\circ} \mathrm{C}\right)$ OF WATER, OCTOBER 1968 TO JUY 1969

DAY

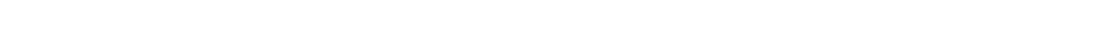

OCTUBFR

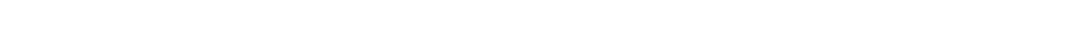

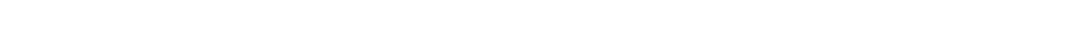

$\begin{array}{llllllllllllllllllllllllllllllllllll}\text { MAXIMUM } & 9 & 9 & 9 & 9 & 9 & 9 & 9 & 9 & 8 & 8 & 9 & 10 & 10 & 10 & 10 & 9 & 7 & 6 & 4 & 4 & 6 & 6 & 6 & 6 & 4 & 4 & 4 & 4 & 4 & 4 & -2 & 7 \\ \text { MINIMUM } & 8 & 8 & 8 & 9 & 8 & 8 & 9 & 8 & 8 & 8 & 8 & 9 & 10 & 9 & 9 & 7 & 6 & 4 & 4 & 4 & 4 & 5 & 6 & 4 & 4 & 4 & 4 & 4 & 4 & 4 & -2 & \end{array}$

MINIMUM

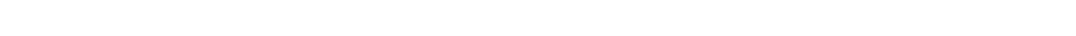

MANUARY

MAXIMUM

FFBRUARY

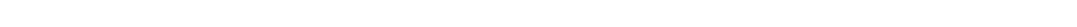

MARCH

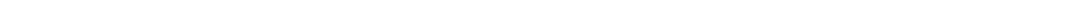

MINIMUM, --

APRIL

$\begin{array}{lllllllllllrllllllllllllllllllllll}\text { MAXIMUM } & 8 & 6 & 7 & 8 & 7 & 7 & B & 9 & 6 & 9 & 10 & 8 & 8 & 7 & 8 & 9 & 9 & 9 & 9 & 9 & 10 & 8 & 7 & 6 & 8 & 9 & 9 & 10 & 9 & 9 & -- & 8 \\ \text { MINIMUM } & 5 & 5 & 5 & 5 & 5 & 4 & 5 & 5 & 6 & 6 & 6 & 6 & 6 & 6 & 5 & 5 & 6 & 5 & 5 & 6 & 6 & 6 & 4 & 4 & 4 & 5 & 5 & 6 & 6 & 5 & -- & 5\end{array}$

MAY

MAXIMUIM:

MINIMUM

JUNE

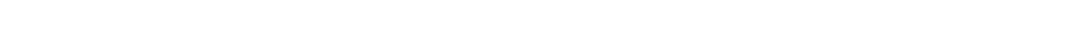

MUIY MIMUM

MAXIMUM 16161617171717181819181819201919202020202122512252212172251217

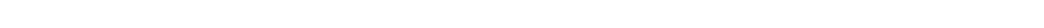

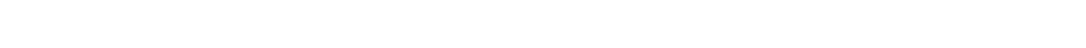

MAXIMUM --

MINIMUM

MAXIMUM

MAXIMUM 
11413520 NORTH YUBA RIVER BELOW NEW BULLARDS BAR DAM, NEAR NORTH SAN JUAN, CALIF.

LOCATION. --Lat $39^{\circ} 22^{\prime} 48^{\prime \prime}$, long $121^{\circ} 08^{\prime} 19^{\prime \prime}$, In SW $\frac{1}{4} \mathrm{NE} \frac{1}{4}$ sec. 36, T.18 N., R.7 E., Yuba County, Plumas Nat1onal Forest, temperature recorder at gaging station on right bank, 1.1 miles downstream from New Builards Bar Dam and
2 miles northwest of North San Juan.

DRAINAGE AREA. - -490 sq $\mathrm{m} 1$.

PERIOD OF RECORD, -Water temperatures: October 1966 to September 1969 (discontinued).

EXTREMES. -- 1966-68:

Water temperatures: Maximum, $25.0^{\circ} \mathrm{C}$ July $7,9,21,1968 ;$ minimum, $2.0^{\circ} \mathrm{C}$ on many days during December 1967
to February 1968.

REMARKS, -- Where no maximum or minimum is shown, temperature is once-daily reading.

TEMPERATURE $\left({ }^{\circ} \mathrm{C}\right)$ OF WATER, WATER YEAR OCTOBER 1968 TO SEPTEMBER 1969

DAY

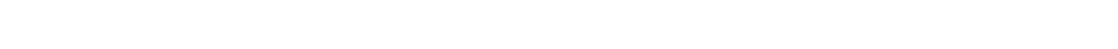

OCTUEER.. - -

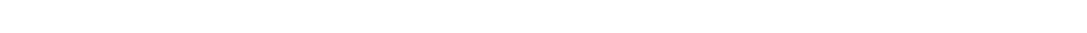

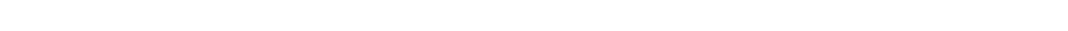

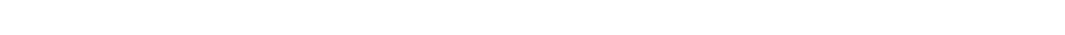

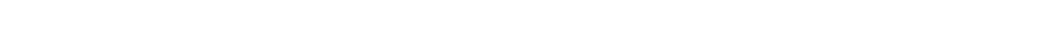

OFCEMHER, - -

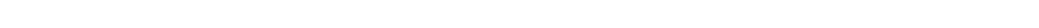
JаvUату.

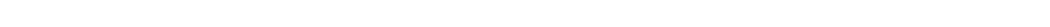
MinimuM

FEBRUARY, MAXIMUM -MIVIMUM -.

МАRСН.... -- -MAXIMUM MINIMUM -MAXIMUM MINIMUM MaY..... -МАXIMUM -MINIMUM MAXIX.. MINIMUM

JULY.....

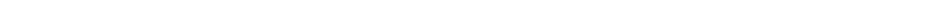

AUGUST... MAXIMUM

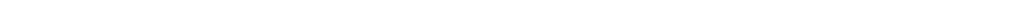
MIYIMUM MAXIMUM MINIMUM 
11417500 SOUTH YUBA RIVER AT JONES BAR, NEAR GRASS YALLEY, CALIF.

LOCATION.--Lat $39^{\circ} 17^{\prime} 32^{\prime \prime}$, long $121^{\circ} 06^{\prime} 13^{\prime \prime}$, near center of sec.32, T.17 N., R. 8 E., Nevada County, temperature recorder at gaging station on left bank at Jones Bar, $100 \mathrm{ft}$ upstream from Rush Creek, 0.9 mile downstream RAINAGE AREA. --308 sq m1.

PERIOD OF RECORD. -Water temperatures: February 1965 to September 1969.

Sediment records: October 1966 to September 1969 (partial records).

EXTREMES. - -1968-69:

Water temperatures: Naximum, $25.0^{\circ} \mathrm{C}$ July 20-30; minimum, freezing point Dec. 21, 22, Jan. $29,31$.

Period of record:

Water temperatures: Maximum, $27.0^{\circ} \mathrm{C}$ Aug. 2-4, 1966, June 27, Aug. 5-7, 1968; m1n1mum, freez1ng point on several days during December and January of most years.

TELPERATURE $\left({ }^{\circ} \mathrm{C}\right)$ OF WATER, WATER YEAR OCTOBER 1968 TO SEPTEMBER 1969

oAY

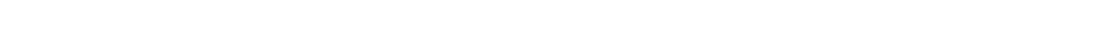

OC TOBER

MAXIMUM $17 \quad 17 \quad 17 \quad 17 \quad 17 \quad 17 \quad 16 \quad 14 \quad 13 \quad 13 \quad 14 \quad 14 \quad 14 \quad 13 \quad 11 \quad 12 \quad 12 \quad 12 \quad 12 \quad 1212 \quad 12 \quad 12 \quad 12 \quad 12 \quad 12 \quad 12 \quad 12 \quad 11 \quad 11 \quad 11 \quad 13$

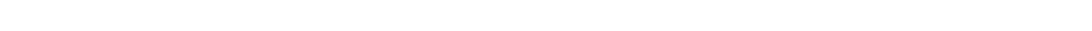

NOVEMBER

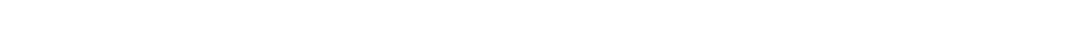

MINIMUM

DEEMAER

MAXIMUM --

MINIMUM

MAXIMUM

MINIMUM

FEBRUARY

MINIMUM

$M A C H$

MAXIMUM $6 \begin{array}{llllllllllllllllllllllllllllllllllll} & 6 & 5 & 6 & 7 & 7 & 7 & 7 & 7 & 6 & 7 & 6 & 6 & 7 & 7 & 7 & 7 & 8 & 8 & 8 & 7 & 8 & 9 & 9 & 9 & 8 & 9 & 9 & 9 & 9 & 10 & 10\end{array}$

MINIMUM

APR IL

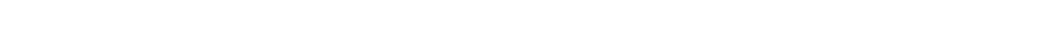
$M M Y$

INIMUM

$\begin{array}{lllllllllllllllllllllllllllllllll} & 11 & 11 & 11 & 12 & 12 & 12 & 13 & 13 & 13 & 11 & 10 & 10 & 10 & 10 & 11 & 11 & 11 & 10 & 10 & 11 & 12 & 12 & 11 & 11 & 10 & 10 & 12 & 12 & 13 & 13\end{array}$ JUNE

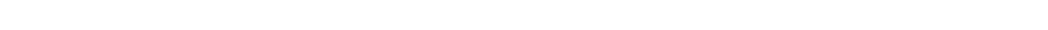

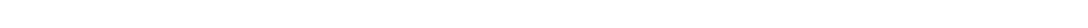
JULY

$\begin{array}{llllllllllllllllllllllllllllllllllll}\text { MAXIMUM } & 20 & 20 & 21 & 21 & 21 & 22 & 22 & 22 & 23 & 23 & 23 & 23 & 23 & 24 & 24 & 24 & 24 & 24 & 24 & 25 & 25 & 25 & 25 & 25 & 25 & 25 & 25 & 25 & 25 & 25 & 24 & 23 \\ \text { MINIMUM } & 16 & 17 & 17 & 18 & 18 & 19 & 21 & 21 & 20 & 20 & 20 & 20 & 20 & 21 & 21 & 20 & 21 & 21 & 21 & 21 & 22 & 22 & 23 & 22 & 22 & 22 & 22 & 21 & 21 & 21 & 20 & 20\end{array}$

AUGUS r

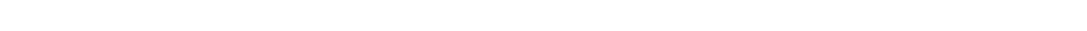

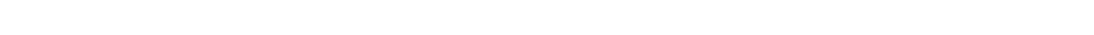

SEPTEMHER $\begin{array}{lllllllllllllllllllllllllllllllllll}\text { MAXIMUM } & 22 & 22 & 23 & 23 & 22 & 22 & 22 & 23 & 23 & 22 & 22 & 22 & 22 & 21 & 20 & 19 & 19 & 19 & 20 & 19 & 19 & 19 & 19 & 19 & 19 & 19 & 19 & 19 & 19 & 18 & -2 & 21 \\ \text { MINIMUM } & 18 & 19 & 19 & 20 & 19 & 19 & 20 & 20 & 20 & 20 & 20 & 19 & 19 & 19 & 17 & 17 & 17 & 17 & 18 & 17 & 16 & 16 & 16 & 16 & 16 & 17 & 17 & 17 & 18 & 17 & -2 & 18\end{array}$

SUSPENDED-SEDIMENT DISCHARGE MEASUREMENTS AND PARTICLE-SIZE DISTRIBUTION, WATER YEAR OCTOBER 1968 TO SEPTEMBER 196 IMETHODS OF ANALYSIS: B, BOTIOM WITHORAWAL IUBE; C, CHEMICALLY DISPERSED; N, IV NATIVE WATER; P, PIPET; S, SIEVE:

\begin{tabular}{|c|c|c|c|c|c|c|c|c|c|c|c|c|c|c|c|c|c|}
\hline \multirow{3}{*}{\multicolumn{2}{|c|}{ DATF }} & \multirow[b]{3}{*}{ TIME } & \multicolumn{4}{|c|}{$\begin{array}{l}\text { WATER } \\
\text { TEM- }\end{array}$} & \multicolumn{11}{|c|}{ PARTICLE SIZE } \\
\hline & & & $\begin{array}{l}\text { PERA- } \\
\text { TURE }\end{array}$ & DISCHARGE & $\begin{array}{l}\text { CONCEN- } \\
\text { TRATIUN }\end{array}$ & $\begin{array}{l}\text { SEDIMENT } \\
\text { DISCHARGE }\end{array}$ & PERCE & & INER & THAN & THE SI & ILE & (IN MII & ILLIMEI & [ERS) & INDIC & ATED \\
\hline & & & $(C)$ & (CFS) & $(M G / L)$ & (TONS/OAY) & .002 & .004 & .008 & .016 & .031 & .062 & 2.125 & 5.250 & .500 & 1.00 & 2.00 \\
\hline AUG & 15,1968 & 1615 & 22 & 44 & 1 & .10 & -- & - & - & -- & -- & - & - & -- & -- & $-\infty$ & -- \\
\hline OC $\mathrm{T}$ & $31 \ldots \ldots$ & 0855 & 9 & 73 & 4 & .79 & -- & -- & - & -- & -- & -- & - & -- & - & -- & -- \\
\hline JAN & 10,1969 & 1400 & 3 & 220 & 2 & 1.2 & -- & -- & - & -- & - & - & -- & -- & -- & -- & - \\
\hline JaN & $22 \ldots \ldots$ & 1200 & 7 & 5370 & 1000 & 14500 & 5 & 8 & 10 & 13 & 16 & 19 & 25 & 36 & 56 & 75 & 88 \\
\hline FEB & $6 \ldots \ldots$ & 1025 & 2 & 1160 & 30 & 94 & -- & -- & $=$ & -- & -- & 55 & 67 & 78 & 92 & 100 & -- \\
\hline MAR & $5 \ldots \ldots$ & 1120 & 5 & 750 & 36 & 73 & -- & -- & - & -- & -- & - & -- & -- & - & $\cdots$ & -- \\
\hline$A P R$ & $3 \ldots \ldots$ & 1035 & 7 & 1000 & 49 & 132 & -- & $-\infty$ & - & - & -- & $\cdots$ & -- & -- & -- & - & -- \\
\hline$A P R$ & $99 . . .$. & 1000 & 10 & 860 & 19 & 44 & -- & -- & - & - & -- & - & -- & - & -- & -- & - \\
\hline MAY & $22 \ldots \ldots$ & 1510 & 10 & 3780 & 121 & 1230 & -- & - & $\sim$ & -- & -- & -- & -- & -- & - & -+ & -- \\
\hline JUN & & 1640 & 12 & 2160 & 26 & 152 & -- & $-\infty$ & - & -- & - & - & -- & -- & - & $-\infty$ & -- \\
\hline JUL & $2 \ldots \ldots$ & 1230 & I 8 & 151 & 25 & 10 & -- & - & -- & - & -- & $\cdots$ & -- & -- & -- & -- & -- \\
\hline SEP & $4 \ldots \ldots$ & 0945 & 20 & 54 & 1 & .15 & -- & -- & $\sim$ & - & -- & $\sim$ & -- & -- & -- & -- & -- \\
\hline EP & $30 \ldots \ldots$ & 1525 & 18 & 55 & 3 & .45 & - & -- & - & -- & -- & - & -- & -- & - & - & \\
\hline
\end{tabular}




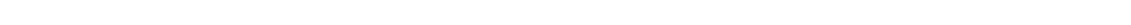
Bridge in Marysville, approximate 1 y 2 miles upstream from mouth and 4.2 miles downstream from gaging station near Marysville.

DRAINAGE AREA. -1, $339 \mathrm{sq} \mathrm{mi}$ (at gaging station).

PERIOD OF RECORD. --Chemical analyses: October 1953 to September 1963.

Water temperatures: October 1963 to September 1969.

EXTREMES, --1968-69:

Matex temperatures: Maximum, $29.0^{\circ} \mathrm{C}$ July 17-22, Aug. 4.

Period of record:

Water temperatures: Maximum (1963-67, 1968-69), $29.5^{\circ} \mathrm{C}$ on several days during July 1964 and August 1966 ; minimum $(1963-68), 4.5^{\circ} \mathrm{CFeb} .17,1966$.

REMARKS. --Recorder malfunction Det. 1-4, Nov. 7-12, Jan. 10-17, Max. 13-27, Apr. 17-25, June 12-16, TEMPERATURE $\left({ }^{\circ} \mathrm{C}\right)$ OF WATER, WATER YEAR OCTOBER 1968 TO SEPTEMBER 1969

DAY

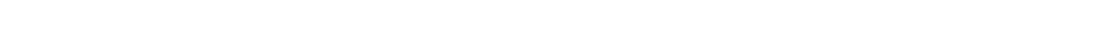

OCTOBER

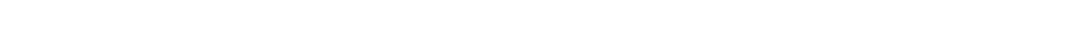
MINIMUM
NOVMBER

$\begin{array}{lllllllllllllllllllllllllllllllllllllll}\text { MAXIMUM } & 17 & 16 & 16 & 17 & 17 & 16 & - & - & -- & -- & - & - & 13 & 12 & 12 & 13 & 14 & 14 & 14 & 13 & 13 & 13 & 13 & 13 & 12 & 12 & 12 & 12 & 11 & 11 & -- & 13 \\ \text { MINIMUM } & 15 & 16 & 16 & 14 & 15 & 14 & -- & -- & -- & -- & - & 11 & 11 & 12 & 12 & 12 & 13 & 12 & 13 & 12 & 12 & 12 & 11 & 11 & 9 & 10 & 9 & 10 & 11 & -- & 12\end{array}$

DINIMUM

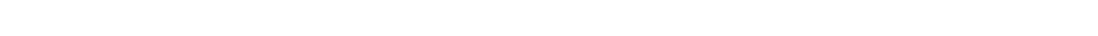

MINIMUM

MAXIMIMUM

FEBRUARY

MAXIMUM

MINIMUM

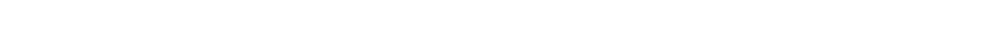

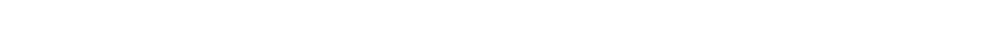

MAXIMUM

MAXIMUM

APRIL

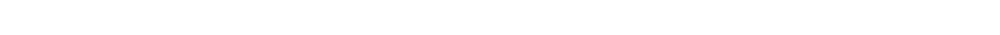

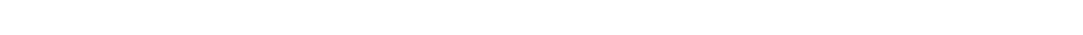

MAY MAXI

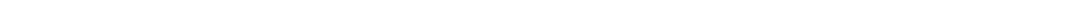

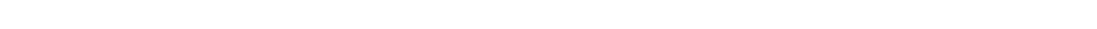

JUNE

$\begin{array}{lllllllllllllllllllllllllllllllllllll}\text { MAXIMUM } & 16 & 16 & 17 & 18 & 18 & 19 & 19 & 18 & 17 & 18 & 19 & -- & -- & -- & -- & 22 & 21 & 22 & 22 & 22 & 22 & 23 & 23 & 23 & 22 & 22 & 22 & 23 & 23 & -- & 20 \\ \text { MINIMUUM } & 13 & 13 & 13 & 13 & 13 & 14 & 14 & 14 & 14 & 14 & 11 & - & -- & -- & -- & 17 & 17 & 17 & 17 & 17 & 17 & 18 & 18 & 19 & 18 & 18 & 19 & 19 & 20 & - & 16\end{array}$ JULY M

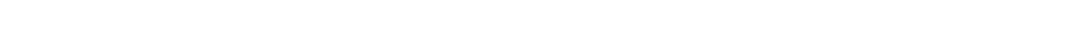

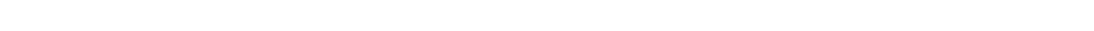
AUGUST

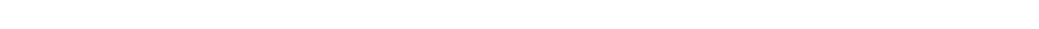

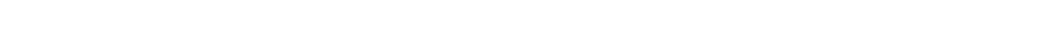
SEPYEMBER

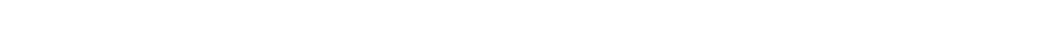

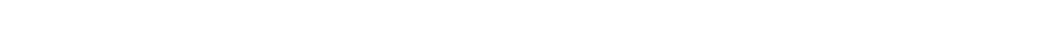


11424000 BEAR RIVER NEAR WHEATLAND, CALIF.

LOCATION. --Lat $39^{\circ} 00^{\prime} 01^{\prime \prime}$, long $121^{\circ} 24^{\prime} 21^{\prime \prime}$, in SEłSwł sec. 3, T. 13 N., R. 5 E., Yuba County, near gaging station at Dridge on U.S. Highway $99 \mathrm{E}, 1 \mathrm{mile}$ southea st of wheatland and $6.5 \mathrm{miles}$ downstream from Rock Creek.

DRAINAGE AREA. - $292 \mathrm{sq}$ mi.

PERIOD OF RECORD. --Chemical analyses: October 1953 to September 1969.

REMARXs. --Records furnished by California Department of water Resources and reviewed by U.S. Geological Survey. CHEMICAL ANALYSES, WATER YEAR OCTOBER 1968 TO SEPTEMBER 1969

\begin{tabular}{|c|c|c|c|c|c|c|c|c|c|c|c|c|}
\hline DATE & TIME & $\begin{array}{l}\text { OIS- } \\
\text { CHARGE } \\
\text { (CFS) }\end{array}$ & $\begin{array}{l}\text { TEMPER- } \\
\text { ATURE } \\
\text { IDEG C) }\end{array}$ & $\begin{array}{l}\text { DIS- } \\
\text { SOLVED } \\
\text { OXYGEN } \\
\text { (MG/L) }\end{array}$ & $\begin{array}{l}\text { CAL- } \\
\text { CIUM } \\
\text { (CA) } \\
\text { (MG/L) }\end{array}$ & $\begin{array}{c}\text { MAG- } \\
\text { NE- } \\
\text { SIUM } \\
\text { (MG) } \\
\text { (MG/L) }\end{array}$ & $\begin{array}{l}\text { SODIUM } \\
\text { (NA) } \\
\text { (MG/L) }\end{array}$ & $\begin{array}{l}\text { PO- } \\
\text { TAS- } \\
\text { SIUM } \\
\text { (K) } \\
\text { (MG/L) }\end{array}$ & $\begin{array}{l}\text { BICAR- } \\
\text { BONATE } \\
\text { (HCO3) } \\
\text { (MG/L) }\end{array}$ & $\begin{array}{l}\text { CAR- } \\
\text { BONATE } \\
\text { (CO3) } \\
\text { (MG/L) }\end{array}$ & $\begin{array}{l}\text { SULFATE } \\
\text { (504) } \\
(\mathrm{MG} / \mathrm{L})\end{array}$ & $\begin{array}{l}\text { CHLO- } \\
\text { RIOE } \\
\text { ICL) } \\
\text { (MGIL }\end{array}$ \\
\hline $\begin{array}{l}\text { Nov. } \\
\text { 07... }\end{array}$ & 1400 & 15 & 16 & 12.4 & 17 & - & 0.0 & -- & 81 & 0 & - & 7. \\
\hline $\begin{array}{l}\text { DEC. } \\
13 \ldots . . \\
\text { JAN. }\end{array}$ & 1040 & 10 & 7 & 13.1 & 17 & -- & 5.8 & - & 81 & 0 & $\cdots$ & 6. \\
\hline FEB... & 1400 & 14 & 10 & 13.5 & 15 & -- & 5.0 & - & 73 & 0 & $\cdots$ & 4. \\
\hline MA... & 1245 & 2870 & 8 & 13.3 & 5.8 & - & $t .8$ & -- & 27 & 0 & $\cdots$ & 2. \\
\hline $\begin{array}{l}05 \ldots \\
\triangle P R .\end{array}$ & 0945 & 1660 & 7 & 13.7 & 6.4 & - & 2.4 & -- & 32 & 0 & -- & 2. \\
\hline MAY & 1230 & 1130 & 16 & 10.7 & 6.9 & $=-$ & 2.7 & -- & 33 & 0 & -- & \\
\hline OQ... & 0945 & 260 & 18 & 9.4 & B. 1 & - & 2.8 & -- & 32 & 0 & $\cdots$ & \\
\hline $\operatorname{JuL}_{\text {Jü }}^{18 .}$ & 1230 & 101 & 22 & 8.6 & 7.8 & - & 3.2 & -- & 35 & 0 & - & \\
\hline $\begin{array}{l}\text { O1... } \\
\text { AUG. }\end{array}$ & 1345 & 21 & 27 & 8.7 & 14 & -- & 4.2 & -- & 63 & 0 & - & 4 \\
\hline $\begin{array}{l}07 . . . \\
\text { SEPT. }\end{array}$ & 1220 & 18 & 27 & 8.8 & 15 & -- & 5.5 & $=-$ & 73 & 0 & -- & \\
\hline $03 . \ldots$ & 0930 & 18 & 23 & 8.5 & 12 & 7.5 & 4.6 & .4 & 60 & 0 & 14 & 5.1 \\
\hline
\end{tabular}

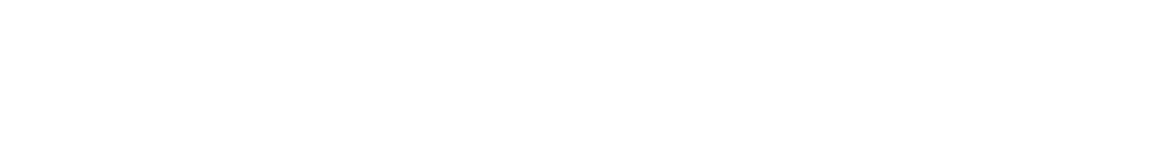

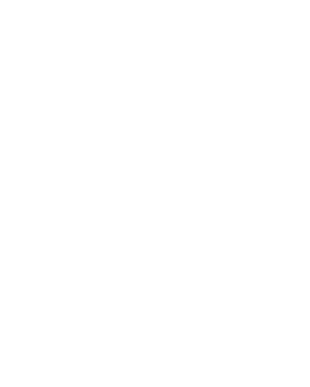

$\begin{array}{rrrrr}- & - & 83 & 17 & 24 \\ -- & -- & 90 & 24 & 23 \\ - & -- & 85 & 25 & 23 \\ -- & - & 28 & 6 & 21 \\ -- & - & 31 & 5 & 25 \\ - & -- & 32 & 5 & 25 \\ - & - & 31 & 5 & 23 \\ - & -- & 34 & 5 & 26 \\ 74 & -- & 62 & 10 & 21 \\ - & -10 & 61 & 12 & 14\end{array}$

$\begin{array}{llll}.4 & 66 & 8.2 & 188 \\ .4 & 66 & 7.7 & 193 \\ .4 & 60 & 7.8 & 172 \\ .2 & 22 & 7.7 & 65 \\ .3 & 26 & 7.1 & 73 \\ .3 & 27 & 7.4 & 75 \\ .3 & 26 & 7.7 & 78 \\ .3 & 29 & 7.7 & 83 \\ .3 & 52 & 7.9 & 129 \\ .4 & 60 & 8.2 & 169 \\ .3 & 49 & 7.6 & 146\end{array}$




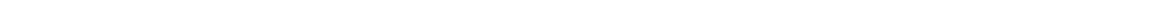
on left bank 3.8 miles downstream from gaging station at Nicolaus, 3.9 miles southwest of Nicolaus, $6.6 \mathrm{miles}$ northeast of Knights Landing, and at mile 5.6.

DRAINAGE AREA, - -5, $921 \mathrm{sq} \mathrm{mi}$ (at gaging station).

PERIOD OF RECORD,--Chemical analy ses: March 1951 to June 1966.

Water temperatures: Harch 1951 to September 1958, November 1959 to September 1969.

EXTREMES. $--1968-69$ :

Water temperatures: Maximum, $28.0^{\circ} \mathrm{C}$ July $17-23 ; \mathrm{minimum}, 6.0^{\circ} \mathrm{C}$ Dec. $21-23$, Jan. $9,10$.

Period of record:
Water temperatures: Maximum, $34.5^{\circ} \mathrm{C}$ July 21,1961 ; minimum, freezing point Jan. 3-6, 1961.

REMARKS.--Prior to 1964 water year thermograph located at gaging station 3.8 miles upstream at highway bridge at Nicolaus, and 2,9 miles downstream from Bear River. Clock stopped Nov. 15-29, Feb. 1-14; ranges 1n temperature, $9.0^{\circ} \mathrm{C}$ to $12.0^{\circ} \mathrm{C}$ and $8.0^{\circ} \mathrm{C}$ to $9.0^{\circ} \mathrm{C}$, respectively.
Sept. $5,9,10,14-30$; no temperature ranges ave 11 able.

TEMPERATURE ( $\left.{ }^{\circ} \mathrm{C}\right)$ OF WATER, WATER YEAR OCTOBER 1968 TO SEPTEMBER 1969

DAY

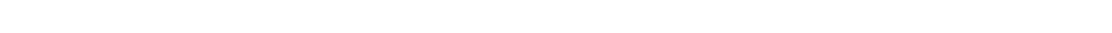

OC TOBER

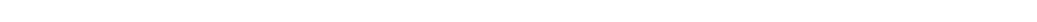

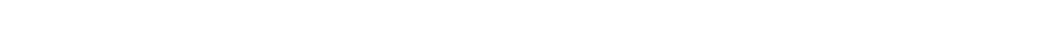

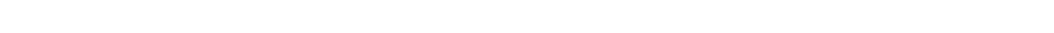

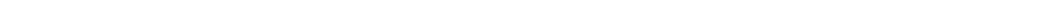
DECEMHER

MAXINUM $10 \begin{array}{lllllllllllllllllllllllllllllllll} & 10 & 9 & 9 & 9 & 9 & 8 & 10 & 11 & 11 & 11 & 10 & 9 & 10 & 10 & 10 & 9 & 9 & 9 & 8 & 7 & 6 & 7 & 8 & 9 & 8 & 8 & 8 & 8 & 8 & 8 & 9\end{array}$

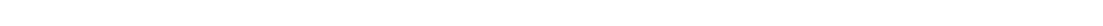

$\begin{array}{rllllllllllllllllllllllllllllllllll}\text { MAXIMUM } & 8 & 8 & 8 & 8 & 8 & 8 & 8 & 8 & 7 & 7 & 7 & 8 & 9 & 9 & 9 & 9 & 9 & 9 & 10 & 10 & 11 & 11 & 10 & 9 & 9 & 10 & 10 & 9 & 8 & 8 & 8 & 9 \\ \text { MINIMUM } & 7 & 8 & 8 & 8 & 8 & 8 & 8 & 7 & 6 & 6 & 7 & 7 & 8 & 9 & 8 & 8 & 8 & 8 & 8 & 10 & 10 & 10 & 9 & 9 & 9 & 9 & 9 & 8 & 7 & 8 & 7 & 8\end{array}$ $\begin{array}{cllllllllllllllllllllllllllllllll}\text { MINIMUM } & 7 & 8 & 8 & 8 & 8 & 8 & 8 & 7 & 6 & 6 & 7 & 7 & 8 & 9 & 8 & 8 & 8 & 8 & 8 & 10 & 10 & 10 & 9 & 9 & 9 & 9 & 9 & 8 & 7 & 8 & 7 & 8\end{array}$

MAXIMUM -.

MINIMUM -

MARCH

$\begin{array}{lllllllllllllllllllllllllllllllll}\text { MAXIMUM } & 9 & 8 & 9 & 9 & 10 & 10 & 10 & 10 & 10 & 10 & 10 & 10 & 10 & 10 & 10 & 10 & 10 & 11 & 11 & 10 & 10 & 10 & 11 & 11 & 11 & 12 & 13 & 13 & 13 & 14 & 14 & 11 \\ \text { MININUM } & 8 & 8 & 8 & 8 & 8 & 9 & 9 & 9 & 9 & 9 & 9 & 9 & 9 & 9 & 9 & 9 & 9 & 9 & 10 & 9 & 9 & 9 & 9 & 9 & 10 & 10 & 11 & 12 & 12 & 12 & 13 & 9\end{array}$ APRIL

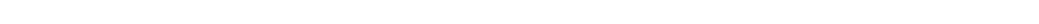

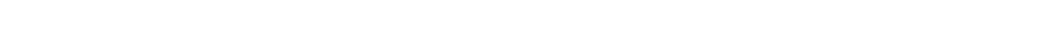
$\begin{array}{llllllllllllllllllllllllllllllll}\text { MAXIMUM } & 14 & 15 & 15 & 16 & 17 & 18 & 18 & 18 & 19 & 19 & 19 & 18 & 17 & 17 & 17 & 16 & 15 & 15 & 15 & 16 & 16 & 16 & 16 & 16 & 16 & 16 & 16 & 17 & 18 & 19 & 19 \\ \text { MINIMUM } & 14 & 14 & 14 & 14 & 15 & 16 & 16 & 16 & 17 & 18 & 18 & 17 & 16 & 16 & 16 & 15 & 14 & 14 & 14 & 14 & 15 & 15 & 15 & 15 & 15 & 15 & 15 & 15 & 16 & 17 & 18\end{array}$ JUNE

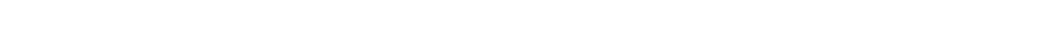

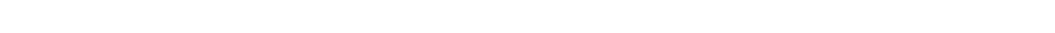

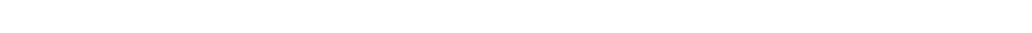
$\begin{array}{lllllllllllllllllllllllllllllllllll}22 & 23 & 23 & 22 & 24 & 24 & 23 & 23 & 24 & 24 & 24 & 23 & 23 & 24 & 25 & 25 & 25 & 25 & 25 & 24 & 25 & 23 & 23 & 22 & 22 & 23 & 23 & 23 & 23\end{array}$

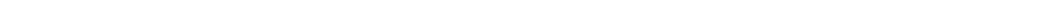

SFPTEMBER

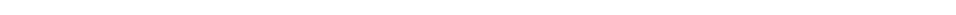

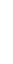


11427000 NORTH FORK AMERICAN RIVER AT NORTH FORK DAM, CALIF,

LOCATION, --Lat $38^{\circ} 56^{\prime} 15^{\prime \prime}$, long $121^{\circ} 01^{\prime} 25^{\prime \prime}$, in SW 1 NW $\frac{1}{4}$ sec. $31, \mathrm{~T} .13 \mathrm{~N} .$, R. 9 E., Placer County, temperature recorder at gaging station on left bank, $50 \mathrm{ft}$ upstream from spiliway of North Fork Dam, 2 mi les upstream from Middle Fork, and 4 miles nor theast of Auburn.

DRAINAGE AREA。--342 sq $\pi 1$.

PERIOD OF RECORD.--Water temperatures: November 1959 to September 1969.

EXTREMES, --1968-69:

Water temperatures: Maximum, $26.0^{\circ} \mathrm{C}$ July 28-30; minimum, 7. $0^{\circ} \mathrm{C}$ on many days during December to March.

Period of record: Water temperatures: Maximum, $26.5^{\circ} \mathrm{C}$ on several days in July and August of rost years; minlmum, $4.5^{\circ} \mathrm{C} \mathrm{Jan} .21$,
1967 .

REMARKS, --Recorder malfunction June 26 to JuIy 1.

TEMPERATURE $\left({ }^{\circ} \mathrm{C}\right)$ OF WATER, WATER YEAR OCTOBER 1968 TO SEPTELBER 1969

DAY

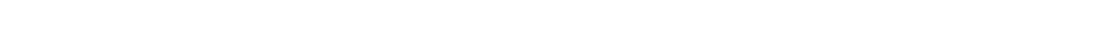

OC TURER

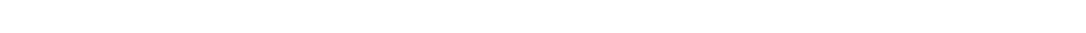

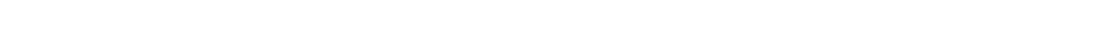

NIVEMBER

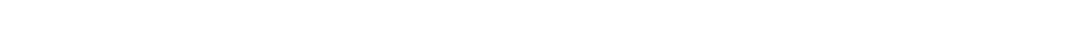

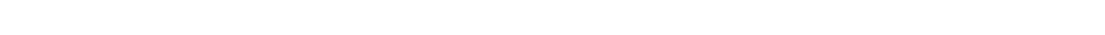

$\begin{array}{llllllllllllllllllllllllllllllllllllll}\text { MAXIMUM } & 11 & 11 & 10 & 10 & 10 & 10 & 10 & 10 & 10 & 10 & 10 & 9 & 9 & 9 & 9 & 9 & 9 & 9 & 9 & 9 & 9 & 9 & 8 & 8 & 8 & 8 & 7 & 7 & 7 & 7 & 7 & 9\end{array}$

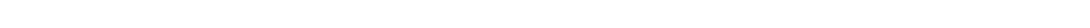

AVUARY

$\begin{array}{lllllllllllllllllllllllllllllllllllll}7 & 7 & 7 & 7 & 7 & 7 & 7 & 7 & 7 & 7 & 7 & 7 & 7 & 8 & 8 & 8 & 8 & 8 & 8 & 8 & 8 & 8 & 8 & 8 & 8 & 8 & 8 & 8 & 8 & 8 & 8 & 8 \\ 7 & 7 & 7 & 7 & 7 & 7 & 7 & 7 & 7 & 7 & 7 & 7 & 7 & 7 & 8 & 8 & 8 & 8 & 7 & 8 & 8 & 8 & 8 & 8 & 8 & 8 & 8 & 8 & 8 & 8 & 7 & 7\end{array}$

MAXIMUM

MINIMUM

MARCH

$\begin{array}{lllllllllllllllllllllllllllllllllllll}1 & 7 & 7 & 7 & 7 & 8 & 8 & 8 & 8 & 8 & 8 & 8 & 8 & 8 & 8 & 8 & 8 & 8 & 8 & 8 & 8 & 8 & 8 & 8 & 8 & 8 & 7 & 7 & -- & - & --\end{array}$

$\begin{array}{llllllllllllllllllllllllllllllllll}8 & 8 & 8 & 8 & 8 & 8 & 8 & 9 & 9 & 9 & 9 & 9 & 9 & 9 & 9 & 9 & 9 & 9 & 9 & 9 & 9 & 10 & 10 & 10 & 10 & 11 & 11 & 11 & 11 & 11 & 11\end{array}$

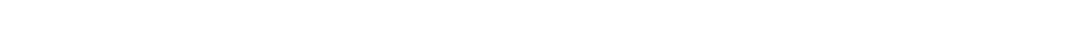

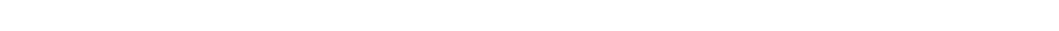

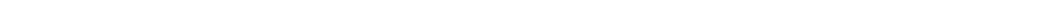
JUNE

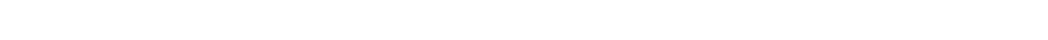
JiY $\begin{array}{llllllllllllllllllllllllllllllll}\text { MAXIMUM } & -- & 21 & 21 & 21 & 22 & 22 & 22 & 22 & 23 & 23 & 23 & 23 & 23 & 23 & 23 & 24 & 24 & 24 & 24 & 24 & 25 & 25 & 25 & 25 & 25 & 25 & 25 & 26 & 26 & 26 & 25 \\ \text { MINIMUM } & -- & 21 & 21 & 21 & 21 & 21 & 22 & 22 & 22 & 23 & 23 & 23 & 23 & 23 & 23 & 23 & 24 & 24 & 24 & 24 & 24 & 24 & 24 & 25 & 25 & 25 & 25 & 25 & 25 & 25 & 25\end{array}$ AUGUSI $\begin{array}{lllllllllllllllllllllllllllllllllll}\text { MAXIMUM } & 25 & 25 & 25 & 25 & 24 & 24 & 24 & 24 & 24 & 24 & 24 & 24 & 24 & 24 & 24 & 24 & 24 & 24 & 24 & 24 & 24 & 24 & 24 & 24 & 23 & 23 & 23 & 23 & 23 & 23 & 23 & 24 \\ \text { MINIMUM } & 25 & 25 & 25 & 24 & 24 & 24 & 24 & 24 & 24 & 24 & 24 & 24 & 24 & 24 & 24 & 24 & 24 & 24 & 24 & 24 & 23 & 23 & 23 & 23 & 23 & 23 & 23 & 23 & 23 & 23 & 23 & 24\end{array}$ MINIMUM

SEPIEMAE $\begin{array}{lllllllllllllllllllllllllllllllllllll}\text { MAXIMUM } & 23 & 23 & 23 & 23 & 23 & 23 & 23 & 23 & 23 & 23 & 23 & 23 & 23 & 23 & 23 & 23 & 23 & 23 & 22 & 22 & 22 & 22 & 21 & 21 & 21 & 21 & 21 & 21 & 21 & 21 & -- & 22 \\ \text { MINIMUM } & 23 & 23 & 23 & 23 & 23 & 23 & 23 & 23 & 23 & 23 & 23 & 23 & 23 & 23 & 23 & 23 & 23 & 22 & 22 & 22 & 22 & 21 & 21 & 21 & 21 & 21 & 21 & 21 & 21 & 21 & -2 & 22\end{array}$ 
LOCATION, --Lat $38^{\circ} 56^{\prime} 03^{\prime \prime}$, long $120^{\circ} 52^{\prime} 21^{\prime \prime}$, In SW $\frac{1}{1}$ IW sec. 33, T. 13 N., R. 10 E., E1 Dorado County, temperature recorder at gaging station on right bank, 0.7 mile downstream from West Canyon and 2.6 miles northwest of

DRAINAGE AREA. $--12.5 \mathrm{sq} \mathrm{mi}$.

PERIOD OF RECORD, -- Water temperatures: July 1966 to September 1969.

EXTREMES. --1968-69: Water temperatures: Maximum, $19,0^{\circ} \mathrm{C}$ on several days during July and August; minimum, 4.0 $0^{\circ} \mathrm{C} \mathrm{Dec} .21,22$,
Jan. 31 , Feb. 3,6.

Period of record:

Water temperatures: Maximum, $23.5^{\circ} \mathrm{C}$ July 22,$1966 ; \operatorname{mint}$ mum, $1.0^{\circ} \mathrm{C}$ Dec. $17,18,1967$.

TEMPERATURE $\left({ }^{\circ} \mathrm{C}\right)$ OF WATER, WATER YEAR OCTOBER 1968 TO SEPTEMBER 1969

DAY

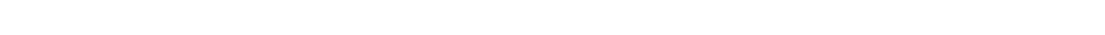

OCTOBER

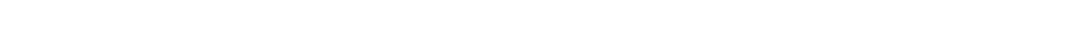

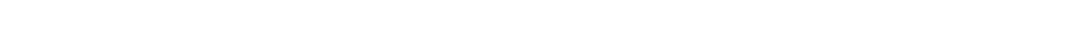

NOVEMBER

$\begin{array}{lllllllllllllllllllllllllllllllllll}\text { MAXIMUM } & 9 & 9 & 10 & 10 & 10 & 9 & 9 & 9 & 9 & 9 & 9 & 9 & 9 & 8 & 8 & 9 & 9 & 9 & 9 & 9 & 9 & 10 & 10 & 9 & 9 & 8 & 8 & 7 & 7 & 7 & -- & 9 \\ \text { MINIMUM } & 8 & 9 & 9 & 10 & 9 & 8 & 9 & 9 & 9 & 9 & 8 & 9 & 8 & 6 & 7 & 8 & 8 & 9 & 8 & 8 & 8 & 9 & 8 & 9 & 8 & 7 & 7 & 6 & 6 & 7 & -2 & 8\end{array}$

DECEMAER

$\begin{array}{llllllllllllllllllllllllllllllllll}\text { MAXIMUM } & 7 & 7 & 0 & 6 & 6 & 6 & 6 & 7 & 7 & 8 & 8 & 8 & 7 & 7 & 7 & 7 & 7 & 6 & 6 & 6 & 5 & 5 & 6 & 7 & 7 & 7 & 7 & 7 & 7 & 7 & 6 & 7\end{array}$

MINIMUM $7 \begin{array}{llllllllllllllllllllllllllllllllllllll}7 & 6 & 5 & 6 & 6 & 6 & 6 & 6 & 7 & 7 & 8 & 7 & 6 & 6 & 7 & 7 & 6 & 6 & 6 & 5 & 4 & 4 & 5 & 6 & 7 & 7 & 6 & 6 & 6 & 6 & 6 & 6\end{array}$

JANUARY

$\begin{array}{llllllllllllllllllllrrrrrrrrrrrrrr}\text { MAXIMUM } & 6 & 6 & 6 & 6 & 6 & 6 & 6 & 7 & 6 & 6 & 6 & 7 & 8 & 8 & 8 & 7 & 7 & 8 & 9 & 10 & 10 & 9 & 9 & 8 & 9 & 9 & 8 & 6 & 6 & 6 & 5 & 7 \\ \text { MINIMUM } & 5 & 5 & 6 & 6 & 5 & 6 & 6 & 6 & 5 & 5 & 5 & 6 & 7 & 8 & 7 & 7 & 6 & 6 & 8 & 9 & 9 & 8 & 8 & 7 & 8 & 8 & 6 & 5 & 5 & 5 & 4 & 6\end{array}$

FEBRUARY

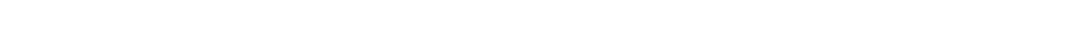

MCH

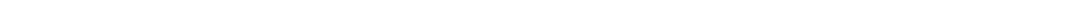

PQIL

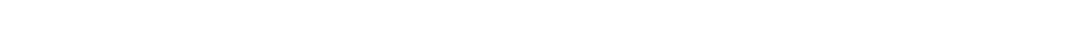

MAY

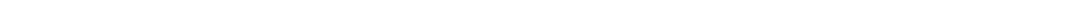

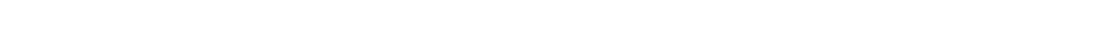

JUNE

$\begin{array}{lllllllllllllllllllllllllllllllllllll}\text { MAXIMUM } & 16 & 17 & 16 & 17 & 17 & 17 & 16 & 16 & 15 & 15 & 15 & 15 & 15 & 16 & 16 & 16 & 16 & 16 & 17 & 17 & 17 & 17 & 17 & 17 & 16 & 16 & 16 & 16 & 16 & 17 & -- \\ \text { MINIMUM } & 15 & 15 & 15 & 15 & 15 & 15 & 15 & 15 & 14 & 14 & 14 & 14 & 14 & 14 & 15 & 15 & 15 & 15 & 15 & 15 & 15 & 15 & 16 & 15 & 15 & 14 & 14 & 14 & 14 & 14 & --\end{array}$

JULY

MAXIMUM $1717 \quad 1717 \quad 17 \quad 1717 \quad 17 \quad 18181818 \quad 18181818191819191919191919191919191919$

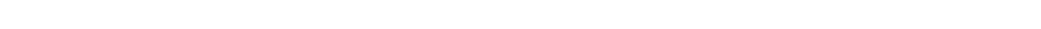
AUGUST

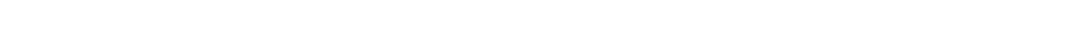

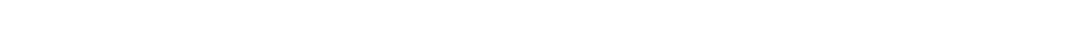
SEPIEMBER

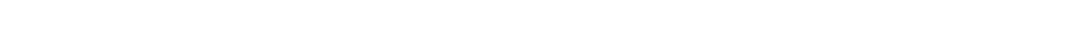


11439500 SOUTH FORK AMERICAN RIVER NEAR KYBURZ, CALIF.

LOCATION. --Lat $38^{\circ} 45^{\prime} 49^{\prime \prime}$, long $120^{\circ} 19^{\prime} 39^{\prime \prime}$, In SW fSW $\frac{1}{4}$ sec.29, T.11 N., R.15 E., E1 Dorado County, Eldorado National Forest, temperature recorder at gaging station on right bank beside U.S. Highway $50,0.8$ mile downstream from Silver Fork of South Fork and 1.9 miles southwest of Kyburz.

DRAINAGE AREA. --193 sq $\mathrm{ml}$.

PERIOD OF RECORD.--Water temperatures: August 1966 to September 1969.

EXTREMES, --1968-69:

Water temperatures: Maximum, $22.0^{\circ} \mathrm{C}$ July 31 , Aug. 14-17; minimum, $2.0^{\circ} \mathrm{C}$ on several days during January.

Period of record: Water temperatures: Maximum, $24.0^{\circ} \mathrm{C}$ June 26, 27, July 4, 8, 1968; minimum, $2.0^{\circ} \mathrm{C}$ on several days during Janu-
ary 1969.

REMARXS. --Recorder stopped Nov, 14-21, Jan. 7, 8, Apr. 13-15, Apr. 24 to May 7.

TEMPERATURE $\left({ }^{\circ} \mathrm{C}\right.$ ) OP WATER, WATER YEAR OCTOBER 1968 TO SEPTEMBER 1969

DAY

A VER-

MONIH

OC TOBER

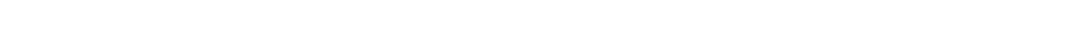

$\begin{array}{llllllllllllllllllllllllllllllllllll}\text { MINIMUM } & 12 & 12 & 12 & 13 & 13 & 13 & 12 & 11 & 10 & 10 & 11 & 11 & 12 & 11 & 10 & 9 & 9 & 9 & 9 & 9 & 9 & 9 & 9 & 9 & 9 & 9 & 9 & 9 & 9 & 8 & 8 & 10\end{array}$

NOVEMBER

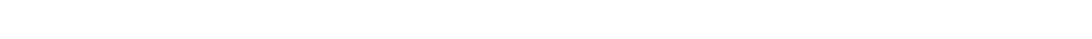

MINIMUM

DECEMBER

MAXIMUM $\quad 6 \quad 4 \quad \begin{array}{llllllllllllllllllllllllllllllll} & 4 & 4 & 4 & 4 & 6 & 6 & 6 & 6 & 4 & 3 & 4 & 4 & 3 & 3 & 3 & 3 & 3 & 3 & 3 & 3 & 3 & 3 & 3 & 3 & 3 & 3 & 3 & 3 & & 4\end{array}$

MINIMUM

JANUARY

MAXIMUM

FEBRTARY

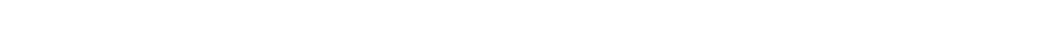

MINIMUM

MAXIMUH

MINIMUM

APRIL

$\begin{array}{lllllllllllllllllllllllllllllllllll}4 & 4 & 4 & 5 & 5 & 5 & 5 & 6 & 4 & 6 & 6 & 6 & 6 & 7 & 7 & 7 & 7 & 8 & 8 & 7 & 8 & 10 & 9 & 9 & 9 & 9 & 9 & 9 & 8 & 8 & 8 \\ 3 & 3 & 3 & 3 & 4 & 4 & 4 & 4 & 4 & 4 & 5 & 5 & 5 & 5 & 5 & 5 & 6 & 6 & 6 & 6 & 6 & 8 & 8 & 8 & 7 & 7 & 7 & 7 & 7 & 7 & 7\end{array}$

MAXIMUM

$\operatorname{MAY}_{\operatorname{MaX}}^{\operatorname{Max}}$

MAXIMUM JUNE

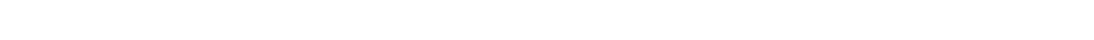
JULY $\begin{array}{lllllllllllllllllllllllllllllllll}\text { MAXIMUM } & 12 & 12 & 12 & 12 & 12 & 12 & 12 & 12 & 12 & 12 & 13 & 13 & 13 & 13 & 13 & 13 & 14 & 14 & 14 & 15 & 15 & 15 & 15 & 16 & 16 & 16 & 16 & 16 & 16 & 16 & 22 & 14 \\ \text { MINIMUM } & 11 & 11 & 11 & 12 & 12 & 12 & 12 & 12 & 12 & 12 & 12 & 13 & 13 & 13 & 13 & 13 & 13 & 14 & 14 & 14 & 14 & 15 & 15 & 15 & 16 & 16 & 16 & 16 & 16 & 16 & 16 & 14\end{array}$ AUGUST

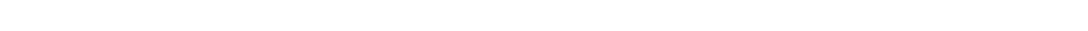

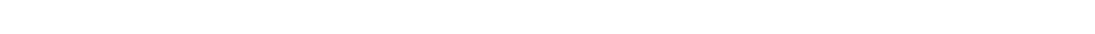
SEP IEMBER

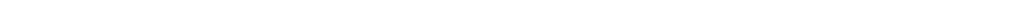

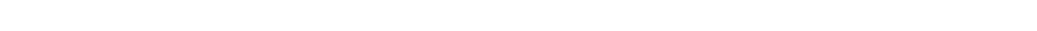




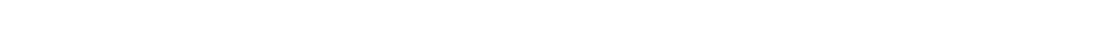
recorder at gaging station on right bank, $2,100 \mathrm{ft}$ downstream f'rom Nimbus Dam, 2.4 miles east of Fair Oaks, 8.1 miles downstream from South Fork, and at mile 22.2.

DRAINAGE AREA, $--1,888 \mathrm{sq} \mathrm{mi}$.

PERIOD OF RECORD. --Chemical analyses: January to December 1906, March 1951 to September 1958, November 1959 to

September 1962 .
Water temperatures: March 1951 to September 1958, November 1959 to September 1969.

EXTREMES. --1968-69:

Water temperatures: Maximum, $19.0^{\circ} \mathrm{C}$ Oct. 1, 3-8; minimum, $7.0^{\circ} \mathrm{C}$ Mar. 15.

Period of record:

Water temperatures: Maximum (1951-58, 1959-64, 1965-69), 27, ${ }^{\circ} \mathrm{C}$ July 27, Aug, 3,1954 ; minimum, freezing point Nov. 25, 26, 1957, Nov. 25-29, 1958.

REMARKS.--Recorder malfunctioned Apr. $6,7,18,19,28,29$.

TEMPERATURE $\left({ }^{\circ} \mathrm{C}\right)$ OF WATER, WATER YEAR OCTOBER 1968 TO SEPTEMBER 1969

DAY

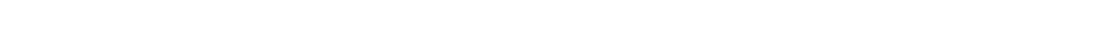

DC TOBER

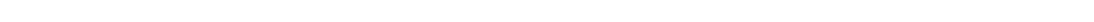

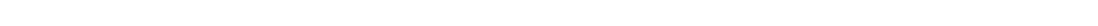
NOVEMBE?

MAXIMUM $16 \quad 15 \quad 15 \quad 15 \quad 16 \quad 15 \quad 15 \quad 15 \quad 15 \quad 15 \quad 15 \quad 16 \quad 15 \quad 14 \quad 14 \quad 14 \quad 14 \quad 14 \quad 15 \quad 15 \quad 15 \quad 15 \quad 15 \quad 15 \quad 15 \quad 14 \quad 14 \quad 14 \quad 14 \quad 14 \quad-2 \quad 15$

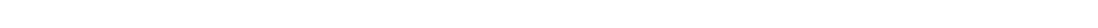

DECEMFEO

$\begin{array}{lllllllllllllllllllllllllllllllllllllllll}\text { MAXIMUM } & 14 & 14 & 13 & 14 & 14 & 13 & 13 & 13 & 13 & 13 & 13 & 12 & 12 & 12 & 12 & 12 & 12 & 12 & 12 & 12 & 12 & 12 & 12 & 12 & 11 & 11 & 11 & 11 & 11 & 11 & 11 & 12 \\ \text { MINIMUM } & 14 & 13 & 13 & 13 & 13 & 13 & 13 & 13 & 13 & 13 & 12 & 12 & 12 & 12 & 12 & 12 & 12 & 12 & 12 & 12 & 12 & 12 & 12 & 11 & 11 & 11 & 11 & 11 & 11 & 10 & 11 & 12\end{array}$

JaVUAPY

MAXIMUM 10101010 to 10101010 to $10101010101010101011111111110101010101010 \quad 9 \quad 10$

MINIMUM 1010101010101010101010101010101010101010101010101010101010999

FFBRUARY

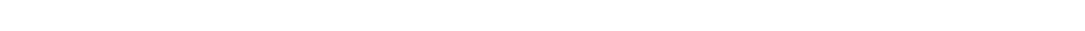

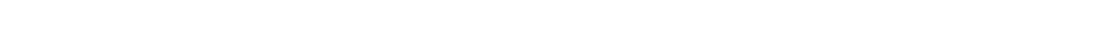

MAXIMUM

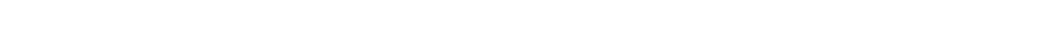

APRIL

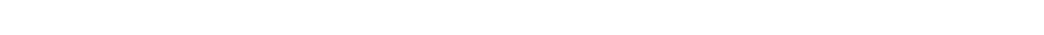
MIVIMUM

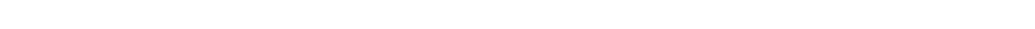

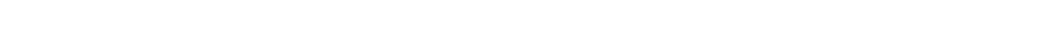
JUNE

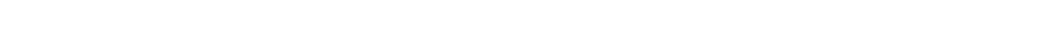
JULY

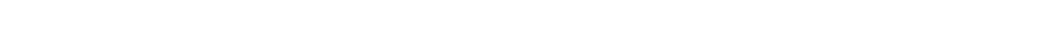
MINIMUM 15 15 15 15 15 15 15 15 15 16 15 15 15 15 16 16 15 15 15 16 16 16 16 16 16 16 16 16 16 16 16 16 16 AUSUST

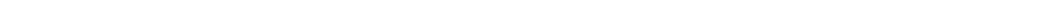

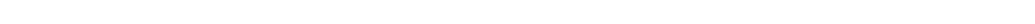

SEPTEMBER

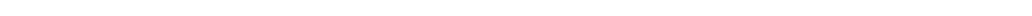

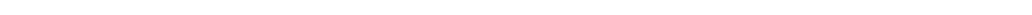




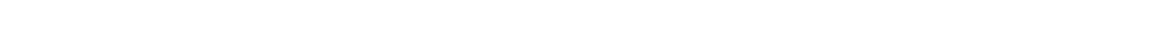
from I Street Bridge in clty of Sacramento and $0.5 \mathrm{mil}$ downtream from Anerican $R 1$ ver.

DRAI NAGE AREA. $--23,530$ aq $\mathrm{ml}$.

PERI OD OF RECORD. - Chemlcal analy ees: October 1952 to May 1960

Water temperatures: Hay 1955 to September 1969

Sediment records: October 1956 to September 1969.

EXTREYES, - -1968-69:

Water temperatures: Maximum, 28. $0^{\circ} \mathrm{c}$ Aug. 21; minimum, $6.0^{\circ} \mathrm{C}$ on several days during December, January, and February.

Sediment concentrations: Maximum da1ly, $430 \mathrm{mg} / 1 \mathrm{Jan} .15 ; \mathrm{m} 1 \mathrm{n} 1 \mathrm{mum}$ da1ly, $14 \mathrm{mg} / 1 \mathrm{Dec} .8$.

Sediment discharge: Maximum da11y, 100,000 tons Jan. 22; minlmum daily, 467 tons Oct. 12.

Perlod of record:

Water temperatures: Maximum (1955-62, 1963-66, 1967-69), 28.0 ${ }^{\circ} \mathrm{C}$ Aug. 21,$1969 ; \mathrm{m} 1 \mathrm{n} 1 \mathrm{mum}, 4.0^{\circ} \mathrm{C} \mathrm{Jan} .30,31$,

Sediment concentrations: Kaximum da1ly, 1,960 mg/1 Dec. 24, 1964; minimum da1ly, $11 \mathrm{mg} / 1$ (est1mated) Nov. 30,

Sedinent d1scharge: Saximum da11y, 525,000 tons Dec. 24, 1964; minimum da11y, 200 tons (estimated) Dec. 14,
1959.

REMARKS, --The chemical-qual1ty data and the maximum-minimum temperature record for the aux111ary stat1on approxt mately 8 miles downstream, Sacramento River at Freeport, Callf. (station 11447650), are considered as be1ng part of this International Hydrological Decado River station.

TEMPERATURE $\left({ }^{\circ} \mathrm{C}\right)$ OF WATER, WATER YEAR OCTOBER 1968 TO SEPTEMBER 1969 (ONCE-DAILY MEASUREMENT)

DAY

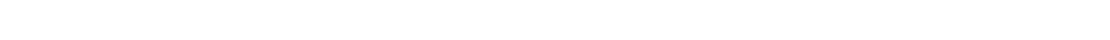

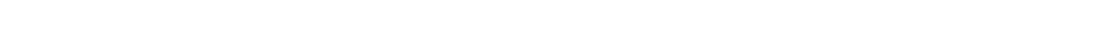

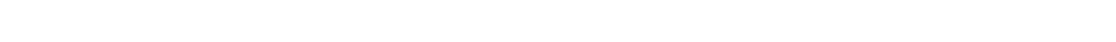

JANUARY..

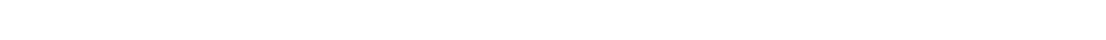

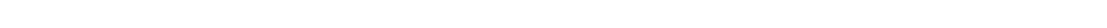
$\begin{array}{llllllllllllllllllllllllllllllllllll}\text { MAY...... } & 14 & 15 & 15 & 17 & - & 18 & - & 17 & 17 & 22 & 18 & 18 & 16 & 18 & 19 & 16 & 19 & 18 & 19 & 17 & - & 17 & 17 & 17 & 16 & 17 & 17 & 17 & 19 & 19 & 20 & 17\end{array}$

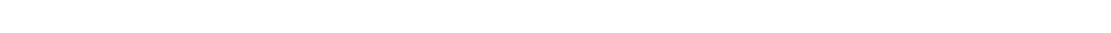

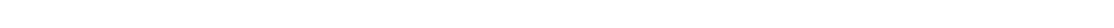

PARTICLE-SIZE DISTRIBUTION OF SUSPENDED SEDIMENT, WATER YEAR OCTOBER 1968 TO SEPTEMBER 1969

IMETHOUS UF ANALYSIS: B, BOTTCM WITHDRAWAL TUBE; C, CHEMICALLY DISPERSED: N, IN NATIVE WATER; P, PIPET: S. SIEVE; $V$. VISUAL ACCUMULATION TUAE; W. IN OISTILLED WATERI

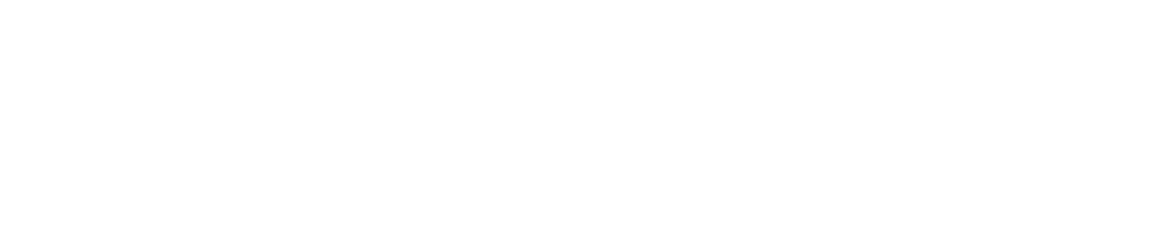

PARTICLE-SIZE DISTRIBUTIDN DF SURFACE BED MATERIAL, WATER YEAR OCTOBER 1968 TD SEPTEMBER 1969 (METHOD OF AVALYSIS: H, HYOROMETER; D, OPTICAL ANALYZER: S, SIEVE; V. VISUAL ACCUMULATION TUBE)

$$
\text { WATER NUMBER PARTICLE SIZE }
$$

PERCENT FINER THAN THE SIZE IIN MILlimetersi INOICATEO OF

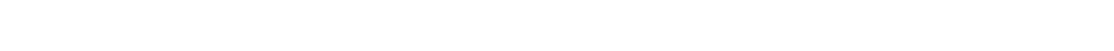

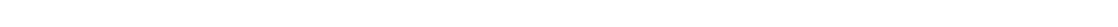

D DAILY MEAN DISCHARGE. 
11447500 SACRAMENTO RIVER AT SACRAMENTO, CALIF,..-Continued

SUSPENDED-SEDIMENT DISCHARGE, WATER YEAR OCTOBER 1968 TO SEPTEMBER 1969

OCTCBER NCVEMBER CECEMBER

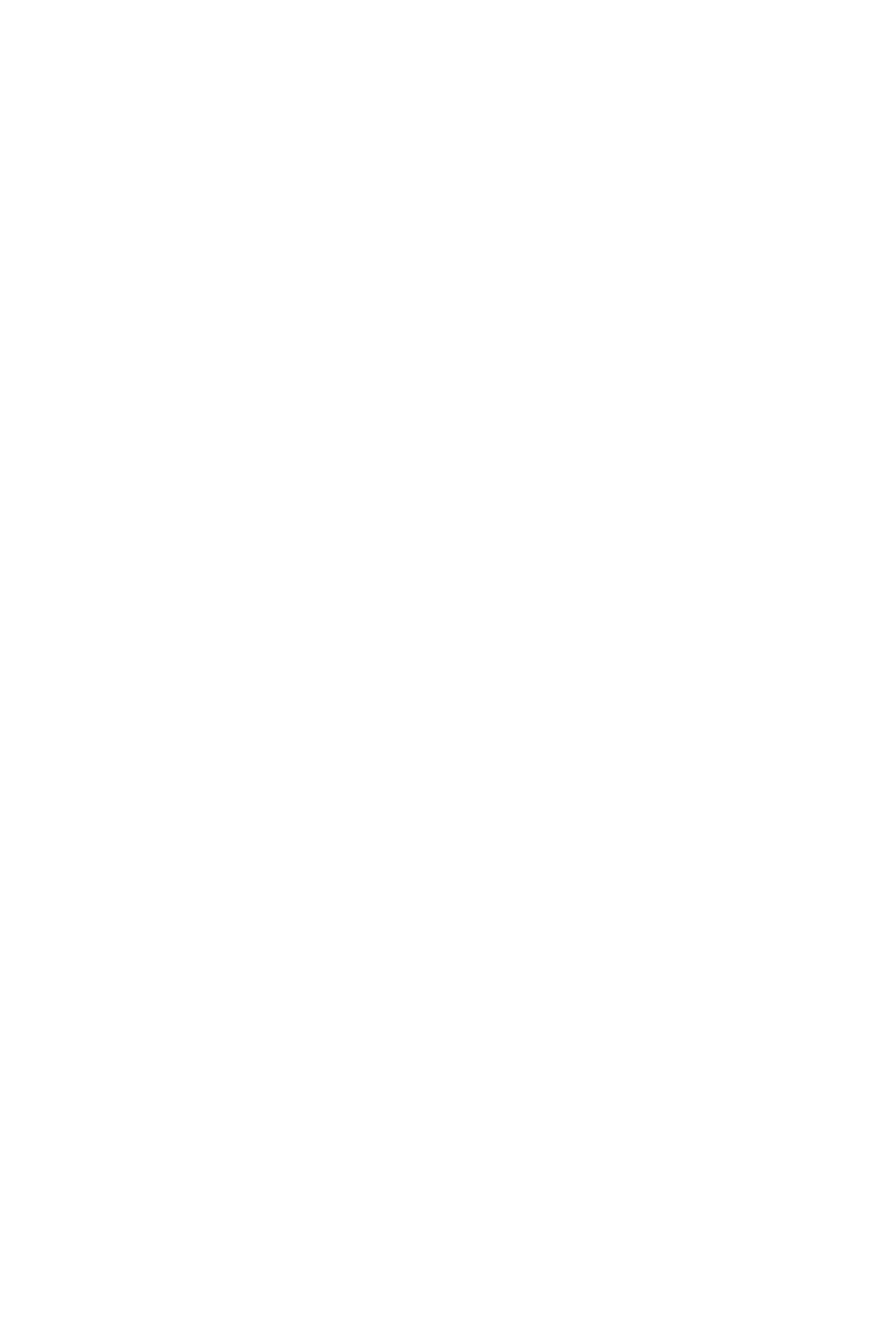


SACRAMENTO RIVER BASIN

11447500 SACRAME NTO RIVER AT SACRAMENTO, CALIF.--Continued

SUSPENDED-SEDIMENT DISCHARGE, WATER YEAR DCTOBER 1968 TO SEPTEMBER 1969

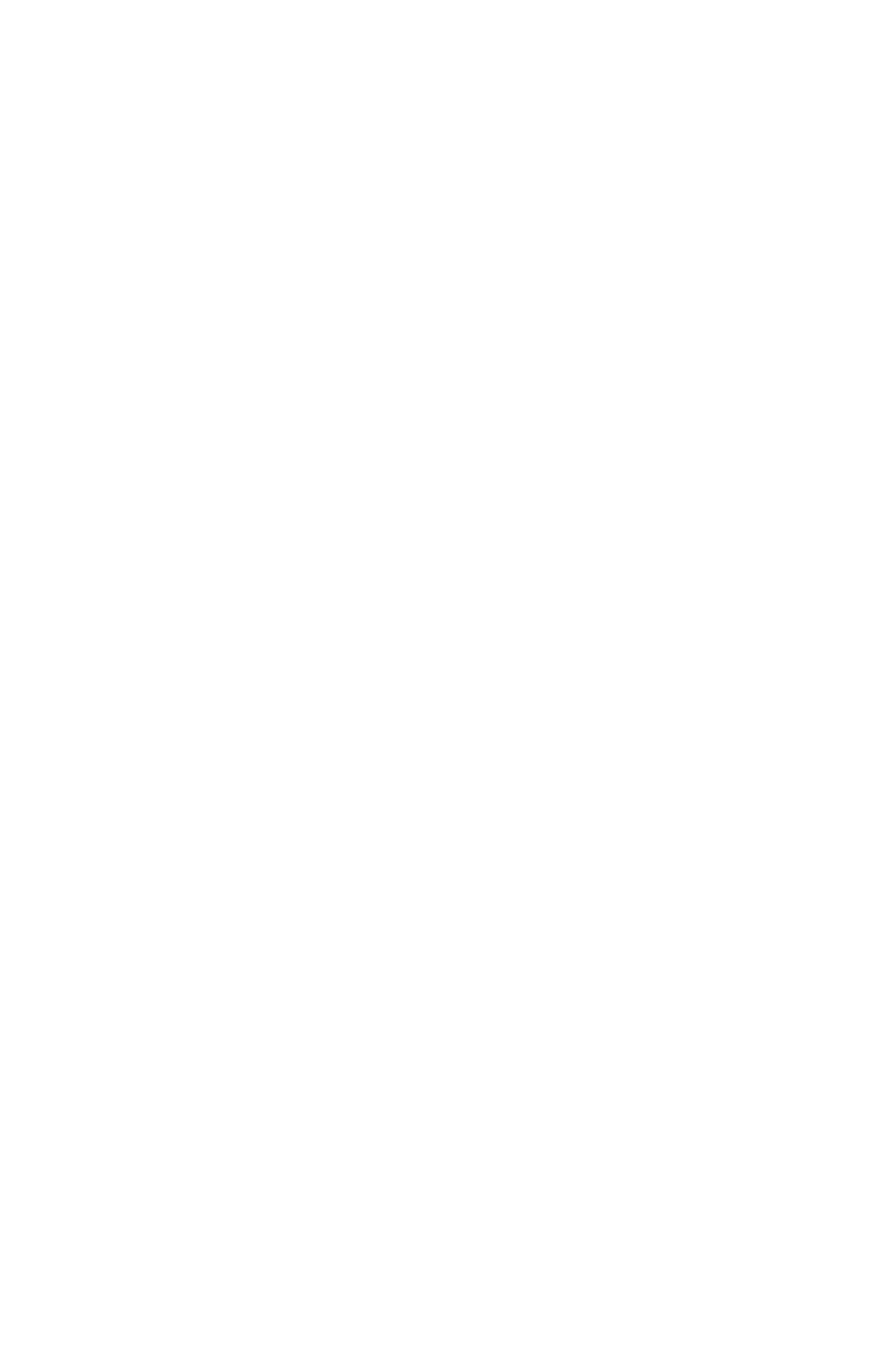


11447650 SACRAMENTO RIVER AT FREEPORT, CALIF,

LOCATION. - Lat $38^{\circ} 27^{\prime} 20^{\prime \prime}$, long $121^{\circ} 30^{\circ} 07^{\prime \prime}$, In sec.14, T. 7 N., R.4 E., Sacramento County, at drawbridge at Freeport approximately 11 miles south of Sacramento.

PERIOD OF RECORD, --Chemical analy ges: June 1960 to September 1969.

Water temperatures: June 1960 to September 1969.

EXTREMES. - $1988-69$ :

Water temperatures: Maximum, $23.0^{\circ} \mathrm{C}$ on several days during July and August; minimum, $7.0^{\circ} \mathrm{C}$ on many days during December to February.

Period of record:

Water temperatures: Maximum, $24.5^{\circ} \mathrm{C}$ June 16, 17, $1961 ; \operatorname{minimum}, 5.0^{\circ} \mathrm{C}$ Jan, $24-27,1962$.

REMARKS, --Chemical-quality samples collected by California Department of Vater Regources. Temperature recorder located on right bank $1.9 \mathrm{mlles}$ northwest of Freeport, and $7.5 \mathrm{miles}$ southwest of State Capitol building $1 \mathrm{n}$ Sacramento. Records of discharge given for Sacramento River at Sacramento (station 11447500). Data collected at this aite are considered as being part of the International Hydrological Decade River Station, Sacramento River at Sacramento, Calif. (station 11447500). CHEMICAL ANALYSES, WATER YEAR OCTOBER 1968 TO SEPTEMBER 1969

\begin{tabular}{|c|c|c|c|c|c|c|c|c|c|c|c|c|}
\hline DATE & $\begin{array}{l}\text { MEAN } \\
\text { DIS- } \\
\text { CHARGE } \\
\text { (CFS) }\end{array}$ & $\begin{array}{l}\text { TEMPER- } \\
\text { ATURE } \\
\text { (DEG C) }\end{array}$ & $\begin{array}{l}\text { DIS- } \\
\text { SDLVED } \\
\text { OXYGEN } \\
\text { (MG/L) }\end{array}$ & $\begin{array}{l}\text { SILICA } \\
\text { (SIOLI) } \\
\text { (MG/L) }\end{array}$ & $\begin{array}{l}\text { DIS- } \\
\text { SOLVED } \\
\text { IRCN } \\
\text { [FE) } \\
\text { (UG/L) }\end{array}$ & $\begin{array}{l}\text { CAL- } \\
\text { CIUM } \\
(C A) \\
(M G / L)\end{array}$ & $\begin{array}{l}\text { MAG- } \\
\text { NE- } \\
\text { SIUM } \\
\text { (MG) } \\
\text { (MG/L) }\end{array}$ & $\begin{array}{l}\text { SODIUM } \\
\text { (NA) } \\
\text { (NG/L) }\end{array}$ & $\begin{array}{l}\text { PO- } \\
\text { TAS- } \\
\text { SIUM } \\
\text { (K) } \\
(M G / L)\end{array}$ & $\begin{array}{l}\text { LIFHIUM } \\
\text { (LI) } \\
\text { (UG/L) }\end{array}$ & $\begin{array}{c}\text { STRON- } \\
\text { TIUA } \\
\text { ISRI } \\
\text { (UG/LI }\end{array}$ & $\begin{array}{l}\text { BICAR } \\
\text { BUNAT } \\
\text { IHCOI } \\
\text { I MG/L }\end{array}$ \\
\hline $\begin{array}{l}\text { OCT. } \\
\text { O2... } \\
\text { NOV. }\end{array}$ & 12900 & 18 & 9.1 & -- & 10 & 12 & 6.3 & 10 & $\rightarrow$ & -- & -- & 77 \\
\hline $\begin{array}{l}06 . . \\
\text { DEC. }\end{array}$ & 12900 & 14 & 10.1 & -- & 0 & 12 & 6.8 & 11 & -- & $\rightarrow$ & $-\infty$ & $T T$ \\
\hline $\begin{array}{l}04 . . \\
\text { JAN. }\end{array}$ & 13500 & 10 & 11.5 & -- & 0 & 12 & 6.1 & 9.2 & -- & $=-$ & $=-$ & 74 \\
\hline OB... & 21100 & 8 & 11.8 & -- & -- & 12 & 8.0 & 9.8 & 1.6 & -- & - & 74 \\
\hline $\begin{array}{l}05 . . \\
\text { MAR. }\end{array}$ & 66100 & 7 & 12.4 & 16 & 50 & 11 & 5.2 & 6.2 & 1.1 & 20 & 80 & 61 \\
\hline $\begin{array}{l}05 \ldots \\
\triangle P R{ }^{0}\end{array}$ & 70800 & 9 & 11.7 & 15 & 10 & 12 & 5.6 & 5.1 & 1.1 & 20 & 80 & 64 \\
\hline MAY & 54600 & 12 & 12.0 & 15 & 50 & 9.9 & 4.6 & 5.5 & 1.0 & 10 & 70 & 54 \\
\hline OUNE... & 32700 & 15 & 10.4 & 15 & 30 & 9.3 & 4.5 & 6.3 & .8 & 10 & 80 & 53 \\
\hline $\begin{array}{l}04 \ldots . \\
\text { JuLr }\end{array}$ & 32100 & 20 & 9.0 & 15 & 40 & 8.8 & 4.2 & 5.7 & .8 & 10 & 80 & 49 \\
\hline $\begin{array}{l}\text { O9... } \\
\text { AUG. }\end{array}$ & 14000 & 21 & 8.9 & 18 & 40 & 11 & 6.3 & 9.3 & 1.1 & 10 & ro & 68 \\
\hline SE... & 17100 & 23 & 7.6 & 16 & 30 & 11 & 6.5 & 10 & 1.0 & 10 & 100 & 73 \\
\hline $03 \ldots$ & 22100 & 21 & 9.1 & 17 & 20 & 11 & 6.8 & 11 & 1.2 & 10 & 90 & 74 \\
\hline
\end{tabular}

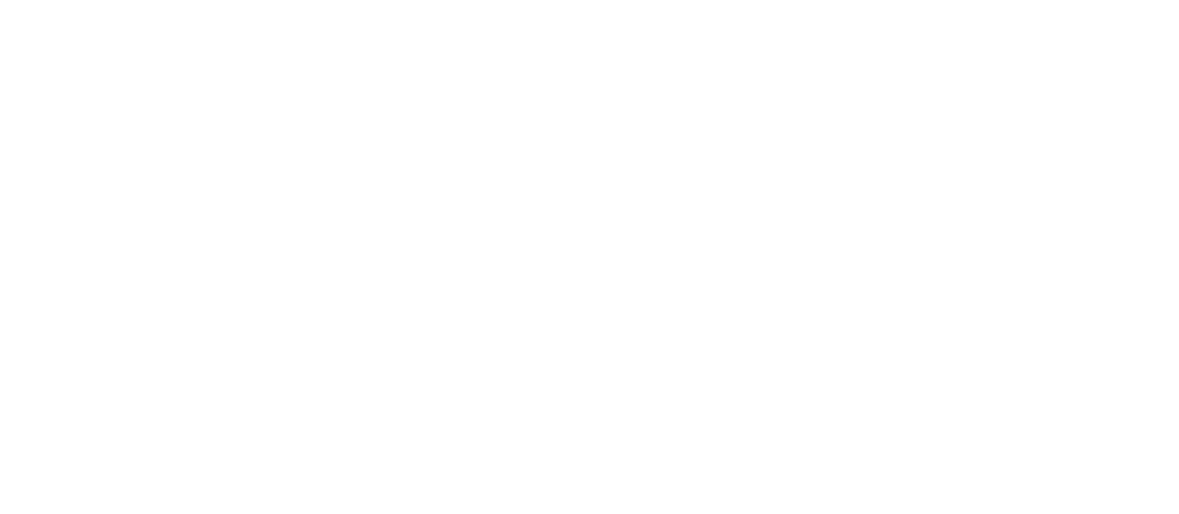


11447650 SACRAMENTO RIVER AT FREEPORT, CALIF.--Cont1 nued

CHEMICAL ANALYSES, WATER YEAR DCTOBER 1968 TO SEPTEMBER 1969

\begin{tabular}{|c|c|c|c|c|c|}
\hline DATE & $\begin{array}{l}\text { DIS- } \\
\text { SOLVED } \\
\text { SOLIDS } \\
\text { ITONS } \\
\text { PER } \\
\text { AC-FT) }\end{array}$ & $\begin{array}{l}\text { PERCENT } \\
\text { SDOIUM }\end{array}$ & $\begin{array}{l}\text { SDOIUM } \\
\text { AD- } \\
\text { SORP- } \\
\text { TION } \\
\text { RATIO }\end{array}$ & $\begin{array}{l}\text { ALKA- } \\
\text { LINITY } \\
\text { AS } \\
\text { CACO3 } \\
\text { (MG /L) }\end{array}$ & $\begin{array}{l}\text { TUR- } \\
\text { BIO- } \\
1 \text { ITY } \\
\text { I MG / }\end{array}$ \\
\hline $\begin{array}{l}\text { OCT. } \\
\text { OC.... } \\
\text { NOV. }\end{array}$ & .11 & 28 & .6 & 38 & -- \\
\hline $\begin{array}{l}\text { DG.... } \\
\text { DEC. }\end{array}$ & .16 & 29 & .6 & 38 & -- \\
\hline $\begin{array}{l}04 \ldots . . \\
\text { JAN. }\end{array}$ & .14 & 27 & .5 & 36 & - \\
\hline $\begin{array}{c}08 . . . \\
F \in B .\end{array}$ & .15 & 25 & .5 & 61 & 43 \\
\hline $\begin{array}{c}05 \ldots . . \\
\text { MAR:. } \\
05 . . .\end{array}$ & .11 & 21 & .4 & 50 & 94 \\
\hline APR... & .11 & 17 & .3 & 52 & 140 \\
\hline MAY & .10 & 21 & .4 & 44 & 30 \\
\hline JUNE & .10 & 24 & .4 & 43 & 10 \\
\hline $\begin{array}{c}\text { JULY. } \\
\text { JU.... }\end{array}$ & .09 & 24 & .4 & 40 & 20 \\
\hline $\begin{array}{l}09 . . . \\
\text { AUG. }\end{array}$ & .13 & 27 & $\cdot 6$ & 56 & 10 \\
\hline SEPT. & .13 & $2 B$ & .6 & 60 & 10 \\
\hline $03 . .$. & .13 & 30 & .6 & 61 & 20 \\
\hline
\end{tabular}

TEMPERATURE $\left({ }^{\circ} \mathrm{C}\right)$ OF MATER, WATER YEAR OCTOBER 1988 TO SEPTEMBER 1989

DAY

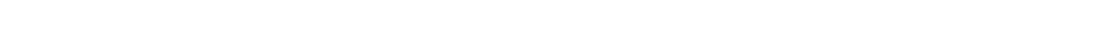

OCTOBER

MAXIMUM 18 18 18 18 18 18 18 18 $17 \begin{array}{lllllllllllllllllllllllllll}17 & 17 & 17 & 16 & 16 & 16 & 16 & 16 & 16 & 16 & 16 & 16 & 16 & 16 & 16 & 16 & 16 & 16 & 16 & 15 & 15 & 14 & 17\end{array}$

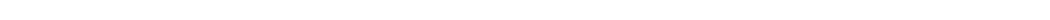

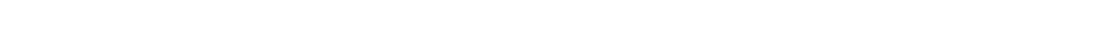

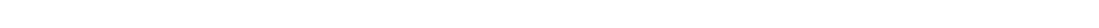

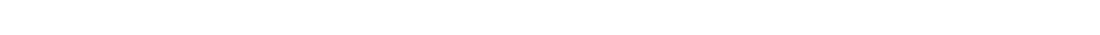

ANUARY

AXIMUM

FERRUARR

$\begin{array}{llllllllllllllllllllllllllllllllll}\text { MAXINUM } & 7 & 7 & 7 & 7 & 7 & 7 & 7 & 7 & 7 & 7 & 7 & 7 & 7 & 7 & 7 & 7 & 7 & 8 & 8 & 8 & 7 & 7 & 7 & 7 & 7 & 8 & 8 & 8 & -- & -2 & -- & 7\end{array}$

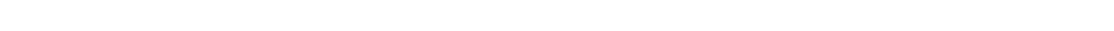
MINIMUM APRIL

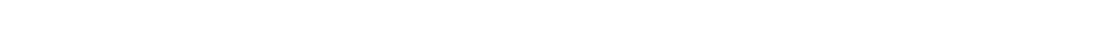
MAY

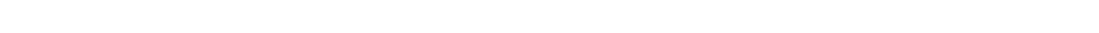
JUNE

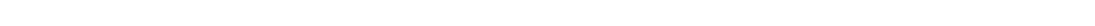

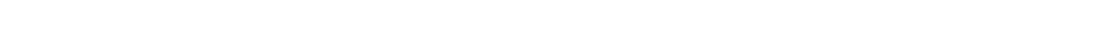
JULY $\begin{array}{lllllllllllllllllllllllllllllllll}\text { MAXIMUN } & 19 & 19 & 19 & 19 & 19 & 19 & 19 & 19 & 19 & 19 & 19 & 21 & 21 & 21 & 22 & 22 & 22 & 22 & 22 & 22 & 23 & 23 & 23 & 23 & 23 & 23 & 22 & 23 & 23 & 23 & 23 & 21 \\ \text { MININUN } & 19 & 19 & 19 & 19 & 19 & 19 & 19 & 19 & 19 & 19 & 19 & 19 & 19 & 21 & 21 & 22 & 22 & 22 & 22 & 22 & 22 & 23 & 23 & 23 & 23 & 22 & 22 & 22 & 23 & 23 & 23 & 21\end{array}$ AUGUST

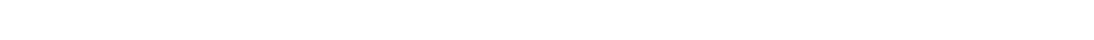
SEPTEMBER

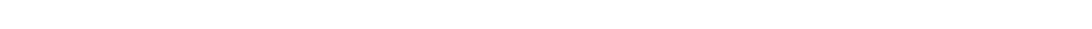

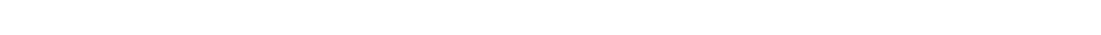


11449010 HIGLLAND CREEK BELOT HIGHLAND CREEK DAM, NEAR KELSEYVILLE, CALIF.

OCATION --Lat $38^{\circ} 56^{\prime} 54^{\prime \prime}$, I ong $122^{\circ} 54^{\prime} 03^{\prime \prime}$, In NEł sec.30, T.13 N, , R.9 W., Lake County, at outlet of Highland Creek Dam, $500 \mathrm{ft}$ (revised) upst ream from gaging station and 4.0 miles southwest of Kelseyville.

DRAINAGE AREA.--14.2 sq mi.

PERIOD OF RECORD. - Chemical analyses: October 1967 to September 1969 (miscellaneous).

Tater temperatures: November 1966 to September 1969.
Sediment records: December 1965 to September 1969.

EXTREMES, --1968-69:

Sediment concentrations: Maximum daily, $145 \mathrm{mg} / 1 \mathrm{Jan} .13$; minimum daily, no flow for many days.

Sediment discharge: Maximum daily, 218 tons Jan. 13; minimum daily, 0 ton on many days.

Period of record:

Sediment concentrations: Maximum daily, $182 \mathrm{mg} / 1 \mathrm{Jan} .5,1966$; mintmum daily, no flow for many days in 1966-69.

Sediment discharge: Maximum daily, 270 tons Jan. 5, 1966; minimum daily, 0 ton on many days in $1966-69$.

REMARKS.--No flow Oct. 1 to Nov. 11, Nov. 13 to Dec. 9, May 21 to June 14, June 19, 20, July 12-14, 17-19, Aug. 27-30.

REVISIONS.--Miscellaneous chemical analyses for this station were incorrectly published in wSP 2099 under station 11448900 Highland Creek above High Iand Creek Dam.

CHEMICAL ANALYSES, WATER YEAR OCTOBER 1968 TO SEPTEMBER 1969

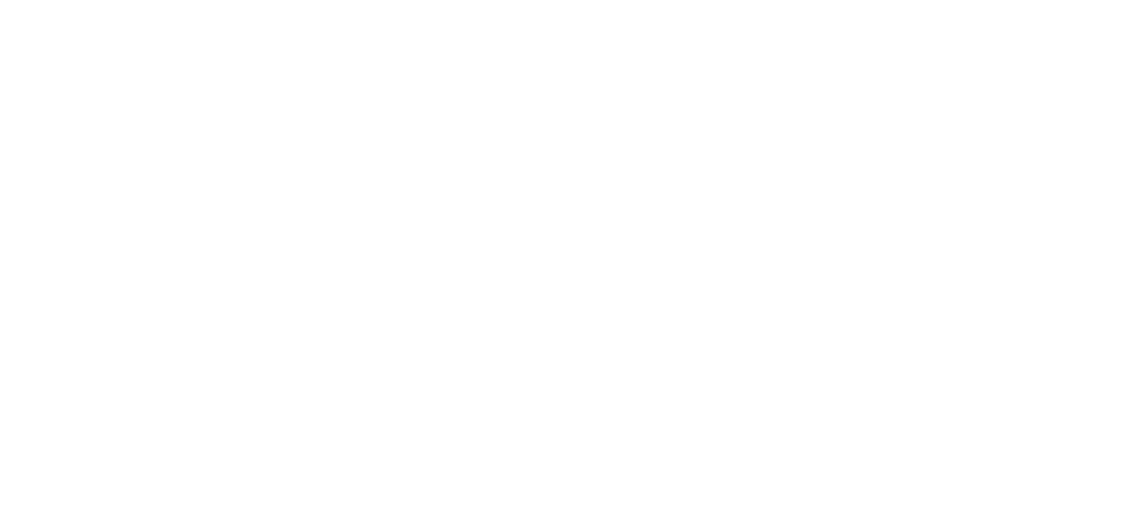

TEMPERATURE $\left({ }^{\circ} \mathrm{C}\right)$ OF WATER, MATER YEAR $O$ CTOBER 1968 TO SEPTEMBER 1969

(ONCE-DAILY MEASUREMENT)

DAY

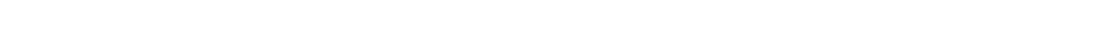

OC TOBER.. . - -

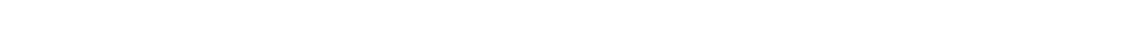

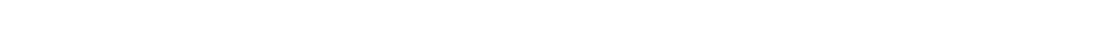

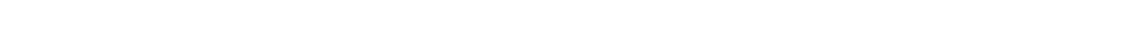

APRIL....

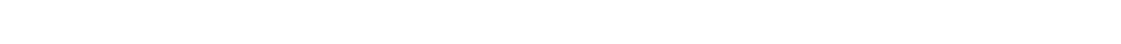

JULY..... --

SUGUST,E,

IMETHODS OF PARTICLE-SIZE DISTRIBUTION OF SUSPENDED SEDIMENT, WATER YEAR OCTOBER 1968 TO SEPTEMBER 1969 (METHODS OF ANALYSIS: B, BOTTOM WITHORAWAL TUBE; C, CHENICALLY OISPERSEO; N, IN NATIVE WATER: P, PIPET; S, SIEVE:

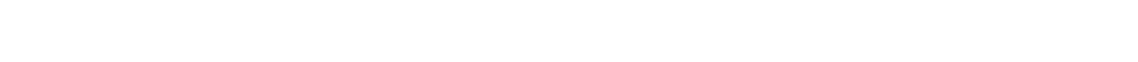

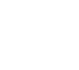

PARTICLE SILE

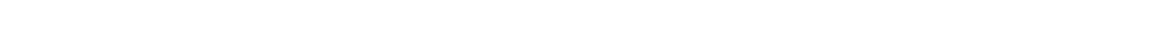


11449010 HIGHLAND CREEK BELON HIGHLAND CREEK DAM, NEAR KELSEYYILLE, CALIF.--Cont1 nued SUSPENDED-SEDIMENT DISCHARGE, WATER YEAR OCTOBER 1968 TO SEPTEMBER 1969

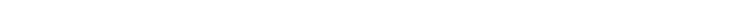

\begin{tabular}{|c|c|c|c|c|c|c|c|c|c|}
\hline & \multicolumn{3}{|c|}{ OC TOBER } & \multicolumn{3}{|c|}{ NOVEMBER } & \multicolumn{3}{|c|}{ DECEMBER } \\
\hline DAY & $\begin{array}{l}\text { MEAN } \\
\text { DISCHARGE } \\
\text { (CFS) }\end{array}$ & $\begin{array}{l}\text { MEAN } \\
\text { CONCEN- } \\
\text { TRATION } \\
\text { (MG/L) }\end{array}$ & $\begin{array}{l}\text { SEDIMENT } \\
\text { DISCHARGE } \\
\text { (TONS/DAY) }\end{array}$ & $\begin{array}{l}\text { MEAN } \\
\text { DISCHARGE } \\
\text { (CFS) }\end{array}$ & $\begin{array}{l}\text { MEAN } \\
\text { CONCEN- } \\
\text { TRATION } \\
\text { (MG/L) }\end{array}$ & $\begin{array}{l}\text { SEDIMENT } \\
\text { DISCHARGE } \\
\text { (TONS/DAY) }\end{array}$ & $\begin{array}{l}\text { MEAN } \\
\text { DISCHARGE } \\
\text { (CFS) }\end{array}$ & $\begin{array}{l}\text { MEAN } \\
\text { CONCEN- } \\
\text { TRAIIDN } \\
\text { \{MG/LI }\end{array}$ & $\begin{array}{l}\text { SEDIMENT } \\
\text { DISCHARGE } \\
\text { (TONS/DAY) }\end{array}$ \\
\hline 1 & & & & 0 & - & 0 & 0 & -- & 0 \\
\hline 2 & & & & 0 & -- & 0 & 0 & - & 0 \\
\hline 3 & & & & 0 & -- & 0 & 0 & -- & 0 \\
\hline 4 & & & & 0 & $-\infty$ & 0 & 0 & -- & 0 \\
\hline 5 & & & & 0 & -- & 0 & 0 & -- & 0 \\
\hline 6 & & & & 0 & -- & 0 & 0 & -- & 0 \\
\hline 7 & & & & 0 & -- & 0 & 0 & -- & 0 \\
\hline 8 & & & & 0 & -- & 0 & 0 & -- & 0 \\
\hline 9 & & & & 0 & - & 0 & 0 & -- & 0 \\
\hline 10 & & & & 0 & -- & 0 & 171 & 18 & 11 \\
\hline II & & & & 0 & -- & 0 & 52 & 50 & 7.0 \\
\hline 12 & & & & .12 & 5 & 0 & 16 & 40 & 1.7 \\
\hline 13 & & & & $0^{\circ}$ & -- & 0 & 19 & 33 & 1.5 \\
\hline 14 & & & & 0 & -- & 0 & 82 & 33 & 6.9 \\
\hline 15 & & & & 0 & - & 0 & 388 & 24 & $25^{\circ}$ \\
\hline 16 & & & & 0 & -- & 0 & 129 & 83 & 31 \\
\hline 17 & & & & 0 & - & 0 & 34 & 68 & 6.2 \\
\hline 18 & & & & 0 & -- & 0 & 19 & 60 & 3.1 \\
\hline 19 & & & & 0 & -- & D & 12 & 40 & 1.3 \\
\hline 20 & & & & 0 & $\cdots$ & 0 & 8.4 & 25 & .57 \\
\hline 21 & & & & 0 & -- & 0 & 6.4 & 21 & .36 \\
\hline 22 & & & & 0 & - & 0 & 4.8 & 20 & .26 \\
\hline 23 & & & & 0 & -- & 0 & 91 & 25 & 7.6 \\
\hline 24 & & & & 0 & -- & 0 & 406 & 104 & 112 \\
\hline 25 & & & & 0 & -- & 0 & 247 & 67 & 45 \\
\hline 26 & & & & 0 & -- & 0 & 163 & 30 & 13 \\
\hline 27 & & & & 0 & -- & 0 & 67 & 20 & 3.6 \\
\hline 28 & & & & 0 & -- & 0 & 65 & 38 & 6.7 \\
\hline 29 & & & & 0 & -- & 0 & 46 & 43 & 5.3 \\
\hline 30 & & & & 0 & $\ldots$ & 0 & 34 & 42 & 3.9 \\
\hline 31 & & & & -- & - &.- & 24 & 43 & 2.8 \\
\hline \multirow[t]{4}{*}{ POTAL } & 0 & - & 0 & .12 & -. & 0 & 2084.6 & - & 295.79 \\
\hline & & JANUARY & & \multicolumn{3}{|c|}{ FERRUARY } & \multicolumn{3}{|c|}{ MARCH } \\
\hline & & MEAN & & \multicolumn{3}{|c|}{ MEAN } & \multicolumn{3}{|c|}{ MEAN } \\
\hline & $\begin{array}{l}\text { MEAN } \\
\text { DISCHARGE } \\
\text { (CFS) }\end{array}$ & $\begin{array}{l}\text { CONCEN- } \\
\text { TRATIUN } \\
\text { (MG/L) }\end{array}$ & $\begin{array}{l}\text { SEDIMENT } \\
\text { DISCHARGE } \\
\text { (TONS/DAY) }\end{array}$ & $\begin{array}{l}\text { MEAN } \\
\text { DISCHARGE } \\
\text { (CFS) }\end{array}$ & $\begin{array}{l}\text { CONCEN- } \\
\text { IRAIIDN } \\
\text { (MG/LI) }\end{array}$ & $\begin{array}{l}\text { SEDI MENT } \\
\text { DI SCHARGE } \\
\text { (TONS/DAY) }\end{array}$ & $\begin{array}{l}\text { MEAN } \\
\text { DISCHARGE } \\
\text { (CFS) }\end{array}$ & $\begin{array}{l}\text { CONCEN- } \\
\text { TRATION } \\
\text { (MG/L) }\end{array}$ & $\begin{array}{l}\text { SEDIMENT } \\
\text { DISCHARGE } \\
\text { (TONS/DAY) }\end{array}$ \\
\hline 1 & 20 & 43 & 2.3 & 73 & 31 & 6.1 & 251 & 20 & 14 \\
\hline 2 & 16 & $\begin{array}{l}43 \\
42\end{array}$ & 1.8 & $\begin{array}{l}57 \\
57\end{array}$ & 39 & $\begin{array}{l}0.1 \\
6.0\end{array}$ & 146 & 21 & 8.2 \\
\hline 3 & 12 & 40 & 1.3 & 48 & 35 & 4.5 & 113 & 19 & 5.8 \\
\hline 4 & 11 & 35 & 1.0 & 43 & 38 & 4.4 & 82 & 18 & 4.0 \\
\hline 5 & 8.4 & 31 & .70 & 130 & 43 & 15 & 63 & 17 & 2.9 \\
\hline 6 & 7.8 & 35 & .74 & 295 & 69 & 54 & 52 & 18 & 2.5 \\
\hline 7 & 7.2 & 31 & .60 & 126 & 31 & 11 & 44 & $\begin{array}{l}10 \\
\text { I } 8\end{array}$ & 2.1 \\
\hline 8 & 6.8 & 30 & .55 & 107 & 31 & 9.0 & 40 & 18 & 1.9 \\
\hline 9 & 6.4 & 28 & .48 & 213 & 52 & 30 & 34 & $\begin{array}{l}18 \\
18\end{array}$ & 1.7 \\
\hline 10 & 6.0 & 18 & .29 & 449 & 58 & 70 & 31 & 18 & $\begin{array}{l}1.7 \\
1.5\end{array}$ \\
\hline 11 & 48 & 16 & 1.8 & 510 & 31 & 43 & 26 & 17 & 1.2 \\
\hline 12 & 364 & 56 & 61 & 266 & 32 & 23 & 25 & 17 & 1.1 \\
\hline 13 & 557 & 145 & 258 & 123 & 33 & 11 & 23 & 16 & .99 \\
\hline 14 & 465 & ili & 143 & 78 & 35 & 7.4 & 20 & 16 & .86 \\
\hline 15 & 88 & 85 & 21 & 202 & 49 & 27 & 18 & 15 & .73 \\
\hline 16 & 49 & 78 & 10 & 131 & 62 & 22 & 16 & 15 & .65 \\
\hline 17 & 34 & 75 & 0.9 & 96 & 37 & 9.6 & 18 & 15 & .73 \\
\hline is & 84 & 61 & $12^{6}$ & 75 & 32 & 6.5 & 16 & 13 & .56 \\
\hline i9 & 413 & 54 & 63 & 57 & 32 & 4.9 & 14 & 10 & .38 \\
\hline 20 & 510 & 46 & 63 & 48 & 35 & 4.5 & 14 & 8 & .30 \\
\hline 21 & 567 & 42 & 64 & 41 & 30 & 3.3 & 19 & 9 & .46 \\
\hline 22 & 562 & 20 & 30 & 37 & 22 & 2.2 & 15 & 9 & .36 \\
\hline 23 & 365 & 21 & 19 & 84 & 41 & B.9 & 11 & $B$ & .24 \\
\hline 24 & 78 & 28 & 5.9 & 170 & 52 & 24 & 9.8 & 7 & .19 \\
\hline 25 & 180 & 32 & 16 & 169 & 39 & 18 & 8.4 & 7 & .16 \\
\hline 26 & 475 & 81 & 105 & 113 & 21 & 0.4 & 7.8 & 7 & .15 \\
\hline 27 & 179 & 35 & 17 & 124 & 21 & 6.9 & 7.2 & 7 & .14 \\
\hline 28 & 96 & 38 & 9.8 & 317 & 43 & 37 & 6.8 & 7 & .13 \\
\hline 29 & 72 & 34 & 6.8 & - & $=$ & - & 6.0 & 6 & .10 \\
\hline 30 & 67 & 44 & 8.0 & -- & -- & -- & 6.0 & 5 & .08 \\
\hline 31 & 54 & 31 & 4.5 & -- & -- & -- & 5.7 & 4 & .06 \\
\hline OtAL & 5408.6 & - & 895.26 & 4182 & -- & 475.6 & 1148.7 & -- & 54.17 \\
\hline
\end{tabular}


SACRAMENTO RIVER BASIN

11449010 HIGHLAND CREEK BELON HIGHLAND CREEK DAM, NEAR KELSEYVILLE, CALIF.--Cont1nUEd SUSPENDED-SEDIMENT DISCHARGE, WATER YEAR OCTOBER 1968 TO SEPTEMBER 1969

\begin{tabular}{|c|c|c|c|c|c|c|c|c|c|}
\hline & \multicolumn{3}{|c|}{ APRIL } & \multicolumn{3}{|c|}{ MAY } & \multicolumn{3}{|c|}{ JUNE } \\
\hline DAY & $\begin{array}{l}\text { MEAN } \\
\text { DISCHARGE } \\
\text { (CFS) }\end{array}$ & $\begin{array}{l}\text { MEAN } \\
\text { CONCEN- } \\
\text { TRATIGN } \\
\text { (MG/L) }\end{array}$ & $\begin{array}{l}\text { SEDIMENT } \\
\text { DISCHARGE } \\
\text { (TONS/DAY) }\end{array}$ & $\begin{array}{l}\text { MEAN } \\
\text { OT SCHARGE } \\
\text { (CFS) }\end{array}$ & $\begin{array}{l}\text { MEAN } \\
\text { CONCEN- } \\
\text { TRATION } \\
\text { (MG/L) }\end{array}$ & $\begin{array}{l}\text { SEDIMENT } \\
\text { DISCHARGE } \\
\text { (TONS/DAY) }\end{array}$ & $\begin{array}{l}\text { MEAN } \\
\text { OISCHARGE } \\
\text { (CFS) }\end{array}$ & $\begin{array}{l}\text { MEAN } \\
\text { CONCEN- } \\
\text { TRATION } \\
\text { (MG/L) }\end{array}$ & $\begin{array}{l}\text { SEDIMENT } \\
\text { DISCHARGE } \\
\text { (TONS/DAY) }\end{array}$ \\
\hline $\begin{array}{l}1 \\
2 \\
3 \\
4 \\
5\end{array}$ & $\begin{array}{r}5.4 \\
6.8 \\
9.8 \\
7.2 \\
44\end{array}$ & $\begin{array}{r}4 \\
5 \\
4 \\
4 \\
10\end{array}$ & $\begin{array}{l}.06 \\
.09 \\
.11 \\
.08 \\
1.2\end{array}$ & $\begin{array}{l}6.4 \\
6.4 \\
5.4 \\
5.7 \\
6.0\end{array}$ & $\begin{array}{l}6 \\
6 \\
6 \\
6 \\
6\end{array}$ & $\begin{array}{l}.10 \\
.10 \\
.09 \\
.09 \\
.10\end{array}$ & $\begin{array}{l}0 \\
0 \\
0 \\
0 \\
0\end{array}$ & $\begin{array}{l}=- \\
=- \\
=-\end{array}$ & $\begin{array}{l}0 \\
0 \\
0 \\
0 \\
0\end{array}$ \\
\hline $\begin{array}{r}6 \\
7 \\
8 \\
9 \\
10\end{array}$ & $\begin{array}{l}42 \\
27 \\
21 \\
19 \\
16\end{array}$ & $\begin{array}{r}10 \\
10 \\
8 \\
8 \\
8\end{array}$ & $\begin{array}{l}1.1 \\
.73 \\
.45 \\
.41 \\
.35\end{array}$ & $\begin{array}{l}5.7 \\
5.1 \\
4.8 \\
5.4 \\
5.1\end{array}$ & $\begin{array}{l}6 \\
6 \\
6 \\
7 \\
7\end{array}$ & $\begin{array}{l}.09 \\
.08 \\
.08 \\
.10 \\
.10\end{array}$ & $\begin{array}{l}0 \\
0 \\
0 \\
0 \\
0\end{array}$ & $\begin{array}{l}= \\
= \\
=\end{array}$ & $\begin{array}{l}0 \\
0 \\
0 \\
0 \\
0\end{array}$ \\
\hline $\begin{array}{l}11 \\
12 \\
13 \\
14 \\
15\end{array}$ & $\begin{array}{l}12 \\
11 \\
9.8 \\
9.0 \\
8.4\end{array}$ & $\begin{array}{l}8 \\
8 \\
7 \\
7 \\
7\end{array}$ & $\begin{array}{l}.26 \\
.24 \\
.19 \\
.17 \\
.16\end{array}$ & $\begin{array}{l}4.8 \\
4.8 \\
4.8 \\
4.8 \\
4.8\end{array}$ & $\begin{array}{l}7 \\
7 \\
8 \\
8 \\
8\end{array}$ & $\begin{array}{l}.09 \\
.09 \\
.10 \\
.10 \\
.10\end{array}$ & $\begin{array}{l}0 \\
0 \\
0 \\
0 \\
.03\end{array}$ & $\begin{array}{l}-- \\
-- \\
-\end{array}$ & $\begin{array}{l}0 \\
0 \\
0 \\
0 \\
0\end{array}$ \\
\hline $\begin{array}{l}16 \\
17 \\
18 \\
19 \\
20\end{array}$ & $\begin{array}{l}8.4 \\
7.8 \\
7.2 \\
6.8 \\
6.4\end{array}$ & $\begin{array}{l}6 \\
5 \\
4 \\
4 \\
4\end{array}$ & $\begin{array}{l}.14 \\
.11 \\
.08 \\
.07 \\
.07\end{array}$ & $\begin{array}{l}4.3 \\
4.1 \\
3.6 \\
3.8 \\
2.0\end{array}$ & $\begin{array}{l}8 \\
8 \\
7 \\
7 \\
4\end{array}$ & $\begin{array}{l}.09 \\
.09 \\
.07 \\
.07 \\
.03\end{array}$ & $\begin{array}{l}.15 \\
.19 \\
.12 \\
0 \\
0\end{array}$ & $\begin{array}{r}7 \\
9 \\
6 \\
-\therefore\end{array}$ & $\begin{array}{l}0 \\
0 \\
0 \\
0 \\
0\end{array}$ \\
\hline $\begin{array}{l}22 \\
22 \\
23 \\
24 \\
25\end{array}$ & $\begin{array}{l}6.4 \\
5.7 \\
22 \\
2.6 \\
15\end{array}$ & $\begin{array}{l}4 \\
3 \\
7 \\
5 \\
6\end{array}$ & $\begin{array}{l}.07 \\
.05 \\
.42 \\
.35 \\
.24\end{array}$ & $\begin{array}{l}0 \\
0 \\
0 \\
0 \\
0\end{array}$ & $\begin{array}{l}-- \\
=- \\
--\end{array}$ & $\begin{array}{l}0 \\
0 \\
0 \\
0 \\
0\end{array}$ & $\begin{array}{l}.01 \\
.01 \\
.01 \\
.01 \\
.02\end{array}$ & $\begin{array}{l}9 \\
y \\
9 \\
9 \\
9\end{array}$ & $\begin{array}{l}0 \\
0 \\
0 \\
0 \\
0\end{array}$ \\
\hline $\begin{array}{l}26 \\
27 \\
28 \\
29 \\
30 \\
31\end{array}$ & $\begin{array}{l}9.8 \\
9.0 \\
7.8 \\
7.2 \\
6.4 \\
-.\end{array}$ & $\begin{array}{r}5 \\
5 \\
5 \\
4 \\
4 \\
--\end{array}$ & $\begin{array}{l}.13 \\
.12 \\
.11 \\
.08 \\
.07 \\
-2\end{array}$ & $\begin{array}{l}0 \\
0 \\
0 \\
0 \\
0 \\
0\end{array}$ & $\begin{array}{l}=- \\
=- \\
-- \\
=- \\
--\end{array}$ & $\begin{array}{l}0 \\
0 \\
0 \\
0 \\
0 \\
0\end{array}$ & $\begin{array}{l}.02 \\
.02 \\
.01 \\
.01 \\
.01 \\
.0\end{array}$ & $\begin{array}{r}9 \\
9 \\
9 \\
9 \\
9 \\
--\end{array}$ & $\begin{array}{r}0 \\
0 \\
0 \\
0 \\
0 \\
--\end{array}$ \\
\hline TOTAL & 400.3 & -- & 7.71 & 97.6 & - & 1.76 & .62 & -- & 0 \\
\hline & & JULY & & & AUGUST & & & SEPTEMHER & \\
\hline DAY & $\begin{array}{l}\text { MEAN } \\
\text { DISCHARGE } \\
\text { (CFS) }\end{array}$ & $\begin{array}{l}\text { MEAN } \\
\text { CONCEN- } \\
\text { TRATION } \\
\text { (MG/L) }\end{array}$ & $\begin{array}{l}\text { SEDIMENT } \\
\text { DISCHARGE } \\
\text { (TONS/DAY) }\end{array}$ & $\begin{array}{l}\text { MEAN } \\
\text { OISCHARGF } \\
\text { (CFS) }\end{array}$ & $\begin{array}{l}\text { MEAN } \\
\text { CONCEN- } \\
\text { TRATION } \\
\text { (MG/L) }\end{array}$ & $\begin{array}{l}\text { SEDIMENT } \\
\text { DISCHARGE } \\
\text { (TONS/DAY) }\end{array}$ & $\begin{array}{l}\text { MEAN } \\
\text { OISCHARGE } \\
\text { (CFS) }\end{array}$ & $\begin{array}{l}\text { MEAN } \\
\text { CONCEN- } \\
\text { TRATION } \\
\text { (MG/L) }\end{array}$ & $\begin{array}{l}\text { SEDIMENT } \\
\text { DISCHARGE } \\
\text { (TONS/DAY) }\end{array}$ \\
\hline
\end{tabular}

$\begin{array}{ll}1 & .01 \\ 2 & .01 \\ 3 & .01 \\ 4 & .01 \\ 5 & .02 \\ 6 & .02 \\ 7 & .01 \\ 8 & .02 \\ 9 & .05 \\ 10 & .03 \\ 11 & .03 \\ 12 & 0 \\ 13 & 0 \\ 14 & 0 \\ 15 & .03 \\ 16 & .05 \\ 17 & 0 \\ 18 & 0 \\ 19 & 0 \\ 20 & .01 \\ 21 & .01 \\ 22 & .01 \\ 23 & .01 \\ 24 & .01 \\ 25 & .02 \\ 26 & .03 \\ 27 & .09 \\ 28 & .09 \\ 29 & .09 \\ 30 & .07 \\ 31 & .05 \\ 15\end{array}$

9
9
9
9
9
9
9
9
9
9
5
-9
-2
73
10
-2
-2
8
8
9
9
9
10
11
15
16
17
18
19
-7

$\begin{array}{ll}0 & .05 \\ 0 & .05 \\ 0 & .05 \\ 0 & .05 \\ 0 & .05 \\ 0 & .05 \\ 0 & .05 \\ 0 & .07 \\ 0 & .23 \\ 0 & .28\end{array}$

.05
.05
.05
.05

20
21
22
23
24

$\begin{array}{ll}0 & \\ 0 & : \\ 0 & : \\ 0 & :\end{array}$

$\begin{array}{ll}.01 & 31 \\ .02 & 31 \\ .01 & 31 \\ .02 & 3 \\ .02 & 3\end{array}$

$\begin{array}{ll}31 & 0 \\ 31 & 0 \\ 31 & 0 \\ 31 & 0 \\ 31 & 0\end{array}$

$\begin{array}{lll}.05 & 25 & 0 \\ .03 & 26 & 0\end{array}$

.07
.23
.28

0
0
0

.02

31
31
31
31

.28
.33

.33
.44
.44

26

4

.33
.33
.33
.33

.02

.03
.03

31

0
0
0
0
0

.02
.03
.03

.05

$\begin{array}{ll}.07 & 31 \\ .09 & 31\end{array}$

.09

31

.0

.01

.02
.02

.12
$: 12$
$: 12$
.15

31
31
31
31
31

.01
.01
.01
.01
.01

$.33 \quad 26$

.33
.33
.09
.02
.01

.02
.02
0.01
0

.15
.15
.12
.12

31
31
31
31
31

$0_{0}^{.01}$
0
0

26
-0
-0
31

TOTAL

.79

-

5.29

-.

TOTAL SUSPENDED-SEDIMENT DISCHARGE FOR YEAR (TONS) 
11451760 CACHE CREEK ABOVE RUMSEY, CALIF.

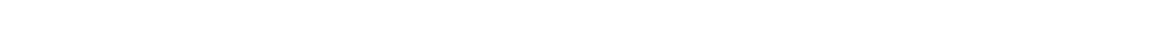
downstream from highway bridge and 2.5 miles northweat of humsey.

DRAINAGE AREA. --955 sq $\mathrm{m} 1$.

PERIOD OF RECORD. - Water temperatures: January 1960 to September 1969.

Sediment records: January 1860 to September 1863, June 1865 to September 1969.

EXTREMES, $--1868-69$ :

Sediment concentrations: Maximum da1ly, 5,830 mg/1 $\mathrm{Jan}, 13 ; \mathrm{m} 1 \mathrm{nimum}$ dally, $3 \mathrm{mg} / 1$ on several days during November and December.

Sediment discharge: Maximum da1ly, 238,000 tons Jan. 21; minimum dally, 0,13 ton Nov. 6 .

Period of record:

Water temperatures (1964-86): Kinlmum, $1.0^{\circ} \mathrm{C}$ Dec. 17,1965

Sediment concentrat 1ons: Naximum da11y, $9,160 \mathrm{mg} / 1$ Jan. 29,$1967 ; \mathrm{mintmum}$ daliy, $1 \mathrm{mg} / 1$ on several days in $1960-62$, Dec. 21, 1965

Sediment digcharge: Maximum da11y, 363,000 tons $J_{a n}, 31,1963 ;$ minimum da11y, 0.01 ton on many days during 1960-61.

TEMPERATURE ( $\left.{ }^{\circ} \mathrm{C}\right)$ OF WATER, WATER YEAR OCTOBER 1968 TO SEPTEMBER 1989

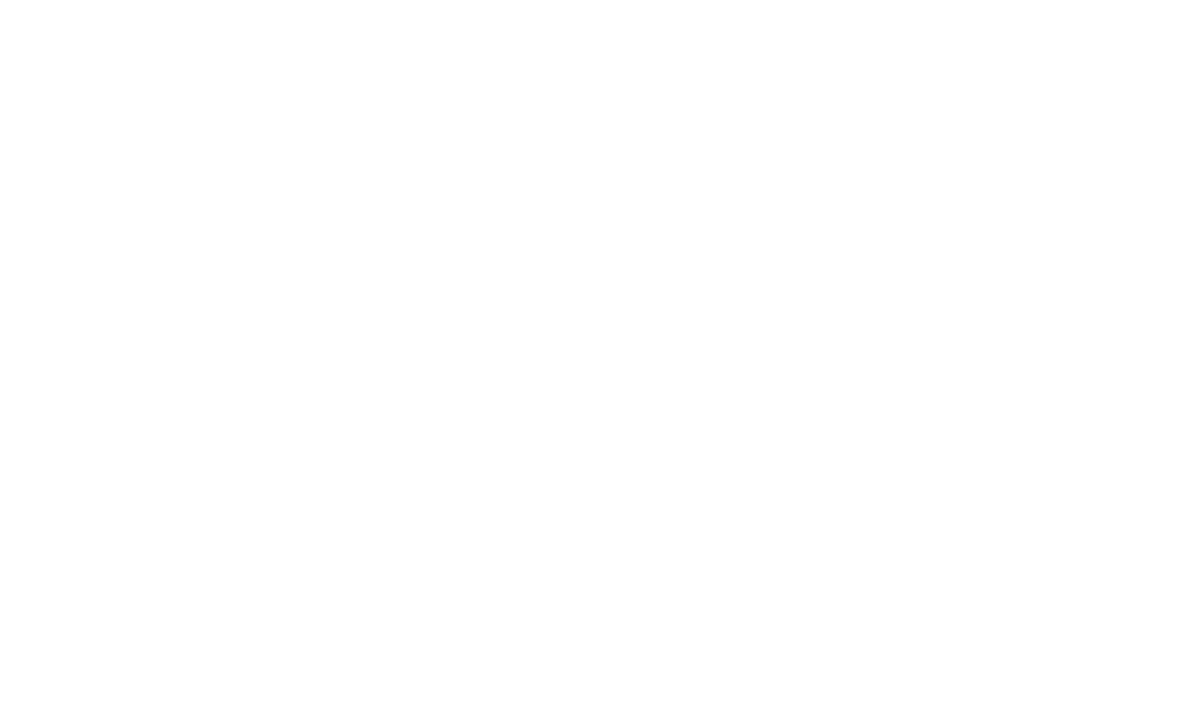

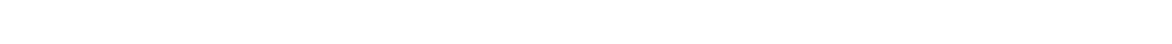
$\checkmark$, VISUAL ACCUMULATION TUHE: W, IN OISTILLEO WATER:

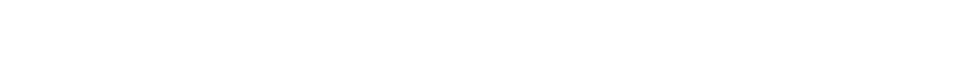

DAF TIME (C) (CFS) (MG/L) (TONS/DAY) $.002 .004 .008 .016 .031 .062 .125 \quad .250 .5001 .002 .00 \quad 51 S$

$\begin{array}{llll}\text { OEC } 11,14611 & \text { l615 } & 9.0 & 479 \\ \text { JAY 13, } 1969 & 0800 & 9.0 & 10800\end{array}$

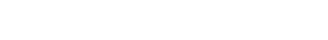

$\begin{array}{lllll}\text { JAN } 16 \ldots \ldots \ldots & 190 & 7.0 & 3450 \\ \text { JAN } 19 \ldots \ldots & 1500 & 9.0 & 1040 \\ & 1700 & 8.0 & 4380\end{array}$

JAV $20 \ldots \ldots$ O900 $10.0 \quad 7440$

JAV $21 \ldots \ldots \ldots$ 090 0900 $10.0 \quad \begin{array}{ll}7440 \\ \text { JaY }\end{array}$

JAN $22 \ldots \ldots$.... 133 7.5 Th 7370

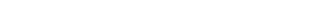

FEB $7 \ldots \ldots \ldots \quad 1700 \quad 7.0 \quad 4280$

$F E B$ B $12 \ldots \ldots$ l... los $9.0 \quad 7400$

$\begin{array}{llllll}\text { FEB } & 13 \ldots \ldots \ldots & 1000 & 8.0 & 6000 \\ F F B & 14 \ldots \ldots & 1706 & \text { R. } & 5950\end{array}$

$\begin{array}{rr}1270 & 1640 \\ 6040 & 176000 \\ 1440 & 13400 \\ 176 & 494 \\ 1380 & 16300 \\ 3310 & 66500 \\ 6430 & 323000 \\ 1540 & 30600 \\ 2890 & 72600 \\ 1220 & 19700 \\ 564 & 6520 \\ 3060 & 80100 \\ 1020 & 20400 \\ 718 & 11600 \\ 556 & 8930 \\ 2880 & 98000 \\ 57 & 154\end{array}$

$\begin{array}{llllll}27 & 36 & 47 & 58 & 69 & 79 \\ 21 & 23 & 28 & 37 & 45 & 55 \\ 33 & 35 & 46 & 59 & 68 & 77 \\ 41 & 55 & 69 & 80 & 87 & 92 \\ 28 & 30 & 40 & 50 & 56 & 65 \\ 15 & 19 & 23 & 31 & 37 & 45 \\ 30 & 33 & 37 & 50 & 60 & 70 \\ 22 & 29 & 39 & 49 & 61 & 70 \\ 21 & 26 & 33 & 43 & 53 & 62 \\ 17 & 19 & 27 & 33 & 39 & 46 \\ 12 & 20 & 27 & 32 & 35 & 47 \\ 14 & 16 & 72 & 28 & 35 & 42 \\ 23 & 25 & 37 & 45 & 54 & 64 \\ 11 & 18 & 24 & 29 & 31 & 42 \\ 17 & 26 & 33 & 40 & 43 & 58 \\ 20 & 21 & 29 & 34 & 42 & 51 \\ 23 & 43 & 58 & 70 & 74 & 84\end{array}$

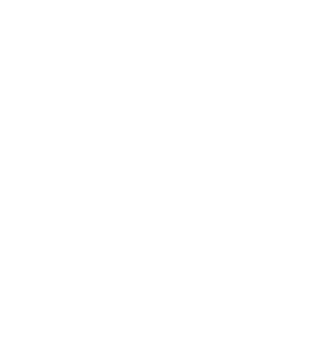


11451760 CACHE CREEK ABOVE RUASEY, CALIF.--Conttnued

SUSPENDED-SEDIMENT DISCHARGE, WATER YEAR OCTOBER 1968 TO SEPTEMBER 1969

DCTOHER

MEA V CONCE MEAV
OISCHARGF $\begin{array}{ll}\text { TRATIUN } & \text { DISCHARGE } \\ \text { (MG, DL) } & \text { (TONS/DAY) }\end{array}$

bar

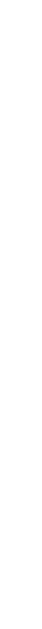

$\begin{array}{ll}3.7 & 13 \\ 2.6 & 15 \\ 1.6 & 21 \\ 2.2 & 22 \\ 2.0 & 18 \\ 1.7 & 16 \\ 1.6 & 15 \\ 1.1 & 14 \\ 1.0 & 13 \\ .80 & 13\end{array}$

.80
.84
1.0
1.1
.91

14

NOVEMBER MEAV CONCFN

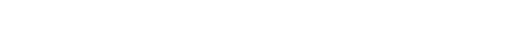
$\begin{array}{lllll}\text { TRATIDN } & \text { DISCHARGE } & \text { DISCHARGE } & \text { TRATION } & \text { DISCHARGE } \\ \text { (MG/L) } & \text { (TONS/DAY) } & \text { (CFS) } & \text { (MG/L) } & \text { (TONS/DAY) }\end{array}$

\begin{tabular}{l}
5 \\
8 \\
6 \\
5 \\
3 \\
5 \\
6 \\
6 \\
6 \\
6 \\
4 \\
4 \\
12 \\
\hline \\
-8 \\
\hline
\end{tabular}

(1)

$\begin{array}{ll}.28 & 2 \\ .32 & 2 \\ .40 & 25 \\ .36 & 24 \\ .24 & 24 \\ .13 & 24 \\ .16 & 2 \\ .19 & 25 \\ .25 & .29 \\ .21 & 276\end{array}$

25
25
25
24
24
24
23
25
29

$\begin{array}{ll}5 & .34 \\ 5 & .34 \\ 4 & .27 \\ 3 & .19 \\ 4 & .26\end{array}$

$.23 \quad 677$

$\begin{array}{ll}.24 & 249 \\ .35 & 152\end{array}$

$\begin{array}{rr}.35 & 152 \\ .46 & 500\end{array}$

$$
\begin{array}{r}
533 \\
1790
\end{array}
$$

1790
249

24
25
459

$.28 \quad 1110$

$\begin{array}{ll}.78 & 434 \\ .31 & 272 \\ .32 & 203\end{array}$

.32
.32

35.41

707

.40

.35
.30
.28

137
120
130
1410

1410
2960

$\begin{array}{rr}.61 & 1470 \\ .78 & 742\end{array}$

.50

.43

.37

731
630

500

10.26

15647

2270

$\begin{array}{rc}836 & 3370 \\ 80 & 94 \\ 25 & 18 \\ 18 & 9.9 \\ 15 & 6.6\end{array}$

10
5
10
1260
2290

$$
\begin{gathered}
3.7 \\
1.6 \\
3.5 \\
5830^{-5} \\
20700
\end{gathered}
$$

$613 \quad 2880$

2880
301

237

128
51

31

\begin{tabular}{|c|c|c|c|c|c|c|c|c|c|}
\hline & \multicolumn{3}{|c|}{ JANUIARY } & \multicolumn{3}{|c|}{ FEBRUARY } & \multicolumn{3}{|c|}{ MARCH } \\
\hline & & MEAV & & & MEAN & & & MEAN & \\
\hline & MEAN & CONCEN- & SED 1MENT & ME AN & CONCEN- & SEDIMENT & MEAN & CONCEN- & SEDIMENT \\
\hline & DISCHARGE & TRATIDN & DI SCHARGE & DISCHARGE & TRATION & DISCHARGE & DISCHARGE & TRATION & DISCHARGE \\
\hline DAY & (CFS) & $(M G / L)$ & (TONS/DAY) & $(C F 5)$ & (MG/L) & (TONS /DAY) & (CFS) & $(M G / L)$ & (TONS /DAY) \\
\hline 1 & 359 & 25 & 24 & 3710 & 840 & 8410 & 7060 & 580 & 11100 \\
\hline ? & 327 & 18 & 16 & 3920 & 1000 & 10600 & 6260 & 348 & 5880 \\
\hline 3 & 311 & is & 13 & 3580 & 785 & 7590 & 5980 & 358 & 5780 \\
\hline 4 & 312 & 13 & it & 3530 & $69^{\circ}$ & 6650 & 5400 & 332 & 4840 \\
\hline 5 & 348 & to & 9.4 & 4900 & 1130 & 17100 & 5080 & 350 & 4800 \\
\hline 6 & 341 & 8 & 7.4 & 7440 & 1760 & 37600 & 4940 & 352 & 4630 \\
\hline 7 & 313 & 8 & 6.8 & 4840 & 645 & 8430 & 4650 & 400 & 5020 \\
\hline B & 283 & 8 & 6.1 & 4330 & 540 & 6310 & 4380 & 350 & 4140 \\
\hline 9 & 255 & 6 & 4.1 & 7370 & 2260 & 47900 & 4260 & 265 & 3050 \\
\hline 10 & 2.36 & 5 & 3.2 & 6270 & 1380 & 23500 & 4470 & 245 & 2960 \\
\hline 11 & 240 & 90 & 58 & 8830 & 2520 & 65400 & 4050 & 222 & 2430 \\
\hline 12 & 2360 & 1760 & 11700 & 8090 & 1530 & 35400 & 7890 & 211 & 2220 \\
\hline 13 & 9180 & 5810 & 156000 & 6090 & 700 & 11500 & 3690 & 228 & 2270 \\
\hline 14 & 3270 & 1350 & 13900 & 6560 & 944 & 20300 & 3570 & 297 & 2860 \\
\hline 15 & 1560 & 435 & 1830 & 10500 & 2710 & 78000 & 3470 & 160 & 1500 \\
\hline 16 & $10 \div 0$ & 202 & 589 & 7320 & 1050 & 20800 & 3390 & 88 & 805 \\
\hline 17 & 830 & 102 & 229 & 6050 & 695 & 11400 & 3080 & 62 & 516 \\
\hline 18 & 1110 & 254 & 1340 & 5740 & 460 & 7130 & 1010 & 55 & 150 \\
\hline 19 & 4850 & 1740 & 22900 & 5390 & 440 & 6400 & 933 & 60 & 151 \\
\hline 20 & 8150 & 3150 & 69300 & 4990 & 425 & 5730 & 892 & 64 & 154 \\
\hline 21 & 15600 & 5510 & 238000 & 4640 & 400 & 5010 & 923 & 60 & 150 \\
\hline 22 & 8380 & 1990 & 48100 & 4400 & 395 & 4690 & 827 & 25 & 56 \\
\hline 23 & 6010 & 1354 & 21900 & 4840 & 408 & 5330 & 778 & 23 & 48 \\
\hline 24 & 5300 & 1100 & 15700 & 5880 & 1000 & 16500 & 746 & 29 & 58 \\
\hline 25 & 5670 & 1590 & 24300 & 5720 & 340 & 9880 & 724 & 22 & 43 \\
\hline 26 & 4650 & 2910 & 82400 & 4970 & 348 & 4670 & 698 & 19 & 36 \\
\hline 27 & 5780 & 1050 & 16400 & 5020 & 400 & 5420 & 682 & 19 & 35 \\
\hline $2 \mathrm{~A}$ & 5250 & 782 & 11100 & 9020 & 2030 & 49400 & 677 & 20 & 37 \\
\hline 29 & 4500 & 625 & 7590 & - & - & - & 830 & 22 & 49 \\
\hline 30 & 4360 & 580 & 6830 & -- & -- & -- & 562 & 19 & 29 \\
\hline 31 & 4030 & 665 & 7240 & -- & -- & -- & 530 & 17 & 24 \\
\hline TUTAL & 40265 & - & 757507.0 & 163940 & $-\cdot$ & 537050 & 88432 & $\sim$ & 65881 \\
\hline
\end{tabular}

59219.12 
SACRANEMTO RIVER BASIN

11451760 CACHE CREEK ABOVE RUMSEY, CALIF.--COntinued

SUSPENDED-SEDIMENT DISCHARGE, WATER YEAR OCTOBER 1968 TO SEPTEMBER 1969

APRIL

MAY

JUNE

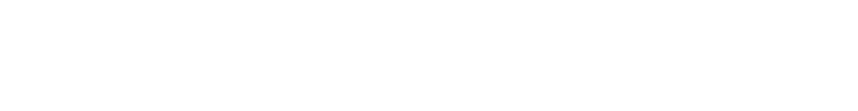

MEAN

CONCEV- SEDIMENT $\begin{array}{ll}\text { (MG/L) } & \text { DISCHARGE } \\ & \end{array}$

$$
\begin{array}{r}
1 \\
2 \\
3 \\
4 \\
5 \\
6 \\
7 \\
8 \\
7 \\
10 \\
11 \\
12 \\
13 \\
14 \\
15 \\
16 \\
17 \\
18 \\
19 \\
20 \\
21 \\
22 \\
23 \\
24 \\
25 \\
26 \\
21 \\
28 \\
29 \\
30 \\
31 \\
19
\end{array}
$$

507
500
554
467
558

11
20
28
17
28

15
27
42
21
42

463
456
454
479

30
45
41
32
36

$\begin{array}{ll}38 & 484 \\ 55 & 505 \\ 50 & 535 \\ 41 & 554 \\ 45 & 587 \\ 52 & 597 \\ 66 & 590 \\ 75 & 571 \\ 66 & 536 \\ 61 & 531 \\ 59 & 466 \\ 62 & 418 \\ 78 & 414 \\ 83 & 414 \\ 67 & 454\end{array}$

484
505
535
554
587
597
590
571
536
531
466
418
414
414
454

35
36
37
36
35
35
35
35
35
35

951
909
866
1030

$\begin{array}{rr}47 & 121 \\ 45 & 110 \\ 45 & 105 \\ 121 & 377\end{array}$

I 350

106

387

1330
1310

1050

364
340

$\begin{array}{rr}82 & 294 \\ 72 & 255 \\ 41 & 116 \\ 15 & 15\end{array}$

318
3144
298

3144
298
289

289
278

16

1590

9.8
114

548
513
507
500

270
261
319

319
374
308

8.7

489

क1

480
515
520
556

8.7
13
19
25

495
507
529
551
546

280
262

262
248

\begin{tabular}{l}
382 \\
452 \\
\hline
\end{tabular}

45

TOTAL 16729

12
18
22
25
27

25
27

21
20
17
27
33

534
485
480

480
448
441

15861

Juer

AUGUST

166

SEPTEMBER

$\begin{array}{clll}\text { MEAV } & \text { CONCEN- } & \text { SEDIMENT } & \text { MEAN } \\ \text { DISCHARGE } & \text { TRATION } & \text { DISCHARGE } & \text { OISCHARGE }\end{array}$

MEAN

CONCENTRATION
(MGILI)

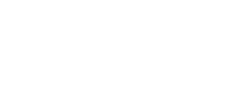

MEAN
CONCEN-

CONCEN- SEDIMENT TRATION DISCHARGE uar

32
35
41
46
47

$\begin{array}{ll}43 & 412 \\ 47 & 407 \\ 59 & 378 \\ 67 & 357 \\ 67 & 374\end{array}$

40
39
39
38
38

$\begin{array}{ll}44 & 311 \\ 43 & 327 \\ 40 & 348 \\ 37 & 346\end{array}$

21
22
22
22

2

18
19
21
21
20

$\begin{array}{rl}6 & 491 \\ 7 & 497 \\ 8 & 568 \\ 9 & 608\end{array}$

62
63
72
76

395
472
485
465

28
22
21
22
23

30
28
27
28
28

342

307

280

21
21
21
21
21

$\begin{array}{lll}11 & 573 & 45 \\ 12 & 557 & 42 \\ 13 & 542 & 39 \\ 14 & 522 & 38 \\ 15 & 549 & 40\end{array}$

$\begin{array}{ll}70 & 430 \\ 63 & 403\end{array}$

63
57
54

416
412
376

23
23
22
22

27
25
25
24

357

27
25
25
24

273
273
270

273
270
269

269
256

$\begin{array}{ll}16 & 581 \\ 17 & 567 \\ 18 & 583 \\ 19 & 608\end{array}$

$\begin{array}{ll}41 & 64 \\ 37 & 57 \\ 37 & 58 \\ 36 & 59\end{array}$

357
329
337
390

21
21
20
20

20
19
18
21
25

262
258

258
234

459

$\begin{array}{lll}34 & 47 & 459 \\ 31 & 43 & 461\end{array}$

$\begin{array}{lll}21 & 512 & 34 \\ 22 & 519 & 31 \\ 23 & 521 & 30 \\ 24 & 534 & 30 \\ 25 & 505 & 30\end{array}$

468
446

20

230

20
20
20
20
20

25
25
25
24
23

226
199
173
170

$\begin{array}{lll}26 & 514 & 30 \\ 27 & 496 & 30 \\ 28 & 465 & 31 \\ 29 & 458 & 32 \\ 30 & 451 & 35 \\ 31 & 436 & 38\end{array}$

428
447

428
447
402
365

20
21
21
21
21
21

TOTAL 16386

-- 1686

12784

IOTAL OISCHARGE FOR YEAR (CFS-OAYS)

TOTAL SUSPENDED-SEDIMENT DISCHARGE FOR YEAR (TONS)

168

156

138

134
139

7315

19
17
16
24
14
15
15
15
15
15
14
13
10
8.2
6.8

5.5
4.3

3.7

2.9

2.2

1.8
1.9

337.5

465435
1427933.

1427933.79 
11452000 CACHE CREEK NEAR CAPAY, CALIF.

LOCATION, --Lat $38^{\circ} 43^{\prime} 44^{\prime \prime}$, long $122^{\circ} 06^{\prime} 13^{\prime \prime}$, In Canada de Capay Grant, Yolo County, at gaging station 1.8 miles upstream from Clear Lake Water Co.'s diversion dam, 3.2 m1les northwest of Capay, and 5.4 miles northwest

DRAINAGE AREA. $-1,044$ sq mi.

PERIOD OF RECORD.--Chemical analyses: October 1952 to September 1969.

REMARKS. --Records furnished by California Department of Water Resources and reviewed by U.S. Geological Survey. CHEMICAL ANALYSES, WATER YEAR OCTOBER 1968 TO SEPTEMBER 1969

\begin{tabular}{|c|c|c|c|c|c|c|c|c|c|c|c|c|}
\hline DATE & TIME & $\begin{array}{l}\text { MEAN } \\
\text { DIS- } \\
\text { CHARGE } \\
\text { (CFS) }\end{array}$ & $\begin{array}{l}\text { TEMPER- } \\
\text { ATURE } \\
\text { (DEG C) }\end{array}$ & $\begin{array}{l}\text { DIS- } \\
\text { SOLVED } \\
\text { OXYGEN } \\
\text { (MG/L) }\end{array}$ & $\begin{array}{l}\text { CAL- } \\
\text { CIUA } \\
\text { (CA) } \\
(M G / L)\end{array}$ & $\begin{array}{c}\text { MAG- } \\
\text { NE- } \\
\text { SIUM } \\
(M G) \\
(M G / L)\end{array}$ & $\begin{array}{l}\text { SODLUM } \\
\text { (NA) } \\
\text { (MG/L) }\end{array}$ & $\begin{array}{l}\text { PO- } \\
\text { TAS- } \\
\text { SIUM } \\
\text { (K) } \\
\text { (MG/L) }\end{array}$ & $\begin{array}{l}\text { BICAR- } \\
\text { BONATE } \\
\text { (HCO3) } \\
\text { (MG/L) }\end{array}$ & $\begin{array}{l}\text { CAR- } \\
\text { BONATE } \\
\text { (CO3) } \\
\text { (MG/L) }\end{array}$ & $\begin{array}{l}\text { SULFATE } \\
\text { (SOL) } \\
\text { (MG/L) }\end{array}$ & $\begin{array}{l}\text { CHLO- } \\
\text { RIDE } \\
\text { (CLI) } \\
\text { (MG/L) }\end{array}$ \\
\hline SE.... & 1300 & 5190 & 8 & 12.4 & 26 & - & 15 & - & 178 & 0 & $-\infty$ & 9.9 \\
\hline
\end{tabular}

\begin{tabular}{|c|c|c|c|c|c|c|c|c|c|c|c|}
\hline DATE & $\begin{array}{l}\text { NITRATE } \\
\text { (NO3) } \\
\text { (MG/L) }\end{array}$ & $\begin{array}{l}\text { BORON } \\
\text { (B) } \\
\text { (UG/L) }\end{array}$ & $\begin{array}{l}\text { OIS- } \\
\text { SOLVEO } \\
\text { SOLIDS } \\
\text { (RESI- } \\
\text { DUE AT } \\
\text { 1BO C) } \\
\text { (MGIL) }\end{array}$ & $\begin{array}{l}\text { DIS- } \\
\text { SOLVED } \\
\text { SOLIDS } \\
\text { ITONS } \\
\text { PER } \\
\text { AC } \sim F T \text { II }\end{array}$ & $\begin{array}{l}\text { HARD- } \\
\text { OESS } \\
\text { ICA, MG } \\
\text { (HG/L) }\end{array}$ & $\begin{array}{l}\text { NON- } \\
\text { CAR- } \\
\text { BONATE } \\
\text { HARD- } \\
\text { NESS } \\
\text { (MG/L) }\end{array}$ & $\begin{array}{l}\text { PERCENT } \\
\text { SODIUH }\end{array}$ & $\begin{array}{c}\text { SOOIUM } \\
\text { AD- } \\
\text { SORP- } \\
\text { TION } \\
\text { RATIO }\end{array}$ & $\begin{array}{l}\text { ALKA- } \\
\text { LINITY } \\
\text { AS } \\
\text { CACO3 } \\
\text { (MG/L) }\end{array}$ & $\begin{array}{c}P H \\
\text { (UNITS) }\end{array}$ & $\begin{array}{l}\text { SPECI- } \\
\text { FIC } \\
\text { COND- } \\
\text { UCTANCE } \\
\text { (MICRO- } \\
\text { MHOSI }\end{array}$ \\
\hline $\begin{array}{l}\text { OCT. } \\
\text { O9... } \\
\text { MAR. }\end{array}$ & -- & -- & -- & $\cdots$ & 178 & 2 & 47 & 1.6 & 176 & 8.2 & 477 \\
\hline OE... & -- & -- & -- & $\sim$ & 153 & 7 & 33 & .8 & 146 & 8.2 & 350 \\
\hline 17. & 1.3 & 1120 & 176 & .24 & 138 & 0 & 22 & .7 & 143 & 7.4 & 337 \\
\hline
\end{tabular}


11453500 PUTAB CREEK NEAR GUENOC, CALIF.

LOCATION.--Lat $38^{\circ} 46^{\prime} 44^{\prime \prime}$, Iong $122^{\circ} 30^{\prime} 59^{\prime \prime}$, in Guenoc Grant, Lake County, temperature recorder at gaging station on right bank Just upstream from Coyote Valloy Dam s1te, 2.8 miles upstream from Soda Creek and $3.2 \mathrm{miles}$ downstream from highway bridge at Guenoc.

DRAINAGE AREA, $--113 \mathrm{sq} \mathrm{mi}$.

PERIOD OF RECORD. --Water temperatures: March 1960 to September 1969

Sediment records: October 1962 to September 1965 (da1ly), October 1965 to September 1969 (part1al records).

EXTREMES,--1968-69:

Water temperatures: Maximum, $29.0^{\circ} \mathrm{C}$ on many days during July and August; minimum, 7. $0^{\circ} \mathrm{C} \mathrm{Dec}, 20,23,24$,
Feb. 6 .

Pertod of record:

Water temperatures: Maximum, $30.0^{\circ} \mathrm{C}$ July 20, 1960; minimum (1960-65, 1966-69), 4.0 $0^{\circ} \mathrm{C}$ Dec. $14,1967$. TEMPERATURE ( $\left.{ }^{\circ} \mathrm{C}\right)$ OF WATER, WATER YEAR OCTOBER 1968 TO SEPTEMBER 1969

DAY

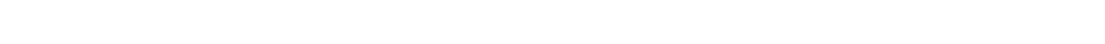

OCTOBER

MAXIMUM $20 \begin{array}{lllllllllllllllllllllllllllllllll} & 20 & 21 & 21 & 21 & 20 & 19 & 19 & 18 & 18 & 18 & 18 & 18 & 18 & 17 & 17 & 17 & 18 & 18 & 18 & 18 & 17 & 17 & 18 & 18 & 18 & 18 & 18 & 17 & 17 & 16\end{array}$

MINIMUM $19192020201919181818181818171717171717171717171717181817 \quad 17 \quad 1616$

NOVEMBER

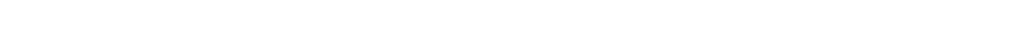

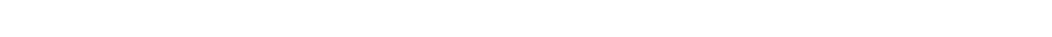

DECEMBER

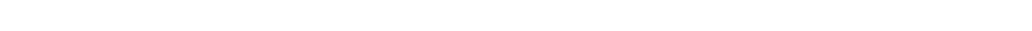

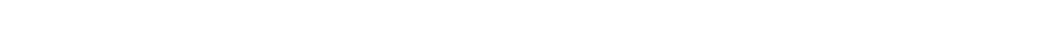

ANUARY

MAXIMUM $101011 \quad 12121211111101010101011111111101012121211101011111010 \quad 91010$

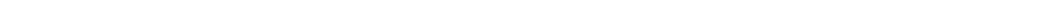
BRUARY

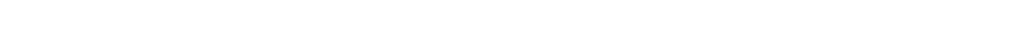

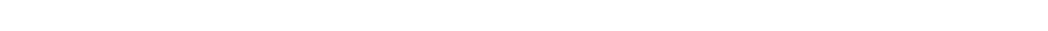
MARCH

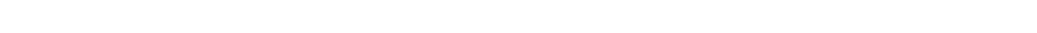
MAXIMUM $17 \quad 14 \quad 15 \quad 15 \quad 13 \quad 14 \quad 16 \quad 16 \quad 14 \quad 17 \quad 18 \quad 17 \quad 14 \quad 17 \quad 17 \quad 18 \quad 18 \quad 19 \quad 19 \quad 21 \quad 21 \quad 18 \quad 16 \quad 16 \quad 17 \quad 1819 \quad 21 \quad 21 \quad 20 \quad-2$ $\begin{array}{llllllllllllllllllllllllllllllll}\text { MAXIMUM } & 17 & 14 & 15 & 15 & 13 & 14 & 16 & 16 & 14 & 17 & 18 & 17 & 14 & 17 & 17 & 18 & 18 & 19 & 19 & 21 & 21 & 18 & 16 & 16 & 17 & 18 & 19 & 21 & 21 & 20 & -5\end{array}$

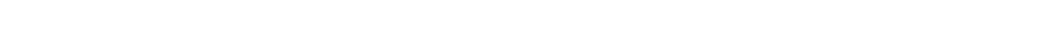

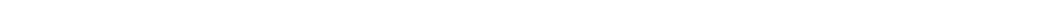
JUNE

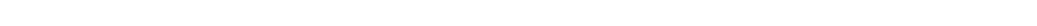
JULY

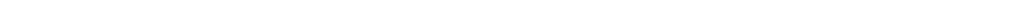
AUGUST

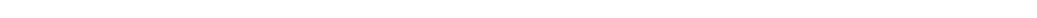

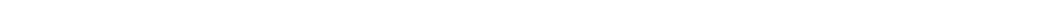

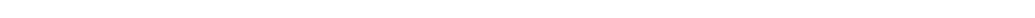

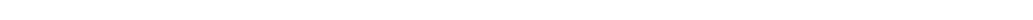

SUSPENDED-SEDIMENT DISCHARGE MEASUREMENTS AND PARTICLE-SIZE DISTRIBUTION, WATER YEAR OCTOBER 1968 TO SEPTEMBER 1969 IMETHODS DF ANALYSIS: B, BDTTIM WITHORAWAL TUBE; C, CHEMICALLY OISPERSED; $N$, IN NATIVE WATER; P, PIPET; S, SIEVE;

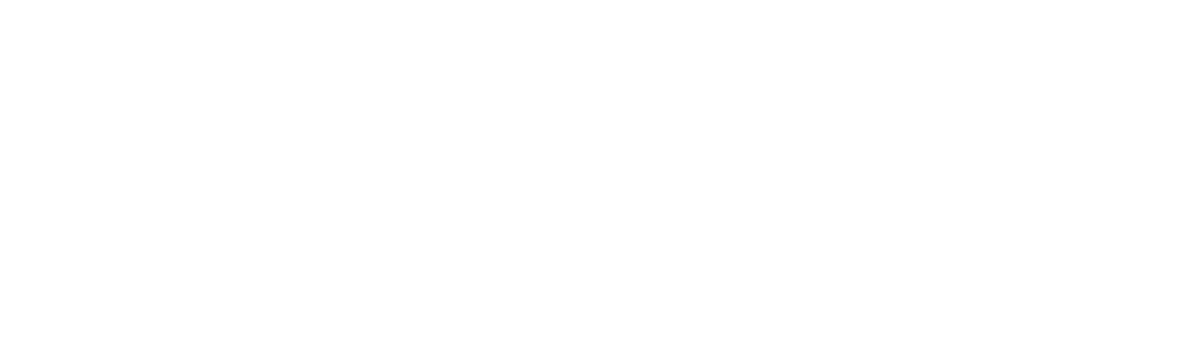

PARTICLE-SIZE DISTRIBUTIDN OF SURFACE BED MATERIAL, WATER YEAR OCTOBER 1968 TO SEPTEMBER 1969

IMETHOI OF ANALYSIS: H. HYOROMETER; O, OPIICAL ANALYZER: S, SIEVE: V, VISUAL ACCUMULATIUN TUHE

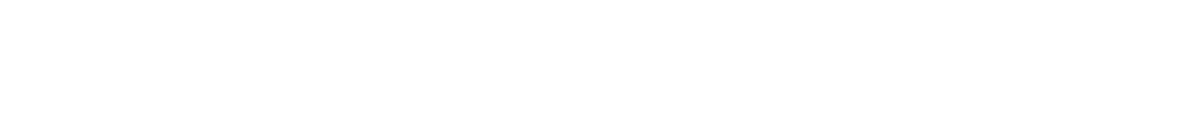




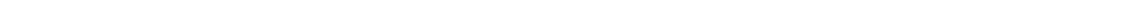
at gaging station 1.3 miles downtream from Monticello Dam, 6 miles west of Winters, and 8 miles downstream from Capell Creek.

DRAI NAGE AREA. $-574 \mathrm{sq} \mathrm{m1}$.

PERIOD OF RECORD. --Chemtcal anal yses: Octobe 1952 to September 1966.

Water temperatures: November 1965 to September 1969.

EXTREMES. --1968-69:

Water temperatures: Maximum, $18.0^{\circ} \mathrm{C} \mathrm{Apr}, 20-23,28,29$.

Period of record:

Water temperatures: Maximum, $22.5^{\circ} \mathrm{C}$ May 21, 1967; mint mu (1966-68), $7.0^{\circ} \mathrm{C}$ on several days during December 1967 and January 1968.

REMARKS.--Recorder malfunction Jan. 7 to Mar. 20, June 13-17, June 23 to July 3 . TEMPERATURE $\left({ }^{\circ} \mathrm{C}\right)$ OF WATER, WATER YBAR OCTOBER 1968 TO SEPTEMBER 1969

nAY

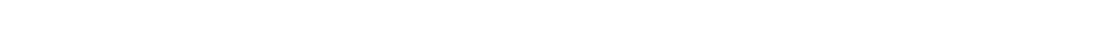

acruarp

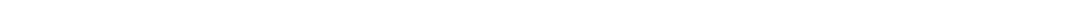

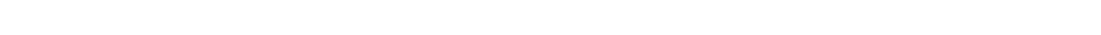

VIJV $=$ at?

$\begin{array}{lllllllllllllllllllllllllllllllllllllllll}\text { NAXIMUM } & 12 & 11 & 12 & 12 & 12 & 11 & 12 & 12 & 12 & 12 & 11 & 12 & 11 & 9 & 9 & 12 & 16 & 11 & 11 & 11 & 11 & 11 & 11 & 10 & 9 & 4 & 9 & 9 & 9 & 1 & -- & 11 \\ \text { MINIMUM } & 11 & 11 & 11 & 11 & 11 & 11 & 11 & 11 & 11 & 11 & 10 & 11 & 9 & 9 & 9 & 9 & 10 & 10 & 10 & 11 & 11 & 11 & 10 & 10 & 9 & 8 & 8 & 8 & 8 & 9 & -- & 10\end{array}$

DTCLMUM

MAXimum 9

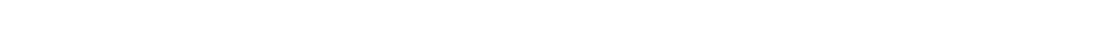

JANUARY

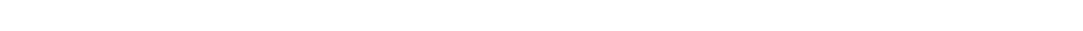

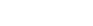

MAXIMUM --

Mivimun -

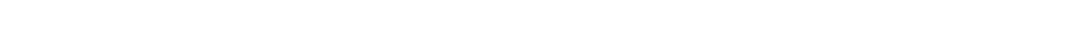

IVIMUM -

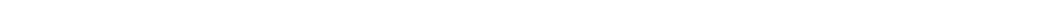

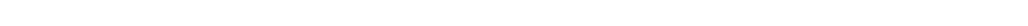

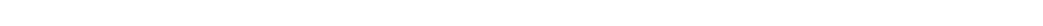
\begin{tabular}{lllllllllllllllllllllllllllllllllll} 
MAXIRUM & 16 & 16 & 15 & 15 & 15 & 14 & 14 & 13 & 13 & 13 & 13 & 13 & 13 & 12 & 11 & 11 & 11 & 11 & 11 & 11 & 11 & 11 & 11 & 11 & 11 & 11 & 11 & 11 & 11 & 11 & 11 \\
MININUM & 16 & 25 & 15 & 14 & 14 & 14 & 13 & 13 & 13 & 13 & 13 & 12 & 12 & 11 & 11 & 11 & 11 & 10 & 11 & 11 & 11 & 11 & 11 & 11 & 11 & 11 & 11 & 11 & 11 & 11 & 10 & & & \\
\hline
\end{tabular} JUivf

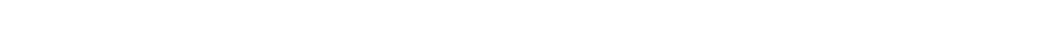

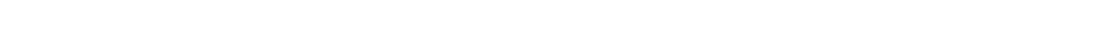
JULY

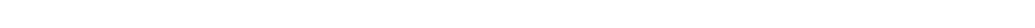

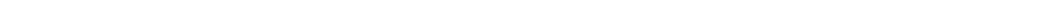

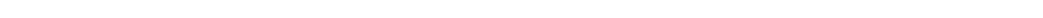
STPTFMAFK

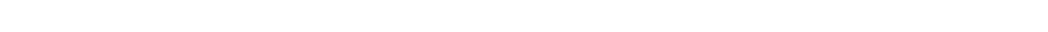


11455400 SACRANENTO RIVER AT RIO VISTA, CALIF.

LOCATION, - Lat $38^{\circ} 09^{\prime} 44^{\prime \prime}$, long $121^{\circ} 41^{\prime} 24^{\prime \prime}$, T, 4 N., R, 3 E, Sacramento County, at Highway 12 drawbridge, 1.1 miles upstrean from tidal gaging station just south' of Rio vista and approximately 2.1 miles downstream from Steam-

PERIOD OF RECORD. --Chemical analyses: October 1953 to September 1969.

REMARKS. --Reported as Sacramento River near Rio Vista, October 1953 to September 1967 . Records furnished by U.S. Bureau of Reclamation and reviewed by U.S. Geological Survey.

CHEMICAL ANALYSES, WATER YEAR OCTOBER 1968 TO SEPTEMBER 1969

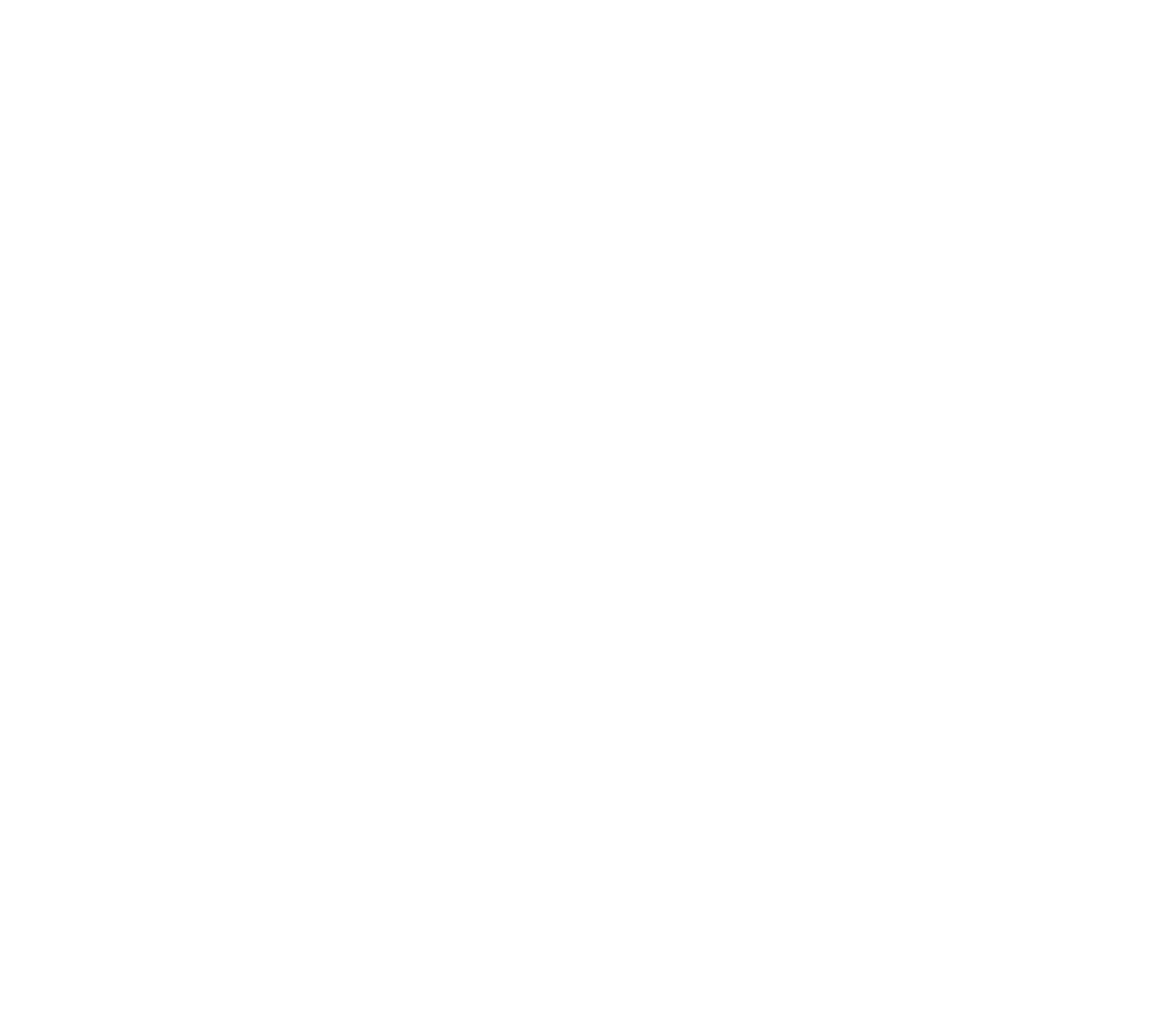




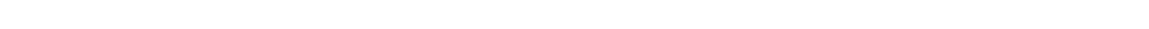

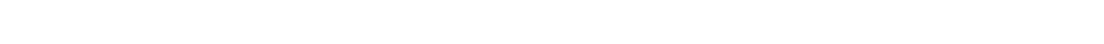

DRAINAGE AREA, --81.4 sq $\mathrm{ml}$.

PERIOD OF RECORD. --Chemical analyses: October 1953 to September 1966,

Water temperatures: October 1957 to September 1969.

Sediment records: December 1958 to June 1962 .

EXTREMES, $-1968-69$ :

Water temperatures: Haximum, $23.0^{\circ} \mathrm{C}$ May 30,31 , July 18,$20 ;$ minimum, $5.0^{\circ} \mathrm{C}$ Dec. $21, \mathrm{Jan} .10$.

Period of record (1961-63, 1964-69): Water temperatures: Maximum (1961-63, 1964-65, 1968-69), 33.0 ${ }^{\circ} \mathrm{C}$ July 18, 1968; minimum (1961-63, 1965-69),
$3.0^{\circ} \mathrm{C}$ Dec. 14,15, 1967 .

REMARKS. --Recorder atopped Feb. 28 to Mar. 2.

TEIPERATURE ( ${ }^{\circ} \mathrm{C}$ ) OF WATER, WATER YEAR OCTOBER 1968 TO SEPTEMBER 1969

DAY

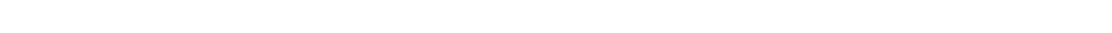

OCTURER

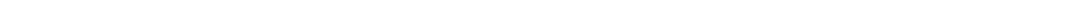

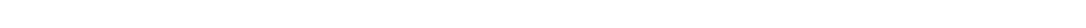

MINIMUA

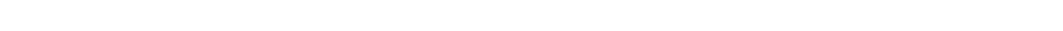

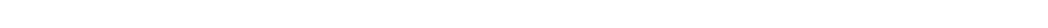
DTCEMDER

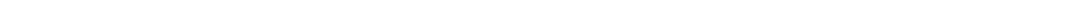

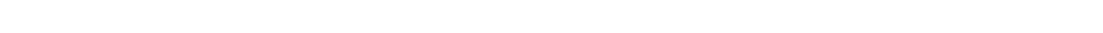

$\begin{array}{lllllllllllllllllllllllllllllllllll}\text { MAXIMUM } & 8 & 9 & 8 & 8 & 8 & 8 & 8 & 8 & 7 & 6 & 6 & 7 & 8 & 8 & 7 & 7 & 7 & 7 & 8 & 9 & 9 & 9 & 8 & 7 & 8 & 8 & 7 & 7 & 6 & 7 & 7 & 8 \\ \text { MINIMUM } & 7 & 7 & 8 & 8 & 8 & 8 & 8 & 7 & 6 & 5 & 6 & 6 & 7 & 7 & 6 & 7 & 6 & 6 & 6 & 8 & 8 & 8 & 7 & 7 & 7 & 7 & 7 & 6 & 6 & 6 & 6 & 7\end{array}$

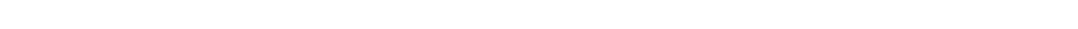

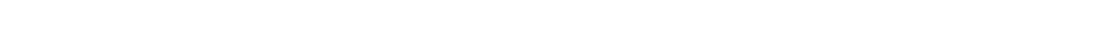

MARCH

MAXIMUM --

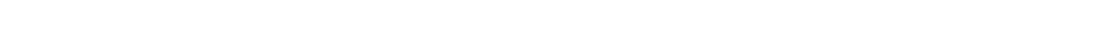

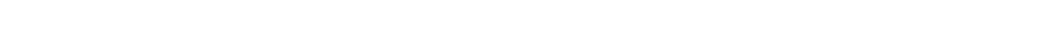

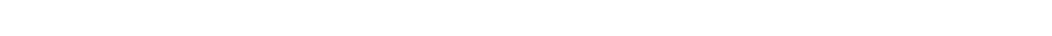
Ar

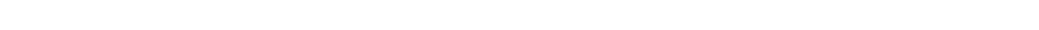

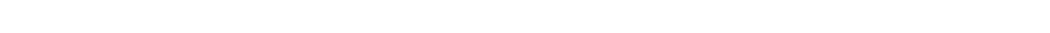
UNE

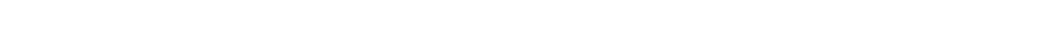

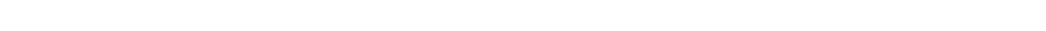
JULY

$\begin{array}{lllllllllllllllllllllllllllllllll}M A X I M U M & 22 & 22 & 22 & 22 & 22 & 21 & 21 & 21 & 21 & 22 & 21 & 22 & 22 & 21 & 21 & 22 & 22 & 23 & 22 & 23 & 22 & 22 & 22 & 22 & 22 & 21 & 21 & 21 & 21 & 20 & 21\end{array}$

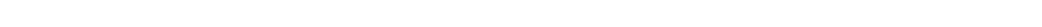
DUGUST

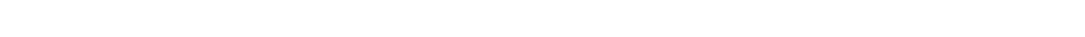
MINIMUM

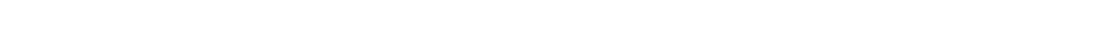


LOCATYON. --Lat $37^{\circ} 35^{\circ} 07^{\prime \prime}$, long $122^{\circ} 41^{\prime} 31^{\prime \prime}$, In Las Baulines Grant, Marin County, at gaging station 100 ft upstream from h1ghway bridge, 0.4 mile upstream from mouth, and 0.9 mile north of Bolinas.

DRAINAGE AREA. -7.83 sq m1.

PERIOD OF RECORD. --Water temperatures: May 1967 to September 1968.

Sediment records: June 1967 to September 1969

EXTREMES, - -1968-69:

Water temperatures: Minimum, $7.0^{\circ} \mathrm{C}$ Dec. 22.
Sediment concentrations: Maximum da1ly, $3,010 \mathrm{mg} / 1$ Dec. $28 ;$ minimum da1ly, $1 \mathrm{mg} / 1$ on many days.

Sediment discharge: Maximu da11y, 3,430 tons Dec. 28; minimum da11y, 0 tón oz many days.

Period of record:

Water temperatures: Minimum, $4.0^{\circ} \mathrm{C}$ Dec. 14,1967

Sediment concentrations: Maximum datly, 3,010 mg/l Dec. 28, 1968; minimum daily, no flow Sept. $22,1968$.

Sediment discharge: Maximum da11y, 3,430 tons Dec. 28, 1968 ; minimum da11y, 0 ton on many days each year.

TEMPERATURE $\left({ }^{\circ} \mathrm{C}\right)$ OF WATER, WATER YEAR OCTOBER 1968 TO SEPTEMBER 1969 (ONCE-DA ILY MEA SCREMENT)

DAY

$\begin{array}{lllllllllllllllllllllllllllllllllllllllll}\text { MUNTH } & 1 & 2 & 3 & 4 & 5 & 6 & 7 & 8 & 9 & 10 & 11 & 12 & 13 & 14 & 15 & 16 & 17 & 18 & 19 & 20 & 21 & 22 & 23 & 24 & 25 & 26 & 27 & 28 & 29 & 30 & 31 & \text { AGE }\end{array}$

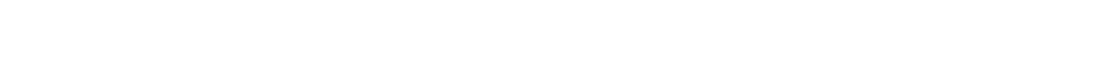

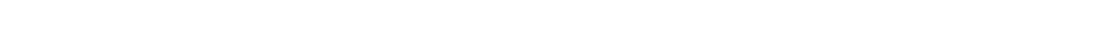

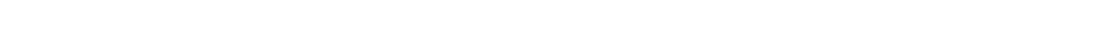

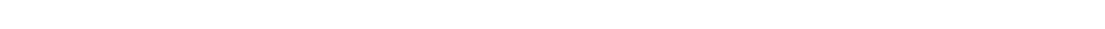
NAY.....

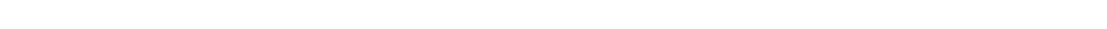
SUGUST:X

SUSPENDED-SEDIMENT DISCHARGE, WATER YEAR OCTOBER 1968 TO SEPTEMBER 1969

DCTOBER

MEAN

AY MEAN DISCHARGE CONCENIMENT TRATION DISCHARGE (MG/L) (ITDNS/DAY)

\begin{tabular}{|c|c|}
\hline $\begin{array}{l}.18 \\
.21 \\
.23 \\
.21 \\
.21\end{array}$ & $\begin{array}{l}1 \\
1 \\
1 \\
1 \\
1\end{array}$ \\
\hline $\begin{array}{l}.21 \\
.18 \\
.14 \\
.14 \\
.12\end{array}$ & $\begin{array}{l}1 \\
1 \\
1 \\
1 \\
1\end{array}$ \\
\hline
\end{tabular}

.37

8. 2

3.1
2.7
2.4

2
84
6
5
3

2.2

2.0
2.0

2.0

1.9
2.0
1.9

1.9
1.9
1.8

1.

2.

2.7

51.30

0
0
0
0
0
0
0
0
0
0
0
3.2
.05
.02
.02
.02
.02
.03
.02
.02
.02
.01
.01
.01
0
0
0
.01
.05
.03
.01
3.55

NOVEMBER

MEAN

CONCEN(CFS) (MG/L) ITONS/DAY)

$\begin{array}{rr}2.2 & 2 \\ 4.8 & 32 \\ 3.3 & 14 \\ 2.7 & 4\end{array}$

2.3

2.1

2.0
2.0
1.9

1.9

2.0
2.7

2.0
3.2

3.2
9.5

3.7

2.8

2.8

2.6
2.5

2.4

2.2
2.1
2.5

2.2

2.1

1.9

2.0
2.4

.03
.01

3.55

80.8

:01

\begin{tabular}{|c|c|}
\hline $\begin{array}{l}.01 \\
.55 \\
.12 \\
.03 \\
.01\end{array}$ & $\begin{array}{l}2.4 \\
2.1 \\
2.0 \\
2.1 \\
2.2\end{array}$ \\
\hline $\begin{array}{l}.01 \\
.01 \\
.01 \\
.01 \\
.01\end{array}$ & $\begin{array}{r}2.2 \\
2.4 \\
5.1 \\
7.6 \\
51\end{array}$ \\
\hline $\begin{array}{l}.02 \\
.04 \\
.02 \\
.17 \\
2.1\end{array}$ & $\begin{array}{l}31 \\
15 \\
14 \\
20 \\
36\end{array}$ \\
\hline $\begin{array}{c}1.5 \\
.08 \\
.04 \\
.03 \\
.02\end{array}$ & $\begin{array}{l}26 \\
18 \\
14 \\
12 \\
10\end{array}$ \\
\hline $\begin{array}{l}.01 \\
.01 \\
.01 \\
.01 \\
.01\end{array}$ & $\begin{array}{r}9.2 \\
8.6 \\
8.2 \\
27 \\
27\end{array}$ \\
\hline $\begin{array}{l}.01 \\
.01 \\
.01 \\
.02 \\
.04 \\
.-\end{array}$ & $\begin{array}{r}28 \\
26 \\
320 \\
78 \\
46 \\
36\end{array}$ \\
\hline 4.93 & 889.1 \\
\hline
\end{tabular}

DECEMBER

CONCEN- SEDIMENT

TRATIDN DISCHARGE

(TONS/DAY) . . .

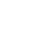

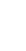


PINE CREEK BASIN

11460170 PINE CREEK AT BOLINAS, CALIF.--Continued

SUSPENDED-SEDIMENT DISCHARGE, WATER YEAR OCTOBER 1968 TO SEPTEMBER 1969

\begin{tabular}{|c|c|c|c|c|c|c|c|c|c|}
\hline DAY & $\begin{array}{l}\text { MEAN } \\
\text { DISCHARGE } \\
\text { ICFSI }\end{array}$ & $\begin{array}{l}\text { JANUARY } \\
\text { MEAN } \\
\text { CONCEN- } \\
\text { TRAIION } \\
\text { (MGLL) }\end{array}$ & $\begin{array}{l}\text { SEDIMENT } \\
\text { DI SCHARGE } \\
\text { (TONS/DAY) }\end{array}$ & $\begin{array}{l}\text { MEAN } \\
\text { DISCHARGE } \\
\text { (CFS) }\end{array}$ & $\begin{array}{l}\text { FEBRUARY } \\
\text { MEAN } \\
\text { CONCEN- } \\
\text { TRATION } \\
\text { IMG/LI }\end{array}$ & $\begin{array}{l}\text { SEDIMENT } \\
\text { DISCHARGE } \\
\text { (TONS/DAY) }\end{array}$ & $\begin{array}{l}\text { MEAN } \\
\text { DISCHARGE } \\
\text { (CFS) }\end{array}$ & $\begin{array}{l}\text { MARCH } \\
\text { MEAN } \\
\text { CONCEN- } \\
\text { IRATION } \\
\text { (MG/L) }\end{array}$ & $\begin{array}{l}\text { SEDI MENT } \\
\text { DI SCHARGE } \\
\text { (TONS/DAY) }\end{array}$ \\
\hline $\begin{array}{l}1 \\
2 \\
3 \\
4 \\
5\end{array}$ & $\begin{array}{l}29 \\
25 \\
22 \\
20 \\
18\end{array}$ & $\begin{array}{l}42 \\
30 \\
25 \\
20 \\
20\end{array}$ & $\begin{array}{l}3.3 \\
2.0 \\
1.5 \\
1.1 \\
.97\end{array}$ & $\begin{array}{l}50 \\
41 \\
38 \\
36 \\
50\end{array}$ & $\begin{array}{r}65 \\
45 \\
25 \\
30 \\
159\end{array}$ & $\begin{array}{l}8.8 \\
5.0 \\
2.6 \\
2.9 \\
17\end{array}$ & $\begin{array}{l}53 \\
49 \\
46 \\
42 \\
38\end{array}$ & $\begin{array}{l}70 \\
42 \\
39 \\
35 \\
32\end{array}$ & $\begin{array}{l}10 \\
5.6 \\
4.8 \\
4.0 \\
3.3\end{array}$ \\
\hline $\begin{array}{r}6 \\
7 \\
8 \\
9 \\
10\end{array}$ & $\begin{array}{l}15 \\
13 \\
13 \\
13 \\
12\end{array}$ & $\begin{array}{r}17 \\
12 \\
8 \\
7 \\
5\end{array}$ & $\begin{array}{l}.69 \\
.42 \\
.28 \\
.25 \\
.16\end{array}$ & $\begin{array}{l}55 \\
49 \\
46 \\
63 \\
78\end{array}$ & $\begin{array}{r}99 \\
70 \\
45 \\
229 \\
175\end{array}$ & $\begin{array}{l}15 \\
9.3 \\
5.6 \\
42 \\
37\end{array}$ & $\begin{array}{l}31 \\
27 \\
25 \\
24 \\
22\end{array}$ & $\begin{array}{l}25 \\
23 \\
21 \\
25 \\
25\end{array}$ & $\begin{array}{l}2.1 \\
1.7 \\
1.4 \\
1.6 \\
1.5\end{array}$ \\
\hline $\begin{array}{l}11 \\
12 \\
13 \\
14 \\
15\end{array}$ & $\begin{array}{r}19 \\
20 \\
114 \\
76 \\
51\end{array}$ & $\begin{array}{r}80 \\
41 \\
631 \\
225 \\
140\end{array}$ & $\begin{array}{r}4.8 \\
2.4 \\
267 \\
46 \\
19\end{array}$ & $\begin{array}{r}178 \\
110 \\
81 \\
124 \\
165\end{array}$ & $\begin{array}{l}930 \\
300 \\
160 \\
641 \\
600\end{array}$ & $\begin{array}{r}448 \\
89 \\
35 \\
326 \\
286\end{array}$ & $\begin{array}{l}21 \\
21 \\
19 \\
18 \\
18\end{array}$ & $\begin{array}{l}20 \\
26 \\
20 \\
16 \\
16\end{array}$ & $\begin{array}{l}1.1 \\
1.5 \\
1.0 \\
.78 \\
.78\end{array}$ \\
\hline $\begin{array}{l}16 \\
17 \\
18 \\
19 \\
20\end{array}$ & $\begin{array}{r}41 \\
36 \\
50 \\
122 \\
204\end{array}$ & $\begin{array}{r}70 \\
50 \\
144 \\
792 \\
1000\end{array}$ & $\begin{array}{r}7.7 \\
4.9 \\
31 \\
283 \\
586\end{array}$ & $\begin{array}{r}111 \\
78 \\
62 \\
54 \\
46\end{array}$ & $\begin{array}{r}210 \\
150 \\
130 \\
92 \\
70\end{array}$ & $\begin{array}{l}63 \\
32 \\
22 \\
14 \\
8.7\end{array}$ & $\begin{array}{l}17 \\
23 \\
18 \\
16 \\
20\end{array}$ & $\begin{array}{l}15 \\
41 \\
22 \\
20 \\
55\end{array}$ & $\begin{array}{l}.69 \\
2.8 \\
1.1 \\
.86 \\
3.4\end{array}$ \\
\hline $\begin{array}{l}21 \\
27 \\
23 \\
24 \\
25\end{array}$ & $\begin{array}{r}173 \\
111 \\
80 \\
67 \\
78\end{array}$ & $\begin{array}{l}757 \\
350 \\
210 \\
180 \\
190\end{array}$ & $\begin{array}{r}373 \\
105 \\
45 \\
33 \\
40\end{array}$ & $\begin{array}{l}44 \\
41 \\
40 \\
43 \\
42\end{array}$ & $\begin{array}{r}65 \\
45 \\
55 \\
139 \\
90\end{array}$ & $\begin{array}{l}7.7 \\
5.0 \\
5.9 \\
16 \\
10\end{array}$ & $\begin{array}{l}20 \\
18 \\
17 \\
16 \\
15\end{array}$ & $\begin{array}{r}28 \\
18 \\
10 \\
8 \\
8\end{array}$ & $\begin{array}{l}1.5 \\
.87 \\
.46 \\
.35 \\
.32\end{array}$ \\
\hline $\begin{array}{l}26 \\
27 \\
28 \\
29 \\
30 \\
31\end{array}$ & $\begin{array}{r}133 \\
94 \\
84 \\
70 \\
65 \\
56\end{array}$ & $\begin{array}{r}613 \\
160 \\
120 \\
80 \\
120 \\
60\end{array}$ & $\begin{array}{c}252 \\
41 \\
27 \\
15 \\
21 \\
9.1\end{array}$ & $\begin{array}{l}40 \\
41 \\
51 \\
-- \\
-- \\
--\end{array}$ & $\begin{array}{r}58 \\
54 \\
126 \\
-- \\
--\end{array}$ & $\begin{array}{l}6.3 \\
6.1 \\
1.8 \\
-- \\
-- \\
--\end{array}$ & $\begin{array}{l}14 \\
13 \\
12 \\
12 \\
11 \\
11\end{array}$ & $\begin{array}{l}8 \\
8 \\
8 \\
7 \\
6 \\
5\end{array}$ & $\begin{array}{l}.30 \\
.28 \\
.26 \\
.23 \\
.18 \\
.15\end{array}$ \\
\hline TOIAL & 1924 & $\rightarrow$ & 2223.57 & 1857 & - & 1543.9 & 707 & - & 54.91 \\
\hline
\end{tabular}

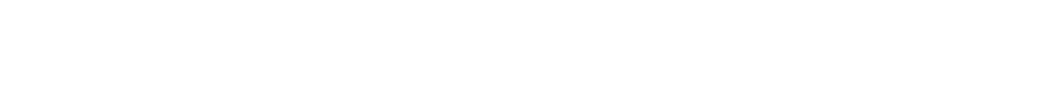

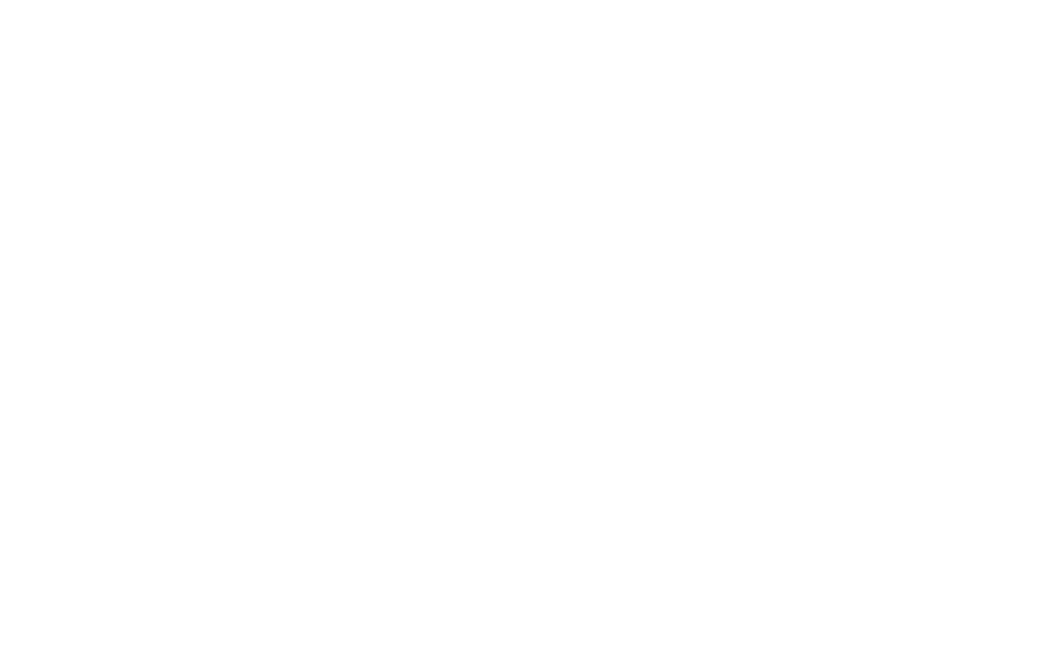


11460170 PINE CREEK AT BOLINAS, CALIF.--Continued

SUSPENDED-SEDIMENT DISCHARGE, WATER YEAR OCTOBER 1968 TO SEPTEMBER 1969

JULY

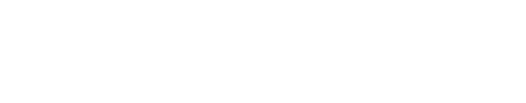

AUGUST

MEAN

CONCEN- SEDIMENT IRATION DISCHARGE DISCHARGE (MGIL) (TDNS/DAY) (CFS)
SEP TEMBER

MEAN

CONCEN- SEDIMENT TRATION DISCHARGE

\begin{tabular}{|c|c|c|c|c|}
\hline $\begin{array}{l}1 \\
2 \\
3 \\
4 \\
5\end{array}$ & $\begin{array}{l}1.9 \\
1.9 \\
1.7 \\
1.7 \\
1.7\end{array}$ & $\begin{array}{l}3 \\
3 \\
2 \\
2 \\
2\end{array}$ & $\begin{array}{l}.02 \\
.02 \\
.01 \\
.01 \\
.01\end{array}$ & $\begin{array}{l}.85 \\
.80 \\
.60 \\
.75 \\
.60\end{array}$ \\
\hline $\begin{array}{r}6 \\
7 \\
8 \\
9 \\
10\end{array}$ & $\begin{array}{l}1.4 \\
1.9 \\
1.9 \\
1.6 \\
1.7\end{array}$ & $\begin{array}{l}2 \\
3 \\
3 \\
4 \\
4\end{array}$ & $\begin{array}{l}.01 \\
.02 \\
.02 \\
.02 \\
.02\end{array}$ & $\begin{array}{l}.65 \\
.70 \\
.70 \\
.70 \\
.70\end{array}$ \\
\hline $\begin{array}{l}11 \\
12 \\
13 \\
14 \\
15\end{array}$ & $\begin{array}{l}1.9 \\
1.4 \\
1.6 \\
1.7 \\
1.6\end{array}$ & $\begin{array}{l}3 \\
3 \\
3 \\
4 \\
5\end{array}$ & $\begin{array}{l}.02 \\
.01 \\
.01 \\
.02 \\
.02\end{array}$ & $\begin{array}{l}.70 \\
.65 \\
.60 \\
.60 \\
.60\end{array}$ \\
\hline $\begin{array}{l}16 \\
17 \\
18 \\
19 \\
20\end{array}$ & $\begin{array}{l}1.3 \\
1.3 \\
1.3 \\
1.4 \\
1.3\end{array}$ & $\begin{array}{l}6 \\
6 \\
5 \\
4 \\
4\end{array}$ & $\begin{array}{l}.02 \\
.02 \\
.02 \\
.02 \\
.01\end{array}$ & $\begin{array}{r}.65 \\
.70 \\
.70 \\
.65 \\
.70\end{array}$ \\
\hline $\begin{array}{l}21 \\
22 \\
23 \\
24 \\
25\end{array}$ & $\begin{array}{l}1.3 \\
1.4 \\
1.3 \\
1.3 \\
1.6\end{array}$ & $\begin{array}{l}4 \\
4 \\
4 \\
4 \\
5\end{array}$ & $\begin{array}{l}.01 \\
.02 \\
.01 \\
.01 \\
.02\end{array}$ & $\begin{array}{l}.70 \\
.65 \\
.65 \\
.65 \\
.60\end{array}$ \\
\hline $\begin{array}{l}26 \\
27 \\
28 \\
29 \\
30 \\
31\end{array}$ & $\begin{array}{l}1.6 \\
1.3 \\
1.3 \\
1.3 \\
1.3 \\
1.2\end{array}$ & $\begin{array}{l}6 \\
7 \\
8 \\
8 \\
8 \\
8\end{array}$ & $\begin{array}{l}.03 \\
.02 \\
.03 \\
.03 \\
.03 \\
.03\end{array}$ & $\begin{array}{l}.60 \\
.60 \\
.60 \\
.55 \\
.55 \\
.55\end{array}$ \\
\hline
\end{tabular}

$\begin{array}{llll}.02 & .60 & 2 & 0 \\ .02 & .70 & 2 & 0 \\ .01 & .70 & 2 & 0 \\ .01 & .75 & 2 & 0 \\ 0 & .70 & 2 & 0 \\ 0 & .65 & 2 & 0 \\ .01 & .65 & 2 & 0 \\ .01 & .60 & 2 & 0 \\ .01 & .65 & 2 & 0 \\ .01 & .60 & 2 & 0\end{array}$

PARTICLE-SIZE DISTRIBUTION OF SUSPENDED SEDIMENT, WATER YEAR OCTOBER 1968 TO SEPTEMBER 1969

PARTICLE-SIZE DISTRIBUTION OF SUSPENDED SEDIMENT, WATER YEAR OCTOBER 1968 TO SEPTEMBER 1969
ANALYSIS: B, BOTTOM WITHDRAHAL TUBE; C, CHEMICALLY DISPERSED; N, IN NATIVE WATER; P, PIPET; S, SIEVE; $\checkmark$, VISUAL ACCUMULATION TUBE; W, IN DISTILLED WATERI

\section{WATER \\ TEM-}

\section{SUSPENDEO}

DATE TIME ( C) OISCHARGE TRATION DISCHARGE

PARTICLE SIZE

$\begin{array}{lllll}\text { DEC } & 10,1968 & 1400 & 11 \\ \text { JAN } & 13,1969 & 1300 & 11 \\ \text { JAN } 20, \ldots \ldots . & 1215 & 12 \\ \text { JAN } & 27, \ldots \ldots & 1130 & 12\end{array}$

JAN $27 \ldots \ldots . .1130 \quad 12$

$\begin{array}{rr}106 & 13 \\ 210 & 10 \\ 236 & 8 \\ 94 & 1 \\ 160 & 6\end{array}$

1310
1010
815
149
618

$\begin{array}{rlll}375 & 23 & 32 & 38 \\ 573 & 21 & 30 & 35 \\ 519 & 18 & 27 & 33 \\ 38 & -7 & -7 & -- \\ 267 & 27 & 31 & 39\end{array}$

PARTICLE-SIZE DISTRIBUTION OF SURFACE BED MATERIAL, WATER YEAR OCTOBER 1968 TO SEPTEMBER 1960

(METHOD DF ANALYSIS: H, HYOROMETER; O, OPIICAL ANALYZER; S, SIEVE; V, VISUAL ACCUMULATIOV TUEE)

WATER NUMBER

WATER NUMB

PERA- SAM-

PARTICLE SIZE

DATE TIME TURE PLING DISCHARGE

PERCENT FINER than tHE SIZE IIN MILLIMETFRs) [NOICATEl

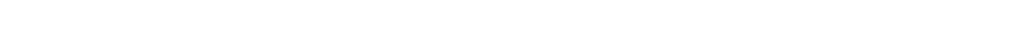

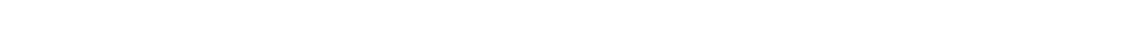


LOCATION. -- Lat $38^{\circ} 20^{\prime} 54^{\prime \prime}$, long $122^{\circ} 58^{\prime} 45^{\prime \prime}$, In Estero Americano Grant, Sonoma County, temperature recorder at gaging station on left bank, $100 \mathrm{ft}$ upstream from private road bridge, $0.3 \mathrm{~m} 11 \mathrm{e}$ upstream from unnamed tributary, and $0.4 \mathrm{mile}$ northwest of Bodega.

DRAINAGE AREA, $--15.7 \mathrm{sq}$ m.

PERIOD OF RECORD, - Water temperatures: October 1964 to September 1969.

EXTREMES, --1968-69:

Water temperatures: Maximum, $21.0^{\circ} \mathrm{C}$ Kay 5; m1nimum, freezing point Dec. $20-22$.

Perlod of record:

Water temperatures: Maximum, 23.5 $\mathrm{C}$ Apr. 26, 1965; m1 nimum (1964-66, 1967-69), freez1ng po1nt on many days during winter periods.

REMARKS, --No flow Oct. 1-11, 20-28, July 19, Aug. 1 to Sept. 30.

TEMPERATURE $\left({ }^{\circ} \mathrm{C}\right)$ OF WATER, WATER YEAR OCTOBER 1968 TO SEPTEMBER 1969

DAY

\begin{tabular}{|c|c|c|c|c|c|c|c|c|c|c|c|c|c|c|c|c|c|c|c|c|c|c|c|c|c|c|c|c|c|c|c|c|c|}
\hline \multirow[b]{2}{*}{ MONTH } & \multirow[b]{2}{*}{1} & \multirow[b]{2}{*}{2} & \multirow[b]{2}{*}{3} & \multirow[b]{2}{*}{4} & \multirow{2}{*}{\multicolumn{2}{|c|}{5}} & \multirow{2}{*}{\multicolumn{2}{|c|}{7}} & \multirow[b]{2}{*}{8} & \multirow[b]{2}{*}{910} & \multirow[b]{2}{*}{11} & \multirow{2}{*}{\multicolumn{2}{|c|}{12}} & \multirow[b]{2}{*}{13} & & & & & & & & & & & & & & & & & & & \\
\hline & & & & & & & & & & & & & & & 15 & 16 & 17 & 18 & 19 & 20 & 21 & 22 & 23 & 24 & 25 & 26 & 27 & 728 & 2 & & 3 & 31 & $\triangle \mathrm{AGE}$ \\
\hline TOBE & & & & & & & & & & & & & & & & & & & & & & & & & & & & & & & & & \\
\hline$M A X I M U M$ & $\cdots$ & -- & - & $=-$ & +- & -- & - & -- & -- & -- & -- & 16 & 16 & 13 & 13 & 14 & 14 & 14 & 13 & -- & & 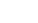 & & . & $-\infty$ & $-\infty$ & - & -- & -1 & & 3 & 13 & -- \\
\hline $\begin{array}{l}\text { INIMUM } \\
\text { I IEBER }\end{array}$ & -- & -- & +- & -- & - & -- & - & -- & -- & -- & - & 10 & 12 & 9 & 9 & 9 & 9 & 9 & 8 & -- & -- & -- & - & -- & $-\infty$ & -- & & & & & & 11 & -- \\
\hline MAXIMUM & 31 & 12 & 13 & 11 & 12 & 13 & 12 & 13 & 316 & & 14 & & & & & & & & & & & & & & & & & & & & & & \\
\hline & & 10 & 11 & 28 & 10 & & 12 & th & 10 & 10 & & 13 & 11 & 7 & 10 & 11 & 11 & 12 & 14 & 12 & 13 & 13 & 13 & 12 & 11 & 9 & 9 & 8 & & & & - & 11 \\
\hline $\begin{array}{l}\text { MINIMUM } \\
\text { ECEMRER }\end{array}$ & 9 & 10 & 11 & 8 & 10 & 10 & 8 & 9 & 1 & 1 & 11 & 9 & 6 & 5 & 6 & 7 & 9 & 11 & 10 & 10 & 10 & 10 & 10 & 9 & 7 & 4 & 3 & 2 & & 3 & $4-$ & -- & 8 \\
\hline MAXIMUM & 9 & 7 & 6 & 6 & 7 & 8 & 6 & 8 & 10 & 11 & 9 & 8 & 6 & 9 & 9 & 8 & 8 & 7 & 6 & 5 & 4 & 2 & 3 & 8 & 7 & 8 & 5 & 8 & & 9 & 8 & 8 & 7 \\
\hline MIN IMUM & 6 & 2 & 1 & 1 & 2 & 5 & 5 & 6 & 7 & 79 & 6 & 3 & 4 & 6 & 6 & 3 & 2 & 2 & 2 & 0 & c & 0 & 2 & 3 & 6 & 3 & 2 & 4 & & 5 & 3 & 3 & 4 \\
\hline IANUARY & & & & & & & & & & & & & & & & & & & & & & & & & & & & & & & & & \\
\hline MAXIMUM & 9 & 8 & 10 & 7 & 7 & 7 & 8 & 8 & 6 & 6 & 8 & 9 & 10 & 8 & 8 & 8 & 8 & & 11 & 11 & 12 & 8 & 6 & 6 & 10 & 11 & 8 & 7 & & 5 & 7 & 7 & 8 \\
\hline MINIMUM & 6 & 4 & 5 & 5 & 5 & 5 & 5 & 3 & 2 & 1 & 4 & 8 & 5 & 4 & 2 & 4 & 2 & s & 8 & 10 & 8 & 5 & 3 & 5 & 6 & 6 & 4 & 4 & & 1 & 3 & $i$ & 4 \\
\hline EBRU & & & & & & & & & & & & & & & & & & & & & & & & & & & & & & & & & \\
\hline MAXIMUM & 10 & 10 & 8 & 6 & 8 & 11 & 10 & 9 & 13 & 12 & 12 & 11 & 10 & 9 & 13 & 13 & 10 & 12 & 12 & 11 & 8 & 9 & 10 & 11 & 11 & 10 & & 311 & - & & -- & - & 10 \\
\hline INIMUM & 4 & 4 & 2 & 4 & 4 & 6 & 4 & 5 & 9 & 910 & 9 & 6 & 4 & 8 & 9 & 9 & 6 & 9 & 9 & 7 & 6 & 5 & 5 & 7 & 7 & 6 & 6 & 8 & - & - & -- & -- & 6 \\
\hline ARCH & & & & & & & & & & & & & & & & & & & & & & & & & & & & & & & & & \\
\hline MAX & 12 & 10 & 11 & 12 & 11 & 11 & 10 & 11 & 9 & 11 & 10 & 8 & 11 & 11 & 13 & 10 & 12 & 14 & 14 & 10 & 12 & 14 & 17 & 18 & 19 & 20 & 19 & $9 \quad 17$ & 17 & & & 16 & 13 \\
\hline$M[N[M !] M$ & 5 & 6 & 5 & 5 & 4 & 4 & 4 & 3 & 3 & 4 & 2 & 5 & 3 & 2 & 5 & 6 & 8 & 9 & 6 & 8 & 6 & 5 & 7 & 9 & 7 & 8 & 8 & 9 & & & 11 & 12 & 6 \\
\hline PRIL & & & & & & & & & & & & & & & & & & & & & & & & & & & & & & & & & \\
\hline MAXIMUM & 16 & 12 & 14 & 12 & 12 & 14 & 15 & 15 & 514 & 16 & 16 & 16 & 13 & 315 & 16 & 17 & 16 & 17 & 17 & 19 & 18 & 14 & 14 & - 15 & 516 & 18 & 320 & 018 & 16 & & 14 & $\rightarrow$ & 16 \\
\hline MINIMUM & 8 & 9 & 5 & 5 & 8 & 6 & 6 & 6 & 10 & 8 & 8 & & 7 & 7 & 7 & 8 & 9 & 9 & 8 & 8 & 10 & 11 & 10 & 8 & 7 & 7 & 9 & 911 & & 9 & & - & 8 \\
\hline AAY & & & & & & & & & & & & & & & & & & & & & & & & & & & & & & & & & \\
\hline MAXIMUM & 16 & 16 & 14 & 18 & 21 & 17 & 16 & 16 & 618 & 917 & 16 & 14 & 14 & 417 & 17 & 20 & 17 & 17 & 17 & 17 & 16 & 16 & 15 & 36 & 17 & 17 & $7 \quad 17$ & $7 \quad 17$ & 1 & & 20 & 18 & 17 \\
\hline$M I I$ & 7 & 9 & 9 & 7 & 10 & 13 & 13 & 13 & 11 & 13 & & & & & & & & & & 12 & & 14 & & 12 & & & $6 \quad 13$ & $3 \quad 12$ & & & & & 12 \\
\hline JUNE & & & & & & & & & & & & & & & & & & & & & & & & & & & & & & & & & \\
\hline MAXIMUM & 17 & 16 & 16 & 16 & 17 & 18 & 16 & 16 & 15 & 516 & 16 & 17 & 17 & $7 \quad 17$ & 17 & 17 & 17 & 17 & 16 & 16 & 17 & 18 & 17 & 18 & 817 & 716 & $6 \quad 15$ & $5 \quad 16$ & 1 & & 18 & -- & 17 \\
\hline$M[N$ & 15 & 14 & 14 & 15 & 15 & 14 & 15 & 14 & - 14 & & & & & & & & & & & & & & & 15 & & & & 211 & 1 & & 12 & - & 14 \\
\hline JULY & & & & & & & & & & & & & & & & & & & & & & & & & & & & & & & & & \\
\hline MAXIMUM & 17 & 17 & 18 & 19 & 17 & 17 & 16 & 16 & b 16 & 617 & 18 & 18 & 17 & 717 & 16 & 18 & 18 & 17 & - & - 16 & 16 & 617 & 17 & 17 & 17 & 16 & $6 \quad 17$ & 717 & 1 & & 16 & 16 & 17 \\
\hline MINIMUM & 14 & 13 & 12 & 13 & 14 & 13 & 12 & 13 & 313 & 314 & 14 & & & 312 & & 12 & & & -- & & & & 14 & & & & 413 & 313 & & & 12 & 12 & 13 \\
\hline augus & & & & & & & & & & & & & & & & & & & & & & & & & & & & & & & & & \\
\hline & & & -- & - & -- & - & -- & - & & - & - & -- & & & -- & -- & & & - & -- & $\cdots$ & -- & -- & $-\cdots$ & $\rightarrow$ & -- & --- & -- & & & - & - & - \\
\hline & & & - & & $=-$ & - & & - & & & - & - & & & & & - & & - & -- & -- & & & 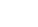 & - & - & -- & $-\cdots$ & 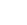 & & -- & $=$ & -- \\
\hline & -- & -- & -- & - & -- & -- & - & -- & -- & -- & - & -- & - & -- & -- & - & - - & -- & - & -- & - & -- & - & - - & & - & - - & -- & - & & & & -- \\
\hline & & & -- & -- & - & & & & & & -- & 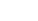 & & & & - & & & - & - - & 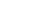 & & & & & & & - & - & & & & - \\
\hline
\end{tabular}


11461500 EAST FORK RUSSIAN RIVER NEAR CALPELLA, CALIF.

LOCATION, - Lat $39^{\circ} 14^{\prime} 48^{\prime \prime}$, long $123^{\circ} 07^{\prime} 45^{\prime \prime}$, in NW 1 NW sec. 18 , T.16 N, , R.11 W., Mendocino County, temperature recorder at gaging station on left bank, $0.1 \mathrm{~m} 1 \mathrm{le}$ downstream from Cold Creek and $3.9 \mathrm{~m} 1 \mathrm{les}$ east of Calpella.

DRAINAGE AREA. --92.2 sq $\mathrm{m} 1$.

PERIOD OF RECORD.--Chemlcal analyses: October 1952 to September 1958.

Water temperatures: March 1964 to September 1969.

Sediment records: March to September 1964, October 1966 to September 1968.

EXTREMES, - -1968-69:

Water temperatures: Maximum, $22.0^{\circ} \mathrm{C}$ June 16, 22-24; mintmum, 4.0 ${ }^{\circ} \mathrm{C}$ Jan. 28-31, Feb. 5, 6 .

Period of record:

Water temperatures: Maximum (1965-66, 1967-69), 26. $0^{\circ} \mathrm{C}$ June 16, 18, 19, 1968 ; minimum (1965-67, 1968-69), $4.0^{\circ} \mathrm{C}$ on several days in 1965 and 1969.

REMARKS.--No record Jan. 1-10, bulb burled. Samples for turbidity data collected by pacific Gas and Electric Company and U.S. Forest Service.

TEMPERATURE ( ${ }^{\circ} \mathrm{C}$ ) OF WATER, WATER YEAR OCTOBER 1968 TO SEPTEMBER 1969

DAY

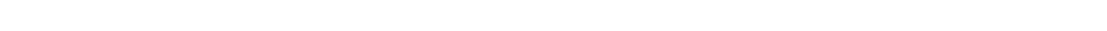

OCTUBFR

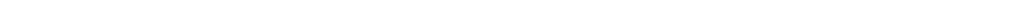

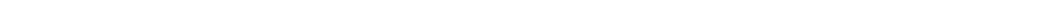
MINIMUM

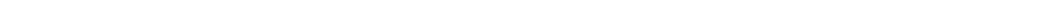
MINIMUM $14 \begin{array}{llllllllllllllllllllllllllllllllllll}4 & 15 & 14 & 14 & 12 & 13 & 13 & 14 & 14 & 13 & 12 & 11 & 9 & 9 & 11 & 11 & 11 & 11 & 11 & 10 & 11 & 10 & 10 & 10 & 9 & 9 & 8 & 8 & 8 & \ldots\end{array}$ DECEMRER MAXIMUM $9 \begin{array}{llllllllllllllllllllllllllllllllllllll} & 9 & 8 & 7 & 9 & 8 & 8 & 9 & 9 & 11 & 9 & 8 & 8 & 9 & 9 & 8 & 9 & 9 & 8 & 8 & 7 & 8 & 9 & 8 & 8 & 10 & 11 & 9 & 9 & 9 & 10\end{array}$

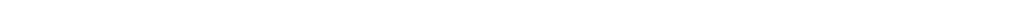
JANUAKY MAXIMUM -

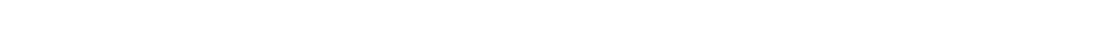

FFPRUARY

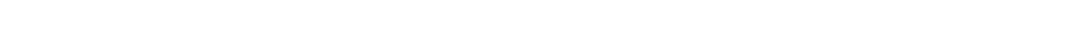

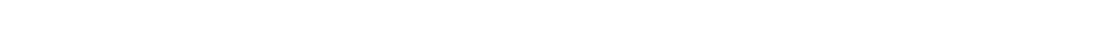

MARCH

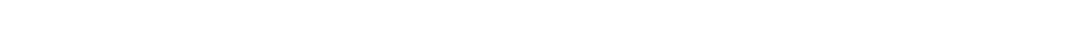
ARIL

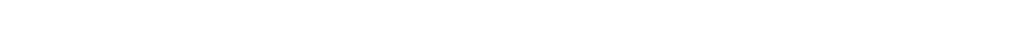

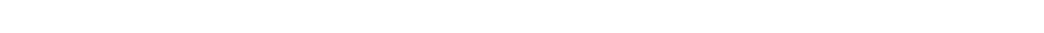
MAY

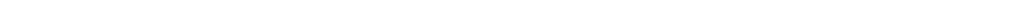

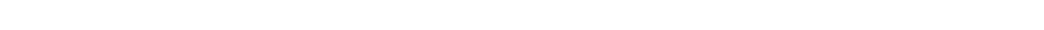

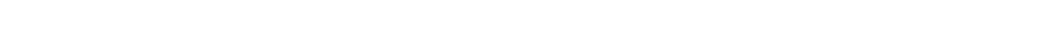

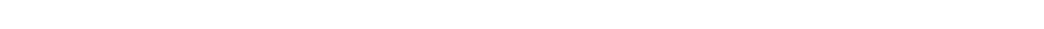
ULY

MAX:MUM 191919191919202120212020212020202021212121212212121202020202020 MINIMUM $15 \quad 15 \quad 14 \quad 14 \quad 15 \quad 15 \quad 15 \quad 16 \quad 16 \quad 17 \quad 16 \quad 17 \quad 17 \quad 17 \quad 16 \quad 16 \quad 16 \quad 17 \quad 17 \quad 17 \quad 17 \quad 17 \quad 17 \quad 17 \quad 17 \quad 17 \quad 17 \quad 16 \quad 16 \quad 16 \quad 16$ MAXI

MAXIMUM $2020 \quad 2020201919202020201920192020201920202020201919191919191919$

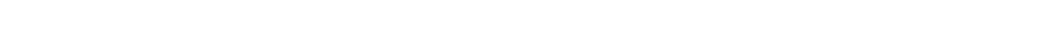

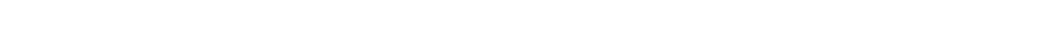

DETERMINATIONS OF TURBIDITY, DECEMBER 1968 TO MAY 1969

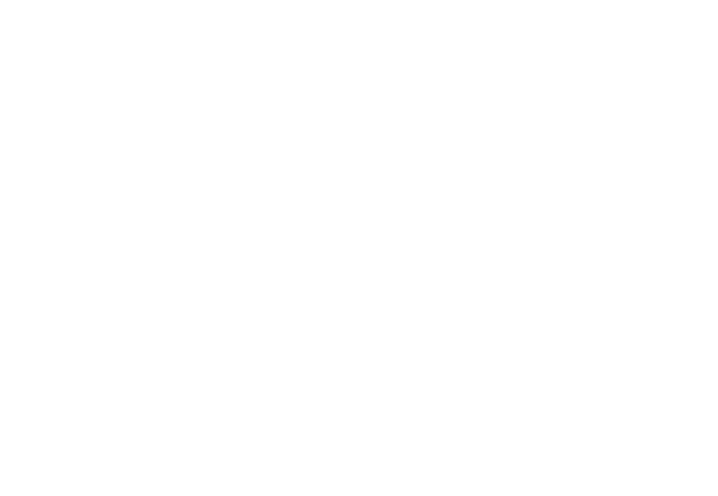

A TURBIDITY MEASURED AFTER A 7-DAY SETTLING PERIOD. 
11462500 RUSSIAN RIVER NEAR HOPLAND, CALIF.

LoCATion. --Lat 39 $01^{\prime} 35^{\prime \prime}$, Iong $123^{\circ} 07^{\prime} 45^{\prime \prime}$, in Rancho de Sanel Grant, Mendocino County, temperature recorder at gaging station on right bank at abandoned highway bridge, 0.2 mile downstream from McNab Creek and 4 miles garth of Hoplana.

DRAINAGE AREA, --362 sq $\mathrm{mi}$.

PERIOJ OF RECORD. --Chemical analyses: October 1953 to September 1965.

Water temperatures: September 1965 to September 1969.

EXTREMES, $-1968-69$ :

Water temperatures: Maximum, $24.0^{\circ} \mathrm{C}$ Sept. 1-3, 6-8.

period of record:

Hater temperatures. Maximum $(1965-66,1968-69), 24.0^{\circ} \mathrm{C}$ Sept. 1-3, 6-8, 1969; manimum $(1965 \sim 68), 6.0^{\circ} \mathrm{C}$ Feb. 8, 9, 1966.

REMARKS, --Recorder stopped Oct, 1-4 and July 26 to Aug. 8; probe 1noperative Jan, 12 to Feb. 4, May 17-22.

TEMPERATURE $\left({ }^{\circ} \mathrm{C}\right)$ OF WATER, WATER YEAR OCTOBER 1968 TO SEPTEMBER 1969

DAY

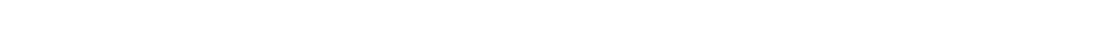

OCTOBFR

MAXIMUM - - - - - - $2022 \quad 20191719191919191817171617171617171717171717171717$ AINIMUM - - - NUVEMBF:

$\begin{array}{llllllllllllllllllllllllllllllllllllll}\text { MAXIMUM } & 16 & 16 & 16 & 15 & 16 & 15 & 15 & 15 & 15 & 15 & 15 & 15 & 15 & 14 & 13 & 13 & 13 & 13 & 14 & 14 & 14 & 14 & 14 & 13 & 14 & 13 & 12 & 12 & 11 & 11 & -7\end{array}$

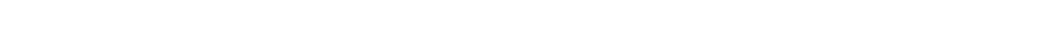
$\begin{array}{llllllllllllllllllllllllllllllll}\text { MAXIMUM } & 11 & 11 & 11 & 10 & 10 & 11 & 12 & 12 & 12 & 12 & 12 & 12 & 12 & 12 & 11 & 11 & 11 & 11 & 11 & 12 & 12 & 10 & 9 & 8 & 9 & 9 & 9 & 9 & 9 & 9 & 10\end{array}$

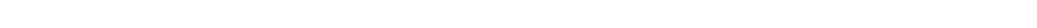

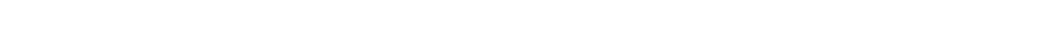

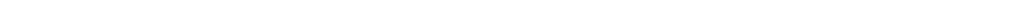
MINIMUM

FERRUIARY

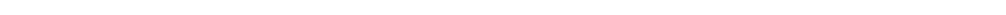

MINIMUM -..

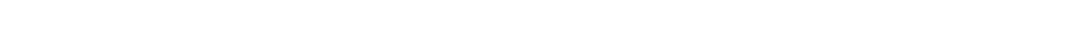
APIL

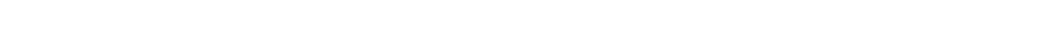
MAY

$\begin{array}{lllllllllllllllllllllllllllllllllll}11 & 11 & 11 & 11 & 11 & 11 & 11 & 11 & 11 & 11 & 11 & 11 & 11 & 11 & 11 & 11 & - & - & - & - & - & - & 18 & 18 & 16 & 15 & 14 & 15 & 15 & 16 & 16 & 13\end{array}$

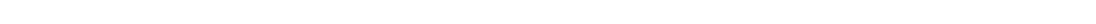

JUNE

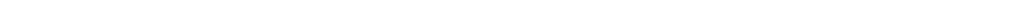
JULY

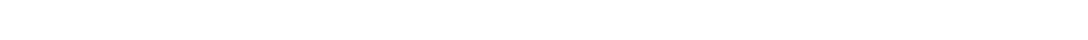
AUSUST

MAxiMuM -

SFPIEMBFR

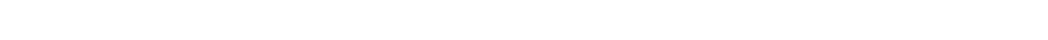

13 19 
11463000 RUSSIAN RIVER NEAR CLOVERDALE, CALIF

LOCATION, - Lat $38^{\circ} 52^{\prime} 55^{\prime \prime}$, Jong $123^{\circ} 03^{\prime} 15^{\prime \prime}$, in SW $\frac{1}{4}$ sec. 14, T.12 N., R.11 w., Mendocino County, at gaging station at Lambert Ranch, $400 \mathrm{ft}$ downstream from Cummisky Creek and 5 miles northwest of CIoverdale.

DRAINAGE AREA, -502 sq mi.

PERIOD OF RECORD. --Water temperatures: November 1963 to September 1969 (discontinued).

Sediment records: November 1963 to September 1966, January 1967 to September 1968.

EXTREMES, --1968-69:

Water temperatures: Minimum, 6.0 $\mathrm{C}$ Dec. 23, Feb. 9, 24, Mar. 13, 14.

Period of record:

Wate $x$ temperatures: Maximum $(1966-68), 26.0^{\circ} \mathrm{C}$ May 28,1968 ; minimun, $4.0^{\circ} \mathrm{C} J a n .3,12,1968$.

RELARKS. --Where no maximum or minimum is shown, temperature is once-daily reading.

TEMPERATURE $\left({ }^{\circ} \mathrm{C}\right.$ ) OF MATER, MATER YEAR OCTOBER 1968 TO SEPTEMBER 1969

CAY

MONTH

TOBER

MAXIMUM TOM

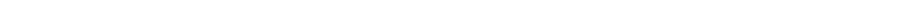
$\begin{array}{llllllllllllllllllllllllllllllll}M & 18 & 18 & 18 & 18 & 19 & 17 & 16 & 16 & 15 & 16 & 17 & 17 & 17 & 15 & 14 & 15 & 16 & 16 & 16 & 16 & 15 & 15 & 16 & 16 & 16 & 16 & 16 & 16 & 15 & 15 & 14\end{array}$

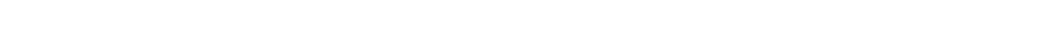
MINIMUM 14 14 $14 \begin{array}{llllllllllllllllllllllllllllllll}5 & 14 & 14 & 14 & 14 & 15 & 16 & 16 & 16 & 14 & 12 & 10 & 10 & 12 & 13 & 13 & 13 & 13 & 13 & 13 & 12 & 12 & 11 & 11 & 10 & 9 & 9 & 9 & --\end{array}$

DECEMBER: - - - -

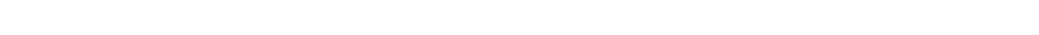
MINIMUM

JANUARY:

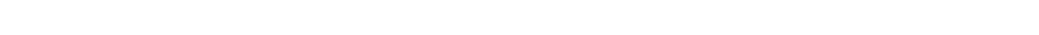

FEBRUARY $\begin{array}{lllllllllllllllllllllllllllllllll}\text { MAXIMUM } & 9 & 9 & 8 & 8 & 8 & 8 & 8 & 8 & 8 & 8 & 8 & 8 & 8 & 8 & 8 & 8 & 8 & 8 & 8 & 9 & 9 & 8 & 7 & 8 & 8 & 8 & 8 & 8 & -2 & -2 & -- \\ \text { MINIMUM } & 8 & 8 & 7 & 7 & 7 & 7 & 7 & 7 & 6 & 8 & 8 & 8 & 7 & 7 & 7 & 8 & 7 & 7 & 7 & 7 & 8 & 7 & 7 & 6 & 7 & 7 & 7 & 7 & -- & -- & --\end{array}$

MARCH.....

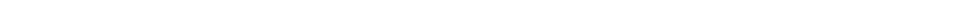

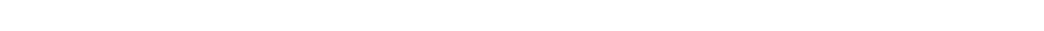

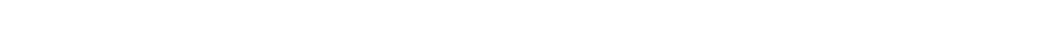

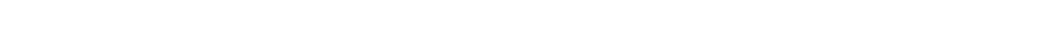

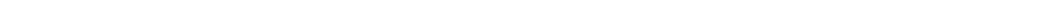

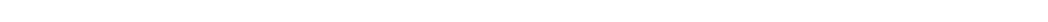
JUNE..... MАXimUM :MINIMUM -ב JULY..... MAXIMÜM MINIMUM -AUGUST..., MAXIMUM -. -MINIMUM -SEPTEMBER -MAXIMUM 
LOCATION, --Lat $38^{\circ} 36^{\prime} 48^{\prime \prime}$, long $122^{\circ} 50^{\prime} 07^{\prime \prime}$, in Sotoyome Grant, Sonoma County, temperature recorder at gaging sta$t$ ion on left bank, 2 miles east of Healdsburg and 3.5 miles upstream from Dry Creek.

DRAINAGE AREA, $-793 \mathrm{sq} \mathrm{m} 1$.

PERIOD OF RECORD. --Chemical analyses: October 1953 to September 1965.
Water temperstures: October 1965 to September 1969 .

EXTREMES. --1968-69:

Water temperatures: Minimum, 7.0 $0^{\circ} \mathrm{Ceb}, 6$.

Period of record:

Water temperatures: Maximum $(1965-68), 26.0^{\circ} \mathrm{C}$ on several days in 1966-68; minimum, 6. $0^{\circ} \mathrm{C}$ Dec. 21-23, 1965,
Jan. 26,1966 ,

REMARKS. --Recorder stopped June 15 to Sept. 30.

TEMPERATURE $\left({ }^{\circ} \mathrm{C}\right.$ ) OF WATER, WATER YEAR OCTOBER 1968 TO SEPTEMBER 1969 DAY

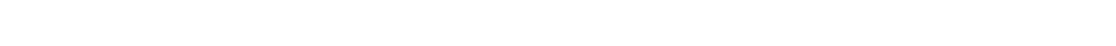

OCTOBFP

MAXIMUM $2121 \quad 1922 \quad 22 \quad 212120 \quad 191918191917 \quad 1818191919191919191919191917 \quad 1717 \quad 17 \quad 19$

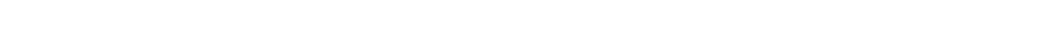
NUVEMBEP

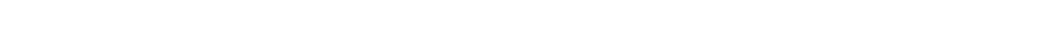

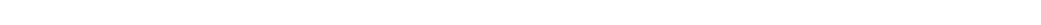
DCFMBER

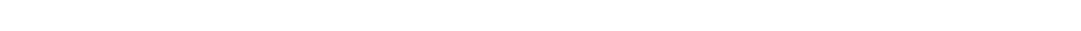

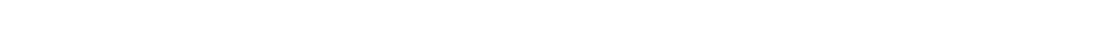

MAXIMUM $1010 \quad 1111121212121210101010111212111010 \quad 9991113131210101111109999$

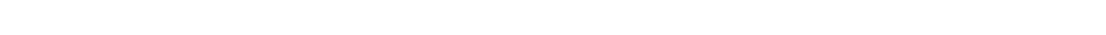

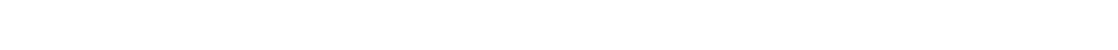

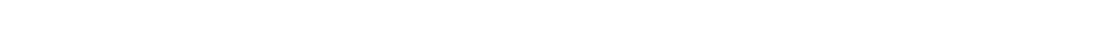

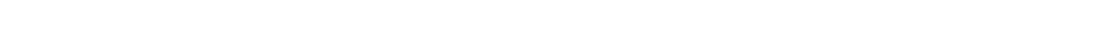

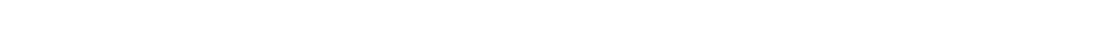

$\begin{array}{llllllllllllllllllllllllllllllllll}\text { MAXIMUM } & 15 & 14 & 13 & 13 & 13 & 13 & 13 & 14 & 14 & 14 & 15 & 15 & 14 & 14 & 15 & 15 & 16 & 16 & 16 & 16 & 16 & 16 & 15 & 14 & 14 & 15 & 16 & 16 & 17 & 16 & -2 & 15 \\ \text { MINIMUM } & 12 & 12 & 11 & 12 & 12 & 12 & 12 & 13 & 14 & 13 & 14 & 14 & 13 & 12 & 13 & 14 & 14 & 14 & 14 & 14 & 15 & 15 & 14 & 13 & 13 & 13 & 15 & 15 & 16 & 15 & -2 & 13\end{array}$

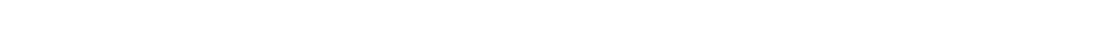

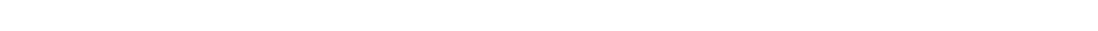
JUNE

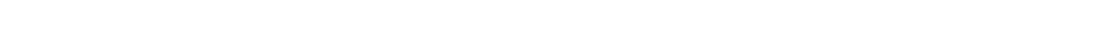
JULY

МАХІМUM +MINIMUM AUGUST

MAXIMUM

SFPIEMHFR

MAXIMUM -.

MIVINUM - 
11464500 DRY CREEK NEAR CLOVERDALE, CALIF.

LOCATION.--Lat $38^{\circ} 44^{\prime} 59^{\prime \prime}$, long $123^{\circ} 05^{\prime} 28^{\prime \prime}$, in NE $\frac{1}{4} \mathrm{NE}_{4}$ sec.5, T.10 N., R.11 W., Sonoma County, temperature recorder

at gaging station on left bank, $500 \mathrm{ft}$ downstream from' Smith Creek and $j$ miles southwest of Cloverdale.

DRAINAGE AREA. $--87.8 \mathrm{sq} \mathrm{ms}$.

PERIOD OF RECORD, -- Water temperatures: May 1965 to September 1969.

EXTREMES, $--1968-69$ :

Water temperatures: Maximum, $32.0^{\circ} \mathrm{C}$ sometime during period Aug. 11-15, and Aug. 16, 20-22; mintmum, $7.0^{\circ} \mathrm{C}$ Dec. 3, 20-22.

Pertod of record:

Nater temperatures: Maximum $(1965-66,1967-69), 33.5^{\circ} \mathrm{C}$ Aug. 6, 7, 1966; mintmum $(1966-69), 3.0^{\circ} \mathrm{C}$ on several days in 1967 and 1968 .

REMARKS. --Recorder stopped July 16 to Aug. 15 ; range in temperature, $18.0^{\circ} \mathrm{C}$ to $32.0^{\circ} \mathrm{C}$,

TEMPERATURE ( ${ }^{\circ} \mathrm{C}$ ) OP WATER, WATER YEAR OCTOBER 1968 TO SEPTEMBER 1969

DAY

MONTH

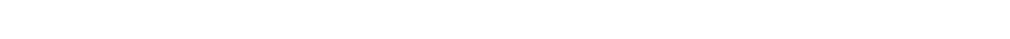

OCTOBER

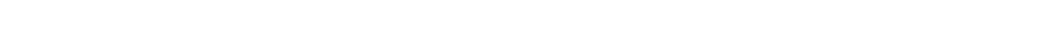

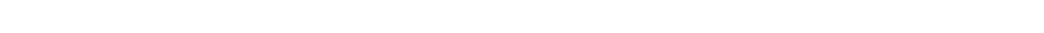
NOVEMBER

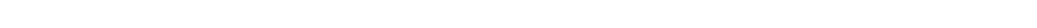

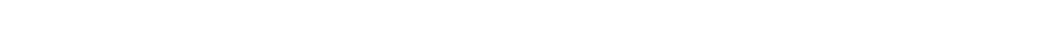
DECEREER

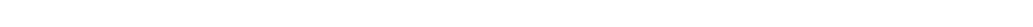
MINIMUM ANUARY

$\begin{array}{llllllllllllllllllllllllllllllllll}\text { MINIMUA } & 11 & 11 & 11 & 11 & 11 & 11 & 12 & 10 & 11 & 11 & 12 & 12 & 11 & 11 & 11 & 10 & 10 & 12 & 12 & 13 & 13 & 12 & 11 & 12 & 12 & 12 & 10 & 9 & 9 & 9\end{array}$ FEBRUARY

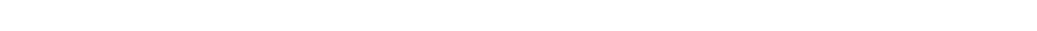

MINIMUM

MINITUM

MAXIMUM

MINIMUN

APRIL

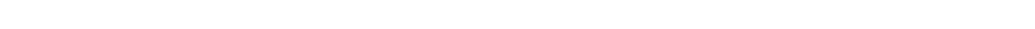

MAY

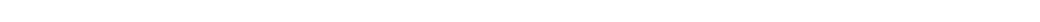
MINIMUM UNE

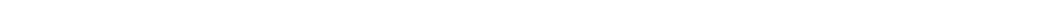

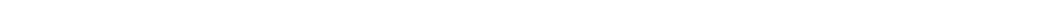
JULYY

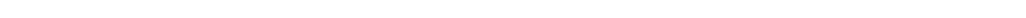
MINIMUM $191919191920202020202020 \quad 2021$ 19 20 20 AUGUST

MAXIMUM -

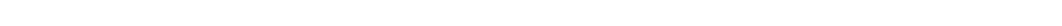

SEPTEMRER

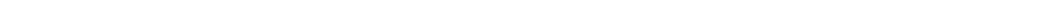

$\begin{array}{llllllllllllllllllllllllllllllll}\text { MAXIMUM } & 31 & 30 & 30 & 30 & 27 & 29 & 28 & 30 & 29 & 29 & 27 & 27 & 27 & 26 & 26 & 26 & 27 & 24 & 23 & 22 & 26 & 26 & 25 & 26 & 26 & 26 & 24 & 25 & 26 & 25 & -5 \\ \text { MINIMUM } & 19 & 19 & 19 & 19 & 19 & 17 & 19 & 19 & 19 & 19 & 19 & 18 & 18 & 17 & 17 & 17 & 16 & 19 & 17 & 16 & 16 & 16 & 16 & 17 & 17 & 17 & 18 & 16 & 18 & 17 & -2\end{array}$ 
11465200 DRY CREEK NEAR GEYSERVILLE, CALIF. LOCATION, --Lat $38^{\circ} 41^{\circ} 55^{\prime \prime}$, long $122^{\circ} 57^{\prime} 25^{\prime \prime}$, in Tzabaco Grant, Sonoma County, at gaging station 0.3 mile downstream
f rom Pena Creek and 3 miles west of Geyserville.

DRAINAGE AREA, - -162 sq $\mathrm{mi}$.

PERIOD OF RECORD.--Water temperatures: March 1964 to September 1969. Sediment records: March 1964 to September 1969.

EXTREMES, --1968-69:

Water temperatures: Maximum, $25.0^{\circ} \mathrm{C}$ July 10-14, 16-19; minimum, $7.0^{\circ} \mathrm{C}$ on several days during December and

January,
Sediment concentrations: Maximum daily, $3,820 \mathrm{mg} / 1 \mathrm{Jan} .13$; minimum daily, $1 \mathrm{mg} / 1$ on many days during October sediment dischar

August, and September.

Period of record:

Water temperatures: Maximum, $25.0^{\circ} \mathrm{C}$ on several days in 1965 and 1969 ; minimum $(1964-66,1967-69)$, 6.0 $0^{\circ} \mathrm{C}$ on several days in $1965,1967-68$.

Sediment concentrations: Maximum daily, 15,000 mg/1 (estimated) Dec. 22, 1964; minimum dafly, no flow for many days in 1964 and 1966. Sediment discharge: Maximum daily, 830,000 tons (estimated) Dec. 22, 1964; minimum daily, 0 ton on many days
in 1964, 1966, 1968-69.

REMARKS. --Temperature probe inoperative Oct. 7-10, Aug. 16 to Sept. 30.

TEMPERATURE ( ${ }^{\circ} \mathrm{C}$ ) OF WATER, WATER YEAR OCTOBER 1968 TO SEPTEMBER 1969

DAY

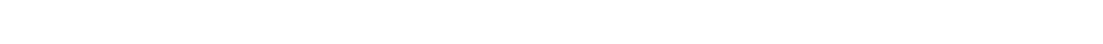

OCTOBFR

$\begin{array}{llllllllllllllllllllllllllllllllll}\text { MAXIMUM } & 19 & 19 & 18 & 19 & 19 & 18 & -- & -- & - & 18 & 19 & 18 & 17 & 17 & 18 & 18 & 18 & 17 & 17 & 17 & 17 & 18 & 18 & 18 & 18 & 18 & 16 & 17 & 17 & 17 & 18 \\ \text { MINIMUM } & 18 & 18 & 17 & 17 & 17 & 16 & - & -- & -- & -- & 14 & 14 & 12 & 12 & 14 & 14 & 15 & 15 & 15 & 14 & 14 & 14 & 16 & 16 & 16 & 16 & 16 & 15 & 14 & 14 & 14 & 15\end{array}$

NOVE MBER

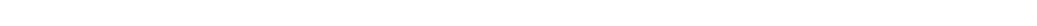

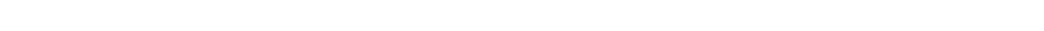
OECEMAER

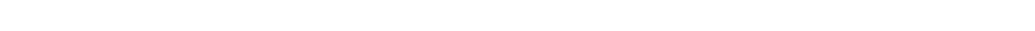

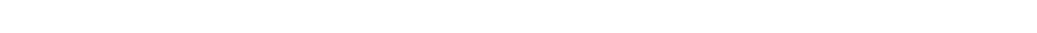
JANUARY

MAXIMUM MINIMUM $99101010101110 \quad 8 \quad 9 \quad 9 \quad 91011111212121211 \quad 12121212111111111111111$ BRUARY

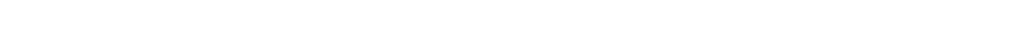

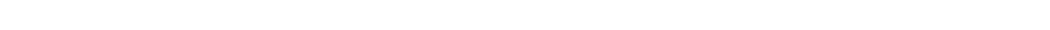
MARCH

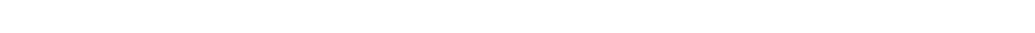
MINIMUM

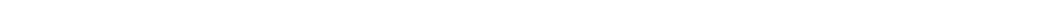

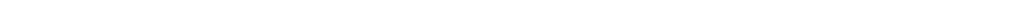
MAY

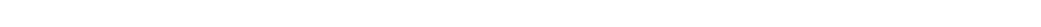

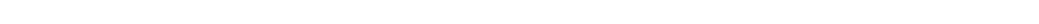
JUNE

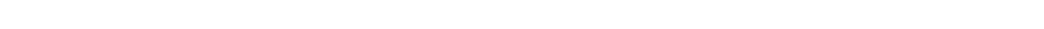
$\begin{array}{lllllllllllllllllllllllllllllllllllllll}\text { MINIMUM } & 17 & 17 & 17 & 17 & 18 & 17 & 17 & 17 & 17 & 17 & 17 & 18 & 17 & 17 & 18 & 17 & 18 & 17 & 18 & 18 & 17 & 18 & 18 & 17 & 17 & 17 & 17 & 16 & 17 & 17 & 0\end{array}$ JULY MAXINUM $23 \begin{array}{llllllllllllllllllllllllllllllll}23 & 23 & 23 & 23 & 23 & 23 & 23 & 23 & 25 & 25 & 25 & 25 & 25 & 24 & 25 & 25 & 25 & 25 & 24 & 24 & 24 & 24 & 24 & 23 & 24 & 24 & 24 & 24 & 24 & 24 \\ \text { MINIMUM } & 17 & 17 & 17 & 1 & 18 & 18 & 18 & 18 & 18 & 19 & 19 & 19 & 19 & 19 & 19 & 19 & 19 & 19 & 19 & 20 & 20 & 20 & 20 & 20 & 20 & 19 & 19 & 19 & 19 & 19 & 19\end{array}$ AUGUST

$\begin{array}{lllllllllllllll} & & & \end{array}$ MINIMUM $19191919201920 \quad 2019201919191919 \ldots \ldots$ SEPTEMBER

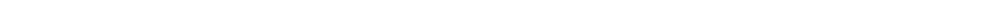
MINIMUM 
11460200 DRY CREEK NEAR GEYSERVILLE, CALIF,--Continued

SUSPENDED-SEDIMENT DISCHARGE, WATER YEAR OCTOBER 1968 TO SEPTEMBER 1969

OCTOBER

NOVEMBER

DECEMBER

OAY

CONCEN- SEDIMENT CONCEN- SEDIMENT
TRATION DEAN
DISCHARGE DISCHARGE

MEAN

SEDIMENT

COAN OISCHAR (MG/L) (TONS/DAY) TRATION DISCHARGE

MEAN
OISCHARGE

CONCEN- SEDIMENT

$$
\begin{array}{r}
.10 \\
.10 \\
.10 \\
.10 \\
.10
\end{array}
$$

3
18
12
2

$\begin{array}{cc}.10 & 39 \\ 6.0 & 37 \\ 2.5 & 30 \\ .16 & 27\end{array}$ (MG/L) (TONS/DAY)
(TISCHARGE

$\begin{array}{rr}6 & .10 \\ 7 & .10 \\ 8 & .10 \\ 9 & .10 \\ 10 & .10\end{array}$

17
16
13
12
12

11.10

11
12
13
14
15

$$
12^{.35}
$$$$
\begin{aligned}
& 0 \\
& 0 \\
& 0 \\
& .23
\end{aligned}
$$

12
12
16
19
123

$\begin{array}{ll}5.1 & 1 \\ 3.3 & 3 \\ 2.1 & 4 \\ 1.3 & 3 \\ 1.1 & 2\end{array}$

.01
.03
.02
.01
.01

57

16
17
18
19
20

$\begin{array}{llll}21 & .64 & 1 & 0 \\ 22 & .50 & 2 & 0 \\ 23 & .35 & 4 & 0 \\ 24 & .35 & 4 & 0\end{array}$

23
24
25

0
0
0
.01

37

. .50

$0^{.01}$

0
0
0

$\frac{012}{0.07}$

$\begin{array}{ll}.11 & 26 \\ .09 & 24 \\ .09 & 23 \\ .11 & 54 \\ .13 & 74\end{array}$

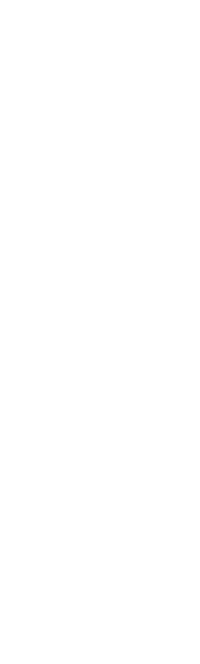

TOTAL

70.19

.62

\begin{tabular}{rr}
.13 & 2990 \\
.19 & 968 \\
.16 & 361 \\
.04 & 378 \\
.55 & 1480 \\
\hline 7
\end{tabular}

$\begin{array}{ll}1.7 & 1480 \\ .50 & 711 \\ .29 & 418 \\ .28 & 311 \\ .40 & 249\end{array}$

$.32 \quad 203$

$\begin{array}{rr}.32 & 203 \\ .14 & 180 \\ .12 & 1710 \\ .06 & 5780\end{array}$

$\begin{array}{rr}.06 & 5780 \\ .08 & 3270\end{array}$

$\begin{array}{ll}.16 & 2180 \\ .21 & 1320 \\ .19 & 1470\end{array}$

.19
.06
.55

$\begin{array}{rr}.06 & 1010 \\ .55 & 797 \\ -. & 651\end{array}$

$32.42 \quad 32361$

MARCH

JANUARY

FEBRUARY

MEAN
CONCEN- SEDIMENT MEAN

MEAN
CONCEN-

MEAN
CONCEN- SEDIMENT MEAN OISCHARGE

TRATIDN DISCHARGE DISCHARGE

TRATION DISCHARGE DISCHARGE

TRATION DISCHARGE (CFS)

$$
\begin{aligned}
& 52 \\
& 41 \\
& 32 \\
& 19 \\
& 10
\end{aligned}
$$$$
\begin{array}{rr}
72 & 1170 \\
45 & 985 \\
28 & 835 \\
14 & 739 \\
6.4 & 1780
\end{array}
$$

162
108
100
72
388

512
287
225
144
3230

(TONS/DAY)

510
402
325
275
238

$5.3 \quad 3640$

220
198

198

182
169

9
7
5
6
5

$\begin{array}{ll}3.7 & 1980 \\ 2.5 & 1690\end{array}$

$\begin{array}{ll}2.5 & 1690 \\ 2.7 & 4740\end{array}$

$\begin{array}{rr}11 & 2400 \\ 12 & 9240 \\ 13 & 13500 \\ 14 & 4050\end{array}$

$\begin{array}{rrr}1240 & 18800 & 5910 \\ 2760 & 84600 & 3640 \\ 3820 & 154000 & 2180 \\ 1590 & 18000 & 1870\end{array}$

$\begin{array}{rrr}3820 & 154000 & 2180 \\ 1590 & 18000 & 1870\end{array}$

$\begin{array}{r}690 \quad 4250 \\ \hline\end{array}$

1870
2670

1570

1270

1610
4180

275

1170
377
2670

$\begin{array}{rr}110 & 377 \\ 397 & 2670 \\ 1130 & 13400 \\ 2850 & 55100\end{array}$

2020

13400
55100

1310
1080

$3390 \quad 99300$

10100

3390
1200 $\quad \begin{aligned} & 99300 \\ & 6700\end{aligned}$

$\begin{array}{rr}610 & 4240 \\ 360 & 1730\end{array}$

894

1110

1110
323
248
1340

12000
1780

1780
1320
17900
4080

2800

$\begin{array}{llr}2000 & 400 & 2160 \\ 1600 & 272 & 1180 \\ 1220 & 190 & 626 \\ 1010 & 122 & 333\end{array}$

$\begin{array}{rr}22 & 4330 \\ 23 & 2520 \\ 24 & 1780 \\ 25 & 2250 \\ 26 & 5000 \\ 27 & 2660 \\ 28 & 1990 \\ 29 & 1550 \\ 30 & 1640 \\ 31 & 1270 \\ & \\ \text { TOTAL } & 84577\end{array}$

$\begin{array}{rrr}716 & 4850 & 188 \\ 1870 & 28300 & 150 \\ 613 & 4460 & 153 \\ 370 & 1990 & 3330 \\ 282 & 1180 & - \\ 249 & 1100 & - \\ 164 & 562 & - \\ - & 514960.7 & 5668\end{array}$

767
684
1010
2270
1880
1500
1530
3330
$=-$
--
56684

854

854
728

640
560

560
495

$91 \quad 210$

$\begin{array}{rr}91 & 210 \\ 75 & 147 \\ 62 & 107 \\ 46 & 70\end{array}$

$835 \quad 14500$

$\begin{array}{rr}835 & 14500 \\ 329 & 3310\end{array}$

$\begin{array}{ll}240 & 1410 \\ 348 & 2020 \\ 408 & 2980\end{array}$

418

402
356

356
304
269

$30 \quad 34$

$\begin{array}{ll}27 & 29 \\ 23 & 22 \\ 20 & 16\end{array}$

$\begin{array}{rr}221 & 1210 \\ 228 & 985\end{array}$

$\begin{array}{ll}228 & 985 \\ 172 & 608 \\ 115 & 335\end{array}$

249
311
263

263
228
225

19

$\begin{array}{rr}81 & 168 \\ 49 & 92 \\ 145 & 424\end{array}$

225

238
208

208
191
178

$\begin{array}{ll}353 & 2440 \\ 257 & 1300\end{array}$

178
169

$\begin{array}{rr}253 & 1020 \\ 203 & 923 \\ 2000 & 18100\end{array}$

2000

$=$

160
156

156
154

154
145
135

135

93535

16799

21
10
08
07
07
06
10
06


11463200 DRY CREEK NEAR GEYSERVILLE, CALIF.--Continued

SUSPENDED-SEDIMENT DISCHARGE, WATER YEAR OCTOBER 1968 TO SEPTEMBER 1969

\begin{tabular}{|c|c|c|c|c|c|c|c|c|c|}
\hline DAY & $\begin{array}{l}\text { MEAN } \\
\text { DISCHARGE } \\
\text { (CFS) }\end{array}$ & $\begin{array}{l}\text { APRIL } \\
\text { MEAN } \\
\text { CONCEN- } \\
\text { TRATION } \\
(M G / L)\end{array}$ & $\begin{array}{l}\text { SEDIMENT } \\
\text { DI SCHARGE } \\
\text { (TONS/DAY) }\end{array}$ & $\begin{array}{l}\text { MEAN } \\
\text { DI SCHARGE } \\
\text { (CFS) }\end{array}$ & $\begin{array}{l}\text { MAY } \\
\text { MEAN } \\
\text { CONCEN- } \\
\text { TRATION } \\
\text { (MG/L) }\end{array}$ & $\begin{array}{l}\text { SEDIMENT } \\
\text { DI SCHARGE } \\
\text { (TONS/DAY) }\end{array}$ & $\begin{array}{l}\text { MEAN } \\
\text { DI SCHARGE } \\
\text { (CFS) }\end{array}$ & $\begin{array}{l}\text { JUNE } \\
\text { MEAN } \\
\text { CONCEN- } \\
\text { TRATION } \\
\text { (MG } L \text { IL) }\end{array}$ & $\begin{array}{l}\text { SEDIMENT } \\
\text { DI SCHARGE } \\
\text { (TONS/DAY) }\end{array}$ \\
\hline $\begin{array}{l}1 \\
2 \\
3 \\
4 \\
5\end{array}$ & $\begin{array}{l}129 \\
147 \\
160 \\
129 \\
323\end{array}$ & $\begin{array}{r}5 \\
8 \\
7 \\
5 \\
310\end{array}$ & $\begin{array}{r}1.7 \\
3.2 \\
3.0 \\
1.7 \\
313\end{array}$ & $\begin{array}{l}86 \\
86 \\
86 \\
82 \\
75\end{array}$ & $\begin{array}{l}2 \\
4 \\
5 \\
4 \\
5\end{array}$ & $\begin{array}{r}.46 \\
.93 \\
1.2 \\
.89 \\
1.0\end{array}$ & $\begin{array}{l}33 \\
31 \\
31 \\
30 \\
30\end{array}$ & $\begin{array}{r}10 \\
8 \\
6 \\
4 \\
5\end{array}$ & $\begin{array}{l}.89 \\
.67 \\
.50 \\
.32 \\
.41\end{array}$ \\
\hline $\begin{array}{r}6 \\
7 \\
8 \\
9 \\
10\end{array}$ & $\begin{array}{l}256 \\
201 \\
180 \\
180 \\
165\end{array}$ & $\begin{array}{r}142 \\
11 \\
5 \\
6 \\
8\end{array}$ & $\begin{array}{r}104 \\
6.0 \\
2.4 \\
2.9 \\
3.6\end{array}$ & $\begin{array}{l}71 \\
68 \\
65 \\
63 \\
61\end{array}$ & $\begin{array}{l}4 \\
3 \\
3 \\
2 \\
2\end{array}$ & $\begin{array}{l}.77 \\
.35 \\
.53 \\
.34 \\
.33\end{array}$ & $\begin{array}{l}29 \\
29 \\
29 \\
29 \\
29\end{array}$ & $\begin{array}{r}6 \\
8 \\
11 \\
14 \\
16\end{array}$ & $\begin{array}{r}.47 \\
.63 \\
.86 \\
1.1 \\
1.3\end{array}$ \\
\hline $\begin{array}{l}12 \\
12 \\
13 \\
14 \\
15\end{array}$ & $\begin{array}{l}151 \\
141 \\
133 \\
127 \\
123\end{array}$ & $\begin{array}{l}4 \\
6 \\
4 \\
2 \\
4\end{array}$ & $\begin{array}{l}1.6 \\
2.3 \\
1.4 \\
.69 \\
1.3\end{array}$ & $\begin{array}{l}60 \\
58 \\
58 \\
55 \\
54\end{array}$ & $\begin{array}{r}2 \\
2 \\
6 \\
10 \\
6\end{array}$ & $\begin{array}{r}.32 \\
.31 \\
.94 \\
1.5 \\
.87\end{array}$ & $\begin{array}{l}29 \\
29 \\
29 \\
29 \\
29\end{array}$ & $\begin{array}{l}18 \\
16 \\
13 \\
11 \\
8\end{array}$ & $\begin{array}{l}1.4 \\
1.3 \\
1.0 \\
.86 \\
.63\end{array}$ \\
\hline $\begin{array}{l}16 \\
17 \\
18 \\
19 \\
20\end{array}$ & $\begin{array}{l}120 \\
116 \\
109 \\
103 \\
101\end{array}$ & $\begin{array}{r}4 \\
5 \\
5 \\
3 \\
11\end{array}$ & $\begin{array}{l}1.3 \\
1.6 \\
1.5 \\
.83 \\
3.0\end{array}$ & $\begin{array}{l}54 \\
53 \\
49 \\
48 \\
45\end{array}$ & $\begin{array}{l}3 \\
4 \\
6 \\
8 \\
8\end{array}$ & $\begin{array}{l}.44 \\
.57 \\
.79 \\
1.0 \\
.97\end{array}$ & $\begin{array}{l}26 \\
25 \\
22 \\
21 \\
21\end{array}$ & $\begin{array}{l}6 \\
4 \\
3 \\
4 \\
5\end{array}$ & $\begin{array}{l}.42 \\
.27 \\
.18 \\
.23 \\
.28\end{array}$ \\
\hline $\begin{array}{l}21 \\
22 \\
23 \\
24 \\
25\end{array}$ & $\begin{array}{r}98 \\
95 \\
183 \\
167 \\
125\end{array}$ & $\begin{array}{r}8 \\
6 \\
18 \\
14 \\
7\end{array}$ & $\begin{array}{l}2.1 \\
1.5 \\
9.4 \\
6.3 \\
2.4\end{array}$ & $\begin{array}{l}40 \\
38 \\
37 \\
35 \\
35\end{array}$ & $\begin{array}{r}8 \\
15 \\
22 \\
15 \\
10\end{array}$ & $\begin{array}{l}.86 \\
1.5 \\
2.2 \\
1.4 \\
.95\end{array}$ & $\begin{array}{l}21 \\
20 \\
19 \\
17 \\
16\end{array}$ & $\begin{array}{r}6 \\
7 \\
8 \\
9 \\
10\end{array}$ & $\begin{array}{l}.34 \\
.38 \\
.41 \\
.41 \\
.43\end{array}$ \\
\hline $\begin{array}{l}26 \\
27 \\
28 \\
29 \\
30 \\
31\end{array}$ & $\begin{array}{r}109 \\
101 \\
95 \\
93 \\
90 \\
--\end{array}$ & $\begin{array}{r}4 \\
3 \\
8 \\
5 \\
--\end{array}$ & $\begin{array}{l}1.2 \\
.82 \\
.77 \\
2.0 \\
1.2 \\
--\end{array}$ & $\begin{array}{l}35 \\
37 \\
37 \\
37 \\
36 \\
36\end{array}$ & $\begin{array}{r}5 \\
10 \\
15 \\
11 \\
7 \\
8\end{array}$ & $\begin{array}{l}.47 \\
1.0 \\
1.5 \\
1.1 \\
.68 \\
.78\end{array}$ & $\begin{array}{l}15 \\
14 \\
13 \\
13 \\
11 \\
--\end{array}$ & $\begin{array}{l}11 \\
13 \\
14 \\
16 \\
17 \\
-\end{array}$ & $\begin{array}{l}.45 \\
.49 \\
.49 \\
.56 \\
.50 \\
.-\end{array}$ \\
\hline TOTAL & 4250 & $\cdots$ & 484.71 & 1680 & - & 27.15 & 719 & $-\infty$ & 18.18 \\
\hline
\end{tabular}

\begin{tabular}{|c|c|c|c|c|c|c|c|c|c|}
\hline \multirow[b]{2}{*}{ OAY } & \multicolumn{3}{|c|}{ JULY } & \multicolumn{3}{|c|}{ AUGUST } & \multicolumn{3}{|c|}{ SEP TEMBER } \\
\hline & $\begin{array}{c}\text { MEAN } \\
\text { OISCHARGE } \\
\text { (CFS) }\end{array}$ & $\begin{array}{l}\text { MEAN } \\
\text { CNACEN- } \\
\text { TRATION } \\
\text { (MG/L) }\end{array}$ & $\begin{array}{l}\text { SEDIMENT } \\
\text { DISCHARGE } \\
\text { (TONS/DAY) }\end{array}$ & $\begin{array}{c}\text { MEAN } \\
\text { OPSCHARGE } \\
\text { (CFS) }\end{array}$ & $\begin{array}{l}\text { MEAN } \\
\text { CNDCEN- } \\
\text { TRATION } \\
\text { (MG/L) }\end{array}$ & $\begin{array}{l}\text { SEDIMENT } \\
\text { DPSCHARGE } \\
\text { (TONSADAYI }\end{array}$ & $\begin{array}{l}\text { MEAN } \\
\text { DISHARGE } \\
\text { (CFS) }\end{array}$ & $\begin{array}{l}\text { MEAN } \\
\text { MONEN- } \\
\text { TRATION } \\
\text { (MGLL) }\end{array}$ & $\begin{array}{l}\text { SEDSMENT } \\
\text { DISSHARGE } \\
\text { (TONS/DAY) }\end{array}$ \\
\hline $\begin{array}{l}1 \\
2 \\
3 \\
4 \\
5\end{array}$ & $\begin{array}{l}11 \\
11 \\
8.7 \\
7.7 \\
7.2\end{array}$ & $\begin{array}{l}18 \\
18 \\
17 \\
16 \\
15\end{array}$ & $\begin{array}{r}.53 \\
.53 \\
-40 \\
: 33 \\
.29\end{array}$ & $\begin{array}{l}2.6 \\
2.6 \\
2.6 \\
2.6 \\
2.4\end{array}$ & $\begin{array}{l}3 \\
3 \\
3 \\
3 \\
3\end{array}$ & $\begin{array}{l}.02 \\
0.02 \\
0.02 \\
0.02 \\
.02\end{array}$ & $\begin{array}{l}.66 \\
.66 \\
.66 \\
.66 \\
.66\end{array}$ & $\begin{array}{l}12 \\
13 \\
13 \\
12 \\
10\end{array}$ & $\begin{array}{l}.02 \\
.02 \\
.02 \\
.02 \\
.02\end{array}$ \\
\hline $\begin{array}{r}6 \\
7 \\
8 \\
9 \\
10\end{array}$ & $\begin{array}{l}6.7 \\
6.7 \\
66.7 \\
6.7 \\
6.7\end{array}$ & $\begin{array}{c}14 \\
13 \\
12 \\
11 \\
3\end{array}$ & $\begin{array}{l}.25 \\
.24 \\
.22 \\
.20 \\
.05\end{array}$ & $\begin{array}{l}1.7 \\
1.2 \\
0.85 \\
.75 \\
.39\end{array}$ & $\begin{array}{l}3 \\
2 \\
2 \\
5 \\
8\end{array}$ & $\begin{array}{l}.01 \\
0.01 \\
.01 \\
.01\end{array}$ & $\begin{array}{l}.57 \\
.57 \\
.48 \\
.48 \\
.48\end{array}$ & $\begin{array}{l}8 \\
6 \\
5 \\
3 \\
3\end{array}$ & $\begin{array}{l}.01 \\
.01 \\
.01 \\
.01 \\
0\end{array}$ \\
\hline $\begin{array}{l}11 \\
12 \\
13 \\
14 \\
15\end{array}$ & $\begin{array}{l}6.7 \\
6.2 \\
5.8 \\
5.8 \\
5.4\end{array}$ & $\begin{array}{l}8 \\
110 \\
113 \\
16 \\
18\end{array}$ & $\begin{array}{r}.14 \\
: 17 \\
.20 \\
.25 \\
.26\end{array}$ & $\begin{array}{l}.75 \\
: 05 \\
111 \\
11.3 \\
1.4\end{array}$ & $\begin{array}{l}12 \\
18 \\
24 \\
30 \\
45\end{array}$ & $\begin{array}{l}.02 \\
0.04 \\
0.07 \\
0.11 \\
.17\end{array}$ & $\begin{array}{r}.48 \\
.48 \\
.57 \\
.48 \\
.48\end{array}$ & $\begin{array}{r}3 \\
3 \\
7 \\
9 \\
11\end{array}$ & $\begin{array}{l}0 \\
0 \\
0.01 \\
0.01 \\
0.01 \\
0.01\end{array}$ \\
\hline $\begin{array}{l}16 \\
17 \\
118 \\
19 \\
20\end{array}$ & $\begin{array}{l}4.7 \\
3.8 \\
3.8 \\
3.8 \\
3.5\end{array}$ & $\begin{array}{l}20 \\
17 \\
14 \\
12 \\
10\end{array}$ & $\begin{array}{r}.25 \\
: 17 \\
016 \\
012 \\
.09\end{array}$ & $\begin{array}{r}1.6 \\
1.3 \\
: 85 \\
: 75 \\
: 57\end{array}$ & $\begin{array}{l}62 \\
40 \\
35 \\
25 \\
15\end{array}$ & $\begin{array}{l}.27 \\
.14 \\
0.08 \\
.05 \\
.02\end{array}$ & $\begin{array}{r}57 \\
.48 \\
.48 \\
.48 \\
.39\end{array}$ & $\begin{array}{l}13 \\
115 \\
13 \\
11 \\
9\end{array}$ & $\begin{array}{l}.02 \\
.02 \\
.02 \\
.01 \\
.01\end{array}$ \\
\hline $\begin{array}{l}21 \\
22 \\
23 \\
24 \\
25\end{array}$ & $\begin{array}{l}3.3 \\
3.3 \\
3.0 \\
2.8 \\
2.8\end{array}$ & $\begin{array}{l}8 \\
6 \\
5 \\
5 \\
5\end{array}$ & $\begin{array}{l}.07 \\
0.05 \\
0.04 \\
.04\end{array}$ & $\begin{array}{l}.75 \\
.66 \\
.75 \\
.66 \\
.66\end{array}$ & $\begin{array}{l}14 \\
15 \\
14 \\
13 \\
11\end{array}$ & $\begin{array}{l}.03 \\
.03 \\
.03 \\
.02 \\
.02\end{array}$ & $\begin{array}{r}.48 \\
.48 \\
.48 \\
.39 \\
.39\end{array}$ & $\begin{array}{l}7 \\
5 \\
3 \\
3 \\
3\end{array}$ & $\begin{array}{l}.01 \\
.01 \\
0 \\
0 \\
0\end{array}$ \\
\hline $\begin{array}{l}26 \\
27 \\
28 \\
29 \\
30 \\
31\end{array}$ & $\begin{array}{l}2.6 \\
2.6 \\
22.6 \\
22.6 \\
2.6 \\
2.6\end{array}$ & $\begin{array}{l}4 \\
4 \\
3 \\
3 \\
3\end{array}$ & $\begin{array}{l}.03 \\
0.03 \\
0.03 \\
0.02 \\
.02 \\
.02\end{array}$ & $\begin{array}{l}.66 \\
.57 \\
.48 \\
.57 \\
.57 \\
.66\end{array}$ & $\begin{array}{r}10 \\
9 \\
9 \\
10 \\
11 \\
12\end{array}$ & $\begin{array}{l}.022 \\
.01 \\
.01 \\
0.02 \\
.02 \\
.02\end{array}$ & $\begin{array}{r}.48 \\
.48 \\
-39 \\
.39 \\
.39 \\
-39\end{array}$ & $\begin{array}{r}3 \\
3 \\
4 \\
4 \\
-\therefore\end{array}$ & $\begin{array}{l}0 \\
0 \\
0 \\
0 \\
0 \\
-0\end{array}$ \\
\hline OTAL & 159.4 & -- & 5.22 & 35.15 & -- & 1.34 & 15.12 & -- & .28 \\
\hline
\end{tabular}


11465200 DRY CREEK NEAR GEYSERVILLE, CALIF,--COnt1nued

PARTICLE-SIZE DISTRIBUTION OF SUSPENDED SEDIMENT, WATER YEAR OCTOBER 1968 TO SEPTEMBER 1969 (METHOOS OF ANALYSIS: B, BOTIOM WITHORAWAL TUBE; C, CHEMICALLY OISPERSEOI N, IN NATIVE WATER; P, PIPET: S, SIEVE,
V, VISUAL ACCUMULATION TUBE; W, IN OISTILLED WATER)

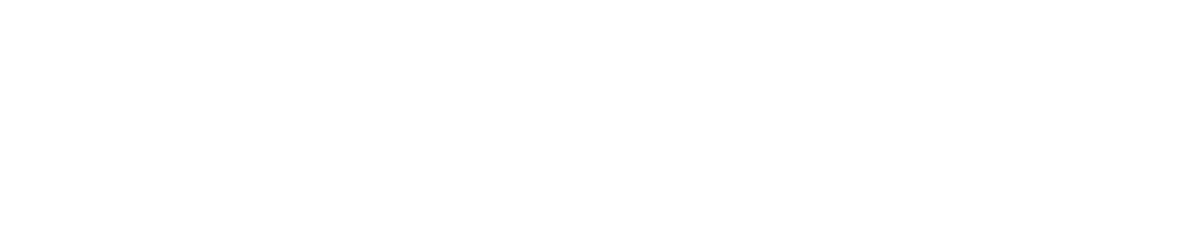

PARTICLE-5IZE DISTRIBUTION OF SURFACE BED MATERIAL, WATER YEAR OCTOBER 1968 TO SEPTEMBER 1969 IMETHOO UF ANALYSIS: H, HYOROMETER; D, OPTICAL ANALYZER; S, SIEVE; $V$, VISUAL ACCUMULATION TUBEI

\begin{tabular}{|c|c|c|c|c|c|c|c|c|c|c|c|c|c|c|}
\hline \multirow{3}{*}{$\begin{array}{l}\text { WATER } \\
\text { TEM- } \\
\text { PERA- } \\
\text { TURE } \\
1 \text { CI }\end{array}$} & \multirow{3}{*}{$\begin{array}{l}\text { NUMBER } \\
\text { OF } \\
\text { SAM- } \\
\text { PLING } \\
\text { POINTS }\end{array}$} & \multirow{3}{*}{$\begin{array}{l}\text { DISCHARGE } \\
\text { (CFS) }\end{array}$} & \multicolumn{11}{|c|}{ PARTICLE SIZE } & \multirow{3}{*}{$\begin{array}{l}\text { METHOU } \\
\text { OF } \\
\text { ANALY- } \\
\text { SIS }\end{array}$} \\
\hline & & & & PERCENT & F[NER & THAN & THE S & $12 \mathrm{E} / \mathrm{IH}$ & MILL & METERS & ;I INO & CATED & & \\
\hline & & & .062 & .125 & .250 & .500 & 1.00 & 2.00 & 4.00 & 8.00 & 16.0 & 32.0 & 64.0 & \\
\hline 16 & 5 & & 1 & 2 & & B & 11 & & & & & & 100 & s \\
\hline & & & $=$ & -- & 1 & 2 & 7 & & & 65 & 88 & 100 & -- & s \\
\hline 11 & 5 & 3000 & - & -- & 1 & 6 & 11 & 21 & 36 & 59 & 88 & 100 & -- & $s$ \\
\hline
\end{tabular}

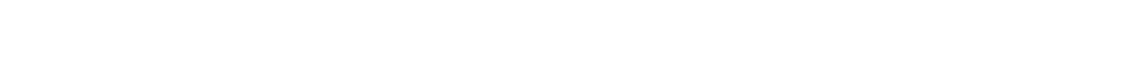

SUSPENDED-SEDIMENT CONCENTRATION AND TURBIDITY, WATER YEAR OCTOBER 1968 TO SEPTEMBER 1969

$\begin{array}{ccc} & \text { CONCENTRATION } & \\ \text { DATE } & \text { OF SUSPENDED } & \\ \text { OF } & \text { SEDIMENT } & \text { TURBIDITY } \\ \text { COLLECTION } & \text { (MG/L) } & \text { (MG/L SILICA) }\end{array}$

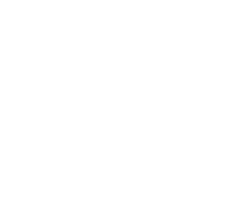

OCT. $25, \ldots \ldots \ldots \ldots$

OCT. $28 \ldots \ldots \ldots \ldots$

act $31, \ldots \cdots \cdots$

NOV. 1 .................

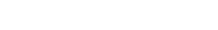

NOV. 6 ................

NOV. 8 ...............

Nov. $13 \ldots \ldots \ldots \ldots \ldots$

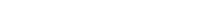

Nov. $20 \ldots \ldots \ldots \ldots$

NOV. $22 \ldots \ldots \ldots \ldots$

Nov. $27 \ldots \ldots \ldots \ldots \ldots$

Nov. $29 \ldots \ldots \ldots \ldots$.

DEC. $2 \ldots \ldots \ldots \ldots \ldots$.

OeC. $4 \ldots \ldots \ldots \ldots \ldots$

DEC. $9 . \ldots \ldots \ldots \ldots \ldots \ldots$

DEC. $10 \ldots \ldots \ldots \ldots$.

DEC. $13 . . . \ldots \ldots \ldots$

DEC. $16 \ldots \ldots \ldots \ldots$.

DEC. $17 \ldots \ldots \ldots \ldots \ldots \ldots$

DEC. $19 . \ldots \ldots \ldots \ldots$.

DEC $20, \ldots \ldots \ldots . .$.

DEC. $21 \ldots .$.

DEC. $26 \ldots \ldots \ldots . . .6$

JAY $4,1969, \ldots \circ$.

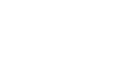

JAN. 5, 1969.

JAN. 60.0.1.........

JAN. $7 \ldots . . . \ldots . . .6$

JAN. $8 \ldots \ldots \ldots \ldots \ldots$

JAN. $10, \ldots . . . . . .$.

JAN. $12, \ldots \ldots \ldots \ldots$

JAN. $13 \ldots \ldots \ldots \ldots \ldots$

JAN. $15 \ldots . . . \ldots \ldots . . .6$

JAN. 16.

JAN. $17 \ldots$

JAN. $18 \ldots \ldots \ldots \ldots$

JAN, $25,0.00000000$

JAN. $23, \ldots \ldots \ldots \ldots$

JAN. $24 \ldots \ldots \ldots \ldots$

JAN. 2500000000

AN. $26, \ldots \ldots \ldots \ldots$

JAN. $27 \ldots . . . . . .$.

JAN. $28 . \ldots \ldots \ldots . .$.

JAN. $29 . . . \ldots \ldots . . . .$.

JAN. 30

JAN. 3

FEB. 1 .............

FEB. $2 \ldots \ldots \ldots \ldots$

FE8.

FEB. 50

FEB. $7 \ldots \ldots \ldots$

FEค. $8 \ldots \ldots \ldots \ldots$

FFB. $9 . \ldots \ldots \ldots \ldots$.

FEB. $10 . \ldots \ldots \ldots \ldots$

FEB. $11 \ldots \ldots \ldots \ldots \ldots$

FEB. $12, \ldots \ldots \ldots \ldots \ldots$
JAN. $11 \ldots \ldots \ldots \ldots \ldots$
CONCENTRATION

OF SUSPENDED TURBIDITY TURBIDITY
(MGIL) 
11465200 DRY CREEK NEAR GEYSERVILEE, CALIF.--COntinued SUSPENDED-SEDIMENT CONCENTRATION AND TURBIDITY, WATER YEAR OCTOBER 1968 TD SEPTEMBER 1969

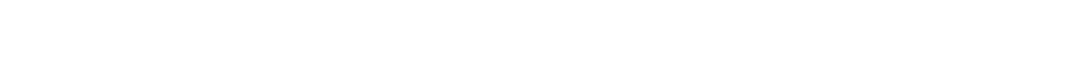

FEB. $14,1969 \ldots \ldots$.

FEB. $15, \ldots \ldots \ldots \ldots \cdots \cdots$

FEB. $17 \ldots \ldots \ldots \ldots \ldots \ldots$

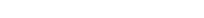

FEB. $19 \ldots \ldots \ldots \ldots$

FEB. $20 \ldots \ldots \ldots \ldots$.

FEB. $22, \ldots \ldots \ldots \cdots \cdots$

FEB. $23, \ldots \ldots \ldots \ldots$.

$F \in B .24 \ldots \ldots \ldots \ldots \ldots$

FEB. $25, \ldots \ldots \ldots \ldots \ldots$

FEB. $27, \ldots$

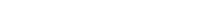

MAR. 1 .............

MAQ. $2, \ldots \ldots \ldots+\cdots, \ldots$

MAR. $3 \ldots \ldots \ldots+\ldots, \ldots$

MAR. $4 \ldots \ldots \ldots \ldots \ldots \ldots$

MAR. $6, \ldots \ldots \ldots \ldots$

MAR. $1, \ldots \ldots \ldots \ldots$

MAR. $8, \ldots \ldots \ldots \ldots \ldots$

MAR. $9 . . . \ldots . . . .$.

MAR. $10, \ldots \ldots \ldots \ldots \ldots$

MAR. $12 \ldots \ldots \ldots \ldots$.

MAR:

MAR. I I

MAR. $15, \ldots \ldots \ldots$

MAR. $16, \ldots \ldots \ldots \ldots$

MAR. $17 \ldots \ldots \ldots \ldots . . .$.

MAR. $18 . . .6 . . .6$.

MAR. $19, \ldots \ldots \ldots \ldots \ldots$

MAR. $20 \ldots \ldots \ldots$

MAR. $22, \ldots \ldots \ldots \ldots$

MAR. $23, \ldots \ldots \ldots \ldots$

MAR. $24, \ldots \ldots \ldots \ldots$

MAR, $26, \ldots \ldots \ldots .$.

MAR. $27 \ldots \ldots \ldots \ldots \ldots$

MAR. $28, \ldots \ldots \ldots \ldots \ldots$

MAR. $30 . \ldots \ldots \ldots \ldots$

MAR. $31, \ldots \ldots \ldots \ldots$

$A P R \cdot 1, \ldots \ldots \ldots \ldots$

APR. $2, \ldots \ldots \ldots \ldots, \cdots$

APR $-3 \ldots \ldots \ldots \ldots$

APR. $4 \ldots \ldots \ldots \ldots \ldots \ldots$

$A P R .6 \ldots \ldots \ldots \ldots$.

$A P R \cdot 7 \ldots \ldots \ldots \ldots$

$A P R \cdot B, \ldots, \ldots \ldots \ldots, \ldots$

$A P R .10$.

$$
\text { SEDIMENT TURBIDITY }
$$

226

956
212

233
170

106

100

68
208

210

309

262
266

134

2110

389

389
$15 ?$

186

151
87

72

58

34

50

40

24

19

18

74
14

14
16
14
16

10
12
14
12
5

il

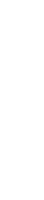

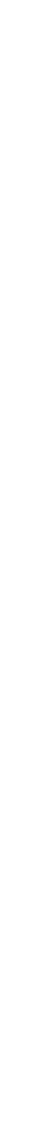

APR. I1, $1969 \ldots \ldots$.

APR. $12, \ldots \ldots \ldots \ldots \ldots$

$A P R$. $13 \ldots \ldots \ldots \ldots$

APR . $14 \ldots \ldots \cdots \cdots$

APQ. $16 \ldots \ldots \ldots \ldots$

APR. $17 \ldots \ldots \ldots . . . .$.

$A P R=18 \ldots \ldots \ldots \ldots$

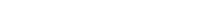

APQ. $20 . . . . . . . . . . .$.

$A P R \cdot 21 \ldots \ldots \ldots \ldots$

$A P R=22, \ldots \ldots \ldots \ldots$

APR. $23 \ldots \ldots \ldots \ldots \ldots$

$A P R .25 \ldots \ldots \ldots \ldots$.

$A P R=26 \ldots \ldots \ldots \ldots \ldots$

$A P R=27 \ldots \ldots \ldots \ldots$

$A P R, 29, \ldots \ldots \ldots \ldots$

APR. $30 \ldots \ldots \ldots \ldots$

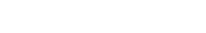

MAYY $2 \ldots \ldots \ldots \ldots \ldots \ldots$

MAY $7 \ldots \ldots \ldots \ldots \ldots$

MaY $9 . . . . . \ldots \ldots . . .$.

MAY $12 \ldots \ldots \ldots \ldots \ldots$

MAY $16 \ldots \ldots \ldots \ldots \ldots \ldots$

maY $19 . \ldots \ldots \ldots \ldots . .$.

MAY $21 \ldots \ldots \ldots \ldots \ldots$

MAY $2 b \ldots \ldots \ldots \ldots \ldots$

MAY $28 . \ldots . \cdots \cdots$

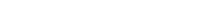

JUNE

JUNE $4 \ldots \ldots \ldots \ldots \ldots \ldots$

JUNE $6 . . . . . . . . .$.

JUNE $11 \ldots \ldots \ldots \ldots \ldots$.

JUNE $25, \ldots . . . \ldots . .$.

JULY $2 \ldots \ldots \ldots \ldots . .$.

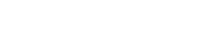

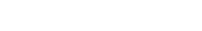

JuLY $16, \ldots \ldots \ldots . . .6$

JULY $23, \ldots \ldots \ldots \ldots$.

JULY $30 . \ldots \ldots \ldots \ldots$.

AUE. B.............

AUG. $16, \ldots \ldots \ldots \ldots$

AUG. $20 . \ldots \ldots \ldots \ldots$.

AUG. $27, \ldots \ldots \ldots \ldots$

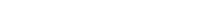

SEPT: $8, \ldots \ldots \ldots \ldots \ldots$

SEPT. $11, \ldots \ldots \ldots \ldots \ldots$
SEPT. $24 \ldots \ldots \ldots \ldots \ldots$ 
11467000 RUSSIAN RI VER NEAR GUERNEVILLE, CALIF.

LOCATION, --Lat $38^{\circ} 30^{\prime} 00^{\prime \prime}$, long $122^{\circ} 56^{\circ} 05^{\prime \prime}$, In NEł sec.35, T.8 N, R. 10 w., Sonoma County, at gaging station 0.6 mile downstream from Hobson Creek' and $3.4 \mathrm{miles}$ éast of Guerneviile.

DRAINAGE AREA. $-1,340$ sq mi.

PERIOD OF RECORD. --Chemical analy ses: October 1953 to September 1965, November 1968 to September 1969 (monthly), October 1965 to September 1967 (miscellaneous).

ater temperatures: January 1964 to September 1969.

Sediment records: November 1965 (revised) to September 1969.

EXTREMES, --1968-69:

Water temperatures: Maximum, $28.0^{\circ} \mathrm{C} \mathrm{Ju} 1 \mathrm{y} 18$; minimum, $8.0^{\circ} \mathrm{C}$ on several days during December to February.

Period of record: Water temperatures: Maximum, $28.0^{\circ} \mathrm{C}$ on several days in $1964,1968-69 ;$ mint mum $(1965-69), 4.0^{\circ} \mathrm{C}$ Dec. 15,1967 ,
Jan. 12, 1968.

REMARKS. - Chemical-quality records furnished by California Department of Water Resources and reviewed by U.S. Geological Survey. Temperature recorder stopped Oct. 2 to Nov, 4, Apr. 17-28; ranges in temperature, $14.0^{\circ} \mathrm{C}$ to $19.0^{\circ} \mathrm{C}$ and $13.0^{\circ} \mathrm{C}$ to $19.0^{\circ} \mathrm{C}$, respectively. No record tor May 2-6, Sept. 6, 7, 19-22.

CHEMICAL ANALYSES, NOVEMBER 1968 TO SEPTEMBER 1969

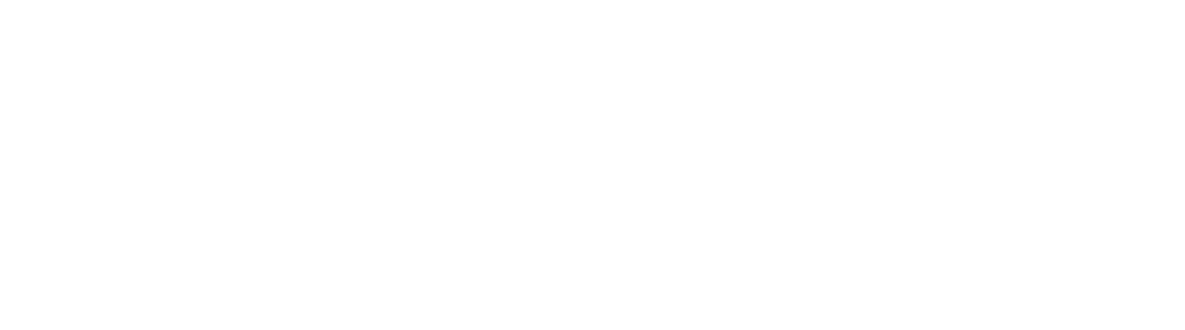

\begin{tabular}{|c|c|c|c|c|c|c|c|c|c|c|c|}
\hline DATE & $\begin{array}{l}\text { NITRATE } \\
\text { (NO3) } \\
\text { (MG/L) }\end{array}$ & $\begin{array}{l}\text { BORON } \\
\text { (B) } \\
(U G / L)\end{array}$ & $\begin{array}{l}\text { DIS- } \\
\text { SOLVED } \\
\text { SOLIDS } \\
\text { (RESI- } \\
\text { DUE AI } \\
\text { IBO CI } \\
\text { (MG/L) }\end{array}$ & $\begin{array}{l}\text { DIS- } \\
\text { SOLVED } \\
\text { SOL IOS } \\
\text { ITONS } \\
\text { PER } \\
\text { AC-FTI }\end{array}$ & $\begin{array}{l}\text { HARD- } \\
\text { NESS } \\
(C A, M G) \\
(M G / L)\end{array}$ & $\begin{array}{l}\text { NON- } \\
\text { CAR- } \\
\text { BONATE } \\
\text { HARD- } \\
\text { NESS } \\
\text { (MG/L) }\end{array}$ & $\begin{array}{l}\text { PERCENT } \\
\text { SOOIUM }\end{array}$ & $\begin{array}{l}\text { SOOIUM } \\
\text { AD- } \\
\text { SORP- } \\
\text { TION } \\
\text { RAT IO }\end{array}$ & $\begin{array}{l}\text { ALKA- } \\
\text { LINITY } \\
\text { AS } \\
\text { CACO3 } \\
\text { (MG/L) }\end{array}$ & $\begin{array}{c}P H \\
\text { (UNITS) }\end{array}$ & $\begin{array}{l}\text { SPECI- } \\
\text { FIC } \\
\text { COND- } \\
\text { UCIANCE } \\
\text { (MICRO- } \\
\text { MHOS) }\end{array}$ \\
\hline $\begin{array}{l}\text { NOV. } \\
\text { O6... } \\
\text { JAN. }\end{array}$ & - & 510 & - & -- & 140 & 14 & 19 & .6 & 126 & 8.1 & 327 \\
\hline O7... & -- & 330 & -- & - & 116 & 5 & 25 & .5 & 111 & 7.6 & 271 \\
\hline $\begin{array}{l}13 \ldots . . \\
\text { APK. }\end{array}$ & - & 120 & -- & $\cdots$ & 119 & 16 & 21 & .4 & 103 & 7.9 & 249 \\
\hline JuLY $24 .$. & $2 \cdot B$ & -- & 153 & .21 & $10 B$ & 5 & 15 & .5 & 103 & 8.2 & 247 \\
\hline $\begin{array}{l}03 \ldots . . \\
\text { SEPT. }\end{array}$ & -- & -- & - & $=$ & 134 & 4 & 27 & .6 & 130 & B. 3 & 292 \\
\hline $16 \ldots$ & $\rightarrow$ & -- & -- & $-\infty$ & 136 & 10 & 26 & .6 & 125 & 7.9 & 283 \\
\hline
\end{tabular}


11467000 RUSSIAN RIVER NEAR GUERNEVILLE, CALIF. --ContI NuEd

TBMPERATURE $\left({ }^{\circ} \mathrm{C}\right.$ ) OF WATER, WATER YEAR OCTOBER 1968 TO SEPYTEMBER 1969

DAY

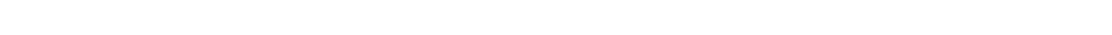

OCTOBER

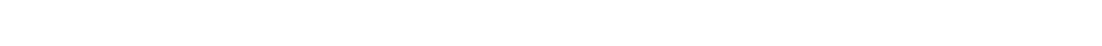

NDVEMRER

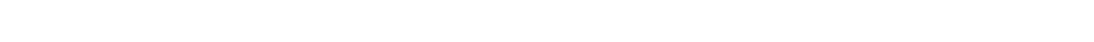

DECEMBER

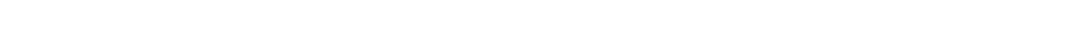

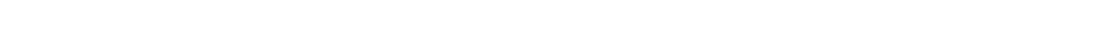

JANUARY

$\begin{array}{rlllllllllllllllllllllllllllllllllll}\text { MAXIMUM } & 8 & 9 & 9 & 9 & 10 & 10 & 11 & 10 & 10 & 10 & 9 & 9 & 10 & 10 & 10 & 9 & 9 & 9 & 10 & 11 & 11 & 11 & 10 & 9 & 9 & 10 & 10 & 9 & 9 & 8 & 8 & 10 \\ \text { MINIMUM } & 8 & 8 & 9 & 9 & 9 & 10 & 10 & 10 & 10 & 9 & 9 & 9 & 9 & 10 & 9 & 9 & 9 & 9 & 9 & 10 & 11 & 10 & 9 & 9 & 9 & 9 & 9 & 9 & 8 & 8 & 8 & \end{array}$

EBRUARY

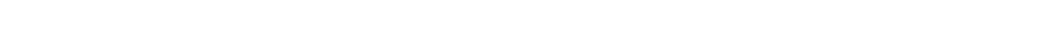

MINIMUM

ARCH

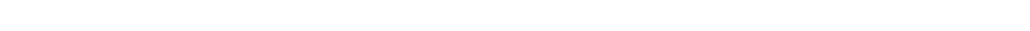

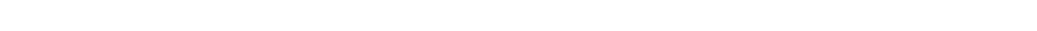

APRIL

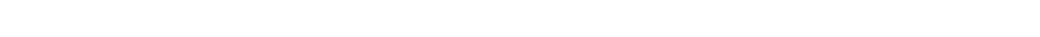

MAY

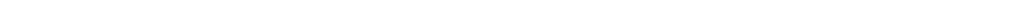

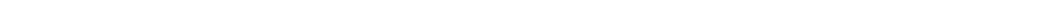
JUNE

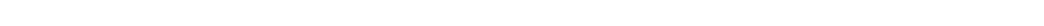
MINIMUM $20 \begin{array}{llllllllllllllllllllllllllllllll} & 20 & 20 & 21 & 20 & 21 & 20 & 19 & 18 & 19 & 20 & 20 & 21 & 22 & 23 & 21 & 21 & 21 & 21 & 21 & 23 & 23 & 23 & 22 & 22 & 21 & 21 & 21 & 22 & --\end{array}$

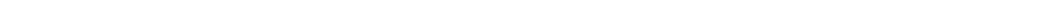

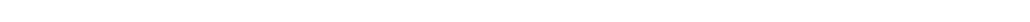
AUGUST

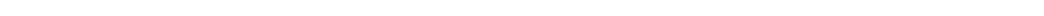
MINIMUM $\begin{array}{lllllllllllllllllllllllllllllllllll}22 & 23 & 23 & 24 & 24 & 23 & 23 & 23 & 22 & 23 & 23 & 23 & 23 & 22 & 22 & 23 & 23 & 22 & 21 & 22 & 23 & 23 & 22 & 21 & 22 & 22 & 22 & 22 & 21 & 22 & 22\end{array}$ SEPTEMBER

MAXIMUM $24 \begin{array}{lllllllllllllllllllllllllllllllllll}24 & 23 & 23 & 23 & - & - & - & 24 & 24 & 23 & 22 & 22 & 22 & 20 & 21 & 21 & 22 & - & - & - & - & 22 & 22 & 23 & 23 & 22 & 21 & 22 & 22 & -\end{array}$

MONTHLY AND ANNUAL SUMMARY OF SUSPENDED-SEDIMENT DISCHARGE,

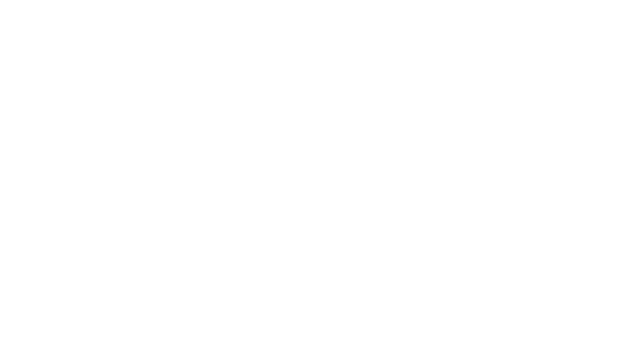

TOTAL FOR YEAR. .... 1, 387,939

$1,745,620.5$ 
11467000 RUSSIAN RIVER NEAR GUERNEVILLE, CALIF. --Continued

PARTICLE-SIZE DISTRIBUTION OF SUSPENDED SEDIMENT, WATER YEAR OCTOBER 1968 TO SEPTEMBER 1969 IMETHODS DF ANALYSIS: B, BDTPOM WITHORAWAL TURE; C, CHEMICALLY OISPERSED: N, IN NATIVE WATER: P. PIPET: S, SIEVE: V. VISUAL ACCUMULATION TUBE: W, IN DISTILLED WATERI

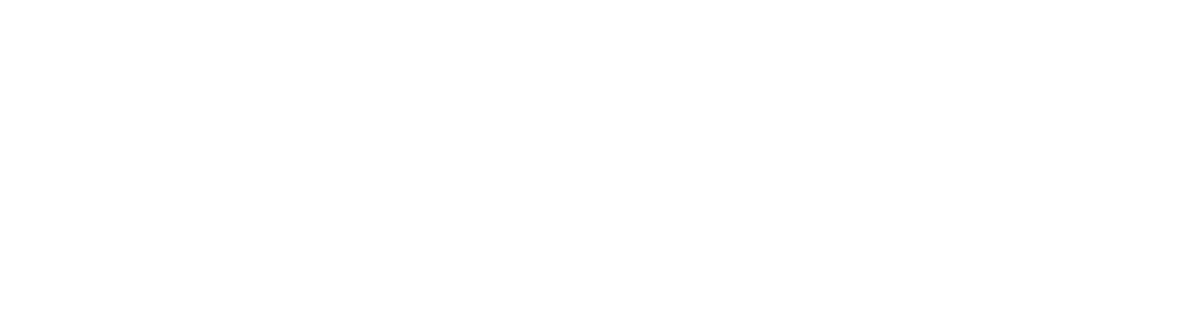

PARTICLE-5IZE DISTRIBUTION OF SURFACE BED MATERIAL, WATER YEAR OCTOBER 1968 TO SEPTEMBER 1969 (METHOD DF ANALYSIS; H, HYDRQMETER; O, OPTICAL ANALYZER; S, SIEVE; V, VISUAL ACCUMULATION TURE)

\begin{tabular}{|c|c|c|c|c|c|c|c|c|c|c|c|c|c|c|c|c|}
\hline \multirow[b]{2}{*}{ OATE } & \multirow[b]{2}{*}{ TIME } & \multirow{2}{*}{\multicolumn{2}{|c|}{$\begin{array}{l}\text { WATER NUMBER } \\
\text { TEM- OF } \\
\text { PERA- SAM- } \\
\text { TURE PLING } \\
\text { I CI PDINTS }\end{array}$}} & \multirow{2}{*}{$\begin{array}{l}\text { DISCHARGE } \\
\text { (CFS) }\end{array}$} & \multicolumn{11}{|c|}{ PARTICLE SIZE } & \multirow[b]{2}{*}{$\begin{array}{l}\text { METHOS } \\
\text { OF } \\
\text { AYALY } \\
\text { SIS }\end{array}$} \\
\hline & & & & & .062 & PERCEN & T FINER & THAN & THES & sizt 1 & N MILL & IMETERS & S) IND & ICATED & 64.0 & \\
\hline$\left\{\begin{array}{l}1968 \\
1969\end{array}\right.$ & $\begin{array}{l}1425 \\
1645\end{array}$ & $\begin{array}{r}11 \\
9\end{array}$ & $\begin{array}{l}5 \\
5\end{array}$ & $\begin{array}{r}7740 \\
20600\end{array}$ & $=-$ & $=$ & -1 & $i$ & $\begin{array}{r}16 \\
3\end{array}$ & 31 & $\begin{array}{l}55 \\
13\end{array}$ & $\begin{array}{l}75 \\
27\end{array}$ & $\begin{array}{r}100 \\
51\end{array}$ & $10 \overline{0}$ & $\overline{-}$ & 5 \\
\hline
\end{tabular}
SUSPENDED-SEDIMENT CONCENTRATION AND TURBIDITY, WATER YEAR OCTOBER 1968 TO SEPTEMBER 1969

\begin{tabular}{|c|c|c|c|c|c|c|}
\hline & $\begin{array}{c}\text { DATE } \\
\text { DF } \\
\text { COLLECTION }\end{array}$ & $\begin{array}{l}\text { CONCENTRATION } \\
\text { OF SUSPENDED } \\
\text { SEDIMENT } \\
\text { (MGLL) }\end{array}$ & $\begin{array}{c}\text { TURBIDITY } \\
\text { IMG/L SILICA) }\end{array}$ & $\begin{array}{c}\text { DATE } \\
\text { DF } \\
\text { COLLECTION }\end{array}$ & $\begin{array}{c}\text { CONCENTRATION } \\
\text { OF SUSPENDED } \\
\text { SEDIMENT } \\
\text { (MG/L) }\end{array}$ & $\begin{array}{l}\text { TURBIDITY } \\
(M G / L \text { SILICA) }\end{array}$ \\
\hline $\begin{array}{l}\text { OCT. } \\
\text { OCT. } \\
\text { OCT. } \\
\text { OCT. } \\
\text { OCT. }\end{array}$ & $\begin{array}{l}2,1968 \ldots \ldots \ldots \ldots \\
4 \ldots \ldots \ldots \ldots \ldots \\
7 \ldots \ldots \ldots \ldots \ldots \ldots \\
11 \ldots \ldots \ldots \ldots \ldots\end{array}$ & $\begin{array}{l}16 \\
17 \\
15 \\
15 \\
16\end{array}$ & $\begin{array}{l}15 \\
17 \\
17 \\
15 \\
13\end{array}$ & 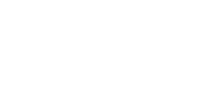 & $\begin{array}{l}944 \\
445 \\
402 \\
287 \\
194\end{array}$ & $\begin{array}{l}114 \\
142 \\
134 \\
135 \\
110\end{array}$ \\
\hline $\begin{array}{l}\text { OCT. } \\
\text { OCT: } \\
\text { OCT: } \\
\text { OCT. } \\
\text { ПCT. }\end{array}$ & $\begin{array}{l}14 \ldots \ldots \ldots \ldots \ldots \\
16 \ldots \ldots \ldots \ldots \ldots \\
18 \ldots \ldots \ldots \ldots \ldots \\
21 \ldots \ldots \ldots \ldots \ldots \\
23 \ldots \ldots \ldots \ldots \ldots\end{array}$ & $\begin{array}{l}15 \\
13 \\
14 \\
14 \\
12\end{array}$ & $\begin{array}{l}15 \\
13 \\
13 \\
13 \\
10\end{array}$ & 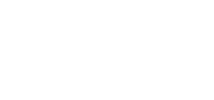 & $\begin{array}{l}470 \\
427 \\
170 \\
574 \\
245\end{array}$ & $\begin{array}{r}143 \\
138 \\
70 \\
132 \\
108\end{array}$ \\
\hline $\begin{array}{l}\text { OCT. } \\
\text { OCT. } \\
\text { NON. } \\
\text { NOV: } \\
\text { OEC. }\end{array}$ & $\begin{array}{l}25 \ldots \ldots \ldots \ldots \ldots \ldots \\
28 \ldots \ldots \ldots \ldots \ldots \ldots \\
4 \ldots \ldots \ldots \ldots \ldots \ldots \ldots \\
29 \ldots \ldots \ldots \ldots \ldots \ldots\end{array}$ & $\begin{array}{r}11 \\
13 \\
21 \\
6 \\
5\end{array}$ & $\begin{array}{l}11 \\
11 \\
20 \\
7 \\
7\end{array}$ & 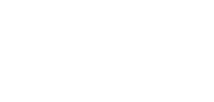 & $\begin{array}{r}214 \\
93 \\
42 \\
68 \\
39\end{array}$ & $\begin{array}{r}121 \\
40 \\
25 \\
48 \\
23\end{array}$ \\
\hline $\begin{array}{l}\text { DEC. } \\
\text { OEC. } \\
\text { DEC. } \\
\text { DEC. } \\
\text { JAN. }\end{array}$ & $\begin{array}{l}11, \ldots \ldots \ldots \ldots \ldots \ldots \\
23 \ldots \ldots \ldots \ldots \ldots \ldots \\
24 \ldots \ldots \ldots \ldots \ldots \\
30 . \ldots \ldots \ldots \ldots \ldots \\
6,1969 \ldots \ldots \ldots \ldots\end{array}$ & $\begin{array}{r}714 \\
154 \\
1580 \\
120 \\
43\end{array}$ & $\begin{array}{r}798 \\
93 \\
488 \\
102 \\
37\end{array}$ & 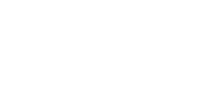 & $\begin{array}{l}24 \\
19 \\
18 \\
17 \\
23\end{array}$ & $\begin{array}{l}11 \\
15 \\
14 \\
15 \\
11\end{array}$ \\
\hline $\begin{array}{l}\text { JAN. } \\
\text { JAN. } \\
\text { JAN. } \\
\text { JAN. } \\
\text { JAN. }\end{array}$ & $\begin{array}{l}10 \ldots \ldots \ldots \ldots \ldots \\
12, \ldots \ldots \ldots \ldots \ldots \\
13 \ldots \ldots \ldots \ldots \ldots \ldots \\
15 \ldots \ldots \ldots \ldots \ldots \\
20 \ldots \ldots \ldots \ldots \ldots\end{array}$ & $\begin{array}{r}22 \\
1050 \\
1290 \\
458 \\
929\end{array}$ & $\begin{array}{l}20 \\
608 \\
960 \\
274 \\
290\end{array}$ & $\begin{array}{l}\text { SEPT. } 8, \ldots \ldots \ldots \ldots \ldots \\
\text { SEPT. } 23 \ldots \ldots \ldots \ldots \ldots\end{array}$ & $\begin{array}{l}? \\
5\end{array}$ & $\begin{array}{l}7 \\
7\end{array}$ \\
\hline
\end{tabular}


11467600 GARCIA RIVER NEAR PUINT ARENA, CALIF.

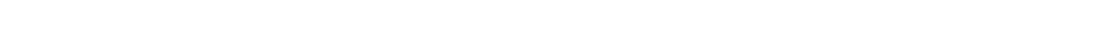
town of Point Arena.

DRAINAGE AREA. $--98.5 \mathrm{sq}$ in 1 .

PERIOD OF RECORD.--Water temperatures: October 1963 to September 1969.

EXTREMES, $-1968-69$ :

Water temperatures: Minimum, $7.0^{\circ} \mathrm{C}$ Dec. 21,22 .

Perlod of record:

Nater temperatures: Maximum $(1963-68), 22.0^{\circ} \mathrm{C}$ June 22,1964 , Aug. $29,30,1968$; minimum, $5.0^{\circ} \mathrm{C}$ Dec. 14-16, 1967.

REMARKS. --Recorder malfunction Feb. 13 to Mar. 10; probe inoperative May 24 to Aug. 11.

TEMPERATURE $\left({ }^{\circ} \mathrm{C}\right.$ ) OF WATER, WATER YEAR OCTOBER 1968 TO SEPTEMBER 1969

DAY

MUVTH $\begin{array}{lllllllllllllllllllllllllllllll}1 & 2 & 3 & 4 & 5 & 6 & 7 & 8 & 9 & 10 & 11 & 12 & 13 & 14 & 15 & 16 & 17 & 18 & 19 & 20 & 21 & 22 & 23 & 24 & 25 & 26 & 27 & 28 & 29 & 30 & 31\end{array}$

OC TUAFR

MAXINUM $1717 \quad 1717 \quad 17 \quad 16 \quad 1516 \quad 15 \quad 17 \quad 16 \quad 16 \quad 16 \quad 15 \quad 15 \quad 15 \quad 16 \quad 16 \quad 15 \quad 16 \quad 15 \quad 16 \quad 1616 \quad 16 \quad 16 \quad 16 \quad 15 \quad 16 \quad 15 \quad 14$

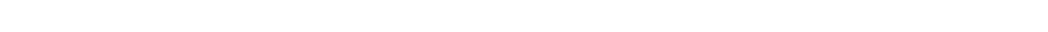

NUVEMRE?

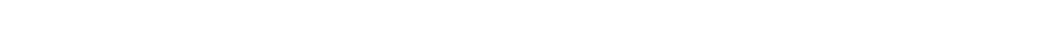

DECEMRER MAXIMUM $1299101211111213131211101212111011 \quad 10 \quad 9 \quad 8 \quad 9101212111011111010$

MINIMUSM

JANUA?Y

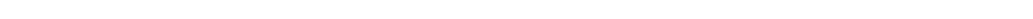

MINIMUM

MAXIMUM

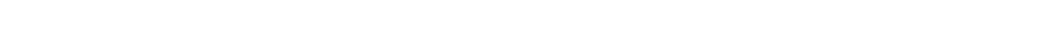

A. $\mathrm{CH}$

MAXINUM -. - - - -

Mlivimum - . - . - . - . -

APQIL

MAXIMUM $15 \quad 13 \quad 14 \quad 13 \quad 12 \quad 13 \quad 14 \quad 14 \quad 13 \quad 15 \quad 15 \quad 14 \quad 13 \quad 15 \quad 15 \quad 15 \quad 15 \quad 16 \quad 16 \quad 17 \quad 16 \quad 14 \quad 14 \quad 15 \quad 15 \quad 16 \quad 17 \quad 18 \quad 16 \quad 16 \quad--$

MY

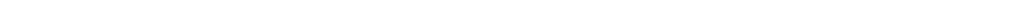

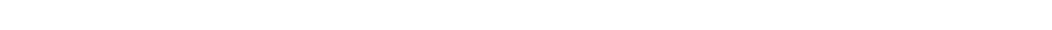
JUNE

MAXINIIM

MINIMUM

ULY

MAXIMUM

MINIMI

MAXIMUM
MUSI

MAXIMUN
MINIMUN.

SEPTEMPFQ

MAXIMUM 21 $2121202020202120201919191919181919191919192020201919191919=$

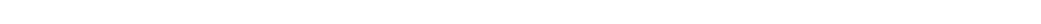


11468000 NAYARRO RIVER NEAR NAVARRO, CALIF.

LOCATYON. --Lat $39^{\circ} 10^{\prime} 15^{\prime \prime}$, long $123^{\circ} 39^{\prime} 55^{\prime \prime}$, in SEl sec.7, T.15 N., R.16 W., Mendocino County, temperature recorder at gagling station on' left bank, 2.7 miles downstream from North Fork, 5.4 miles upstream from mouth, and
6.6 miles west of Navarro.

DRAINAGE AREA, $--303 \mathrm{sq} \mathrm{mi}$.

PERIOD OF RECORD. --Chemical analyses: January 1959 to July 1965.

Water temperatures: October 1965 to September 1969.

EXTREMES. - Period of record (1965-68): Vater temperatures: Maximum, $25.0^{\circ} \mathrm{C}$ Aug. 20,1966 , June 30,1967 ; mi nimum $(1967-68), 6,0^{\circ} \mathrm{C}$ on several days
in 1967 and 1968 .

REMARKS. -- No record Jan. 13 to Sept. 30, probe buried. Where no maximun or minimum is shown, temperature is once-dally reading.

TEIPERATURE $\left({ }^{\circ} \mathrm{C}\right)$ OF WATER, MATER YEAR OCTOBER 1968 TO SEPTEMBER 1969

DAY

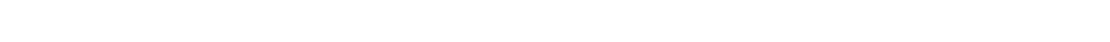

OCTOBER.. - - - - - -

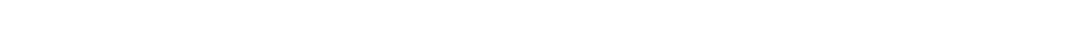

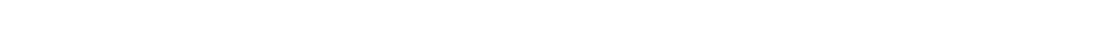
NOVEMBER. -- -- - - - MAXIMUM 13 13 14 13 $14 \begin{array}{llllllllllllllllllllllllllllll}14 & 14 & 14 & 15 & 15 & 15 & 15 & 14 & 12 & 10 & 11 & 12 & 13 & 13 & 13 & 13 & 13 & 13 & 13 & 13 & 12 & 11 & 10 & 10 & 10 & -\end{array}$

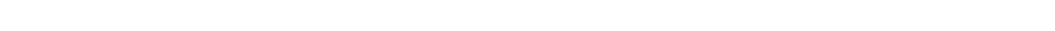

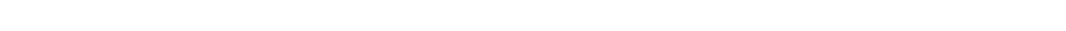

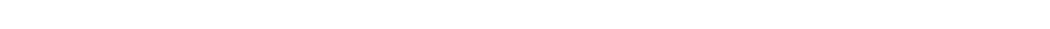

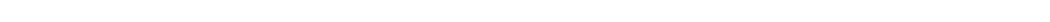
JANUARY,

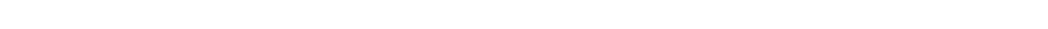

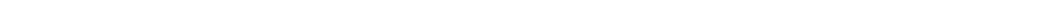
FE BRUARY; MAXIMUM MINI MUM MAXIMUM :MAXINUM

APRIL.... MAXIMUM MINIMUM

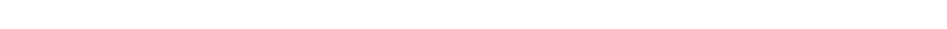
MAXIMUK

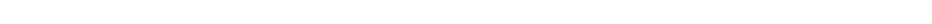
MINIMUMA -SUNE..... MAXIMUM -MINIMUM -

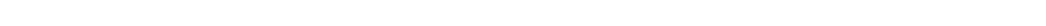
MAXIMUM AUGUST TMUM

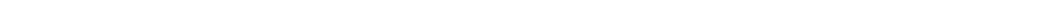
MINIMUM SEPIEMPER MAXIMUM MAXINIMUM 
11468500 NOYO RIVER NEAR FORT BRAGG, CALIF,

LOCATION (revised), - - Lat $39^{\circ} 25^{\prime} 42^{\prime \prime}$, long $123^{\circ} 44^{\prime} 12^{\prime \prime}$, in NEt sec.15, T.18 N., R, 17 *., Wendocino County, temperature recorder at gaging station on right bank, $0.7 \mathrm{mile}$ downetream from South Fork and $3.3 \mathrm{miles}$ east of Fort Brags.

DRAINAGE AREA. --106 sq $\mathrm{mi}$.

PERIOD OF RECORD. --Chemicel analy ees: January $195 \theta$ to September 1965.

Tater temperatures: December 1965 to September 1969 .

EXTREMES, -1968-68:

Pater temperatures: Maximum, $21.0^{\circ} \mathrm{C}$ July 7,$8 ;$ minimum, $3.0^{\circ} \mathrm{C} \mathrm{Dec}, 2,3$.

Period of record:

Water temperatures: Maximum, $22.0^{\circ} \mathrm{C}$ on several daye in 1966-68; minimum, 2. $0^{\circ} \mathrm{C}$ Dec. 17-21, 1965 .

REMARKS. -No rocord Aug. 8 to Sept. 3.

TEMPERATURE ('C) OF WATER, WATER YEAR OCTOBEA 1968 TO SEPTEMER 1960

DAY

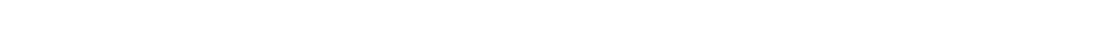

OCTDBER

MAXIMUM $16 \begin{array}{lllllllllllllllllllllllllllllllllllllll}16 & 16 & 15 & 16 & 16 & 14 & 13 & 13 & 12 & 14 & 14 & 14 & 14 & 14 & 14 & 13 & 14 & 14 & 13 & 13 & 13 & 13 & 13 & 13 & 13 & 13 & 13 & 12 & 13 & 13 & 13 & 14 \\ \text { MINIMUM } & 14 & 14 & 14 & 14 & 14 & 12 & 11 & 10 & 9 & 11 & 13 & 13 & 13 & 12 & 11 & 11 & 12 & 12 & 11 & 11 & 11 & 11 & 11 & 11 & 11 & 11 & 11 & 11 & 12 & 12 & 12 & 12\end{array}$

NOVEMBER

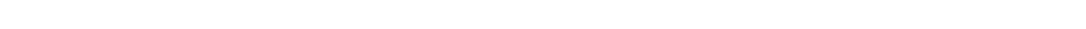

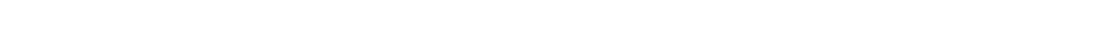

DECEMBER

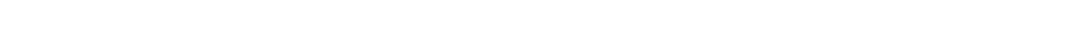

MINIMUM

JANUARY

MAXIMUM

FEORTARY

MAXIMUM

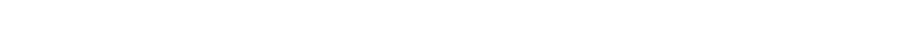

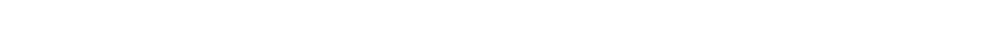

MINIMUM

MARCH

MAXIMUM
MINIMUM

APRIL

MAXIMUM

MaY MITUM

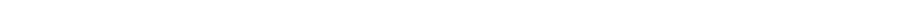

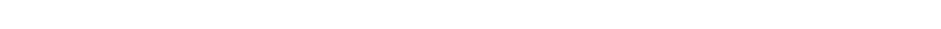

$\begin{array}{cccccccccccccccccccccccccccccccc}8 & 8 & 8 & 8 & 9 & 9 & 9 & 8 & 8 & 8 & 8 & 9 & 9 & 8 & 9 & 9 & 10 & 11 & 10 & 9 & 10 & 11 & 11 & 11 & 11 & 11 & 12 & 12 & 12 & 13 & 13 \\ 8 & 8 & 8 & 7 & 8 & 9 & 8 & 8 & 7 & 7 & 8 & 7 & 7 & 6 & 6 & 7 & 9 & 9 & 8 & 8 & 9 & 9 & 8 & 8 & 7 & 8 & 8 & 9 & 10 & 11 & 12\end{array}$

$\begin{array}{llllllllllllllllllllllllllllllll}12 & 11 & 11 & 11 & 10 & 11 & 11 & 11 & 12 & 13 & 13 & 13 & 12 & 12 & 13 & 13 & 12 & 14 & 14 & 14 & 13 & 13 & 12 & 13 & 13 & 13 & 14 & 15 & 14 & 13 & \ldots\end{array}$

MAXIMUM $13 \quad 14 \quad 13 \quad 14 \quad 15 \quad 16 \quad 17 \quad 16 \quad 15 \quad 15 \quad 16 \quad 15 \quad 14 \quad 16 \quad 16 \quad 17 \quad 18 \quad 17 \quad 17 \quad 18 \quad 17 \quad 16 \quad 15 \quad 15 \quad 17 \quad 16 \quad 18 \quad 18 \quad 1919 \quad 20$

MINIMUM

MAXIMUM

MAXIMUM

JULY MINIMUM AUGUST

MAXIMUK

MINIMUM

SEPTEMBER

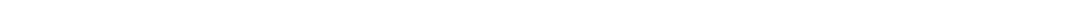


11468600 MIDDLE FORK TENUILE RIVER NEAR FORT BRAGG, CALIF.

LOCATION (rev1sed). --Lat $39^{\circ} 34^{\prime} 22^{\prime \prime}$, long $123^{\circ} 41^{\prime} 57^{\prime \prime}$, in NEłNE \& sec. 25, T. 20 N., R. 17 W. Mendocino County, temperature recorder at gaging station on right bank, 0.8 mile upst ream from confluence with North Fork Tenmile ature recorder at gaging station on right
River and 10 miles northeast of Fort Bragg.

DRAINAGE AREA. $-\mathbf{- 3 2 . 9} \mathrm{sq} \mathrm{mi}$.

PERIOD OF RECORD. - Water temperatures: October 1964 to September 1969.

EXTREMES. $-1968-69$ :

Water temperatures: Maximum, $19.0^{\circ} \mathrm{C}$ on several days during June and July; minimum, $6.0^{\circ} \mathrm{C}$ Dec. 3.

Period of record:

Water temperatures: Maximum, $20.5^{\circ} \mathrm{C}$ June $14,18,1966 ;$ młnimum $(1964-65,1966-69), 4.0^{\circ} \mathrm{C}$ on several days 1n 1967 and 1968

\section{TEMPERATURE $\left({ }^{\circ} \mathrm{C}\right)$ OF WATER, MATER YEAR OCTOBER 1968 TO SEPTEUBER 1969}

DAY

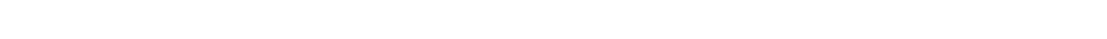

OCTUBER

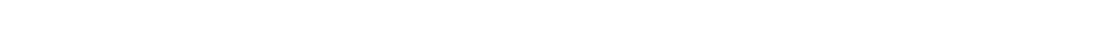

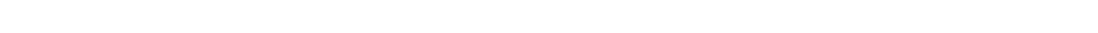

$\begin{array}{lllllllllllllllllllllllllllllllllllll}\text { MAXIMMUM } & 12 & 12 & 12 & 12 & 12 & 12 & 12 & 12 & 13 & 13 & 12 & 12 & 11 & 10 & 9 & 11 & 11 & 12 & 12 & 11 & 11 & 11 & 11 & 10 & 10 & 9 & 9 & 8 & 8 & 7 & -2 & 11 \\ \text { MINIMUM } & 11 & 12 & 12 & 12 & 12 & 11 & 11 & 12 & 12 & 12 & 12 & 11 & 10 & 9 & 9 & 9 & 11 & 11 & 11 & 11 & 10 & 11 & 10 & 10 & 9 & 8 & 8 & 8 & 7 & 7 & -5 & 10\end{array}$

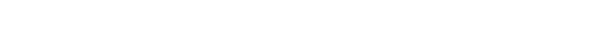

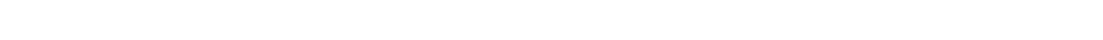

JAVUARY

$\begin{array}{lllllllllllllllllllllllllllllllll}\text { MAXIMUM } & 9 & 9 & 9 & B & B & 8 & 9 & 9 & 7 & 8 & 9 & 9 & 9 & 9 & 9 & 9 & 9 & 9 & 9 & 10 & 10 & 10 & 9 & 9 & 10 & 10 & 9 & 9 & 9 & 9 & 9 & 9 \\ \text { MINIMUM } & 9 & 9 & 8 & 8 & B & B & B & 7 & 7 & 7 & 8 & 9 & 9 & 9 & 9 & 9 & 8 & 8 & 9 & 9 & 10 & 8 & 8 & 8 & 9 & 9 & 9 & 9 & 9 & 9 & 9 & 9\end{array}$

FERRIJARY

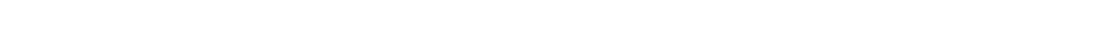

MINIMUM

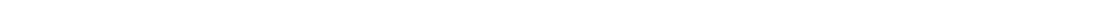

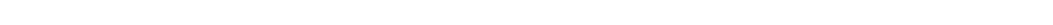

APRIL

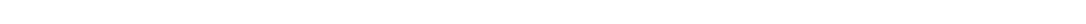

MAY MUN

MINIMUM

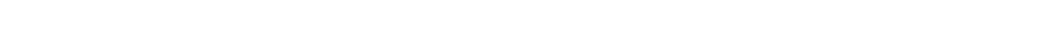
JUVE

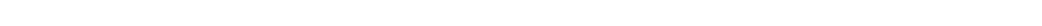

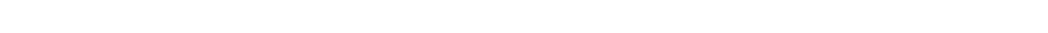
JULY $\begin{array}{lllllllllllllllllllllllllllllllll}\text { MAXIMUM } & 1 B & 18 & 18 & 1 B & 18 & 18 & 18 & 18 & 1 B & 18 & 18 & 19 & 19 & 18 & 18 & 18 & 18 & 18 & 18 & 19 & 18 & 18 & 18 & 17 & 17 & 17 & 18 & 18 & 17 & 17 & 17 \\ \text { MINIMUM } & 17 & 17 & 17 & 17 & 17 & 17 & 17 & 17 & 16 & 16 & 16 & 16 & 16 & 16 & 16 & 15 & 15 & 16 & 16 & 16 & 16 & 16 & 16 & 17 & 16 & 16 & 16 & 16 & 16 & 16 & 15\end{array}$

AUGUST

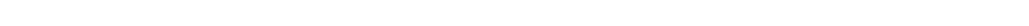
$\begin{array}{lllllllllllllllllllllllllllllllllll}\text { MAXINUM } & 16 & 17 & 16 & 16 & 16 & 16 & 14 & 14 & 15 & 15 & 15 & 16 & 16 & 15 & 15 & 16 & 16 & 16 & 16 & 16 & 17 & 17 & 16 & 16 & 16 & 16 & 16 & 16 & 16 & 16 & 17 \\ \text { MINIMUM } 14 & 14 & 14 & 14 & 13 & 13 & 13 & 13 & 13 & 14 & 13 & 14 & 14 & 14 & 13 & 14 & 14 & 14 & 14 & 14 & 16 & 16 & 15 & 15 & 15 & 15 & 14 & 14 & 14 & 15 & 16\end{array}$ SEPTEMRER

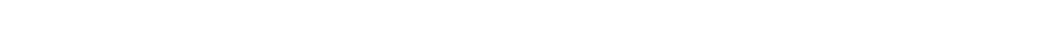

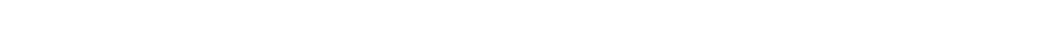


LOCATION.--Lat $40^{\circ} 18^{\prime} 42^{\prime \prime}$, long $124^{\circ} 15^{\prime} 48^{\prime \prime}$, in NW $\frac{1}{4}$ sec.11, T.2 S., R. 2 W., Humboldt County, at gaging station on right bank, $0.2 \mathrm{mile}$ upstream from Clear Creek, 1.5 miles southeast of Petrolia, and $1.7 \mathrm{miles}$ upstream from

DRAINAGE AREA, -240 sq $\mathrm{mI}$.

PERIOD OF RECORD. --Chemical analyses: January 1959 to September 1969

Water temperatures: November 1965 to September 1969.

EXTREMES, --1968-69

Water temperatures: Minimum, $3.0^{\circ} \mathrm{C} \mathrm{Jan.} 9$.

period of record (1966-69):

Water temperatures: Maximum $(1966-68), 27.0^{\circ} \mathrm{C}$ on several days in 1968 ; minimum, $3.0^{\circ} \mathrm{C} \mathrm{Jan.} 9,1969$.

REMARKS. - Chemical-quality records furnished by California Department of Water Resources and reviewed by U.S. Geological Survey. Temperature probe inoperative May 14 to Aug. 11.

CHEMICAL ANALYSES, hateR YEAR OCTOBER 1968 TO SEPTEMBER 1969

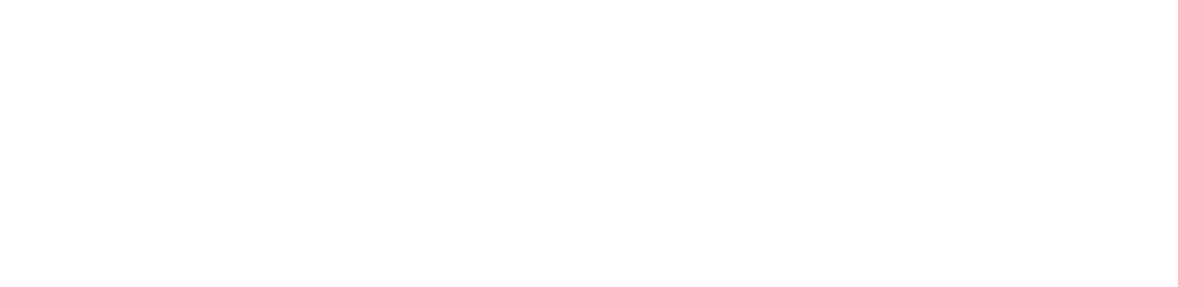

\begin{tabular}{|c|c|c|c|c|c|c|c|c|c|c|c|}
\hline DATE & $\begin{array}{l}\text { NITRATE } \\
\text { (ND3) } \\
\text { (MG/L) }\end{array}$ & $\begin{array}{l}\text { BORON } \\
\text { (B) } \\
\text { (UG/L) }\end{array}$ & $\begin{array}{l}\text { OIS- } \\
\text { SOLVEO } \\
\text { SOLIOS } \\
\text { IRESI- } \\
\text { DUE AT } \\
\text { IBO C) } \\
\text { (MG IL) }\end{array}$ & $\begin{array}{l}\text { DIS- } \\
\text { SOLVED } \\
\text { SOLIDS } \\
\text { ITONS } \\
\text { PER } \\
\text { AC-FTI }\end{array}$ & $\begin{array}{l}\text { HARD- } \\
\text { NESS } \\
(C A, M G) \\
(M G / L)\end{array}$ & $\begin{array}{l}\text { NON- } \\
\text { CAR- } \\
\text { BONATE } \\
\text { HARD- } \\
\text { NESS } \\
\text { (MG/L) }\end{array}$ & $\begin{array}{l}\text { PERCENT } \\
\text { SODIUM }\end{array}$ & $\begin{array}{l}\text { SOOIUM } \\
\text { AO- } \\
\text { SORP- } \\
\text { TION } \\
\text { RATIO }\end{array}$ & $\begin{array}{l}\text { ALKA- } \\
\text { IINITY } \\
\text { AS } \\
\text { CACO3 } \\
\text { (MG/L) }\end{array}$ & $\begin{array}{c}\text { PH } \\
\text { (UNITS) }\end{array}$ & $\begin{array}{l}\text { SPECI- } \\
\text { FIC } \\
\text { COND- } \\
\text { UCTANCE } \\
\text { CMICRO- } \\
\text { MHOSI }\end{array}$ \\
\hline $\begin{array}{l}\text { DCT. } \\
\text { O2... } \\
\text { Nov. }\end{array}$ & -- & 130 & -- & - & $12 B$ & 30 & 14 & .4 & 98 & 7.9 & 272 \\
\hline $\begin{array}{l}13 \ldots . . \\
\text { JAN. }\end{array}$ & $\cdots$ & 20 & -- & -- & 70 & 15 & 18 & .4 & 55 & 7.9 & 168 \\
\hline $\operatorname{MAY}_{\text {MAY }}^{21}$ & -- & 50 & -- & - & 39 & 8 & 20 & .3 & 31 & 7.3 & 86 \\
\hline $\begin{array}{l}13 . . . \\
\text { SEPT. }\end{array}$ & .0 & 90 & B8 & .12 & 70 & 6 & 16 & .3 & 64 & 7.8 & 170 \\
\hline $09 . .$. & .0 & 50 & 93 & .13 & 104 & 17 & 17 & .4 & 87 & 8.2 & 235 \\
\hline
\end{tabular}

TEMPERATURE $\left({ }^{\circ} \mathrm{C}\right.$ ) OF WATER, WATER YEAR OCTOBER 1968 TO SEPTELBER 1969

DAY

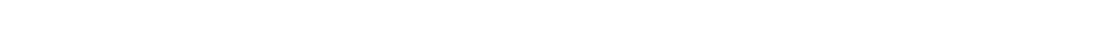

OCTUBER

MAXIMUM $21 \quad 20 \quad 1918 \quad 1920 \quad 1918 \quad 18 \quad 1917 \quad 16 \quad 17 \quad 17 \quad 17 \quad 18 \quad 18 \quad 17 \quad 17 \quad 18 \quad 16 \quad 17 \quad 18 \quad 18 \quad 18 \quad 18 \quad 18 \quad 16 \quad 16 \quad 16 \quad 15$

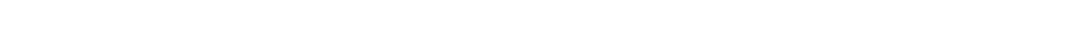
NTVEMRER

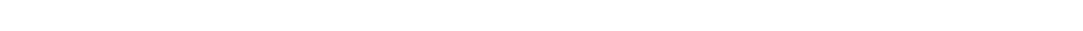

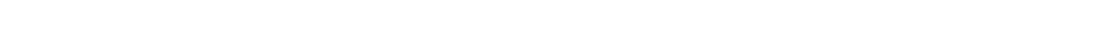

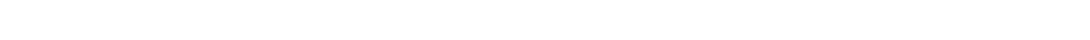
MANIMUM

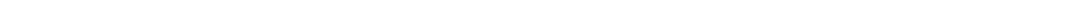

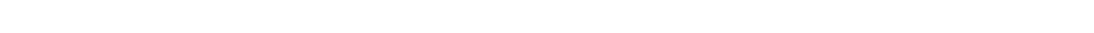

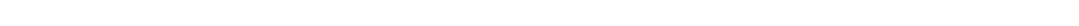
MINIMUM MARCH $\begin{array}{lllllllllllllrlrrrrrrrrrrrrrrrrrrrr}\text { MAXIMUM } & 9 & 9 & 9 & 9 & 9 & 9 & 9 & 9 & 9 & 8 & 9 & 9 & 10 & 9 & 10 & 10 & 10 & 11 & 10 & 10 & 12 & 12 & 13 & 13 & 13 & 14 & 15 & 15 & 14 & 16 & 15 & 11 \\ \text { MINIMUM } & 9 & 9 & 9 & 9 & 9 & 8 & 8 & 7 & 8 & 7 & 7 & 8 & 8 & 8 & 8 & 8 & 9 & 10 & 8 & 9 & 9 & 10 & 10 & 10 & 10 & 11 & 12 & 12 & 13 & 13 & 14 & 9\end{array}$ APRIL MAXIMUM $14 \quad 1311 \quad 11 \quad 1314 \quad 192020201917 \quad 17 \quad 12 \quad 161812 \quad 1517 \quad 181614 \quad 11 \quad 16151517 \quad 151511 \quad--\quad 15$

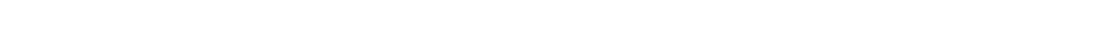
MAY

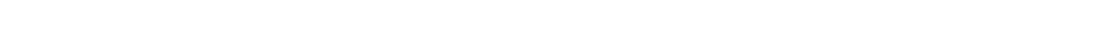
JUNE

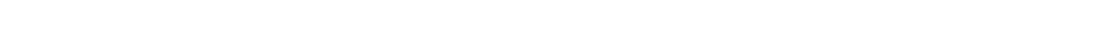
MINIMUM JULY MAXIMUM AUGUST

MAXIMUM _. MINIMUM

$\begin{array}{lllllllllllllllllllllllllllllllllllllll}\text { SEPTEMBER } & 19 & 18 & 19 & 19 & 19 & 19 & 19 & 18 & 18 & 18 & 18 & 18 & 18 & 18 & 18 & 18 & 17 & 17 & 17 & 18 & 18 & 17 & 17 & 17 & 17 & 16 & 16 & 16 & 16 & 16 & \cdots\end{array}$ $\begin{array}{lllllllllllllllllllllllllllllllll}19 & 18 & 19 & 19 & 19 & 19 & 19 & 18 & 18 & 18 & 18 & 18 & 18 & 18 & 18 & 18 & 17 & 17 & 17 & 18 & 18 & 17 & 17 & 17 & 17 & 16 & 16 & 16 & 16 & 16 & \ldots\end{array}$ .

西


11470500 EEL RIVER BELOW SCOTT DAM, NEAR POTTER VALLEY, CALIF.

LOCATION, --Lat $39^{\circ} 24^{\prime} 29^{\prime \prime}$, long $122^{\circ} 58^{\prime} 13^{\prime \prime}$, in SE sec.15, T.18 N., R.10 W., Lake County, Mendocino National Forest, temperature recorder at gaging station on left bank, 0.4 mile upstream from Soda Creek, $0.7 \mathrm{mile}$ downstream
from Scott Dam, and 9.7 miles northeast of town of potter Valley.

DRAINAGE AREA, --290 sq mi.

PERIOD OF RECORD, --Water temperatures: October 1963 to September 1969.

EXTREUES, --1968-69: Nater temperatures: Maximum, $21.0^{\circ} \mathrm{C}$ Sept. 1, 10-30; minimum, $4.0^{\circ} \mathrm{C}$ on several days during January and Febru-
ary.

Period of record:

Water temperatures: Maximum, $23.0^{\circ} \mathrm{C}$ on several days in September 1967; minimum (1966-69), 4.0 $0^{\circ} \mathrm{C}$ on several days during January and February 1969. REMARXs, - No record May 26 to July 1 . Samples for turbidity data were collected by Pacific Gas and Electric Com-
pany and U,S. Forest Service.

TBMPERATURE $\left({ }^{\circ} \mathrm{C}\right)$ OF WATER, MATER YEAR OCTOBER 1968 TO SEPTEMBER 1969

DAY

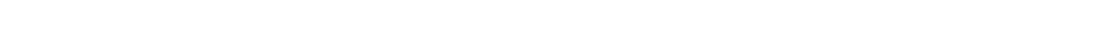

OC TOBER

MAXIMUM $20191919191919191918181818181818171717171716161616 \quad 161616161615$

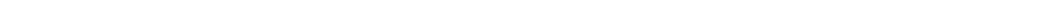
NOVEMBER $\begin{array}{lllllllllllllllllllllllllllllllllllllllll}\text { MAXIMUM } & 14 & 14 & 14 & 14 & 14 & 14 & 14 & 14 & 14 & 14 & 14 & 14 & 14 & 13 & 13 & 13 & 12 & 12 & 12 & 12 & 12 & 12 & 12 & 12 & 11 & 11 & 12 & 12 & 11 & 11 & -2 \\ \text { MINIMUM } & 14 & 14 & 14 & 14 & 14 & 14 & 14 & 14 & 14 & 14 & 14 & 14 & 13 & 13 & 13 & 12 & 12 & 12 & 12 & 12 & 12 & 12 & 12 & 11 & 11 & 11 & 11 & 11 & 11 & 11 & -1\end{array}$ DECEMBER

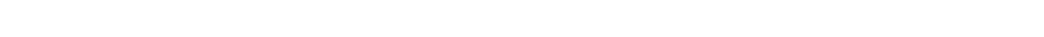

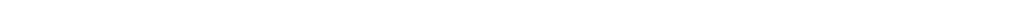

JANUARY

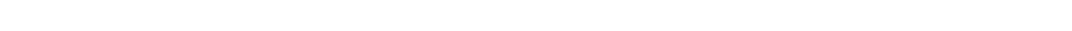

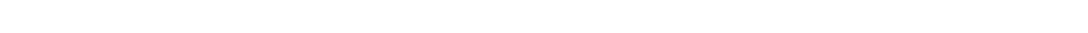
FEBRUARY

$\begin{array}{lllllllllllllllllllllllllllllllll}\text { MAXIMUM } & 4 & 4 & 4 & 4 & 4 & 4 & 4 & 4 & 4 & 4 & 4 & 5 & 5 & 5 & 5 & 5 & 5 & 6 & 6 & 6 & 6 & 6 & 6 & 6 & 6 & 6 & 6 & 6 & -- & -- & -- & -\end{array}$

MARCH

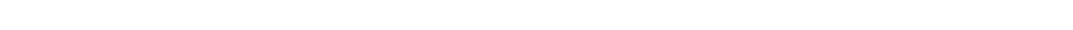

$\begin{array}{lllllllllllllllllllllllllllllllllllll}\text { MINIMUM } & 5 & 5 & 5 & 5 & 5 & 5 & 5 & 5 & 5 & 5 & 5 & 5 & 5 & 6 & 6 & 6 & 6 & 6 & 6 & 6 & 6 & 6 & 7 & 7 & 7 & 7 & 7 & 7 & 7 & 7 & 7 & \end{array}$

APRIL

$\begin{array}{rllllllllllllllllllllllllllllllllll}\text { MAXIMUM } & 8 & 8 & 8 & 8 & 7 & 7 & 8 & 8 & 8 & 8 & 8 & 8 & 8 & 8 & 8 & 8 & 8 & 8 & 8 & 8 & 8 & 8 & 8 & 8 & 8 & 8 & 8 & 9 & 9 & 9 & - \\ \text { MINIMUM } & 7 & 8 & 7 & 7 & 7 & 7 & 7 & 7 & 7 & 8 & 8 & 7 & 8 & 8 & 8 & 8 & 8 & 8 & 8 & 8 & 8 & 8 & 8 & 8 & 8 & 8 & 8 & 8 & 8 & 8 & \cdots\end{array}$

mar

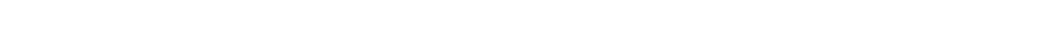
MINIMUM JUN

MAXIMUM -MINIMUM

JULY

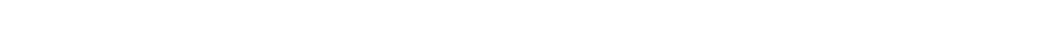
AUGUS!

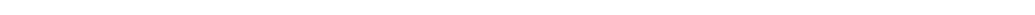

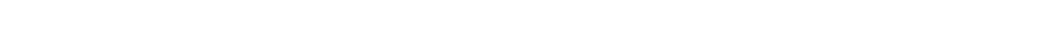
SEPTEMBER

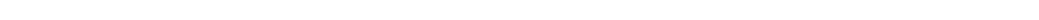

$\begin{array}{llllllllllllllllllllllllllllllll}\text { MAXINUM } & 21 & 20 & 20 & 20 & 20 & 20 & 20 & 20 & 20 & 21 & 21 & 21 & 21 & 21 & 21 & 21 & 21 & 21 & 21 & 21 & 21 & 21 & 21 & 21 & 21 & 21 & 21 & 21 & 21 & 21 & - \\ \text { MINIMUM } & 20 & 20 & 20 & 19 & 19 & 20 & 20 & 20 & 20 & 20 & 20 & 21 & 21 & 21 & 21 & 21 & 21 & 21 & 21 & 21 & 21 & 21 & 21 & 21 & 21 & 21 & 21 & 20 & 20 & 20 & -\end{array}$

DETERMINATIONS OF TURBIDITY, HATER YEAR OCTOBER 1968 TO SEPTEMBER 1969

\begin{tabular}{|c|c|c|c|c|c|c|}
\hline \multirow{2}{*}{\multicolumn{2}{|c|}{ DATE }} & \multirow[b]{2}{*}{$\underset{(24-H R)}{\text { TIME }}$} & \multirow{2}{*}{$\begin{array}{l}\text { WATER } \\
\text { TEM- } \\
\text { PERA- } \\
\text { TURE } \\
\left({ }^{\circ} \mathrm{C}\right)\end{array}$} & \multirow{2}{*}{$\begin{array}{l}\text { DIS- } \\
\text { CHARGE } \\
\text { (CFS) }\end{array}$} & \multicolumn{2}{|c|}{$\begin{array}{c}\text { TURBIDITY } \\
\text { (MG/L SILICA) }\end{array}$} \\
\hline & & & & & TOTAL & RESIDUAL \\
\hline $\begin{array}{l}\text { DEC. } \\
\text { OEC: } \\
\text { DEC. } \\
\text { JAN. } \\
\text { JAN. }\end{array}$ & $\begin{array}{l}18,1968 \ldots \ldots \ldots \\
20, \ldots \ldots \ldots \ldots \\
27, \ldots \ldots \ldots \ldots \ldots \\
3,1969 \ldots \ldots \ldots \ldots \\
10 \ldots \ldots \ldots \ldots \ldots\end{array}$ & $\begin{array}{l}1420 \\
1130 \\
1130 \\
1030 \\
0900\end{array}$ & $\begin{array}{r}8 \\
8 \\
-- \\
4\end{array}$ & $\begin{array}{r}157 \\
200 \\
1220 \\
644 \\
735\end{array}$ & $\begin{array}{l}803 \\
680 \\
437 \\
283 \\
297\end{array}$ & $\begin{array}{l}78 \\
74 \\
66 \\
51 \\
56\end{array}$ \\
\hline $\begin{array}{l}\text { JAN. } \\
\text { JAN. } \\
\text { JAN. } \\
\text { FEB. } \\
\text { FEQ. }\end{array}$ & $\begin{array}{l}17 \ldots \ldots \ldots \ldots \ldots \\
24 \ldots \ldots \ldots \ldots \ldots \\
31 \ldots \ldots \ldots \ldots \ldots \\
7 \ldots \ldots \ldots \ldots \ldots \ldots \\
14 \ldots \ldots \ldots \ldots \ldots \ldots\end{array}$ & $\begin{array}{l}1000 \\
1000 \\
0930 \\
1000 \\
1000\end{array}$ & $\begin{array}{r}4 \\
-4 \\
4 \\
5\end{array}$ & $\begin{array}{l}1760 \\
3180 \\
1690 \\
1600 \\
2910\end{array}$ & $\begin{array}{l}145 \\
189 \\
260 \\
135 \\
127\end{array}$ & $\begin{array}{l}38 \\
51 \\
41 \\
37 \\
42\end{array}$ \\
\hline $\begin{array}{l}\text { FEB. } \\
\text { FEB. } \\
\text { MAR: } \\
\text { MAR: } \\
\text { MAR. }\end{array}$ & $\begin{array}{l}21 \ldots \ldots \ldots \ldots \ldots \\
28 \ldots \ldots \ldots \ldots \ldots \\
7 \ldots \ldots \ldots \ldots \ldots \ldots \\
14 \ldots \ldots \ldots \ldots \ldots \ldots\end{array}$ & $\begin{array}{l}0930 \\
0900 \\
0900 \\
0900 \\
1000\end{array}$ & $\begin{array}{r}4 \\
4 \\
6 \\
6 \\
--\end{array}$ & $\begin{array}{r}1390 \\
1750 \\
1180 \\
774 \\
1440\end{array}$ & $\begin{array}{r}112 \\
94 \\
76 \\
72 \\
53\end{array}$ & $\begin{array}{l}25 \\
23 \\
21 \\
17 \\
16\end{array}$ \\
\hline $\begin{array}{l}\text { MAR. } \\
\text { APR. } \\
\text { MAY } \\
\text { JUNE }\end{array}$ & $\begin{array}{r}28 \ldots \ldots \ldots \ldots \ldots \\
q_{11} \ldots \ldots \ldots \ldots \ldots \ldots \ldots\end{array}$ & $\begin{array}{l}0900 \\
1000 \\
1000 \\
1015\end{array}$ & $\begin{array}{l}-- \\
-\overline{20}\end{array}$ & $\begin{array}{r}1790 \\
838 \\
987 \\
326\end{array}$ & $\begin{array}{r}53 \\
59 \\
21 \\
8\end{array}$ & $\begin{array}{r}11 \\
8 \\
1 \\
1\end{array}$ \\
\hline
\end{tabular}

A TURBIDITY MEASUREd AFTER a 7-DAY SETTLING PERIOD. 
LOCATION. --Lat $39^{\circ} 21^{\prime} 42^{\prime \prime}$, long $123^{\circ} 07^{\prime} 38^{\prime \prime}$, In SW 1 NW $\frac{1}{4}$ sec.6, T.17 N., R.11 W., Mendocino County, tempergture recorder at gaging station $100 \mathrm{ft}$ downstream from powerhouse of Pacific Gs and Electric Company, $1.8 \mathrm{miles}$ southwest of Van Arsdale Dam, and 2.9 miles northwest of town of Potter valley.

PERIOD OF RECORD. --Chemical analyse s: October 1953 to September 1965.

Water temperatures: March 1964 to September 1969.

Sediment records: MBrch 1964 to MBy 1968.

EXTREMES. --1968-69:

Water temperatures: Maximum, $24.0^{\circ} \mathrm{C}$ June 22 ; minimum, $5.0^{\circ} \mathrm{C}$ on several days during December to February.

Period of record (1964-65, 1966-69):

Water temperatures: Maximum (1967-69), $24.0^{\circ} \mathrm{C}$ June 22,1969 ; minimum, $4.0^{\circ} \mathrm{C}$ on many days in 1967 and 1968.

REMaRKS. --Recorder stopped Nov, 5-7, Nov, 12 to Dec, 27, Mar. 24 to May 6; probe buried May 12 to June 1. Samples for turbidity data were collected by Pacific Gas and Electric Company, and U.S, Forest Service.

TEMPERATURE $\left({ }^{\circ} \mathrm{C}\right)$ OF WATER, WATER YEAR OCTOBER 1968 TO SEPTEMBER 1969

DAY

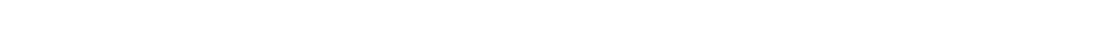

OCTOBER

MAXIMUM $1719201920191818 \quad 1818181717 \quad 1617 \quad 171717 \quad 17 \quad 16161617 \quad 171716 \quad 1616161515 \quad 17$

MINIMUM $16 \quad 17 \quad 17 \quad 17 \quad 18 \quad 17 \quad 16 \quad 16 \quad 15 \quad 16 \quad 17 \quad 17 \quad 16 \quad 14 \quad 14 \quad 14 \quad 14 \quad 14 \quad 14 \quad 14 \quad 14 \quad 14 \quad 14 \quad 14 \quad 14 \quad 14 \quad 14 \quad 13 \quad 14 \quad 14 \quad 13 \quad 15$

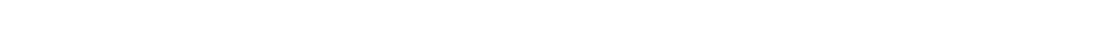

MINIMUM

DEEMBER

MAXIMUM -- - - - - - - - - - - - -

MINIMUM

MAXIMUM

MINIMUM

FAXARY

$\begin{array}{llllllllllllllllllllllllllllllllllllll} & 6 & 6 & 6 & 6 & 6 & 6 & 6 & 7 & 7 & 7 & 7 & 7 & 7 & 7 & 7 & 7 & 7 & 8 & 8 & 7 & 7 & 7 & 7 & 7 & 7 & 7 & 7 & - & -- & -- & 7\end{array}$

MARCH

MAXIMUM

MINIMUM

APRIL

MAXIMUM

MAY

MAXIMUM -.

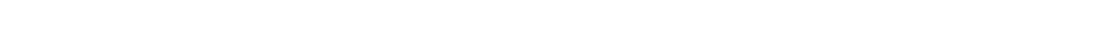

JUNE

$\begin{array}{lllllllllllllllllllllllllllllllllll}\text { MAXIMUM } & - & 22 & 23 & 23 & 22 & 21 & 21 & 20 & 20 & 20 & 20 & 22 & 23 & 23 & 23 & 23 & 22 & 21 & 23 & 23 & 23 & 24 & 23 & 23 & 22 & 22 & 21 & 21 & 18 & 18 & - & 22 \\ \text { MINIMUM } & - & 19 & 19 & 19 & 19 & 19 & 19 & 19 & 19 & 18 & 18 & 18 & 19 & 19 & 19 & 20 & 20 & 20 & 20 & 21 & 20 & 20 & 21 & 20 & 20 & 19 & 19 & 16 & 15 & 15 & - & 19 & 19\end{array}$

JULY MIN

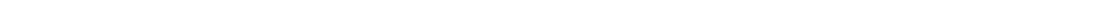

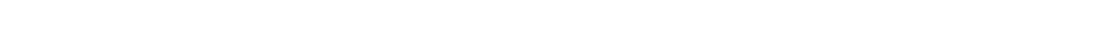

AUGUST

$\begin{array}{llllllllllllllllllllllllllllllllll}\text { MAXIMUM } & 18 & 18 & 18 & 18 & 17 & 17 & 17 & 17 & 18 & 18 & 18 & 18 & 18 & 18 & 18 & 18 & 18 & 18 & 18 & 19 & 19 & 18 & 18 & 18 & 18 & 18 & 18 & 18 & 18 & 18 & 19 & 18\end{array}$

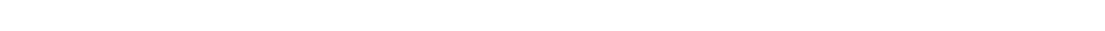

SEPTEMBER

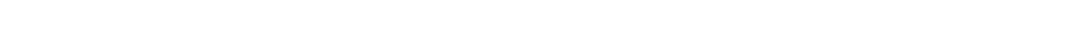

$\begin{array}{lllllllllllllllllllllllllllllllll}\text { MAXIMUM } & 19 & 19 & 19 & 19 & 19 & 19 & 19 & 20 & 21 & 21 & 21 & 21 & 21 & 21 & 21 & 21 & 21 & 21 & 21 & 21 & 21 & 21 & 21 & 21 & 21 & 21 & 21 & 21 & 21 & 21 & -- & 21 \\ \text { MINIMUM } & 16 & 16 & 16 & 17 & 17 & 16 & 17 & 17 & 16 & 17 & 18 & 18 & 19 & 18 & 18 & 18 & 18 & 20 & 19 & 19 & 18 & 18 & 18 & 18 & 19 & 19 & 19 & 18 & 19 & 18 & -2 & 18\end{array}$

DETERMINATIONS DF TURBIDITY, WATER YEAR OCTOBER 1968 TO SEPTEMBER 1969

\begin{tabular}{|c|c|c|c|c|c|}
\hline \multirow[b]{2}{*}{ DATE } & \multirow[b]{2}{*}{$\begin{array}{c}T I M E \\
(24-H R)\end{array}$} & \multirow{2}{*}{$\begin{array}{l}\text { WATER } \\
\text { TEM- } \\
\text { PERA- } \\
\text { TURE } \\
\left({ }^{\circ} \mathrm{C}\right)\end{array}$} & \multirow{2}{*}{$\begin{array}{l}\text { DIS- } \\
\text { CHARGE } \\
\text { (CFS) }\end{array}$} & \multicolumn{2}{|c|}{$\begin{array}{c}\text { TURBIDITY } \\
\text { (MG/L SILICA) }\end{array}$} \\
\hline & & & & TOTAL & RESIDUAL A \\
\hline $\begin{array}{l}\text { DEC. } 20,1968 \ldots \ldots \ldots \\
\text { DEC. } 27, \ldots \ldots \ldots \ldots \ldots \ldots \\
\text { JAN. } 3,1969 \ldots \ldots \ldots \ldots \\
\text { JAN. } 10, \ldots \ldots \ldots \ldots \ldots \ldots \\
\text { JAN. } 17 \ldots \ldots \ldots \ldots \ldots\end{array}$ & $\begin{array}{l}0800 \\
1400 \\
0830 \\
0900 \\
1100\end{array}$ & $\begin{array}{r}10 \\
6 \\
6 \\
6 \\
6\end{array}$ & $\begin{array}{l}296 \\
293 \\
296 \\
290 \\
289\end{array}$ & $\begin{array}{l}460 \\
325 \\
188 \\
235 \\
415\end{array}$ & $\begin{array}{l}46 \\
46 \\
42 \\
36 \\
74\end{array}$ \\
\hline 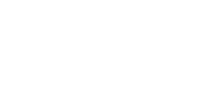 & $\begin{array}{l}1500 \\
0900 \\
0900 \\
0830 \\
0900\end{array}$ & $\begin{array}{l}8 \\
6 \\
6 \\
7 \\
7\end{array}$ & $\begin{array}{l}290 \\
302 \\
291 \\
286 \\
296\end{array}$ & $\begin{array}{r}150 \\
127 \\
120 \\
92 \\
91\end{array}$ & $\begin{array}{l}58 \\
35 \\
32 \\
24 \\
23\end{array}$ \\
\hline 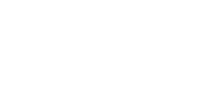 & $\begin{array}{l}0900 \\
0900 \\
1300 \\
0900 \\
0900\end{array}$ & $\begin{array}{r}8 \\
6 \\
8 \\
8 \\
10\end{array}$ & $\begin{array}{l}293 \\
294 \\
289 \\
290 \\
291\end{array}$ & $\begin{array}{l}58 \\
62 \\
46 \\
38 \\
38\end{array}$ & $\begin{array}{r}14 \\
14 \\
8 \\
8 \\
7\end{array}$ \\
\hline 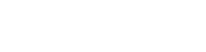 & $\begin{array}{l}0900 \\
0900 \\
0900\end{array}$ & $=$ & $\begin{array}{l}300 \\
280 \\
213\end{array}$ & $\begin{array}{l}5 \\
2 \\
6\end{array}$ & $\begin{array}{l}1 \\
1 \\
1\end{array}$ \\
\hline
\end{tabular}

a TURBIDITY MEASUREd AFTER a 7-DAY SETTLING PERIOD. 
11472150 EEL RIVER NEAR DOS RIOS, CALIF.

LOCATION,--Lat $39^{\circ} 37^{\prime} 30^{\prime \prime}$, long $123^{\circ} 20^{\prime} 25^{\prime \prime}$, in SW 1,100 ft upstream from Cutlet Creek and 6.3 miles south of Dos Rios.

DRAINAGE AREA, $--528 \mathrm{sq} \mathrm{m} 1$.

PERIOD OF RECORD.--Chemical analyses: October 1958 to September 1989.

Water temperatures: October 1966 to September 1989.

Sediment records: October 1966 to September 1969

EXTREMES. $-1968-69$ :

Water temperatures: Minimum, $2.0^{\circ} \mathrm{C}$ Dec, 21

Sediment concentrations: Maximum dally, 3,000 mg/1 Dec. 10 ; minimum daily, $1 \mathrm{mg} / 1$ on many days during Qctober, November, and June to September.

Sediment discharge: Maximum daily, 172,000 tons Jan. 13; minimum dally, 0.01 ton on many days during. October, August, and September.

period of record:

Water temperatures (1966-67, 1968-69): Minimun, $1.5^{\circ} \mathrm{C}$ Dec. $29,1968$.

Sediment concentrations: Maximum daily, 3,590 mg/i Jan. 21 , 1967 ; mintmum daily, 1 mg/1 on many days in

$1966-69$

Sediment discharge: Maximum daily, 204,000 tons Jan. 21, 1967; minimum daily, 0.01 ton on many days in 1966-69.

REMARKS. - Chemical-quality records furnished by California Department of Water Resources and reviewed by $U$. S. Geo-

logical Survey. During period Octobe 1958 to September 1966, chemical quality station located at
lat $39^{\circ} 37^{\prime} 36^{\prime \prime}$, long $123^{\circ} 20^{\prime} 36^{\prime \prime}$. Flow partly regulated by Lake Pillsbury and by diversion through Potter Valley powerhouse.

CHEMICAL ANALYSES, hateR YEAR OCTOBER 1968 TO SEPTEMBER 1969

\begin{tabular}{|c|c|c|c|}
\hline DATE & TIME & $\begin{array}{l}\text { DIS- } \\
\text { CHARGE } \\
\text { (CFS) }\end{array}$ & $\begin{array}{l}\text { TEMPER- } \\
\text { ATURE } \\
\text { (DEG C) }\end{array}$ \\
\hline $\begin{array}{c}\text { OCT. } \\
03 . . .\end{array}$ & 1050 & 4.4 & 18 \\
\hline Nov. & & & \\
\hline $\begin{array}{l}14 \ldots . . \\
D E C .\end{array}$ & 0915 & 37 & B \\
\hline $\begin{array}{l}04 . . \\
\text { JAN. }\end{array}$ & 1535 & 63 & 6 \\
\hline & 1205 & 16100 & 6 \\
\hline $\begin{array}{l}05 \ldots . . \\
\text { MAR. }\end{array}$ & 0725 & 4170 & 5 \\
\hline $\begin{array}{l}05 \ldots . . \\
\text { APR. }\end{array}$ & 1315 & 2220 & B \\
\hline 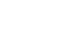 & 0925 & 1130 & 10 \\
\hline$\underset{\text { JUNE }}{14 \ldots . .}$ & 0805 & 410 & 14 \\
\hline $\operatorname{JuLy}_{11}$ & 1220 & 39 & 22 \\
\hline $\begin{array}{l}16 \ldots . . \\
\text { AUG. }\end{array}$ & 1045 & 13 & 22 \\
\hline $\begin{array}{l}\text { OS... } \\
\text { SEPT. }\end{array}$ & 0910 & 5.1 & 18 \\
\hline $10 \ldots$ & 1055 & $4 \cdot 3$ & 23 \\
\hline
\end{tabular}

\begin{tabular}{|c|c|c|c|c|c|}
\hline $\begin{array}{l}\text { DIS- } \\
\text { SOLVED } \\
\text { OXYGEN }\end{array}$ & $\begin{array}{l}\text { CAL- } \\
\text { CIUM } \\
\text { (CA) }\end{array}$ & $\begin{array}{l}\text { MAG- } \\
\text { NE- } \\
\text { SIUM } \\
(M G)\end{array}$ & $\begin{array}{l}\text { SOOIUM } \\
\text { (NA) }\end{array}$ & $\begin{array}{l}\text { PO- } \\
\text { IAS- } \\
\text { SIUM } \\
\text { (K) }\end{array}$ & $\begin{array}{l}\text { BICAR- } \\
\text { BONATE } \\
\text { (HCO3) }\end{array}$ \\
\hline$(M G / L)$ & (MG/L) & (MG/L) & $(M G / L)$ & $(M G / L)$ & $(M G / L)$ \\
\hline
\end{tabular}

CAR-
BONATE SULFATE RIOE$\begin{array}{lll}(\mathrm{CO} 3) & (\mathrm{SO}) \mathrm{T}) & \text { RIOE } \\ (\mathrm{CL})\end{array}$ $\begin{array}{lll}\text { (MG/L) } & (\mathrm{SOA}) & \text { (CL) } \\ & & \end{array}$

$\begin{array}{rrrrr}8.7 & -- & -- & 11 & -- \\ 11.2 & -- & -- & 12 & - \\ 12.8 & -- & -- & 9.4 & -- \\ 12.7 & -- & -- & 2.8 & -- \\ 12.5 & -- & -- & 3.6 & - \\ 12.4 & -- & -- & 3.2 & - \\ 11.4 & -- & -- & 3.6 & - \\ 10.5 & 17 & 4.7 & 4.0 & .8 \\ 10.6 & -- & -- & 6.4 & - \\ 9.1 & -- & -- & 8.9 & -- \\ 9.2 & -- & -- & 9.6 & -- \\ 8.8 & 30 & 8.3 & 12 & -\end{array}$

113
136
111
48
55
64
66
76
105
137
117
116

$\begin{array}{ll}-- & 7.3 \\ -- & 8.2 \\ -- & 5.8 \\ -- & 1.6 \\ -- & 2.0 \\ -- & 1.7 \\ -- & 2.4 \\ 3.1 & 1.6 \\ -- & 4.1 \\ -- & 4.5 \\ -- & 5.4 \\ -- & 5.6\end{array}$

\begin{tabular}{|c|c|c|c|c|c|c|c|c|c|c|c|c|}
\hline ATE & $\begin{array}{l}\text { N1TRATE } \\
\text { (ND3) } \\
\text { (MG/L) }\end{array}$ & $\begin{array}{l}\text { PHOS- } \\
\text { PHATE } \\
\text { (PO4) } \\
\text { (MG/L) }\end{array}$ & $\begin{array}{l}\text { BORON } \\
\text { (B) } \\
\text { (UG/L) }\end{array}$ & $\begin{array}{l}\text { OIS- } \\
\text { SOLVEO } \\
\text { SOLIDS } \\
\text { IRESI- } \\
\text { DUE AT } \\
\text { IBO C) } \\
\text { (HG/L) }\end{array}$ & $\begin{array}{l}\text { OIS- } \\
\text { SOLVEO } \\
\text { SOLIDS } \\
\text { ITONS } \\
\text { PER } \\
\text { AC-FTI }\end{array}$ & $\begin{array}{l}\text { HARD- } \\
\text { NESS } \\
\text { (CA,MG) } \\
\text { (MG/L) }\end{array}$ & $\begin{array}{l}\text { NON- } \\
\text { CAR- } \\
\text { BONATE } \\
\text { HARO- } \\
\text { NESS } \\
\text { (MG/L) }\end{array}$ & $\begin{array}{l}\text { PERCENT } \\
\text { SOOIUM }\end{array}$ & $\begin{array}{c}\text { SODIUM } \\
\text { AD- } \\
\text { SORP- } \\
\text { TION } \\
\text { RATIO }\end{array}$ & $\begin{array}{l}\text { ALKA- } \\
\text { LINITY } \\
\text { AS } \\
\text { CACOB } \\
\text { (MG/L) }\end{array}$ & $\begin{array}{c}P H \\
\text { (UNITS) }\end{array}$ & $\begin{array}{l}\text { SPECI- } \\
\text { FIC } \\
\text { COND- } \\
\text { UCTANCE } \\
\text { (MICRO- } \\
\text { MHOS) }\end{array}$ \\
\hline
\end{tabular}

\begin{tabular}{|c|c|c|c|}
\hline OCT. & .3 & .01 & 480 \\
\hline NOV. & .0 & .00 & 670 \\
\hline & .1 & .40 & 420 \\
\hline $\begin{array}{l}\text { JAN, } \\
22 \ldots . .\end{array}$ & & & . \\
\hline FEB. & .6 & .26 & 0 \\
\hline $\begin{array}{l}05 . . . \\
\text { MAR. }\end{array}$ & .2 & .18 & 30 \\
\hline $\begin{array}{l}05 \ldots \\
A P R .\end{array}$ & .1 & .00 & 50 \\
\hline$\underset{\text { MAY }}{09 . \cdots}$ & .2 & .09 & 0 \\
\hline $\begin{array}{l}14 \ldots . . \\
\text { JUNE }\end{array}$ & .1 & .03 & 200 \\
\hline JULY & .0 & .02 & 260 \\
\hline $\begin{array}{l}\text { JULY } \\
\text { 16... }\end{array}$ & .1 & .00 & 300 \\
\hline AUG. & & & \\
\hline $\begin{array}{l}06 . . \\
\text { SEPT. }\end{array}$ & .2 & -- & 350 \\
\hline $10 \ldots$ & .0 & -- & 390 \\
\hline
\end{tabular}

$\begin{array}{rrr}-- & -- & 118 \\ -- & -- & 130 \\ -- & - & 110 \\ -- & -- & 48 \\ -- & -- & 58 \\ -- & -- & 55 \\ -- & -- & 56 \\ 82 & .11 & 62 \\ -- & -- & 100 \\ - & -- & 107 \\ - & - & 109 \\ 124 & .17 & 109\end{array}$

$\begin{array}{rrr}25 & 17 & .4 \\ 18 & 17 & .5 \\ 19 & 16 & . \\ 9 & 11 & . \\ 13 & 12 & . \\ 2 & 11 & .2 \\ 2 & 12 & . \\ 0 & 12 & . \\ 9 & 12 & . \\ 0 & 15 & .4 \\ 13 & 16 & .4 \\ 14 & 19 & .\end{array}$

IMGIL

(T), MHOS


11472150 EEL RIVER NEAR DOS RIOS, CALIF.-.CONTI nued

TEMPERATURE $\left({ }^{\circ} \mathrm{C}\right)$ OF WATER, NATER YEAR OCTOBER 1968 TO SEPTEMBER 1969 (ONCE-DAILY MEASUREMENT)

DAY

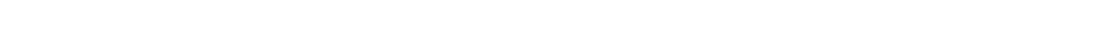

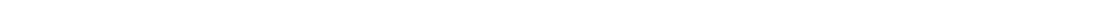

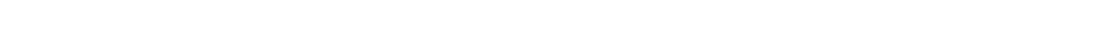

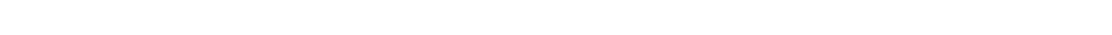

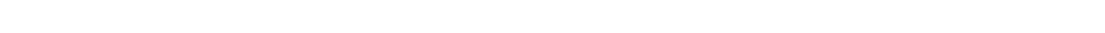

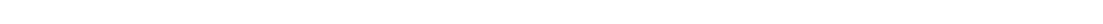

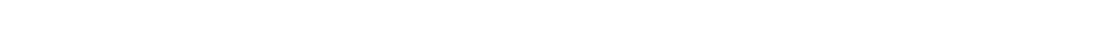

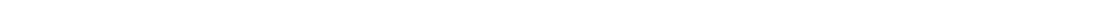

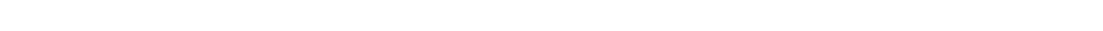

PARTICLE-SIZE DETERMINATIONS OF SUSPENDED SEDIMENT, WATER YEAR OCTOBER 1968 TO SEPTEMBER 1969 IMETHODS OF ANALYSIS: B, BJTIOM HITHURAWAL TUBE: C, CHEMICALLY DISPERSED; N, IN NATIVE HATER; P, PIPET; S, SIEVE: $\checkmark$, VISUAL ACCUMULATION TUBE; H, IN DISTILLEO WATER)

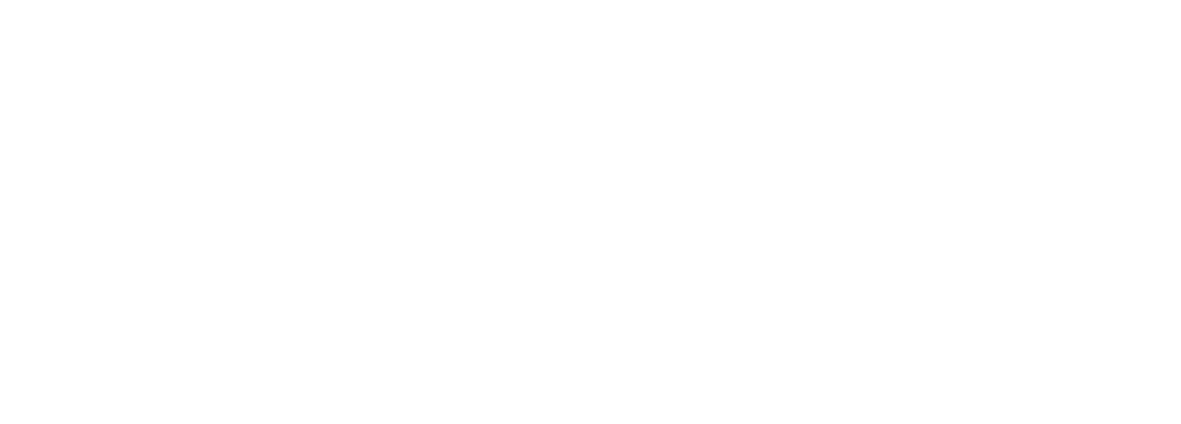


11472150 EEL RIVER NEAR DOS RIOS, CALIF.--Continued

SUSPENDED-SEDIMENT DISCHARGE, WATER YEAR OCTOBER 1968 TO SEPTEMBER 1969

OC TOBER

NOVEMBER

DECEMBER $\begin{array}{clcc}\text { MEAN } & \text { CONCEN- } & \text { SEDIMENT } & \text { MEAN } \\ \text { DISCHARGE } & \text { TRAIION } & \text { DISCHARGE } & \text { DISCHARGE } \\ \text { (CFS) } & \text { (MG/L) } & \text { (TONS/DAY) } & \text { (CFS) }\end{array}$

MEAN

CONCEN- SEDIMEN TRATION DISCHARGE MEAN MG/L) (TONS/DAY) DISCHARGE

CONCEN- SEDIMEN (CFS) (MG/L) (TONS/DAY)

20
33
61
42
26
20
16
13
11
9.6

$$
\begin{array}{r}
1 \\
2 \\
3 \\
15 \\
1
\end{array}
$$

$\begin{array}{cr}.05 & 111 \\ .18 & 150 \\ .49 & 96 \\ 1.7 & 68 \\ .07 & 54\end{array}$ (MG/L) (TONS/DAY)

$$
6
$$$$
\begin{aligned}
& 3.7 \\
& 4.4 \\
& 4.4 \\
& 4.4 \\
& 5.5
\end{aligned}
$$$$
\begin{aligned}
& .01 \\
& .01 \\
& .01 \\
& .01 \\
& .01
\end{aligned}
$$$$
\begin{aligned}
& .01 \\
& .01 \\
& .01 \\
& .01
\end{aligned}
$$$$
\begin{aligned}
& 4.9 \\
& 3.0 \\
& 3.7 \\
& 3.7
\end{aligned}
$$$$
.01
$$$$
9.6
$$$$
\begin{aligned}
& 3 \\
& 5 \\
& 1 \\
& 1
\end{aligned}
$$

11
12
13
14
15

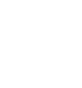

1616

17
18
19
20

16
11
8.6
8.3
7.5

.02
.38
.44
.10
.06

11
39
35
47
114

.04

.04
.03
.02

114
86
102
153
88

.02

7.0
6.5
6.5
5.8

5.5
5.8

5.8
5.8
5.8

27

34

$$
341.6
$$

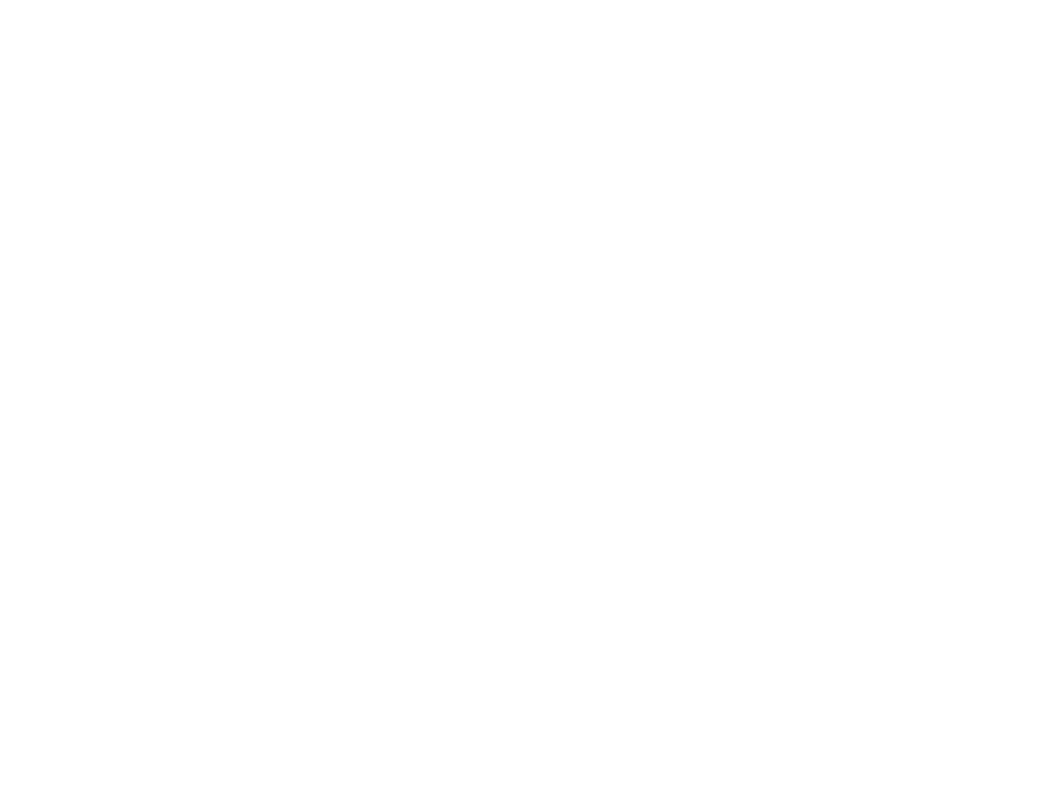


11472150 EEL RIVER NEAR DOS RIOS, CALIF.--Cont1nued

SUSPENDED-SEDIMENT DISCHARGE, WATER YEAR OCTOBER 1968 TO SEPTEMBER 1969

\begin{tabular}{|c|c|c|c|c|c|c|c|c|c|}
\hline \multirow[b]{2}{*}{ DAY } & \multicolumn{3}{|c|}{ APRIL } & \multicolumn{3}{|c|}{ MAY } & \multicolumn{3}{|c|}{ JUNE } \\
\hline & $\begin{array}{l}\text { MEAN } \\
\text { OISCHARGE } \\
\text { (CFS) }\end{array}$ & $\begin{array}{l}\text { MEAN } \\
\text { CONCEN- } \\
\text { RRAION } \\
\text { IMG/L) }\end{array}$ & $\begin{array}{l}\text { SEDIMENT } \\
\text { DISCHARGE } \\
\text { (TONS/DAY) }\end{array}$ & $\begin{array}{l}\text { MEAN } \\
\text { DISCHARGE } \\
\text { (CFS) }\end{array}$ & $\begin{array}{l}\text { MEAN } \\
\text { CONCEN- } \\
\text { TRATION } \\
\text { (MG/L) }\end{array}$ & $\begin{array}{l}\text { SEDIMENT } \\
\text { DISCHARGE } \\
\text { (TONS/DAY) }\end{array}$ & $\begin{array}{l}\text { MEAN } \\
\text { OISCAARGE } \\
\text { (CFS) }\end{array}$ & $\begin{array}{l}\text { MEAN } \\
\text { CONCEN- } \\
\text { TRATION } \\
\text { (MG/L) }\end{array}$ & $\begin{array}{l}\text { SEDIMENT } \\
\text { DI SCHARGE } \\
\text { (TONS/DAY) }\end{array}$ \\
\hline $\begin{array}{l}1 \\
2 \\
3 \\
4 \\
5\end{array}$ & $\begin{array}{l}1780 \\
1610 \\
1500 \\
1270 \\
1700\end{array}$ & $\begin{array}{l}39 \\
32 \\
28 \\
26 \\
58\end{array}$ & $\begin{array}{r}187 \\
139 \\
113 \\
89 \\
281\end{array}$ & $\begin{array}{l}300 \\
330 \\
360 \\
350 \\
290\end{array}$ & $\begin{array}{l}8 \\
7 \\
6 \\
6 \\
6\end{array}$ & $\begin{array}{l}6.5 \\
6.2 \\
5.8 \\
5.7 \\
4.7\end{array}$ & $\begin{array}{l}52 \\
52 \\
49 \\
37 \\
27\end{array}$ & $\begin{array}{l}4 \\
4 \\
3 \\
3 \\
3\end{array}$ & $\begin{array}{r}.56 \\
.56 \\
.40 \\
.30 \\
.22\end{array}$ \\
\hline $\begin{array}{r}6 \\
7 \\
8 \\
9 \\
10\end{array}$ & $\begin{array}{l}1670 \\
1380 \\
1190 \\
1130 \\
1080\end{array}$ & $\begin{array}{l}31 \\
22 \\
18 \\
18 \\
18\end{array}$ & $\begin{array}{r}140 \\
82 \\
58 \\
55 \\
52\end{array}$ & $\begin{array}{l}240 \\
274 \\
363 \\
377 \\
598\end{array}$ & $\begin{array}{l}6 \\
5 \\
5 \\
4 \\
5\end{array}$ & $\begin{array}{l}3.9 \\
3.7 \\
4.9 \\
4.1 \\
8.1\end{array}$ & $\begin{array}{l}25 \\
33 \\
33 \\
37 \\
39\end{array}$ & $\begin{array}{l}3 \\
3 \\
2 \\
2 \\
2\end{array}$ & $\begin{array}{l}.20 \\
.27 \\
.18 \\
.20 \\
.21\end{array}$ \\
\hline $\begin{array}{l}11 \\
12 \\
13 \\
14 \\
15\end{array}$ & $\begin{array}{l}748 \\
736 \\
962 \\
242 \\
202\end{array}$ & $\begin{array}{r}15 \\
14 \\
16 \\
14 \\
8\end{array}$ & $\begin{array}{l}30 \\
28 \\
42 \\
9.1 \\
4.4\end{array}$ & $\begin{array}{l}694 \\
688 \\
598 \\
449 \\
310\end{array}$ & $\begin{array}{r}6 \\
8 \\
9 \\
10 \\
7\end{array}$ & $\begin{array}{c}11 \\
15 \\
15 \\
12 \\
5.9\end{array}$ & $\begin{array}{l}39 \\
33 \\
31 \\
25 \\
25\end{array}$ & $\begin{array}{l}2 \\
2 \\
2 \\
2 \\
1\end{array}$ & $\begin{array}{l}.21 \\
: 18 \\
: 17 \\
: 14 \\
.07\end{array}$ \\
\hline $\begin{array}{l}16 \\
17 \\
18 \\
19 \\
20\end{array}$ & $\begin{array}{l}242 \\
306 \\
514 \\
748 \\
780\end{array}$ & $\begin{array}{r}6 \\
8 \\
14 \\
16 \\
16\end{array}$ & $\begin{array}{l}3.9 \\
6.6 \\
19 \\
32 \\
34\end{array}$ & $\begin{array}{l}242 \\
274 \\
298 \\
302 \\
302\end{array}$ & $\begin{array}{l}6 \\
6 \\
5 \\
5 \\
4\end{array}$ & $\begin{array}{l}3.9 \\
4.4 \\
4.0 \\
4.1 \\
3.3\end{array}$ & $\begin{array}{l}24 \\
20 \\
22 \\
41 \\
35\end{array}$ & $\begin{array}{l}1 \\
1 \\
1 \\
1 \\
1\end{array}$ & $\begin{array}{l}.06 \\
.05 \\
.06 \\
.11 \\
.09\end{array}$ \\
\hline $\begin{array}{l}21 \\
22 \\
23 \\
24 \\
25\end{array}$ & $\begin{array}{l}780 \\
262 \\
395 \\
485 \\
600\end{array}$ & $\begin{array}{l}14 \\
13 \\
27 \\
18 \\
15\end{array}$ & $\begin{array}{l}29 \\
9.2 \\
29 \\
24 \\
24\end{array}$ & $\begin{array}{r}206 \\
126 \\
75 \\
83 \\
93\end{array}$ & $\begin{array}{l}4 \\
4 \\
5 \\
4 \\
4\end{array}$ & $\begin{array}{l}2.2 \\
1.4 \\
1.0 \\
.90 \\
1.0\end{array}$ & $\begin{array}{l}59 \\
31 \\
27 \\
27 \\
27\end{array}$ & $\begin{array}{r}1 \\
2 \\
31 \\
15 \\
4\end{array}$ & $\begin{array}{l}.16 \\
.17 \\
2.3 \\
1.1 \\
.29\end{array}$ \\
\hline $\begin{array}{l}26 \\
27 \\
28 \\
29 \\
30 \\
31\end{array}$ & $\begin{array}{l}640 \\
630 \\
330 \\
230 \\
270 \\
--\end{array}$ & $\begin{array}{l}11 \\
10 \\
10 \\
71 \\
11 \\
-2\end{array}$ & $\begin{array}{r}19 \\
17 \\
8.9 \\
4.3 \\
8.0 \\
--\end{array}$ & $\begin{array}{r}117 \\
143 \\
133 \\
126 \\
93 \\
59\end{array}$ & $\begin{array}{l}3 \\
4 \\
4 \\
3 \\
3 \\
4\end{array}$ & $\begin{array}{l}.95 \\
1.5 \\
1.4 \\
1.0 \\
.75 \\
.64\end{array}$ & $\begin{array}{l}25 \\
24 \\
22 \\
22 \\
22 \\
-\end{array}$ & $\begin{array}{r}3 \\
2 \\
2 \\
2 \\
1 \\
-\end{array}$ & $\begin{array}{l}.20 \\
.13 \\
: 12 \\
: 12 \\
.06 \\
-0\end{array}$ \\
\hline TOTAL & 24412 & $\cdots$ & 1577.4 & 8893 & AUGUST & 144.94 & 965 & SEPTEMBER & 8.89 \\
\hline
\end{tabular}

Ar $\begin{array}{clcc}\text { MEAN } & \text { MEAN } & & \\ \text { CONCEN- } & \text { SEDIMENT } & \text { MEAN } \\ \text { DISCHARGE } & \text { TRATION } & \text { DISCHARGE } & \text { OISCHARGE } \\ \text { (CFS) } & \text { (MG/L) } & \text { (TONS/DAY) } & \text { (CFS) }\end{array}$

CONCEN- SEDIMENT MEAN CONCEN- SEDIMENT TRATION DISCHARGE DISCHARGE TRATION DISCHARGE (MG/L) (TONS/DAY) (CFS) (MG/L) (TONS/DAY)

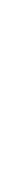

$\begin{array}{llll}22 & 1 & .06 & 4.4 \\ 20 & 1 & .05 & 4.4 \\ 19 & 1 & .05 & 4.4 \\ 19 & 1 & .05 & 4.4 \\ 19 & 1 & .05 & 4.4\end{array}$

1
1
1

.01
.01
.01
.01
.01
.01
.01
.01
.02
.02

5.1
5.1
5.1
4.9
4.9

.07

.04

.03

$\begin{array}{rl}6 & 15 \\ 7 & 17 \\ 8 & 17 \\ 9 & 16 \\ 10 & 16\end{array}$

$\begin{array}{ll}.04 & 5.1 \\ .05 & 5.1 \\ .05 & 5.1 \\ .04 & 5.8 \\ .04 & 5.8\end{array}$

4.6

4.3
4.3
4.3

.05

.01

$\begin{array}{ll}11 & 16 \\ 12 & 15 \\ 13 & 15 \\ 14 & 14 \\ 15 & 13\end{array}$

.04
.04
.08
.15

5.8
5.1
5.1
5.1

.03
.01
.03
.01

.03
.01
.01

$4 \cdot 3$
$4 \cdot 3$
$4 \cdot 3$
$4 \cdot 1$

$\begin{array}{ll}16 & 13 \\ 17 & 12 \\ 18 & 12 \\ 19 & 12\end{array}$

$\begin{array}{ll}.04 & 5 . \\ .03 & 5 . \\ .03 & 5 . \\ .03 & 5 .\end{array}$

01
0.01
0.01
.01
.01

4.1
4.1
4.9
5.6
5.9

4.1
4.9
. .6
.9

$\begin{array}{ll}.03 & 5.4 \\ .03 & 5.4 \\ .02 & 5.4 \\ .02 & 5.4\end{array}$

01

6.2
6.2
6.2
6.2

6.2

6.2
5.9

$\begin{array}{lll}.02 & 5.4 & 1 \\ .02 & 5.4 & 1 \\ .02 & 5.4 & 1 \\ .02 & 5.4 & 1 \\ .02 & 5.1 & 1 \\ .02 & 5.1 & 1\end{array}$

1.30

159.7

TOTAL OISCHARGE FOR YEAR (CFS-DAYS)

TOTAL SUSPENDED-SEDIMENT DISCHARGE FOR YEAR (TONS)

th


11472200 OUTLET CREEK NEAR LONGVALE, CALIP.

LOCATION, --Lat $39^{\circ} 37^{\prime} 05^{\prime \prime}$, Iong $123^{\circ} 21^{\prime} 20^{\prime \prime}$, in NE sec.1, T.20 N, R. 14 W., Mendocino County, at gaging atetion 0.2 mile downtrean from Bloody Run Croek, $0.9 \mathrm{mlle}$ uptream from mouth, and 6.2 miles downstream 1 rom Longvale.

DRAINAGE AREA, --161 sq $m 1$.

PERIOD OF RECORD, --ChemicaI anaIy men: October 1958 to September 1966.

Water temperatures: October 1967 to September 1969.

Sediment records: October 1966 to September 1969.

EXTREMES. --1968-69:

Water temperatures: Mini mum, $3.0^{\circ} \mathrm{C}$ Dec, 22

Sediment concentrations: Maximum dally $1,430 \mathrm{mg} / 1$ Dec, $10 ; \mathrm{m} / \mathrm{n} 1 \mathrm{mum}$ da1ly, $1 \mathrm{mg} / 1$ on many daya.

Sediment d1mcharge: Maximum daily, 41,200 tons Jan. 12 ; minimum dally, 0 ton on everal day during October and JuIy to September.

Perlod of record:

Water temperature. $(1968-69)$ : Minimum, $3.0^{\circ} \mathrm{C}$ Dec, 22,1968

Sediment concentrations: Maximum da11y, $1,430 \mathrm{mg} / 1$ Dec, 10, 1968; minimum da1ly, $1 \mathrm{mg} / 1$ on many day erch

Sediment dimcharge: Maximum daily, 41,200 tons Jan. 12, 1969; minimum daliy, 0 ton on many day each year. TEMPERATURE $\left({ }^{\circ} \mathrm{C}\right)$ OF WATER, WATER YEAR OCTOBER 1968 TO SEPTEMBER 1969 (ONCE-DAILY MEASUREMENT)

DAY

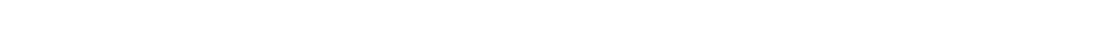

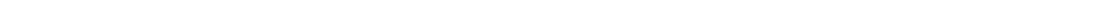

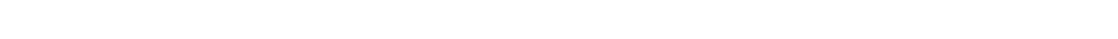

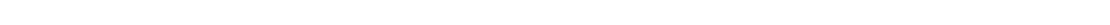

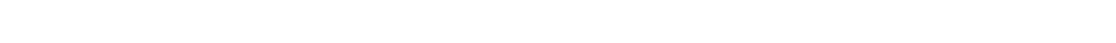

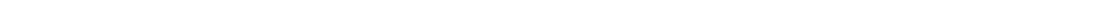

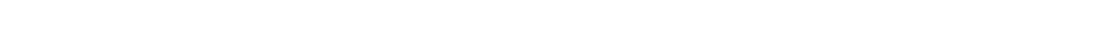

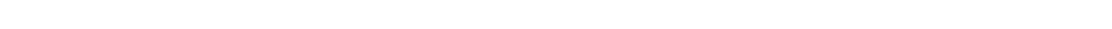

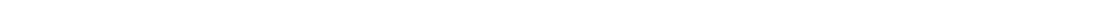

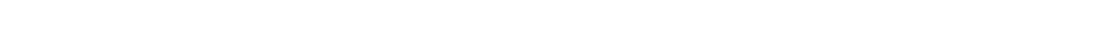

PARTICLE-SIZE DISTRIBUTION OF SUSPENDED SEDIMENT, WATER YEAR DCTOBER 1968 TO SEPTEMBER 1969 IMETHODS OF ANALYSIS: B, BOTTOM WITHDRAWAL TUBE; C, CHEMICALLY DISPERSED; N. IN NATIVE WATER: P. PIPET; S, SILVE:

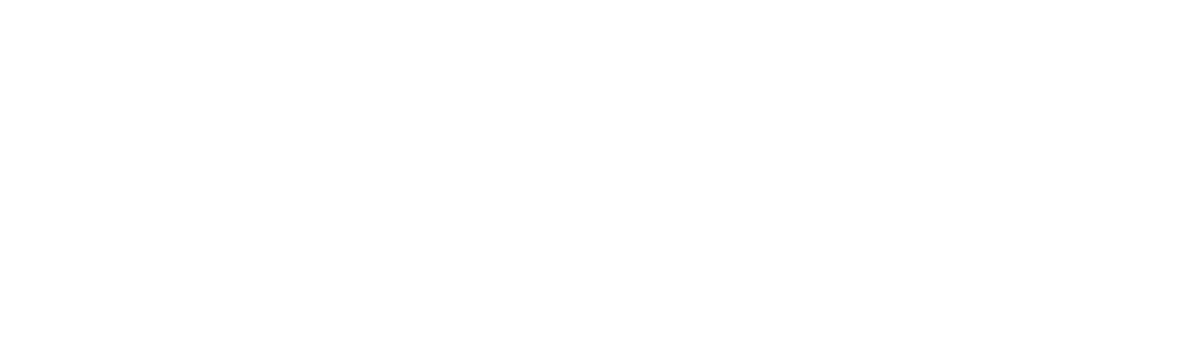


11472200 OUTLET CREEK NEAR LONGVALE, CALIF.--Cont1nued SUSPENDED-SEDIMENT DISCHARGE, WATER YEAR OCTOBER 1968 TO SEPTEMBER 1969 OCTOBER NOVEMBER OECEMBER

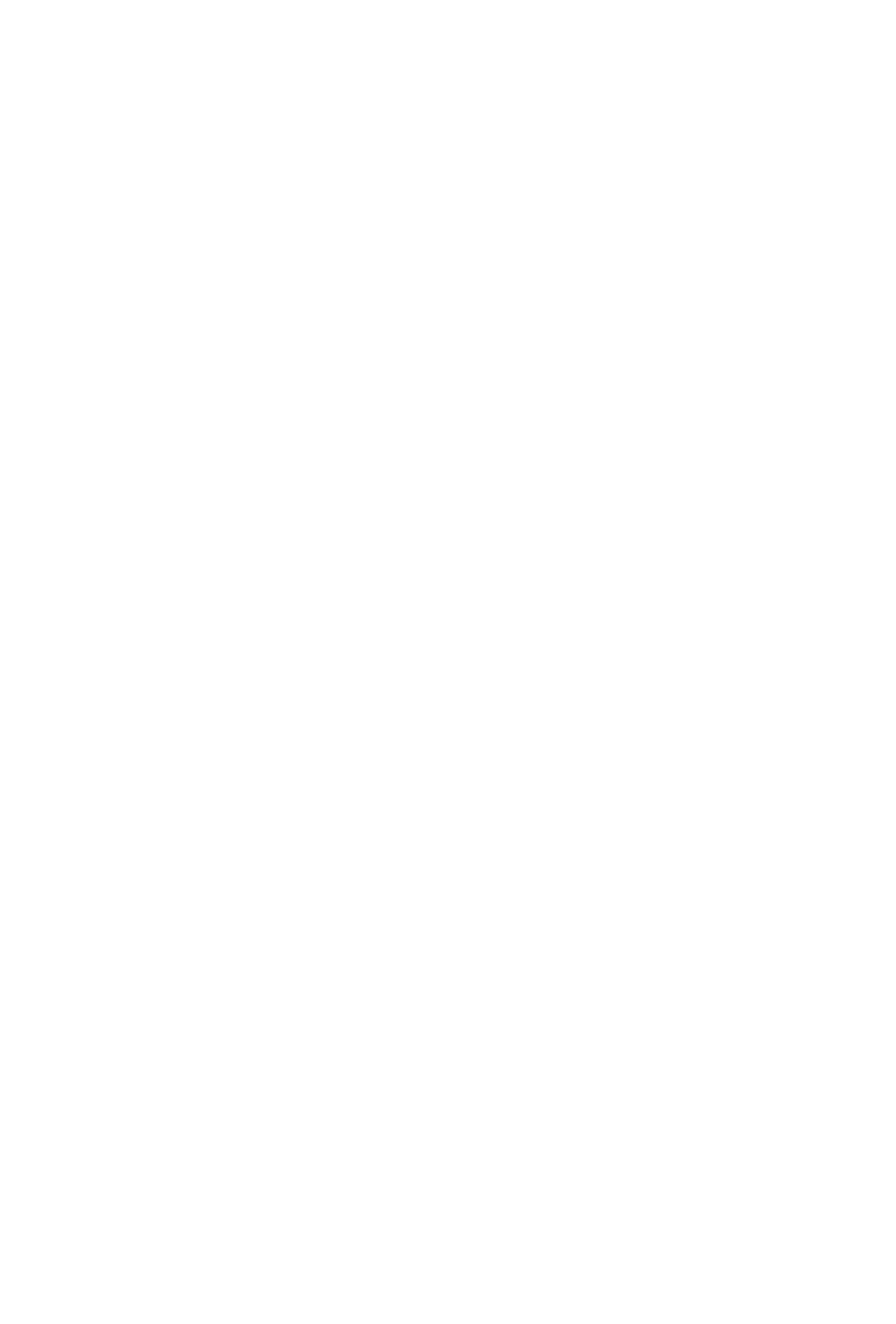


11472200 OUTLET CREEK NEAR LONGVALE, CALIF.--Continued

SUSPENDED-SEDIMENT DISCHARGE, WATER YEAR OCTOBER 1968 TO SEPTEMBER 1969

APRIL

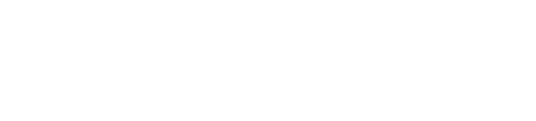

$$
\text { MAY }
$$

MEAN $\begin{array}{lll}\text { CONCEN- } & \text { SEDIMENT } & \text { MEAN } \\ \text { TRATION } & \text { DISCHARGE } & \text { DISCHARGE }\end{array}$ (MG/L) (TONS/DAY) (CFS)
83
77

$\begin{array}{cc}.87 & 83 \\ .96 & 77 \\ 2.66 & 72 \\ 4.6 & 68 \\ 76 & 65\end{array}$

47

13
4.9
3.7

4.0

3.8
2.2
1.3
1.1
.69

.944

.94
.94
1.0

1.95
18
22

22.7

3.9
1.6
1.1
1.0
.71
-1

230.63

TDTAL 5335

JULY

AUgust $\begin{array}{ll}.67 & 20 \\ .62 & 19 \\ .58 & 18 \\ .55 & 17 \\ .35 & 17\end{array}$

MEAN

CONCEN- SEDIMENT TRATION DISCHARGE (FS) (MG/L) (TONS/DAY)$$
\begin{aligned}
& \text { MEAN } \\
& \text { DISCHARGE }
\end{aligned}
$$

MEAN

SEDIMENT

$$
\begin{array}{lcc}
\text { SEDIMENT } & \text { MEAN } & \text { CONCEN } \\
\text { DISCHARGE } & \text { DISCHARGE } & \text { TRATION }
\end{array}
$$

CONCEN- SEDIMENT (MGIL)

\section{DISCHARGE MEAN} (TONS/DAY)

.49
.45
.43
.54
.39

$\begin{array}{ll}20 & 3 \\ 19 & 2 \\ 18 & 3 \\ 17 & 4 \\ 17 & 3\end{array}$

$$
\begin{aligned}
& .01 \\
& .01 \\
& .01 \\
& .01
\end{aligned}
$$
I SCHARGE
(CFS)

$\begin{array}{lll}.36 & 20 & 4 \\ .33 & 20 & 3 \\ .32 & 19 & 2 \\ .42 & 17 & 2 \\ .31 & 16 & 2\end{array}$

$\begin{array}{ll}.28 & 14 \\ .27 & 13 \\ .25 & 13 \\ .23 & 18 \\ .23 & 18\end{array}$

.22
.27
.19

17
14
12
11

$\begin{array}{ll}.19 & 9.3 \\ .22 & 8.9 \\ .22 & 8.6\end{array}$

.19

10.35

462.8

SEP TEMBER

MEAN

CONCEN- SEDIMENT TRATION DISCHARGE
(MG/L) (IONS/DAY)

$\begin{array}{rl}5 & 5.6 \\ 6 & 5.3 \\ 7 & 5.0 \\ 8 & 4.2 \\ 9 & 4.2 \\ 10 & 3.9\end{array}$

$\begin{array}{ll}.03 & 1.3 \\ .03 & 1.3 \\ .01 & 1.3 \\ .01 & 1.3\end{array}$

.01

.95
.95
.83
.83
.83

.

1.3

.01

1.3
1.2
1.2
1.1
1.1

.01
.01
.01
.01

.01

.01

0 .01
.01
.01

$\begin{array}{lll}16 & 2.9 & 2\end{array}$

$\begin{array}{ll}.02 & 1.1 \\ .02 & 1.1\end{array}$

2.9
2.8
2.6
2.6
2.5

1.1
1.1
.95
.95
.95

.01
.01
0

.01

$0_{0}^{.01}$

.83

.02

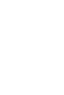

.01
.01
.01
0.01

.95
.95
.83
.78
.83

$\begin{array}{ll}.01 & .95 \\ .01 & .95 \\ .01 & .95 \\ .01 & .95 \\ .01 & .95 \\ .01 & .95\end{array}$

.44

34.79

IOTAL

106.3

YEAR (CFS-DAYS)

TOTAL SUSPENDED-SEDIMENT DISCHARGE FOR YEAR (TONS) 


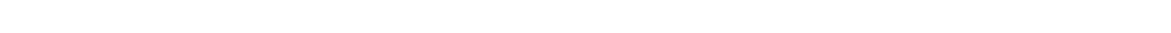
at ite of former gaging station on left bank, 1.8 miles upat ream from Middle Fork and 2.1 miles south of Do. Rios.

DRAI NAGE AREA. $-705: 9 \mathrm{ml}$.

PERIOD OF RBCORD. -Water temperaturea: October 1957 to September 1958, October 1960 to September 1965 , May 1966

Sediment records: Detober 1957 to September 1988.

EXTREYas, --Perlod of record (1962-65, 1966):

Nater temperaturea: Maximum, 29.0 $0^{\circ} \mathrm{C}$ June 15, 1966; minimum $(1962-65), 3.5^{\circ} \mathrm{C}$ Nov. $23,1964$. REMarks, - No recorde aval1eble for Oct. 1 to Nov, 1, Nov. 6 to Jan. 14, probe buried; Jan. 15 to Sept. 12 ,
Sept. 18, 19, recorder maifunction.

TEMPERATURE ( ${ }^{\circ} \mathrm{C}$ ) OY WATER, WATER YEAR OCTOBER 1968 TO SEPTEMBER 1969

DAY

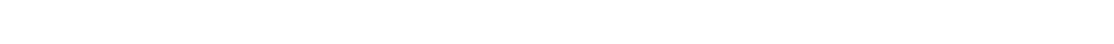

OCTOBER

MAXIMUM

NOVEMBER

MAXIMUM --

MINIMUM

DECEMBER

MAXINUM -

MINIMUM

JAVUARY

MINIMIJM

FERUARY

MAXIMUM

MAXIMUM

MARCH

MAXIMUM

MINIMUM

MPINIMUM
APRILIMUM

MAXIMUM

Minimum

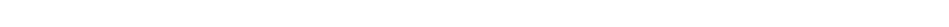

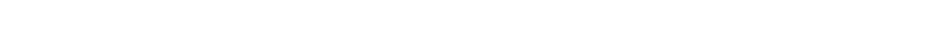

MAY

MAXIMUM

JUNE

MAXIMUM
MINIMUM

Jut $Y$

MAXIMUM

MINI
AUGUST

MAXIMUM

MINIMUM

TP TEMHER MAXIMUM MINIMUM 2-

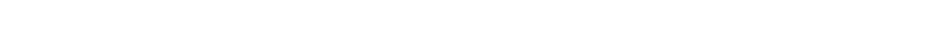

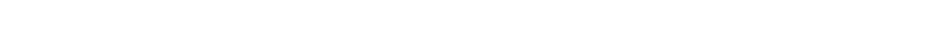

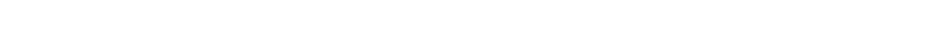

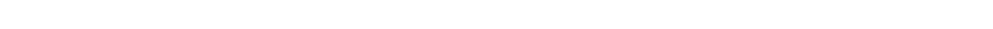

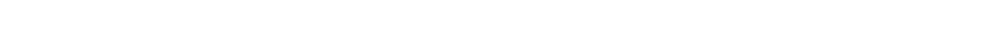


11472800 HIDOLE FORK EEL RIVER ABOVE BLACK BUTTE RIVER, NEAR COVELO, CALIF.

LOCATION. --Lat $39^{\circ} 49^{\prime} 45^{\prime \prime}$, I Ong $123^{\circ} 04^{\prime} 11^{\prime \prime}$, In SEłsw sec.22, T.23 N., R.11 W., Mendocino County, at gag1ng station $1.2 \mathrm{~m} 1 \mathrm{les}$ upetream from Black Butte River and $9.8 \mathrm{~m} 1 \mathrm{les}$ northeast of Covelo.

DRAINAGE AREA, --204 sq $\mathrm{m} 1$.

PERIOD OP RECORD, --Water temperatures: Hay 1966 to September 1969.

Sediment records: October 1967 to September 1989.

EXTREMES. $--1968-69$ :

Water temperatures: Min $1 \mathrm{mum}, 1.0^{\circ} \mathrm{C}$ on several days during December and January.

Sediment concentrations: Maximum da11y, 3,650 $\mathrm{mg} / 2 \mathrm{Jan}, 20 ; \mathrm{m} 1 \mathrm{n} 1 \mathrm{mum} \mathrm{da} 1 \mathrm{ly}, 1 \mathrm{mg} / \mathrm{I}$ on many days during October

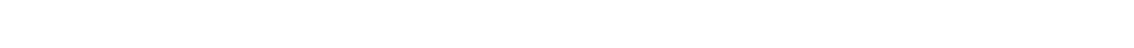
ber.

Perlod of record:

Fater temperatures: Maximum (1966, 1967-68), 29. $0^{\circ} \mathrm{C}$ July 5,1968 ; minimum, $1.0^{\circ} \mathrm{C}$ on several days 1 in $1968-69$. Sediment concentrations: Maximum daily, 7,150 mg/I Jan. 14, 1966; min1mum daily, $1 \mathrm{mg} / 1$ on many days $1 \mathrm{n}$ $1967-69$.

Sed1ment discharge: Maximum da1ly, 329,000 tons Jan. 20, 1969; minimum da11y, 0.02 ton on several days 1n

REMARKS. --No temperature record Oct, 1-7 and June 10 to Sept. 30; probe out of water. Where no maximum or mintmum 1: wown, temperature 1 once-dally reading.

TEMPERATURE $\left({ }^{\circ} \mathrm{C}\right)$ OF WATER, WATER YEAR OCTOBER 1968 TO SEPTEMBER 1969

DAY

MONTH

123

OCTOBER..

MAXIMUM

MINIMUM

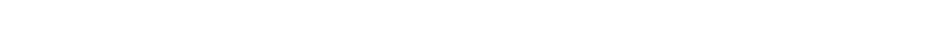

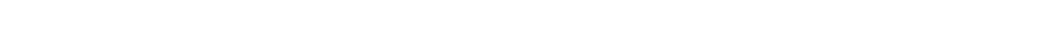

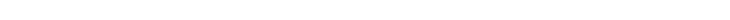
MAXIMUM MINIMUM

JANUARY.

MAXIMUM $\begin{array}{lllllllllllllllllllllllllllllllll}\text { MAXIMUM } & 2 & 2 & 2 & 3 & 3 & 3 & 3 & 3 & 4 & 4 & 4 & 6 & 6 & 7 & 6 & 4 & 3 & 6 & 6 & 7 & 7 & 6 & 4 & 6 & 7 & 6 & 4 & 4 & 4 & 3 & 3 \\ \text { MINIMUM } & 1 & 1 & 2 & 2 & 3 & 3 & 3 & 3 & 3 & 4 & 4 & 4 & 6 & 6 & 4 & 3 & 3 & 3 & 5 & 6 & 6 & 3 & 3 & 4 & 6 & 4 & 4 & 4 & 3 & 2 & 2\end{array}$

FEBRUARY.

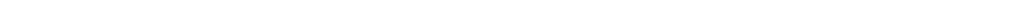

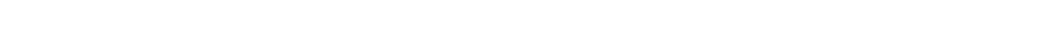
MARCH... MINIMUM $4 \begin{array}{llllllllllllllllllllllllllllllll} & 4 & 4 & 4 & 4 & 5 & 4 & 5 & 5 & 4 & 4 & 4 & 4 & 4 & 5 & 6 & 6 & 7 & 6 & 6 & 7 & 7 & 7 & 6 & 6 & 7 & 6 & 6 & 6 & 7 & 7\end{array}$

APRILI..... -

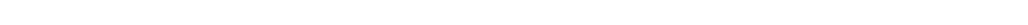

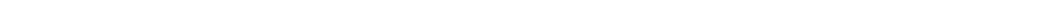

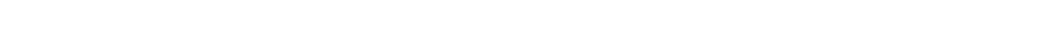

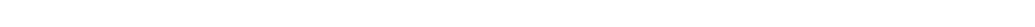
JUNE..... -

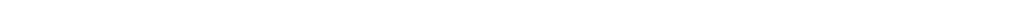

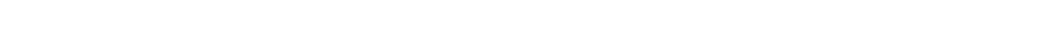

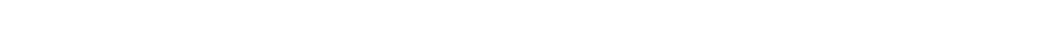
MAXIMUM MINIMUM

AGUST....

[-

MINIMUM

MAXIMUM

PARTICLE-SIZE DISTRIBUTION OF SUSPENDED SEDIMENT, WATER YEAR OCTOBER 1968 TO SEPTEMBER 1969
(METHOOS DF ANALYIS: B, BOTTOM WITHORAWAL TUBE: C, CHEMICALLY DISPERSED: N, IN NATIVE WATER: P, PIPET: S, SIEVE $\checkmark$, VISUAL ACCUMULATIUN TUBE: W, IN DISTILLEO WATER)

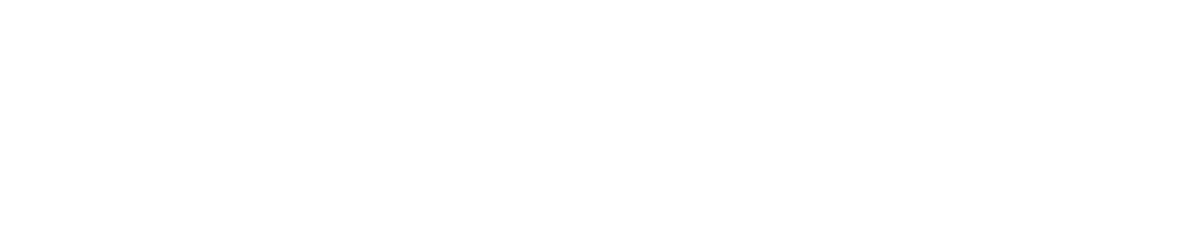


EEL RIVER BASIN

11472800 MIDDLE FORK EEL RIVER ABOVE BLACK BUTTE RIVER, NEAR COVELO, CALIF.--Cont1nued SUSPENDED-SEDIMENT DISCHARGE, WATER YEAR OCTOBER 1968 TO SEPTEMBER 1969

\begin{tabular}{|c|c|c|c|c|c|c|c|c|c|}
\hline & & OCTOBER & & & NOVEMBFR & & & DECEMBER & \\
\hline DAY & $\begin{array}{l}\text { MEAN } \\
\text { DISCHARGF } \\
\text { (CFS) }\end{array}$ & $\begin{array}{l}\text { MEAN } \\
\text { CONCEV- } \\
\text { TRAT ION } \\
\text { (MGIL) }\end{array}$ & $\begin{array}{l}\text { SEDIMENT } \\
\text { DISCHARGE } \\
\text { (TONS/DAY) }\end{array}$ & $\begin{array}{l}\text { MEAN } \\
\text { OISCHAKGE } \\
\text { (CFS) }\end{array}$ & $\begin{array}{l}\text { MEAN } \\
\text { CONCEN- } \\
\text { TRAIION } \\
\text { (MG/L) }\end{array}$ & $\begin{array}{l}\text { SEDI MENT } \\
\text { DISCHARGE } \\
\text { (TONS/DAY) }\end{array}$ & $\begin{array}{l}\text { MEAN } \\
\text { DISCHARGE } \\
\text { (CFS) }\end{array}$ & $\begin{array}{l}\text { MEAN } \\
\text { CONCEN- } \\
\text { TRATION } \\
\text { (MG/L) }\end{array}$ & $\begin{array}{l}\text { SEDIMENT } \\
\text { DISCHARGE } \\
\text { (TONS/DAY) }\end{array}$ \\
\hline I & 8.0 & l & .02 & 70 & 7 & 1.3 & 238 & 12 & 7.7 \\
\hline 2 & 8.0 & $i$ & .02 & 419 & 217 & 343 & 195 & 8 & 4.2 \\
\hline 3 & 8.0 & $i$ & .02 & 289 & 21 & 16 & 180 & 6 & 2.9 \\
\hline 4 & 8.0 & 1 & .02 & 139 & 12 & 4.5 & 174 & 5 & 2.3 \\
\hline 5 & 8. 0 & $i$ & .02 & 116 & 7 & 2.2 & 228 & 5 & 3.1 \\
\hline 6 & 8.0 & 1 & .02 & 105 & 4 & 1.1 & 269 & 5 & 3.6 \\
\hline 7 & 8.0 & $i$ & .02 & 90 & 3 & .73 & 240 & 14 & 9.1 \\
\hline s & B. 0 & $i$ & .02 & 81 & 2 & .44 & 629 & 90 & 153 \\
\hline 9 & 8.0 & 2 & .04 & 115 & $?$ & .62 & 496 & 20 & 27 \\
\hline 10 & 8.4 & 4 & .09 & 127 & $?$ & .69 & 1,5200 & 3610 & 234000 \\
\hline 11 & 10 & 8 & .22 & 151 & 10 & 4.1 & 876 & 960 & 2270 \\
\hline 12 & 17. & 10 & .46 & 558 & 68 & 102 & 100 & 245 & 66 \\
\hline 13 & 10 & 15 & .41 & 266 & 25 & 18 & 139 & 305 & 286 \\
\hline 14 & 10 & 2 & .05 & 195 & 16 & 8.4 & 273 & 504 & 371 \\
\hline is & 10 & 2 & .05 & 202 & 11 & 6.0 & 618 & 662 & 1470 \\
\hline 16 & 10 & 1 & .03 & 254 & 13 & 8.9 & 165 & 210 & 94 \\
\hline 17 & 10 & i & .03 & 352 & 15 & 14 & 173 & 150 & 70 \\
\hline is & 10 & i & .03 & 1440 & 285 & 1300 & 134 & 90 & 33 \\
\hline 19 & 10 & 1 & .03 & 600 & 45 & 73 & 100 & 45 & 12 \\
\hline 20 & 10 & $\hat{i}$ & .03 & 361 & 16 & 16 & 101 & 31 & 8.5 \\
\hline 21 & 10 & 2 & .05 & 260 & 10 & 7.0 & 97 & 19 & 5.0 \\
\hline 22 & 10 & 2 & .05 & 215 & 3 & 1.7 & 98 & 17 & 4.5 \\
\hline 23 & 10 & 2 & .05 & 191 & 8 & 4.1 & 7160 & 2080 & 64000 \\
\hline 24 & 10 & 3 & .08 & 198 & 13 & 6.9 & 8490 & 1440 & 33000 \\
\hline 25 & 20 & 3 & .08 & 218 & 8 & 4.7 & 4170 & 530 & 5970 \\
\hline 26 & 10 & 5 & .14 & 194 & 8 & 4.2 & 1800 & 205 & 996 \\
\hline 27 & io & 5 & .14 & 179 & 7 & 3.4 & 1090 & 125 & 368 \\
\hline 28 & in & 7 & .19 & 176 & 7 & 3.3 & 1100 & 130 & 386 \\
\hline 29 & 12 & 7 & .23 & 181 & 12 & 5.9 & 1040 & 60 & 168 \\
\hline 30 & 17 & 8 & .37 & 259 & 20 & 14 & 813 & 45 & 99 \\
\hline $3 i$ & 27 & 7 & .51 & - & - & - & 807 & 30 & 65 \\
\hline \multirow[t]{5}{*}{ TOTAL } & 323.4 & -- & 3.52 & 8001 & -- & 1976.18 & 47193 & - & 343954.9 \\
\hline & & JANUARY & & & FEBRUARY & & & MARCH & \\
\hline & & MEAN & & & MEAN & & & MEAN & \\
\hline & MEAN & CONCEN- & SEDIMENT & MEAN & CONCEN- & SEDIMENT & MEAN & CONCEN- & SEDIMENT \\
\hline & DISCHARGE & TRATION & DISCHARGE & OISCHARGE & TRATION & DISCHARGE & DISCHARGE & TRATION & DISCHARGE \\
\hline DAY & (CFS) & $(M G / L)$ & (TONS / DAY $)$ & (CFS) & $(M G / L)$ & (TONS/DAY) & (CFS) & (MG/L) & (TONS/DAY) \\
\hline 1 & 663 & 26 & 47 & 1520 & 68 & 279 & 502 & 47 & 64 \\
\hline 2 & 638 & 24 & 41 & 1380 & 98 & 365 & 493 & 28 & 37 \\
\hline 3 & 730 & 28 & 55 & $\$ 320$ & 140 & 499 & 480 & 17 & 22 \\
\hline 4 & 1010 & 50 & 136 & 1210 & 90 & 294 & 472 & 15 & 19 \\
\hline 5 & 1100 & 64 & 190 & 1210 & 85 & 278 & 467 & 13 & 16 \\
\hline 6 & 1180 & 66 & 210 & 1120 & 60 & $|B|$ & 465 & 12 & 15 \\
\hline 7 & 1040 & 55 & 154 & 965 & 30 & 78 & 460 & iI & 14 \\
\hline 8 & 870 & 40 & 94 & 1270 & 219 & 1050 & 455 & ii & 14 \\
\hline 9 & 747 & 30 & 61 & 2130 & 460 & 2780 & 450 & 9 & 11 \\
\hline 10 & 674 & 25 & 45 & 1720 & 245 & 1140 & 445 & 9 & ii \\
\hline 11 & 2480 & 639 & 8600 & 3900 & 1190 & 12800 & 440 & 6 & 7.1 \\
\hline i2 & 23400 & 3210 & 211000 & 3120 & 320 & 2700 & 435 & 6 & 7.0 \\
\hline 13 & 23900 & 3420 & 245000 & 1710 & 170 & 785 & 430 & 6 & 7.0 \\
\hline 14 & 4710 & 1400 & 17800 & 1320 & 140 & 499 & 425 & 6 & 6.9 \\
\hline 15 & 1960 & 610 & 3230 & 1300 & 145 & 509 & 435 & 8 & 9.4 \\
\hline 16 & 1140 & 330 & 1020 & 1180 & 70 & 223 & 555 & 13 & 19 \\
\hline 17 & 1160 & 220 & 689 & 1040 & 40 & 112 & 1080 & 118 & 359 \\
\hline 13 & 1190 & 230 & 739 & 902 & 31 & 75 & 1280 & 83 & 287 \\
\hline 19 & 12700 & 2650 & 120000 & 825 & 27 & 60 & 1080 & 33 & 96 \\
\hline 20 & 33600 & 3650 & 329000 & 742 & 22 & 44 & 1060 & 33 & 94 \\
\hline 21 & 16600 & 3030 & 141000 & 665 & 19 & 34 & 944 & 36 & 92 \\
\hline 22 & 2440 & 1890 & 12500 & 610 & 14 & 23 & 930 & 26 & 65 \\
\hline 23 & 754 & 590 & 1200 & 610 & 20 & 33 & 1170 & 43 & 136 \\
\hline 24 & 670 & 506 & 917 & 585 & 38 & 60 & 1300 & 52 & 183 \\
\hline 25 & 2150 & 1000 & 6410 & 570 & 18 & 28 & 1410 & 64 & 244 \\
\hline 26 & 7800 & 2040 & 48500 & 535 & 13 & 19 & 1630 & 81 & 356 \\
\hline 27 & 3780 & 560 & 5720 & 507 & 31 & 42 & 2070 & 128 & 715 \\
\hline 28 & 2620 & 450 & 3180 & 545 & 83 & 122 & 2460 & 187 & 1240 \\
\hline 29 & 2120 & 190 & 1090 & + & - & - & 2920 & 248 & 1960 \\
\hline 30 & 1820 & 115 & 565 & -- & -- & -- & 3480 & 277 & 2600 \\
\hline 31 & 1590 & 105 & 451 & -- & - & - & 3200 & 209 & 1810 \\
\hline TUTAL & 157236 & -- & 1159644 & 34511 & -- & 25112 & 33423 & 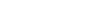 & 10516.4 \\
\hline
\end{tabular}


11472800 MIDDLE FORK EEL RIVER ABOVE BLACK BUTTE RIVER, NEAR COVELO, CALIF.--COntınued SUSPENDED-SEDIMENT DISCHARGE, WATER YEAR OCTOBER 1968 TO SEPTEMBER 1969

\begin{tabular}{|c|c|c|c|c|c|c|c|c|c|}
\hline \multirow[b]{2}{*}{ DAY } & \multicolumn{3}{|c|}{ APRIL } & \multicolumn{3}{|c|}{ may } & \multicolumn{3}{|c|}{ JUNE } \\
\hline & $\begin{array}{l}\text { MEAN } \\
\text { DI SCHARGF } \\
\text { (CFS) }\end{array}$ & $\begin{array}{l}\text { MEAN } \\
\text { CONCEN- } \\
\text { TRATION } \\
\text { (MG/L) }\end{array}$ & $\begin{array}{l}\text { SEDIMENT } \\
\text { DISCHARGE } \\
\text { (TONS/DAY) }\end{array}$ & $\begin{array}{l}\text { MEAN } \\
\text { DI SCHARGE } \\
\text { (CFS) }\end{array}$ & $\begin{array}{l}\text { MEAN } \\
\text { CONCEN- } \\
\text { TRATION } \\
\text { (MG/L) }\end{array}$ & $\begin{array}{l}\text { SEDIMENT } \\
\text { DISCHARGE } \\
\text { (TONS/DAY) }\end{array}$ & $\begin{array}{l}\text { MEAN } \\
\text { DISCHARGE } \\
\text { (CFS) }\end{array}$ & $\begin{array}{l}\text { MEAN } \\
\text { CONCEN- } \\
\text { TRATION } \\
\text { IMG/L) }\end{array}$ & $\begin{array}{l}\text { SEDIMENT } \\
\text { DISCHARGE } \\
\text { (TONS/DAY) }\end{array}$ \\
\hline 1 & 2100 & 146 & 828 & 1860 & 10 & 352 & 802 & 14 & 30 \\
\hline 2 & 1940 & 130 & 681 & 1650 & 55 & 245 & 760 & 14 & 29 \\
\hline 3 & 1450 & 84 & 329 & 1600 & 43 & 186 & 718 & 12 & 23 \\
\hline 4 & 1250 & 52 & 176 & 1380 & 28 & 104 & 682 & 12 & 22 \\
\hline 5 & 1510 & 121 & 493 & 1550 & 40 & 167 & 640 & 4 & 6.9 \\
\hline 6 & 1230 & 61 & 203 & 1900 & 104 & 534 & 555 & 2 & 3.0 \\
\hline 7 & 1080 & 38 & 111 & $\angle 300$ & 184 & 1140 & 493 & 5 & 6.7 \\
\hline 8 & 1050 & 30 & 85 & 2480 & 165 & 1100 & 440 & 7 & 8.3 \\
\hline 9 & 1100 & 32 & 95 & 2610 & 189 & 1330 & 400 & 6 & 6.5 \\
\hline 10 & 1140 & 37 & 114 & 2750 & 212 & 1570 & 360 & 5 & 4.9 \\
\hline 11 & 1410 & 60 & 228 & 2540 & 181 & 1240 & 335 & 4 & 3.6 \\
\hline 12 & 1790 & 109 & 527 & 2350 & 156 & 990 & 310 & 4 & 3.3 \\
\hline 13 & 1510 & 62 & 253 & 2020 & 117 & 638 & 285 & 4 & 3.1 \\
\hline 14 & 1260 & 42 & 143 & 1640 & 79 & 350 & 260 & 4 & 2.8 \\
\hline 15 & 1140 & 35 & 108 & 1370 & 56 & 207 & 240 & 4 & 2.6 \\
\hline 16 & 1210 & 36 & 118 & 1300 & 53 & 186 & 225 & 3 & 1.8 \\
\hline 17 & 1470 & 61 & 242 & 1380 & 54 & 201 & 210 & 3 & 1.7 \\
\hline 18 & 1740 & 90 & 423 & 1480 & 55 & 220 & 195 & 3 & 1.6 \\
\hline 19 & 1590 & 55 & 236 & 1340 & 45 & 163 & 180 & 3 & 1.5 \\
\hline 20 & 1760 & 79 & 375 & 1260 & 30 & 102 & 168 & 3 & 1.4 \\
\hline 21 & 2140 & 105 & 607 & 1100 & 27 & 80 & 158 & 3 & 1.3 \\
\hline 22 & 2900 & 178 & 1390 & 1060 & 35 & 100 & 148 & 3 & 1.2 \\
\hline 23 & 2770 & 168 & 1260 & 1110 & 31 & 93 & 140 & 3 & 1.1 \\
\hline 24 & 1910 & 94 & 485 & 1140 & 23 & 71 & 132 & 2 & .71 \\
\hline 25 & 1510 & 51 & 208 & 1020 & 24 & 68 & 126 & 2 & .68 \\
\hline 26 & 1410 & 38 & 145 & 970 & 23 & 60 & 119 & 2 & .64 \\
\hline 27 & 1520 & 46 & 189 & 950 & 24 & 62 & 114 & 2 & .62 \\
\hline 28 & 1960 & 84 & 445 & 870 & 16 & 38 & 108 & I & .29 \\
\hline 29 & 2290 & 98 & 606 & 810 & 23 & 50 & 102 & $i$ & .28 \\
\hline 30 & 2040 & 72 & 397 & 900 & 28 & 68 & 98 & $i$ & .26 \\
\hline 31 & -- & - & - & 860 & 20 & 46 & -- & - & - \\
\hline \multirow[t]{5}{*}{ TOIAL } & 49180 & - & 11500 & 47550 & -- & 11759 & 9503 & -- & 170.78 \\
\hline & \multicolumn{3}{|c|}{ JULy } & \multicolumn{3}{|c|}{ AUGUST } & \multicolumn{3}{|c|}{ SEPTEMBER } \\
\hline & & MEAN & & & MEAN & & & MEAN & \\
\hline & MEAN & CONCEN- & SEDIMENT & MEAN & CONCEN- & SEDIMENT & MEAN & CONCEN- & SEDIMENT \\
\hline & $\begin{array}{l}\text { DISCHARGE } \\
\text { (CFS) }\end{array}$ & $\begin{array}{l}\text { TRAIION } \\
\text { (MGIL) }\end{array}$ & $\begin{array}{l}\text { DISCHARGE } \\
\text { (TONS/DAY) }\end{array}$ & $\begin{array}{l}\text { DI SCHARGE } \\
\text { (CFS) }\end{array}$ & TRATION & $\begin{array}{l}\text { DISCHARGE } \\
\text { (TONS/DAY) }\end{array}$ & $\begin{array}{l}\text { DISCHARGE } \\
\text { (CFSI) }\end{array}$ & TRATION & DISCHARGE \\
\hline & & & & & & & & & (TONS/DAY) \\
\hline 1 & 93 & 2 & .50 & 18 & 1 & .05 & 11 & l & .03 \\
\hline 2 & 87 & 2 & .47 & 18 & i & .05 & ii & $i$ & .03 \\
\hline 3 & 81 & 2 & .44 & 17 & i & .05 & ii & i & .03 \\
\hline 4 & 77 & 2 & .42 & 17 & i & .05 & 11 & 1 & .03 \\
\hline 5 & 73 & 3 & .59 & 16 & $i$ & .04 & 10 & 1 & .03 \\
\hline 6 & 70 & 3 & .57 & 16 & 1 & .04 & 10 & 1 & .03 \\
\hline 7 & 67 & 3 & .54 & 16 & 1 & .04 & 10 & i & .03 \\
\hline 8 & 65 & 4 & .70 & is & i & .04 & 10 & i & .03 \\
\hline 9 & 81 & 4 & .66 & 15 & 1 & .04 & 10 & 1 & .03 \\
\hline 10 & 58 & 4 & .63 & 15 & i & .04 & 10 & i & .03 \\
\hline 11 & 56 & 3 & .45 & 14 & 1 & .04 & 10 & 1 & .03 \\
\hline 12 & 53 & 3 & .43 & 14 & i & .04 & 10 & 1 & .03 \\
\hline 13 & 50 & 2 & .27 & 14 & $i$ & .04 & 10 & 1 & .03 \\
\hline 14 & 48 & 2 & .26 & 13 & i & .04 & 10 & $i$ & .03 \\
\hline 15 & 45 & 2 & .24 & 13 & 1 & .04 & 10 & i & .03 \\
\hline 16 & 41 & 2 & .22 & 13 & 1 & .04 & 10 & 1 & .03 \\
\hline 17 & 38 & $i$ & .10 & 13 & $\mathrm{i}$ & .04 & 9.8 & 1 & .03 \\
\hline 18 & 36 & $\mathrm{i}$ & .10 & 12 & i & .03 & 9.8 & 1 & .03 \\
\hline 19 & 34 & i & .09 & 12 & I & .03 & 9.8 & I & .03 \\
\hline 20 & 32 & $i$ & .09 & 12 & $\mathrm{i}$ & .03 & 9.8 & $\mathrm{i}$ & .03 \\
\hline 21 & 30 & 1 & .08 & 12 & 1 & .03 & 9.8 & 1 & .03 \\
\hline 22 & 29 & $i$ & .08 & 12 & $i$ & .03 & 9.8 & $i$ & .03 \\
\hline 23 & 27 & $i$ & .07 & 12 & 1 & .03 & 9.8 & i & .03 \\
\hline 24 & 26 & $i$ & .07 & 12 & i & .03 & 9.8 & i & .03 \\
\hline 25 & 24 & i & .06 & 11 & $i$ & .03 & 9.8 & $i$ & .03 \\
\hline 26 & 23 & 1 & .06 & 11 & 1 & .03 & 9.8 & 1 & .03 \\
\hline 27 & 22 & $i$ & .06 & 11 & 1 & .03 & 9.8 & $i$ & .03 \\
\hline 28 & 22 & 2 & .12 & ii & 1 & .03 & 9.8 & i & .03 \\
\hline 29 & 21 & 2 & .11 & 11 & $i$ & .03 & 9.8 & $i$ & .03 \\
\hline 30 & 20 & 1 & .05 & 11 & i & .03 & 9.8 & $i$ & .03 \\
\hline 31 & 19 & 1 & .05 & il & i & .03 & - & -- & -- \\
\hline TOTAL & 1428 & -- & 8.58 & 418 & -- & 1.14 & 301.2 & -- & .90 \\
\hline TOTAL & CHARGE FO & YEAR & -DAYSI & & & & & & 389067.6 \\
\hline TOTAL & PENDED-SE & & E FOR & YEAR (TONS) & & & & & .7 .40 \\
\hline
\end{tabular}


11472900 BLACK BUTTE RIVER NEAR COVELO, CALIF,

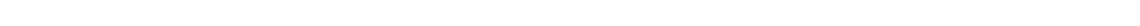
$10 \mathrm{ft}$ upstream from highay bridge, 0.5 m1lo upstream from mouth, and $\theta, 5$ miles oast of covelo.

DRAINAGE AREA. -162 sq $m 1$.

PERIOD OF RECORD. -.Chemical analyses: November 1964 to September 1966.

Specific conductance: October 1966 to September 1968.

Water temperature: May 1964 to September 1969.

Sediment records: October 1965 to September 1969.

EXTREMES, $-1988-69$ :

Water temperatures: Minimum, freez1ng point Dec, 20-23, Jan, 17

Sediment concentrat1ons: Maximum da11y, 8,170 ag/1 Jan, 20; m1nimum da11y, 1 mg/1 on many daye during October,

November, and July to Saptember. Niment discharge: Maximum daily, 218,000 tons Jan. 20; min1mum daily, 0.01 ton on many days during October,
No vember, and September.

Perlod of record;

Water temperatures: Maximum (1964-68), 31. $5^{\circ} \mathrm{C}$ Aug. 23, 1964, Aug. 2, 1967; min1mum (1965-69), freezing point on several days in $1965-69$

Sediment concentrations: Maximum dally, 10,600 mg/1 Jan. 4, 1968; minimum da1ly, 2 mg/1 on many days in $1967-69$. Sedimant d1scharge: Maximum da1ly, 218,000 tons Jan, 20, 1989; minimum da1ly, 0,01 ton on many daye 1n
1967-69.

REMARKS. --No tempe rature record Jan. 20 to Sept. 13; probe out of water. Where no maxi num or minimum $1 \mathrm{~s}$ shown, temperature is once-da1ly reading.

TEMPERATURE $\left({ }^{\circ} \mathrm{C}\right)$ OF FATER, WATER YEAR OCTOBER 1988 TO SEPTEMBER 1969

DAY

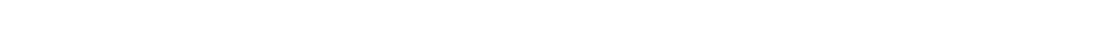

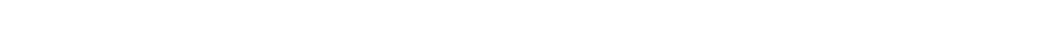

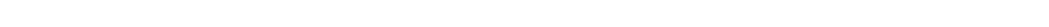

NOVFMER.

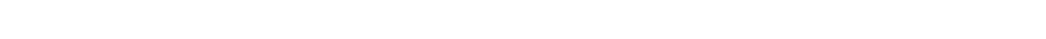

DECEMBER. --

MAXIMUM 7 6 $6 \begin{array}{llllllllllllllllllllllllllllllll} & 5 & 8 & 5 & 5 & 7 & 7 & 7 & 5 & 3 & 4 & 5 & 4 & 4 & 4 & 3 & 3 & 2 & 2 & 0 & 3 & 4 & 3 & 2 & 2 & 3 & 3 & 3\end{array}$

MINIMUM

ANUARY.

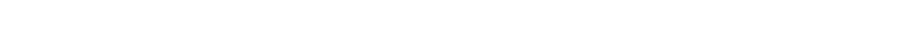

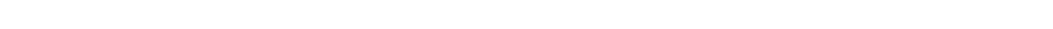

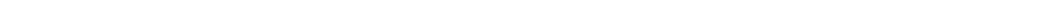

MAXIMUM -- --

MINIMUM --

MAXIMUM

MINIMUM -.

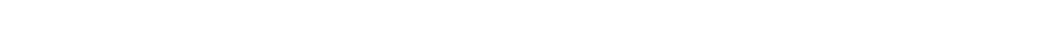
MAXIMUM

MANIMUM

MAXімÜ

MINIMUM

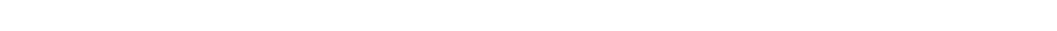

MAXIMUM :-

MINIMUM

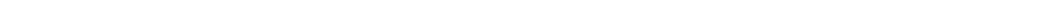

MAXIMUM

AJGUST.

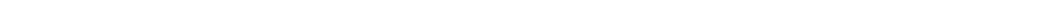

MAXIMUM

SEPTEMBER --

MAXIMUM -_ -

MAXIMUM

PARTICLE-SIZE DISTR 1BUTION OF SUSPENDED SED1MENT, WATER YEAR DCTOBER 1968 TO SEPTEMBER 1969
IMETHOOS OF ANALYS1S: B. BOT TOM WITHDRAWAL TUHE: C. CHEMICALLY DISPERSEDi N, IN NATIVE WATER; P. PIPET; S, SIEVE; V. VISUAL ACCUMULATION TUBE; W, IN DISTILLED WATERI

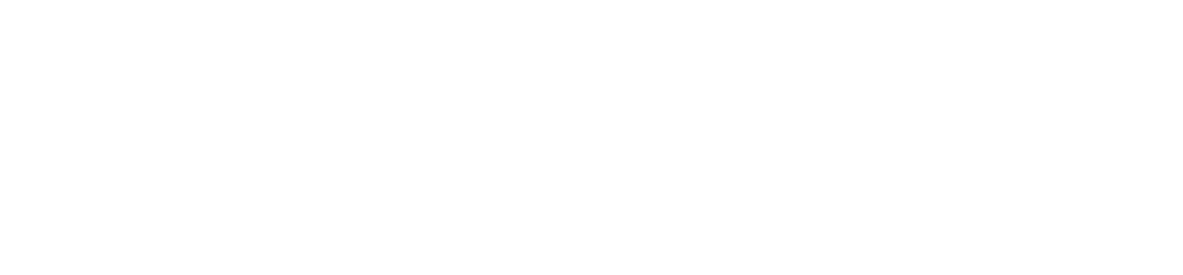


11172900 BLACK BUTTE RIVER NEAR COVELO, CALIF.--Cont1nued

SUSPENDED-SEDIMENT DISCHARGE, WATER YEAR OCTOBER 1968 TO SEPTEMBER 1969

\begin{tabular}{|c|c|c|c|c|c|c|c|c|c|}
\hline \multirow[b]{2}{*}{ DAY } & \multicolumn{3}{|c|}{ OCTOBER } & \multicolumn{3}{|c|}{ NOVEMBER } & \multicolumn{3}{|c|}{ DECEMBER } \\
\hline & $\begin{array}{l}\text { MEAN } \\
\text { DISCHARGE } \\
\text { (CFS) }\end{array}$ & $\begin{array}{l}\text { MEAN } \\
\text { CDNCEN- } \\
\text { TRATIUN } \\
\text { (MG/L) }\end{array}$ & $\begin{array}{l}\text { SEDIMENT } \\
\text { DISCHARGE } \\
\text { (TDNS/DAY) }\end{array}$ & $\begin{array}{l}\text { MEAN } \\
\text { DISCHARGE } \\
\text { (CFS) }\end{array}$ & $\begin{array}{l}\text { MEAN } \\
\text { CONCEN- } \\
\text { TRATION } \\
\text { IMG/LI) }\end{array}$ & $\begin{array}{l}\text { SEDIMENT } \\
\text { D I SCHARGE } \\
\text { (TONS / DAY) }\end{array}$ & $\begin{array}{l}\text { MEAN } \\
\text { OISCHARGE } \\
\text { (CFS) }\end{array}$ & $\begin{array}{l}\text { MEAN } \\
\text { CONCEN- } \\
\text { TRATION } \\
\text { (MG /L) }\end{array}$ & $\begin{array}{l}\text { SEDIMENT } \\
\text { DISCHARGE } \\
\text { (TONS/DAY) }\end{array}$ \\
\hline 1 & 3.0 & 1 & .01 & 5.3 & 1 & .01 & 79 & 12 & 2.6 \\
\hline 2 & 3.0 & $i$ & .01 & 23 & 62 & 4.3 & 55 & 6 & .89 \\
\hline 3 & 3.0 & $i$ & .01 & 36 & 10 & .97 & 44 & 3 & .36 \\
\hline 4 & 3.0 & $i$ & .01 & 21 & 4 & .23 & 39 & 2 & .21 \\
\hline 5 & 3.0 & $i$ & .01 & 16 & 2 & .09 & 50 & 4 & .54 \\
\hline 6 & 3.0 & 1 & .01 & 15 & 2 & .08 & 62 & $?$ & 1.2 \\
\hline 3 & 3.0 & 1 & .01 & 14 & 1 & .04 & 61 & 4 & .66 \\
\hline 8 & 3.3 & $i$ & .01 & 15 & $i$ & .04 & 145 & 35 & 14 \\
\hline 9 & 3.3 & $i$ & .01 & 19 & 2 & .10 & נ11 & 3 & .90 \\
\hline 10 & 3.3 & 2 & .02 & 20 & 2 & .11 & 3490 & 3710 & 48100 \\
\hline 12 & 5.0 & 3 & .04 & 24 & 5 & .55 & 702 & 580 & 1100 \\
\hline 12 & 8.6 & 4 & .09 & 71 & 15 & 3.0 & 156 & 130 & 55 \\
\hline 13 & 14 & 6 & .23 & 35 & 9 & .85 & 170 & 362 & 374 \\
\hline 14 & 12 & 4 & .13 & 33 & 47 & 5.6 & 831 & 374 & 888 \\
\hline 15 & 9.4 & 4 & .10 & 45 & 74 & 9.4 & 2830 & 1600 & 16600 \\
\hline 16 & 8.6 & 4 & .09 & 54 & 68 & 9.9 & 1010 & 290 & 791 \\
\hline i? & 8.1 & 4 & .09 & 70 & 18 & 3.4 & 250 & 95 & 64 \\
\hline 18 & 7.1 & 4 & .08 & 412 & 248 & 309 & 154 & 62 & 26 \\
\hline 19 & 6.5 & 4 & .07 & 140 & 19 & 7.2 & 125 & 37 & 12 \\
\hline 20 & 6.2 & 3 & .05 & 59 & 6 & .96 & 75 & 20 & 4.1 \\
\hline 21 & 5.9 & 3 & .05 & 39 & 4 & .42 & 54 & 11 & 1.6 \\
\hline 22 & 5.9 & 3 & .05 & 32 & 2 & .17 & 55 & 10 & 1.5 \\
\hline 23 & 5.6 & 3 & .05 & 29 & 2 & .16 & 4950 & 3820 & 61500 \\
\hline 24 & 5.3 & 2 & .03 & 49 & 18 & 2.7 & 3570 & 2160 & 21700 \\
\hline 25 & 5.3 & 2 & .03 & 94 & 15 & 4.4 & 2040 & 940 & 5) 80 \\
\hline 26 & 5.3 & 2 & .03 & 50 & 7 & .95 & 930 & 340 & 854 \\
\hline 27 & 5.0 & 2 & .03 & 41 & 4 & .44 & 398 & 152 & 163 \\
\hline 28 & 5.0 & 2 & .01 & 38 & 3 & .31 & 494 & 355 & 527 \\
\hline 29 & 5.2 & $i$ & .01 & 42 & 6 & .80 & 574 & 176 & 273 \\
\hline 30 & 5.3 & 1 & .01 & 104 & 34 & 9.7 & 365 & 105 & 103 \\
\hline 31 & 5.6 & i & .02 & - & -- & - & 270 & 76 & 55 \\
\hline \multirow[t]{5}{*}{ TUTAL } & 175.8 & -- & 1.40 & 1645.3 & -- & 375.88 & 24139 & -- & 158393.56 \\
\hline & & JANUARY & & & FEBRUARY & & & MARCH & \\
\hline & & MEAN & & & MEAN & & & MEAN & \\
\hline & MEAN & $\begin{array}{l}\text { CONCENA- } \\
\text { TRATION }\end{array}$ & SEDIMENT & MEAN & CONCEN- & SEDIMENT & $\begin{array}{l}\text { MEAN } \\
\text { MISCHARGF }\end{array}$ & CONCEN- & SEDIMENT \\
\hline & $\begin{array}{l}\text { DISCHARGE } \\
\text { (CFS) }\end{array}$ & $\begin{array}{l}\text { TRATIUN } \\
\text { (MG/L) }\end{array}$ & $\begin{array}{l}\text { DISCHARGE } \\
\text { (TONS/DAY) }\end{array}$ & $\begin{array}{l}\text { DISCHARGE } \\
\text { (CFS) }\end{array}$ & $\begin{array}{l}\text { TRATION } \\
(M G / L)\end{array}$ & $\begin{array}{l}\text { DISCHARGE } \\
\text { (IONS/DAY) }\end{array}$ & $\begin{array}{l}\text { DISCHARGE } \\
\text { (CFS) }\end{array}$ & $\begin{array}{l}\text { TRATIDN } \\
\text { (MG/L) }\end{array}$ & $\begin{array}{l}\text { DISCHARGE } \\
\text { (TONS/DAY) }\end{array}$ \\
\hline I & 246 & 56 & 37 & 730 & 790 & 1560 & 750 & 231 & 468 \\
\hline 7 & 227 & 50 & 31 & 720 & 750 & 1460 & 720 & 157 & 305 \\
\hline 3 & 275 & 81 & 60 & 675 & 560 & 1020 & 574 & 123 & 191 \\
\hline 4 & 720 & 226 & 439 & 693 & 570 & 1070 & 468 & 306 & 134 \\
\hline 5 & 1150 & 227 & 705 & 740 & 660 & 1320 & 404 & 78 & 85 \\
\hline 6 & $1] 90$ & 204 & 655 & 370 & 690 & 1430 & 284 & 70 & 54 \\
\hline 7 & 942 & 158 & 402 & 639 & 460 & 794 & 234 & 68 & 43 \\
\hline 8 & 919 & 120 & 298 & 790 & 1450 & 4750 & 184 & 64 & 32 \\
\hline 9 & 453 & 71 & 87 & 1840 & 2070 & 10600 & 162 & 67 & 29 \\
\hline 10 & 340 & 55 & 50 & 1550 & 1290 & 5400 & 135 & 60 & 22 \\
\hline 11 & 3270 & 3020 & 42300 & 3950 & 3690 & 40200 & 123 & 49 & 16 \\
\hline 12 & 6180 & 3560 & 60900 & 2320 & 1580 & 9900 & 112 & 42 & 13 \\
\hline 13 & 6500 & 4900 & 91900 & 1520 & 1100 & 4510 & 91 & 38 & 9.3 \\
\hline 14 & 2650 & 1810 & 13000 & 1530 & 1000 & 4130 & 86 & 35 & 8.1 \\
\hline is & 1580 & 910 & 3880 & 1800 & 1720 & 8360 & 95 & 44 & 11 \\
\hline 16 & 1060 & 620 & 1770 & 1520 & 1360 & 5580 & 123 & 61 & 20 \\
\hline 17 & 842 & 530 & 1200 & 1350 & 490 & 3790 & 462 & 599 & 807 \\
\hline 19 & $1] 80$ & 1190 & 5320 & 1220 & 420 & 1380 & 606 & 392 & 641 \\
\hline 19 & 7200 & 6150 & 148000 & 1130 & 350 & 1070 & 432 & 206 & 240 \\
\hline 20 & 9550 & 8170 & 218000 & 1040 & 290 & 814 & 450 & 218 & 265 \\
\hline 21 & 8480 & 75 TO & 177000 & 1040 & 275 & 772 & 376 & 171 & 174 \\
\hline 22 & 3250 & 4020 & 35300 & 1010 & 280 & 764 & 320 & 132 & 114 \\
\hline 23 & 1620 & 2460 & 10800 & 1040 & 252 & 708 & 415 & 158 & 177 \\
\hline 24 & 1130 & 1980 & 6040 & 1000 & 260 & 702 & 398 & 198 & 213 \\
\hline 25 & 3050 & 3510 & 31200 & 990 & 280 & 748 & 426 & 222 & 255 \\
\hline 26 & 5370 & 4680 & 73900 & 886 & 275 & 658 & 720 & 366 & 712 \\
\hline 27 & 1670 & 2210 & 9960 & 886 & 250 & 598 & 1030 & 640 & 1780 \\
\hline 28 & 1340 & 2600 & 5790 & 908 & 380 & 932 & 1170 & 780 & 2460 \\
\hline 29 & 1050 & 1060 & 3010 & - & - & -- & 1460 & 905 & 3570 \\
\hline 30 & 875 & 1040 & 2460 & - & -- & -- & 1830 & 1020 & 5040 \\
\hline 31 & 693 & 920 & 1720 & - & -- & -- & 1720 & 840 & 3900 \\
\hline TUTAL & 75002 & - & 946214 & 34287 & -- & 113020 & 16359 & - & 21788.4 \\
\hline
\end{tabular}


11472900 BLACK BUTTE RIVER NEAR COVELO, CALIF.--Continued SUSPENDED-SEDIMENT DISCHARGE, WATER YEAR OCTOBER 1968 TD SEPTEMBER 1969 APRIL MAY JUNE

oAY

CONCEN- SEDIMENT

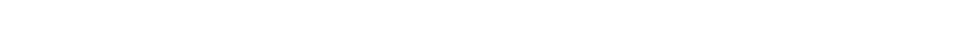

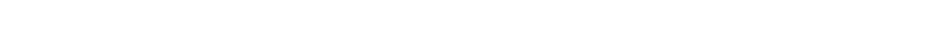

MEAN
OISCHARGE

MEAN

CONCFN- SEDIMENT

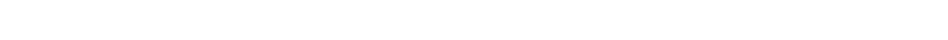

MEAN

MEAN
CONCEN- SEDIMENT

4

1
1
1
1
1
1
1
1
1
1
1
2
2
2
2
24
2
2
2
2
2
3
31

1290
1110
805
693

$\begin{array}{rrr}645 & 2250 & 760 \\ 490 & 1470 & 702 \\ 430 & 935 & 702 \\ 435 & 814 & 639 \\ 405 & 929 & 684\end{array}$

760
702
702

235396

$\begin{array}{ll}624 & 235 \\ 553 & 195\end{array}$

$\begin{array}{lll}540 & 1950 & 298\end{array}$

$\begin{array}{lll}567 & 134 & 205 \\ 537 & 126\end{array}$

593

$\begin{array}{ll}158 & 253 \\ 228 & 470 \\ 174 & 269\end{array}$

763
573
450
370

$\begin{array}{rrrr}573 & 174 & 269 & 864 \\ 450 & 112 & 136 & 720 \\ 370 & 90 & 90 & 630\end{array}$

$\begin{array}{rrrr}573 & 174 & 269 & 864 \\ 450 & 112 & 136 & 720 \\ 370 & 90 & 90 & 630\end{array}$

94
75
54
44

193
142
102
76

195
182
173
163

$20 \quad 11$

875
942
1010
1030

110

145
131
142

260
369

369
357
395

140

1030
1080

159

395
464

132
122
122

$\begin{array}{rr}1010 & 157 \\ 954 & 121 \\ 864 & 98 \\ 720 & 87 \\ 630 & 78\end{array}$

428
312
229

229
169
133

124

$\begin{array}{rr}90 & 101 \\ 112 & 172\end{array}$

417
569
712

712
648
719

124

98
128

$101 \quad 622$

172
238
171
248

622
630
598

598
543
469

58
58
41

41
31
26

133

$\begin{array}{ll}99 & 73 \\ 66 & 74 \\ 45 & 94\end{array}$

987
1460
1260

1260
757
462

448
1180

$\begin{array}{rr}168 & 448 \\ 300 & 1180 \\ 247 & 840\end{array}$

438
420

438
420
409

368

370
340

22

22
21
23

23
24
24

33

$86 \quad 109$

$\begin{array}{rr}86 & 109 \\ 96 & 132 \\ 131 & 266 \\ 139 & 316\end{array}$

469
508
752
908

800

132
316

101

313
306
249
233
228
209

10

22

26
24
25
24

$24 \quad 6$

14
12
8.7
8.8

8.8
9.2

13856

18978

9.2

4270.3

AUGUST

JULY

CONCEN

TRATION DEDIMENT

DISCHARGE DISCHARGE

$\begin{array}{cll}\text { MEAN } & \text { CONCEN- } & \text { SEDIMENT } \\ \text { DISCHARGE } & \text { TRATIUN } & \text { DISCHARGE }\end{array}$

TRATIUN DISCHARGE
(MG/L) (TONS/DAY)

DISCHARGE
(CFS) (CFS)
(CFARGE

Dar

4

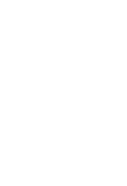

$\begin{array}{ll}.40 & 12 \\ .36 & 12 \\ .35 & 12 \\ .73 & 12 \\ .42 & 11\end{array}$

12
12
12
12
11

.06
.06
.03
.03

6.4
6.2

5.8
5.7

5.7
5.6

5.6

$40 \quad 11$

.45
.43
.42

10
9.8
9.5

.03
.05
.05

.05
.05
.05

5.6
5.5
5.5
5.4

CONCEN- SEDIMENT TRATION DISCHARGE
(MGIL) (TONS/DAY)

.31
.23
.14
.14

9.2

9.0
8.7

8.7
8.6
8.5

.05
.07
.07

.07
.07

5.4

5.4
5.3
5.3

5.3
5.3
5.3

.07

$\begin{array}{ll}.12 & 8.5 \\ .11 & 8.4\end{array}$

8.4
8.4
8.4

8.4
8.1

.05
.02
.02
.02

5.3
5.3
5.3
5.3

1
1
1
1
1
1
1
1

.02

.02
.02
.02
.02

.02
.02

.10

7.6
7.2
6.9

6.9
6.7
6.6

.02
.02
.02
.02

5.2
5.0
5.0

5.0
5.0
5.4

6.6

6.6

6.4

6.4
6.4

5.5
5.2

5.0

5.0
5.0
5.0

268.5

TOTAL

779

6.17

61.7

1.17

TOTAL SUSPENDED-SEDIMENT DISCHARGE FOR YEAR (TONS)

196557.3
1258007.09 
11473000 MIDDLE FORK EEL RIVER BELOW BLACK BUTTE RIVER, NEAR COVELO, CALIF,

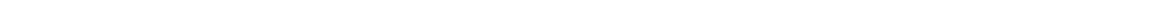
at site of former gaging station, 0.2 mile downstream from Black Butte River and 8.6 miles east of Covelo.

DRAINAGE AREA. $-\infty 367 \mathrm{sq} \mathrm{mi}$.

PERIOD OF RECORD. --Chemical analyses: November 1964 to September 1966

Water temperatures: July to November 1961, October 1962 to September 1969.

Sediment records: October 1962 to September 1967.

EXTREMES. --Period of record (1962-63, 1965-66, 1967-68):

Water temperatures: Maximum, $27,0^{\circ} \mathrm{C}$ on several days in 1963, 1966, and 1968.

REMARKS.--Recorder stopped Nov. 1, Dec. 4-21; recorder malfunction Dec, 26 to Jan, 9, Feb. 12 to Mar. 31, Apr. 29 to June 3, July 17 to Aug. 20 ; probe out of water Sept. 21-30.

TEMPERATURE $\left({ }^{\circ} \mathrm{C}\right)$ OF WATER, WATER YEAR OCTOBER 1968 TO SEPTEMBER 1969

DAY

MONTH

\begin{tabular}{llllllllllllllllllllllllllllllll}
\hline & 2 & 4 & 5 & 6 & 7 & 8 & 9 & 10 & 11 & 12 & 13 & 14 & 15 & 16 & 17 & 18 & 19 & 20 & 21 & 22 & 23 & 24 & 25 & 26 & 27 & 28 & 29 & 30 & 31 & AGER
\end{tabular}

OC TOBER

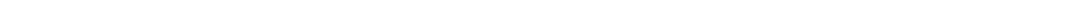

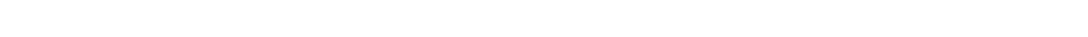

NOVEMBER

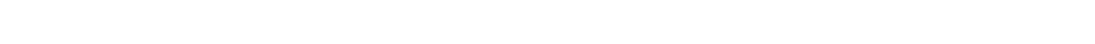

OECEMBER

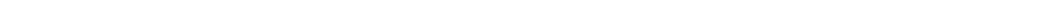

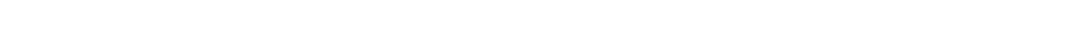

JANUARY

MAXIMUM

MINIMUM

FEBRUARY

$\begin{array}{llllllllllllllllllllllllllll}4 & 5 & 6 & 7 & 7 & 6 & 6 & 5 & 5 & 6 & 7 & 7 & 7 & 6 & 6 & 7 & 6 & 5 & 5 & 4 & 4 & 4\end{array}$

MAXIMUA

MARCH

MAXIMUM

MINIMUM

PRIL

MAXIMUM

MINIMUM

mar

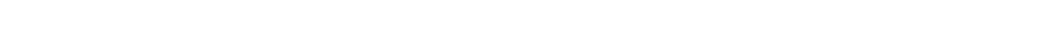

JUNF

MAXIMUA MINIMUA

JULY

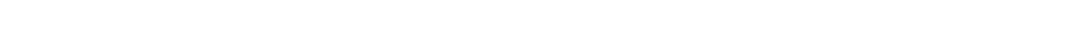
AUGUST

MAXIMUM

MINIMUM

SEPIEMBER

MAXIMUM

MINIMUM

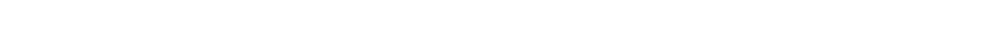

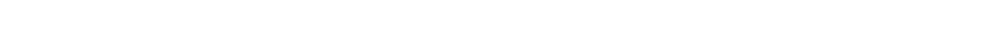


11473800 ELK CREEK NEAR HEARST, CALIF.

LOCATION.--Lat $39^{\circ} 38^{\prime} 57^{\prime \prime}$, long $123^{\circ} 07^{\prime} 12^{\prime \prime}$, in NE 1 sec, 30 , T.21 N., R. 11 w., Mendocino County, temperature recorder at gaging station on right bank, $300 \mathrm{ft}$ upstream from unnamed tributary and $13.5 \mathrm{~m} 1 \mathrm{les}$ northeast
of hearst.

DRAI NAGE AREA, --84.1 sq $\mathrm{ml}$.

PERIOD OF RECORD, -- Water temperatures: October 1964 to September 1969.

Sediment records: October 1965 to September 1969 (partial records).

EXTRE MES . $-1968-69$ :

Water temperatures: Maximum, $22.0^{\circ} \mathrm{C}$ July 23 to Aug. 8 .

Period of record (1965-67, 1968-69):

Water temperatures: Maximum, $34,5^{\circ} \mathrm{C}$ Aug. 2, 1967; minimum (1966-67), 3. $0^{\circ} \mathrm{C}$ Feb, $19-22,1967$.

REMARKS.--Tempe rature recorder malf unction Dec. 3 to Jan. 6.

TEMPERATURE $\left({ }^{\circ} \mathrm{C}\right)$ OF WATER, WATER YEAR OCTOBER 1968 TO SEPTEMBER 1969

DAY

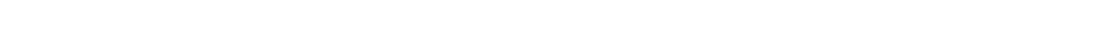

DCTIOEER

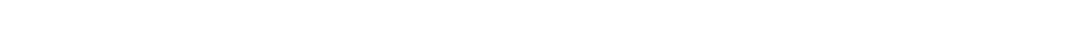

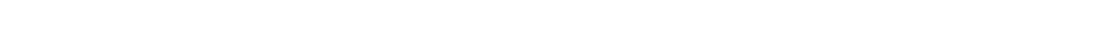

NUVEMBE?

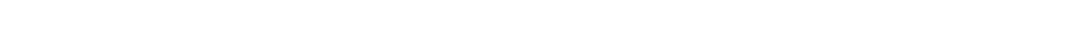

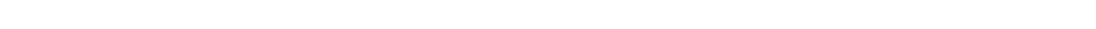

DFEMBER

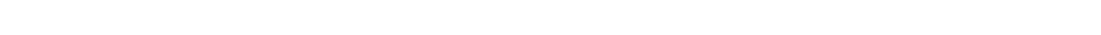

MINIMUM

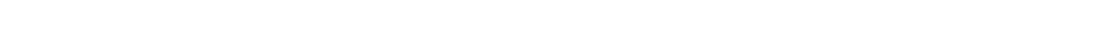

FF RRUARY

MAXIMUM 78 B

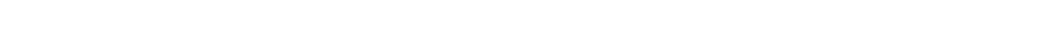

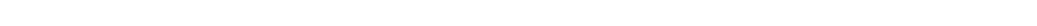

MINIMUM

ADRIL

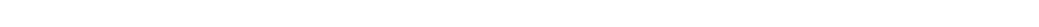

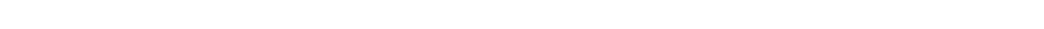

MAX[MUM $12 \quad 13 \quad 13 \quad 14 \quad 13 \quad 14 \quad 13 \quad 12 \quad 12 \quad 13 \quad 13 \quad 13 \quad 14 \quad 14 \quad 15 \quad 15 \quad 16 \quad 15 \quad 15 \quad 15 \quad 15 \quad 15 \quad 16 \quad 16 \quad 16 \quad 17 \quad 17 \quad 17 \quad 15 \quad 15 \quad 15$ JUNE

MAXIMUM $15 \quad 16 \quad 16 \quad 17 \quad 17 \quad 17 \quad 17 \quad 18 \quad 17 \quad 17 \quad 17 \quad 16 \quad 16 \quad 16 \quad 16 \quad 17 \quad 17 \quad 18 \quad 18 \quad 18 \quad 18 \quad 18 \quad 18 \quad 18 \quad 18 \quad 18 \quad 18 \quad 18 \quad 18 \quad 18 \quad \cdots$

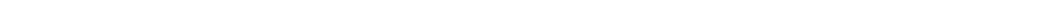
JULY

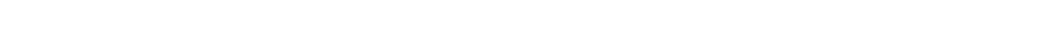

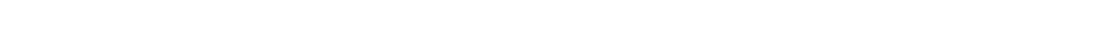
ALGUST

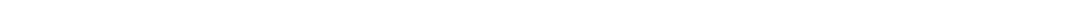

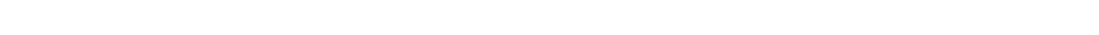

SEPTEMBED

$\begin{array}{lllllllllllllllllllllllllllllllll}\text { MAXIMUM } & 20 & 20 & 20 & 20 & 20 & 20 & 20 & 20 & 20 & 20 & 20 & 20 & 20 & 20 & 20 & 20 & 20 & 20 & 20 & 20 & 19 & 19 & 19 & 18 & 18 & 18 & 18 & 18 & 18 & 18 & - \\ \text { MINIMUM } & 20 & 20 & 20 & 20 & 20 & 20 & 20 & 20 & 20 & 20 & 20 & 20 & 20 & 20 & 20 & 20 & 20 & 20 & 20 & 19 & 19 & 18 & 18 & 18 & 18 & 18 & 18 & 18 & 17 & 17 & --\end{array}$

PARTICLE-SIZE DISTRIBUTION DF SUSPENDED SEDIMENT, WATER YEAR DCTOBER 1968 TD SEPTEMBER 1969

(METHODS OF ANALYSIS: B, BOTTOM WITHDRAWAL TUBE; C, CHEMICALLY DISPERSED; N, IN NATIVE WATER; P, PIPET; S, SIEVE $v$, VISUAL ACCUMULATION TUBE; W, IN DISTILLED WATER

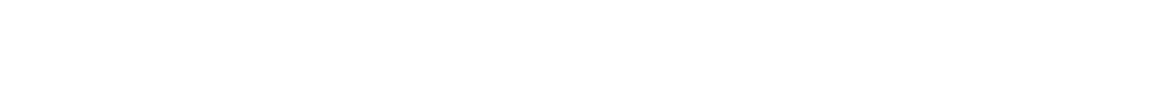

$\begin{array}{llrrrr}\text { OCT } & 9,1968 & 1125 & 13 & 1.7 \\ \text { NOV } & 6 \ldots \ldots \ldots & 1205 & 12 & 11 \\ \text { DEC } & 3 \ldots \ldots . & 1205 & 5 & 26 \\ \text { JAN } & 7,1969 & 1145 & 6 & 314 & 1 \\ \text { APR } & 3 \ldots \cdots & 1520 & 11 & 291 \\ \text { MAY } & 1 \ldots \ldots & 1325 & 12 & 226 \\ \text { JUN } & 3 \ldots \ldots & 0840 & 16 & 58\end{array}$

2
4
1
124
85
32
4

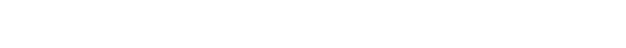

$$
\begin{aligned}
& \begin{array}{llllllllllll}
105^{\circ} & -07 & -- & -- & -- & -- & -5 & -- & -- & -- & \cdots & -\infty
\end{array} \\
& \begin{array}{lllllllllllll}
67 & 31 & 40 & 50 & 58 & 53 & 60 & 64 & 69 & 80 & 90 & 100 & \text { SBKC }
\end{array}
\end{aligned}
$$

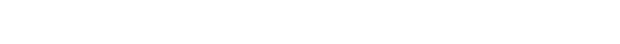


11473900 MIDDLE FORK EEL RIVER NEAR DOS RIOS, CALIF.

LOCATION. --Lat $39^{\circ} 42^{\prime} 23^{\prime \prime}$, long $123^{\circ} 19^{\prime} 27^{\prime \prime}$, in NEł⿱ SEł sec. 5, T. 21 N., R.13 w., Mendocino Caunty, at gaging station 0.6 mile upstream from Eastman Creek, 1.7 miles southeast of Dos Rios, and $1.9 \mathrm{miles}$ upstream from mouth.

DRAINAGE AREA. $-745 \mathrm{sq} \mathrm{mi}$.

PERIOD OF RECORD. --Chemical analyses: October 1958 to September 1966.

Specific conductance: October 1966 to September 1967

October 1960 to September 1969

Sediment records: October 1957 to September 1969.

EXTREMES $--1968-69$

Water temperatures: Minimum, freezing point Dec 22.

Sediment concentrations: Maximum daily, 5,990 mg/1 Jan, 21; minimum daily, $1 \mathrm{mg} / 1$ on many days during Octo-

ber and July to September.

Sediment discharge: Maximum daily, 741,000 tons Jan, 20; minimum daily, 0.04 ton on several days during October and September.

Period of record:

Water temperatures (1968-69): Minimum, freezing point Dec, 22,1968

Sediment concentrations: Maximum dally, $11,800 \mathrm{mg} / 1 \mathrm{Jan} .4,1966 ; \mathrm{minimum} \mathrm{dally,} 1 \mathrm{mg} / 1$ on $\mathrm{many}$ days in 1965-69.

Sediment discharge: Maximum daily, 1,430,000 tons Jan. 4, 1966; minimum daily, 0.04 ton on several days in 1966 and 1968-69.

TEMPERATURE $\left({ }^{\circ} \mathrm{C}\right)$ OF MATER, TATER YEAR OCTOBER 1968 TO SEPTEMBER 1969 (ONCE-DAILY MEASUREMENT)

DAY

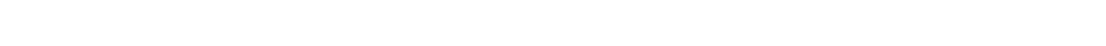

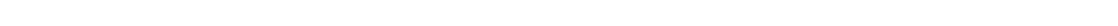

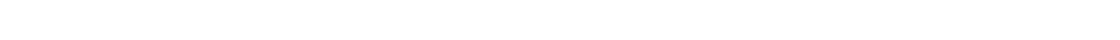
$\begin{array}{lllllllllllllllllllllllllllllllllllll}\text { JANUARY.. } & 5 & 6 & 7 & 6 & 7 & 6 & 5 & 5 & 4 & 4 & 6 & 7 & 8 & 7 & 6 & 6 & 4 & 5 & 8 & 9 & 8 & 5 & 4 & 5 & 8 & 6 & 4 & 4 & 4 & 4 & 4 & 6\end{array}$ $\begin{array}{llllllllllllllllllllllllllllllllll}\text { FEBRUARY. } & 5 & 6 & 5 & 4 & 4 & 7 & 6 & 6 & 7 & 7 & 8 & 7 & 6 & 6 & 7 & 7 & 7 & 6 & 7 & 7 & 6 & 5 & 6 & 6 & 4 & 4 & 7 & 7 & -2 & -- & -1 & 6 \\ \text { MARCH.... } & 6 & 5 & 6 & 7 & 6 & 7 & 6 & 7 & 6 & 6 & 6 & 7 & 7 & 7 & 6 & 7 & 8 & 8 & 6 & 8 & 7 & 8 & 7 & 7 & 8 & 9 & 9 & 8 & 9 & 9 & 11 & 7\end{array}$ APP.1L...

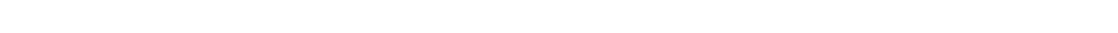

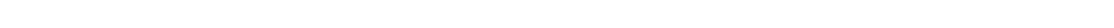

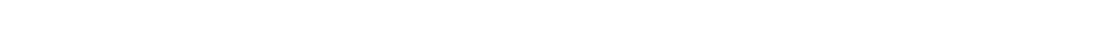

SUSPENDED-SEDIMENT DISCHARGE, HATER YEAR OCTOBER 1968 TO SEPTEMBER 1969

OC TOBER

$\begin{array}{ccc}\text { MEAN } & \\ \text { MEAN } & \text { CONCEN- } & \text { SEDIMENT } \\ \text { OISCHARGE } & \text { TRATION } & \text { DISCHARG } \\ \text { (CFS) } & \text { (MG/L) } & \text { (TONS/DAY }\end{array}$

NOVEMBER

MEAN

MEAN
OISCHARGE
(CFS) CONCEN(MG/L)

$$
\begin{aligned}
& .04 \\
& .04 \\
& .04 \\
& .04 \\
& .04 \\
& .05 \\
& .05
\end{aligned}
$$

131
296

296
532

244

188

180

153
131

129

188

.06
.12
1.4

173
628

628
440
316

252
195

135

$16 \quad 1$

17

101
90
77

57

60
55

55
52
49

49
37

43
42

42
40
42

86
160

TOIAL 1923

3
10
24
16
8
2
2
2
3
4
7
5
537
125
83
84
37
27
583
320
60
21
20
20
48
206
33
10
6
6
54
$7-$
$7-$

DECEMBER

MEAN

CONCEN- SEDIMENT DISCHARGE DISCHARGE
(TONS/DAY)
(CFSI $\begin{gathered}\text { IMAIION DIST DCHARG } \\ \text { (TDNS/DAY }\end{gathered}$

$\begin{array}{cr}1.1 & 664 \\ 17 & 526 \\ 34 & 370 \\ 11 & 348 \\ 4.1 & 344 \\ & \\ .97 & 460 \\ 1.83 & 420 \\ 1.1 & 1090 \\ 3.6 & 1000 \\ & 19400\end{array}$

$\begin{array}{rc}62 & 111 \\ 25 & 36 \\ 9 & 9.0 \\ 6 & 5.6 \\ 11 & 10 \\ 29 & 36 \\ 12 & 14 \\ 92 & 271 \\ 104 & 281 \\ 150 & 312000 \\ & \\ 1580 & 40600 \\ 470 & 2970 \\ 797 & 5640 \\ 1460 & 19800 \\ 3020 & 114000 \\ 964 & 14800 \\ 450 & 2880 \\ 510 & 2310 \\ 290 & 1240 \\ 110 & 377 \\ 75 & 221 \\ 100 & 281 \\ 4570 & 360000 \\ 3580 & 230000 \\ 1690 & 55700 \\ 880 & 13900 \\ 580 & 5070 \\ 770 & 8050 \\ 490 & 4830 \\ 260 & 1930 \\ 340 & 2070 \\ & \\ 100 & \end{array}$

$6052.00 \quad 146552$ 
11473900 MIDDLE FORK EEL RIVER NEAR DOS RIOS, CALIF.--Continued SUSPENDED-SEDIMENT DISCHARGE, WATER YEAR OCTOBER 1968 TO SEPTEMBER 1969

\begin{tabular}{|c|c|c|c|c|c|c|c|c|c|}
\hline \multirow[b]{2}{*}{ DAY } & \multicolumn{3}{|c|}{ JANUARY } & \multicolumn{3}{|c|}{ FEBRUARY } & \multicolumn{3}{|c|}{ MARCH } \\
\hline & $\begin{array}{l}\text { MEAN } \\
\text { DISCHARGE } \\
\text { (CFS) }\end{array}$ & $\begin{array}{l}\text { MEAN } \\
\text { CONCEN- } \\
\text { TRATION } \\
\text { (MG/L) }\end{array}$ & $\begin{array}{l}\text { SEDIMENT } \\
\text { DI SCHARGE } \\
\text { (TONS/DAY) }\end{array}$ & $\begin{array}{l}\text { MEAN } \\
\text { DISCHARGE } \\
\text { (CFS) }\end{array}$ & $\begin{array}{l}\text { MEAN } \\
\text { CONCEN- } \\
\text { TRATION } \\
\text { (MG/L) }\end{array}$ & $\begin{array}{l}\text { SEDIMENT } \\
\text { DISCHARGE } \\
\text { (TONS/DAY) }\end{array}$ & $\begin{array}{l}\text { MEAN } \\
\text { DISCHARGE } \\
\text { (CFS) }\end{array}$ & $\begin{array}{l}\text { MEAN } \\
\text { CONCEN- } \\
\text { TRAT ION } \\
\text { (MG/L) }\end{array}$ & $\begin{array}{l}\text { SEDIMENT } \\
\text { DISCHARGE } \\
\text { (TONS/DAY) }\end{array}$ \\
\hline 1 & 2060 & 380 & 2110 & 3980 & 680 & 7310 & 3480 & 510 & 4790 \\
\hline 2 & 2000 & 250 & 1350 & 3310 & 490 & 4380 & 3050 & 540 & 4450 \\
\hline 3 & 2090 & 350 & 1980 & 3560 & 490 & 4710 & 3130 & 490 & 4140 \\
\hline 4 & 2600 & 490 & 3440 & 3360 & 580 & 5260 & 2620 & 290 & 2050 \\
\hline 5 & 3080 & 430 & 3580 & 4460 & 790 & 9510 & 2510 & 315 & 2130 \\
\hline 6 & 3160 & 320 & 2730 & 4800 & 730 & 9460 & 2480 & 320 & 2080 \\
\hline 7 & 2960 & 300 & 2400 & 3960 & 405 & 4330 & 2340 & 280 & $177 \mathrm{C}$ \\
\hline B & 2720 & 295 & 2170 & 4470 & 810 & 9780 & 2210 & 230 & 1370 \\
\hline 9 & 2440 & 215 & 1420 & 13400 & 2630 & 95200 & 2130 & 295 & 1700 \\
\hline 10 & 2250 & 200 & 1220 & 8610 & 990 & 23000 & 2040 & 255 & 1400 \\
\hline 11 & 11200 & 2120 & 100000 & 15900 & 3540 & 163000 & 1950 & 135 & 711 \\
\hline 12 & 35600 & 4170 & 401000 & 11700 & 1730 & 57900 & 1870 & 80 & 404 \\
\hline 13 & 34800 & 4100 & 400000 & 6110 & 910 & 15000 & 1800 & 110 & 535 \\
\hline 14 & 13600 & 2380 & 92900 & 5280 & 910 & 13000 & 1770 & 100 & 478 \\
\hline 15 & 6630 & 1260 & 22600 & 8800 & 1710 & 40600 & 1810 & 145 & 709 \\
\hline 16 & 4240 & 810 & 9270 & 6750 & 760 & 13900 & 2010 & 230 & 1250 \\
\hline 17 & 3200 & 580 & 5010 & 4270 & 500 & 5760 & 3240 & 815 & 7510 \\
\hline 18 & 3360 & 650 & 5900 & 3340 & 440 & 3970 & 3670 & 650 & 6440 \\
\hline 19 & 21600 & 4430 & 321000 & 2940 & 420 & 3330 & 3000 & 430 & 3480 \\
\hline 20 & 46200 & 5840 & 741000 & 2570 & 400 & 2780 & 2940 & 395 & 3140 \\
\hline 21 & 29000 & 5990 & 469000 & 2320 & 290 & 1820 & 2830 & 345 & 2640 \\
\hline 22 & 18000 & 3180 & 155000 & 2180 & 200 & 1180 & 2600 & 350 & 2460 \\
\hline 23 & 11000 & 1900 & 56400 & 2300 & 380 & 2360 & 2830 & 460 & 3510 \\
\hline 24 & 7620 & 1660 & 34200 & 2720 & 660 & 4850 & 2990 & 420 & 3390 \\
\hline 25 & 11200 & 3420 & 103000 & 3160 & 700 & 5970 & 3120 & 425 & 3580 \\
\hline 26 & 22900 & 3850 & 238000 & 2830 & 410 & 3130 & 3440 & 605 & 5620 \\
\hline 27 & 11100 & 1700 & 50900 & 2600 & 300 & 2110 & 3910 & 845 & 8920 \\
\hline 28 & 8190 & 1170 & 25900 & 4560 & 1270 & 17500 & 4420 & 1080 & 12900 \\
\hline 29 & 5660 & 860 & 13100 & -- & - & -- & 4850 & 900 & 11800 \\
\hline 30 & 4660 & 740 & 9310 & - & - & -- & 5400 & 735 & 10700 \\
\hline 31 & 4070 & 740 & 8130 & -- & -- & -- & 5220 & 730 & 10300 \\
\hline \multirow[t]{5}{*}{ TOTAL } & 339190 & -- & 3284020 & 144240 & -- & 531100 & 91660 & -- & 126357 \\
\hline & & APRIL & & & MAY & & & JUNE & \\
\hline & & MEAN & & & MEAN & & & MEAN & \\
\hline & $\begin{array}{l}\text { MEAN } \\
\text { MEAMGE }\end{array}$ & CONCEN- & SED IMENT & MEAN & CONCEN- & SEDIMENT & MEAN & CONCEN- & SEDIMENT \\
\hline & $\begin{array}{l}\text { DISCHARGE } \\
\text { ICFSI }\end{array}$ & TRATION & DISCHARGE & DISCHARGE & TRATION & DISCHARGE & OISCHARGE & TRATION & DISCHARGE \\
\hline DAY & & & (TONS/DAY) & (CFS) & $(M G / L)$ & (TONS/DAY) & (CFS) & (MG/L) & (TONS / DAY) \\
\hline 1 & 4470 & 605 & 7300 & 2920 & 380 & 3000 & 1250 & 44 & 149 \\
\hline 2 & 3980 & 490 & 5270 & 2670 & 255 & 1840 & 1160 & 42 & 132 \\
\hline 3 & 3360 & 460 & 4170 & 2600 & 280 & 1970 & 1100 & 27 & 80 \\
\hline 4 & 2840 & 450 & 3450 & 2290 & 190 & 1170 & 1030 & 36 & 100 \\
\hline 5 & 3670 & 840 & 8320 & 2390 & 225 & 1450 & 984 & 36 & 96 \\
\hline 6 & 3080 & 350 & 2910 & 3120 & 430 & 3620 & 897 & 36 & 87 \\
\hline 7 & 2680 & 285 & 2060 & 3690 & 740 & 7370 & 808 & 32 & 70 \\
\hline B & 2560 & 290 & 2000 & 3850 & 755 & 7850 & 724 & 26 & 51 \\
\hline 9 & 2720 & 305 & 2240 & 4200 & 815 & 9240 & 640 & 24 & 41 \\
\hline 10 & 2840 & 285 & 2190 & 4400 & 780 & 9270 & 610 & 16 & 26 \\
\hline 11 & 3070 & 425 & 3520 & 4110 & 655 & 7270 & 570 & 15 & 23 \\
\hline & 3520 & 650 & 6180 & 4000 & 620 & 6700 & 580 & 14 & 22 \\
\hline 13 & 3080 & 410 & 3410 & 3610 & 490 & 4780 & 555 & 13 & 19 \\
\hline 14 & 2750 & 280 & 2080 & 3080 & 370 & 3080 & 515 & ii & 15 \\
\hline 15 & 2500 & 240 & 1620 & 2480 & 270 & 1810 & 486 & 10 & 13 \\
\hline 16 & 2620 & 270 & 1910 & 2410 & 265 & 1720 & $4 B I$ & 8 & 10 \\
\hline 17 & 2970 & 410 & 3290 & 2500 & 300 & 2030 & 454 & 6 & 7.4 \\
\hline iB & 3360 & 605 & 5490 & 2750 & 300 & 2230 & 424 & 5 & 5.7 \\
\hline 19 & 3070 & 445 & 3690 & 2500 & 180 & 1220 & 436 & 4 & 4.7 \\
\hline 20 & 3230 & 460 & 4010 & $21 B 0$ & 120 & 706 & 387 & 4 & 4.2 \\
\hline 21 & 3670 & 890 & 8820 & 2080 & 121 & 680 & 372 & 6 & 6.0 \\
\hline 22 & 4050 & 1000 & 10900 & 2020 & 120 & 654 & 327 & $?$ & 6.2 \\
\hline 23 & 4270 & 1000 & 11500 & 2090 & 143 & 807 & 340 & 9 & 8.3 \\
\hline 24 & 3460 & 500 & 4670 & 2130 & 135 & 776 & 313 & 6 & 5.1 \\
\hline 25 & 2830 & 305 & 2330 & 1880 & 94 & 477 & 303 & 3 & 2.5 \\
\hline 26 & 2510 & 255 & 1730 & 1590 & 79 & 339 & 287 & 3 & 2.3 \\
\hline 27 & 2590 & 345 & 2410 & 1570 & 86 & 365 & 237 & 3 & 1.9 \\
\hline 28 & 3050 & 510 & 4200 & 1370 & 60 & 222 & 230 & 3 & 1.9 \\
\hline 29 & 3440 & 600 & 5570 & 1300 & 60 & 211 & 225 & 2 & 1.2 \\
\hline 30 & 3080 & 420 & 3490 & 1420 & 65 & 249 & 219 & 2 & 1.2 \\
\hline 31 & -- & -- & -- & 1390 & 61 & 229 & $\because$ & -- & - \\
\hline TOTAL & 95320 & -- & 130730 & 80590 & $=$ & 83335 & 16944 & -- & 992.6 \\
\hline
\end{tabular}


EEL RIVER BASIN

11473900 MIDDLE FORK EEL RIVER NEAR DOS RIOS, CALIF.--CONTInUEd SUSPENDED-SEDIMENT DISCHARGE, WATER YEAR OCTOBER 1968 TD SEPTEMBER 1969

\begin{tabular}{|c|c|c|c|c|c|c|c|c|c|}
\hline \multirow[b]{2}{*}{ DAY } & \multicolumn{3}{|c|}{ JULY } & \multicolumn{3}{|c|}{ AUGUST } & \multicolumn{3}{|c|}{ SEP TEMBER } \\
\hline & $\begin{array}{c}\text { MEAN } \\
\text { DISCHARGE } \\
\text { (CFS) }\end{array}$ & $\begin{array}{l}\text { MEAN } \\
\text { CONCEN- } \\
\text { TRATION } \\
\text { (MG LL) }\end{array}$ & $\begin{array}{l}\text { SEDIMENT } \\
\text { DISCHARGE } \\
\text { (TONS /DAY) }\end{array}$ & $\begin{array}{l}\text { ME AN } \\
\text { DISCHARGE } \\
\text { (CFS) }\end{array}$ & $\begin{array}{l}\text { MEAN } \\
\text { CONCEN- } \\
\text { TRATION } \\
\text { (MGIL) }\end{array}$ & $\begin{array}{l}\text { SEDIMENT } \\
\text { DI SCHARGE } \\
\text { (TONS / DAY) }\end{array}$ & $\begin{array}{l}\text { MEAN } \\
\text { DISCHARGE } \\
\text { (CFS) }\end{array}$ & $\begin{array}{l}\text { MEAN } \\
\text { CONCEN- } \\
\text { TRATIDN } \\
\text { (MG/L) }\end{array}$ & $\begin{array}{l}\text { SEDIMENT } \\
\text { DISCHARGE } \\
\text { (TONS/DAY) }\end{array}$ \\
\hline 1 & 218 & 2 & 1.2 & 38 & 1 & .10 & 29 & 1 & .08 \\
\hline 2 & 217 & 2 & 1.2 & 37 & $i$ & .10 & 32 & 2 & .17 \\
\hline 3 & 208 & 3 & 1.7 & 37 & 1 & .10 & 32 & 3 & .26 \\
\hline 4 & 197 & 5 & 2.7 & 37 & 1 & .10 & 32 & 2 & .17 \\
\hline 5 & 186 & 5 & 2.5 & 34 & 1 & .09 & 32 & 1 & .09 \\
\hline 6 & 168 & 8 & 3.6 & 34 & 1 & .09 & 32 & I & .09 \\
\hline 7 & 156 & 12 & 5.1 & 34 & i & .09 & 32 & $\hat{\imath}$ & .09 \\
\hline 8 & 143 & 8 & 3.1 & 34 & 1 & .09 & 32 & 1 & .09 \\
\hline 9 & 132 & 2 & .71 & 33 & 1 & .09 & 32 & i & .09 \\
\hline 10 & 120 & 3 & .97 & 31 & 1 & .08 & 32 & 1 & .09 \\
\hline 11 & 118 & 3 & .96 & 30 & 1 & .08 & 25 & 1 & .07 \\
\hline 12 & 105 & 4 & 1.1 & 30 & i & .08 & 19 & 1 & .05 \\
\hline 13 & 91 & 5 & 1.2 & 30 & 1 & .08 & 18 & i & .05 \\
\hline 14 & 88 & 7 & 1.7 & 30 & 2 & .16 & 18 & 1 & .05 \\
\hline Is & 83 & 5 & 1.1 & 30 & 3 & .24 & 18 & i & .05 \\
\hline 16 & 85 & 3 & .69 & 29 & 4 & .31 & 18 & 1 & .05 \\
\hline 17 & 78 & 3 & .63 & 28 & 5 & .38 & 17 & $i$ & .05 \\
\hline 18 & 69 & 4 & .75 & 27 & 7 & .51 & $1 T$ & 1 & .05 \\
\hline 19 & 63 & 5 & .85 & 27 & 2 & .15 & 14 & 2 & .08 \\
\hline 20 & 59 & 6 & .96 & 27 & 1 & .07 & 15 & 2 & .08 \\
\hline 21 & 58 & 7 & 1,1 & 27 & 1 & .07 & 15 & 1 & .04 \\
\hline 22 & 58 & 5 & .78 & 27 & i & .07 & 15 & i & .04 \\
\hline 23 & 56 & 3 & .45 & 26 & 1 & .07 & 15 & I & .04 \\
\hline 24 & 48 & 5 & .65 & 25 & 1 & .07 & 15 & 1 & .04 \\
\hline 25 & 48 & 6 & .78 & 25 & 1 & .07 & 15 & 1 & .04 \\
\hline 26 & 48 & 5 & .65 & 27 & 1 & .07 & 15 & 1 & .04 \\
\hline 27 & 45 & 2 & .24 & 25 & 1 & .07 & 15 & 1 & .04 \\
\hline 28 & 43 & i & .12 & 24 & i & .06 & 15 & 1 & .04 \\
\hline 29 & 43 & i & .12 & 24 & I & .06 & 15 & 1 & .04 \\
\hline 30 & 43 & I & .12 & 24 & 1 & .06 & 15 & $i$ & .04 \\
\hline 31 & 40 & 1 & .11 & 24 & 1 & .06 & - & - & -- \\
\hline TOTAL & 3114 & $-\infty$ & 37.84 & 915 & -- & 3.72 & 646 & - & 2.20 \\
\hline $\begin{array}{l}\text { TOTAL } \\
\text { TOTAL }\end{array}$ & $\begin{array}{l}\text { OISCHARGE } \\
\text { SUSPENDED- }\end{array}$ & $\begin{array}{l}R \text { YEAR } \\
\text { DIMEN T }\end{array}$ & $\begin{array}{l}\text { CFS-DAYSI } \\
\text { ISCHARGE FDR }\end{array}$ & 7 & & & & & $\begin{array}{c}934312^{\circ} \\
5362080.95\end{array}$ \\
\hline
\end{tabular}

PARTICLE-SIZE DISTRIBUTION OF SUSPENDED SEDIMENT, WATER YEAR OCTOBER 1968 TO SEPTEMBER 1969

(METHODS OF ANALYSIS: B̈, BOTTOM WITHDRAMAL TUBE; C, CHEMICALLY DISPERSEO; N, IN NATIVE WATER; P, PIPET: S, SIEVE:

\begin{tabular}{|c|c|c|c|c|c|c|c|c|c|c|c|c|c|c|c|c|c|c|c|c|}
\hline & DATE & IIME & $\begin{array}{l}\text { WATER } \\
\text { TEM- } \\
\text { PERA- } \\
\text { TURE } \\
\text { ( C) }\end{array}$ & $\begin{array}{l}\text { R } \\
\text { OI SCHARGE } \\
\text { (CFS) }\end{array}$ & $\begin{array}{l}\text { CONCEN- } \\
\text { IRAYION } \\
\text { (MG/L) }\end{array}$ & $\begin{array}{l}\text { SUSPENDED } \\
\text { SEOIMENT } \\
\text { OISCHARGE } \\
\text { OIONSIOAY) }\end{array}$ & PERCE & & FINER & & & $\begin{array}{r}\text { THE S } \\
.031\end{array}$ & TICLE & ( IN M & MILLL & .250 & .500 & $\begin{array}{l}\text { INOIC } \\
1.00\end{array}$ & $\begin{array}{r}\text { CA TEO } \\
2.00\end{array}$ & $\begin{array}{l}\text { METHDD } \\
\text { DF } \\
\text { ANALY- } \\
\text { SIS }\end{array}$ \\
\hline $\begin{array}{l}\text { NOV } \\
\text { DEC } \\
\text { DEC } \\
\text { OEC } \\
\text { OEC }\end{array}$ & $\begin{array}{l}12,1968 \\
10 \ldots \ldots \\
11 \ldots \ldots \\
15 \ldots \ldots \\
19 \ldots \ldots\end{array}$ & $\begin{array}{l}0900 \\
0855 \\
1120 \\
0930 \\
1130\end{array}$ & $\begin{array}{r}11 \\
10 \\
6 \\
7 \\
6\end{array}$ & $\begin{array}{r}670 \\
12600 \\
6520 \\
13300 \\
1590\end{array}$ & $\begin{array}{r}608 \\
8190 \\
1390 \\
5070 \\
246\end{array}$ & $\begin{array}{r}1100 \\
279000 \\
24500 \\
182000 \\
1060\end{array}$ & $\begin{array}{l}23 \\
19 \\
16 \\
19\end{array}$ & $\begin{array}{l}28 \\
27 \\
20 \\
25\end{array}$ & $\begin{array}{l}\overline{4} \\
7 \\
0 \\
5\end{array}$ & $\begin{array}{l}36 \\
36 \\
29 \\
30\end{array}$ & $\begin{array}{l}-7 \\
42 \\
44 \\
39 \\
35\end{array}$ & $\begin{array}{l}-- \\
54 \\
51 \\
51 \\
37\end{array}$ & $\begin{array}{l}27 \\
62 \\
63 \\
60 \\
40\end{array}$ & $\begin{array}{l}3 \\
7 \\
7 \\
7 \\
4\end{array}$ & $\begin{array}{l}32 \\
77 \\
74 \\
76 \\
44\end{array}$ & $\begin{array}{l}45 \\
90 \\
87 \\
91 \\
49\end{array}$ & $\begin{array}{l}76 \\
97 \\
97 \\
99 \\
62\end{array}$ & $\begin{array}{r}100 \\
99 \\
100 \\
100 \\
88\end{array}$ & $\frac{100}{100}$ & $\begin{array}{l}\text { V } \\
\text { VPWC } \\
\text { VBWC } \\
\text { VPWC } \\
\text { SBWC }\end{array}$ \\
\hline $\begin{array}{l}\text { DEC } \\
\text { DEC } \\
\text { DEC } \\
\text { JAN } \\
\text { JAN }\end{array}$ & $\begin{array}{r}23 \ldots \ldots \ldots \\
24 \ldots \ldots \ldots \\
25 \ldots \ldots \\
8, \ldots 1969 \\
11 \ldots \ldots\end{array}$ & $\begin{array}{l}1115 \\
1445 \\
1130 \\
0950 \\
1230\end{array}$ & $\begin{array}{l}5 \\
7 \\
6 \\
7 \\
6\end{array}$ & $\begin{array}{r}23200 \\
18300 \\
13400 \\
2810 \\
6520\end{array}$ & $\begin{array}{r}4980 \\
2920 \\
1880 \\
227 \\
2630\end{array}$ & $\begin{array}{r}312000 \\
144000 \\
68000 \\
1720 \\
46300\end{array}$ & $\begin{array}{l}19 \\
22 \\
22 \\
29 \\
21\end{array}$ & $\begin{array}{l}23 \\
26 \\
25 \\
38 \\
25\end{array}$ & $\begin{array}{l}3 \\
6 \\
5 \\
8 \\
5\end{array}$ & $\begin{array}{r}31 \\
35 \\
35 \\
49 \\
34\end{array}$ & $\begin{array}{l}40 \\
44 \\
45 \\
57 \\
44\end{array}$ & $\begin{array}{l}49 \\
53 \\
54 \\
61 \\
55\end{array}$ & $\begin{array}{l}60 \\
63 \\
64 \\
70 \\
67\end{array}$ & & $\begin{array}{l}72 \\
74 \\
75 \\
74 \\
80\end{array}$ & $\begin{array}{l}87 \\
86 \\
89 \\
80 \\
94\end{array}$ & $\begin{array}{r}98 \\
94 \\
98 \\
91 \\
100\end{array}$ & $\begin{array}{r}100 \\
100 \\
100 \\
98 \\
--\end{array}$ & $\begin{array}{l}-- \\
\overline{--} \\
100\end{array}$ & $\begin{array}{l}\text { VPWC } \\
\text { VPWC } \\
\text { VPWC } \\
\text { SBWC } \\
\text { VPWC }\end{array}$ \\
\hline $\begin{array}{l}\text { JAN } \\
\text { JAN } \\
\text { JAN } \\
\text { JAN } \\
\text { JAN }\end{array}$ & $\begin{array}{l}12 \ldots \ldots \\
13 \ldots \ldots \\
15 \ldots \ldots \\
19 \ldots \ldots \\
20 \ldots \ldots\end{array}$ & $\begin{array}{l}1105 \\
1015 \\
1115 \\
1330 \\
1050\end{array}$ & $\begin{array}{l}7 \\
8 \\
6 \\
8 \\
9\end{array}$ & $\begin{array}{r}35300 \\
44400 \\
6520 \\
19400 \\
43200\end{array}$ & $\begin{array}{l}3350 \\
4890 \\
1260 \\
3950 \\
5390\end{array}$ & $\begin{array}{r}319000 \\
586000 \\
22200 \\
207000 \\
629000\end{array}$ & $\begin{array}{l}22 \\
23 \\
21 \\
20 \\
22\end{array}$ & $\begin{array}{l}27 \\
24 \\
30 \\
26 \\
25\end{array}$ & $\begin{array}{l}3 \\
3 \\
4 \\
3 \\
3\end{array}$ & $\begin{array}{l}37 \\
36 \\
40 \\
34 \\
34\end{array}$ & $\begin{array}{l}49 \\
49 \\
50 \\
44 \\
45\end{array}$ & $\begin{array}{l}60 \\
60 \\
58 \\
56 \\
57\end{array}$ & $\begin{array}{l}72 \\
72 \\
65 \\
66 \\
68\end{array}$ & $\begin{array}{l}8 \\
86 \\
73 \\
77 \\
8\end{array}$ & $\begin{array}{l}83 \\
86 \\
73 \\
77 \\
81\end{array}$ & $\begin{array}{l}93 \\
96 \\
83 \\
90 \\
93\end{array}$ & $\begin{array}{l}99 \\
99 \\
32 \\
99 \\
99\end{array}$ & $\begin{array}{r}100 \\
100 \\
95 \\
100 \\
100\end{array}$ & $\begin{array}{l}-- \\
100 \\
--\end{array}$ & $\begin{array}{l}\text { VPWC } \\
\text { VDWC } \\
\text { SBWC } \\
\text { VPWC } \\
\text { VPWC }\end{array}$ \\
\hline $\begin{array}{l}\text { JAN } \\
\text { JAN } \\
\text { FEB } \\
\text { FEB } \\
\text { APR }\end{array}$ & $\begin{array}{l}21 \ldots \ldots \ldots \\
26 \ldots \ldots \ldots \\
13 \ldots \ldots \ldots \\
23 \ldots \ldots \ldots \\
28 \ldots \ldots\end{array}$ & $\begin{array}{l}0900 \\
0945 \\
1420 \\
1510 \\
1350\end{array}$ & $\begin{array}{r}8 \\
6 \\
5 \\
6 \\
13\end{array}$ & $\begin{array}{r}\mathrm{D} 29000 \\
33800 \\
5730 \\
2270 \\
3150\end{array}$ & $\begin{array}{r}5790 \\
3850 \\
965 \\
301 \\
458\end{array}$ & $\begin{array}{r}453000 \\
351000 \\
14900 \\
1840 \\
3900\end{array}$ & $\begin{array}{r}22 \\
18 \\
24 \\
6 \\
16\end{array}$ & $\begin{array}{l}28 \\
24 \\
28 \\
26 \\
23\end{array}$ & $\begin{array}{l}8 \\
4 \\
8 \\
6 \\
3\end{array}$ & $\begin{array}{l}38 \\
33 \\
37 \\
33 \\
32\end{array}$ & $\begin{array}{l}49 \\
43 \\
47 \\
38 \\
40\end{array}$ & $\begin{array}{l}61 \\
54 \\
54 \\
41 \\
47\end{array}$ & $\begin{array}{l}72 \\
64 \\
63 \\
49 \\
54\end{array}$ & & $\begin{array}{l}85 \\
76 \\
71 \\
54 \\
59\end{array}$ & $\begin{array}{l}95 \\
88 \\
84 \\
60 \\
67\end{array}$ & $\begin{array}{r}100 \\
97 \\
96 \\
75 \\
80\end{array}$ & $\begin{array}{r}-- \\
100 \\
100 \\
95 \\
95\end{array}$ & $\begin{array}{r}-- \\
=- \\
100 \\
100\end{array}$ & $\begin{array}{l}\text { VPWC } \\
\text { VPWC } \\
\text { VPWC } \\
\text { S } 8 W C \\
\text { SBWC }\end{array}$ \\
\hline
\end{tabular}

PARTICLE-SIZE DISTRIBUTION OF SURFACE BED MATERIAL, WATER YEAR OCTOBER 1968 TO SEPTEMBER 1969

IMETHOD OF ANALYSIS: H. HYOROMETER: D, DPTICAL ANALYZE: S, SIEVE; V, VISUAL ACCUMULATION TUBE

$$
\text { WATER NUMBER PARIICLE SIZE }
$$

PERA- SAM- PERCENT FINER IHAN THE SIZE (IN MILLIMETERS) (NNDICATED OF

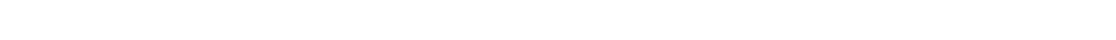

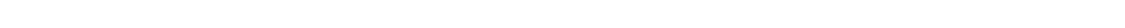

D DAILY MEAN DISCHARGE. 
11475000 EEL RIVER AT FORT SETARD, CALIF.

LOCATION.--Lat $40^{\circ} 13^{\prime} 05^{\prime \prime}$, Iong $123^{\circ} 37^{\prime} 54^{\prime \prime}$, in SE $\frac{1}{\mathrm{~N} E}$ sec. 8 , T. 3 S., R.5 E., Humboldt County, at gaging station at bridge, 1.0 mile southeast of Fort Seward, 1.9 miles upstream from Dobbyn Creek, and 11.8 miles northeast of Garbervilie.

DRAINAGE AREA, $--2,107 \mathrm{sq} \mathrm{ml}$.

PERIOD OF RECORD. --Water temperatures: November 1960 to September 1969. Sediment records: October 1965 to September 1969.

EXTREMES. --1968-69:

Water temperatures: Maximum, $33.0^{\circ} \mathrm{C} J u l y ~ 22 ;$ minimum, $2.0^{\circ} \mathrm{C}$ Dec. $20-22, \mathrm{Jan} .29,30$.
Sediment concentrations: Maximum daily, 4,790 mg/1 Dec. $25 ;$ minimum daily, $1 \mathrm{mg} / 1$ on many days during October, August, and September.

Sediment discharge: Maximum daily, 1,230,000 tons Jan. 20; minimum daily, 0,09 ton on several days during September.

Period of record:

Fater temperatures (1960-64, 1965-69): Maximum, $34.0^{\circ} \mathrm{C}$ June 25, July 7, 1968; minimum, freezing point Dec. 14-17, 1968

Sediment concentrations: Maximum dally, $13,900 \mathrm{mg} / 1 \mathrm{Jan} .4,1966$; minimum dally, $1 \mathrm{mg} / 1$ on many days in $1965-69$.

Sediment discharge: Maximum da1ly, 4,270,000 tons Jan. 4, 1966; minimum da1ly, 0.09 ton on many days in 1968 and 1969

REMARKS. --No temperature record May 20 to June 3, probe out of water; Aug. 13 to Sept. 30, recorder malfunction. Where no maximum or minimum is shown, temperature is once-dally reading.

TEMPERATURE $\left({ }^{\circ} \mathrm{C}\right)$ OF WATER, WATER YEAR OCTOBER 1968 TO SEPTEMBER 1969

OAY

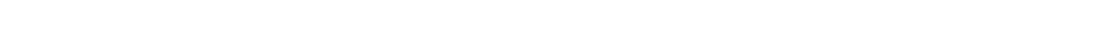

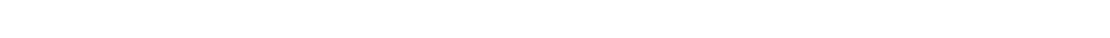

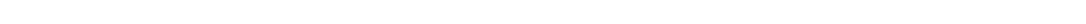

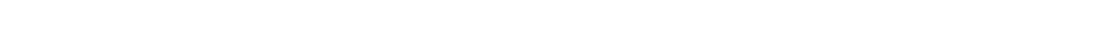

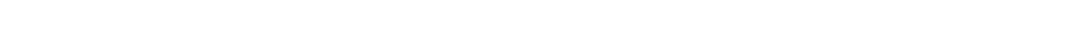

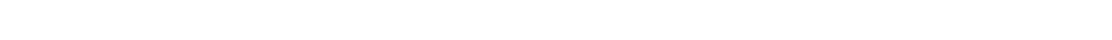
$\begin{array}{rrrrrrrrrrrrrrrrrrrrrrrrrrrrrrrrrrr}\text { MAXIMUM } & 7 & 8 & 7 & 7 & 8 & 9 & 8 & 9 & 10 & 11 & 9 & 7 & 6 & 8 & 8 & 7 & 8 & 6 & 6 & 5 & 4 & 3 & 6 & 7 & 7 & 6 & 5 & 5 & 7 & 7 & 7 & \\ \text { MINIMUM } & 6 & 5 & 5 & 6 & 6 & 7 & 7 & 7 & 8 & 9 & 6 & 5 & 5 & 6 & 7 & 6 & 6 & 5 & 4 & 2 & 2 & 2 & 3 & 6 & 5 & 4 & 4 & 4 & 5 & 5 & 5 & & 5\end{array}$ JANUARY.: $\begin{array}{lllllllllllllllllllllllllllllllll}\text { MAXIMUM } & 7 & 8 & 8 & 9 & 9 & 9 & 7 & 7 & 5 & 5 & 6 & 8 & 8 & 7 & 7 & 7 & 6 & 6 & 8 & 9 & 9 & 7 & 6 & 6 & 9 & 8 & 5 & 5 & 5 & 5 \\ \text { MINIMUM } & 5 & 6 & 6 & 6 & 7 & 7 & 5 & 3 & 3 & 4 & 5 & 6 & 7 & 6 & 5 & 5 & 4 & 4 & 6 & 8 & 7 & 6 & 4 & 4 & 6 & 5 & 4 & 4 & 2 & 2 & 3\end{array}$

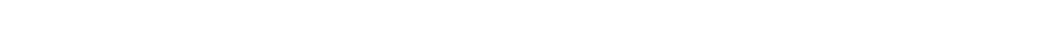
\begin{tabular}{l} 
MAXIMUM \\
\hline
\end{tabular} MINIMUM $4 \begin{array}{lllllllllllllllllllllllllllllllllll} & 5 & 5 & 4 & 4 & 4 & 5 & 6 & 6 & 7 & 9 & 6 & 5 & 5 & 6 & 6 & 6 & 6 & 7 & 6 & 5 & 4 & 4 & 5 & 4 & 4 & 5 & 5 & -- & -- & --\end{array}$ MARCH....
MAXIMUM

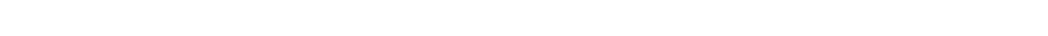

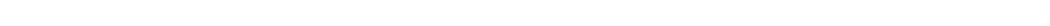

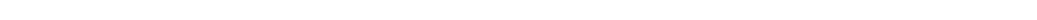
MAY... MUM 10 -

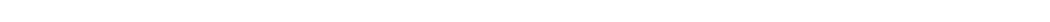

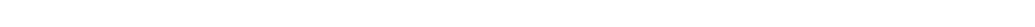
JUNE..... --

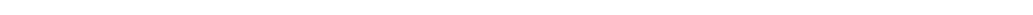

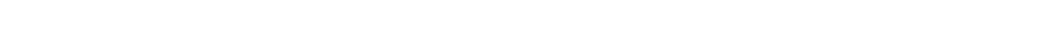

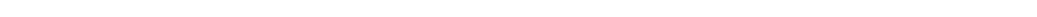
AuguSt... -- - - - - - - - - - -

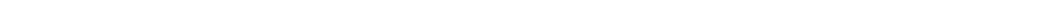

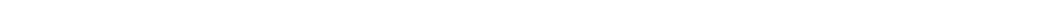

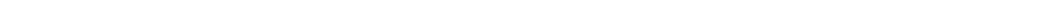

MAXIMUM

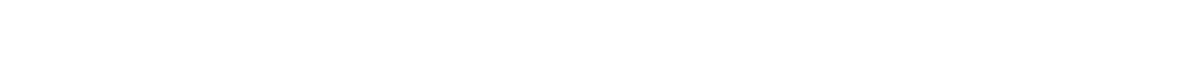

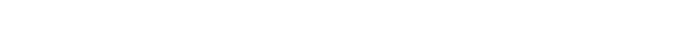

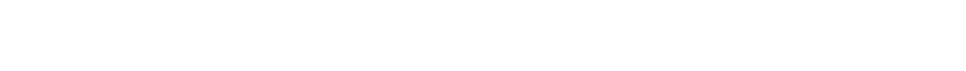

TURE OISCHARGE TRATION OISCHARGE
DATE IIME ICI
(CFS) (MG/L) (TONS/DAY)

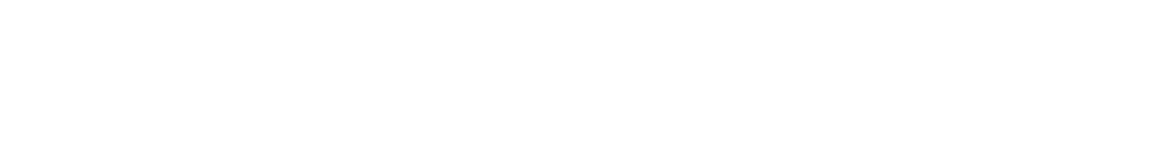

PARTICLE-SIZE DISTRIBUTION OF SURFACE BED MATERIAL, HATER YEAR OCTOBER 1968 TO SEPTEMBER 1969 IMETHOD DF ANALYSIS: H, HYDROMETER: D, OPTICAL ANALYZER; S, SIEVE; V, VISUAL ACCUMULATION TUBEI

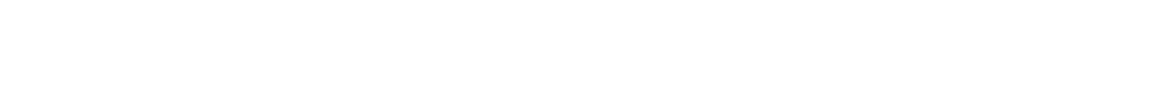

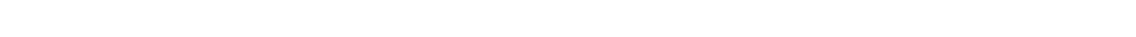

D DAILY MEAN DISCHARGE. 
11475000 BEL RIVER AT FORT SEWARD, CALIF,--COnt1nUed

SUSPENDED-SEDIMENT DISCHARGE, WATER YEAR OCTOBER 1968 TO SEPTEMBER 1969

\begin{tabular}{|c|c|c|c|c|c|c|c|c|c|}
\hline \multirow[b]{2}{*}{ OAY } & \multicolumn{3}{|c|}{ OCTOBER } & \multicolumn{3}{|c|}{ NOVEMBER } & \multicolumn{3}{|c|}{ DECEMBER } \\
\hline & $\begin{array}{l}\text { MEAN } \\
\text { DISCHARGE } \\
\text { (CFS) }\end{array}$ & $\begin{array}{l}\text { MEAN } \\
\text { CONCEN- } \\
\text { TRATION } \\
\text { (MG/L) }\end{array}$ & $\begin{array}{l}\text { SEDIMENT } \\
\text { DISCHARGE } \\
\text { (TONS/DAY) }\end{array}$ & $\begin{array}{l}\text { MEAN } \\
\text { OISCHARGE } \\
\text { (CFS) }\end{array}$ & $\begin{array}{l}\text { MEAN } \\
\text { CONCEN- } \\
\text { IRATION } \\
\text { (MGIL) }\end{array}$ & $\begin{array}{l}\text { SEDIMENT } \\
\text { DISCHARGE } \\
\text { (TONS/DAY) }\end{array}$ & $\begin{array}{l}\text { MEAN } \\
\text { DISCHARGE } \\
\text { (CFS) }\end{array}$ & $\begin{array}{l}\text { MEAN } \\
\text { CONCEN- } \\
\text { TRATION } \\
\text { (MG/L) }\end{array}$ & $\begin{array}{l}\text { SEDIMENT } \\
\text { DISCHARGE } \\
\text { (TONS/DAY) }\end{array}$ \\
\hline $\begin{array}{l}1 \\
2 \\
3 \\
4 \\
5\end{array}$ & $\begin{array}{l}38 \\
37 \\
37 \\
37 \\
37\end{array}$ & $\begin{array}{l}1 \\
1 \\
1 \\
1 \\
1\end{array}$ & $\begin{array}{r}.10 \\
.10 \\
110 \\
.10 \\
.10\end{array}$ & $\begin{array}{l}218 \\
260 \\
690 \\
865 \\
487\end{array}$ & $\begin{array}{r}8 \\
7 \\
19 \\
30 \\
15\end{array}$ & $\begin{array}{l}4.7 \\
4.9 \\
51 \\
70 \\
20\end{array}$ & $\begin{array}{l}1760 \\
2080 \\
1380 \\
1060 \\
905\end{array}$ & $\begin{array}{r}65 \\
80 \\
22 \\
10 \\
8\end{array}$ & $\begin{array}{r}309 \\
449 \\
82 \\
29 \\
20\end{array}$ \\
\hline $\begin{array}{r}6 \\
7 \\
8 \\
9 \\
10\end{array}$ & $\begin{array}{l}37 \\
37 \\
36 \\
36 \\
36\end{array}$ & $\begin{array}{l}1 \\
1 \\
1 \\
1 \\
1\end{array}$ & $\begin{array}{l}.10 \\
.10 \\
.10 \\
.10 \\
.10\end{array}$ & $\begin{array}{l}354 \\
313 \\
288 \\
254 \\
240\end{array}$ & $\begin{array}{l}4 \\
4 \\
4 \\
3 \\
3\end{array}$ & $\begin{array}{l}3.8 \\
3.4 \\
3.1 \\
2.1 \\
1.9\end{array}$ & $\begin{array}{r}905 \\
972 \\
2350 \\
2820 \\
23500\end{array}$ & $\begin{array}{r}10 \\
13 \\
118 \\
112 \\
3590\end{array}$ & $\begin{array}{r}24 \\
34 \\
850 \\
853 \\
321000\end{array}$ \\
\hline $\begin{array}{l}11 \\
12 \\
13 \\
14 \\
15\end{array}$ & $\begin{array}{r}38 \\
50 \\
66 \\
175 \\
313\end{array}$ & $\begin{array}{l}1 \\
4 \\
2 \\
1 \\
1\end{array}$ & $\begin{array}{l}.10 \\
.54 \\
.36 \\
.47 \\
.85\end{array}$ & $\begin{array}{r}300 \\
760 \\
1310 \\
815 \\
1280\end{array}$ & $\begin{array}{l}11 \\
35 \\
62 \\
39 \\
67\end{array}$ & $\begin{array}{r}11 \\
76 \\
226 \\
86 \\
257\end{array}$ & $\begin{array}{r}26300 \\
11500 \\
6760 \\
12900 \\
27900\end{array}$ & $\begin{array}{r}2470 \\
900 \\
500 \\
1590 \\
2910\end{array}$ & $\begin{array}{r}197000 \\
27900 \\
9130 \\
57900 \\
251000\end{array}$ \\
\hline $\begin{array}{l}16 \\
17 \\
18 \\
19 \\
20\end{array}$ & $\begin{array}{l}248 \\
214 \\
196 \\
180 \\
170\end{array}$ & $\begin{array}{l}1 \\
1 \\
1 \\
1 \\
1\end{array}$ & $\begin{array}{l}.67 \\
.58 \\
.53 \\
.49 \\
.46\end{array}$ & $\begin{array}{l}1760 \\
1210 \\
1590 \\
3530 \\
1820\end{array}$ & $\begin{array}{r}97 \\
26 \\
122 \\
555 \\
125\end{array}$ & $\begin{array}{r}464 \\
85 \\
783 \\
5560 \\
614\end{array}$ & $\begin{array}{r}22300 \\
11000 \\
6510 \\
5580 \\
4500\end{array}$ & $\begin{array}{r}1770 \\
640 \\
225 \\
130 \\
85\end{array}$ & $\begin{array}{r}117000 \\
19000 \\
3950 \\
2260 \\
1030\end{array}$ \\
\hline $\begin{array}{l}21 \\
22 \\
23 \\
24 \\
25\end{array}$ & $\begin{array}{l}162 \\
158 \\
153 \\
149 \\
146\end{array}$ & $\begin{array}{l}1 \\
1 \\
1 \\
1 \\
1\end{array}$ & $\begin{array}{l}.44 \\
.43 \\
.41 \\
.40 \\
.39\end{array}$ & $\begin{array}{r}1150 \\
805 \\
646 \\
800 \\
2480\end{array}$ & $\begin{array}{r}25 \\
12 \\
7 \\
32 \\
193\end{array}$ & $\begin{array}{r}78 \\
26 \\
12 \\
84 \\
1350\end{array}$ & $\begin{array}{r}3420 \\
3170 \\
48900 \\
79500 \\
67000\end{array}$ & $\begin{array}{r}60 \\
119 \\
4130 \\
3840 \\
4790\end{array}$ & $\begin{array}{r}554 \\
1240 \\
765000 \\
824000 \\
867000\end{array}$ \\
\hline $\begin{array}{l}26 \\
27 \\
28 \\
29 \\
30 \\
31\end{array}$ & $\begin{array}{l}146 \\
146 \\
144 \\
144 \\
144 \\
152\end{array}$ & $\begin{array}{l}1 \\
1 \\
1 \\
1 \\
1 \\
1\end{array}$ & $\begin{array}{l}.39 \\
.39 \\
.39 \\
.39 \\
.39 \\
.41\end{array}$ & $\begin{array}{r}1930 \\
1220 \\
925 \\
755 \\
1000 \\
--\end{array}$ & $\begin{array}{r}68 \\
25 \\
8 \\
6 \\
20 \\
-2\end{array}$ & $\begin{array}{r}354 \\
82 \\
20 \\
12 \\
54 \\
--\end{array}$ & $\begin{array}{l}32200 \\
20900 \\
19400 \\
18700 \\
14900 \\
11800\end{array}$ & $\begin{array}{r}1810 \\
900 \\
840 \\
780 \\
500 \\
255\end{array}$ & $\begin{array}{r}164000 \\
50800 \\
44000 \\
39400 \\
20100 \\
8120\end{array}$ \\
\hline TOTAL & 3662 & - & 10.48 & 30055 & - & 10398.9 & 492472 & - & 3794034 \\
\hline DAY & $\begin{array}{l}\text { MEAN } \\
\text { OISCHARGE } \\
\text { (CFS) }\end{array}$ & $\begin{array}{l}\text { JANUARY } \\
\text { MEAN } \\
\text { CONCEN- } \\
\text { TRATION } \\
\text { (MG/L) }\end{array}$ & $\begin{array}{l}\text { SEDIMENT } \\
\text { DISCHARGE } \\
\text { (TONS/DAY) }\end{array}$ & $\begin{array}{l}\text { MEAN } \\
\text { DISCHARGE } \\
\text { (CFS) }\end{array}$ & $\begin{array}{l}\text { FEBRUARY } \\
\text { MEAN } \\
\text { CONCEN- } \\
\text { TRATION } \\
\text { (MG/L) }\end{array}$ & $\begin{array}{l}\text { SEDIMENT } \\
\text { DISCHARGE } \\
\text { (TONS/DAY) }\end{array}$ & $\begin{array}{l}\text { MEAN } \\
\text { OISCHARGE } \\
\text { (CFS) }\end{array}$ & $\begin{array}{l}\text { MARCH } \\
\text { MEAN } \\
\text { CONCEN- } \\
\text { TRATION } \\
\text { (MG/L) }\end{array}$ & $\begin{array}{l}\text { SEDIMENT } \\
\text { DISCHARGE } \\
\text { (TONS/DAY) }\end{array}$ \\
\hline $\begin{array}{l}1 \\
2 \\
3 \\
4 \\
5\end{array}$ & $\begin{array}{l}9300 \\
7900 \\
7600 \\
7800 \\
8500\end{array}$ & $\begin{array}{l}190 \\
158 \\
150 \\
145 \\
180\end{array}$ & $\begin{array}{l}4770 \\
3370 \\
3080 \\
3050 \\
4130\end{array}$ & $\begin{array}{l}15400 \\
15900 \\
14100 \\
13000 \\
16200\end{array}$ & $\begin{array}{l}560 \\
520 \\
355 \\
310 \\
650\end{array}$ & $\begin{array}{l}23300 \\
22300 \\
13500 \\
10900 \\
28400\end{array}$ & $\begin{array}{r}17100 \\
13300 \\
13900 \\
11100 \\
9560\end{array}$ & $\begin{array}{l}840 \\
448 \\
450 \\
285 \\
235\end{array}$ & $\begin{array}{r}38800 \\
16100 \\
16900 \\
8540 \\
6070\end{array}$ \\
\hline $\begin{array}{r}6 \\
7 \\
8 \\
9 \\
10\end{array}$ & $\begin{array}{l}8300 \\
7100 \\
6400 \\
5800 \\
5020\end{array}$ & $\begin{array}{r}178 \\
142 \\
137 \\
122 \\
97\end{array}$ & $\begin{array}{l}3990 \\
2720 \\
2370 \\
1910 \\
1310\end{array}$ & $\begin{array}{l}18800 \\
16400 \\
14700 \\
31800 \\
27600\end{array}$ & $\begin{array}{r}880 \\
510 \\
479 \\
2200 \\
1150\end{array}$ & $\begin{array}{r}44700 \\
22600 \\
20900 \\
190000 \\
85700\end{array}$ & $\begin{array}{l}8790 \\
8010 \\
7160 \\
6490 \\
6050\end{array}$ & $\begin{array}{l}200 \\
168 \\
135 \\
120 \\
100\end{array}$ & $\begin{array}{l}4750 \\
3630 \\
2610 \\
2100 \\
1630\end{array}$ \\
\hline $\begin{array}{l}11 \\
12 \\
13 \\
14 \\
15\end{array}$ & $\begin{array}{r}15300 \\
96400 \\
107000 \\
53800 \\
29700\end{array}$ & $\begin{array}{l}1400 \\
3980 \\
3290 \\
2400 \\
1750\end{array}$ & $\begin{array}{r}99300 \\
1030000 \\
550000 \\
349000 \\
140000\end{array}$ & $\begin{array}{l}38700 \\
37800 \\
23500 \\
19000 \\
23700\end{array}$ & $\begin{array}{r}2200 \\
1430 \\
980 \\
730 \\
1290\end{array}$ & $\begin{array}{r}244000 \\
146000 \\
62200 \\
37400 \\
87100\end{array}$ & $\begin{array}{l}5650 \\
5130 \\
4870 \\
4680 \\
4520\end{array}$ & $\begin{array}{l}88 \\
77 \\
70 \\
62 \\
57\end{array}$ & $\begin{array}{r}1340 \\
1070 \\
920 \\
783 \\
698\end{array}$ \\
\hline $\begin{array}{l}16 \\
17 \\
18 \\
19 \\
20\end{array}$ & $\begin{array}{r}21700 \\
16200 \\
13600 \\
36700 \\
101000\end{array}$ & $\begin{array}{r}1050 \\
700 \\
650 \\
3110 \\
4620\end{array}$ & $\begin{array}{r}62500 \\
30800 \\
23900 \\
353000 \\
1230000\end{array}$ & $\begin{array}{l}25300 \\
18300 \\
14800 \\
36600 \\
10500\end{array}$ & $\begin{array}{r}1190 \\
580 \\
450 \\
370 \\
300\end{array}$ & $\begin{array}{r}81300 \\
28700 \\
18000 \\
38800 \\
8510\end{array}$ & $\begin{array}{l}4660 \\
6030 \\
5010 \\
8220 \\
7120\end{array}$ & $\begin{array}{r}70 \\
177 \\
497 \\
280 \\
170\end{array}$ & $\begin{array}{r}881 \\
3180 \\
12100 \\
5770 \\
3270\end{array}$ \\
\hline $\begin{array}{l}21 \\
27 \\
23 \\
24 \\
25\end{array}$ & $\begin{array}{r}109000 \\
61000 \\
35700 \\
26200 \\
26000\end{array}$ & $\begin{array}{l}3850 \\
2710 \\
1780 \\
1310 \\
2140\end{array}$ & $\begin{array}{r}1140000 \\
446000 \\
172000 \\
92700 \\
157000\end{array}$ & $\begin{array}{r}8790 \\
7560 \\
7490 \\
8780 \\
11900\end{array}$ & $\begin{array}{l}250 \\
210 \\
210 \\
380 \\
530\end{array}$ & $\begin{array}{r}5930 \\
4290 \\
4250 \\
9010 \\
17000\end{array}$ & $\begin{array}{l}6870 \\
6300 \\
6050 \\
6130 \\
6180\end{array}$ & $\begin{array}{l}150 \\
125 \\
118 \\
118 \\
130\end{array}$ & $\begin{array}{l}2780 \\
2130 \\
1930 \\
1950 \\
2170\end{array}$ \\
\hline $\begin{array}{l}26 \\
27 \\
28 \\
29 \\
30 \\
31\end{array}$ & $\begin{array}{l}42700 \\
34000 \\
26000 \\
20800 \\
17600 \\
15100\end{array}$ & $\begin{array}{r}3850 \\
1380 \\
1200 \\
900 \\
630 \\
490\end{array}$ & $\begin{array}{r}430000 \\
173000 \\
84200 \\
50500 \\
29900 \\
20000\end{array}$ & $\begin{array}{r}11000 \\
9380 \\
15600 \\
=- \\
=-\end{array}$ & $\begin{array}{r}360 \\
265 \\
1240 \\
-- \\
--\end{array}$ & $\begin{array}{r}10700 \\
6710 \\
58300 \\
=- \\
=-\end{array}$ & $\begin{array}{l}6180 \\
6600 \\
7860 \\
8450 \\
8450 \\
8630\end{array}$ & $\begin{array}{l}148 \\
210 \\
345 \\
405 \\
495 \\
535\end{array}$ & $\begin{array}{r}2470 \\
3740 \\
7320 \\
9240 \\
11300 \\
12500\end{array}$ \\
\hline$A L$ & 979220 & -- & 7093300 & 512800 & - & 1328300 & 239050 & -- & 188670 \\
\hline
\end{tabular}


11475000 EEL RI VER AT FORT SEWARD, CALIF,--Conti nued

SUSPENDED-SEDIMENT DISCHARGE, WATER YEAR OCTOBER 1968 TO SEPTEMBER 1969

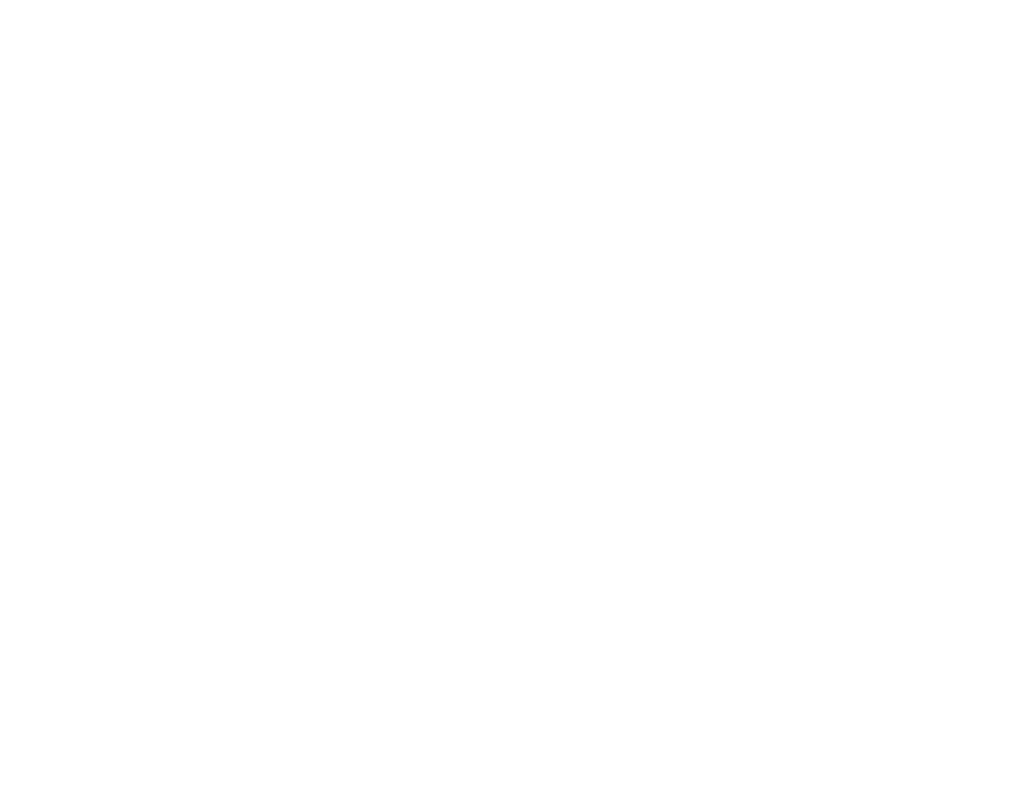

\begin{tabular}{|c|c|c|c|c|c|c|c|c|c|}
\hline & & Juty & & & AUGUST & & & SEPTEMBER & \\
\hline OAY & $\begin{array}{l}\text { MEAN } \\
\text { DISCHARGE } \\
\text { (CFS) }\end{array}$ & $\begin{array}{l}\text { MEAN } \\
\text { CONCEN- } \\
\text { TRATION } \\
\text { IMG/LI) }\end{array}$ & $\begin{array}{l}\text { SEDIMENT } \\
\text { DISCHARGE } \\
\text { (TONS/DAY) }\end{array}$ & $\begin{array}{l}\text { MEAN } \\
\text { DISCHARGE } \\
\text { (CFS) }\end{array}$ & $\begin{array}{l}\text { MEAN } \\
\text { CONCEN- } \\
\text { TRATION } \\
\text { (MG/L) }\end{array}$ & $\begin{array}{l}\text { SEDIMENT } \\
\text { DISCHARGE } \\
\text { (TONS/DAY) }\end{array}$ & $\begin{array}{l}\text { MEAN } \\
\text { DISCHARGE } \\
\text { (CFS) }\end{array}$ & $\begin{array}{l}\text { MEAN } \\
\text { CONCEN- } \\
\text { TRATION } \\
\text { (MG/L) }\end{array}$ & $\begin{array}{l}\text { SEDIMENT } \\
\text { DI SCHARGE } \\
\text { (TONS/DAY) }\end{array}$ \\
\hline
\end{tabular}

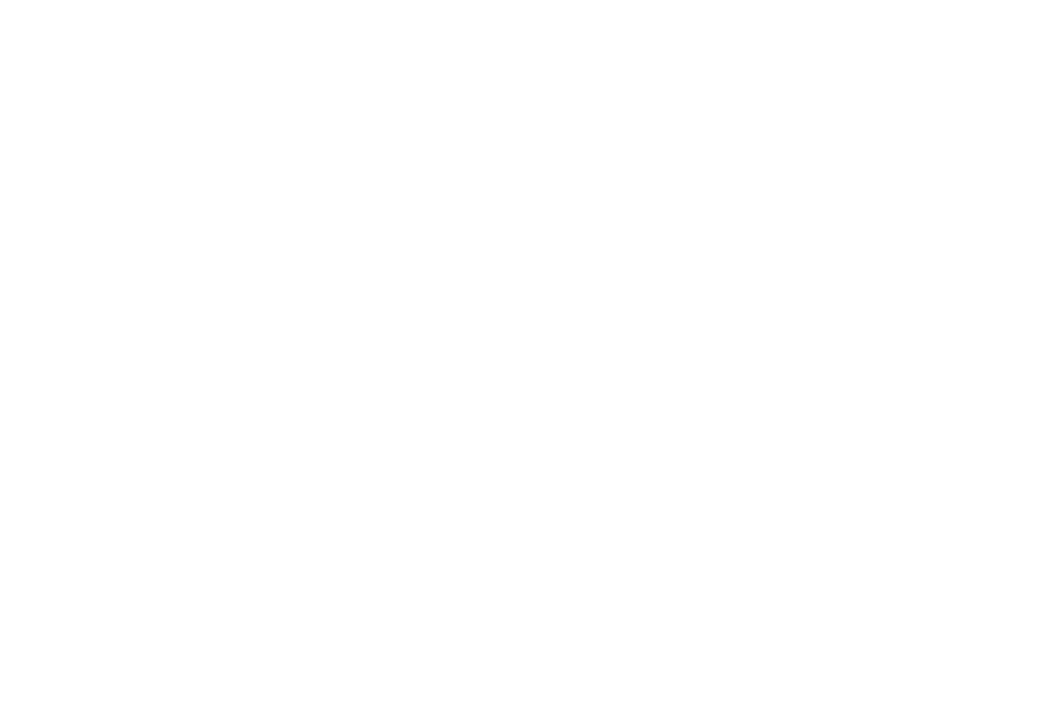


11475250 EEL RIVER AT SOUTH FORK, CALIF.

LOCATION. - Lat $40^{\circ} 21^{\prime} 04^{\prime \prime}$, long $123^{\circ} 54^{\prime} 48^{\prime \prime}$, in SE⿺廴́net sec. 2, T. 1 S., R. 2 E., Humboldt County, 0.2 mile upstream from Northwestern Pacific Railroad Bridge, $0.4 \mathrm{mile}$ north of town of South Fork, and $0.5 \mathrm{mile}$ upstream from South Fork.

PERTOD OF RECORD.--Chemical analyses: October 1953 to September 1969.

REMARKS.--Records furnished by California Department of Water Resources and reviewed by U.S. Geological Survey. Exact sampling location subject to change due to seasonal accessibility to river. Records of discharge given for Eel River at Fort Seward (station 11475000). Published as EeI River at McCann, October 1953 to Septem-

CHEMICAL ANALYSES, WATER YEAR OCTOBER 1968 TO SEPTEMBER 1969

\begin{tabular}{|c|c|c|c|c|c|c|c|c|c|c|c|}
\hline DATE & $\begin{array}{l}\text { MEAN } \\
\text { DIS- } \\
\text { CHARGE } \\
\text { (CFS) }\end{array}$ & $\begin{array}{l}\text { TEMPER- } \\
\text { ATURE } \\
\text { (DEG C) }\end{array}$ & $\begin{array}{l}\text { DIS- } \\
\text { SOLVED } \\
\text { DXYGEN } \\
\text { (AG/L) }\end{array}$ & $\begin{array}{l}\text { CAL- } \\
\text { CIUH } \\
\text { (CA) } \\
\text { (MG/L) }\end{array}$ & $\begin{array}{c}\text { MAG- } \\
\text { NE- } \\
\text { SIUM } \\
\text { (MGI } \\
\text { (MG/L) }\end{array}$ & $\begin{array}{l}\text { SODIUM } \\
\text { (NA) } \\
\text { (MG/L) }\end{array}$ & $\begin{array}{l}\text { PO- } \\
\text { TAS- } \\
\text { SIUM } \\
\text { (K) } \\
\text { (MG/L) }\end{array}$ & $\begin{array}{l}\text { BICAR- } \\
\text { BONATE } \\
\text { (HCO3) } \\
\text { (MG/L) }\end{array}$ & $\begin{array}{l}\text { CAR- } \\
\text { BONATE } \\
\text { (CO3) } \\
\text { (MG/L) }\end{array}$ & $\begin{array}{l}\text { SULFATE } \\
\text { (SO4) } \\
\text { (MG/L) }\end{array}$ & $\begin{array}{l}\text { CHLO- } \\
\text { RIDE } \\
\text { ICLI } \\
\text { IMG/LI }\end{array}$ \\
\hline $\begin{array}{l}\text { OCT. } \\
\text { O2... }\end{array}$ & 37 & 17 & 8.9 & - & - & 9.2 & -- & 158 & 0 & -- & 7.9 \\
\hline $\begin{array}{l}13 \ldots \\
\text { DEC . }\end{array}$ & 1310 & 11 & 10.5 & - & - & 8.2 & - & 121 & 0 & -- & 6.5 \\
\hline J $04 . .$. & 1060 & 6 & 12.5 & - & -- & 6.0 & -- & 93 & 0 & -- & 3.7 \\
\hline FEB. & 61000 & 8 & 12.7 & -- & 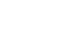 & 3.0 & -- & 60 & 0 & - & 1.6 \\
\hline $\begin{array}{l}04 \ldots . . \\
\text { MAR. }\end{array}$ & 13000 & 6 & 12.7 & - & -- & 4.0 & - & 72 & 0 & -- & 2.0 \\
\hline $\begin{array}{l}04 \ldots . \\
\text { APR. }\end{array}$ & 11100 & 8 & 12.6 & -- & - & 3.4 & -- & 72 & 0 & - & 1.9 \\
\hline$\underset{\text { MAY }}{\text { OB... }}$ & 5380 & 12 & 11.5 & -- & -- & 3.7 & -- & 73 & 0 & -- & 1.7 \\
\hline $\begin{array}{l}\text { I3.... } \\
\text { JUNE }\end{array}$ & 5200 & 16 & 10.6 & 16 & 2.9 & 2.7 & 1.0 & 60 & 0 & 4.3 & 1.6 \\
\hline JuLy & 825 & 17 & 9.9 & -- & -- & 3.4 & -- & 85 & 0 & -- & 2.7 \\
\hline $\begin{array}{l}15 . . . \\
\text { AUG. }\end{array}$ & 155 & 22 & 9.1 & -- & -- & 6.1 & - & 136 & 0 & -- & 3.7 \\
\hline $\begin{array}{l}\text { O5... } \\
\text { SEPT. }\end{array}$ & 66 & 21 & 9.6 & - & -- & 6.8 & -- & 156 & 0 & -- & 4.3 \\
\hline $10 \ldots$ & 35 & 19 & 9.2 & 44 & 10 & B.6 & 1.2 & 154 & 0 & 29 & 5.3 \\
\hline
\end{tabular}

\begin{tabular}{|c|c|c|c|c|c|c|c|c|c|c|c|}
\hline DATE & $\begin{array}{l}\text { NI TRATE } \\
\text { (ND3) } \\
\text { (MG/L) }\end{array}$ & $\begin{array}{l}\text { BORDN } \\
\text { (B) } \\
(U G / L)\end{array}$ & $\begin{array}{l}\text { DIS- } \\
\text { SOLVED } \\
\text { SOLIDS } \\
\text { (RESI- } \\
\text { DUE AT } \\
\text { IBO C) } \\
\text { I MG LI) }\end{array}$ & $\begin{array}{l}\text { DIS- } \\
\text { SOLVED } \\
\text { SOL IDS } \\
\text { ITONS } \\
\text { PER } \\
\text { AC-FTI }\end{array}$ & $\begin{array}{l}\text { HARD- } \\
\text { NESS } \\
\text { (CA, MG) } \\
\text { (MG/L) }\end{array}$ & $\begin{array}{l}\text { NDN- } \\
\text { CAR- } \\
\text { BONATE } \\
\text { HARO- } \\
\text { NESS } \\
\text { (MG/L) }\end{array}$ & $\begin{array}{l}\text { PERCENT } \\
\text { SODIUM }\end{array}$ & $\begin{array}{c}\text { SDDIUM } \\
\text { AD- } \\
\text { SORP- } \\
\text { TION } \\
\text { RAT IO }\end{array}$ & $\begin{array}{l}\text { ALKA- } \\
\text { LINITY } \\
\text { AS } \\
\text { CACD } 3 \\
\text { (MG/L) }\end{array}$ & $\begin{array}{c}\text { PH } \\
\text { (UNITS) }\end{array}$ & $\begin{array}{l}\text { SPECI- } \\
\text { FIC } \\
\text { CONO- } \\
\text { UCTANCE } \\
\text { (MICRO- } \\
\text { MHOSI }\end{array}$ \\
\hline $\begin{array}{l}\text { DCT. } \\
02 \ldots . .\end{array}$ & -- & 160 & -- & - & 168 & 38 & 11 & .3 & 130 & 8.0 & 370 \\
\hline $\begin{array}{l}\text { NDV. } \\
13 . . . \\
\text { DEC. }\end{array}$ & - & 260 & -- & - & 124 & 25 & 13 & .3 & 99 & 7.9 & 266 \\
\hline $\begin{array}{l}04 \ldots . . \\
\text { JAN. }\end{array}$ & - & 110 & 99 & $\cdot 13$ & 99 & 23 & 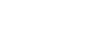 & $\cdots$ & 76 & 6.1 & 198 \\
\hline FEB. & -- & 0 & - & - & 65 & 16 & 9 & .2 & 49 & 7.9 & 110 \\
\hline $\begin{array}{l}04 . . . \\
\text { MAR. }\end{array}$ & -- & 10 & -- & -- & 70 & 11 & 11 & .2 & 59 & 8.1 & 146 \\
\hline $\begin{array}{l}04 \ldots . . \\
A P R .\end{array}$ & -- & 40 & -- & -- & 74 & 15 & 9 & .2 & 59 & 7.5 & 140 \\
\hline MAY & -- & 50 & - & -- & 64 & 4 & 11 & .2 & 60 & 8.0 & 142 \\
\hline JUNE & .1 & 10 & 63 & .09 & 52 & 3 & 10 & .2 & 49 & 7.8 & 114 \\
\hline JuLY & -- & 20 & -- & - & 80 & 10 & 8 & .2 & 70 & A.1 & 167 \\
\hline $\begin{array}{l}15 \ldots . . \\
\text { AUG. }\end{array}$ & -- & 40 & - & - & 128 & 16 & 9 & .2 & 112 & 8.3 & 260 \\
\hline $\begin{array}{l}05 . . . \\
\text { SEPT. }\end{array}$ & - & 100 & - & - & 145 & 17 & 9 & .2 & 128 & 6.3 & 302 \\
\hline $10 \ldots$ & .1 & 100 & 162 & .22 & 151 & 25 & 11 & .3 & 126 & 8.0 & 312 \\
\hline
\end{tabular}


11475500 SOUTH FORK EEL RIVER NEAR BRANSCOYB, CALIF.

LOEATION--Lat $39^{\circ} 43^{\circ} 09^{\prime \prime}$, long $123^{\circ} 39^{\circ} 08^{\prime \prime}$, In NW sec.32, T. 22 N., R.16 W., Wendocino County, at gaging station 0.4 mile upstream from Jack of Heart's Creek and $4.7 \mathrm{miles}$ north of Branscomb.

DRAINAGE AREA. $-\mathbf{- 4 3 . 8}: \mathrm{q} \mathrm{m1}$.

PERIOD OF RECORD.--Water temperatures: October 1960 to September 1968.

Sediment recorda: October 1962 to September 1969.

EXTREMES. $-1868-69$ :

Sediment concentrations: Yaximum dally, $1,360 \mathrm{mg} / 1 \mathrm{Jan} .12$; minimum daily, $1 \mathrm{mg} / 1$ on several days during October, May to August. Sediment discharge: Maximum da1ly, 17,400 tons Jan. 12; minimum dally, 0.01 ton on many days during October,
August, and September.

Perlod of record:

Hater temperatures: Maximum $(1960-61,1962-68), 28.0^{\circ} \mathrm{C}$ Aug. 7,1861 ; minimum $(1861-65,1866-68), 3.0^{\circ} \mathrm{C}$ Nov. $17,18,1961$

mant concentrations: Maximum dally, 4,900 mg/1 (estimated) Dec. 22, 1964; minimum dally, $1 \mathrm{mg} / 1$ on Sediment discherge:

in $1864-65,1967$.

REMARXS. - Where no maximum or minlmum is shown, temperature is once-dally reading.

TEXPERATURE $\left({ }^{\circ} \mathrm{C}\right)$ OF WATER, WATER YEAR OCTOBER 1968 TO SEPTEMAER 1968 oAY

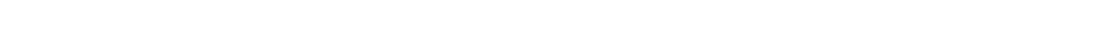

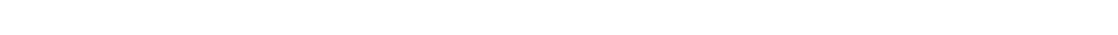
MAXIMUM MINIMUM

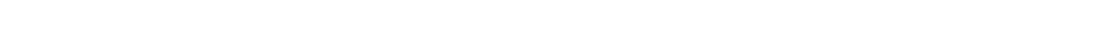
MAXIMUM -

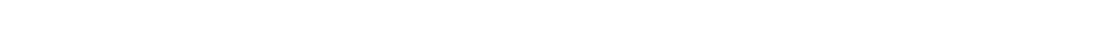
МАХІМUМ MINIMUM -

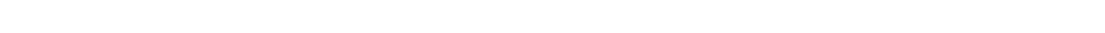
МАХІмUМ -

FERRUARY. ㄱ. MAXIMUM -. MINCH.... MAXIMUM MINIMUM

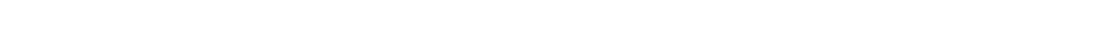

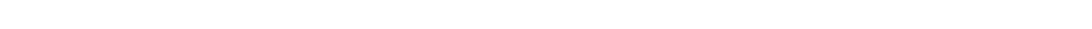

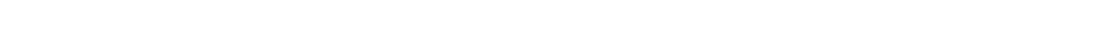
MINIMUM -

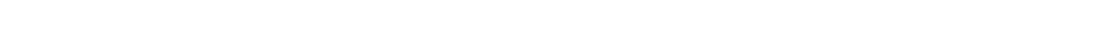
MAXIMUM -

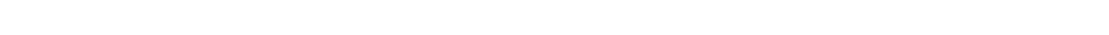
мікімUM --

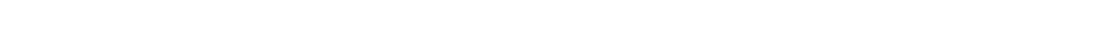
MAXIMUM -MINIMUM -

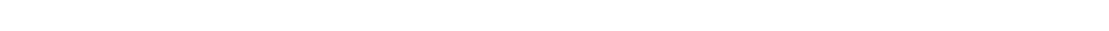
MAXIMUM

IMETHODS OF PARTICLE-SIZE DISTRIBUTION OF SUSPENDED SEDIMENT, WATER YEAR OCTOBER 1968 TO SEPTEMBER 1969 ANALYSIS: B, BOTTOM WITHDRAWAL TUBE: C. CHEMICALLY OISPERSED: N, IN NATIVE WATER; P, PIPET: S, SIEVE:
V, VISUAL ACCUMULATION TUBE: W, IN DISTILLED WATERI

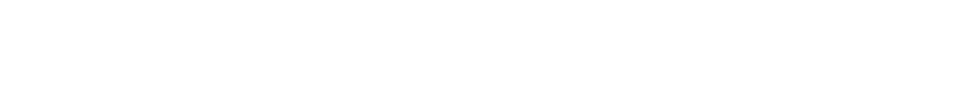

NUV $12,1968 \quad 0720 \quad 10$

DEC $10 \ldots \ldots \ldots . .1245 \quad 11$

JAN 12, 1969 1515 11

JAN $15 \ldots \ldots 1535$

$\begin{array}{rrr}62 & 183 & 31 \\ 3200 & 2470 & 21300 \\ 2780 & 805 & 6040 \\ 4860 & 1250 & 16400 \\ 678 & 67 & 123\end{array}$

$\begin{array}{lll}78 & 92 & 98 \\ 28 & 36 & 5 \\ 27 & 38 & 5 \\ 25 & 29 & 4 \\ 26 & 39 & 49 \\ & & \end{array}$

$\begin{array}{ll}8 & 98 \\ 51 & 63 \\ 42 & 54 \\ 4 & 56 \\ 9 & 61\end{array}$

$\begin{array}{rr}99 & 100 \\ 74 & 83 \\ 74 & 84 \\ 68 & 76 \\ 66 & 86\end{array}$

88
84
84

$\begin{array}{ll}94 & 100 \\ 99 & 100 \\ 73 & 100 \\ 37 & 100\end{array}$

APR $\quad 5 \ldots \ldots .0820 \quad 8$

190

91

38

$96 \quad 100$

$\begin{array}{lll}-- & -- & \text { SBWC } \\ -- & -- & \text { VPWC } \\ -- & -- & \text { VBWC } \\ -- & -- & \text { YPWC } \\ -- & -- & \text { SBWC }\end{array}$ 
EEL RIVER BASIN

11475500 SOUTH FORK EEL RIVER NEAR BRANSCOMB, CALIF.--Cont1nued

SUSPENDED-SEDIMENT DISCHARGE, WATER YEAR OCTOBER 1968 TO SEPTEMBER 1969

OCTOBER

MEAN

CONCEN- SEDIMENT TRATION DISCHARGE
(MG/L) (TONS/DAY)
NOVEMBER MEAN
OISCHARGE
(CFS)

$$
\text { MEAN }
$$

CONCEN- SEDIMENT TRATION DISCHARGE
(MG/L) (TDNS/DAY)

13
31
31
22
21
18
16
15
14
13

11
12
13
14
15

$\begin{array}{ll}3.9 & 1 \\ 3.6 & 2 \\ 3.4 & 2 \\ 3.1 & 2\end{array}$

.01
.02
.02
.02
.03
.02
.02
.02
.02
.02

$\begin{array}{rr}13 & 4 \\ 31 & 15 \\ 31 & 9 \\ 22 & 6\end{array}$

4
15
9
6
5

.14
1.4
.75
.36
.28 (CFS)
(CHARGE

5
5
5
5
5

.24
.22
.20
.19

120
90
68
58
53
46
49
129
99
1770

$\begin{array}{ll}1.6 & 21 \\ 1.2 & 55 \\ .36 & 33 \\ .29 & 31 \\ .22 & 97\end{array}$

21
37
22
18
16

$\begin{array}{rcr}53 & 5.7 & 975 \\ 158 & 24 & 519 \\ 65 & 5.8 & 390 \\ 52 & 4.4 & 400 \\ 229 & 63 & 1300\end{array}$

16

17
18
19

13
11
10

9.1

21
22
23
24

24
25

7.7
7.3
7.0
6.6
6.6

6.6

6.3
5.9
5.9

14
20
16

302.6

TorA

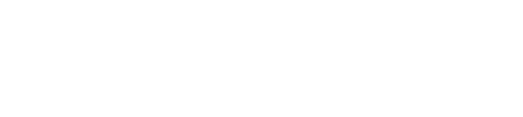

FEBRUARY

.14
.09

.09
.08
.07

65

$\begin{array}{ll}11 & 875 \\ 1.5 & 498 \\ 38 & 364 \\ 11 & 280\end{array}$

11.860
$.86 \quad 219$

.68180

.06
.06
.06

.06
.06
.05
.05

$22^{.42}$

180
170
1950
2030
1920

$\begin{array}{ll}.05 & 74 \\ .05 & 56 \\ .05 & 45 \\ .57 & 42 \\ .38 & 65 \\ .17 & -0\end{array}$

$\begin{array}{rlr}18 & 3.6 & 1360 \\ 9 & 1.4 & 870 \\ 8 & .97 & 795 \\ 35 & 4.7 & 674\end{array}$

14

$\begin{array}{rrr}18 & 3.6 & 1360 \\ 9 & 1.4 & 870 \\ 8 & .97 & 795\end{array}$

35
75
--

248.46

674
512
406

$+$

CONCEN- SEDIMENT RRATION DISCHARGE
(MG/L) (TONS/DAY)

MEATION DISCHARGE DISCHARGE
(CFS) (MGIL) (TONS/DAY)

MEAN

CONCEN- SEDIMENT MEAN DISCHARGE DISCHARG

$\begin{array}{rr}129 & 47 \\ 55 & 13\end{array}$

47
13
3.3
1.1

3.3
1.1
.72

(1)

$323 \quad 14$

IMG

$\begin{array}{rrr}166 & 233 & 674 \\ 140 & 194 & 568 \\ 34 & 42 & 498 \\ 53 & 68 & 422 \\ 36 & 60 & 361\end{array}$

ME AN

CONCEN- SEDIMENT

TRATION DISCHARGE

$$
\begin{aligned}
& 268 \\
& 228 \\
& 298
\end{aligned}
$$

14
12
11
12
9

$\begin{array}{cc}12 & 519 \\ 8.7 & 512 \\ 6.8 & 460 \\ 6.4 & 477\end{array}$

$\begin{array}{ll}6.8 & 460 \\ 6.4 & 477 \\ 4.3 & 622\end{array}$

153
136

122
109

109
105

9
7
5
5
13

1030
4730

4730
3270
1290

744

726

$\begin{array}{rr}3.7 & 726 \\ 2.6 & 638 \\ 1.6 & 785 \\ 1.5 & 1440\end{array}$

3

439
1360
920
224
70

$\begin{array}{rr}1.5 & 1440 \\ 3.7 & 975\end{array}$

498
387
384
1320
3160

30
20
38
340
826

1850
17400
9050
780

1420

\begin{tabular}{ll}
780 & 674 \\
141 & 519 \\
\hline & 750
\end{tabular}

$196 \quad 3 B 4 \quad 310$

$\begin{array}{rrr}196 & 384 & 310 \\ 82 & 141 & 268 \\ B 7 & 299 & 233\end{array}$

$\begin{array}{rrr}B 7 & 299 & 233 \\ 207 & 864 & 206\end{array}$

$\begin{array}{lll}207 & 864 & 206 \\ 159 & 419 & 183\end{array}$

$\begin{array}{rrr}273 & 1070 & 160 \\ 86 & 237 & 145\end{array}$

$\begin{array}{rrr}86 & 237 & 145 \\ 34 & 62 & 134 \\ 22 & 31 & 124\end{array}$

$\begin{array}{rr}30 & 55 \\ 15 & 23 \\ 18 & 24 \\ 12 & 14 \\ B & 7.8 \\ 10 & 8.4 \\ 7 & 5.1 \\ 9 & 5.7 \\ 4 & 2.2 \\ 7 & 3.5 \\ 10 & 4.3 \\ 11 & 4.3 \\ 10 & 3.6 \\ 7 & 2.3 \\ 7 & 2.2\end{array}$

$\begin{array}{rr}40 & 509 \\ 21 & 435 \\ 39 & 374 \\ 1210 & 313 \\ 7170 & 262\end{array}$

$\begin{array}{ll}2660 & 399 \\ 1390 & 184\end{array}$

855
561

2940
691

2940
691
185
45

222
200
211
268

58

117

118

$\begin{array}{ll}45 & 118 \\ 18 & 163 \\ 10 & 170 \\ 7.6 & 153\end{array}$

$\begin{array}{ll}7.6 & 153 \\ 8.4 & 145\end{array}$

9
14
15
12

55
23
24
14
7.8
8.4
5.1
5.7
2.2
3.5
4.3
4.3
3.6
2.3
2.2
2.9
6.2
6.9
5.0
3.1
2.3
1.8
1.6
1.6
1.7
1.6
1.5
1.4
1.5
1.5
1.6

55
23
24
14
7.8
8.4
5.1
5.7
2.2
3.5
4.3
4.3
3.6
2.3
2.2
2.9
6.2
6.9
5.0
3.1
2.3
1.8
1.6
1.6
1.7
1.6
1.5
1.4
1.5
1.5
1.6

$\begin{array}{rll}8 & 4.8 & 140 \\ 9 & 4.9 & 131 \\ 21 & 12 & 122 \\ 47 & 34 & 116 \\ 50 & 49 & 107\end{array}$

1040

30
185

45
338

268
364

170
49 $\quad 49$

$\begin{array}{ll}491 & 374 \\ 107 & 380\end{array}$

46
35
25
30

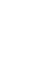

$\begin{array}{rr}18 & 18 \\ 35 & 36 \\ 156 & 367 \\ -- & --\end{array}$

49

42685.3

16274

$-$

4833.7

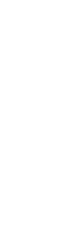

33

5710

329
63
96

130
2230

626
148

51
24
12

9.7

5660

2800
4450

${ }_{193}^{845}$

118
47

23719.54

207.6 
$11478 B 00$ SOUTH FORK EKL RIVER NEAR BRANSCONB, CALIF.--COntinued

SUSPENDED=SEDIMENT DISCHARGE, WATER YEAR OCTOGER 1968 TO SEPTEMHER 1969

\begin{tabular}{|c|c|c|c|c|c|c|c|c|c|}
\hline & & APR IL & & & MAY & & & JUNE & \\
\hline DAY & $\begin{array}{l}\text { MEAN } \\
\text { MISCAARGE } \\
\text { (CFS) }\end{array}$ & $\begin{array}{l}\text { MEAN } \\
\text { CONCEN- } \\
\text { TRATION } \\
\text { (MG/L) }\end{array}$ & $\begin{array}{l}\text { SEDTMENT } \\
\text { DISGHARGE } \\
\text { (TONS/DAY) }\end{array}$ & $\begin{array}{l}\text { MEAN } \\
\text { DISCHARGE } \\
\text { (CFS) }\end{array}$ & $\begin{array}{l}\text { MEAN } \\
\text { CONCEN- } \\
\text { TRAT TON } \\
\text { (MG/L) }\end{array}$ & $\begin{array}{l}\text { SEDIMENT } \\
\text { DISCHAROE } \\
\text { (TONS /DAY) }\end{array}$ & $\begin{array}{l}\text { MEAN } \\
\text { DISEHARGE } \\
\text { (CFS) }\end{array}$ & $\begin{array}{l}\text { MEAN } \\
\text { CONCEN- } \\
\text { TRATION } \\
\text { IMG/L) }\end{array}$ & $\begin{array}{l}\text { SEDIMENT } \\
\text { DISCHAKGE } \\
\text { (TONS/DAY) }\end{array}$ \\
\hline $\begin{array}{l}1 \\
2 \\
3 \\
4 \\
5\end{array}$ & $\begin{array}{r}70 \\
79 \\
79 \\
68 \\
140\end{array}$ & $\begin{array}{l}7 \\
16 \\
20 \\
15 \\
51\end{array}$ & $\begin{array}{l}1.3 \\
3.3 \\
4.3 \\
2.8 \\
19\end{array}$ & $\begin{array}{l}68 \\
61 \\
57 \\
54 \\
48\end{array}$ & $\begin{array}{l}2 \\
2 \\
2 \\
2 \\
2\end{array}$ & $\begin{array}{l}.37 \\
.33 \\
.31 \\
.29 \\
.26\end{array}$ & $\begin{array}{l}21 \\
20 \\
20 \\
20 \\
20\end{array}$ & $\begin{array}{l}2 \\
2 \\
2 \\
1 \\
2\end{array}$ & $\begin{array}{l}.11 \\
.11 \\
.11 \\
.05 \\
.11\end{array}$ \\
\hline $\begin{array}{r}6 \\
7 \\
8 \\
9 \\
10\end{array}$ & $\begin{array}{r}122 \\
105 \\
97 \\
97 \\
93\end{array}$ & $\begin{array}{r}6 \\
5 \\
7 \\
10 \\
5\end{array}$ & $\begin{array}{l}2.0 \\
1.4 \\
1.8 \\
2.6 \\
1.3\end{array}$ & $\begin{array}{l}45 \\
42 \\
40 \\
37 \\
36\end{array}$ & $\begin{array}{l}2 \\
2 \\
4 \\
2 \\
2\end{array}$ & $\begin{array}{l}.24 \\
.23 \\
.43 \\
.20 \\
.19\end{array}$ & $\begin{array}{l}20 \\
20 \\
19 \\
19 \\
19\end{array}$ & $\begin{array}{l}2 \\
2 \\
2 \\
3 \\
5\end{array}$ & $\begin{array}{l}.11 \\
.11 \\
.10 \\
.15 \\
.26\end{array}$ \\
\hline $\begin{array}{l}11 \\
12 \\
13 \\
14 \\
15\end{array}$ & $\begin{array}{l}83 \\
84 \\
79 \\
74 \\
70\end{array}$ & $\begin{array}{l}5 \\
7 \\
8 \\
8 \\
7\end{array}$ & $\begin{array}{l}1.1 \\
1.6 \\
1.7 \\
1.6 \\
1.3\end{array}$ & $\begin{array}{l}34 \\
33 \\
32 \\
31 \\
31\end{array}$ & $\begin{array}{l}2 \\
2 \\
2 \\
2 \\
3\end{array}$ & $\begin{array}{l}.18 \\
.18 \\
.17 \\
.17 \\
.25\end{array}$ & $\begin{array}{l}20 \\
19 \\
18 \\
18 \\
17\end{array}$ & $\begin{array}{l}4 \\
3 \\
3 \\
3 \\
3\end{array}$ & $\begin{array}{l}.22 \\
.15 \\
.15 \\
.15 \\
.14\end{array}$ \\
\hline $\begin{array}{l}16 \\
17 \\
18 \\
19 \\
20\end{array}$ & $\begin{array}{l}65 \\
63 \\
64 \\
57 \\
54\end{array}$ & $\begin{array}{l}5 \\
4 \\
4 \\
4 \\
4\end{array}$ & $\begin{array}{l}.88 \\
.68 \\
.69 \\
.62 \\
.58\end{array}$ & $\begin{array}{l}30 \\
28 \\
28 \\
27 \\
26\end{array}$ & $\begin{array}{l}2 \\
2 \\
1 \\
2 \\
2\end{array}$ & $\begin{array}{l}.16 \\
.15 \\
.08 \\
.15 \\
.14\end{array}$ & $\begin{array}{l}16 \\
15 \\
14 \\
15 \\
17\end{array}$ & $\begin{array}{l}4 \\
5 \\
6 \\
4 \\
3\end{array}$ & $\begin{array}{l}.17 \\
.20 \\
.23 \\
.16 \\
.14\end{array}$ \\
\hline $\begin{array}{l}21 \\
22 \\
23 \\
24 \\
25\end{array}$ & $\begin{array}{r}50 \\
49 \\
133 \\
154 \\
124\end{array}$ & $\begin{array}{r}4 \\
5 \\
69 \\
13 \\
3\end{array}$ & $\begin{array}{c}.54 \\
30^{.66} \\
5.4 \\
1.0\end{array}$ & $\begin{array}{l}25 \\
24 \\
24 \\
24 \\
24\end{array}$ & $\begin{array}{l}2 \\
2 \\
2 \\
2 \\
2\end{array}$ & $\begin{array}{r}14 \\
.13 \\
.13 \\
.13 \\
.13\end{array}$ & $\begin{array}{l}18 \\
17 \\
16 \\
15 \\
14\end{array}$ & $\begin{array}{l}3 \\
3 \\
2 \\
2 \\
2\end{array}$ & $\begin{array}{l}.15 \\
.14 \\
.09 \\
.08 \\
.08\end{array}$ \\
\hline $\begin{array}{l}26 \\
27 \\
28 \\
29 \\
30 \\
31\end{array}$ & $\begin{array}{r}112 \\
98 \\
89 \\
79 \\
73 \\
--\end{array}$ & $\begin{array}{r}2 \\
2 \\
2 \\
2 \\
2 \\
--\end{array}$ & $\begin{array}{r}.60 \\
.53 \\
.48 \\
.43 \\
.39 \\
.-\end{array}$ & $\begin{array}{l}25 \\
26 \\
23 \\
23 \\
22 \\
21\end{array}$ & $\begin{array}{l}3 \\
5 \\
7 \\
2 \\
2 \\
3\end{array}$ & $\begin{array}{l}.20 \\
.35 \\
.43 \\
.12 \\
.12 \\
.17\end{array}$ & $\begin{array}{l}14 \\
13 \\
13 \\
13 \\
13 \\
--\end{array}$ & $\begin{array}{r}2 \\
2 \\
2 \\
2 \\
2 \\
--\end{array}$ & $\begin{array}{l}.08 \\
.07 \\
.07 \\
.07 \\
.07 \\
-.\end{array}$ \\
\hline rotal & 2602 & -- & 90.58 & 1049 & -- & 6.53 & 513 & $\cdots$ & 3.83 \\
\hline & \multicolumn{3}{|c|}{ JULY } & \multicolumn{3}{|c|}{ AUGUST } & \multicolumn{3}{|c|}{ SEPTEMBER } \\
\hline DAY & $\begin{array}{l}\text { MEAN } \\
\text { OISCHARGE } \\
\text { (CFS) }\end{array}$ & $\begin{array}{l}\text { MEAN } \\
\text { CONCEN- } \\
\text { TRATION } \\
\text { (MG/L) }\end{array}$ & $\begin{array}{l}\text { SEDIMENT } \\
\text { DISCHARGE } \\
\text { (TONS/DAY) }\end{array}$ & $\begin{array}{l}\text { MEAN } \\
\text { DISCHARGE } \\
\text { (CFS) }\end{array}$ & $\begin{array}{l}\text { MEAN } \\
\text { CONCEN- } \\
\text { TRATION } \\
\text { (MG/L) }\end{array}$ & $\begin{array}{l}\text { SEDIMENT } \\
\text { DISCHARGE } \\
\text { (TONS/DAY) }\end{array}$ & $\begin{array}{l}\text { MEAN } \\
\text { OISCHARGE } \\
\text { (CFS) }\end{array}$ & $\begin{array}{l}\text { MEAN } \\
\text { CONCEN- } \\
\text { IRATION } \\
\text { (MG LL) }\end{array}$ & $\begin{array}{l}\text { SEDIMENT } \\
\text { DISCHARGE } \\
\text { (TONS / DAY) }\end{array}$ \\
\hline
\end{tabular}
(MG/L) (TONS/DAY)

TOTAL

8.5
8.2
8.2
7.2
7.2

$\begin{array}{ll}.06 & 4.0 \\ .05 & 4.0\end{array}$

.05
.08 $\quad 3.9$

$.10 \quad 3.9$

.09
.11
.06
.04

3.9
3.5
3.5
3.5
3.5

.03
.03
.03
.03

2.0
2.0
2.0

2.0
1.9

3
4
5
4

.02
.02
.03
.02

1.9

1.9
1.9
1.9
1.9

.04

1

11
11
11
05 83 


\section{SEO}

LOCATION.

(HY ALODER CABEK NEAR BAANSCOM

on right 39"43'47", lang 193"

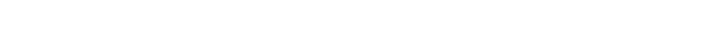

Period of necond, aq ai.

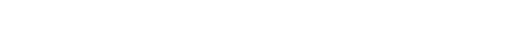

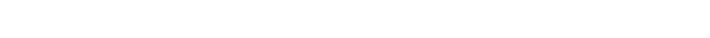

XTRURS, $-1088-69$ :

ret or temperatures:

Period of record.

days during Jans: Meximum, $21.0^{\circ} \mathrm{c}$

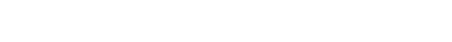

to Harch in 1969 .
several days during July in 1088 and CHEMICAL ANALYSES, WATER YEAR

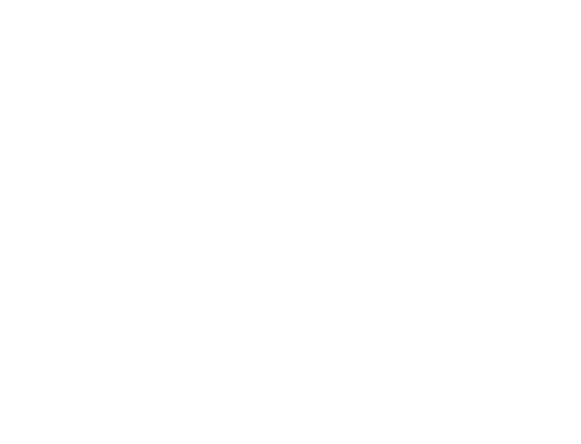

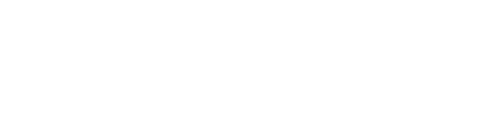

$\begin{array}{llllll}- & 15 & 4.6 & 0.1 & .7\end{array}$

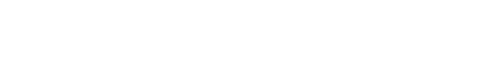

$\begin{array}{llllll}10 & 7.3 & 2.7 & 4.7 & .6 & 43\end{array}$

$-$

B.9

8.9

8.82.

$\begin{array}{llll}3.0 & 5.2 & .6 & 44\end{array}$

10

10

II

13

3.4

$\begin{array}{cccc}3.4 & 6.0 & .5 & 5 \\ 3.7 & 6.7 & .6 & 63 \\ 4.1 & 7.4 & .6 & \end{array}$

4.5

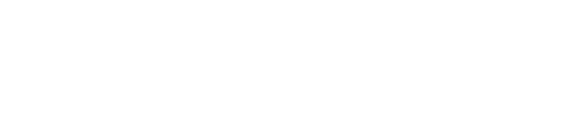

DIS-

SOLVED

SUN OF SOLVED

CONSII SDCIDS HARO

ITONS HARD-

$P E R, \quad(C A, M G)$
$C-F Y)$

7.8

IUG/LS TUES

$\begin{array}{cccc}\text { NuV. } & 5.0 & 1.8 & .1 \\ \text { OT... } & - & & \end{array}$

DEC.

11.
JAN.
15.

MAR.

APR.

OPR.

MAY

JUNE.

Juti 04

15. .

Auc.

$26 . .$.

2.0
2.0
2.0
2.0
3.0
3.0
3.0
5.0

2.3
1.4
1.1
2.7
2.0
2.7
2.0
2.7

.0
.0
.2
.8
.1
.0
.9
.0
.1
.1

$\begin{array}{ccc}08 & .12 & 56 \\ -0 & -0 & -5 \\ 55 & .07 & 31 \\ 56 & .08 & 28 \\ 63 & .09 & 34 \\ 59 & .08 & 34 \\ 69 & .09 & 39 \\ 72 & .10 & 42 \\ 80 & .11 & 50 \\ 85 & .11 & 54\end{array}$

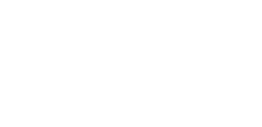

$\begin{array}{ccc}0 & 7.5 & 143 \\ -- & \cdots & \cdots \\ 0 & 7.2 & 83 \\ 0 & 7.5 & 78 \\ 0 & 7.6 & 90 \\ 0 & 7.7 & 90 \\ 0 & 7.9 & 106 \\ 0 & 7.6 & 116 \\ 0 & 7.3 & 128 \\ 0 & 7.0 & 135\end{array}$


11475560 ELDER CREEK NEAR BRANSCOMB, CALIF.--CONTInUEd

CHFMICAL ANALYSES, WATER YEAR OCTOBER 1968 TO SEPTEMBER 1969

\begin{tabular}{|c|c|c|c|c|c|c|c|c|c|}
\hline DATE & $\begin{array}{l}\text { PERCE VT } \\
\text { SOD IUM }\end{array}$ & $\begin{array}{c}\text { SODIUH } \\
\text { AD- } \\
\text { SORP- } \\
\text { TION } \\
\text { RATIO }\end{array}$ & $\begin{array}{l}\text { ALKA- } \\
\text { LINIIY } \\
\text { AS } \\
\text { CACJ3 } \\
\text { (MG/L) }\end{array}$ & $\begin{array}{l}\text { PHOS- } \\
\text { PHATE } \\
\text { (PO4) } \\
\text { (MG/L) }\end{array}$ & $\begin{array}{l}\text { ORTHO } \\
\text { PHOS- } \\
\text { PHATE } \\
\text { (PO4) } \\
\text { (MG } / L \text { ) }\end{array}$ & $\begin{array}{l}\text { ORGANIC } \\
\text { NITRO- } \\
\text { GEN } \\
\text { (N) } \\
\text { (MG/L) }\end{array}$ & $\begin{array}{l}\text { AMMONIA } \\
\text { (NHA) } \\
\text { (MG/L) }\end{array}$ & $\begin{array}{c}\text { CDLI- } \\
\text { FORM } \\
\text { (COL- } \\
\text { ONIES } \\
\text { PER } \\
\text { PEML) }\end{array}$ & $\begin{array}{l}\text { BIO- } \\
\text { CHEM- } \\
\text { ICAL } \\
\text { OXYGEN } \\
\text { DEMAND } \\
\text { (MG/L) }\end{array}$ \\
\hline
\end{tabular}

\begin{tabular}{|c|c|c|c|c|c|c|c|c|c|}
\hline $\begin{array}{l}\text { OCT. } \\
02 \ldots\end{array}$ & 23 & .5 & 66 & .11 & .11 & 1.5 & 1.5 & -- & 1.4 \\
\hline $\begin{array}{l}\text { NOV. } \\
\text { O7.... }\end{array}$ & -- & -- & $\sim$ & 12 & .12 & .21 & .04 & - & 1.0 \\
\hline DEC. & & & & & & & & & \\
\hline $\begin{array}{l}11 \ldots \\
\text { JAN. }\end{array}$ & 24 & .4 & 35 & .15 & .09 & .21 & .08 & 37 & - \\
\hline $\begin{array}{l}15 \ldots . . \\
\text { MAR. }\end{array}$ & 26 & .4 & 36 & .21 & .09 & .16 & .12 & -- & 1.4 \\
\hline $\begin{array}{l}11 \ldots . . \\
\triangle P R_{0}\end{array}$ & 24 & .4 & 44 & .14 & .07 & .47 & .12 & $3 !$ & .0 \\
\hline MAY... & 25 & .4 & 39 & .10 & .05 & .47 & .31 & $\cdots$ & .0 \\
\hline JUNE & 25 & .4 & 48 & - & - & -- & - & 26 & 2.6 \\
\hline $\begin{array}{l}04 \ldots . . \\
\text { JULY }\end{array}$ & 25 & .4 & 52 & .06 & .01 & .05 & .33 & 37 & 3.6 \\
\hline $\begin{array}{l}15 \ldots \\
\text { AUG. }\end{array}$ & 24 & .5 & 57 & .06 & .03 & .94 & .05 & 12 & 2.2 \\
\hline $26 \ldots$ & 24 & .5 & 60 & .09 & $.0 B$ & .00 & .18 & - & 1.7 \\
\hline
\end{tabular}

TEMPERATUEE ( ${ }^{\circ} \mathrm{C}$ ) OF TATER, TATER YEAR OCTOBER 1968 TO SEPTEMBER 1969 DAY

$\begin{array}{llllllllllllllllllllllllllllllll} & 12 & 12 & 12 & 12 & 12 & 12 & 11 & 11 & 10 & 10 & 10 & 10 & 10 & 10 & 10 & 10 & 10 & 10 & 12 & 11 & 10 & 10 & 10 & 10 & 10 & 10 & 10 & 10 & 10 & 10\end{array}$ NOVEMBER

MAXI MUM
MINIMUM MINIMUM

MAXIMUM

MINIMUM

MNUARY

MAXIMUM

FEBRUARY

MAXIMUM

MINIMUM

MARCH

MAXIMUM

APRIL

MAXIMUM

MINIMUM

MAXIMUM MINIMUM

JUNE

MAXIMUM

MINIMUM

JuLr

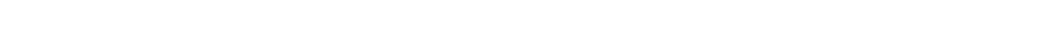

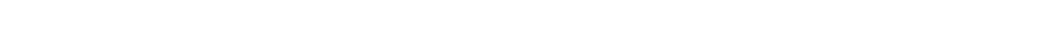
AUGUST

MAX1MUM 19191929182818191920191919191919191919191919191716161616161617

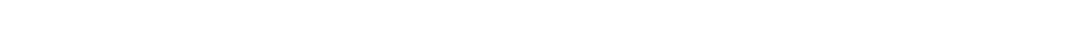

$\begin{array}{llllllllllllllllllllllllllllllllllll}\text { MAXIMIJM } & 17 & 17 & 17 & 17 & 17 & 16 & 17 & 17 & 17 & 17 & 17 & 17 & 17 & 16 & 15 & 14 & 14 & 14 & 14 & 14 & 14 & 14 & 13 & 23 & 13 & 13 & 13 & 13 & 13 & 13 & \ldots-\end{array}$

$\begin{array}{lllllllllllllllllllllllllllllll}10 & 10 & 10 & 10 & 10 & 10 & 10 & 10 & 10 & 10 & 10 & 10 & 10 & 9 & 8 & 8 & 9 & 9 & 9 & 9 & 9 & 9 & 9 & 9 & 9 & 9 & 8 & 8 & 8 & 8 & -- \\ 10 & 10 & 10 & 10 & 10 & 10 & 10 & 10 & 10 & 10 & 10 & 9 & 9 & 8 & 8 & 8 & 8 & 8 & 9 & 9 & 9 & 9 & 9 & 9 & 9 & 8 & 8 & 8 & 8 & 7 & -\end{array}$

$\begin{array}{llllllllllllllllllllllllllllllllllll}7 & 7 & 7 & 7 & 7 & 8 & 8 & 8 & 8 & 8 & 9 & 8 & 8 & 8 & 8 & 8 & 8 & 8 & 8 & 7 & 7 & 7 & 7 & 7 & 7 & 7 & 7 & 7 & 7 & 7 & 7 \\ 7 & 7 & 7 & 7 & 7 & 7 & 8 & 8 & 8 & 8 & 8 & 8 & 8 & 8 & 8 & 8 & 8 & 8 & 7 & 7 & 7 & 7 & 7 & 7 & 7 & 7 & 7 & 7 & 7 & 7 & 7\end{array}$

$\begin{array}{lllllllllllllllllllllllllllllllll}7 & 7 & 8 & 8 & 8 & 8 & 8 & 8 & 8 & 8 & 7 & 8 & 8 & 8 & 8 & 8 & 8 & 8 & 8 & 9 & 9 & 9 & 9 & 8 & 8 & 8 & 8 & 8 & 8 & 5 & 5 & 8 & 8 \\ 7 & 7 & 7 & 8 & 8 & 8 & 8 & 8 & 8 & 7 & 7 & 7 & 8 & 8 & 8 & 8 & 8 & 8 & 8 & 8 & 9 & 9 & 8 & 8 & 8 & 8 & 8 & 8 & 5 & 5 & 5 & & 8\end{array}$

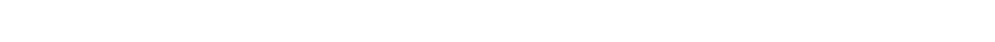

$\begin{array}{lllllllllllllllllllllllllllllllllll}7 & 7 & 7 & 7 & 7 & 7 & 7 & 7 & 7 & 7 & 7 & 7 & 7 & 8 & 8 & 8 & 8 & 8 & 8 & 8 & 8 & 9 & 9 & 10 & 10 & 10 & 10 & 10 & 10 & 11 & 10 & 8\end{array}$

$\begin{array}{cccccccccccccccccccccccccccccccc}9 & 9 & 9 & 9 & 8 & 8 & 9 & 9 & 9 & 10 & 10 & 10 & 9 & 9 & 9 & 10 & 10 & 10 & 10 & 11 & 11 & 10 & 10 & 9 & 9 & 10 & 11 & 11 & 11 & 10 & -5 & 10 \\ 8 & 8 & 9 & 6 & 8 & 8 & 8 & 8 & 9 & 9 & 9 & 9 & 9 & 9 & 8 & 9 & 10 & 9 & 9 & 9 & 10 & 10 & 9 & 9 & 9 & 9 & 10 & 10 & 10 & 9 & -5 & 9\end{array}$

$10101012 \quad 13 \quad 14 \quad 13 \quad 13 \quad 14 \quad 25 \quad 15 \quad 14 \quad 12 \quad 13 \quad 13 \quad 14 \quad 15 \quad 13 \quad 13 \quad 14 \quad 15 \quad 15 \quad 15 \quad 13 \quad 13 \quad 13 \quad 12 \quad 14 \quad 15 \quad 1617 \quad 13$ $\begin{array}{llllllllllllllllllllllllllllllllllll}9 & 9 & 10 & 11 & 12 & 10 & 11 & 11 & 12 & 12 & 11 & 11 & 10 & 10 & 11 & 12 & 11 & 11 & 12 & 12 & 13 & 12 & 12 & 12 & 12 & 11 & 12 & 13 & 13 & 12\end{array}$

$\begin{array}{llllllllllllllllllllllllllllllll}6 & 16 & 16 & 17 & 15 & 14 & 14 & 15 & 14 & 14 & 15 & 17 & 17 & 27 & 18 & 18 & 18 & 16 & 17 & 18 & 18 & 18 & 18 & 18 & 16 & 26 & 25 & 16 & 17 & 18 & \cdots & 16\end{array}$

\begin{tabular}{|c|c|c|c|c|c|c|}
\hline & DATE & TIME & $\begin{array}{l}\text { WATER } \\
\text { TEM- } \\
\text { PERA- } \\
\text { TURE } \\
\text { (C) }\end{array}$ & $\begin{array}{l}\text { DISCHARGE } \\
\text { (CFS) }\end{array}$ & $\begin{array}{l}\text { CONCEN- } \\
\text { TRATION } \\
\text { (MG/L) }\end{array}$ & $\begin{array}{l}\text { SUSPENDED } \\
\text { SEDIMENT } \\
\text { OISCHARGE } \\
\text { (TONS/DAY) }\end{array}$ \\
\hline $\begin{array}{l}\text { DEC } \\
\text { AUG }\end{array}$ & $\begin{array}{l}11,1968 \\
26,1969\end{array}$ & $\begin{array}{l}1210 \\
1445\end{array}$ & $\begin{array}{r}8 \\
15\end{array}$ & $\begin{array}{l}135 \\
1.0\end{array}$ & $\begin{array}{r}13 \\
3\end{array}$ & $\begin{array}{l}4.7 \\
.01\end{array}$ \\
\hline
\end{tabular}


11475800 SOUTH FORK EEL RIVER AT LEGGETT, CALIF.

LOCATION, - Lat $39^{\circ} 52^{\prime} 30^{\prime \prime}$, long $123^{\circ} 43^{\prime} 10^{\prime \prime}$, in NE $\frac{1}{4}$ SE sec. 3, T. 23 N., R.17 W., Mendocino County, temperature recorder at gaging station on right bank near Standish-Hickey State Park, 0.2 mile upstream from Rock Creek
and $0.5 \mathrm{mil}$ le northwest of Leggett.

DRAI NAGE AREA. --248 sq $\mathrm{mi}$.

PERIOD OF RECORD. -- Hater temperatures: October 1965 to September 1969.

EXTREMES. $--1968-69$,

Water temperatures: Maximum, $26.0^{\circ} \mathrm{C}$ on several days in July; minimum, $6.0^{\circ} \mathrm{C}$ on several days during December to February.

Period of record:

Water temperatures: Maximum, $26.0^{\circ} \mathrm{C}$ on several days in July 1969; minimum, $3.0^{\circ} \mathrm{C}$ on several days in $1967-68$. TEMPERATURE ( ${ }^{\circ} \mathrm{C}$ ) OF WATER, WATER YEAR OCTOBER 1968 TO SEPTEMBER 1969

DAY

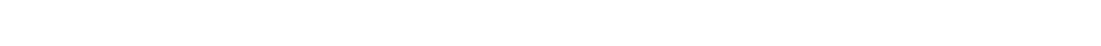

OCTOBER

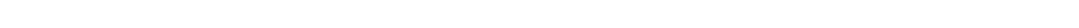
MINIMUM $16 \quad 15 \quad 16 \quad 1617 \quad 1513 \quad 13 \quad 13 \quad 14 \quad 16 \quad 16 \quad 14 \quad 14 \quad 14 \quad 14 \quad 14 \quad 14 \quad 13 \quad 14 \quad 1313 \quad 14 \quad 14 \quad 13 \quad 13 \quad 1313 \quad 14 \quad 14 \quad 13 \quad 14$ NUVEMBER

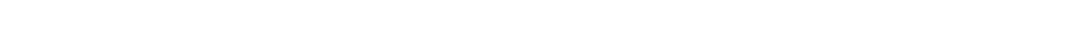

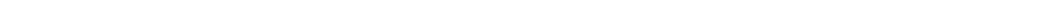
MEMRER

MAXIMUM

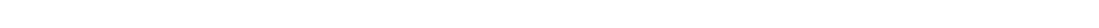

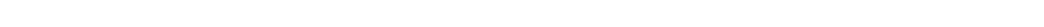

FEBRUARY

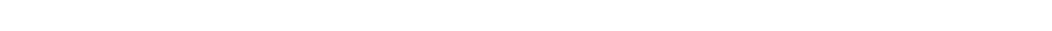

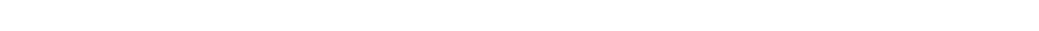

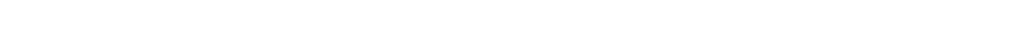
MINIMUM

MAXIMUH $14 \begin{array}{llllllllllllllllllllllllllllllll} & 14 & 13 & 14 & 15 & 17 & 17 & 15 & 18 & 18 & 19 & 16 & 15 & 17 & 18 & 19 & 19 & 18 & 19 & 19 & 20 & 20 & 19 & 17 & 19 & 16 & 18 & 19 & 20 & 21 & 21 \\ \text { MINIMUM } & 10 & 10 & 10 & 10 & 11 & 12 & 13 & 14 & 14 & 14 & 14 & 14 & 14 & 13 & 13 & 14 & 14 & 14 & 13 & 13 & 14 & 14 & 15 & 15 & 15 & 15 & 14 & 13 & 14 & 16 & 15\end{array}$ JUNE

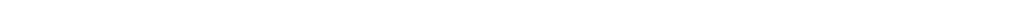

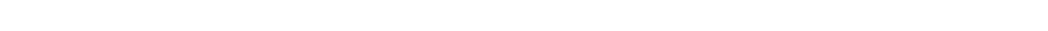
JULY

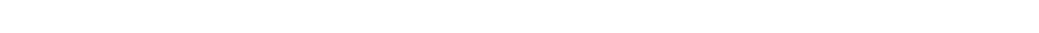
MINIMUM $171818191919191920 \quad 2020201919192020 \quad 202020202121 \quad 21212121202020 \quad 20$ AUGUST

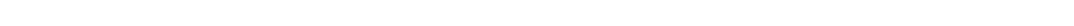

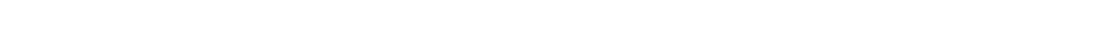
SEPTEMBER

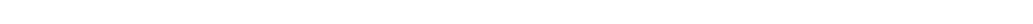

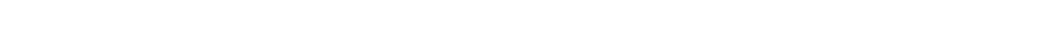


11476500 SOUTH FORK REL RIVER NEAR MIRANDA, CALIP.

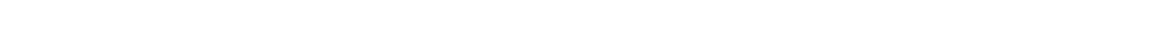

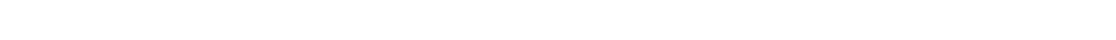

DRAINAGE AREA. --537 $₫ q$ mi.

PERIOD OF RRCORD. --Chemleal anRly gea: October 1953 to september 1960.

Weter temperatures: November 1960 to September 1988.

EXTAZMES, - -1988-69:

Water temperaturen: Minimum, $8.0^{\circ} \mathrm{C}$ on geveral days during Decegber to February.

Pariod of record (1960-64, 1968-69)

Water temperatures: Maximum $(1960-61,1963-84,1985-68), 34.0^{\circ} \mathrm{C}$ July 28,$1964 ;$ minimum, $1.0^{\circ} \mathrm{C} \mathrm{Jan} .20,21$,

REMARKS, - Chemicnl-qunlity recorde furnished by California Department of Water flegourcen and reviewed by U,s, Geo-

logical Survey. Temperature recorder malfunction Apr. 17-24, May 3, 4 , June 2 to Sept. 30 . CHEMICAL ANALYSES, WATER YEAR OCTOBER 1968 TO SEPTEMBER 1969

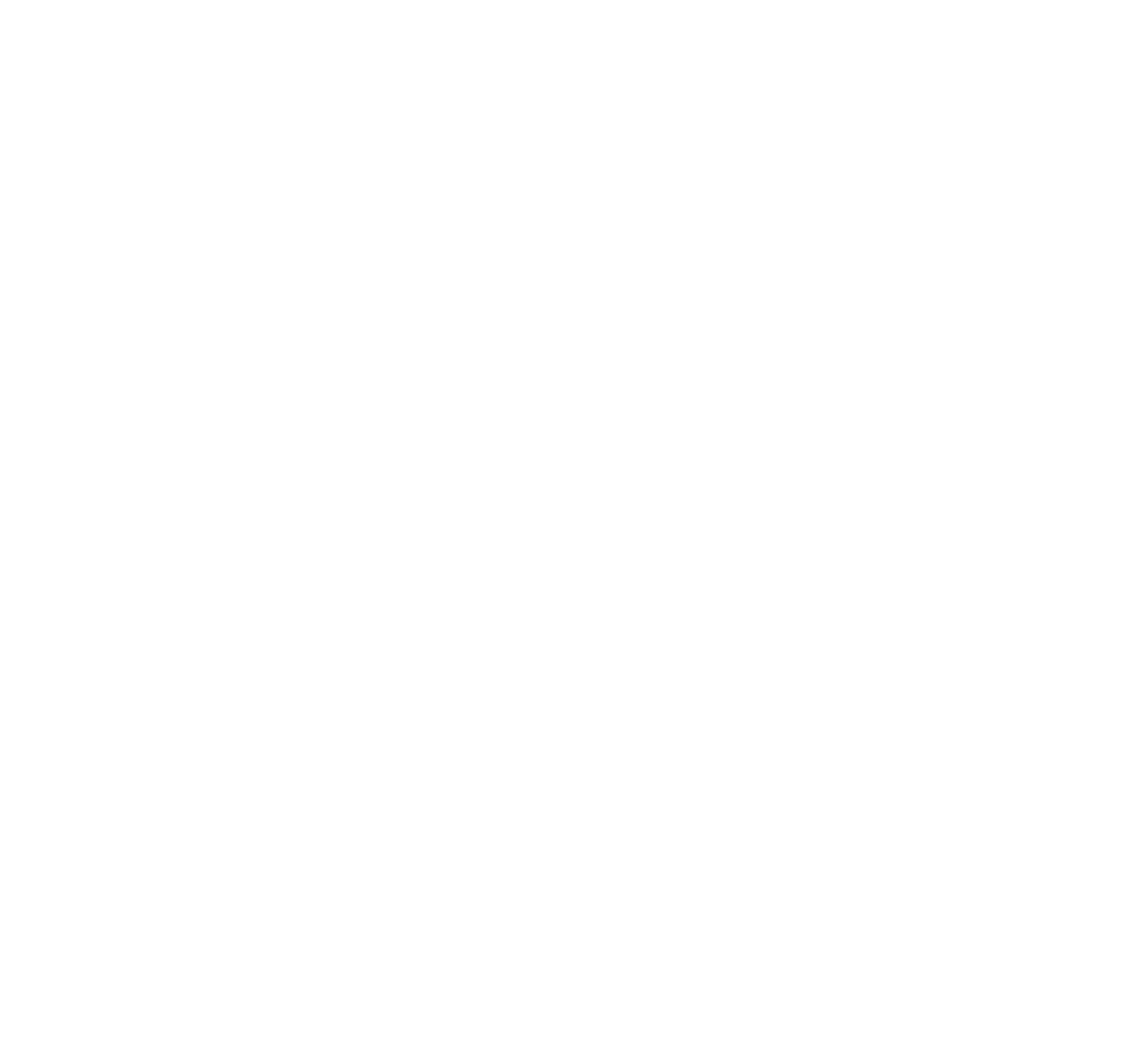


ERI RIVER BASIN

11476500 SOUTH FORX EEL BIVER NEAR MIRANDA, CALIF,--CONTInUEd

TBIPREATURE ('C) OV WATER, WATRB YRAR OCTOBER 1968 TO sRPTEMBER 1968

DAY

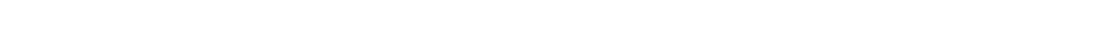

DCTOBER

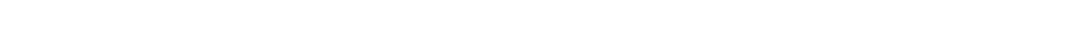

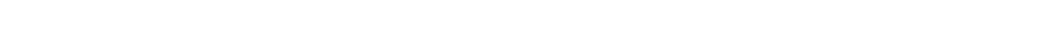
NOVEMBER

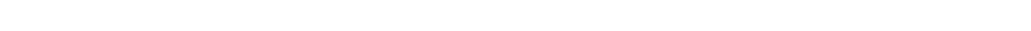
MINI MUM

DE CEMAER

$\begin{array}{rllllllllllllllllllllllllllllllllll}\text { MAXIMUM } & 9 & 9 & 8 & 8 & 10 & 10 & 9 & 10 & 11 & 12 & 11 & 10 & 9 & 10 & 10 & 9 & 10 & 9 & 9 & 7 & 6 & 6 & 9 & 10 & 10 & 9 & 9 & 9 & 9 & 8 & 8 \\ \text { MINIMUM } & 8 & 8 & 7 & 7 & 8 & 9 & 9 & 9 & 10 & 11 & 10 & 9 & 8 & 9 & 9 & 9 & 9 & 8 & 7 & 6 & 6 & 6 & 6 & 9 & 9 & 8 & 8 & 9 & 8 & 8 & 8\end{array}$

MINTMUM

MAXIMUA

MAXI MUM

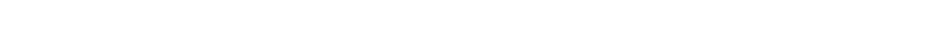

MAXIMUN

(6)

MINIMUM

$\begin{array}{llllllllllllllllllllllllllllllll}9 & 8 & 9 & 8 & 8 & 8 & 9 & 9 & 10 & 10 & 10 & 10 & 9 & 9 & 9 & 9 & 9 & 9 & 10 & 10 & 10 & 9 & 8 & 8 & 8 & 9 & 9 & 8 & -5 & \ldots & \ldots\end{array}$

MARCH

$\begin{array}{llllrllllllllllllllllllllllllllllll}\text { MAXIMUM } & 8 & 8 & 8 & 10 & 9 & 9 & 9 & 9 & 9 & 9 & 9 & 9 & 9 & 9 & 10 & 10 & 11 & 11 & 11 & 11 & 11 & 12 & 12 & 12 & 13 & 13 & 14 & 16 & 14 & 15 & 15 \\ \text { MINIMUM } & 7 & 8 & 7 & 7 & 8 & 8 & 8 & 8 & 8 & 7 & 8 & 8 & 9 & 8 & 9 & 9 & 9 & 10 & 9 & 9 & 9 & 10 & 11 & 11 & 10 & 11 & 12 & 12 & 12 & 13 & 14\end{array}$ MANIMUM

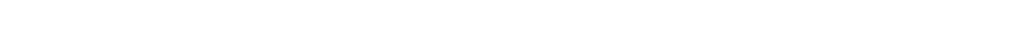
MAY

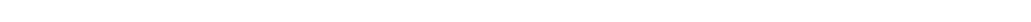

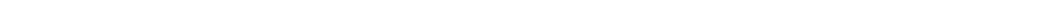
JUNE

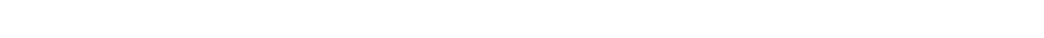
JuLY

MAXIMUM -. MINIMUM AUGUS MAXIMUM

SEPTEMBER

MAXIMUM -.

MINIMUM - 
11477000 EEL RIVER AT SCOTIA, CALIF.

(International Hydrological Decade River Station)

LOCATION, --Lat $40^{\circ} 29^{\circ} 30^{\prime \prime}$, long $124^{\circ} 05^{\prime} 55^{\prime \prime}$, in SW sec. 5, T.1 N., R.1 E., Humboldt County, at gaging station at bridge on U.S. Highway $101,0.5 \mathrm{mile}$ north of Scotia and 6 miles upstream from Van Duzen River.

DRAINAGE AREA. $--3,113 \mathrm{sq} \mathrm{m} 1$.

PERIOD OF RECORD. -Chemical analyses: October 1953 to September 1969.

Water temperatures: October 1957 to September 1969

Sediment records: October 1957 to September 1969.

EXTREMES. - $1968-69$ :

Water temperatures: Maximum, $24.0^{\circ} \mathrm{C}$ June $17 ; \mathrm{minimum}, 7.0^{\circ} \mathrm{C} \mathrm{Jan,} 29$ to Feb. 1 ,

Sediment concentrations: Maximum dafly, 7,570 mg/1 Jan. 12; minimum dafly, $3 \mathrm{mg} / 1$ on several days durtng October and September.

Sediment discharge: Maxtmum daily, 2,720,000 tons Jan, 12; minimum da1ly, 0.88 ton Oct. 9.

Pertod of record:

Water temperatures: Maximum $(1360-64,1965-69), 24.0^{\circ} \mathrm{C}$ on several days $1 \mathrm{n} 1962,1967-69 ; \mathrm{minlmum}, 3.5^{\circ} \mathrm{C}$ Jan. 13, 14, 1963

Sediment concentrations: Maximum datly, 33,000 mg/1 (estimated) Dec. 23, 1964; minimum datly, $1 \mathrm{mg} / 1$ on many days in 1958-64, 1966-67.

Sediment discharge: Maximum daily, 57,000,000 tons (estimated) Dec, 23, 1964; minimum daily, 0.3 ton on many days in 1958-63, 1966

REMARKS.--Chemical-quality samples collected by Californta Department of Water Resources. No temperature record June 2-29, Sept. 13-23. Where no maximum or mintmum is shown, temperature is once-datly readtng. CHEMICAL ANALYSES, WATER YEAR DCTOBER 1968 TO SEPTEMBER 1969

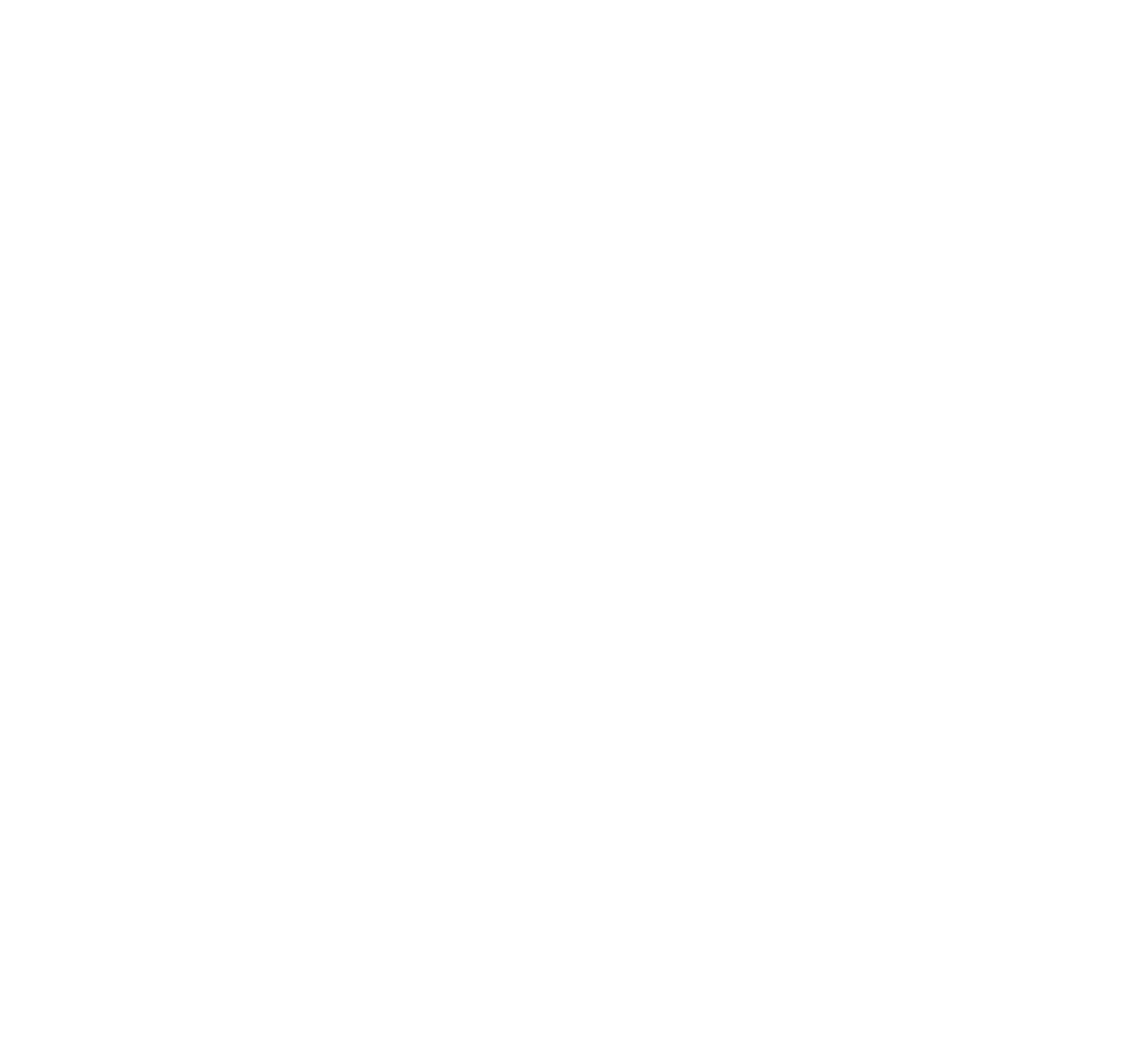


11477000 EEL RIVER AT SCOTIA, CALIF,--Continued

CHEMICAL ANALYSES, hater yeAR OCTUBER 1968 TO SEPTEMBER 1969

\begin{tabular}{|c|c|c|c|c|c|c|}
\hline JATE & $\begin{array}{l}\text { SPECI- } \\
\text { FIC } \\
\text { CLND- } \\
\text { UCTANCE } \\
\text { IMICKO- } \\
\text { MHUSI }\end{array}$ & $\begin{array}{l}\text { DIS- } \\
\text { SOLVEO } \\
\text { SOLIUS } \\
\text { ITONS } \\
\text { PER } \\
\text { AC-FII }\end{array}$ & $\begin{array}{l}\text { PERCENT } \\
\text { SCUIUM }\end{array}$ & $\begin{array}{l}\text { SUDIUM } \\
\text { AU- } \\
\text { SURP- } \\
\text { TION } \\
\text { RATIO }\end{array}$ & $\begin{array}{l}\text { ALKA- } \\
\text { LINIIY } \\
\text { AS } \\
\text { CACO3 } \\
\text { IMG/L) }\end{array}$ & $\begin{array}{l}\text { TUR- } \\
810- \\
\text { ITY } \\
\text { IMG/L) }\end{array}$ \\
\hline $\begin{array}{c}\text { ocr. } \\
02 . . . \\
\text { Nuv. }\end{array}$ & 343 & .27 & 12 & .3 & 147 & -- \\
\hline $\begin{array}{l}\text { NUV. } \\
\text { L } 3 . . . \\
\text { DEC. }\end{array}$ & 242 & .20 & 14 & .4 & \$1 & 270 \\
\hline JAN.". & 191 & .15 & 15 & .3 & 73 & 10 \\
\hline$\underset{F E B}{21 . \cdots}$ & 99 & .09 & 16 & .3 & 45 & 550 \\
\hline $\begin{array}{l}04 \ldots \\
\text { MAR:. }\end{array}$ & 142 & .12 & 13 & .2 & $6 C$ & $\$ 50$ \\
\hline $\begin{array}{l}\text { O4.... } \\
\text { APR. }\end{array}$ & 152 & .13 & 14 & .3 & 63 & 540 \\
\hline MAY... & 155 & .13 & 13 & .2 & 00 & 60 \\
\hline $\begin{array}{l}13 \ldots . . \\
\text { JUNE }\end{array}$ & 123 & $.1 \mathrm{~L}$ & 11 & .2 & 57 & 95 \\
\hline $\operatorname{suty}^{10}$ & $19 \mathrm{I}$ & .15 & 10 & .2 & 80 & 4.0 \\
\hline $\begin{array}{l}15 . . \\
\text { AuG. }\end{array}$ & 281 & .21 & 11 & .3 & $1<2$ & 2.0 \\
\hline $\begin{array}{l}\text { OS... } \\
\text { SEPT. }\end{array}$ & 314 & .24 & $1 \mathrm{t}$ & .3 & 138 & 1.0 \\
\hline $09 \ldots$ & 301 & .22 & 13 & .3 & $1 \angle 8$ & L.0 \\
\hline
\end{tabular}

TEMPERATURE $\left({ }^{\circ} \mathrm{C}\right)$ OF WATER, WATER YEAR OCTOBER 1968 TO SEPTEMBER 1969

DAY

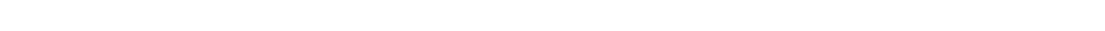

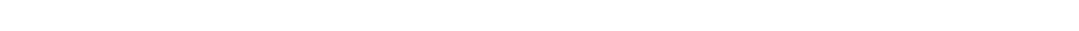

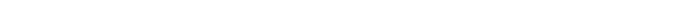
MUVEMAER. --

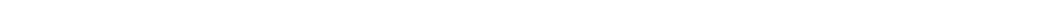

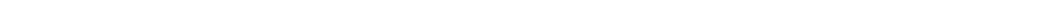

OFCEMBER. --

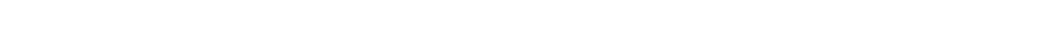

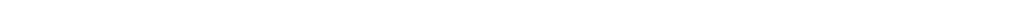

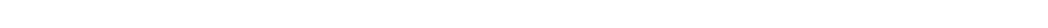
MINIMUM $10 \begin{array}{llllllllllllllllllllllllllllllll}10 & 10 & 10 & 10 & 10 & 10 & 9 & 8 & 8 & 8 & 9 & 10 & 10 & 9 & 9 & 9 & 9 & 9 & 9 & 10 & 10 & 9 & 8 & 8 & 9 & 8 & 8 & 7 & 7 & 7\end{array}$

FEBRUARY. -

MAXIMUM

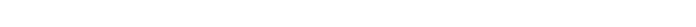

MAXIMUM $8 \begin{array}{llllllllllllllllllllllllllllllllllll} & 8 & 8 & 10 & 9 & 9 & 9 & 9 & 9 & 9 & 9 & 10 & 10 & 10 & 11 & 10 & 10 & 11 & 11 & 11 & 11 & 11 & 12 & 12 & 12 & 12 & 12 & 13 & 13 & 13 & 13\end{array}$

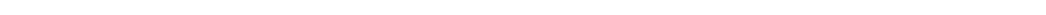

ADRILZOM -

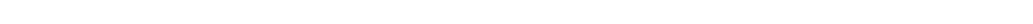

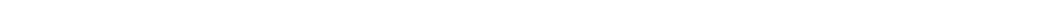

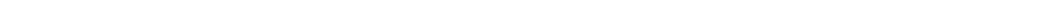

JIJNE.....

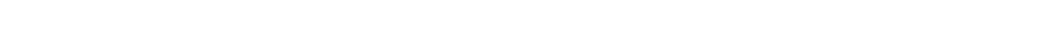

SULY:...

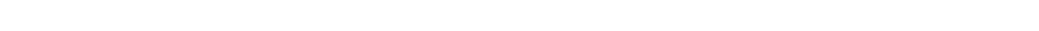

MINIMUM $17 \begin{array}{lllllllllllllllllllllllllllllll}16 & 16 & 16 & 16 & 15 & 16 & 17 & 17 & 17 & 16 & 16 & 16 & 16 & 16 & 16 & 16 & 16 & 17 & 18 & 17 & 18 & 18 & 18 & 18 & 18 & 17 & 17 & 17 & 17 & 17\end{array}$

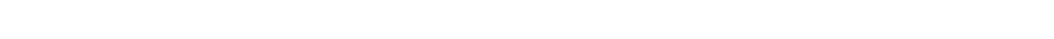

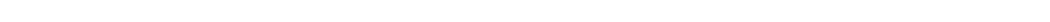

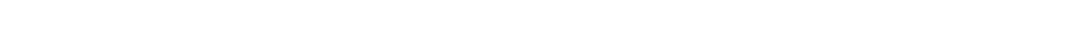

PARTICLE-SIZE DISTRIBUTION OF SUSPENDED SEDIMENT, WATER YEAR OCTOBER 1958 TO SEPTEMBER 1969 IMETHODS OF ANALYSIS: B, BOTTOM WITHDRAWAL TUBE; C, CHEMICALLY DISPERSED; N. IN NATIVE WATER; P. PIPET: S. SIEVE: $Y$, VISUAL ACCUMULATION TUBE: W. IN OISTILLED WATER]

WATER
IEM
PERA-

PARTICLE SILE

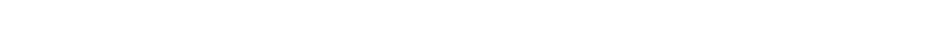

TURE DISCMARGE TRATION DISCHARGE PERCENT FINER THAN THE SILE IIN MILLLIMETERSI INDICATED DF ANY

DATE TIME (C) (CFS) IMG/L) (TONSIDAY) $.002 .004 .008 .016 .031 .062 \quad .125 .250 .5001 .002 .00 \quad 5 I S$

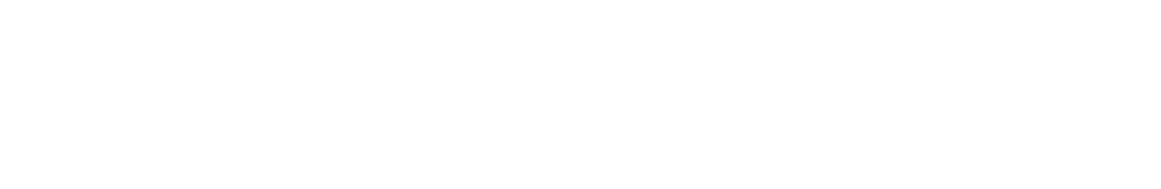

D DAILY MEAN DISCHARGE. 
EEL RIVRR BABIN

11477000 EEL RIVER AT SCOTIA, CALIF,--ContınuEd

SUSPENDED-SEDIMENT DISCHARGE, WATER YEAR OCTOBER 1968 TO SEPTEMBER 1969

OCTOBER

DECEMBER

our

TONCEN- SEDIMENT

CONCEN- SEDIMENT MEAN

TRATION DISCHARGE DISCHARGE

TRATION DISCHARGE DISCHARGE

MEAN (CFS) (MG/L) (TONS/DAY) (CFS)

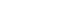

CONCEN- SEDIMENT TRATION DISCHARGE
IMG/L) (TONS/DAY)

$\begin{array}{ccc}132 & 5 & 1 \\ 130 & 4 & 1 \\ 146 & 4 & 1 \\ 194 & 3 & 1 \\ 128 & 3 & 1 \\ 123 & 3 & 1 \\ 153 & 3 & 1 \\ 168 & 3 & 1 \\ 109 & 3 & \\ 84 & 4 & \end{array}$

$\begin{array}{rr}1.8 & 498 \\ 1.4 & 914 \\ 1.6 & 1550 \\ 1.6 & 1650 \\ 1.0 & 1350 \\ & \\ 1.0 & 1020 \\ 1.2 . & 896 \\ 1.4 & 788 \\ .88 & 738 \\ .91 & 746\end{array}$

$\begin{array}{rl}6 & 8.1 \\ 99 & 312 \\ 223 & 933 \\ 102 & 454 \\ 31 & 113\end{array}$

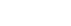

$\begin{array}{rr}88 & 653 \\ 110 & 1130 \\ 106 & 979 \\ 28 & 223 \\ 14 & 97\end{array}$

17029

121

315
706
589

$\begin{array}{ll}2.6 & 738 \\ 19 & 1780 \\ 71 & 2120\end{array}$

$\begin{array}{ll}41 & 2120 \\ 30 & 2350\end{array}$

$\begin{array}{ll}25 & 3250 \\ 15 & 2590\end{array}$

$\begin{array}{rr}15 & 2590 \\ 9.6 & 2930 \\ 7.2 & 5690\end{array}$

$\begin{array}{ll}7.2 & 5690 \\ 5.5 & 3970\end{array}$

$\begin{array}{ll}4.3 & 2640 \\ 3.8 & 2070\end{array}$

$\begin{array}{ll}3.8 & 1150 \\ 2.3 & 1960\end{array}$

$2.1 \quad 2910$

$\begin{array}{ll}1.6 & 4820 \\ 1.5 & 3170\end{array}$

$1.5 \quad 2350$

$\begin{array}{ll}2.0 & 1930 \\ 4.7 & 2120 \\ 7.8 & -1\end{array}$

TOTAL 8054

$273.29 \quad 63408$

3800
3420
2950
2570
2350
2290
3500
5550

$\begin{array}{rr}17 & 108 \\ 42 & 260 \\ 253 & 2440 \\ 233 & 3670\end{array}$

$\begin{array}{rr}233 & 3670 \\ 3730 & 582000\end{array}$

$\begin{array}{rrr}6 & 12 & 5550 \\ 10 & 20 & 36800\end{array}$

$\begin{array}{rrr}12 & 24 & 54800 \\ 114 & 548 & 22600\end{array}$

$\begin{array}{lll}114 & 548 & 22600 \\ 150 & 859 & 14300 \\ 117 & 670 & 22100\end{array}$

$\begin{array}{rr}670 & 22100 \\ 1280 & 49100\end{array}$

$306 \quad 2660 \quad 36000$

$\begin{array}{rrr}306 & 2660 & 36000 \\ 121 & 846 & 21000 \\ 61 & 483 & 14000 \\ 224 & 3700 & 12000\end{array}$

2352950

$\begin{array}{rrr}82 & 584 & 8200 \\ 36 & 201 & 7250 \\ 25 & 118 & 58200\end{array}$

$\begin{array}{rrr}25 & 118 & 58200 \\ 53 & 280 & 151000 \\ 553 & 4520 & 103000\end{array}$

3730

$4150 \quad 706000$

$1710 \quad 104000$

$1700 \quad 38600$
$1500 \quad 89500$

$4460 \quad 665000$

2840
1220

1220
720

$520 \quad 16800$

$\begin{array}{rr}300 & 6640 \\ 300 & 5870 \\ 2490 & 428000 \\ 5220 & 2200000\end{array}$

$\begin{array}{rr}2490 & 428000 \\ 5220 & 2200000 \\ 3600 & 1000000\end{array}$

84
68 $\quad 500 \quad 80400$

$\begin{array}{rrr}68 & 582 & 63200\end{array}$

$\begin{array}{ccc}18 & 114 & 37600 \\ 20 & 104 & 33100 \\ 56 & 321 & 25700 \\ -- & - & 19600\end{array}$

$2320 \quad 504000$

$1720 \quad 294000$

$\begin{array}{ll}1410 & 143000 \\ 1120 & 100000\end{array}$

$850 \quad 59000$

$640 \quad 33900$

-. 7368260

\begin{tabular}{|c|c|c|c|c|c|c|c|c|c|}
\hline \multirow[b]{2}{*}{ DAY } & \multicolumn{3}{|c|}{ JANUARY } & \multicolumn{3}{|c|}{ FEBRUARY } & \multicolumn{3}{|c|}{ MARCH } \\
\hline & $\begin{array}{l}\text { MEAN } \\
\text { DISCHARGE } \\
\text { (CFS) }\end{array}$ & $\begin{array}{l}\text { MEAN } \\
\text { CONCEN- } \\
\text { IRATION } \\
\text { (MG/L) }\end{array}$ & $\begin{array}{l}\text { SEDI MEN T } \\
\text { DI SCHARGE } \\
\text { (TONS/DAY) }\end{array}$ & $\begin{array}{l}\text { MEAN } \\
\text { OISCHARGE } \\
\text { (CFS) }\end{array}$ & $\begin{array}{l}\text { MEAV } \\
\text { CDNCEN- } \\
\text { TRATION } \\
\text { (MG/L) }\end{array}$ & $\begin{array}{l}\text { SEDIMENT } \\
\text { DISCHARGE } \\
\text { (TONS/DAY) }\end{array}$ & $\begin{array}{l}\text { MEAN } \\
\text { DI SCHARGE } \\
\text { (CFS) }\end{array}$ & $\begin{array}{l}\text { MEAN } \\
\text { CONCEN- } \\
\text { TRAIION } \\
\text { (MGILI) }\end{array}$ & $\begin{array}{l}\text { SEDIMENT } \\
\text { DISCHARGE } \\
\text { (TONS/DAY) }\end{array}$ \\
\hline $\begin{array}{l}1 \\
2 \\
3 \\
4 \\
5\end{array}$ & $\begin{array}{l}15900 \\
13800 \\
12600 \\
12000 \\
12200\end{array}$ & $\begin{array}{l}460 \\
360 \\
390 \\
300 \\
420\end{array}$ & $\begin{array}{r}19700 \\
13400 \\
9870 \\
9720 \\
13800\end{array}$ & $\begin{array}{l}21800 \\
24100 \\
20700 \\
18900 \\
24200\end{array}$ & $\begin{array}{r}1390 \\
1620 \\
980 \\
820 \\
1360\end{array}$ & $\begin{array}{r}81800 \\
105000 \\
54800 \\
41800 \\
88900\end{array}$ & $\begin{array}{l}37800 \\
26900 \\
29000 \\
27000 \\
23200\end{array}$ & $\begin{array}{r}1270 \\
592 \\
714 \\
414 \\
336\end{array}$ & $\begin{array}{r}130000 \\
43000 \\
55900 \\
30200 \\
21000\end{array}$ \\
\hline $\begin{array}{r}6 \\
7 \\
8 \\
9 \\
10\end{array}$ & $\begin{array}{r}12000 \\
11300 \\
10300 \\
8900 \\
7710\end{array}$ & $\begin{array}{l}450 \\
290 \\
410 \\
210 \\
130\end{array}$ & $\begin{array}{r}14600 \\
8850 \\
11400 \\
5050 \\
2710\end{array}$ & $\begin{array}{l}30600 \\
28300 \\
24000 \\
55000 \\
47800\end{array}$ & $\begin{array}{r}2190 \\
1220 \\
955 \\
3440 \\
1630\end{array}$ & $\begin{array}{r}181000 \\
93200 \\
70800 \\
503000 \\
210000\end{array}$ & $\begin{array}{r}19800 \\
15900 \\
12200 \\
11100 \\
9650\end{array}$ & $\begin{array}{l}289 \\
268 \\
292 \\
342 \\
357\end{array}$ & $\begin{array}{r}15400 \\
11500 \\
9620 \\
10200 \\
9300\end{array}$ \\
\hline $\begin{array}{l}11 \\
12 \\
13 \\
14 \\
15\end{array}$ & $\begin{array}{r}14900 \\
136000 \\
187000 \\
104000 \\
53700\end{array}$ & $\begin{array}{l}2250 \\
7570 \\
5060 \\
3420 \\
2260\end{array}$ & $\begin{array}{r}124000 \\
2720000 \\
2550000 \\
1010000 \\
328000\end{array}$ & $\begin{array}{l}66900 \\
72100 \\
44500 \\
32700 \\
40200\end{array}$ & $\begin{array}{r}3090 \\
2440 \\
1180 \\
860 \\
1300\end{array}$ & $\begin{array}{r}599000 \\
475000 \\
142000 \\
75900 \\
141000\end{array}$ & $\begin{array}{l}8600 \\
7800 \\
7180 \\
6730 \\
6500\end{array}$ & $\begin{array}{l}262 \\
263 \\
319 \\
201 \\
137\end{array}$ & $\begin{array}{l}6080 \\
5540 \\
6180 \\
3650 \\
2400\end{array}$ \\
\hline $\begin{array}{l}16 \\
17 \\
18 \\
19 \\
20\end{array}$ & $\begin{array}{r}36500 \\
21000 \\
16500 \\
52500 \\
154000\end{array}$ & $\begin{array}{r}1480 \\
1000 \\
760 \\
3340 \\
5290\end{array}$ & $\begin{array}{r}146000 \\
56700 \\
33900 \\
473000 \\
2170000\end{array}$ & $\begin{array}{l}46700 \\
32500 \\
24700 \\
20200 \\
17000\end{array}$ & $\begin{array}{r}1440 \\
740 \\
600 \\
560 \\
520\end{array}$ & $\begin{array}{r}182000 \\
64900 \\
40000 \\
30500 \\
23900\end{array}$ & $\begin{array}{r}6580 \\
7700 \\
12500 \\
12200 \\
10200\end{array}$ & $\begin{array}{l}136 \\
163 \\
408 \\
318 \\
246\end{array}$ & $\begin{array}{r}2420 \\
3390 \\
13800 \\
10500 \\
6770\end{array}$ \\
\hline $\begin{array}{l}21 \\
22 \\
23 \\
24 \\
25\end{array}$ & $\begin{array}{r}190000 \\
122000 \\
66000 \\
42400 \\
38300\end{array}$ & $\begin{array}{l}4350 \\
3640 \\
2290 \\
1580 \\
1640\end{array}$ & $\begin{array}{r}2220000 \\
1200000 \\
408000 \\
181000 \\
172000\end{array}$ & $\begin{array}{l}14800 \\
14600 \\
14600 \\
16800 \\
22900\end{array}$ & $\begin{array}{r}530 \\
570 \\
600 \\
640 \\
1020\end{array}$ & $\begin{array}{l}21200 \\
22500 \\
23700 \\
29000 \\
63100\end{array}$ & $\begin{array}{l}9820 \\
9290 \\
8550 \\
8540 \\
8440\end{array}$ & $\begin{array}{l}211 \\
200 \\
192 \\
150 \\
150\end{array}$ & $\begin{array}{l}5590 \\
5020 \\
4430 \\
3460 \\
3420\end{array}$ \\
\hline $\begin{array}{l}26 \\
27 \\
28 \\
29 \\
30 \\
31\end{array}$ & $\begin{array}{l}67200 \\
60800 \\
43100 \\
31800 \\
25300 \\
20900\end{array}$ & $\begin{array}{r}3500 \\
2120 \\
1320 \\
1030 \\
930 \\
700\end{array}$ & $\begin{array}{r}628000 \\
348000 \\
154000 \\
88400 \\
63500 \\
39500\end{array}$ & $\begin{array}{r}20000 \\
17000 \\
33500 \\
=- \\
--\end{array}$ & $\begin{array}{l}810 \\
550 \\
660 \\
-- \\
-- \\
--\end{array}$ & $\begin{array}{r}43700 \\
25200 \\
59700 \\
=- \\
--\end{array}$ & $\begin{array}{r}8440 \\
8760 \\
9460 \\
10100 \\
10600 \\
11100\end{array}$ & $\begin{array}{l}182 \\
232 \\
348 \\
461 \\
508 \\
537\end{array}$ & $\begin{array}{r}4150 \\
5490 \\
8890 \\
12600 \\
14500 \\
16100\end{array}$ \\
\hline OTAL & 605610 & - & 15223100 & 847100 & -- & 3492600 & 401640 & - & 480500 \\
\hline
\end{tabular}


TLL RIVRR BASIN

11477000 REL RIVR AT BCOTIA, CALIF,--Continued SUSPENDED-SEDIMENT DISCHARGE, WATER YEAR OCTOBER 1968 TO SEPTEMBER 1969

\begin{tabular}{|c|c|c|c|c|c|c|c|c|c|}
\hline \multirow[b]{2}{*}{ OAY } & \multicolumn{3}{|c|}{ APRIL } & \multicolumn{3}{|c|}{ MAY } & \multicolumn{3}{|c|}{ JUNE } \\
\hline & $\begin{array}{l}\text { MEAN } \\
\text { DISCHARGE } \\
\text { (CFS) }\end{array}$ & $\begin{array}{l}\text { MEAN } \\
\text { CONCEN- } \\
\text { TRATION } \\
\text { (MGIL) }\end{array}$ & $\begin{array}{l}\text { SEDIMENT } \\
\text { DISCHARGE } \\
\text { (TONS/DAY) }\end{array}$ & $\begin{array}{l}\text { MEAN } \\
\text { OI SCHARGE } \\
\text { (CF S) }\end{array}$ & $\begin{array}{l}\text { MEAN } \\
\text { CDNCEN- } \\
\text { TRATION } \\
\text { (MG/L) }\end{array}$ & $\begin{array}{l}\text { SEDIMENT } \\
\text { DISCHARGE } \\
\text { (TONS/DAY) }\end{array}$ & $\begin{array}{l}\text { MEAN } \\
\text { OISCHARGE } \\
\text { (CFS) }\end{array}$ & $\begin{array}{l}\text { MEAN } \\
\text { CONCEN- } \\
\text { TRATION } \\
\text { (MGLLI }\end{array}$ & $\begin{array}{l}\text { SEDIMENT } \\
\text { DISCHARGE } \\
\text { (TONS/DAY) }\end{array}$ \\
\hline $\begin{array}{l}1 \\
2 \\
3 \\
4 \\
5\end{array}$ & $\begin{array}{r}10600 \\
9610 \\
9310 \\
7820 \\
9080\end{array}$ & $\begin{array}{l}461 \\
352 \\
306 \\
282 \\
219\end{array}$ & $\begin{array}{r}13200 \\
9130 \\
7690 \\
5950 \\
5370\end{array}$ & $\begin{array}{l}6030 \\
5830 \\
5480 \\
5220 \\
4850\end{array}$ & $\begin{array}{r}131 \\
121 \\
102 \\
88 \\
96\end{array}$ & $\begin{array}{l}2130 \\
1900 \\
1510 \\
1240 \\
1260\end{array}$ & $\begin{array}{l}2240 \\
2100 \\
1990 \\
1900 \\
1810\end{array}$ & $\begin{array}{l}22 \\
22 \\
23 \\
20 \\
17\end{array}$ & $\begin{array}{r}133 \\
125 \\
124 \\
103 \\
83\end{array}$ \\
\hline $\begin{array}{r}6 \\
7 \\
8 \\
9 \\
10\end{array}$ & $\begin{array}{r}11600 \\
9190 \\
7830 \\
7250 \\
7180\end{array}$ & $\begin{array}{l}168 \\
139 \\
138 \\
108 \\
111\end{array}$ & $\begin{array}{l}5260 \\
3450 \\
2920 \\
2110 \\
2150\end{array}$ & $\begin{array}{l}4740 \\
5310 \\
6010 \\
6330 \\
6740\end{array}$ & $\begin{array}{l}78 \\
103 \\
196 \\
242 \\
296\end{array}$ & $\begin{array}{l}998 \\
1480 \\
3180 \\
4140 \\
5390\end{array}$ & $\begin{array}{l}1740 \\
1670 \\
1610 \\
1500 \\
1420\end{array}$ & $\begin{array}{l}16 \\
15 \\
17 \\
20 \\
19\end{array}$ & $\begin{array}{l}75 \\
68 \\
74 \\
81 \\
73\end{array}$ \\
\hline $\begin{array}{l}11 \\
12 \\
13 \\
14 \\
15\end{array}$ & $\begin{array}{l}6800 \\
6730 \\
7410 \\
7120 \\
5860\end{array}$ & $\begin{array}{l}132 \\
133 \\
144 \\
181 \\
168\end{array}$ & $\begin{array}{l}2420 \\
2420 \\
2880 \\
3480 \\
2660\end{array}$ & $\begin{array}{l}6990 \\
6630 \\
6450 \\
5850 \\
5020\end{array}$ & $\begin{array}{l}314 \\
268 \\
220 \\
184 \\
148\end{array}$ & $\begin{array}{l}5930 \\
4800 \\
3830 \\
2910 \\
2010\end{array}$ & $\begin{array}{l}1350 \\
1300 \\
1270 \\
1180 \\
1100\end{array}$ & $\begin{array}{l}18 \\
17 \\
15 \\
18 \\
21\end{array}$ & $\begin{array}{l}66 \\
60 \\
51 \\
57 \\
62\end{array}$ \\
\hline $\begin{array}{l}16 \\
17 \\
18 \\
19 \\
20\end{array}$ & $\begin{array}{l}5220 \\
5180 \\
5790 \\
6240 \\
6210\end{array}$ & $\begin{array}{l}161 \\
159 \\
157 \\
162 \\
194\end{array}$ & $\begin{array}{l}2270 \\
2220 \\
2450 \\
2730 \\
3250\end{array}$ & $\begin{array}{l}4290 \\
4080 \\
4130 \\
4200 \\
3920\end{array}$ & $\begin{array}{r}114 \\
96 \\
91 \\
89 \\
82\end{array}$ & $\begin{array}{r}1320 \\
1060 \\
1010 \\
1010 \\
868\end{array}$ & $\begin{array}{r}1060 \\
1020 \\
963 \\
973 \\
968\end{array}$ & $\begin{array}{l}18 \\
17 \\
16 \\
16 \\
17\end{array}$ & $\begin{array}{l}52 \\
47 \\
42 \\
42 \\
44\end{array}$ \\
\hline $\begin{array}{l}21 \\
22 \\
23 \\
24 \\
25\end{array}$ & $\begin{array}{r}6290 \\
6710 \\
7900 \\
10400 \\
8790\end{array}$ & $\begin{array}{l}188 \\
221 \\
352 \\
572 \\
281\end{array}$ & $\begin{array}{r}3190 \\
4000 \\
7510 \\
16100 \\
6670\end{array}$ & $\begin{array}{l}3520 \\
3310 \\
3140 \\
3050 \\
3000\end{array}$ & $\begin{array}{l}75 \\
71 \\
66 \\
61 \\
59\end{array}$ & $\begin{array}{l}713 \\
635 \\
560 \\
502 \\
478\end{array}$ & $\begin{array}{l}999 \\
927 \\
898 \\
818 \\
765\end{array}$ & $\begin{array}{r}18 \\
12 \\
6 \\
7 \\
8\end{array}$ & $\begin{array}{l}49 \\
30 \\
15 \\
15 \\
17\end{array}$ \\
\hline $\begin{array}{l}26 \\
27 \\
28 \\
29 \\
30 \\
31\end{array}$ & $\begin{array}{r}7150 \\
6620 \\
6480 \\
11000 \\
6630 \\
--\end{array}$ & $\begin{array}{l}179 \\
122 \\
100 \\
106 \\
124 \\
--\end{array}$ & $\begin{array}{r}3460 \\
2180 \\
1750 \\
3150 \\
2220 \\
--\end{array}$ & $\begin{array}{l}2770 \\
2610 \\
2670 \\
2420 \\
2280 \\
2330\end{array}$ & $\begin{array}{l}48 \\
47 \\
43 \\
36 \\
30 \\
30\end{array}$ & $\begin{array}{l}359 \\
331 \\
310 \\
235 \\
185 \\
189\end{array}$ & $\begin{array}{l}760 \\
756 \\
691 \\
616 \\
598 \\
--\end{array}$ & $\begin{array}{r}8 \\
7 \\
7 \\
7 \\
6 \\
--\end{array}$ & $\begin{array}{l}16 \\
14 \\
13 \\
12 \\
9.7 \\
--\end{array}$ \\
\hline \multirow[t]{3}{*}{ TOTAL } & 230000 & -- & 134240 & 139200 & -- & 52473 & 36992 & - & 1652.7 \\
\hline & & JULY & & & AUGUST & & & SEPTEMBER & \\
\hline & $\begin{array}{c}\text { MEAN } \\
\text { OISCHARGE } \\
\text { (CFS) }\end{array}$ & $\begin{array}{l}\text { MEAN } \\
\text { CONCEN- } \\
\text { TRATIDN } \\
\text { IMG/LI }\end{array}$ & $\begin{array}{l}\text { SEDIMENT } \\
\text { DI SCHARGE } \\
\text { (TONS/DAY) }\end{array}$ & $\begin{array}{l}\text { MEAN } \\
\text { DISCHARGE } \\
\text { (CFSI }\end{array}$ & $\begin{array}{l}\text { MEAN } \\
\text { CONCEN- } \\
\text { TRATIDN } \\
\text { (MG/L) }\end{array}$ & $\begin{array}{l}\text { SEDI MENT } \\
\text { DI SCHARGE } \\
\text { (TONS / DAY) }\end{array}$ & $\begin{array}{l}\text { MEAN } \\
\text { DISCHARGE } \\
\text { ICFSI }\end{array}$ & $\begin{array}{l}\text { MEAN } \\
\text { CONCEN- } \\
\text { TRATION } \\
\text { (MG/L) }\end{array}$ & $\begin{array}{l}\text { SEDIMENT } \\
\text { DISCHARGE } \\
\text { (TONS/DAY) }\end{array}$ \\
\hline $\begin{array}{l}1 \\
2 \\
3 \\
4 \\
5\end{array}$ & $\begin{array}{l}570 \\
540 \\
518 \\
505 \\
496\end{array}$ & $\begin{array}{l}6 \\
6 \\
6 \\
6 \\
6\end{array}$ & $\begin{array}{l}9.2 \\
8.7 \\
8.4 \\
8.2 \\
8.0\end{array}$ & $\begin{array}{l}217 \\
208 \\
197 \\
191 \\
185\end{array}$ & $\begin{array}{r}10 \\
9 \\
8 \\
7 \\
7\end{array}$ & $\begin{array}{l}5.9 \\
5.1 \\
4.3 \\
3.6 \\
3.5\end{array}$ & $\begin{array}{l}120 \\
119 \\
115 \\
120 \\
117\end{array}$ & $\begin{array}{l}8 \\
8 \\
8 \\
8 \\
7\end{array}$ & $\begin{array}{l}2.6 \\
2.6 \\
2.5 \\
2.6 \\
2.2\end{array}$ \\
\hline $\begin{array}{r}6 \\
7 \\
8 \\
9 \\
10\end{array}$ & $\begin{array}{l}462 \\
450 \\
438 \\
425 \\
410\end{array}$ & $\begin{array}{l}7 \\
19 \\
15 \\
12 \\
13\end{array}$ & $\begin{array}{l}8.7 \\
23 \\
18 \\
14 \\
14\end{array}$ & $\begin{array}{l}180 \\
179 \\
173 \\
169 \\
166\end{array}$ & $\begin{array}{r}8 \\
11 \\
11 \\
11 \\
10\end{array}$ & $\begin{array}{l}3.9 \\
5.3 \\
5.1 \\
5.0 \\
4.5\end{array}$ & $\begin{array}{l}116 \\
112 \\
110 \\
110 \\
111\end{array}$ & $\begin{array}{l}6 \\
5 \\
3 \\
4 \\
4\end{array}$ & $\begin{array}{l}2.9 \\
1.5 \\
.89 \\
1.2 \\
1.2\end{array}$ \\
\hline $\begin{array}{l}11 \\
12 \\
13 \\
14 \\
15\end{array}$ & $\begin{array}{l}398 \\
384 \\
376 \\
371 \\
358\end{array}$ & $\begin{array}{r}14 \\
12 \\
10 \\
7 \\
6\end{array}$ & $\begin{array}{l}15 \\
12 \\
10 \\
7.0 \\
5.8\end{array}$ & $\begin{array}{l}162 \\
159 \\
158 \\
155 \\
152\end{array}$ & $\begin{array}{l}9 \\
8 \\
8 \\
8 \\
9\end{array}$ & $\begin{array}{l}3.9 \\
3.4 \\
3.4 \\
3.3 \\
3.7\end{array}$ & $\begin{array}{l}121 \\
115 \\
110 \\
115 \\
110\end{array}$ & $\begin{array}{l}5 \\
5 \\
5 \\
5 \\
5\end{array}$ & $\begin{array}{l}1.6 \\
1.6 \\
1.5 \\
1.6 \\
1.5\end{array}$ \\
\hline $\begin{array}{l}16 \\
17 \\
18 \\
19 \\
20\end{array}$ & $\begin{array}{l}346 \\
332 \\
320 \\
308 \\
292\end{array}$ & $\begin{array}{r}6 \\
6 \\
6 \\
12 \\
13\end{array}$ & $\begin{array}{l}5.6 \\
5.4 \\
5.2 \\
10 \\
10\end{array}$ & $\begin{array}{l}149 \\
148 \\
148 \\
144 \\
139\end{array}$ & $\begin{array}{l}10 \\
10 \\
10 \\
10 \\
10\end{array}$ & $\begin{array}{l}4.0 \\
4.0 \\
4.0 \\
3.9 \\
3.8\end{array}$ & $\begin{array}{l}119 \\
117 \\
121 \\
123 \\
141\end{array}$ & $\begin{array}{l}5 \\
4 \\
3 \\
4 \\
4\end{array}$ & $\begin{array}{l}1.6 \\
1.3 \\
.98 \\
1.3 \\
1.5\end{array}$ \\
\hline $\begin{array}{l}21 \\
22 \\
23 \\
24 \\
25\end{array}$ & $\begin{array}{l}284 \\
284 \\
276 \\
269 \\
260\end{array}$ & $\begin{array}{r}17 \\
9 \\
8 \\
9 \\
10\end{array}$ & $\begin{array}{r}13 \\
6.9 \\
6.0 \\
6.5 \\
7.0\end{array}$ & $\begin{array}{l}137 \\
132 \\
130 \\
130 \\
130\end{array}$ & $\begin{array}{l}9 \\
8 \\
6 \\
5 \\
5\end{array}$ & $\begin{array}{l}3.3 \\
2.9 \\
2.1 \\
1.8 \\
1.8\end{array}$ & $\begin{array}{l}178 \\
175 \\
204 \\
211 \\
146\end{array}$ & $\begin{array}{l}9 \\
8 \\
7 \\
5 \\
4\end{array}$ & $\begin{array}{l}4.3 \\
3.8 \\
3.9 \\
2.8 \\
1.6\end{array}$ \\
\hline $\begin{array}{l}26 \\
27 \\
28 \\
29 \\
30 \\
31\end{array}$ & $\begin{array}{l}250 \\
240 \\
231 \\
224 \\
224 \\
223\end{array}$ & $\begin{array}{r}12 \\
18 \\
15 \\
12 \\
9 \\
10\end{array}$ & $\begin{array}{r}12.1 \\
9.4 \\
7.3 \\
5.4 \\
6.0\end{array}$ & $\begin{array}{l}128 \\
125 \\
122 \\
121 \\
120 \\
120\end{array}$ & $\begin{array}{r}10 \\
9 \\
8 \\
7 \\
6 \\
5\end{array}$ & $\begin{array}{l}3.5 \\
3.0 \\
2.6 \\
2.3 \\
1.9 \\
1.6\end{array}$ & $\begin{array}{r}147 \\
149 \\
149 \\
150 \\
151 \\
--\end{array}$ & $\begin{array}{r}3 \\
4 \\
6 \\
5 \\
5 \\
--\end{array}$ & $\begin{array}{l}1.2 \\
1.6 \\
2.4 \\
2.0 \\
2.0 \\
--\end{array}$ \\
\hline ROTAL & 11064 & -- & 293.8 & 4774 & -- & 110.4 & 4002 & -- & 59.27 \\
\hline $\begin{array}{l}\text { TOTAL } \\
\text { TOTAL }\end{array}$ & $\begin{array}{l}\text { DISCHARGE } \\
\text { SUSPENDED- }\end{array}$ & $\begin{array}{ll}\text { OR YEAR } & 10 \\
\text { EDIMENT } & \text { DI }\end{array}$ & $\begin{array}{l}\text { CFS-DAYS ) } \\
\text { I SCHARGE FOR }\end{array}$ & EAR (TO & & & & & $\begin{array}{l}4260974 \\
26780049.56\end{array}$ \\
\hline
\end{tabular}


11477500 VAN DUZEN RI VER NEAR DINSMORES, CALIF,

LOCATION.--Lat $40^{\circ} 29^{\prime} 05^{\prime \prime}$, long $123^{\circ} 39^{\prime} 25^{\prime \prime}$, in NW $\frac{1}{4}$ sec. 7, T. 1 N., R. 5 E., Humboldt County, temperature recorder at gaging station on right bank, $10 \mathrm{ft}$ upstream from private road bridge, 0.3 mile upstream from South Fork, and 2.8 miles west of Dinsmores.

DRAINAGE AREA.--85.1 sq mi.

PERIOD OF RECORD. --Water temperatures: October 1965 to September 1969.

EXTREMES. --1968-69:

Water temperatures: Maximum, $25.0^{\circ} \mathrm{C}$ July $22-24$.

Period of record: water temperatures: Maximum, $25.0^{\circ} \mathrm{C}$ July 22-24, 1969; minimum (1965-68), freezing point on several days during REMARKS.--Recorder malfunction Oct. 1, 2, Nov, 7 to Feb. 25, Feb. 28 to Mar. 5, Mar. 7 to Apr. 7 , Apr. 19-27,
June 9 to July 8, Aug. 18, Sept. 10-16.

TEMPERATURE ( ${ }^{\circ} \mathrm{C}$ ) OF WATER, WATER YEAR OCTOBER 1968 TO SEPTEMBER 1969

DAY

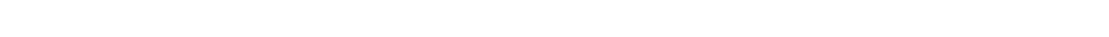

OCTIBFR

MAXIMUM -- -- $18 \quad 17 \quad 18 \quad 17 \quad 17 \quad 16 \quad 16 \quad 17 \quad 16 \quad 16 \quad 16 \quad 16 \quad 16 \quad 16 \quad 16 \quad 16 \quad 16 \quad 16 \quad 16 \quad 16 \quad 16 \quad 16 \quad 16 \quad 16 \quad 16 \quad 1515 \quad 1614$

$\begin{array}{lllllllllllllllllllllllllllllllll}\text { MAXIMUM } & -- & -- & 18 & 17 & 18 & 17 & 17 & 16 & 16 & 17 & 16 & 16 & 16 & 16 & 16 & 16 & 16 & 16 & 16 & 16 & 16 & 16 & 16 & 16 & 16 & 16 & 16 & 15 & 15 & 16 & 14 \\ \text { MINIMUM }-- & -- & 17 & 16 & 17 & 16 & 15 & 15 & 14 & 15 & 16 & 15 & 15 & 15 & 15 & 15 & 15 & 15 & 15 & 16 & 15 & 15 & 16 & 16 & 15 & 15 & 15 & 14 & 14 & 14 & 14\end{array}$

MINIMUM
NUYEMBE?

MAXIMUM

MINIMUM

DECEMBEQ

MAXIMUM

MINIMUM
J ANUARY

MAXI MUM
MINI MUM

MINI MUM
FEBRUARY

MAXIMUM

MIVIMUM

MARCH

MAXIMUM --

APRIL

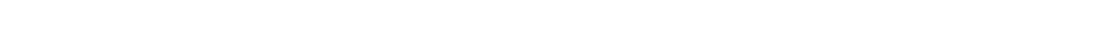

MAY

$\begin{array}{rrrrrrrrrrrrrrrrrrrrrrrrrrrrrrrrrrrr}\text { MAXIMUM } & 11 & 9 & 11 & 9 & 10 & 13 & 16 & 16 & 18 & 18 & 18 & 17 & 16 & 16 & 17 & 17 & 17 & 15 & 15 & 18 & 20 & 21 & 20 & 18 & 17 & 17 & 13 & 16 & 19 & 20 & 21 & 16 \\ \text { MINIMUM } & 5 & 4 & 4 & 3 & 1 & 3 & 9 & 8 & 9 & 12 & 12 & 12 & 12 & 12 & 12 & 11 & 12 & 10 & 9 & 11 & 11 & 12 & 12 & 12 & 12 & 12 & 10 & 11 & 12 & 13 & 14 & 10\end{array}$

JUNE

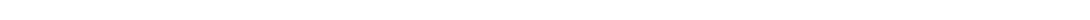

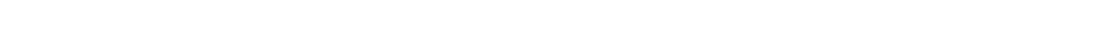

JULY

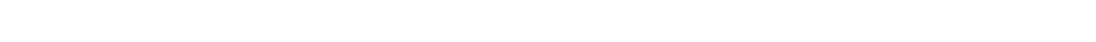

AUGUST

MAXIMUM $\begin{array}{llllllllllllllllllllllllllllllllll}22 & 23 & 23 & 22 & 22 & 22 & 22 & 23 & 22 & 23 & 22 & 22 & 24 & 24 & 24 & 24 & 24 & -2 & 24 & 24 & 24 & 24 & 24 & 23 & 23 & 23 & 22 & 22 & 22 & 22 & 23 & 23\end{array}$

MINIMUM

SEPTEMBER

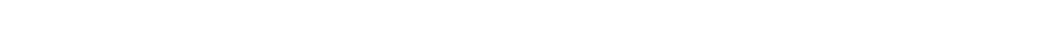


11478500 VAN DJZEN RIVER NEAR BRIDGEVILLE, CALIF.

LOCATION.--Lat $40^{\circ} 28^{\prime} 50^{\prime \prime}$, long $123^{\circ} 53^{\prime} 23^{\prime \prime}$, in NE fSE sec.12, T.1 N., R. 2 E., Humboldt County, at gaging station at bridge on State Highwa $36,0.9$ mile upstream from Grizzly Creek and 5 miles west of Bridgeville.

DRAINAGE AREA. --222 sq $m i$.

PERIOD OF RECORD. --Chemical analyses: October 1958 to September 1969.

Water temperatures: December 1960 to September 1369.

Water temperatures: December 1960 to september 196

EXTREMES. --1968-69:

Water temperatures: Maximum, $27.0^{\circ} \mathrm{C} \mathrm{July} \mathrm{22;} \mathrm{minimum,} 1.0^{\circ} \mathrm{C} \mathrm{Jan,} 30$.

period of record (1960-64, 1965-69):

Water temperatures: Maximum, $29.5^{\circ} \mathrm{C}$ July 1, 2, 1967; minimum, $0.5^{\circ} \mathrm{C}$ Dec. 18-20, 23,1965 .

REMARKS. - Chemical-quality records furnished by California Department of Water Resources and reviewed by U.S. Geological Survey.

CHEMICAL ANALYSES, WATER YEAR OCTHBER 1968 TO SEPTEMBER 1969

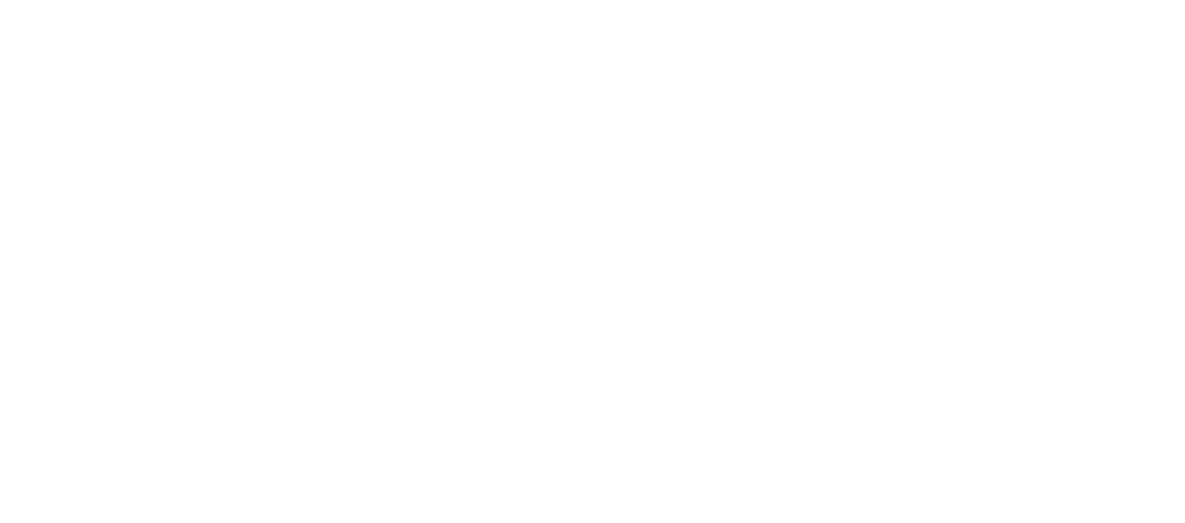

\begin{tabular}{|c|c|c|c|c|c|c|c|c|c|c|c|}
\hline UATE & $\begin{array}{c}\text { N1TRATE } \\
\text { (NDB) } \\
\text { (MG/L) }\end{array}$ & $\begin{array}{l}\text { RORUN } \\
\text { IBI } \\
\text { IUG/L) }\end{array}$ & $\begin{array}{l}\text { DIS- } \\
\text { SULVEO } \\
\text { SOLLUS } \\
\text { IRESI- } \\
\text { OUE AT } \\
130 \text { CC) } \\
\text { (MGILI) }\end{array}$ & $\begin{array}{l}\text { DIS- } \\
\text { SOLVED } \\
\text { SOLIUS } \\
\text { (TONS } \\
\text { PER } \\
\text { AC } \rightarrow F T \text { ) }\end{array}$ & $\begin{array}{l}\text { HARO- } \\
\text { NESS } \\
(C A, M G) \\
(M G / L)\end{array}$ & $\begin{array}{l}\text { NON- } \\
\text { CAR- } \\
\text { BONATE } \\
\text { HARD- } \\
\text { NESS } \\
\text { (MG/L) }\end{array}$ & $\begin{array}{l}\text { PERCENT } \\
\text { SODIUM }\end{array}$ & $\begin{array}{l}\text { SODIUM } \\
\text { AD- } \\
\text { SORP- } \\
\text { TION } \\
\text { RATIO }\end{array}$ & $\begin{array}{l}\text { ALKA- } \\
\text { LINITY } \\
\text { AS } \\
\text { CACU3 } \\
\text { IMG /LI }\end{array}$ & $\begin{array}{c}\text { PH } \\
\text { (UNITS) }\end{array}$ & $\begin{array}{l}\text { SPECI- }- \\
\text { FIC } \\
\text { COND- } \\
\text { UCTANCE } \\
\text { IMICRO- } \\
\text { MHOSI }\end{array}$ \\
\hline $\begin{array}{l}\text { Uct. } \\
\text { ol... }\end{array}$ & -- & 90 & -- & -- & 146 & 31 & 11 & .3 & 115 & 8.0 & 306 \\
\hline $\begin{array}{l}\text { Nuv. } \\
12 . . . \\
D t C .\end{array}$ & -- & BO & -- & - & 68 & 15 & 11 & .2 & 53 & 7,6 & $14 B$ \\
\hline $\begin{array}{l}\text { DEC. } \\
0_{3} . . . \\
\text { JAiv. }\end{array}$ & -- & 0 & -- & -- & 85 & 22 & 10 & .2 & 63 & 8.2 & 160 \\
\hline$<1 \ldots$ & -- & 40 & -- & - & 52 & 6 & 11 & .2 & 46 & 7.8 & 98 \\
\hline $04 \ldots$ & -- & $n$ & -- & -- & 61 & 11 & 12 & .2 & 50 & 7.9 & 121 \\
\hline MAR. & -- & 0 & -- & $\cdots$ & 57 & 9 & 11 & .2 & 48 & 7.3 & $11 \mathrm{~B}$ \\
\hline $\begin{array}{l}\text { APX. } \\
\text { Od... } \\
\text { MAYY }\end{array}$ & -- & 0 & $\cdots$ & $=$ & 54 & 6 & 10 & .2 & 48 & 7.8 & 111 \\
\hline JUNEE & .1 & 0 & 80 & .11 & 52 & 4 & 9 & .2 & 48 & 8.0 & 116 \\
\hline $10 \ldots$ & -- & 20 & -- & -- & $B 2$ & 7 & 9 & .2 & 75 & 8.2 & 173 \\
\hline $15 \ldots$ & -- & 0 & -- & -- & 114 & 21 & 10 & .2 & 93 & 8.3 & 224 \\
\hline $\begin{array}{l}405 . . \\
050 .\end{array}$ & -- & 40 & -- & - & 127 & 12 & 10 & .3 & 115 & 8.3 & 267 \\
\hline טY... & .0 & 50 & 105 & .14 & 107 & 14 & 15 & .4 & 93 & 7.9 & 251 \\
\hline
\end{tabular}


11478500 VAN DUZEN RIVER NEAR GRTDOEVILLE, CALIF. -.-Cont1HUEd

TEUPYATURE ("C) OF WATER, WATKR YEAR OCTOBER 1968 TO GXPTELBER 1969

DAY

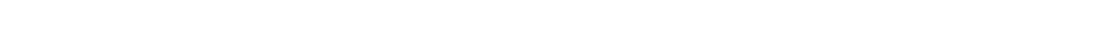

OC TOBER

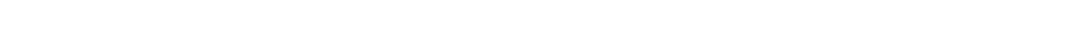
$\begin{array}{lllllllllllllllllllllll}11 & 14 & 15 & 13 & 12 & 11 & 12 & 12 & 13 & 12 & 13 & 13 & 12 & 11 & 13 & 13 & 13 & 12 & 12 & 11 & 13 & 12 & 11\end{array}$

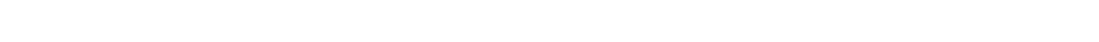

DECEMRER

MAXIMUM

JANUARY

MAXIMUA $6 \begin{array}{lllllllllllllllllllllllllllllll} & 7 & 6 & 7 & 7 & 7 & 7 & 5 & 4 & 5 & 5 & 7 & 7 & 6 & 5 & 5 & 4 & 5 & 7 & 8 & 8 & 6 & 5 & 5 & 8 & 8 & 4 & 3 & 3 & 3 & 3\end{array}$

MINIMUA

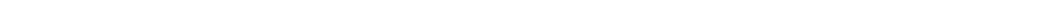

MINIMUM

MARCA MIM

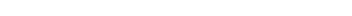

MINIMUM

APRIL

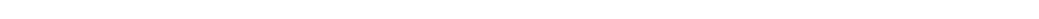

MaY

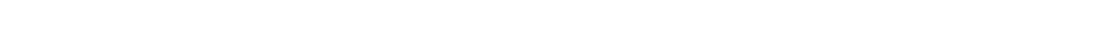
JUNE $\begin{array}{llllllllllllllllllllllllllllllllll}\text { MAXIMUM } & 23 & 23 & 24 & 23 & 20 & 19 & 17 & 17 & 17 & 17 & 18 & 20 & 20 & 18 & 18 & 24 & 24 & 22 & 21 & 20 & 21 & 23 & 23 & 23 & 20 & 21 & 19 & 23 & 24 & 24 & -2 & 21 \\ \text { MINIMUM } & 16 & 16 & 27 & 17 & 17 & 16 & 15 & 15 & 15 & 15 & 15 & 15 & 16 & 16 & 16 & 17 & 17 & 18 & 17 & 17 & 17 & 17 & 17 & 17 & 17 & 15 & 15 & 14 & 16 & 17 & -2 & 16\end{array}$ SuLY

$\begin{array}{lllllllllllllllllllllllllllllllllll}\text { MAXIMUM } & 19 & 22 & 23 & 23 & 23 & 23 & 25 & 25 & 25 & 23 & 22 & 25 & 25 & 25 & 24 & 25 & 25 & 26 & 26 & 26 & 26 & 27 & 26 & 24 & 26 & 26 & 20 & 25 & 25 & 24 & 21 & 24 \\ \text { MINIMUM } & 17 & 17 & 17 & 17 & 18 & 17 & 17 & 18 & 18 & 18 & 18 & 17 & 17 & 17 & 18 & 17 & 16 & 17 & 16 & 18 & 18 & 18 & 19 & 19 & 19 & 17 & 17 & 17 & 17 & 17 & 17 & 17\end{array}$ QUGUST

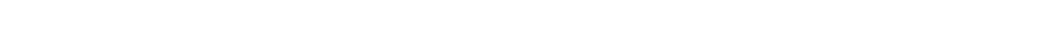
MINIMUM

SEPTEMBER

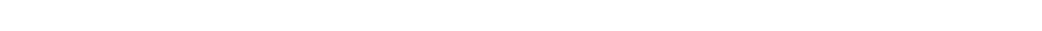

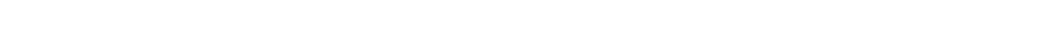
6 6 8 11 8 24 24 17 22 
11480500 MAD RIVER NEAR FOREST GLEN, CALIF.

LOCAT ION, --Lat $40^{\circ} 27^{\prime} 30^{\prime \prime}$, long $123^{\circ} 30^{\prime} 35^{\prime \prime}$, in sw \& sec.16, T.1 N., R. B E. , Trinity County, Six Rivers National Forest, temperature recorder at gaging station on right bank, 0.7 mile downstream from Lamb Creek and
$11.1 \mathrm{mi}$ les northwest of Fore git gien.

DRAINAGE AREA, $--143: 4 \mathrm{~m} 1$.

PERIOD OP RECORD, - Tater tomperatures: November 1960 to Septomber 1969

Sodiment recorda: January 1957 to Soptember 1969 (partial recorda).

EXTREMES, --1968-69:

Mater tomperatures: Maximum, $21.0^{\circ} \mathrm{C}$ June 18; minimum, 2. $0^{\circ} \mathrm{C}$ Feb. 28, Mar. 13, 14.

Period of record:

Water temperatures: Maxinum $(1900-66,1967-69), 26.0^{\circ} \mathrm{C}$ June 25,1961 ; minimum, freezing point Jan. 5 ,

REMARKS.--Recorder stopped Apr. 24 to June 2, Aug. 14-19, Aug. 23 to Sept. 30

TEMPERATURE $\left({ }^{\circ} \mathrm{C}\right.$ ) OF WATER, WATER YEAR OCTOBER 1968 TO SEPTEMBER 1969

Dar

MONTH

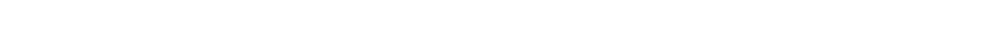

OCTOBER

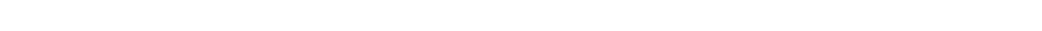

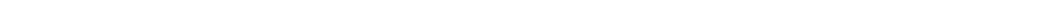

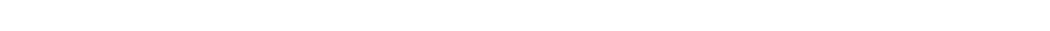
DECEMBER MAXIMUM JANUARY $\begin{array}{lllllllllllllllllllllllllllllllll}8 & 8 & 8 & 8 & 8 & 8 & 8 & 8 & 9 & 8 & 7 & 7 & 6 & 6 & 6 & 7 & 6 & 6 & 5 & 5 & 5 & 4 & 4 & 5 & 6 & 5 & 5 & 5 & 4 & 4 & 4\end{array}$

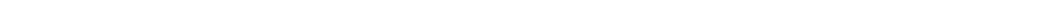

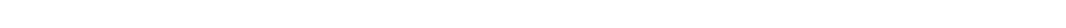
MINIKUA MARCH

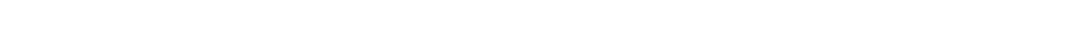
APRIL

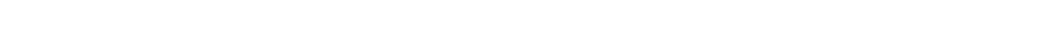

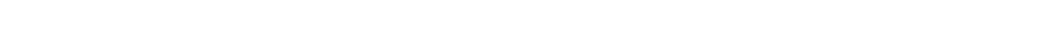
MAY MAXIMUM

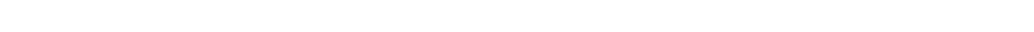

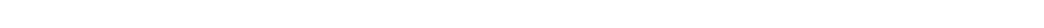
JULY

MAXiMUM 19191819191919202020202019191919181919191919192020191919191918

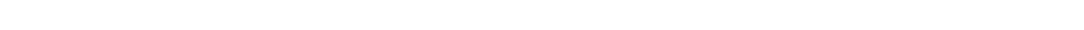
AUGUST

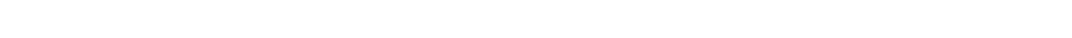
MINTMUH

MAXIMUM

MAXI MUM

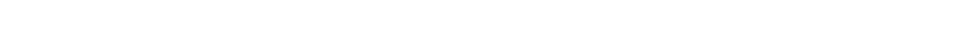
SUSPENDED-SEDIMENT DISCHARGE MEASUREMENTS, WATER YEAR OCTOBER 1968 TO SEPTEMBER 1969

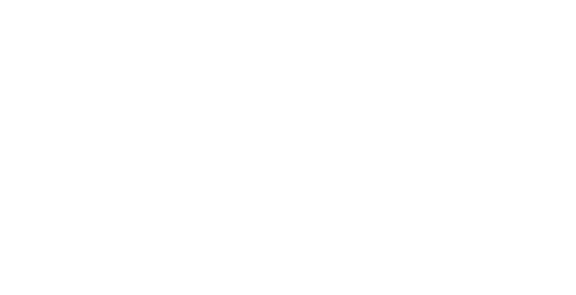

PARTICLE-SIZE DISTRIBUTION OF SURFACE BED MATERIAL, WATER YEAR OCTOBER 1968 TO SEPTEMBER 1969
IMETHOD OF ANALYS IS: H. HYDROMESER: D, OPTICAL ANALYZR: S. SIEVE; $V$, VISUAL ACCUMULATION TUHE

\begin{tabular}{|c|c|c|c|c|c|c|c|c|c|c|c|c|c|c|c|c|}
\hline & & WATER & NUM8ER & & & & & & PART & TICLE SI & & & & & & \\
\hline$A T E$ & TIME & $\begin{array}{l}\text { PERA- } \\
\text { TURE } \\
\text { I CI }\end{array}$ & $\begin{array}{l}\text { SAM- } \\
\text { PLING } \\
\text { POINTS }\end{array}$ & $\begin{array}{l}\text { OISCHARGE } \\
\text { (CFS) }\end{array}$ & .062 & $\begin{array}{c}\text { PERCENT } \\
.125\end{array}$ & $\begin{array}{l}\text { FINER } \\
.250\end{array}$ & $\begin{array}{l}\text { THAN } \\
.500\end{array}$ & $\begin{array}{l}\text { THE S } \\
1.00\end{array}$ & SIZE IIN & N MILL & I METERSI & 1 IND & 1CATEO & 64.0 & $\begin{array}{l}\text { METHUIS } \\
\text { UF } \\
\text { A.VALY - } \\
\text { SIS }\end{array}$ \\
\hline 4 & 0930 & 8 & 3 & 497 & $\cdots$ & - & 2 & 3 & 8 & 23 & 44 & 83 & 100 & -. & -- & s \\
\hline
\end{tabular}




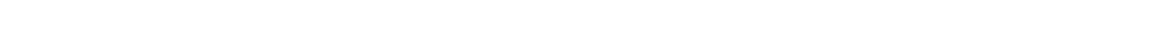
at gaging station on' left bank at mouth of Maple Creek, $30 \mathrm{ft}$ upstream $\mathrm{fromb}$ bridge and 5.4 miles east of
kneeland. DRAINAGE AREA, $--352 \mathrm{sq} \mathrm{mi}$.

PERIOD OF RECORD.--Water temperatures: November 1965 to September 1969.

EXTREMES, --1968-69:

Water temperatures: Maximum, $24.0^{\circ} \mathrm{C}$ on many days during July and August; minimum, 3.0 $0^{\circ} \mathrm{C}$ Feb. $12-15$.

Period of record:

Water temperatures: Maximum, $28.0^{\circ} \mathrm{C}$ July 19-22, 1968 ; minimum, 2. $0^{\circ} \mathrm{C}$ Mar. 2, 1966.

REMARKS.--Recorder malfunction Nov. 15 to Dec, 10, Jan, 21 to Feb. 5, Apr. 6, 9-11, May 5 to June 2.

TEMPERATURE ( ${ }^{\circ} \mathrm{C}$ ) OF WATER, WATER YEAR OCTOBER 1968 TO SEPTEMBER 1969

DAY

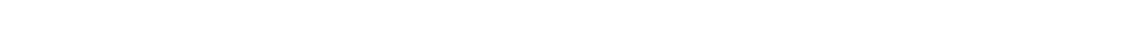

OCTOBER

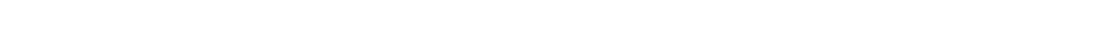

MINIMUM $2019191919191716161716171412 \quad 1616161616161616161716161516161616 \quad 17$

NUVEMBER

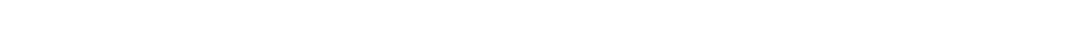

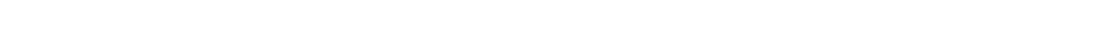

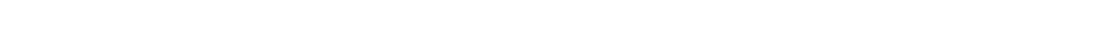

MINIMUM - -
IANUARY

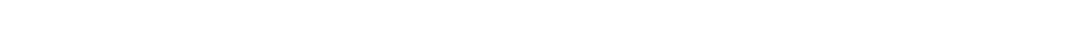

FEBRUARY

MAXIMUM _.

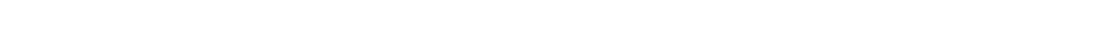

$\begin{array}{llllllllllllllllllllllllrrrrrrrrrr}\text { MAXIMUM } & 6 & 6 & 6 & 6 & 6 & 7 & 7 & 7 & 7 & 6 & 6 & 6 & 6 & 7 & 7 & 7 & 7 & 7 & 7 & 7 & 7 & 8 & 8 & 10 & 10 & 10 & 10 & 11 & 11 & 11 & 12 & 8 \\ \text { MINIMUM } & 6 & 6 & 6 & 6 & 6 & 6 & 6 & 6 & 6 & 6 & 6 & 6 & 6 & 6 & 6 & 6 & 7 & 7 & 7 & 7 & 7 & 7 & 8 & 8 & 9 & 9 & 10 & 10 & 11 & 10 & 10 & 7\end{array}$

MINIMUM

$\begin{array}{lllllllllllllllllllllllllllllllll}\text { MAXIMUM } & 11 & 11 & 10 & 11 & 10 & - & 12 & 12 & -- & -- & -2 & 13 & 13 & 13 & 13 & 14 & 14 & 14 & 14 & 15 & 15 & 16 & 16 & 15 & 15 & 15 & 15 & 15 & 15 & 15 & -- \\ \text { MINIMUM } & 10 & 10 & 9 & 10 & 10 & -- & 11 & 11 & - & -- & - & 13 & 12 & 13 & 13 & 13 & 14 & 13 & 13 & 13 & 14 & 15 & 15 & 14 & 14 & 14 & 14 & 15 & 15 & 15 & --\end{array}$ Mar

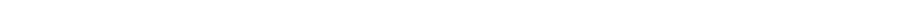

MINIMUM 15 15 15 15 15 : JUNE

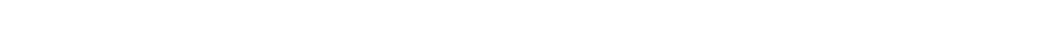
MINIM

MAXIMUM $\begin{array}{llllllllllllllllllllllllllllllll}23 & 23 & 23 & 23 & 23 & 23 & 23 & 23 & 23 & 23 & 24 & 24 & 24 & 24 & 23 & 23 & 23 & 23 & 23 & 23 & 24 & 24 & 24 & 24 & 24 & 24 & 24 & 24 & 24 & 24 & 24\end{array}$

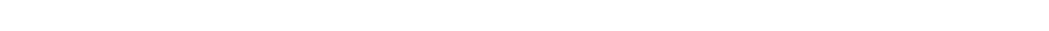
AUGUST

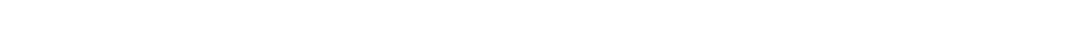

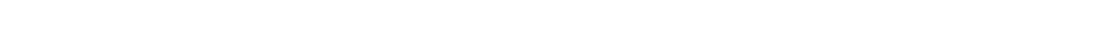
STPIEMBER $\begin{array}{lllllllllllllllllllllllllllllllllll}\text { MAXIMUM } & 22 & 21 & 21 & 21 & 21 & 21 & 21 & 21 & 21 & 21 & 21 & 21 & 21 & 20 & 20 & 20 & 20 & 20 & 20 & 19 & 19 & 19 & 19 & 19 & 19 & 19 & 18 & 18 & 18 & 18 & -- & 20 \\ \text { MINIMUM } & 21 & 21 & 20 & 20 & 20 & 20 & 20 & 20 & 20 & 21 & 20 & 21 & 20 & 19 & 20 & 19 & 19 & 19 & 19 & 19 & 19 & 19 & 19 & 18 & 18 & 18 & 18 & 17 & 17 & 17 & -- & 19\end{array}$ 
11481000 MAD RIVER NEAR ARCATA, CALIF,

LOCATION. --Lat $40^{\circ} 54^{\prime} 35^{\prime \prime}$, long $124^{\circ} 03^{\prime} 35^{\prime \prime}$, 1n NW sec.15, T. 6 N, , R. 1 E., Humboldt County, at gaging station $100 \mathrm{ft}$ upstream from bridge on U.S. Highway 299, 1.0 mile downstream from Warren Creeks and $2.8 \mathrm{miles}$ northeast of Arcata.

DRAINAGE AREA, --485 sq mi.

PERIOD OF RECORD. --Chemical analy Ses: November 1958 to September 1969. Water temperatures: December 1957 to September 1969.

Sediment records: December 1957 to september 1969.

EXTREMES. --1968-69:

Fater temperatures: Maximum, $26.0^{\circ} \mathrm{C}$ July 7 ; minimum, $3.0^{\circ} \mathrm{C}$ Dec. 21

Water temperatures: Maximum, $26.0^{\circ} \mathrm{C}$ July $7 ;$ minimum, $3.0^{\circ} \mathrm{C}$ Dec. 21. ber, June, and August.

Sediment discharge: Maximum da1ly, 472,000 tons Jan. 13; minimum da1ly, 0.11 ton Oct. 7.

Period of record:

a ter temperatures: Maximum $(1963-64,1965-69), 27.0^{\circ} \mathrm{C}$ on several days in July $1968 ; \mathrm{m} 1 \mathrm{nimum}, 0.5^{\circ} \mathrm{C}$

Dec. $17-20,1965$

Sediment concentrations: Maximum da1ly, 21,900 mg/l Dec. 23, 1964; minimum da1ly, 1 mg/l on many days $1 \mathrm{n}$ $1965,1967-68$

Sediment discharge: Maximum da1ly, 3,140,000 tons Dec. 22, 1964; min1mum da1ly, 0,02 ton June 13, Aug. 8 , 1968 .

REMARKS.--Chemical-quality records Purn1shed by Cal1fornia Department of Wate $r$ Resources and reviewed by U.S. Geological Survey. Temperature recorder stopped Dec. 13 to Jan. 30, Aug. 13-18, Aug. 22 to Sept. 30 . Where no maximum or minimum is shown, temperature is once-dally reading.

CHEMICAL ANALYSES, WATER YEAR OCTOBER 1968 TO SEPTEMBER 1969

\begin{tabular}{|c|c|c|c|c|c|c|c|c|c|c|c|c|}
\hline DATE & $T I M E$ & $\begin{array}{l}\text { DIS- } \\
\text { CHARGE } \\
\text { (CFS) }\end{array}$ & $\begin{array}{l}\text { TEMPER- } \\
\text { ATURE } \\
\text { (DEG C) }\end{array}$ & $\begin{array}{l}\text { DIS- } \\
\text { SDLVED } \\
\text { OXYGEN } \\
\text { (MG/L) }\end{array}$ & $\begin{array}{l}\text { CAL- } \\
\text { CIUM } \\
(C A) \\
(M G / L)\end{array}$ & $\begin{array}{l}M A G- \\
\text { NE- } \\
\text { SIUM } \\
\text { (MG) } \\
\text { (MG/L) }\end{array}$ & $\begin{array}{l}\text { SOD LUM } \\
\text { (NA) } \\
\text { (MG/L) }\end{array}$ & $\begin{array}{l}\text { PO- } \\
\text { TAS- } \\
\text { SIUM } \\
\text { (K) } \\
\text { (MGIL) }\end{array}$ & $\begin{array}{l}\text { 8ICAR- } \\
\text { BONATE } \\
\text { (HCO3) } \\
\text { (MG/L) }\end{array}$ & $\begin{array}{l}\text { CAR- } \\
\text { BONATE } \\
\text { (CO3) } \\
\text { (MG/L) }\end{array}$ & $\begin{array}{l}\text { SULFATE } \\
\text { (SO4) } \\
(M G / L)\end{array}$ & $\begin{array}{l}\text { CHLO- } \\
\text { RIDE } \\
\text { ICLI } \\
\text { IMGIL }\end{array}$ \\
\hline $\begin{array}{c}\text { OCT. } \\
\text { D2.... }\end{array}$ & 0710 & 24 & 15 & 9.5 & - & -- & 4.9 & $\cdots$ & 110 & 0 & -- & \\
\hline $\begin{array}{l}\text { NOV. } \\
\text { I2.... } \\
\text { OEC. }\end{array}$ & 1230 & 2540 & 11 & 11.3 & - & -- & 4.5 & - & 46 & 0 & - & \\
\hline JAN. & 1110 & 1590 & 7 & 12.8 & -- & -- & 4.2 & $-\infty$ & 60 & 0 & -- & 3. \\
\hline FEB. & 1315 & 21000 & 7 & 12.8 & $-\infty$ & -- & 3.3 & -- & 51 & 0 & - & \\
\hline$\underset{\text { MAR. }}{03 . . .}$ & 1240 & 3250 & 7 & 12.9 & -- & $-\infty$ & 3.6 & - & 45 & 0 & -- & \\
\hline $\begin{array}{l}03 \ldots . . \\
\text { APR. }\end{array}$ & 1345 & 3260 & 7 & 12.9 & -- & -- & 2.9 & -- & 44 & 0 & - & \\
\hline MAY $_{\text {MA }}^{07 . .}$ & 1445 & 1760 & 11 & 12.2 & -- & - & 2.9 & - & 51 & D & -- & \\
\hline JUNE & 1050 & 726 & 13 & 11.1 & 15 & 2.8 & 2.7 & 1.3 & 54 & 0 & 5.6 & \\
\hline JULY... & 1120 & 177 & 15 & 10.7 & -- & - & 3.6 & -- & 82 & 0 & -- & \\
\hline $\begin{array}{l}15 \ldots . \\
\text { AUG. }\end{array}$ & 1250 & 41 & 22 & 8.6 & -- & -- & 4.5 & -- & 110 & 0 & -- & \\
\hline $\begin{array}{l}05 . . * \\
\text { SEPT. }\end{array}$ & 1025 & 56 & $1 B$ & 10.1 & - & -- & 4.4 & $-=$ & 102 & 0 & -- & \\
\hline $09 . .$. & 1050 & 29 & 18 & 10.1 & 32 & 4.4 & 4.6 & .8 & 109 & 0 & 11 & \\
\hline
\end{tabular}

\begin{tabular}{|c|c|c|c|c|c|c|c|c|c|c|c|}
\hline OATE & $\begin{array}{l}\text { NITRATE } \\
\text { (NO3) } \\
\text { (MG/L) }\end{array}$ & $\begin{array}{l}\text { BORON } \\
(8) \\
(U G / L)\end{array}$ & $\begin{array}{l}\text { DIS- } \\
\text { SOLVEO } \\
\text { SOLIDS } \\
\text { IRESI- } \\
\text { OUE AT } \\
\text { I80 C) } \\
\text { (MG LL) }\end{array}$ & $\begin{array}{l}\text { OIS- } \\
\text { SOLVED } \\
\text { SOLIDS } \\
\text { ITONS } \\
\text { PER } \\
\text { AC-FTI }\end{array}$ & $\begin{array}{l}\text { HARD- } \\
\text { NESS } \\
(C A, M G) \\
(M G / L)\end{array}$ & $\begin{array}{l}\text { NON- } \\
\text { CAR- } \\
\text { BONATE } \\
\text { HARO- } \\
\text { NESS } \\
\text { (MG/L) }\end{array}$ & $\begin{array}{l}\text { PERCENT } \\
\text { SODIUM }\end{array}$ & $\begin{array}{l}\text { SODIUM } \\
\text { AO- } \\
\text { SORP- } \\
\text { TION } \\
\text { RATIOO }\end{array}$ & $\begin{array}{l}\text { ALKA- } \\
\text { LINITY } \\
\text { AS } \\
\text { CACO3 } \\
\text { (MG/L) }\end{array}$ & $\begin{array}{c}P H \\
\text { (UNITS) }\end{array}$ & $\begin{array}{l}\text { SPECI- } \\
\text { FICC } \\
\text { COND- } \\
\text { UCTANCE } \\
\text { IMIICRO- } \\
\text { MHOSI }\end{array}$ \\
\hline $\begin{array}{c}\text { OCT. } \\
02 . . . \\
\text { NOY. }\end{array}$ & -- & 50 & -- & -- & 106 & 16 & 9 & .2 & 90 & 8.0 & 213 \\
\hline $12 \ldots$ & -- & 70 & -. & -- & 48 & 10 & 17 & .3 & 38 & 7.2 & 117 \\
\hline $03 \ldots$ & -- & 40 & -- & -- & 68 & 19 & 12 & .2 & 49 & 8.1 & 130 \\
\hline $\begin{array}{l}\mathrm{JAN} . \\
200 .\end{array}$ & -- & 30 & -- & -- & 58 & 16 & 11 & .2 & 42 & 1.8 & 100 \\
\hline $\begin{array}{l}F E B . \\
03 . . .\end{array}$ & -- & 0 & - & -- & 49 & 12 & 14 & .2 & 37 & 7.6 & 96 \\
\hline $\begin{array}{l}\text { MAR. } \\
\text { OB3... } \\
\text { APR. }\end{array}$ & -- & 20 & -- & - & 43 & 7 & 13 & .2 & 36 & 7.7 & 93 \\
\hline $07 . .$. & -- & 40 & - & -- & 42 & 0 & 13 & .2 & 42 & 7.8 & 103 \\
\hline JUNEE & .2 & Bo & 54 & .07 & 49 & 5 & 10 & .2 & 44 & 7.7 & 108 \\
\hline $10 \ldots$ & -- & 40 & - & -- & 73 & 6 & 10 & .2 & 67 & 7.9 & 158 \\
\hline JULY $15 . \ldots$ & -- & 0 & -- & - & 102 & 12 & 9 & .2 & 90 & 8.3 & 207 \\
\hline & -- & 0 & - & -- & 96 & 12 & 9 & .2 & 84 & 8.2 & 194 \\
\hline $\begin{array}{l}\text { SEPT. } \\
09 . . .\end{array}$ & .0 & 10 & 100 & .14 & 98 & 9 & 9 & .2 & 89 & 7.8 & 206 \\
\hline
\end{tabular}


11481000 MAD RIVER NEAR ARCATA, CALIF.--Cont1

TEMPERATURE ( ${ }^{\circ} \mathrm{C}$ ) OF WATER, WATER YBAR OCTOEER 1968 TO SEPTEUAER 1969

DAY

MUNith

12345678910111213141516171819202122232425262728293031

OC TUBER.

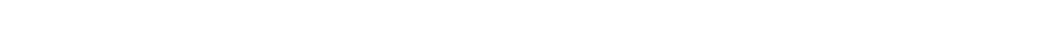

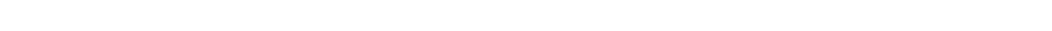

$\begin{array}{llllllllllllllllllllllllllllllllllllll}\text { MAXIMUM } & 12 & 13 & 14 & 13 & 14 & 12 & 14 & 14 & 14 & 15 & 14 & 14 & 12 & 10 & 10 & 10 & 12 & 12 & 12 & 12 & 12 & 13 & 12 & 11 & 11 & 10 & 10 & 9 & 9 & 9 & -2\end{array}$

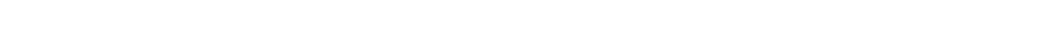

DECEMER. -

MAXIMUM 99969

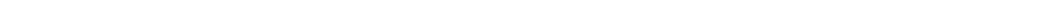

MAXIMUM -

MINIMUM --

FEBRUARY.

MAXIMUM

MINIMUIM

MARCH.....

MINIMUM

APRIL.....

MAXIMUM

MINIMUM

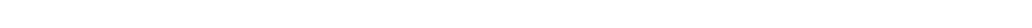

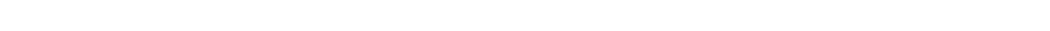

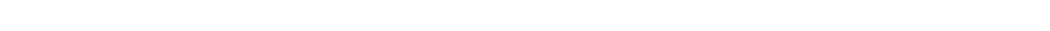

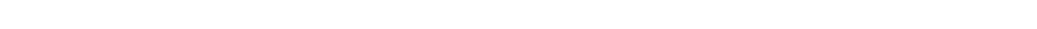

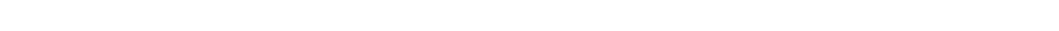

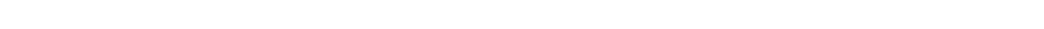
AUGUST...

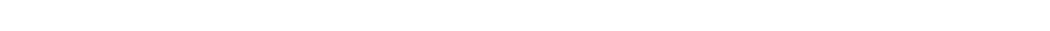

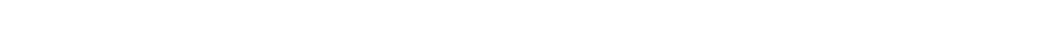

SEPTEMBER

MAXIMUM

MINIMUM

SUSPENDED-SEDIMENT DISCHARGE, HATER YEAR OCTOBER 1968 TO SEPTEMBER 1969

OCTOHER

\begin{tabular}{|c|c|c|c|c|}
\hline OAY & $\begin{array}{c}\text { MEAN } \\
\text { OISCHARGE } \\
\text { (CFS) }\end{array}$ & $\begin{array}{l}\text { MEAN } \\
\text { CONCEN- } \\
\text { TRAIION } \\
\text { (MG/L) }\end{array}$ & $\begin{array}{l}\text { SEDIMENT } \\
\text { DISCHARGE } \\
\text { (TONS/DAY) }\end{array}$ & $\begin{array}{l}\text { MEAN } \\
\text { OISCHARGE } \\
\text { (CFS) }\end{array}$ \\
\hline 1 & 22 & 5 & .30 & 110 \\
\hline 2 & 19 & 7 & .36 & 149 \\
\hline 3 & 18 & 9 & .44 & 380 \\
\hline 4 & 20 & 10 & .54 & 215 \\
\hline 5 & 20 & 9 & .49 & 187 \\
\hline 6 & 16 & 4 & .17 & 199 \\
\hline 7 & 20 & 2 & $.1 i$ & 215 \\
\hline 8 & 33 & 2 & .18 & 252 \\
\hline 9 & 29 & 3 & .23 & 610 \\
\hline 10 & 28 & 4 & .30 & 677 \\
\hline 11 & 26 & 6 & .42 & 737 \\
\hline 12 & 122 & 69 & 23 & 2410 \\
\hline 13 & 165 & 79 & 35 & 1120 \\
\hline 14 & 113 & 23 & 7.0 & 866 \\
\hline 15 & 130 & 19 & 6.7 & 1350 \\
\hline 16 & 112 & 16 & 4.8 & 1220 \\
\hline 17 & 75 & 9 & 1.8 & 1130 \\
\hline 18 & 60 & 4 & .65 & 2530 \\
\hline 19 & 47 & 6 & .76 & 2040 \\
\hline 20 & 66 & 20 & 3.6 & 1240 \\
\hline 21 & 86 & 44 & 10 & 953 \\
\hline 22 & 63 & 38 & 6.5 & 1050 \\
\hline 23 & 48 & 18 & 2.3 & 939 \\
\hline 24 & 34 & 6 & .55 & 2100 \\
\hline 25 & 35 & 3 & .28 & 4330 \\
\hline 26 & 34 & 2 & .18 & 2660 \\
\hline 27 & 32 & 3 & .26 & 1820 \\
\hline 28 & 30 & 4 & .32 & 1500 \\
\hline 29 & 34 & 8 & .73 & 1430 \\
\hline 30 & 71 & 49 & 9.4 & 1850 \\
\hline 31 & 151 & 50 & 20 & -- \\
\hline TOTAL & 1759 & -- & 137.37 & 36259 \\
\hline
\end{tabular}

NOVEMBER

MEAN

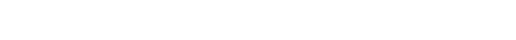

TMGLL ITONS/DAY

25
57
184
36

7.4
33
197
21

2230
2030
1560
1460
2380

IMGIL) (TONS/DAY)

16

8.1

18
22
11
330

330
110

119

768
135
82

82
336

100

80
640
265

13

$\begin{array}{ll}7.5 & 1700 \\ 544 & 1670 \\ 201 & 5000\end{array}$

2140
1620

1700
1670

319
5380

408
192

6560
3960

3110
5220

1240

9550

327
266

266

4240
1460

7140
4550
3540

3430

341

68
72
35
580

35
580

175

175
204
89

89
4310

4310
11900

1690

1690
$48 ?$

312

340
609

609

35325.7

\begin{tabular}{rr}
122 & 735 \\
99 & 543 \\
52 & 219 \\
39 & 154 \\
168 & 1080 \\
110 & \\
61 & 636 \\
86 & 267 \\
72 & 395 \\
3480 & 425 \\
& 47000 \\
2260 & 40000 \\
400 & 4280 \\
290 & 2440 \\
1480 & 21900 \\
2740 & 74800 \\
1540 & 29700 \\
420 & 5160 \\
330 & 3150 \\
720 & 6670 \\
260 & 1690 \\
170 & 826 \\
140 & 624 \\
1660 & 37900 \\
3970 & 127000 \\
1080 & 30300 \\
810 & 16100 \\
522 & 6460 \\
358 & 3940 \\
282 & 2680 \\
236 & 1660 \\
220 & 1180 \\
& \\
\hline 0 & 469814 \\
& \\
&
\end{tabular}


MAD RIVER BASIN

11481000 MAD RIVER NEAR ARCATA, CALIF.--Cont1nued

SUSPENDED-SEDIMENT DISCHARGE, WATER YEAR OCTOBER 1968 TO SEPTEMBER 1969

\begin{tabular}{|c|c|c|c|c|c|c|c|c|c|}
\hline DAY & $\begin{array}{l}\text { MEAN } \\
\text { OISCHARGE } \\
\text { ICFSI }\end{array}$ & $\begin{array}{l}\text { JANUARY } \\
\text { MEAN } \\
\text { CONCEN- } \\
\text { TRATION } \\
\text { (MGIL) }\end{array}$ & $\begin{array}{l}\text { SEDIMENT } \\
\text { DISCHARGE } \\
\text { (TONS/DAY) }\end{array}$ & $\begin{array}{l}\text { MEAN } \\
\text { DISCHARGE } \\
\text { (CFS) }\end{array}$ & $\begin{array}{l}\text { FEBRUARY } \\
\text { MEAN } \\
\text { CONCEN- } \\
\text { TRATION } \\
\text { IMG/LI) }\end{array}$ & $\begin{array}{l}\text { SED IMENT } \\
\text { DISCHARGE } \\
\text { (TONS/DAY) }\end{array}$ & $\begin{array}{l}\text { MEAN } \\
\text { DISCHARGE } \\
\text { (CFS) }\end{array}$ & $\begin{array}{l}\text { MARCH } \\
\text { MEAN } \\
\text { CONCEN- } \\
\text { TRATIION } \\
\text { (MG/LI) }\end{array}$ & $\begin{array}{l}\text { SEDIMENT } \\
\text { DISCHARGE } \\
\text { (TONS/DAY) }\end{array}$ \\
\hline $\begin{array}{l}1 \\
2 \\
3 \\
4 \\
5\end{array}$ & $\begin{array}{l}1640 \\
1560 \\
1510 \\
1670 \\
2040\end{array}$ & $\begin{array}{l}162 \\
147 \\
150 \\
216 \\
320\end{array}$ & $\begin{array}{r}717 \\
619 \\
612 \\
974 \\
1760\end{array}$ & $\begin{array}{l}7160 \\
4450 \\
3260 \\
2950 \\
3280\end{array}$ & $\begin{array}{r}1420 \\
525 \\
402 \\
356 \\
206\end{array}$ & $\begin{array}{r}27500 \\
6310 \\
3540 \\
2850 \\
1820\end{array}$ & $\begin{array}{l}2110 \\
2070 \\
3380 \\
2360 \\
1940\end{array}$ & $\begin{array}{l}210 \\
234 \\
363 \\
140 \\
124\end{array}$ & $\begin{array}{r}1200 \\
1310 \\
3310 \\
892 \\
650\end{array}$ \\
\hline $\begin{array}{r}6 \\
7 \\
8 \\
9 \\
10\end{array}$ & $\begin{array}{l}2490 \\
2710 \\
2560 \\
2100 \\
1840\end{array}$ & $\begin{array}{l}330 \\
245 \\
238 \\
183 \\
151\end{array}$ & $\begin{array}{r}2220 \\
1790 \\
1650 \\
1040 \\
750\end{array}$ & $\begin{array}{l}3400 \\
2960 \\
2840 \\
7580 \\
6040\end{array}$ & $\begin{array}{r}443 \\
346 \\
311 \\
2710 \\
1390\end{array}$ & $\begin{array}{r}4070 \\
2770 \\
2660 \\
56500 \\
22700\end{array}$ & $\begin{array}{l}2010 \\
1930 \\
1830 \\
1680 \\
1500\end{array}$ & $\begin{array}{r}142 \\
128 \\
88 \\
84 \\
82\end{array}$ & $\begin{array}{l}771 \\
667 \\
435 \\
381 \\
332\end{array}$ \\
\hline $\begin{array}{l}11 \\
12 \\
13 \\
14 \\
15\end{array}$ & $\begin{array}{r}3070 \\
16900 \\
25100 \\
12900 \\
7900\end{array}$ & $\begin{array}{l}1030 \\
6460 \\
6630 \\
3600 \\
1780\end{array}$ & $\begin{array}{r}13000 \\
313000 \\
472000 \\
125000 \\
38000\end{array}$ & $\begin{array}{r}11900 \\
10100 \\
6820 \\
4820 \\
6260\end{array}$ & $\begin{array}{l}5970 \\
3180 \\
1710 \\
1010 \\
1580\end{array}$ & $\begin{array}{r}202000 \\
86700 \\
31500 \\
13100 \\
26700\end{array}$ & $\begin{array}{r}1330 \\
1220 \\
1060 \\
988 \\
1030\end{array}$ & $\begin{array}{r}74 \\
59 \\
52 \\
59 \\
103\end{array}$ & $\begin{array}{l}266 \\
194 \\
149 \\
157 \\
286\end{array}$ \\
\hline $\begin{array}{l}16 \\
17 \\
18 \\
19 \\
20\end{array}$ & $\begin{array}{r}5660 \\
4580 \\
4020 \\
8850 \\
20000\end{array}$ & $\begin{array}{r}880 \\
490 \\
1140 \\
2990 \\
5700\end{array}$ & $\begin{array}{r}13400 \\
6000 \\
12400 \\
71400 \\
335000\end{array}$ & $\begin{array}{l}6580 \\
4670 \\
3580 \\
2910 \\
2530\end{array}$ & $\begin{array}{r}1080 \\
1040 \\
920 \\
646 \\
436\end{array}$ & $\begin{array}{r}19200 \\
13100 \\
8890 \\
5080 \\
2980\end{array}$ & $\begin{array}{l}1210 \\
1480 \\
2640 \\
2540 \\
2260\end{array}$ & $\begin{array}{l}126 \\
284 \\
623 \\
370 \\
278\end{array}$ & $\begin{array}{l}412 \\
1130 \\
4440 \\
2540 \\
1700\end{array}$ \\
\hline $\begin{array}{l}21 \\
22 \\
23 \\
24 \\
25\end{array}$ & $\begin{array}{r}22200 \\
12500 \\
8040 \\
5620 \\
6480\end{array}$ & $\begin{array}{l}5160 \\
3280 \\
2060 \\
1350 \\
2250\end{array}$ & $\begin{array}{r}323000 \\
111000 \\
44700 \\
20500 \\
40700\end{array}$ & $\begin{array}{l}2110 \\
1800 \\
1880 \\
1970 \\
2180\end{array}$ & $\begin{array}{l}340 \\
299 \\
328 \\
176 \\
209\end{array}$ & $\begin{array}{r}1940 \\
1450 \\
1660 \\
936 \\
1230\end{array}$ & $\begin{array}{l}2020 \\
1940 \\
1950 \\
1900 \\
2020\end{array}$ & $\begin{array}{l}224 \\
211 \\
211 \\
216 \\
278\end{array}$ & $\begin{array}{l}12220 \\
111 \\
11100 \\
11110 \\
1520\end{array}$ \\
\hline $\begin{array}{l}26 \\
27 \\
28 \\
29 \\
30 \\
31\end{array}$ & $\begin{array}{r}11000 \\
8230 \\
6180 \\
4520 \\
4100 \\
3460\end{array}$ & $\begin{array}{r}4410 \\
1840 \\
1010 \\
560 \\
530 \\
400\end{array}$ & $\begin{array}{r}132000 \\
40900 \\
16900 \\
8050 \\
5870 \\
3740\end{array}$ & $\begin{array}{r}1970 \\
1720 \\
2210 \\
=- \\
--\end{array}$ & $\begin{array}{r}170 \\
144 \\
236 \\
-- \\
-- \\
--\end{array}$ & $\begin{array}{r}904 \\
669 \\
1410 \\
- \\
-\end{array}$ & $\begin{array}{l}2030 \\
2190 \\
2560 \\
2830 \\
2830 \\
2840\end{array}$ & $\begin{array}{l}266 \\
330 \\
362 \\
372 \\
298 \\
311\end{array}$ & $\begin{array}{l}1460 \\
1950 \\
2500 \\
2840 \\
2280 \\
2380\end{array}$ \\
\hline TOTAL & 221430 & -- & 2158752 & 119940 & -- & 550169 & 61678 & -- & 40702 \\
\hline
\end{tabular}

APRIL MAY JUNE

\begin{tabular}{|c|c|c|c|c|c|c|c|c|c|}
\hline DAY & $\begin{array}{l}\text { MEAN } \\
\text { DI SCHARGE } \\
\text { |CFS I }\end{array}$ & $\begin{array}{l}\text { MEAN } \\
\text { CONCEN- } \\
\text { TRATION } \\
\text { (MG } / L)\end{array}$ & $\begin{array}{l}\text { SEDIMENT } \\
\text { DI SCHARGE } \\
\text { (TONS/DAY) }\end{array}$ & $\begin{array}{l}\text { MEAN } \\
\text { DISCHARGE } \\
\text { (CFS) }\end{array}$ & $\begin{array}{l}\text { MEAN } \\
\text { CONCEN- } \\
\text { TRATION } \\
\text { (MGIL) }\end{array}$ & $\begin{array}{l}\text { SEDIMENT } \\
\text { DISCHARGE } \\
\text { (TONS / DAY) }\end{array}$ & $\begin{array}{l}\text { MEAN } \\
\text { OISCHARGE } \\
\text { (CFS) }\end{array}$ & $\begin{array}{l}\text { MEAN } \\
\text { CONCEN- } \\
\text { TRATION } \\
\text { (MG/L) }\end{array}$ & $\begin{array}{l}\text { SEDIMENT } \\
\text { DISCHARGE } \\
\text { (TONS/DAY) }\end{array}$ \\
\hline $\begin{array}{l}1 \\
2 \\
3 \\
4 \\
5\end{array}$ & $\begin{array}{l}2430 \\
2010 \\
1840 \\
1530 \\
2010\end{array}$ & $\begin{array}{l}229 \\
193 \\
169 \\
124 \\
221\end{array}$ & $\begin{array}{r}1500 \\
1050 \\
840 \\
512 \\
1200\end{array}$ & $\begin{array}{r}1190 \\
1040 \\
925 \\
860 \\
794\end{array}$ & $\begin{array}{l}37 \\
41 \\
42 \\
45 \\
61\end{array}$ & $\begin{array}{l}119 \\
115 \\
105 \\
104 \\
131\end{array}$ & $\begin{array}{l}252 \\
199 \\
185 \\
173 \\
175\end{array}$ & $\begin{array}{l}7 \\
7 \\
7 \\
7 \\
8\end{array}$ & $\begin{array}{l}4.8 \\
3.8 \\
3.5 \\
3.3 \\
3.8\end{array}$ \\
\hline $\begin{array}{r}6 \\
7 \\
8 \\
9 \\
10\end{array}$ & $\begin{array}{l}2120 \\
1790 \\
1540 \\
1460 \\
1430\end{array}$ & $\begin{array}{r}154 \\
122 \\
101 \\
89 \\
92\end{array}$ & $\begin{array}{l}881 \\
590 \\
420 \\
351 \\
355\end{array}$ & $\begin{array}{l}806 \\
890 \\
939 \\
812 \\
715\end{array}$ & $\begin{array}{l}68 \\
67 \\
66 \\
66 \\
65\end{array}$ & $\begin{array}{l}148 \\
161 \\
167 \\
145 \\
125\end{array}$ & $\begin{array}{l}173 \\
171 \\
175 \\
173 \\
169\end{array}$ & $\begin{array}{r}15 \\
9 \\
7 \\
6 \\
6\end{array}$ & $\begin{array}{l}7.0 \\
4.2 \\
3.3 \\
2.8 \\
2.7\end{array}$ \\
\hline $\begin{array}{l}11 \\
12 \\
13 \\
14 \\
15\end{array}$ & $\begin{array}{l}1320 \\
1360 \\
1320 \\
1150 \\
1030\end{array}$ & $\begin{array}{l}86 \\
78 \\
71 \\
69 \\
80\end{array}$ & $\begin{array}{l}307 \\
286 \\
253 \\
214 \\
222\end{array}$ & $\begin{array}{l}743 \\
721 \\
704 \\
650 \\
565\end{array}$ & $\begin{array}{l}61 \\
53 \\
46 \\
39 \\
33\end{array}$ & $\begin{array}{r}127 \\
103 \\
87 \\
68 \\
50\end{array}$ & $\begin{array}{l}175 \\
167 \\
157 \\
144 \\
109\end{array}$ & $\begin{array}{l}6 \\
5 \\
5 \\
4 \\
4\end{array}$ & $\begin{array}{l}2.8 \\
2.3 \\
2.1 \\
1.6 \\
1.2\end{array}$ \\
\hline $\begin{array}{l}16 \\
17 \\
18 \\
19 \\
20\end{array}$ & $\begin{array}{r}939 \\
925 \\
1250 \\
1090 \\
925\end{array}$ & $\begin{array}{r}92 \\
114 \\
131 \\
66 \\
52\end{array}$ & $\begin{array}{l}233 \\
285 \\
442 \\
194 \\
130\end{array}$ & $\begin{array}{l}565 \\
560 \\
488 \\
470 \\
406\end{array}$ & $\begin{array}{l}28 \\
24 \\
21 \\
18 \\
16\end{array}$ & $\begin{array}{l}43 \\
36 \\
28 \\
23 \\
18\end{array}$ & $\begin{array}{r}79 \\
60 \\
53 \\
65 \\
133\end{array}$ & $\begin{array}{l}5 \\
5 \\
5 \\
6 \\
7\end{array}$ & $\begin{array}{l}1.1 \\
.81 \\
.72 \\
1.1 \\
2.5\end{array}$ \\
\hline $\begin{array}{l}21 \\
22 \\
23 \\
24 \\
25\end{array}$ & $\begin{array}{r}836 \\
842 \\
1130 \\
2410 \\
2140\end{array}$ & $\begin{array}{r}53 \\
60 \\
166 \\
434 \\
168\end{array}$ & $\begin{array}{r}120 \\
136 \\
506 \\
2820 \\
971\end{array}$ & $\begin{array}{l}394 \\
363 \\
346 \\
325 \\
316\end{array}$ & $\begin{array}{l}14 \\
13 \\
13 \\
12 \\
13\end{array}$ & $\begin{array}{l}15 \\
13 \\
12 \\
11 \\
11\end{array}$ & $\begin{array}{r}106 \\
84 \\
73 \\
72 \\
72\end{array}$ & $\begin{array}{l}6 \\
6 \\
4 \\
2 \\
2\end{array}$ & $\begin{array}{r}1.7 \\
1.4 \\
.79 \\
.39 \\
.39\end{array}$ \\
\hline $\begin{array}{l}26 \\
27 \\
28 \\
29 \\
30 \\
31\end{array}$ & $\begin{array}{r}1840 \\
1660 \\
1530 \\
1470 \\
1320 \\
-0\end{array}$ & $\begin{array}{l}90 \\
85 \\
73 \\
88 \\
52 \\
--\end{array}$ & $\begin{array}{r}447 \\
381 \\
302 \\
349 \\
185 \\
--\end{array}$ & $\begin{array}{l}325 \\
422 \\
336 \\
310 \\
301 \\
295\end{array}$ & $\begin{array}{r}15 \\
19 \\
12 \\
6 \\
6 \\
7\end{array}$ & $\begin{array}{l}13 \\
22 \\
11 \\
5.0 \\
4.9 \\
5.6\end{array}$ & $\begin{array}{l}75 \\
68 \\
64 \\
60 \\
64 \\
-6\end{array}$ & $\begin{array}{r}3 \\
2 \\
2 \\
3 \\
3 \\
--\end{array}$ & $\begin{array}{r}.61 \\
.37 \\
.35 \\
.49 \\
.52 \\
.--\end{array}$ \\
\hline TOTAL & 44647 & - & 16482 & 18576 & -- & 2021.5 & 3725 & -- & 62.44 \\
\hline
\end{tabular}


11481000 MAD RIVER NEAR ARCATA, CALIF,--Cont 1nued SUSPENDED-SEDIMENT DISCHARGE, WATER YEAR DCTOBER 1968 TO SEPTEMBER 1969

\begin{tabular}{|c|c|c|c|c|c|c|c|c|c|}
\hline \multirow[b]{2}{*}{ DAY } & \multicolumn{3}{|c|}{ JULY } & \multicolumn{3}{|c|}{ AUGUST } & \multicolumn{3}{|c|}{ SEP JEMBER } \\
\hline & $\begin{array}{l}\text { MEAN } \\
\text { OISCHARGE } \\
\text { (CFS) }\end{array}$ & $\begin{array}{l}\text { MEAN } \\
\text { CONCEN- } \\
\text { TRATIUN } \\
\text { (MG/L) }\end{array}$ & $\begin{array}{l}\text { SEDIMENT } \\
\text { DISCHARGE } \\
\text { (TDNS/DAY) }\end{array}$ & $\begin{array}{l}\text { MEAN } \\
\text { DISCHARGE } \\
\text { (CFS) }\end{array}$ & $\begin{array}{l}\text { MEAN } \\
\text { CONCEN- } \\
\text { TRATION } \\
\text { (MG/L) }\end{array}$ & $\begin{array}{l}\text { SEDIMENT } \\
\text { DISCHARGE } \\
\text { (TONS/DAY) }\end{array}$ & $\begin{array}{l}\text { MEAN } \\
\text { DISCHARGE } \\
\text { (CFS) }\end{array}$ & $\begin{array}{l}\text { MEAN } \\
\text { CONCEN- } \\
\text { IRAIION } \\
\text { (MG/L) }\end{array}$ & $\begin{array}{l}\text { SEDIMENT } \\
\text { DISCHARGE } \\
\text { (TONS/DAY) }\end{array}$ \\
\hline 1 & 74 & 3 & .60 & 52 & 5 & .70 & 39 & 3 & .32 \\
\hline 2 & 72 & 4 & .78 & 55 & 4 & .59 & 37 & 3 & .30 \\
\hline 3 & 73 & 3 & .59 & 54 & 4 & .58 & 34 & 3 & .28 \\
\hline 4 & 110 & 3 & .89 & 50 & 4 & .54 & 24 & 3 & .29 \\
\hline 5 & 98 & 3 & .79 & 52 & 4 & .56 & 21 & 3 & .17 \\
\hline 6 & 74 & 3 & .60 & 48 & 3 & .39 & 20 & 4 & .22 \\
\hline 7 & 49 & 3 & .40 & 49 & 2 & .26 & 23 & 4 & .25 \\
\hline \& & 38 & 3 & .31 & $4 B$ & 3 & .39 & 26 & 3 & .21 \\
\hline 9 & 39 & 3 & .32 & 49 & 5 & .66 & 27 & 3 & .22 \\
\hline 10 & 40 & 3 & .32 & 52 & 3 & .42 & 32 & 3 & .26 \\
\hline 11 & 39 & 4 & .42 & 49 & 2 & .26 & 32 & 3 & .26 \\
\hline 12 & 45 & 4 & .49 & 49 & 2 & .26 & 33 & 3 & .27 \\
\hline 13 & 47 & 4 & .51 & 48 & 2 & .26 & 37 & 3 & .30 \\
\hline 14 & 38 & 4 & .41 & 44 & 2 & .24 & 35 & 3 & .28 \\
\hline 15 & 30 & 5 & .41 & 40 & 2 & .22 & 33 & 3 & .27 \\
\hline 16 & 20 & 6 & .32 & 41 & 2 & .22 & 24 & 4 & .26 \\
\hline 17 & 17 & 5 & .23 & 42 & 2 & .23 & 18 & 7 & .34 \\
\hline is & 23 & 5 & .31 & 39 & 3 & .32 & 24 & 6 & .39 \\
\hline 19 & 41 & 5 & .55 & 40 & 15 & 1.6 & 53 & 5 & .72 \\
\hline 20 & 44 & 5 & .59 & 37 & 8 & .80 & 53 & 4 & .57 \\
\hline 21 & 41 & 5 & .55 & 39 & 3 & .32 & 51 & 4 & .55 \\
\hline 22 & 39 & 5 & .53 & 38 & 3 & .31 & 46 & 4 & .50 \\
\hline 23 & 56 & 5 & .76 & 37 & 3 & .30 & 44 & 3 & .36 \\
\hline 24 & 53 & 9 & 1.3 & 39 & 3 & .32 & 37 & 4 & .40 \\
\hline 25 & 49 & 6 & .79 & 35 & 2 & .19 & 32 & 10 & .86 \\
\hline 26 & 51 & 4 & .55 & 37 & 3 & .30 & 29 & 8 & .63 \\
\hline 27 & 50 & 5 & .68 & 36 & 4 & .39 & 30 & 6 & .49 \\
\hline 28 & 49 & 5 & .66 & 35 & 5 & .47 & 32 & 5 & .43 \\
\hline 29 & 48 & 4 & .52 & 38 & 6 & .62 & 28 & 3 & .23 \\
\hline 30 & 45 & 4 & .49 & 38 & 4 & .41 & 27 & 3 & .22 \\
\hline 31 & 46 & 4 & .50 & 35 & 2 & .19 & - & - & $\rightarrow$ \\
\hline IUTAL & $153 \mathrm{~B}$ & -- & 17.17 & 1345 & -- & 13.32 & 981 & 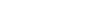 & 10.75 \\
\hline $\begin{array}{l}\text { TUTAL } \\
\text { TOTAL }\end{array}$ & $\begin{array}{l}\text { DISCHARGE } \\
\text { SUSPENDED - }\end{array}$ & $\begin{array}{l}\text { DR YEAR } \\
\text { EDIMENT }\end{array}$ & $\begin{array}{l}\text { (CFS-OAYS) } \\
\text { DISCHARGE FOR }\end{array}$ & 侸 & & & & & $\begin{array}{c}638328 \\
3273507.25\end{array}$ \\
\hline
\end{tabular}

PARTICLE-SIZE DISTRIBUTIDN OF SUSPENDED SEDIMENT, WATER YEAR OCTOBER 1968 TO SEPTEMBER 1969
(METHODS OF ANALYSIS:
B. BOTIOM WITHDRAWAL TUBE: C, CHEMICALLY DISPERSEO: N, IN NATIVE WATER: P, PIPET: S, SIEVE; $\checkmark$, VISUAL ACCUMULATION TUBE; W, IN DISTILLED WATER)

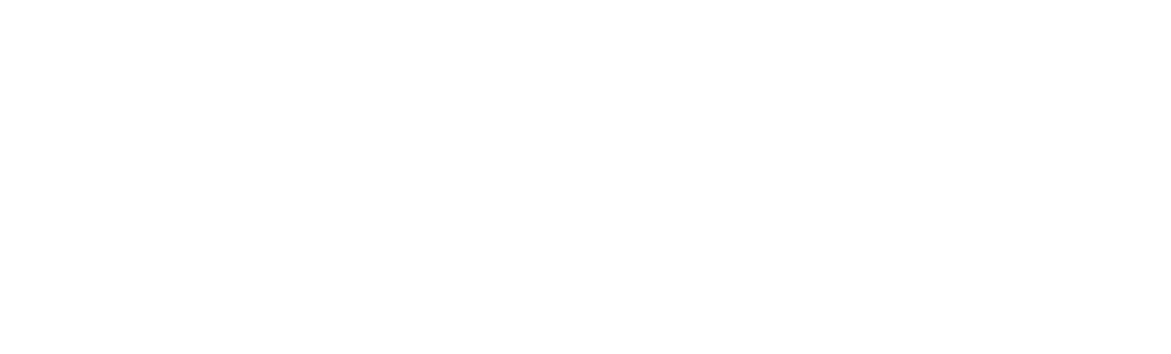




\section{REDWOOD CREEK AT ORICK, CALIF,}

LOCAT ION, -Lat $41^{\circ} 17^{\prime} 20^{\prime \prime}$, long $124^{\circ} 03^{\prime} 30^{\prime \prime}$, in NE sec.4, T.10 N., R. 1 E., Humboldt County, temperature recorder at gaging station on pier of bridge on U.S. Highway $10 \mathrm{i}$ at Órick, 0.9 mile downstream from Pra1rie Creek.

DRAI NAGE AREA. $--278 \mathrm{sq} \mathrm{m}$.

PERIOD OF RECORD. --Chemical analyses: November 1958 to September 1966.

Water temperatures: October 1965 to September 1969.

EXTREMES, -- Period of record (1966-68).

Water temperatures: Minimum, 1.0 $\mathrm{C}$ Dec. 14, 1967.

REMARKS. --Recorder stopped Dec. 21 to Feb. 10; probe buried Mar. 7-26, July 3 to Aug. 6.

TEMPERATURE $\left({ }^{\circ} \mathrm{C}\right)$ OF WATER, WATER YEAR OCTOBER 1968 TO SEPTEMBER 1969

DAY

MUNTH

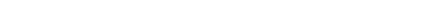

OC TOBED

MAXIMUM 18 18 $16 \quad 16 \quad 16 \quad 17 \quad 16 \quad 16 \quad 16 \quad 15 \quad 14 \quad 15 \quad 15 \quad 14 \quad 14 \quad 16 \quad 16 \quad 16 \quad 15 \quad 16 \quad 15 \quad 16 \quad 16 \quad 16 \quad 16 \quad 16 \quad 16 \quad 14 \quad 1515 \quad 14$ MINIMUM 15 14 $14 \begin{array}{lllllllllllllllllllllllllllll}14 & 13 & 12 & 12 & 12 & 14 & 13 & 13 & 12 & 12 & 12 & 13 & 13 & 13 & 12 & 13 & 12 & 12 & 13 & 13 & 13 & 13 & 13 & 13 & 13 & 12 & 12\end{array}$ MINIMUM

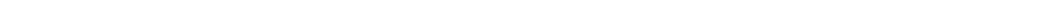

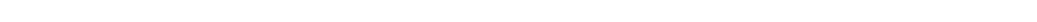
DECEMARE

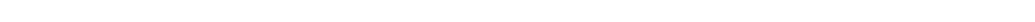
MINIMUM JANUARY

MAXIMUM MINIMIJM -

FFRRUARY

MAXIMUM -MINIMUM -... - MPC.

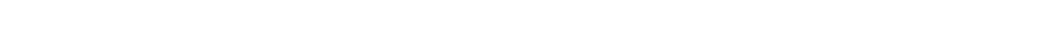

$\triangle P Q I L$

$\begin{array}{lllllllllllllllllllllllllllllllllllllll}\text { MAXIMUM } & 12 & 12 & 12 & 12 & 12 & 12 & 12 & 12 & 12 & 12 & 11 & 11 & 11 & 11 & 11 & 11 & 11 & 11 & 12 & 11 & 11 & 11 & 11 & 11 & 11 & 11 & 11 & 11 & 11 & 11 & -- \\ \text { MINIMUM } & 12 & 12 & 12 & 12 & 12 & 12 & 12 & 12 & 12 & 11 & 11 & 11 & 11 & 11 & 11 & 11 & 11 & 11 & 11 & 11 & 11 & 11 & 11 & 11 & 11 & 11 & 11 & 11 & 11 & 11 & -\end{array}$ MAY MINIMUM

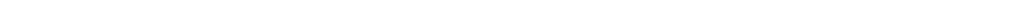

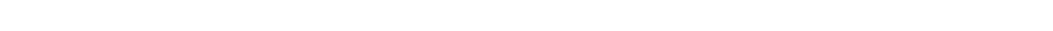
JUNE

$\begin{array}{lllllllllllllllllllllllllllllllllll}\text { MAXIMUM } & 13 & 13 & 13 & 13 & 13 & 14 & 14 & 14 & 14 & 14 & 14 & 14 & 15 & 15 & 15 & 15 & 15 & 15 & 15 & 15 & 15 & 15 & 15 & 15 & 15 & 16 & 17 & 17 & 17 & 17 & -1\end{array}$

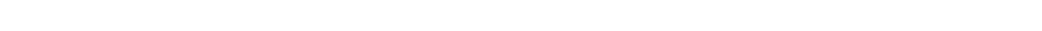
JuLY

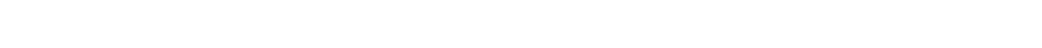
AUGUST

MAXIMUA --

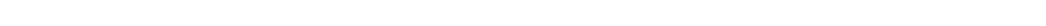

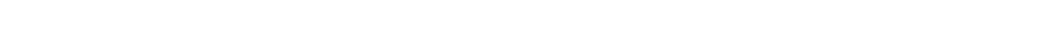

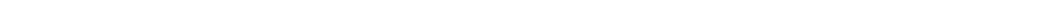


11492200 CRATER LAKE NEAR CRATER LAKE, OREG.
(Hydrologic bench-mark station)

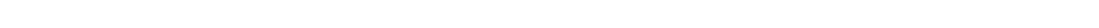
Klamath County, temperature recorder at gaging station at boat harbor at end of trail in Cleatwood Cove, 6 miles northeast of Crater Lake Post office.

DRAINAGE AREA. $-26.2 \mathrm{sq} \mathrm{mi}$, of which $20.5 \mathrm{sq} \mathrm{ml}$ is lake area at olevation $6,176 \mathrm{ft}$.

PERIOD OF RECORD. --Chemical analyses: October 1963 to September 1965, October 1966 to September 1969 (m1sce1laneous).

Water temperatures: October 1963 to September 1969.

EXTREMES, $--1968-69$ :

Water temperatures: Maximum, $15.0^{\circ} \mathrm{C}$ on several days in August; minimum, $1.0^{\circ} \mathrm{C}$ on many days during February to April.

Period of record: Water temperatures: Maximum, $18.0^{\circ} \mathrm{C}$ on several days during August and September 1967; minimum (1963-64,
$1965-69), 1.0^{\circ} \mathrm{C}$ on many days during February to April 1969.

CHEMICAL ANALYSES, WATER YEAR OCYOBER 1968 TO SEPTEMBER 1969

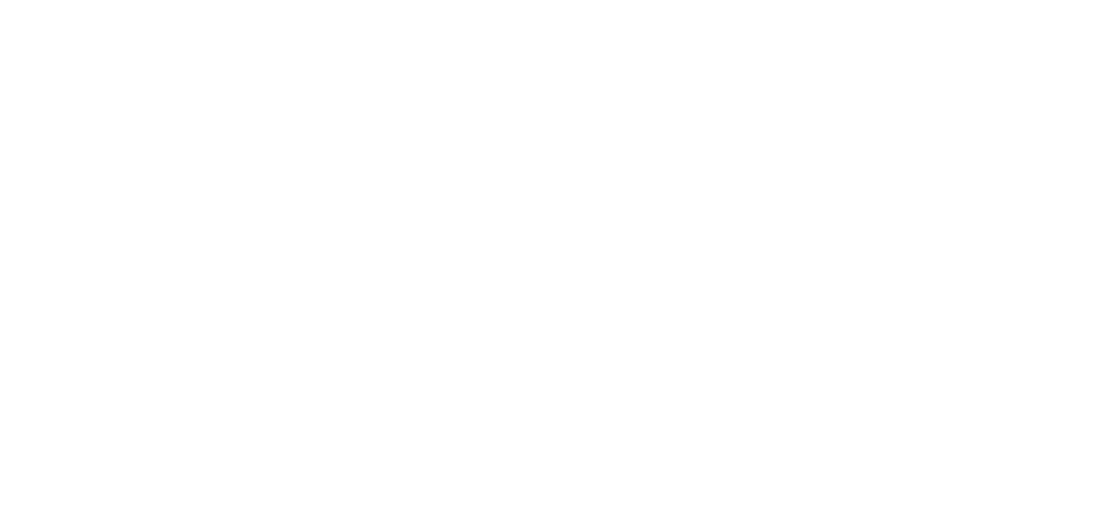

ANALYSES OF ADDITIONAL SAMPLES

\begin{tabular}{|c|c|c|c|c|c|c|c|}
\hline UAIE & $\begin{array}{l}\text { TOTAL } \\
\text { IKLV } \\
\text { (FE) } \\
(U G / L)\end{array}$ & $\begin{array}{l}\text { TOIAL } \\
\text { ALUM- } \\
\text { IAUM } \\
\text { (ALL) } \\
\text { (UG/L) }\end{array}$ & $\begin{array}{l}\text { TCTAL } \\
\text { MAN- } \\
\text { GANESE } \\
\text { (MNI } \\
\text { (UG/L) }\end{array}$ & $\begin{array}{l}\text { TUTAL } \\
\text { CHIRU- } \\
\text { *IUM } \\
\text { (CR) } \\
\text { (UG/L) }\end{array}$ & $\begin{array}{l}\text { NICKEL } \\
\text { (NI) } \\
\text { (UG/L) }\end{array}$ & $\begin{array}{l}\text { COPPEK } \\
(C U) \\
(U S, L)\end{array}$ & $\begin{array}{l}Z(N C) \\
(Z N) \\
(U G / L)\end{array}$ \\
\hline $\begin{array}{l}\text { JUL Y } \\
22 \ldots\end{array}$ & 0 & 0 & 0 & 2 & 13 & 0 & 0 \\
\hline UATE & $\begin{array}{l}\text { LEAD } \\
(P B) \\
\{\cup G / L\}\end{array}$ & $\begin{array}{c}\text { ARSEIVIC } \\
\text { (AS) } \\
\text { (UG/L) }\end{array}$ & $\begin{array}{l}\text { COBALT } \\
(\text { CO) } \\
(U G / L)\end{array}$ & $\begin{array}{l}\text { JAKI UM } \\
(O A) \\
(U G / L)\end{array}$ & $\begin{array}{l}\text { CALE } \\
M(U M \\
(C D) \\
(U G / L)\end{array}$ & $\begin{array}{l}\text { SILVEK } \\
(A G) \\
(U G / L)\end{array}$ & $\begin{array}{l}\text { STRUN- } \\
\text { IIUM } \\
\text { ISR } \\
\text { IUG/LI }\end{array}$ \\
\hline & 11 & 20 & 2 & 0 & 2 & 1 & 60 \\
\hline
\end{tabular}


11492200 chater laKe near crateb lake, obeg.--Continued ANALYSES OF ADDITI ONAL BANDLES DISSOLVED

$\begin{array}{cccccc}\text { DATE } & \begin{array}{c}\text { URANIUM } \\ (U G / L)\end{array} & \begin{array}{c}\text { RADIUM } \\ (\mathrm{PC} / \mathrm{L})\end{array} & \begin{array}{c}\text { GROSS } \\ (\mathrm{UG} U / \mathrm{L})\end{array} & \begin{array}{l}\text { GROSS } \\ (\mathrm{PC} / \mathrm{L})\end{array} & \begin{array}{c}\text { TOTAL } \\ \text { D1S8OLVED } \\ \text { SOLIDS } \\ (\mathrm{MG} / \mathrm{L})\end{array} \\ \text { O2... } & .01 & .05 & <.4 & 2.4 & 78\end{array}$

TELPERATURE ('C) OP WATER, WATER YEAR OCTOBER 1968 TO SEPTELBER 1969

DaY

MONTH

OCTBBER

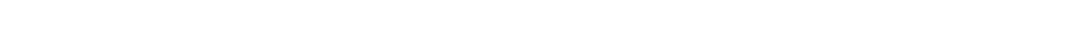

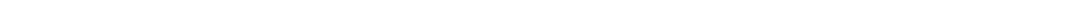

MAXIMUM

MINIMUM

MAXIMUM

MINIMUM

MAXIMUM

MINIMUU

FEBRUARY

MAXIMUM

MIN NM

MAXIMUM

MINIMUM

MAXIMUM

MAXIMUM

MINIMUM

UNE

MAXIMUM
MINIMUM

JulY

MAX I MUM

MINIMUM

AUGUST

MAXIMUM

MINIMUM
SEPIEMBER

MAXIMUM

MAXI MUM $\begin{array}{llllllllllllllllllllllllllllllll}7 & 7 & 7 & 7 & 7 & 7 & 7 & 7 & 7 & 7 & 7 & 6 & 6 & 6 & 6 & 6 & 6 & 6 & 6 & 6 & 6 & 6 & 6 & 6 & 6 & 6 & 5 & 5 & 5 & 5 & - & 6 \\ 7 & 7 & 7 & 7 & 7 & 7 & 7 & 7 & 7 & 7 & 6 & 6 & 6 & 6 & 6 & 6 & 6 & 6 & 6 & 6 & 6 & 6 & 6 & 6 & 6 & 5 & 5 & 5 & 5 & 5 & -2 & 6\end{array}$ $\begin{array}{llllllllllllllllllllllllllllllll}5 & 5 & 5 & 5 & 5 & 5 & 5 & 5 & 4 & 4 & 4 & 4 & 4 & 4 & 4 & 4 & 4 & 4 & 4 & 4 & 3 & 3 & 3 & 3 & 3 & 3 & 3 & 3 & 3 & 3 & 3 & 4\end{array}$ $\begin{array}{lllllllllllllllllllllllllllllllll}3 & 3 & 3 & 3 & 3 & 3 & 3 & 3 & 3 & 3 & 3 & 3 & 3 & 3 & 3 & 3 & 3 & 2 & 2 & 2 & 2 & 2 & 2 & 2 & 2 & 2 & 2 & 2 & 2 & 2 & 2 & 2 \\ 3 & 3 & 3 & 3 & 3 & 3 & 3 & 3 & 3 & 3 & 3 & 3 & 3 & 3 & 3 & 3 & 2 & 2 & 2 & 2 & 2 & 2 & 2 & 2 & 2 & 2 & 2 & 2 & 2 & 2 & 2 & 2\end{array}$

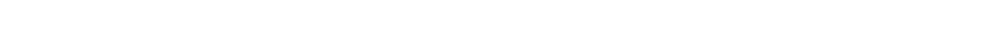
$\begin{array}{lllllllllllllllllllllllllllllllll}1 & 1 & 1 & 1 & 1 & 1 & 1 & 1 & 1 & 1 & 1 & 1 & 1 & 1 & 1 & 1 & 1 & 1 & 1 & 1 & 1 & 1 & 1 & 1 & 1 & 1 & 1 & 1 & 1 & 1 & 1 & 1 \\ 1 & 1 & 1 & 1 & 1 & 1 & 1 & 1 & 1 & 1 & 1 & 1 & 1 & 1 & 1 & 1 & 1 & 1 & 1 & 1 & 1 & 1 & 1 & 1 & 1 & 1 & 1 & 1 & 1 & 1 & 1 & 1 & 1\end{array}$ $\begin{array}{lllllllllllllllllllllllllllllllllllll}1 & 1 & 1 & 2 & 2 & 2 & 2 & 2 & 2 & 2 & 2 & 2 & 2 & 2 & 2 & 2 & 2 & 2 & 2 & 2 & 2 & 2 & 3 & 3 & 3 & 3 & 3 & 3 & 3 & 3 & -- & 2 \\ 1 & 1 & 1 & 1 & 2 & 2 & 2 & 2 & 2 & 2 & 2 & 2 & 2 & 2 & 2 & 2 & 2 & 2 & 2 & 2 & 2 & 2 & 2 & 3 & 3 & 3 & 3 & 3 & 3 & 3 & -- & 2\end{array}$ $\begin{array}{llllllllllllllllllllllllllllllllll} & 3 & 3 & 3 & 3 & 3 & 3 & 3 & 3 & 3 & 3 & 3 & 3 & 3 & 3 & 3 & 3 & 3 & 3 & 3 & 3 & 3 & 3 & 3 & 3 & 3 & 3 & 3 & 3 & 4 & 4 & & 3\end{array}$ $\begin{array}{lllllllllllllllllllllllllllllllllllllllllll}4 & 4 & 4 & 4 & 4 & 4 & 4 & 4 & 4 & 4 & 4 & 4 & 4 & 4 & 4 & 5 & 5 & 5 & 5 & 6 & 7 & 7 & 7 & 6 & 7 & 7 & 7 & 7 & 7 & 7 & -2 & 5 \\ 4 & 4 & 4 & 4 & 4 & 4 & 4 & 4 & 4 & 4 & 4 & 4 & 4 & 4 & 4 & 4 & 5 & 5 & 5 & 5 & 6 & 7 & 6 & 6 & 6 & 7 & 7 & 7 & 7 & 7 & -2 & 5\end{array}$ $\begin{array}{llllllllllllllllllllllllllllllllllll}7 & 7 & 8 & 8 & 8 & 8 & 8 & 8 & 8 & 10 & 11 & 11 & 11 & 11 & 11 & 10 & 10 & 11 & 11 & 11 & 12 & 12 & 13 & 13 & 13 & 13 & 13 & 13 & 14 & 14 & 14 & 11\end{array}$ $1415151515141313131415151514141414141414 \quad 1414141515151514941414$

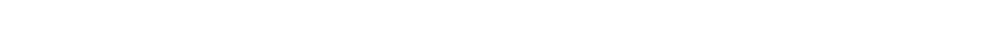

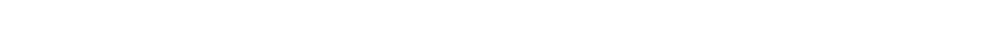


11516530 KLAMATH RIVER BELOW IRON GATE DAM, CALIF.

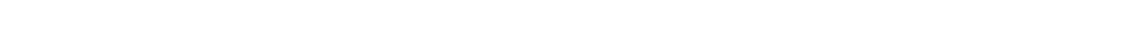
on left bank, $0.1 \mathrm{mile}$ downstream from Bogus Creek, $0.6 \mathrm{mile}$ downstream from Iron Gate Dam, and $5.9 \mathrm{miles}$ nor the ast of Hornbrook.

DRAINAGE AREA, - 4,630 sq mI, approximately (not including Lost River or Lower K1amath Lake basins).

PERIOD OF RECORD. --Chemical analyses: October 1961 to September 1969.

Water temperatures: October 1962 to September 1969.

EXTREMES. - -1968-69:

Water temperatures: Maximum, $22.0^{\circ} \mathrm{C}$ Aug. 4 ; minimum, $1.0^{\circ} \mathrm{C}$ on several days during December to February.

Period of record: Water temperatures: Haximum, $23.0^{\circ} \mathrm{C}$ Aug. 6, 1967; minimum, $1.0^{\circ} \mathrm{C}$ on several days durting January 1965 , and

REMARKS. --Chemical-quality records furnished by California Department of Water Resources and reviewed by U.S. Geological Survey. Thermograph clock stopped Dec. 29 to Jan. 1 ; range in temperature, 4.0 $0^{\circ} \mathrm{C}$ to $5.0^{\circ} \mathrm{C}$

CHEMICAL ANALYSES, WATER YEAR OCTOBER 1968 TO SEPTEMBER 1969

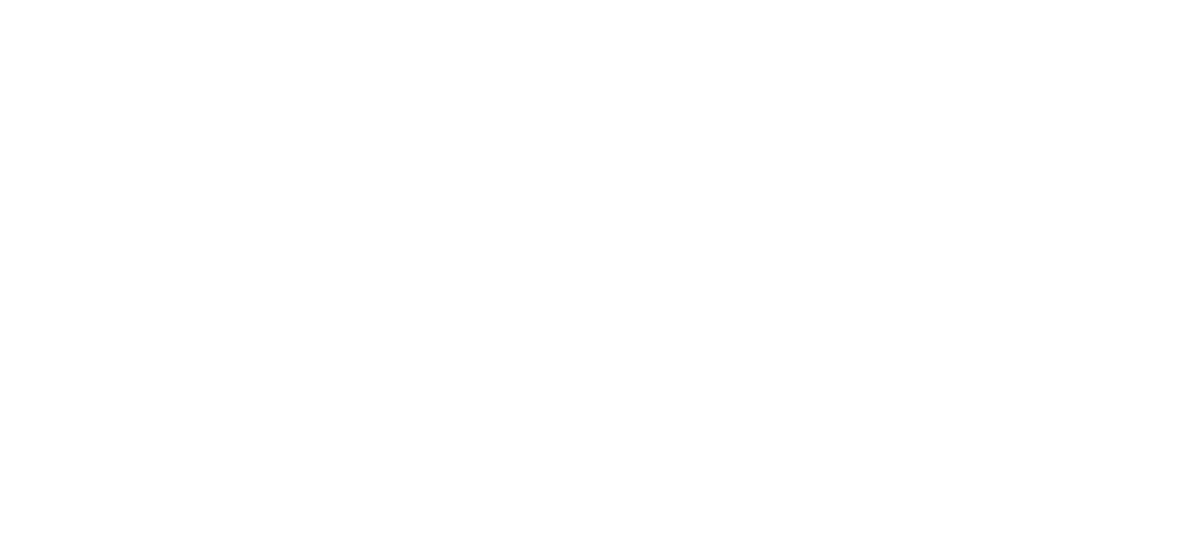

\begin{tabular}{|c|c|c|c|c|c|c|c|c|c|c|c|}
\hline DATE & $\begin{array}{l}\text { PHOS- } \\
\text { PHATE } \\
\text { (PO4) } \\
\text { (MG/L) }\end{array}$ & $\begin{array}{l}\text { BORON } \\
\text { (B) } \\
\text { (UG/L) }\end{array}$ & $\begin{array}{l}\text { CIS- } \\
\text { SGLVED } \\
\text { SOLIOS } \\
\text { RRESI- } \\
\text { DUE AT } \\
\text { LBO CI } \\
\text { SMGLL) }\end{array}$ & $\begin{array}{l}\text { OIS- } \\
\text { SOLVED } \\
\text { SOLIDS } \\
\text { STONS } \\
\text { PER } \\
\text { AC-FT, }\end{array}$ & $\begin{array}{l}\text { HARD- } \\
\text { NESS } \\
(C A, M G) \\
(M G / L)\end{array}$ & $\begin{array}{l}\text { NON- } \\
\text { CAR- } \\
\text { BONATE } \\
\text { HARD- } \\
\text { NESS } \\
\text { (MG/L) }\end{array}$ & $\begin{array}{l}\text { PERCENT } \\
\text { SOOIUM }\end{array}$ & $\begin{array}{l}\text { SOOIUM } \\
\text { AD- } \\
\text { SORP- } \\
\text { TION } \\
\text { RATIO }\end{array}$ & $\begin{array}{l}\text { ALKA- } \\
\text { LINITY } \\
\text { AS } \\
\text { CACO3 } \\
\text { (MG/L) }\end{array}$ & $\begin{array}{c}P H \\
\text { (UNI TSI }\end{array}$ & $\begin{array}{l}\text { SPECI- } \\
\text { FIC } \\
\text { COND- } \\
\text { UC IANE } \\
\text { IMICRO- } \\
\text { MHOSI }\end{array}$ \\
\hline OCT. & .74 & 120 & -- & - & 85 & 0 & 39 & 1.2 & 92 & 8.1 & 259 \\
\hline $13 \ldots$ & .68 & 70 & -- & -- & 78 & 0 & 36 & 1.0 & 78 & B.1 & 209 \\
\hline $10 . .$. & .81 & 100 & -- & -- & 77 & 0 & 42 & 1.3 & 91 & 7.9 & 262 \\
\hline $\begin{array}{l}\text { JAN. } \\
20 . . .\end{array}$ & .69 & 0 & -- & -- & 64 & 0 & 32 & .8 & 67 & 7.5 & 170 \\
\hline FEB. & .57 & 10 & - & -- & 74 & 0 & 37 & 1.0 & 78 & 7.5 & 218 \\
\hline $\begin{array}{l}\text { MAR. } \\
10 . . .\end{array}$ & .53 & 50 & -- & -- & 79 & 0 & 34 & .9 & 81 & 7.5 & 240 \\
\hline $\begin{array}{l}\text { APR. } \\
08 . . . \\
\text { MAY }\end{array}$ & .74 & 0 & - & $=$ & 62 & 0 & 36 & .9 & 62 & 1.2 & 198 \\
\hline JIINE & .28 & 50 & 133 & .18 & 54 & 0 & 37 & .9 & 59 & 7.4 & 178 \\
\hline $09 . .$. & .37 & 100 & -- & -- & 51 & 0 & 39 & .9 & 62 & 7.9 & 168 \\
\hline $07 . .$. & -- & 20 & -- & - & 62 & 0 & 33 & .8 & 62 & 8.4 & 174 \\
\hline $\begin{array}{l}A 2 \\
12 \ldots \\
S E P\end{array}$ & -- & 170 & - & -- & 82 & 0 & 43 & 1.3 & 90 & 8.2 & 279 \\
\hline $15 \ldots$ & -- & 80 & 158 & .21 & 73 & 0 & 38 & 1.1 & 81 & 8.3 & 247 \\
\hline
\end{tabular}


21516530 KLAMATH RIVER BELOW IRON GATE DAM, CALIF.--Continued

TEMPERATURE $\left({ }^{\circ} \mathrm{C}\right)$ OF WATER, WATER YEAR OCTOBER 1968 TO SEPTEMBER 1969

$$
\text { DAY }
$$

MONTH

OCTOBFR

MAXIMUM $16 \quad 16 \quad 16 \quad 16 \quad 16 \quad 16 \quad 16 \quad 16 \quad 16 \quad 15 \quad 15 \quad 14 \quad 14 \quad 14 \quad 14 \quad 14 \quad 14 \quad 14 \quad 14 \quad 13 \quad 13 \quad 13 \quad 13 \quad 12 \quad 13 \quad 13 \quad 12 \quad 12 \quad 12 \quad 11 \quad 11 \quad 14$

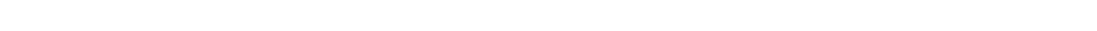

MAXIMUA

$\begin{array}{llllllllllllllllllllllllllllllllllllll}\text { MAXIMUM } & 11 & 11 & 11 & 11 & 11 & 11 & 11 & 11 & 11 & 11 & 10 & 10 & 10 & 10 & 10 & 10 & 10 & 10 & 10 & 10 & 10 & 10 & 9 & 9 & 8 & 8 & 8 & 8 & 8 & 8 & -- & 10 \\ \text { MINIMUM } & 11 & 11 & 11 & 11 & 11 & 11 & 11 & 11 & 11 & 10 & 10 & 10 & 10 & 10 & 10 & 10 & 10 & 10 & 10 & 10 & 10 & 9 & 8 & 8 & 8 & 8 & 8 & 8 & 8 & 8 & -- & 1 C\end{array}$

DECEMBER

MAXIMUM

JANUAHY

$\begin{array}{lllllllllllllllllllllllllllllllll}\text { MAXIMUM } & -- & 4 & 4 & 4 & 4 & 4 & 4 & 4 & 4 & 4 & 4 & 4 & 4 & 3 & 3 & 2 & 2 & 2 & 2 & 2 & 2 & 2 & 2 & 2 & 2 & 2 & 2 & 2 & 2 & 2 & 1 \\ M I N I M U M & -- & 4 & 4 & 4 & 4 & 4 & 4 & 4 & 4 & 4 & 4 & 4 & 3 & 3 & 2 & 2 & 2 & 2 & 2 & 2 & 2 & 2 & 2 & 2 & 2 & 2 & 2 & 2 & 2 & 1 & 1\end{array}$

FFRRUARY

MAXIMUM

MINIMUM

ARCH

MPRIM

MAXIMUM

MaY

MAXIMUM

$\begin{array}{lllllllllllllllllllllllllllllll}1 & 1 & 1 & 1 & 1 & 1 & 1 & 1 & 1 & 2 & 2 & 2 & 2 & 2 & 2 & 2 & 2 & 2 & 2 & 2 & 2 & 3 & 3 & 3 & 3 & 3 & 3 & 3 & \cdots & \cdots & \cdots\end{array}$

$\begin{array}{lllllllllllllllllllllllllllllllll}4 & 4 & 4 & 4 & 4 & 4 & 4 & 4 & 4 & 4 & 4 & 4 & 4 & 4 & 4 & 4 & 4 & 5 & 5 & 5 & 5 & 6 & 6 & 6 & 6 & 6 & 6 & 6 & 6 & 6 & 8\end{array}$

$8 \begin{array}{cccccccccccccccccccccccccccccccc}8 & 8 & 8 & 8 & 8 & 8 & 8 & 8 & 8 & 8 & 8 & 8 & 8 & 8 & 8 & 9 & 9 & 9 & 10 & 10 & 10 & 10 & 10 & 10 & 10 & 10 & 11 & 10 & 11 & 11 & \ldots\end{array}$

$\begin{array}{lllllllllllllllllllllllllllllllllll} & 16 & 16 & 16 & 12 & 12 & 12 & 13 & 14 & 13 & 14 & 14 & 14 & 14 & 14 & 14 & 14 & 14 & 15 & 16 & 16 & 16 & 16 & 16 & 16 & 14 & 16 & 16 & 16 & 18 & 18\end{array}$ Maxin

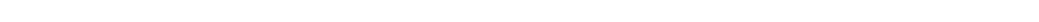
JULY

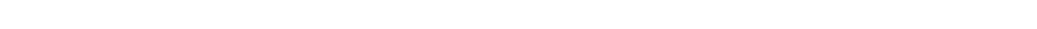

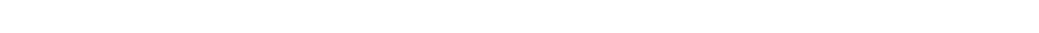
AUGUST

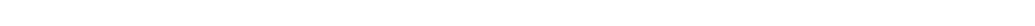

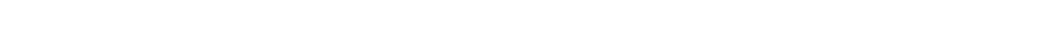
SEPIEMBER

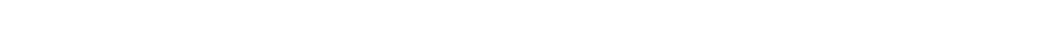

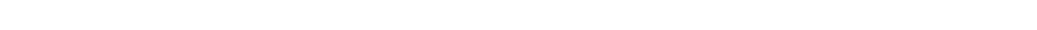


11516600 COTTONWOOD CREEX AT HORNBHOK, CALYY.

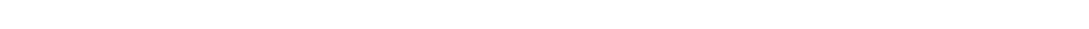
recorder at gaging station on right bank, 0.3 mile upstream from hancheric Gulch and 0.6 mile northwast of Hornbrook.

DRAINAGE AREA. $--89,8 \mathrm{sq} \pi \mathrm{\pi}$,

PERIOD OF RECORD, -- Fater temperatures: October 1964 to September 1969.

EXTREMES. - 1968-69:

Water temperatures: Maximum, $25.0^{\circ} \mathrm{C}$ Aug. 15,21 ; minimum, treezing point on several days during January to March.

Period of record: Water temperatures:

TEMPERATURE (' $\mathrm{C}$ ) OF WATER, WATER YBAR OCTOBER 1968 TO SEPTBMBER 1969

OAY

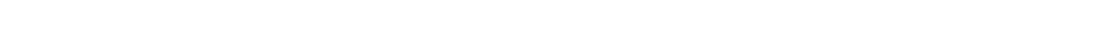

OCTOAER

MAXIMUM $19 \begin{array}{lllllllllllllllllllllllllllllllll}19 & 19 & 18 & 19 & 19 & 17 & 17 & 16 & 17 & 16 & 16 & 16 & 15 & 15 & 16 & 16 & 16 & 14 & 17 & 15 & 16 & 16 & 16 & 15 & 16 & 16 & 14 & 14 & 14 & 14 & 16 \\ \text { MINIMUM } & 16 & 16 & 16 & 16 & 16 & 16 & 14 & 12 & 12 & 13 & 15 & 14 & 13 & 12 & 12 & 12 & 12 & 12 & 11 & 13 & 12 & 12 & 12 & 12 & 12 & 13 & 12 & 16 & 13 & 12 & 11 & 13\end{array}$

NUVEMBER

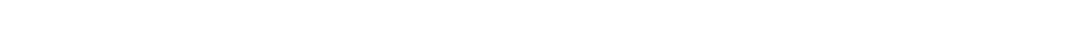

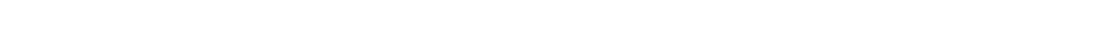

DECEMAER

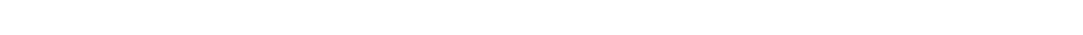

ANUARY

MAXIMUM

MLXINIMUM

MAXIMUM $\begin{array}{llllllllllllllllllllllllllllllll}6 & 6 & 6 & 7 & 7 & 6 & 6 & 8 & 8 & 9 & 5 & 3 & 4 & 4 & 6 & 4 & 3 & 4 & 3 & 2 & 2 & 3 & 3 & 3 & 3 & 3 & 2 & 2 & 1 & 1 & 1 & \end{array}$ $4 \begin{array}{llllllllllllllllllllllllllllll}4 & 5 & 5 & 5 & 6 & 5 & 4 & 2 & 4 & 4 & 4 & 4 & 5 & 4 & 3 & 2 & 2 & 2 & 2 & 4 & 3 & 2 & 1 & 2 & 2 & 2 & 1 & 1 & 1 & 1\end{array}$

MINIMUM

MINIMUM

$\begin{array}{lllllllllllllllllllllllllllllllllllll}4 & 3 & 4 & 2 & 4 & 4 & 4 & 5 & 5 & 6 & 4 & 5 & 4 & 5 & 7 & 6 & 6 & 6 & 6 & 4 & 5 & 5 & 5 & 5 & 6 & 6 & 5 & 5 & -- & \cdots & \cdots\end{array}$

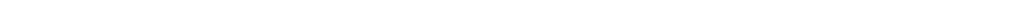

MINIMUM

$\begin{array}{lllllllllllllllllllllllllllllllll} & 4 & 5 & 7 & 7 & 5 & 7 & 6 & 5 & 6 & 6 & 7 & 7 & 7 & 8 & 7 & 7 & 8 & 8 & 6 & 10 & 10 & 9 & 9 & 10 & 11 & 11 & 11 & 9 & 11 & 9 & & \end{array}$

MRIL

MAXIMUM $10 \quad 7 \quad 8 \begin{array}{lllllllllllllllllllllllllllllll} & 9 & 7 & 9 & 11 & 11 & 8 & 12 & 12 & 11 & 10 & 9 & 10 & 11 & 10 & 12 & 12 & 13 & 14 & 12 & 10 & 11 & 12 & 14 & 14 & 14 & 12 & 12 & =-\end{array}$

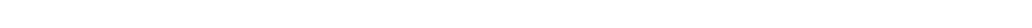

MINIMUM JUNE

MAXIMUM $2 \begin{array}{lllllllllllllllllllllllllllllllll}22 & 23 & 24 & 23 & 22 & 22 & 22 & 18 & 17 & 20 & 21 & 23 & 23 & 23 & 23 & 21 & 23 & 24 & 22 & 22 & 23 & 20 & 19 & 21 & 18 & 18 & 17 & 20 & 21 & 21 & -0\end{array}$

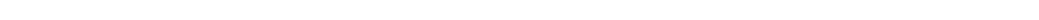
JULY

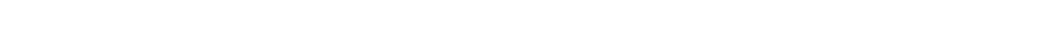

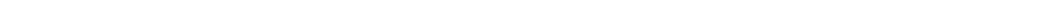
AUGUST

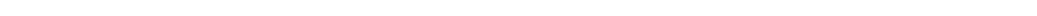

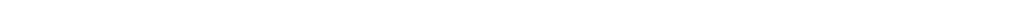

SEPTEMBER

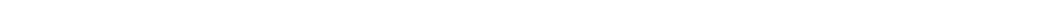

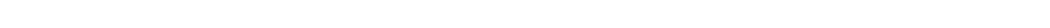
4 
11517500 SHASTA RIVER MRAR YRFKa, CALIF.

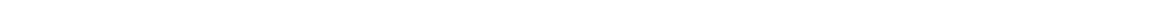
op ripht bank, 0.5 mile upat ream 1 rom mouth and 7 miles north of Yroka.

DRAI NAGE ARZA, --793 a $\mathrm{mi}$.

PRRIOD OP RECORD. - Chemical andy you: December 1958 to September 1969.

Tater temporatureat: June 1985 to Soptember 1969.

EXTREMES, $--1968-68$ :

Water temperaturea: Maximum, $29.0^{\circ} \mathrm{C}$ July 21, 22; minimum, $1.0^{\circ} \mathrm{C}$ sometime during period Jan. 8 to Peb. 3 .

Poriod of rocord:

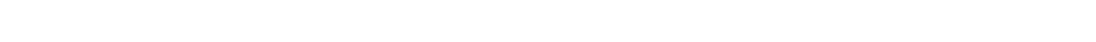

REMARks, - Chomical-quality recorda furnighed by California Department of Water Remources and roviewod by U.s. Geo-

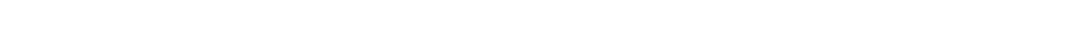
CHEMICAL ANALYSES, WATER yeAR OCTOBER 1968 TO SEPTEMBER 1969

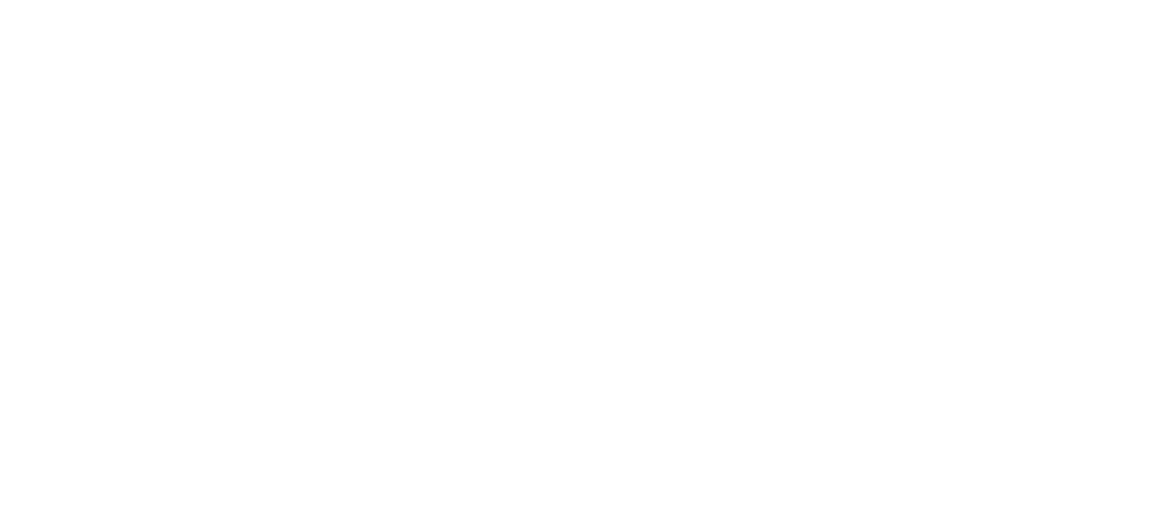

\begin{tabular}{|c|c|c|c|c|c|c|c|c|c|c|c|}
\hline OATE & $\begin{array}{c}\text { NITRATE } \\
\text { (NO3) } \\
\text { (MG/L) }\end{array}$ & $\begin{array}{l}\text { BORON } \\
(B) \\
(U G /)\end{array}$ & $\begin{array}{l}\text { DIS- } \\
\text { SOLVED } \\
\text { SOLIOS } \\
\text { IRESI- } \\
\text { DUE AT } \\
\text { IBO C) } \\
\text { (MG/L) }\end{array}$ & $\begin{array}{l}\text { DIS- } \\
\text { SOLVEO } \\
\text { SOLIDS } \\
\text { ITONS } \\
\text { PER } \\
\text { AC-FU }\end{array}$ & $\begin{array}{l}\text { HARO- } \\
\text { NESS } \\
\text { (CA,MG) } \\
\text { (MG/L) }\end{array}$ & $\begin{array}{l}\text { NON- } \\
\text { CAR- } \\
\text { BONATE } \\
\text { HARD- } \\
\text { NESS } \\
\text { (MG/L) }\end{array}$ & $\begin{array}{l}\text { PERCENT } \\
\text { SODIUM }\end{array}$ & $\begin{array}{l}\text { SOOLUM } \\
\text { AD- } \\
\text { SORP- } \\
\text { TION } \\
\text { RATIO }\end{array}$ & $\begin{array}{l}\text { ALKA- } \\
\text { LINITY } \\
\text { AS } \\
\text { CACO3 } \\
\text { (MG/L) }\end{array}$ & $\begin{array}{c}\text { PH } \\
\text { (UNITS) }\end{array}$ & $\begin{array}{l}\text { SPECI- } \\
\text { FIIC } \\
\text { COND- } \\
\text { UCTANCE } \\
\text { (MICRO- } \\
\text { MHOS) }\end{array}$ \\
\hline ocr. & -- & 500 & -- & - & 251 & 0 & 30 & 1.4 & 298 & B. 5 & 627 \\
\hline $\begin{array}{l}\text { Nov. } \\
13 . . .\end{array}$ & -- & 470 & - & -- & 202 & 0 & 31 & 1.3 & 244 & B.6 & 530 \\
\hline $\begin{array}{l}\text { DEC. } \\
10 . . .\end{array}$ & -- & 470 & - & - & 189 & 0 & 30 & 1.2 & 228 & 8.5 & 497 \\
\hline $\begin{array}{l}\text { JAN. } \\
20 . . .\end{array}$ & -- & 270 & - & -- & 152 & 0 & 27 & .9 & 168 & 8.1 & 392 \\
\hline FEB. & -- & 290 & - & - & 218 & 0 & 22 & .8 & 239 & 8.4 & 516 \\
\hline $\begin{array}{l}\text { MAR. } \\
10 . . .\end{array}$ & -- & 360 & -- & - & 216 & 0 & 23 & .9 & 239 & 8.3 & 513 \\
\hline $\begin{array}{l}A P R . \\
O B . . .\end{array}$ & $\cdots$ & 250 & -- & - & 207 & 0 & 25 & .9 & 234 & 8.0 & 496 \\
\hline $\begin{array}{c}\text { MAY } \\
13 . . .\end{array}$ & .8 & 520 & 307 & .42 & 203 & 0 & 26 & 1.0 & 241 & B.1 & 505 \\
\hline $\begin{array}{l}\text { JUNE } \\
\text { OS.... }\end{array}$ & - & 410 & - & -- & 240 & 0 & 26 & 1.1 & 276 & 8.0 & 554 \\
\hline $\begin{array}{l}\text { JULY } \\
07 . . .\end{array}$ & $=$ & 400 & - & - & 236 & 0 & 4 & .1 & 276 & 8.6 & 558 \\
\hline $\begin{array}{l}\text { AUG. } \\
12 \ldots . .\end{array}$ & - & 600 & -- & -- & 270 & 0 & 29 & 1.3 & 319 & 8.5 & 639 \\
\hline $\begin{array}{l}\text { SEPT: } \\
\text { 15.... }\end{array}$ & 3.8 & 580 & 326 & .46 & 256 & 0 & 29 & 1.4 & 310 & 8.7 & 617 \\
\hline
\end{tabular}


11517500 SHASTA RIVER NEAR YREKA, CALIF.--ContInued

TEMPERATURE $\left({ }^{\circ} \mathrm{C}\right)$ OF WATER, WATER YEAR OCTOBER 1968 TO SEPTEMBER 1969

DAY

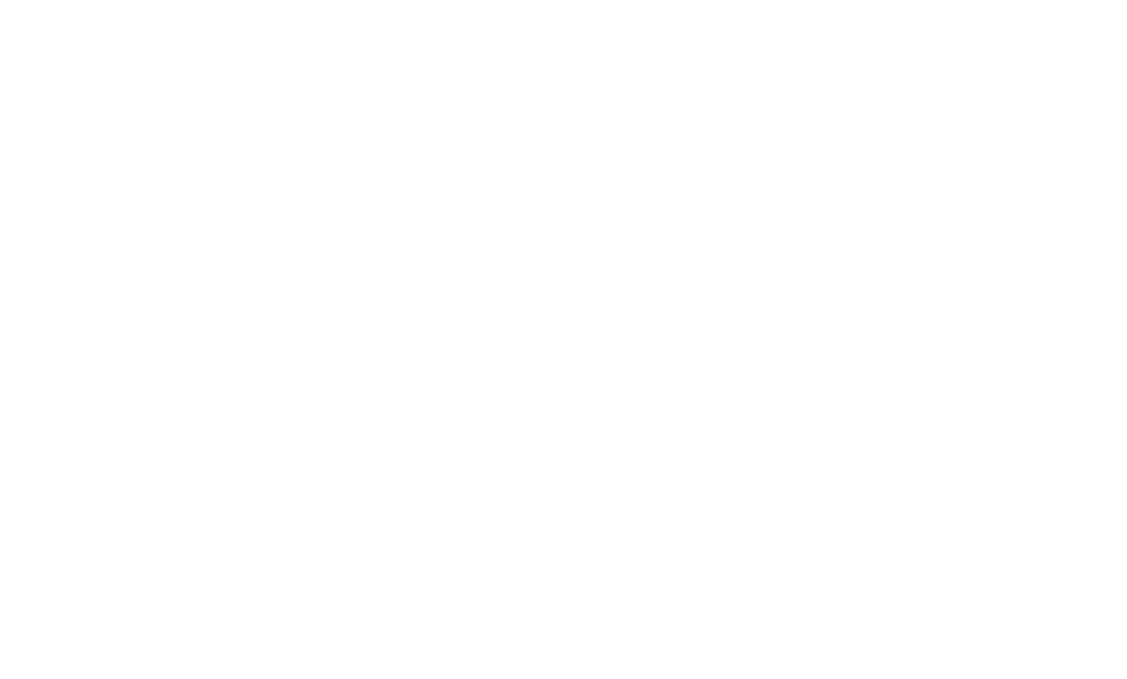


11519500 SCOTT RIVER NEAR FORT JONES, CALIF.

LOCATION, --Lat $41^{\circ} 38^{\prime} 28^{\prime \prime}$, long $123^{\circ} 00^{\prime} 54^{\prime \prime}$, 1n NE 1 NE $\mathrm{sec}, 29, T .44$ N., R. 10 W., Siskiyou County, at gaging station

1.7 miles upstream from Snow Creek and 10.8 miles downstream from Fort Jones.

DRAINAGE AREA. --653 sq $\mathrm{mi}$.

PERIOD OF RECORD. --Chemical analyses: November 1958 to September 1969.

REMARKS. --Records furnished by California Department of Water Resources and reviewed by U.S. Geological Survey. CHEMICAL ANALYSES, WATER YEAR OCTOBER 1968 TO SEPTEMBER 1969

\begin{tabular}{|c|c|c|c|c|c|c|c|c|c|c|c|c|}
\hline OATE & TIME & $\begin{array}{l}\text { DIS- } \\
\text { CHARGE } \\
\text { (CFS) }\end{array}$ & $\begin{array}{l}\text { TEMPER- } \\
\text { ATURE } \\
\text { IOEG CI }\end{array}$ & $\begin{array}{l}\text { DIS- } \\
\text { SQLVED } \\
\text { OXYGEN } \\
\text { (MG/L) }\end{array}$ & $\begin{array}{l}\text { CAL- } \\
\text { CIUM } \\
\text { (CA) } \\
\text { (MG/L) }\end{array}$ & $\begin{array}{l}\text { MAG- } \\
\text { NE- } \\
\text { SIUM } \\
\text { (MG) } \\
(M G / L)\end{array}$ & $\begin{array}{l}\text { SOOIUM } \\
\text { (NA) } \\
\text { (MG/L) }\end{array}$ & $\begin{array}{l}\text { PO- } \\
\text { YAS- } \\
\text { SIUM } \\
\text { IKI } \\
\text { ING/LI }\end{array}$ & $\begin{array}{l}\text { BICAR- } \\
\text { BONATE } \\
\text { (HCO3) } \\
\text { (MG/C) }\end{array}$ & $\begin{array}{l}\text { CAR- } \\
\text { BONATE } \\
\text { (COMI) } \\
\text { (MG/L) }\end{array}$ & $\begin{array}{l}\text { SULFATE } \\
\text { (SOA) } \\
\text { (MG/L) }\end{array}$ & $\begin{array}{l}\text { CHLO- } \\
\text { RIOE } \\
\text { ICLI } \\
(\mathrm{MG} / \mathrm{L}\end{array}$ \\
\hline $\begin{array}{l}\text { OCT. } \\
\text { O9... } \\
\text { NOV. }\end{array}$ & 1100 & 56 & 11 & 11.8 & -- & -- & 5.8 & $=$ & 179 & 0 & $\cdots$ & 5.0 \\
\hline JAN.". & 0755 & 140 & 6 & 10.7 & - & -- & 3.4 & - & 117 & 0 & $-\infty$ & \\
\hline$\underset{\text { MAR... }}{20 . .}$ & 1635 & 2420 & 2 & 12.0 & $\cdots$ & -- & 2.7 & - & 84 & 0 & -- & 2.0 \\
\hline$\underset{\text { MAY }}{10 . . .}$ & 1120 & 670 & 4 & 12.7 & $\cdots$ & $=$ & 3.1 & $\cdots$ & 140 & 0 & -- & 2.0 \\
\hline JuLY $^{12 \ldots}$ & 1235 & 3880 & 12 & 10.5 & 7.8 & 5.2 & 1.4 & .4 & 48 & 0 & 1.2 & 1.6 \\
\hline SEPT... & 0730 & 258 & 15 & 9.8 & - & - & 3.7 & 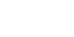 & 134 & 0 & -- & 2.7 \\
\hline $16 \ldots$ & 0925 & 42 & 13 & 10.5 & 31 & 13 & 6.6 & .4 & 157 & 0 & 5.4 & 6.5 \\
\hline
\end{tabular}

\begin{tabular}{|c|c|c|c|c|c|c|c|c|c|c|c|}
\hline DATE & $\begin{array}{l}\text { NITRATE } \\
\text { (NO3) } \\
\text { (MGILI }\end{array}$ & $\begin{array}{l}\text { BORON } \\
(8) \\
\text { IUG/L) }\end{array}$ & $\begin{array}{l}\text { DIS- } \\
\text { SOLVEO } \\
\text { SOLIDS } \\
\text { (RESI- } \\
\text { DUE AI } \\
\text { I80 CI } \\
\text { (MG IL) }\end{array}$ & $\begin{array}{l}\text { DIS- } \\
\text { SOLVED } \\
\text { SOLIDS } \\
\text { ITONS } \\
\text { PER } \\
\text { AC-FT) }\end{array}$ & $\begin{array}{l}\text { HARD- } \\
\text { NESS } \\
(C A, M G) \\
(M G / L)\end{array}$ & $\begin{array}{l}\text { NON- } \\
\text { CAR- } \\
\text { BONATE } \\
\text { HARD- } \\
\text { NESS } \\
\text { (MG'L) }\end{array}$ & $\begin{array}{l}\text { PERCENT } \\
\text { SODIUM }\end{array}$ & $\begin{array}{l}\text { SOOIUM } \\
\text { AD- } \\
\text { SORP- } \\
\text { TION } \\
\text { RATIO }\end{array}$ & $\begin{array}{l}\text { ALKA- } \\
\text { LINITY } \\
\text { AS } \\
\text { CACO3 } \\
\text { (MG } / \text { LI) }\end{array}$ & $\begin{array}{c}\text { PH } \\
\text { IUNITSI }\end{array}$ & $\begin{array}{l}\text { SPECI- } \\
\text { FIC } \\
\text { COND- } \\
\text { UCTANCE } \\
\text { IMICRO- } \\
\text { MHOSI }\end{array}$ \\
\hline $\begin{array}{l}\text { OCT. } \\
\text { O9... } \\
\text { Nov. }\end{array}$ & -- & 0 & -- & - & 157 & 10 & 7 & .2 & 147 & 8.2 & 300 \\
\hline JAN. & $=-$ & 0 & -- & 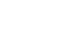 & 102 & 6 & 7 & .1 & 96 & 8.3 & 196 \\
\hline MAR:. & -- & 0 & -- & - & 86 & 17 & 6 & .1 & 69 & 8.0 & 151 \\
\hline $\operatorname{MAY}_{\text {MA }}^{10}$ & -- & 0 & -- & - & 121 & 6 & 5 & .1 & 115 & 8.0 & 234 \\
\hline JuLY... & .9 & 20 & 60 & .08 & 41 & 2 & 7 & $\cdot 1$ & 39 & 7.4 & 85 \\
\hline SEPT... & -- & 0 & -- & $=$ & 123 & 13 & 6 & . 1 & 110 & 8.3 & 228 \\
\hline $16 \ldots$ & 1.0 & 0 & 142 & .19 & I 3D & 1 & 10 & .3 & 129 & 8.3 & 276 \\
\hline
\end{tabular}


11620600 KLAKATH RIVER NEAR SEIAD VALLEY, GALIF.

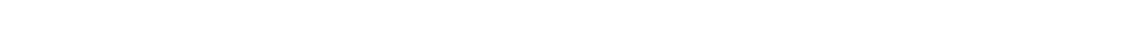

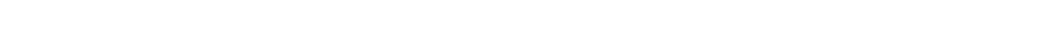

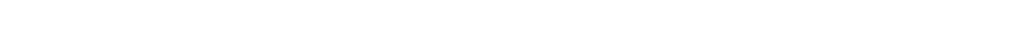

PSRIOD OF RECORD. -- Chenickl inkiy eas: Decenber 1958 to september 1868.

Nater temperaturen: Oetober 1963 to Boptember 1869.

EXTREIES. $-1968-69$ :

Water temperatures: Maximum, $26.0^{\circ} \mathrm{C} J u 1 y 22,26$; minimum, $1.0^{\circ} \mathrm{C}$ on several days during January and February. Period of record: Water temperatures: Maximum, $27.0^{\circ} \mathrm{C} J u 1 y$ 28-30, 1968; minimum (1963-64, 1966-69), $1.0^{\circ} \mathrm{C}$ on several days
during December to Februsy 1n 1967-69.

TEMPERATURE $\left({ }^{\circ} \mathrm{C}\right)$ OF WATER, WATER TEAR OCTOBER 1968 TO SEPTEMBER 1968 CAY

MONTH \begin{tabular}{lllllllllllllllllllllllllllllllllllll}
\hline & 2 & 3 & 4 & 5 & 6 & 7 & 8 & 9 & 10 & 11 & 12 & 13 & 14 & 15 & 16 & 17 & 18 & 19 & 20 & 21 & 22 & 23 & 24 & 25 & 26 & 27 & 28 & 29 & 30 & 31 & AVER
\end{tabular}

OC TOBER

$\begin{array}{llllllllllllllllllllllllllllllllll}M A X I M U M & 17 & 17 & 17 & 17 & 17 & 17 & 16 & 14 & 14 & 14 & 14 & 14 & 13 & 13 & 12 & 13 & 13 & 13 & 12 & 13 & 13 & 13 & 14 & 13 & 13 & 13 & 13 & 13 & 13 & 12 & 12 & 14 \\ \text { MINIMUM } & 15 & 16 & 16 & 16 & 15 & 15 & 14 & 13 & 12 & 13 & 14 & 13 & 12 & 12 & 12 & 12 & 12 & 12 & 12 & 12 & 13 & 13 & 13 & 13 & 13 & 13 & 13 & 13 & 12 & 12 & 12 & 13\end{array}$ NOVEMBER

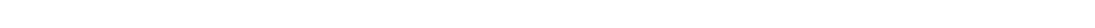

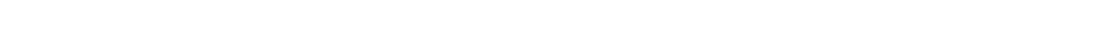

OECEMHER

MAXIMUM $6 \begin{array}{llllllllllllllllllllllllllllllllllll} & 6 & 6 & 6 & 7 & 7 & 7 & 7 & 7 & 7 & 7 & 7 & 6 & 5 & 5 & 5 & 5 & 5 & 5 & 5 & 5 & 4 & 4 & 3 & 4 & 4 & 4 & 4 & 4 & 5 & 4 & 4 & 5\end{array}$

MINIMUM

JANUARY

MAXIMUM $4 \begin{array}{lllllllllllllllllllllllllllllllllll} & 4 & 5 & 5 & 5 & 5 & 5 & 5 & 4 & 3 & 3 & 3 & 3 & 3 & 3 & 3 & 3 & 3 & 3 & 3 & 3 & 3 & 3 & 2 & 2 & 2 & 1 & 1 & 1 & 1 & 1 & 3\end{array}$

MINIMUM

MAXIMUM
1

MINIMU

MARCH

$\begin{array}{lllllllllllllllllllllllllllllllllllll}\text { MAXIMUM } & 4 & 4 & 4 & 5 & 5 & 5 & 5 & 5 & 5 & 5 & 5 & 5 & 5 & 5 & 5 & 5 & 6 & 6 & 6 & 6 & 7 & 7 & 7 & 7 & 7 & 7 & 7 & B & 8 & B & B \\ \text { MINIMUM } & 4 & 4 & 4 & 4 & 5 & 5 & 5 & 5 & 5 & 5 & 4 & 4 & 5 & 5 & 5 & 5 & 5 & 6 & 6 & 6 & 6 & 7 & 7 & 7 & 7 & 7 & 7 & 7 & 7 & 7 & B\end{array}$

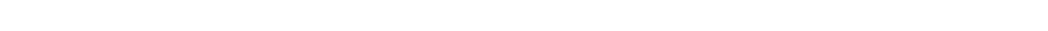
MINIMUM MAY

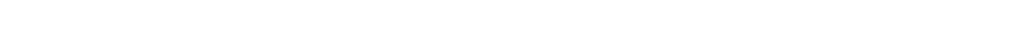
MINIMUM

MAXIMUM MINIMUA

JULY

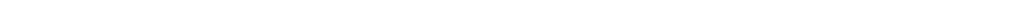
MINIMUM AUGUST

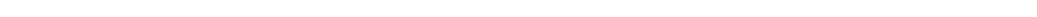

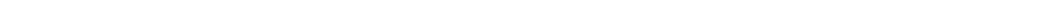
SEPTEMBER

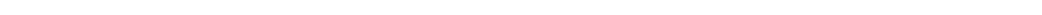

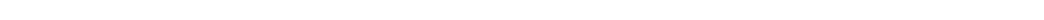$$
3
$$ 


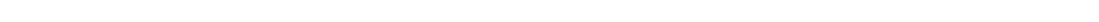
Fotest, temperature recorder at gaging etati on on left bank st somes Bar, 1.0 mile upst rean fron nouth. DRAINAOY ARBA. -781 Eq all.

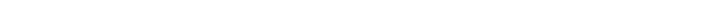

Water tomperaturen: October 1968 to September 1968.

EXTREITS, --1968-69:

Wuter temperatures: Maximum, $24.0^{\circ} \mathrm{C}$ July 22, 24-26; minimum, $2.0^{\circ} \mathrm{C}$ Jan. $29,30$.

Pariod of record: rlod of rocord:
15, 1967.

REMARKS. --Recorder malfunction Hov. 25 to Dec. 25.

TELPERATURE $\left({ }^{\circ} \mathrm{C}\right.$ ) OF WATER, WATER YEAR CTOBER 1968 TO SEPTEMBER 1969

DAY

MONTH

$123456789101112131415161718192021222324252627282930 \quad 31$ AGE

OCTOBER

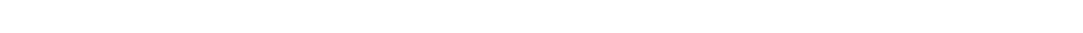

MAXIMUM

MAXIMUM

DECEMBER

MAXIMUM

MINIMUM

JANUARY

MAXIMUM

FEBRUARY

MAXIMUM

MINIMUM
MARCH
MAX

MAX LMUM

APR IL

MAXIMUN

MAY

MINIMUM

$\begin{array}{llllllllllllllllllllllllllllllllllll}11 & 11 & 11 & 11 & 10 & 11 & 12 & 13 & 13 & 12 & 11 & 9 & B & B & 8 & 9 & 9 & 9 & 9 & 9 & 10 & 10 & 9 & \ldots & \ldots & \ldots & \ldots & \ldots & \ldots & \ldots & 10\end{array}$

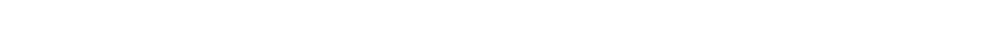

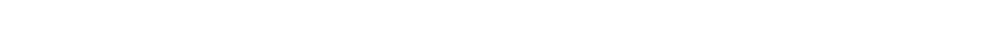

$\begin{array}{lllllllllllllllllllllllllllllllllllll}6 & 6 & 7 & 7 & 7 & 7 & 7 & 6 & 5 & 6 & 6 & 7 & 7 & 7 & 6 & 6 & 5 & 5 & 6 & 7 & 9 & 7 & 6 & 5 & 6 & 6 & 4 & 4 & 4 & 4 & 4 & 6 \\ 5 & 6 & 6 & 6 & 6 & 6 & 6 & 5 & 4 & 5 & 6 & 6 & 7 & 6 & 6 & 5 & 4 & 4 & 5 & 6 & 7 & 6 & 5 & 5 & 4 & 4 & 3 & 3 & 2 & 2 & 3 & 5\end{array}$

$\begin{array}{llllllllllllllllllllllllllllllllll}5 & 5 & 5 & 5 & 5 & 6 & 6 & 6 & 7 & 7 & 7 & 7 & 6 & 6 & 7 & 7 & 7 & 7 & 8 & 7 & 7 & 6 & 6 & 7 & 6 & 6 & 6 & 6 & \ldots & \ldots & \ldots & 6 \\ 3 & 4 & 5 & 5 & 5 & 5 & 6 & 6 & 6 & 6 & 7 & 6 & 6 & 6 & 6 & 6 & 6 & 6 & 7 & 6 & 5 & 5 & 6 & 6 & 5 & 5 & 5 & 5 & \ldots & \ldots & \ldots & 0\end{array}$

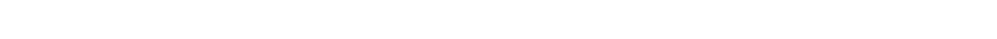

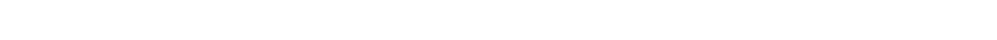

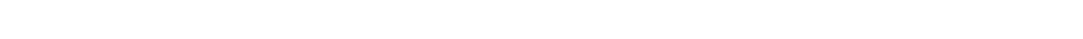

JUNE

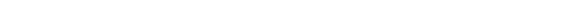

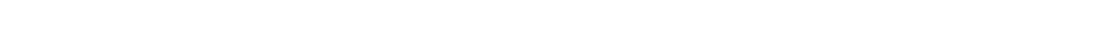

JULY

$\begin{array}{lllllllllllllllllllllllllllllllllllll}\text { MAXIMUM } & 18 & 18 & 17 & 18 & 19 & 19 & 19 & 20 & 20 & 20 & 20 & 20 & 20 & 20 & 20 & 20 & 21 & 21 & 22 & 23 & 23 & 24 & 23 & 24 & 24 & 24 & 23 & 22 & 22 & 22 & 22 & 21 \\ \text { MINIMUM } & 16 & 16 & 15 & 15 & 16 & 16 & 16 & 17 & 18 & 18 & 18 & 18 & 18 & 18 & 18 & 18 & 18 & 19 & 20 & 20 & 21 & 21 & 21 & 21 & 21 & 22 & 21 & 20 & 20 & 20 & 20 & 19\end{array}$

MAXINUH

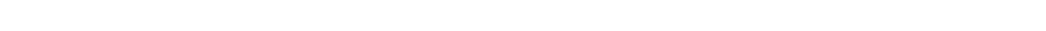

SEPTEMBER

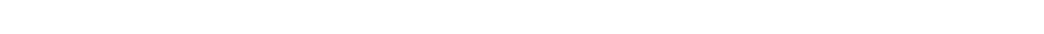


11523000 KLAMath RIVER AT ORLEANS, CALIF.

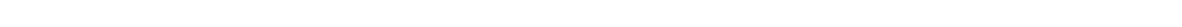
Orleans, $25 \mathrm{ft}$ upstréam from high way bridge and 0.2 mile downstream from Cheentich Creek.

DRAI NAGE AREA, $--8,500 \mathrm{sq} \mathrm{m} i$, approximately (not including Lost R1ver or Lower Klamath Lake basins).

PERIOD OF RECORD. --Chemical analyses: October 1953 to September 1969.

Water temperatures: October 1965 to September 1969.

Sediment records: January 1967 to September 1969 .

EXTREMES. - - 1968-69:

Water temperatures: Maximum, $27,0^{\circ} \mathrm{C}$ July 22 , minlmum, freezing point Dec, 22, 23.

Sediment concentrations: Maximum da11y, 1,390 mg/1 Jan. 22; minimum daily, $2 \mathrm{mg} / 1$ on several days during October.

Sediment discharge: Maximum da11y, 212,000 tons Jan, 21; mintmum da11y, 7.7 tons Oct. 9.

Period of record:

Water temperatures: Maximum, $28.0^{\circ} \mathrm{C}$ on several days in 1967-68; minimum (1965-66, 1967-69), freezing point Dec. $22,23,1968$.

Sedment concentrations: Maximum da11y, 3,220 mg/1 Feb, 23, 1968; mintmum da11y, $2 \mathrm{mg} / 1$ on several days in September and October 1968.

Sediment discharge: Maximum dai1y, 825,000 tons Feb, 28, 1968; m1n1mum da1ly, 7,7 tons Oct, 9, 1968.

REMARKS, --Chemical-quality records furntshed by California Department of Water Resources and reviewed by U.S. Geological Survey. No temperature record Apr, 5-21; recorder malfunction. Where no maximum or minimum 1s shown, temperature is once-daily reading.

CHEMICAL ANALYSES, WATER YEAR OCTOBER 1968 TO SEPTEMBER 1969

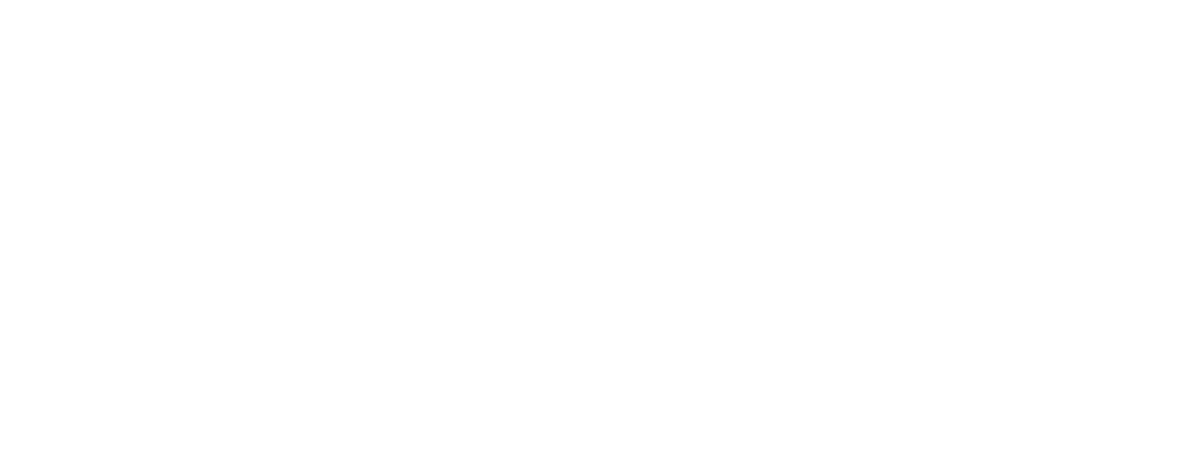

\begin{tabular}{|c|c|c|c|c|c|c|c|c|c|c|c|}
\hline DATE & $\begin{array}{l}\text { NITRATE } \\
\text { (NO3) } \\
\text { (MG/L) }\end{array}$ & $\begin{array}{l}\text { BORON } \\
(B) \\
(U G / L)\end{array}$ & $\begin{array}{l}\text { OLS- } \\
\text { SOL VED } \\
\text { SOL IDS } \\
\text { IRESI- } \\
\text { OUE AT } \\
180 \text { C) } \\
\text { (MG IL) }\end{array}$ & $\begin{array}{l}\text { OIS- } \\
\text { SOLVED } \\
\text { SOL IDS } \\
\text { (TONS } \\
\text { PER } \\
\text { AC-FT) }\end{array}$ & $\begin{array}{l}\text { HARD- } \\
\text { NESS } \\
(C A, M G) \\
\text { (MG/L) }\end{array}$ & $\begin{array}{l}\text { NON- } \\
\text { CAR- } \\
\text { SONATE } \\
\text { HARD- } \\
\text { NESS } \\
\text { (NG/L) }\end{array}$ & $\begin{array}{l}\text { PERCENT } \\
\text { SODIUM }\end{array}$ & $\begin{array}{l}\text { SOOIUM } \\
\text { AD- } \\
\text { SORP- } \\
\text { TION } \\
\text { RATIO }\end{array}$ & $\begin{array}{l}\text { ALKA- } \\
\text { LINITY } \\
\text { AS } \\
\text { CACO } 3 \\
\text { (MGG/L) }\end{array}$ & $\begin{array}{c}\text { PH } \\
\text { (UNITS) }\end{array}$ & $\begin{array}{l}\text { SPECI- } \\
\text { FIC } \\
\text { COND- } \\
\text { UCTANCE } \\
\text { I MICRO- } \\
\text { MHOSI }\end{array}$ \\
\hline $\begin{array}{l}\text { NOV. } \\
11 \ldots . . \\
\text { OEC. }\end{array}$ & -- & 100 & - & -- & 66 & 0 & 24 & .5 & 71 & 7.9 & 169 \\
\hline FEB. & -- & 20 & -- & - & BO & 4 & 23 & .5 & 76 & B. 2 & 186 \\
\hline MAR... & 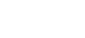 & 0 & - & $\cdots$ & B 2 & 7 & 18 & .4 & 75 & B. 0 & 176 \\
\hline $\begin{array}{l}03 \ldots \\
\triangle P R\end{array}$ & -- & 20 & $m$ & - & 87 & 7 & 19 & .4 & 80 & 7.4 & 193 \\
\hline MAY $07 .$. & - & 20 & -- & - & 68 & 0 & 24 & .5 & 70 & 7.6 & 182 \\
\hline$\underset{\text { JUNE }}{12 \ldots}$ & .4 & 10 & 44 & .06 & 36 & 1 & 12 & .2 & 35 & 7.4 & 80 \\
\hline JULY... & -- & 20 & -- & - & 43 & 0 & 15 & .2 & 44 & 7.7 & 100 \\
\hline $\begin{array}{l}14 \ldots . . \\
\text { AUG. }\end{array}$ & -- & 0 & - & $\cdots$ & 70 & 0 & 17 & $\cdot 3$ & 74 & 7.8 & 159 \\
\hline SEPT. & - & 80 & - & $m$ & 76 & 0 & 24 & .5 & 83 & 8.2 & 194 \\
\hline $08 . .$. & .0 & 90 & 141 & .19 & 85 & 0 & 33 & .9 & 92 & 7.7 & 255 \\
\hline
\end{tabular}


11523000 KLAMATH RIVER AT ORLEANS, CALIF.--CONtI nued

TEMPERATURE $\left({ }^{\circ} \mathrm{C}\right)$ OF WATER, WATER YEAR OCTOBER 1968 TO SEPTEMBER 1969

DAY

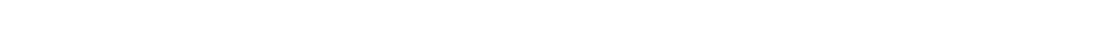

OCTOBER.. - - - - - - - - - -

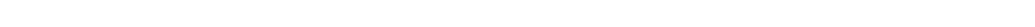
$\begin{array}{llllllllllllllllllllllllllllllll}\text { MINIMUM } & 16 & 17 & 17 & 17 & 17 & 16 & 16 & 14 & 13 & 14 & 16 & 14 & 13 & 13 & 13 & 13 & 13 & 14 & 13 & 13 & 13 & 13 & 13 & 13 & 14 & 13 & 13 & 14 & 13 & 13 & 12\end{array}$ $\begin{array}{lllllllllllllllllllllllllllllllllllllllll}\text { MAXIMUM } & 12 & 11 & 12 & 12 & 11 & 11 & 11 & 12 & 13 & 13 & 13 & 12 & 10 & 9 & 7 & 8 & 9 & 9 & 10 & 10 & 10 & 10 & 10 & 10 & 8 & 7 & 7 & 7 & 6 & 6 & -1\end{array}$

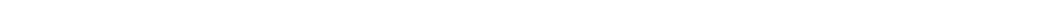
DECEMER, --

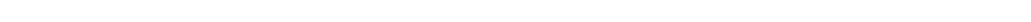
JANUARY.. -

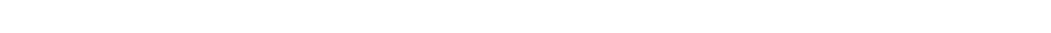

MINIMUM

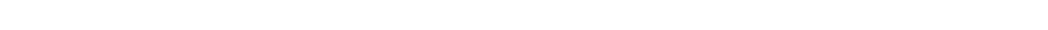

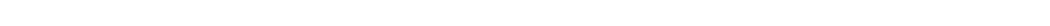

MARCH... - MANIMUM $6 \begin{array}{llllllllllllllllllllllllllllll}6 & 6 & 5 & 6 & 6 & 6 & 6 & 6 & 6 & 5 & 5 & 7 & 7 & 6 & 6 & 7 & 8 & 8 & 7 & 8 & 8 & 8 & 8 & 9 & 8 & 8 & 9 & 9 & 9 & 9\end{array}$

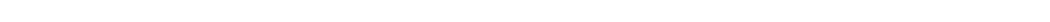

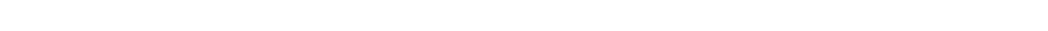

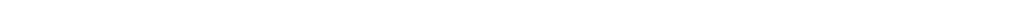

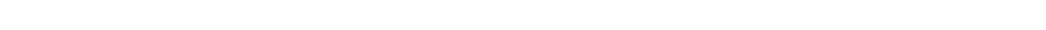

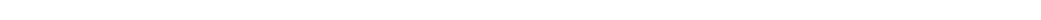
JUNE..... T-

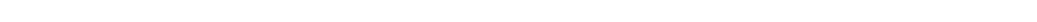
JULY..... - - - - - - - - - -

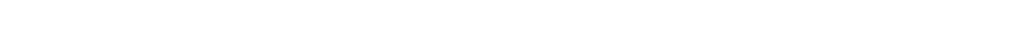
AUGUST... - -

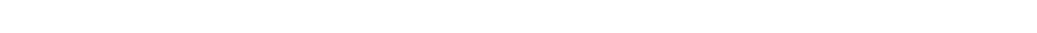

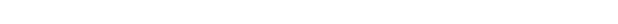

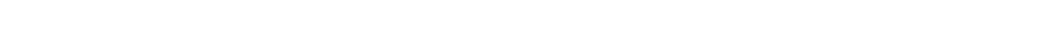

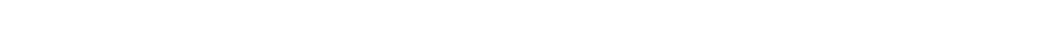

PARTICLE-SIZE DISTRIBUTION OF SUSPENDED SEDIMENT, WATER YEAR OCTOBER 1968 TO SEPTEMBER 1969

IMETHODS OF ANALYSIS: B, BOTTOM WITHORAWAL TUBF; C, CHEMICALLY OISPERSED; N, IN NATIVE WATER: P, PIPET: S, SIEVE: $\checkmark$, VISUAL ACCUMULATION TUBE; W, IN OISTILLED WATER

WATER PARTICLE SIZE

SUSPENDED
PEMA- CONCEN- SEOIMENT PERCENT FINER THAN THE SIZE (IN MILLIMETERS) 1NDICATED

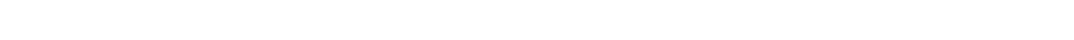
METHOD ANALY SIS $\begin{array}{rrrrrrrrrrrrrrrrrrr}\text { FEB } & 4,1969 & 1430 & 5 & 12100 & 105 & 3430 & 1 & 14 & 25 & 36 & 40 & 53 & 61 & 76 & 89 & 99 & 100 \\ & & 1050 & 1300 & 6 & 10500 & 59 & 1670 & -- & 4 & 19 & 30 & 42 & 50 & 60 & 71 & 87 & 100 & --\end{array}$ SBWC 
11523000 KLAMATH RI VER AT ORLEANS, CALIF.--CONt Inued

SUSPENDED-SEDIMENT DISCHARGE, WATER YEAR OCTOBER 1968 TO SEPTEMBER 1969

\begin{tabular}{|c|c|c|c|c|c|c|c|c|c|}
\hline \multirow[b]{2}{*}{ DAY } & \multicolumn{3}{|c|}{ OC TOBER } & \multicolumn{3}{|c|}{ NOVEMBER } & \multicolumn{3}{|c|}{ DECEMBER } \\
\hline & $\begin{array}{l}\text { MEAN } \\
\text { OISCHARGE } \\
\text { (CFS) }\end{array}$ & $\begin{array}{l}\text { MEAN } \\
\text { CDNCEN- } \\
\text { TRATION } \\
\text { (MG/L) }\end{array}$ & $\begin{array}{l}\text { SEDIMENT } \\
\text { DI SCHARGE } \\
\text { (TONS/DAY) }\end{array}$ & $\begin{array}{l}\text { MEAN } \\
\text { DI SCHARGE } \\
\text { (CFS) }\end{array}$ & $\begin{array}{l}\text { MEAN } \\
\text { CONCEN- } \\
\text { TRATION } \\
\text { (MG /LI }\end{array}$ & $\begin{array}{l}\text { SEDI MENT } \\
\text { DI SCHARGE } \\
\text { (TONS/DAY) }\end{array}$ & $\begin{array}{c}\text { MEAN } \\
\text { OISCHARGE } \\
\text { (CFS) }\end{array}$ & $\begin{array}{l}\text { MEAN } \\
\text { CONCEN- } \\
\text { TRAIION } \\
\text { (AG/L) }\end{array}$ & $\begin{array}{l}\text { SEDIMENT } \\
\text { DISCHARGE } \\
\text { (TONS/DAY) }\end{array}$ \\
\hline 1 & 1510 & 2 & 8.2 & 2800 & 10 & 76 & 4660 & 9 & 113 \\
\hline 2 & 1500 & 3 & 12 & 4310 & 523 & 8060 & 4380 & 7 & $B 3$ \\
\hline 3 & 1500 & 3 & 12 & 4880 & 590 & 7770 & 4110 & 7 & 78 \\
\hline 4 & 1490 & 3 & 12 & 3530 & 210 & 2000 & 3990 & 8 & 86 \\
\hline 5 & 1490 & 2 & 8.0 & 3510 & 70 & 663 & 5920 & 62 & 1080 \\
\hline 6 & 1480 & 2 & 8.0 & 3460 & 52 & 486 & 5930 & 80 & 1280 \\
\hline 7 & 1470 & 2 & 7.9 & 3420 & 36 & 332 & 5240 & 58 & 821 \\
\hline 8 & 1440 & 2 & 7.8 & 3500 & 42 & 397 & 6180 & 53 & 884 \\
\hline 9 & 1430 & 2 & 7.7 & 6160 & 334 & 5560 & 6020 & 47 & 764 \\
\hline 10 & 1430 & 3 & 12 & 4970 & 142 & 1910 & 17400 & 90 & 4770 \\
\hline 11 & 1430 & 3 & 12 & 4500 & 39 & 474 & 19600 & 90 & 4830 \\
\hline 12 & 2800 & 5 & 38 & 8160 & 136 & 3000 & 12100 & 60 & 1960 \\
\hline 13 & 3800 & 13 & 133 & 5700 & 21 & 323 & 9690 & 41 & 1070 \\
\hline 14 & 3400 & 14 & 129 & 4700 & 12 & 152 & 10500 & 31 & 879 \\
\hline 15 & 3200 & 10 & 86 & 4570 & 10 & 123 & 13600 & 40 & 1550 \\
\hline 16 & 3050 & 8 & 66 & 4280 & 12 & 139 & 15300 & 39 & 1610 \\
\hline I7 & 2850 & 6 & 46 & 4240 & 16 & 183 & 11000 & 19 & 564 \\
\hline 18 & 2800 & 10 & 76 & 9330 & 114 & 3060 & 8870 & 15 & 359 \\
\hline 19 & 2780 & 13 & 98 & 9280 & 84 & 2100 & 7580 & 12 & 246 \\
\hline 20 & 2740 & 16 & 118 & 6810 & 54 & 393 & 6660 & 16 & 288 \\
\hline 21 & 2700 & 20 & 146 & 5610 & 37 & 560 & 6100 & 14 & 231 \\
\hline 22 & 2660 & 25 & 180 & 6520 & 27 & 475 & 5780 & 16 & 250 \\
\hline 23 & 2580 & 26 & 181 & 6230 & 18 & 303 & 8400 & 88 & 2300 \\
\hline 24 & 2510 & 26 & 176 & 5910 & 12 & 191 & 14100 & 223 & 8490 \\
\hline 25 & 2420 & 25 & 163 & 5310 & 10 & 143 & 13300 & 112 & 4020 \\
\hline 26 & 2400 & 23 & 149 & 5520 & 11 & 164 & 10600 & 63 & 1800 \\
\hline 27 & 2380 & 22 & 141 & 4990 & 17 & 229 & 9180 & 53 & 1310 \\
\hline 28 & 2360 & 19 & 121 & 4620 & 20 & 249 & 9250 & 47 & 1170 \\
\hline 29 & 2360 & 16 & 102 & 4430 & 22 & 263 & 8850 & 43 & 1030 \\
\hline 30 & 2700 & 13 & 95 & 4660 & 19 & 239 & 7980 & 39 & 840 \\
\hline 31 & 3200 & 10 & 86 & - & -- & -- & 7240 & 38 & 743 \\
\hline \multirow[t]{5}{*}{ TOTAL } & 71860 & -- & 2437.6 & 155910 & $-\infty$ & 40617 & 279510 & -- & 45499 \\
\hline & & JANUARY & & & FEBRUARY & & & MARCH & \\
\hline & & MEAN & & & MEAN & & & MEAN & \\
\hline & MEAN & CONCEN- & SEDIMENT & MEAN & CONCEN- & SEDIMENT & MEAN & CONCEN- & SEDI MENT \\
\hline & DISCHARGE & IRATION & DI SCHARGE & OI SCHARGE & IRATION & DISCHARGE & DISCHARGE & TRATION & DISCHARGE \\
\hline DAY & (CFS) & $(M G / L)$ & (TONS/DAY) & (CFS) & $(\mathrm{MG} / \mathrm{L})$ & (TONS / DAY) & (CFS) & $(M G / L)$ & (TONS / DAY) \\
\hline 1 & 6840 & 40 & 739 & 14900 & 420 & 16900 & 9910 & 49 & 1310 \\
\hline 2 & 7240 & 40 & 782 & 13300 & 280 & 10100 & 9920 & 50 & 1340 \\
\hline 3 & 7780 & 45 & 945 & 12500 & 175 & 5910 & 9630 & 51 & 1330 \\
\hline 4 & 9350 & 54 & 1360 & 12200 & 110 & 3620 & 9170 & 51 & 1260 \\
\hline 5 & 10400 & 60 & 1680 & 12200 & 65 & 2140 & 8930 & 51 & 1230 \\
\hline 6 & 10800 & 62 & 1810 & 11700 & 40 & 1260 & 8870 & 55 & 1320 \\
\hline 7 & 10700 & 63 & 1820 & 11000 & 40 & 1190 & 8450 & 60 & 1370 \\
\hline 8 & 10300 & 63 & 1750 & 11000 & 65 & 1930 & 8060 & 45 & 979 \\
\hline 9 & 9450 & 62 & 1580 & 15900 & 510 & 22100 & 7190 & 41 & 796 \\
\hline 10 & 8900 & 62 & 1490 & 15900 & 545 & 23400 & 6970 & 48 & 903 \\
\hline 11 & 11200 & 394 & 13200 & 20600 & 699 & 39900 & 6750 & 50 & 911 \\
\hline 12 & 21300 & 756 & 46300 & 25600 & 940 & 65000 & 6710 & 40 & 725 \\
\hline 13 & 48400 & 1380 & 182000 & 21300 & 785 & 45100 & 7330 & 44 & 871 \\
\hline 14 & 32100 & 721 & 66000 & 18100 & 665 & 32500 & 7390 & 46 & 918 \\
\hline 15 & 20800 & 320 & 18000 & 17200 & 545 & 25300 & 7320 & 53 & 1050 \\
\hline 16 & 16100 & 135 & 5870 & 17100 & 440 & 20300 & 7050 & 58 & 1100 \\
\hline 17 & 13300 & 65 & 2330 & 15800 & 345 & 14700 & 7960 & 72 & 1550 \\
\hline 18 & 11500 & 30 & 932 & 14900 & 265 & 10700 & 10700 & 132 & 3810 \\
\hline 19 & 12500 & 97 & 3600 & 14300 & 210 & 8110 & 10700 & 112 & 3240 \\
\hline 20 & 25300 & 370 & 27100 & 13700 & 165 & 6100 & 10100 & 76 & 2070 \\
\hline 21 & 10000 & 1120 & 212000 & 13000 & 135 & 4740 & 9750 & 66 & 1740 \\
\hline 22 & 52000 & 1390 & 195000 & 12200 & 115 & 3790 & 10300 & 73 & 2030 \\
\hline 23 & 39000 & 985 & 104000 & 11900 & 100 & 3210 & 11200 & 98 & 2660 \\
\hline 24 & 35000 & 770 & 72800 & 11600 & 85 & 2660 & 11600 & 86 & 2690 \\
\hline 25 & 31800 & 630 & 54100 & 11000 & 75 & 2230 & 12100 & 86 & 2810 \\
\hline $\begin{array}{l}26 \\
27\end{array}$ & $\begin{array}{l}23200 \\
19400\end{array}$ & $\begin{array}{l}555 \\
505\end{array}$ & $\begin{array}{l}34800 \\
26500\end{array}$ & $\begin{array}{r}10400 \\
9910\end{array}$ & $\begin{array}{l}65 \\
55\end{array}$ & $\begin{array}{l}1830 \\
1470\end{array}$ & $\begin{array}{l}14600 \\
17200\end{array}$ & $\begin{array}{l}146 \\
188\end{array}$ & $\begin{array}{l}5760 \\
8730\end{array}$ \\
\hline $\begin{array}{l}27 \\
28\end{array}$ & $\begin{array}{l}19400 \\
18700\end{array}$ & $\begin{array}{l}505 \\
560\end{array}$ & $\begin{array}{l}26500 \\
28600\end{array}$ & $\begin{array}{l}9910 \\
9920\end{array}$ & 50 & $\begin{array}{l}1470 \\
1340\end{array}$ & $\begin{array}{l}17200 \\
20700\end{array}$ & 210 & $\begin{array}{r}8730 \\
11700\end{array}$ \\
\hline 29 & 23700 & 951 & 61000 & - & -- & $\ldots$ & 24500 & 227 & 15000 \\
\hline 30 & 22000 & 795 & 47200 & -- & -- & -- & 28200 & 341 & 26200 \\
\hline 31 & 20900 & 600 & 33900 & -- & - & -- & 31300 & 399 & 33600 \\
\hline rorAL & 659960 & -- & 1249188 & 399130 & - & 377530 & 360560 & - & 141003 \\
\hline
\end{tabular}


11523000 K.AMATH RIVER AT ORLEANS, CALIF.--Cont1nued

SUSPENDED-SEDIMENT DISCHARGE, WATER YEAR OCTOBER 1968 TO SEPTEMBER 1969

\begin{tabular}{|c|c|c|c|c|c|c|c|c|c|}
\hline \multirow[b]{2}{*}{ DAY } & \multicolumn{3}{|c|}{ APRIL } & \multicolumn{3}{|c|}{ MAY } & \multicolumn{3}{|c|}{ JUNE } \\
\hline & $\begin{array}{l}\text { MEAN } \\
\text { DISCHARGE } \\
\text { (CFS) }\end{array}$ & $\begin{array}{l}\text { MEAN } \\
\text { CONCEN- } \\
\text { TRATION } \\
\text { (MG/L) }\end{array}$ & $\begin{array}{l}\text { SEDIMENT } \\
\text { DISCHARGE } \\
\text { (TONS/DAY) }\end{array}$ & $\begin{array}{l}\text { MEAN } \\
\text { OI SCHARGE } \\
\text { (CFS ) }\end{array}$ & $\begin{array}{l}\text { MEAN } \\
\text { CONCEN- } \\
\text { TRATION } \\
\text { (MGIL) }\end{array}$ & $\begin{array}{l}\text { SEDI MENT } \\
\text { DISCHARGE } \\
\text { (TONS/DAY) }\end{array}$ & $\begin{array}{l}\text { MEAN } \\
\text { DISCHARGE } \\
\text { (CFS) }\end{array}$ & $\begin{array}{l}\text { MEAN } \\
\text { CONCEN- } \\
\text { TRATION } \\
\text { (MG/L) }\end{array}$ & $\begin{array}{l}\text { SEDIMENT } \\
\text { DISCHARGE } \\
\text { (TONS/DAY) }\end{array}$ \\
\hline $\begin{array}{l}1 \\
2 \\
3 \\
4 \\
5\end{array}$ & $\begin{array}{l}29100 \\
25400 \\
22700 \\
21300 \\
21300\end{array}$ & $\begin{array}{l}303 \\
252 \\
237 \\
246 \\
290\end{array}$ & $\begin{array}{l}23800 \\
17300 \\
14500 \\
14100 \\
16700\end{array}$ & $\begin{array}{l}18000 \\
17400 \\
18200 \\
17600 \\
17000\end{array}$ & $\begin{array}{r}102 \\
98 \\
96 \\
95 \\
95\end{array}$ & $\begin{array}{l}4960 \\
4600 \\
4720 \\
4510 \\
4360\end{array}$ & $\begin{array}{l}14300 \\
14500 \\
14600 \\
14500 \\
14900\end{array}$ & $\begin{array}{l}62 \\
55 \\
48 \\
44 \\
42\end{array}$ & $\begin{array}{l}2390 \\
2150 \\
1890 \\
1720 \\
1690\end{array}$ \\
\hline $\begin{array}{r}6 \\
7 \\
8 \\
9 \\
10\end{array}$ & $\begin{array}{l}20400 \\
19200 \\
18200 \\
17500 \\
16600\end{array}$ & $\begin{array}{l}286 \\
246 \\
216 \\
208 \\
203\end{array}$ & $\begin{array}{r}15800 \\
12800 \\
10600 \\
9830 \\
9100\end{array}$ & $\begin{array}{l}18700 \\
22600 \\
26400 \\
29000 \\
30800\end{array}$ & $\begin{array}{l}104 \\
153 \\
240 \\
264 \\
316\end{array}$ & $\begin{array}{r}5250 \\
9340 \\
17100 \\
20700 \\
26300\end{array}$ & $\begin{array}{r}13600 \\
12600 \\
11000 \\
9980 \\
9650\end{array}$ & $\begin{array}{l}41 \\
40 \\
40 \\
41 \\
42\end{array}$ & $\begin{array}{l}1510 \\
1360 \\
1190 \\
1100 \\
1090\end{array}$ \\
\hline $\begin{array}{l}11 \\
12 \\
13 \\
14 \\
15\end{array}$ & $\begin{array}{l}16200 \\
17900 \\
18700 \\
17500 \\
16200\end{array}$ & $\begin{array}{l}207 \\
213 \\
207 \\
179 \\
141\end{array}$ & $\begin{array}{r}9050 \\
10300 \\
10500 \\
8460 \\
6170\end{array}$ & $\begin{array}{l}30400 \\
29900 \\
28700 \\
26500 \\
24000\end{array}$ & $\begin{array}{l}335 \\
342 \\
294 \\
267 \\
244\end{array}$ & $\begin{array}{l}27500 \\
27600 \\
22800 \\
19100 \\
15800\end{array}$ & $\begin{array}{l}8930 \\
9040 \\
9120 \\
8820 \\
8870\end{array}$ & $\begin{array}{l}43 \\
45 \\
46 \\
47 \\
48\end{array}$ & $\begin{array}{l}1040 \\
1100 \\
1130 \\
1120 \\
1150\end{array}$ \\
\hline $\begin{array}{l}16 \\
17 \\
18 \\
19 \\
20\end{array}$ & $\begin{array}{l}15300 \\
16000 \\
19200 \\
18700 \\
17600\end{array}$ & $\begin{array}{l}122 \\
144 \\
190 \\
172 \\
170\end{array}$ & $\begin{array}{l}5040 \\
6220 \\
9850 \\
8680 \\
8080\end{array}$ & $\begin{array}{l}24500 \\
25900 \\
27500 \\
25500 \\
20900\end{array}$ & $\begin{array}{l}240 \\
250 \\
292 \\
221 \\
193\end{array}$ & $\begin{array}{l}15900 \\
17500 \\
21700 \\
15200 \\
10900\end{array}$ & $\begin{array}{l}8550 \\
8190 \\
7620 \\
7500 \\
7160\end{array}$ & $\begin{array}{l}50 \\
51 \\
52 \\
51 \\
51\end{array}$ & $\begin{array}{r}1150 \\
1130 \\
1070 \\
1030 \\
986\end{array}$ \\
\hline $\begin{array}{l}21 \\
22 \\
23 \\
24 \\
25\end{array}$ & $\begin{array}{l}18500 \\
21900 \\
24900 \\
22400 \\
18500\end{array}$ & $\begin{array}{l}177 \\
234 \\
288 \\
188 \\
132\end{array}$ & $\begin{array}{r}8840 \\
13800 \\
19400 \\
11400 \\
6590\end{array}$ & $\begin{array}{l}19700 \\
20600 \\
21300 \\
20700 \\
18200\end{array}$ & $\begin{array}{l}192 \\
193 \\
175 \\
160 \\
147\end{array}$ & $\begin{array}{r}10200 \\
10700 \\
10100 \\
8940 \\
7220\end{array}$ & $\begin{array}{l}6550 \\
5890 \\
5500 \\
5280 \\
5010\end{array}$ & $\begin{array}{l}50 \\
48 \\
46 \\
34 \\
20\end{array}$ & $\begin{array}{l}884 \\
763 \\
683 \\
485 \\
271\end{array}$ \\
\hline $\begin{array}{l}26 \\
27 \\
28 \\
29 \\
30 \\
31\end{array}$ & $\begin{array}{r}16300 \\
15500 \\
16700 \\
19100 \\
19300 \\
--\end{array}$ & $\begin{array}{r}97 \\
84 \\
112 \\
161 \\
115 \\
--\end{array}$ & $\begin{array}{r}4270 \\
3520 \\
5050 \\
8300 \\
5990 \\
--\end{array}$ & $\begin{array}{l}17800 \\
17500 \\
14400 \\
13700 \\
14700 \\
15300\end{array}$ & $\begin{array}{r}139 \\
123 \\
107 \\
91 \\
80 \\
70\end{array}$ & $\begin{array}{l}6680 \\
5810 \\
4160 \\
3370 \\
3180 \\
2890\end{array}$ & $\begin{array}{l}4840 \\
4580 \\
4490 \\
4300 \\
4130 \\
--\end{array}$ & $\begin{array}{l}14 \\
13 \\
13 \\
12 \\
12 \\
-2\end{array}$ & $\begin{array}{l}183 \\
161 \\
158 \\
139 \\
134 \\
--\end{array}$ \\
\hline \multirow[t]{3}{*}{ TOTAL } & 578100 & $=$ & 314040 & 673400 & + & 369090 & 264000 & - & 30857 \\
\hline & & JULY & & & AUGUST & & & SEPTEMAER & \\
\hline & $\begin{array}{l}\text { MEAN } \\
\text { DISCHARGE } \\
\text { (CFS) }\end{array}$ & $\begin{array}{l}\text { MEAN } \\
\text { CONCEN- } \\
\text { TRAIION } \\
\text { (MG/L) }\end{array}$ & $\begin{array}{l}\text { SEDIMENT } \\
\text { DISCHARGE } \\
\text { (TONS / DAY) }\end{array}$ & $\begin{array}{l}\text { MEAN } \\
\text { DISCHARGE } \\
\text { (CFS) }\end{array}$ & $\begin{array}{l}\text { MEAN } \\
\text { CONCEN- } \\
\text { TRATION } \\
\text { (MG/L) }\end{array}$ & $\begin{array}{l}\text { SEDIMENT } \\
\text { DISCHARGE } \\
\text { \{TONS / DAY }\}\end{array}$ & $\begin{array}{l}\text { MEAN } \\
\text { DISCHARGE } \\
\text { (CFS) }\end{array}$ & $\begin{array}{l}\text { MEAN } \\
\text { CONCEN- } \\
\text { TRATION } \\
\text { IMG/LI) }\end{array}$ & $\begin{array}{l}\text { SEDIMENT } \\
\text { DISCHARGE } \\
\text { (TONS/DAY) }\end{array}$ \\
\hline $\begin{array}{l}1 \\
2 \\
3 \\
4 \\
5\end{array}$ & $\begin{array}{l}4000 \\
3870 \\
3690 \\
3570 \\
3450\end{array}$ & $\begin{array}{l}12 \\
14 \\
16 \\
17 \\
17\end{array}$ & $\begin{array}{l}130 \\
146 \\
159 \\
164 \\
158\end{array}$ & $\begin{array}{l}2300 \\
2460 \\
2420 \\
2400 \\
2390\end{array}$ & $\begin{array}{l}13 \\
13 \\
13 \\
13 \\
12\end{array}$ & $\begin{array}{l}81 \\
86 \\
85 \\
84 \\
77\end{array}$ & $\begin{array}{l}1650 \\
1960 \\
1980 \\
1980 \\
1950\end{array}$ & $\begin{array}{l}8 \\
13 \\
18 \\
15 \\
13\end{array}$ & $\begin{array}{l}36 \\
69 \\
96 \\
80 \\
68\end{array}$ \\
\hline $\begin{array}{r}6 \\
7 \\
8 \\
9 \\
10\end{array}$ & $\begin{array}{l}3340 \\
3220 \\
3150 \\
3100 \\
3060\end{array}$ & $\begin{array}{l}17 \\
18 \\
18 \\
18 \\
19\end{array}$ & $\begin{array}{l}153 \\
156 \\
153 \\
151 \\
157\end{array}$ & $\begin{array}{l}2350 \\
2270 \\
2220 \\
2160 \\
2110\end{array}$ & $\begin{array}{l}12 \\
12 \\
12 \\
12 \\
12\end{array}$ & $\begin{array}{l}76 \\
74 \\
72 \\
70 \\
68\end{array}$ & $\begin{array}{l}1890 \\
1870 \\
1870 \\
1860 \\
1840\end{array}$ & $\begin{array}{r}13 \\
13 \\
10 \\
7 \\
11\end{array}$ & $\begin{array}{l}66 \\
66 \\
50 \\
35 \\
55\end{array}$ \\
\hline $\begin{array}{l}11 \\
12 \\
13 \\
14 \\
15\end{array}$ & $\begin{array}{l}3000 \\
2930 \\
2820 \\
2750 \\
2690\end{array}$ & $\begin{array}{l}19 \\
20 \\
20 \\
20 \\
19\end{array}$ & $\begin{array}{l}154 \\
158 \\
152 \\
149 \\
138\end{array}$ & $\begin{array}{l}2050 \\
2010 \\
1980 \\
1940 \\
1900\end{array}$ & $\begin{array}{l}12 \\
11 \\
11 \\
11 \\
11\end{array}$ & $\begin{array}{l}66 \\
60 \\
59 \\
58 \\
56\end{array}$ & $\begin{array}{l}1800 \\
1790 \\
1790 \\
1790 \\
1800\end{array}$ & $\begin{array}{r}16 \\
12 \\
8 \\
11 \\
14\end{array}$ & $\begin{array}{l}78 \\
58 \\
39 \\
53 \\
68\end{array}$ \\
\hline $\begin{array}{l}16 \\
17 \\
18 \\
19 \\
20\end{array}$ & $\begin{array}{l}2620 \\
2570 \\
2530 \\
2500 \\
2480\end{array}$ & $\begin{array}{l}19 \\
18 \\
17 \\
17 \\
16\end{array}$ & $\begin{array}{l}134 \\
125 \\
116 \\
115 \\
107\end{array}$ & $\begin{array}{l}1830 \\
1780 \\
1710 \\
1650 \\
1600\end{array}$ & $\begin{array}{l}11 \\
11 \\
10 \\
10 \\
10\end{array}$ & $\begin{array}{l}54 \\
53 \\
46 \\
45 \\
43\end{array}$ & $\begin{array}{l}1840 \\
1900 \\
1970 \\
2040 \\
2120\end{array}$ & $\begin{array}{l}9 \\
4 \\
4 \\
4 \\
4\end{array}$ & $\begin{array}{l}45 \\
21 \\
21 \\
22 \\
23\end{array}$ \\
\hline $\begin{array}{l}21 \\
22 \\
23 \\
24 \\
25\end{array}$ & $\begin{array}{l}2420 \\
2370 \\
2330 \\
2460 \\
2430\end{array}$ & $\begin{array}{l}15 \\
15 \\
14 \\
14 \\
14\end{array}$ & $\begin{array}{l}98 \\
96 \\
88 \\
93 \\
92\end{array}$ & $\begin{array}{l}1560 \\
1540 \\
1520 \\
1490 \\
1470\end{array}$ & $\begin{array}{r}10 \\
10 \\
10 \\
9 \\
9\end{array}$ & $\begin{array}{l}42 \\
42 \\
41 \\
36 \\
36\end{array}$ & $\begin{array}{l}2200 \\
2290 \\
2340 \\
2320 \\
2300\end{array}$ & $\begin{array}{l}4 \\
4 \\
4 \\
4\end{array}$ & $\begin{array}{l}24 \\
25 \\
25 \\
25 \\
25\end{array}$ \\
\hline $\begin{array}{l}26 \\
27 \\
28 \\
29 \\
30 \\
31\end{array}$ & $\begin{array}{l}2460 \\
2440 \\
2330 \\
2270 \\
2210 \\
2160\end{array}$ & $\begin{array}{l}14 \\
14 \\
14 \\
14 \\
13 \\
13\end{array}$ & $\begin{array}{l}93 \\
92 \\
88 \\
86 \\
78 \\
76\end{array}$ & $\begin{array}{l}1450 \\
1450 \\
1450 \\
1460 \\
1460 \\
1450\end{array}$ & $\begin{array}{l}9 \\
9 \\
9 \\
9 \\
8 \\
8\end{array}$ & $\begin{array}{l}35 \\
35 \\
35 \\
35 \\
32 \\
31\end{array}$ & $\begin{array}{r}2280 \\
2260 \\
2220 \\
2200 \\
1980 \\
=-\end{array}$ & $\begin{array}{r}4 \\
4 \\
4 \\
4 \\
4 \\
-\end{array}$ & $\begin{array}{l}25 \\
24 \\
24 \\
24 \\
21 \\
--\end{array}$ \\
\hline TOTAL & 87220 & -- & 3855 & 57830 & -- & 1713 & 60080 & -- & 1291 \\
\hline $\begin{array}{l}\text { TOTAL } \\
\text { TOTAL }\end{array}$ & $\begin{array}{l}\text { DISCHARGE F } \\
\text { SUSPENDED-S }\end{array}$ & $\begin{array}{l}\text { OR YEAR } \\
\text { EDIMENT D }\end{array}$ & $\begin{array}{l}\text { CFS-DAYSI } \\
\text { ISCHARGE FOR }\end{array}$ & YEAR (TONS) & & & & & $\begin{array}{l}3647560 \\
2577120.6\end{array}$ \\
\hline
\end{tabular}


11525500 TRINITY RIVER AT LEWISTON, CALIF.

LOCATION.--Lat $40^{\circ} 43^{\prime} 10^{\prime \prime}$, long $122^{\circ} 48^{\prime} 09^{\prime \prime}$, in SW $\frac{1}{4} N_{W} \frac{1}{4}$ sec.17, T. 33 N., R. 8 w., Trinity County, at gaging station on right bank, $400 \mathrm{ft}$ upstream from Deadwood Creek and 0.8 mile northeast of Lewiston.

DRAI NAGE AREA. $\rightarrow 728$ sq $\mathrm{mi}$.

PERIOD OF RECORD.--Chemical analyses: December 1953 to September 1969

Water temperatures: September 1951 to September 1955 , October 1957 to september 1958 , July 1959 to September 1969 .

EXTREMES. --1968-69:

Water temperatures: Maximum, $13.0^{\circ} \mathrm{C}$ May 9-20; minimum, $4.0^{\circ} \mathrm{C} \mathrm{Jan,} 26$ to Feb. 18.

Perlod of record: Maxtmum (1951-55, 1957-58, 1959-63, 1964-69), 26. $0^{\circ} \mathrm{C}$ July 20, 21, 28, 29, 1960; minimum,
$0.5^{\circ} \mathrm{C}$ on several days in January 1952 .

REMARKS. --Chemical-quality records furnished by California Department of Water Resources and reviewed by U.S. Geological Survey.

CHEMICAL ANALYSES, WATER YEAR OCTOBER 1968 TO SEPTEMBER 1969

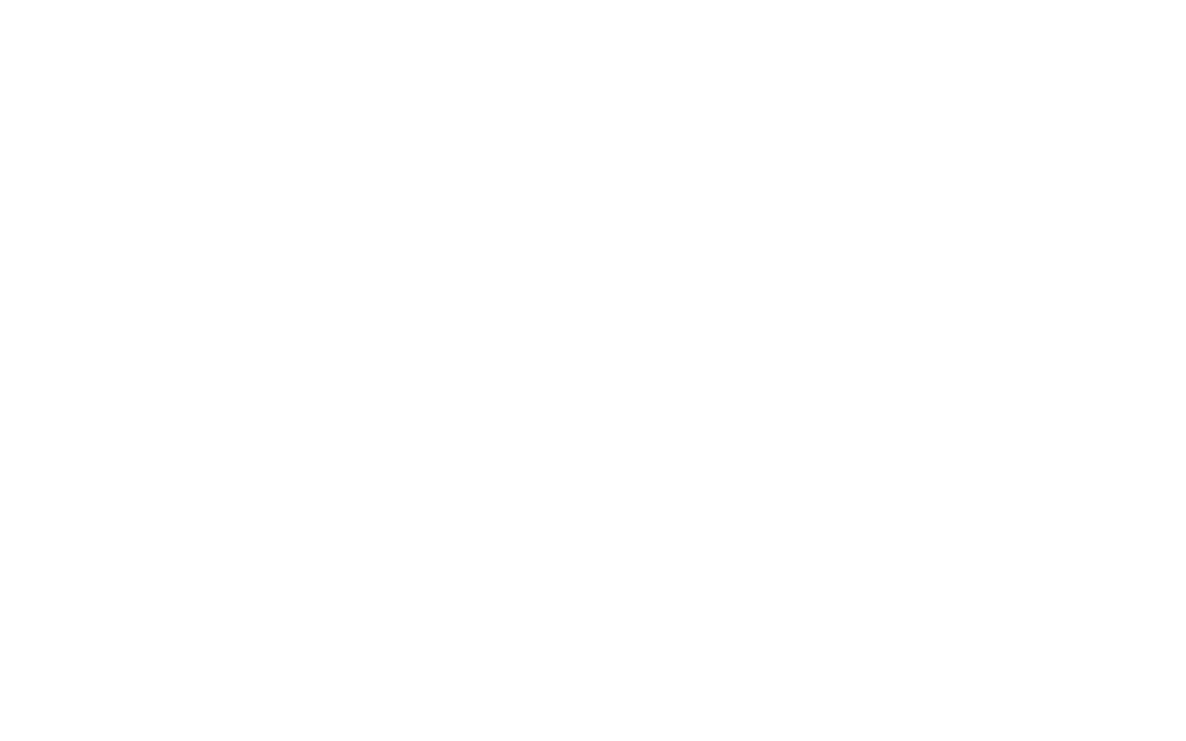


11525500 TRINITY RIVER AT LEWISTON, CALIF.--.-Cont1 nued

TEMPERATURE $\left({ }^{\circ} \mathrm{C}\right)$ OF WATER, WATER YEAR OCTOBER 1968 TO SEPTEMBER 1969

DAY

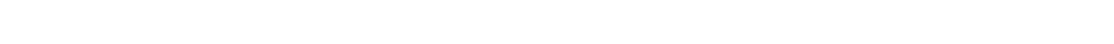

OCTOBER

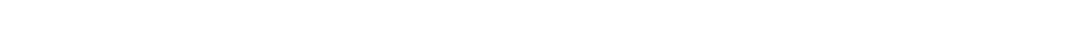

NOVEMBER

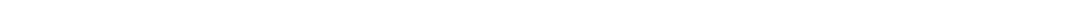

$\begin{array}{lllllllllllllllllllllllllllllllllll}\text { MINIMUM } & 9 & 9 & 9 & 9 & 9 & 9 & 9 & 9 & 9 & 9 & 9 & 9 & 9 & 9 & 9 & 8 & 8 & 8 & 8 & 8 & 8 & 8 & 8 & 8 & 8 & 8 & 8 & 8 & 8 & 8 & -- & 4\end{array}$

DECEMBER

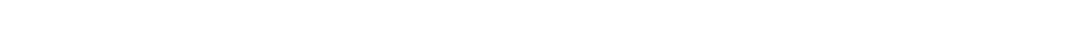

JANUARY

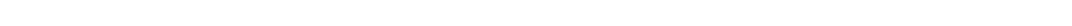

MINIMUM $60 \begin{array}{lllllllllllllllllllllllllllllll} & 6 & 6 & 6 & 6 & 6 & 6 & 6 & 6 & 6 & 5 & 5 & 5 & 5 & 5 & 5 & 5 & 5 & 5 & 5 & 5 & 5 & 5 & 5 & 4 & 4 & 4 & 4 & 4 & 4 & 4\end{array}$

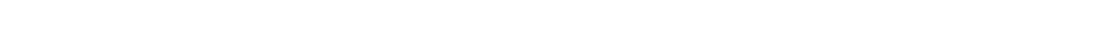

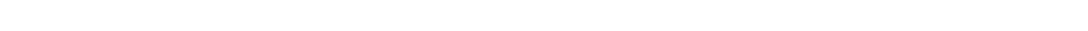

RCH

$\begin{array}{llllllllllllllllllllllllllllllllll}\text { MAXIMUM } & 5 & 5 & 6 & 6 & 6 & 6 & 6 & 6 & 6 & 6 & 6 & 6 & 6 & 7 & 7 & 7 & 7 & 7 & 7 & 7 & 7 & 8 & 8 & 8 & 8 & 9 & 9 & 9 & 9 & 9 & 9 \\ \text { MINIMUM } & 5 & 5 & 5 & 5 & 5 & 5 & 5 & 5 & 6 & 6 & 6 & 6 & 6 & 6 & 6 & 6 & 7 & 7 & 7 & 7 & 7 & 7 & 7 & 7 & 7 & 8 & 8 & 8 & 8 & 8 & 8\end{array}$

APRIL

$\begin{array}{llllllllllllllllllllllllllllllllllllllll}\text { MAXIMUM } & 9 & 8 & 9 & 9 & 9 & 9 & 9 & 9 & 9 & 10 & 10 & 10 & 10 & 10 & 10 & 10 & 10 & 10 & 11 & 11 & 11 & 11 & 10 & 11 & 11 & 11 & 11 & 11 & 11 & 11 & -- & 1 \\ \text { MINIMUM } & 8 & 8 & 8 & 8 & 8 & 8 & 8 & 8 & 8 & 9 & 9 & 9 & 9 & 9 & 9 & 9 & 9 & 9 & 9 & 9 & 9 & 9 & 9 & 9 & 9 & 9 & 9 & 9 & 9 & 9 & -- & & \end{array}$

MAY

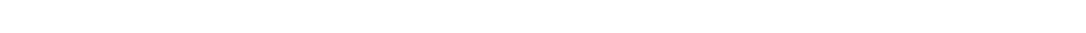
JUNE

MAXIMUM

MAXIMUM

JULY

MAXIMUM

MINIMUM

MAXI MUM

MINIMUM

SEP TEMBER

MAXIMUM

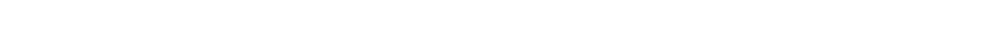

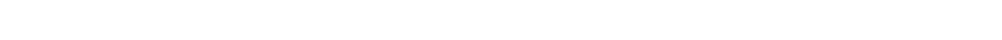

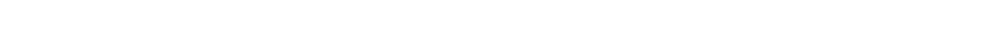

$\begin{array}{lllllllllllllllllllllllllllllllll}8 & 8 & 8 & 8 & 8 & 8 & 8 & 8 & 8 & 8 & 8 & 8 & 9 & 9 & 9 & 9 & 9 & 9 & 9 & 9 & 9 & 9 & 9 & 9 & 9 & 9 & 9 & 9 & 9 & 9 & -- & 9 & 9 \\ 8 & 8 & 8 & 8 & 8 & 8 & B & 8 & 8 & 8 & 8 & 8 & 8 & 8 & 8 & 8 & 8 & 8 & 9 & 9 & 8 & 8 & 8 & 8 & 8 & 8 & 8 & 8 & 8 & 8 & -- & & 8\end{array}$ 
11527000 TRINITY RIVER NEAR BURNT RANCH, CALIF.

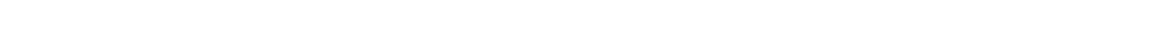
temperature recorder at gaging station on left bank, 500 ft upstream from Cedar Flat Creek, 700 ft upstream temperature recorder at gaging station on left bank,

DRAI NAGE AREA. $--1,439$ sq $\mathrm{mi}$.

PERIOD OF RECORD. --Chemica1 analyses: C tober 1958 to September 1966.

Water temperatures: October 1961 to September 1964, October 1966 to September 1967, October 1968 to September 1969.

EXTRSME S. $-1968-69$ :

Water temperatures: Maximum, $21.0^{\circ} \mathrm{C}$ Aug. 22; minimum, $4.0^{\circ} \mathrm{C} J a n .29,30$.

Period of record:

Water temperatures: Maximum, $27.0^{\circ} \mathrm{C}$ Aug. 17-19, 24, 1967; minimum (1962 63, 1966-67, 1968-69), 1.0 $0^{\circ} \mathrm{C}$ Dec, 28, 29,1966 .

Remarks, -- Recorder stopped Oct. 1-10, Dec. 15 to Jan. 8, Feb, 3-6.

TBUPERATURE $\left({ }^{\circ} \mathrm{C}\right)$ OF VATER, WATER YEAR OCTOBER 1968 TO SEPTEMBER 1969

DAY

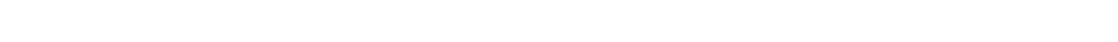

OCTOBFR

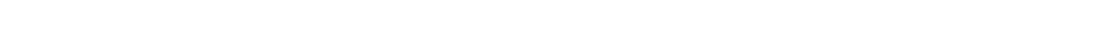

NOVEMBER

$\begin{array}{llllllllllllllllllllllllllllllllll}\text { MAXIMUM } & 12 & 12 & 12 & 12 & 12 & 11 & 12 & 13 & 13 & 13 & 13 & 12 & 10 & 8 & 9 & 9 & 10 & 11 & 11 & 10 & 11 & 11 & 11 & 10 & 9 & 9 & 9 & 8 & 9 & 8 & -2 & 11 \\ \text { MINIMUM } & 11 & 11 & 11 & 11 & 11 & 11 & 11 & 12 & 12 & 12 & 12 & 10 & 8 & 8 & 8 & 8 & 9 & 10 & 10 & 10 & 10 & 11 & 10 & 9 & 8 & 8 & 8 & 8 & 7 & 7 & -5 & 10\end{array}$

MAXIMUM

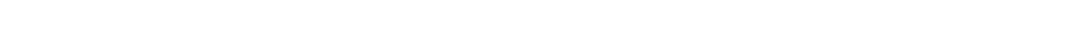

JANUARY

MAXIMUM

MINIMUM

$\begin{array}{lllllllllllllllllllllllllllllllllllllllll}\text { MAXIMUM } & 6 & 6 & \ldots & \ldots & \ldots & \ldots & 7 & 7 & 8 & 9 & 8 & 7 & 7 & 7 & 7 & 7 & 8 & 8 & 8 & 7 & 7 & 7 & 7 & 7 & 7 & 7 & 7 & 7 & \ldots & \ldots & \ldots\end{array}$

MINIMUM

RCH

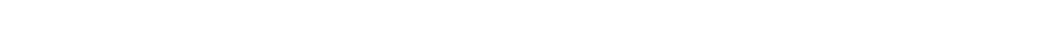

MINIMUM

APRIL

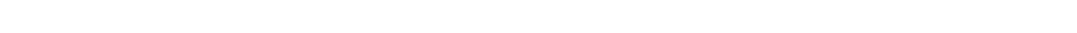

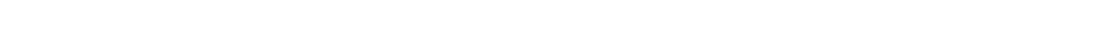

MAXINUM $9 \begin{array}{rrrrrrrrrrrrrrrrrrrrrrrrrrrrrrrrrrrrrr}10 & 8 & 12 & 13 & 13 & 13 & 12 & 12 & 12 & 12 & 12 & 10 & 11 & 11 & 12 & 12 & 11 & 11 & 12 & 12 & 12 & 12 & 12 & 10 & 9 & 10 & 11 & 11 & 9 & 12\end{array}$

JUNE MINIMUM $\quad \begin{array}{rlllllllllllllllllllllllllllllllll}8 & 10 & 11 & 12 & 12 & 12 & 12 & 11 & 11 & 10 & 11 & 11 & 12 & 12 & 13 & 12 & 13 & 13 & 13 & 12 & 12 & 13 & 13 & 13 & 12 & 12 & 11 & 11 & 11 & 12 & -\end{array}$ Jury

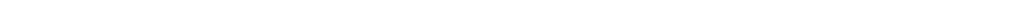
AINIMUM $12 \quad 13 \quad 13 \quad 12 \quad 13 \quad 13 \quad 13 \quad 14 \quad 14 \quad 14 \quad 14 \quad 14 \quad 15 \quad 15 \quad 1515 \quad 15 \quad 14 \quad 15 \quad 15 \quad 16 \quad 16 \quad 16 \quad 16 \quad 16 \quad 16 \quad 15 \quad 15 \quad 15 \quad 15 \quad 16$ AUGUST

MAXIMUM $19191918 \quad 1818 \quad 18 \quad 1918191818 \quad 1818 \quad 18181919192020 \quad 21 \quad 201919191618191920$

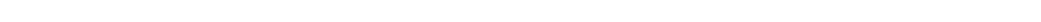

SEPTEMBFR

$\begin{array}{llllllllllllllllllllllllllllllll}\text { MAXIMUM } & 20 & 20 & 19 & 19 & 20 & 20 & 19 & 19 & 20 & 20 & 20 & 19 & 19 & 19 & 18 & 18 & 18 & 18 & 17 & 17 & 18 & 18 & 18 & 18 & 18 & 18 & 18 & 18 & 18 & 17 & - \\ \text { MINIMUM } & 16 & 16 & 16 & 16 & 16 & 16 & 17 & 17 & 17 & 17 & 17 & 17 & 16 & 15 & 15 & 15 & 15 & 16 & 16 & 15 & 15 & 15 & 16 & 16 & 16 & 16 & 16 & 15 & 15 & 15 & --\end{array}$ . 7 6 9

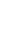


11528500 HAYFORK CREEK NEAR HYAMPOM, CALIF.

LOCATrON, -- Lat $40^{\circ} 37^{\prime} 35^{\prime \prime}$, long $123^{\circ} 28^{\circ} 00^{\prime \prime}$, In NW 1 sec. 19, T. 3 N., R. 7 E., Trinity County, temperature recorder at gaging station on right bank, $1.2 \mathrm{miles}$ upstream from mouth and 1.3 miles northeast of Hyampom,

DRAINAGE AREA, - 378 sq $m 1$.

PERIOD OF RECORD, - Water temperatures: December 1960 to September 1969.

EXTREMES. - Period of record:

Water temperatures: Maximum (1960-61, 1962-66, 1967-68), 28.5 $5^{\circ} \mathrm{July} 13,1961$; minimun, freezing point on several days in January 1962 and 1968 .

REMARKS.--Recorder stopped Jan. 13 to June 9, June 12-25, June 28 to Sept. 30. Where no maximum or minimum 1s show, temperature is once-dally reading.

TEITPEATURE $\left({ }^{\circ} \mathrm{C}\right)$ OF WATER, WATER YEAR OCTOBER 1968 TO SEPTEMBER 1969

DAY

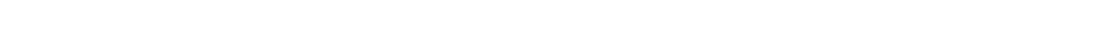

OCtOBER. . --

$\begin{array}{lllllllllllllllllllllllllllllllllllllllll}\text { MAXIMUM } & 17 & 17 & 17 & 16 & 17 & 16 & 15 & 13 & 13 & 14 & 13 & 13 & 14 & 12 & 12 & 13 & 13 & 13 & 12 & 12 & 12 & 12 & 12 & 12 & 12 & 12 & 12 & 11 & 11 & 12 & 12 & 13 \\ \text { MINIMUM } & 14 & 14 & 14 & 14 & 14 & 14 & 13 & 12 & 11 & 11 & 13 & 13 & 12 & 11 & 11 & 11 & 11 & 11 & 12 & 11 & 11 & 10 & 10 & 10 & 10 & 10 & 10 & 10 & 11 & 11 & 11 & 12\end{array}$

NOVEMBER. $\begin{array}{lllllllllllllllllllllllllllllllllll}\text { MAXIMUM } & 11 & 11 & 12 & 11 & 11 & 10 & 11 & 12 & 13 & 13 & 13 & 12 & 11 & 9 & 6 & 6 & 8 & 9 & 9 & 9 & 9 & 9 & 9 & 9 & 8 & 8 & 8 & 7 & 6 & 6 & -1 \\ \text { MINIMUM } & 11 & 11 & 11 & 10 & 10 & 10 & 10 & 11 & 12 & 12 & 12 & 10 & 8 & 6 & 5 & 5 & 6 & 8 & 9 & 8 & 8 & 9 & 8 & 8 & 7 & 7 & 7 & 6 & 6 & 6 & -2\end{array}$

DFCEMBER.

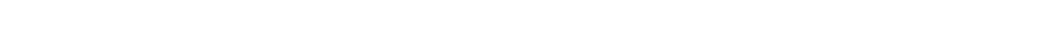

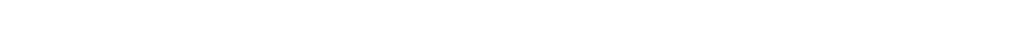

JANUARY.:

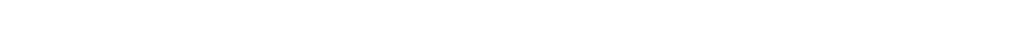

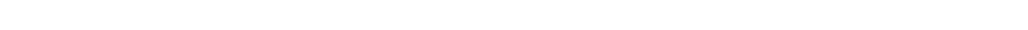

FERRUAR,

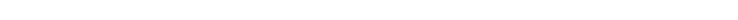

MARCH.... MAXIMUM MINIMUM -APRIL. MAXIRUA

MYNINOA

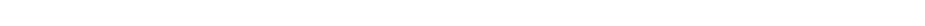
MAXIMUM MINIMUM

MAXIMÜ MINIMUM махіми MaximuM MINIMUM -

AUGST:Mi:

MAXIMUH SEPTEMBER - -

MAXIMUM

MAXIMUM 
11528700 SOUTH FORK TRINITY RIVER BELOW HYAMPOK, CALIF.

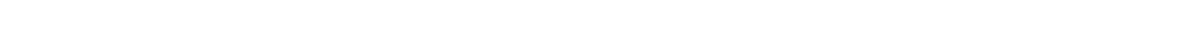
est, at gaging station 0.3 mile downstream from Big Creek, $3.0 \mathrm{~m} 1 \mathrm{les}$ northeast of Hyampom, and $3.5 \mathrm{mtles}$ downstream from Hayfork Creek.

DRAINAGE AREA, $--764 \mathrm{sq} \mathrm{mt}$.

PERIOD OF RECORD.--Water temperatures: October 1965 to September 1969.

Sediment records: October 1966 to September 1969.

EXTREMES. --1968-69:

Water temperatures: Maximum, $27.0^{\circ} \mathrm{C}$ July 21-23, 25, 26; minimum, freezing point Dec. 22-24.

Sedment concentrations: Maximum datiy, 3,570 $\mathrm{mg} / 1$ Jan. 21 ; minimum datIy, $1 \mathrm{mg} / 1$ on several days during

September.
Sedtment discharge: Maximum dally, 326,000 tons Jan. 21; mintmum dally, 0.41 ton Sept. 30.

Period of record:

Water temperatures: Maximum, $29.0^{\circ} \mathrm{C}$ June 30 , July 1, 3, 1967, Aug. 1, 2, 1968; mintmum, freezing point on several days in $1965,1967-68$.

Sedtment concentrattons: Maximum da11y, 3,890 mg/1 Jan. 29, 1967; mintmum da1ly, $1 \mathrm{mg} / 1$ on several days in

1967-69,
Sediment discharge: Maximum datly, 326,000 tons Jan. 21, 1969; minimum dally, 0.28 ton July $29,1968$.

REMARKS, -Temperature recorder stopped Mar. 10-15. Where no maximum or mintmum ts shown, temperature ts oncedaily reading.

TEMPERATURE $\left({ }^{\circ} \mathrm{C}\right.$ ) OF WATER, WATER YEAR OCTOBER 1968 TO SEPTEMBER 1969

DAY

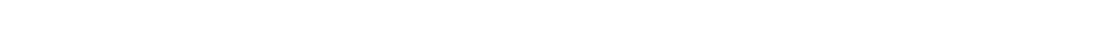

OCTOBER.. - - - - - - -

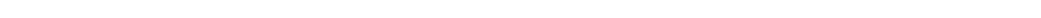

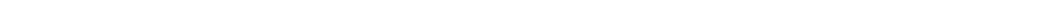

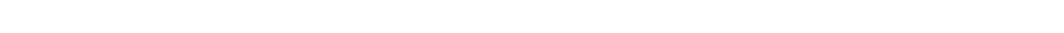

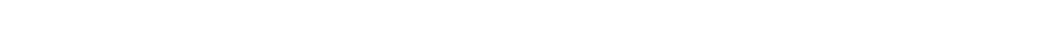

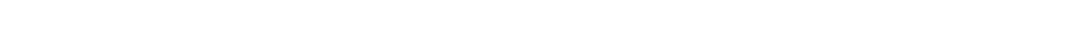

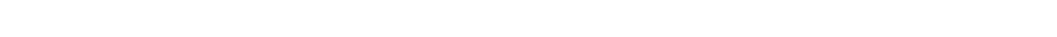

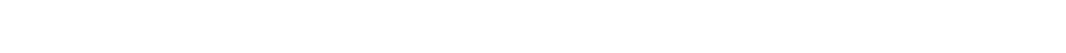

$\begin{array}{lllllllllllllllllllllllllllllllll}\text { MAXIMUM } & 4 & 5 & 5 & 5 & 5 & 5 & 4 & 4 & 2 & 4 & 4 & 5 & 5 & 5 & 5 & 5 & 4 & 4 & 4 & 6 & 6 & 5 & 4 & 4 & 6 & 6 & 3 & 3 & 2 & 3 & 3 \\ \text { MINIMUM } & 3 & 3 & 3 & 3 & 3 & 3 & 3 & 2 & 1 & 2 & 3 & 3 & 4 & 5 & 4 & 4 & 3 & 3 & 3 & 4 & 5 & 4 & 3 & 3 & 4 & 3 & 3 & 2 & 1 & 2 & 2\end{array}$

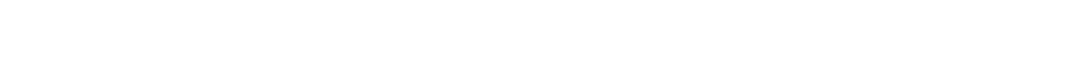

MARCH....

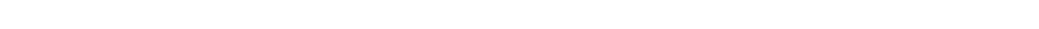

APRIL...:

MINIMUM $60 \begin{array}{lllllllllllllllllllllllllllllll} & 6 & 5 & 6 & 7 & 6 & 6 & 6 & 7 & 6 & 6 & 6 & 5 & 6 & 6 & 6 & 7 & 7 & 7 & 7 & 8 & 8 & 8 & 5 & 5 & 6 & 6 & 7 & 6 & 5 & --\end{array}$

MAY...... - - -

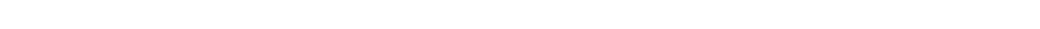

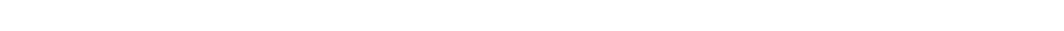

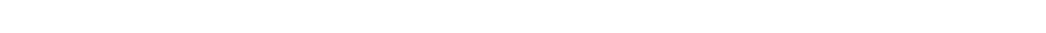

$\begin{array}{lllllllllllllllllllllllllllllllll}\text { JuXIMUM } & 22 & 22 & 22 & 22 & 22 & 23 & 23 & 25 & 25 & 25 & 24 & 24 & 26 & 26 & 25 & 26 & 26 & 25 & 26 & 26 & 27 & 27 & 27 & 26 & 27 & 27 & 25 & 26 & 26 & 26 & 25\end{array}$

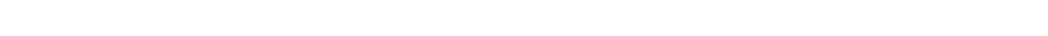

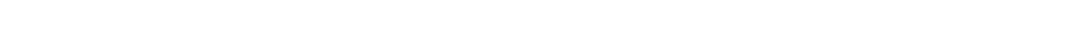

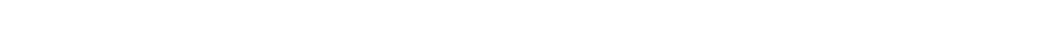

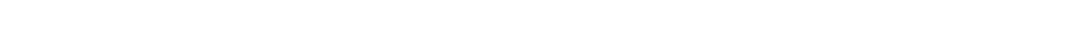

$\begin{array}{lllllllllllllllllllllllllllllllll}\text { MAXIMUM } & 25 & 23 & 23 & 24 & 24 & 25 & 23 & 24 & 24 & 24 & 24 & 24 & 23 & 23 & 23 & 23 & 23 & 19 & 18 & 20 & 21 & 22 & 20 & 22 & 22 & 22 & 21 & 22 & 20 & 20 & -- \\ \text { MINIMUM } & 15 & 16 & 15 & 15 & 15 & 15 & 17 & 16 & 17 & 16 & 16 & 16 & 15 & 14 & 14 & 15 & 15 & 16 & 16 & 15 & 15 & 14 & 15 & 16 & 15 & 15 & 15 & 14 & 15 & 14 & --\end{array}$

PARTICLE-SIZE DISTRIBUTIDN DF SUSPENDED SEDIMENT, WATER YEAR OCTDBER 1968 TO SEPTEMBER 1969

IMETHODS OF ANALYSIS: B, BOTTOM WITHDRAWAL IUBE: C, CHEMICALLY DISPERSEO: N. IN NATIVE WATER: P, PIPET: S, SIEVE: $V$, VISUAL ACCUMULATION TUBE; W, IN OISTILLEO WATER)

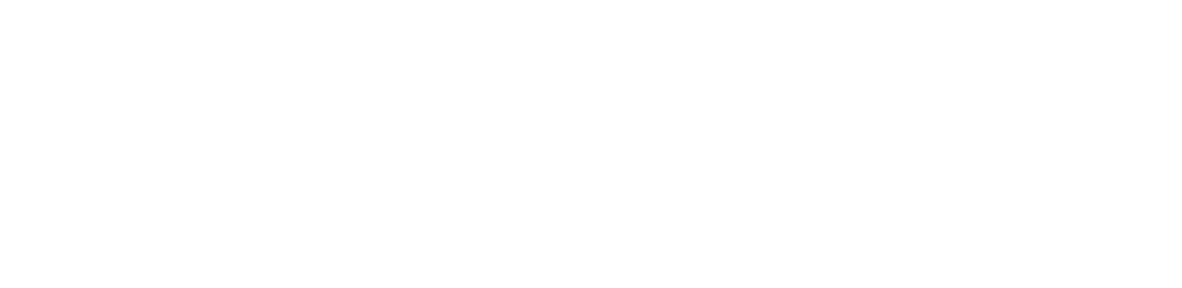

D DAILY MEAN DISCHARGE.

PARTICLE-SIZE DISTRIBUTION OF SURFACE BED MATERIAL, WATER YEAR OCTOBER 1968 TO SEPTEMBER 1969

(METHOD JF ANALYSIS: H, HYOROMETER: O, OPTICAL ANALYZER; S, SIEVE; $V$, VISUAL ACCUMULATION TUBE)

$$
\text { HATER NUMBER PARTICLE SIZE }
$$

TEM- OF

PERA- SAM-

OATE TIME TURE PLING DISCHARGE

PERCENT FINER than the SIZE IIN MILLIMETERSI INOICATEO

MAR 28,19690900

6060

062

\begin{tabular}{rr}
.250 & .500 \\
\hline & 7
\end{tabular}

$\begin{array}{lllllll}1.00 & 2.00 & 4.00 & 8.00 & 16.0 & 32.0 & 64.0\end{array}$ 
11528700 SOUTH FORK TRINITY RIVER BELOW HYAMPOH, CALIF.--Cont1 nued

SUSPENDED-SEDIMENT DISCHARGE, WATER YEAR OCTOBER 1968 TO SEPTEMBER 1969

$$
\text { DCTDBER }
$$

NOVEMBER

DECEMBER

\begin{tabular}{|c|c|c|c|c|c|c|c|c|c|}
\hline DAY & $\begin{array}{l}\text { MEAN } \\
\text { OISCHARGE } \\
\text { (CFS) }\end{array}$ & $\begin{array}{l}\text { MEAN } \\
\text { CONCEN- } \\
\text { TRATION } \\
\text { (MG/L) }\end{array}$ & $\begin{array}{l}\text { SEDIMENT } \\
\text { DISCHARGE } \\
\text { (TONS/DAY) }\end{array}$ & $\begin{array}{l}\text { MEAN } \\
\text { DISCHARGE } \\
\text { (CFS) }\end{array}$ & $\begin{array}{l}\text { MEAN } \\
\text { CDNCEN- } \\
\text { TRATIDN } \\
\text { (MG/L) }\end{array}$ & $\begin{array}{l}\text { SEDIMENT } \\
\text { DISCHARGE } \\
\text { (TONS/DAY) }\end{array}$ & $\begin{array}{l}\text { MEAN } \\
\text { DISCHARGE } \\
\text { (CFS) }\end{array}$ & $\begin{array}{l}\text { MEAN } \\
\text { CONCEN- } \\
\text { IRATIDN } \\
\text { (MG/L) }\end{array}$ & $\begin{array}{c}\text { SEDIMENT } \\
\text { DISCHARGE } \\
\text { (TONS/DAY) }\end{array}$ \\
\hline $\begin{array}{l}1 \\
2 \\
3 \\
4 \\
5\end{array}$ & $\begin{array}{l}62 \\
62 \\
62 \\
62 \\
62\end{array}$ & $\begin{array}{l}3 \\
5 \\
8 \\
8 \\
6\end{array}$ & $\begin{array}{l}.50 \\
.84 \\
1.3 \\
1.3 \\
1.0\end{array}$ & $\begin{array}{l}130 \\
295 \\
450 \\
260 \\
218\end{array}$ & $\begin{array}{r}4 \\
172 \\
110 \\
27 \\
10\end{array}$ & $\begin{array}{c}1.4 \\
159 \\
134 \\
19 \\
5.9\end{array}$ & $\begin{array}{l}335 \\
320 \\
310 \\
305 \\
295\end{array}$ & $\begin{array}{l}25 \\
25 \\
25 \\
30 \\
50\end{array}$ & $\begin{array}{l}23 \\
22 \\
21 \\
25 \\
40\end{array}$ \\
\hline $\begin{array}{r}6 \\
7 \\
8 \\
9 \\
10\end{array}$ & $\begin{array}{l}62 \\
62 \\
62 \\
62 \\
62\end{array}$ & $\begin{array}{l}5 \\
4 \\
4 \\
5 \\
5\end{array}$ & $\begin{array}{l}.84 \\
.67 \\
.67 \\
.67 \\
.84\end{array}$ & $\begin{array}{l}174 \\
161 \\
154 \\
154 \\
154\end{array}$ & $\begin{array}{r}10 \\
9 \\
8 \\
8 \\
7\end{array}$ & $\begin{array}{l}4.7 \\
3.9 \\
3.3 \\
3.3 \\
2.9\end{array}$ & $\begin{array}{r}330 \\
370 \\
580 \\
700 \\
6000\end{array}$ & $\begin{array}{r}87 \\
160 \\
257 \\
215 \\
1520\end{array}$ & $\begin{array}{r}78 \\
160 \\
402 \\
406 \\
24600\end{array}$ \\
\hline $\begin{array}{l}11 \\
12 \\
13 \\
14 \\
15\end{array}$ & $\begin{array}{l}73 \\
144 \\
186 \\
152 \\
144\end{array}$ & $\begin{array}{l}6 \\
7 \\
6 \\
5 \\
4\end{array}$ & $\begin{array}{l}1.2 \\
2.7 \\
3.0 \\
2.1 \\
1.6\end{array}$ & $\begin{array}{l}161 \\
274 \\
289 \\
244 \\
252\end{array}$ & $\begin{array}{r}7 \\
32 \\
45 \\
20 \\
8\end{array}$ & $\begin{array}{l}3.0 \\
24 \\
35 \\
13 \\
5.4\end{array}$ & $\begin{array}{l}4600 \\
3000 \\
2100 \\
2400 \\
5500\end{array}$ & $\begin{array}{r}1320 \\
810 \\
650 \\
720 \\
1410\end{array}$ & $\begin{array}{r}16400 \\
6560 \\
3690 \\
4670 \\
20900\end{array}$ \\
\hline $\begin{array}{l}16 \\
17 \\
18 \\
19 \\
20\end{array}$ & $\begin{array}{l}126 \\
113 \\
108 \\
104 \\
102\end{array}$ & $\begin{array}{l}3 \\
3 \\
3 \\
3 \\
3\end{array}$ & $\begin{array}{l}1.0 \\
.92 \\
.87 \\
.84 \\
.83\end{array}$ & $\begin{array}{l}246 \\
258 \\
420 \\
690 \\
500\end{array}$ & $\begin{array}{r}9 \\
15 \\
30 \\
40 \\
42\end{array}$ & $\begin{array}{l}6.0 \\
10 \\
34 \\
75 \\
57\end{array}$ & $\begin{array}{l}3700 \\
2580 \\
2150 \\
1980 \\
1750\end{array}$ & $\begin{array}{r}495 \\
225 \\
165 \\
100 \\
55\end{array}$ & $\begin{array}{r}4950 \\
1570 \\
958 \\
535 \\
260\end{array}$ \\
\hline $\begin{array}{l}21 \\
22 \\
23 \\
24 \\
25\end{array}$ & $\begin{array}{r}102 \\
100 \\
99 \\
99 \\
99\end{array}$ & $\begin{array}{l}3 \\
3 \\
4 \\
5 \\
5\end{array}$ & $\begin{array}{l}.83 \\
.81 \\
1.1 \\
1.3 \\
1.3\end{array}$ & $\begin{array}{l}390 \\
330 \\
300 \\
300 \\
440\end{array}$ & $\begin{array}{l}35 \\
25 \\
18 \\
13 \\
10\end{array}$ & $\begin{array}{l}37 \\
22 \\
15 \\
11 \\
12\end{array}$ & $\begin{array}{l}1620 \\
1530 \\
1920 \\
3920 \\
3480\end{array}$ & $\begin{array}{r}45 \\
43 \\
76 \\
187 \\
121\end{array}$ & $\begin{array}{r}197 \\
178 \\
541 \\
2020 \\
1140\end{array}$ \\
\hline $\begin{array}{l}26 \\
27 \\
28 \\
29 \\
30 \\
31\end{array}$ & $\begin{array}{r}99 \\
95 \\
95 \\
97 \\
142 \\
152\end{array}$ & $\begin{array}{l}5 \\
4 \\
4 \\
4 \\
5 \\
5\end{array}$ & $\begin{array}{l}1.3 \\
1.0 \\
1.0 \\
1.0 \\
1.9 \\
2.1\end{array}$ & $\begin{array}{r}360 \\
315 \\
280 \\
265 \\
300 \\
--\end{array}$ & $\begin{array}{l}12 \\
17 \\
23 \\
25 \\
25 \\
--\end{array}$ & $\begin{array}{l}12 \\
14 \\
17 \\
18 \\
20 \\
--\end{array}$ & $\begin{array}{l}2600 \\
2200 \\
2110 \\
2060 \\
1920 \\
1800\end{array}$ & $\begin{array}{l}89 \\
70 \\
60 \\
60 \\
57 \\
50\end{array}$ & $\begin{array}{l}625 \\
416 \\
342 \\
334 \\
295 \\
243\end{array}$ \\
\hline TDTAL & $305 \mathrm{~L}$ & -- & 37.33 & 8764 & -- & 777.8 & 64465 & -- & 92601 \\
\hline DAY & $\begin{array}{l}\text { MEAN } \\
\text { DISCHARGE } \\
\text { (CFS) }\end{array}$ & $\begin{array}{l}\text { JANUARY } \\
\text { MEAN } \\
\text { CONCEN- } \\
\text { TRATION } \\
\text { (MGG/L) }\end{array}$ & $\begin{array}{l}\text { SED I MENT } \\
\text { D I SCHARGE } \\
\text { (TONS / DAY) }\end{array}$ & $\begin{array}{l}\text { MEAN } \\
\text { DISCHARGE } \\
\text { (CFS) }\end{array}$ & $\begin{array}{l}\text { FEBRUARY } \\
\text { MEAN } \\
\text { CDNCEN- } \\
\text { TRATION } \\
\text { (MG/L) }\end{array}$ & $\begin{array}{l}\text { SEDIMENT } \\
\text { DISCHARGE } \\
\text { (TDNS/DAY) }\end{array}$ & $\begin{array}{c}\text { MEAN } \\
\text { DISCHARGE } \\
\text { (CFS) }\end{array}$ & $\begin{array}{l}\text { MARCH } \\
\text { MEAN } \\
\text { CONCEN- } \\
\text { TRATIDN } \\
\text { (MG/L) }\end{array}$ & $\begin{array}{l}\text { SEDIMENT } \\
\text { DISCHARGE } \\
\text { (TONS /DAY) }\end{array}$ \\
\hline $\begin{array}{l}1 \\
2 \\
3 \\
4 \\
5\end{array}$ & $\begin{array}{l}1750 \\
1750 \\
1790 \\
2000 \\
2350\end{array}$ & $\begin{array}{l}40 \\
36 \\
36 \\
45 \\
64\end{array}$ & $\begin{array}{l}189 \\
170 \\
174 \\
243 \\
406\end{array}$ & $\begin{array}{l}2700 \\
2480 \\
2330 \\
2270 \\
2310\end{array}$ & $\begin{array}{l}600 \\
550 \\
520 \\
485 \\
470\end{array}$ & $\begin{array}{l}4370 \\
3680 \\
3270 \\
2970 \\
2930\end{array}$ & $\begin{array}{l}2630 \\
2580 \\
2570 \\
2400 \\
2340\end{array}$ & $\begin{array}{l}90 \\
90 \\
92 \\
90 \\
92\end{array}$ & $\begin{array}{l}639 \\
627 \\
638 \\
583 \\
581\end{array}$ \\
\hline $\begin{array}{r}6 \\
7 \\
8 \\
9 \\
10\end{array}$ & $\begin{array}{l}2630 \\
2710 \\
2690 \\
2460 \\
2270\end{array}$ & $\begin{array}{l}280 \\
600 \\
740 \\
770 \\
670\end{array}$ & $\begin{array}{l}1990 \\
4390 \\
5370 \\
5110 \\
4110\end{array}$ & $\begin{array}{l}2240 \\
2070 \\
2220 \\
4510 \\
4460\end{array}$ & $\begin{array}{r}450 \\
440 \\
562 \\
1550 \\
1280\end{array}$ & $\begin{array}{r}2720 \\
2460 \\
3630 \\
18900 \\
15500\end{array}$ & $\begin{array}{l}2350 \\
2290 \\
2170 \\
2110 \\
2040\end{array}$ & $\begin{array}{l}90 \\
88 \\
90 \\
92 \\
94\end{array}$ & $\begin{array}{l}571 \\
544 \\
527 \\
524 \\
518\end{array}$ \\
\hline $\begin{array}{l}11 \\
12 \\
13 \\
14 \\
15\end{array}$ & $\begin{array}{r}2990 \\
22900 \\
33800 \\
13600 \\
7420\end{array}$ & $\begin{array}{r}929 \\
3430 \\
2930 \\
1600 \\
900\end{array}$ & $\begin{array}{r}8820 \\
234000 \\
275000 \\
61600 \\
18000\end{array}$ & $\begin{array}{r}10700 \\
10400 \\
6300 \\
4950 \\
4810\end{array}$ & $\begin{array}{r}1990 \\
1130 \\
660 \\
460 \\
320\end{array}$ & $\begin{array}{r}57900 \\
31700 \\
11200 \\
6150 \\
4160\end{array}$ & $\begin{array}{l}1950 \\
1890 \\
1840 \\
1820 \\
1860\end{array}$ & $\begin{array}{r}97 \\
102 \\
107 \\
112 \\
116\end{array}$ & $\begin{array}{l}511 \\
521 \\
532 \\
550 \\
583\end{array}$ \\
\hline $\begin{array}{l}16 \\
17 \\
18 \\
19 \\
20\end{array}$ & $\begin{array}{r}5120 \\
3790 \\
3360 \\
8780 \\
28600\end{array}$ & $\begin{array}{r}550 \\
390 \\
375 \\
1500 \\
3540\end{array}$ & $\begin{array}{r}7600 \\
3990 \\
3400 \\
46800 \\
290000\end{array}$ & $\begin{array}{l}4610 \\
4020 \\
3740 \\
3540 \\
3340\end{array}$ & $\begin{array}{l}220 \\
165 \\
150 \\
130 \\
118\end{array}$ & $\begin{array}{l}2740 \\
1790 \\
1510 \\
1240 \\
1060\end{array}$ & $\begin{array}{l}2010 \\
2530 \\
3610 \\
3470 \\
3340\end{array}$ & $\begin{array}{l}124 \\
158 \\
196 \\
175 \\
148\end{array}$ & $\begin{array}{r}673 \\
1080 \\
1910 \\
1640 \\
1330\end{array}$ \\
\hline $\begin{array}{l}21 \\
22 \\
23 \\
24 \\
25\end{array}$ & $\begin{array}{r}32500 \\
15500 \\
10300 \\
7540 \\
7440\end{array}$ & $\begin{array}{r}3570 \\
1830 \\
950 \\
540 \\
400\end{array}$ & $\begin{array}{r}326000 \\
79300 \\
26400 \\
11000 \\
8040\end{array}$ & $\begin{array}{l}3080 \\
2830 \\
2780 \\
2720 \\
2650\end{array}$ & $\begin{array}{l}115 \\
113 \\
112 \\
110 \\
108\end{array}$ & $\begin{array}{l}956 \\
863 \\
841 \\
808 \\
773\end{array}$ & $\begin{array}{l}3620 \\
3830 \\
4130 \\
4200 \\
4290\end{array}$ & $\begin{array}{l}126 \\
115 \\
113 \\
113 \\
115\end{array}$ & $\begin{array}{l}1230 \\
1190 \\
1260 \\
1280 \\
1330\end{array}$ \\
\hline $\begin{array}{l}26 \\
27 \\
28 \\
29 \\
30 \\
31\end{array}$ & $\begin{array}{r}12800 \\
7480 \\
5170 \\
3960 \\
3290 \\
2830\end{array}$ & $\begin{array}{r}1980 \\
1530 \\
1100 \\
860 \\
725 \\
660\end{array}$ & $\begin{array}{r}70500 \\
32900 \\
15400 \\
9200 \\
6440 \\
5040\end{array}$ & $\begin{array}{r}2410 \\
2410 \\
2720 \\
=- \\
=- \\
=-\end{array}$ & $\begin{array}{r}104 \\
100 \\
93 \\
=- \\
-0 \\
-\end{array}$ & $\begin{array}{r}677 \\
651 \\
683 \\
-- \\
-- \\
--\end{array}$ & $\begin{array}{l}4590 \\
5390 \\
6380 \\
7230 \\
7870 \\
7540\end{array}$ & $\begin{array}{l}120 \\
135 \\
160 \\
200 \\
265 \\
265\end{array}$ & $\begin{array}{l}3810 \\
1960 \\
2760 \\
3900 \\
5630 \\
5390\end{array}$ \\
\hline OTAL & 261570 & -- & 1561582 & 105600 & -- & 186132 & 106870 & -- & 44822 \\
\hline
\end{tabular}


KLAMATH RIVER BASIN

11528700 SOUTH FORK TRINITY RIVER BELOW HYAMPOH, CALIF,--Cont1 nued

SUSPENDED-SEDIMENT DISCHARGE, WATER YEAR OCTOBER 1968 TO SEPTEMBER 1969

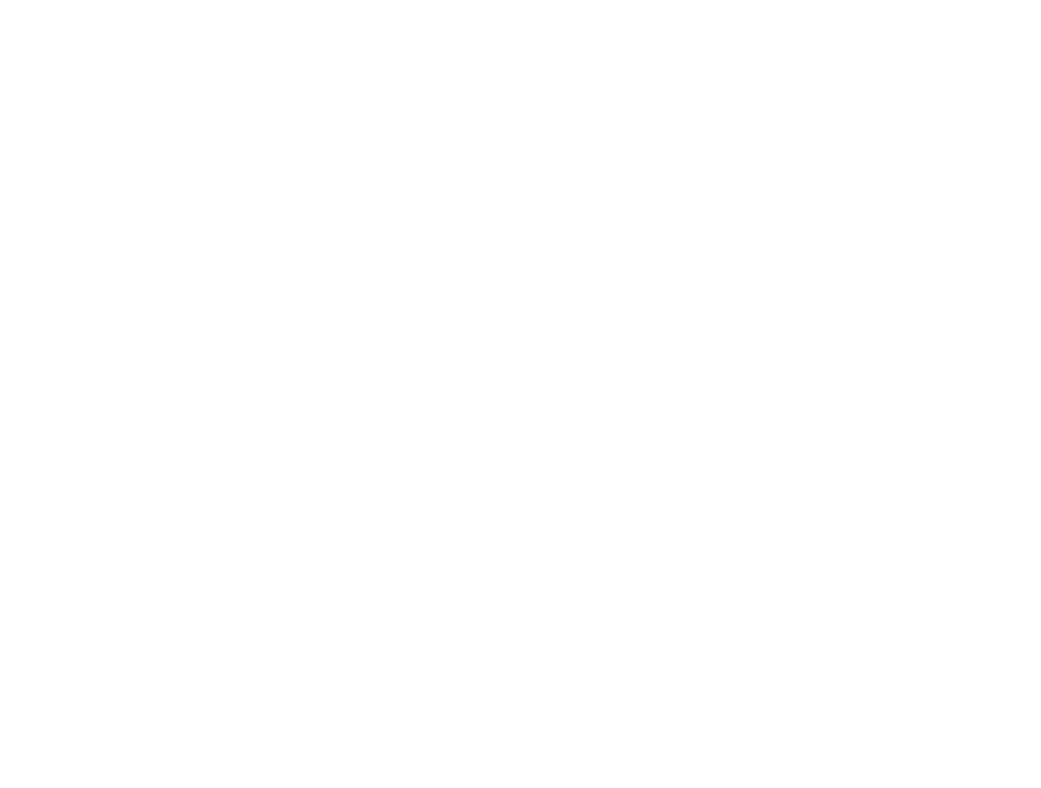

\begin{tabular}{|c|c|c|c|c|c|c|c|c|c|}
\hline \multirow[b]{2}{*}{ DAY } & \multicolumn{3}{|c|}{ JULY } & \multicolumn{3}{|c|}{ AUGUST } & \multicolumn{3}{|c|}{ SEPTE MBER } \\
\hline & $\begin{array}{c}\text { MEAN } \\
\text { OISCHARGF } \\
\text { (CFS) }\end{array}$ & $\begin{array}{l}\text { MEAN } \\
\text { CONCEN- } \\
\text { TRATION } \\
\text { (MG/L) }\end{array}$ & $\begin{array}{l}\text { SEDIMENT } \\
\text { DISCHARGE } \\
\text { (TONS/DAY) }\end{array}$ & $\begin{array}{l}\text { MEAN } \\
\text { DISCHARGE } \\
\text { (CF5) }\end{array}$ & $\begin{array}{l}\text { MEAN } \\
\text { CONCEN- } \\
\text { TRATION } \\
\text { (MG/L) }\end{array}$ & $\begin{array}{l}\text { SEDIMENT } \\
\text { DI SCHARGE } \\
\text { (TONS/DAY) }\end{array}$ & $\begin{array}{l}\text { KEAN } \\
\text { DISCHARGE } \\
\text { (CFS) }\end{array}$ & $\begin{array}{l}\text { MEAN } \\
\text { CONCEN- } \\
\text { IRATION } \\
\text { (MG/L) }\end{array}$ & $\begin{array}{l}\text { SEDIMENT } \\
\text { DI SCHARGE } \\
\text { (TONS/DAY) }\end{array}$ \\
\hline 1 & 328 & 2 & 1.8 & 176 & 7 & 3.3 & 106 & 8 & 2.3 \\
\hline 2 & 319 & 2 & 1.7 & 173 & 10 & 4.7 & 105 & 7 & 2.0 \\
\hline 3 & 307 & 2 & 1.7 & 169 & 13 & 5.9 & 103 & 7 & 1.9 \\
\hline 4 & 304 & 3 & 2.5 & 164 & 13 & 5.8 & 100 & 7 & 1.9 \\
\hline 5 & 301 & 3 & 2.4 & 160 & 12 & 5.2 & 100 & $B$ & 2.2 \\
\hline 6 & 290 & 3 & 2.3 & 159 & 12 & 5.2 & 100 & 9 & 2.4 \\
\hline 7 & 277 & 2 & 1.5 & 155 & 11 & 4.6 & 100 & 9 & 2.4 \\
\hline 8 & 274 & 2 & 1.5 & 154 & 11 & 4.6 & 99 & 9 & 2.4 \\
\hline 9 & 274 & 4 & 3.0 & 151 & 10 & 4.1 & 99 & 9 & 2.4 \\
\hline 10 & 274 & 4 & 3.0 & 151 & 10 & 4.1 & 100 & 8 & 2.2 \\
\hline 11 & 269 & 3 & 2.2 & 148 & 10 & 4.0 & 98 & B & 2.1 \\
\hline 12 & 252 & 4 & 2.7 & 144 & 10 & 3.9 & 97 & 7 & 1.8 \\
\hline 13 & 241 & 5 & 3.3 & 142 & 10 & 3.8 & 96 & 7 & 1.8 \\
\hline 14 & 238 & 2 & 1.3 & 138 & 12 & 4.5 & 93 & 6 & 1.5 \\
\hline 15 & 227 & 5 & 3.1 & 137 & 15 & 5.5 & 91 & 5 & 1.2 \\
\hline 16 & 225 & 6 & 3.6 & 135 & 20 & 7.3 & 90 & 5 & 1.2 \\
\hline 17 & 225 & 4 & 2.4 & 132 & 16 & 5.7 & 143 & 4 & 1.5 \\
\hline 18 & 219 & 3 & 1.8 & 132 & 12 & 4.3 & 156 & 3 & 1.3 \\
\hline 19 & 215 & 2 & 1.2 & 129 & 9 & 3.1 & 169 & 3 & 1.4 \\
\hline 20 & 216 & 2 & 1.2 & 125 & 9 & 3.0 & 193 & 3 & 1.6 \\
\hline 21 & 218 & 2 & 1.2 & 124 & 9 & 3.0 & 193 & 3 & 1.6 \\
\hline 22 & 217 & 3 & 1.8 & 123 & 9 & 3.0 & $\begin{array}{l}150 \\
150\end{array}$ & 2 & .81 \\
\hline 23 & 214 & 4 & 2.3 & 123 & 9 & 3.0 & 158 & 2 & .85 \\
\hline 24 & 212 & 4 & 2.3 & 118 & 9 & 2.9 & 170 & 1 & .46 \\
\hline 25 & 206 & 5 & 2.8 & 112 & 8 & 2.4 & 184 & i & .50 \\
\hline 26 & 204 & 5 & 2.8 & 111 & 8 & 2.4 & 190 & 1 & .51 \\
\hline 27 & 195 & 4 & 2.1 & 109 & 8 & 2.4 & 190 & $i$ & .51 \\
\hline 28 & 191 & 9 & 4.6 & 100 & 8 & 2.3 & 175 & $i$ & .47 \\
\hline 29 & 189 & 9 & 4.6 & 108 & $B$ & 2.3 & 160 & $i$ & .43 \\
\hline 30 & 184 & 8 & 4.0 & 108 & 8 & 2.3 & 152 & $i$ & -41 \\
\hline 31 & 180 & 8 & 3.9 & 108 & 8 & 2.3 & - & -- & - \\
\hline TUTAL & 7484 & -- & 76.6 & 4226 & -- & 120.9 & 3960 & -- & 44.05 \\
\hline $\begin{array}{l}\text { TOTAL } \\
\text { TOTAL }\end{array}$ & $\begin{array}{l}\text { DISCHARGE } \\
\text { SUSPENDED-S }\end{array}$ & $\begin{array}{l}\text { R Y YEAR } \\
\text { DI MENT }\end{array}$ & $\begin{array}{l}\text { (FS-DAYS) } \\
\text { I SCHARGE FOR }\end{array}$ & YEAR (TONS) & & & & & $\begin{array}{c}785191 \\
1934633.98\end{array}$ \\
\hline
\end{tabular}


11830000 TRINITY RIVER AT HOOPA, CALIF.

LOCATION,--Lat $41^{\circ} 03^{\prime} 00^{\prime \prime}$, long $123^{\circ} 40^{\prime} 13^{\prime \prime}$, in SEłNm sec.25, T.8 N., R.4 E., Humboldt County, Hoopa Valley Indian

Howervation, gaging station at Hoopa, 0.4 mile upstream from Supply Creek.

DRAINAGE AREA, $--2,865$ sq $m 1$.

PERIOD OF RECORD. --Chemical analyses: October 1953 to September 1969.

Water temperatures: November 1958 to September 1969.

Sediment records: November 1956 to September 1969.

EXTREMES, --1968-69:

Water temperatures: Maximum, $24,0^{\circ} \mathrm{C}$ on several days during July and August; minimum, 2. $0^{\circ} \mathrm{C}$ Dec, $22-24$

Sediment concentrations: Maximum da1ly, 6,000 mg/1 Jan. 21 ; minimum daily, $1 \mathrm{mg} / 1$ on several days during October and September.

Sediment discharge: Maximum da1ly, 880,000 tons Jan. 21; minimum da11y, 0.81 ton Sept. 30 .

Period of record:

Water temperatures (1963-69): Max $1 \mathrm{mum}(1963-66,1968-69), 26.5^{\circ} \mathrm{C}$ July 16, 1965; minimum (1964-69), 2.0 ${ }^{\circ} \mathrm{C}$ Dec. 17,1967 , Dec. 22-24, 1968 .

Sediment concentrations: Maximum dally, 20,400 mg/1 Dec. 23, 1964; minimum daily, 1 mg/1 on many days $1 \mathrm{n}$ $1957-64,1968$, and 1969 .

Sediment discharge: Maximum daily, 6,900,000 tons Dec. 23, 1964; min1mum da1ly, 0.81 ton Sept. $30,1969$.

REMARKS. --Chemical-quality records furnished by California Department of Water Resources and reviewed by U.S. Geological Survey. Where no maximum or minimum is shown, temperature is once-daily reading. Measurement of suspended sediment made at bridge on State Highway $96,1.0$ mile downstream from gaging station. No appreciable inflow between sampling point and gaging station except during perlods of heavy runoff.

CHEMICAL ANALYSES, hater YEAR OCTOBER 1968 TO SEPTEMBER 1969

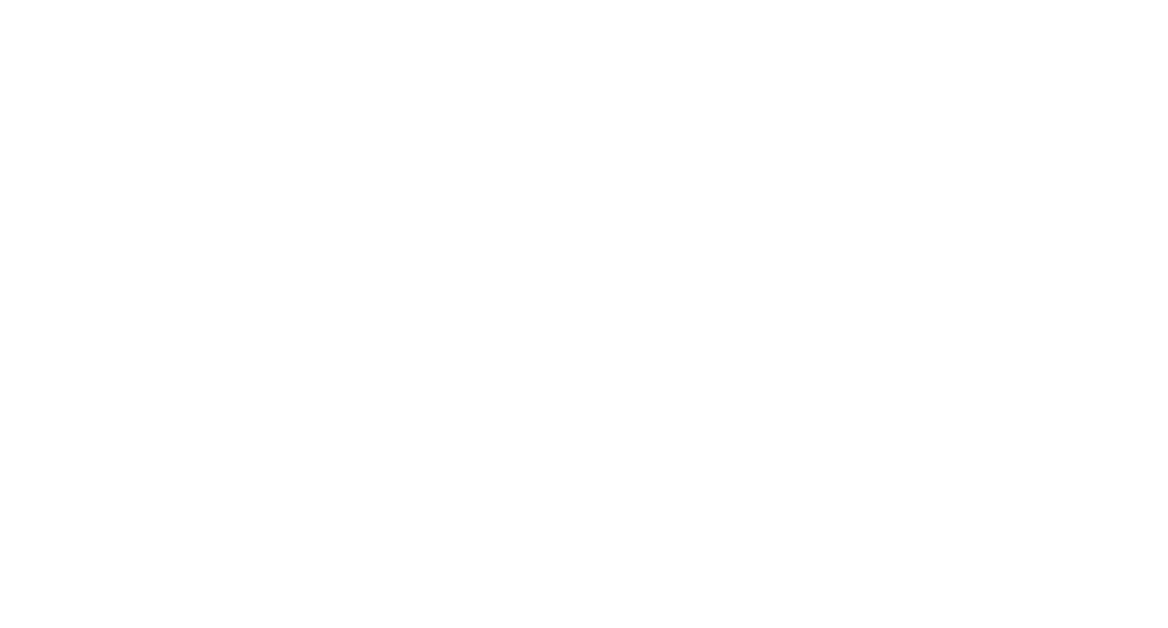

\begin{tabular}{|c|c|c|}
\hline $11 . .$. & .0 & .08 \\
\hline $\begin{array}{l}\text { DEC. } \\
\text { O2... } \\
\text { FEB. }\end{array}$ & .2 & .07 \\
\hline $\begin{array}{l}03 . . . \\
\text { MAR. }\end{array}$ & .2 & .09 \\
\hline $\begin{array}{l}\text { O3.... } \\
\text { APR. }\end{array}$ & - I & .04 \\
\hline $\begin{array}{c}07 . \cdots \\
\text { MaY }\end{array}$ & .3 & .83 \\
\hline $\begin{array}{l}12 \ldots \\
\text { JUNE }\end{array}$ & .0 & .72 \\
\hline $\begin{array}{c}09 . . . \\
\text { juL }\end{array}$ & .1 & .20 \\
\hline $\begin{array}{l}14 . . . \\
\text { AUG. }\end{array}$ & - I & -- \\
\hline $\begin{array}{l}\text { O4.... } \\
\text { SEP T. } \\
08 . . .\end{array}$ & .1 & -- \\
\hline
\end{tabular}

$-$

$\begin{array}{rrr}-- & 77 & 11 \\ -- & 90 & 14 \\ -- & 93 & 17 \\ -- & 92 & 13 \\ -- & 67 & 3 \\ .07 & 44 & 2 \\ -- & 55 & 2 \\ -- & 80 & 5 \\ -- & 93 & 13 \\ .3 & 102 & 10\end{array}$

$\begin{array}{rr}8.0 & 164 \\ 8.3 & 188 \\ 8.2 & 175 \\ 7.7 & 173 \\ 7.9 & 139 \\ 7.7 & 92 \\ 7.6 & 120 \\ 8.1 & 167 \\ 8.1 & 198 \\ 7.7 & 215\end{array}$


11530000 TRINITY RIVER AT HOOPA, CALIF, --Cont1nued

TEMPERATURE $\left({ }^{\circ} \mathrm{C}\right)$ OF WATER, WATER YEAR OCTOBER 1968 TO SEPTEMBER 1969

DAY

MONIH $\begin{array}{llllllllllllllllllllllllllllllll}3 & 4 & 5 & 6 & 7 & 8 & 9 & 10 & 11 & 12 & 13 & 14 & 15 & 16 & 17 & 18 & 19 & 20 & 21 & 22 & 23 & 24 & 25 & 26 & 27 & 28 & 29 & 30 & 31 & A G & & \end{array}$ OCTUBER.: - - - MAXIMUM $16 \begin{array}{llllllllllllllllllllllllllllllllll}17 & 17 & 16 & 15 & 15 & 14 & 13 & 13 & 14 & 14 & 13 & 13 & 12 & 12 & 12 & 13 & 13 & 12 & 13 & 12 & 12 & 12 & 12 & 12 & 13 & 12 & 12 & 12 & 11 & 11\end{array}$

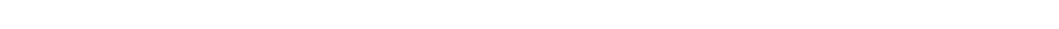

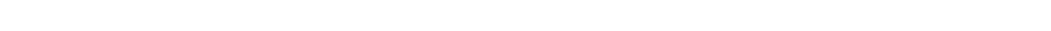
MINIMUM $9 \begin{array}{lllllllllllllllllllllllllllllllll} & 10 & 10 & 9 & 9 & 9 & 9 & 10 & 10 & 10 & 10 & 9 & 8 & 6 & 5 & 6 & 7 & 7 & 7 & 7 & 7 & 8 & 8 & 6 & 6 & 6 & 6 & 6 & 5 & 5 & -1\end{array}$

DECEMRER. - $\begin{array}{llllllllllllllllllllllllllllllllll}\text { MAXIMUM } & 5 & 7 & 5 & 6 & 7 & 6 & 6 & 7 & 7 & 8 & 7 & 6 & 5 & 5 & 6 & 6 & 6 & 6 & 6 & 5 & 4 & 4 & 3 & 4 & 4 & 5 & 5 & 5 & 5 & 5 & 5 \\ \text { MINIMUM } & 5 & 5 & 5 & 5 & 6 & 6 & 5 & 6 & 6 & 7 & 5 & 5 & 5 & 5 & 5 & 5 & 6 & 6 & 5 & 4 & 4 & 2 & 2 & 2 & 4 & 4 & 5 & 5 & 5 & 5 & 4\end{array}$

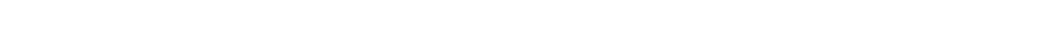

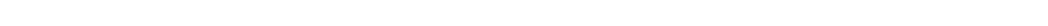

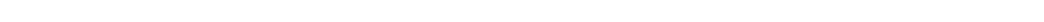

FEBRUARY.

$\begin{array}{llllllllllllllllllllllllllllllllll}\text { MAXIMUM } & 5 & 5 & 6 & 6 & 5 & 5 & 5 & 5 & 5 & 6 & 6 & 6 & 5 & 5 & 5 & 6 & 6 & 6 & 7 & 6 & 6 & 5 & 5 & 5 & 5 & 6 & 6 & 6 & -- & -- & -- \\ \text { MINIMUM } & 4 & 5 & 5 & 5 & 5 & 5 & 5 & 5 & 5 & 5 & 6 & 5 & 5 & 5 & 5 & 5 & 5 & 5 & 6 & 5 & 5 & 4 & 5 & 5 & 4 & 4 & 5 & 6 & -- & -- & --\end{array}$

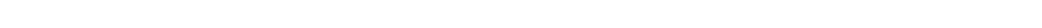
MINIMUM MAXIMUM

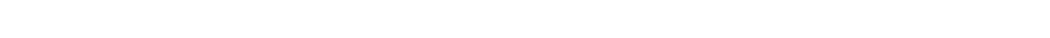

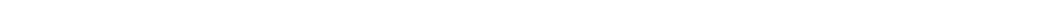

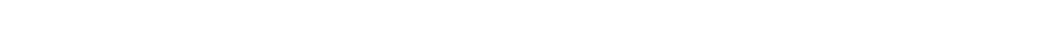

$\begin{array}{lllllllllllllllllllllllllllllllll}\text { MAXIMUM } & 17 & 17 & 17 & 17 & 17 & 16 & 15 & 14 & 15 & 14 & 15 & 16 & 17 & 17 & 18 & 19 & 18 & 18 & 17 & 18 & 18 & 18 & 17 & 18 & 17 & 17 & 15 & 17 & 18 & 18 & -2\end{array}$

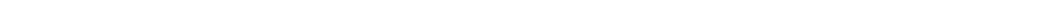

JULY.....

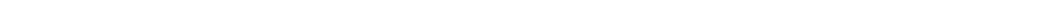

AUGUST...

MAXIMUM --

MINIMUM --

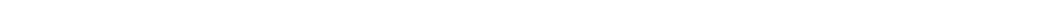

MANIMUM

PARTICLE-SIZE DISTRIBUTION OF SUSPENDED SEDIMENT, WATER YEAR OCTOBER 1968 TO SEPTEMBER 1969

(METHOOS OF ANALYSIS: 8, BOTTOM WITHDRAWAL TUBE; C. CHEMICALLY DISPERSED; N, IN NATIVE WAIER: P, PIPET; S, SIEYE

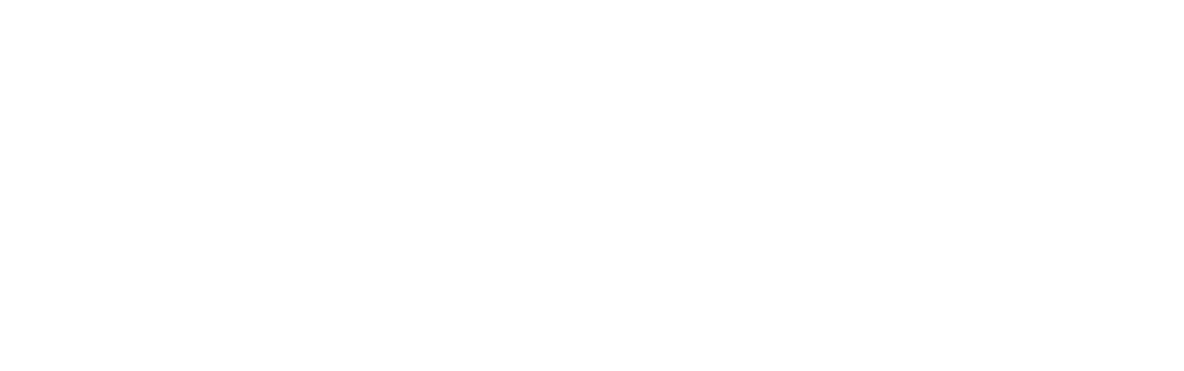

PARTICLE-SIZE DISTRIBUTION OF SURFACE BED MATERIAL. WATER YEAR OCTOBER 1968 TO SEPTEMBER 1969 IMETHOD OF ANALYSIS: H, HYOROMETER; O, OPTICAL ANALVZER: S, SIEVE: V. VISUAL ACCUMULATION TUBE) WATER NUMBER PARTICLE SIZF

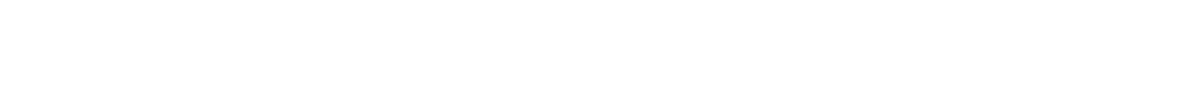

SEP $29,1969,1800$ 
11530000 TRINITY RIVER AT HOOPA, CALIF.--Continued

SUSPENDED-SEDIMENT DISCHARGE, WATER YEAR OCTOBER 1968 TO SEPTEMBER 1969

OCTOBER

MEAN

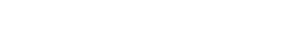

DAY

\section{457}

460

457
462

468

468
468

468
464

465

$11 \quad 516$

$\begin{array}{rr}11 & 516 \\ 13 & 890 \\ 13 & 1170 \\ 15 & 1050\end{array}$

16
17
18
19
20

858

826
834
794

834

$\begin{array}{ll}22 & 794 \\ 23 & 746 \\ 24 & 730\end{array}$

$\begin{array}{ll}24 & 730 \\ 25 & 714\end{array}$

$\begin{array}{ll}26 & 698 \\ 27 & 690\end{array}$

$\begin{array}{ll}27 & 690 \\ 28 & 674 \\ 29 & 714 \\ 30 & 922\end{array}$

922
$31 \quad 1070$

TOTAL 21978
CONCEN- SEDIMENT

$21 \quad 834$ $\begin{array}{rr}1.2 & 946 \\ 1.2 & 1290 \\ 2.5 & 1820 \\ 2.5 & 1490 \\ 1.2 & 1290 \\ & \\ 1.3 & 1230 \\ 1.3 & 1230 \\ 1.3 & 1240 \\ 1.3 & 2010 \\ 2.5 & 2150\end{array}$

$\begin{array}{ll}47 & 2620 \\ 62 & 2020\end{array}$

$\begin{array}{ll}23 & 1920 \\ 16 & 1960\end{array}$

$\begin{array}{cc}16 & 1960 \\ 11 & 4020 \\ 6.4 & 5100\end{array}$

6.8

$\begin{array}{cc}6.8 & 2140 \\ 8.6 & 2030 \\ 10 & 1900\end{array}$

$\begin{array}{cc}10 & 1900 \\ 7.9 & 2120\end{array}$

$5.7 \quad 2520$

$\begin{array}{ll}5.7 & 2520 \\ 5.6 & 2040\end{array}$

$\begin{array}{ll}7.3 & 1760 \\ 7.7 & 1620\end{array}$

$\begin{array}{ll}7.7 & 1620 \\ 12 & 1750 \\ 14 & --\end{array}$

$342.5 \quad 63256$ $\begin{array}{ll}5.6 & 1740 \\ 17 & 2940\end{array}$

NOVEMBER

MEAN

CONCEN- SEDIMENT TRATION DISCHARGE
(MG/LI) (TONS/DAY)

$\begin{array}{rr}7 & 18 \\ 80 & 279 \\ 195 & 958 \\ 70 & 282 \\ 30 & 104 \\ 30 & 100 \\ 34 & 113 \\ 18 & 60 \\ 173 & 1090\end{array}$

1980

1870
1640

1640
1510

1970

2200

2030
2300

2300
2580

2580
10700

$\begin{array}{rrr}141 & 714 & 11100 \\ 307 & 2490 & 8660 \\ 163 & 1170 & 6710\end{array}$

$\begin{array}{rrr}163 & 1170 & 6710 \\ 98 & 534 & 7840\end{array}$

120

58
70
610
425

697

13600

$\begin{array}{rr}301 & 13000 \\ 370 & 8990 \\ 7640 & 6730 \\ 5850 & 5710\end{array}$

6730
5710
3840

133

13
87
7
105

75
105

768
477
385
635

3700

3700
3760
5830

5830
10900
11000

8520

8520
7040
6570

6570
6260

6260
5560
4820

188920

32886

OECEMBER

MEAN

CONCEN- SEDIMENT TRATION DISCHARGE
(MG/L) (TONS/DAY)

$\begin{array}{rr}85 & 454 \\ 75 & 379 \\ 58 & 257 \\ 67 & 273 \\ 105 & 558 \\ 115 & 683 \\ 80 & 438 \\ 75 & 466 \\ 55 & 383 \\ 749 & 32400 \\ 624 & 20000 \\ 224 & 5390 \\ 350 & 6510 \\ 800 & 16900 \\ 1400 & 57800 \\ 1120 & 40400 \\ 680 & 16500 \\ 490 & 8900 \\ 400 & 6170 \\ 390 & 4040 \\ 342 & 3420 \\ 345 & 3500 \\ 692 & 11500 \\ 1260 & 37400 \\ 1030 & 30600 \\ 500 & 11500 \\ 220 & 4180 \\ 140 & 2480 \\ 97 & 1640 \\ 100 & 1500 \\ 98 & 1280 \\ & \\ -2 & 327901 \\ & \\ & \\ 100 & \end{array}$

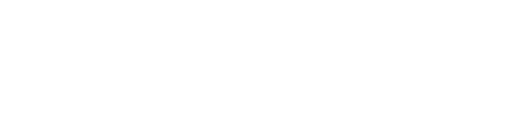

FEBRUARY

MARCH

MEAN
CONCEN- SEDIMENT

MEAN

MEAN
ISCHARGE

MEAN

CONCEN- SEDIMENT

4650
4620

4620
4880

4880
5740

73
72
56
78

917
898
738
1210

11700
10600
9880

850

(MGIL) (TONS/DAY)

8140

8580
8440
7400

223

$223 \quad 4900$
$210 \quad 4860$

4960
3650

6950

160
118
92

8100
23300

8100
23300
56100

56100

7440

8240
13600

13600
13800

30000

23500
20000

235000
17500

17500
15300

27500

3820
2920
217000

119000

14000

19600
14300
11500

11500
28000

2250
1900

1640
2330

73400

50900
72300

12500

12500
134000

12000

54300

34700
24900

24900
21900

6000
3140

880000

304000

157000

136000
102000

10600

9800

9540
9200

9200
9060

27700

23900

19900

16500
14300

$4040 \quad 303000$

$3000 \quad 194000$

2150

1650
1800

116000

73500
69500

8160
7780
8870
--

-- 4745763

TOTAL 578020

347000
26900

9180

850
1050
1150
1310
850

26900
30100

30700
33400

33400
21800

8620
9110

9110
8300

$\begin{array}{lll}750 & 18600 & 798\end{array}$

$900 \quad 20300 \quad 7660$

$\begin{array}{ll}900 & 20300 \\ 750 & 16700\end{array}$

$\begin{array}{ll}1550 & 56900 \\ 1450 & 54000\end{array}$

$3600 \quad 292000$

$1840 \quad 117000$

$1320 \quad 71300$

1100

41600

31600
39800

33000
35700

1150

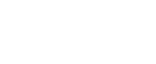

700
620
600

14900
14700

7660
7420

$\begin{array}{rr}600 & 14900 \\ 500 & 11600 \\ 620 & 15300 \\ 400 & 8960 \\ 300 & 6510\end{array}$

$300 \quad 6510$

$400 \quad 8620$

$\begin{array}{ll}350 & 7240 \\ 450 & 9020\end{array}$

$\begin{array}{ll}450 & 970 \\ 350 & 6770 \\ 500 & 9380\end{array}$

6570

6570
6370

6250

6170
6260

520

$300 \quad 9220$

$390 \quad 6580$

$\begin{array}{ll}380 & 6330 \\ 510 & 8620\end{array}$

6860
8060

11100

11100

10800

490

$500 \quad 10900$

$\begin{array}{ll}1520 & 45600\end{array}$

11100

11700

12800
13300

13300
13600

14100

9910

$\begin{array}{ll}5880 & 14100 \\ 3900 & 15700\end{array}$

20200
22500

22500
23000

$650 \quad 19500$

$\begin{array}{ll}720 & 22700 \\ 700 & 24200\end{array}$

$700 \quad 26600$

$\begin{array}{ll}700 & 26600 \\ 880 & 37300\end{array}$

$1120 \quad 54700$

$\begin{array}{ll}1400 & 76400 \\ 1600 & 97200\end{array}$

$1450 \quad 90000$ $\begin{array}{ll}1300 & 61400 \\ 1400 & 57800\end{array}$

7420
7160

18100
$-0 \quad 2800$

$680 \quad 19800$

$620 \quad 22300$ 
11530000 TRINITY RIVER AT HOOPA, CALIF,--COntinued

SUSPENDED-SEDIMENT DISCHARGE, WATER YEAR OCTOBER 1968 TO SEPTEMBER 1969

\begin{tabular}{|c|c|c|c|c|c|c|c|c|c|}
\hline \multirow[b]{2}{*}{ DAY } & \multicolumn{3}{|c|}{ APRIL } & \multicolumn{3}{|c|}{ MaY } & \multicolumn{3}{|c|}{ JUNE } \\
\hline & $\begin{array}{l}\text { MEAN } \\
\text { OI SCHARGE } \\
\text { (CFS) }\end{array}$ & $\begin{array}{l}\text { MEAN } \\
\text { CONCEN- } \\
\text { TRATION } \\
\text { IMG LL) }\end{array}$ & $\begin{array}{l}\text { SEDIMENT } \\
\text { DI SCHARGE } \\
\text { (TONS/DAY) }\end{array}$ & $\begin{array}{l}\text { MEAN } \\
\text { DI SCHARGE } \\
\text { (CFS) }\end{array}$ & $\begin{array}{l}\text { MEAN } \\
\text { CONCEN- } \\
\text { TRATION } \\
\text { IMG/L) }\end{array}$ & $\begin{array}{l}\text { SEDIMENT } \\
\text { DISCHARGE } \\
\text { (TONS/DAY) }\end{array}$ & $\begin{array}{l}\text { MEAN } \\
\text { DISCHARGE } \\
\text { (CFS) }\end{array}$ & $\begin{array}{l}\text { MEAN } \\
\text { CONCEN- } \\
\text { TRAIION } \\
\text { (MG/LI) }\end{array}$ & $\begin{array}{l}\text { SEDI MENT } \\
\text { DISCHARGE } \\
\text { (TONS/DAY) }\end{array}$ \\
\hline $\begin{array}{l}1 \\
2 \\
3 \\
4 \\
5\end{array}$ & $\begin{array}{l}20900 \\
17900 \\
15600 \\
12800 \\
13500\end{array}$ & $\begin{array}{l}940 \\
800 \\
700 \\
610 \\
692\end{array}$ & $\begin{array}{l}53000 \\
38700 \\
29500 \\
21100 \\
25200\end{array}$ & $\begin{array}{l}8040 \\
7520 \\
7160 \\
6750 \\
6570\end{array}$ & $\begin{array}{r}100 \\
94 \\
76 \\
80 \\
108\end{array}$ & $\begin{array}{l}2170 \\
1910 \\
1470 \\
1460 \\
1920\end{array}$ & $\begin{array}{l}4190 \\
4630 \\
5020 \\
5440 \\
5620\end{array}$ & $\begin{array}{l}38 \\
40 \\
33 \\
36 \\
36\end{array}$ & $\begin{array}{l}430 \\
500 \\
447 \\
529 \\
546\end{array}$ \\
\hline $\begin{array}{r}6 \\
7 \\
8 \\
9 \\
10\end{array}$ & $\begin{array}{r}12500 \\
10700 \\
9900 \\
9880 \\
10200\end{array}$ & $\begin{array}{l}658 \\
570 \\
545 \\
490 \\
465\end{array}$ & $\begin{array}{l}22200 \\
16500 \\
14600 \\
13100 \\
12800\end{array}$ & $\begin{array}{r}7360 \\
9060 \\
10200 \\
11100 \\
11800\end{array}$ & $\begin{array}{l}123 \\
128 \\
160 \\
175 \\
220\end{array}$ & $\begin{array}{l}2440 \\
3130 \\
4410 \\
5240 \\
7010\end{array}$ & $\begin{array}{l}5420 \\
5080 \\
4660 \\
4260 \\
4020\end{array}$ & $\begin{array}{l}33 \\
31 \\
28 \\
26 \\
18\end{array}$ & $\begin{array}{l}483 \\
425 \\
352 \\
299 \\
195\end{array}$ \\
\hline $\begin{array}{l}11 \\
12 \\
13 \\
14 \\
15\end{array}$ & $\begin{array}{r}10600 \\
12200 \\
12400 \\
10900 \\
9590\end{array}$ & $\begin{array}{l}440 \\
578 \\
570 \\
410 \\
340\end{array}$ & $\begin{array}{r}12600 \\
19000 \\
19100 \\
12100 \\
8800\end{array}$ & $\begin{array}{r}11900 \\
11400 \\
10700 \\
9540 \\
8040\end{array}$ & $\begin{array}{l}248 \\
210 \\
185 \\
158 \\
132\end{array}$ & $\begin{array}{l}7970 \\
6460 \\
5340 \\
4070 \\
2870\end{array}$ & $\begin{array}{l}3810 \\
3560 \\
3440 \\
3260 \\
3070\end{array}$ & $\begin{array}{l}13 \\
13 \\
14 \\
14 \\
16\end{array}$ & $\begin{array}{l}134 \\
125 \\
130 \\
123 \\
133\end{array}$ \\
\hline $\begin{array}{l}16 \\
17 \\
18 \\
19 \\
20\end{array}$ & $\begin{array}{r}9230 \\
9850 \\
11100 \\
10500 \\
10000\end{array}$ & $\begin{array}{l}350 \\
349 \\
530 \\
535 \\
510\end{array}$ & $\begin{array}{r}8720 \\
9280 \\
15900 \\
15200 \\
13800\end{array}$ & $\begin{array}{l}7480 \\
7540 \\
7760 \\
6880 \\
6080\end{array}$ & $\begin{array}{r}115 \\
105 \\
105 \\
105 \\
97\end{array}$ & $\begin{array}{l}2320 \\
2140 \\
2200 \\
1950 \\
1590\end{array}$ & $\begin{array}{l}3010 \\
2750 \\
2560 \\
3110 \\
3280\end{array}$ & $\begin{array}{l}18 \\
15 \\
12 \\
30 \\
50\end{array}$ & $\begin{array}{r}146 \\
111 \\
83 \\
252 \\
443\end{array}$ \\
\hline $\begin{array}{l}21 \\
22 \\
23 \\
24 \\
25\end{array}$ & $\begin{array}{r}10400 \\
12000 \\
13600 \\
11600 \\
9080\end{array}$ & $\begin{array}{l}570 \\
540 \\
318 \\
195 \\
147\end{array}$ & $\begin{array}{r}16000 \\
17500 \\
11700 \\
6110 \\
3600\end{array}$ & $\begin{array}{l}5850 \\
6030 \\
6280 \\
6260 \\
5470\end{array}$ & $\begin{array}{l}70 \\
65 \\
59 \\
55 \\
51\end{array}$ & $\begin{array}{r}1110 \\
1060 \\
1000 \\
930 \\
753\end{array}$ & $\begin{array}{l}2700 \\
2430 \\
2290 \\
2230 \\
2120\end{array}$ & $\begin{array}{r}40 \\
13 \\
6 \\
4 \\
3\end{array}$ & $\begin{array}{r}292 \\
85 \\
37 \\
24 \\
17\end{array}$ \\
\hline $\begin{array}{l}26 \\
27 \\
28 \\
29 \\
30 \\
31\end{array}$ & $\begin{array}{r}8100 \\
7920 \\
8500 \\
9160 \\
8600 \\
--\end{array}$ & $\begin{array}{r}132 \\
115 \\
120 \\
138 \\
112 \\
-=\end{array}$ & $\begin{array}{r}2890 \\
2460 \\
2750 \\
3410 \\
2600 \\
--\end{array}$ & $\begin{array}{l}5260 \\
5270 \\
4470 \\
4090 \\
4330 \\
4520\end{array}$ & $\begin{array}{l}49 \\
48 \\
46 \\
46 \\
59 \\
42\end{array}$ & $\begin{array}{l}696 \\
683 \\
555 \\
508 \\
690 \\
513\end{array}$ & $\begin{array}{c}2020 \\
1910 \\
1830 \\
1750 \\
1700 \\
\ldots\end{array}$ & $\begin{array}{r}11 \\
11 \\
10 \\
9 \\
8 \\
-0\end{array}$ & $\begin{array}{l}60 \\
57 \\
49 \\
43 \\
37 \\
--\end{array}$ \\
\hline \multirow[t]{3}{*}{ TOTAL } & 339210 & - & 450220 & 230710 & - & 76568 & 101170 & $=-$ & 6587 \\
\hline & & JULY & & & AUGUST & & & SEPTEMBER & \\
\hline & $\begin{array}{l}\text { MEAN } \\
\text { OISCHARGE } \\
\text { ICFSI }\end{array}$ & $\begin{array}{l}\text { MEAN } \\
\text { CONCEN- } \\
\text { IRATION } \\
\text { (MG/L) }\end{array}$ & $\begin{array}{l}\text { SEDIMENT } \\
\text { DISCHARGE } \\
\text { (TONS/DAY) }\end{array}$ & $\begin{array}{l}\text { MEAN } \\
\text { DISCHARGE } \\
\text { (CFS) }\end{array}$ & $\begin{array}{l}\text { MEAN } \\
\text { CONCFN- } \\
\text { TRATIDN } \\
\text { IMG/L) }\end{array}$ & $\begin{array}{l}\text { SEDIMENT } \\
\text { DISCHARGE } \\
\text { (TONS/DAY) }\end{array}$ & $\begin{array}{l}\text { MEAN } \\
\text { DISCHARGE } \\
\text { (CFS) }\end{array}$ & $\begin{array}{l}\text { MEAN } \\
\text { CONCEN- } \\
\text { IRATION } \\
\text { (MG/L) }\end{array}$ & $\begin{array}{l}\text { SEDIMENT } \\
\text { DI SCHARGE } \\
\text { (TONS/DAY) }\end{array}$ \\
\hline $\begin{array}{l}1 \\
2 \\
3 \\
4 \\
5\end{array}$ & $\begin{array}{l}1680 \\
1690 \\
1660 \\
1600 \\
1570\end{array}$ & $\begin{array}{l}7 \\
7 \\
6 \\
6 \\
5\end{array}$ & $\begin{array}{l}32 \\
32 \\
27 \\
26 \\
22\end{array}$ & $\begin{array}{l}898 \\
818 \\
722 \\
674 \\
650\end{array}$ & $\begin{array}{l}7 \\
5 \\
5 \\
6 \\
5\end{array}$ & $\begin{array}{l}17 \\
11 \\
9.7 \\
11 \\
8.8\end{array}$ & $\begin{array}{l}330 \\
306 \\
330 \\
342 \\
342\end{array}$ & $\begin{array}{l}3 \\
2 \\
2 \\
2 \\
2\end{array}$ & $\begin{array}{l}2.7 \\
1.7 \\
1.8 \\
1.8 \\
1.8\end{array}$ \\
\hline $\begin{array}{r}6 \\
7 \\
8 \\
9 \\
10\end{array}$ & $\begin{array}{l}1550 \\
1490 \\
1440 \\
1370 \\
1380\end{array}$ & $\begin{array}{l}5 \\
4 \\
6 \\
8 \\
6\end{array}$ & $\begin{array}{l}21 \\
16 \\
23 \\
30 \\
22\end{array}$ & $\begin{array}{l}634 \\
618 \\
610 \\
586 \\
570\end{array}$ & $\begin{array}{l}5 \\
4 \\
3 \\
3 \\
2\end{array}$ & $\begin{array}{l}8.6 \\
6.7 \\
4.9 \\
4.7 \\
3.1\end{array}$ & $\begin{array}{l}336 \\
330 \\
330 \\
324 \\
324\end{array}$ & $\begin{array}{l}2 \\
1 \\
1 \\
1 \\
2\end{array}$ & $\begin{array}{r}1.8 \\
.89 \\
.89 \\
.87 \\
1.7\end{array}$ \\
\hline $\begin{array}{l}11 \\
12 \\
13 \\
14 \\
15\end{array}$ & $\begin{array}{l}1360 \\
1320 \\
1300 \\
1250 \\
1230\end{array}$ & $\begin{array}{r}4 \\
6 \\
8 \\
12 \\
3\end{array}$ & $\begin{array}{l}15 \\
21 \\
28 \\
41 \\
10\end{array}$ & $\begin{array}{l}554 \\
530 \\
522 \\
506 \\
482\end{array}$ & $\begin{array}{l}2 \\
2 \\
2 \\
2 \\
2\end{array}$ & $\begin{array}{l}3.0 \\
2.9 \\
2.8 \\
2.7 \\
2.6\end{array}$ & $\begin{array}{l}324 \\
318 \\
312 \\
306 \\
306\end{array}$ & $\begin{array}{l}2 \\
2 \\
2 \\
3 \\
3\end{array}$ & $\begin{array}{l}1.7 \\
1.7 \\
1.7 \\
2.5 \\
2.5\end{array}$ \\
\hline $\begin{array}{l}16 \\
17 \\
18 \\
19 \\
20\end{array}$ & $\begin{array}{l}1190 \\
1150 \\
1120 \\
1100 \\
1080\end{array}$ & $\begin{array}{l}3 \\
3 \\
3 \\
4 \\
4\end{array}$ & $\begin{array}{l}9.6 \\
9.3 \\
9.1 \\
12 \\
12\end{array}$ & $\begin{array}{l}466 \\
466 \\
450 \\
418 \\
410\end{array}$ & $\begin{array}{l}2 \\
3 \\
4 \\
3 \\
3\end{array}$ & $\begin{array}{l}2.5 \\
3.8 \\
4.9 \\
3.4 \\
3.3\end{array}$ & $\begin{array}{l}312 \\
306 \\
348 \\
384 \\
396\end{array}$ & $\begin{array}{l}3 \\
4 \\
3 \\
2 \\
2\end{array}$ & $\begin{array}{l}2.5 \\
3.3 \\
2.8 \\
2.1 \\
2.1\end{array}$ \\
\hline $\begin{array}{l}21 \\
22 \\
23 \\
24 \\
25\end{array}$ & $\begin{array}{r}1060 \\
1030 \\
994 \\
978 \\
970\end{array}$ & $\begin{array}{l}5 \\
4 \\
3 \\
5 \\
8\end{array}$ & $\begin{array}{l}14 \\
11 \\
8.1 \\
13 \\
21\end{array}$ & $\begin{array}{l}402 \\
386 \\
378 \\
356 \\
349\end{array}$ & $\begin{array}{l}3 \\
2 \\
2 \\
2 \\
2\end{array}$ & $\begin{array}{l}3.3 \\
2.1 \\
2.0 \\
1.9 \\
1.9\end{array}$ & $\begin{array}{l}402 \\
390 \\
378 \\
366 \\
354\end{array}$ & $\begin{array}{l}3 \\
3 \\
3 \\
2 \\
1\end{array}$ & $\begin{array}{l}3.3 \\
3.2 \\
3.1 \\
2.0 \\
.96\end{array}$ \\
\hline $\begin{array}{l}26 \\
27 \\
28 \\
29 \\
30 \\
31\end{array}$ & $\begin{array}{r}978 \\
954 \\
1030 \\
1130 \\
1090 \\
986\end{array}$ & $\begin{array}{r}7 \\
6 \\
5 \\
5 \\
7 \\
11\end{array}$ & $\begin{array}{l}18 \\
15 \\
14 \\
15 \\
21 \\
29\end{array}$ & $\begin{array}{l}348 \\
348 \\
348 \\
342 \\
342 \\
336\end{array}$ & $\begin{array}{l}2 \\
3 \\
3 \\
3 \\
3 \\
3\end{array}$ & $\begin{array}{l}2.9 \\
2.8 \\
2.8 \\
2.8 \\
2.8 \\
2.7\end{array}$ & $\begin{array}{l}342 \\
330 \\
312 \\
306 \\
300 \\
--\end{array}$ & $\begin{array}{r}1 \\
1 \\
1 \\
1 \\
1 \\
--\end{array}$ & $\begin{array}{l}.92 \\
.89 \\
.84 \\
.83 \\
.81 \\
---\end{array}$ \\
\hline TOTAL & 38730 & -- & 596.1 & 15519 & -- & 144.4 & 10086 & - & 55.7 \\
\hline $\begin{array}{l}\text { TOTAL } \\
\text { TOTAL }\end{array}$ & $\begin{array}{l}\text { DISCHARGF } \\
\text { SUSPENDED- }\end{array}$ & $\begin{array}{l}\text { R YEAR } \\
\text { DIMENT D }\end{array}$ & $\begin{array}{l}\text { (CFS-OAYS) } \\
\text { DISCHARGE FOR }\end{array}$ & YEAR (TONS) & & & & & $\begin{array}{l}2271059 \\
7607843.7\end{array}$ \\
\hline
\end{tabular}


11530300 BLUE CREEK NEAR KLAMATH, CALIF.

LOCATION, - Lat $41^{\circ} 27^{\prime} 00^{\prime \prime}$, long $123^{\circ} 53^{\prime} 40^{\prime \prime}$, in NE recorder at gaging station on left bank, $600 \mathrm{ft}$ downstream from West Fork, 3.0 miles upstream from mouth, and 9.2 miles southeast of Ki amath.

DRAI NAGE AREA, - $-120 \mathrm{sq} \mathrm{mi}$.

PERIOD OF RECORD, - Water temperatures: October 1965 to September 1969.

EXTREMES, --1968-69:

Water temperatures: Haximum, $22.0^{\circ} \mathrm{C}$ July $20-22,25,26 ;$ minimum, $6.0^{\circ} \mathrm{C}$ on several days during January to March.

Period of record:

Water temperatures: Maximum, $22.0^{\circ} \mathrm{C}$ July $20-22,25,26,1969$; minimum, $4.0^{\circ} \mathrm{C}$ Feb. 15, Mar. 3,1967, Jan. 27-29, 1968.

TELPERATURE $\left({ }^{\circ} \mathrm{C}\right)$ OF TATER, WATER YEAR OCTOBER 1968 TO SEPTEMBER 1969

$$
\text { DAY }
$$

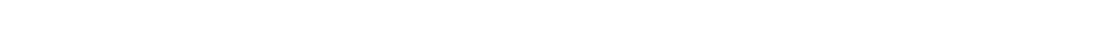

DC TORER

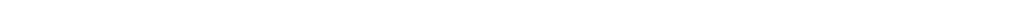
MINIMUM $15 \quad 14 \quad 14 \quad 14 \quad 15 \quad 14 \quad 14 \quad 13 \quad 13 \quad 15 \quad 16 \quad 14 \quad 14 \quad 14 \quad 14 \quad 14 \quad 14 \quad 14 \quad 14 \quad 15 \quad 15 \quad 15 \quad 15 \quad 15 \quad 16 \quad 16 \quad 16 \quad 16 \quad 16 \quad 15 \quad 14$

NOVEMBER

MAXIMUM $16 \quad 16 \quad 1617 \quad 17 \quad 16 \quad 17 \quad 17 \quad 18 \quad 17 \quad 17 \quad 15 \quad 15 \quad 14 \quad 15 \quad 14 \quad 14 \quad 14 \begin{array}{lllllllllllllll}14 & 13 & 14 & 14 & 13 & 13 & 11 & 11 & 11 & 11 & 11 & 10 & -\end{array}$

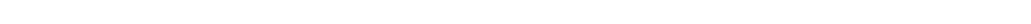
DECEMBER MAXIMUM $10101011111111121212101010101099101010 \quad 99999101010101010 \quad 91010 \quad 10$

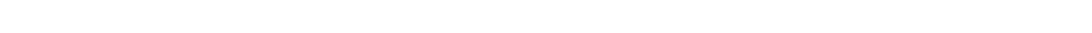

JANUARY

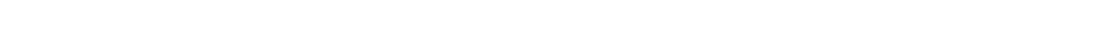

MINIMUM

MAXIMUM 7 B

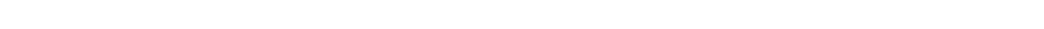
MARCH

MAXIMUM $8 \begin{array}{llllllllllllllllllllllllllllllll} & 8 & 8 & 8 & 9 & 9 & 9 & 9 & 8 & 9 & 8 & 9 & 9 & 9 & 10 & 9 & 9 & 8 & 9 & 9 & 10 & 10 & 10 & 10 & 10 & 16 & 10 & 10 & 10 & 10 & 9\end{array}$ MINI MUM APRIL

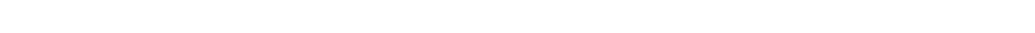
MINIMUM

MAXIMUM MINIMUM JUNE

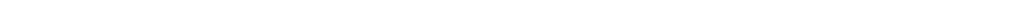
JuLY

MAXIMUM

AUGUST

MAXIMUM

SEPTFMBER

MAXIMUM

MINIMUM

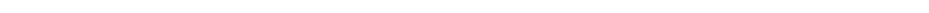
$\begin{array}{lllllllllllllllllllllllllllllllllll}7 & 7 & 8 & 7 & 8 & 9 & 9 & 11 & 9 & 9 & 9 & 10 & 10 & 9 & 9 & 9 & 10 & 10 & 10 & 9 & 10 & 11 & 11 & 11 & 11 & 10 & 10 & 10 & 11 & 12 & 11\end{array}$

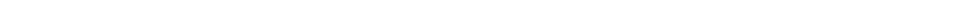
$\begin{array}{lllllllllllllllllllllllllllllll}20 & 17 & 19 & 20 & 20 & 20 & 20 & 21 & 21 & 20 & 19 & 20 & 20 & 20 & 20 & 20 & 21 & 21 & 21 & 22 & 22 & 22 & 21 & 19 & 22 & 22 & 21 & 21 & 21 & 21 & 21\end{array}$

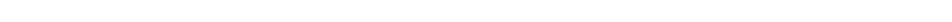
$\begin{array}{lllllllllllllllllllllllllllllll}21 & 21 & 21 & 21 & 20 & 21 & 21 & 21 & 21 & 22 & 21 & 21 & 21 & 21 & 21 & 21 & 21 & 21 & 21 & 22 & 21 & 21 & 21 & 19 & 20 & 20 & 20 & 20 & 20 & 20 & 20\end{array}$

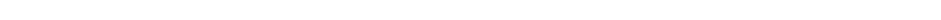

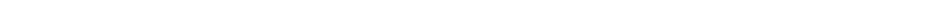

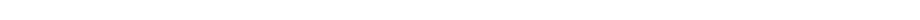


11530500 KLAMATH RI VER NEAR KLAMATH, CALIF.

(International Hydrological Decade R1 ver station)

LOCATION, --Lat $41^{\circ} 30^{\circ} 45^{\prime \prime}$, long $123^{\circ} 58^{\prime} 30^{\prime \prime}$, in SW sec, $17, T, 13 \mathrm{~N}$, , R. $2 \mathrm{E}$. Del Norte Caunty, at.gaging station on right bank, 2.8 miles upstream from Turwar Creek and $3.3 \mathrm{~m} 1 \mathrm{les}$ east of Klamath.

DRAINAGE AREA. -12,100 sq mi, approximately (not including Lost River or Lower Klamath Lake brsins),

PERIOD OF RECORD.--Chemical analyses: October 1953 to September 1969.

Water temperatures: November 1965 to September 1969.

EXTREMES, --1968-69:

Water temperatures: Min1mum, $5.0^{\circ} \mathrm{C}$ on several days during January to March,

period of record:

Water temperatures: Maximum $(1966-68), 26.0^{\circ} \mathrm{C}$ on several days during July and August $1968 ; \mathrm{min} 1 \mathrm{mum}, 4.0^{\circ} \mathrm{C}$ on several days in December 1967.

REMARKS. --Chemical-quality samples collected by California Department of Water Resources. No temperature record July 1 to Sept. 30; probe buried. CHEMICAL ANALYSES, WATER YEAR OCTOBER 1968 TO SEPTEMBER 1969

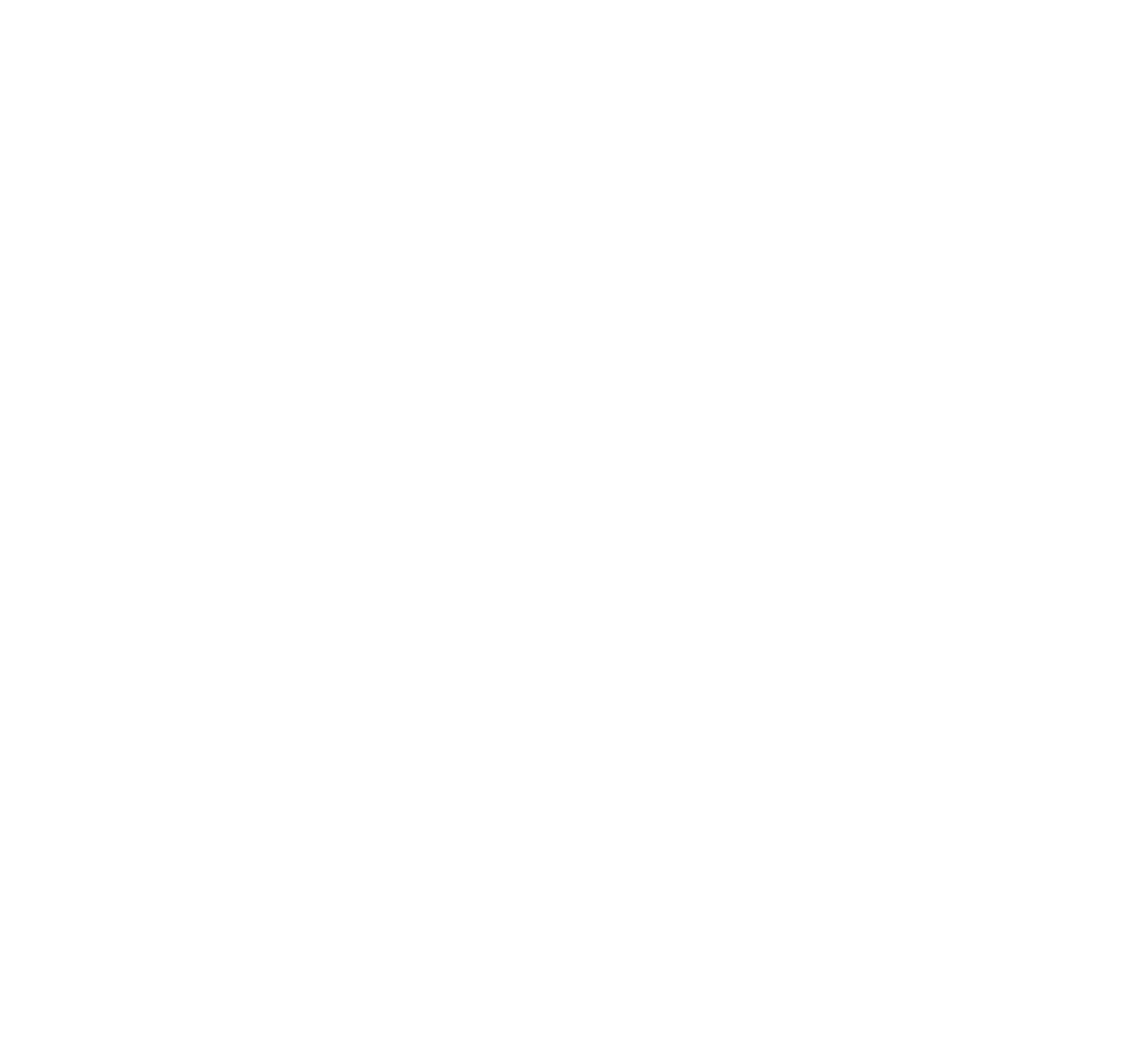


11530500 KLAMATH RIVBR NEAR KLAMATH, CALIF,--Continued

CHEMICAL ANALYSES, WATER YEAR DCTOBER 1968 TO SEPTEMBER 1969

\begin{tabular}{|c|c|c|c|c|c|c|}
\hline DATE & $\begin{array}{l}\text { SPECI- } \\
\text { FIC } \\
\text { COND- } \\
\text { UCTANCE } \\
\text { (YICRD- } \\
\text { MHOSI }\end{array}$ & $\begin{array}{l}\text { DIS- } \\
\text { SDLVFD } \\
\text { SOLIDS } \\
\text { TTONS } \\
\text { PER } \\
\text { AC-FT) }\end{array}$ & $\begin{array}{l}\text { PERCENT } \\
\text { SDDIUM }\end{array}$ & $\begin{array}{l}\text { SODIUM } \\
\text { AD- } \\
\text { SORP- } \\
\text { TION } \\
\text { RATIO }\end{array}$ & $\begin{array}{l}\text { ALKA- } \\
\text { LINITY } \\
\text { AS } \\
\text { CACD3 } \\
\text { (MG/L) }\end{array}$ & $\begin{array}{l}\text { TUR- } \\
\text { BID- } \\
\text { ITY } \\
(M G / L)\end{array}$ \\
\hline OCT. & 234 & 20.0 & 21 & .5 & 99 & - \\
\hline DEC... & 137 & .12 & 15 & .3 & 55 & 350 \\
\hline $\begin{array}{l}03 . . . \\
\text { JAN. }\end{array}$ & 166 & .14 & 17 & .4 & 67 & 5.0 \\
\hline $\begin{array}{c}20 \ldots \\
\text { FEB. }\end{array}$ & 123 & .11 & 10 & .2 & 56 & 200 \\
\hline MAR... & 155 & .13 & 13 & $\cdot 3$ & 66 & 44 \\
\hline $\begin{array}{l}03 . . . \\
\text { APP. }\end{array}$ & 163 & .14 & 15 & .3 & 72 & 150 \\
\hline MAY... & 157 & .13 & 17 & .4 & 66 & 90 \\
\hline JUNE & 91 & .07 & 11 & .2 & 39 & 95 \\
\hline sutr & 112 & .09 & 12 & .2 & 48 & 30 \\
\hline $\begin{array}{l}15 . . \\
\text { Aug. }\end{array}$ & 166 & .13 & 13 & .3 & 71 & 3.0 \\
\hline SEP & 197 & .15 & 18 & .4 & 83 & 2.0 \\
\hline $09 \ldots$ & 241 & .20 & 25 & .7 & 93 & 4.0 \\
\hline
\end{tabular}

TEMPERATURE ( $\left.{ }^{\circ} \mathrm{C}\right)$ OF WATER, WATER YEAR OCTOBER 1968 TO SEPTEMBER 1969 DAY

MONTH

OC TUBHR

$\begin{array}{llllllllllllllllllllllllllllllllll}\text { MAXIMUM } & 20 & 20 & 20 & 20 & 20 & 19 & 19 & 19 & 18 & 17 & 17 & 17 & 17 & 17 & 17 & 17 & 17 & 17 & 17 & 17 & 17 & 17 & 17 & 17 & 17 & 17 & 17 & 17 & 17 & 17 & 17 \\ \text { MINIMUM } & 17 & 19 & 20 & 20 & 19 & 19 & 18 & 18 & 17 & 17 & 17 & 17 & 16 & 17 & 17 & 16 & 16 & 16 & 17 & 17 & 17 & 17 & 16 & 16 & 17 & 17 & 17 & 17 & 17 & 17 & 16\end{array}$

NOVEMRER

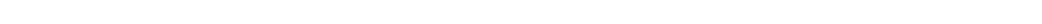

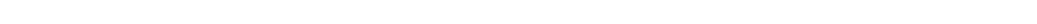

DECEMAER

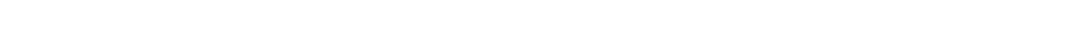

$\begin{array}{lllllllllllllllllllllllllllllllllllll}\text { MINIMUM } & 9 & 9 & 7 & 9 & 8 & 8 & 9 & 9 & 9 & 9 & 8 & 8 & 8 & 8 & 8 & 8 & 7 & 8 & 8 & 6 & 7 & 7 & 7 & 7 & 7 & 7 & 7 & 7 & 8 & 8 & 8 & 8\end{array}$

JAVUARY

$\begin{array}{lllllllllllllllllllllllllllllllllll}\text { MAXIMUM } & 8 & 8 & 8 & 8 & 8 & 8 & 8 & 8 & 8 & 8 & 8 & 8 & 8 & 7 & 7 & 7 & 7 & 7 & 8 & 8 & 8 & 8 & 8 & 7 & 6 & 7 & 6 & 6 & 6 & 6 & 5 & 7 \\ \text { MINIMUM } & 8 & 8 & 8 & 8 & 8 & 8 & 8 & 8 & 8 & 8 & 8 & 8 & 7 & 7 & 7 & 7 & 7 & 7 & 7 & 6 & 8 & 8 & 7 & 6 & 6 & 6 & 6 & 6 & 5 & 5 & 5 & & 7\end{array}$

FERRUARY

$\begin{array}{llllllllllllllllllllllllllllllll}\text { MAXIMUM } & 6 & 6 & 6 & 7 & 7 & 7 & 7 & 7 & 7 & 7 & 7 & 8 & 8 & 8 & 7 & 7 & 7 & 7 & 7 & 7 & 8 & 8 & 8 & 8 & 8 & 8 & 7 & 6 & -- & -- & -- \\ \text { MINIMUM } & 5 & 6 & 6 & 6 & 6 & 7 & 7 & 7 & 7 & 7 & 7 & 7 & 8 & 7 & 7 & 7 & 7 & 7 & 7 & 7 & 7 & 8 & 8 & 8 & 8 & 7 & 6 & 6 & -- & -- & --\end{array}$

MRCH

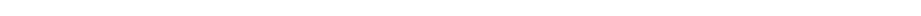

$\begin{array}{llllllllllllllllllllllllllllllll}\text { MAXIMUM } & 6 & 6 & 7 & 6 & 6 & 6 & 7 & 7 & 7 & 8 & 7 & 7 & 7 & 8 & 9 & 9 & 9 & 9 & 9 & 9 & 9 & 9 & 9 & 10 & 9 & 9 & 9 & 9 & 9 & 9 & 10 \\ \text { MINIMUM } & 5 & 6 & 5 & 5 & 6 & 6 & 6 & 6 & 6 & 7 & 7 & 7 & 7 & 7 & 8 & 8 & 9 & 9 & 9 & 9 & 9 & 9 & 9 & 9 & 8 & 8 & 8 & 8 & 9 & 9 & 9\end{array}$

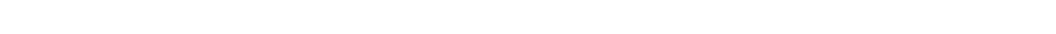

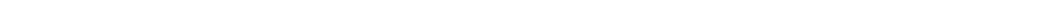
MAXIM

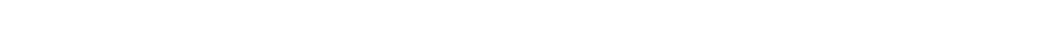
$\begin{array}{lllllllllllllllllllllllllllllllll}\text { MINIMUM } & 11 & 11 & 12 & 11 & 11 & 12 & 14 & 14 & 14 & 14 & 14 & 14 & 13 & 13 & 13 & 13 & 13 & 14 & 14 & 14 & 14 & 15 & 15 & 16 & 15 & 15 & 14 & 14 & 14 & 15 & 16\end{array}$

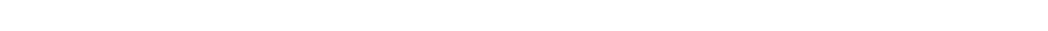
$\begin{array}{llllllllllllllllllllllllllllllllll}\text { MAXIMUM } & 17 & 17 & 17 & 19 & 19 & 19 & 19 & 19 & 18 & 18 & 18 & 17 & 18 & 18 & 19 & 19 & 20 & 20 & 20 & 20 & 20 & 20 & 20 & 20 & 19 & 18 & 18 & 18 & 17 & 18 & \cdots \\ \text { MIVIMUM } & 16 & 17 & 17 & 17 & 19 & 19 & 19 & 18 & 18 & 18 & 17 & 17 & 17 & 18 & 18 & 19 & 19 & 20 & 20 & 19 & 19 & 20 & 20 & 19 & 18 & 18 & 17 & 17 & 17 & 17 & -2\end{array}$

MAXIMUM -- - - - - - - - -

MINIMUH

MAXIMUM

MINIMUM

STP IEMHER

PIEMRER
MAXIMUM
MINIMUM 
LOCATION.--Lat $41^{\circ} 47^{\prime} 20^{\prime \prime}$, long $124^{\circ} 03^{\prime} 20^{\prime \prime}$, in SW $\frac{1}{4}$ sec. 10 , T.16 N., R.1 E., Del Norte County, at gaging station on left bank, 0.5 mile downstream from South Fork and 8 miles east of Crescent City.

DRAINAGE AREA. --609 sq mi.

PERIOD OF RECORD.--Chemical anaIyses: October 1953 to September 1969

Water temperatures: October 1965 to September 1969.

EXTREMES, --1968-69:

Water temperatures: Maximum, $23.0^{\circ} \mathrm{C}$ July 19-22, 26; mininum, $6.0^{\circ} \mathrm{C}$ Jan. $29,30$.

Period of record (1966-69)

Mater temperatures: Maximum, $23.0^{\circ} \mathrm{C}$ on several days during 1968 and 1969 ; minimum, $4.0^{\circ} \mathrm{C}$ on several days during 1967 and 1968 .

REMARKS. --Chemical-quality records furnished by California Department of Water Resources and reviewed by U.S. Geological Survey. No temperature record Aug. 31 to Sept. 16, probe out of water.

CHEMICAL ANALYSES, hater yeAR OCTOBER 1968 TO SEPTEMBER 1969

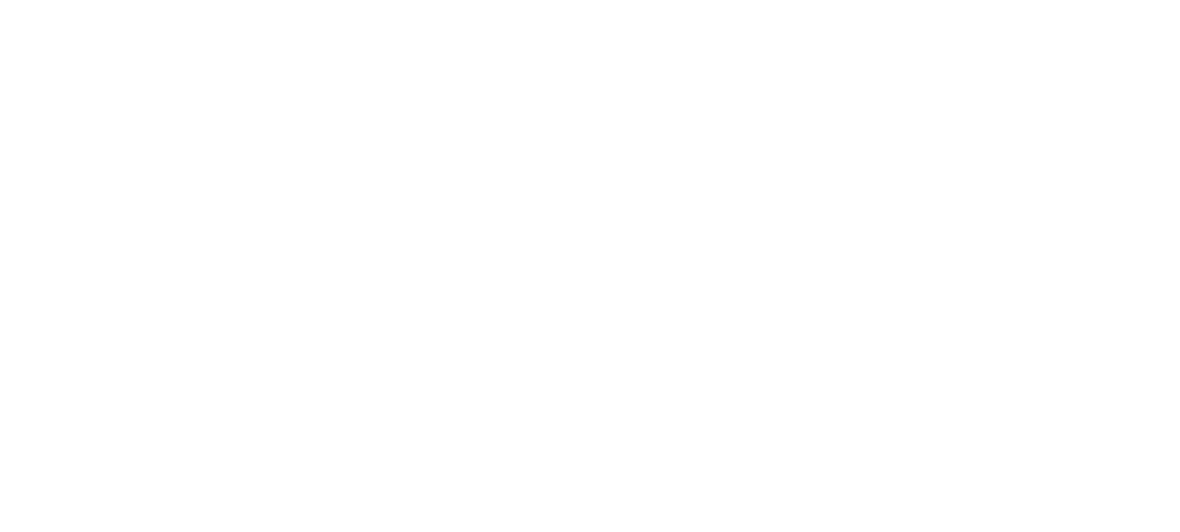

\begin{tabular}{|c|c|c|c|c|c|c|c|c|c|c|c|}
\hline DATE & $\begin{array}{l}\text { NITRATE } \\
\text { (NOB) } \\
\text { (MG/L) }\end{array}$ & $\begin{array}{l}\text { BORON } \\
(B) \\
(\mathrm{B}) / \mathrm{L})\end{array}$ & $\begin{array}{l}\text { CIS- } \\
\text { SOLED } \\
\text { SOLIOS } \\
\text { (RESI- } \\
\text { DUE AT } \\
\text { IBO C L } \\
\text { (MG II) }\end{array}$ & $\begin{array}{l}\text { OIS- } \\
\text { SOL VED } \\
\text { SOLIOS } \\
\text { ITONS } \\
\text { PER } \\
\text { AC-FTI }\end{array}$ & $\begin{array}{l}\text { HARD- } \\
\text { NESS } \\
(C A, M G) \\
(M G / L)\end{array}$ & $\begin{array}{l}\text { NON- } \\
\text { CAR- } \\
\text { BONATE } \\
\text { HARD- } \\
\text { NESS } \\
\text { (MG/L) }\end{array}$ & $\begin{array}{l}\text { PERCENT } \\
\text { SOOIUM }\end{array}$ & $\begin{array}{l}\text { SODIUM } \\
\text { AD- } \\
\text { SORP- } \\
\text { TION } \\
\text { RATIO }\end{array}$ & $\begin{array}{l}\text { ALKA- } \\
\text { LINITY } \\
\text { AS } \\
\text { CACD } \\
\text { (MG }\end{array}$ & $\begin{array}{c}P H \\
\text { (UNITS) }\end{array}$ & $\begin{array}{l}\text { SPECCI- } \\
\text { FICC } \\
\text { CDND- } \\
\text { UC IANCE } \\
\text { (MIICRD- } \\
\text { MHOS) }\end{array}$ \\
\hline $\begin{array}{l}\text { ocr. } \\
\text { ol.... }\end{array}$ & $\cdots$ & 0 & -- & -- & 81 & 9 & 7 & .1 & 72 & 7.8 & 161 \\
\hline NOV. & -- & 0 & $\cdots$ & -- & 49 & l & 7 & .1 & 48 & 7.8 & 101 \\
\hline $\begin{array}{l}\text { DEC. } \\
03 . . .\end{array}$ & - & 0 & $\cdots$ & -- & 63 & 13 & 6 & .1 & 50 & 8.1 & 105 \\
\hline $\begin{array}{l}\text { SAN. } \\
21 \ldots . .\end{array}$ & -- & 0 & -- & -- & 44 & 5 & 11 & .2 & 39 & 7.8 & 84 \\
\hline $\begin{array}{l}\text { FEB. } \\
04 . . .\end{array}$ & -- & 0 & - & -- & 43 & 2 & 9 & .1 & 41 & 7.9 & 89 \\
\hline $\begin{array}{l}\text { MAR. } \\
03 \ldots . . .\end{array}$ & -- & 0 & -- & -- & 47 & 8 & 6 & .1 & 39 & 7.3 & 89 \\
\hline OB.... & -- & 0 & -- & -- & 45 & 2 & 6 & .1 & 43 & 7.8 & 90 \\
\hline $13 \ldots$ & .0 & 0 & 38 & .05 & 35 & 3 & 7 & .1 & 32 & 7.6 & 70 \\
\hline INE... & -- & 0 & -- & -- & 49 & 1 & 6 & .1 & 48 & 7.8 & 101 \\
\hline $\begin{array}{l}\text { JULYY } \\
\text { L5.... }\end{array}$ & - & 0 & -- & -- & 69 & 4 & 6 & .1 & 65 & 7.9 & 134 \\
\hline $\begin{array}{l}05 . . . \\
056\end{array}$ & -- & 0 & -- & -- & 73 & 4 & 6 & .1 & 69 & 8.2 & 146 \\
\hline $\begin{array}{c}\text { SEPT: } \\
\text { O9.... }\end{array}$ & .0 & 0 & 75 & .10 & 79 & 6 & 6 & .1 & 73 & 8.2 & 160 \\
\hline
\end{tabular}


SWITH RIYER BASIN

11532500 SMITH RIVER NEAR CRESCENT CITY, CALIF.--COntinued

TEMPERATURE $\left({ }^{\circ} \mathrm{C}\right.$ ) OF WATER, WATER YEAR OCTOBER 1968 TO SEPTEMBER 1969

DAY

MONIH

$\begin{array}{llllllllllllllllllllllllllllllllllllllll}\text { MAXIMUM } & 17 & 16 & 16 & 15 & 15 & 14 & 14 & 13 & 13 & 13 & 13 & 13 & 12 & 11 & 12 & 13 & 13 & 13 & 12 & 13 & 13 & 13 & 13 & 13 & 13 & 14 & 14 & 14 & 14 & 13 & 12 \\ \text { MINIMUM } & 15 & 16 & 14 & 14 & 14 & 14 & 13 & 12 & 12 & 13 & 13 & 12 & 11 & 11 & 11 & 12 & 12 & 12 & 11 & 12 & 12 & 12 & 12 & 12 & 13 & 13 & 13 & 13 & 13 & 12 & 11\end{array}$

OC TOBER

MINIMUH

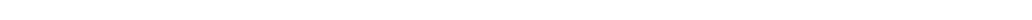

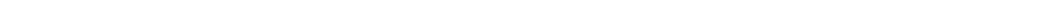

DECEMBER

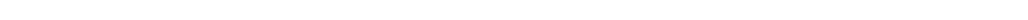

MINIMUM $999 \begin{array}{llllllllllllllllllllllllllllllll} & 9 & 10 & 9 & 10 & 11 & 11 & 10 & 10 & 9 & 9 & 10 & 9 & 9 & 9 & 9 & 8 & 7 & 7 & 7 & 9 & 10 & 10 & 10 & 10 & 9 & 9 & 9 & 9\end{array}$

JANUAR

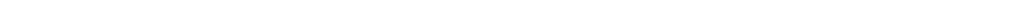

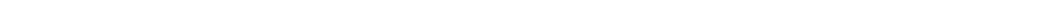

FEBRUARY

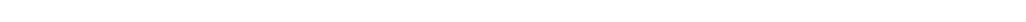

MINIMUM

MARCH

MINIMUH

MAXIMUM

MINIHUH

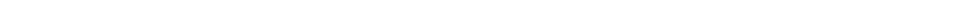

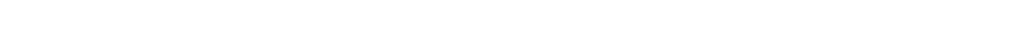

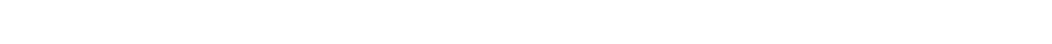

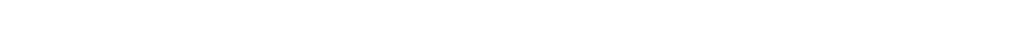

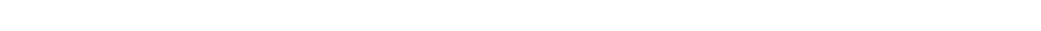
Jutr

MAXIHUM 19 $19 \begin{array}{llllllllllllllllllllllllllllll} & 20 & 21 & 21 & 21 & 21 & 21 & 22 & 21 & 21 & 22 & 21 & 21 & 22 & 22 & 22 & 22 & 23 & 23 & 23 & 23 & 22 & 22 & 22 & 23 & 22 & 22 & 22 & 21 & 20\end{array}$

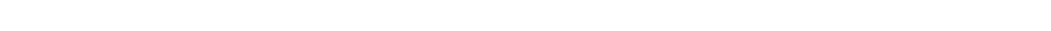
GUST

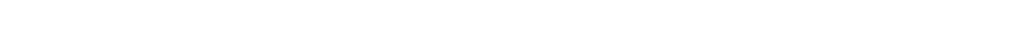
SEPTEMBES

MAXIMUM - - - -

MINIMUH

_. 


\begin{tabular}{|c|c|c|c|c|c|c|c|c|c|c|c|c|}
\hline & & $\begin{array}{l}\text { DIS- } \\
\text { CHARGE }\end{array}$ & $\begin{array}{l}\text { TEMPER- } \\
\text { ATURE }\end{array}$ & $\begin{array}{l}\text { SILICA } \\
\text { (SIDZ) }\end{array}$ & $\begin{array}{l}\text { DIS- } \\
\text { SOLVED } \\
\text { IRON } \\
\text { (FE) }\end{array}$ & $\begin{array}{l}\text { CAL- } \\
\text { CIUM } \\
\text { (CA) }\end{array}$ & $\begin{array}{l}\text { MAG- } \\
\text { NE- } \\
\text { SIUM } \\
\text { (MG) }\end{array}$ & SODIUM & $\begin{array}{l}\text { PO- } \\
\text { TAS- } \\
\text { SIUM } \\
\text { (K) }\end{array}$ & $\begin{array}{l}\text { BICAR- } \\
\text { BONATE } \\
\text { (HCO3) }\end{array}$ & $\begin{array}{l}\text { CAR- } \\
\text { BONATE } \\
\text { (CO3) }\end{array}$ & $\begin{array}{l}\text { SULFATE } \\
\text { (SO4) }\end{array}$ \\
\hline DATE & TIME & (CFS) & $(D E G C)$ & $(M G / L)$ & $(U G / L)$ & $(M G / L)$ & (MG/L) & $(M G / L)$ & (MG/L) & $(M G / L)$ & $(M G / L)$ & \\
\hline
\end{tabular}

$$
\text { SANTA ANA RIVER BASIN }
$$

11059300 SANTA ANA RIVER AT E STREET, NEAR SAN BERNARDINO, CALIF. (LAT 3404 O5 LONG 1171736 )

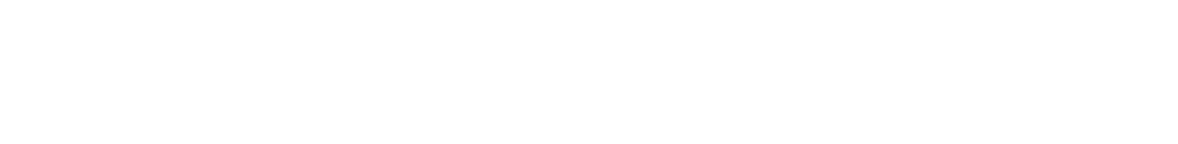

11066500 SANTA ANA RIVER AT RIVERSIDE NARROWS, NEAR ARLINGTON, CALIF, (LAT 335753 LONG 1172755 )

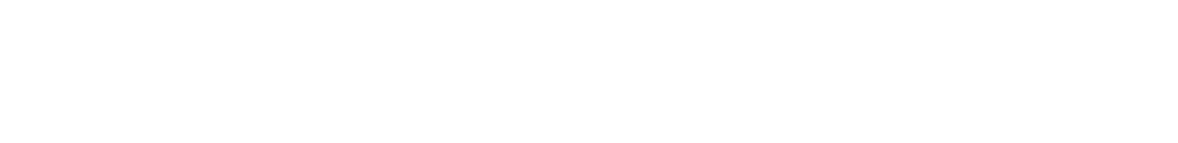

11058000 SANTA ANA RIVER AT AUBURNDALE BRIDGE, NEAR CORONA, CALIF. (LAT 335525 LONG 1173550 )

DEC 1968
O9.

11072200 TEMESCAL CREEK AT CORDNA, CALIF. (LAT $33 \quad 5346$ LONG 1173450 )

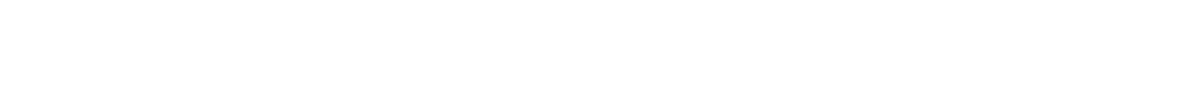

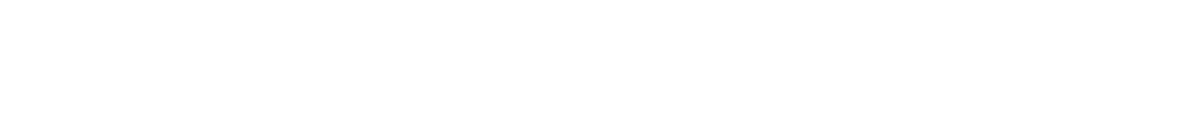

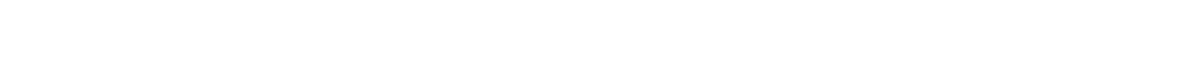

\begin{tabular}{|c|c|c|c|c|c|c|c|c|c|c|c|c|}
\hline DATE & TIME & $\begin{array}{l}\text { DIS- } \\
\text { CHARGE } \\
\text { (CFS) }\end{array}$ & $\begin{array}{l}\text { TEMPER- } \\
\text { ATURE } \\
\text { (DEG C) }\end{array}$ & $\begin{array}{l}\text { DIS- } \\
\text { SOLVED } \\
\text { DXYGEN } \\
\text { (MG/L) }\end{array}$ & $\begin{array}{l}\text { CAL- } \\
\text { CIUM } \\
\text { (CA) } \\
\text { (MG/L) }\end{array}$ & $\begin{array}{l}\text { MAG- } \\
\text { NE- } \\
\text { SIUM } \\
\text { (MG) } \\
\text { (MG/L) }\end{array}$ & $\begin{array}{l}\text { SODIUM } \\
\text { (NA) } \\
(M G / L)\end{array}$ & $\begin{array}{l}\text { PO- } \\
\text { TAS- } \\
\text { SIUM } \\
\text { (K) } \\
(M G / L)\end{array}$ & $\begin{array}{l}\text { BICAR- } \\
\text { BONATE } \\
\text { (HCD } \\
\text { (MG/L) }\end{array}$ & $\begin{array}{l}\text { CAR- } \\
\text { BONATE } \\
\text { (CD3) } \\
(M G / L)\end{array}$ & $\begin{array}{l}\text { SULFATE } \\
(S O 4) \\
(M G / L)\end{array}$ & $\begin{array}{l}\text { CHLO- } \\
\text { RIDE } \\
\text { (CL) } \\
\text { (MG/L) }\end{array}$ \\
\hline
\end{tabular}
VENTURA RIVER BASIN

11114500 MATILIJA CREEK ABOVE RESERVOIR, NEAR MATILIJA HOT SPRINGS, CALIF. (LAT 342941 LONG 1191948 )A

\begin{tabular}{|c|c|c|c|c|c|c|c|c|c|c|c|c|}
\hline JAN 1969 & $=$ & B2. 9 & 21 & 8.2 & 122 & 31 & 96 & 4.0 & 248 & 0 & 260 & 112 \\
\hline${ }_{A P R}^{13} \cdots$ & $=$ & B5.6 & 13 & 8.3 & 123 & 32 & 74 & 3.0 & 258 & 0 & 275 & 66 \\
\hline & -- & B61 & 18 & 9.0 & 105 & 30 & 28 & 2.0 & 196 & 0 & 260 & 9.0 \\
\hline $25 \ldots$ & -. & B14 & 26 & 8.2 & 105 & 29 & 39 & 3.0 & 190 & 0 & 268 & 18 \\
\hline
\end{tabular}

SANTA MARIA RIVER BASIN

11138100 CUYAMA RIVER BELOW TWITCHELL DAM, CALIF. ILAT 345640 LONG 1201730$)^{\mathrm{A}}$

\begin{tabular}{|c|c|c|c|c|c|c|c|c|c|c|c|c|}
\hline JUL $21 . \cdots$ & -- & -- & 25 & 8.1 & 204 & 95 & 137 & 6.0 & 364 & 0 & 738 & 83 \\
\hline
\end{tabular}

BUENA VISTA LAKE BASIN

11186000 KERN RIVER NEAR KERNVILLE, CALIF. (LAT 355643 LONG 1182836 ) A

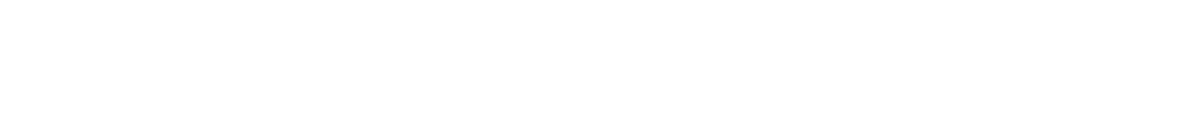

A CHEMICAL-QUALITY RECORDS FURNISHED BY CALIFORNIA DEPARTMENT DF WATER RESOURCES AND REVIEWED BY U.S. GEOLOGICAL B DAILY MEAN DISCHARGE. 
CHEMICAL ANALYSES, WATER YEAR OCTOBER 1968 TO SEPTEMBER 1969

\begin{tabular}{|c|c|c|c|c|c|c|c|c|c|c|c|c|}
\hline DATE & $\begin{array}{l}\text { CHLO- } \\
\text { RIDE } \\
\text { (CLL) } \\
(M G / L)\end{array}$ & $\begin{array}{l}\text { FLUD- } \\
\text { RIDE } \\
\text { (F) } \\
(M G / L)\end{array}$ & $\begin{array}{l}\text { NITRATE } \\
\text { (NO3) } \\
\text { (MG/L) }\end{array}$ & $\begin{array}{l}\text { BORON } \\
(B) \\
(U G / L)\end{array}$ & $\begin{array}{l}\text { DIS- } \\
\text { SOLVED } \\
\text { SOLIDS } \\
\text { (RESI- } \\
\text { DUE AT } \\
180 \text { C) } \\
\text { (MG/L) }\end{array}$ & $\begin{array}{l}\text { DIS- } \\
\text { SOLVED } \\
\text { SOLIDS } \\
\text { (SUM OF } \\
\text { CONSTIT } \\
\text { UENTS) } \\
\text { (MG/L) }\end{array}$ & $\begin{array}{l}\text { HARD- } \\
\text { NESS } \\
\text { (CA,MG) } \\
\text { (MG LL) }\end{array}$ & $\begin{array}{l}\text { NON- } \\
\text { CAR- } \\
\text { BONATE } \\
\text { HARD- } \\
\text { NESS } \\
\text { (MG/L) }\end{array}$ & $\begin{array}{l}\text { PERCENT } \\
\text { SODIUM }\end{array}$ & $\begin{array}{l}\text { ALKA- } \\
\text { LINITY } \\
\text { AS } \\
\text { CACO3 } \\
\text { (MG/L) }\end{array}$ & $\begin{array}{l}\text { SPE- } \\
\text { CIFIC } \\
\text { CON- } \\
\text { DUCT- } \\
\text { ANCE } \\
\text { (MICRO- } \\
\text { MHOS) }\end{array}$ & $\begin{array}{c}\text { PH } \\
\text { (UNITS) }\end{array}$ \\
\hline
\end{tabular}

SANTA ANA RIVER BASIN

11059300 SANTA ANA RIVER AT E STREET, NEAR SAN BERNARDINO, CALIF. (LAT 340405 LONG 1171736 )

\begin{tabular}{|c|c|c|c|c|c|c|c|c|c|c|}
\hline JAN $\ddot{1969}$ & 66 & 8.0 & 2.7 & 650 & 470 & 500 & 164 & 0 & 54 & 297 \\
\hline $\begin{array}{l}14 \ldots \\
21 \ldots \\
25 \ldots\end{array}$ & $\begin{array}{r}42 \\
7.6 \\
2.8 \\
6.4\end{array}$ & $\begin{array}{l}.6 \\
.4 \\
.4\end{array}$ & $\begin{array}{r}14 \\
4.1 \\
4.8\end{array}$ & $\begin{array}{r}200 \\
90 \\
70 \\
70\end{array}$ & $\begin{array}{l}320 \\
129 \\
206\end{array}$ & $\begin{array}{l}308 \\
131 \\
188\end{array}$ & $\begin{array}{r}177 \\
95 \\
158\end{array}$ & $\begin{array}{r}24 \\
5 \\
4\end{array}$ & $\begin{array}{r}30 \\
18 \\
7\end{array}$ & $\begin{array}{r}153 \\
90 \\
154\end{array}$ \\
\hline
\end{tabular}

11066500 SANTA ANA RIVER AT RIVERSIDE NARROWS, NEAR ARLINGTON, CALIF. (LAT 335753 LONG 1172755 )

\begin{tabular}{|c|c|c|c|c|c|c|c|c|c|c|}
\hline $\begin{array}{l}\text { DEC } 1968 \\
\text { JAN } \ddot{1969}^{\circ}\end{array}$ & 120 & 1.3 & 14 & 410 & 572 & 568 & 253 & 20 & 46 & 233 \\
\hline $\begin{array}{l}14 \ldots \\
21 \ldots\end{array}$ & $\begin{array}{l}12 \\
18\end{array}$ & $\begin{array}{r}.6 \\
.4\end{array}$ & $\begin{array}{l}5.1 \\
4.1\end{array}$ & $\begin{array}{r}90 \\
140\end{array}$ & $\begin{array}{l}137 \\
468\end{array}$ & $\begin{array}{l}141 \\
445\end{array}$ & $\begin{array}{r}88 \\
353\end{array}$ & $\begin{array}{l}0 \\
0\end{array}$ & $\begin{array}{l}25 \\
13\end{array}$ & $\begin{array}{r}92 \\
366\end{array}$ \\
\hline $24 \ldots$ & 47 & .5 & 6.8 & 230 & 313 & 279 & 176 & 43 & 31 & 133 \\
\hline $25 \ldots$ & 10 & .5 & 5.2 & 150 & 295 & 287 & 234 & 26 & 13 & 208 \\
\hline
\end{tabular}

11068000 SANTA ANA RIVER AT AUBURNDALE BRIDGE, NEAR CORONA, CALIF. (LAT 335525 LONG 1173550 )

\begin{tabular}{|c|c|c|c|c|c|c|c|c|c|c|c|c|}
\hline $\begin{array}{l}\text { DEC } 1968 \\
\text { O9. } \\
\text { JAN } 1969\end{array}$ & 125 & 1.1 & 21 & 460 & 646 & 639 & 312 & 63 & 42 & 249 & 1100 & 7.1 \\
\hline $\begin{array}{l}14 \ldots \\
21 \ldots\end{array}$ & $\begin{array}{l}48 \\
31\end{array}$ & .6 & $\begin{array}{l}9.9 \\
3.1\end{array}$ & $\begin{array}{l}200 \\
170\end{array}$ & $\begin{array}{l}268 \\
310\end{array}$ & $\begin{array}{l}292 \\
255\end{array}$ & $\begin{array}{l}148 \\
210\end{array}$ & $\begin{array}{r}23 \\
115\end{array}$ & $\begin{array}{l}37 \\
26\end{array}$ & $\begin{array}{r}125 \\
95\end{array}$ & $\begin{array}{l}522 \\
571\end{array}$ & $\begin{array}{l}7.0 \\
6.8\end{array}$ \\
\hline $22 \ldots$ & 25 & .5 & 6.2 & 230 & 294 & 265 & 183 & 32 & 25 & 151 & 491 & 7.0 \\
\hline $24 \ldots$ & 51 & .6 & 11 & 270 & 332 & 314 & 168 & 35 & 34 & 133 & 509 & 7.0 \\
\hline
\end{tabular}

11072200 TEMESCAL CREEK AT CORONA, CALIF. (LAT $33 \quad 5346$ LONG 1173450 )

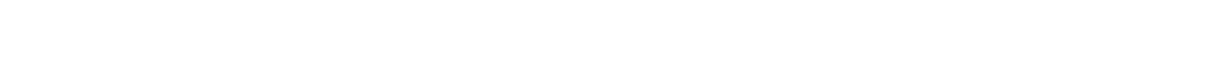
11073495 CUCAMONGA CREEK NEAR MIRA LOMA, CALIF. (LAT 335858 LONG 1173555 )

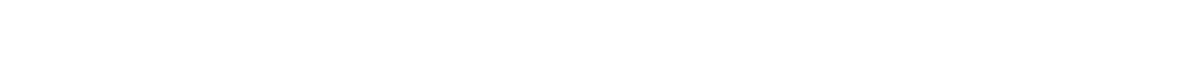
SANTA CLARA RIVER BASIN

11110500 HOPPER CREEK NEAR PIRU, CALIF. (LAT $34 \quad 2403$ LONG 1184932 )

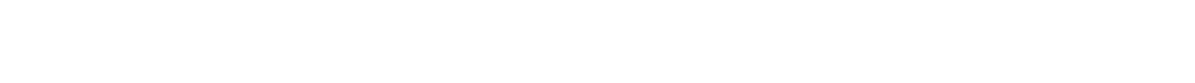

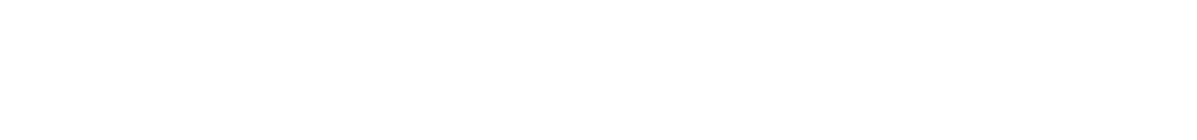
VENTURA RIVER BASIN

11114500 MATILIJA CREEK ABOVE RESERVOIR, NEAR MATILIJA HOT SPRINGS, CALIF. (LAT 342941 LONG 1191948 )A OCT 1968

\begin{tabular}{|c|c|c|c|c|c|c|c|c|c|c|c|c|}
\hline $\begin{array}{l}\text { OCT } 1968 \\
14 . . \\
\text { JAN } 1969\end{array}$ & 1.4 & .8 & 2900 & 811 & 1.10 & 432 & 229 & 32 & 2.0 & 203 & 1200 & 7.8 \\
\hline$\underset{A P R}{13} \ldots$ & 1.0 & .0 & 1700 & 793 & 1.08 & 439 & 227 & 27 & 1.5 & 212 & 1080 & 8.0 \\
\hline JUL $21 \ldots$ & .6 & .0 & 250 & 537 & .73 & 386 & 225 & 14 & .6 & 161 & 804 & 7.8 \\
\hline $25 \ldots$ & .8 & .0 & 680 & 583 & .79 & 381 & 225 & 18 & .9 & 156 & 819 & 8.1 \\
\hline
\end{tabular}

SANTA MARIA RIVER BASIN

11138100 CUYAMA RIVER BELOW TWITCHELL DAM, CALIF. (LAT 345640 LONG 1201730$)^{A}$

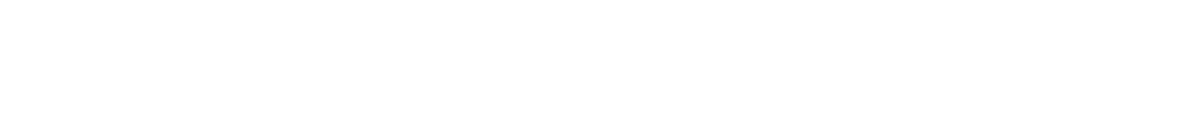

11186000 KERN RIVER NEAR KERNVILLE, CALIF. (LAT 355643 LONG 1182836 ) A

\begin{tabular}{|c|c|c|c|c|c|c|c|c|c|c|c|c|}
\hline $\begin{array}{c}\text { JAN } 1969 \\
07 \ldots\end{array}$ & -- & -- & 70 & -- & - & 52 & 0 & 35 & .8 & 53 & 146 & 7.9 \\
\hline MAY & -- & 1.0 & -- & 50 & 70 & 18 & 0 & 26 & 3 & 19 & 46 & 8.2 \\
\hline JUL & & & & & & & & & & & & \\
\hline $07 \ldots$ & - & -- & 20 & -- & -- & 15 & 0 & 30 & .3 & 16 & 40 & \\
\hline
\end{tabular}

A CHEMICAL-QUALITY RECORDS FURNISHED BY CALIFORNIA DEPARTMENT OF WATER RESOURCES AND REVIEWED BY U.S. GEOLOGICAL SURVEY. 
SUSPENDED-SEDIMENT DISCHARGE MEASUREMENTS AND PARTICLE-SIZE DISTRIBUTION, WATER YEAR OCTOBER 1968 TO SEPTEMBER 1969 IMETHODS OF ANALYSIS: B, BOTTOM WITHDRAWAL TUBE; C, CHEMICALLY DISPERSED; N, IN NATIVE WATER; P, PIPET; S, SIEVE;

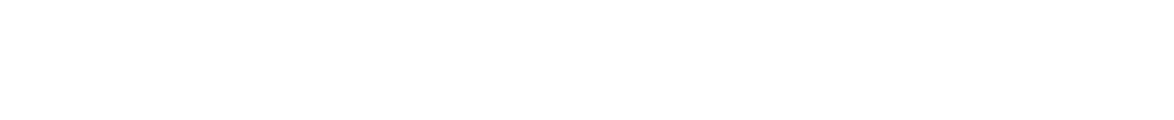
SAN JOAQUIN RIVER BASIN

11323500 MOKELUMNe RIVER BeLOW CAMANCHE DAM, CALIF. (LAT 381314 LONG 1210219 )

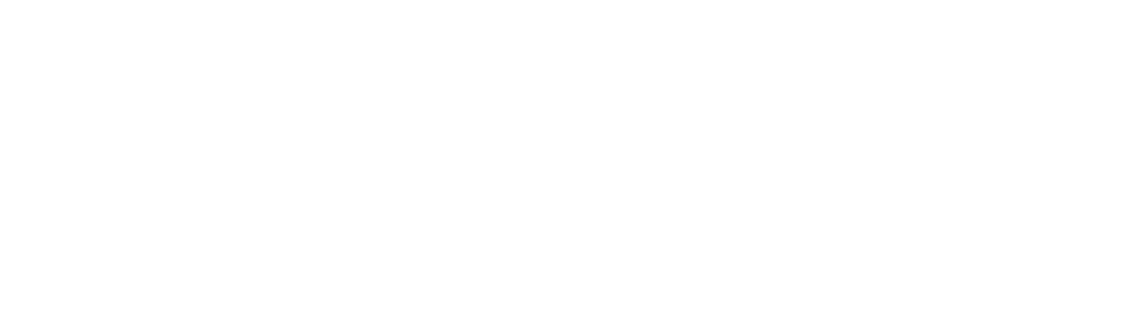

11375820 SOUTH FORK COTTONWOOD CREEK NEAR COTTONWOOD, CALIF. (LAT 401859 LONG 1222652 )

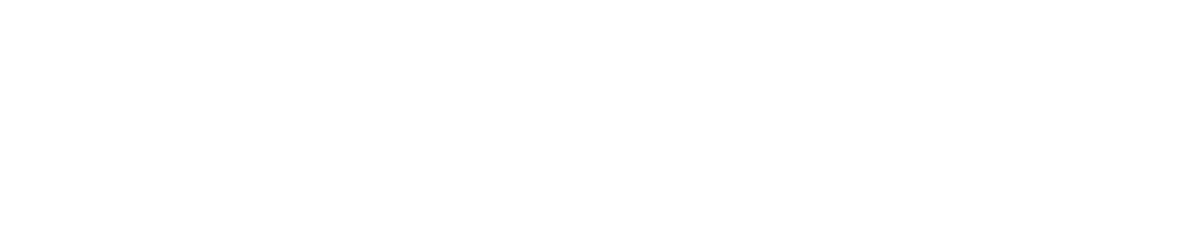

11378860 RED BANK CREEK AT RAWSON ROAD BRIDGE, NEAR RED BLUFF, CALIF. (LAT 400820 LONG 1221420 )

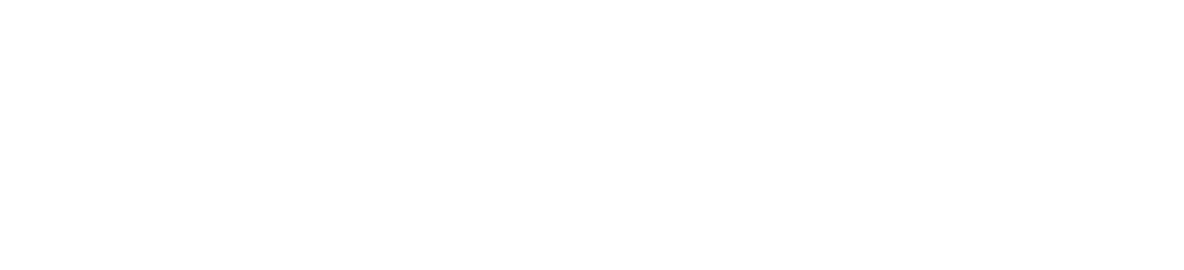

11379500 ELDER CREEK NEAR PASKENTA, CALIF. (LAT 400129 LONG 1223031 )

\begin{tabular}{|c|c|c|c|c|c|c|c|c|c|c|c|c|c|c|c|c|c|c|}
\hline OCT & 71968 & 1025 & 12 & 1.9 & 3 & .02 & -- & -- & -- & -- & -- & -- & -- & -- & -- & -- & -2 & \\
\hline Nov & $14 \ldots \ldots$ & 1015 & 6 & 6.9 & 1 & .02 & -- & -- & -- & -- & -- & -- & -- & -- & -- & - & - & \\
\hline DEC & $18, \ldots$ & 1000 & 4 & 51 & 5 & .69 & -- & -- & -- & -- & $=-$ & -- & -- & $=$ & -- & -- & $=$ & \\
\hline JAN & 131969 & 1700 & 8 & 1500 & 911 & 3690 & 19 & 28 & 38 & 48 & 57 & 66 & 72 & 80 & 87 & 93 & 98 & SBh \\
\hline JAN & $15 \ldots \ldots$ & 1500 & 7 & 358 & 39 & 38 & -- & -- & -- & -- & -- & -- & -- & -- & -- & $\cdots$ & - & \\
\hline JAN & $23 \ldots \ldots$ & 1700 & 4 & 502 & 68 & 92 & - & 5 & 14 & 24 & 30 & 52 & 63 & 76 & 91 & 97 & 100 & \\
\hline FEB & $5 \ldots \ldots$ & 1000 & - & 202 & 60 & 33 & $\cdots$ & $=-$ & -- & -- & -- & -- & -- & -- & -- & -- & -- & \\
\hline MAR & $6 \ldots .$. & 0945 & 4 & 236 & 7 & 4.5 & -- & -- & $=$ & $z$ & -- & -- & $-\overline{-}$ & $=$ & $=$ & - & -- & \\
\hline$A P R$ & $2 \ldots \ldots$ & 1130 & 7 & 393 & 30 & 32 & 1 & 13 & 40 & 55 & 69 & 81 & 87 & 91 & 95 & 100 & - & \\
\hline$A P R$ & $22 \ldots \ldots$ & 0955 & 10 & 386 & 179 & 187 & -- & - & -- & -- & -- & -- & -- & $\cdots$ & -- & -- & -- & \\
\hline MAY & $2 \ldots \ldots$ & 0845 & 8 & 219 & 106 & 63 & 43 & 60 & 76 & 90 & 97 & 99 & 99 & 100 & -- & -- & - & \\
\hline JUN & $9 \ldots$. & 1015 & 15 & 48 & 5 & .65 & - & -- & -- & $=$ & -- & -- & - & - & -- & - & -- & \\
\hline JUL & $17 \ldots \ldots$ & 1100 & 20 & 11 & 4 & .12 & - & $\cdots$ & -- & -- & -- & -- & -- & - & -- & $-\infty$ & -- & \\
\hline AUG & $13 \ldots \ldots$ & 0915 & 18 & 4.2 & 2 & .02 & -- & -- & -- & -- & -- & -- & $=-$ & - & -- & -- & - & \\
\hline SEP & $8 \ldots \ldots$ & 1000 & 20 & 3.8 & 4 & .04 & -- & -- & -- & -- & -- & $=$ & -- & -- & -- & -- & $=-$ & \\
\hline
\end{tabular}

11386500 GRINDSTONE CREEK NEAR ELK CREEK, CALIF. (LAT 394038 LONG 1223151 )

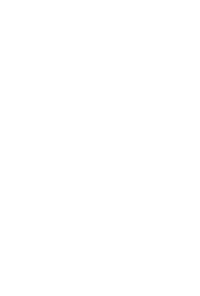

D. 60
6.0
20
238
126
1220
2140
346
373
958
420
138
28
3.4
1.5

7
3
1
474
25
2760
5260
483
200
1180
193
12
5
7
1

\begin{tabular}{|c|c|c|c|c|}
\hline 0 & -- & -- & $=$ & -- \\
\hline .05 & -- & $\cdots$ & -- & -- \\
\hline .05 & -- & -- & -- & $\overline{7}$ \\
\hline $\begin{array}{r}80 \\
8.5\end{array}$ & 26 & $\begin{array}{l}43 \\
--\end{array}$ & $\begin{array}{l}60 \\
--\end{array}$ & $\begin{array}{l}72 \\
--\end{array}$ \\
\hline 9090 & 20 & 29 & 38 & 49 \\
\hline 30400 & 19 & 28 & 35 & 50 \\
\hline 451 & 28 & 44 & 69 & 74 \\
\hline 201 & 23 & 35 & 47 & 56 \\
\hline 3050 & 15 & 24 & 32 & 45 \\
\hline 219 & -- & -. & - & - \\
\hline 4.5 & -2 & & & \\
\hline .06 & - & $\approx$ & $=$ & $\overline{-1}$ \\
\hline 0 & - & -- & $=$ & - \\
\hline
\end{tabular}

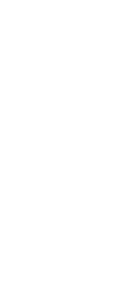

D DAILY MEAN DISCHARGE. 
SUSPENDED-SEDIMENT DISCHARGE MEASUREMENTS AND PARTICLE-SIZE DISTRIBUTION, WATER YEAR OCTOBER 1968 TO SEPTEMBER 1969 (METHODS OF ANALYSIS: B, BOTTOM WITHDRAWAL TUBE, C, CHEMICALLY DISPERSEDI N, IN NATIVE WATERI P, PIPETI S, SIEVE, $\checkmark$, VISUAL-ACCUMULATION TUBE, $W$, IN DISTILLED WATER)

DATE

WATER PARTICLE SIZE

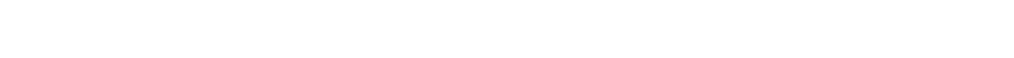

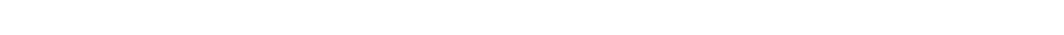

MORSES CREEK BASIN

11460160 MORSES CREEK AT BOLINAS, CALIF. (LAT 375509 LONG 1224009 )

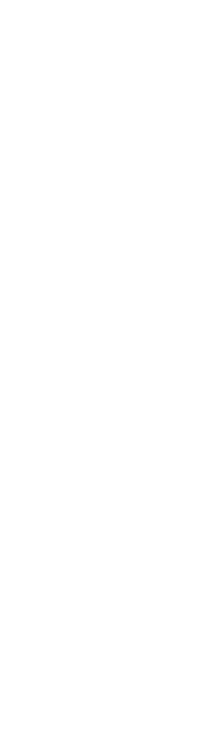

\begin{tabular}{|c|c|c|}
\hline $\begin{array}{l}12 \\
12 \\
12 \\
12 \\
11\end{array}$ & $\begin{array}{r}.04 \\
.20 \\
.01 \\
7.7 \\
4.6\end{array}$ & $\begin{array}{r}16 \\
1 \\
36 \\
84 \\
14\end{array}$ \\
\hline $\begin{array}{l}11 \\
11 \\
11 \\
11 \\
10\end{array}$ & $\begin{array}{r}2.3 \\
3.3 \\
6.0 \\
4.8 \\
10\end{array}$ & $\begin{array}{r}6 \\
16 \\
58 \\
12 \\
171\end{array}$ \\
\hline $\begin{array}{l}10 \\
11 \\
11 \\
11 \\
10\end{array}$ & $\begin{array}{c}4.3 \\
1.8 \\
.28 \\
5.4 \\
18\end{array}$ & $\begin{array}{r}23 \\
6 \\
2 \\
78 \\
77\end{array}$ \\
\hline $\begin{array}{l}11 \\
11 \\
11 \\
11 \\
11\end{array}$ & $\begin{array}{l}12 \\
7.8 \\
15 \\
21 \\
14\end{array}$ & $\begin{array}{r}18 \\
7 \\
32 \\
98 \\
27\end{array}$ \\
\hline $\begin{array}{l}11 \\
12 \\
12 \\
12 \\
10\end{array}$ & $\begin{array}{l}9.6 \\
8.3 \\
14 \\
11 \\
9.1\end{array}$ & $\begin{array}{r}7 \\
5 \\
26 \\
8 \\
4\end{array}$ \\
\hline $\begin{array}{l}11 \\
11 \\
11 \\
11 \\
11\end{array}$ & $\begin{array}{r}3.5 \\
6.0 \\
4.9 \\
8.8 \\
11\end{array}$ & $\begin{array}{r}15 \\
9 \\
3 \\
29 \\
35\end{array}$ \\
\hline $\begin{array}{l}11 \\
12 \\
10 \\
15 \\
12 \\
14\end{array}$ & $\begin{array}{c}13 \\
1.0 \\
.25 \\
.32 \\
.03 \\
.04\end{array}$ & $\begin{array}{r}107 \\
4 \\
1 \\
2 \\
2 \\
4\end{array}$ \\
\hline
\end{tabular}

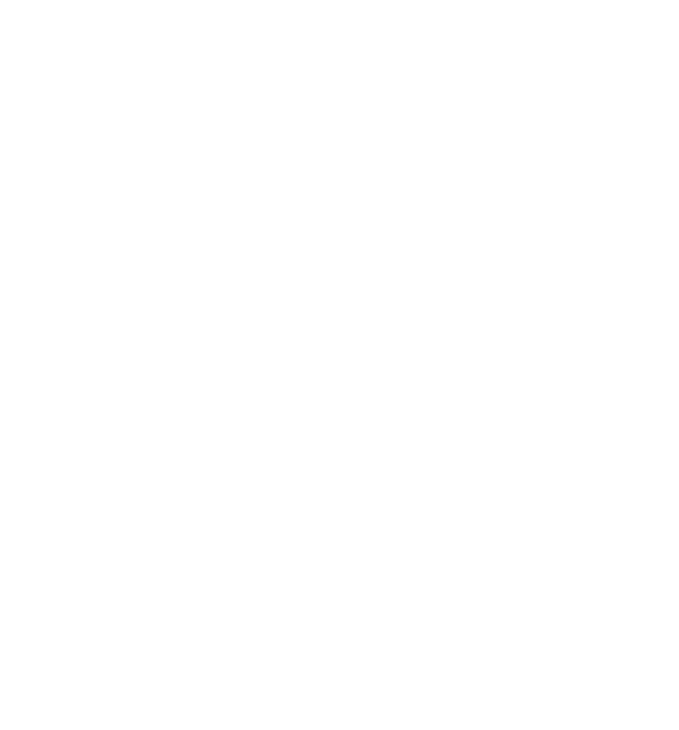

AUDUBON CREEK BASIN

11460165 AUDUBON CREEK NEAR BOLINAS, CALIF. (LAT 375547 LONG 1224051 )

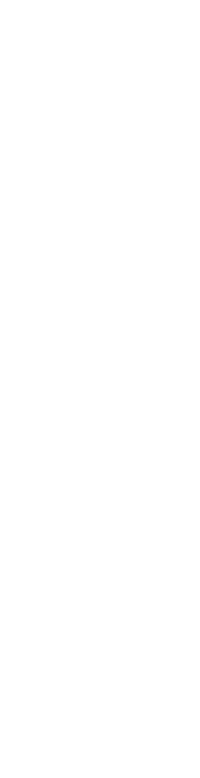

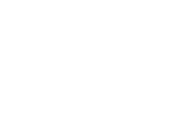

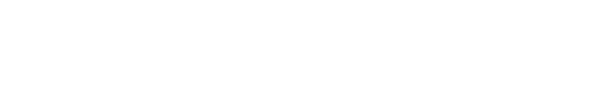

$\begin{array}{lr}1.8 & 4 \\ .55 & 2 \\ 1.6 & 3 \\ 2.7 & 10 \\ 2.0 & 3\end{array}$

10
6.3
3.9
.30

$\begin{array}{rr}10^{.30} & 4 \\ & 191\end{array}$

11

9.5

30
18

19

16

13

13
12
8.8

11.8

12

23.8

2.1

.18 $\begin{array}{ccc}0.02 & - & = \\ .01 & = & = \\ .07 & = & =\end{array}$

.07

$\begin{array}{ccc}2.5 & = & - \\ .17 & = & = \\ 0 & =05 & =\end{array}$

$\begin{array}{lll}0.05 & \cdots & =\end{array}$

$\begin{array}{cccccccccccc}4.3 & -- & -- & -- & -- & -- & -- & -- & -- & -- & -- & --\end{array}$

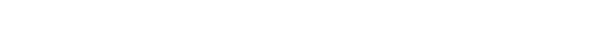

$\begin{array}{llllllllllll}2.3 & - & - & - & - & - & - & - & - & - & - & -\end{array}$

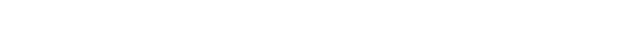

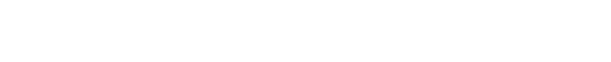

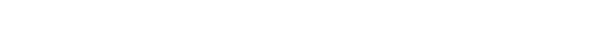

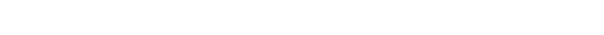

$\begin{array}{cccccccccccc}.75 & - & -- & -- & -- & -- & - & -- & - & - & -- & - \\ 1.2 & -- & -- & -- & -- & -- & - & -- & -- & - & -- & -\end{array}$

$\begin{array}{llllllllllll}1.2 & - & - & - & - & - & - & - & - & - & - & - \\ 4.2 & - & - & -- & -- & -- & -- & - & -- & - & - & -\end{array}$

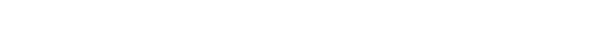

$\begin{array}{cccccccccccc}.01 & - & -- & - & - & -- & - & -- & -- & -- & -- & -\end{array}$

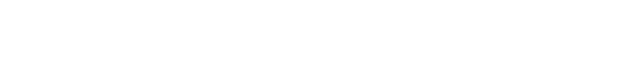


SUSPENDED-SEDIMENT DISCHARGE MEASUREMENTS AND PARTICLE-SIZE DISTRIBUTION, WATER YEAR OCTOBER 1968 TD SEPTEMBER 1969 IMETHODS OF ANALYSIS: B, BOTTOM WITHDRAWAL TUBE; C, CHEMICALLY DISPERSED; N, IN NATIVE WATER; P, PIPET; S, SIEVE; $V$, VISUAL-ACCUMULATION TUBE; $W$, IN DISTILLED WATER)
,

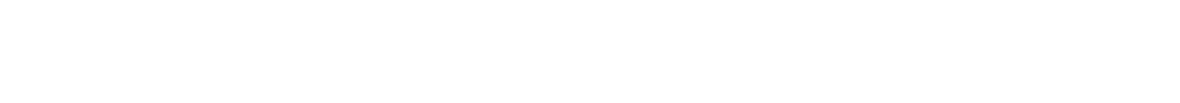
EEL RIVER BASIN

11473100 WILLIAMS CREEK NEAR COVELO, CALIF. (LAT 394630 LONG 1230825 )

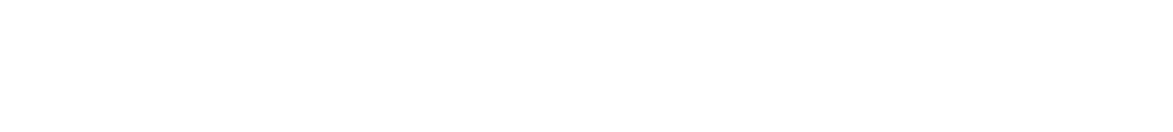

11473700 MILL CREEK NEAR COVELO, CALIF. (LAT $3944 \quad 45$ LONG 1231015 )

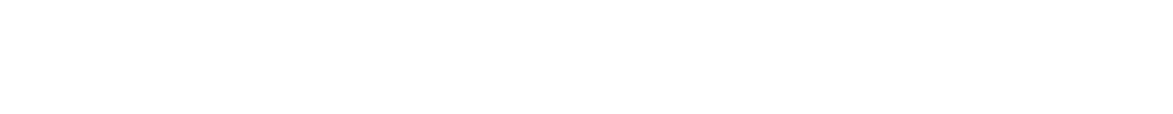

KLAMATH RIVER BASIN

11525800 HEAVER CREEK NEAR DOUGLAS CITY, CALIF. (LAT 4040 O6 LONG 1225631 )

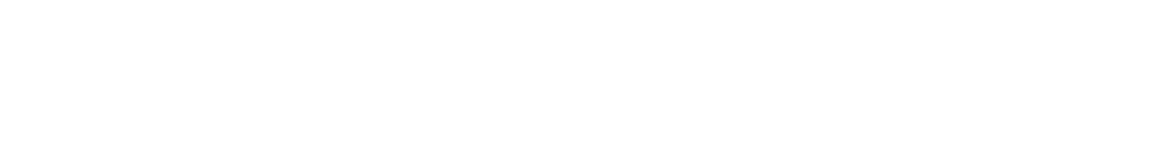

11526500 NORTH FORK TRINITY RIVER AT HELENA, CALIF. (LAT 404655 LONG 1230738 )

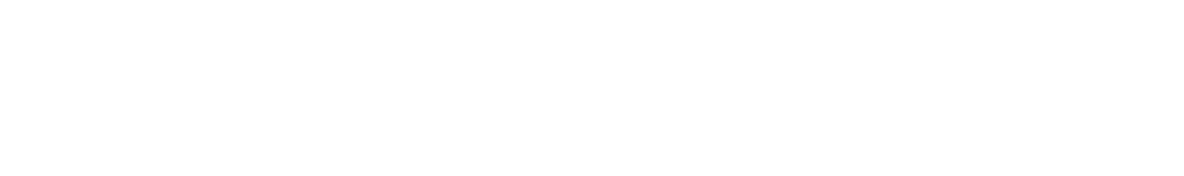

DAILY MEAN DISCHARGE.

PARTICLE-SIZE DISTRIBUTION OF SURFACE BED MATERIAL, WATER YEAR OCTOBER 1968 TO SEPTEMBER 1969

(METHODS OF ANALYSIS: H, HYDROMETER; 0 , OPTICAL ANALYZER; S, SIEVE; $V$, VISUAL-ACCUMULATION TUBE)

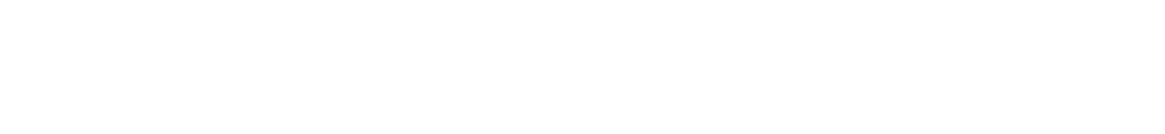

11460160 MORSES CREEK AT BOLINAS, CALIF. (LAT 3755 O9 LONG 12240 09)

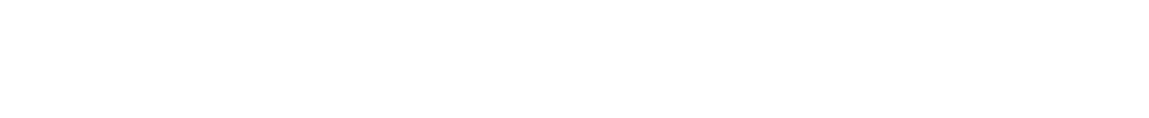

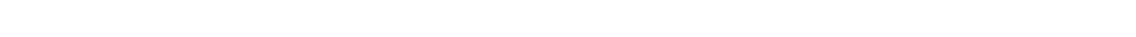



DETERMINATIONS OF TURBIDITY, WATER YEAR OCTOBER 1968 TO SEPTEMBER 1969

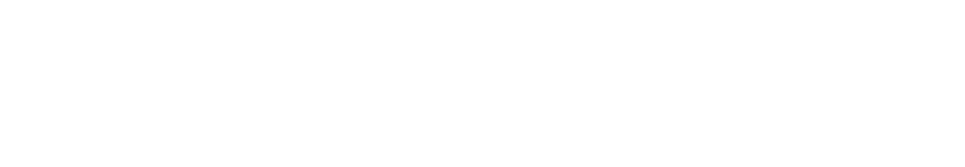

11462000 EAST FORK RUSSIAN RIVER NEAR UKIAH, CALIF. ILAT 391145 LONG 1231130$)^{B}$

\begin{tabular}{|c|c|c|c|c|c|c|c|}
\hline $\begin{array}{l}\text { DEC. } 18,1968 \ldots \ldots \ldots \ldots \\
\text { DEC. } 20, \ldots \ldots \ldots \ldots \ldots \ldots \\
\text { DEC. } 27, \ldots \ldots \ldots \ldots \ldots \ldots \\
\text { JAN. } 3,1969 \ldots \ldots \ldots \ldots \\
\text { JAN. } 10, \ldots \ldots \ldots \ldots \ldots\end{array}$ & $\begin{array}{r}1100 \\
1000 \\
1130 \\
=-\end{array}$ & $\begin{array}{r}12 \\
10 \\
9 \\
9 \\
9\end{array}$ & $\begin{array}{r}2830 \\
27 \\
=- \\
--\end{array}$ & $\begin{array}{r}54 \\
62 \\
150 \\
235 \\
96\end{array}$ & $\begin{array}{r}6 \\
10 \\
38 \\
51 \\
33\end{array}$ & $\begin{array}{l}=- \\
-- \\
--\end{array}$ & $\begin{array}{l}=- \\
=- \\
=-\end{array}$ \\
\hline 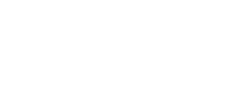 & $09 \overline{-}$ & $\begin{array}{r}9 \\
10 \\
9 \\
9 \\
9\end{array}$ & $\begin{array}{r}-- \\
\overline{--} \\
648\end{array}$ & $\begin{array}{l}111 \\
109 \\
108 \\
131 \\
105\end{array}$ & $\begin{array}{l}33 \\
59 \\
66 \\
17 \\
25\end{array}$ & $\begin{array}{ll}- \\
\therefore \\
-\end{array}$ & $\begin{array}{l}=- \\
=- \\
--\end{array}$ \\
\hline 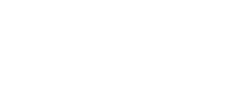 & $\begin{array}{l}=- \\
=- \\
=-\end{array}$ & $\begin{array}{l}10 \\
10 \\
10 \\
10 \\
11\end{array}$ & $\begin{array}{l}=- \\
=- \\
=-\end{array}$ & $\begin{array}{l}94 \\
72 \\
71 \\
58 \\
43\end{array}$ & $\begin{array}{r}22 \\
6 \\
23 \\
21 \\
5\end{array}$ & $\begin{array}{l}-- \\
\overline{-} \\
--\end{array}$ & $\begin{array}{l}=- \\
=- \\
=-\end{array}$ \\
\hline 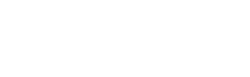 & $\begin{array}{r}0945 \\
\overline{--} \\
0915\end{array}$ & $\begin{array}{l}10 \\
10 \\
11 \\
12\end{array}$ & $\begin{array}{r}29 \\
=-- \\
482\end{array}$ & $\begin{array}{l}44 \\
46 \\
76 \\
52\end{array}$ & $\begin{array}{r}7 \\
34 \\
0 \\
4\end{array}$ & $\begin{array}{l}-- \\
\overline{--}\end{array}$ & $\begin{array}{l}= \\
=- \\
=\end{array}$ \\
\hline
\end{tabular}

EEL RIVER BASIN

12470000 LAKE PILLSBURY NEAR POTTER VALLEY, CALIF. (LAT 392430 LONG 2225730 ) B

\begin{tabular}{|c|c|c|c|c|c|c|c|c|}
\hline $\begin{array}{l}\text { DEC. } \\
\text { DEC. } \\
\text { JAN. } \\
\text { JAN. } \\
\text { JAN. } \\
\text { JAN. }\end{array}$ & $\begin{array}{r}18,1968 \ldots \ldots \ldots \ldots \\
27, \ldots \ldots \ldots \ldots \ldots \ldots \\
3,1969 \ldots \ldots \ldots \ldots \\
10 \ldots \ldots \ldots \ldots \ldots \ldots \\
17 \ldots \ldots \ldots \ldots \ldots \ldots \\
24, \ldots \ldots \ldots \ldots \ldots \ldots\end{array}$ & $\begin{array}{l}1510 \\
1115 \\
1030 \\
1000 \\
1000 \\
1030\end{array}$ & $\begin{array}{r}-- \\
4 \\
6 \\
4 \\
4 \\
3\end{array}$ & $\begin{array}{l}= \\
= \\
= \\
=\end{array}$ & $\begin{array}{l}700 \\
315 \\
200 \\
240 \\
135 \\
150\end{array}$ & $\begin{array}{l}85 \\
77 \\
40 \\
49 \\
35 \\
40\end{array}$ & $\begin{array}{l}-1 \\
490 \\
350 \\
350 \\
276 \\
274\end{array}$ & $\begin{array}{l}78 \\
78 \\
74 \\
62 \\
51 \\
62\end{array}$ \\
\hline $\begin{array}{l}\text { JAN. } \\
\text { FEB. } \\
\text { FEB. } \\
\text { FEB. } \\
\text { FEB. } \\
\text { MAR. }\end{array}$ & $\begin{array}{r}31 \ldots \ldots \ldots \ldots \ldots \ldots \ldots \\
7 \ldots \ldots \ldots \ldots \ldots \ldots \ldots \\
14 \ldots \ldots \ldots \ldots \ldots \ldots \\
21 \ldots \ldots \ldots \ldots \ldots \ldots \\
28 \ldots \ldots \ldots \ldots \ldots \ldots \\
7 \ldots \ldots \ldots \ldots \ldots \ldots\end{array}$ & $\begin{array}{l}1015 \\
1000 \\
1000 \\
0930 \\
0930 \\
0900\end{array}$ & $\begin{array}{l}4 \\
4 \\
5 \\
4 \\
4 \\
6\end{array}$ & $\begin{array}{l}=- \\
-- \\
-- \\
--\end{array}$ & $\begin{array}{r}116 \\
92 \\
121 \\
126 \\
95 \\
76\end{array}$ & $\begin{array}{l}44 \\
28 \\
40 \\
27 \\
23 \\
23\end{array}$ & $\begin{array}{r}139 \\
142 \\
128 \\
214 \\
76 \\
82\end{array}$ & $\begin{array}{l}58 \\
51 \\
42 \\
27 \\
20 \\
22\end{array}$ \\
\hline $\begin{array}{l}\text { MAR: } \\
\text { MAR: } \\
\text { APR: } \\
\text { MAY } \\
\text { JUNE }\end{array}$ & 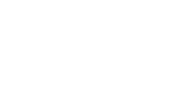 & $\begin{array}{l}0900 \\
0900 \\
1200 \\
0930 \\
1000\end{array}$ & $\begin{array}{r}5 \\
11 \\
12 \\
17 \\
22\end{array}$ & $\begin{array}{l}= \\
=- \\
z\end{array}$ & $\begin{array}{r}74 \\
43 \\
34 \\
18 \\
3\end{array}$ & $\begin{array}{r}21 \\
9 \\
6 \\
1 \\
1\end{array}$ & $\begin{array}{r}74 \\
54 \\
31 \\
20 \\
5\end{array}$ & $\begin{array}{r}23 \\
19 \\
7 \\
2 \\
1\end{array}$ \\
\hline
\end{tabular}

A TURBIDITY MEASURED AFTER A 7-DAY SETTLING PERIOD.
B SAMPLES COLLECTED BY PACIFIC GAS AND ELECTRIC COMPANY, AND U.S. FOREST SERVICE. 


\section{INDEX}

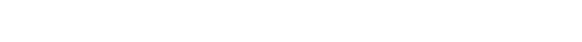

Al ameda Creek near Niles, Calif...............106-109

Al amedd Creek basin.......................105-109

Al uminum.

merican River, at Fair Oaks, Cailif.

North Fork, at North Fork Dam, Calif.......... 22

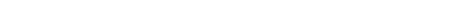
sites in Pacific slope basins in Califor sites in Pacific slope basins in Califor-

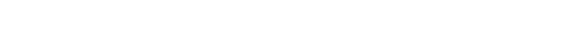
Arcata, Calif., Mad River near ................. Arlington, Calif., Santa Ana River near........340-341 Arroyo Grande, Call1., Arroyo Grande near....... 66-68 Arroyo Grande above Phoenix Creek, near Ar royo Grande, Calif..

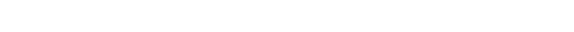
Arroyo seco near Greenileid, Cailf............ 84-86 Ar royo Valle near Live rmore, Cai if ............... 105

Atwell Creek above in nerai $x$ ing $H$ ighway, near Hampond, Calif

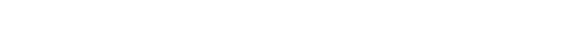

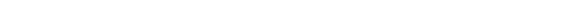

Audubon Creek basin. ................................ 34,344

Azusa, Calif., San Gabriel kiver at.............

Balch Camp, Calif., North Fork kiag

Battle Creek below Coieman Fi sh Hatchery, near Cottonwood, Calif.

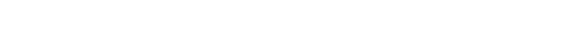

Bicarbonate, carbonate and hydroxide............ 10

B1g Chico Creek near Chico, Calif .............. 188

Big Creek below Huntington Lake, $\mathrm{C}_{\mathrm{g}}$ lif $\ldots \ldots \ldots \ldots \ldots, 144$

Big Sur River near Big Sur, Calif.......
Big Trees, Calif., San Lorenzo River at

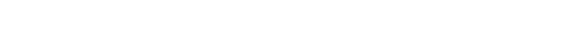

Blue Creek near Kl amath, CaIif.................

Bodega, Calif., Salmon Creek at.

Bolinas, Calif., Audubon Creek near.................

Morses Creek at $\ldots \ldots \ldots \ldots \ldots \ldots \ldots \ldots \ldots \ldots \ldots, \ldots \ldots \ldots \ldots \ldots \ldots \ldots \ldots, 344$

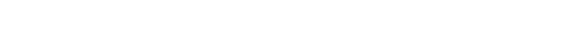

Borel Canal below Isabella Dam, Calif.......... 112

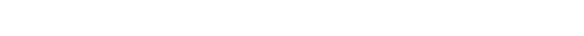

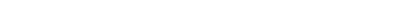

Bridgevil le, Calif., Van Duze $n$ River near.......

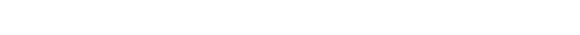

Bryson, Calif., Nacimiento River near. . . .

Buena Vista Lake basin................. 109-112,340-341

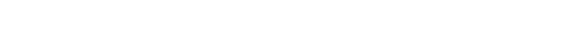

Cache Creek, above Rumsey, Cal1f...........233-235

near Capay, Calif $\ldots \ldots \ldots \ldots \ldots \ldots \ldots \ldots \ldots \ldots \ldots, 236$

Cadmium.

Calleguas Creek at Camariilo State Hospitai

Calif ......................... $41-43$

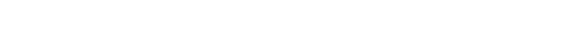

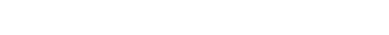

$\mathbf{2 4 5}$

Camar1llo state Hospital, Callf., Calleguas Creek

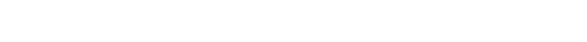

Canyon Creek near Georgetown, Caiif............. 222

Capay, Calif., Cache Creek near.............. 236

Chemical oxygen demand...

Chemical quality.

Chico, Calif., Big Chico Creek near.

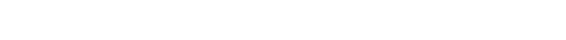

Chloride...

Chromium.

Chualar, Caiif., Sainas River nea

Clear Creek near Igo, Calif.

Cl 1o, Cal1f. , Middle Fork Feather $\mathrm{Bi} \ldots \ldots \ldots \ldots$

Cloverdale, Calif., Dry Creek aear...... 196

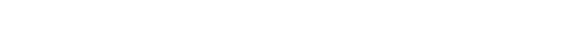

Cobalt

Collection and examination of data.

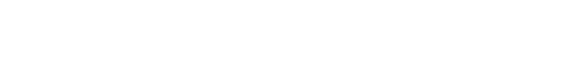

Colton, Cailif., Santa Ana River at.

Colusa Trough near Colusa, Calif
Composition of surface waters...

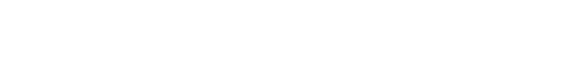

reme scal Creek at..............................

Cottonwood, Calif., Battle Creek near............

Cottono , Creek near. . .

South Fork Cottonwood Creek near......................

Cottonwood Creek ( $X 1$ amath $R 1$ ver basin) at Horn-

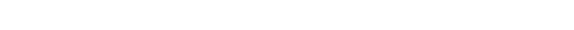

Cottonwood Creek (Sacramento River basin), Middie Fork, near Ono, Cal if

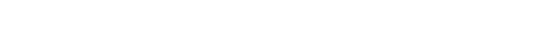

Covelo, Calif. Black Butte River near...........

Middie Fork Eel River near. . . . . . . . . 273-275, 279

M111 Creek near......................

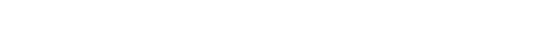

Cow Creek near Mllivilie, Cailif............... 175

Coyote Creek near Gilroy, Calif...............

Crater Lake near Crater Lake, Oreg.............310-311

Crescent Mills, Calif., Indian Creek near......... 199

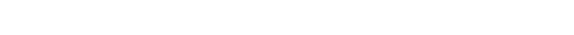

Cucamong a Creek near Mira Loma, Caif..............340-341

Cuyama River below Twitchell Dam, Calif..........340-341

Data, colleation and examination of $\ldots \ldots \ldots \ldots \ldots$ is6-167

Delta, Calif., Sacramento River at.............166-167

Delta-Mendota Canal, above Tracy pumptng plant

near Tracy, Calff...................... 156

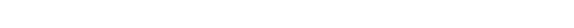

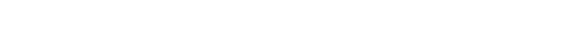

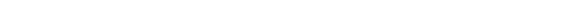

Dissol ved solids. . . . . . . . . .

Dos Rios, Calif., Eei Ri ver above.................

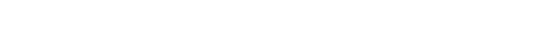

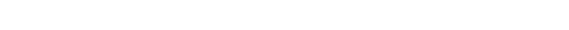

Douglas City, Calif., Weaver Creek near........

near Geyserville, Cal1f......................250 249

Eel River, above Dos Rios, Calif ........... 272

at Fort Seward, Cal1f..................284-286

at Scotia, Calif..................

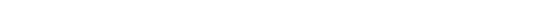

Middle Fork, above Black Butte River, near

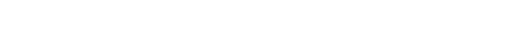

below Black Butte River, near Covelo

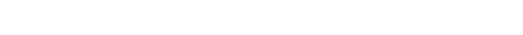

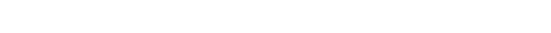

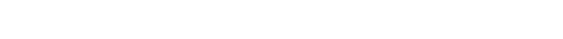

near Branscomb, Cal1f...................

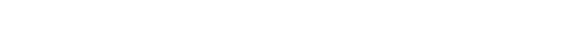
near Paskenta, Calif..............................

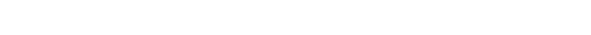

Fair Oaks, Calif., Amertcan River at .......... 224 Fallbrook, Calif., Santa Margarita River near..... 25

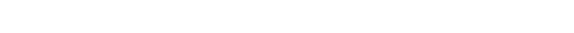
Middle Fork, near Clio, Cal1f............ 196 near Merrimac, Calif ................... 197

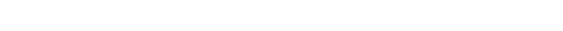
near Nicolaus, Calte..................... 220

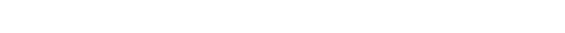
Fillmore, Calif., Sespe Creek near............

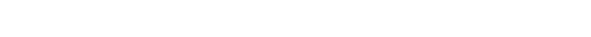
Fort Bragg, Callf., Middle Fork Tenmile River

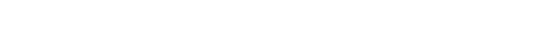

Fort Jones, Calif., Scott River near........... 317 Fort Seward, Cal1f., Eel River at. . . . . . . Garcia River near point Arena, Cal1f......... 258 Genesee, Calif i Little Grizzly Creek near....... Geyserville, Calif., Dry Creek near...............250-254 Gilroy, Calif., Coyóte Creek near.............. 102-104 Goose Lake, at Everly Ranch, near Wiiiow Ranch, at West Shore Log Landing, near wiliow Ranch, " 
Goose Lake, at W1llow Ranch, Calif........... $\begin{gathered}\text { Page } \\ 164\end{gathered}$

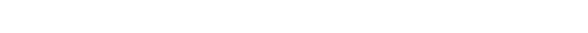
Grass Valley, Calif. South Yuba Ri ver near..... 217 Gridley, Cglif., Feather River near..............27-209 Grimes, Calif., Sacramento River near............ 193 Grindstone Creek near Elk Creek, Calif ......... 342 Guadalupe, Calif., Santa Maria River at........ 64-65 Guerneville, Cálif., Russian R1 ver near..........255-257

Hamil ton City, Calif., Sacramento River near..... 187 Hammond, Calif., Atwe il Creek near............128-129

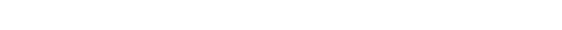
Monarch Creek near. . . . . . . . . . . . . . . 118-121 Redwood Creek near.......................130-131 Squitrel Creek near.....................132-133

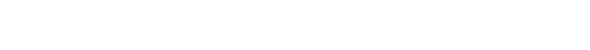
Healdsburg, Calif, Russtan River near......... 248 Hearst, Caltf., Elk Creek near................. Helena, Calif., North Fork Trinity River at.... Kelseyvilie, Calif... Hoopa, Caltf , Trintty River at............331-334

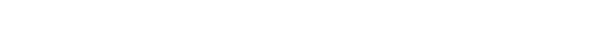
Hopper Creek near P1ru, Calif $\ldots \ldots \ldots \ldots \ldots \ldots \ldots \ldots \ldots \ldots$
Hornbrook, Calif., Cottonwood Creek at
314

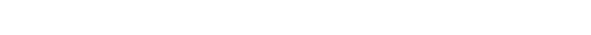

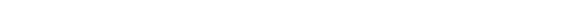

Hydrogen-ton concentratt on .

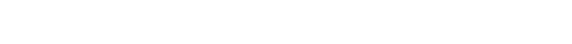

Indian Creek near Cresce nt Milis, Calif..........

Iodide. . . . . . . . . . . . . .

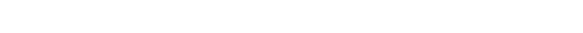

Isabella Dam, Callf., Borel Canal below......... 112

Kaweah River, at Three Rivers, Cal1f......... 138

East Fork, above Monarch Creek, near Hammond

at Sequoia Nationai Park boundary, near

Hammond, Calif.

139

below Monarch Cree near Hammond, Calif.......116-117

below Mosquito Creek, near Hammond, Calif....122-124

near Three Rivers, Calif............... 135-137

Marble Fork, at Potwisha Camp, Cai if........... 115

Kelseyville, Calif.., Highland Creek near........230-232

Kern River, at Kernville, Calif .............. 11

(1)............

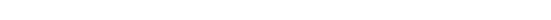

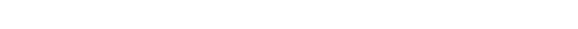

Kings River, above North Fork, near Trimmer

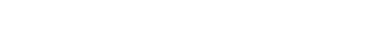

at People's Weir, near Kingsburg, Calif......... 140

below North Fork, near Trimmer, Calif ..........142-143

North Fork, above Dinkey Creek, at Baich

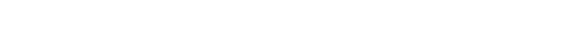

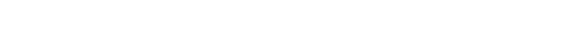

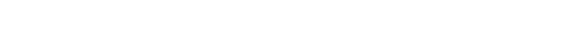

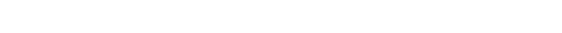

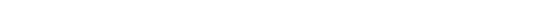

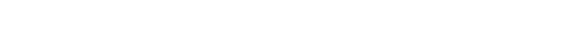

Kneel and, Calif., Mad River near............ 304

$\begin{array}{lll}\text { Knights Ferry, Calif, , Standslaus River near...... } & 151 \\ \text { Knights Landing, Calif., Sacramento River at..... } & 194\end{array}$ , Calif., South Fork American Rive

Lake pillsbury near potter Valley, Calif....... 345

Crater lake near Crat

Crater Lake near Crater Lake, Oreg............310-311

ose Lake, at Everly Ranch, near Willow Ranch,

at West Shore Log Landing, near viliow Ranch,

Callf....................

at Willow Ranch, Calif .......................

Lead........................ 13

Legget $\xi$, Cailif., South Fork Bei Ri ver at.......... 293 Lewiston, Calif., Trinity River at........... Likely, Creek near pinecrest, Calif................

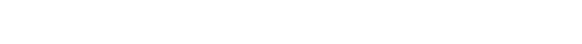

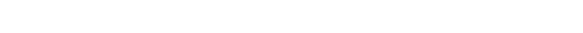

Little Stony Creek above East park Reservoir.

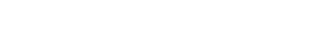

Li vermore, Calif., Ar royo Valle near...

Lodoga, Calif. Little Stony Creek near.

Longvale, Calif., Outlet Creek near.......

Lopez Creek near Arroyo Grande, Calif...

Los Angeles River at Los Angeles, Calif.

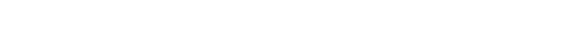

McCloud River above Shasta Lake, Cal1f........ 171 Mad River, near Arcata, Calif ................ 305-308

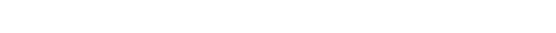

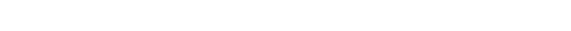

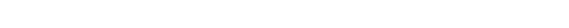

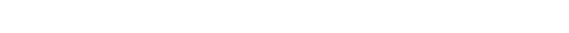

Marysville, Calif., Yuba River at............ 218 Matili ja Creek above reservoir, near Matili ja
Hot Springs, Calif . 340-341 Mat tole River near Petrolia, Caiif................ 262 Mendota, Calif., Delta-Mendota Canal near.......... 15 Merced River at Happy Isles Bridge, near

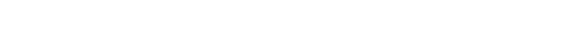

Merrimac, cai if., , Middie Fork Feather Ri ver $\cdots$

Mich igan Bar, Caiif., Cosumnes River at........... ${ }^{197}$

Middle Yuba River above Oregon Creek, near $\ldots \ldots .213$

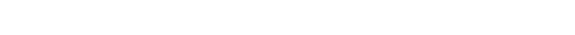

Mill Creek (Sacramento River basin) at mouth,

Millville, Caltf, , Cow Creek near..................

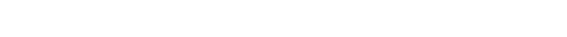

Mineral constituents 1 n solution................

Mira Loma, Calif. , Cucamonga Creek near........340-341

Mission Creek ne ar Montebel lo, Calif............

Mode sto, Calif., Tuolumne River at............... 149

Mokelumne River, at Woodbridge, Calif............. 159

below Camanche Dam, Calif............... 342

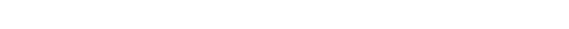

Mona rch Creek near Hammond, Calif $\ldots \ldots \ldots \ldots \ldots \ldots \ldots \ldots \ldots$ 118-12

Montebello, Calif., Mission Creek near............

Morgan $\mathrm{H} 111$, Calif., Uvas Creek near............9.9.9.

Morses Creek at Bolinas, Calif....................

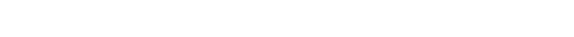

Nacimiento River near Bryson, Calif......... 78-80

Napa River near St. Helena, Calif $\ldots \ldots \ldots \ldots \ldots \ldots . \mathbf{2 4 0}$

Navarro River near Navarro, Calif................ 259

Nickel..... Caij..., Feather River near................ 220

Niles, Calif., Alameda Creek near.................

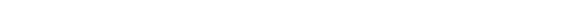

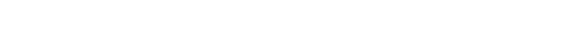

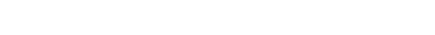

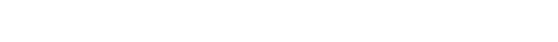

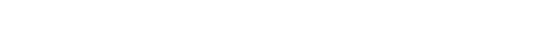

North Yuba River, above siate Creek, near

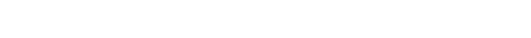

below New Bullards Bar Dam, near North San

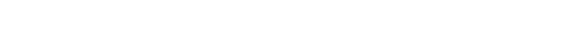

Oceanside, Calif., San Luis Rey River at........ 24

Ono, Cal1f., Middie Fork Cottomwod Creek near.... 17

Oregon Creek near North San Juan, Cal1f........... $\mathbf{1 0}^{214}$

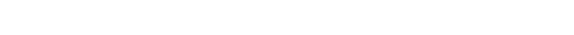

Orland, Cal1f., Stony Creek near.............. 19

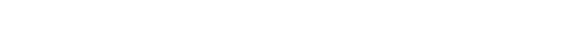

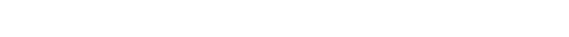

Outlet Creek near Longvale, Caiif................ 202

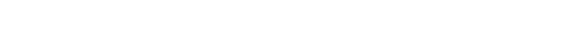

Pajaro River basin............................. 91-94

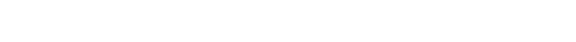

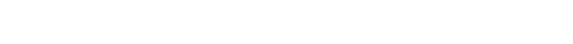

Pescadero Creek near Pescadero, Cailif............

Petrolia, Calif., Mattole River near............ 262

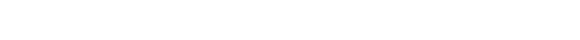

pinecrest, Calif., Lily Creek near..................

Middle Fork Stanislaus River near.............

Piru, Cal1f., Hopper Creek near............ 340-341

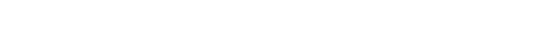

South Fork, near Likely, Calif............ 167

point Arena, Calif., Garcia River near.............

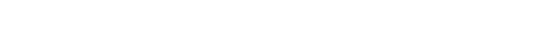

potter Valley Powerhouse tallrace near Potier

Valley, Calif....................... 264

isha Camp, Calif., Marbie Fork Kaweah

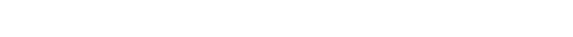

preface............................. II

Properties and characteristics of water..........

Pulga, Calif., North Fork Feather hiver

Putah Creek, near Guenoc, Calif.................

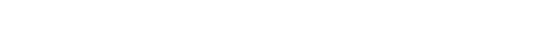


Page
109

Quaking Aspen Camp, Cal1f., Kern River near......

Red Bank Creek at Rawson Bridge, near Red Bluff,

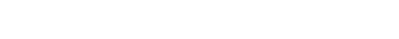

Redwood Creek (tributary to East Fork Kaweah River) above Mineral King Highway, nea

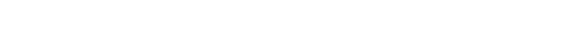
Orick, Calif.............................. 399 Rio vista, Cal if ., Sacramento River at......... 239 Rumsey, Calif., Cache Creek above ... near Cloverdale, Cal1f.................... near Guerneville, Calif........................ $255-257$ near Healdsburg, Cal1f...................

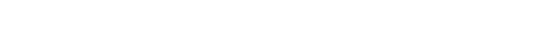

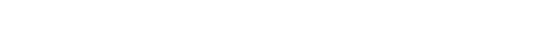
Russtan R1 ver basin.........................

Sacramento River, above Colusa Trough, at Kn 1ghts Landing, Cal1f................. 194

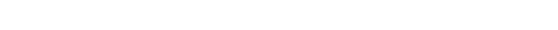

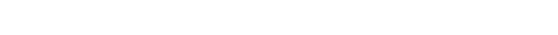

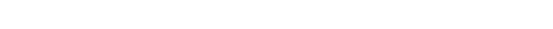

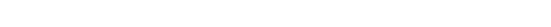

at Keswick Dam, near Keswick, Cailf............. 172

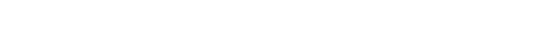

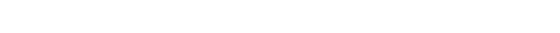

be1ow Wilkins Slough, near Grimes, Calif........ 193

near Hamil ton Ctty, Callf................ 187

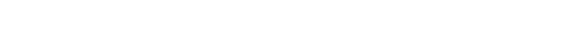

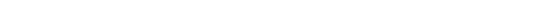

Saitnas R1 ver, near Chualar, Cal1f.............. 87-89

near Sprecke 1s, Calif . . . . . . . . . .

Sal1 nas River basin.................. 730

Salmon Creek at Bodega, Calif...............

Salmon River, at Somes Bar, Calif............. 319

San An tonto River near Lockwood, Cailif............ 81.83

San Bernardino, Calif., Santa Ana River near.......340-341

San Gabriel River, at Azusa powerhouse, at Azusa, Ca11f.

at Whitter Narrows, Cai $\ldots \ldots \ldots \ldots \ldots \ldots \ldots \ldots \ldots \ldots \ldots, \quad 35$

San Gabriel River basin.................... 35-36

San Joaquin River, at Antioch, Cailif.............. 163

near vernalis, Calif ....................

San Joaquin River basin.................144-163,342

San Lorenzo River at Big Trees, Calif.............
San Luis Rey River at Oceanside, Calif..........

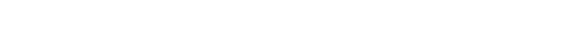

at Colton, Calte...... $\mathrm{E}$ Street, near San Bernarino, Caiif.......

at Riverside Narrows, near Arling ton, Calif. . ,340-341

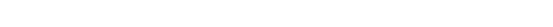

Santa Ana River basin. $\ldots \ldots \ldots \ldots \ldots \ldots \ldots \ldots \ldots \ldots \ldots \ldots \ldots \ldots \ldots \ldots \ldots$
Santa Clara R1 ver, at Los Angeles-Ventura County

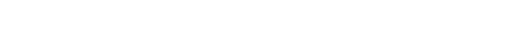

at Saticoy, Calif.

near Santa Paula, Calif................. 54

Santa Margartta River, at Ysidora, Caiif......... 26-28

near Fallbrook, Calif......................

Santa Margarita River basin...................... 25-28

Santa Maria R1ver at Guadalupe, Caiif............64-65

Santa Maria River basin...................

Santa Paula, Calif., Santa Clara River near..... 54

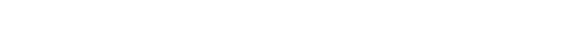

Sant a R1ta Creek near Templeton, Calif.......... 75-78

Santa Rita Creek tributary near Templeton, Caiif.. 73-75

Saticoy, Calif., Santa Clara River at......... 58-60

Satic oy diversion near........................... 57

Sattcoy diversion near Saticoy, Calif........... 57

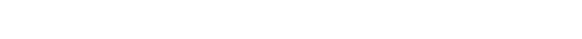

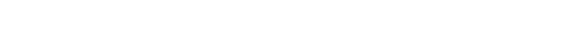

Selad Valley, Calif, Kl amath River near....... 518

Sespe Creek, near Filimore, Calif........... 50-54

near Wheelex Springs, Calif $\ldots \ldots \ldots \ldots \ldots \ldots \ldots \ldots,{ }_{171}^{49}$

Shasta R1 ver near Ýreka, Calif.................. 315-316

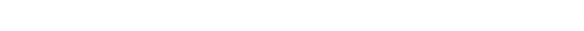

Smith River near Crescent C1ty, Caijf..........
Page

Sodium adsorption ratio. ................. 15-16

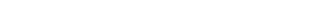

Somes Bar, Calif., Salmon River.............. 319

Soquel Creek at Soquel, Calif............. 95

South Cow Creek near Millville, Calif......... 174

South Fork, Calif., Eel River at............. 287

South San Francisco, Calif., Colma Creek at..... 98-100 South Yuba River at Jones Bar, near Grass Vailiey, Calif.

ecific conduct ance.

preckels, Calif., Salinas ki ver nea $x \ldots \ldots \ldots \ldots \ldots \ldots$.

pringville, Calf., Tule River near........... 11

Squirrel Creek below Mineral King Highway, near Hammond, Cal1f....................132-133

tanislaus River, below Goodwin Dam, near

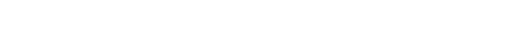

Middle Fork, at Hells Half Acre Bridge, near

ton Ship Canal at iight 40 , near Stockton,

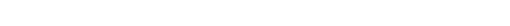

Stony Creek beiow Biack But

Orland, Cal1f..................... 190

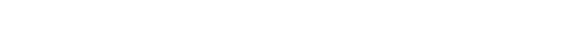

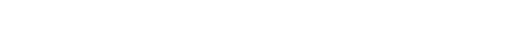

Stront lum

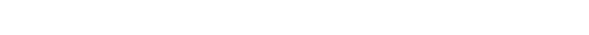

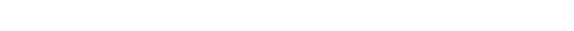

Temperature.........................., 16-17

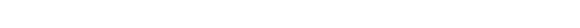
Templeton, Calif., Santa Rita Creek near....... 75-78 Santa Rita Creek tributary near................
Tenmile River, Middle Fork, near Fort Bragg

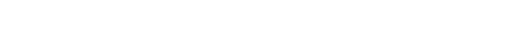
Terminus Dam, Caiif., Kaweah ii ve $\mathbf{r}$ below.......... Thermal to a terbay release to Feather River .... 20 Thomes Creek at Paskenta, Cailf...................

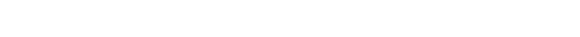

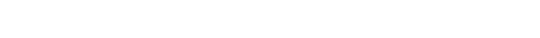
racy, Calif, Deita-Mendota Canai near............ Trimmer, Calif. , Ktngs River near.........140,142-143 Trintty River, near Burnt Ranch, Caiif............. 326

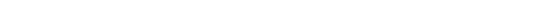

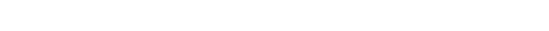
North Fork, at Helena, Calif. . . . . . . . . South Fork, below Hyampom, Cal1f..........328-330

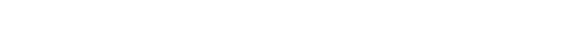

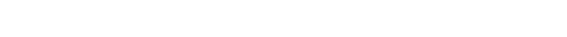
Tw1tchell Dam, Cailif., Cuy ama Ri ver below.........340-341

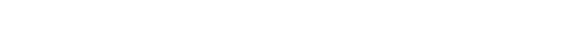
vas Creek above Uvas Re servoir, near Morgan H111, Ca11f...................... 91-93

Van Duzen River, near Dinsmores, Ca11f......... 300 near Bridgevilie, Cali ..... . . . . . . ........... Ventura River near Pentura River basin...................................

Water-quality records..................... 24

We aver Creek near Douglas City, Calif...........

Wheatland, Cal1f. Bear River near............ 21

Whittier Narrows, Calif., San Gabriel River at.....

Willtams Creek near Coveio, Calif....

Willow Creek at mouth, near Auberry, Caiif.........

Willow Ranch, Calif., Goose Lake near..............

Ninters, Calif., Putah Creek near.............. 238

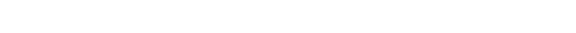

Yosem1te, Cal1f., Merced River near......... 146-147 Yreka, Calif., Shasta River near.............315-316 Ysidora, Calif., Santa Margarita River at...... 26-28 Yuba City, Calif., Feather River at.........210-212 Yuba River at Marysuille, Calif .................. 218

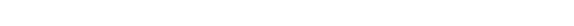

